NATIONAL LABORATORY

\title{
New York State 2009 \\ NHTS Comparison Report
}

\author{
June 2012
}

\section{Prepared by}

Frank Southworth

Timothy Reuscher

Ho-Ling Hwang

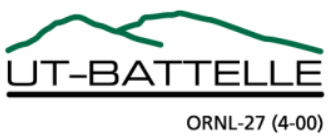




\section{DOCUMENT AVAILABILITY}

Reports produced after January 1, 1996, are generally available free via the U.S. Department of Energy (DOE) Information Bridge.

Web site http://www.osti.gov/bridge

Reports produced before January 1,1996, may be purchased by members of the public from the following source.

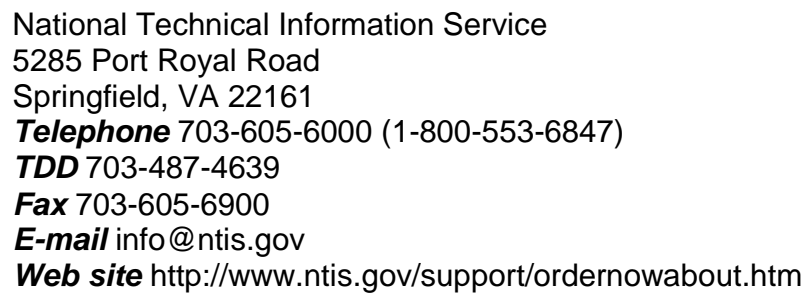

Reports are available to DOE employees, DOE contractors, Energy Technology Data Exchange (ETDE) representatives, and International Nuclear Information System (INIS) representatives from the following source.

Office of Scientific and Technical Information

P.O. Box 62

Oak Ridge, TN 37831

Telephone 865-576-8401

Fax 865-576-5728

E-mail reports@osti.gov

Web site http://www.osti.gov/contact.html

This report was prepared as an account of work sponsored by an agency of the United States Government. Neither the United States Government nor any agency thereof, nor any of their employees, makes any warranty, express or implied, or assumes any legal liability or responsibility for the accuracy, completeness, or usefulness of any information, apparatus, product, or process disclosed, or represents that its use would not infringe privately owned rights. Reference herein to any specific commercial product, process, or service by trade name, trademark, manufacturer, or otherwise, does not necessarily constitute or imply its endorsement, recommendation, or favoring by the United States Government or any agency thereof. The views and opinions of authors expressed herein do not necessarily state or reflect those of the United States Government or any agency thereof. 
Energy and Transportation Science Division

\title{
NEW YORK STATE 2009 NHTS COMPARISON REPORT
}

\author{
Frank Southworth \\ Timothy Reuscher \\ Ho-Ling Hwang
}

Final: June 2012

Prepared by

OAK RIDGE NATIONAL LABORATORY

Oak Ridge, Tennessee 37831-6283

managed by

UT-BATTELLE, LLC

for the

U.S. DEPARTMENT OF ENERGY

under contract DE-AC05-00OR22725 



\section{CONTENTS}

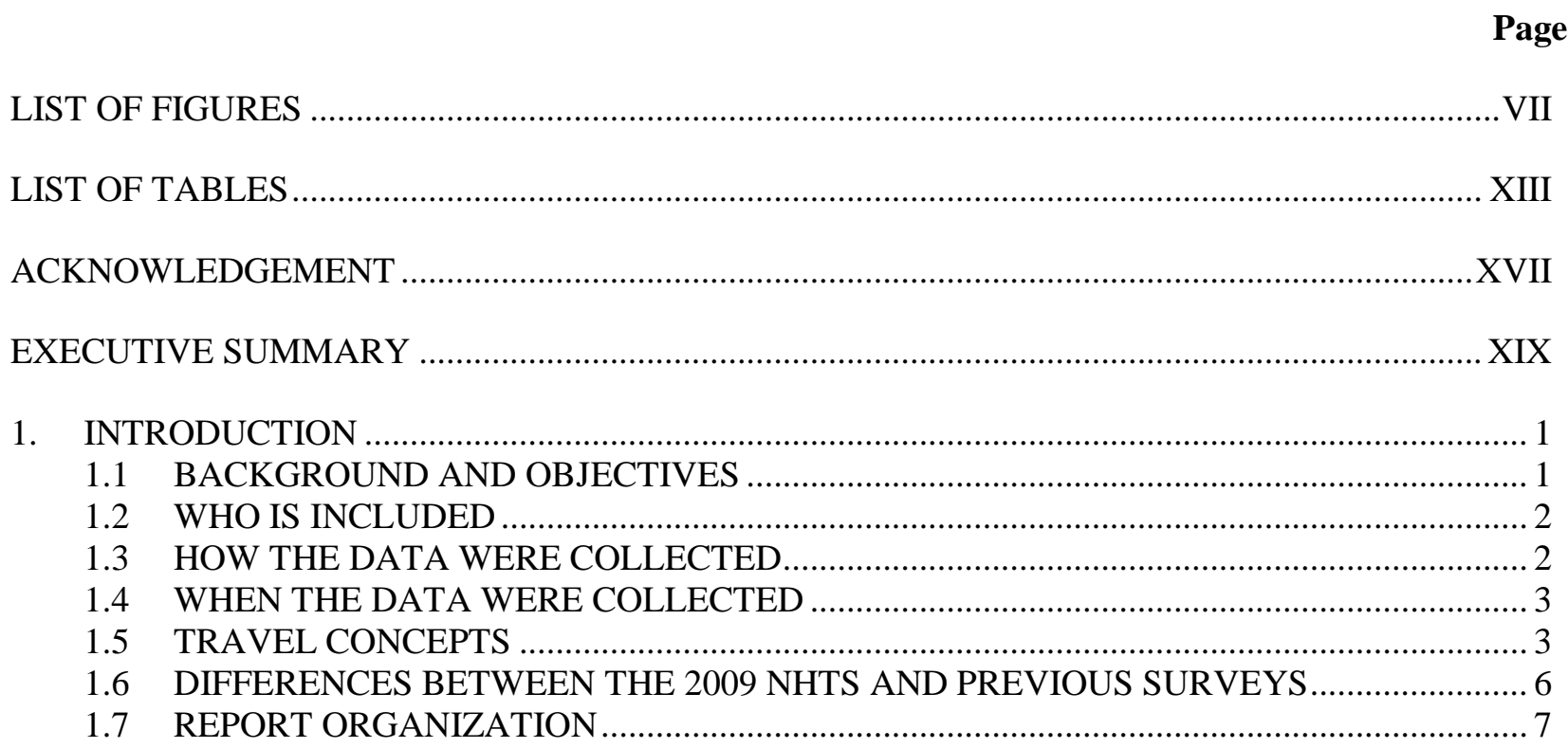

2. COMPARISON OF NEW YORK STATE DATA TO THE REST OF THE UNITED

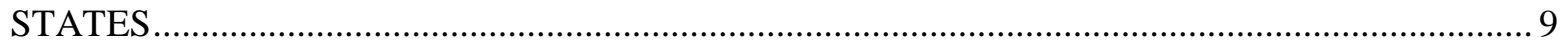

2.1 PROFILE OF NEW YORK STATE HOUSEHOLDS VERSUS HOUSEHOLDS IN

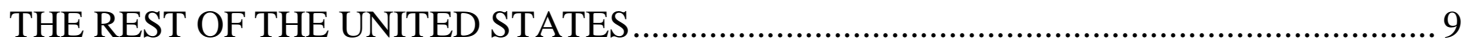

2.1.1 Number of Household Drivers, Licenses, Workers and Vehicles ............................... 10

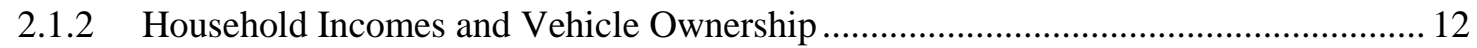

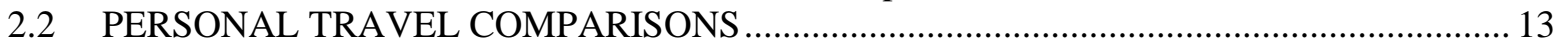

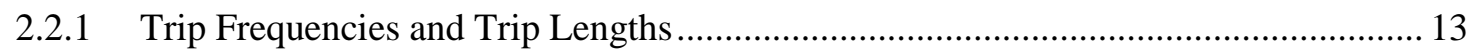

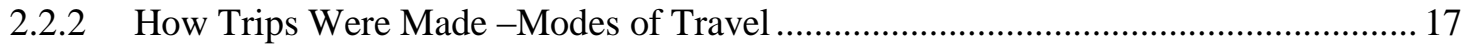

2.2.3 Why Trips Were Made - Purpose of Travel ......................................................... 20

2.2.4 Differences in Travel Pattern by Gender and Age Group .......................................... 21

2.2.5 Travel Differences and Vehicle Ownership............................................................ 23

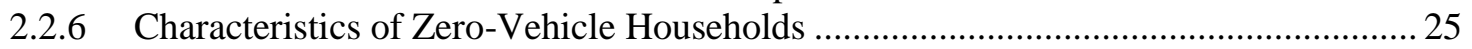

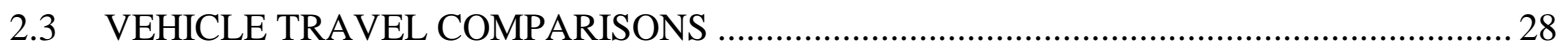

2.3.1 Types and Ages of Vehicles in Use .......................................................................... 31

2.3.2 Energy and Greenhouse Gas Emissions Associated With Vehicle Travel ....................36

2.4 COMPARISONS OF COMMUTING PATTERNS ....................................................... 38

3. INFLUENCE OF NEW YORK CITY ON NEW YORK STATE TRAVEL PATTERNS ............... 43

3.1 PROFILE OF NEW YORK CITY HOUSEHOLDS ....................................................... 44

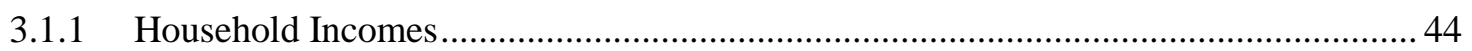

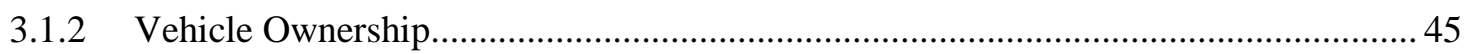

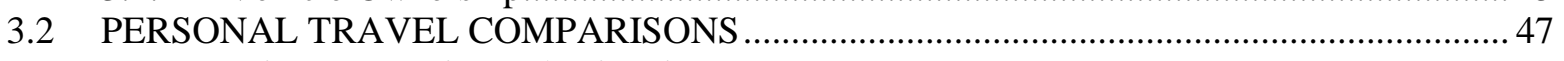

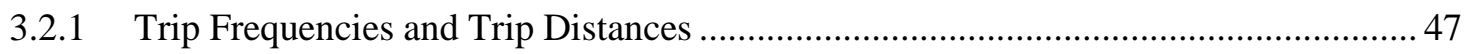

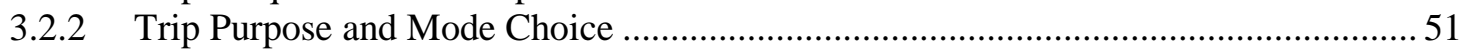

3.2.3 Differences in Travel by Gender and Age ...........................................................52

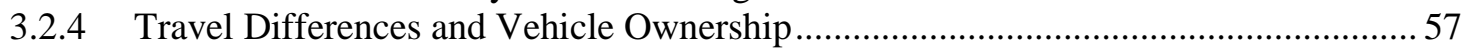

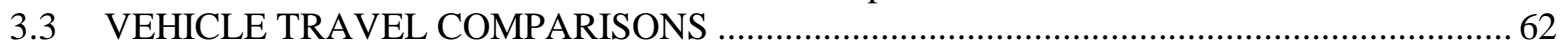

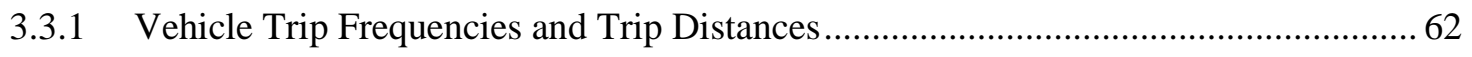




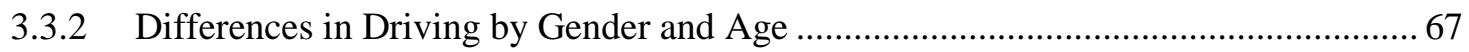

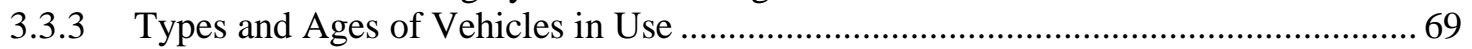

3.3.4 Energy and Greenhouse Gas Emissions Associated With Vehicle Travel .................. 72

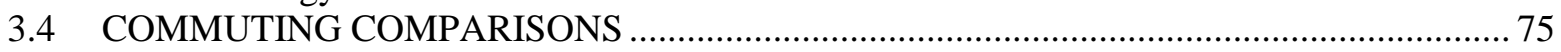

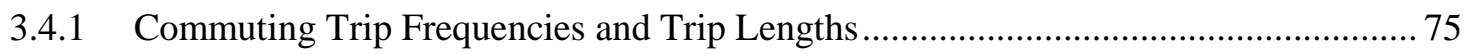

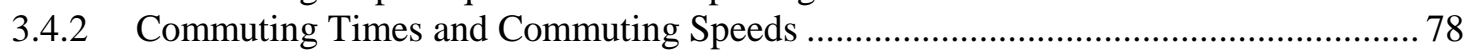

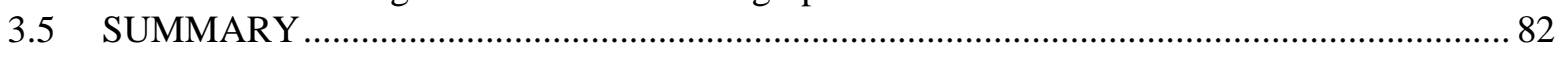

4. URBAN TRAVEL AND POPULATION DENSITY …................................................................ 83

4.1 PROFILE OF NYS ADD-ON STRATA HOUSEHOLDS BY POPULATION

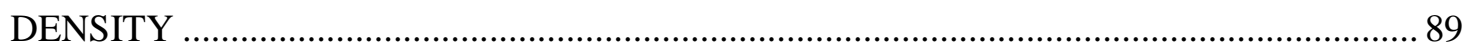

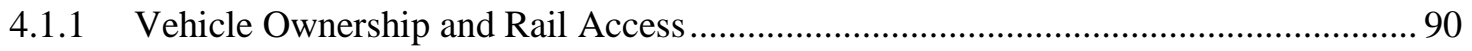

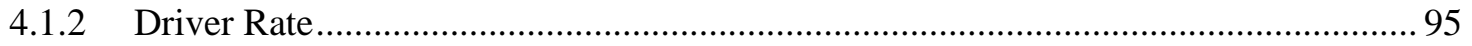

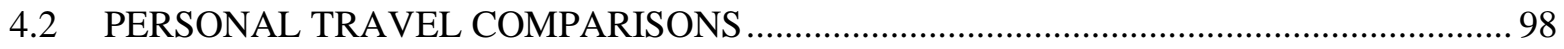

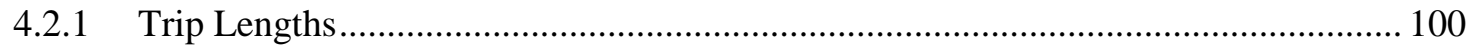

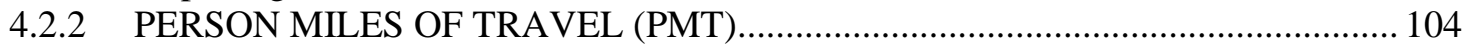

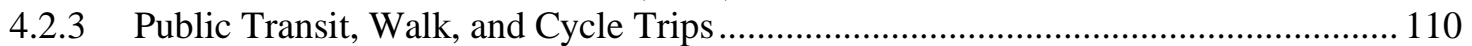

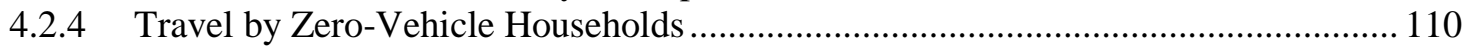

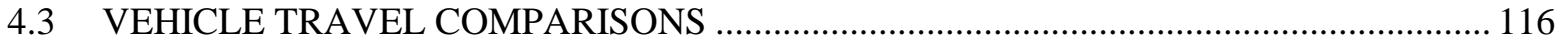

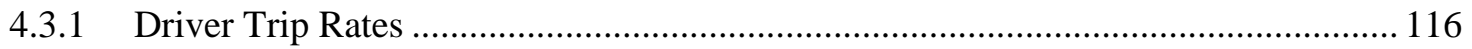

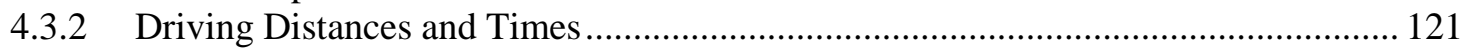

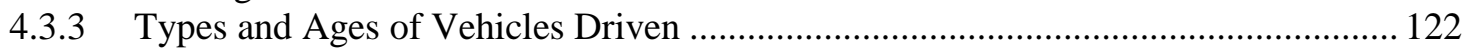

4.3.4 Greenhouse Gas Emissions Associated With Vehicle Travel.................................... 127

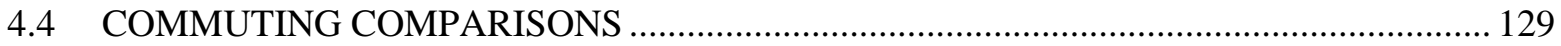

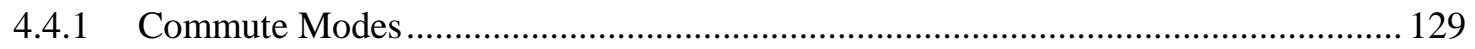

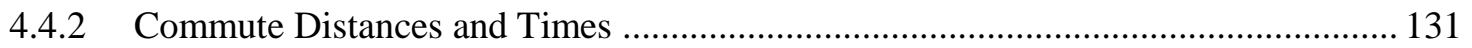

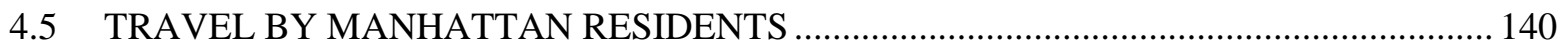

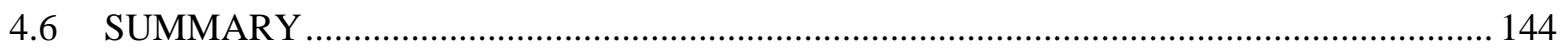

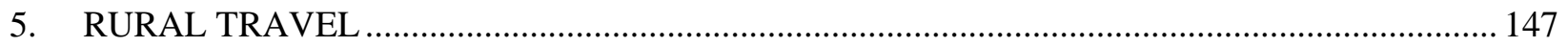

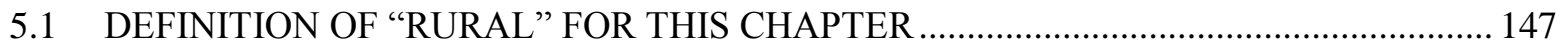

5.2 PROFILE OF RURAL NEW YORK STATE HOUSEHOLDS BY POPULATION

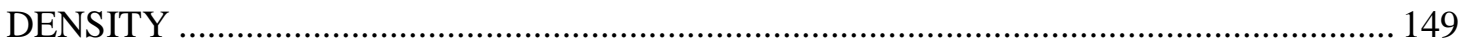

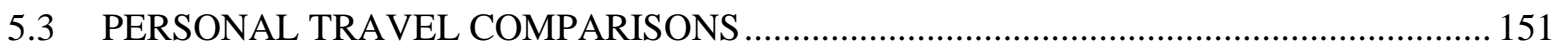

5.3.1 Trip Frequencies, Trip Lengths and Travel Times............................................... 151

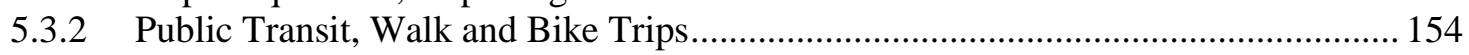

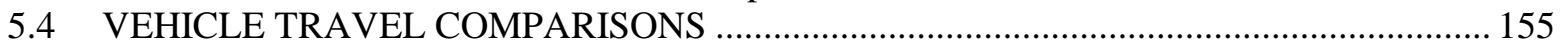

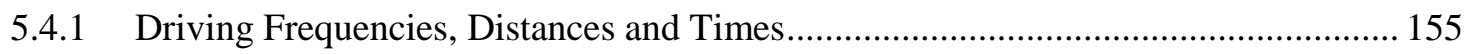

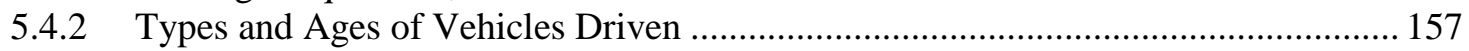

5.4.3 Energy and Greenhouse Gas Emissions Associated With Vehicle Travel ................. 159

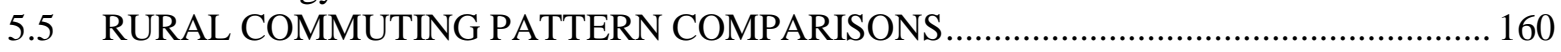

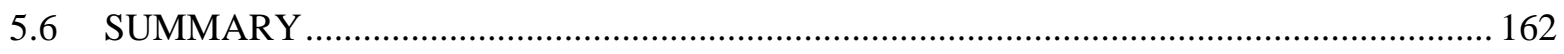

6. COMPARISON OF TRAVEL PATTERNS AMONG NEW YORK STATE

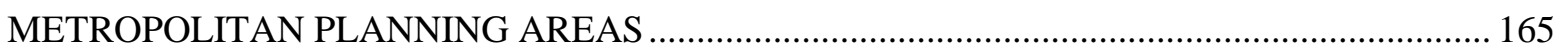

6.1 PROFILE OF NEW YORK STATE METRO AREA HOUSEHOLDS BY MSA SIZE....... 167

6.1.1 Workers Per Household, Vehicles Per Household, and Vehicles Per Driver ............ 167

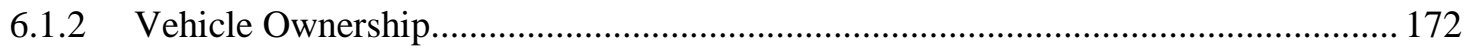

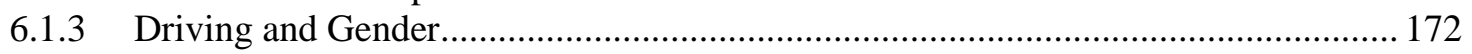

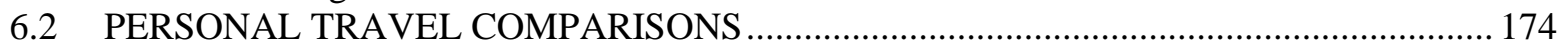

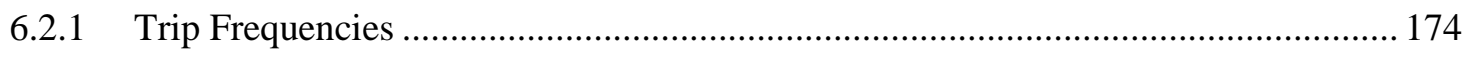




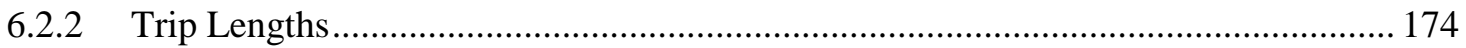

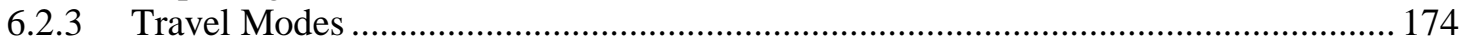

6.2.4 Vehicle Occupancy Rates ................................................................................. 182

6.2.5 Public Transit, Walk and Cycle Trips ...................................................................... 182

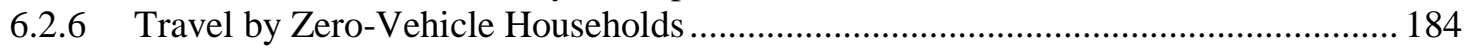

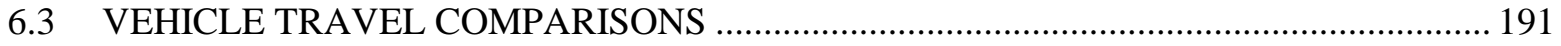

6.3.1 Driving Frequencies, Distances and Times............................................................... 191

6.3.2 Types and Ages of Vehicles Driven ………………………………………..... 200

6.3.3 Greenhouse Gas Emissions Associated With Vehicle Travel.................................... 202

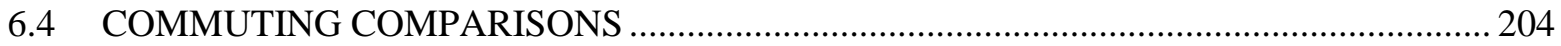

6.4.1 Commuting Trip Frequencies and Miles of Travel by Mode …………………….... 204

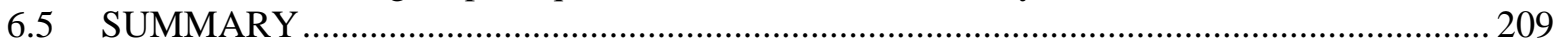

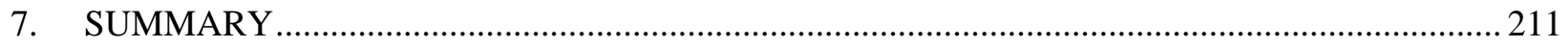

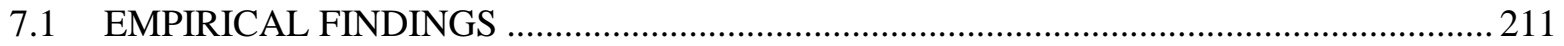

7.1.1 Sample Sizes and Weighted Sums ......................................................................211

7.1.2 Vehicle Ownership........................................................................................2215

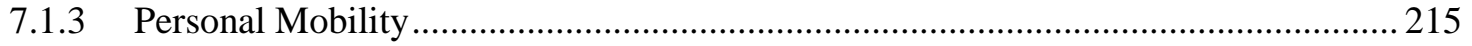

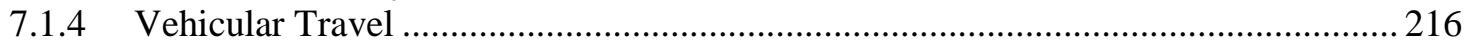

7.1.5 Impact of Not Owning a Vehicle on Mode Choice................................................... 216

7.1.6 Energy Related CO2 Emissions Associated with Travel.........................................2217

7.2 THE INFLUENCE OF NEW YORK CITY ON THE STATE'S PERSONAL TRAVEL

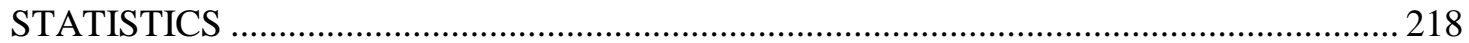

7.2.1 Vehicle Ownership and Income ......................................................................... 218

7.2.2 Trip Rates and Trip Distances........................................................................ 219

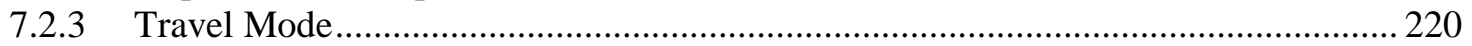

7.2.4 Carbon Dioxide Emissions ................................................................................... 220

7.3 HOW PERSONAL TRAVEL STATISTICS VARY WITH URBAN POPULATION

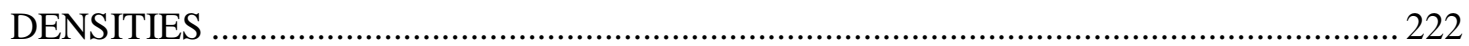

7.3.1 Trip Rates, Mode Choice and Population Density ……………………………….... 222

7.3.2 Commuting and Density ..................................................................................... 224

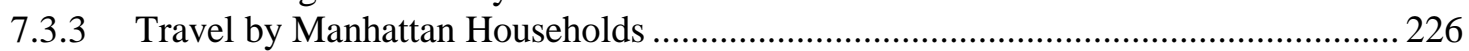

7.3.4 Rural Household Travel Comparisons ......................................................................226

7.3.5 MPO Specific Travel Characteristics...………………………………………...222

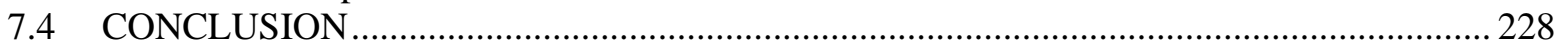

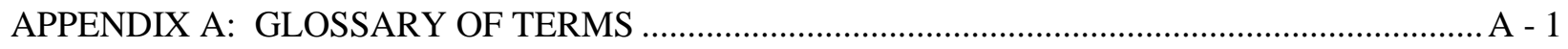

APPENDIX B: MAPS OF NEW YORK STATE AREAS ……………………………………..... B - 1

APPENDIX C: SUPPLEMENTAL TRAVEL TABLES BY CHAPTER............................................ C - 1

APPENDIX D: EMMISSIONS RATES BY MODE OF TRANSPORTATION..................................... D - 1 



\section{LIST OF FIGURES}

Figure

Page

Figure ES.1 Person Trip Percentages by Selected Modes, New York City, Remainder of New York State, and Rest of the United States in 2009. xxi

Figure ES.2 Daily Person Trips by Population Density: New York State Metros vs. Metros Found Outside New York State. xxiii

Figure ES.3 Combined Transit/Walk Share of Person Trips by Population Density, 2009 NHTS: New York State Metros vs. Metros Found Outside New York State. xxiii

Figure 1.1 Distinctions between Person Trip, Person Miles of Travel, Vehicle Trip, and Vehicle Miles of Travel.

Figure 2.1 Percent Differences in Number of Households, Drivers, Workers, and Vehicles from 1995 to 2001, 2001 to 2009, and 1995 to 2009.

Figure 2.2 Household (HH) Vehicle Ownership New York State vs. Rest of the United States in 1995, 2001, and 2009.

Figure 2.3 Weekday and Weekend Person Trips per Person in 1995, 2001, and 2009. (Note:

Weekend trips $=$ Saturday and Sunday trips)

Figure 2.4 Average Person Trip Lengths (in miles) in 1995, 2001, and 2009: New York State vs.

Rest of the United States.

Figure 2.5 Average Time Spent Walking and/or Biking to Places (in minutes) per day by Age

Group: New York State vs. Rest of the United States in 1995, 2001, and 2009.

Figure 2.6 Percentages of People Who Reported No Walk/Bike Trips in the Last Week,

Differentiated by Age Groups, in 2001 and 2009.

Figure 2.7 Daily Person Trips Rate by Age Group New York State vs. Rest of the United States in 2009.

Figure 2.8 Average Daily Person Trips per Person by Age Group: New York State vs. Rest of the United States 1995-2001-2009.

Figure 2.9 Person Trips Rate by Household Vehicle Ownership: New York State vs. Rest of the United States in 1995, 2001, and 2009.

Figure 2.10 Modal Shares for Vehicle Owning vs. Non-Vehicle Owning Households in 2009:

New York State vs. the Rest of the United States.

Figure 2.11 Modal Share Trends in Person Trips by Persons in Households That Don't Own a Vehicle: New York State vs. the Rest of the Nation.

Figure 2.12 Average Annual Miles Driven per Household Vehicle, by Vehicle Type in 1995, 2001, and 2009.

Figure 2.13 Trends in Average Annual Miles Driven per Household Vehicle, by Vehicle Age Group in 1995, 2001, and 2009.

Figure 2.14 Annual Carbon Dioxide (Metric Tons of CO2) Emissions from Travel* per Household in 2001 and 2009: New York State vs. Rest of the United States.

Figure 2.15 Temporal Trends in Average Daily Commute Trip Distance and Time in New York State vs. Rest of the United States.

Figure 3.1 New York City Boroughs.

Figure 3.2 NYC and Rest of State Traveler Population Statistics Shown as Percentages of NYS

Totals in 2009.

Figure 3.3 Trends in NYC Traveler Population Statistics as Percentage of Statewide Totals. 45

Figure 3.4 Distribution of Households by Number of Vehicles in 1995, 2001, and 2009. 47

Figure 3.5 Person Trip Percentages by Selected Modes, New York City, Remainder of New York State, and Rest of the United States in 2009. 
Figure 3.6 Daily Person Miles Traveled by Age for New York City, Remainder of New York

State, and Rest of the United States in 2009.

Figure 3.7 Distribution of Zero-Vehicle Households by Annual Income in 1995, 2001, and 2009

(in 2009 dollars) in New York City.

Figure 3.8 Distribution of Zero-Vehicle Households by Annual Income in 1995, 2001, and 2009 (in 2009 dollars) Rest of New York State.

Figure 3.9 Distribution of Zero-Vehicle Households by Annual Income in 1995, 2001, and 2009 (in 2009 dollars)Rest of United States.

Figure 3.10 Effects of Not Owning a Vehicle on Daily Travel in 1995, 2001, and 2009 Daily Person Trips per Person.

Figure 3.11 Effects of Not Owning a Vehicle on Daily Travel in 1995, 2001, and 2009 Daily Person Miles of Travel per Person.

Figure 3.12 Daily Driver Trip Rates in 1995, 2001, and 2009

Figure 3.13 Comparison of Driver Trip Purpose Shares in 2009: NYC, NYS, and Rest of the United States.

Figure 3.14 Daily Driver Vehicle Miles of Travel (VMT) by Gender in 1995, 2001, and 2009.

Figure 3.15 Daily Driver Vehicle Miles of Travel (VMT) by Age Group for New York City, Remainder of New York State, and Rest of the United States in 1995 and 2009, Average Daily VMT per Driver in 1995.

Figure 3.16 Daily Driver Vehicle Miles of Travel (VMT) by Age Group for New York City, Remainder of New York State, and Rest of the United States in 1995 and 2009, Average Daily VMT per Driver in 2001.

Figure 3.17 Daily Driver Vehicle Miles of Travel (VMT) by Age Group for New York City, Remainder of New York State, and Rest of the United States in 1995 and 2009, Average Daily VMT per Driver in 2009.

Figure 3.18 Average Annual Emissions of Carbon Dioxide (Metric Tons of CO2) from Household Travel* in 2001 and 2009

Figure 3.19 Trends in Daily Commute Trip Mode Shares for New York City, Remainder of New York State, and Rest of the United States: 1995, 2001, and 2009, New York City.

Figure 3.20 Trends in Daily Commute Trip Mode Shares for New York City, Remainder of New York State, and Rest of the United States: 1995, 2001, and 2009, Remainder of New York State.

Figure 3.21 Trends in Daily Commute Trip Mode Shares for New York City, Remainder of New

York State, and Rest of the United States: 1995, 2001, and 2009, Rest of the United States......... 77

Figure 3.22 Commute Patterns on Privately-Owned Vehicles New York City, Remainder of New

York State, and Rest of the United States, Year $=1995$.

Figure 3.23 Commute Patterns on Privately-Owned Vehicles New York City, Remainder of New

York State, and Rest of the United States, Year $=2001$.

Figure 3.24 Commute Patterns on Privately-Owned Vehicles New York City, Remainder of New

York State, and Rest of the United States, Year $=2009$.

Figure 3.25 Commute Patterns on Public Transit in New York City, Remainder of New York

State, and Rest of the United States, Year $=1995$.

Figure 3.26 Commute Patterns on Public Transit in New York City, Remainder of New York

State, and Rest of the United States, Year $=2001$.

Figure 3.27 Commute Patterns on Public Transit in New York City, Remainder of New York

State, and Rest of the United States, Year $=2009$.

Figure 4.1 The 2009 NHTS Metro Add-On Areas.

Figure 4.2 Distribution of New York State Households by Population Density in 1995, 2001, and 2009 (persons per square mile, based on census tracts). 
Figure 4.3 2009 Distribution of Households in New York Metros versus Metro Households in the Rest of the United States, by Population Density (persons per square mile, based on census tracts).

Figure 4.4 Percent of Households Having Access to Rail in New York State Metros vs. Metros Outside New York State, in 2001 and 2009.

Figure 4.5 Percentages of Households Without a Vehicle Broken Down by Population Density, New York Metros vs. Metros Outside New York State.* .

Figure 4.6 Driver Rates* by Gender and Population Density in 2009: New York State Metros vs. Metros Outside New York State.

Figure 4.7 Driver Rates* by Gender and Population Density in 2001: New York State Metros vs. Metros Outside New York State.

Figure 4.8 Driver Rates* by Gender and Population Density in 1995: New York State Metros vs. Metros Outside New York State.

Figure 4.9 Daily Person Trips by Population Density for New York State Metros vs. Metros Found Outside New York State (data based on census tracts).

Figure 4.10 Percentage Changes in Daily Person Trip Rates per Person (PTR) by Gender and Population Density.

Figure 4.11 Average Person Trip Lengths by Population Density Class: New York State Metros vs. Metros Outside New York State.*

Figure 4.12 Percentage Differences in Trip Length from 2001 to 2009 and from 1995 to 2009: New York State Metros versus Metros Outside New York State.

Figure 4.13 Distribution of Person Trips by Trip Length and Population Density for New York Metros.

Figure 4.14 Daily Person Miles of Travel by Population Density in NYS and Rest of US Metro Areas for 1995, 2001, and 2009.

Figure 4.15 Public Transit Trip Percentages of Daily Person Trips by Population Density................... 108

Figure 4.16 Walking Trip Percentages of Daily Person Trips by Population Density. ........................... 109

Figure 4.17 Average Minutes Spent on Walking Trips per Day by Population Density......................... 111

Figure 4.18 Average Daily Person Trips (in miles) of Individuals without a Vehicle New York State Metros vs. Metros Outside New York State by Population Density (persons per square mile, based on census tract data).

Figure 4.19 Percentage of Trips Taken by Public Transit by Those without a Vehicle, by

Population Density in 1995, 2001, and 2009 (in persons per square mile, based on census tract data).

Figure 4.20 Percentage of Trips Taken by Walking by Those without a Vehicle, by Population

Density in 2001 and 2009* (in persons per square mile, based on census tract data)...

Figure 4.21 Daily Vehicle Trip Rates in 1995, 2001, and 2009, for New York Metros and Metros Outside New York State (persons per square mile, based on census tract data).

Figure 4.22 Percentage Differences in Daily Vehicle Trip (VT) Rates Between New York Metros and Metros Outside New York State (persons per square mile, based on census tract data)

Figure 4.23 Average Driving Distances (in miles) for Drivers in New York Metros and for Metros Outside New York State, by Population Density (in persons per square mile, based on census tract data).

Figure 4.24 Average Driving Times (in minutes) for Drivers in New York Metros and Metros Outside New York State, by Population Density (in persons per square mile, based on census tract data).

Figure 4.25 Household In-Use Vehicle Fleet Percentages, by Vehicle Type and Population Density (in persons per square mile, based on census tract data).

Figure 4.26 Temporal Trend in Auto Share by Population Density (persons per square mile, based on census tract data). 
Figure 4.27 Variation in Age in Years of Privately Owned Household Vehicles with Population

Residential Density in 2009 (persons per square mile, based on census tract data). 126

Figure 4.28 Trends in Average Age of Privately Owned Household Vehicles with Population Density for 1995, 2001, and 2009.

Figure 4.29 Average Annual Emissions of Carbon Dioxide (Metric Tons of CO2) from

Household Travel in 2009 by Population Density (in persons per square mile, based on census tract data).

Figure 4.30 Estimated Average Annual Emissions of Carbon Dioxide (Metric Tons of CO2) from Household Travel for 2001 and 2009.

Figure 4.31 Commute Trips by Mode and Population Density for Households in NYS Metro Areas in 2009.

Figure 4.32 Commute Trips by Mode and Population Density for Households in Metro Areas Outside NYS in 2009.

Figure 4.33 Trends in Commute Times and Distances: New York State Metros versus Rest of the United States Metro Areas Compared, by Population Density Class (persons per square mile, based on census tract data).

Figure 4.34 Metro Area Commute Trip Lengths and Times on Public Transit Broken Down by Population Density in 2009: (density in persons per square mile, based on census tract data).

Figure 4.35 Average Daily Commute Trip Times by Public Transit in NYS Metro Areas in 1995, 2001 and 2009 by Population Density (in persons per square mile, based on census tract data)......

Figure 4.36 Percentage Increases in Commute Times: Public Transit versus Private Vehicle Trips in 2009, by Population Density

Figure 4.37 Temporal Trends in Commute Times (Percentage Differences) Between Public Transit and Private Vehicles, 1995, 2001, and 2009.

Figure 4.38 Commuting PMT* per Person by Density Class and Survey Year.

Figure 4.39 Driver Rates (Drivers per Adult >16 Years Old) for Those Living in Very Densely Populated Areas (areas with more than 50,000 people per square mile, based on census tract data).

Figure 4.40 Mode Choices Made by Households Living in Very Densely Populated Areas in 1995, 2001 and 2009 (areas with more than 50,000 people per square mile, based on census tract data).

Figure 5.1 Average Annual Miles Driven* per Rural Driver New York State (NYS) vs. Rest of the United States (US) (based on census tracts of less than 500 people per square mile).

Figure 5.2 Average Daily Person Trips per Person for Households Located in Census Tracts with

$<500$ Persons per Square Mile: New York State (NYS) vs. Rest of the United States (US). ...... 153

Figure 5.3 Average Person Trip Lengths for Households Located in Census Tracts with $<500$

Persons per Square Mile: New York State (NYS) vs. Rest of the United States (US).

Figure 5.4 Distribution of Vehicle Trips in Rural Areas by Trip Length New York State (NYS)

vs. Rest of the United States (US).* (based on census tracts of less than 500 people per square mile)

Figure 5.5 Comparison of Urban (Metro) and Rural Area Carbon Dioxide Emissions: Average

Metric Tons of CO2 Emitted Per Household Per Year in 2001 and 2009.*.....

Figure 5.6 Daily Commute Patterns in Rural Areas New York State (NYS) vs. Outside New York State (US) (based on census tracts of less than 500 people per square mile) .............................. 162

Figure 6.1 Population Densities by 2010 Census Tracts in New York State......................................... 166

Figure 6.2 New York State Metro Area Households (000s) by MSA Size Class and Share................... 168

Figure 6.3 Percentage of Population Who Drive Categorized by Gender for New York State Metro Areas in 1995, 2001, and 2009: Male Drivers. 
Figure 6.4 Percentage of Population Who Drive Categorized by Gender for New York State

Metro Areas in 1995, 2001, and 2009: Female Drivers.

Figure 6.5 Average Daily Person Trips in New York Metro Areas in 1995, 2001, and 2009................ 178

Figure 6.6 Average Person Trip Distances in New York Metro Areas in 1995, 2001, and 2009............ 178

Figure 6.7 Daily Person Trips by Selected Modes: New York State Metro Areas in 2009..................... 179

Figure 6.8 Daily Person Trips by Selected Modes: New York State Metro Areas in 2001 ..................... 180

Figure 6.9 Daily Person Trips by Selected Modes: New York State Metro Areas in 1995..................... 181

Figure 6.10 Personal Travel Trends of Zero-Vehicle Households in New York Metro Areas:

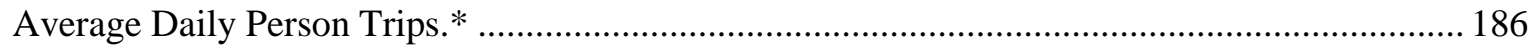

Figure 6.11 Personal Travel Trends of Zero-Vehicle Households in New York Metro Areas:

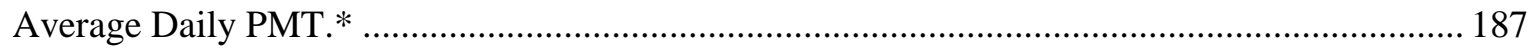

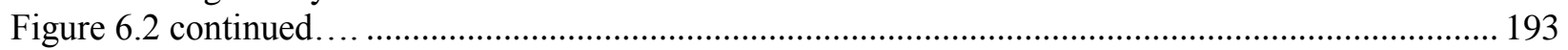

Figure 6.12 Vehicle Travel Statistics by New York State Metro Areas in 1995, 2001, and 2009. .......... 193

Figure 6.13 Average Time Driving a Private Vehicle and Daily VMT by New York State Metro

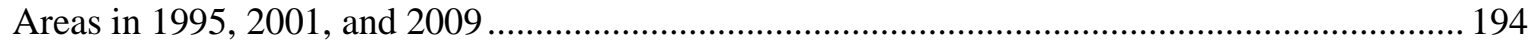

Figure 6.14 Distribution of Vehicle Trips by Household Trip Purpose in NYS Metro Areas in

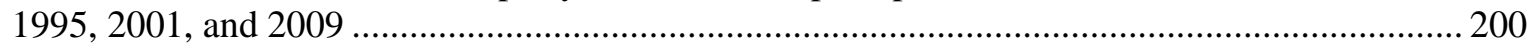

Figure 6.15 Annual Estimated Vehicle Mileages Driven by NYS Metro Areas, in 1995, 2201 and 2009. ${ }^{\mathrm{a}}$

Figure 6.16 Average Annual Emissions of Carbon Dioxide (Metric Tons of CO2) from Household Travel by NYS Metro Area in 2009 by Private/Public Modes of Transportation.

Figure 6.17 Average Commuting Distances and Travel Times for Individual NYS Metro Areas in

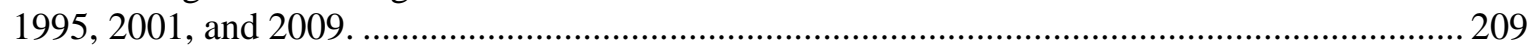

Figure 7.1 2009 NHTS New York Add-on Areas.................................................................................. 212

Figure 7.2 Distribution of Households Owning Vehicles in New York vs. Rest of the United

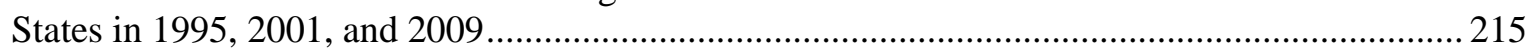

Figure 7.3 Personal Mobility Statistics in New York State vs. Rest of the United States...................... 216

Figure 7.4 Annual Carbon Dioxide Emissions (Metric Tons of CO2) from Travel per Household in 2001 and 2009: New York State vs. Rest of the United States. .......................................... 217

Figure 7.6 Effects of Not Owning a Vehicle on Daily Person Trips per Person. ................................... 219

Figure 7.7 Daily Person Trips per Person and Average Trip Length (miles). ......................................220

Figure 7.8 Person Trip Percentages by Selected Modes, New York City, Remainder of New York

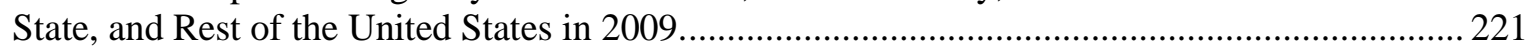

Figure 7.9 Average Annual Emissions of Carbon Dioxide (Metric Tons of CO2) from Household

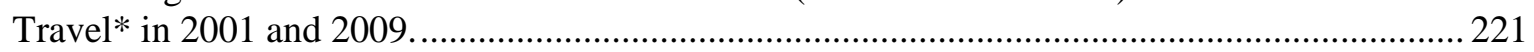

Figure 7.10 Percentages of Households Without a Vehicle Broken Down by Population Density, New York Metros vs. Metros Outside New York State............................................................... 222

Figure 7.11 Daily Person Trips by Population Density: New York State Metros vs. Metros Found

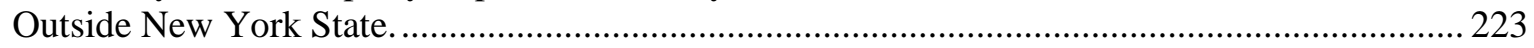

Figure 7.12 Combined Transit/Walk Share of Person Trips by Population Density, 2009 NHTS: New York State Metros vs. Metros Found Outside New York State ......................................... 223

Figure 7.13 Daily Vehicle Trip Rates in 1995, 2001, and 2009: New York Metros and Metros Outside New York State by Population Density Class (persons per square mile). ...................... 224

Figure 7.14 Commute Trips by Mode and Population Density for Households in NYS Metro Areas in 2009. 225

Figure 7.15 Commute Trips by Mode and Population Density for Households in Metro Areas

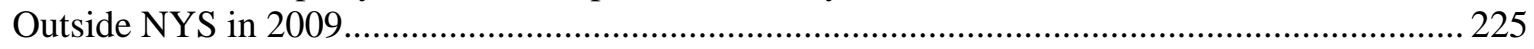

Figure 7.16 Population Densities by 2010 Census Tracts.....................................................................22

Figure 7.17 Daily Person Trips by Selected Modes for New York State Metro Areas in 2009............. 229 



\section{LIST OF TABLES}

Table

Table 2.1 Summary of Household Characteristics and Vehicle Licensing Rate New York State vs. the Rest of the United States in 1995, 2001, and 2009

Table 2.2 Household Vehicle Ownership Levels in 1995, 2001, and 2009.

Table 2.3 Personal Travel Statistics by Demographic Characteristics for New York State vs. Rest of the United States in 1995, 2001, and 2009

Table 2.4 Person Travel Rates and Mode Shares New York State vs. Rest of the United States 1995, 2001, and 2009

Table 2.5 Average Minutes Spent Walking and/or Biking Per Day in 1995, 2001, and 2009 by Different Age Groups

Table 2.6 Daily Person Trips Rate by Trip Purpose in New York State vs. Rest of the United States in 1995, 2001, and 2009

Table 2.7 Daily Person Trips Rate by Gender and by Age Groupings New York State vs. Rest of the United States in 1995, 2001, and 2009.

Table 2.8 Distribution of Households (Hhs) Without A Vehicle Across Income Groups: New

York State vs. the Rest of the United States in 1995, 2001, and 2009

Table 2.9 Travel Patterns and Characteristics for Zero-Vehicle Households: New York State vs. the Rest of the Nation in 1995, 2001, and 2009

Table 2.10 Daily Vehicle Travel Statistics: New York State vs. Rest of the United States

Table 2.11 Comparison of Vehicle Types Driven in New York State vs. the Rest of the United States in 1995, 2001, and 2009

Table 2.12 Characteristics of Households' Private Vehicle Fleets by Vehicle Age New York State vs. Rest of the United States

Table 2.13 Average Annual VMT Per Household Vehicle, by Vehicle Type and Vehicle Age Group in 1995, 2001, and 2009.

Table 2.14 Average Annual Carbon Dioxide (CO2) Emissions Per Household in New York State vs. the Rest of the United States, 2001 and 2009

Table 2.15 Commute Statistics New York State vs. Rest of the United States in 1995, 2001, and 2009.

Table 2.16 Commute Travel Distances, Times and Average Speeds for New York State vs. Rest of the United States in 1995, 2001, and 2009

Table 3.1 Household Characteristics and Vehicle Ownership Trends in New York City, Rest of New York State, and Rest of the United States in 1995, 2001, and 2009.

Table 3.2 Person Trip Statistics by Mode of Transportation and Trip Purpose New York City, Remainder of New York State, and Rest of the United States.

Table 3.3 Person Miles of Travel Statistics by Mode of Transportation and Trip Purpose New York City, Remainder of New York State, and Outside New York State

Table 3.4 Statistics on Walking and/or Biking for Nyc, Remainder of NYS, and Rest of United States Compared: 1995, 2001, and 2009 by Different Age Groups...

Table 3.5 Daily Personal Travel Statistics by Demographics New York City, Remainder of New York State, and Rest of the United States: 1995, 2001, and 2009

Table 3.6 Percentage of Zero-Vehicle Households by Annual income Classes in 1995, 2001, and 2009 (in 2009 Dollars)

Table 3.7 Average Daily Person Trips Per Person by Mode for Zero-Vehicle Owning Households in 1995,2001 , and 2009

Table 3.8 Daily Vehicle Trips Per Driver Statistics for New York City, Rest of New York State, and Rest of the United States in 1995, 2001, and 2009 
Table 3.9 Daily Vehicle Miles of Travel (VMT) Per Driver Statistics for New York City, Rest of

New York State, and Rest of the United States in 1995, 2001, and 2009 and Rest of the

United States in 1995, 2001, and 2009.

Table 3.10 Comparison of Vehicle Types Driven in 1995, 2001, and 2009 (Fleet Percentages)

Table 3.11 Percentage of Households' Private Vehicle Fleets Over Ten Years Old: New York

City, Remainder of New York State and Rest of the United States Compared

Table 3.12 Average Vehicle Miles Driven Per Household Vehicle, by Vehicle Type and Vehicle

Age Group in 1995, 2001, and 2009

Table 3.13 Percentage of Household Vehicle Fleets, by Vehicle Type and Vehicle Age Group in 1995, 2001, and 2009

Table 3.14 Average Annual Emissions of Carbon Dioxide From Household Travel Summed Over All Modes of Travel

Table 3.15 Daily Commute Statistics by Mode of Transportation in New York City, Remainder of

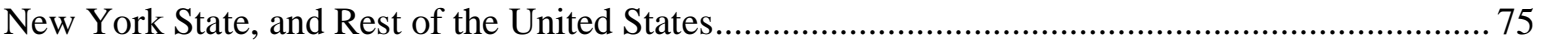

Table 3.16 Commuting Distances, Times, and Speeds for Private and Public Modes of

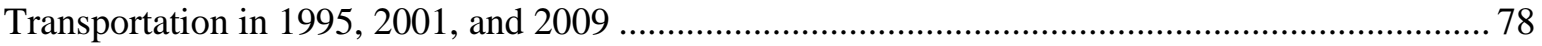

Table 4.1 2009 New York State Household Distribution by Metro Area and Population Density ............ 86

Table 4.2 2001 New York State Household Distribution by Metro Area and Population Density ............87

Table 4.3 1995 New York State Household Distribution by Metro Area and Population Density ............ 88

Table 4.4 2009 Household Characteristics and Vehicle Ownership Patterns by Population

Density: New York State Metros vs. Metros Found Outside New York State ................................ 91

Table 4.5 2001 Household Characteristics and Vehicle Ownership Patterns by Population

Density: New York State Metros vs. Metros Found Outside New York State ................................ 92

Table 4.6 1995 Household Characteristics and Vehicle Ownership Patterns by Population Density for New York State Metros vs. Metros Found Outside New York State

Table 4.7 Personal Travel Statistics by Mode of Transportation and Population Density New

York State Metros (NYS) vs. Metros Outside New York State (U.S.) in 2009

Table 4.8 Personal Travel Statistics by Mode of Transportation and Population Density New

York State Metros (NYS) vs. Metros Outside New York State (U.S.) in 2001 ............................ 106

Table 4.9 Personal Travel Statistics by Mode of Transportation and Population Density New

York State Metros (NYS) vs. Metros Outside New York State (U.S.) in 1995.

Table 4.10 Average Person Trip Lengths (in Miles) by Population Density and Vehicle

Ownership in 1995, 2001, and 2009

Table 4.11 Statistics on Daily Vehicle Travel by Population Density New York State Metros

(NYS) vs. Metros Outside New York State (U.S.), 2009

Table 4.12 Statistics on Daily Vehicle Travel by Population Density New York State Metros

(NYS) vs. Metros Outside New York State (U.S.), 2001

Table 4.13 Statistics on Daily Vehicle Travel by Population Density for New York State Metros

(NYS) vs. Metros Outside New York State (U.S.), 1995

Table 4.14 Daily Commute Statistics by Population Density Between New York State Metro

Areas (NYS) vs. Metro Areas in the Rest of the United States (U.S.), 2009.

Table 4.15 Daily Commute Statistics by Population Density Between New York State Metro Areas (NYS) vs. Metro Areas in the Rest of the Nation (U.S.), 2001

Table 4.16 Daily Commute Statistics by Population Density New York State Metro Areas (NYS) vs. Metro Areas in the Rest of the United States (U.S.), 1995

Table 4.17 Household and Travel Characteristics of Manhattan, Other Nyc Residents, and Residents Living in Very Dense Metro Areas, in 1995, 2001, and 2009.

Table 5.1 Distribution of Rural Households by Census Block Group's Population Density: New York State vs. Rest of the United States in 2009. 148

Table 5.2 Rural Household Distribution by Census Tract Population Density in the 2009 NHTS 149 
Table 5.3 Characteristics of Rural Households New York State (NYS) vs. Rest of the United States (US) (Based on Rural Census Tracts With < 500 Persons Per Square Mile) ... 150

Table 5.4 Personal Travel Statistics of Rural Households by Mode and Trip Purpose New York State (NYS) vs. in the Rest of the United States (US) ............................................................ 152

Table 5.5 Rural Area Per Person Walking and Biking Activity Statistics for 1995, 2001, and 2009 New York State (NYS) vs. Rest of the United States (US) ..................................................... 155

Table 5.6 Vehicle Travel Statistics by Drivers in Rural Areas New York State (NYS) vs. Rest of the United States (US). 156

Table 5.7 Types and Ages of Vehicles Used by Rural Households in New York State and in the Rest of the United States. 158

Table 5.8 Comparison of Average Annual Vehicle Miles of Travel by Vehicle Type for Rural Households in New York State and in the Rest of the United States..... 158

Table 5.9 Daily Commute Statistics in Rural Areas by Mode of Transportation: New York State

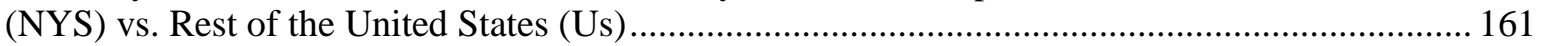

Table 6.1 New York State Mpo-Based Metro Areas Categorized by Population Size Class ................... 167

Table 6.2 Household Characteristics and Vehicle Ownership Patterns for New York State Metro Areas by MSA Size in 2009.

Table 6.3 Household Characteristics and Vehicle Ownership Patterns for New York State Metro Areas by MSA Size in 2001.

Table 6.4 Household Characteristics and Vehicle Ownership Patterns for New York State Metro

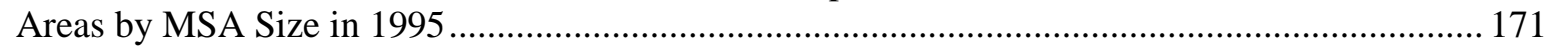

Table 6.5 Personal Travel Statistics New York State Metro Areas by Msa Size in 2009 ...................... 175

Table 6.6 Personal Travel Statistics New York State Metro Areas by Msa Size in 2001 ....................... 176

Table 6.7 Personal Travel Statistics New York State Metro Areas by Msa Size in 1995 ...................... 177

Table 6.8 Walking and Biking Trip Activity in NYS Metro Areas in 1995, 2001, and 2009 ................. 183

Table 6.9 Number of New York Households With Completed interviews in 2009 NHTS, by Number of Vehicles 184

Table 6.10 Person Travel for Zero-Vehicle Households by Mode of Transportation New York

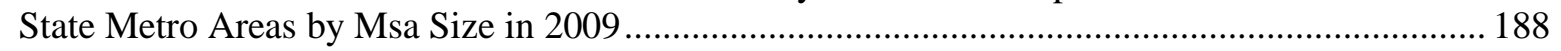

Table 6.11 Person Travel for Zero-Vehicle Households by Mode of Transportation New York State Metro Areas by Msa Size in 2001.

Table 6.12 Person Travel for Zero-Vehicle Households by Mode of Transportation New York State Metro Areas by Msa Size in 1995.

Table 6.13 Daily Vehicle Travel Statistics of New York State Metro Area Drivers by Msa Size in 1995, 2001, and 2009.

Table 6.14 Daily Vehicle Travel Statistics for New York State Metro Area Drivers, by Trip Purpose and MSA Size in 2009 196

Table 6.15 Daily Vehicle Travel Statistics for New York State Metro Area Drivers, by Trip Purpose and MSA Size in 2001

Table 6.16 Daily Vehicle Travel Statistics for New York State Metro Area Drivers, by Trip Purpose and MSA Size in 1995. 198

Table 6.17 Household in-Use Vehicle Fleet Percentages for NYS Metro Areas, by Vehicle Types in 1995, 2001, and 2009, and Vehicle Age in 2009. 201

Table 6.18 Commute Statistics by Mode of Transportation New York State Metro Areas by MSA Size in 2009 ..... 206

Table 6.19 Commute Statistics by Mode of Transportation New York State Metro Areas by MSA Size in 2001. 207

Table 6.20 Commute Statistics by Mode of Transportation New York State Metro Areas by MSA Size in 1995. 208

Table 7.1 Summary Statistics on Demographic Characteristics Based on 1995, 2001, and 2009 NPTS/NHTS for New York State and the Rest of the United States. 213 
Table 7.2 Summary Statistics on Travel Based on 1995, 2001, and 2009 NPTS/NHTS for New York State and the Rest of the United States 


\section{ACKNOWLEDGEMENT}

In Memoriam: The authors would like to dedicate this report to the memory of Nathan Erlbaum of the New York State Department of Transportation, who initiated, oversaw and made many invaluable contributions to this and all past New York State NHTS Comparison Reports. These reports represent just some of the many contributions Nathan made over a number of decades to the collection and in-depth analysis of travel and transportation data both within New York State and the nation at large. His understanding of data needs and of the importance of data quality to sound decision-making had a positive influence on all who knew and worked with him. His dedication, insight into and passion for his profession serves as a model for the rest of us. 
xviii 


\section{EXECUTIVE SUMMARY}

The U.S. Department of Transportation (USDOT) initiated an effort in 1969 to collect detailed data on personal travel, with the most recent surveys being the 1995 Nationwide Personal Transportation Survey (NPTS) and the 2001 and 2009 National Household Travel Surveys (NHTS). The primary objective of these surveys is to collect trip-based data on the nature and characteristics of personal travel so that the relationships between the characteristics of personal travel and the socio-economic and demographic characteristics of the traveler and his/her household can be established. In addition to the number of sample households that the national NPTS/NHTS survey allotted to New York State, NYDOT procured an additional sample of households in the 1995, 2001, and 2009 surveys. The comparisons drawn in this report compare the results from these NYS sampled households to the results from households drawn for the rest of the nation.

\section{COMPARISONS BETWEEN NEW YORK STATE AND THE REST OF THE NATION}

From a statewide perspective, personal travel in New York State (NYS) and the rest of the nation differs in a couple of significant ways:

Personal Mobility: New York State residents consistently have taken fewer and shorter trips, and have driven considerably fewer miles than those in the

New York State residents consistently have taken fewer and shorter trips, and have driven considerably fewer miles than those in the rest of the U.S.

rest of the U.S. over the three survey years. Specifically, NYS

drivers traveled just under 20 miles daily, on the average, versus about 30 miles by drivers from the rest of the nation.

Vehicular Travel: In 2009, NYS drivers made an average of 2.3 trips daily, versus just over 3 trips daily by drivers in the rest of the nation. In $2009,70 \%$ of the NYS households' private vehicle fleet was made up of vehicles reported to be less than 10 years old. In the rest of the nation this percentage was $60 \%$. 


\section{THE INFLUENCE OF NEW YORK CITY ON THE STATE'S PERSONAL TRAVEL STATISTICS}

As expected, the travel patterns of New York City (NYC) residents differ significantly in a number of ways from patterns found elsewhere in the state, as well as in the nation as a whole. These differences include the following:

Vehicle Ownership and Income: Only $72 \%$ of NYC residents over the age of 16 held a driver's license in 2009 , versus $89 \%$ of residents in the rest of the state and also $89 \%$ in the rest of the nation. Households in the rest of NYS resemble

Over half of New York City households do not own any vehicles. households elsewhere in the United States in terms of vehicle ownership; with more than $90 \%$ of households owning at least one vehicle. Over half of NYC households do not own any vehicles in all three NPTS/NHTS survey years. NYC households are also far less likely on the average to own more than one vehicle than other NYS households, or households elsewhere.

Approximately $60 \%$ of zero-vehicle households in the rest of the state and nation have incomes below $\$ 20,000$, while this proportion is only around one third for NYC. However, NYC households that do not own a vehicle are much more mobile than similar households in the rest of the state and nation, with daily person trip rates maintained by larger numbers of public transit and walk trips. As a result, while zero-vehicle owning households in the rest of the state and nation typically take roughly one third fewer person trips than the average household, this mobility gap is not evident for New York City households.

Travel Mode: Residents of NYC are nearly four times more likely to walk to their destinations and twelve times more likely to use public transit Residents of New York City are four times more likely to walk and twelve times more likely to use public transit than those in the rest of the state. than those in the rest of the state, with such differences even larger compared to those outside NYS (Figure ES.1). 


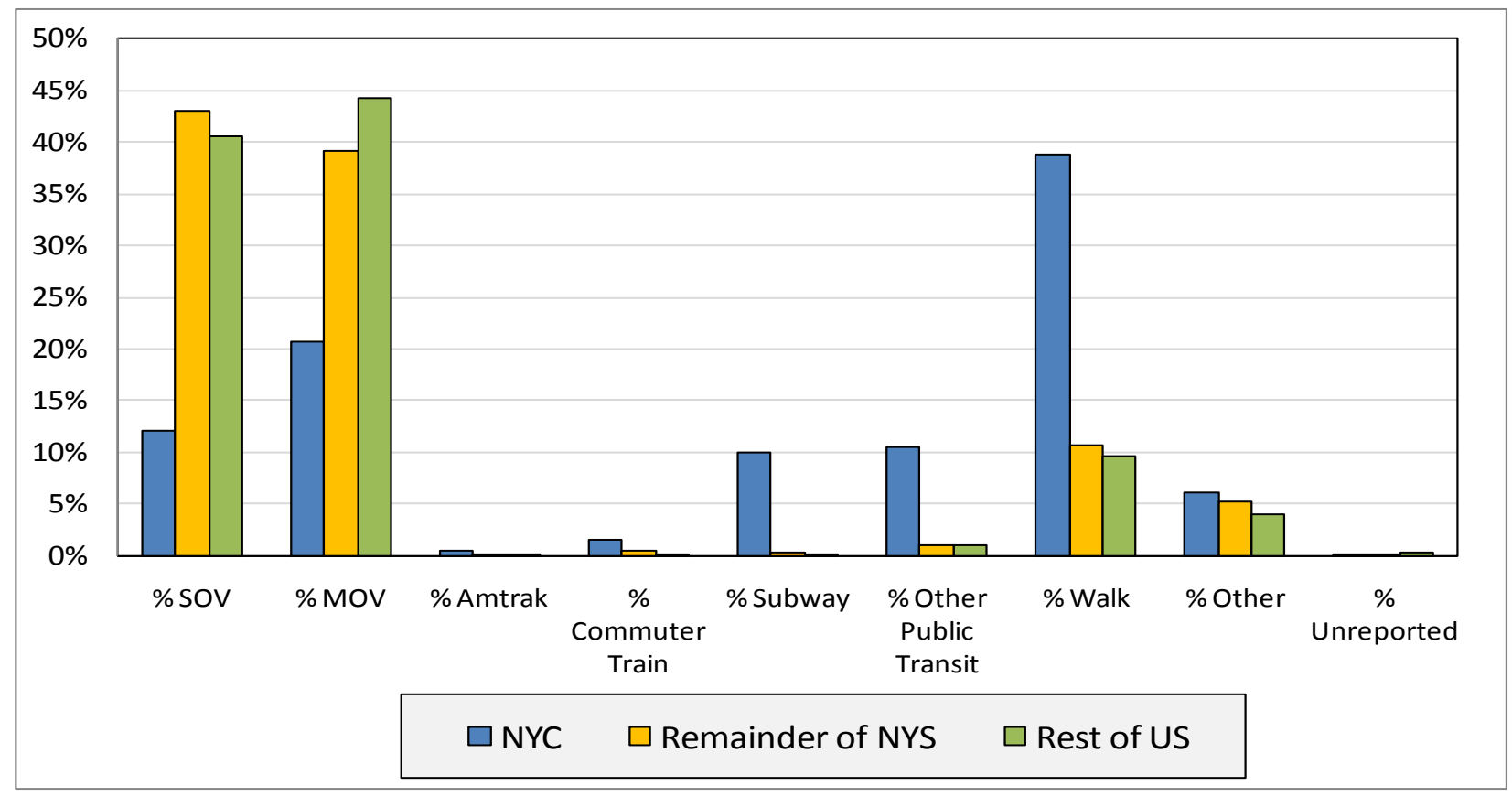

Figure ES.1 Person Trip Percentages by Selected Modes for New York City, Remainder of New York State, and Rest of the United States in 2009.

On average, New York City households emitted less than $40 \%$ of the personal travel related $\mathrm{CO} 2$ emissions in the rest of the state.

\section{Carbon Dioxide Emissions:}

Significantly greater use of nonmotorized forms of travel (walk and cycle) and of public transit modes, a significantly lower average trip length, and lower

daily trip rates meant that New York State households on average emitted far fewer carbon dioxide emissions annually from their daily travel activities than did households in the rest of the nation, in both 2001 and 2009. Much of this difference is attributable to the travel characteristics of NYC households, who have shorter average trip distances, who walk a good deal more to activities, and who make much greater use of public transit modes for their daily travel needs. On average, NYC households in 2009 emitted less than $40 \%$ of the personal travel related CO2 emissions of households in the rest of the state, and only one third the emissions of households in the rest of the nation.

Excluding NYC households, households in the rest of the state exhibit travel characteristics that are, for the most part, quite similar to those for the rest of the nation. 


\section{HOW PERSONAL TRAVEL STATISTICS VARY WITH URBAN POPULATION DENSITIES}

NYC residential and employment densities are much higher than those in most of the rest of the state and nation. This begs the question how such densities affect travel activity patterns, both within and outside the state. The percentage of households without a vehicle is, as one might expect, positively correlated with higher population density. Such relationships with density also exist between driver rates (which fall as density increases) and the availability of public transit (which rises as density increases).

\section{Trip Rates, Mode Choice and}

\section{Population Density: Figure}

ES. 2 below shows the relationship between daily trip rate and population density -
The mode share of person trips by transit and walk increases with population density.

first increasing, then declining as population density increases. Also of note is the reduced difference in 2009 between the generally higher 1995 and 2001 NYS person trip rates versus those in the rest of the US, at most density levels. In terms of mode choice, public transit and walk modes accounted for ten times the percentage of NYS metro area trips among 2009 travelers in the highest density class than they did in the lowest density class, with the metro areas in the rest of the nation in 2009 displaying a similar result (Figure ES.3).

Population density plays a similar role with respect to vehicle trip frequencies both within and outside the state. A typical NYS metro area driver in the most densely populated areas takes about one vehicle trip a day. As reported earlier, residents in these very high density areas, notably NYC, either walk or ride public transit most of the time. 


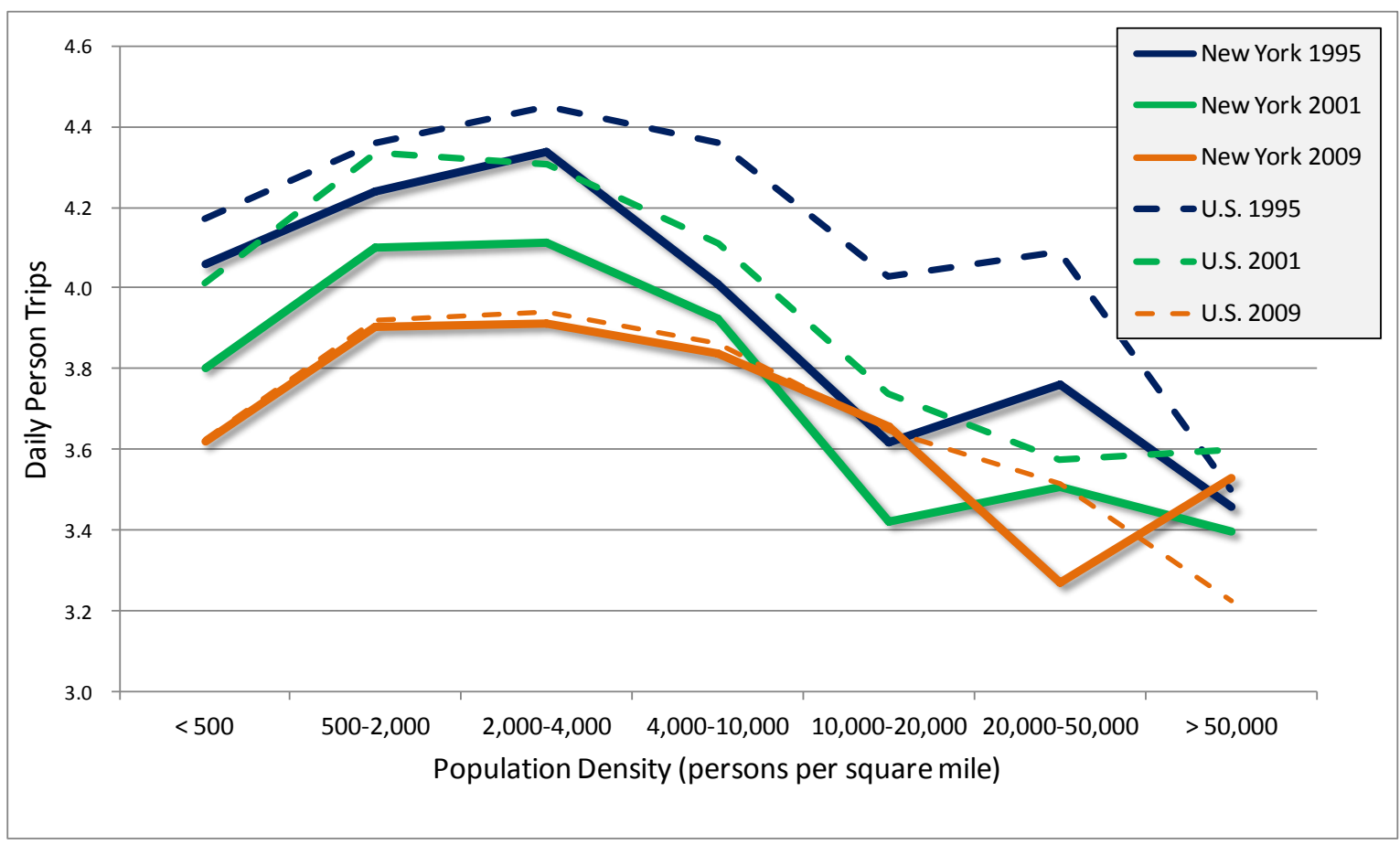

Figure ES.2 Daily Person Trips by Population Density: New York State Metros vs. Metros Found Outside New York State.

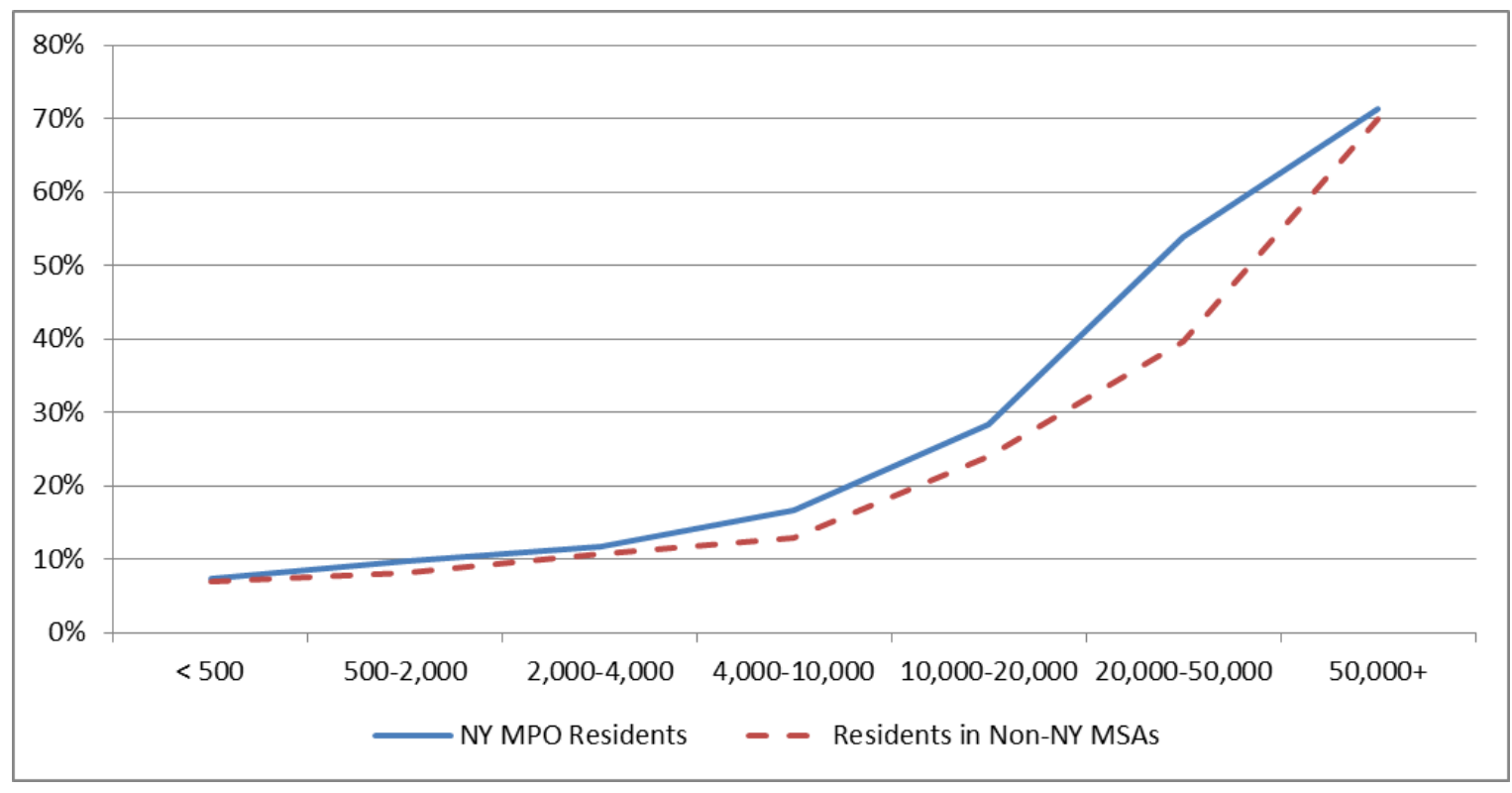

Figure ES.3 Combined Transit/Walk Share of Person Trips by Population Density, 2009 NHTS: New York State Metros vs. Metros Found Outside New York State. 
Commuting and Density: While metro areas both inside and outside the state display a significant shift from private automobile trips to public transit trips with increasing population density, and noticeably so at densities over 20,000 persons per square mile (ppsm), this shift is much more noticeable within NYS, principally due to the higher rates of transit ridership and also walk trips within the NYC metro area. This pattern has remained essentially the same since 1995. Among the highest density areas of over 50,000 ppsm that were sampled outside the state in 2009 , some $44 \%$ of commuter trips still used private household vehicles. Within NYS (effectively households found within NYC) only some $16 \%$ of commutes are privately owned vehicle at these very high population densities: with public transit and walk trips accounting for three quarters of all commutes daily.

Travel by Manhattan Households: With roughly ninety percent of its households situated in populated areas with more than 50,000 people per square mile, the question of whether Manhattan residents travel differently from Americans living in similarly dense urban areas elsewhere in the nation presents itself. Some $77 \%$ of Manhattan households did not own a vehicle in 2009 (up from 69\% in 2001, and closer to the 74\% figure for 1995). This compares with $63 \%$ in the rest of NYC, and a $27 \%$ average in the non-NYS metros (which may be a low estimate: in 1995 and 2001 this value was around 48\%). Despite this, more Manhattan residents considered themselves to be a driver than did their neighbors

Manhattan residents make more person trips than others living in areas with similar population densities, largely due to walk living elsewhere, at similar residential densities, in the rest and transit trips. of NYC; with the driver rate for Manhattan residents increasing from $57 \%$ to $73 \%$ since 1995 . In

terms of travel, Manhattan residents make more person trips than others living in areas with similar population densities, either inside or outside NYS. Daily person trip rates for Manhattan residents were around 3.9 trips in 2001 and 2009, up from 3.7 trips in 1995. This compares to daily person trip rates of 3.2 to 3.6 elsewhere. This difference is again largely due to more walk and transit trips being taken by Manhattan residents.

\section{RURAL HOUSEHOLD TRAVEL COMPARISONS}

Many similarities, as well as a few differences, are found to exist between New York State's rural household travel statistics and those for the rest of rural America. On average, drivers in New York rural areas make marginally fewer and shorter trips than those in rural areas elsewhere. The average age of a vehicle owned by a rural household in NYS in 2009 was over two years older than for rural households elsewhere in the nation. These rural NYS households drive their vehicles a few more miles each year than NYS urban households, on the average. 
Carbon dioxide emissions associated with rural highway travel are found to be significantly higher than for their urban area counterparts, and also about $20 \%$ higher than the emissions from NYS households in similarly low density ( $<500 \mathrm{ppsm})$ urban areas. Most of this difference is attributable to the much higher share of public transit and walk trips taken by residents living in the nation's higher density urban locations.

\section{MPO SPECIFIC TRAVEL CHARACTERISTICS}

Travel patterns among the state's thirteen MPO-based metropolitan areas were examined, which includes: Albany; Binghamton; Buffalo; Elmira; Glens Falls; Ithaca; Kingston; the New York Metropolitan Transportation Council (NYMTC) area; Newburgh; Poughkeepsie; Rochester; Syracuse; and Utica-Rome. Almost all comparisons suggest that NYS metro areas can be categorized into three distinctive groups, regardless of the size of the Metropolitan Statistical Area (MSA) within which each is located. The first group consists of New York/Manhattan, the second group consists of the remaining four counties of NYC, and the last group consists of all of the remaining metro areas, including the rest of the NYMTC MPO areas located outside NYC (i.e., the Nassau and Suffolk, and Putnam, Rockland, and Westchester county portions of the NYMTC). The second group has travel patterns that tend to fall somewhere between those of the first and the third groups. When data for New York/Manhattan residents are combined with those for the rest of the NYC, the unique travel characteristics of these Manhattan residents become obscured. Therefore, any comparisons in travel characteristics based on MPO boundaries should be made with caution. 



\section{INTRODUCTION}

\subsection{BACKGROUND AND OBJECTIVES}

Policymakers rely on transportation statistics, including data on personal travel behavior, to formulate strategic transportation policies, and to improve the safety and efficiency of the U.S. transportation system. Data on personal travel trends are needed to examine the reliability, efficiency, capacity, and flexibility of the nation's transportation system to meet current demands and accommodate future demands; to assess the feasibility and efficiency of alternative congestion-alleviating technologies (e.g., high-speed rail, intelligent vehicle and highway systems); to evaluate the merits of alternative transportation investment programs; and to assess the energy-use and air-quality impacts of various policies.

To address these data needs, the U.S. Department of Transportation (USDOT) initiated an effort in 1969 to collect detailed data on personal travel. The 1969 survey was the first Nationwide Personal Transportation Survey (NPTS). The survey was conducted again in 1977, 1983, 1990, 1995, 2001, and, most recently, in 2009. Data on daily travel were collected in 1969, 1977, 1983, 1990, and 1995. Longer-distance travel was collected in 1977 and 1995. In 2001 the survey was renamed the National Household Travel Survey (NHTS) and it collected both daily and longer-distance trips in one survey. Long distance travel was recorded for a four-week sample period. For 2009, the NHTS returned to the single day data collection scheme where data on trips taken by all members of a household during a designated travel day were collected. As a result, only very limited data was collected on long distance tripmaking. The primary objective of these surveys is to collect trip-based data on the nature and characteristics of personal travel so that the relationships between the characteristics of personal travel and the socio-economic and demographic characteristics of the traveler can be established.

Sponsorship of the various surveys has changed somewhat over the years. The 2009 NHTS was conducted as usual under the primary sponsorship of the Federal Highway Administration (FHWA). The Federal Transit Administration (FTA), the American Automobile Association (AAA) and the Public Policy Institute of the American Association of Retired Persons (AARP) also contributed funding to support a 2009 national sample of some 25,510 U.S. households. A much larger 2009 NHTS sample, however, totaling some 124,637 households was sponsored by 14 state and 6 metropolitan transportation planning organizations, each of which supported variously sized "add-on" samples for their own jurisdictions. The complete NHTS dataset used in this report includes both the initial national sample plus all of these regional addon samples, totaling 151,147 household responses, with weighting to adjust for over-sampling in add-on areas where nationwide statistics are reported. ${ }^{1}$

\footnotetext{
${ }^{1}$ Additional survey details, including changes survey size, content and data collection methods over time can be found in the 2009 NHTS User's Guide, accessible at: http://nhts.ornl.gov/publications.shtml.
} 
The New York State (NYS) add-on sample targeted 14,102 additional households. When combined with data on NYS households captured by the national dataset, this produced a sample size of 16,165 usable household interviews within the state. The comparisons drawn in this report compare the results from these NYS sampled households to the results from households drawn for the rest of the nation. These additional sample households also allow the NYSDOT to address transportation planning issues pertinent to geographic areas significantly smaller than what the national NHTS data are intended for.

This report is the third in a series of comparison reports commissioned by NYSDOT. As in the 1995 and 2001 reports $^{2}$, this report also addresses four key questions. First, are New York residents different from residents elsewhere in the nation with respect to personal mobility? Second, to what extent do the travel patterns of New York City (NYC) residents skew the overall travel patterns in the state? If the impact is substantial, the next question is whether New York residents outside NYC travel differently from the rest of the nation. Finally, are there significant differences in travel patterns between 1995, 2001, and 2009, and are there any strong trends in the data over time? Note that in addressing each of these issues, this report focuses on highlighting the similarities and differences in New York residents' daily travel patterns. It does not, however, address the causes of these differences.

\subsection{WHO IS INCLUDED}

The 2009 NHTS collected travel data from the civilian, non-institutionalized population of the United States. People living in hotels, college dormitories, nursing homes, other medical institutions, prisons, military bases, convents or monasteries or any living quarters where 10 or more unrelated roommates were excluded from the sample.

Twenty geographic areas (including NYS) participated in the NHTS add-on program to purchase additional samples that purchased NHTS add-on contracts increased the sample size within their planning areas. The increased sample sizes within these areas provided small-area data that should provide more reliable statistics for use in transportation planning.

\subsection{HOW THE DATA WERE COLLECTED}

The 2009 NHTS was conducted as a telephone survey, using Computer-Assisted Telephone Interviewing (CATI) technology. The sample was selected based on a list-assisted random digit dialing telephone number sample frame. Each household in the sample was assigned a specific 24-hour "Travel Day" and kept diaries to record all travel taken by all household members for the assigned day. The variation in travel by day of the week was

\footnotetext{
2 “1995 New York NPTS: A Comparison Study.” P.S. Hu and J. Young. Oak Ridge National Laboratory,
} 
balanced by assigning the travel days for one-seventh of the sample telephone numbers to each day of the week. The diary package was mailed within a day or two following the completion of the household recruitment interview. It was sent via United States Postal Service Priority Mail and contained the following:

- A letter from the USDOT thanking the household for completing the household interview and agreeing to participate in the survey;

- A brochure describing the survey;

- A travel day diary and a two-dollar cash incentive in individual envelopes personalized for each household member at least five years old. The reverse side of each diary provided guidance on completing the diary and included an example of a completed diary;

- A reminder card identifying the household's travel date; and

- An odometer mileage form identifying the make, model, and year of each household vehicle, with spaces to enter the odometer readings and the dates they were taken.

\subsection{WHEN THE DATA WERE COLLECTED}

The 2009 NHTS was conducted over a period from March 2008 through May 2009, with the New York add-on covering March 2008 through April 2009. Travel data were collected for all seven days of the week, including all holidays. A travel day is taken to begin at 4 AM on the sampled travel day, and to end at 3:59 AM on the following day. The survey was conducted over at least a 12-month period so that data would account for seasonal variations in travel. To correct for this seasonal variation, sample weighting was developed to specifically address this issue. Each household and person weight was adjusted so that each month in the year contained equal numbers of household and person interviews.

\subsection{TRAVEL CONCEPTS}

Appendix A contains a full glossary of terms used in this report. However, a few basic terms and concepts need to be introduced before any statistics are presented:

Person Trip - A trip made by one person using any mode of transportation. This is the most basic and universal measure of personal travel. Each record in the Travel Day and Travel Period files in the NHTS dataset represents one person trip. An example of this is if two people are traveling together in one car, two person trips are recorded. Based on 2009 NHTS data, residents of NYS made an estimated 24,281 million person-trips during the survey year.

Person Miles of Travel (PMT) - The number of miles traveled by each person on a trip. An example of this is two people taking a six-mile subway trip results in 12 person miles 
of travel. A four-mile van trip with a driver and three passengers will be counted as 16 person miles of travel.

Person-miles are often called passenger miles, particularly in the transit and airline industries. New York State residents engaged in an estimated 171,875 million personmiles of travel over the 2009 NHTS reporting period.

Vehicle Trip - A trip made using a single privately operated vehicle (POV) regardless of the number of persons in the vehicle. For example, two people traveling together in a car would be counted as one vehicle trip. Four people going to a restaurant in a van are also considered as one vehicle trip.

To be counted as a vehicle trip in the NHTS, a trip must be made in a POV and the driver must be a member of a household in the NHTS sample. A POV can be a household-based car, van, sport utility vehicle, pickup truck, other truck, recreational vehicle, motorcycle, or other POV. The vehicle does not need to belong to the household.

Trips made in other highway vehicles, such as buses, streetcars, taxis, and school buses are collected in the NHTS. However, these trips are not counted as vehicle trips because these vehicles are not privately operated vehicles. An estimated 10,877 million vehicle trips were made by the residents of New York State in 2009.

Vehicle Miles of Travel (VMT) - One vehicle mile of travel represents the movement of one POV for one mile, regardless of the number of people in the vehicle. For example, when one person drives her/his car 12 miles to work, 12 vehicle miles of travel have been made. If two people travel three miles in a pickup truck, three vehicle miles of travel have been made. The distinction among person trip, person miles of travel, vehicle trip, and vehicle miles of travel is illustrated in Figure 1.1. In 2009 NYS households engaged in an estimated 92,171 million vehicle miles of travel.

Vehicle Occupancy - For NHTS data, vehicle occupancy is generally computed as person miles of travel per vehicle mile (i.e., PMT/VMT which is referred to as the travel method). Note that the other commonly-used definition of vehicle occupancy is persons per vehicle trip (referred to as the trip method). 


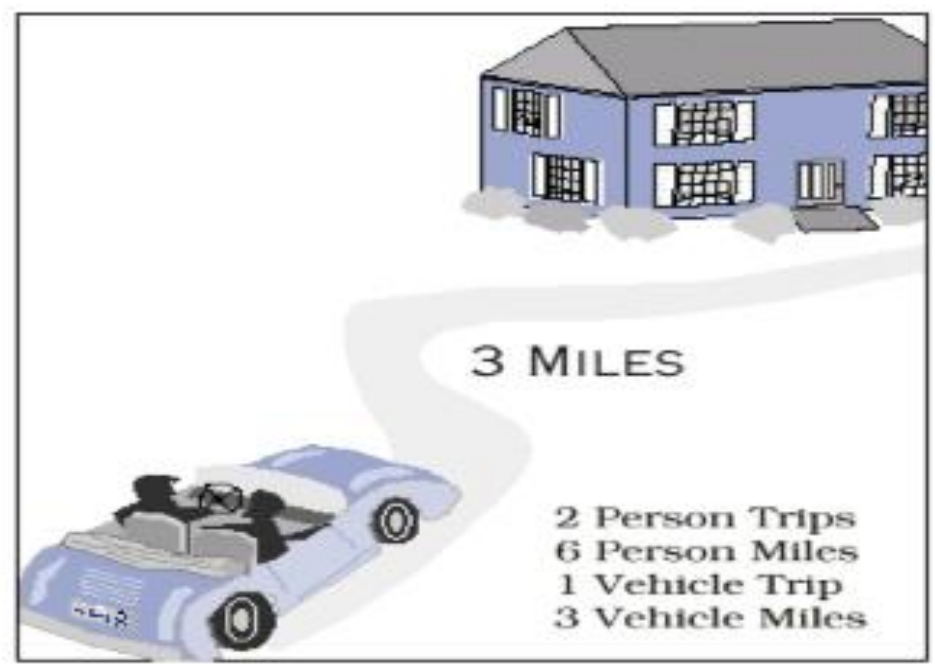

Figure 1.1 Distinctions between Person Trip, Person Miles of Travel, Vehicle Trip, and Vehicle Miles of Travel.

Because longer trips often have higher occupancies, the travel method generally yields a higher vehicle occupancy rate than the trip method. For example, according to the 2009 NHTS, the average person-miles of travel per vehicle mile for the state of New York was 1.86 in 2009 , compared to a vehicle occupancy of 1.67 persons per vehicle trip. Note that calculation of the travel method requires that trip miles be reported, but trip miles are not always reported, thus it is calculated based on a slightly smaller number of trips than the trip method.

Daily Trip Rates - Rather than presenting total travel, much of the data presented in this report are in units of daily trip rate, such as the number of trips taken by an individual on a typical day. Daily trip rates are derived by dividing the total daily travel (e.g., total person trips) by the total number of entities (e.g., households, workers, drivers, persons). This method implies that even if someone did not travel on the designated travel day, he/she is included in the calculation.

Average Daily Person Travel per Person - The average daily number of person trips or person miles of travel taken by a person. This includes persons who did not travel during the designated travel day (i.e., entire New York State population was considered). The estimated "average daily person trips per person" in the state of New York, according to the 2009 NHTS, was 3.64. Similarly, the estimated average daily miles traveled per person was 25.8 .

Average Daily Vehicle Travel per Driver - The average number of daily vehicle trips or vehicle miles of travel driven by an individual driver in NYS. This includes drivers who did not drive during the designated travel day (i.e., all NYS drivers are considered in the 
calculation). On average, the 2009 NHTS indicates that a NYS driver engaged in vehicle 2.32 trips and drove 19.7 miles per day.

Average Daily Journey-to-Work Travel per Worker - The average number of daily journeys to or from work for any day of the week. This includes travel by workers who work at home and workers who did not go to work during the designated travel day. On average, a typical New York worker took 1.06 trips to work per day in 2009 (see Chapter 2).

Average Daily Travel per Household - The average daily number of person trips, vehicle trips, person miles of travel, vehicle miles of travel, or journey-to-work trips taken by a typical NYS household. This includes households that did not travel during the designated travel day. For NYS, the 2009 NHTS estimates are as follows: the average daily person trips per household was 9.32, the average daily person miles per household was 66.0, the average daily vehicle trips per household was 4.18 , and the average daily vehicle miles per household was 35.4. The average daily journey-to-work trips taken by a NYS household was 1.5 during the 2009 NHTS survey period (see Chapter 2).

\subsection{DIFFERENCES BETWEEN THE 2009 NHTS AND PREVIOUS SURVEYS}

While the core of the NHTS has remained unchanged from earlier surveys, for the 2009 survey some changes were made to data content that have implications for this report: ${ }^{3}$

1. The 2009 NHTS was modified to eliminate the retrospective collection of long distant trip data. Detailed travel information was collected for only daily travel. Therefore statistics for long distance tripmaking are limited and potentially unreliable.

2. While all household members were enumerated, only those household members who were 5 years and older were eligible for the interview process. In doing this, the 2009 NHTS returned to the age guidelines used in surveys prior to 2001.

3. Changes to the household recruitment interview for the 2009 NHTS included the addition of questions to determine if an enumerated vehicle had a commercial license plate. For each vehicle with a model year of 2002 or newer, the interviewee was asked if the vehicle was a hybrid or alternate fuel use vehicle. As in past surveys, the total number of all household vehicles was asked for. In the 2009 survey the wording of the response category was modified to include motorbikes.

4. Additional questions were added to better understand details of work related travel (e.g., usual start time, availability of flex time).

5. Questions were added about purchases made through the internet and whether those purchases were delivered to a subject's home.

\footnotetext{
${ }^{3}$ A full list of changes, including a number of less import to this present report, are documented in the 2009 NHTS User's Guide (FHWA, February 2011) found at http://nhts.ornl.gov/publications.shtml
} 
6. A follow up question was added for those household members who were at least 18 years old and reported as not being drivers, to determine if they had ever driven a vehicle.

7. The list of transportation modes was revised to reflect changes in often used modes. A new coding option was added to attempt to capture the impact of Light Electric Vehicles.

8. Subjects were asked how many times they have driven a motorcycle or moped on public roadways in the past month.

9. Response categories for type of transportation used on travel day trips were modified to be more specific about the type of vehicle used.

10. A second odometer reading for household vehicles was not collected in the 2009 NHTS.

11. Data users are therefore unable to generate independent validations of annual mileage estimates.

\subsection{REPORT ORGANIZATION}

Chapter 1 introduces the reader to the basic purpose and content of the NPTS/NHTS national and NYS add-on surveys, summarizing how the data is collected, and defining a number of frequent referenced statistics. Chapter 2 compares NYS statewide statistics against their counterparts covering the rest of the nation. Most comparisons are presented as the differences between statistical averages, with standard errors associated with such averages computed in order to infer or refute statistical significances. Chapter 3 focuses on the impacts of New York City on these within-state statistics, showing clear differences between NYC personal travel patterns and those in the rest of the state and rest of the nation. Delving further into these differences, Chapter 4 asks the question whether the very high population densities associated with NYC, and in particular those in Manhattan, are associated with differences in such variables as vehicle ownership, daily trip rates and trip lengths, choice of travel modes and trip purposes, types of vehicles on the road, and travel related carbon dioxide emissions. Chapter 5 of the report similarly examines whether rural travel in New York State differs from rural travel in the rest of the United States, and whether the generally much lower population densities associated with such areas have any bearing on the travel patterns of rural New Yorkers.

Chapter 6 makes use of the NYS add-on sample to examine travel patterns among the state's thirteen Metropolitan Planning Organization (MPO) based metropolitan areas (i.e. Albany, Binghamton, Buffalo, Elmira, Glens Falls, Ithaca, Kingston, the New York Metropolitan Transportation Council (NYMTC); Newburgh, Poughkeepsie, Rochester, Syracuse, and UticaRome). Finally, Chapter 7 summarizes findings throughout the report. Many additional statistical tables, including tables of standard errors and sample sizes as well as statistical means are reported in a series of report appendices. Appendix B provides a map of each of the state's 13 MPO areas showing the differences in population density at the level of census tracts as referenced in the body of the report. 


\section{COMPARISON OF NEW YORK STATE DATA TO THE REST OF THE UNITED STATES}

This chapter examines whether NYS residents travel more or less frequently than people in the rest of the country, whether they take longer or shorter trips to work or for other trip purposes, and whether they use the same modes of travel, and the same types of vehicles as people in the rest of the country. This chapter also investigates how differences in age, sex, household income, and vehicle ownership, among other personal and household traits, affect trip making rates and vehicle miles of travel, and how these measures of travel activity differ between NYS residents and other Americans.

Particular attention is also given in this chapter to examine the socio-economic and demographic characteristics and modal choices of these NYS residents in comparisons to their counterparts from the rest of the United States. This chapter attempts to answer questions such as: Are the households that do not own any vehicles as mobile as those residents who do own one or more private vehicles? How does their travel behavior differ from residents in the rest of the country who also do not own a vehicle? Among the majority of NYS households that do own and operate private vehicles, what types of vehicle are these? How old are they, and do these NYS households own more or fewer vehicles on the average than households in the rest of the country?

Furthermore, with respect to walking and cycling, just how different are NYS households? Are they in line with trends in non-motorized travel in the rest of the nation? How does such activity compare to the sort of daily activity profiles associated today with healthier, more 'active' lifestyles?

Given some significant differences in vehicle ownership and use patterns, how much fossil fuel is used to support these and other NYS residents' multi-modal travel activity patterns compared to those in the rest of the country? Does within-state household travel produce more or less greenhouse gas emissions per person-mile than household travel in the rest of the nation?

\subsection{PROFILE OF NEW YORK STATE HOUSEHOLDS VERSUS HOUSEHOLDS IN THE REST OF THE UNITED STATES}

Table 2.1 compares household characteristics and vehicle ownership patterns between the state of New York and the rest of the United States. Figure 2.1 presents some of the percentage changes in these characteristics for the three periods of 1995 to 2001, 2001 to 2009, and, combining these changes, from 1995 to 2009. It shows some noticeable differences between NYS and the rest of the nation. 
Table 2.1 Summary of Household Characteristics and Vehicle Licensing Rate New York State vs. the Rest of the United States in 1995, 2001, and 2009

\begin{tabular}{|c|c|c|c|c|c|c|}
\hline & \multicolumn{2}{|c|}{1995} & \multicolumn{2}{|c|}{2001} & \multicolumn{2}{|c|}{2009} \\
\hline & $\begin{array}{l}\text { New } \\
\text { York }\end{array}$ & $\begin{array}{c}\text { Rest of } \\
\text { US }\end{array}$ & $\begin{array}{l}\text { New } \\
\text { York }\end{array}$ & $\begin{array}{c}\text { Rest of } \\
\text { US }\end{array}$ & $\begin{array}{l}\text { New } \\
\text { York }\end{array}$ & $\begin{array}{c}\text { Rest of } \\
\text { US }\end{array}$ \\
\hline Households (000) & 6,848 & 92,858 & 7,183 & 100,182 & 7,137 & 105,964 \\
\hline Drivers $(000)$ & 10,469 & 165,861 & 11,167 & 179,258 & 12,838 & 199,471 \\
\hline Workers (000) & 8,775 & 122,922 & 9,645 & 135,627 & 9,759 & 141,614 \\
\hline Household Vehicles (000) & 7,922 & 168,145 & 9,545 & 193,041 & 9,144 & 202,357 \\
\hline Workers per Household & 1.28 & 1.32 & 1.34 & 1.35 & 1.37 & 1.34 \\
\hline Vehicles per Household & 1.16 & 1.81 & 1.33 & 1.93 & 1.28 & 1.91 \\
\hline Vehicles per Driver & 0.76 & 1.01 & 0.85 & 1.08 & 0.71 & 1.01 \\
\hline \multicolumn{7}{|l|}{ Income (in 2009 dollars) } \\
\hline$\%<\$ 10,000$ Households & 5.5 & 4.9 & 7.3 & 6.6 & 7.8 & 7.7 \\
\hline$\% \$ 10$ to $\$ 20,000$ Households & 8.5 & 9.3 & 10.2 & 10.0 & 11.5 & 12.5 \\
\hline$\% \$ 20$ to $\$ 30,000$ Households & 10.2 & 10.6 & 9.2 & 9.7 & 10.2 & 11.6 \\
\hline$\% \$ 30$ to $\$ 40,000$ Households & 14.0 & 15.5 & 15.0 & 16.9 & 9.5 & 10.0 \\
\hline$\% \$ 40$ to $\$ 50,000$ Households & 3.9 & 4.3 & 4.3 & 5.1 & 8.8 & 8.9 \\
\hline$\% \$ 50$ to $\$ 60,000$ Households & 7.0 & 8.8 & 7.9 & 8.5 & 6.7 & 7.5 \\
\hline$\% \$ 60$ to $\$ 70,000$ Households & 7.2 & 7.6 & 6.1 & 6.7 & 5.9 & 6.0 \\
\hline$\% \$ 70$ to $\$ 80,000$ Households & 4.2 & 4.4 & 4.9 & 5.4 & 5.3 & 6.0 \\
\hline$\% \$ 80$ to $\$ 100,000$ Households & 7.9 & 8.0 & 8.4 & 8.7 & 7.4 & 7.6 \\
\hline$\% \$ 100,000+$ Households & 12.2 & 10.1 & 16.5 & 14.3 & 18.3 & 15.4 \\
\hline$\%$ Unreported Households & 19.5 & 16.5 & 10.3 & 8.1 & 8.8 & 6.8 \\
\hline \multicolumn{7}{|l|}{ Licensing Rate } \\
\hline \% Female Drivers/Female 16+ & $68.4 \%$ & $86.6 \%$ & $71.1 \%$ & $87.7 \%$ & $77.2 \%$ & $86.8 \%$ \\
\hline$\%$ Male Drivers/Male $16+$ & $84.1 \%$ & $93.2 \%$ & $83.5 \%$ & $93.3 \%$ & $86.4 \%$ & $91.6 \%$ \\
\hline
\end{tabular}

a 1995 and 2001 income categories are adjusted to 2009 dollars.

b Driver rate is determined using the self-reported response to the question "Are you a driver?" in the NHTS survey. As such, this rate should not be compared to the official NYS Department of Transportation drivers' licensing statistics. ${ }^{\mathrm{c}} 8.8 \%$ of NYS households declined to provide information on their income, compared $6.8 \%$ in the rest of the United States.

\subsubsection{Number of Household Drivers, Licenses, Workers and Vehicles}

While the number of drivers increased a significantly more in percentage terms in NYS than in the rest of the country between 2001 and 2009 (Figure 2.1), the state saw very little growth in number of workers and a small decline in number of households, but a significant drop 
in the number of household vehicles $(-4.2 \%)^{4}$. In contrast, the rest of the nation saw increases in the number of households, vehicles, and workers of around 5\% over this same period. This drop in number of vehicles in NYS between 2001 and 2009 was in sharp contrast to the over $20 \%$ increase in the size of the state's household vehicle fleet between 1995 and 2001 (see Figure 2.1). As a result, compared to the rest of the country, a NYS household still owns, on average, fewer vehicles than households elsewhere (1.3 versus 1.9 vehicles: see Table 2.1 ): with only 0.71 vehicles per driver in NYS compared to just over 1 vehicle per driver in the rest of the nation in 2009.

The percentage of 16+ year-olds who are drivers also continues to be much lower among NYS residents than among other Americans. However, as shown in Table 2.1, a clear trend towards increased number of licenses being held among NYS women is evident, climbing from $68.4 \%$ in 1995 , through $71.1 \%$ in 2001 , to $77.2 \%$ in 2009 . Despite this trend, a significantly smaller percentage of women held licenses in the state than in the rest of America in 2009 (77.2\% versus $86.8 \%$ ). The discrepancy in licenses per male resident is smaller, but also remains statistically significant - at $86.4 \%$ of male residents in NYS vs. $91.6 \%$ in the rest of the United States. Combining the results from the two time periods (see Figure 2.1), over the 14 years between 1995 and 2009, while the percentage growth in number of NYS drivers outstripped that in the rest of the nation, the rate of growth in the number of households, household vehicles, and number of workers were all significantly lower for the state.

\footnotetext{
${ }^{4}$ This number may reflect an overestimate for 2001 , however.
} 


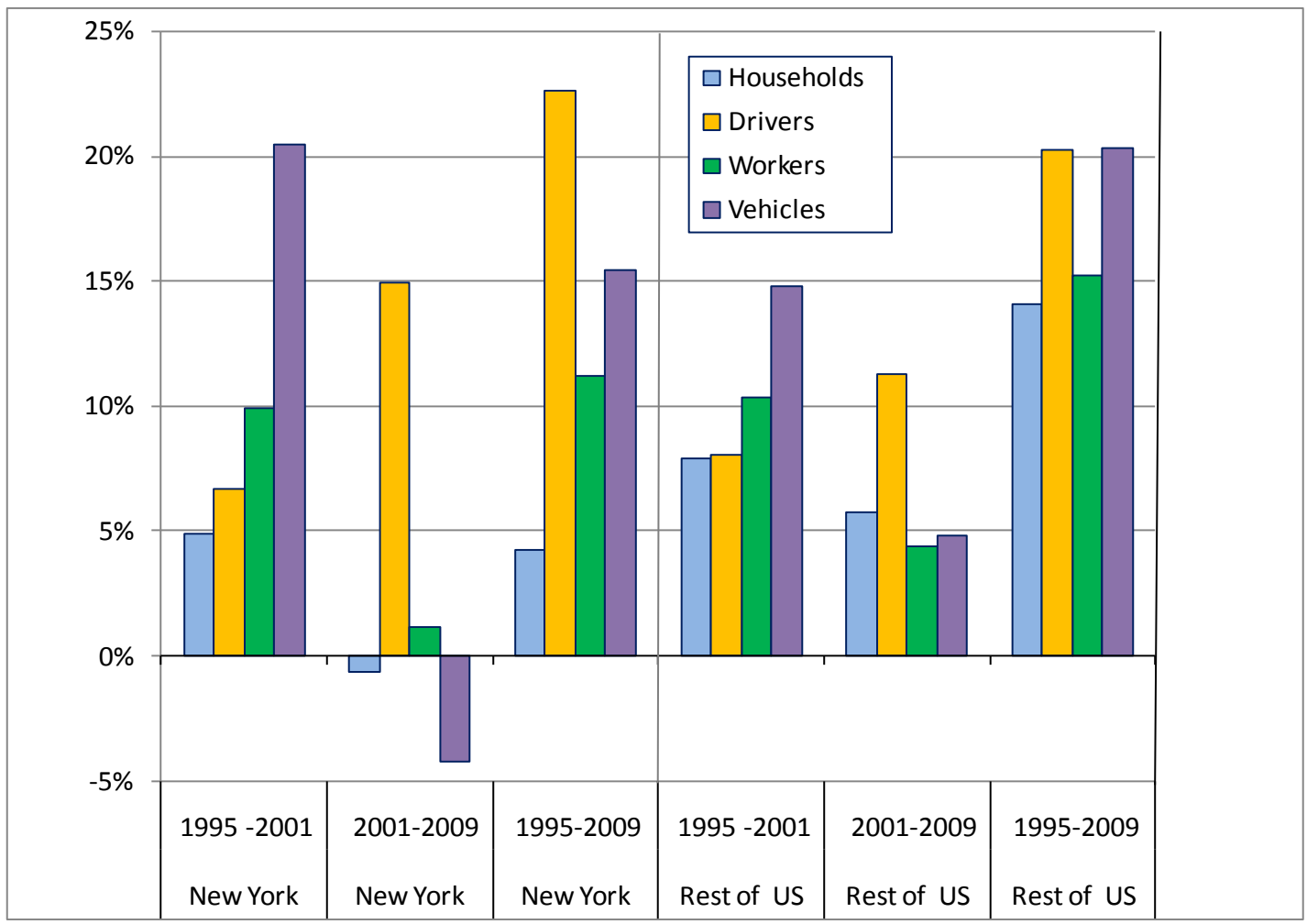

Figure 2.1 Percent Differences in Number of Households, Drivers, Workers, and Vehicles from 1995 to 2001, 2001, to 2009 and 1995 to 2009.

\subsubsection{Household Incomes and Vehicle Ownership}

Among households that reported their annual income (Table 2.1), those that earned more than $\$ 80,000$ in 2009 accounted for a somewhat greater proportion in NYS than in other parts of the country (25.7\% vs. $23.0 \%$ ). Table 2.2 shows the distribution of vehicle ownership levels for NYS households compared to their U.S. counterparts. Figure 2.2 graphs some of these results.

Table 2.2 Household Vehicle Ownership Levels in 1995, 2001, and 2009

\begin{tabular}{|c|rrr||rrr}
\hline \multirow{2}{*}{ Household (HH) Vehicle Ownership } & \multicolumn{4}{|c||}{ New York State } & \multicolumn{3}{c}{ Rest of United States } \\
\cline { 2 - 7 }$\%$ 0 Vehicles/HH & $\mathbf{1 9 9 5}$ & $\mathbf{2 0 0 1}$ & $\mathbf{2 0 0 9}$ & $\mathbf{1 9 9 5}$ & $\mathbf{2 0 0 1}$ & $\mathbf{2 0 0 9}$ \\
\hline \% 1 Vehicles/HH & 26.8 & 26.5 & 28.5 & 6.9 & 6.8 & 7.4 \\
$\%$ 2 Vehicles/HH & 32.9 & 33.2 & 32.4 & 32.4 & 31.3 & 32.3 \\
$\% 3$ Vehicles/HH & 29.7 & 27.2 & 27.1 & 41.1 & 37.9 & 36.9 \\
$\%$ 4+ Vehicles/HH & 7.8 & 9.3 & 8.4 & 14.4 & 15.4 & 14.8 \\
$\%>1$ Vehicle/HH & 2.9 & 3.9 & 3.6 & 5.3 & 8.6 & 8.6 \\
\hline$\%>1$ Vehicle $\mathrm{HH} />=1$ Vehicle/HH & 40.4 & 40.4 & 39.1 & 60.8 & 61.9 & 60.3 \\
\hline
\end{tabular}




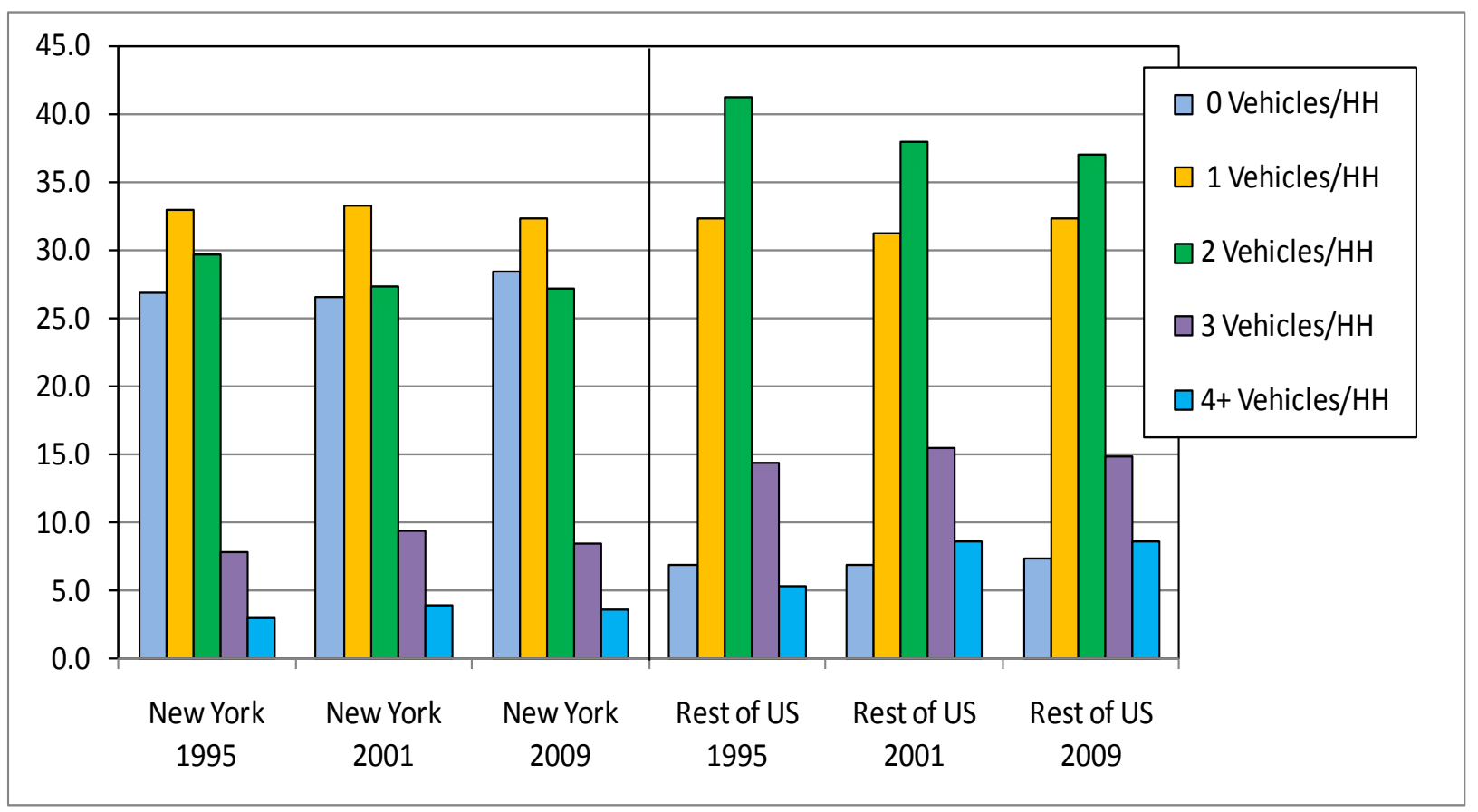

Figure 2.2 Household (HH) Vehicle Ownership New York State vs. Rest of the United States in 1995, 2001, and 2009.

As shown in Table 2.2 and Figure 2.2, NYS households are much more likely to be zerovehicle households than they are in the rest of the nation. This is largely due to the availability of public transit in the NYC metropolitan area (see Chapter 3). Some $40 \%$ of households in the state owned more than one vehicle throughout the period of years 1995 to 2009, while above $60 \%$ of households owned more than one vehicle elsewhere in the country. Again there is no significant change in this percentage over the 14-year period. Among households owning vehicles, NYS households were on average also less likely to own more than one vehicle than were households elsewhere in the U.S. (holding steady at around 55\%, versus around $65 \%$ of households in the rest of the nation throughout the 14 year analysis period: as shown on the last line of Table 2.2).

\subsection{PERSONAL TRAVEL COMPARISONS}

\subsubsection{Trip Frequencies and Trip Lengths}

The number of daily person trips per person continued to show a gradual decline, both across the state and across the nation, during the 14 years between 1995 and 2009 (Table 2.3). There is a more noticeable decline in the average trip rate in the rest of the nation between 2001 and 2009, as a result of which NYS and rest of U.S. trip rates were closer in 2009 than in previous survey years. In terms of average person trip lengths, both NYS and the rest of America experienced an overall decline in average distances traveled between 2001 and 2009, after experiencing average trip length increases between 1995 and 2001. However, this decline was 
only marginally significant at the national level (-2.5\%), while it was more significant in NYS: where a decline of $9.8 \%$ caused average person trip length to fall below its 1995 level at 7.5 miles per trip (versus 9.9 miles in the rest of the U.S: see bottom line of Table 2.3 and Figure 2.4).

The decline in daily person trip rates affected all household income groups, with varying degrees and no obvious trend across income groups. The largest declines between 2001 and 2009 in NYS were in the under $\$ 10,000$ per year $(-10.5 \%)$, $\$ 40-50,000$ per year $(-12.1 \%)$ and $\$ 70$ 80,000 per year $(-8.0 \%)$ household income categories. As in 1995 and 2001, trip frequencies increase gradually with household income, rising from an average rate of 2.6 trips per day by persons in the lowest income NYS households, to a daily person trip rate of 4.2 by persons living in NYS households making over $\$ 100,000$ per year (compared to a range of 2.9 to 4.3 trips per day in the rest of the country: see Table 2.3).

Weekend daily person trip rates (Table 2.3 and Figure 2.3) were lower than weekday trip rates for all three surveys, in both NYS and the rest of the nation. Both average weekday and average weekend daily person trip rates declined in NYS between 1995 and 2009, while showing a downward trend between 2001 and 2009 in the rest of the nation. 
Table 2.3 Personal Travel Statistics by Demographic Characteristics for New York State vs. Rest of the United States in 1995, 2001, and 2009

\begin{tabular}{|c|c|c|c|c|c|c|c|c|c|c|}
\hline & \multicolumn{3}{|c|}{ New York State } & \multicolumn{3}{|c|}{$\begin{array}{c}\text { Rest of United } \\
\text { States }\end{array}$} & \multicolumn{2}{|c|}{ New York State } & \multicolumn{2}{|c|}{ Rest of United States } \\
\hline & 1995 & 2001 & 2009 & 1995 & 2001 & 2009 & $\begin{array}{c}\% \\
\text { difference } \\
1995- \\
2001\end{array}$ & $\begin{array}{c}\% \\
\text { difference } \\
2001- \\
2009\end{array}$ & $\begin{array}{c}\% \\
\text { difference } \\
1995- \\
2001\end{array}$ & $\begin{array}{c}\% \\
\text { difference } \\
2001- \\
2009\end{array}$ \\
\hline Person Trips per Person & 3.88 & 3.73 & 3.64 & 4.33 & 4.11 & 3.81 & $-3.9 \%$ & $-2.4 \%$ & $-5.1 \%$ & $-7.3 \%$ \\
\hline Male & 3.93 & 3.77 & 3.63 & 4.36 & 4.11 & 3.76 & $-4.1 \%$ & $-3.7 \%$ & $-5.7 \%$ & $-8.5 \%$ \\
\hline Female & 3.84 & 3.70 & 3.64 & 4.30 & 4.12 & 3.85 & $-3.6 \%$ & $-1.6 \%$ & $-4.2 \%$ & $-6.6 \%$ \\
\hline Person Trips per Person & 3.88 & 3.73 & 3.64 & 4.33 & 4.11 & 3.81 & $-3.9 \%$ & $-2.4 \%$ & $-5.0 \%$ & $-7.3 \%$ \\
\hline$<\$ 10,000$ & 3.06 & 2.95 & 2.64 & 3.19 & 3.11 & 2.86 & $-3.6 \%$ & $-10.5 \%$ & $-2.5 \%$ & $-8.0 \%$ \\
\hline$\$ 10$ to $\$ 20,000$ & 3.53 & 3.24 & 3.07 & 3.80 & 3.49 & 3.27 & $-8.2 \%$ & $-5.2 \%$ & $-8.2 \%$ & $-6.3 \%$ \\
\hline$\$ 20$ to $\$ 30,000$ & 3.61 & 3.39 & 3.36 & 4.06 & 3.83 & 3.60 & $-6.1 \%$ & $-0.9 \%$ & $-5.7 \%$ & $-6.0 \%$ \\
\hline$\$ 30$ to $\$ 40,000$ & 3.95 & 3.60 & 3.40 & 4.46 & 4.08 & 3.67 & $-8.9 \%$ & $-5.6 \%$ & $-8.5 \%$ & $-10.0 \%$ \\
\hline$\$ 40$ to $\$ 50,000$ & 3.77 & 3.98 & 3.50 & 4.65 & 4.09 & 3.82 & $5.6 \%$ & $-12.1 \%$ & $-12.0 \%$ & $-6.6 \%$ \\
\hline$\$ 50$ to $\$ 60,000$ & 4.07 & 3.78 & 3.75 & 4.57 & 4.29 & 3.92 & $-7.1 \%$ & $-0.8 \%$ & $-6.1 \%$ & $-8.6 \%$ \\
\hline$\$ 60$ to $\$ 70,000$ & 4.23 & 3.94 & 4.04 & 4.62 & 4.35 & 3.95 & $-6.9 \%$ & $2.5 \%$ & $-5.8 \%$ & $-9.2 \%$ \\
\hline$\$ 70$ to $\$ 80,000$ & 4.08 & 4.14 & 3.81 & 4.73 & 4.44 & 4.12 & $1.5 \%$ & $-8.0 \%$ & $-6.1 \%$ & $-7.2 \%$ \\
\hline$\$ 80$ to $\$ 100,000$ & 4.38 & 3.97 & 4.09 & 4.64 & 4.46 & 4.13 & $-9.4 \%$ & $3.0 \%$ & $-3.9 \%$ & $-7.4 \%$ \\
\hline$\$ 100,000+$ & 4.36 & 4.25 & 4.23 & 4.73 & 4.56 & 4.30 & $-2.5 \%$ & $-0.5 \%$ & $-3.6 \%$ & $-5.7 \%$ \\
\hline Weekday Person Trips/Person & 4.00 & 3.85 & 3.74 & 4.46 & 4.21 & 3.92 & $-3.8 \%$ & $-2.7 \%$ & $-5.7 \%$ & $-6.8 \%$ \\
\hline Weekend Person Trips/Person & 3.61 & 3.46 & 3.37 & 3.99 & 3.89 & 3.52 & $-4.3 \%$ & $-2.3 \%$ & $-2.5 \%$ & $-9.4 \%$ \\
\hline Average Person Trip Length & 7.74 & 8.30 & 7.49 & 9.23 & 10.14 & 9.89 & $7.2 \%$ & $-9.8 \%$ & $9.9 \%$ & $-2.5 \%$ \\
\hline
\end{tabular}

${ }^{a} 1995$ and 2001 income categories are adjusted to 2009 dollars. 


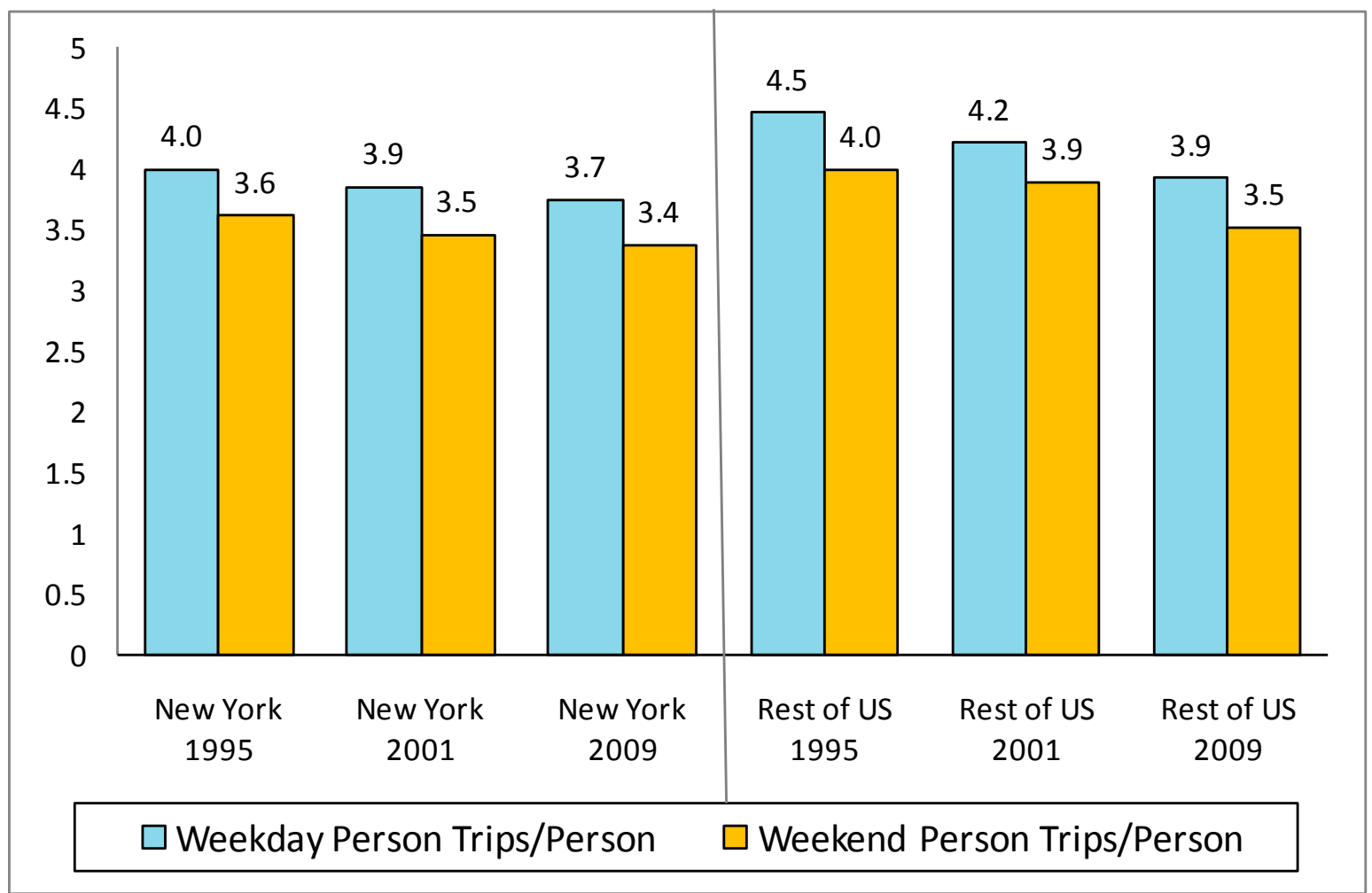

Figure 2.3 Weekday and Weekend Person Trips per Person in 1995, 2001, and 2009. (Note: Weekend trips = Saturday and Sunday trips.)

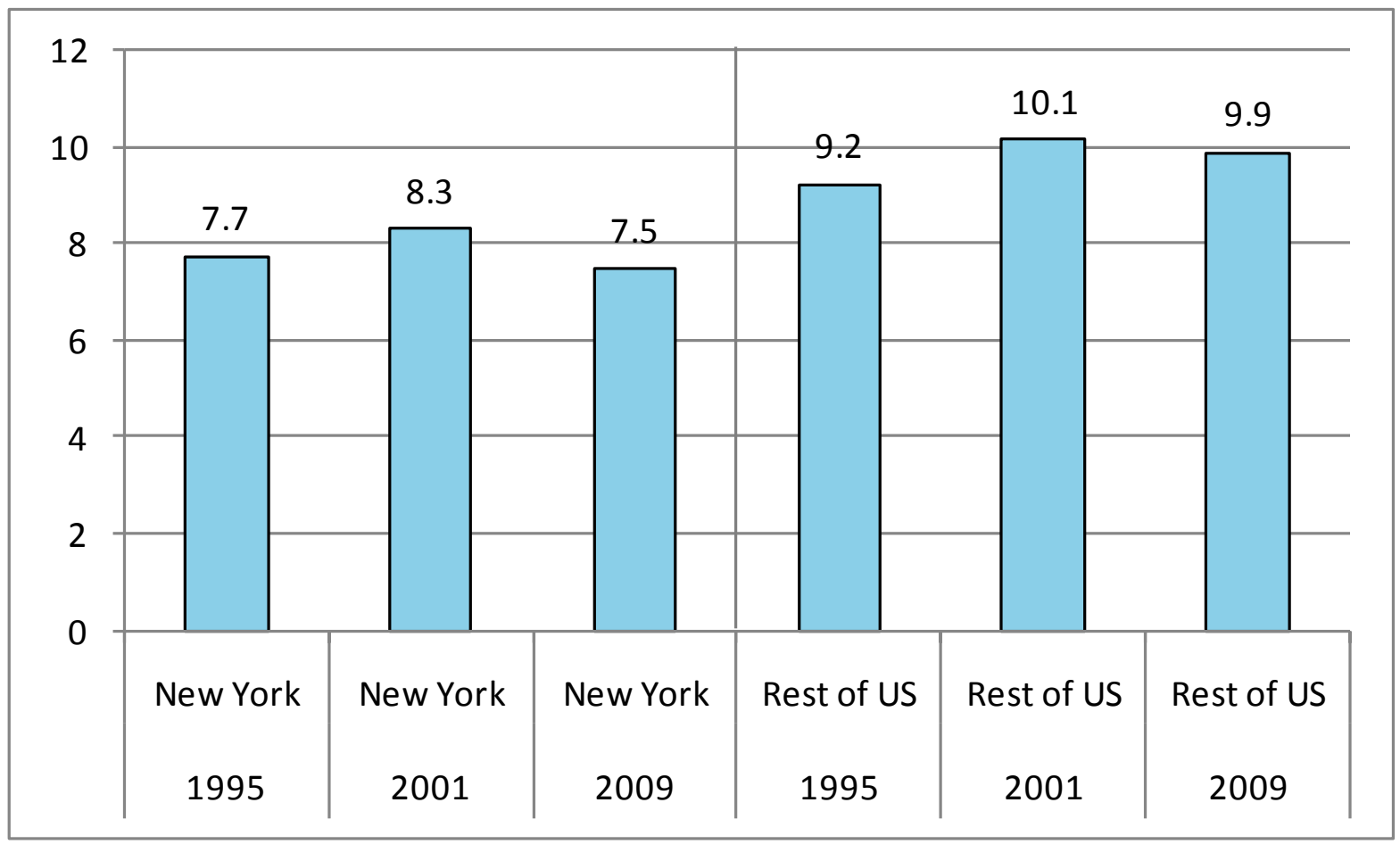

Figure 2.4 Average Person Trip Lengths (in miles) in 1995, 2001, and 2009: New York State vs. Rest of the United States. 


\subsubsection{How Trips Were Made-Modes of Travel}

As in 1995 and 2001, NYS residents, like people in the rest of the nation, relied heavily on their POVs for much of their day to day mobility in 2009. POV trips accounted for $79 \%$ of NYS households' total PMT in 2009, versus $89 \%$ in the rest of the United States (Table 2.4). However, due in large part to travelers in the NYC metropolitan area (see Chapter 3), NYS residents used public transit modes (notably rail and bus sub-modes) significantly more frequently and for longer distance than residents in the rest of the nation. Specifically in 2009, public transit accounted for $9.9 \%$ of NYS residents' total person trips, and 5.5\% of their PMT; while this mode of transportation was used only for $1.2 \%$ of person trips and $0.5 \%$ of PMT in the rest of the nation.

\section{Table 2.4 Person Travel Rates and Mode Shares New York State vs. Rest of the United States 1995, 2001, and 2009}

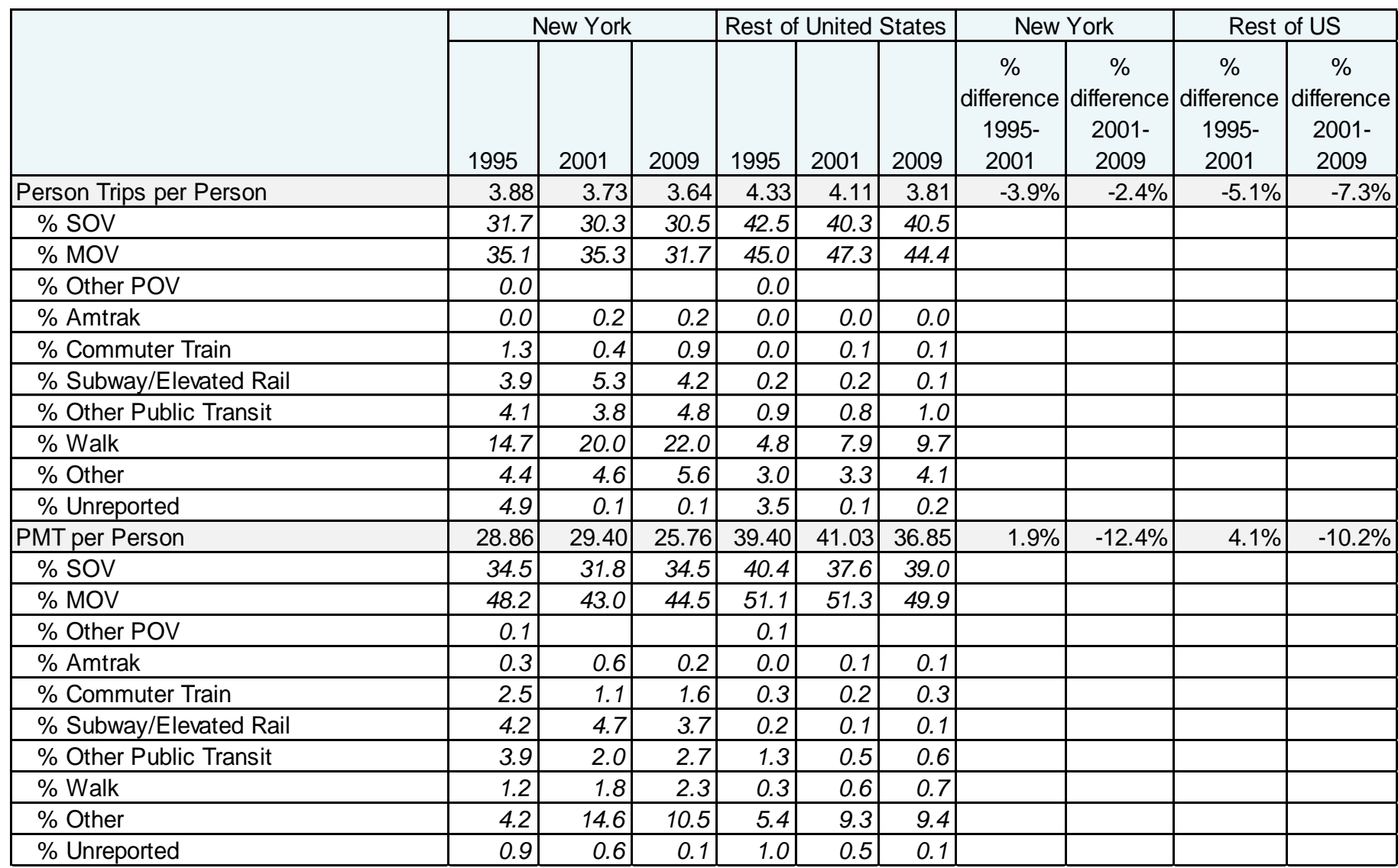

Note: Other POV was not a "mode" available to the survey respondents in 2001 or 2009.

Looking at POV use, just under half of all POV trips involved trips by single occupant vehicles (SOVs), with multiple occupants vehicle (MOV) trips accounting for the rest. This SOV/MOV split has changed little over the 14 year period covered by the three NHTS surveys, in either NYS or within the rest of the nation (Table 2.4). 
The issue of walk and also cycle trips has become an increasingly popular one in recent years. As noted in a recent U.S. Department of Transportation News Brief:

"Good health is based on good nutrition and adequate physical activity. Policies aimed at improving American's health-including efforts to reduce childhood obesity--are focusing on the public infrastructure to ensure safe and convenient opportunities for physically active transport such as walking and biking. "5

Table 2.4 shows that a much higher percentage of person trips by NYS residents involved walking from place to place than is observed in the rest of the nation. While the percentage of total person trips made and the percentage of person miles of travel (PMT) associated with walking both more than doubled in the rest of the country, a nearly $50 \%$ increase in the percentage of walk trips in NYS between 1995 and 2009 is associated with a 22\% modal share in 2009 for walk trips in the state. This is more than twice the share of trips attributed to walking averaged over other states in the nation. In terms of person miles of travel shares, these NYS walk trips accounted for $2.3 \%$ of PMT in the state in 2009, three times the $0.7 \%$ of PMT reported for the rest of the nation.

Table 2.5 shows that NYS residents have spent about twice as much time, on the average, walking and/or cycling per day than residents in the rest of the nation since the mid-1990s. However, while in both NYS and the nation as a whole the average number of minutes spent walking or biking has increased significantly over the three survey years, the 2009 averages of 12.3 minutes per day for NYS residents and 6.2 minutes per day for the rest of the nation are both well below the 30 minutes of activity often suggested as important to good health. Also of note, in NYS the two most active age groups in 2009, in terms of average number of minutes spent walking per day, are the 21-35 year olds, followed by the 36-64 year olds. In 1995 the most active age group was the 11-15 year olds. In the rest of the nation, in contrast, this 11-15 year olds group remains noticeably the highest in all three survey years (see Figure 2.5).

5 "Active Travel" NHTS News Brief. Federal Highway Administration, U.S. Department of Transportation. December, 2010. http://nhts.ornl.gov 
Table 2.5 Average Minutes Spent Walking and/or Biking per Day in 1995, 2001, and 2009 by Different Age Groups

\begin{tabular}{l|rrr||ccc}
\hline \multirow{2}{*}{$\begin{array}{c}\text { Average Minutes } \\
\text { Spent Walking/Biking } \\
\text { Per Day }\end{array}$} & \multicolumn{3}{c||}{ New York State } & \multicolumn{3}{c}{ Rest of United States } \\
\cline { 2 - 8 } & $\mathbf{1 9 9 5}$ & $\mathbf{2 0 0 1}$ & $\mathbf{2 0 0 9}$ & $\mathbf{1 9 9 5}$ & $\mathbf{2 0 0 1}$ & $\mathbf{2 0 0 9}$ \\
\hline All Ages & 5.96 & 10.74 & 12.34 & 2.51 & 5.50 & 6.24 \\
\hline 5 to 10 year-olds & 5.86 & 10.17 & 8.68 & 3.16 & 7.15 & 5.13 \\
11 to 15 year-olds & 8.40 & 12.92 & 10.06 & 5.66 & 8.23 & 9.02 \\
16 to 20 year-olds & 6.40 & 10.54 & 10.70 & 3.24 & 5.05 & 5.90 \\
21 to 35 year-olds & 6.95 & 12.47 & 15.38 & 2.31 & 4.85 & 6.25 \\
36 to 64 year-olds & 4.93 & 10.39 & 13.35 & 1.81 & 5.00 & 6.59 \\
65+ year-olds & 5.27 & 8.46 & 9.21 & 2.04 & 5.05 & 4.48 \\
\hline
\end{tabular}

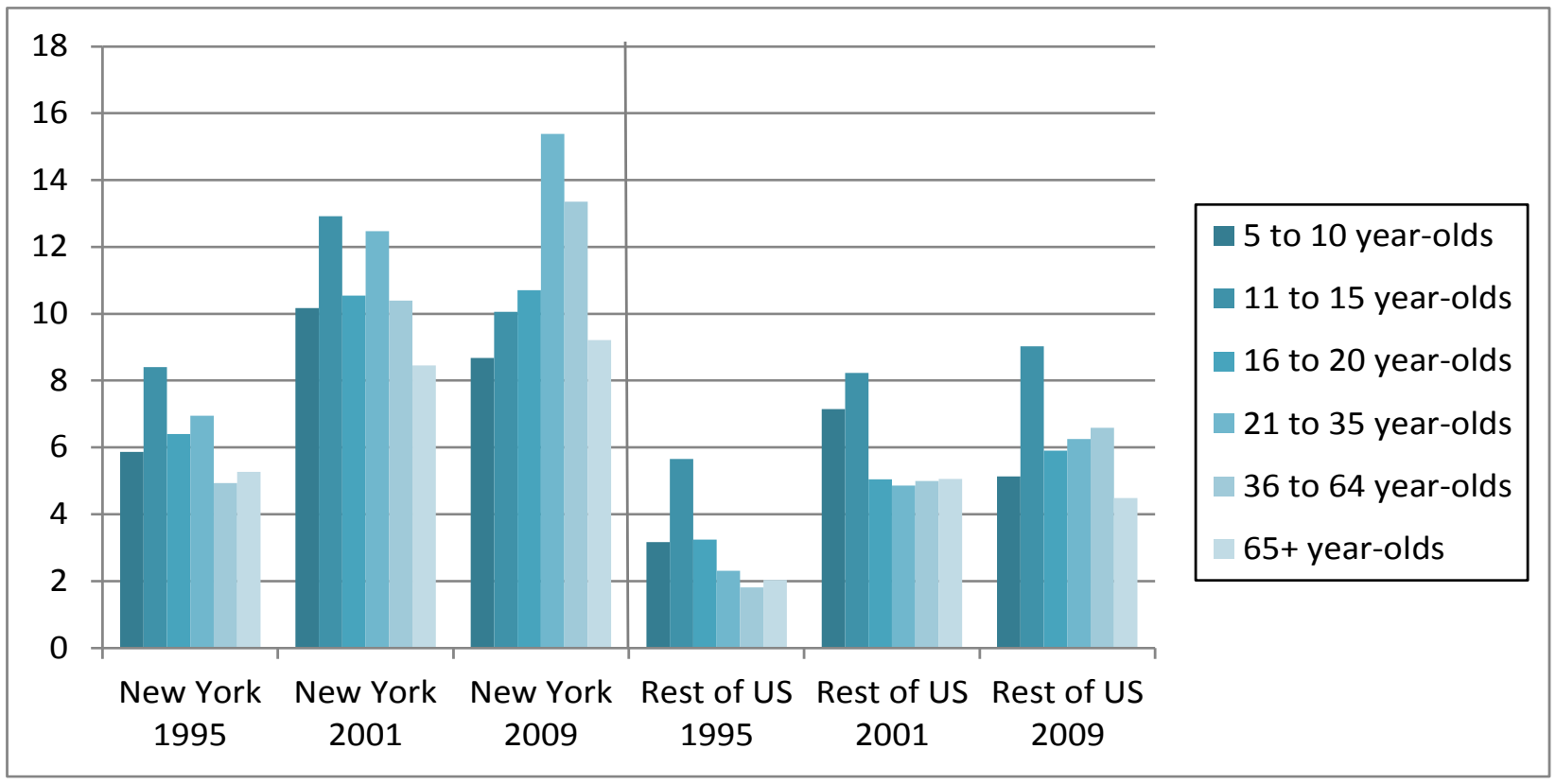

Figure 2.5 Average Time Spent Walking and/or Biking to Places (in minutes) per day by Age Group: New York State vs. Rest of the United States in 1995, 2001, and 2009.

It should be noted that the averages reported in Table 2.5 and shown in Figure 2.5 was calculated based on all population, including both those respondents who did and those who did not report walking or biking as part of the survey. When asked, a significant percentage of people reported no walk trips at all over the week prior to their reporting, especially in the 65 and older age group (see Figure 2.6). Again, the percentage of NYS residents who did do some walking over the week prior to being surveyed was significantly higher than in the rest of the nation, in both 2001 and 2009. 


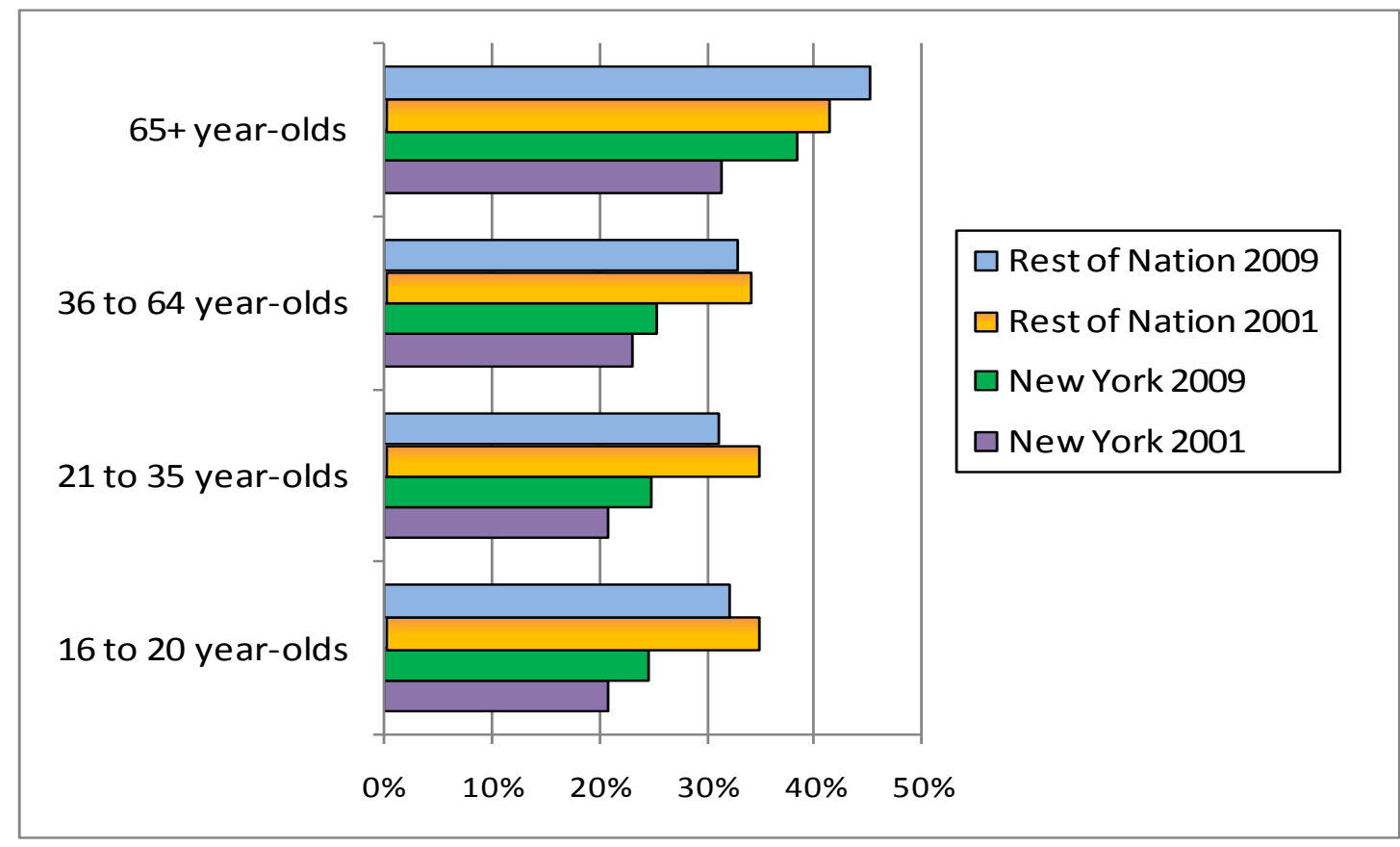

Figure 2.6 Percentages of People Who Reported No Walk/Bike Trips in the Last Week, Differentiated by Age Groups, in 2001 and 2009.

Note: This walk trip question was not asked of persons under 16 years old in 2001, or at all in 1995

\subsubsection{Why Trips Were Made - Purpose of Travel}

Table 2.6 shows the distribution of person trips according to five broad trip purpose categories. Trip purpose shares are essentially the same for NYS as they are in the rest of the nation. Over time a roughly $1.5 \%$ decrease in work-related tripmaking and a $3 \%$ decrease in family and personal trips has been replaced by increases in social and recreational trips, both within and outside the state.

Table 2.6 Daily Person Trips Rate by Trip Purpose in New York State vs. Rest of the United States in 1995, 2001, and 2009

\begin{tabular}{|c|c|c|c|c|c|c|c|c|}
\hline \multirow[b]{2}{*}{ Trip Purpose } & \multicolumn{3}{|c|}{ New York State } & \multicolumn{3}{|c|}{ Rest of United States } & \multicolumn{2}{|c|}{$\begin{array}{c}\% \text { Changes } \\
1995-2009\end{array}$} \\
\hline & 1995 & 2001 & 2009 & 1995 & 2001 & 2009 & $\begin{array}{l}\text { New } \\
\text { York } \\
\text { State }\end{array}$ & $\begin{array}{l}\text { Rest } \\
\text { of US }\end{array}$ \\
\hline Average Daily Trip Rate & 3.88 & 3.73 & 3.64 & 4.33 & 4.11 & 3.81 & & \\
\hline$\%$ Earning a Living & $19.8 \%$ & $19.3 \%$ & $18.3 \%$ & $20.3 \%$ & $18.8 \%$ & $18.7 \%$ & $-1.5 \%$ & $-1.6 \%$ \\
\hline \% Family \& Personal Business & $45.9 \%$ & $43.3 \%$ & $43.2 \%$ & $45.7 \%$ & $43.9 \%$ & $42.4 \%$ & $-2.7 \%$ & $-3.3 \%$ \\
\hline$\%$ Civic, Educational \& Religious & $9.3 \%$ & $9.7 \%$ & $9.5 \%$ & $8.8 \%$ & $9.8 \%$ & $9.6 \%$ & $0.2 \%$ & $0.8 \%$ \\
\hline \% Social \& Recreational & $25.0 \%$ & $26.2 \%$ & $27.0 \%$ & $24.9 \%$ & $26.6 \%$ & $27.5 \%$ & $2.0 \%$ & $2.6 \%$ \\
\hline$\%$ Other & $0.0 \%$ & $1.2 \%$ & $1.1 \%$ & $0.2 \%$ & $0.8 \%$ & $0.8 \%$ & $1.1 \%$ & $0.6 \%$ \\
\hline
\end{tabular}




\subsubsection{Differences in Travel Pattern by Gender and Age Group}

Men and women make roughly the same number of trips per day, on average, in both NYS and in the rest of the country (Table 2.7). In 2009, differences in person trip rates by age group also follow a similar pattern in NYS to those in the rest of America (Figure 2.7). The highest daily person trip rates are in the 30-39 and 40-49 year age groups; with higher rates also in the 50-59 and 60-64 age groups than among travelers under 30 years of age.

Table 2.7 Daily Person Trips Rate by Gender and by Age Groupings New York State vs. Rest of the United States in 1995, 2001, and 2009

\begin{tabular}{|c|c|c|c|c|c|c|}
\hline \multirow[b]{2}{*}{ Daily Person Trips per Person } & \multicolumn{3}{|c|}{ New York State } & \multicolumn{3}{|c|}{$\begin{array}{c}\text { Rest of United } \\
\text { States }\end{array}$} \\
\hline & 1995 & 2001 & 2009 & 1995 & 2001 & 2009 \\
\hline TOTAL & 3.88 & 3.73 & 3.64 & 4.33 & 4.11 & 3.81 \\
\hline \multicolumn{7}{|l|}{ Gender } \\
\hline Male & 3.93 & 3.77 & 3.63 & 4.36 & 4.11 & 3.76 \\
\hline Female & 3.84 & 3.70 & 3.64 & 4.30 & 4.12 & 3.85 \\
\hline \multicolumn{7}{|l|}{ Age Group } \\
\hline 5-15 years & 3.31 & 3.02 & 2.99 & 3.73 & 3.46 & 3.20 \\
\hline $16-19$ years & 3.76 & 3.53 & 3.32 & 4.69 & 4.19 & 3.54 \\
\hline 20-29 years & 4.02 & 3.76 & 3.38 & 4.60 & 4.24 & 3.75 \\
\hline 30-39 years & 4.35 & 4.16 & 4.12 & 4.84 & 4.57 & 4.21 \\
\hline $40-49$ years & 4.39 & 4.35 & 4.35 & 4.83 & 4.67 & 4.33 \\
\hline $50-59$ years & 3.83 & 3.97 & 3.91 & 4.23 & 4.30 & 4.13 \\
\hline $60-64$ years & 3.80 & 3.88 & 4.03 & 4.16 & 4.12 & 3.90 \\
\hline $65+$ years & 3.29 & 3.18 & 2.96 & 3.44 & 3.43 & 3.22 \\
\hline Unreported & & 3.33 & & & 3.71 & \\
\hline
\end{tabular}




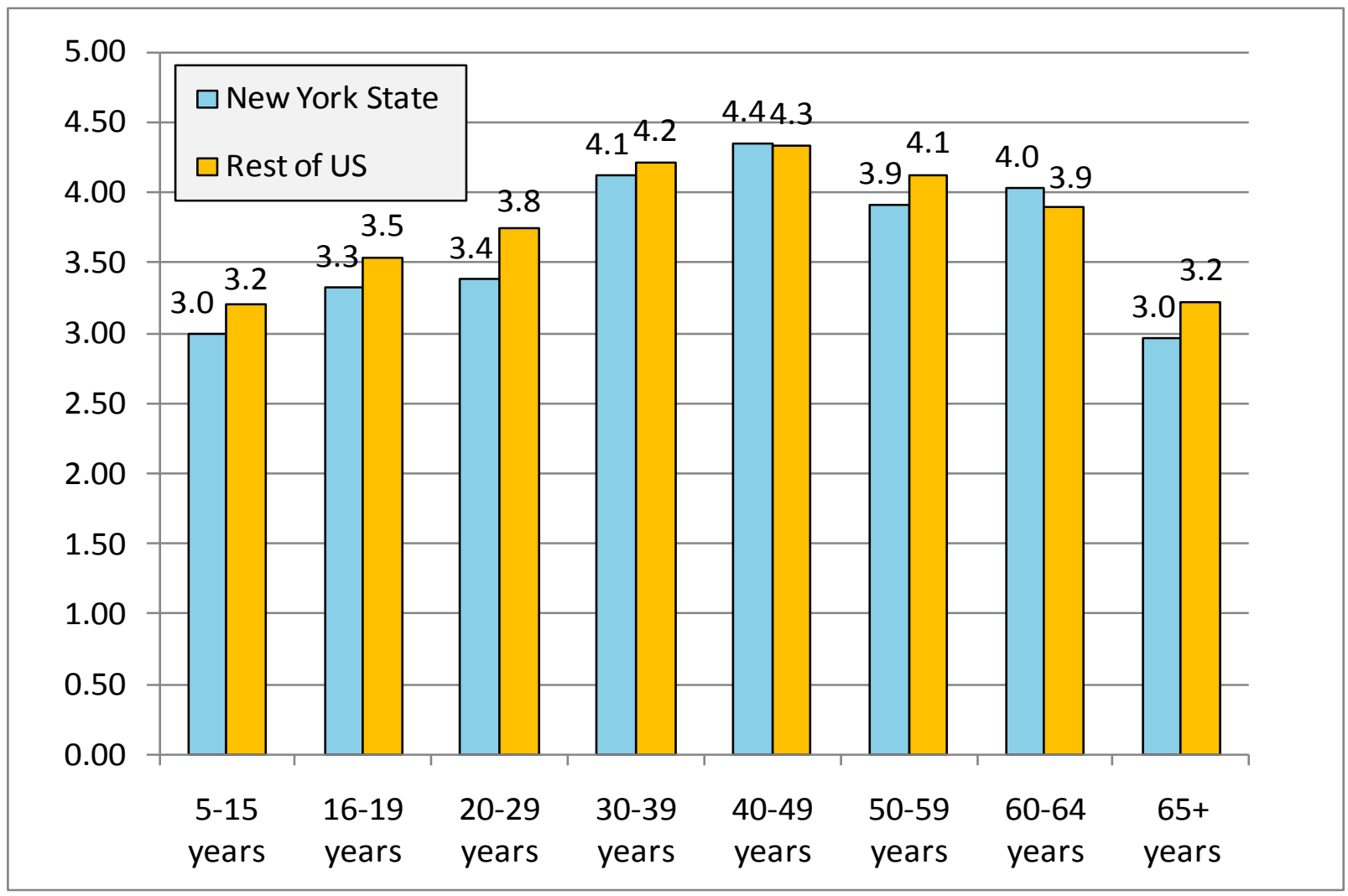

Figure 2.7 Daily Person Trips Rate by Age Group New York State vs. Rest of the United States in 2009.

Looked at over time (Figure 2.8) this peaking in average trip rates in a person's thirties and forties appears to have become more significant both nationally and within the state, due largely to lower average person trips rates among the younger age groups, especially in the rest of the nation. In contrast to the rest of the Unites States, there has been no decline in average daily person trip rates among NYS travelers in the 50-59 and 60-64 year age groups. 


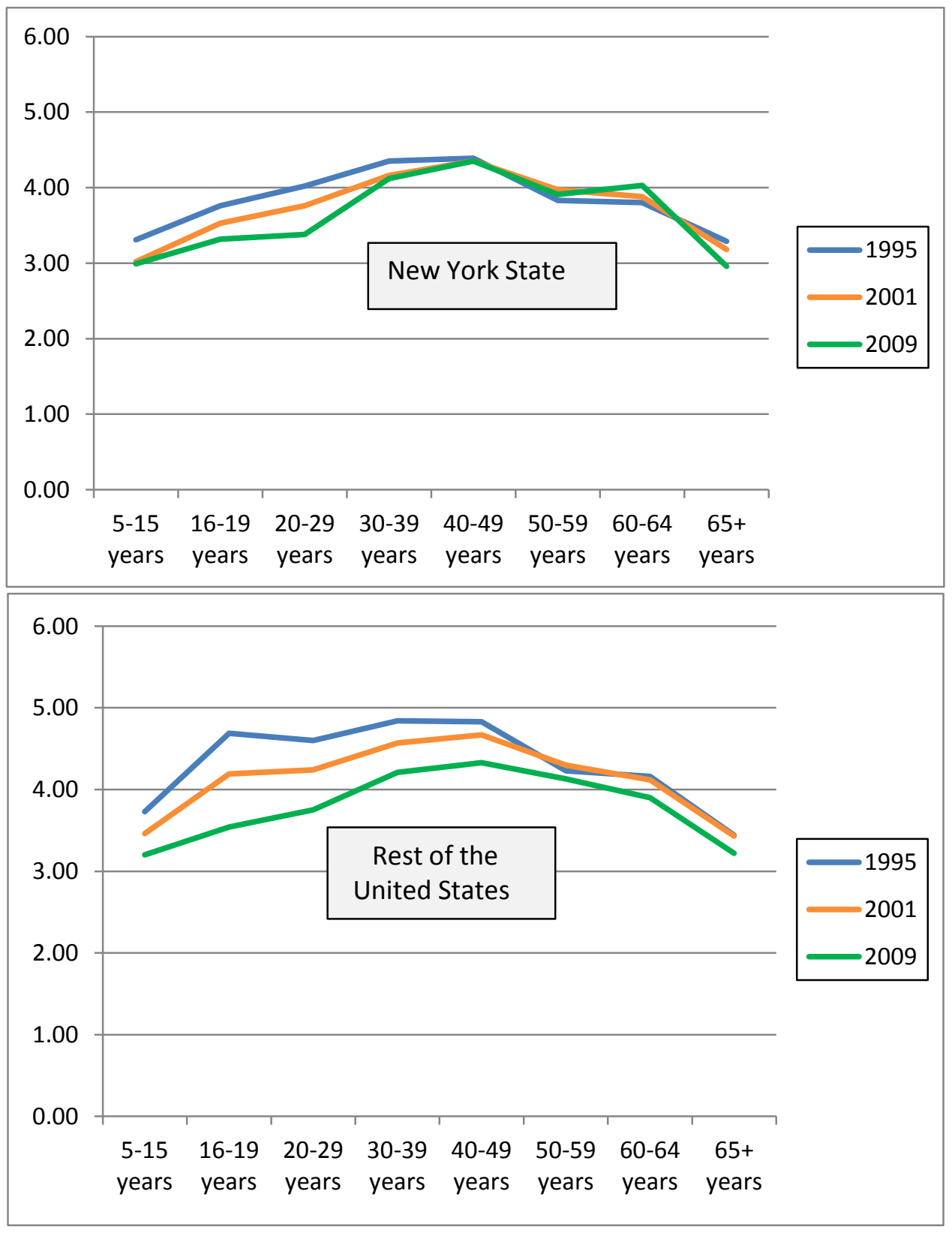

Figure 2.8 Average Daily Person Trips per Person by Age Group: New York State vs. Rest of the United States 1995-2001-2009.

\subsubsection{Travel Differences and Vehicle Ownership}

Significant differences exist between households that do versus do not own at least one private vehicle. These include differences in average per person daily trip rates (Figure 2.9) as well as differences in the choice of travel modes (Figures 2.10 and 2.11). 


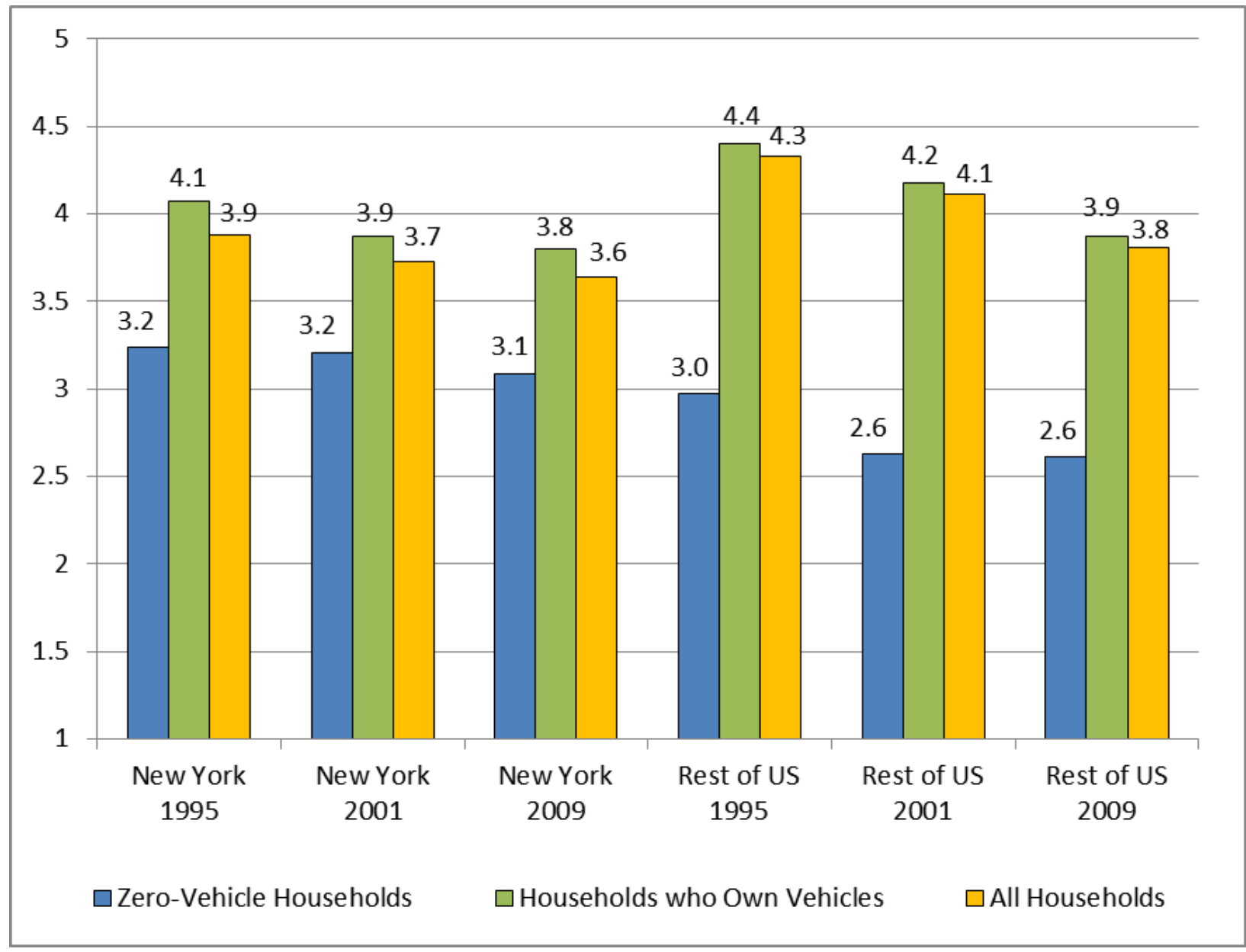

Figure 2.9 Person Trips Rate by Household Vehicle Ownership: New York State vs. Rest of the United States in 1995, 2001, and 2009.

As in other parts of the country, individuals in NYS households that do not own a vehicle take significantly fewer trips per day on average than do those in households that own a vehicle, 3.1 vs. 3.8 trips in 2009 (Figure 2.9). However, the lack of a vehicle has a much greater percentage impact on the daily person trip rates of households in the rest of the country, 2.6 person trips per day by zero-vehicle households, versus 3.9 trips a day for non-NYS households who own at least one vehicle. NYS residents in households that didn't own a vehicle in 2009 took more than $18 \%$ more trips than those elsewhere in the country, at a rate of 3.1 versus 2.6 person trips per day, respectively. This is largely a case of the "Manhattan effect" in that the socioeconomic profiles, and the resulting travel patterns, of Manhattan residents who do not own a vehicle are significantly different from those of non-Manhattan residents who do not own a vehicle (see Chapter 3).

As one would expect, the modal shares (i.e., the percentages of a person's trips taken by a given mode) for people in households that do not own a vehicle is also very different from 
vehicle owning households (see Figure 2.10), with walking and riding public transit as the two major modes for both NYS residents and travelers in other states.

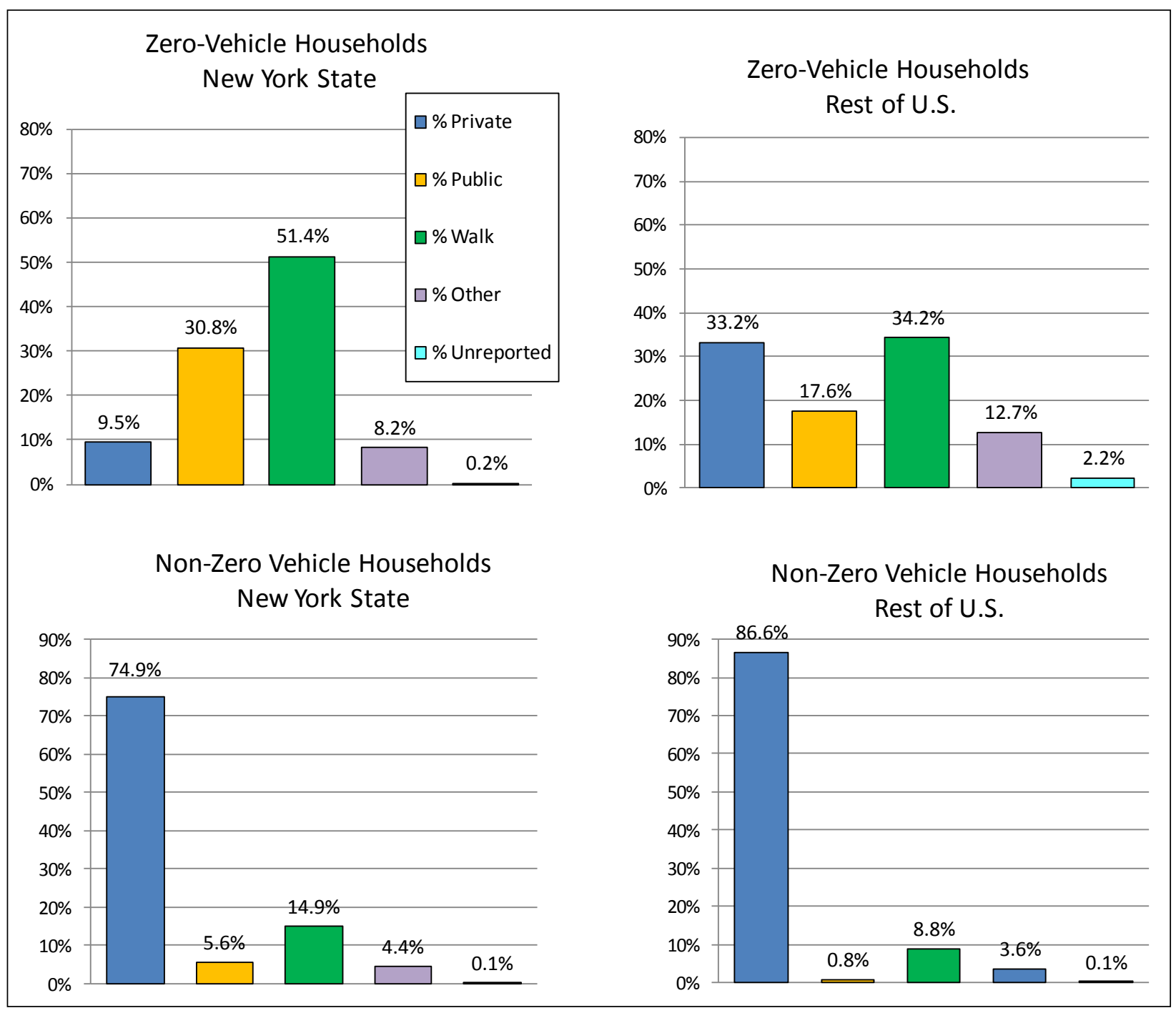

Figure 2.10 Modal Shares for Vehicle Owning vs. Non-Vehicle Owning Households in 2009: New York State vs. the Rest of the United States.

\subsubsection{Characteristics of Zero-Vehicle Households}

As pointed out in previous editions of this Comparisons Report, clear differences exist between NYS households and those households in other states who do not own a private vehicle (Table 2.8). Not only is there a much higher percentage of zero-vehicle owning households in NYS (28.5\% versus $7.4 \%$ in 2009), but many more of these households are in higher income groups. 
Table 2.8 Distribution of Households (HHs) without a Vehicle Across Income Groups: New York State vs. the Rest of the United States in 1995, 2001, and 2009

\begin{tabular}{l|rrr||rrr}
\hline \multirow{2}{*}{} & \multicolumn{3}{|c||}{ New York State } & \multicolumn{3}{c}{ Rest of United States } \\
\cline { 2 - 7 }$\%$ Zero-Vehicle $($ Veh) HHs by Income & $\mathbf{1 9 9 5}$ & $\mathbf{2 0 0 1}$ & $\mathbf{2 0 0 9}$ & $\mathbf{1 9 9 5}$ & $\mathbf{2 0 0 1}$ & $\mathbf{2 0 0 9}$ \\
\hline$\%$ of Zero-Veh HHs -- All Income Groups & $26.8 \%$ & $26.5 \%$ & $28.5 \%$ & $6.9 \%$ & $6.8 \%$ & $7.4 \%$ \\
\hline$\%<\$ 10,000$ 0-Veh HHs & 17.7 & 21.2 & 21.2 & 30.7 & 40.3 & 40.7 \\
$\% \$ 10$ to $\$ 20,000$ 0-Veh HHs & 20.5 & 21.1 & 22.6 & 36.7 & 28.8 & 33.1 \\
$\% \$ 20$ to $\$ 30,000$ 0-Veh HHs & 17.4 & 14.4 & 12.4 & 17.0 & 13.5 & 11.4 \\
$\% \$ 30$ to $\$ 40,000$ 0-Veh HHs & 18.3 & 14.0 & 10.8 & 8.1 & 9.0 & 6.4 \\
$\% \$ 40$ to $\$ 50,000$ 0-Veh HHs & 4.4 & 3.5 & 7.4 & 1.4 & 1.9 & 3.9 \\
$\% \$ 50$ to $\$ 60,000$ 0-Veh HHs & 5.2 & 7.6 & 4.1 & 2.9 & 2.8 & 0.8 \\
$\% \$ 60$ to $\$ 70,000$ 0-Veh HHs & 5.6 & 3.3 & 4.4 & 1.7 & 0.9 & 0.5 \\
$\% \$ 70$ to $\$ 80,000$ 0-Veh HHs & 3.1 & 2.7 & 2.5 & 0.5 & 0.2 & 0.8 \\
$\% \$ 80$ to $\$ 100,000$ 0-Veh HHs & 2.5 & 2.8 & 4.9 & 0.5 & 0.6 & 0.4 \\
$\% \$ 100,000+0-V e h ~ H H s$ & 5.3 & 9.5 & 9.5 & 0.7 & 2.0 & 1.9 \\
\hline
\end{tabular}

Note: 1995 and 2001 income categories are adjusted to 2009 dollars.

While over $70 \%$ of households without a vehicle fell into the lowest two income groups (i.e., < $\$ 20,000$ a year) in the rest of the country in both 2001 and 2009 , only about $43 \%$ had similarly low incomes in NYS. Approximately $15 \%$ of these NYS households reported incomes of more than $\$ 70,000$ in 2001 , while about $17 \%$ reported similarly high income in 2009 . It seems clear that many NYS households do not own a vehicle for reasons that are not tied to vehicle ownership and the associated operating costs.

Among NYS residents without a vehicle, personal trip making propensity declined only slightly between 1995 and 2009 (Table 2.9). Outside of NYS, those in households who did not own a vehicle took $11 \%$ fewer trips in 2001 than in 1995, but this rate did not change measurably between 2001 and 2009 (Table 2.9 and Figure 2.9). There are also significant differences in the choice of mode between NYS residents and those elsewhere when they do not own a vehicle, reflecting at least in part differences in the availability of public transit as well as the density of destination opportunities close by for many residents of NYC (see Chapters 3 and 4). While one third of those travelers outside the state who do not own a vehicle relied heavily on non-public modes to meet their transportation needs in 2009, NYS residents more often used public transit or walked to places (Table 2.9 and Figure 2.10). Examined over time (Figure 2.11), the percentage of daily walk trips has increased both in NYS and in the rest of the nation, while their uses of private vehicle have declined over the same period of time. 
Table 2.9 Travel Patterns and Characteristics for Zero-Vehicle Households: New York State vs. the Rest of the Nation in 1995, 2001, and 2009

\begin{tabular}{|c|c|c|c|c|c|c|c|c|c|c|}
\hline \multirow{3}{*}{$\begin{array}{l}\text { Statistics for Zero- } \\
\text { Vehicle Households }\end{array}$} & \multirow{2}{*}{\multicolumn{3}{|c|}{ New York State }} & \multirow{2}{*}{\multicolumn{3}{|c|}{$\begin{array}{l}\text { Rest of United } \\
\text { States }\end{array}$}} & \multicolumn{2}{|c|}{ New York State } & \multicolumn{2}{|c|}{ Rest of US } \\
\hline & & & & & & & \multirow{2}{*}{$\begin{array}{c}\% \\
\text { difference } \\
1995- \\
2001 \\
\end{array}$} & \multirow{2}{*}{$\begin{array}{c}\% \\
\text { difference } \\
2001 \text { - } \\
2009 \\
\end{array}$} & \multirow{2}{*}{$\begin{array}{c}\% \\
\text { difference } \\
1995- \\
2001 \\
\end{array}$} & \multirow{2}{*}{$\begin{array}{c}\% \\
\text { difference } \\
2001- \\
2009\end{array}$} \\
\hline & 1995 & 2001 & 2009 & 1995 & 2001 & 2009 & & & & \\
\hline $\begin{array}{l}\text { Person Trips per } \\
\text { Person }\end{array}$ & 3.24 & 3.21 & 3.09 & 2.97 & 2.63 & 2.61 & $-0.9 \%$ & $-3.7 \%$ & $-11.4 \%$ & $-0.8 \%$ \\
\hline $\begin{array}{l}\text { Mode Share } \\
\% \text { Private vehicle } \\
\text { trips }\end{array}$ & 14.8 & 15.5 & 9.5 & 46.5 & 43.6 & 33.2 & & & & \\
\hline $\begin{array}{l}\text { \% Public transit } \\
\text { trips }\end{array}$ & 32.1 & 30.8 & 30.8 & 14.5 & 16.7 & 17.6 & & & & \\
\hline$\%$ Walk trips & 39.2 & 46.1 & 51.4 & 24.6 & 31.9 & 34.2 & & & & \\
\hline$\%$ Other trips & 6.8 & 7.3 & 8.2 & 6.7 & 7.6 & 12.7 & & & & \\
\hline$\%$ Unreported & 7.1 & 0.2 & 0.2 & 7.7 & 0.1 & 2.2 & & & & \\
\hline $\begin{array}{l}\text { Person Trips per } \\
\text { Person }\end{array}$ & 3.24 & 3.21 & 3.09 & 2.97 & 2.63 & 2.61 & $-0.9 \%$ & $-3.7 \%$ & $-11.4 \%$ & $-0.8 \%$ \\
\hline Income Group & & & & & & & & & & \\
\hline$<\$ 10,000$ & 2.89 & 2.78 & 2.41 & 2.57 & 2.45 & 2.43 & $-3.8 \%$ & $-13.3 \%$ & $-4.7 \%$ & $-0.8 \%$ \\
\hline$\$ 10$ to $\$ 20,000$ & 3.21 & 2.97 & 2.96 & 3.27 & 2.42 & 2.63 & $-7.5 \%$ & $-0.3 \%$ & $-26.0 \%$ & $8.7 \%$ \\
\hline$\$ 20$ to $\$ 30,000$ & 3.45 & 3.15 & 3.18 & 3.59 & 3.25 & 3.23 & $-8.7 \%$ & $1.0 \%$ & $-9.5 \%$ & $-0.6 \%$ \\
\hline$\$ 30$ to $\$ 40,000$ & 3.26 & 3.13 & 2.83 & 3.32 & 2.75 & 3.08 & $-4.0 \%$ & $-9.6 \%$ & $-17.2 \%$ & $12.0 \%$ \\
\hline$\$ 40$ to $\$ 50,000$ & 3.38 & 3.88 & 2.77 & 3.85 & 2.54 & 3.22 & $14.8 \%$ & $-28.6 \%$ & $-34.0 \%$ & $26.8 \%$ \\
\hline$\$ 50$ to $\$ 60,000$ & 3.55 & 3.41 & 3.26 & 2.52 & 3.77 & 3.76 & $-3.9 \%$ & $-4.4 \%$ & $49.6 \%$ & $-0.3 \%$ \\
\hline$\$ 60$ to $\$ 70,000$ & 4.19 & 4.31 & 4.58 & 2.62 & 3.94 & 3.32 & $2.9 \%$ & $6.3 \%$ & $50.4 \%$ & $-15.7 \%$ \\
\hline$\$ 70$ to $\$ 80,000$ & 4.54 & 3.80 & 3.23 & 6.24 & 1.95 & 2.74 & $-16.3 \%$ & $-15.0 \%$ & $-68.8 \%$ & $40.5 \%$ \\
\hline$\$ 80$ to $\$ 100,000$ & 3.49 & 4.44 & 3.74 & 8.10 & 3.79 & 3.88 & $27.2 \%$ & $-15.8 \%$ & $-53.2 \%$ & $2.4 \%$ \\
\hline$\$ 100,000+$ & 4.16 & 4.43 & 4.79 & 4.23 & 4.13 & 3.77 & $6.5 \%$ & $8.1 \%$ & $-2.4 \%$ & $-8.7 \%$ \\
\hline
\end{tabular}

Note: 1995 and 2001 income categories are adjusted to 2009 dollars.

In NYS, walking continued to be the most common mode of choice for those who do not own a vehicle, followed by public transit. While public transit's share of these trips remained steady across all three survey years at around 30\%, the walking share of NYS tripmaking by zero-vehicle household members grew from $40 \%$ in 1995 to over $50 \%$ in 2009 . A similar $10 \%$ increase in the share of walking trips from one survey to the next is also evident in the rest of the nation, representing one third of all person trips by zero-vehicle households in 2009. (However, on a cautionary note, non-reporting in 1995 may dampen this apparent gain somewhat, while a sharply increased share of walk trips in 2001 may be an artifact of the improvement in the 2001 survey where special prompting was carried out to better recall walk and bicycle trips). 


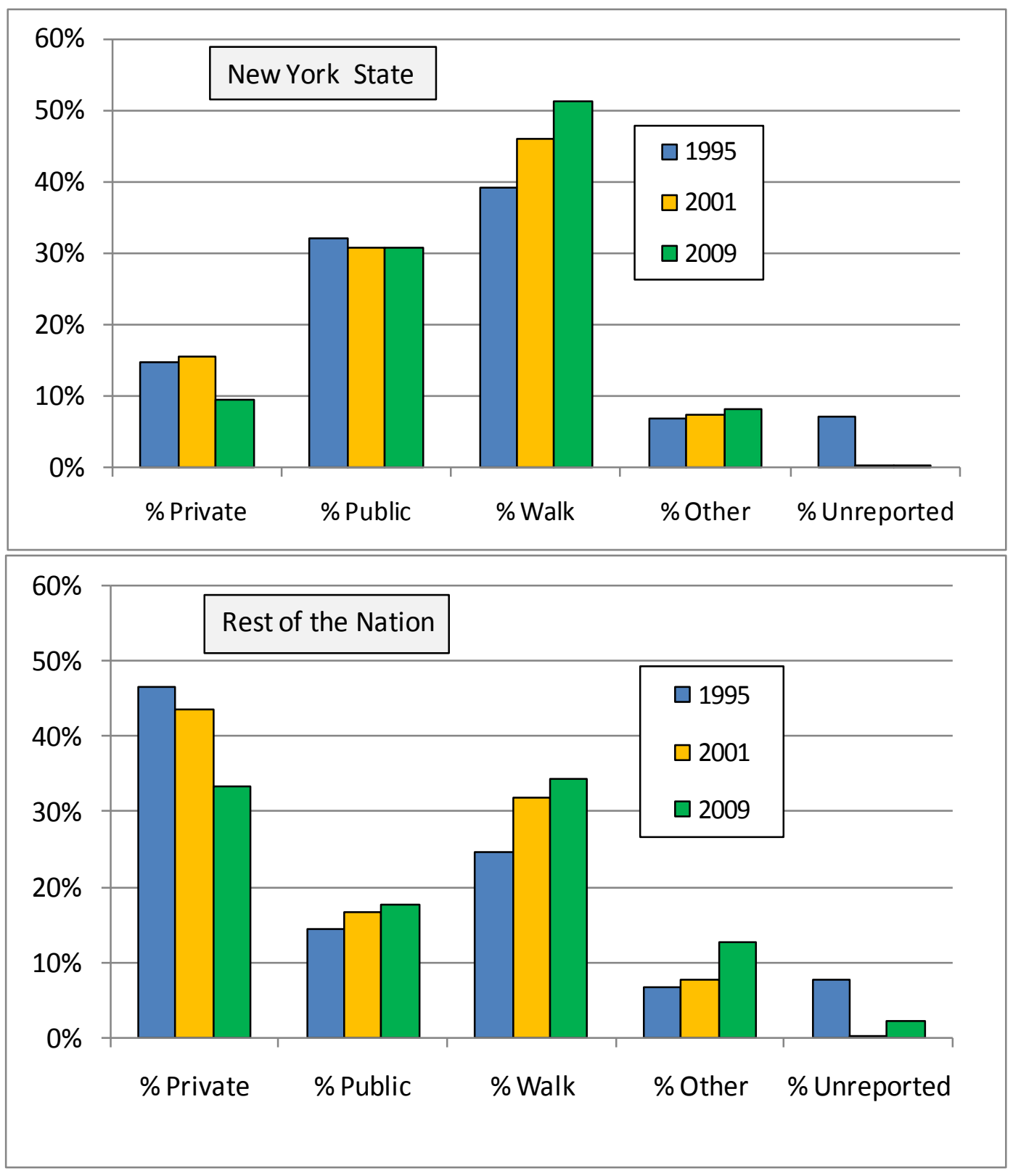

Figure 2.11 Modal Share Trends in Person Trips by Persons in Households That Don't Own a Vehicle: New York State vs. the Rest of the Nation.

\subsection{VEHICLE TRAVEL COMPARISONS}

The NYS drivers logged both fewer and, on the average, shorter trips in 2009 than they did in either 2001 or 1995 (Table 2.10). A similar trend in reduced daily vehicle trip rates, as well as shorter average trip lengths, is also evident in the rest of the country, if to a lesser extent. These shorter average trip lengths represent a reversal in trend from the period 1995 to 2001, when trip lengths increased, especially in the rest of the nation. 
Table 2.10 Daily Vehicle Travel Statistics: New York State vs. Rest of the United States

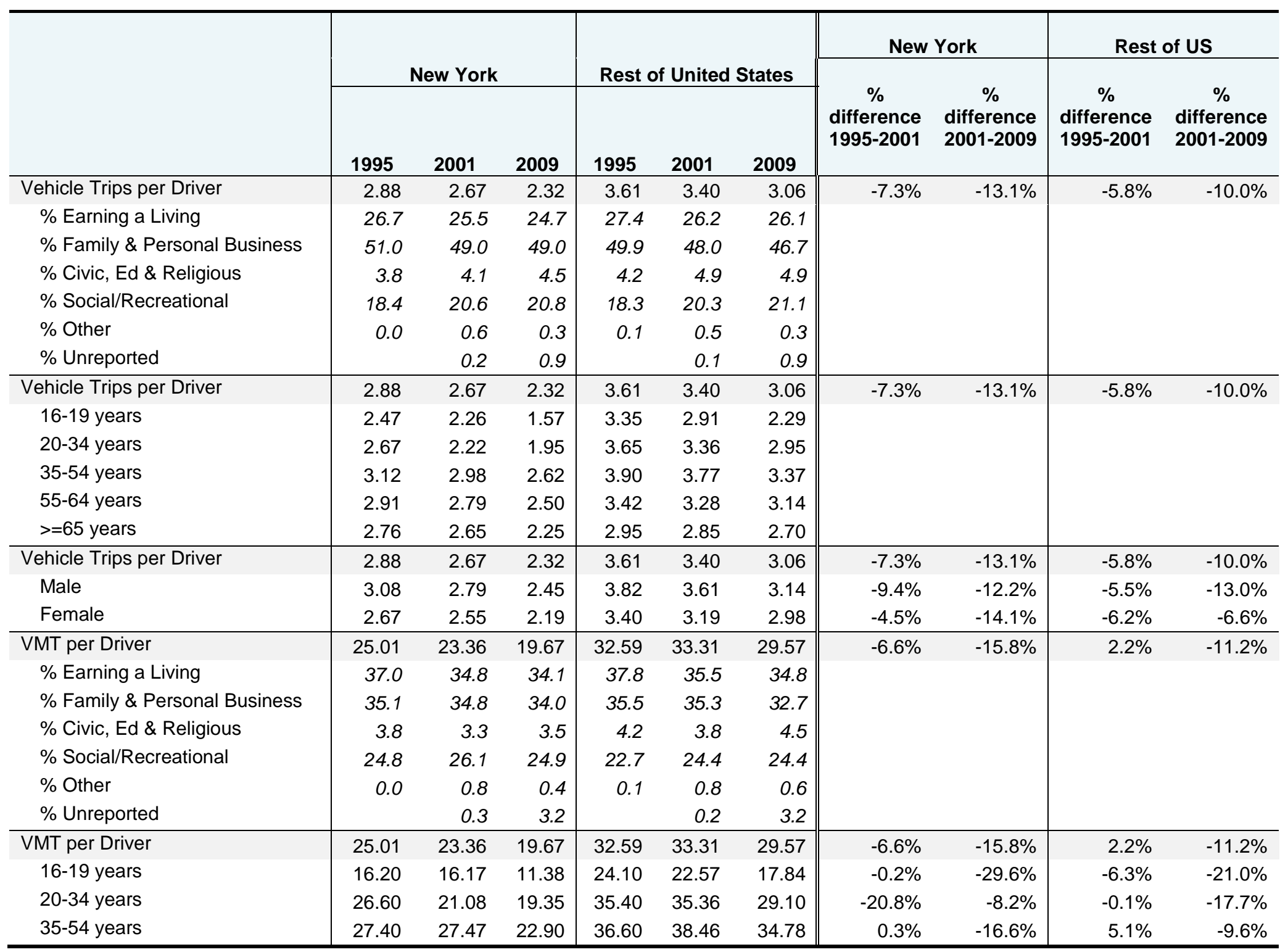




\begin{tabular}{|c|c|c|c|c|c|c|c|c|c|c|}
\hline & \multirow{2}{*}{\multicolumn{3}{|c|}{ New York }} & \multirow{2}{*}{\multicolumn{3}{|c|}{ Rest of United States }} & \multicolumn{2}{|c|}{ New York } & \multicolumn{2}{|c|}{ Rest of US } \\
\hline & & & & & & & \multirow{2}{*}{$\begin{array}{c}\% \\
\text { difference } \\
\text { 1995-2001 }\end{array}$} & \multirow{2}{*}{$\begin{array}{c}\% \\
\text { difference } \\
\text { 2001-2009 }\end{array}$} & \multirow{2}{*}{$\begin{array}{c}\% \\
\text { difference } \\
\text { 1995-2001 }\end{array}$} & \multirow{2}{*}{$\begin{array}{c}\% \\
\text { difference } \\
2001-2009\end{array}$} \\
\hline & 1995 & 2001 & 2009 & 1995 & 2001 & 2009 & & & & \\
\hline $55-64$ years & 23.30 & 23.19 & 19.92 & 30.60 & 32.60 & 31.00 & $-0.5 \%$ & $-14.1 \%$ & $6.5 \%$ & $-4.9 \%$ \\
\hline$>=65$ years & 17.40 & 17.82 & 15.05 & 19.70 & 21.34 & 19.97 & $2.4 \%$ & $-15.5 \%$ & $8.3 \%$ & $-6.4 \%$ \\
\hline VMT per Driver & 25.01 & 23.36 & 19.67 & 32.59 & 33.31 & 29.57 & $-6.6 \%$ & $-15.8 \%$ & $2.2 \%$ & $-11.2 \%$ \\
\hline Male & 30.80 & 28.58 & 23.44 & 40.60 & 41.63 & 35.76 & $-7.2 \%$ & $-18.0 \%$ & $2.5 \%$ & $-14.1 \%$ \\
\hline Female & 18.60 & 17.86 & 15.79 & 24.50 & 25.12 & 23.31 & $-4.0 \%$ & $-11.6 \%$ & $2.5 \%$ & $-7.2 \%$ \\
\hline Weekday Vehicle Trips/Driver & 3.01 & 2.79 & 2.41 & 3.84 & 3.60 & 3.26 & $-7.2 \%$ & $-13.9 \%$ & $-6.1 \%$ & $-9.5 \%$ \\
\hline Weekend Vehicle Trips/Driver & 2.58 & 2.37 & 2.10 & 3.00 & 2.88 & 2.56 & $-8.3 \%$ & $-11.4 \%$ & $-4.1 \%$ & $-11.0 \%$ \\
\hline Average Vehicle Trip Length & 8.78 & 8.92 & 8.62 & 9.07 & 9.91 & 9.77 & $1.6 \%$ & $-3.4 \%$ & $9.3 \%$ & $-1.4 \%$ \\
\hline$\%$ Vehicle Trips/Person Trips & $46.3 \%$ & $45.9 \%$ & $44.8 \%$ & $61.6 \%$ & $61.6 \%$ & $60.6 \%$ & & & & \\
\hline$\%$ VMT/PMT & $54.0 \%$ & $51.0 \%$ & $53.6 \%$ & $61.0 \%$ & $60.6 \%$ & $60.5 \%$ & & & & \\
\hline
\end{tabular}

Note: Weekend trips = Saturday and Sunday trips. 
Despite generally similar temporal trends in daily vehicular trip rates and vehicle miles traveled, NYS residents drove $24 \%$ fewer trips on average than residents in other states during 2009; increasing this gap a little from 21\% fewer vehicle trips per day between 1995 and 2001. The VMT per NYS driver also fell by a little more than trip frequency did (a 16\% drop versus a 13\% drop) between 2001 and 2009. In the rest of the country VMT per driver dropped by an average of $11 \%$, again just a little over the drop in number of trips per driver (-10\%). This downward temporal trend in daily vehicle trip rates was consistent across all age categories and for either gender, both within and outside the state, as was VMT per driver. There were some differences across trip purposes. Both trip rates and VMT per driver have been trending down for travel that involves making a living or engaging in family or personal business. In contrast, both average vehicle trips per driver and average VMT per driver were relatively stable or marginally increasing for social/recreational as well as civic, educational, and religious trip purposes, both within and outside NYS (Table 2.10).

The percentage of vehicle trips devoted to earning a living remained relatively stable across the 14 year period from 1995 to 2009, at around one quarter of all trips made for both NYS residents and other Americans. The percentage of VMT devoted to work related activity shows a slight and near identical downward trend from around 37\% to below 35\% for both within and outside the state. Weekend trips per NYS driver decreased by $11.4 \%$ from 2001 to 2009 , while in the rest of the U.S. they decreased by $11 \%$. Weekday trips per driver dropped by $14 \%$ between 2001 and 2009 in NYS, versus a 9.5\% drop in the rest of the nation. Consistent with the trends in personal travel, the ratio of vehicle trips to person trips, given as a percentage towards the bottom of Table 2.10, was $45 \%$ for NYS travelers, versus $61 \%$ for travelers elsewhere in the country. Similarly, the ratio of vehicle miles traveled to person miles traveled (VMT/PMT) yields a value of 54\% for NYS travelers versus $61 \%$ for the rest of the nation. This reflects once again the finding that NYS residents rely more heavily on non-private vehicle modes of travel than other Americans do when averaged over all travel activity within the year.

\subsubsection{Types and Ages of Vehicles in Use}

The private vehicle market in the United States includes a wide variety of vehicle makes, models, and types. A comparison of the major vehicle types driven in NYS and the rest of the country yields some significant differences. One such difference is the percentage of pickup trucks in the NYS fleet (Table 2.11). At less than 9\% of the NYS fleet in 2009, versus over $18 \%$ in the rest of the nation, this continues a trend that has persisted, and remained essentially the same, since 1995. 
Table 2.11 Comparison of Vehicle Types Driven in New York State vs. the Rest of the United States in 1995, 2001, and 2009

\begin{tabular}{l|rrr||rrr}
\hline \multirow{2}{*}{\multicolumn{1}{c|}{ Vehicle Types }} & \multicolumn{3}{c||}{ New York State } & \multicolumn{3}{c}{ Rest of United States } \\
\cline { 2 - 7 } & \multicolumn{1}{c|}{$\mathbf{1 9 9 5}$} & $\mathbf{2 0 0 1}$ & $\mathbf{2 0 0 9}$ & $\mathbf{1 9 9 5}$ & $\mathbf{2 0 0 1}$ & $\mathbf{2 0 0 9}$ \\
\hline Auto & $75.4 \%$ & $66.0 \%$ & $58.0 \%$ & $64.7 \%$ & $56.4 \%$ & $49.7 \%$ \\
Van & $7.4 \%$ & $9.9 \%$ & $9.1 \%$ & $8.0 \%$ & $9.0 \%$ & $8.2 \%$ \\
Sports Utility & $6.9 \%$ & $12.0 \%$ & $21.5 \%$ & $7.0 \%$ & $12.1 \%$ & $19.4 \%$ \\
Pickup & $8.9 \%$ & $9.3 \%$ & $8.6 \%$ & $18.3 \%$ & $19.0 \%$ & $18.3 \%$ \\
Other Truck & $0.3 \%$ & $0.3 \%$ & $0.2 \%$ & $0.4 \%$ & $0.5 \%$ & $0.4 \%$ \\
RV & $0.3 \%$ & $0.4 \%$ & $0.3 \%$ & $0.5 \%$ & $0.7 \%$ & $0.5 \%$ \\
Motorcycle & $0.7 \%$ & $2.1 \%$ & $2.4 \%$ & $1.0 \%$ & $2.3 \%$ & $3.4 \%$ \\
Other POV & $0.1 \%$ & $*$ & $*$ & $0.1 \%$ & $*$ & $*$ \\
\hline TOTAL & $100.0 \%$ & $100.0 \%$ & $100.0 \%$ & $100.0 \%$ & $100.0 \%$ & $100.0 \%$ \\
\hline
\end{tabular}

Note: * Other POV not present in 2001 or 2009.

Both the median and average age of the household vehicle fleet is lower in NYS than elsewhere in 2009 (Table 2.12). While there was an increase of approximately $2 \%$ in the older vehicle fleet percentage in the rest of the nation between 2001 and 2009, there was a roughly $3 \%$ decrease in older vehicle ownership in NYS between 2001 and 2009. As a result, in 2009 about $70 \%$ of the NYS households' private vehicle fleet was made up of vehicles that were under 10 years old. In the rest of the nation this percentage was significantly lower, at just over $60 \%$.

Table 2.12 Characteristics of Households' Private Vehicle Fleets by Vehicle Age New York State vs. Rest of the United States

\begin{tabular}{|c|c|c|c|c|c|c|}
\hline \multirow[b]{2}{*}{ Statistics by Vehicle Age } & \multicolumn{3}{|c|}{ New York State } & \multicolumn{3}{|c|}{ Rest of United States } \\
\hline & 1995 & 2001 & 2009 & 1995 & 2001 & 2009 \\
\hline Average Vehicle Age & 7.43 & 7.85 & 7.79 & 8.38 & 8.92 & 9.47 \\
\hline Median Vehicle Age & 7 & 7 & 7 & 7 & 7 & 8 \\
\hline $\begin{array}{l}\text { Percent } \mathrm{VMT}^{\mathrm{a}} \\
\text { Less than } 10 \text { years } \\
10 \text { years or more }\end{array}$ & $\begin{array}{l}75.2 \% \\
24.8 \% \\
\end{array}$ & $\begin{array}{l}73.2 \% \\
26.8 \% \\
\end{array}$ & $\begin{array}{l}74.8 \% \\
25.2 \% \\
\end{array}$ & $\begin{array}{l}76.4 \% \\
23.6 \% \\
\end{array}$ & $\begin{array}{l}71.0 \% \\
29.0 \% \\
\end{array}$ & $\begin{array}{l}67.8 \% \\
32.2 \% \\
\end{array}$ \\
\hline $\begin{array}{c}\text { Percent Vehicle Fleet } \\
\text { Less than } 10 \text { years } \\
10 \text { years or more }\end{array}$ & $\begin{array}{l}71.6 \% \\
28.4 \% \\
\end{array}$ & $\begin{array}{l}66.5 \% \\
33.5 \% \\
\end{array}$ & $\begin{array}{l}69.3 \% \\
30.7 \% \\
\end{array}$ & $\begin{array}{l}66.0 \% \\
34.0 \% \\
\end{array}$ & $\begin{array}{l}62.6 \% \\
37.5 \% \\
\end{array}$ & $\begin{array}{l}60.7 \% \\
39.3 \% \\
\end{array}$ \\
\hline Average Fuel Consumption (gallons)/HH & ** & 709 & 615 & ** & 1,036 & 1,020 \\
\hline $\begin{array}{l}\text { Less than } 10 \text { years } \\
10 \text { years or more }\end{array}$ & ** & $\begin{array}{l}74.5 \% \\
25.5 \% \\
\end{array}$ & $\begin{array}{l}73.6 \% \\
26.5 \% \\
\end{array}$ & ** & $\begin{array}{l}71.3 \% \\
28.7 \% \\
\end{array}$ & $\begin{array}{l}66.3 \% \\
33.7 \% \\
\end{array}$ \\
\hline Average CO2 Emissions $(\mathrm{kg}) / \mathrm{HH}$ & ** & 6,235 & 5,416 & ** & 9,106 & 8,985 \\
\hline $\begin{array}{l}\text { Less than } 10 \text { years } \\
10 \text { years or more }\end{array}$ & ** & $\begin{array}{l}74.5 \% \\
25.5 \%\end{array}$ & $\begin{array}{l}73.6 \% \\
26.4 \%\end{array}$ & ** & $\begin{array}{l}71.3 \% \\
28.7 \%\end{array}$ & $\begin{array}{l}66.3 \% \\
33.7 \%\end{array}$ \\
\hline
\end{tabular}

\footnotetext{
${ }^{\mathrm{a}}$ Numbers reflect BESTMILE Estimates. Due to data being unavailable, self-reported annual miles were substituted for Rest of U.S. 1995 estimates.

** Statistics not available in 1995.
} 
In 1995 the percentage of annual VMT in these over 10 year old vehicles was marginally higher in NYS households than in the rest of the nation. However, this situation had reversed by 2001, and by 2009 the gap in older vehicle utilization had widened further, largely due to a continued increase in the percentage of older vehicle VMT within the rest of the national fleet: a trend not mirrored in NYS. As a result, three quarters of NYS household private vehicle VMT in 2009 was driven in vehicles under 10 years of age, compared to only two thirds of this VMT in the rest of the nation (Table 2.12).

The type of vehicle driven also reflects different levels of utilization, when measured in terms of annual miles driven (VMT per vehicle); with automobiles on average driven significantly fewer miles per vehicle than either vans or SUVs (Sports Utility Vehicles), and in NYS also driven less than pickup trucks (Figure 2.12). Some significant differences also exist between NYS annual vehicle utilization rates (i.e., annual miles driven per vehicle) and those in the rest of the nation. Whether driving an automobile, van, SUV, or pickup truck, vehicle utilization rates declined faster in the state than in the rest of the nation for all four vehicle types over the period 1995 to 2009 ( Figure 2.12).

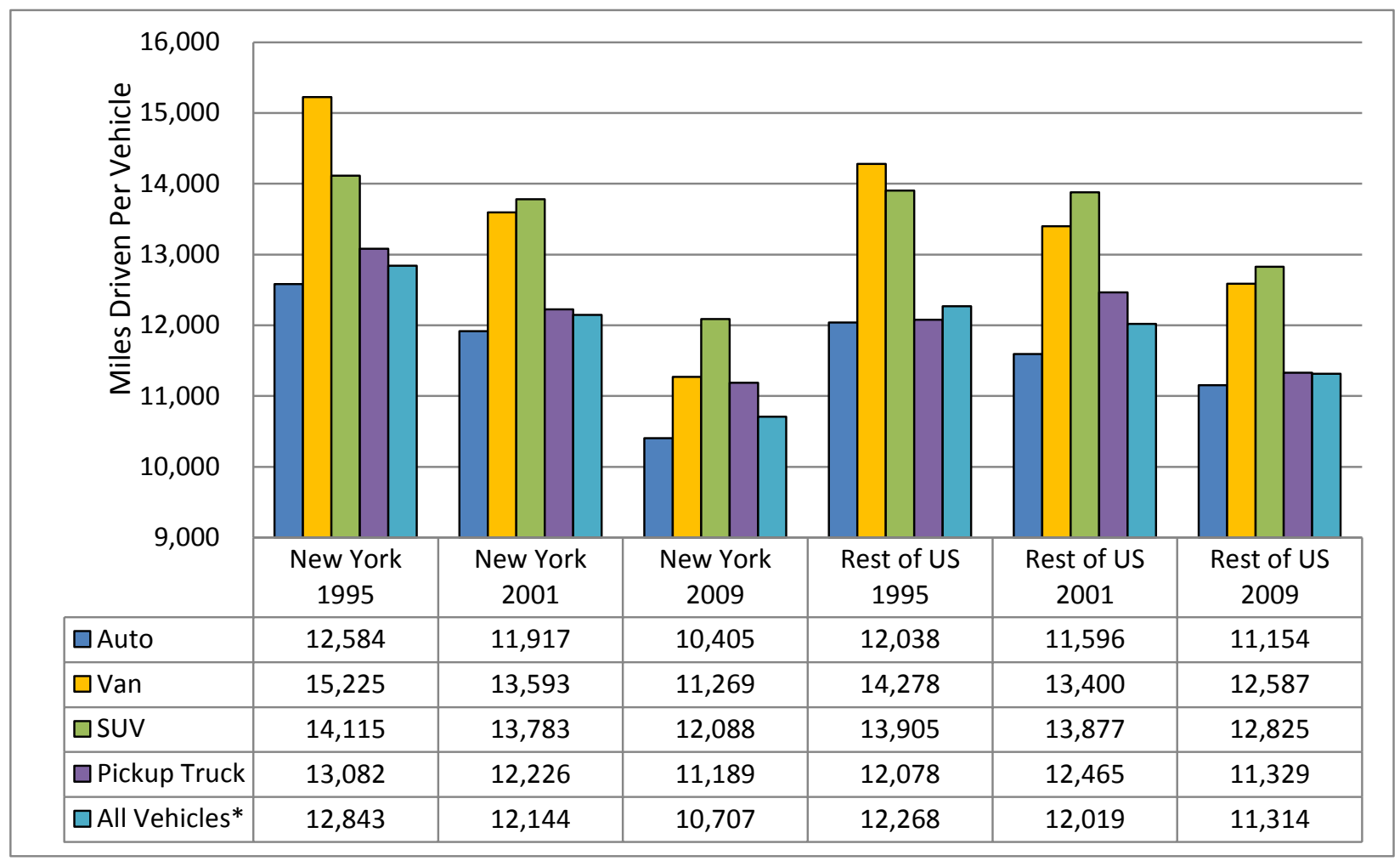

Figure 2.12 Average Annual Miles Driven per Household Vehicle, by Vehicle Type in 1995, 2001, and 2009.

Note: ${ }^{*}$ All Vehicles includes 'Other POVs" not otherwise defined. 
The age of a vehicle is also known to play a significant role in annual miles driven per vehicle. This effect is clearly shown in Figure 2.13, where its impact is evident in all three NHTS survey years, for the household vehicle fleet as a whole. Table 2.13 shows that significant reductions in annual vehicle utilization with vehicle age occurs in all four of the major types of private vehicle in use today (i.e., in automobiles, vans, SUVs, and pickup trucks). ${ }^{6}$

Table 2.13 Average Annual VMT per Household Vehicle, by Vehicle Type and Vehicle Age Group in 1995, 2001, and 2009

\begin{tabular}{|c|c|c|c|c|c|c|}
\hline \multirow{2}{*}{$\begin{array}{l}\text { Average Annual VMT per } \\
\text { HH Vehicle }\end{array}$} & \multicolumn{3}{|c|}{ New York State } & \multicolumn{3}{|c|}{ Rest of United States } \\
\hline & 1995 & 2001 & 2009 & 1995 & 2001 & 2009 \\
\hline \multicolumn{7}{|l|}{ All HH Vehicles* } \\
\hline 0 to 2 years & 14,976 & 13,474 & 12,424 & 16,22 & 14,701 & 14,216 \\
\hline 3 to 5 years & 13,232 & 13,797 & 11,609 & 14,076 & 14,191 & 12,735 \\
\hline 6 to 9 years & 12,608 & 12,614 & 10,910 & 12,665 & 12,512 & 11,754 \\
\hline 10 years or more & 11,300 & 9,857 & 8,872 & 8,748 & 9,360 & 9,319 \\
\hline Unreported & 15,289 & 12,247 & 10,366 & 11,975 & 10,925 & 11,143 \\
\hline \multicolumn{7}{|l|}{ Autos } \\
\hline 0 to 2 years & 14,597 & 13,137 & 11,914 & 15,524 & 14,054 & 14,230 \\
\hline 3 to 5 years & 12,600 & 13,805 & 10,970 & 13,652 & 13,471 & 12,465 \\
\hline 6 to 9 years & 12,458 & 11,975 & 10,641 & 12,387 & 12,028 & 11,336 \\
\hline 10 years or more & 11,331 & 10,115 & 9,059 & 8,928 & 9,433 & 9,477 \\
\hline Unreported & 15,779 & 12,081 & 10,503 & 11,369 & 11,292 & 11,425 \\
\hline \multicolumn{7}{|l|}{ SUVs } \\
\hline 0 to 2 years & 15,642 & 13,400 & 13,230 & 16,232 & 14,968 & 15,038 \\
\hline 3 to 5 years & 14,305 & 14,336 & 12,609 & 14,567 & 15,235 & 13,672 \\
\hline 6 to 9 years & 13,494 & 15,471 & 11,741 & 14,806 & 14,308 & 12,860 \\
\hline 10 years or more & 12,331 & 11,496 & 10,286 & 9,391 & 10,687 & 10,184 \\
\hline Unreported & 15,660 & 15,606 & 14,283 & 17,640 & 16,552 & 15,068 \\
\hline \multicolumn{7}{|l|}{ Vans } \\
\hline 0 to 2 years & 16,121 & 15,273 & 13,652 & 17,759 & 15,86 & 15,495 \\
\hline 3 to 5 years & 16,668 & 14,597 & 13,154 & 15,129 & 15,526 & 14,105 \\
\hline 6 to 9 years & 14,172 & 13,559 & 12,202 & 13,313 & 13,597 & 13,389 \\
\hline 10 years or more & 14,309 & 10,759 & 8,599 & 10,685 & 10,274 & 10,119 \\
\hline Unreported & 12,728 & 18,916 & 11,335 & 17,465 & 11,547 & 14,513 \\
\hline \multicolumn{7}{|l|}{ Pickup Trucks } \\
\hline 0 to 2 years & 15,660 & 15,606 & 14,283 & 17,640 & 16,552 & 15,068 \\
\hline 3 to 5 years & 15,472 & 13,185 & 12,909 & 15,001 & 15,420 & 13,233 \\
\hline 6 to 9 years & 12,521 & 14,536 & 11,761 & 12,862 & 12,888 & 12,016 \\
\hline 10 years or more & 11,274 & 9,258 & 8,698 & 8,348 & 9,536 & 9,544 \\
\hline Unreported & 13,069 & 9,057 & 10,959 & 11,984 & 11,879 & 11,759 \\
\hline
\end{tabular}

* Includes all Autos, SUVs, Vans, Pickup trucks and "Other POVs" not otherwise specified.

\footnotetext{
${ }^{6}$ The reader should note that the vehicle age distributions estimated from the NHTS survey data has a lower average vehicle age than reported by R.L. Polk \& Co. which was based on its historical tracking of vehicle

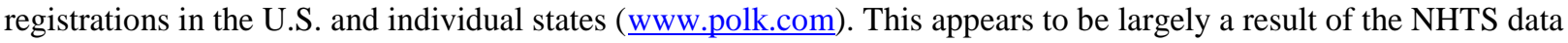
lacking a sufficiently long 'tail' to its distribution which includes many of the oldest vehicles on the road.
} 

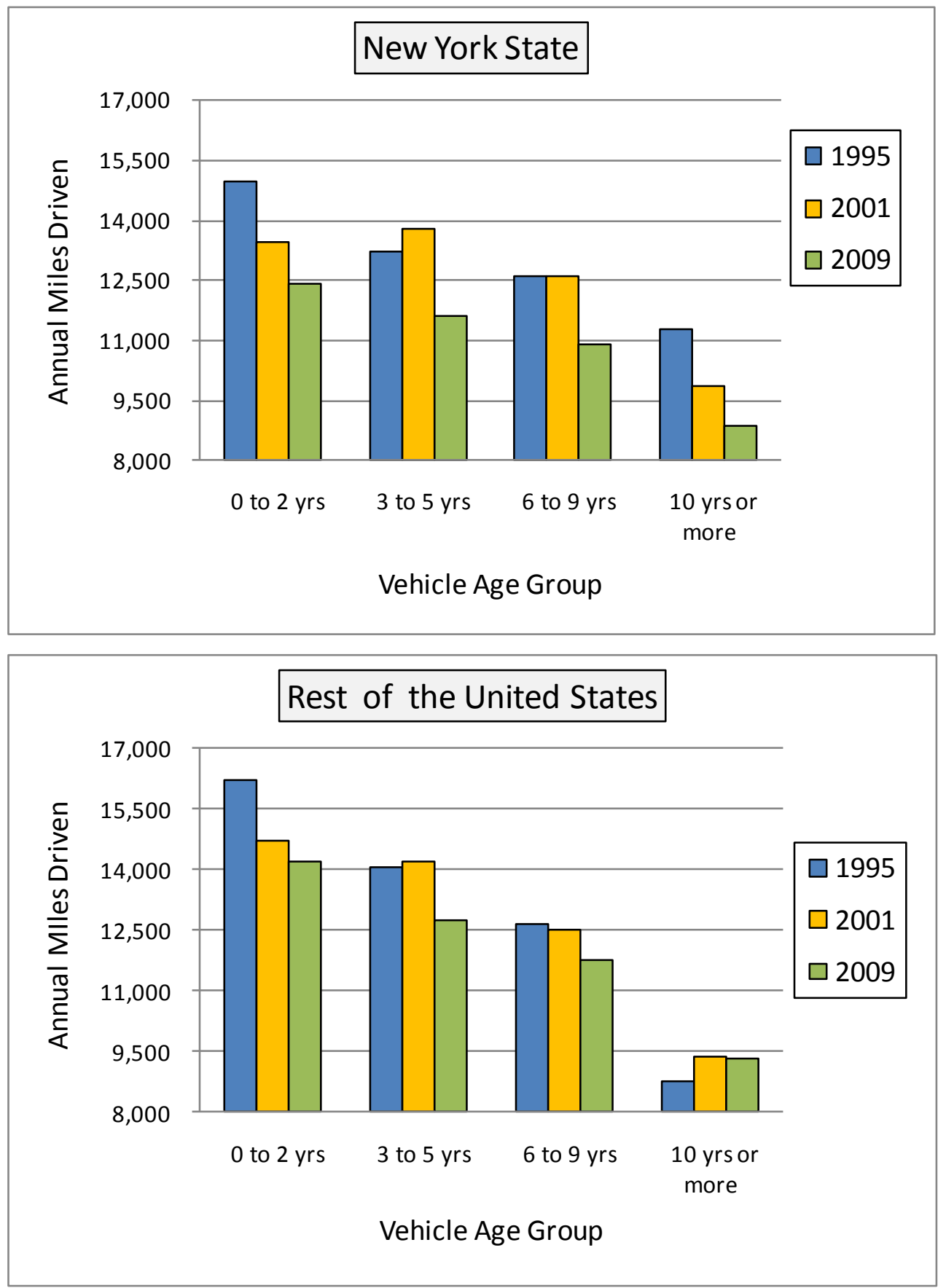

Figure 2.13 Trends in Average Annual Miles Driven per Household Vehicle, by Vehicle Age Group in 1995, 2001 and 2009.

As shown in Figure 2.13, vehicles under 2 years of age generally have a higher average annual VMT than older vehicles in all four classes in 2009, both within and outside the NYS. There is a clear decline, for all three survey years, in the average annual miles driven as the vehicle age increases. Significant differences in average annual miles driven are evident for vehicles over 10 years of age for all four vehicle types, particularly in NYS. 
In comparing NYS to the rest of the nation, while average annual miles driven for vehicles 10 year or older was much higher in the state compared to the rest of the nation in 1995 , across all vehicle types, this annual mileage has fallen significantly over time, to the point where these older vehicles were driven fewer miles annually, on average, in NYS in 2009 than they were in the rest of the nation. In contrast, utilization rates (when measured as average annual VMT) for this oldest vehicle age group increased between 1995 and 2001 in the rest of the country, and remained at this higher level of utilization in 2009 (Table 2.13, Figure 2.13).

\subsubsection{Energy and Greenhouse Gas Emissions Associated With Vehicle Travel}

Significantly greater use of non-motorized forms of travel (walk and cycle) and of public transit modes, a significantly lower average tip length, and lower daily trip rates (cf. Tables 2.4 and 2.10) meant that NYS households on average emitted far fewer annual carbon dioxide emissions from their daily travel activities than did households in the rest of the nation, in both 2001 and 2009, and with the gap widening over this 8 year period (Table 2.14, Figure 2.14).

Table 2.14 Average Annual Carbon Dioxide (CO2) Emissions per Household in New York State vs. the Rest of the United States, 2001 and 2009

\begin{tabular}{l|r|r||r|r}
\hline \multirow{2}{*}{ Average CO2 Emissions (kg)/HH } & \multicolumn{2}{c|}{ New York } & \multicolumn{2}{c}{ Rest of US } \\
\cline { 2 - 5 } POVs & $\mathbf{2 0 0 1}$ & $\mathbf{2 0 0 9}$ & $\mathbf{2 0 0 1}$ & $\mathbf{2 0 0 9}$ \\
\hline Other Modes & 6,235 & 5,416 & 9,106 & 8,985 \\
Average CO2 Emissions (kg)/HH & 470 & 499 & 141 & 216 \\
\hline 0 Workers & 6,705 & 5,915 & 9,247 & 9,201 \\
1 Workers & 2,945 & 2,773 & 4,128 & 4,599 \\
2 Workers & 5,271 & 5,264 & 7,608 & 8,537 \\
3 or more Workers & 9,508 & 9,161 & 12,298 & 13,336 \\
Average CO2 Emissions (kg)/HH & 12,776 & 13,481 & 17,137 & 19,073 \\
\hline 0 Drivers & 6,705 & 5,915 & 9,247 & 9,201 \\
1 Drivers & 532 & 248 & 238 & 242 \\
2 Drivers & 3,918 & 2,942 & 4,774 & 4,872 \\
3 or more Drivers & 9,389 & 8,002 & 10,947 & 10,934 \\
Average CO2 Emissions (kg)/HH & 14,104 & 12,540 & 16,261 & 16,882 \\
\hline 0 Vehicles & 6,705 & 5,915 & 9,247 & 9,201 \\
\hline Vehicles & 782 & 875 & 356 & 539 \\
2 Vehicles & 4,700 & 4,098 & 4,344 & 4,356 \\
3 or more Vehicles & 10,382 & 9,274 & 10,275 & 10,125 \\
\hline
\end{tabular}

Note: Air travel is excluded. 


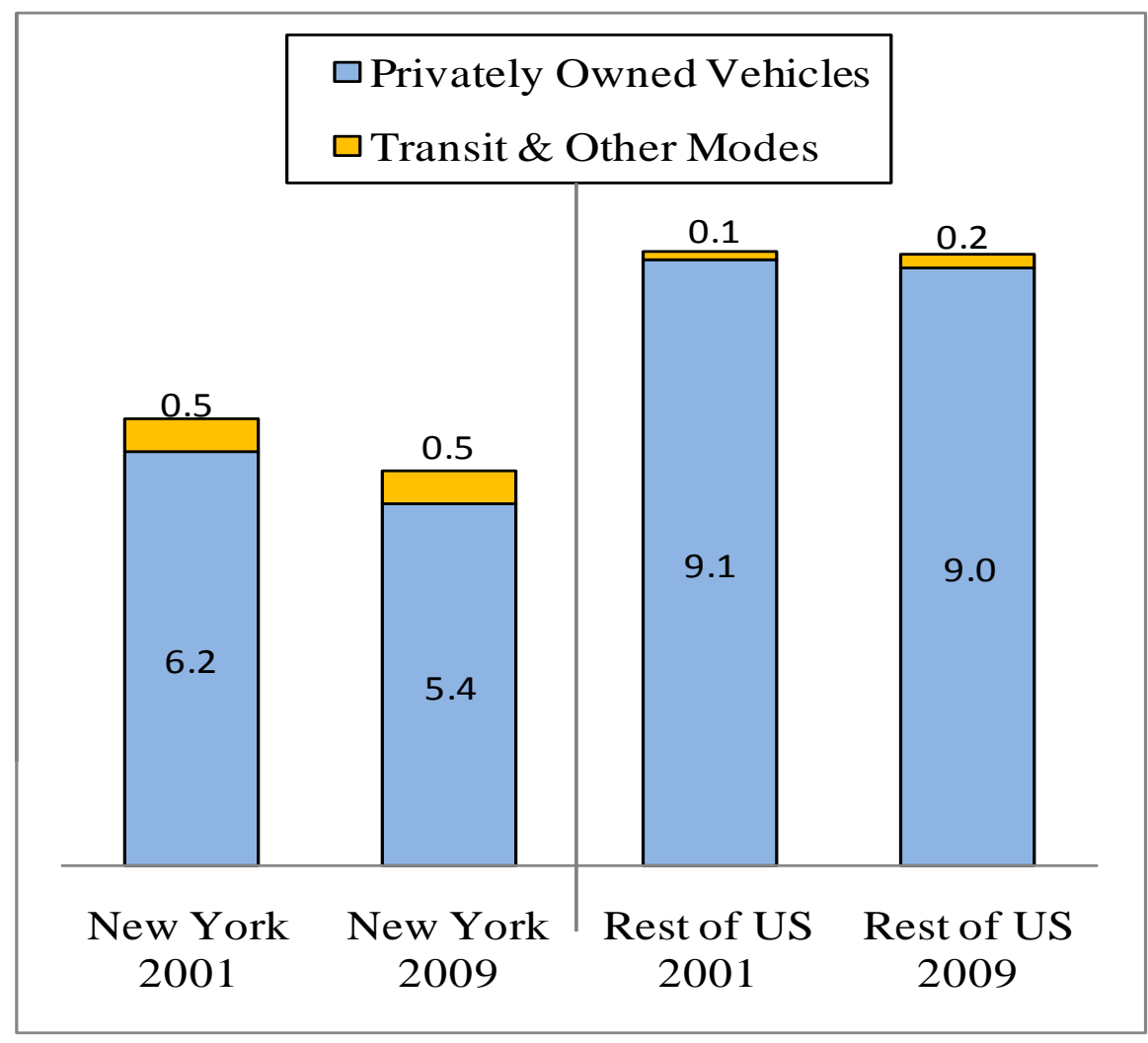

Figure 2.14 Annual Carbon Dioxide (Metric Tons of CO2) Emissions from Travel* per Household in 2001 and 2009: New York State vs. Rest of the United States.

Note: * Direct, vehicle operating emissions only, no "upstream" vehicle or fuel production or infrastructure provision related emissions are included. Air travel is excluded. The emissions rates used for each NHTS mode of travel are reported in Appendix D, and make use of US EPA recommended fuel use to $\mathrm{CO} 2$ emissions conversions, and emissions rate estimates derived from the Federal Transit Administration's rail, bus and ferry transit energy consumption database, and average vehicle fuel efficiencies reported by or derived from Federal Highway Administration, American Bus Association, American School Bus Association, and the New York City Taxi and Limousine Commission estimates.

Average annual CO2 emissions from travel made by NYS residents are estimated to be just under 6 metric tons per household in 2009. For the rest of the country this estimate is 9.2 metric tons, or roughly 50\% higher per household. Note that these figures apply only to direct emissions as a result of vehicle operations. In 2009 (Figure 2.14), 8.4\% of NYS's CO2 emissions came from non- privately owned vehicle sources. Three-quarters of these non-POV emissions, or $6.4 \%$ of the total annual household travel emissions in 2009 , were associated with the use of public transit modes, principally rail and bus transit, with travel by taxi making up much of the 
non-POV remainder (air travel was excluded). In the rest of the nation this public transit contribution was only $1.6 \%$ of total $\mathrm{CO} 2$ emissions. While average annual $\mathrm{CO} 2$ emissions per household appears not to have changed between 2001 and 2009 (at 9.20 metric tons), the emissions per NYS household are estimated to have fallen by more than $11 \%$ (down from 6.7 to 5.9 metric tons per year).

\subsection{COMPARISONS OF COMMUTING PATTERNS}

Efficient commutes are essential to a productive workforce and therefore to the economic vitality of a state and the regions within it. The percentage of NYS commuters using their private vehicles (SOV plus MOV) to get to work remained steady at around 68\% of all trips for all three survey periods. In the rest of the nation some $93 \%$ of all commutes did the same, again with no discernible change over the 14 year period covered by the last three NHTS surveys (Table 2.15). While about $8.5 \%$ of NYS's commuters walked to work in 2009 , roughly the same percentage as in 2001 , less than $3 \%$ did so in the rest of the nation.

Although commute distances are shorter in NYS than elsewhere (Table 2.16), on average, NYS workers spent about 7 more minutes commuting (one way) than commuters elsewhere in 2009 and 2001. Average commute distance increased between 1995 and 2001, and then fell back closer to 1995 levels in the rest of the nation. In NYS, however, a significant drop in average commute distance (from 11.3 to 10.4 miles) was followed by only a marginal change between 2001 and 2009 from 10.4 to 10.3 miles (Table 2.16 and Figure 2.15). 
Table 2.15 Commute Statistics New York State vs. Rest of the United States in 1995, 2001, and 2009

\begin{tabular}{|c|c|c|c|c|c|c|c|c|c|c|}
\hline & \multicolumn{3}{|c|}{ New York State } & \multicolumn{3}{|c|}{ Rest of United States } & \multicolumn{2}{|c|}{ New York State } & \multicolumn{2}{|c|}{ Rest of United States } \\
\hline & 1995 & 2001 & 2009 & 1995 & 2001 & 2009 & $\begin{array}{c}\% \\
\text { difference } \\
1995- \\
2001 \\
\end{array}$ & $\begin{array}{c}\% \\
\text { difference } \\
2001- \\
2009 \\
\end{array}$ & $\begin{array}{c}\% \\
\text { difference } \\
1995- \\
2001 \\
\end{array}$ & $\begin{array}{c}\% \\
\text { difference } \\
2001- \\
2009 \\
\end{array}$ \\
\hline $\begin{array}{l}\text { Commute Person Trips per } \\
\text { Worker }\end{array}$ & 1.31 & 1.12 & 1.06 & 1.40 & 1.15 & 1.11 & $-14.5 \%$ & $-5.4 \%$ & $-17.9 \%$ & $-3.5 \%$ \\
\hline \% POV by Occupancy & 69.5 & 67.9 & 67.6 & 92.1 & 94.1 & 93.0 & & & & \\
\hline$\%$ SOV & 56.5 & 55.3 & 56.0 & 75.7 & 77.7 & 78.4 & & & & \\
\hline$\% \mathrm{MOV}$ & 13.0 & 12.6 & 11.5 & 16.4 & 16.4 & 14.6 & & & & \\
\hline \% POV by Vehicle Type & 69.5 & 67.9 & 67.6 & 92.1 & 94.1 & 93.0 & & & & \\
\hline$\%$ Car & 51.1 & 44.7 & 39.6 & 59.2 & 53.6 & 52.2 & & & & \\
\hline$\%$ Van & 5.0 & 7.0 & 6.0 & 7.5 & 8.3 & 6.9 & & & & \\
\hline$\%$ SUV & 4.9 & 8.6 & 14.8 & 6.7 & 12.7 & 17.5 & & & & \\
\hline$\%$ Pickup Truck & 7.1 & 7.1 & 6.5 & 17.5 & 18.6 & 15.1 & & & & \\
\hline$\%$ Other Truck & 0.9 & 0.3 & 0.4 & 1.2 & 0.5 & 0.6 & & & & \\
\hline$\% R V$ & 0.0 & 0.0 & 0.0 & 0.0 & 0.0 & 0.0 & & & & \\
\hline$\%$ Motorcycle & 0.1 & 0.2 & 0.2 & 0.2 & 0.3 & 0.6 & & & & \\
\hline \% Public Transit & 18.3 & 20.1 & 19.6 & 2.9 & 2.5 & 2.3 & & & & \\
\hline$\%$ Commuter Train & 3.1 & 1.8 & 2.3 & 0.7 & 0.3 & 0.3 & & & & \\
\hline \% Subway/Elevated Rail & 9.9 & 12.8 & 10.6 & 0.7 & 0.5 & 0.3 & & & & \\
\hline$\%$ Other Public & 5.3 & 5.5 & 6.6 & 1.4 & 1.6 & 1.7 & & & & \\
\hline$\%$ Amtrak & 0.0 & 0.7 & 0.4 & 0.0 & 0.1 & 0.0 & & & & \\
\hline$\%$ Walk & 6.1 & 8.7 & 8.5 & 2.1 & 2.4 & 2.7 & & & & \\
\hline$\%$ Other & 2.3 & 2.4 & 3.9 & 1.4 & 0.9 & 1.8 & & & & \\
\hline \% Unreported & 3.8 & 0.1 & 0.2 & 1.6 & 0.1 & 0.2 & & & & \\
\hline Commute PMT per Worker & 13.97 & 10.79 & 10.15 & 16.08 & 13.78 & 12.99 & $-22.8 \%$ & $-5.9 \%$ & $-14.3 \%$ & $-5.7 \%$ \\
\hline \% POV by Occupancy & 77.5 & 77.5 & 80.8 & 94.0 & 93.8 & 95.2 & & & & \\
\hline$\% \mathrm{SOV}$ & 62.5 & 64.7 & 67.5 & 76.8 & 77.7 & 81.7 & & & & \\
\hline$\% \mathrm{MOV}$ & 15.0 & 12.8 & 13.3 & 17.2 & 16.1 & 13.5 & & & & \\
\hline \% POV by Vehicle Type & 77.5 & 77.5 & 80.8 & 94.0 & 93.8 & 95.2 & & & & \\
\hline$\%$ Car & 55.4 & 50.8 & 46.0 & 57.1 & 51.0 & 53.7 & & & & \\
\hline$\%$ Van & 5.4 & 7.3 & 6.2 & 7.1 & 7.8 & 6.3 & & & & \\
\hline
\end{tabular}




\begin{tabular}{|c|c|c|c|c|c|c|c|c|c|c|}
\hline & \multicolumn{3}{|c|}{ New York State } & \multicolumn{3}{|c|}{ Rest of United States } & \multicolumn{2}{|c|}{ New York State } & \multicolumn{2}{|c|}{ Rest of United States } \\
\hline & 1995 & 2001 & 2009 & 1995 & 2001 & 2009 & $\begin{array}{c}\% \\
\text { difference } \\
1995- \\
2001\end{array}$ & $\begin{array}{c}\% \\
\text { difference } \\
2001- \\
2009\end{array}$ & $\begin{array}{c}\% \\
\text { difference } \\
1995- \\
2001\end{array}$ & $\begin{array}{c}\% \\
\text { difference } \\
2001- \\
2009\end{array}$ \\
\hline$\%$ SUV & 5.5 & 9.6 & 17.9 & 7.0 & 12.5 & 16.3 & & & & \\
\hline$\%$ Pickup Truck & 8.3 & 9.2 & 7.9 & 19.2 & 20.8 & 16.7 & & & & \\
\hline$\%$ Other Truck & 2.6 & 0.4 & 2.7 & 3.3 & 1.4 & 1.6 & & & & \\
\hline$\% \mathrm{RV}$ & 0.0 & 0.0 & 0.0 & 0.0 & 0.0 & 0.0 & & & & \\
\hline$\%$ Motorcycle & 0.1 & 0.2 & 0.1 & 0.2 & 0.3 & 0.6 & & & & \\
\hline \% Public Transit & 17.9 & 18.0 & 14.2 & 2.6 & 2.1 & 1.7 & & & & \\
\hline$\%$ Commuter Train & 5.9 & 4.5 & 3.1 & 0.7 & 0.7 & 0.5 & & & & \\
\hline$\%$ Subway/Elevated Rail & 8.4 & 10.9 & 7.3 & 0.4 & 0.5 & 0.2 & & & & \\
\hline$\%$ Other Public & 3.7 & 2.7 & 3.8 & 1.5 & 1.0 & 1.1 & & & & \\
\hline$\%$ Amtrak & 0.0 & 1.0 & 0.6 & 0.1 & 0.3 & 0.0 & & & & \\
\hline \% Walk & 0.6 & 1.1 & 1.3 & 0.1 & 0.2 & 0.2 & & & & \\
\hline$\%$ Other & 3.1 & 2.1 & 2.8 & 2.2 & 3.5 & 2.7 & & & & \\
\hline \% Unreported & 0.7 & 0.2 & 0.2 & 0.9 & 0.1 & 0.2 & & & & \\
\hline
\end{tabular}


Table 2.16 Commute Travel Distances, Times and Average Speeds for New York State vs. Rest of the United States in 1995, 2001, and 2009

\begin{tabular}{|c|c|c|c|c|c|c|c|c|c|c|}
\hline & \multirow{2}{*}{\multicolumn{3}{|c|}{ New York State }} & \multirow{2}{*}{\multicolumn{3}{|c|}{$\begin{array}{c}\text { Rest of United } \\
\text { States }\end{array}$}} & \multicolumn{2}{|c|}{ New York State } & \multicolumn{2}{|c|}{ Rest of United States } \\
\hline & & & & & & & \multirow{2}{*}{$\begin{array}{c}\% \\
\text { difference } \\
1995- \\
2001\end{array}$} & \multirow{2}{*}{$\begin{array}{c}\% \\
\text { difference } \\
2001- \\
2009\end{array}$} & \multirow{2}{*}{$\begin{array}{c}\% \\
\text { difference } \\
1995- \\
2001\end{array}$} & \multirow{2}{*}{$\begin{array}{c}\% \\
\text { difference } \\
2001- \\
2009\end{array}$} \\
\hline & 1995 & 2001 & 2009 & 1995 & 2001 & 2009 & & & & \\
\hline Commute Trip Distance (miles) & 11.29 & 10.39 & 10.25 & 11.65 & 12.22 & 11.89 & $-8.0 \%$ & $-1.3 \%$ & $4.9 \%$ & $-2.7 \%$ \\
\hline POV & 12.15 & 11.31 & 11.61 & 11.82 & 12.13 & 12.11 & $-6.9 \%$ & $2.7 \%$ & $2.6 \%$ & $-0.2 \%$ \\
\hline Public Transit & 12.6 & 11.32 & 9.04 & 13 & 11.94 & 10.71 & $-10.2 \%$ & $-20.1 \%$ & $-8.2 \%$ & $-10.3 \%$ \\
\hline Commute Travel Time (minutes) & 25.66 & 30.40 & 29.89 & 20.23 & 23.11 & 23.45 & $18.5 \%$ & $-1.7 \%$ & $14.2 \%$ & $1.5 \%$ \\
\hline POV & 22.57 & 23.87 & 24.49 & 19.97 & 22.42 & 22.77 & $5.8 \%$ & $2.6 \%$ & $12.3 \%$ & $1.6 \%$ \\
\hline Public Transit & 44.32 & 57.79 & 51.92 & 39.94 & 54.18 & 53.54 & $30.4 \%$ & $-10.2 \%$ & $35.7 \%$ & $-1.2 \%$ \\
\hline Commute Trip Speed (mph) & 28.83 & 26.40 & 26.08 & 35.00 & 32.82 & 31.54 & $-8.4 \%$ & $-1.2 \%$ & $-6.2 \%$ & $-3.9 \%$ \\
\hline POV & 32.28 & 28.49 & 28.45 & 35.53 & 32.51 & 31.92 & $-11.7 \%$ & $-0.1 \%$ & $-8.5 \%$ & $-1.8 \%$ \\
\hline Public Transit & 17.06 & 11.75 & 10.45 & 19.53 & 13.22 & 12 & $-31.1 \%$ & $-11.1 \%$ & $-32.3 \%$ & $-9.2 \%$ \\
\hline
\end{tabular}

Note: Average commute speeds do not include any segmented trips, which are defined in the 2001 and 2009 surveys as trips with public transit as a segment of the trip. 


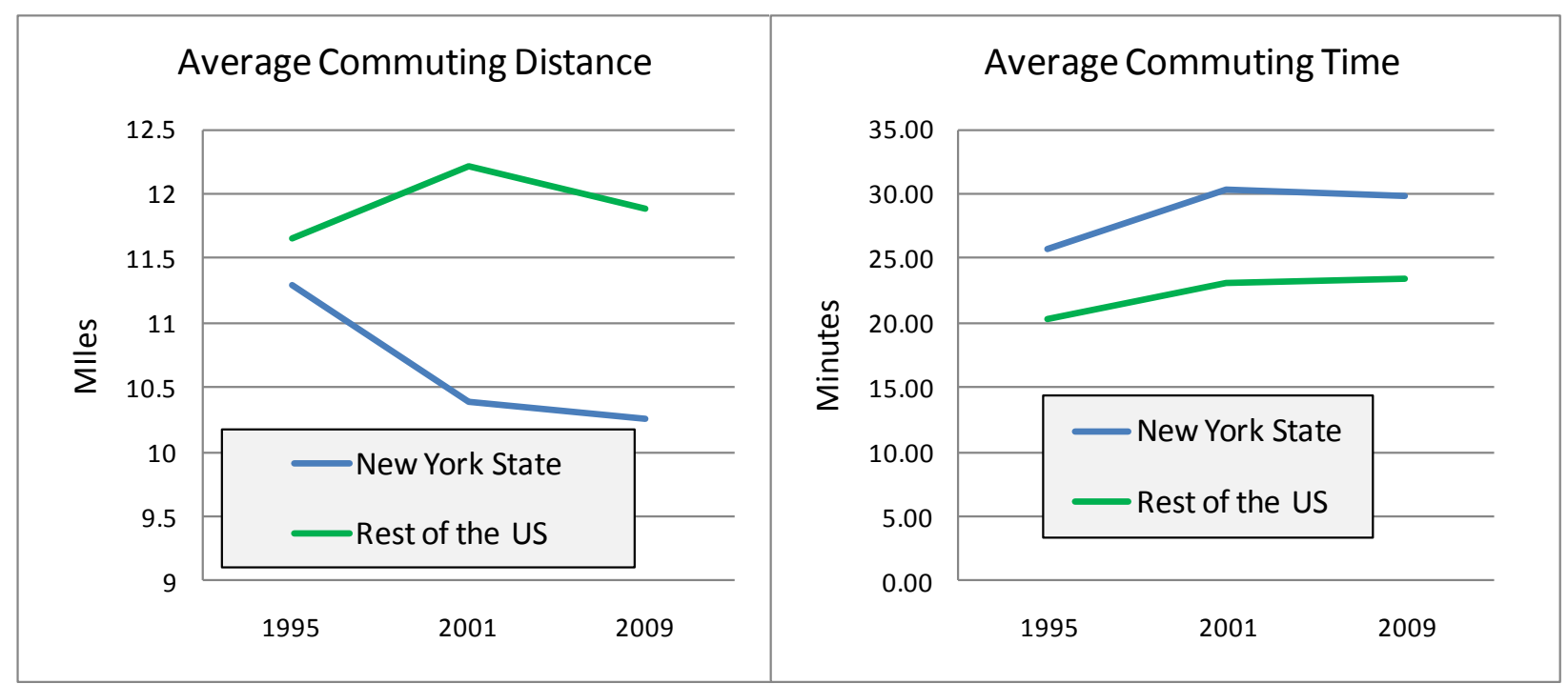

Figure 2.15 Temporal Trends in Average Daily Commute Trip Distance and Time in New York State vs. Rest of the United States.

In contrast, average commute times show a similar temporal trend in NYS and elsewhere in the rest of the nation, with essentially no difference between the average 2001 and 2009 commute times both in the state and the nation. Combining these two results means that average POV commute speed in NYS was about 5 mile per hour (mph) slower on average than in the rest of the nation in 2009 (at $26.1 \mathrm{mph}$ versus $31.5 \mathrm{mph}$ ). However, the average public transit commute time in NYS in 2009 was lower than it had been in 2001, dropping from almost 58 to 52 minutes, a roughly $10 \%$ decrease. This reversed a significant trend toward higher average transit commute times over the period 1995 to 2001. This decrease in travel times was accompanied by a reduction in the average trip distance for public transit between 2001 and 2009 within the state, from 11.3 miles to 9 miles. Even so, average commute speeds on public transit continued to decline and as a result, average travel time on public transit remained more than double that by privately-owned vehicles in the state: a condition that is also true in the rest of the country Table 2.16). 


\section{INFLUENCE OF NEW YORK CITY ON NEW YORK STATE TRAVEL PATTERNS}

It is apparent from the analysis results in Chapter 2 that travel patterns of NYS residents are different from patterns found elsewhere in the United States with respect to trip frequency, trip lengths, amount of driving, and mode choice. This chapter examines the influence of NYC travel on these comparisons, in the process bringing out some of the unique features of travel by NYC households. Comparative statistics reported in this Chapter are presented showing temporal trends in both household characteristics and travel activities from the 1995, 2001, and 2009 NHTS. The geographic regions used for these comparisons are:

- the NYC area, defined as the five boroughs of the Bronx, Kings (Brooklyn), New York (Manhattan), Queens, and Richmond (Staten Island) (see Figure 3.1);

- the remainder of New York State ; and

- the rest of the United States (with responses averaged across all NYS households and across rest of the nation households excluding the NYS samples).

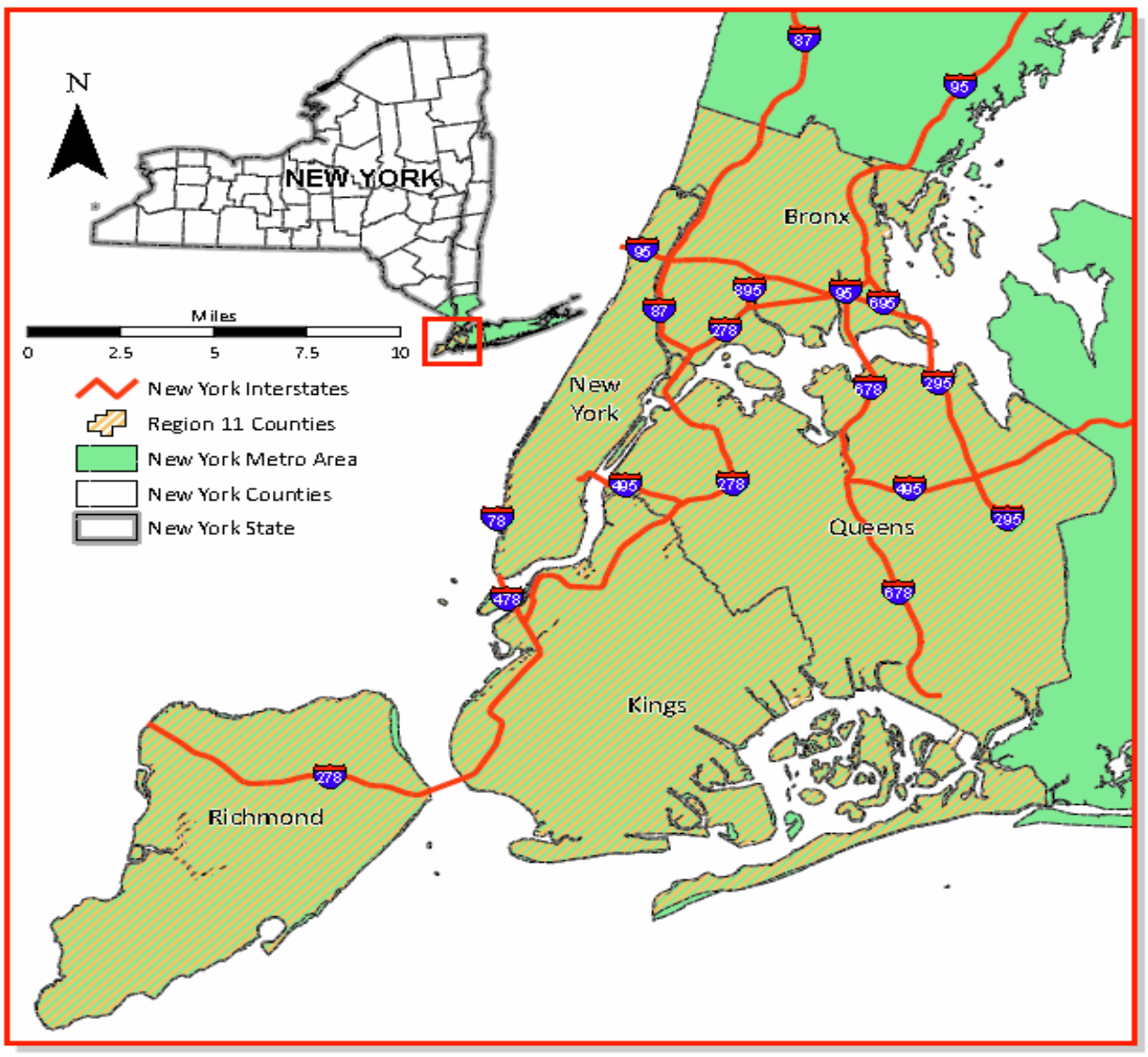

Figure 3.1 New York City Boroughs. 
While small in area, NYC had a population of some 8.4 million people in 2009, representing about $43 \%$ of NYS's total population. As expected, its higher population densities and different land-use mix have a significant effect on many of the state's travel statistics.

\subsection{PROFILE OF NEW YORK CITY HOUSEHOLDS}

Figures 3.2 and 3.3 show a number of NYC population and travel statistics in the form of percentages of statewide totals. While almost $43 \%$ of the State's households are found in NYC, only $21 \%$ of the privately owned vehicles belong to NYC residents, and NYC contains $82 \%$ of the State's zero-vehicle households (Figure 3.2): although the percentage of NYS drivers located in NYC has continued to increase gradually since 1995 (Figure 3.3).

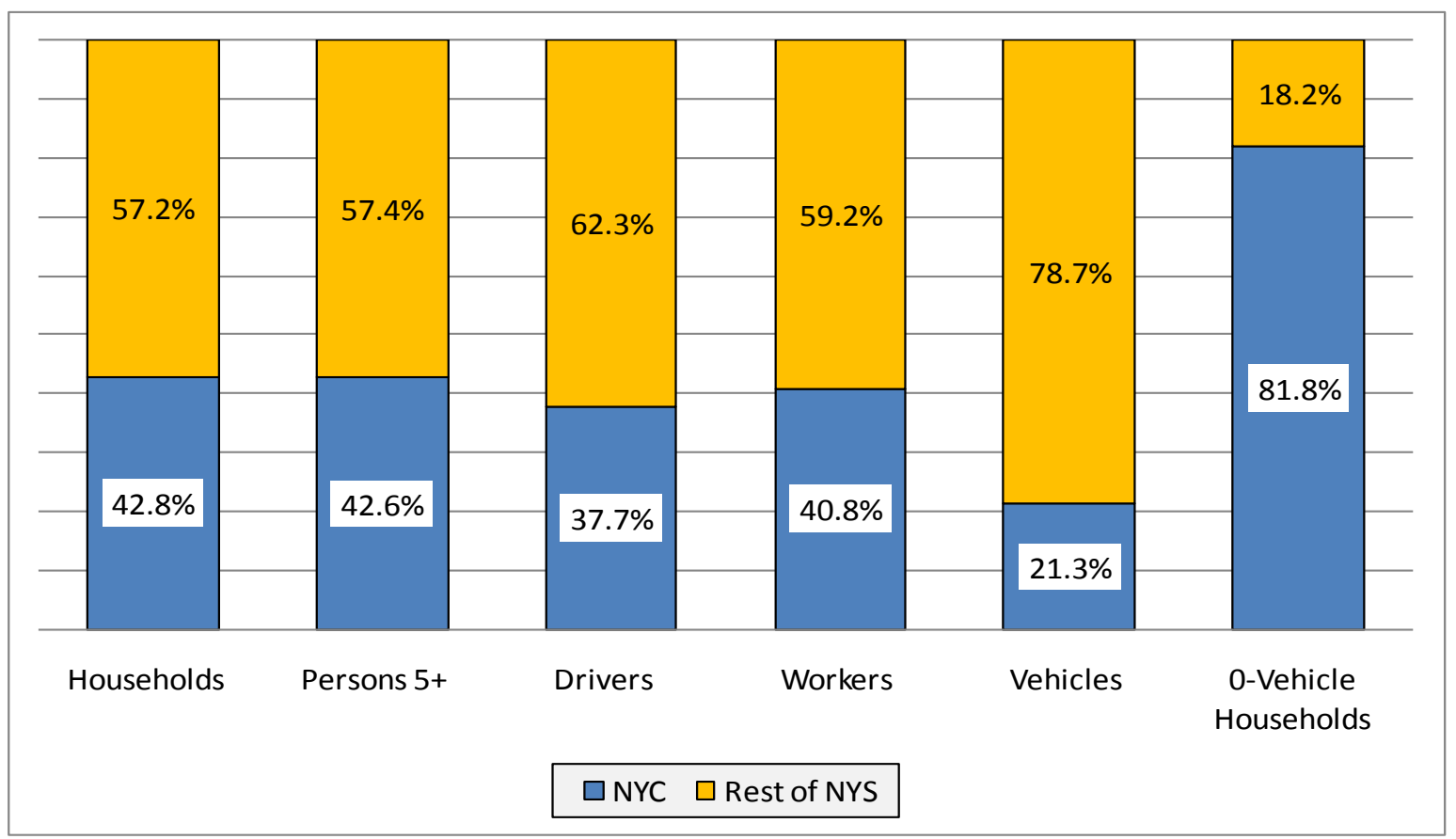

Figure 3.2 NYC and Rest of State Traveler Population Statistics Shown as Percentages of NYS Totals in 2009.

\subsubsection{Household Incomes}

While a greater percentage of NYC households have low incomes than households in either the rest of NYS or in the rest of the nation (Table 3.1), the percentages in the two lowest income groups are a little lower in the rest of the state than in the rest of the country. At the other end of the income scale, both NYC and especially the remainder of the state have a higher percentage of households in the over $\$ 100,000$ per year category than in the rest of the nation. 


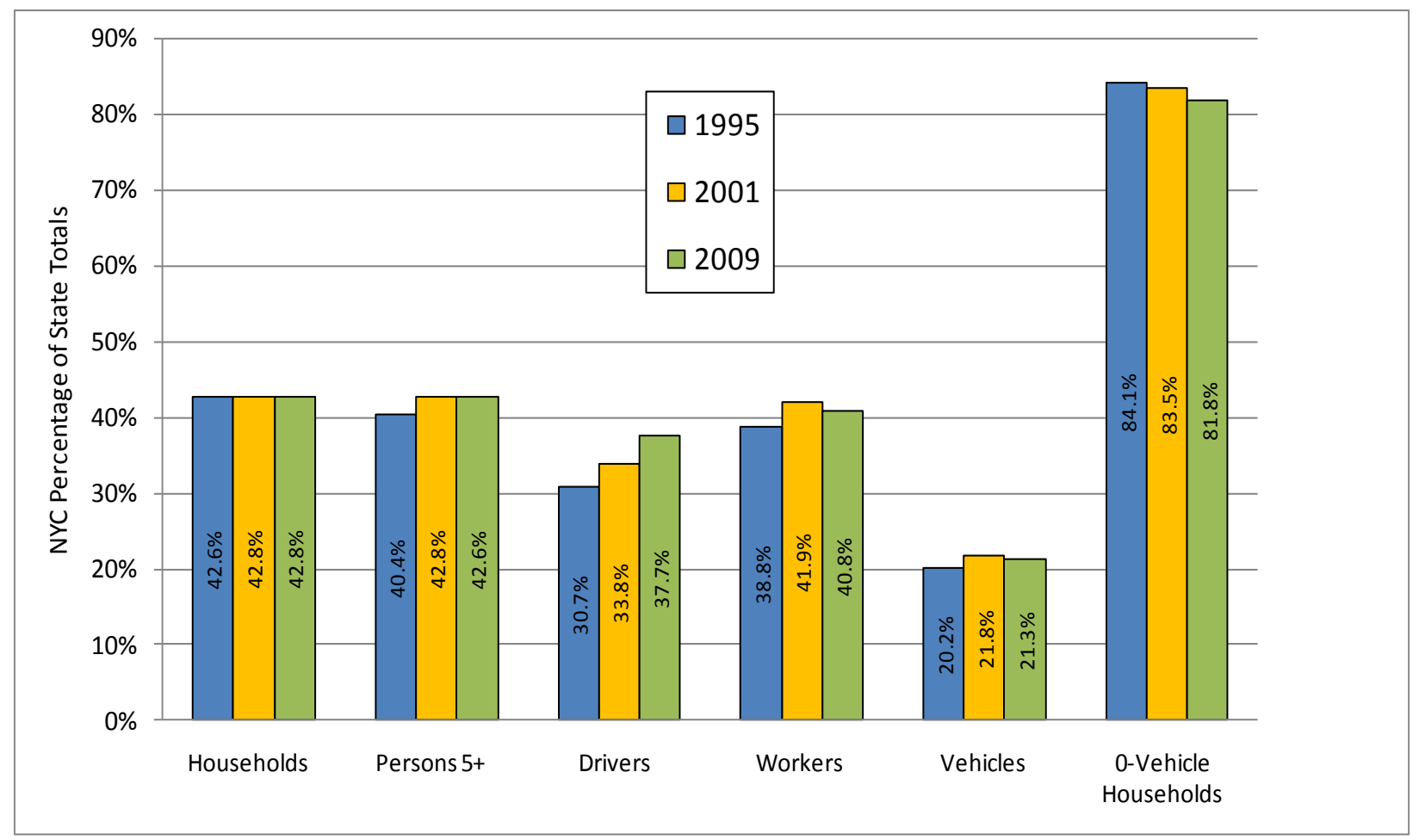

Figure 3.3 Trends in NYC Traveler Population Statistics as Percentage of Statewide Totals

\subsubsection{Vehicle Ownership}

Some $82 \%$ of NYS households who do not own a vehicle reside within the NYC area (Figure 3.2). Over time these percentages have shown a slight declining trend (Figure 3.3). As shown in Table 3.1, vehicle ownership patterns among NYC households continued to be quite different from those in households elsewhere. In contrast, households in the rest of NYS resemble households elsewhere in the United States in terms of vehicle ownership; with more than $90 \%$ of households owning at least one vehicle. In NYC, more than one in two households did not own a vehicle in 1995, 2001, and 2009 (Table 3.1). In contrast, less than 1 in 10 households did not own any vehicles in the rest of the state and nation. Even for households that did own a vehicle, NYC households are far less likely on the average to own more than one vehicle than other NYS households, or households elsewhere (Figure 3.4). As in previous survey years, the percentage of households who own 2 vehicles continues to be significantly higher than the number who own just one vehicle, in the rest of the state as well as in the rest of the nation. Outside NYC, some 58\% of households owned more than one vehicle in 2009. In the rest of the nation this number was $60 \%$ (Table 3.1, Figure 3.4). As shown in Table 3.1, $72 \%$ of NYC residents over age 16 held a driver's license in 2009 (65\% of women, 79\% of men), versus 89\% of residents in the rest of the state and also $90 \%$ in the rest of the nation. 
Table 3.1 Household Characteristics and Vehicle Ownership Trends in New York City, Rest of New York State, and Rest of the United States in 1995, 2001, and 2009

\begin{tabular}{|c|c|c|c|c|c|c|c|c|c|}
\hline & \multicolumn{3}{|c|}{ New York City } & \multicolumn{3}{|c|}{$\begin{array}{c}\text { Remainder of New } \\
\text { York State }\end{array}$} & \multicolumn{3}{|c|}{ Rest of United States } \\
\hline & 1995 & 2001 & 2009 & 1995 & 2001 & 2009 & 1995 & 2001 & 2009 \\
\hline \multicolumn{10}{|l|}{ Household Income } \\
\hline$\%<\$ 10,000$ Households & 7.9 & 9.9 & 9.6 & 3.7 & 5.4 & 6.5 & 4.9 & 6.6 & 7.7 \\
\hline$\% \$ 10$ to $\$ 20,000$ Households & 9.2 & 11.2 & 12.0 & 7.9 & 9.4 & 11.1 & 9.3 & 10.0 & 12.5 \\
\hline$\% \$ 20$ to $\$ 30,000$ Households & 11.4 & 10.4 & 10.6 & 9.3 & 8.4 & 9.8 & 10.6 & 9.7 & 11.6 \\
\hline$\% \$ 30$ to $\$ 40,000$ Households & 14.6 & 14.2 & 9.6 & 13.5 & 15.6 & 9.4 & 15.5 & 16.9 & 10.0 \\
\hline$\% \$ 40$ to $\$ 50,000$ Households & 3.8 & 4.2 & 8.7 & 4.0 & 4.3 & 8.8 & 4.3 & 5.1 & 8.9 \\
\hline$\% \$ 50$ to $\$ 60,000$ Households & 6.1 & 7.2 & 5.4 & 7.7 & 8.5 & 7.7 & 8.8 & 8.5 & 7.5 \\
\hline$\% \$ 60$ to $\$ 70,000$ Households & 6.3 & 5.4 & 5.5 & 7.9 & 6.6 & 6.1 & 7.6 & 6.7 & 6.0 \\
\hline$\% \$ 70$ to $\$ 80,000$ Households & 3.5 & 4.8 & 5.0 & 4.7 & 5.0 & 5.5 & 4.4 & 5.4 & 6.0 \\
\hline$\% \$ 80$ to $\$ 100,000$ & & & & & & & & & \\
\hline House & 6.4 & 6.3 & 7.4 & 9.0 & 9.9 & 7.4 & 8.0 & 8.7 & 7.6 \\
\hline$\% \$ 100,000+$ Households & 10.3 & 14.7 & 16.8 & 13.6 & 17.8 & 19.4 & 10.1 & 14.3 & 15.4 \\
\hline$\%$ Unreported H & 20.5 & 11.9 & 9.4 & 18.8 & 9.1 & 8.3 & 16.5 & 8.1 & 6.8 \\
\hline \multicolumn{10}{|l|}{ Licensing Rate $^{b}$} \\
\hline$\%$ Drivers/Persons $16+$ & 60.0 & 61.9 & 72.2 & 89.2 & 90.1 & 89.1 & 89.9 & 90.5 & 89.2 \\
\hline$\%$ Female Drivers/Female 16+ & 44.5 & 49.7 & 65.1 & 85.9 & 87.8 & 86.5 & 86.6 & 87.7 & 86.8 \\
\hline$\%$ Male Drivers/Male $16+$ & 71.4 & 71.5 & 78.9 & 92.4 & 92.5 & 91.7 & 93.2 & 93.3 & 91.6 \\
\hline \multicolumn{10}{|l|}{ Vehicle Ownership } \\
\hline$\% 0$ vehicle Households & 52.9 & 51.6 & 54.5 & 7.4 & 7.6 & 9.1 & 6.9 & 6.8 & 7.4 \\
\hline$\% 1$ vehicle Households & 33.8 & 33.7 & 31.4 & 32.1 & 32.8 & 33.1 & 32.4 & 31.3 & 32.3 \\
\hline$\% 2$ vehicle Households & 11.2 & 11.3 & 10.9 & 43.3 & 39.0 & 39.2 & 41.1 & 37.9 & 36.9 \\
\hline$\% 3$ vehicle Households & 1.6 & 2.7 & 2.2 & 12.4 & 14.3 & 13.0 & 14.4 & 15.4 & 14.8 \\
\hline$\% 4+$ vehicle Households & 0.5 & 0.7 & 0.9 & 4.7 & 6.3 & 5.6 & 5.3 & 8.6 & 8.6 \\
\hline
\end{tabular}

${ }^{\text {a }}$ All percents may not add to $100 \%$ due to rounding. All incomes are reported in 2009 equivalent dollars.

b The licensing rate is computed using the self-reported response to the survey question "Are you a driver?" and may not give the same results as that derived from NYS DOT licensing statistics. 


\subsection{PERSONAL TRAVEL COMPARISONS}

\subsubsection{Trip Frequencies and Trip Distances}

Although residents in NYS took, on average, fewer trips per day than others in the United States, the difference from the national average is much more pronounced for NYC residents than for New Yorkers elsewhere (Tables 3.2). This is a trend that has continued from 1995 through 2009: and one that is true also for both weekend and weekday trip rates. Daily average person trip rates remained stable across all three surveys for NYC residents, at around 3.5 trips per person per day. This compares with 3.8 trips per person per day in the rest of the state and nation in 2009, with these rates coming down from 1995 levels in the rest of the state (down by 0.3 trips) and in the rest of the nation (down by 0.5 trips).

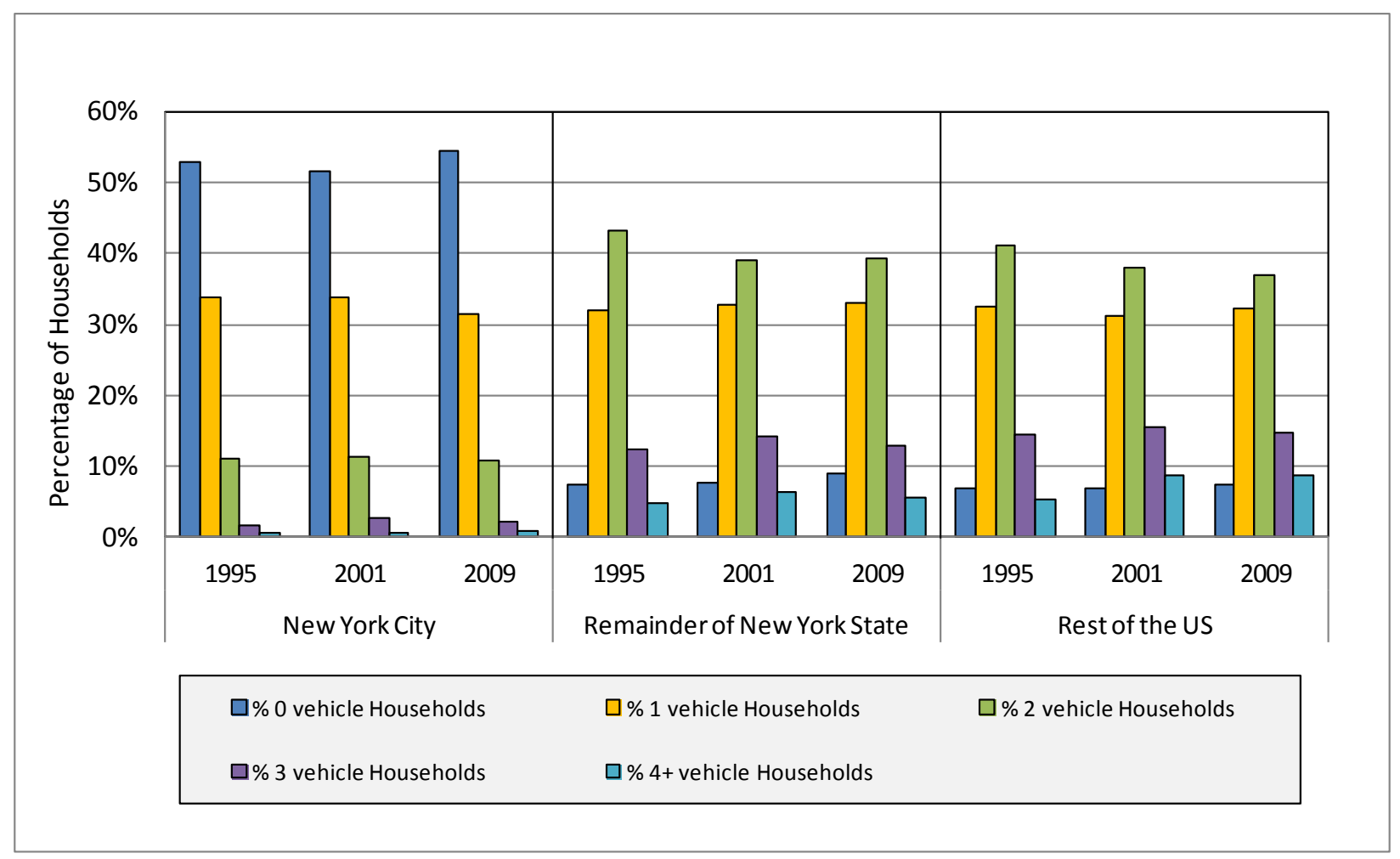

Figure 3.4 Distribution of Households by Number of Vehicles in 1995, 2001, and 2009.

Regardless of location, people took shorter as well as fewer trips in 2009 than in 2001 (Table 3.3). Residents in NYC not only take fewer trips, their trips were also considerably shorter on average (at 5.2 miles per trip) than the trips in other parts of NYS (at 8.9 miles per trip) and in the rest of the United States (9.9 miles per trip) (see bottom line of Table 3.3). One reason for this difference is that $39 \%$ of all trips made by NYC residents in 2009 were walk trips, compared to approximately $10 \%$ in the rest of the state and rest of the nation. As a result, in 2009 
NYC residents traveled about 16 miles per day, less than half the 37 miles average daily distance traveled by residents in the rest of state and nation.

The higher residential and employment densities in NYC are another reason for this trip length difference (see Chapter 4). Over time, average trip lengths fell back closer to their 1995 levels in all three geographic regions, after increasing significantly in 2001. 
Table 3.2 Person Trip Statistics by Mode of Transportation and Trip Purpose New York City, Remainder of New York State, and Rest of the United States ${ }^{a}$

\begin{tabular}{|c|c|c|c|c|c|c|c|c|c|}
\hline & \multicolumn{3}{|c|}{ New York City } & \multicolumn{3}{|c|}{$\begin{array}{c}\text { Remainder of New } \\
\text { York State }\end{array}$} & \multicolumn{3}{|c|}{ Rest of United States } \\
\hline & 1995 & 2001 & 2009 & 1995 & 2001 & 2009 & 1995 & 2001 & 2009 \\
\hline Person Trips per Person & 3.58 & 3.44 & 3.46 & 4.08 & 3.95 & 3.78 & 4.33 & 4.11 & 3.81 \\
\hline$\%$ SOV & 14.00 & 14.14 & 12.03 & 42.40 & 40.80 & 43.09 & 42.50 & 40.33 & 40.49 \\
\hline$\% \mathrm{MOV}$ & 21.80 & 21.92 & 20.61 & 43.10 & 44.05 & 39.22 & 45.00 & 47.34 & 44.36 \\
\hline$\%$ Amtrak & 0.00 & 0.39 & 0.43 & 0.00 & 0.10 & 0.02 & 0.00 & 0.02 & 0.01 \\
\hline$\%$ Commuter Train & 2.50 & 0.40 & 1.59 & 0.50 & 0.42 & 0.43 & 0.00 & 0.07 & 0.09 \\
\hline$\% \mathrm{~S}$ & 10.30 & 12.97 & 9.95 & 0.20 & 0.31 & 0.23 & 0.20 & 0.16 & 0.14 \\
\hline$\%$ Other Public Transit & 9.20 & 8.66 & 10.52 & 1.00 & 0.59 & 0.96 & 0.90 & 0.81 & 0.98 \\
\hline \% Walk & 31.00 & 36.75 & 38.74 & 4.90 & 9.07 & 10.64 & 4.80 & 7.86 & 9.69 \\
\hline$\%$ Other & 5.00 & 4.63 & 6.06 & 4.20 & 4.57 & 5.24 & 3.00 & 3.31 & 4.06 \\
\hline$\%$ Unreported & 6.10 & 0.14 & 0.07 & 3.70 & 0.09 & 0.18 & 3.50 & 0.10 & 0.19 \\
\hline Person Trips per Person & 3.58 & 3.44 & 3.46 & 4.08 & 3.95 & 3.78 & 4.33 & 4.11 & 3.81 \\
\hline \% Earning a Living & 19.60 & 20.14 & 16.63 & 20.00 & 18.76 & 19.47 & 20.30 & 18.79 & 18.68 \\
\hline$\%$ Family and Personal & 45.80 & 42.65 & 44.05 & 45.90 & 43.73 & 42.65 & 45.70 & 43.88 & 42.43 \\
\hline$\%$ Civic, Ed, and Religious & 10.60 & 11.07 & 9.63 & 8.50 & 8.79 & 9.36 & 8.80 & 9.81 & 9.62 \\
\hline$\%$ Social \& Recreational & 24.00 & 24.55 & 27.31 & 25.40 & 27.28 & 26.70 & 24.90 & 26.59 & 27.51 \\
\hline$\%$ Other & 0.00 & 1.32 & 1.35 & 0.20 & 1.11 & 0.95 & 0.20 & 0.81 & 0.79 \\
\hline$\%$ Unreported & & 0.27 & 1.03 & & 0.32 & 0.87 & & 0.13 & 0.96 \\
\hline Weekday Person Trips/Person & 3.71 & 3.61 & 3.53 & 4.19 & 4.02 & 3.90 & 4.46 & 4.21 & 3.92 \\
\hline Weekend Person Trips/Person & 3.29 & 3.03 & 3.28 & 3.84 & 3.78 & 3.45 & 3.99 & 3.89 & 3.52 \\
\hline
\end{tabular}

${ }^{\text {a }}$ All percents may not add to $100 \%$ due to rounding. 
Table 3.3 Person Miles of Travel Statistics by Mode of Transportation and Trip Purpose New York City, Remainder of New York State, and Outside New York State

\begin{tabular}{|c|c|c|c|c|c|c|c|c|c|}
\hline & \multicolumn{3}{|c|}{ New York City } & \multicolumn{3}{|c|}{$\begin{array}{c}\text { Remainder of New } \\
\text { York State }\end{array}$} & \multicolumn{3}{|c|}{ Rest of United States } \\
\hline & 1995 & 2001 & 2009 & 1995 & 2001 & 2009 & 1995 & 2001 & 2009 \\
\hline PMT per Person & 19.08 & 21.11 & 16.10 & 35.50 & 35.60 & 32.92 & 39.40 & 41.03 & 36.85 \\
\hline$\%$ SOV & 20.50 & 16.54 & 16.49 & 39.60 & 38.57 & 40.98 & 40.40 & 37.56 & 38.95 \\
\hline$\% \mathrm{MOV}$ & 38.90 & 28.24 & 43.29 & 51.50 & 49.52 & 44.91 & 51.10 & 51.31 & 49.86 \\
\hline$\%$ Amtrak & 0.30 & 0.98 & 0.11 & 0.30 & 0.38 & 0.24 & 0.00 & 0.07 & 0.06 \\
\hline$\%$ Commuter Train & 5.00 & 0.59 & 2.35 & 1.60 & 1.31 & 1.31 & 0.30 & 0.16 & 0.29 \\
\hline \% Subway & 14.80 & 14.24 & 13.27 & 0.30 & 0.40 & 0.23 & 0.20 & 0.13 & 0.10 \\
\hline$\%$ Other Public Transit & 9.20 & 5.43 & 8.35 & 2.00 & 0.42 & 0.63 & 1.30 & 0.48 & 0.56 \\
\hline \% Walk & 3.50 & 3.92 & 6.49 & 0.30 & 0.84 & 0.79 & 0.30 & 0.56 & 0.67 \\
\hline$\%$ Other & 6.60 & 29.13 & 9.58 & 3.30 & 8.11 & 10.76 & 5.40 & 9.27 & 9.37 \\
\hline$\%$ Unreported & 0.80 & 0.92 & 0.06 & 1.00 & 0.43 & 0.16 & 1.00 & 0.45 & 0.12 \\
\hline PMT per Person & 19.08 & 21.11 & 16.10 & 35.50 & 35.60 & 32.92 & 39.40 & 41.03 & 36.85 \\
\hline \% Earning a Livir & 31.20 & 34.17 & 29.28 & 28.20 & 25.90 & 26.55 & 28.20 & 27.45 & 25.16 \\
\hline$\%$ Family and Personal & 32.20 & 23.61 & 27.53 & 34.20 & 32.89 & 29.96 & 35.00 & 32.94 & 29.57 \\
\hline$\%$ Civic, Ed, and Religious & 6.70 & 5.28 & 5.47 & 5.10 & 5.07 & 5.67 & 5.70 & 5.88 & 6.24 \\
\hline$\%$ Social \& Recreational & 30.00 & 24.25 & 34.23 & 32.20 & 33.27 & 28.00 & 30.60 & 30.01 & 30.30 \\
\hline$\%$ Other & 0.00 & 9.07 & 1.34 & 0.30 & 2.39 & 5.46 & 0.40 & 3.40 & 5.02 \\
\hline$\%$ Unreported & & 3.62 & 2.16 & & 0.47 & 4.37 & & 0.32 & 3.73 \\
\hline Average Person Trip Length ${ }^{a}$ & 5.74 & 6.82 & 5.20 & 8.86 & 9.18 & 8.91 & 9.23 & 10.14 & 9.89 \\
\hline
\end{tabular}

${ }^{a}$ Average trip length is calculated using only those records with trip mileage information present. 


\subsubsection{Trip Purpose and Mode Choice}

Travelers in NYC households devoted a higher percentage of their personal trips to social and recreational pursuits and to family and personal trips than they did in 2001, largely at the expense of trips involved with making a living (16.6\% of trips in 2009, versus $20.1 \%$ in 2001). No such trend was found in the rest of the state or in the rest of the nation; with the result that NYC residents engaged in a lower percentage $(16.6 \%)$ of work trips than residents in the rest of the state (about 19.5\%) and nation (around 18.7\%) in 2009, but a slightly higher percentage of family and personal trips. The percentages of social and recreational trips were similar for residents in all three regions (at around 27\%), as was the percentage of civic, educational and religious trips (at roughly $9.5 \%$ ).

However, how people in NYC get to places is very different from those elsewhere (Table 3.2). While there is a close similarity in mode choice among New York residents located outside NYC and those in the rest of the country, the NYC mode split is very different. As well as walking, NYC residents make much greater use of public transit, both the subway system and transit bus (captured under "other public transit modes"). NYC households also take a higher percentage of taxi trips (captured under "other" modes, which also includes ferry trips). In contrast, they take far fewer POV trips than residents elsewhere. Within these POV trips, residents in the rest of the state traveled more in single occupant vehicles than in multiple occupant vehicles (43\% vs. $39 \%$ ) in 2009 , reversing the trend in previous survey years. This reversal did not occur in 2009 in the rest of the nation (40\% SOV vs. 44 \% MOV trips: see Figure 3.5). According to the American Public Transit Association, which documents transit agency statistics for the Federal Transportation Administration, over $36 \%$ of all public transit trips and over $32 \%$ of all public transit passenger-miles occurred in NYS in 2009, with over $92 \%$ of these NYS trips and $89 \%$ of these NYS passenger miles reported by NYC based transit agencies (representing some 3.43 million trips and 14.52 million passenger miles of travel in 2009).

Some re-distribution of trips also occurred within public transit modes in NYC between 2001 and 2009. Some $10 \%$ of all NYC household trips were by subway in 2009, with an additional $10 \%$ by 'other public transit modes', principally by transit bus: with the subway losing about 3 percentage points since 2001 while the other transit modes increased their share of NYC trips by 2 percentage points. Commuter rail's share of these NYC trips also increased by a percentage point between 2001 and 2009; although it was down by a percentage point from its 1995 share (Table 3.2). It is possible that the events of September 11, 2001 in NYC influenced these ridership numbers: while the economic recession of 2008-9 may also be playing a role here. 


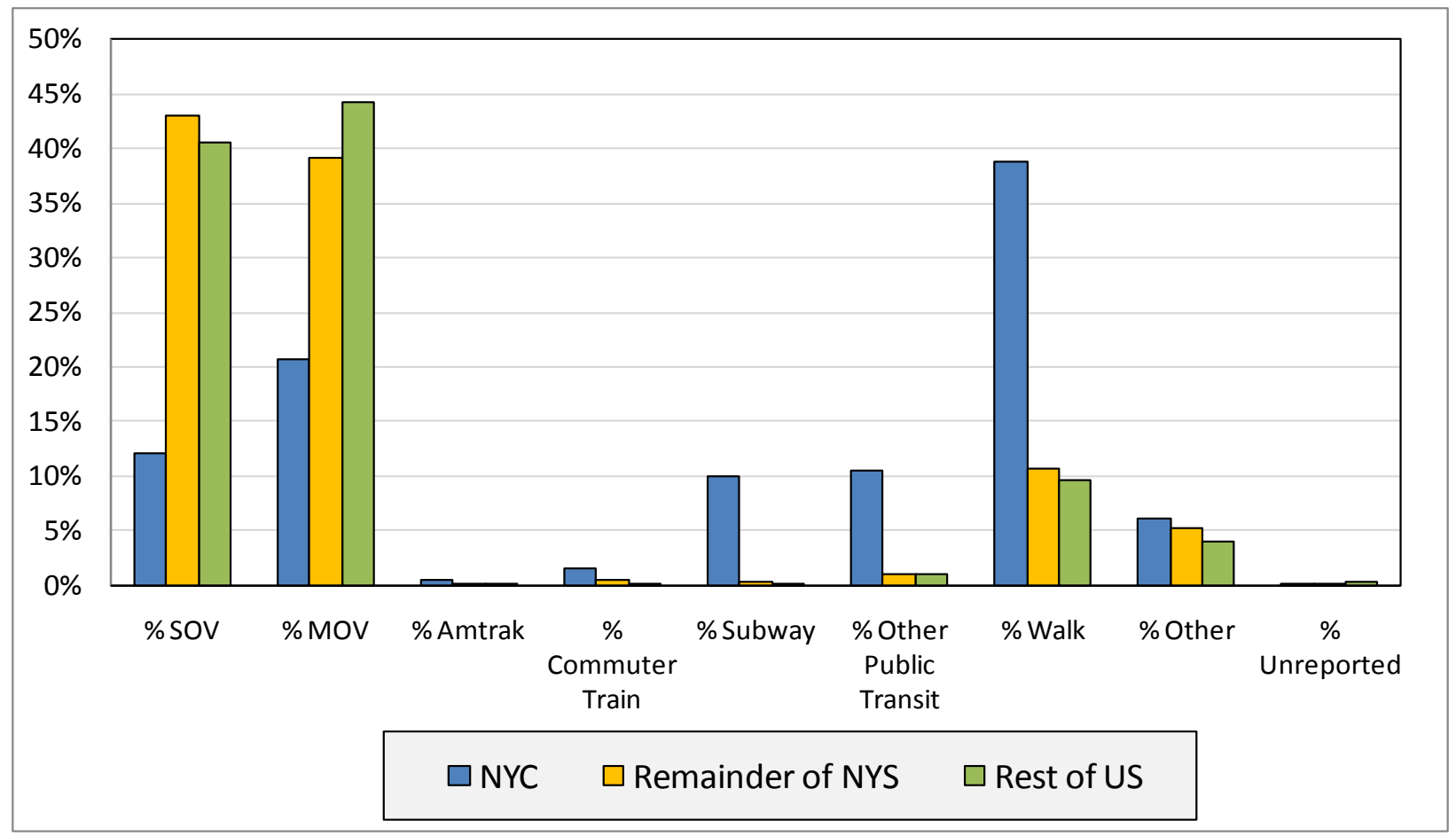

Figure 3.5 Person Trip Percentages by Selected Modes, New York City, Remainder of New York State, and Rest of the United States in 2009.

As noted in Chapter 2 of this report, NYS residents have spent about twice as much time, on the average, walking and/or cycling per day than residents in the rest of the nation since the mid-1990s. Table 3.4 below shows that a good deal of this activity is associated with NYC residents, who walk a great deal more on average than other New Yorkers or others in the rest of the nation. Indeed, the significant statistical differences reported in Chapter 2 are seen to be largely attributable to NYC households. Similarly, the percentage of people reporting that they did not take walk trips in the past week is about half that for NYC residents as it is for the rest of state and rest of the U.S., and again this effect carries through all age groups to some degree. Summed over all age groups, over $83 \%$ of NYC residents indicated that they walked somewhere during the previous week. Elsewhere this percentage drops, on the average, to just 2 in every 3 people in the rest of the nation.

\subsubsection{Differences in Travel by Gender and Age}

Gender differences remained negligible where daily trip frequencies are concerned in all three NHTS surveys (Table 3.5). In contrast, daily person miles of travel were much higher for men than women. In absolute terms these differences range over the three regions represented between 6 to almost 10 miles per day, with the largest percentage differences occurring in NYC, where men traveled almost $50 \%$ farther on average each day than women in 2009 (in the rest of NYS they traveled $27 \%$ more, in the rest of the nation $30 \%$ more). 
The impact of age of traveler on the number of miles traveled is certainly noticeable. Across all age categories, residents in NYC traveled considerably fewer miles than their similarly aged counterparts elsewhere. Figure 3.6 shows these results for 2009 (based on statistics shown in Table 3.5). The differences are especially obvious in the younger and the older groups. In 2009, NYC residents 65 years or older traveled on average less than 9 miles per day, compared to 25 miles in other parts of NYS and in the rest of the country. A similar result occurs at the other end of the age spectrum, where NYC travelers between 5 and 15 years old travel under 9 miles per day, while in the rest of NYS they average 22 miles, and in the rest of the nation they average 26 miles per day.

There is also a NYC difference in the distribution of average person miles of travel (PMT) across age groups. While the 35 to 54 year olds travel the most miles per day on average in the rest of the state and nation, in NYC the most traveled group is the 20 to 34 year olds. Travelers in the remainder of NYS have a very similar distribution of average daily PMT to those in the rest of the nation, with generally lower miles traveled, most noticeably in 2009 in the 34 to 54 , and 55 to 64 age groups.

Each of these patterns has remained consistent over time, whether comparing differences between the three regions, or comparing differences across age groups within each region, and plotting the 1995 or 2001 statistics produces very similar graphs to Figure 3.6. 
Table 3.4 Statistics on Walking and/or Biking for NYC, Remainder of NYS, and Rest of United States

Compared: 1995, 2001, and 2009 by Different Age Groups

\begin{tabular}{|c|c|c|c|c|c|c|c|c|c|}
\hline & \multicolumn{3}{|c|}{ New York City } & \multicolumn{3}{|c|}{$\begin{array}{c}\text { Remainder of New York } \\
\text { State }\end{array}$} & \multicolumn{3}{|c|}{ Rest of United States } \\
\hline & 1995 & 2001 & 2009 & 1995 & 2001 & 2009 & 1995 & 2001 & 2009 \\
\hline $\begin{array}{l}\text { Percent Not Taking Walk Trips in the last } \\
\text { week }\end{array}$ & * & $15.5 \%$ & $16.8 \%$ & * & $29.9 \%$ & $33.4 \%$ & * & $35.5 \%$ & $32.8 \%$ \\
\hline 5 to 10 year-olds & * & * & $18.6 \%$ & * & * & $27.2 \%$ & * & * & $24.3 \%$ \\
\hline 11 to 15 year-olds & * & * & $11.5 \%$ & * & * & $24.6 \%$ & * & * & $24.0 \%$ \\
\hline 16 to 20 year-olds & * & $13.2 \%$ & $21.2 \%$ & * & $28.7 \%$ & $27.3 \%$ & * & $34.9 \%$ & $32.1 \%$ \\
\hline 21 to 35 year-olds & * & $11.6 \%$ & $12.5 \%$ & * & $29.8 \%$ & $36.6 \%$ & * & $34.8 \%$ & $31.1 \%$ \\
\hline 36 to 64 year-olds & * & $16.1 \%$ & $15.9 \%$ & * & $27.9 \%$ & $31.4 \%$ & * & $34.0 \%$ & $33.0 \%$ \\
\hline $65+$ year-olds & * & $23.8 \%$ & $26.2 \%$ & * & $36.1 \%$ & $46.6 \%$ & * & $41.3 \%$ & $45.2 \%$ \\
\hline $\begin{array}{l}\text { Percent Not Taking Bike Trips in the last } \\
\text { week }\end{array}$ & * & $94.4 \%$ & $93.4 \%$ & * & $92.2 \%$ & $88.9 \%$ & * & $92.6 \%$ & $87.2 \%$ \\
\hline 5 to 10 year-olds & * & * & $79.7 \%$ & * & * & $58.6 \%$ & * & * & $50.3 \%$ \\
\hline 11 to 15 year-olds & * & * & $92.7 \%$ & * & * & $70.0 \%$ & * & * & $68.6 \%$ \\
\hline 16 to 20 year-olds & * & $88.5 \%$ & $95.3 \%$ & * & $84.8 \%$ & $88.0 \%$ & * & $87.4 \%$ & $88.9 \%$ \\
\hline 21 to 35 year-olds & * & $92.8 \%$ & $89.7 \%$ & * & $91.5 \%$ & $92.7 \%$ & * & $91.2 \%$ & $91.7 \%$ \\
\hline 36 to 64 year-olds & * & $95.3 \%$ & $95.5 \%$ & * & $92.1 \%$ & $92.6 \%$ & * & $93.2 \%$ & $92.1 \%$ \\
\hline $65+$ year-olds & * & $99.0 \%$ & $98.2 \%$ & * & $96.4 \%$ & $98.0 \%$ & * & $96.3 \%$ & $97.0 \%$ \\
\hline $\begin{array}{l}\text { Average Minutes Spent Walking and/or } \\
\text { Biking per Day }\end{array}$ & 11.52 & 16.76 & 20.73 & 2.19 & 6.25 & 6.12 & 2.51 & 5.50 & 6.24 \\
\hline 5 to 10 year-olds & 11.23 & 16.83 & 14.68 & 2.22 & 5.57 & 4.67 & 3.16 & 7.15 & 5.13 \\
\hline 11 to 15 year-olds & 15.80 & 16.09 & 14.12 & 4.64 & 11.18 & 6.80 & 5.66 & 8.23 & 9.02 \\
\hline 16 to 20 year-olds & 10.57 & 14.22 & 17.82 & 3.16 & 6.72 & 5.46 & 3.24 & 5.05 & 5.90 \\
\hline 21 to 35 year-olds & 12.51 & 19.78 & 24.22 & 1.68 & 5.39 & 6.58 & 2.31 & 4.85 & 6.25 \\
\hline 36 to 64 year-olds & 10.20 & 16.31 & 22.95 & 1.76 & 6.35 & 6.84 & 1.81 & 5.00 & 6.59 \\
\hline $65+$ year-olds & 11.11 & 14.22 & 16.77 & 2.35 & 4.90 & 4.21 & 2.04 & 5.05 & 4.48 \\
\hline
\end{tabular}




\begin{tabular}{|c|c|c|c|c|c|c|c|c|c|}
\hline & \multicolumn{3}{|c|}{ New York City } & \multicolumn{3}{|c|}{$\begin{array}{c}\text { Remainder of New York } \\
\text { State }\end{array}$} & \multicolumn{3}{|c|}{ Rest of United States } \\
\hline & 1995 & 2001 & 2009 & 1995 & 2001 & 2009 & 1995 & 2001 & 2009 \\
\hline Average Minutes Spent Walking per Day & 11.20 & 16.11 & 20.35 & 1.88 & 5.61 & 5.51 & 2.08 & 4.71 & 5.47 \\
\hline 5 to 10 year-olds & 11.13 & 14.79 & 14.49 & 1.86 & 4.13 & 3.71 & 2.50 & 4.89 & 3.89 \\
\hline 11 to 15 year-olds & 15.59 & 13.18 & 14.10 & 3.17 & 8.58 & 5.33 & 4.32 & 6.18 & 7.43 \\
\hline 16 to 20 year-olds & 9.98 & 14.14 & 17.68 & 2.85 & 6.47 & 4.72 & 2.71 & 4.35 & 5.19 \\
\hline 21 to 35 year-olds & 11.97 & 19.24 & 23.79 & 1.39 & 5.02 & 5.85 & 1.91 & 4.42 & 5.66 \\
\hline 36 to 64 year-olds & 9.94 & 15.91 & 22.38 & 1.61 & 6.01 & 6.35 & 1.51 & 4.44 & 5.82 \\
\hline $65+$ year-olds & 11.11 & 14.17 & 16.62 & 2.31 & 4.44 & 4.03 & 1.98 & 4.79 & 4.10 \\
\hline Average Minutes Spent Biking per Day & 0.33 & 0.65 & 0.38 & 0.31 & 0.64 & 0.61 & 0.43 & 0.79 & 0.78 \\
\hline 5 to 10 year-olds & 0.10 & 2.04 & 0.19 & 0.37 & 1.44 & 0.96 & 0.67 & 2.25 & 1.24 \\
\hline 11 to 15 year-olds & 0.21 & 2.92 & 0.02 & 1.47 & 2.60 & 1.47 & 1.34 & 2.05 & 1.59 \\
\hline 16 to 20 year-olds & 0.59 & 0.08 & 0.14 & 0.31 & 0.26 & 0.74 & 0.54 & 0.70 & 0.71 \\
\hline 21 to 35 year-olds & 0.54 & 0.54 & 0.42 & 0.29 & 0.37 & 0.73 & 0.39 & 0.44 & 0.59 \\
\hline 36 to 64 year-olds & 0.26 & 0.40 & 0.57 & 0.16 & 0.34 & 0.49 & 0.30 & 0.56 & 0.77 \\
\hline $65+$ year-olds & 0.00 & 0.05 & 0.15 & 0.04 & 0.47 & 0.18 & 0.05 & 0.26 & 0.38 \\
\hline
\end{tabular}

* Walk trip questions were not asked of persons under 16 years old in 2001, or at all in 1995. 
Table 3.5 Daily Personal Travel Statistics by Demographics New York City, Remainder of New York State, and Rest of the United States: 1995, 2001, and 2009

\begin{tabular}{|c|c|c|c|c|c|c|c|c|c|}
\hline & \multicolumn{3}{|c|}{ New York City } & \multicolumn{3}{|c|}{$\begin{array}{c}\text { Remainder of New York } \\
\text { State }\end{array}$} & \multicolumn{3}{|c|}{ Rest of United States } \\
\hline & 1995 & 2001 & 2009 & 1995 & 2001 & 2009 & 1995 & 2001 & 2009 \\
\hline Person Trips per Person & 3.58 & 3.44 & 3.46 & 4.08 & 3.95 & 3.78 & 4.33 & 4.11 & 3.81 \\
\hline Male & 3.63 & 3.54 & 3.46 & 4.12 & 3.93 & 3.76 & 4.36 & 4.11 & 3.76 \\
\hline Female & 3.54 & 3.35 & 3.45 & 4.05 & 3.97 & 3.79 & 4.30 & 4.12 & 3.85 \\
\hline Person Trips per Person & 3.58 & 3.44 & 3.46 & 4.08 & 3.95 & 3.78 & 4.33 & 4.11 & 3.81 \\
\hline $5-15$ years & 3.09 & 2.71 & 2.76 & 3.44 & 3.21 & 3.17 & 3.73 & 3.46 & 3.20 \\
\hline $16-19$ years & 3.18 & 3.08 & 2.95 & 4.22 & 3.97 & 3.61 & 4.69 & 4.19 & 3.54 \\
\hline 20-34 years & 3.96 & 3.77 & 3.52 & 4.29 & 3.98 & 3.64 & 4.67 & 4.30 & 3.91 \\
\hline $35-54$ years & 3.84 & 3.89 & 4.04 & 4.55 & 4.47 & 4.32 & 4.75 & 4.64 & 4.27 \\
\hline $55-64$ years & 3.28 & 3.66 & 3.96 & 4.15 & 4.18 & 3.98 & 4.19 & 4.13 & 3.99 \\
\hline $65+$ years & 2.95 & 2.57 & 2.55 & 3.46 & 3.56 & 3.24 & 3.44 & 3.43 & 3.22 \\
\hline PMT per Person & 19.08 & 21.11 & 16.10 & 35.50 & 35.60 & 32.92 & 39.40 & 41.03 & 36.85 \\
\hline Male & 21.54 & 25.92 & 19.37 & 39.69 & 39.66 & 36.94 & 44.70 & 45.84 & 41.66 \\
\hline Female & 16.91 & 16.88 & 13.14 & 31.41 & 31.82 & 29.06 & 34.38 & 36.47 & 32.17 \\
\hline PMT per Person & 19.08 & 21.11 & 16.10 & 35.50 & 35.60 & 32.92 & 39.40 & 41.03 & 36.85 \\
\hline $5-15$ years & 11.62 & 5.61 & 8.57 & 22.57 & 20.19 & 22.64 & 25.43 & 25.18 & 25.79 \\
\hline $16-19$ years & 15.97 & 10.87 & 13.24 & 28.61 & 30.99 & 27.26 & 36.91 & 37.58 & 29.89 \\
\hline 20-34 years & 24.97 & 31.58 & 22.45 & 44.30 & 36.91 & 36.16 & 46.37 & 46.31 & 37.67 \\
\hline $35-54$ years & 21.39 & 27.24 & 17.53 & 42.66 & 45.73 & 40.57 & 47.66 & 52.02 & 46.16 \\
\hline $55-64$ years & 15.51 & 19.71 & 19.78 & 35.58 & 41.15 & 33.32 & 41.93 & 42.62 & 41.58 \\
\hline $65+$ years & 10.99 & 8.74 & 8.78 & 24.83 & 27.49 & 25.11 & 25.60 & 28.62 & 25.42 \\
\hline
\end{tabular}




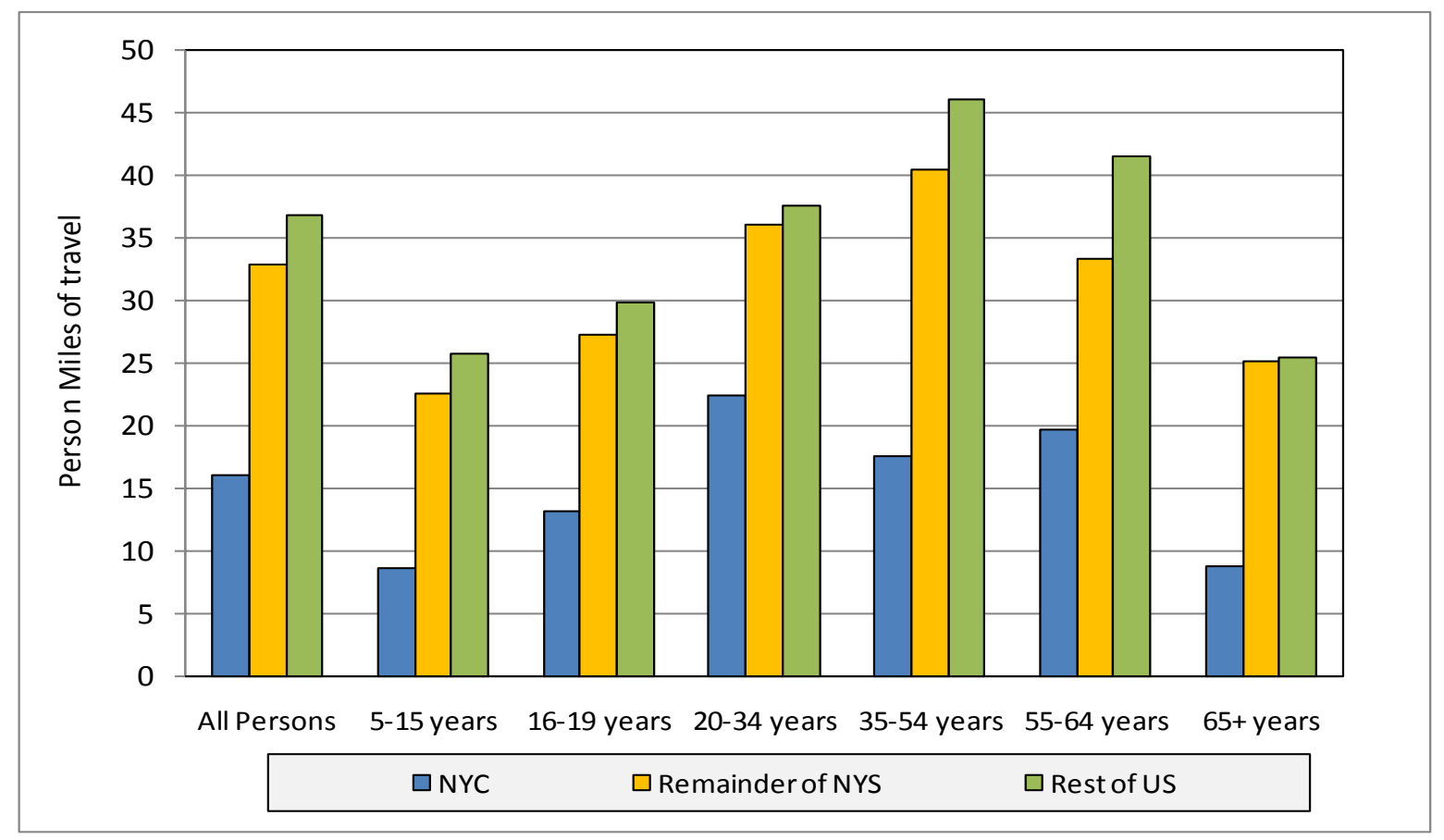

Figure 3.6 Daily Person Miles Traveled by Age for New York City, Remainder of New York State, and Rest of the United States in 2009.

\subsubsection{Travel Differences and Vehicle Ownership}

The fact that one out of every two households in NYC does not own a vehicle (Table 3.1) prompts the following questions: (1) are they demographically different from zero-vehicle households in other parts of the state and country? And if so (2) how do these households meet their travel needs? Also, after excluding NYC households from the comparison, (3) how different are NYS households in the rest of the state, on the average, from households in the rest of the nation?

An important distinction between zero-vehicle owning households in NYC and much of the rest of the state and country is their distribution of annual incomes. Table 3.6 and Figures 3.7, 3-8 and 3-9 show these differences. Most zero-vehicle households in NYC tend on the average to have higher incomes than households elsewhere. While only 1 in 3 of these zero-vehicle NYC households had an income under $\$ 20,000$ in 2009, 2 in 3 zero-vehicle households were in these two lowest income classes in both the rest of NYS and the rest of the nation in the same year. Over 40\% of zero-vehicle households in NYC earned between $\$ 20,000$ and \$80,000 annually, compared to about $21 \%$ in the rest of NYS and the same percent in the rest of nation. In fact $15.4 \%$ of these 'no-car' NYC households had an annual income over $\$ 80,000$ in 2009 , versus $1.4 \%$ in the rest of NYS and $2.1 \%$ in the rest of the nation for the same year. Examining this over time (Table 3.5 and Figures 3.7, 3.8 and 3.9), the number of these over $\$ 80,000$ annual income zero-vehicle households increased significantly in NYC, from $7.1 \%$ in 1995 to $12.3 \%$ in 2001 , up to the $15.4 \%$ reported in 2009. 
Table 3.6 Percentage of Zero-Vehicle Households by Annual Income Classes in 1995, 2001, and 2009 (in 2009 dollars)

\begin{tabular}{|c|c|c|c|c|c|c|c|c|c|}
\hline & \multicolumn{3}{|c|}{ New York City } & \multicolumn{3}{|c|}{ Remainder of New York State } & \multicolumn{3}{|c|}{ Rest of United States } \\
\hline & 1995 & 2001 & 2009 & 1995 & 2001 & 2009 & 1995 & 2001 & 2009 \\
\hline \% Zero Vehicle HHs & 52.9 & 51.6 & 54.5 & 7.4 & 7.6 & 9.1 & 6.9 & 6.8 & 7.4 \\
\hline$\%<\$ 10,000$ household income & 13.3 & 16.3 & 15.7 & 16.4 & 27.2 & 33.7 & 24.3 & 34.5 & 35.9 \\
\hline$\% \$ 10$ to $\$ 20,000$ household income & 14.2 & 15.6 & 17.6 & 26.0 & 30.1 & 32.0 & 29.1 & 24.6 & 29.2 \\
\hline$\% \$ 20$ to $\$ 30,000$ household income & 12.9 & 12.0 & 11.3 & 17.5 & 14.0 & 10.3 & 13.4 & 11.6 & 10.1 \\
\hline$\% \$ 30$ to $\$ 40,000$ household income & 14.9 & 12.5 & 10.4 & 10.8 & 8.9 & 6.3 & 6.4 & 7.7 & 5.7 \\
\hline$\% \$ 40$ to $\$ 50,000$ household income & 3.9 & 3.4 & 7.5 & 1.2 & 0.8 & 2.8 & 1.1 & 1.7 & 3.4 \\
\hline$\% \$ 50$ to $\$ 60,000$ household income & 4.7 & 7.6 & 4.4 & 0.7 & 1.0 & 0.6 & 2.3 & 2.4 & 0.7 \\
\hline$\% \$ 60$ to $\$ 70,000$ household income & 5.0 & 3.2 & 4.7 & 1.0 & 0.7 & 0.6 & 1.4 & 0.8 & 0.4 \\
\hline$\% \$ 70$ to $\$ 80,000$ household income & 2.8 & 2.7 & 2.7 & 0.6 & 0.3 & 0.3 & 0.4 & 0.2 & 0.7 \\
\hline$\% \$ 80$ to $\$ 100,000$ household income & 2.3 & 2.8 & 5.3 & 0.2 & 0.6 & 0.2 & 0.4 & 0.5 & 0.4 \\
\hline$\% \$ 100,000+$ household income & 4.8 & 9.5 & 10.1 & 0.5 & 1.1 & 1.2 & 0.5 & 1.7 & 1.7 \\
\hline$\%$ Unreported household income & 21.3 & 14.5 & 10.3 & 25.2 & 15.2 & 12.1 & 20.8 & 14.4 & 11.9 \\
\hline
\end{tabular}

Note: Percentages may not add to $100 \%$ due to rounding. 


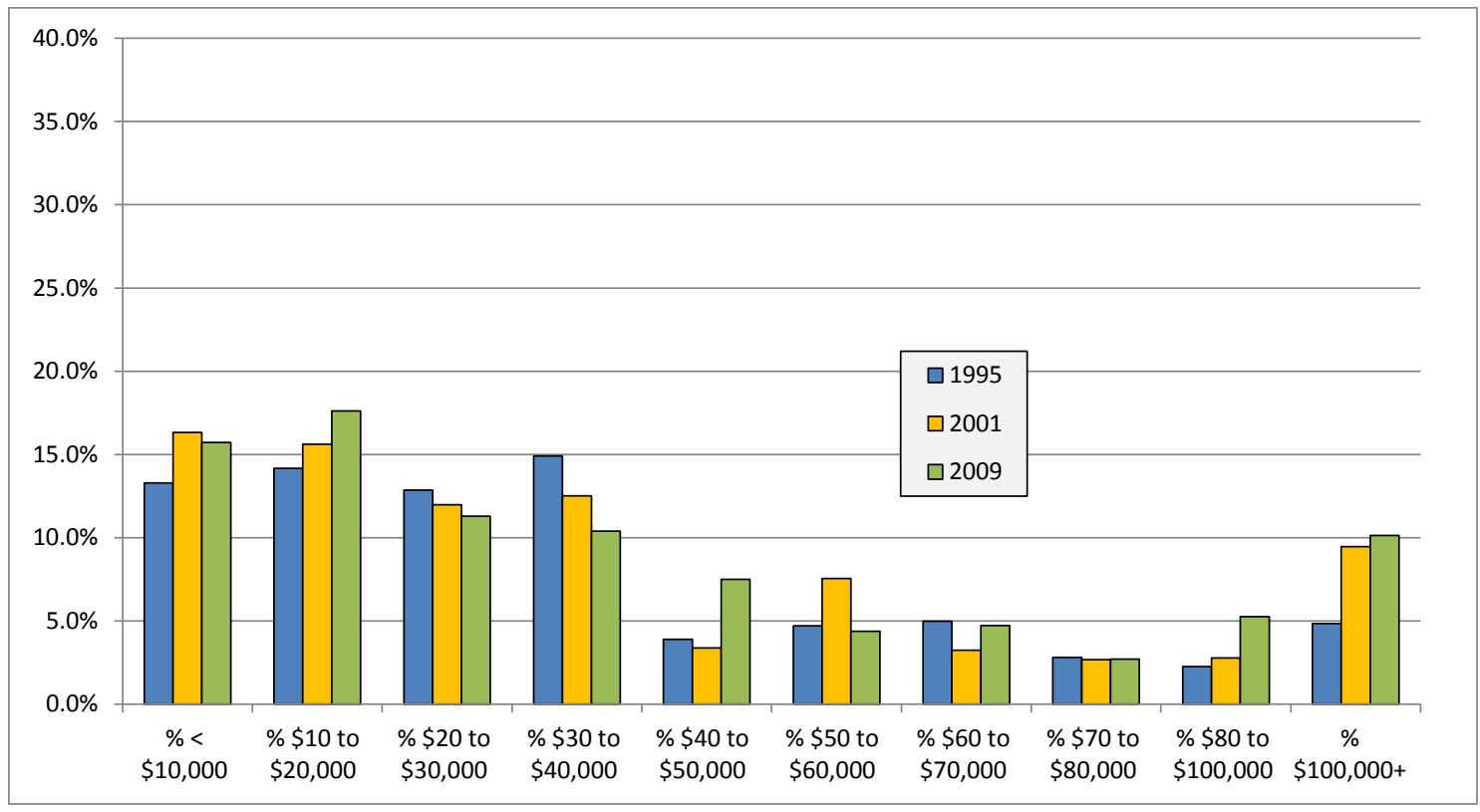

Figure 3.7 Distribution of Zero-Vehicle Households by Annual Income in 1995, 2001, and 2009 (in 2009 dollars) in New York City.

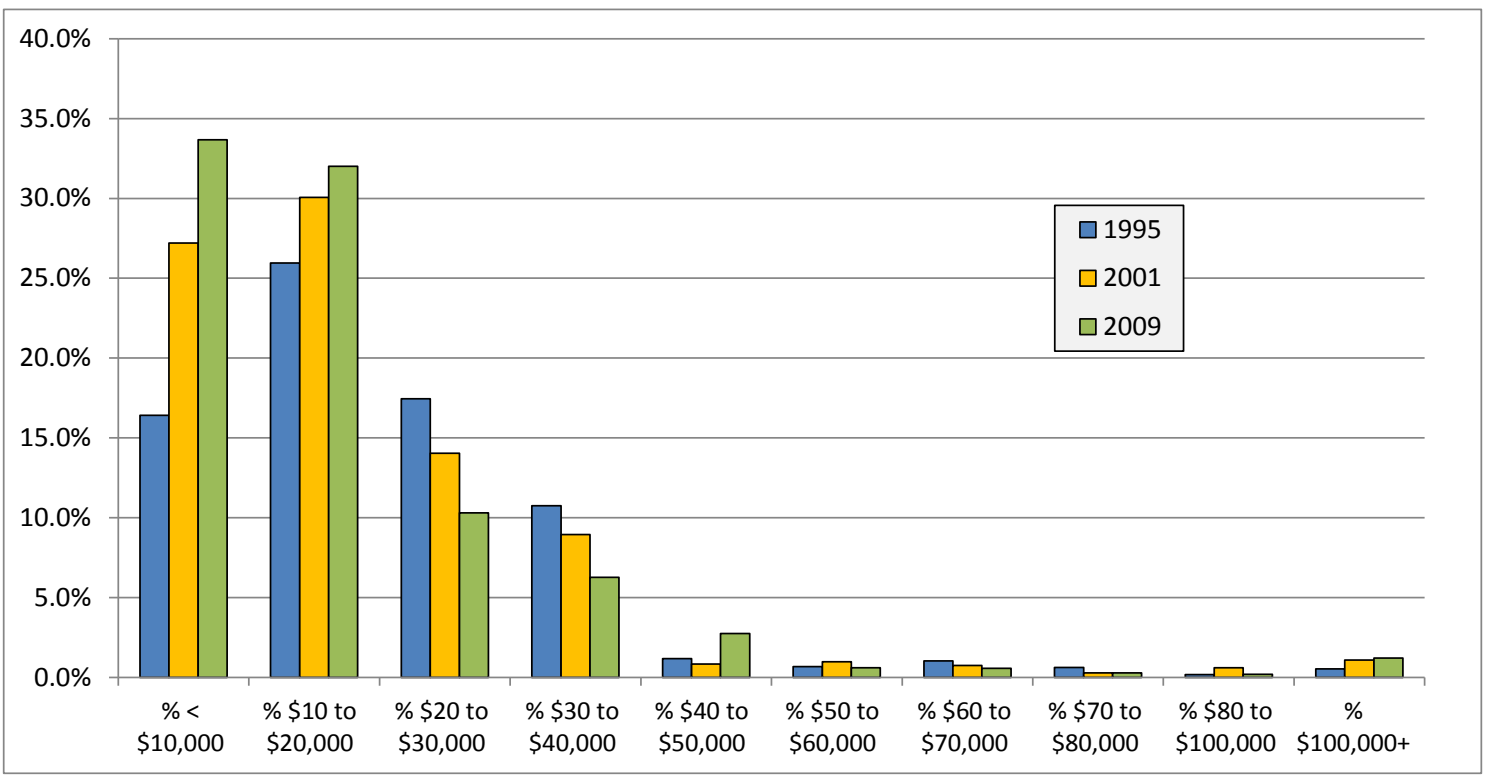

Figure 3.8 Distribution of Zero-Vehicle Households by Annual Income in 1995, 2001, and 2009 (in 2009 dollars) Rest of New York State. 


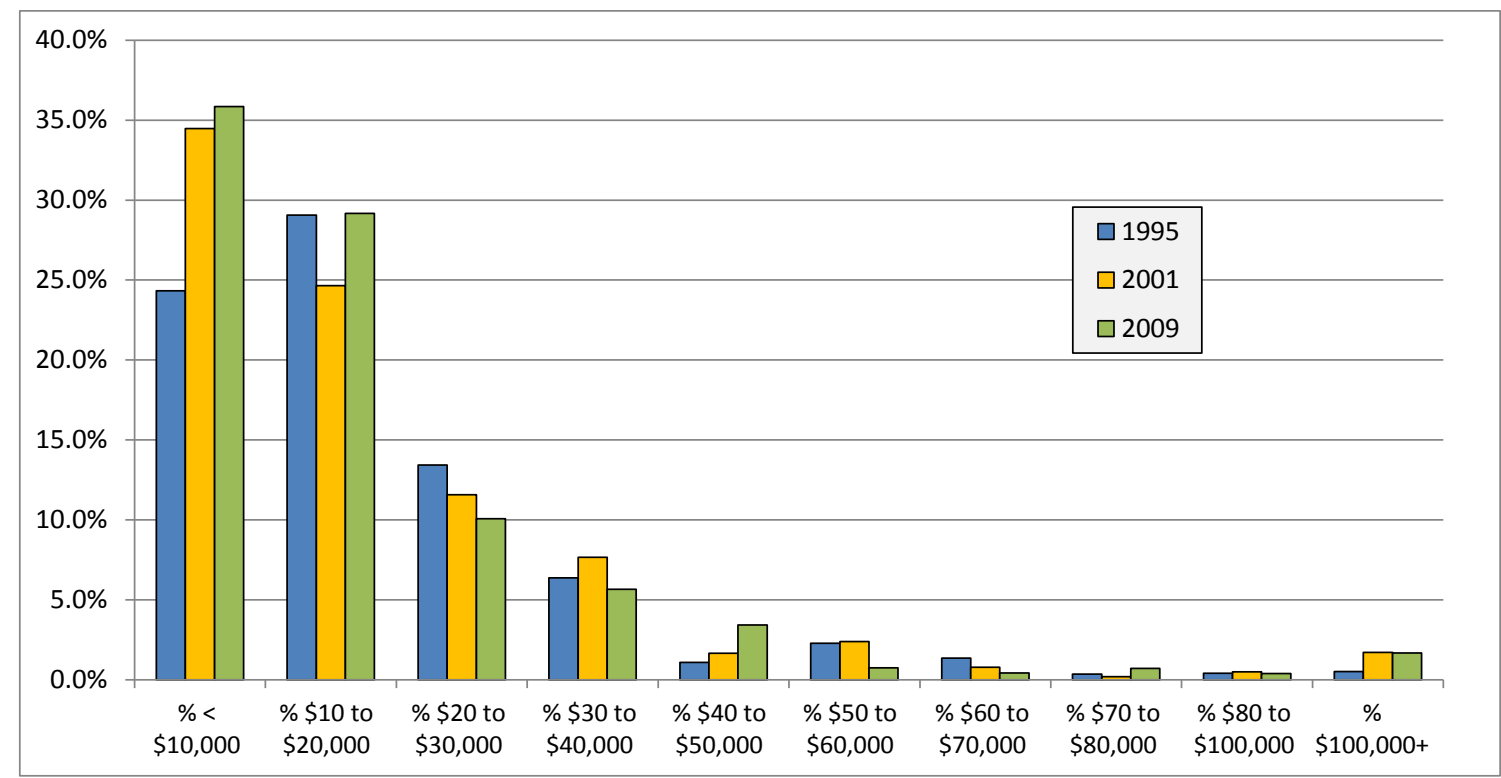

Figure 3.9 Distribution of Zero-Vehicle Households by Annual Income in 1995, 2001, and 2009 (in 2009 dollars)Rest of United States.

Note: Household income was adjusted to 2009 dollars. Distributions were computed for households with reported income information only.

As Table 3.7 shows, zero-vehicle owning households in NYC make significantly more trips, on average, than do those who do not own a vehicle elsewhere. In 2009, zero-vehicle households in NYC took $28 \%$ more trips than zero-vehicle households in other parts of NYS, and $21 \%$ more trips than zero-vehicle households outside NYS. Average person trips rates are very similar in the rest of NYS and the rest of the country.

Table 3.7 Average Daily Person Trips per Person by Mode for Zero-Vehicle Owning Households in 1995, 2001, and 2009

\begin{tabular}{l|rrr||rrr||rrr}
\hline & \multicolumn{4}{|c||}{ New York City } & \multicolumn{3}{c||}{$\begin{array}{c}\text { Remainder of } \\
\text { New York State }\end{array}$} & \multicolumn{3}{c}{ Rest of United States } \\
\cline { 2 - 10 } & \multicolumn{1}{|c|}{$\mathbf{1 9 9 5}$} & $\mathbf{2 0 0 1}$ & $\mathbf{2 0 0 9}$ & $\mathbf{1 9 9 5}$ & $\mathbf{2 0 0 1}$ & $\mathbf{2 0 0 9}$ & $\mathbf{1 9 9 5}$ & $\mathbf{2 0 0 1}$ & $\mathbf{2 0 0 9}$ \\
\hline Person Trips per Person & 3.32 & 3.30 & 3.20 & 2.78 & 2.53 & 2.50 & 2.97 & 2.63 & 2.61 \\
\% Private Vehicle & 11.4 & 13.3 & 7.4 & 39.2 & 36.8 & 24.3 & 46.5 & 43.6 & 33.2 \\
\% Public Transit & 34.3 & 32.7 & 32.5 & 16.9 & 13.5 & 18.5 & 14.5 & 16.7 & 17.6 \\
\% Walk & 41.6 & 47.2 & 52.7 & 21.2 & 35.8 & 41.8 & 24.6 & 31.9 & 34.2 \\
\% Other & 6.3 & 6.6 & 7.3 & 10.4 & 13.8 & 14.3 & 6.7 & 7.6 & 12.7 \\
$\%$ Unreported & 6.3 & 0.2 & 0.1 & 12.2 & 0.2 & 1.2 & 7.7 & 0.1 & 2.2 \\
\hline
\end{tabular}


Table 3.7 also shows the modal breakdown of the trips made by zero-vehicle households. Walking remains a popular mode among zero-vehicle households in NYS as a whole, and not just in NYC, than it does in the rest of the country. While public transit share is very similar in the rest of NYS and rest of nation (18.5\% vs. $17.6 \%$ in 2009), public transit trips in NYC account for almost one in every three trips, or almost double the percentage share elsewhere.

When the travel activity of NYC households that do not own any vehicles is compared against the tripmaking of the entire NYC households population some differences are also evident: but differences are less significant, on the average, than they are in the rest of the state and nation in terms of either daily person trip rates or daily PMT (see Figures 3.10 and 3.11). Higher density living supported by more transit and walk trip opportunities for most NYC residents plays an important role here (see Chapter 4).

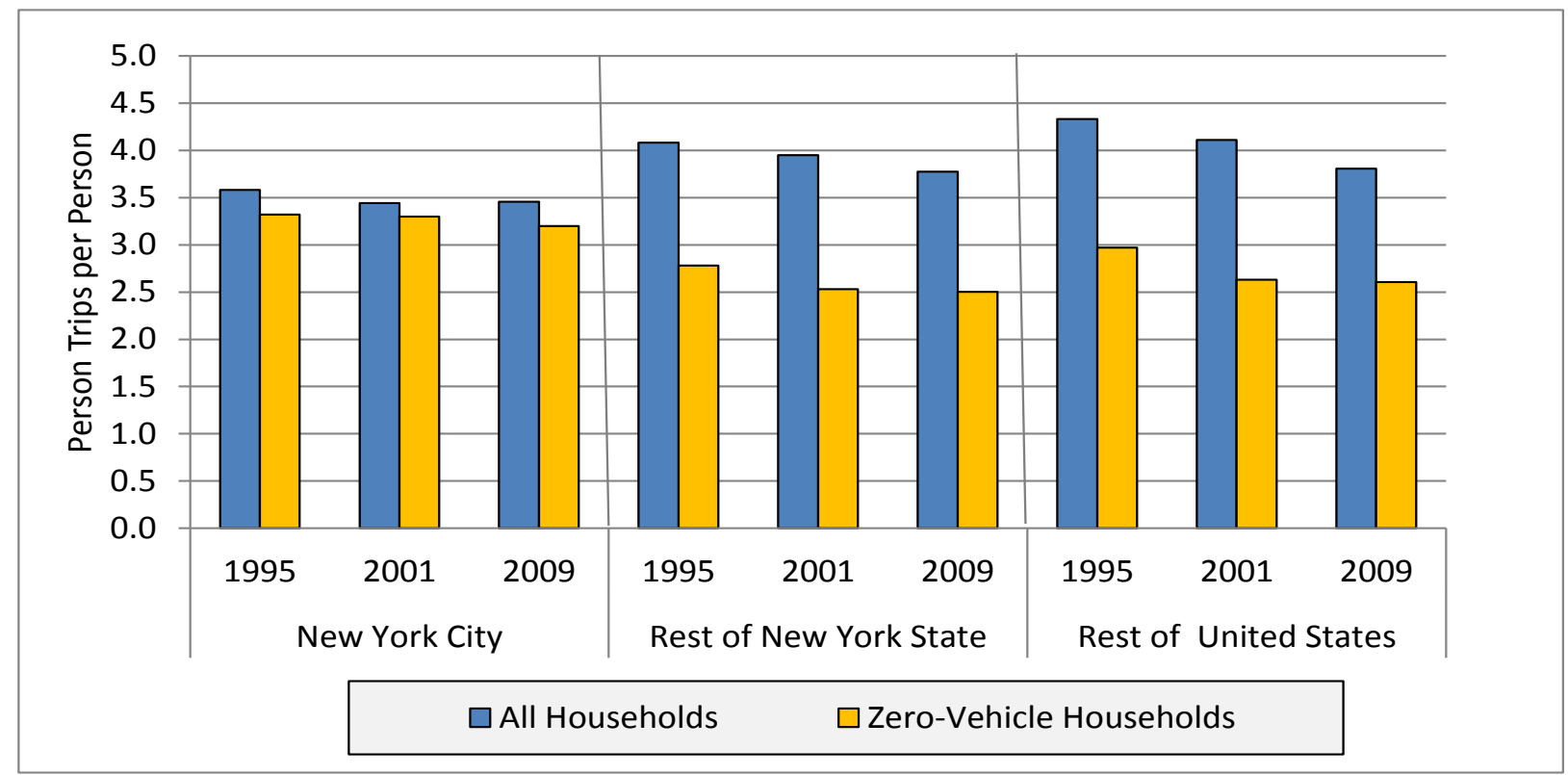

Figure 3.10 Effects of Not Owning a Vehicle on Daily Travel in 1995, 2001, and 2009Daily Person Trips per Person. 


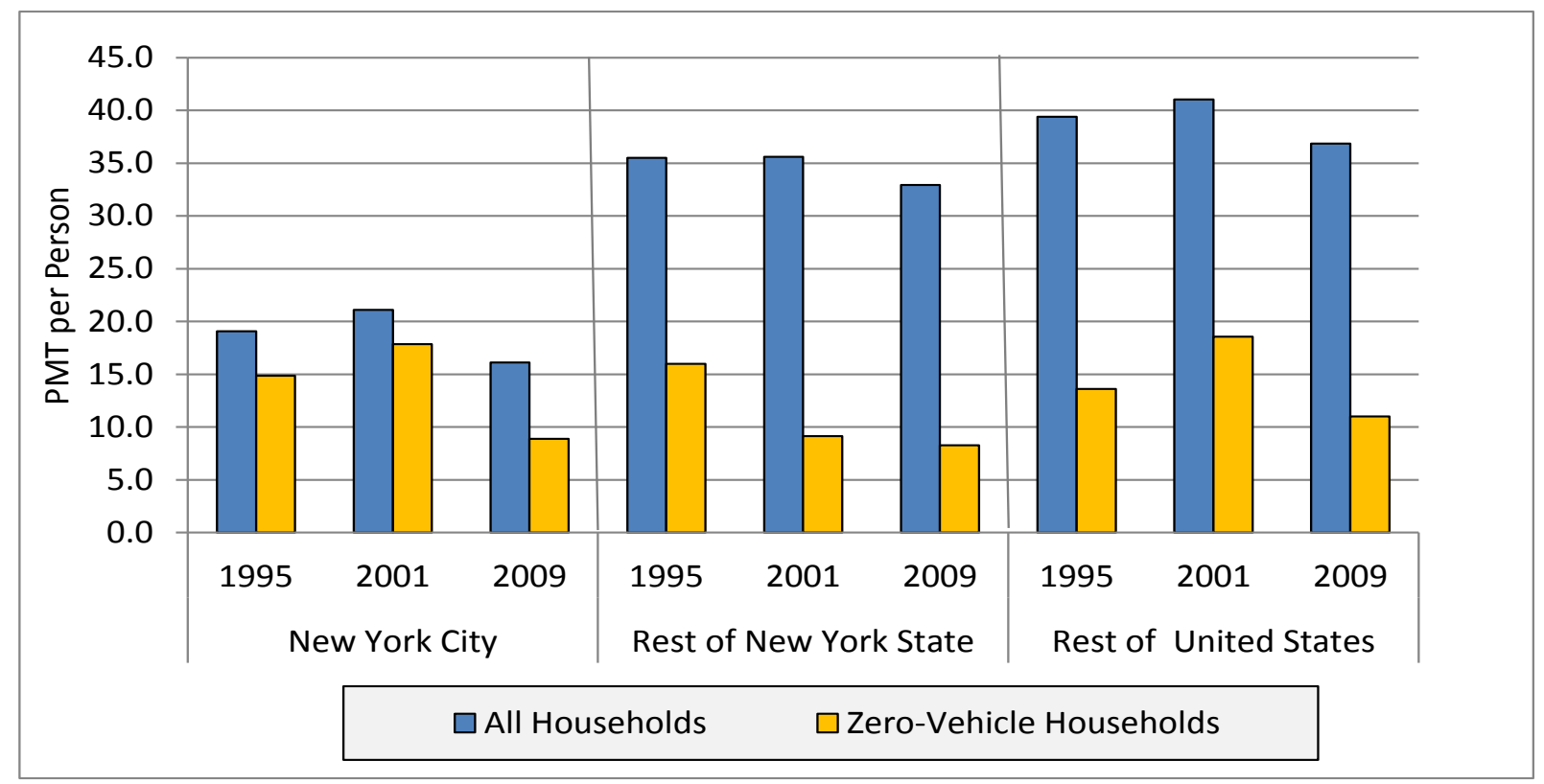

Figure 3.11 Effects of Not Owning a Vehicle on Daily Travel in 1995, 2001, and 2009Daily Person Miles of Travel per Person.

\subsection{VEHICLE TRAVEL COMPARISONS}

\subsubsection{Vehicle Trip Frequencies and Trip Distances}

Not surprisingly, drivers in NYC engaged in significantly less vehicle travel, on the average, than drivers elsewhere. On the average, NYC drivers in 2009 continued to take only one third as many trips per day as drivers in the rest of the state and nation, at just over 1 trip per day versus 3 trips per day elsewhere (top line of Table 3.7a below). While a steady decline in the number of driver trips is evident for all three regions, the decline in this trip rate since 1995 is much greater in percentage terms in NYC $(-32 \%)$ than elsewhere. This decline is almost identical to the rest of the nation in absolute terms (a decline of 0.54 trips per day, which the small standard errors involved show to be a statistically significant difference). Driving trip rates declined less in the rest of NYS, but the difference is still marginally significant (see Figure 3.12 below). Table 3.8 shows some significant drops in trips per NYC driver among both 20-34 year olds (from 1.5 trips in 1995 to 0.98 trips in 2001 and 0.83 trips in 2009), and among the over 65 year olds (from 1.94 trips in 1995 to 1.67 trips in 2001, down to 1.07 trips in 2009). 


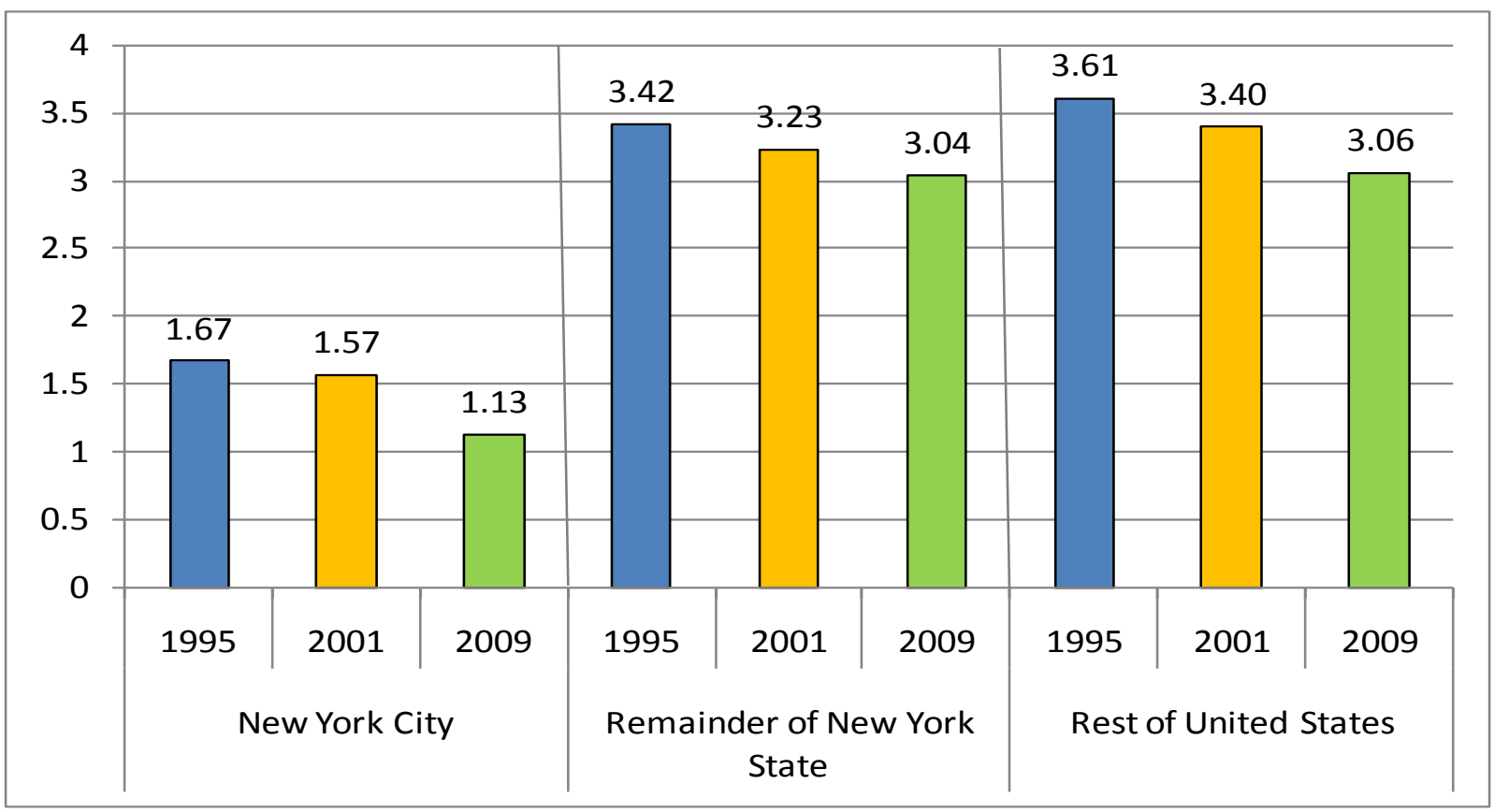

Figure 3.12 Daily Driver Trip Rates in 1995, 2001, and 2009

As with the person trip statistics reported in Table 3.2, trip purpose shares by drivers in all three regions were very similar in 1995 and 2001. However, in 2009, while NYS drivers outside of NYC once again reported a distribution of trips across trip purposes very similar to that reported by drivers in the rest of the nation, a much larger percentage of driver trips in NYC $(55.5 \%)$ were taken for family and personal reasons (versus $47 \%$ elsewhere); while only $18 \%$ of NYC driver trips are taken for purposes of making a living (versus 26\% elsewhere). In 2009 an increased share of driver trips were also allocated to social and recreational trips. Other changes in NYC driver tripmaking in 2009 over previous survey years include a slight drop in civic, educational, and religious trips. The other major trip purpose category, social and recreational tripmaking, has grown from $17 \%$ to $21 \%$ in NYC, reflecting similar shares in the rest of the state and rest of the nation (Table 3.8 and Figure 3.13).

Another difference between private vehicle trips in NYC and elsewhere is that more NYC trips occur on weekends than weekdays. This finding is consistent with the lower percentage of vehicle trips for work purpose by NYC residents, especially in 2009. The pie charts in Figure 3.13 show this breakdown of driver trips by trip purpose, based on the 2009 NHTS data.

In terms of daily (VMT per driver (top line of Table 3.9), drivers in NYC drove only a little over 8 miles per day, dropping significantly from 12 miles in 2001 and 14 miles in 1995: largely mirroring the drop in private vehicle trip rates shown in Table 3.8. Daily VMT per driver was 26.6 miles for the rest of NYS drivers in 2009, and 29.6 miles per day on average in the rest of the nation: well over three times the miles driven by drivers in NYC households. 
Table 3.8 Daily Vehicle Trips per Driver Statistics for New York City, Rest of New York State, and Rest of the United States in 1995, 2001, and 2009

\begin{tabular}{|c|c|c|c|c|c|c|c|c|c|}
\hline & \multicolumn{3}{|c|}{ New York City } & \multicolumn{3}{|c|}{$\begin{array}{c}\text { Remainder of } \\
\text { New York State }\end{array}$} & \multicolumn{3}{|c|}{ Rest of United States } \\
\hline & 1995 & 2001 & 2009 & 1995 & 2001 & 2009 & 1995 & 2001 & 2009 \\
\hline Vehicle Trips per Driver & 1.67 & 1.57 & 1.13 & 3.42 & 3.23 & 3.04 & 3.61 & 3.40 & 3.06 \\
\hline \% Earning a Living & 25.7 & 25.6 & 18.2 & 26.9 & 25.5 & 26.1 & 27.4 & 26.2 & 26.1 \\
\hline$\%$ Family and Personal & 52.7 & 50.4 & 55.5 & 50.9 & 48.7 & 47.5 & 49.9 & 48.0 & 46.7 \\
\hline$\%$ Civic, Ed, and Religious & 4.2 & 3.8 & 3.4 & 3.5 & 4.2 & 4.7 & 4.2 & 4.9 & 4.9 \\
\hline \% Social \& Recreational & 17.4 & 19.0 & 21.3 & 18.7 & 21.0 & 20.7 & 18.3 & 20.3 & 21.1 \\
\hline$\%$ Other & 0.0 & 1.0 & 0.2 & 0.0 & 0.5 & 0.3 & 0.1 & 0.5 & 0.3 \\
\hline$\%$ Unreported & & 0.1 & 1.5 & & 0.2 & 0.7 & & 0.1 & 0.9 \\
\hline Vehicle Trips per Driver & 1.67 & 1.57 & 1.13 & 3.42 & 3.23 & 3.04 & 3.61 & 3.40 & 3.06 \\
\hline $16-19$ years of age & 0.63 & 1.34 & 0.41 & 2.98 & 2.60 & 2.15 & 3.35 & 2.91 & 2.29 \\
\hline 20-34 years of age & 1.50 & 0.98 & 0.83 & 3.41 & 3.05 & 2.78 & 3.65 & 3.36 & 2.95 \\
\hline $35-54$ years of age & 1.82 & 1.87 & 1.30 & 3.67 & 3.58 & 3.42 & 3.90 & 3.77 & 3.37 \\
\hline $55-64$ years of age & 1.82 & 2.06 & 1.50 & 3.32 & 3.12 & 3.09 & 3.42 & 3.28 & 3.14 \\
\hline$>=65$ years of age & 1.94 & 1.67 & 1.07 & 2.96 & 2.96 & 2.76 & 2.95 & 2.85 & 2.70 \\
\hline Vehicle Trips per Driver & 1.67 & 1.57 & 1.13 & 3.42 & 3.23 & 3.04 & 3.61 & 3.40 & 3.06 \\
\hline Male & 1.86 & 1.75 & 1.34 & 3.70 & 3.39 & 3.14 & 3.82 & 3.61 & 3.14 \\
\hline Female & 1.41 & 1.33 & 0.91 & 3.14 & 3.08 & 2.95 & 3.40 & 3.19 & 2.98 \\
\hline Weekday Vehicle Trips/Driver & 1.63 & 1.61 & 1.08 & 3.61 & 3.39 & 3.22 & 3.84 & 3.60 & 3.26 \\
\hline Weekend Vehicle Trips/Driver & 1.76 & 1.47 & 1.26 & 2.95 & 2.85 & 2.58 & 3.00 & 2.88 & 2.56 \\
\hline
\end{tabular}

${ }^{\text {a }}$ All percents may not add to $100 \%$ due to rounding. 


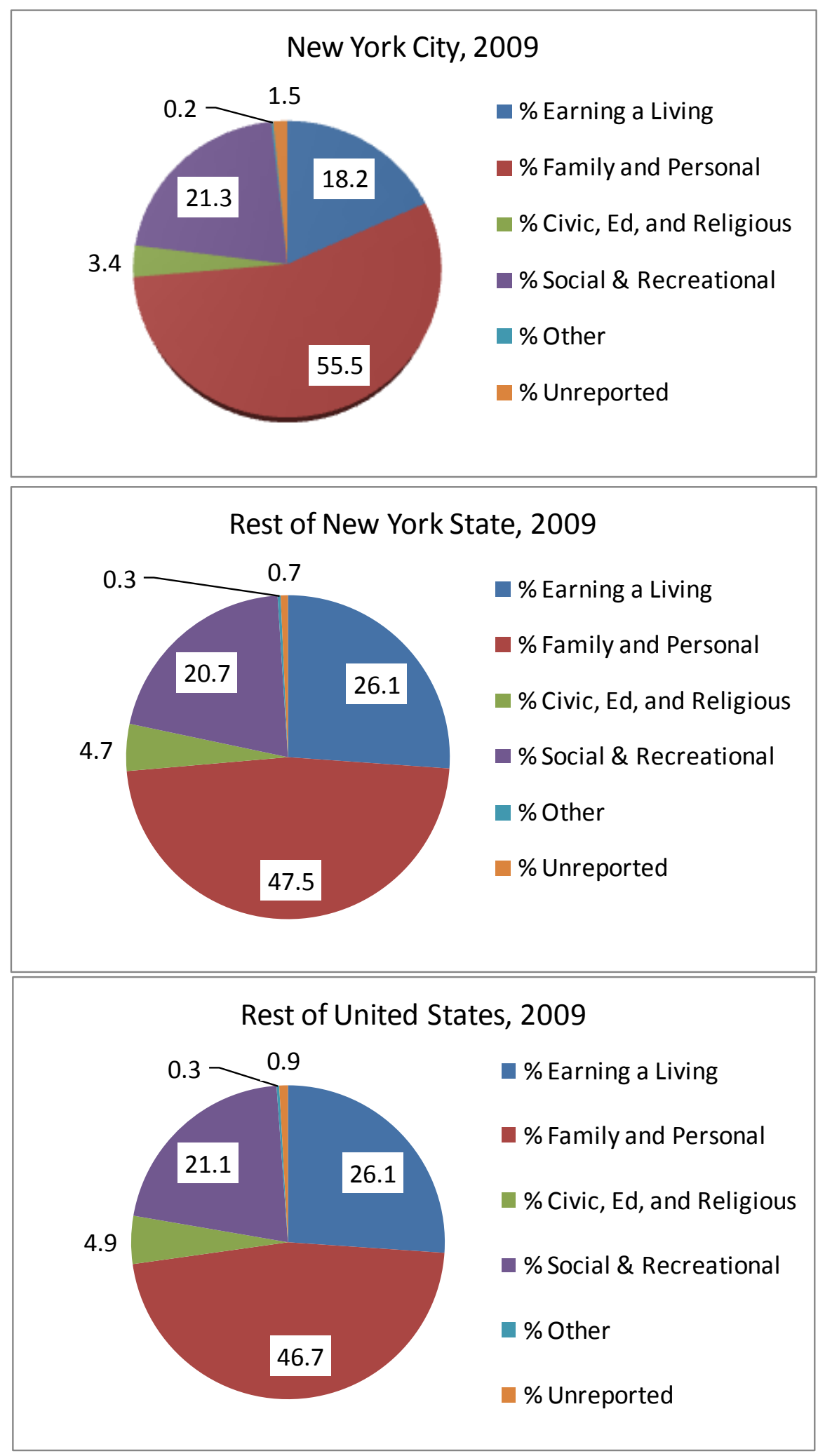

Figure 3.13 Comparison of Driver Trip Purpose Shares in 2009: NYC, NYS, and Rest of the United States. 
Table 3.9 Daily Vehicle Miles of Travel (VMT) per Driver Statistics for New York City, Rest of New York State, and Rest of the United States in 1995, 2001, and 2009 and Rest of the United States in 1995, 2001, and 2009

\begin{tabular}{|c|c|c|c|c|c|c|c|c|c|}
\hline & \multicolumn{3}{|c|}{ New York City } & \multicolumn{3}{|c|}{$\begin{array}{c}\text { Remainder of New York } \\
\text { State }\end{array}$} & \multicolumn{3}{|c|}{ Rest of United States } \\
\hline & 1995 & 2001 & 2009 & 1995 & 2001 & 2009 & 1995 & 2001 & 2009 \\
\hline VMT per Driver & 13.86 & 11.86 & 8.13 & 29.96 & 29.24 & 26.64 & 32.59 & 33.31 & 29.57 \\
\hline \% Earning a Living & 35.9 & 34.6 & 24.1 & 37.2 & 34.8 & 35.9 & 37.8 & 35.5 & 34.7 \\
\hline$\%$ Family and Personal & 31.5 & 35.7 & 34.5 & 35.8 & 34.7 & 33.9 & 35.5 & 35.3 & 32.7 \\
\hline$\%$ Civic, Ed, and Religious & 3.5 & 3.9 & 2.3 & 2.7 & 3.2 & 3.7 & 3.8 & 3.8 & 4.4 \\
\hline$\%$ Social \& Recreational & 29.1 & 25.1 & 36.8 & 24.0 & 26.3 & 22.7 & 22.7 & 24.4 & 24.4 \\
\hline$\%$ Other & 0.0 & 0.6 & 0.4 & 0.2 & 0.9 & 0.4 & 0.1 & 0.8 & 0.6 \\
\hline$\%$ Unreported & & 0.2 & 1.9 & & 0.3 & 3.5 & & 0.2 & 3.2 \\
\hline VMT per Driver & 13.86 & 11.86 & 8.13 & 29.96 & 29.24 & 26.64 & 32.59 & 33.31 & 29.57 \\
\hline $16-19$ years of age & 3.82 & 5.57 & 2.30 & 19.64 & 20.05 & 15.88 & 24.07 & 22.57 & 17.84 \\
\hline $20-34$ years of age & 14.95 & 9.28 & 9.32 & 34.06 & 29.02 & 26.78 & 35.43 & 35.36 & 29.10 \\
\hline $35-54$ years of age & 14.27 & 14.52 & 8.39 & 32.95 & 34.35 & 31.68 & 36.57 & 38.46 & 34.78 \\
\hline $55-64$ years of age & 11.50 & 12.54 & 9.36 & 27.69 & 27.83 & 26.24 & 30.59 & 32.60 & 31.00 \\
\hline$>=65$ years of age & 12.59 & 8.98 & 6.45 & 18.63 & 20.63 & 18.78 & 19.68 & 21.34 & 19.97 \\
\hline VMT per Driver & 13.86 & 11.86 & 8.13 & 29.96 & 29.24 & 26.64 & 32.59 & 33.31 & 29.57 \\
\hline Male & 17.28 & 15.02 & 10.56 & 37.62 & 36.47 & 31.46 & 40.64 & 41.63 & 35.76 \\
\hline Female & 9.22 & 7.88 & 5.54 & 22.15 & 22.28 & 21.80 & 24.53 & 25.12 & 23.31 \\
\hline Average Vehicle Trip Length & 8.54 & 7.91 & 7.55 & 8.84 & 9.16 & 8.85 & 9.07 & 9.91 & 9.77 \\
\hline$\%$ Vehicle Trips/Person Trips & $22.1 \%$ & $23.2 \%$ & $20.3 \%$ & $60.7 \%$ & $60.7 \%$ & $61.5 \%$ & $61.6 \%$ & $61.6 \%$ & $60.6 \%$ \\
\hline$\%$ VMT/PMT & $34.4 \%$ & $28.6 \%$ & $31.4 \%$ & $61.1 \%$ & $61.0 \%$ & $61.7 \%$ & $61.0 \%$ & $60.6 \%$ & $60.5 \%$ \\
\hline
\end{tabular}

Notes: -All percents may not add to $100 \%$ due to rounding. Average trip length is calculated using only those records with trip mileage information present. 


\subsubsection{Differences in Driving by Gender and Age}

While daily person trip rate differences between men and women are negligible (cf. Table 3.5), driving trip rates do show more tripmaking by male drivers across all three regions studied (Table 3.8). This situation has been true for all three NHTS survey years (Figure 3.14), and in 2009 this situation translated into almost double the daily VMT by NYC male drivers than female drivers (10.6 miles vs.5.5 miles per day). A similar, 2-to-1 ratio was also evident in 2001 and 1995. In this regard NYC drivers also differ from those in the rest of state and country, where male driver VMT fell more noticeably than female driver VMT between 2001 and 2009 (Table 3.9 and Figure 3.14). Compared to drivers elsewhere in the state, NYC drivers travel significantly less miles in their cars annually. This is true for both men and women (Figure 3.14).

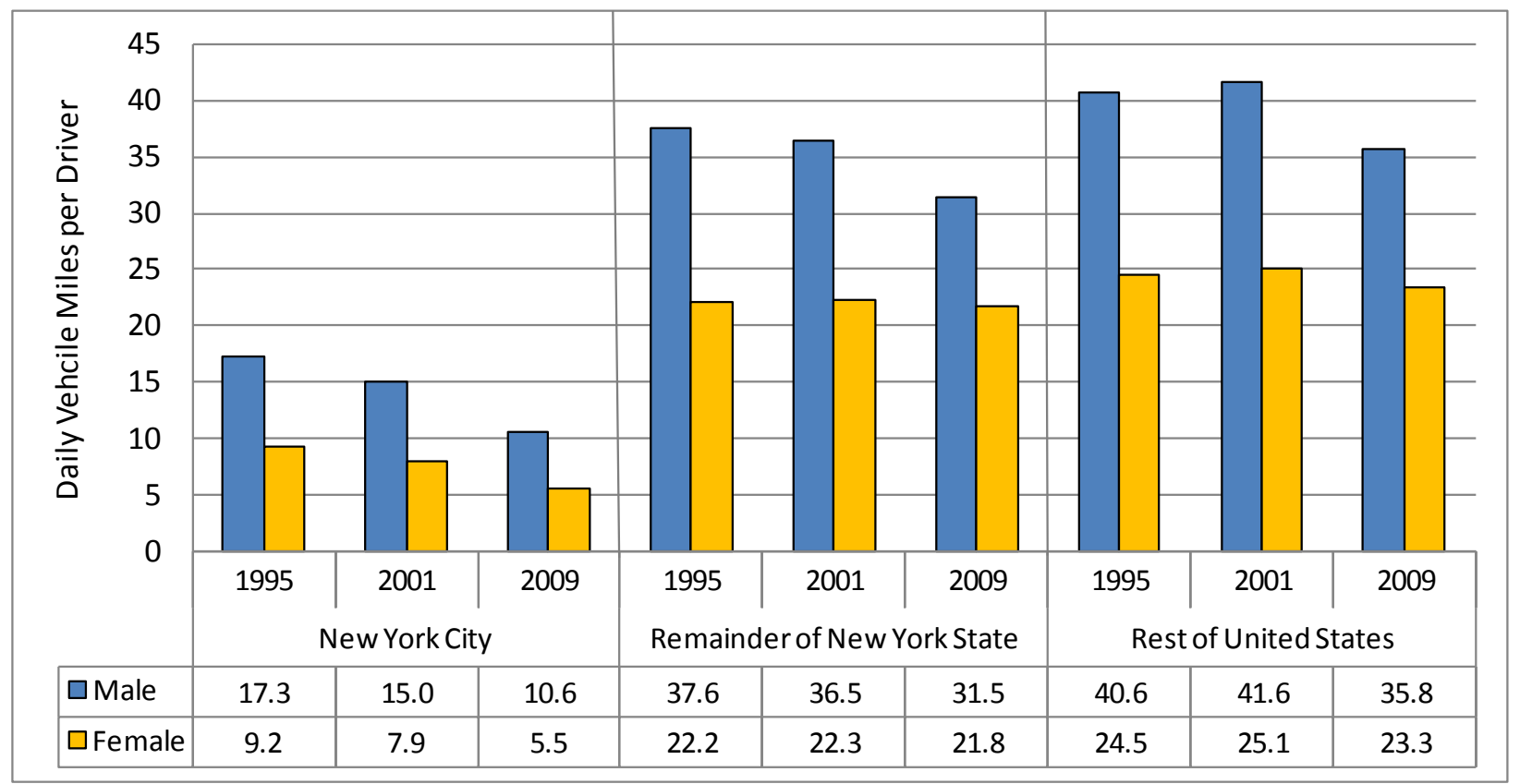

Figure 3.14 Daily Driver Vehicle Miles of Travel (VMT) by Gender in 1995, 2001, and 2009.

As shown in Table 3.8 and Figure 3.15, teenager drivers drove significantly fewer miles in 2009 than they did in either 1995 or 2001, in all three regions. In NYC drivers over 65 years of age also saw a significant drop in their daily mile driven. However, unlike the drop in teenage driving, in the case of these elderly drivers this drop in VMT was not reflected in the rest of state or nation. 


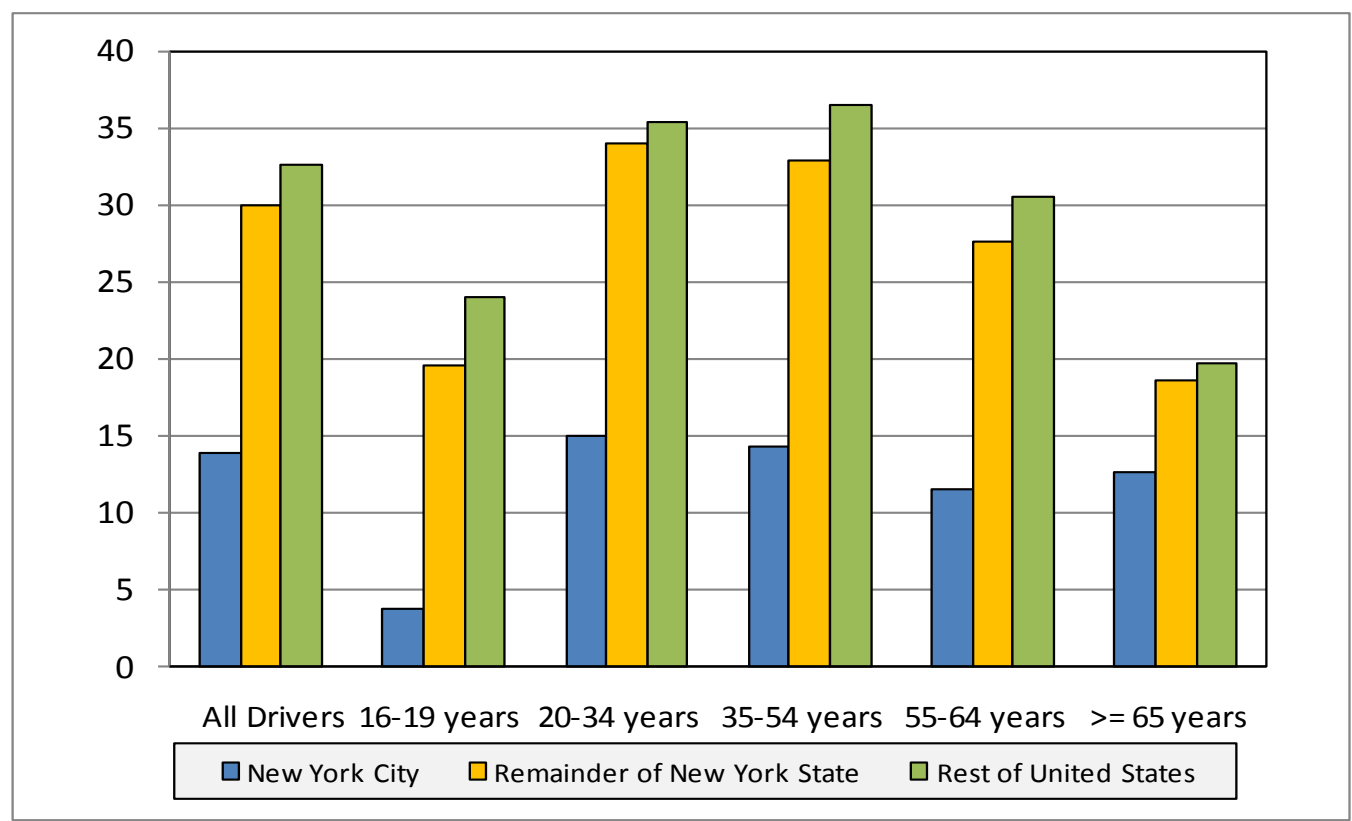

Figure 3.15 Daily Driver Vehicle Miles of Travel (VMT) by Age Group for New York City, Remainder of New York State, and Rest of the United States in 1995 and 2009, Average Daily VMT per Driver in 1995.

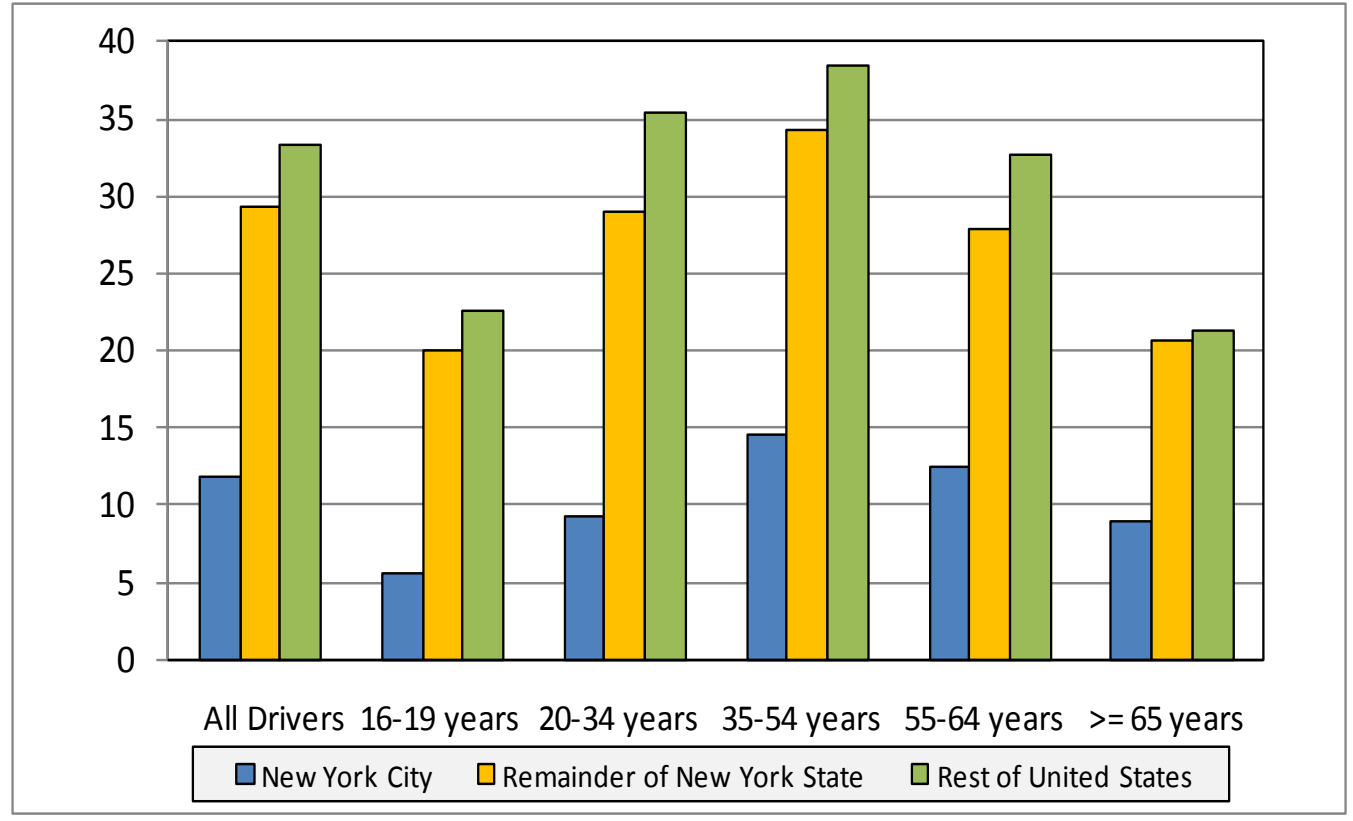

Figure 3.16 Daily Driver Vehicle Miles of Travel (VMT) by Age Group for New York City, Remainder of New York State, and Rest of the United States in 1995 and 2009, Average Daily VMT per Driver in 2001. 


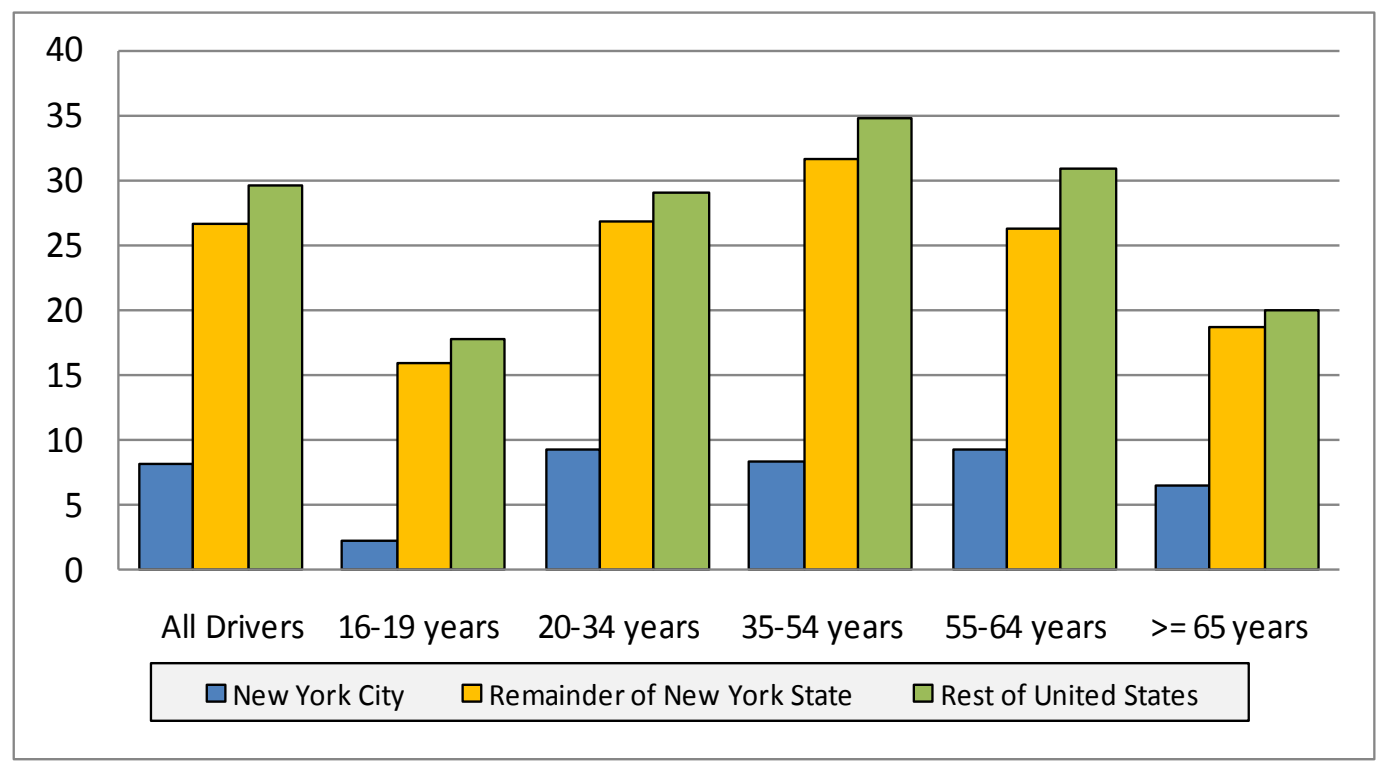

Figure 3.17 Daily Driver Vehicle Miles of Travel (VMT) by Age Group for New York City, Remainder of New York State, and Rest of the United States in 1995 and 2009, Average Daily VMT per Driver in 2009.

\subsubsection{Types and Ages of Vehicles in Use}

Table 3.10 compares the types of NYC household vehicles to those used elsewhere. The principal difference is the very low use of pickup trucks in NYC: although these vehicles are also used significantly less in the rest of NYS than in the rest of the country. All three regions show a significant increase in the popularity of SUVs since the mid-1990s.

Table 3.10 Comparison of Vehicle Types Driven in 1995, 2001, and 2009 (Fleet Percentages)

\begin{tabular}{l|rrr||rrr||rrr}
\hline & \multicolumn{3}{|c||}{ New York City } & \multicolumn{3}{c||}{$\begin{array}{c}\text { Remainder of } \\
\text { New York State }\end{array}$} & \multicolumn{3}{c}{ Rest of United States } \\
\cline { 2 - 10 } & $\mathbf{1 9 9 5}$ & $\mathbf{2 0 0 1}$ & $\mathbf{2 0 0 9}$ & $\mathbf{1 9 9 5}$ & $\mathbf{2 0 0 1}$ & $\mathbf{2 0 0 9}$ & $\mathbf{1 9 9 5}$ & $\mathbf{2 0 0 1}$ & $\mathbf{2 0 0 9}$ \\
\hline Auto & 87.4 & 75.7 & 64.7 & 72.3 & 63.2 & 56.2 & 64.7 & 56.4 & 49.7 \\
Van & 5.6 & 9.3 & 9.9 & 7.8 & 10.1 & 8.9 & 8.0 & 9.0 & 8.2 \\
Sports Utility Vehicle & 5.3 & 12.4 & 22.6 & 7.3 & 11.9 & 21.1 & 7.0 & 12.1 & 19.4 \\
Pickup & 1.2 & 1.0 & 1.2 & 10.8 & 11.6 & 10.6 & 18.3 & 19.0 & 18.3 \\
Other Truck & 0.1 & 0.4 & 0.0 & 0.3 & 0.3 & 0.3 & 0.4 & 0.5 & 0.4 \\
RV & 0.0 & 0.0 & 0.0 & 0.4 & 0.5 & 0.4 & 0.5 & 0.7 & 0.5 \\
Motorcycle & 0.2 & 1.3 & 1.6 & 0.8 & 2.3 & 2.6 & 1.0 & 2.3 & 3.4 \\
Other POV & 0.2 & $*$ & $*$ & 0.1 & $*$ & $*$ & 0.1 & $*$ & $*$ \\
\hline TOTAL & $100.0 \%$ & $100.0 \%$ & $100.0 \%$ & $100.0 \%$ & $100.0 \%$ & $100.0 \%$ & $100.0 \%$ & $100.0 \%$ & $100.0 \%$ \\
\hline
\end{tabular}

* Other Privately Owned Vehicles not present in 2001 or 2009. 
Both the median and average age of the household vehicle fleet is lower in both NYC and the rest of NYS than elsewhere in the country in 2009, as it was in 1995 and 2001 also (Table 3.11). The average age of vehicles in NYC was a little higher than in the rest of the state throughout the 14 year period, but with the gap narrowing between the two regions in 2009 . Average age of vehicle dropped slightly in NYC between 2001 and 2009, and stayed the same in the remainder of NYS. In contrast, the average age of vehicles increased by about half a year in the rest of the nation between 1995 and 2001, and again by an additional half a year between 2001 and 2009. As in previous years, there were more older vehicles (> 10 years old) in use in NYC than in the rest of the state in 2009. In this regard NYC household vehicles are closely in line with those in the rest of the nation, with $65 \%$ of NYC household vehicle fleet under 10 years old: while roughly $70 \%$ of privately owned household vehicles in the remainder of the state are under 10 years old, versus roughly 60\% in the rest of the nation in 2009.

Table 3.11 Percentage of Households' Private Vehicle Fleets Over Ten Years Old: New York City, Remainder of New York State and Rest of the United States Compared

\begin{tabular}{|c|c|c|c|c|c|c|c|c|c|}
\hline & \multicolumn{3}{|c|}{ New York City } & \multicolumn{3}{|c|}{$\begin{array}{l}\text { Remainder of } \\
\text { New York State }\end{array}$} & \multicolumn{3}{|c|}{ Rest of United States } \\
\hline & 1995 & 2001 & 2009 & 1995 & 2001 & 2009 & 1995 & 2001 & 2009 \\
\hline \multicolumn{10}{|l|}{ Age Statistics } \\
\hline Average Vehicle Age & 7.82 & 8.18 & 7.98 & 7.33 & 7.76 & 7.74 & 8.38 & 8.92 & 9.47 \\
\hline Median Vehicle Age & 8 & 7 & 7 & 7 & 7 & 7 & 7 & 7 & 8 \\
\hline Percent VMT* & & & & & & & & & \\
\hline Less than 10 years & $70.6 \%$ & $69.3 \%$ & $71.1 \%$ & $76.2 \%$ & $74.2 \%$ & $75.6 \%$ & $76.4 \%$ & $71.0 \%$ & $67.8 \%$ \\
\hline 10 years or more & $29.4 \%$ & $30.7 \%$ & $28.9 \%$ & $23.8 \%$ & $25.8 \%$ & $24.4 \%$ & $23.6 \%$ & $29.0 \%$ & $32.2 \%$ \\
\hline \multicolumn{10}{|l|}{ Percent Vehicle Fleet } \\
\hline Less than 10 years & $68.6 \%$ & $61.3 \%$ & $64.9 \%$ & $72.4 \%$ & $68.0 \%$ & $70.5 \%$ & $66.0 \%$ & $62.6 \%$ & $60.7 \%$ \\
\hline 10 years or more & $31.5 \%$ & $38.7 \%$ & $35.1 \%$ & $27.6 \%$ & $32.0 \%$ & $29.5 \%$ & $34.0 \%$ & $37.5 \%$ & $39.3 \%$ \\
\hline $\begin{array}{l}\text { Average Fuel Consumption } \\
\text { (gallons)/HH }\end{array}$ & ** & 325 & 258 & $\star \star *$ & 968 & 883 & ** & 1,036 & 1,020 \\
\hline Less than 10 years & ** & $70.8 \%$ & $69.9 \%$ & $* *$ & $75.4 \%$ & $74.3 \%$ & ** & $71.3 \%$ & $66.3 \%$ \\
\hline 10 years or more & ** & $29.2 \%$ & $30.1 \%$ & $* \star$ & $24.6 \%$ & $25.7 \%$ & ** & $28.7 \%$ & $33.7 \%$ \\
\hline $\begin{array}{l}\text { Average CO2 Emissions } \\
(\mathrm{kg}) / \mathrm{HH}\end{array}$ & ** & 2,866 & 2,265 & $\star *$ & 8,508 & 7,774 & $* \star$ & 9,106 & 8,985 \\
\hline Less than 10 years & ** & $70.8 \%$ & $70.0 \%$ & $\star *$ & $75.4 \%$ & $74.3 \%$ & $* *$ & $71.3 \%$ & $66.3 \%$ \\
\hline 10 years or more & ** & $29.2 \%$ & $30.0 \%$ & $\star \star$ & $24.6 \%$ & $25.7 \%$ & ** & $28.7 \%$ & $33.7 \%$ \\
\hline
\end{tabular}

${ }^{a}$ Numbers reflect BESTMILE Estimates. Due to data being unavailable, self-reported annual miles were substituted for Rest of U.S. 1995 estimates.

** Statistics not available in 1995. Excludes unreported \%s.

Table 3.12 shows how miles driven annually change over age of vehicle, broken down by vehicle types (Auto, Van, SUV, Pickup Trucks, and other Personally Owned Vehicles). Table 3.13 shows the percentage of vehicles in the NYC, rest of NYS, and rest of the nation fleets, 
cross-classified by these same vehicle types and vehicle age groups, with fleet sizes given on the top data line to allow the reader to compute average annual vehicle miles in each vehicle type/vehicle age group cell.

Table 3.12 Average Vehicle Miles Driven per Household Vehicle, by Vehicle Type and Vehicle Age Group in 1995, 2001, and 2009

\begin{tabular}{|c|c|c|c|c|c|c|c|c|c|}
\hline & \multicolumn{3}{|c|}{ New York City } & \multicolumn{3}{|c|}{$\begin{array}{l}\text { Remainder of } \\
\text { New York State }\end{array}$} & \multicolumn{3}{|c|}{ Rest of United States } \\
\hline & 1995 & 2001 & 2009 & 1995 & 2001 & 2009 & 1995 & 2001 & 2009 \\
\hline ALL HH VEHICLES* & 12,281 & 11,446 & 9,460 & 12,982 & 12,338 & 11,033 & 12,268 & 12,019 & 11,314 \\
\hline 0 to 2 years & 13,182 & 12,583 & 10,500 & 15,314 & 13,712 & 12,977 & 16,225 & 14,701 & 14,216 \\
\hline 3 to 5 years & 11,965 & 13,799 & 9,871 & 13,445 & 13,796 & 11,981 & 14,076 & 14,191 & 12,735 \\
\hline 6 to 9 years & 12,014 & 12,177 & 10,348 & 12,786 & 12,722 & 11,040 & 12,665 & 12,512 & 11,754 \\
\hline 10 years or more & 11,591 & 9,178 & 7,876 & 11,221 & 10,080 & 9,173 & 8,748 & 9,360 & 9,319 \\
\hline Unreported & 17,519 & 11,854 & 10,228 & 14,300 & 12,443 & 10,423 & 11,975 & 10,925 & 11,143 \\
\hline Auto & 11,851 & 11,003 & 9,529 & 12,802 & 12,220 & 10,665 & 12,038 & 11,596 & 11,154 \\
\hline 0 to 2 years & 12,685 & 11,992 & 10,065 & 15,047 & 13,471 & 12,522 & 15,524 & 14,054 & 14,230 \\
\hline 3 to 5 years & 11,287 & 14,235 & 8,898 & 12,841 & 13,681 & 11,471 & 13,652 & 13,471 & 12,465 \\
\hline 6 to 9 years & 11,809 & 11,264 & 10,836 & 12,693 & 12,183 & 10,588 & 12,387 & 12,028 & 11,336 \\
\hline 10 years or more & 11,079 & 8,861 & 8,383 & 11,415 & 10,610 & 9,282 & 8,928 & 9,433 & 9,477 \\
\hline Unreported & 17,117 & 11,407 & 11,254 & 15,074 & 12,448 & 10,153 & 11,369 & 11,292 & 11,425 \\
\hline Van & 13,754 & 14,728 & 7,991 & 15,486 & 13,307 & 12,237 & 14,278 & 13,400 & 12,587 \\
\hline 0 to 2 years & 16,147 & 19,632 & 8,130 & 16,118 & 14,270 & 15,848 & 17,759 & 15,862 & 15,495 \\
\hline 3 to 5 years & 16,790 & 12,969 & 11,890 & 16,647 & 14,863 & 13,365 & 15,129 & 15,526 & 14,105 \\
\hline 6 to 9 years & 11,453 & 14,718 & 10,315 & 14,660 & 13,292 & 12,389 & 13,313 & 13,597 & 13,389 \\
\hline 10 years or more & 13,181 & 12,594 & 6,385 & 14,606 & 10,086 & 9,737 & 10,685 & 10,274 & 10,119 \\
\hline Unreported & 10,471 & 18,233 & 8,453 & 13,897 & 19,268 & 13,635 & 17,465 & 11,547 & 14,513 \\
\hline SUV & 14,430 & 13,108 & 10,475 & 14,059 & 13,972 & 12,552 & 13,905 & 13,877 & 12,825 \\
\hline 0 to 2 years & 15,654 & 11,628 & 12,190 & 15,640 & 13,982 & 13,505 & 16,232 & 14,968 & 15,038 \\
\hline 3 to 5 years & 12,665 & 12,296 & 11,150 & 14,654 & 14,753 & 12,992 & 14,567 & 15,235 & 13,672 \\
\hline 6 to 9 years & 14,108 & 17,161 & 9,786 & 13,367 & 15,062 & 12,329 & 14,806 & 14,308 & 12,860 \\
\hline 10 years or more & 16,341 & 12,325 & 8,577 & 11,803 & 11,217 & 10,829 & 9,391 & 10,687 & 10,184 \\
\hline Unreported & ** & 15,521 & 9,457 & 16,292 & 11,579 & 11,770 & 16,851 & 11,117 & 13,167 \\
\hline Pickup Truck & ** & 9,597 & 9,467 & 12,786 & 12,291 & 11,242 & 12,078 & 12,465 & 11,329 \\
\hline 0 to 2 years & ** & 16,542 & 22,178 & 15,709 & 15,564 & 14,145 & 17,640 & 16,552 & 15,068 \\
\hline 3 to 5 years & ** & 6,833 & 12,504 & 15,312 & 13,240 & 12,917 & 15,001 & 15,420 & 13,233 \\
\hline 6 to 9 years & ** & 6,792 & 8,505 & 12,169 & 14,660 & 11,884 & 12,862 & 12,888 & 12,016 \\
\hline 10 years or more & ** & 7,071 & 7,422 & 10,688 & 9,330 & 8,742 & 8,348 & 9,536 & 9,544 \\
\hline Unreported & ** & 11,516 & 6,107 & 13,446 & 9,044 & 11,121 & 11,984 & 11,879 & 11,759 \\
\hline Other POV & $\star *$ & 1,182 & 1,270 & 5,110 & 3,626 & 2,885 & 7,626 & 5,094 & 3,459 \\
\hline 0 to 2 years & ** & 1,944 & 3,665 & 14,622 & 5,379 & 4,765 & 18,632 & 7,612 & 5,078 \\
\hline 3 to 5 years & ** & 2,500 & 1,777 & 5,407 & 4,238 & 3,144 & 12,882 & 8,478 & 4,077 \\
\hline 6 to 9 years & ** & 6,000 & 1,386 & 7,507 & 3,717 & 2,809 & 10,827 & 7,350 & 4,198 \\
\hline 10 years or more & ** & 1,042 & 479 & 3,197 & 2,406 & 2,060 & 4,726 & 3,101 & 2,470 \\
\hline Unreported & ** & 632 & 171 & 3,218 & 9,504 & 3,613 & 4,394 & 2,189 & 2,666 \\
\hline
\end{tabular}

* includes all Autos, SUVs, Vans, Pickup trucks and "Other POVs" not otherwise specified. ** sample size limited, very large standard errors. 
Table 3.13 Percentage of Household Vehicle Fleets, by Vehicle Type and Vehicle Age Group in 1995, 2001, and 2009

\begin{tabular}{|c|c|c|c|c|c|c|c|c|c|}
\hline & \multicolumn{3}{|c|}{ New York City } & \multicolumn{3}{|c|}{$\begin{array}{l}\text { Remainder of } \\
\text { New York State }\end{array}$} & \multicolumn{3}{|c|}{ Rest of United States } \\
\hline & 1995 & 2001 & 2009 & 1995 & 2001 & 2009 & 1995 & 2001 & 2009 \\
\hline \# HH Vehicles ('000s) & 1,600 & 2,085 & 1,943 & 6,322 & 7,461 & 7,201 & 168,145 & 193,041 & 202,357 \\
\hline All HH Vehicles & $100 \%$ & $100 \%$ & $100 \%$ & $100 \%$ & $100 \%$ & $100 \%$ & $100 \%$ & $100 \%$ & $100 \%$ \\
\hline 0 to 2 years & $12.9 \%$ & $17.7 \%$ & $17.9 \%$ & $17.1 \%$ & $18.3 \%$ & $16.5 \%$ & $15.8 \%$ & $15.6 \%$ & $12.0 \%$ \\
\hline 3 to 5 years & $14.3 \%$ & $18.5 \%$ & $19.3 \%$ & $21.8 \%$ & $23.2 \%$ & $23.8 \%$ & $20.9 \%$ & $21.3 \%$ & $20.6 \%$ \\
\hline 6 to 9 years & $37.5 \%$ & $21.8 \%$ & $24.2 \%$ & $31.7 \%$ & $24.6 \%$ & $28.0 \%$ & $27.5 \%$ & $23.5 \%$ & $25.8 \%$ \\
\hline 10 years or more & $29.1 \%$ & $36.6 \%$ & $33.2 \%$ & $26.9 \%$ & $31.2 \%$ & $28.6 \%$ & $33.1 \%$ & $36.2 \%$ & $37.9 \%$ \\
\hline Unreported & $6.2 \%$ & $5.4 \%$ & $5.5 \%$ & $2.6 \%$ & $2.7 \%$ & $3.2 \%$ & $2.7 \%$ & $3.4 \%$ & $3.7 \%$ \\
\hline Auto & $87.4 \%$ & $75.7 \%$ & $64.7 \%$ & $72.3 \%$ & $63.2 \%$ & $56.2 \%$ & $64.7 \%$ & $56.4 \%$ & $49.7 \%$ \\
\hline 0 to 2 years & $10.5 \%$ & $11.4 \%$ & $11.0 \%$ & $11.2 \%$ & $10.8 \%$ & $8.6 \%$ & $9.4 \%$ & $7.7 \%$ & $5.8 \%$ \\
\hline 3 to 5 years & $11.8 \%$ & $13.9 \%$ & $11.2 \%$ & $16.2 \%$ & $13.6 \%$ & $12.2 \%$ & $13.7 \%$ & $11.5 \%$ & $9.4 \%$ \\
\hline 6 to 9 years & $33.9 \%$ & $17.1 \%$ & $16.5 \%$ & $23.5 \%$ & $16.4 \%$ & $16.2 \%$ & $18.9 \%$ & $14.1 \%$ & $12.9 \%$ \\
\hline 10 years or more & $27.1 \%$ & $29.4 \%$ & $22.6 \%$ & $19.7 \%$ & $20.8 \%$ & $17.4 \%$ & $21.0 \%$ & $21.4 \%$ & $19.8 \%$ \\
\hline Unreported & $4.2 \%$ & $3.8 \%$ & $3.4 \%$ & $1.8 \%$ & $1.6 \%$ & $1.7 \%$ & $1.7 \%$ & $1.7 \%$ & $1.7 \%$ \\
\hline Van & $5.6 \%$ & $9.3 \%$ & $9.9 \%$ & $7.8 \%$ & $10.1 \%$ & $8.9 \%$ & $8.0 \%$ & $9.0 \%$ & $8.2 \%$ \\
\hline 0 to 2 years & $0.9 \%$ & $1.5 \%$ & $1.6 \%$ & $2.3 \%$ & $1.9 \%$ & $1.0 \%$ & $1.7 \%$ & $1.5 \%$ & $0.7 \%$ \\
\hline 3 to 5 years & $1.2 \%$ & $1.6 \%$ & $1.3 \%$ & $1.7 \%$ & $2.7 \%$ & $2.1 \%$ & $2.1 \%$ & $2.1 \%$ & $1.8 \%$ \\
\hline 6 to 9 years & $1.8 \%$ & $2.4 \%$ & $1.1 \%$ & $2.4 \%$ & $2.9 \%$ & $2.8 \%$ & $2.2 \%$ & $2.5 \%$ & $2.5 \%$ \\
\hline 10 years or more & $1.3 \%$ & $3.2 \%$ & $5.1 \%$ & $1.3 \%$ & $2.4 \%$ & $2.7 \%$ & $1.8 \%$ & $2.6 \%$ & $3.0 \%$ \\
\hline Unreported & $0.4 \%$ & $0.6 \%$ & $0.9 \%$ & $0.2 \%$ & $0.3 \%$ & $0.3 \%$ & $0.2 \%$ & $0.4 \%$ & $0.3 \%$ \\
\hline SUV & $5.3 \%$ & $12.4 \%$ & $22.6 \%$ & $7.3 \%$ & $11.9 \%$ & $21.1 \%$ & $7.0 \%$ & $12.1 \%$ & $19.4 \%$ \\
\hline 0 to 2 years & $1.4 \%$ & $4.3 \%$ & $5.0 \%$ & $2.0 \%$ & $3.5 \%$ & $5.3 \%$ & $1.9 \%$ & $3.1 \%$ & $3.3 \%$ \\
\hline 3 to 5 years & $1.4 \%$ & $2.8 \%$ & $6.5 \%$ & $1.7 \%$ & $3.8 \%$ & $6.5 \%$ & $1.7 \%$ & $3.5 \%$ & $5.5 \%$ \\
\hline 6 to 9 years & $1.7 \%$ & $2.1 \%$ & $5.7 \%$ & $2.0 \%$ & $2.5 \%$ & $5.2 \%$ & $1.7 \%$ & $2.6 \%$ & $5.3 \%$ \\
\hline 10 years or more & $0.7 \%$ & $2.5 \%$ & $4.2 \%$ & $1.4 \%$ & $1.9 \%$ & $3.6 \%$ & $1.6 \%$ & $2.6 \%$ & $4.7 \%$ \\
\hline Unreported & ** & $0.6 \%$ & $1.1 \%$ & $0.2 \%$ & $0.3 \%$ & $0.5 \%$ & $0.2 \%$ & $0.3 \%$ & $0.5 \%$ \\
\hline Pickup Truck & ** & $1.0 \%$ & $1.2 \%$ & $10.8 \%$ & $11.6 \%$ & $10.6 \%$ & $18.3 \%$ & $19.0 \%$ & $18.3 \%$ \\
\hline 0 to 2 years & ** & $0.3 \%$ & $0.1 \%$ & $1.5 \%$ & $1.7 \%$ & $1.2 \%$ & $2.6 \%$ & $2.9 \%$ & $1.6 \%$ \\
\hline 3 to 5 years & ** & $0.1 \%$ & $0.2 \%$ & $2.0 \%$ & $2.7 \%$ & $2.3 \%$ & $3.3 \%$ & $3.6 \%$ & $3.1 \%$ \\
\hline 6 to 9 years & ** & $0.1 \%$ & $0.4 \%$ & $3.5 \%$ & $2.5 \%$ & $3.0 \%$ & $4.4 \%$ & $3.9 \%$ & $4.2 \%$ \\
\hline 10 years or more & ** & $0.5 \%$ & $0.5 \%$ & $3.6 \%$ & $4.4 \%$ & $3.7 \%$ & $7.4 \%$ & $8.0 \%$ & $8.6 \%$ \\
\hline Unreported & ** & $0.0 \%$ & $0.0 \%$ & $0.3 \%$ & $0.3 \%$ & $0.4 \%$ & $0.6 \%$ & $0.7 \%$ & $0.8 \%$ \\
\hline Other POV & ** & $1.7 \%$ & $1.7 \%$ & $1.7 \%$ & $3.1 \%$ & $3.2 \%$ & $2.0 \%$ & $3.5 \%$ & $4.3 \%$ \\
\hline 0 to 2 years & ** & $0.2 \%$ & $0.2 \%$ & $0.1 \%$ & $0.4 \%$ & $0.4 \%$ & $0.1 \%$ & $0.5 \%$ & $0.6 \%$ \\
\hline 3 to 5 years & ** & $0.1 \%$ & $0.1 \%$ & $0.2 \%$ & $0.4 \%$ & $0.7 \%$ & $0.2 \%$ & $0.5 \%$ & $0.8 \%$ \\
\hline 6 to 9 years & ** & $0.1 \%$ & $0.5 \%$ & $0.3 \%$ & $0.4 \%$ & $0.7 \%$ & $0.4 \%$ & $0.5 \%$ & $0.8 \%$ \\
\hline 10 years or more & ** & $0.9 \%$ & $0.8 \%$ & $0.9 \%$ & $1.6 \%$ & $1.2 \%$ & $1.2 \%$ & $1.7 \%$ & $1.8 \%$ \\
\hline Unreported & ** & $0.4 \%$ & $0.0 \%$ & $0.1 \%$ & $0.2 \%$ & $0.3 \%$ & $0.1 \%$ & $0.3 \%$ & $0.4 \%$ \\
\hline
\end{tabular}

* includes all Autos, SUVs, Vans, Pickup trucks and "Other POVs" not otherwise specified ** Sample size limited, very large standard errors.

\subsubsection{Energy and Greenhouse Gas Emissions Associated With Vehicle Travel}

As described in Chapter 2 of this report, New York households on the average emit significantly fewer travel generated carbon dioxide emissions annually than do residents in the rest of the nation. Table 3.14 and Figure 3.18 show that much of this difference is attributable to the travel characteristics of NYC households, who as reported above have shorter average trip distances, who walk a good deal more to activities, and who make much greater use of public transit modes for their daily travel needs. 
Table 3.14 Average Annual Emissions of Carbon Dioxide* from Household Travel Summed over all Modes of Travel

\begin{tabular}{|c|c|c|c|c|c|c|}
\hline & \multicolumn{2}{|c|}{ New York City } & \multicolumn{2}{|c|}{$\begin{array}{c}\text { Remainder of } \\
\text { NYS }\end{array}$} & \multicolumn{2}{|c|}{$\begin{array}{c}\text { Rest of United } \\
\text { States }\end{array}$} \\
\hline & 2001 & 2009 & 2001 & 2009 & 2001 & 2009 \\
\hline Average $\mathrm{CO} 2$ Emissions $(\mathrm{kg}) / \mathrm{HH}$ & 3,603 & 3,070 & 8,779 & 8,045 & 9,247 & 9,201 \\
\hline 0 Workers & 1,681 & 1,347 & 3,700 & 3,886 & 4,128 & 4,599 \\
\hline 1 Workers & 2,841 & 2,790 & 7,378 & 7,375 & 7,608 & 8,537 \\
\hline 2 Workers & 4,654 & 5,267 & 12,156 & 11,592 & 12,298 & 13,336 \\
\hline 3 or more Workers & 9,388 & 7,475 & 14,650 & 16,027 & 17,137 & 19,073 \\
\hline Average $\mathrm{CO} 2$ Emissions $(\mathrm{kg}) / \mathrm{HH}$ & 3,603 & 3,070 & 8,779 & 8,045 & 9,247 & 9,201 \\
\hline 0 Drivers & 578 & 319 & 354 & 102 & 238 & 242 \\
\hline 1 Drivers & 3,049 & 1,821 & 4,600 & 4,102 & 4,774 & 4,872 \\
\hline 2 Drivers & 5,697 & 4,738 & 10,721 & 9,589 & 10,947 & 10,934 \\
\hline 3 or more Drivers & 11,293 & 8,071 & 14,966 & 14,652 & 16,261 & 16,882 \\
\hline Average CO2 Emissions $(\mathrm{kg}) / \mathrm{HH}$ & 3,603 & 3,070 & 8,779 & 8,045 & 9,247 & 9,201 \\
\hline 0 Vehicles & 862 & 927 & 374 & 644 & 356 & 539 \\
\hline 1 Vehicles & 4,896 & 4,214 & 4,548 & 4,016 & 4,344 & 4,356 \\
\hline 2 Vehicles & 8,235 & 7,789 & 10,754 & 9,584 & 10,275 & 10,125 \\
\hline 3 or more Vehicles & 17,707 & 12,569 & 15,364 & 15,588 & 16,324 & 17,132 \\
\hline
\end{tabular}

Note: Direct, vehicle operating emissions only, no "upstream" vehicle or fuel production or infrastructure provision related emissions are included. Air travel is excluded. The emissions rates used for each NHTS mode of travel are reported in Appendix D, and make use of US EPA recommended fuel use-to$\mathrm{CO} 2$ emissions conversions, and emissions rate estimates derived from the Federal Transit Administration's rail, bus and ferry transit energy consumption database and average vehicle fuel efficiencies reported by, or derived from Federal Highway Administration, American Bus Association, American School Bus Association, and the New York City Taxi and Limousine Commission estimates. Equivalent data sources for 1995 were not available or not compatible with 2001 and 2009 data sources for all modes. 


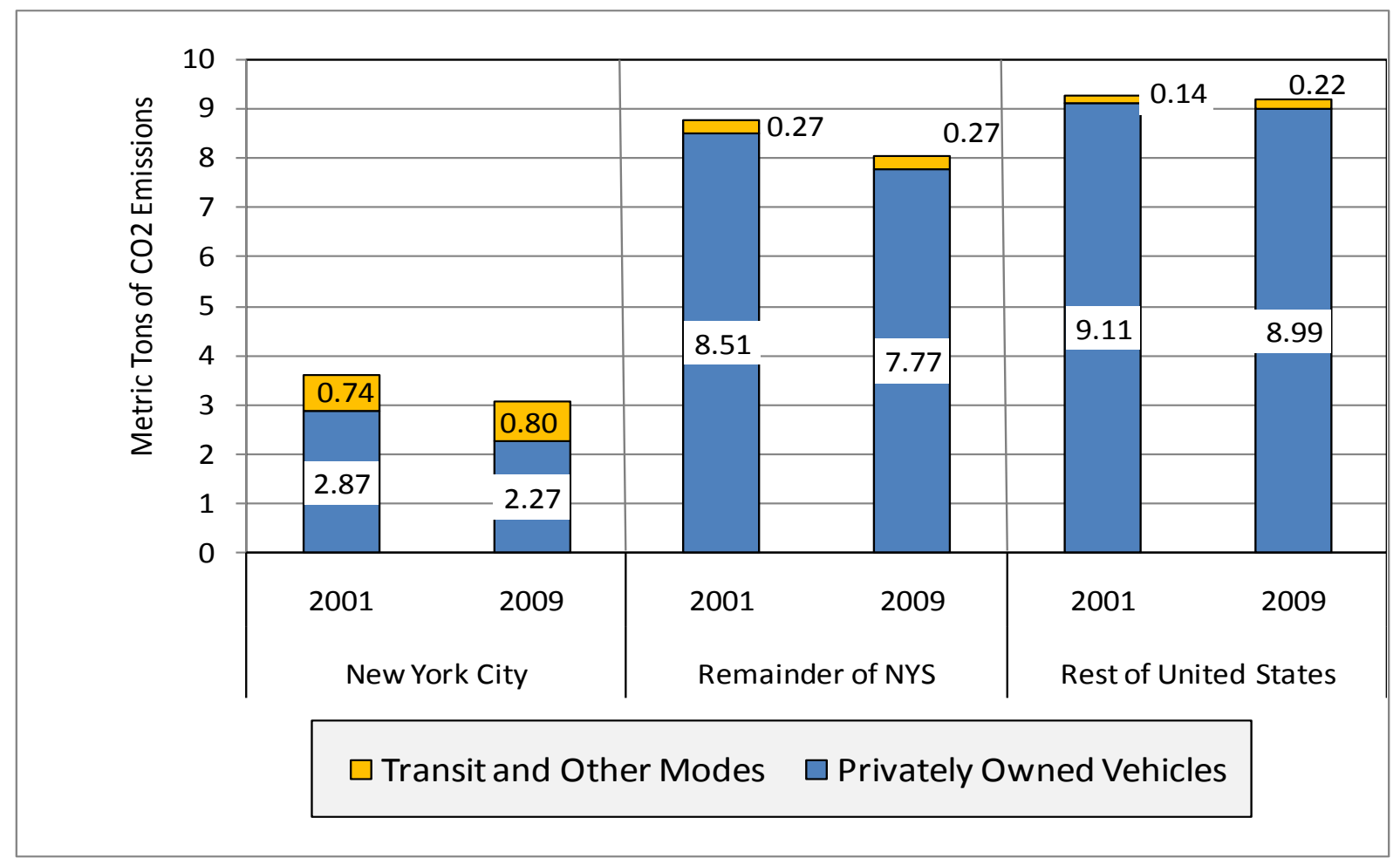

Figure 3.18 Average Annual Emissions of Carbon Dioxide (Metric Tons of CO2) from Household Travel* in 2001 and 2009.

Note: * direct, vehicle operating emissions only, no "upstream" emissions associated with fuel or vehicle production or infrastructure supply included. See Notes below Table 3.14 for data sources.

While the average annual travel-related $\mathrm{CO} 2$ emissions estimated across all of the state's households in 2009 was 5.9 metric tons (cf. Table 2.14), the average for NYC households' travel was less than 3.1 metric tons. For households in the remainder of NYS this estimate is just over 8 metric tons. For the rest of the nation average annual emissions per household are estimated to be somewhat higher, at about 9.2 metric tons. This means that on average, NYC households in 2009 emitted less than $40 \%$ of the personal travel related $\mathrm{CO} 2$ as emitted by households in the rest of the state, and only one third the emissions of households in the rest of the nation.

The only NYC household grouping to have higher annual CO2 emissions from travel is the zero-vehicles owned category. As described above (cf. Table 3.6 and Figures 3.7, 3.8 and 3.9), many NYC households in this category have higher incomes than they do in other regions, and are likely on the average to spend more on travel than their counterparts in the rest of the state or nation.

Between 2001 and 2009, NYC emissions rates also appear to have declined, by about half a metric ton (from 3.6 to 3.1 metric tons), and by about 0.8 metric tons in the rest of NYS. In comparison, there appears to have been very little if any change in the emissions rate for the rest 
of the nation over this period. As Chapter 4 of this report confirms, household travel emission rates are significantly lower in regions with higher residential population densities, such as those associated with a large fraction of NYC's residential household population. The decline in the CO2 emissions rate since 2001 in NYC results from a combination of the lower VMT rates and the increased use of walk and transit trips reported above.

\subsection{COMMUTING COMPARISONS}

Providing efficient forms of travel to work is an important contribution to a state's, and the nation's economy. Limiting the length of time spent commuting daily is also seen by many people as an important quality of life issue.

\subsubsection{Commuting Trip Frequencies and Trip Lengths}

Daily commute trip frequencies have declined since 1995, so that in 2009 NYC daily commute trip frequencies dipped just below one trip (0.95 trips) per worker. In the rest of the state and the nation this rate has also declined since 1995, but did not change significantly between 2001 and 2009, at just over 1.1 commute trips per worker (Table 3.15).

Table 3.15 Daily Commute Statistics by Mode of Transportation in New York City, Remainder of New York State, and Rest of the United States ${ }^{a}$

\begin{tabular}{|c|c|c|c|c|c|c|c|c|c|}
\hline & \multicolumn{3}{|c|}{ New York City } & \multicolumn{3}{|c|}{$\begin{array}{c}\text { Remainder of } \\
\text { New York State }\end{array}$} & \multicolumn{3}{|c|}{ Rest of United States } \\
\hline & 1995 & 2001 & 2009 & 1995 & 2001 & 2009 & 1995 & 2001 & 2009 \\
\hline Commute Person Trips per & & & & & & & & & \\
\hline Worker & 1.26 & 1.08 & 0.95 & 1.34 & 1.14 & 1.14 & 1.40 & 1.15 & 1.11 \\
\hline$\%$ SOV & 25.4 & 25.0 & 19.9 & 75.4 & 76.1 & 76.7 & 75.7 & 77.7 & 78.4 \\
\hline$\% \mathrm{MOV}$ & 9.5 & 9.7 & 7.7 & 14.9 & 14.7 & 13.7 & 16.4 & 16.4 & 14.6 \\
\hline$\%$ Amtrak & 0.0 & 1.2 & 0.8 & 0.0 & 0.4 & 0.1 & 0.0 & 0.1 & 0.0 \\
\hline$\%$ Commuter Train & 5.6 & 1.4 & 4.1 & 2.2 & 2.1 & 1.3 & 0.7 & 0.3 & 0.3 \\
\hline$\%$ Subway & 26.2 & 30.3 & 28.7 & 0.7 & 0.7 & 0.3 & 0.7 & 0.5 & 0.3 \\
\hline$\%$ Other Public Transit ${ }^{\mathrm{b}}$ & 11.9 & 12.2 & 14.9 & 1.5 & 1.0 & 1.9 & 1.4 & 1.6 & 1.7 \\
\hline \% Walk & 13.5 & 16.0 & 17.5 & 2.2 & 3.8 & 3.3 & 2.1 & 2.4 & 2.7 \\
\hline$\%$ Other & 5.6 & 4.2 & 6.5 & 1.5 & 1.2 & 2.3 & 1.4 & 0.9 & 1.8 \\
\hline$\%$ Unreported & 2.4 & 0.0 & 0.0 & 1.5 & 0.2 & 0.2 & 1.6 & 0.1 & 0.2 \\
\hline Commute PMT per Worker & 10.70 & 7.48 & 6.17 & 16.04 & 13.18 & 12.89 & 16.08 & 13.78 & 12.99 \\
\hline$\%$ SOV & 33.6 & 33.5 & 30.7 & 74.8 & 77.4 & 79.7 & 76.8 & 77.7 & 81.7 \\
\hline$\% \mathrm{MOV}$ & 13.7 & 13.0 & 15.5 & 15.5 & 12.8 & 12.6 & 17.2 & 16.1 & 13.5 \\
\hline$\%$ Other POV & 0.2 & & 0.0 & 0.0 & & 0.0 & 0.1 & & 0.0 \\
\hline$\%$ Amtrak & 0.0 & 1.4 & 0.2 & 0.1 & 0.9 & 0.8 & 0.1 & 0.3 & 0.0 \\
\hline$\%$ Commuter Train & 6.6 & 2.3 & 3.4 & 5.5 & 5.3 & 3.0 & 0.7 & 0.7 & 0.5 \\
\hline \% Subway & 26.2 & 35.1 & 28.1 & 0.9 & 1.0 & 0.5 & 0.4 & 0.5 & 0.2 \\
\hline$\%$ Other Public Transit & 9.2 & 7.7 & 11.9 & 1.4 & 0.6 & 1.1 & 1.5 & 1.0 & 1.1 \\
\hline \% Walk & 1.7 & 2.8 & 4.7 & 0.1 & 0.4 & 0.2 & 0.1 & 0.2 & 0.2 \\
\hline$\%$ Other & 8.1 & 4.1 & 5.5 & 0.9 & 1.3 & 1.9 & 2.2 & 3.5 & 2.7 \\
\hline$\%$ Unreported & 0.7 & 0.0 & 0.0 & 0.9 & 0.3 & 0.3 & 0.9 & 0.1 & 0.2 \\
\hline
\end{tabular}


Commuting trip mode shares for NYC residents are very different from those in the rest of the state and nation (see Figures 3.19, 3.20 and 3.21 below). In 2009, as in 2001, almost one in every three commute trips, and one in every three miles of travel in NYC was taken on the subway, while these percentages are less than $1 \%$ elsewhere (of course, most areas do not have a subway). Walking was the most common non-motorized mode in NYC for commuters, and has continued to grow with each NHTS survey in terms of both daily trips taken (from $13.5 \%$ to $17.5 \%$ of commutes between 1995 and 2009) and daily person miles of travel (from 1.7\% to 4.7 $\%$ of NYC worker PMT during the same time). While average daily PMT by commuters continue to fall across the board, first from 1995 to 2001 and then from 2001 to 2009, this decline was more noticeable in percentage terms in NYC, dropping 43\% between 1995 and 2001 and a further $21 \%$ between 2001 and 2009 (for a 14 year decline of $73 \%$ from 1995 level).

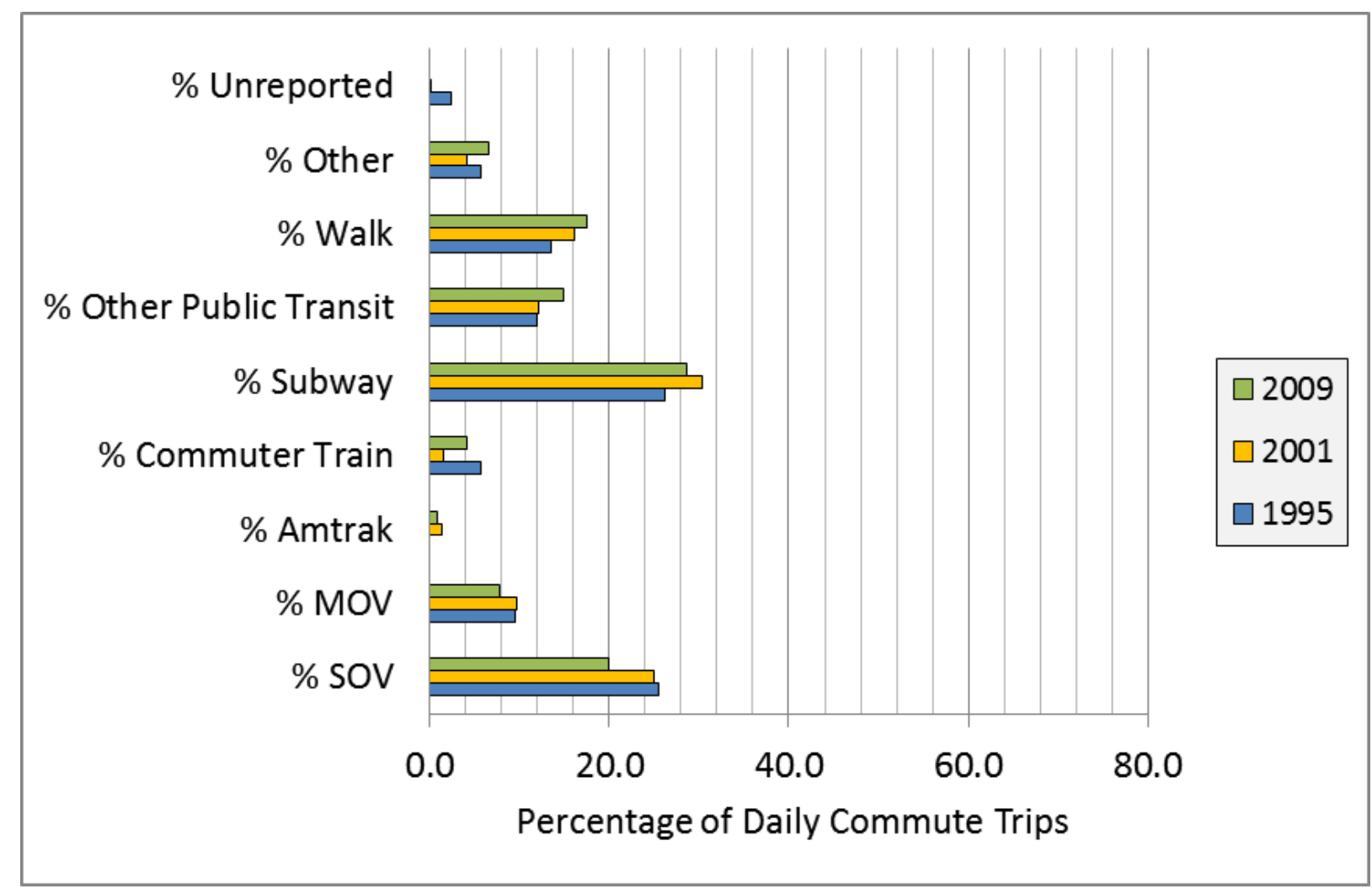

Figure 3.19 Trends in Daily Commute Trip Mode Shares for New York City, Remainder of New York State, and Rest of the United States: 1995, 2001, and 2009, New York City. 


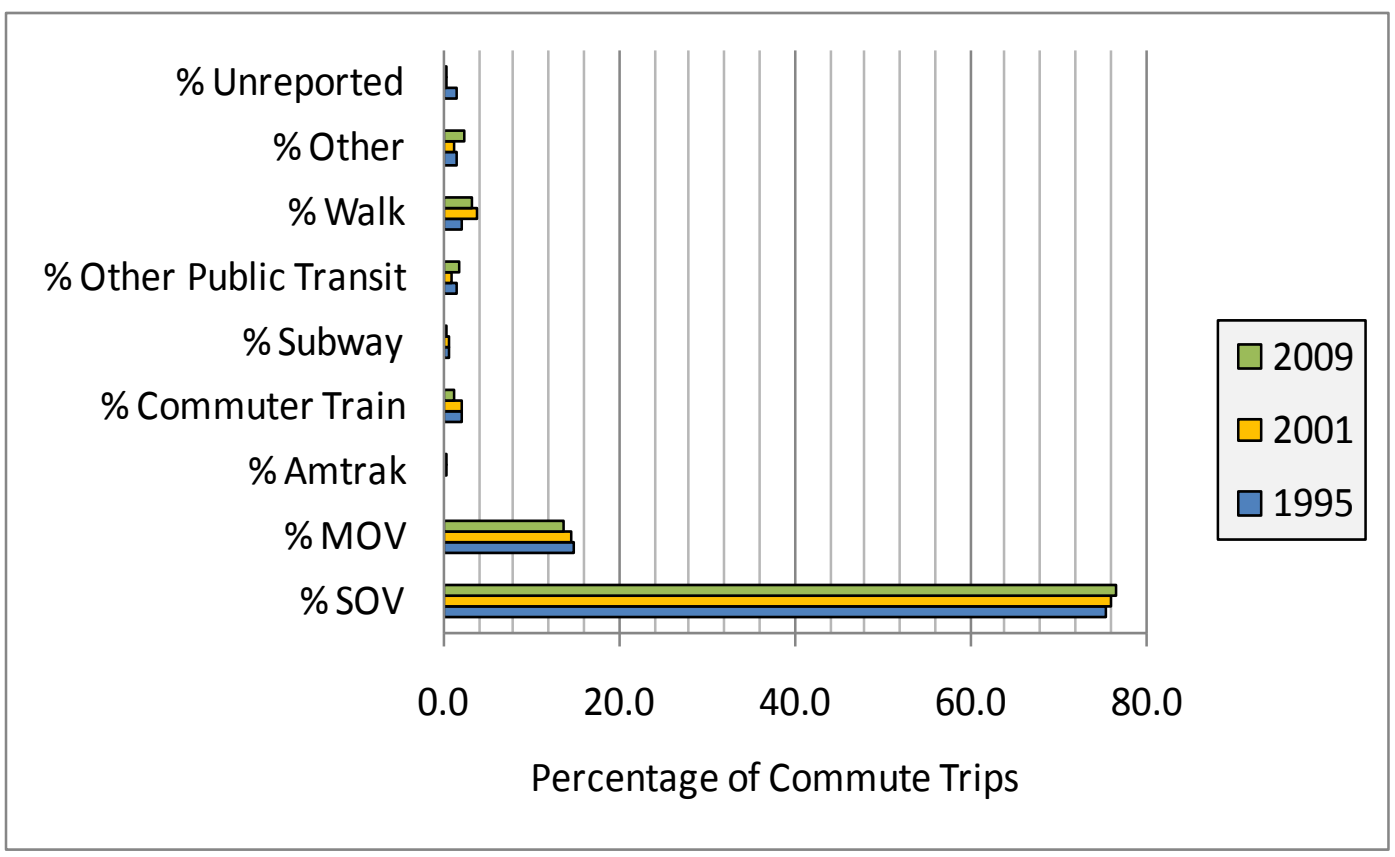

Figure 3.20 Trends in Daily Commute Trip Mode Shares for New York City, Remainder of New York State, and Rest of the United States: 1995, 2001, and 2009, Remainder of New York State.

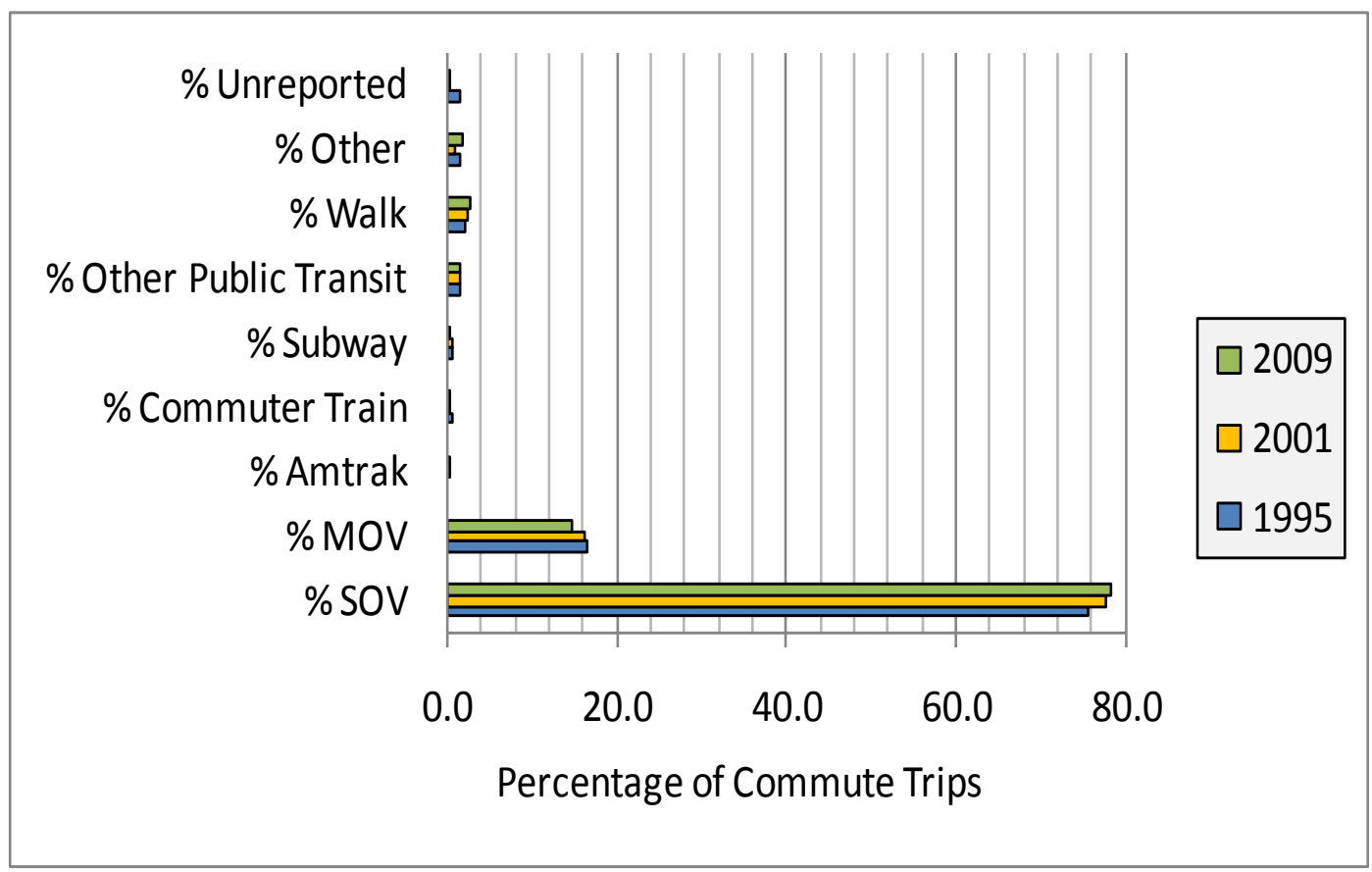

Figure 3.21 Trends in Daily Commute Trip Mode Shares for New York City, Remainder of New York State, and Rest of the United States: 1995, 2001, and 2009, Rest of the United States. 


\subsubsection{Commuting Times and Commuting Speeds}

Table 3.16 compares average commuting distances, travel times, and speeds for privately owned and publicly operated vehicles in each of the three regions and for each survey year. Based on these statistics, Figures 3.22, 3.23 and 3.24 below shows the differences in average private vehicle commute distances, travel times, and average speeds between NYC commuters and those in the rest of the state and nation, for each survey year. The principal conclusion to be drawn from these three graphs is that while average commute distances remained similar across all three geographic regions in each survey year, the average speeds remained much lower, and therefore the average commute times remained much higher for $\mathrm{NYC}$ workers than for workers elsewhere. In all three survey years NYC commuters were taking about 10 minutes longer on average to get to work than commuters elsewhere. By comparison, average commute trip speeds and times as well as average commute trip lengths for the rest of the state are very similar to those in the rest of the country, when looked at within each survey year.

Table 3.16 Commuting Distances, Times, and Speeds for Private and Public Modes of Transportation in 1995, 2001, and 2009

\begin{tabular}{|c|c|c|c|c|c|c|c|c|c|}
\hline & \multicolumn{3}{|c|}{ New York City } & \multicolumn{3}{|c|}{$\begin{array}{l}\text { Remainder of } \\
\text { New York State }\end{array}$} & \multicolumn{3}{|c|}{ Rest of United States } \\
\hline & 1995 & 2001 & 2009 & 1995 & 2001 & 2009 & 1995 & 2001 & 2009 \\
\hline \multicolumn{10}{|c|}{ Length (miles) } \\
\hline TOTAL & 9.7 & 8.0 & 7.8 & 12.1 & 11.8 & 11.4 & 11.7 & 12.2 & 11.9 \\
\hline Private & 12.2 & 9.9 & 11.5 & 12.1 & 11.7 & 11.6 & 11.8 & 12.1 & 12.1 \\
\hline Public & 10.4 & 9.3 & 7.9 & 24.1 & 24.4 & 15.9 & 13.0 & 11.9 & 10.7 \\
\hline \multicolumn{10}{|c|}{ Time (minutes) } \\
\hline TOTAL & 33.0 & 40.2 & 40.2 & 21.4 & 24.0 & 24.0 & 20.2 & 23.1 & 23.5 \\
\hline Private & 30.2 & 31.4 & 33.5 & 20.8 & 21.9 & 22.9 & 20.0 & 22.4 & 22.8 \\
\hline Public & 43.4 & 55.8 & 51.0 & 51.0 & 72.5 & 58.9 & 39.9 & 54.2 & 53.5 \\
\hline \multicolumn{10}{|c|}{ Miles per Hour } \\
\hline TOTAL & 19.7 & 15.8 & 15.8 & 34.1 & 31.2 & 29.9 & 35.0 & 32.8 & 31.5 \\
\hline Private & 24.3 & 18.8 & 20.7 & 34.9 & 32.1 & 30.4 & 35.5 & 32.5 & 31.9 \\
\hline Public & 14.3 & & & 27.0 & & & 21.1 & & \\
\hline
\end{tabular}

Notes: TOTAL trips include walk and other modal trips. Comparable public transit speeds are not readily computed from the 2001 and 2009 surveys. 


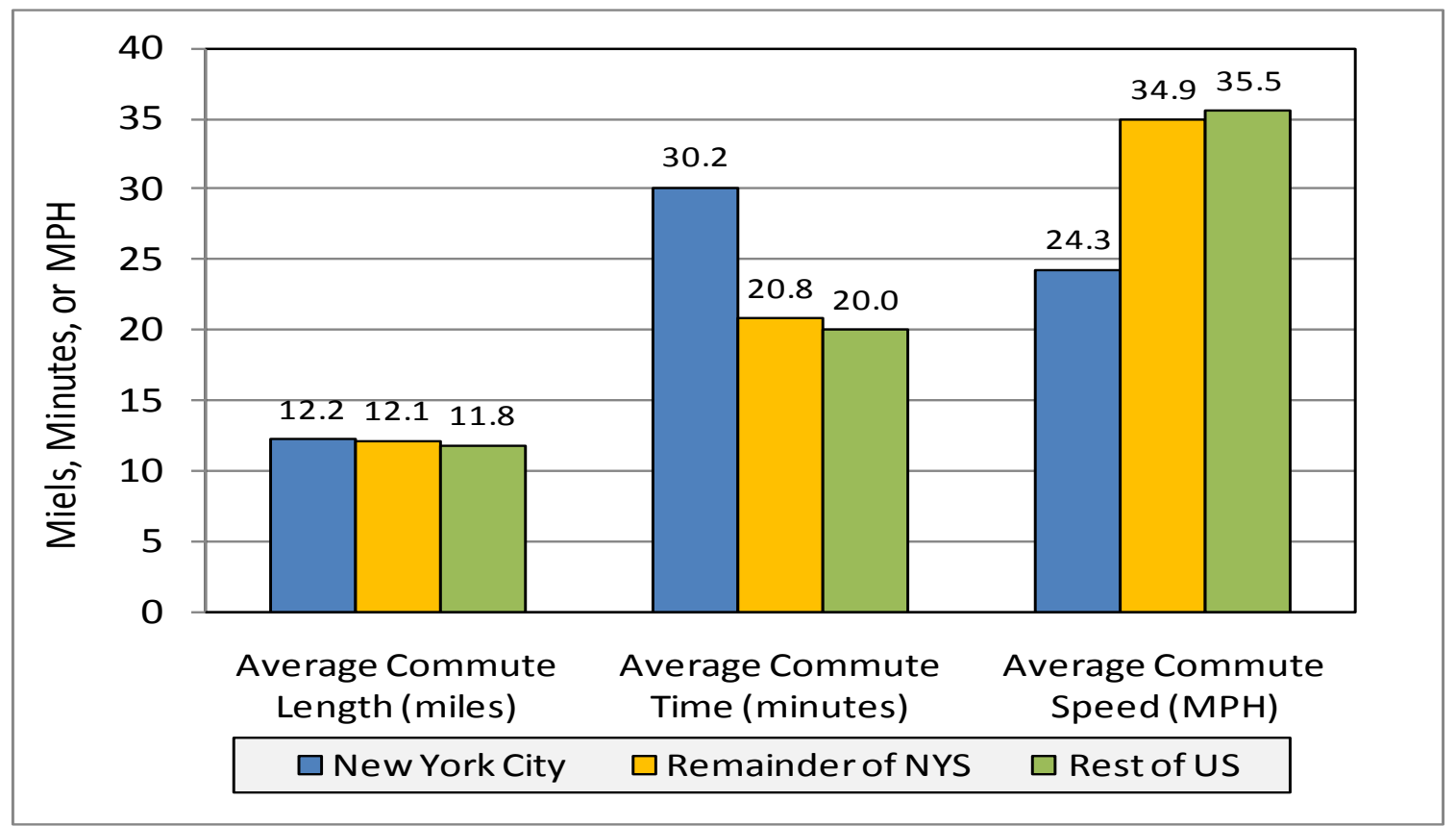

Figure 3.22 Commute Patterns on Privately-Owned Vehicles New York City, Remainder of New York State, and Rest of the United States, Year $=1995$.

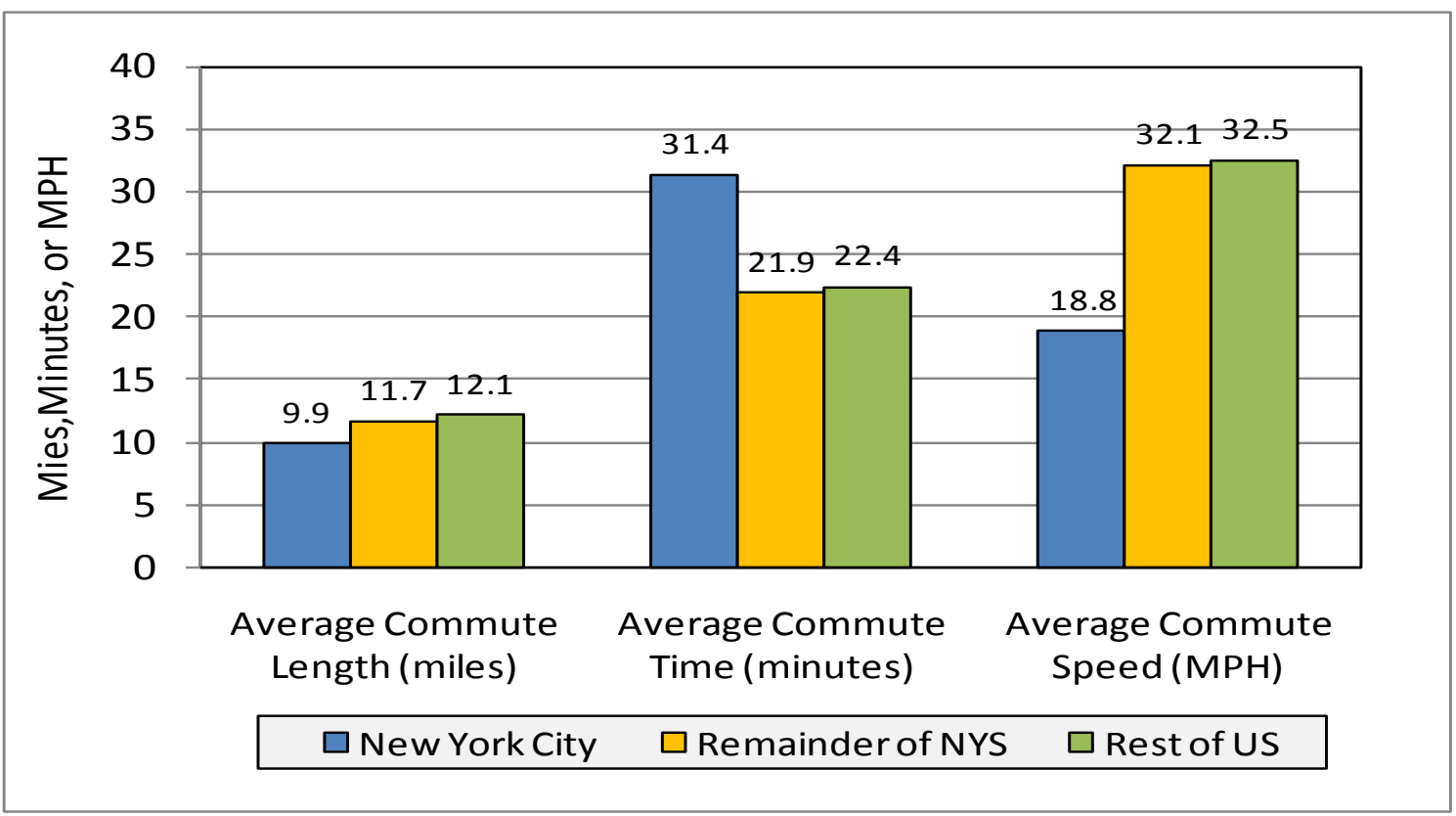

Figure 3.23 Commute Patterns on Privately-Owned Vehicles New York City, Remainder of New York State, and Rest of the United States, Year $=2001$. 


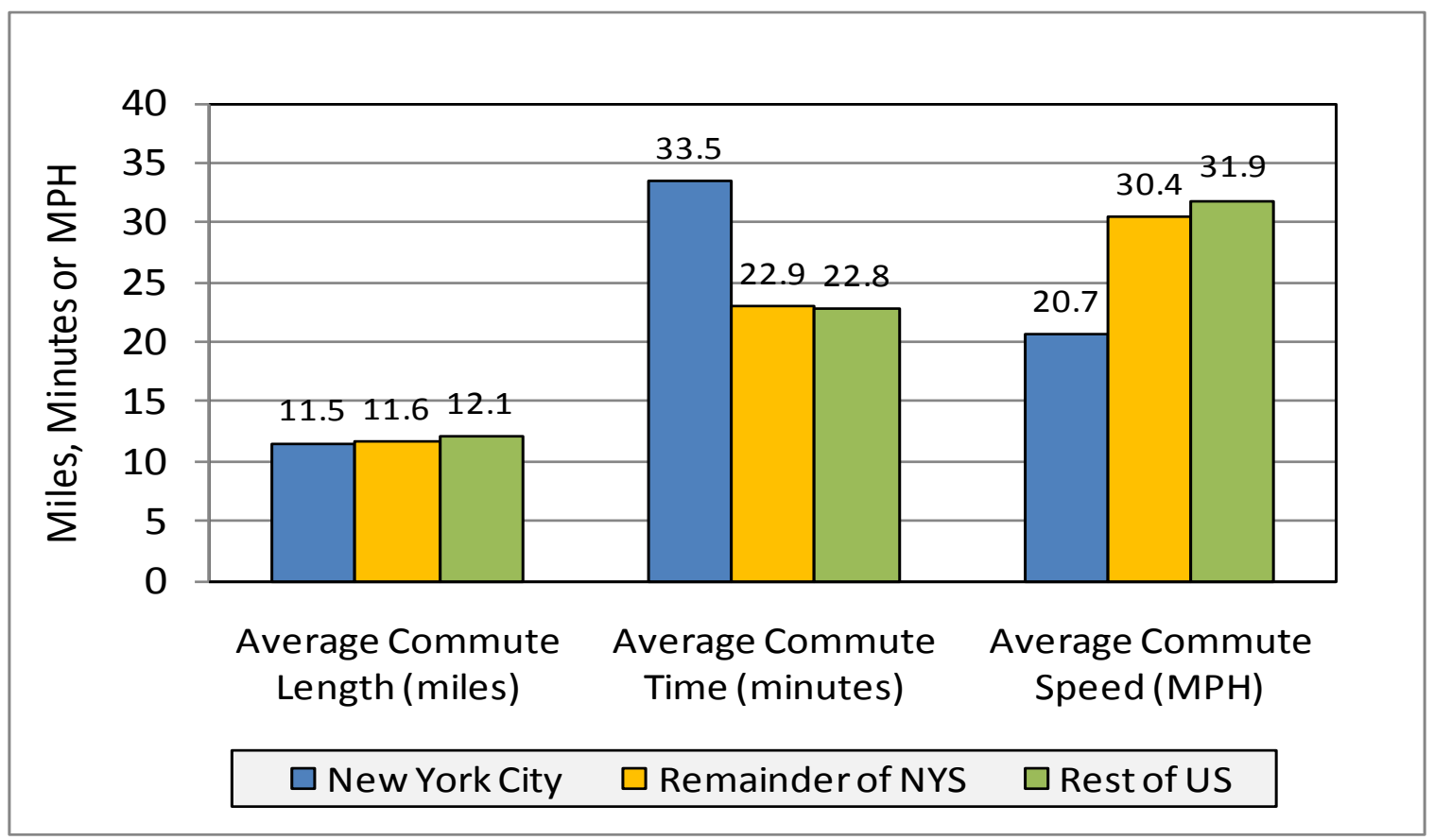

Figure 3.24 Commute Patterns on Privately-Owned Vehicles New York City, Remainder of New York State, and Rest of the United States, Year $=2009$.

Differences in average privately owned vehicle trip speeds were marginal between 2001 and 2009 in all three geographic regions, once standard errors on these estimates are taken into account. Average travel time for these NYC commuters did increase slightly however, due to a significantly longer average trip length (up from 9.9 miles in 2001 to 11.5 miles in 2009: see Table 3.16). In 1995 the average speed for NYC privately owned vehicle commutes was over 24 mpg. But the average commute distance was also longer, at 12.2 miles.

Although commute trips on public transit by NYC residents were noticeably shorter than those by privately-owned vehicles (at 7.9 miles versus 11.5 miles in 2009: see Table 3.16), they take a good deal longer, on average, to complete (at 33.5 minutes versus 51 minutes). Figures 3.25, 3.26 and 3.27 show these public transit trip times to be much higher for commuters in the rest of NYS than in either NYC or the rest of the nation. In 2009 this across-regions difference has been reduced significantly, due in large part to these remainder of NYS transit trips reporting a much reduced average trip length (from 24.2 to 15.9 miles) and a subsequent reduction in average commute time from 72.5 minutes to 58.9 minutes from 2001 to 2009 . It is unclear to what extent this large change is a result of changes in data reporting between the two surveys. 


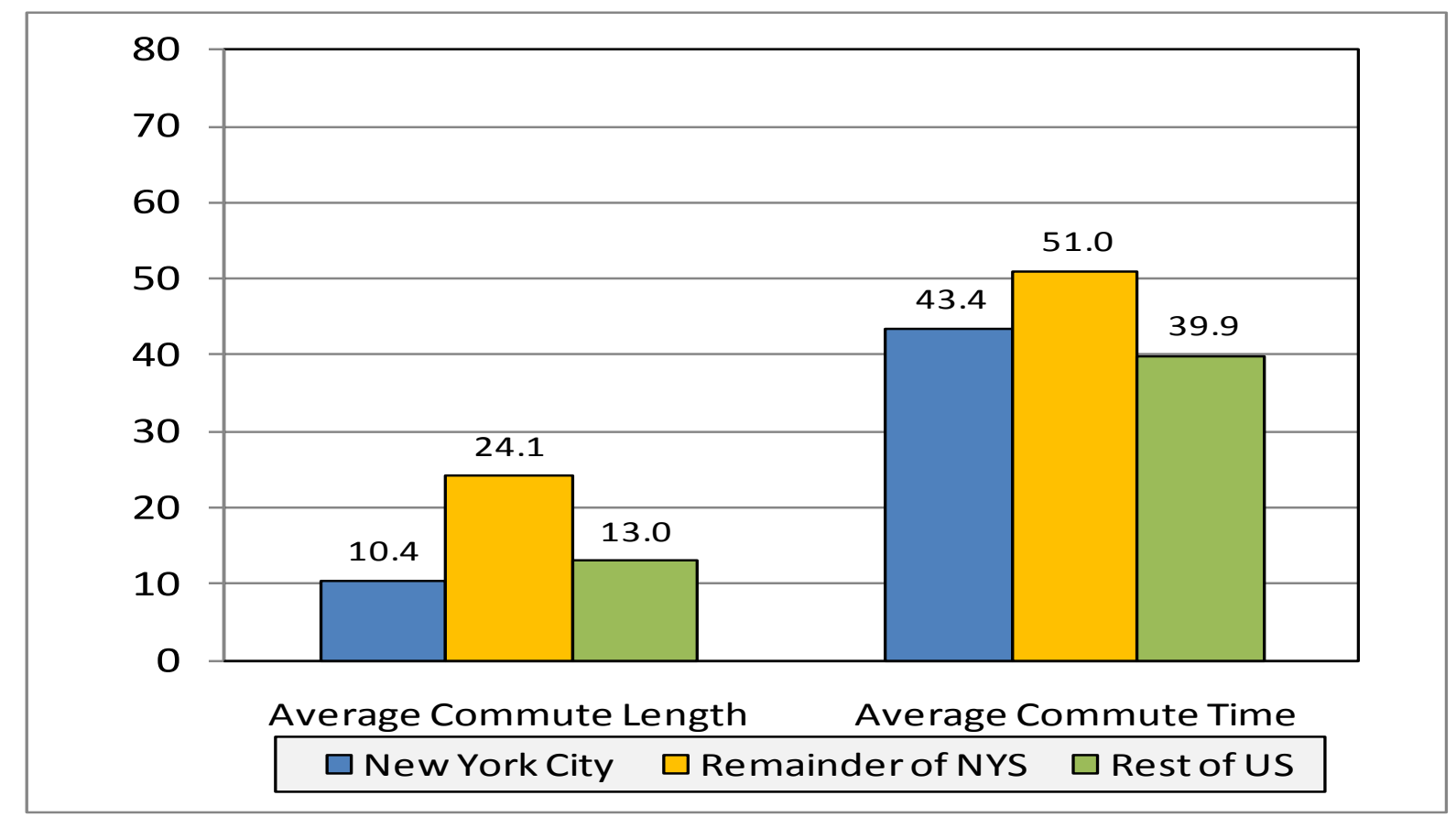

Figure 3.25 Commute Patterns on Public Transit in New York City, Remainder of New York State, and Rest of the United States, Year = 1995.

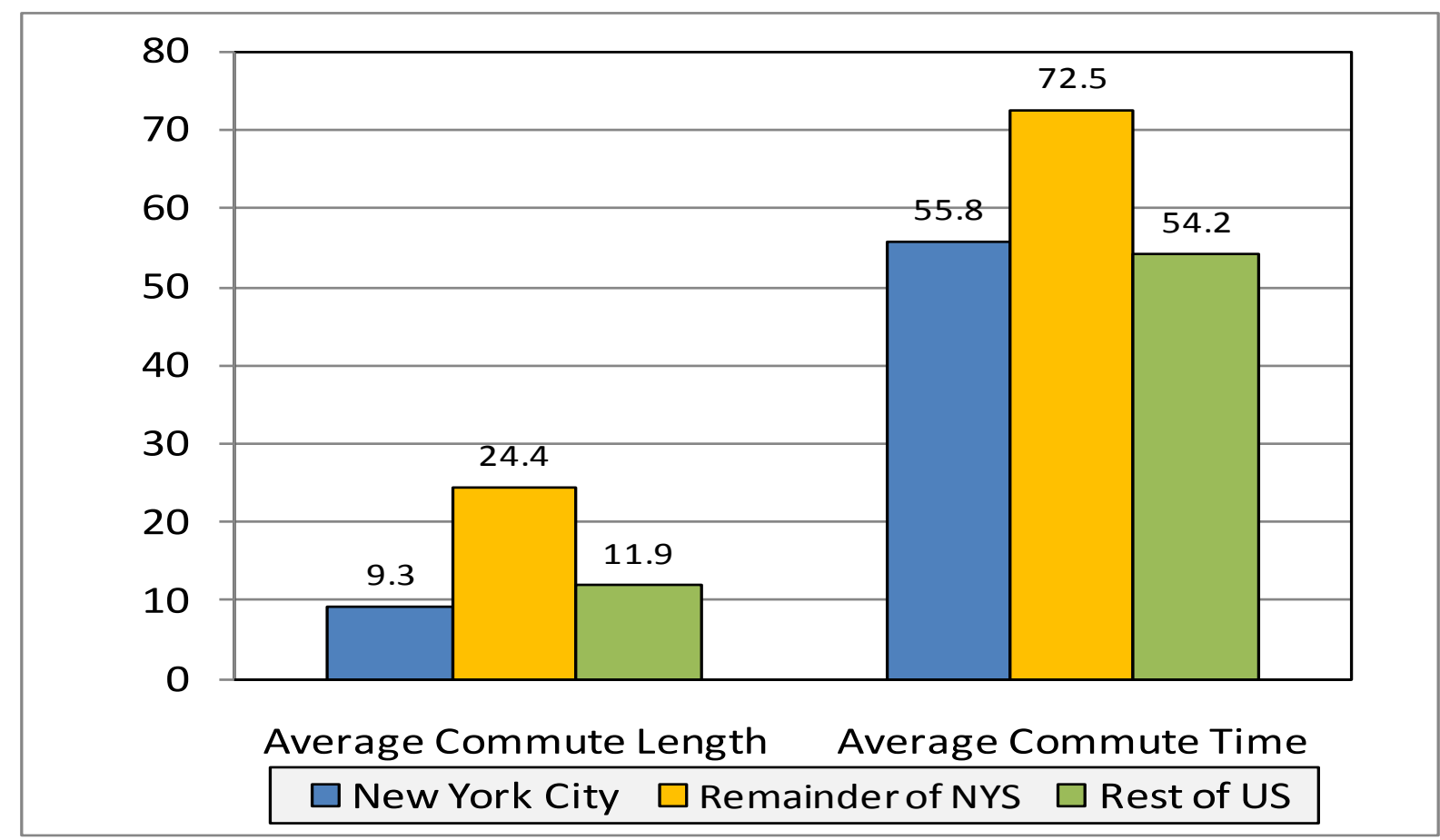

Figure 3.26 Commute Patterns on Public Transit in New York City, Remainder of New York State, and Rest of the United States, Year = 2001. 


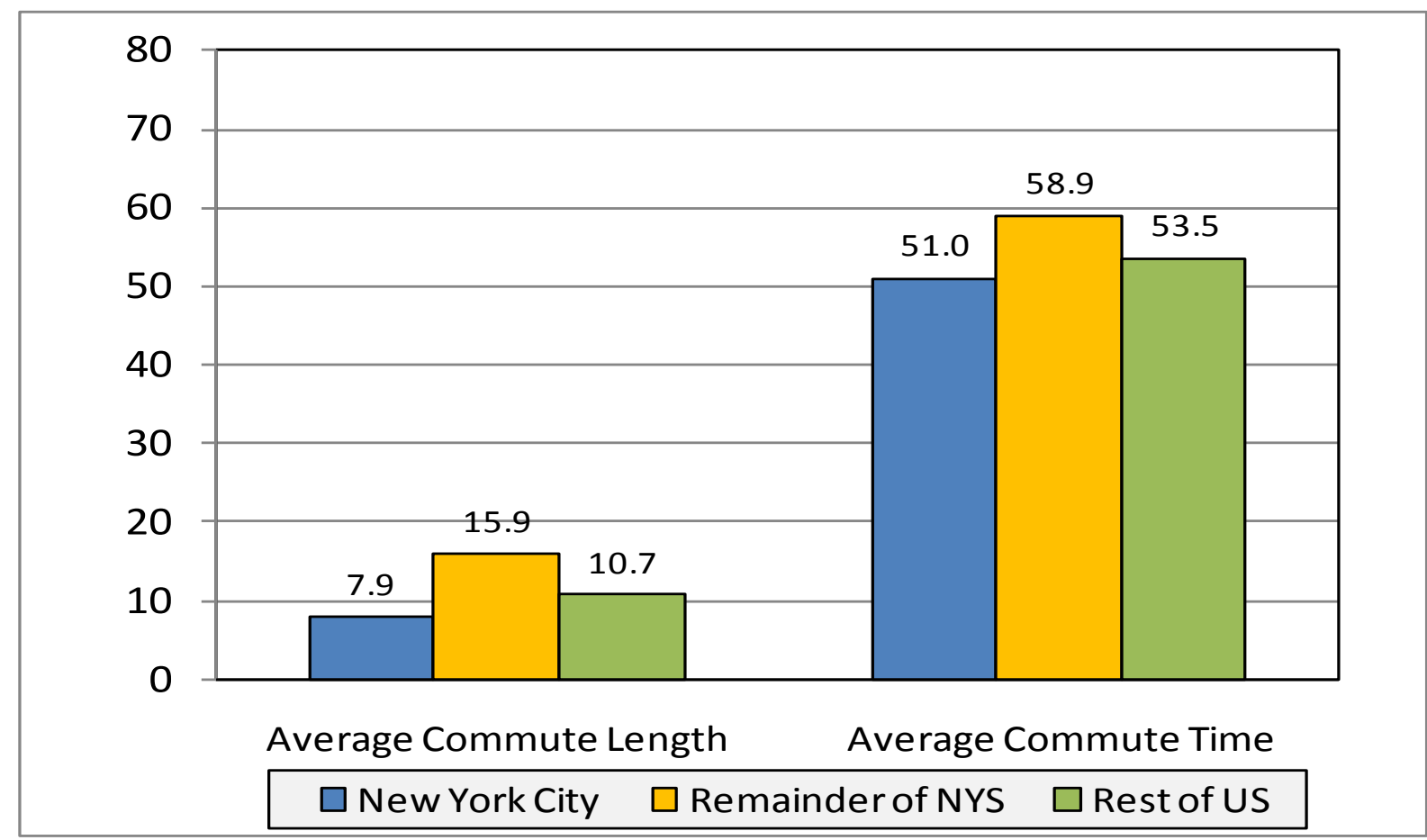

Figure 3.27 Commute Patterns on Public Transit in New York City, Remainder of New York State, and Rest of the United States, Year = 2009.

\subsection{SUMMARY}

In summary, the travel behavior of NYC residents has a tremendous impact on the reporting of travel patterns for the entire state of New York. Excluding NYC households, households in the rest of the state exhibit average travel characteristics that are, for the most part, quite similar to those for the rest of the nation. This is to be expected. NYC residential and employment densities are much higher than those in most of the rest of the state and nation. As a result, many more opportunities exist for walking to nearby destinations, and there is a good deal more "mass" in NYC's mass transit ridership. That said, most of the statistics presented in this chapter are averages, and raise the question of whether other urban areas within NYS might more or less closely resemble those in other parts of the nation than the above statistics appear to indicate. Just how does population density affect travel activity within and outside the state? Also of interest to planning and policy making agencies are the travel patterns of the state's rural households. How different are their travel patterns from those of urban household in the state? And are they consistent with those households found in rural areas elsewhere in the nation, or are there significant differences here that warrant further attention? The rest of this report addresses these questions. 


\section{URBAN TRAVEL AND POPULATION DENSITY}

Urban travel patterns are analyzed in this chapter with respect to population density, that is, with respect to the number of persons in residence per square mile. These densities are measured on a census tract basis and include only the land area of a tract. ${ }^{7}$ Specifically, the travel patterns of urban residents in New York State's thirteen MPO areas (see Figure 4.1) are compared to the travel patterns of residents in Metropolitan Statistical Areas (MSAs) outside NYS (NHTS sample households outside NYS cannot be identified by specific MPO, only by MSA, hence the difference).

The thirteen New York Add-On strata, (using their common names) are (see Figure 4.1):

- Albany,

- Binghamton,

- Buffalo,

- Elmira,

- Glens Falls,

- Ithaca,

- Kingston,

- New York Metropolitan Transportation Council (NYMTC)

- (Including Nassau, Suffolk, the five boroughs of New York City (Bronx, Kings, Queens, New York, and Richmond), Putnam, Rockland, and Westchester Counties),

- Newburgh,

- Poughkeepsie,

- Rochester,

- Syracuse, and

- Utica-Rome. $^{8}$

In this chapter we refer to these 13 areas as metro areas, or metros, noting that since the NYS Add-On NHTS sampling frame is comprised of the primary urban counties in which each MPO lies, an entire MPO area may not be represented by the survey in every case. Within each

${ }^{7}$ That is, if part of a census tract includes a large water body the surface area of that water body is subtracted prior to the density computation.

${ }^{8}$ The 2000 Census identified 3 new urbanized areas: Kingston, Saratoga Springs, and Middletown. Unfortunately, knowledge of these new areas was unknown at the time when the 2001 survey was conducted, and they were not sampled accordingly. As a result, Kingston, which was in Ulster County, was categorized as part of the rural aggregate strata in both 1995 and 2001. The remaining two urban areas were already part of other urban strata: Saratoga Springs was already part of the Albany strata, and Middletown was already part of the Newburgh strata. 
metro area, these sampled households are then grouped into appropriate population-density classes, based on the census tract in which they are located (see density maps in Appendix B).

To remain consistent with the 1995 and 2001 NYS's NHTS add-on analyses, households are divided into seven density classes, starting with households in tracts that average less than 500 persons per square mile, and increasing to households in tracts where densities exceed 50,000 persons per square mile, or ppsm (see Tables 4.1, 4.2 and 4.3). In some instances, where the statistics have been broken down into a number of additional dimensions (e.g. by vehicle ownership level, trip purpose, and mode of travel combinations) small sample sizes and larger standard errors hinder reporting over all three survey years. However, for the most part, the NHTS data offer statistically robust insights into the effects of density on metropolitan area travel both within and outside NYS.

Also of note, almost all households in the state's highest density areas (i.e. areas with more than 50,000 people per square mile) are found in NYC: see Table 4.1). However, comparisons between NYS data and data from other large urban areas in the U.S. can be misleading because NYS was significantly over-sampled in the NHTS compared to these other areas. The 2009 NHTS national sample, for example, includes a total of 870 households located in census tracts with more than 50,000 people per square mile, of which 819 are included in the NYS sample. Thus, data comparing these very dense areas should be viewed with a good deal of caution.

In 2009, ninety percent of NYS's households were located within the jurisdictions of the 13 New York add-on strata shown in Figure 4.1, up slightly from 88\% in 1995 and 2001 (derived from Tables 4.1, 4.2, and 4.3). Some 42.8\% of NYS households lived in the five NYC boroughs in 2009. As a result of this heavy concentration of population in the NYC strata when compared to metropolitan populations concentrations in the rest of the country, a significantly greater percentage of NYS households are in extremely densely populated areas. In $200938 \%$ of NYS households were located in census tracts with more than 20,000 people per square mile (see Figure 4.2). By comparison, this percentage is only $3 \%$ in the rest of the country. And these two in- and out-of state percentages have changed very little since 1995. At the other end of the density scale, some $16.5 \%$ of NYS households lived in the least dense areas with less than 500 people per square mile in both 2009 and 2001, down marginally from 17\% in 1995 (derived Tables 4.1, 4.2, 4.3). With these statewide statistics as background, the rest of this chapter focuses on the household and travel characteristics of residents in the above 13 NYS metro areas, and in the MSA-based metro areas in other states to which they are being compared. (Note that densities are measured here and in all of the other tables and graphs in this chapter on the basis of population and usable land area data reported at the level of census tracts. These densities are then reported for specific metro areas or groups of metro areas in persons per square mile, or ppsm.) 


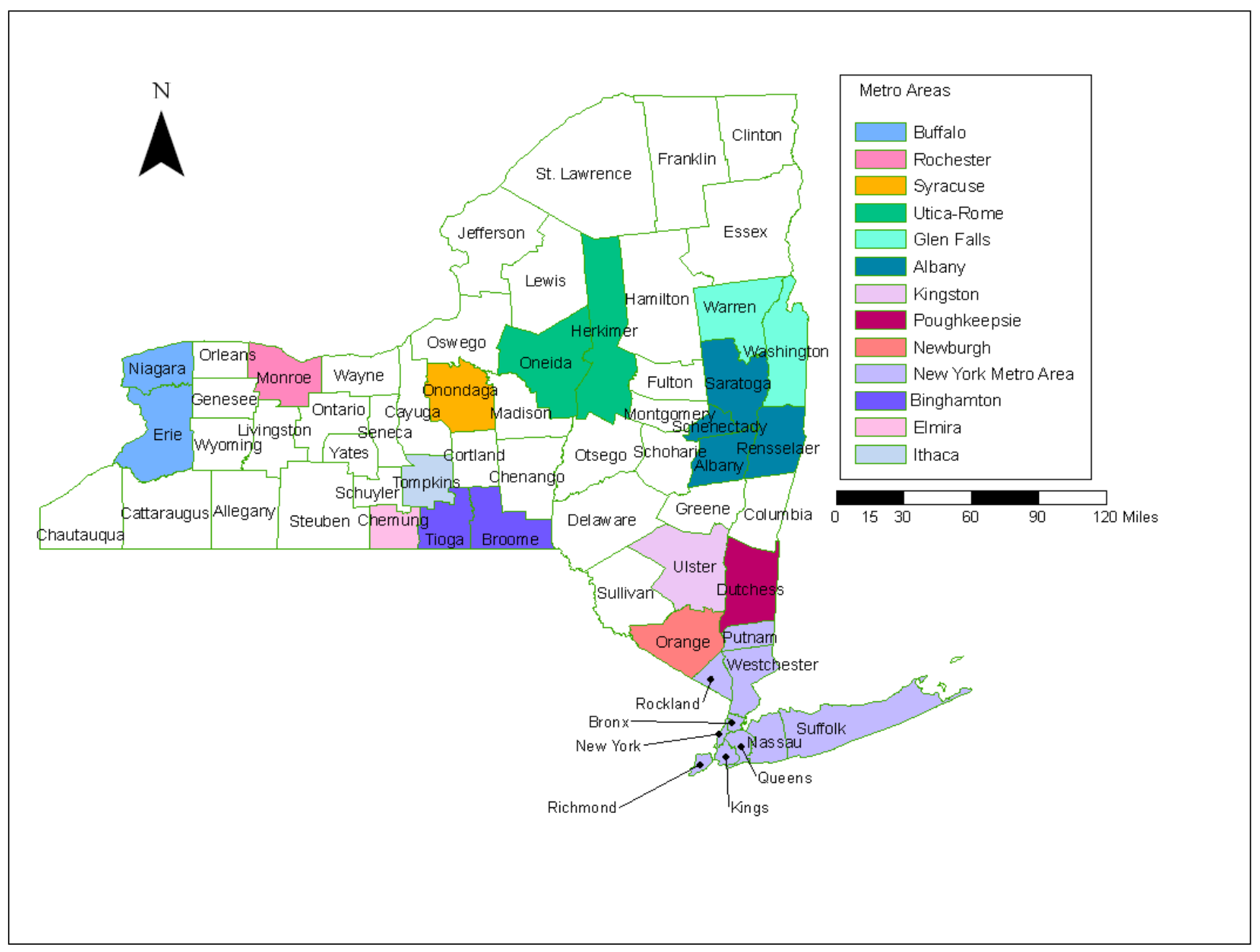

Figure 4.1 The 2009 NHTS Metro Add-On Areas. 
Table 4.1 2009 New York State Household Distribution by Metro Area and Population Density (population density based on census tracts)

\begin{tabular}{|c|c|c|c|c|c|c|c|c|}
\hline & \multicolumn{8}{|c|}{ Population Density (population per square mile) } \\
\hline & Total & $<500$ & $\begin{array}{l}500- \\
2,000 \\
\end{array}$ & $\begin{array}{c}2,000- \\
4,000\end{array}$ & $\begin{array}{l}4,000- \\
10,000\end{array}$ & $\begin{array}{l}10,000- \\
20,000\end{array}$ & $\begin{array}{l}20,000- \\
50,000\end{array}$ & $50,000+$ \\
\hline ALL & $7,137,482$ & $1,178,437$ & 873,916 & 780,844 & $1,065,752$ & 522,296 & 926,455 & $1,789,781$ \\
\hline Albany & 320,181 & 77,607 & 117,979 & 63,311 & 53,997 & 7,287 & & \\
\hline Glen Falls & 58,260 & 36,617 & 10,173 & 3,465 & 8,005 & & & \\
\hline Utica-Rome & 116,223 & 47,118 & 34,714 & 20,101 & 10,875 & 3,415 & & \\
\hline Syracuse & 184,815 & 30,393 & 64,786 & 34,400 & 49,540 & 5,696 & & \\
\hline Ithaca & 37,443 & 20,966 & 6,380 & 5,489 & 4,508 & & 100 & \\
\hline Rochester & 383,077 & 102,330 & 107,713 & 84,962 & 64,010 & 24,061 & & \\
\hline Buffalo & 471,544 & 61,838 & 109,723 & 99,956 & 160,510 & 39,517 & & \\
\hline Elmira & 34,853 & 12,719 & 10,944 & 5,261 & 5,930 & & & \\
\hline Poughkeepsie & 103,204 & 37,783 & 43,639 & 13,051 & 6,481 & 2,250 & & \\
\hline Binghamton & 97,837 & 36,063 & 26,441 & 12,026 & 21,512 & 1,795 & & \\
\hline Newburgh & 122,233 & 50,182 & 31,491 & 20,620 & 12,459 & 7,481 & & \\
\hline \multicolumn{9}{|l|}{ Kingston** } \\
\hline \multicolumn{9}{|l|}{ NYMTC } \\
\hline New York City & $3,055,273$ & 4,303 & 4,262 & 7,988 & 80,107 & 287,547 & 882,485 & $1,788,582$ \\
\hline Bronx & 473,884 & & & & 3,120 & 16,370 & 119,541 & 334,853 \\
\hline Brooklyn (Kings Cnty) & 888,404 & 1,396 & & & 4,118 & 31,565 & 341,876 & 509,449 \\
\hline Manhattan (NY County) & 749,335 & & & & 4,701 & 4,117 & 75,197 & 665,320 \\
\hline Queens & 777,224 & 1,612 & & 3,412 & 34,042 & 138,638 & 320,560 & 278,959 \\
\hline $\begin{array}{l}\text { Staten Island (Richmond } \\
\text { Cnty) }\end{array}$ & 166,425 & 1,295 & 4,262 & 4,575 & 34,126 & 96,857 & 25,310 & \\
\hline Nassau, Suffolk & 911,037 & 38,832 & 129,158 & 232,549 & 433,867 & 63,356 & 13,275 & \\
\hline $\begin{array}{l}\text { Putnam, Rockland, } \\
\text { Westchester }\end{array}$ & 469,399 & 34,618 & 109,245 & 97,446 & 116,404 & 79,891 & 30,595 & 1,200 \\
\hline Rest of State & 702,055 & 545,452 & 51,694 & 70,990 & 33,918 & & & \\
\hline
\end{tabular}

* includes Saratoga.

** Kingston was part of the Rest of State rural aggregate in 2001. 
Table 4.2 2001 New York State Household Distribution by Metro Area and Population Density (population density based on census tracts)

\begin{tabular}{|c|c|c|c|c|c|c|c|c|c|}
\hline & \multicolumn{9}{|c|}{ Population Density (population per square mile) } \\
\hline & Total & $<500$ & $\begin{array}{l}500- \\
2,000\end{array}$ & $\begin{array}{c}2,000- \\
4,000\end{array}$ & $\begin{array}{l}4,000- \\
10,000\end{array}$ & $\begin{array}{l}10,000- \\
20,000\end{array}$ & $\begin{array}{l}20,000- \\
50,000\end{array}$ & $50,000+$ & Unreported \\
\hline ALL & $7,183,208$ & $1,186,731$ & 813,608 & 752,260 & $1,073,037$ & 635,381 & $1,001,682$ & $1,719,602$ & 906 \\
\hline Albany* & 323,953 & 76,618 & 113,160 & 56,277 & 59,204 & 18,178 & 96 & & 420 \\
\hline Glen Falls & 49,047 & 33,958 & 6,500 & 4,608 & 3,980 & & & & \\
\hline Utica-Rome & 118,311 & 50,849 & 32,415 & 20,238 & 12,794 & 2,014 & & & \\
\hline Syracuse & 184,396 & 27,098 & 49,006 & 38,194 & 51,809 & 18,290 & & & \\
\hline Ithaca & 37,072 & 21,299 & 4,853 & 5,906 & 3,876 & & 1,138 & & \\
\hline Rochester & 291,642 & 23,949 & 89,634 & 70,432 & 66,215 & 41,412 & & & \\
\hline Buffalo & 477,111 & 65,689 & 94,217 & 88,470 & 174,441 & 54,294 & & & \\
\hline Elmira & 35,677 & 13,416 & 10,872 & 3,726 & 7,664 & & & & \\
\hline Poughkeepsie & 101,318 & 33,897 & 40,667 & 13,606 & 10,736 & 2,412 & & & \\
\hline Binghamton & 102,273 & 40,523 & 22,557 & 11,024 & 26,518 & 1,651 & & & \\
\hline Newburgh & 116,843 & 53,270 & 34,915 & 15,139 & 7,757 & 5,393 & & & 368 \\
\hline \multicolumn{10}{|l|}{ Kingston** } \\
\hline \multicolumn{10}{|l|}{ NYMTC } \\
\hline New York City & $3,075,688$ & 15,957 & 5,155 & 11,285 & 59,211 & 304,948 & 961,727 & $1,717,404$ & \\
\hline Bronx & 471,506 & 1,256 & & 370 & 6,983 & 25,615 & 151,096 & 286,185 & \\
\hline Brooklyn (Kings Cnty) & 896,496 & 780 & 3,335 & & 1,453 & 31,479 & 337,402 & 522,047 & \\
\hline Manhattan (NY County) & 751,869 & 9,521 & 265 & 1,704 & 1,329 & 11,035 & 54,347 & 673,667 & \\
\hline Queens & 796,677 & 2,485 & 385 & 4,243 & 17,462 & 146,039 & 391,161 & 234,902 & \\
\hline $\begin{array}{l}\text { Staten Island (Richmond } \\
\text { Cnty) }\end{array}$ & 159,140 & 1,914 & 1,169 & 4,968 & 31,984 & 90,780 & 27,722 & 604 & \\
\hline Nassau, Suffolk & 933,098 & 37,360 & 117,460 & 231,227 & 438,220 & 102,188 & 6,644 & & \\
\hline $\begin{array}{l}\text { Putnam, Rockland, } \\
\text { Westchester }\end{array}$ & 470,801 & 36,488 & 116,293 & 93,432 & 105,594 & 84,601 & 32,078 & 2,198 & 119 \\
\hline Rest of State & 865,978 & 656,360 & 75,905 & 88,696 & 45,017 & & & & \\
\hline
\end{tabular}

* includes Saratoga.

** Kingston was part of the Rest of State rural aggregate in 2001. 
Table 4.3 1995 New York State Household Distribution by Metro Area and Population Density (population density based on census tracts)

\begin{tabular}{|c|c|c|c|c|c|c|c|c|c|}
\hline & \multicolumn{9}{|c|}{ Population Density (population per square mile) } \\
\hline & Total & $<500$ & $\begin{array}{l}500- \\
2,000\end{array}$ & $\begin{array}{r}2,000- \\
4,000 \\
\end{array}$ & $\begin{array}{l}4,000- \\
10,000\end{array}$ & $\begin{array}{l}10,000- \\
20,000\end{array}$ & $\begin{array}{l}20,000- \\
50,000\end{array}$ & $50,000+$ & Unreported \\
\hline ALL & $6,848,091$ & $1,178,102$ & 796,380 & 672,210 & $1,044,564$ & 616,582 & 977,772 & $1,528,190$ & 34,292 \\
\hline Albany* & 325,710 & 86,937 & 105,054 & 50,287 & 60,411 & 15,419 & 3118 & & 4,483 \\
\hline Glen Falls & 45,500 & 30,125 & 6,318 & 3,884 & 4,616 & & & & 557 \\
\hline Utica-Rome & 116,864 & 50,394 & 29,621 & 22,132 & 10,857 & 2,916 & & & 944 \\
\hline Syracuse & 179,526 & 29,249 & 62,101 & 37,977 & 37,442 & 12,756 & & & \\
\hline Ithaca & 34,879 & 22,054 & 5,237 & 2,276 & 3,946 & & 1,210 & & 156 \\
\hline Rochester & 279,228 & 27,475 & 94,749 & 63,057 & 65,087 & 28,859 & & & \\
\hline Buffalo & 465,261 & 72,505 & 87,032 & 74,691 & 147,188 & 78,153 & 3892 & & 1,800 \\
\hline Elmira & 35,162 & 13,124 & 8,487 & 6,185 & 5,937 & 1258 & & & 171 \\
\hline Poughkeepsie & 94,551 & 37,606 & 34,047 & 13,549 & 3,671 & 4,451 & & & 1,228 \\
\hline Binghamton & 100,577 & 43,560 & 23,832 & 10,000 & 21,642 & 1,380 & & & 165 \\
\hline Newburgh & 108,147 & 41,902 & 34,265 & 16,697 & 12,685 & 1,626 & & & 972 \\
\hline \multicolumn{10}{|l|}{ Kingston ${ }^{* *}$} \\
\hline \multicolumn{10}{|l|}{ NYMTC } \\
\hline New York City & $2,920,494$ & 18,225 & 4,278 & 14,185 & 89,850 & 325,165 & 934,660 & $1,525,464$ & 8,669 \\
\hline Bronx & 443,662 & 1,969 & & 3,978 & 7,189 & 26,599 & 156,198 & 244,927 & 2,802 \\
\hline Brooklyn (Kings Cnty) & 854,463 & 1,942 & & 3,104 & 8,318 & 12,552 & 387,639 & 439,521 & 1,387 \\
\hline Manhattan (NY County) & 727,533 & 12,286 & & & 10,211 & 13,073 & 41,763 & 647,314 & 2,887 \\
\hline Queens & 751,406 & & 2,244 & 3,108 & 25,341 & 189,613 & 337,976 & 191,531 & 1,594 \\
\hline $\begin{array}{l}\text { Staten Island (Richmond } \\
\text { Cnty) }\end{array}$ & 143,430 & 2,028 & 2,034 & 3,995 & 38,790 & 83,328 & 11,084 & 2,171 & \\
\hline Nassau, Suffolk & 886,460 & 42,165 & 118,103 & 210,207 & 420,173 & 87,419 & 1,845 & & 6,549 \\
\hline $\begin{array}{l}\text { Putnam, Rockland, } \\
\text { Westchester }\end{array}$ & 447,759 & 53,206 & 113,463 & 75,643 & 110,708 & 57,179 & 33,048 & 2,726 & 1,785 \\
\hline Rest of State & 807,972 & 609,577 & 69,793 & 71,441 & 50,350 & & & & 6,812 \\
\hline
\end{tabular}

\footnotetext{
* Includes Saratoga.

** Kingston was part of the Rest of State rural aggregate in 1995.
} 


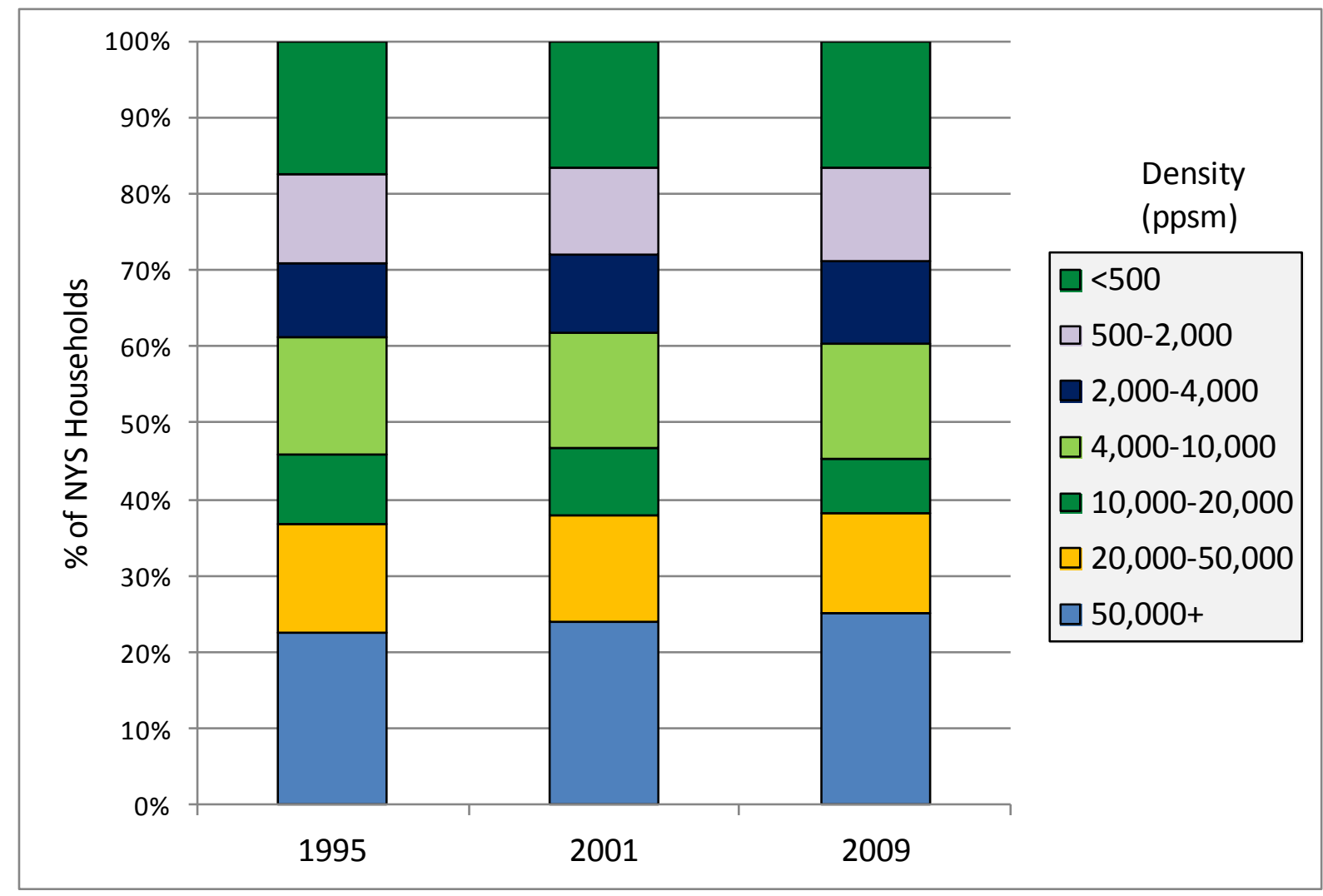

Figure 4.2 Distribution of New York State Households by Population Density in 1995, 2001, and 2009 (persons per square mile, based on census tracts).

\subsection{PROFILE OF NYS ADD-ON STRATA HOUSEHOLDS BY POPULATION DENSITY}

Figure 4.3 below compares the population densities experienced by urban households located in metro areas in the rest of the nation in 2009, against those experienced by NYS households located in one of the state's 13 metro areas. The contrast is striking. While $28 \%$ of households located in the state's 13 metro areas lived in densities of over 50,000 persons per square mile (ppsm) in 2009 (nearly all of which are located in the NYC five county metro area), well below $1 \%$ of households live in such high density conditions in the rest of the nation, and only $3 \%$ lived in densities above 20,000 ppsm. $^{9}$ And while $40 \%$ of metro area households in the rest of the country outside NYS lived in census tracts with densities of less than 2,000 persons per square mile in 2009 , only $23 \%$ of NYS metro area households lived in these same lower density areas. Tables $4.4,4.5$, and 4.6 show these and other statistics for survey years 2009 , 2001, and 1995 respectively.

${ }^{9}$ While an initial look a Tables $4.4,4.5$, and 4.6 also suggests that the size of the NYS household population went down within the $10,000-20,000$ ppsm density class in 2009, the standard errors on the 1995,2001 and 2009 datasets suggest that this decrease is less significant than it appears. 

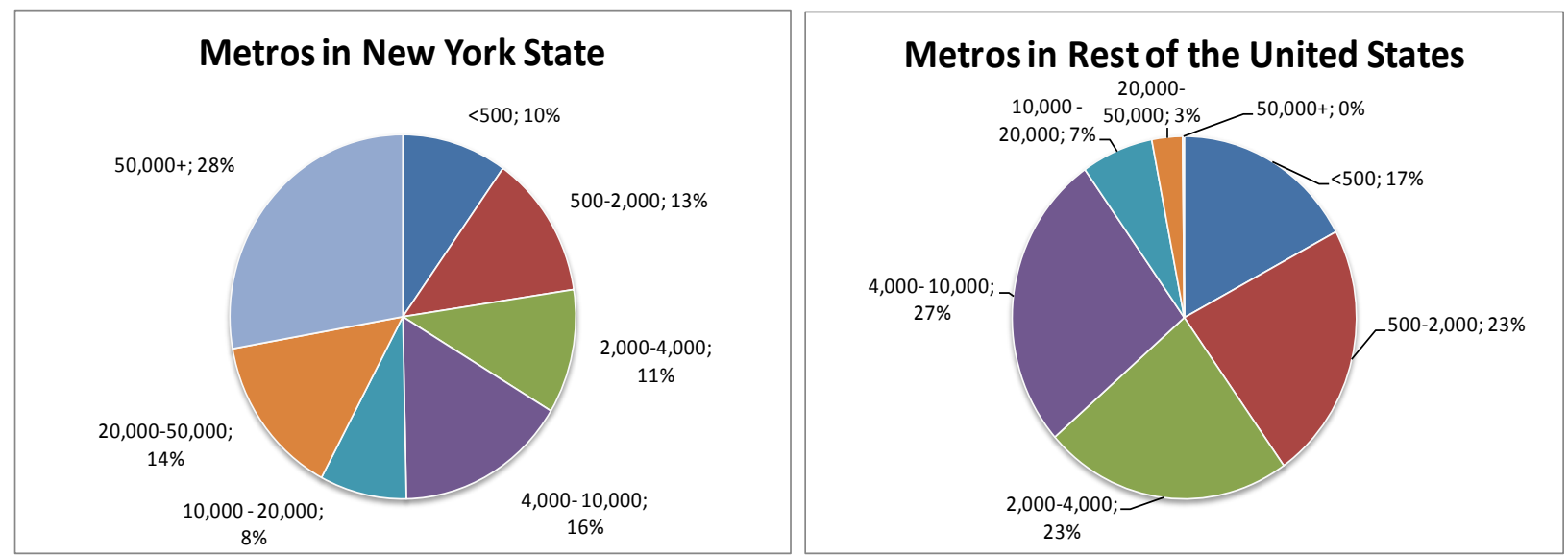

Figure 4.3 2009 Distribution of Households in New York Metros versus Metro Households in the Rest of the United States, by Population Density (persons per square mile, based on census tracts).

\subsubsection{Vehicle Ownership and Rail Access}

In general, households in New York State's metro area continue to have fewer vehicles than those in other urban areas (Tables 4.4, 4.5, and 4.6). This disparity in vehicle ownership increases with density, becoming noticeable at densities above 4,000 persons per square mile; and greatest in areas of more than 50,000 ppsm. In 2009, there was roughly one vehicle for every three drivers within areas of the state with more than 50,000 people per square mile, compared to just over one vehicle for every two drivers in the highest density areas outside the state. These findings confirm those reported in Chapter 3. 
Table 4.4 2009 Household Characteristics and Vehicle Ownership Patterns by Population Density: New York State Metros vs. Metros Found Outside New York State

(persons per square mile, based on census tract data)

\begin{tabular}{|c|c|c|c|c|c|c|c|c|c|c|c|c|c|c|}
\hline & \multicolumn{14}{|c|}{ Population Density (population per square mile) } \\
\hline & \multicolumn{2}{|c|}{$<500$} & \multicolumn{2}{|c|}{$500-2,000$} & \multicolumn{2}{|c|}{$2,000-4,000$} & \multicolumn{2}{|c|}{$4,000-10,000$} & \multicolumn{2}{|c|}{$10,000-20,000$} & \multicolumn{2}{|c|}{$20,000-50,000$} & \multicolumn{2}{|c|}{$50,000+$} \\
\hline & NYS & U.S. ${ }^{a}$ & NYS & U.S. & NYS & U.S. & NYS & U.S. & NYS & U.S. & NYS & U.S. & NYS & U.S. \\
\hline Households $(000)$ & 633 & 14,480 & 822 & 19,448 & 710 & 19,717 & 1,032 & 22,496 & 522 & 5,711 & 926 & 2,430 & 1,790 & 133 \\
\hline $\begin{array}{l}\% \text { households in an } \\
\text { MSA with rail }\end{array}$ & $26.2 \%$ & $15.8 \%$ & $38.7 \%$ & $25.4 \%$ & $52.4 \%$ & $26.3 \%$ & $62.9 \%$ & $36.0 \%$ & $84.3 \%$ & $74.1 \%$ & $100.0 \%$ & $92.7 \%$ & $100.0 \%$ & $90.1 \%$ \\
\hline Workers per Household & 1.53 & 1.43 & 1.45 & 1.38 & 1.44 & 1.33 & 1.40 & 1.35 & 1.36 & 1.21 & 1.35 & 1.32 & 1.26 & 1.75 \\
\hline Vehicles per Driver & 1.00 & 1.12 & 0.93 & 1.01 & 0.90 & 0.97 & 0.80 & 0.94 & 0.71 & 0.81 & 0.48 & 0.67 & 0.27 & 0.54 \\
\hline \multicolumn{15}{|c|}{ Distribution of Households by Number of Household Vehicles ${ }^{b}$} \\
\hline 0 vehicles & $4.0 \%$ & $2.8 \%$ & $6.1 \%$ & $5.1 \%$ & $6.7 \%$ & $6.2 \%$ & $12.7 \%$ & $9.4 \%$ & $21.9 \%$ & $18.8 \%$ & $43.1 \%$ & $30.1 \%$ & $67.9 \%$ & $27.0 \%$ \\
\hline 1 vehicle & $25.5 \%$ & $24.4 \%$ & $32.0 \%$ & $28.9 \%$ & $30.8 \%$ & $35.2 \%$ & $39.5 \%$ & $37.3 \%$ & $40.1 \%$ & $43.6 \%$ & $38.4 \%$ & $40.1 \%$ & $25.6 \%$ & $65.5 \%$ \\
\hline 2 vehicles & $44.6 \%$ & $39.1 \%$ & $41.8 \%$ & $42.8 \%$ & $43.5 \%$ & $38.6 \%$ & $32.8 \%$ & $36.1 \%$ & $28.0 \%$ & $26.9 \%$ & $15.0 \%$ & $23.0 \%$ & $5.4 \%$ & $6.2 \% *$ \\
\hline 3 vehicles & $16.9 \%$ & $19.6 \%$ & $13.7 \%$ & $15.7 \%$ & $13.8 \%$ & $13.6 \%$ & $11.7 \%$ & $11.4 \%$ & $6.9 \%$ & $7.2 \%$ & $2.3 \%$ & $5.1 \%$ & $1.0 \%$ & $1.4 \% *$ \\
\hline$A L L$ & $100 \%$ & $100 \%$ & $100 \%$ & $100 \%$ & $100 \%$ & $100 \%$ & $100 \%$ & $100 \%$ & $100 \%$ & $100 \%$ & $100 \%$ & $100 \%$ & $100 \%$ & $100 \%$ \\
\hline
\end{tabular}

a Columns labeled "U.S." include metro area data from outside New York State only.

b All percentages may not add to $100 \%$ due to rounding. 
Table 4.5 2001 Household Characteristics and Vehicle Ownership Patterns by Population Density: New York State Metros vs. Metros Found Outside New York State

(persons per square mile, based on census tract data)

\begin{tabular}{|c|c|c|c|c|c|c|c|c|c|c|c|c|c|c|}
\hline & \multicolumn{14}{|c|}{ Population Density (population per square mile) } \\
\hline & \multicolumn{2}{|c|}{$<500$} & \multicolumn{2}{|c|}{$500-2,000$} & \multicolumn{2}{|c|}{$2,000-4,000$} & \multicolumn{2}{|c|}{$4,000-10,000$} & \multicolumn{2}{|c|}{$10,000-20,000$} & \multicolumn{2}{|c|}{$20,000-50,000$} & \multicolumn{2}{|c|}{$50,000+$} \\
\hline & NYS & U.S. ${ }^{a}$ & NYS & U.S. & NYS & U.S. & NYS & U.S. & NYS & U.S. & NYS & U.S. & NYS & U.S. \\
\hline Households (000) & 530 & 14,822 & 738 & 16,982 & 664 & 17,629 & 1,028 & 21,548 & 635 & 5,893 & 1,002 & 2,380 & 1,720 & 197 \\
\hline $\begin{array}{l}\% \text { households in an } \\
\text { MSA with rail }\end{array}$ & $33.4 \%$ & $15.3 \%$ & $42.6 \%$ & $24.5 \%$ & $55.0 \%$ & $25.5 \%$ & $60.5 \%$ & $35.1 \%$ & $78.6 \%$ & $68.3 \%$ & $99.9 \%$ & $92.1 \%$ & $100.0 \%$ & $95.6 \%$ \\
\hline Workers per Household & 1.42 & 1.46 & 1.42 & 1.41 & 1.33 & 1.32 & 1.39 & 1.35 & 1.50 & 1.40 & 1.28 & 1.27 & 1.26 & 1.11 \\
\hline Vehicles per Driver & 1.05 & 1.15 & 1.03 & 1.06 & 0.98 & 1.05 & 0.96 & 1.00 & 0.80 & 0.93 & 0.61 & 0.84 & 0.44 & 0.62 \\
\hline \multicolumn{15}{|c|}{ Distribution of Households by Number of Household Vehicles ${ }^{\mathrm{b}}$} \\
\hline 0 vehicles & $4.0 \%$ & $3.3 \%$ & $3.2 \%$ & $3.5 \%$ & $7.5 \%$ & $5.6 \%$ & $10.2 \%$ & $8.7 \%$ & $21.8 \%$ & $15.6 \%$ & $45.0 \%$ & $28.0 \%$ & $61.5 \%$ & $49.1 \%$ \\
\hline 1 vehicle & $24.0 \%$ & $22.9 \%$ & $30.2 \%$ & $28.4 \%$ & $33.7 \%$ & $33.9 \%$ & $35.6 \%$ & $37.1 \%$ & $38.2 \%$ & $41.7 \%$ & $36.6 \%$ & $42.2 \%$ & $32.5 \%$ & $43.7 \%$ \\
\hline 2 vehicles & $45.0 \%$ & $39.9 \%$ & $44.1 \%$ & $43.1 \%$ & $40.7 \%$ & $39.2 \%$ & $37.4 \%$ & $36.6 \%$ & $26.5 \%$ & $30.1 \%$ & $15.2 \%$ & $22.6 \%$ & $5.2 \%$ & $6.9 \%$ \\
\hline 3 vehicles & $18.0 \%$ & $20.1 \%$ & $15.9 \%$ & $16.4 \%$ & $12.9 \%$ & $15.3 \%$ & $12.6 \%$ & $12.4 \%$ & $10.2 \%$ & $8.4 \%$ & $2.5 \%$ & $5.5 \%$ & $0.6 \%$ & $0.3 \%$ * \\
\hline$A L L$ & $100 \%$ & $100 \%$ & $100 \%$ & $100 \%$ & $100 \%$ & $100 \%$ & $100 \%$ & $100 \%$ & $100 \%$ & $100 \%$ & $100 \%$ & $100 \%$ & $100 \%$ & $100 \%$ \\
\hline
\end{tabular}

a Columns labeled "U.S." include metro area data from outside New York State only.

b All percentages may not add to $100 \%$ due to rounding. 
Table 4.6 1995 Household Characteristics and Vehicle Ownership Patterns by Population Density for New York State Metros vs. Metros Found Outside New York State

(persons per square mile, based on census tract data)

\begin{tabular}{|c|c|c|c|c|c|c|c|c|c|c|c|c|c|c|}
\hline & \multicolumn{14}{|c|}{ Population Density (population per square mile) } \\
\hline & \multicolumn{2}{|c|}{$<500$} & \multicolumn{2}{|c|}{$500-2,000$} & \multicolumn{2}{|c|}{$2,000-4,000$} & \multicolumn{2}{|c|}{$4,000-10,000$} & \multicolumn{2}{|c|}{$10,000-20,000$} & \multicolumn{2}{|c|}{$20,000-50,000$} & \multicolumn{2}{|c|}{$50,000+$} \\
\hline & NYS & U.S. ${ }^{a}$ & NYS & U.S. & NYS & U.S. & NYS & U.S. & NYS & U.S. & NYS & U.S. & NYS & U.S. \\
\hline Households (000) & 568 & 14,723 & 727 & 15,721 & 601 & 15,126 & 994 & 19,726 & 617 & 5,230 & 978 & 1,962 & 1,528 & 83 \\
\hline $\begin{array}{l}\% \text { households in an } \\
\text { MSA with rail }\end{array}$ & $47.7 \%$ & $30.8 \%$ & $78.3 \%$ & $62.5 \%$ & $87.0 \%$ & $81.8 \%$ & $94.8 \%$ & $92.8 \%$ & $98.2 \%$ & $97.9 \%$ & $99.4 \%$ & $98.9 \%$ & $98.8 \%$ & $100.0 \%$ \\
\hline Workers per Household & 1.40 & 1.38 & 1.39 & 1.40 & 1.39 & 1.36 & 1.41 & 1.32 & 1.28 & 1.18 & 1.16 & 1.19 & 1.12 & 1.18 \\
\hline Vehicles per Driver & 0.92 & 1.09 & 0.90 & 1.03 & 0.85 & 0.99 & 0.81 & 0.95 & 0.73 & 0.87 & 0.58 & 0.74 & 0.35 & 0.60 \\
\hline \multicolumn{15}{|c|}{ Distribution of Households by Number of Household Vehicles ${ }^{b}$} \\
\hline 0 vehicles & $4.2 \%$ & $3.4 \%$ & $2.8 \%$ & $3.2 \%$ & $6.1 \%$ & $6.1 \%$ & $11.3 \%$ & $8.3 \%$ & $21.9 \%$ & $18.5 \%$ & $42.2 \%$ & $35.3 \%$ & $68.2 \%$ & $47.1 \%$ \\
\hline 1 vehicle & $26.8 \%$ & $23.1 \%$ & $28.1 \%$ & $28.8 \%$ & $32.1 \%$ & $33.7 \%$ & $36.1 \%$ & $38.6 \%$ & $43.0 \%$ & $45.1 \%$ & $39.2 \%$ & $43.9 \%$ & $27.2 \%$ & $40.4 \%$ \\
\hline 2 vehicles & $48.1 \%$ & $46.4 \%$ & $48.8 \%$ & $46.4 \%$ & $43.4 \%$ & $42.3 \%$ & $39.5 \%$ & $38.6 \%$ & $28.5 \%$ & $28.0 \%$ & $15.2 \%$ & $16.6 \%$ & $4.3 \%$ & $12.1 \%$ \\
\hline 3 vehicles & $15.5 \%$ & $19.6 \%$ & $14.1 \%$ & $16.0 \%$ & $13.8 \%$ & $12.8 \%$ & $8.8 \%$ & $11.0 \%$ & $5.4 \%$ & $6.4 \%$ & $2.9 \%$ & $3.9 \%$ & $0.3 \%$ & $0.4 \%$ \\
\hline$A L L$ & $100 \%$ & $100 \%$ & $100 \%$ & $100 \%$ & $100 \%$ & $100 \%$ & $100 \%$ & $100 \%$ & $100 \%$ & $100 \%$ & $100 \%$ & $100 \%$ & $100 \%$ & $100 \%$ \\
\hline
\end{tabular}

a Columns labeled "U.S." include metro area data from outside New York State only.

b All percentages may not add to $100 \%$ due to rounding. 
In both 2001 and 2009, subway and commuter rail transport continued to offer alternative modes of travel to a significantly higher percentage of NYS metro area households located in the lower density tracts $(<10,000$ persons per square mile (ppsm)) within the state's metro areas than to households at similar metro area densities outside the state (see Figure 4.4) (in 1995 the rail access question was not asked directly). Commuter rail access percentages are much closer to national levels at densities over 10,000 ppsm.

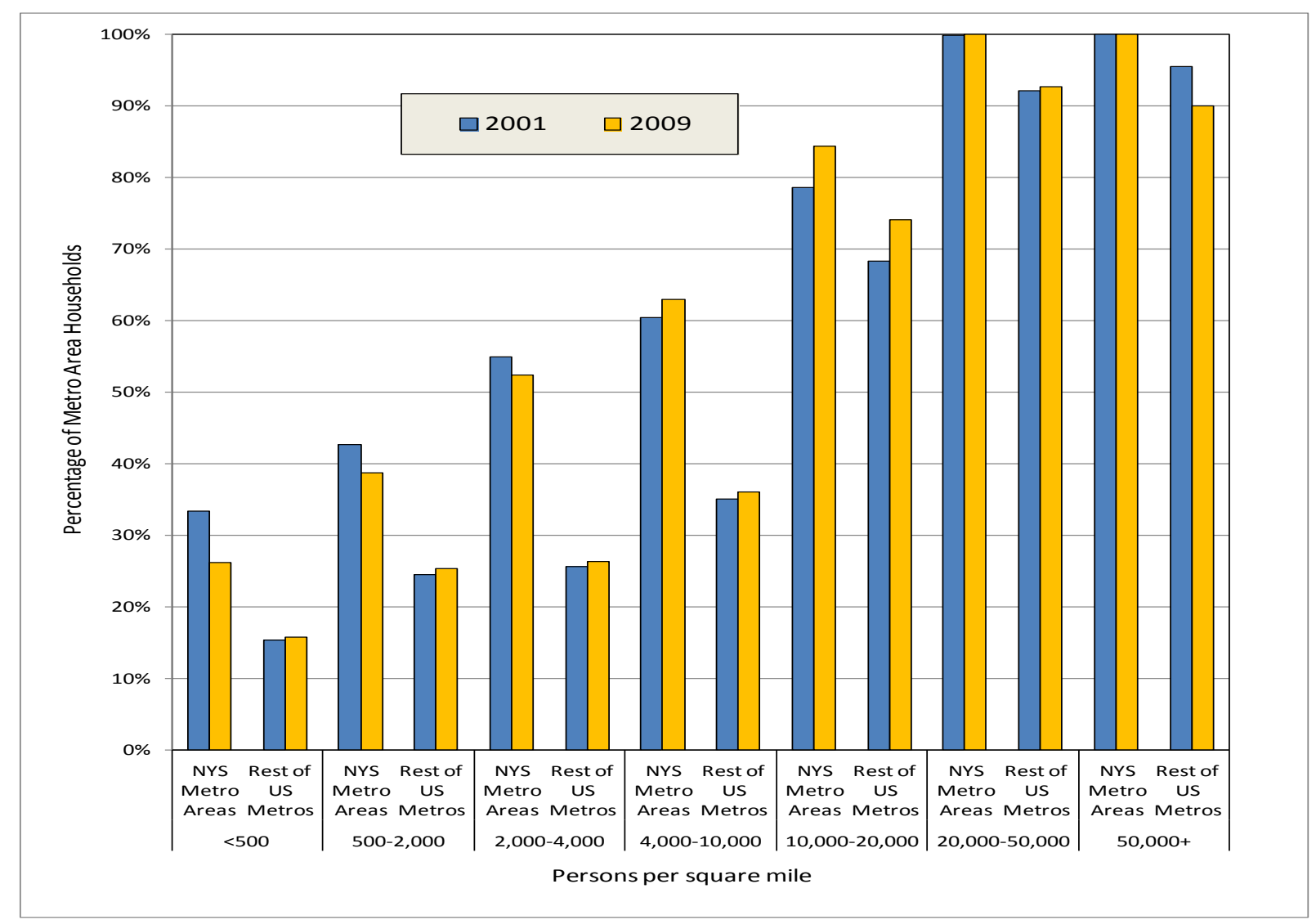

Figure 4.4 Percent of Households Having Access to Rail in New York State Metros vs. Metros Outside New York State, in 2001 and 2009.

Note: The 1995 NHTS data does not provide rail access data compatible with the 2001 and 2009 surveys.

The percentage of households without a vehicle is also, as one might expect, positively correlated with higher population density (Figure 4.5). This is true both for NYS metro households as well as households in metros outside NYS. As many as two in every three NYS households in the most densely populated areas of the state (households located within NYC) don't own a vehicle. The equivalent figure outside NYS is a good deal lower and appears to have dropped significantly, from one in every two, to closer to one in every three households since 2001 (see the last bar in Figure 4.5). Note that this observation is based on a very small sample size. Also compared to 2001, a marginally greater percentage of NYS households living in these 
very dense areas did not own a vehicle in 2009, reverting to the 1995 level of around 68\% (Table 4.4; Figure 4.5).

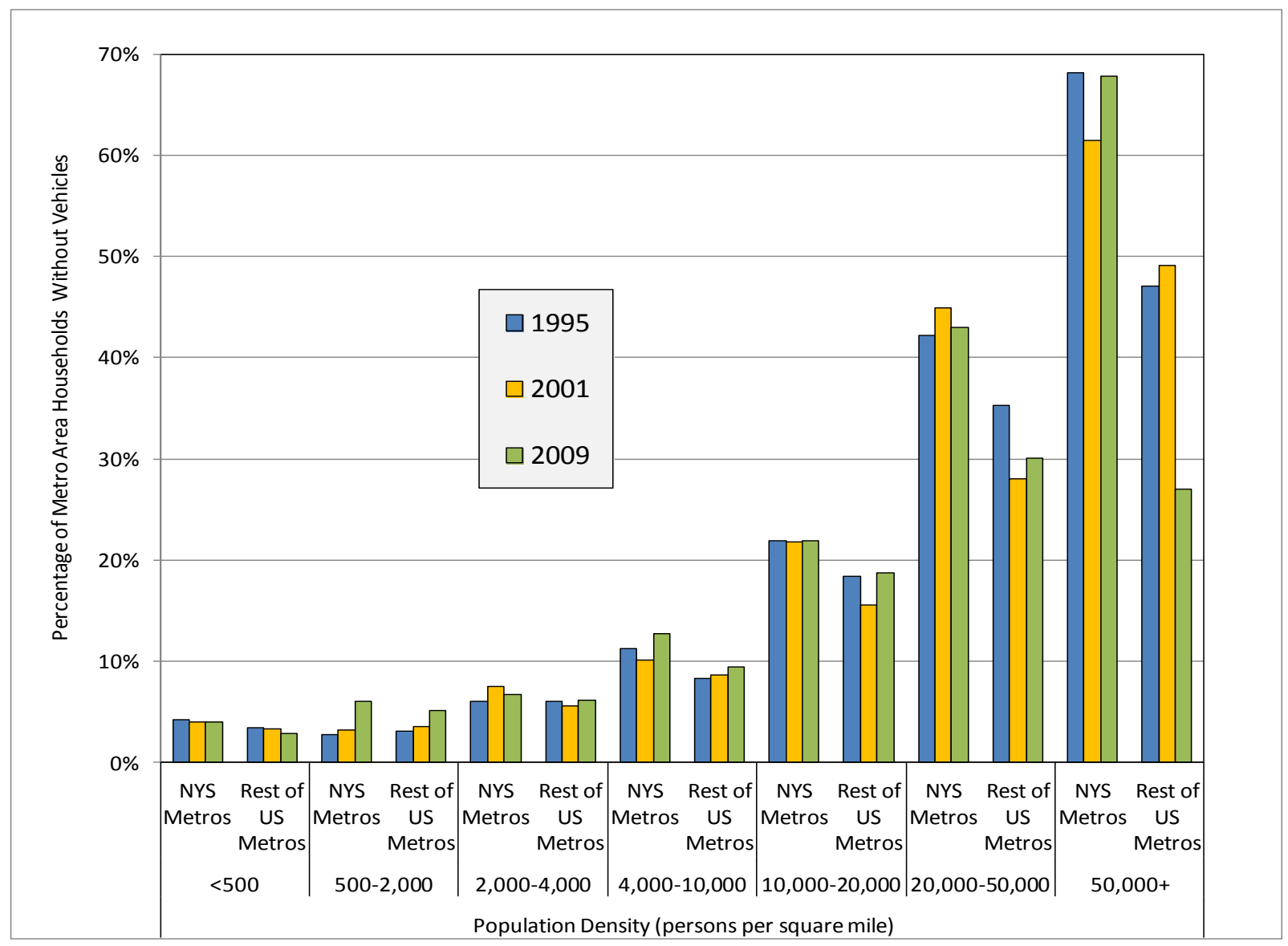

Figure 4.5 Percentages of Households Without a Vehicle Broken Down by Population Density, New York Metros vs. Metros Outside New York State.*

Note: Differences in \%s for the_Rest of US Metros in the $>50,000$ ppsm class are based on small sample sizes and may be overstated.

\subsubsection{Driver Rate}

Figures 4.6, 4.7, and 4.8 show the relationship between population density and number of persons over the age of 16 years indicating that they were drivers ("driver rates"). ${ }^{10}$ Similar to vehicle ownership patterns, driver rates vary significantly across population density classes, with both NYS and rest of the United States residents in highly populated areas significantly less likely to be drivers. At densities below 10,000 ppsm there is no significant difference in either male or female driver rates between metro areas inside or outside NYS. However, in the higher

\footnotetext{
${ }^{10}$ Note that NHTS respondents were asked for their driver status (i.e. “Are you a driver?"), rather than license status. Therefore, the driver rates reported in this chapter refer to the percentage of New York residents who state that they are drivers, and should not be compared directly to driver license rates maintained by the New York Department of Motor Vehicles.
} 
density ranges between 10,000 to 20,000 and 20,000 to 50,000 ppsm, NYS metro area male driver rates are marginally lower than male metro area driver rates in the rest of the country. ${ }^{11}$ For women, the NYS metro driver rates are reported to be marginally higher in 2009, which if true reverses the situation in 2001 and 1995, when these female driver rates were significantly lower in NYS than in metro areas outside the state at densities over 20,000 ppsm. However, the apparent differences in rates shown for the highest, 50,000+ density areas in Figures 4.6, 4.7, and 4.8 can be misleading, since this data has large standard errors (on the order of $20 \%$ where female drivers per number of females over the age of 16 are concerned in 2009).

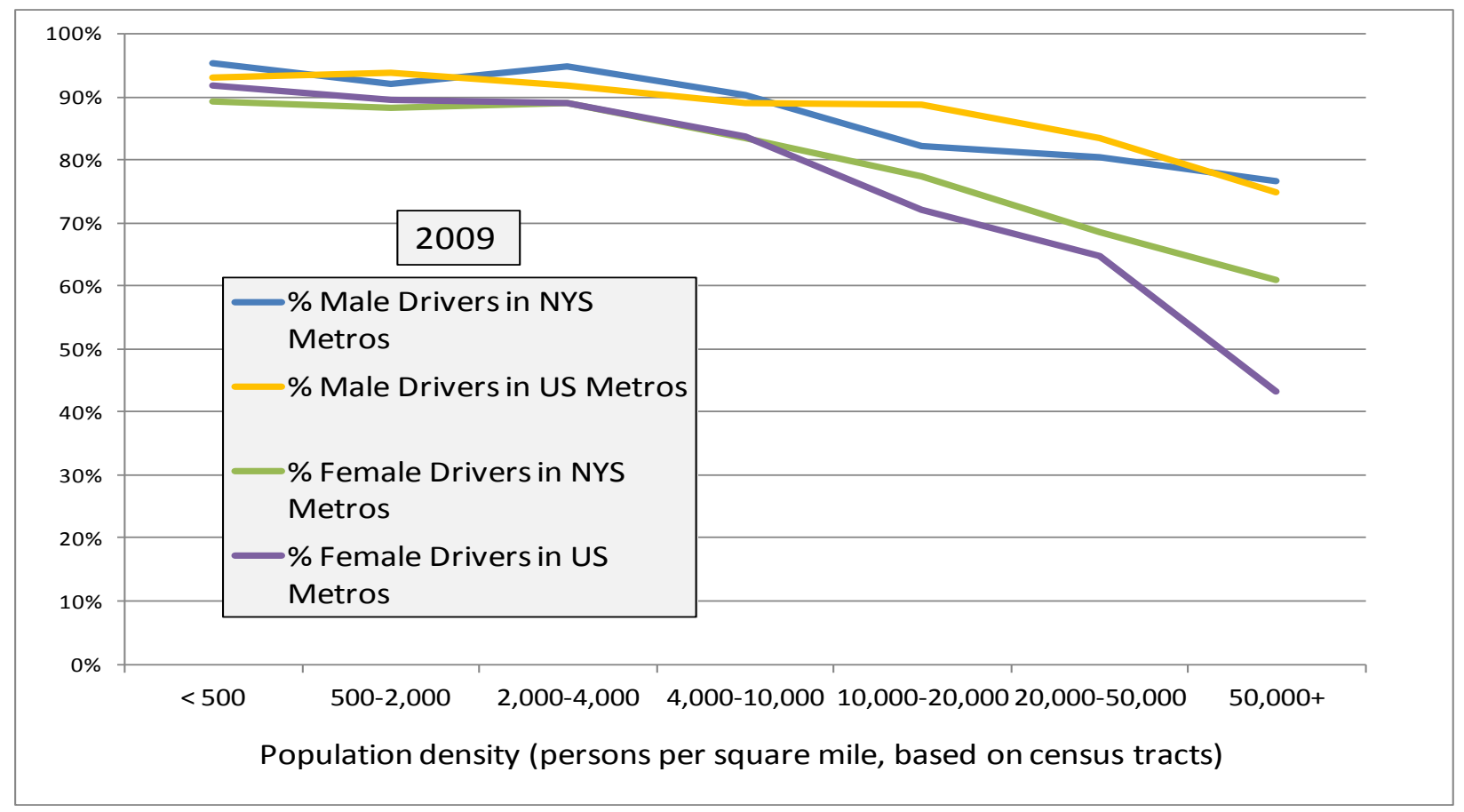

Figure 4.6 Driver Rates* by Gender and Population Density in 2009: New York State Metros vs. Metros Outside New York State.

${ }^{11}$ About half of the NYS metro area households in the 10,000 to 20,000 ppsm density range are located in NYC, while about $90 \%$ of the 20,000 to 50,000 ppsm households are in NYC. 


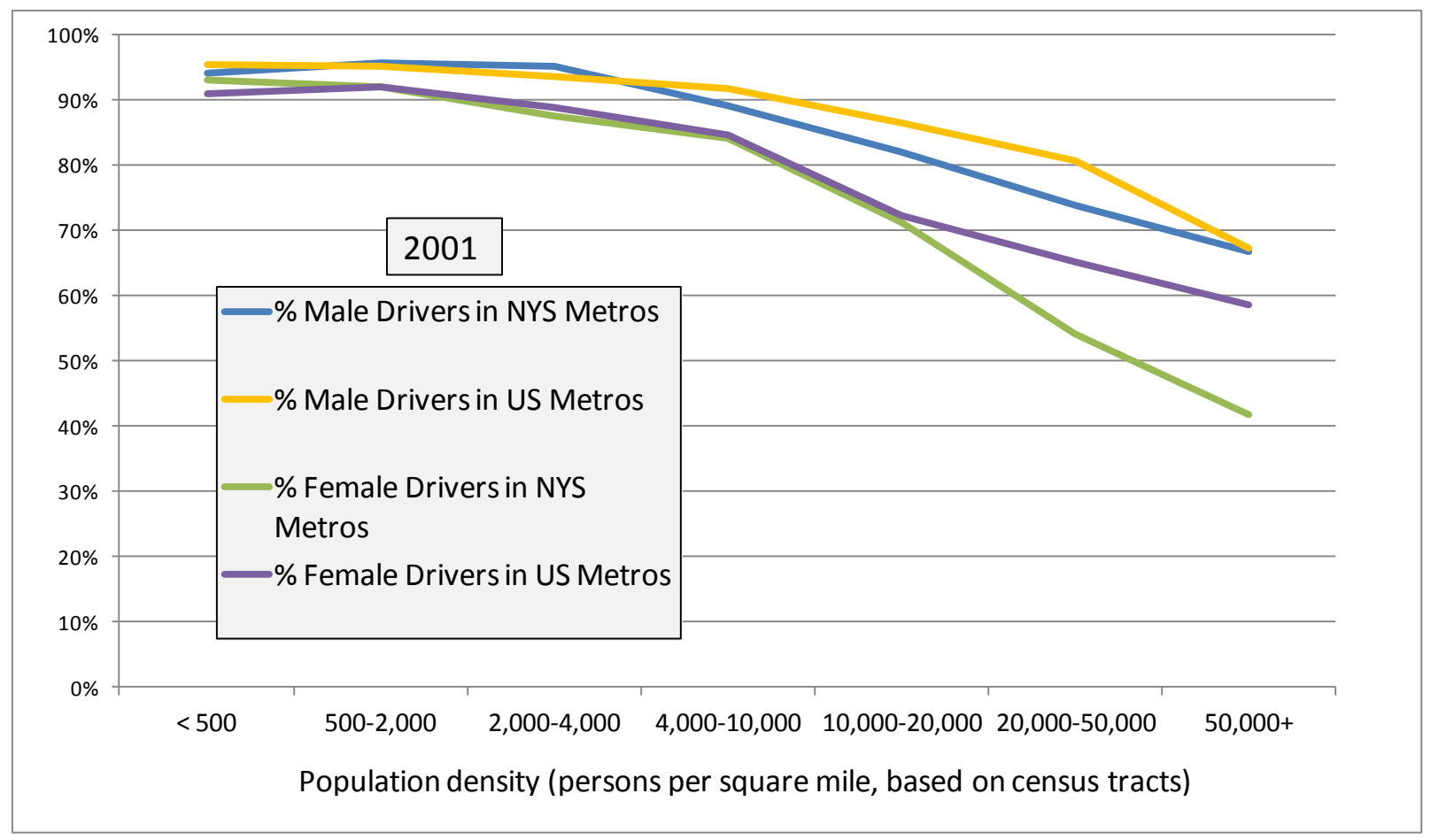

Figure 4.7 Driver Rates* by Gender and Population Density in 2001: New York State Metros vs. Metros Outside New York State.

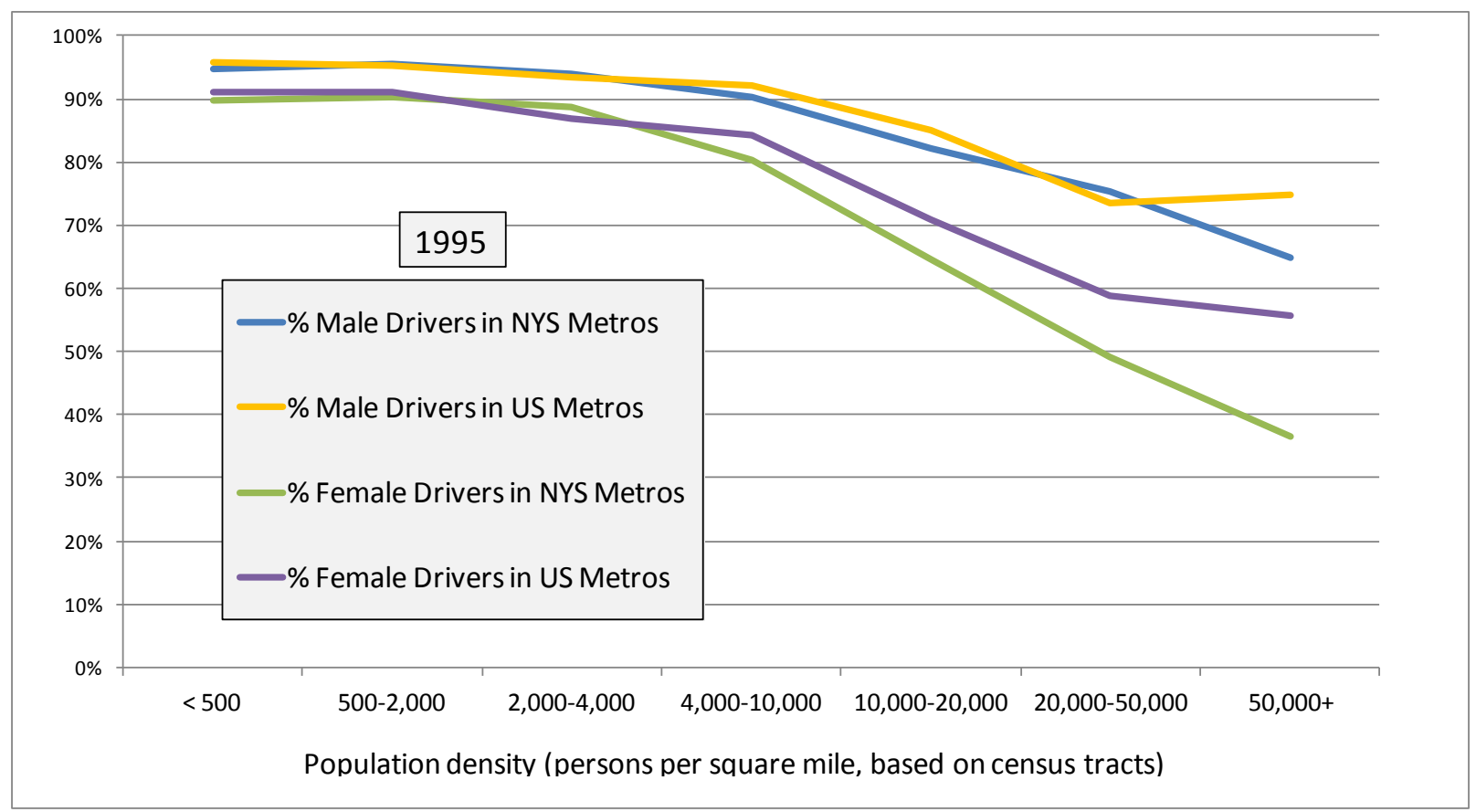

Figure 4.8 Driver Rates* by Gender and Population Density in 1995: New York State Metros vs. Metros Outside New York State. 


\subsection{PERSONAL TRAVEL COMPARISONS}

Trip Frequencies: The personal travel activities of households in metro areas within and outside NYS show broad similarities but also some statistically significant differences.

Beginning with a comparison of trip frequencies, the number of daily trips taken by households decreased from 1995 to 2001 and again in 2009, in both NYS and in the rest of the nation's metro areas (Figure 4.9). The only exception here is NYS households located in the 10,000 to 20,000 and 50,000+ density class.

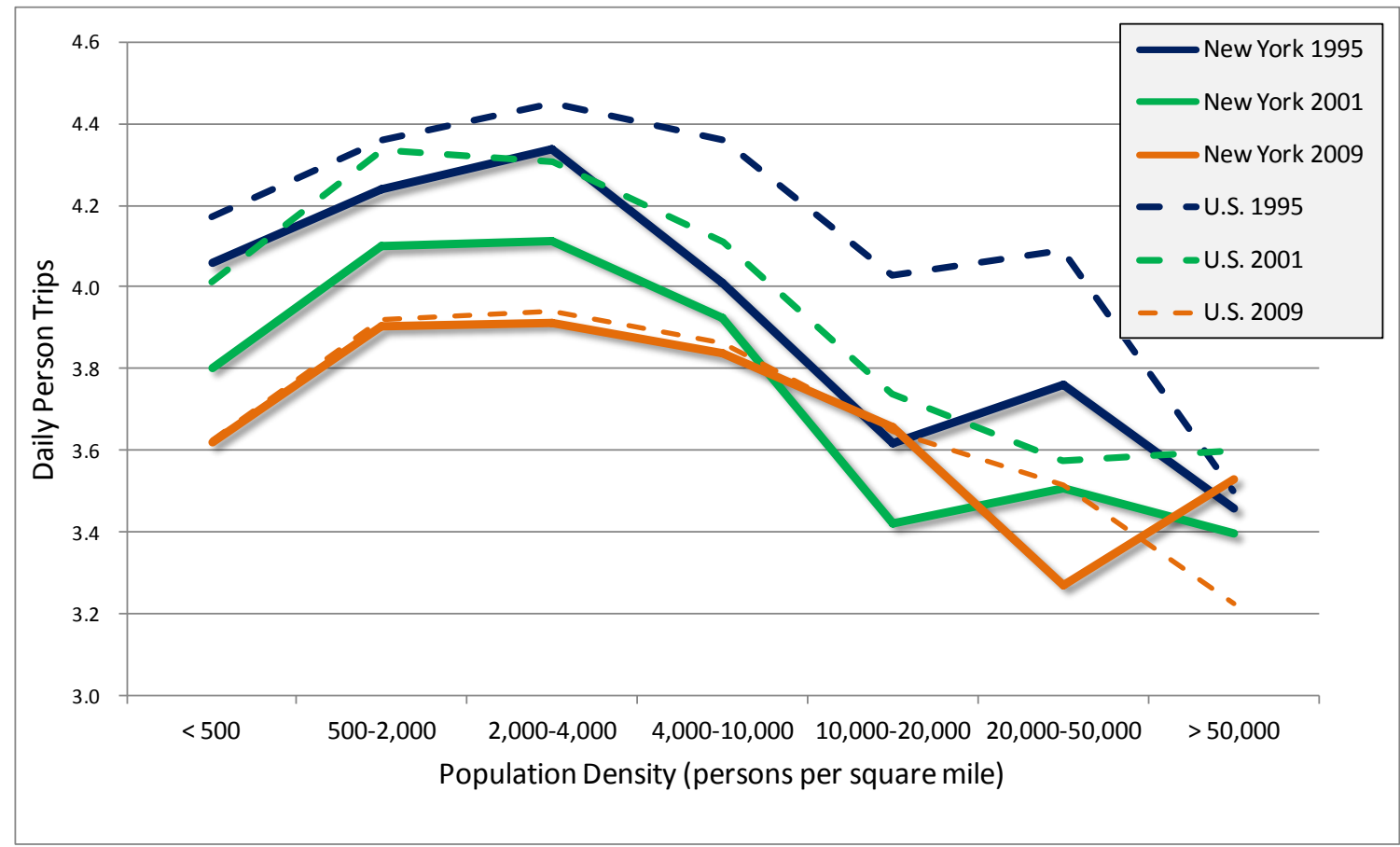

Figure 4.9 Daily Person Trips by Population Density for New York State Metros vs. Metros Found Outside New York State (data based on census tracts).

Figure 4.9 shows that daily person trip rates were consistently highest in the 500 through 10,000 ppsm density ranges, whether looked at across all three survey years or across state lines. Across all years, locations and density classes, rates vary from a high of over 4.4 trips per person per day to a low of just over 3.2 trips per day. Also noticeable in Figure 4.9 is the reduced gap in 2009 in the differences between the generally higher 1995 and 2001 NYS person trip rates, versus those metro areas in the rest of the United States, at most density levels (see the two brown lines in Figure 4.9). Consistent both within and outside the state, the relationship between daily trip rate and population density is quasi bell-shaped - first increasing, then declining with 
increasing population density. Residents in the densest areas take the fewest number of trips per day. ${ }^{12}$

Consistent with the person trip rate statistics reported in Chapters 2 and 3 of this report, and regardless of either location or gender, most people living in metro area households took fewer trips on the average in 2009 than they did in 1995. Figure 4.10 above shows this trend. While not all differences shown are statistically significant for all density classes, the trend towards fewer trips is evident when looked at across all density classes, with the exception of trips in the 10,000 to 20,000 ppsm density class for NYS metro areas. (Comparisons for densities greater than 50,000 ppsm are excluded from Figure 4.8 because of small sample sizes for nonNYS metro area households).

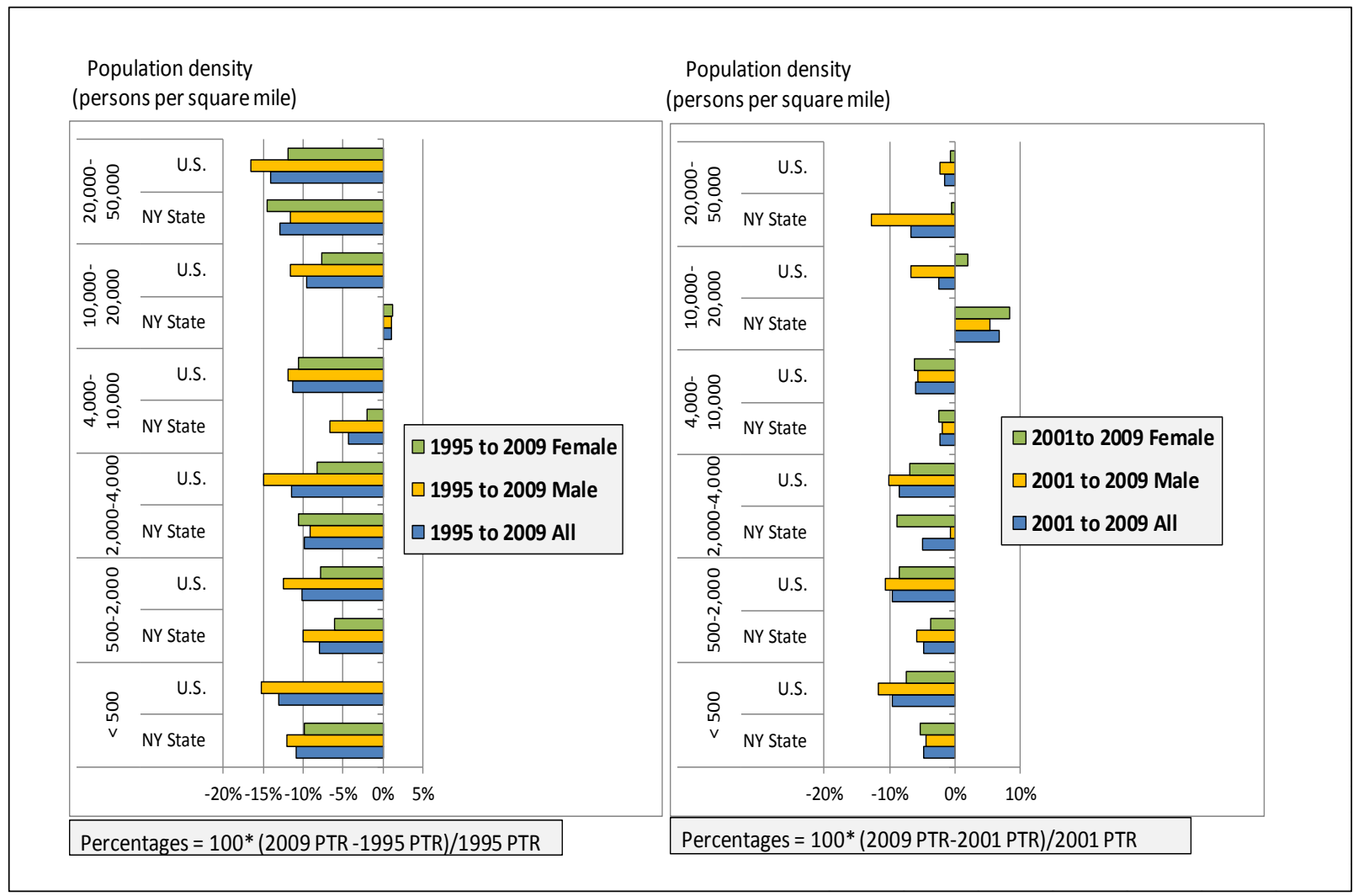

Figure 4.10 Percentage Changes in Daily Person Trip Rates per Person (PTR) by Gender and Population Density.

${ }^{12}$ The upswing in the 2009 trip rate for NYS metro areas with > 50,000 ppsm shown in Figure 4.7 exaggerated the change in rate between 2001 and 2009, from 3.40 to 3.51 person trips per day, with standard errors of 0.12 and 0.08 respectively. Similarly, the apparent drop in the 2009 trip rate in the 20,000 to 50,000 ppsm density class is a little misleading in this figure, with only a marginal difference between 2001 and 2009 estimates once standard errors for each year are taken into account. 


\subsubsection{Trip Lengths}

Trip lengths are also affected significantly by population densities. Outside NYS, the average trip length declines with increasing population density, ranging from 12.5 miles per trip in the least populated metro areas to 2.6 miles per trip in the densest metro areas in 2009 (Figure 4.11).

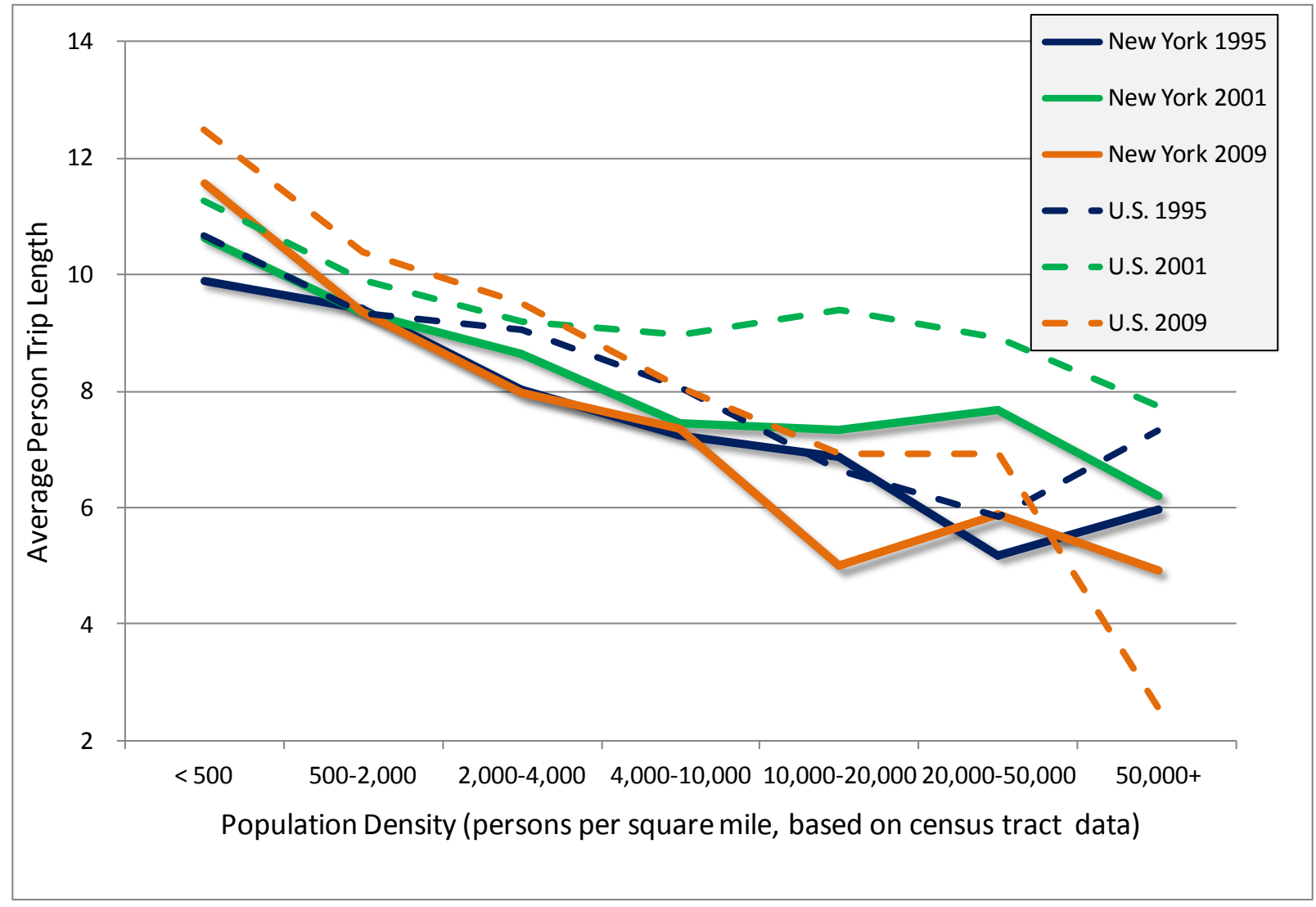

Figure 4.11 Average Person Trip Lengths by Population Density Class: New York State Metros vs. Metros Outside New York State.*

While average trip lengths by residents of NYS metro areas were generally a little lower than those in metro areas in the rest of the nation, in all three survey years, once the standard errors of these estimates are taken into account these differences are quite small for most density classes (see Appendix C.4 for details). In 2009, a very low average trip length of 2.6 miles is associated with the highest density metro areas in the rest of the United States, and while based on a small sample size is still statistically lower than the 4.9 mile average reported for the highest density areas within NYS metros (principally within NYC).

Average trip lengths from residents of NYS metro areas were slightly longer in 2001 than in 1995 for the highest density areas. In 2009, these highest density area trip lengths were lower than in 2001. The 2001 increased trip lengths may have resulted from many workers commuting 
to new employment locations away from Manhattan post ' $9 / 11$ ', or traveling by auto instead of taking air travel. Evidence from elsewhere suggests that it took about two years for the NYC employment payroll to begin to recover. ${ }^{13}$ The return to shorter average trip distances for 2009 may reflect something of a return to pre-9/11 employment conditions in Manhattan: although this is speculative and other factors, such as increased telecommuting, may be at work here.

The temporal changes in average trip lengths between the 2001 and 2009 surveys, as well as over the longer period from 1995 to 2009, are presented in Figure 4.12. Between 2001 and 2009 average trip lengths increased in a number of the lower density metro areas, but decreased more significantly in areas over 20,000 ppsm. Between 1995 and 2009, however, in all but one case (NYS metros in the 10,000 to 20,000 ppsm class) average trip lengths increased at both ends of the density spectrum and stayed roughly the same in the middle density range.

Figure 4.13 shows the distribution of trip lengths by population density class for NYS metro areas for 1995, 2001, and 2009. The distributions remained quite stable over the fourteen year period, with the percentage of trips over 5 miles in length significantly lower in the high versus low population density classes. The percentage of trips shorter than 10 miles in length remains relatively stable over the three survey years.

13 "Taking the Pulse of the New York City Economy," Current Issues in Economics and Finance, Volume 12, Number 4. Federal Reserve Bank of New York, May/June 2006. 


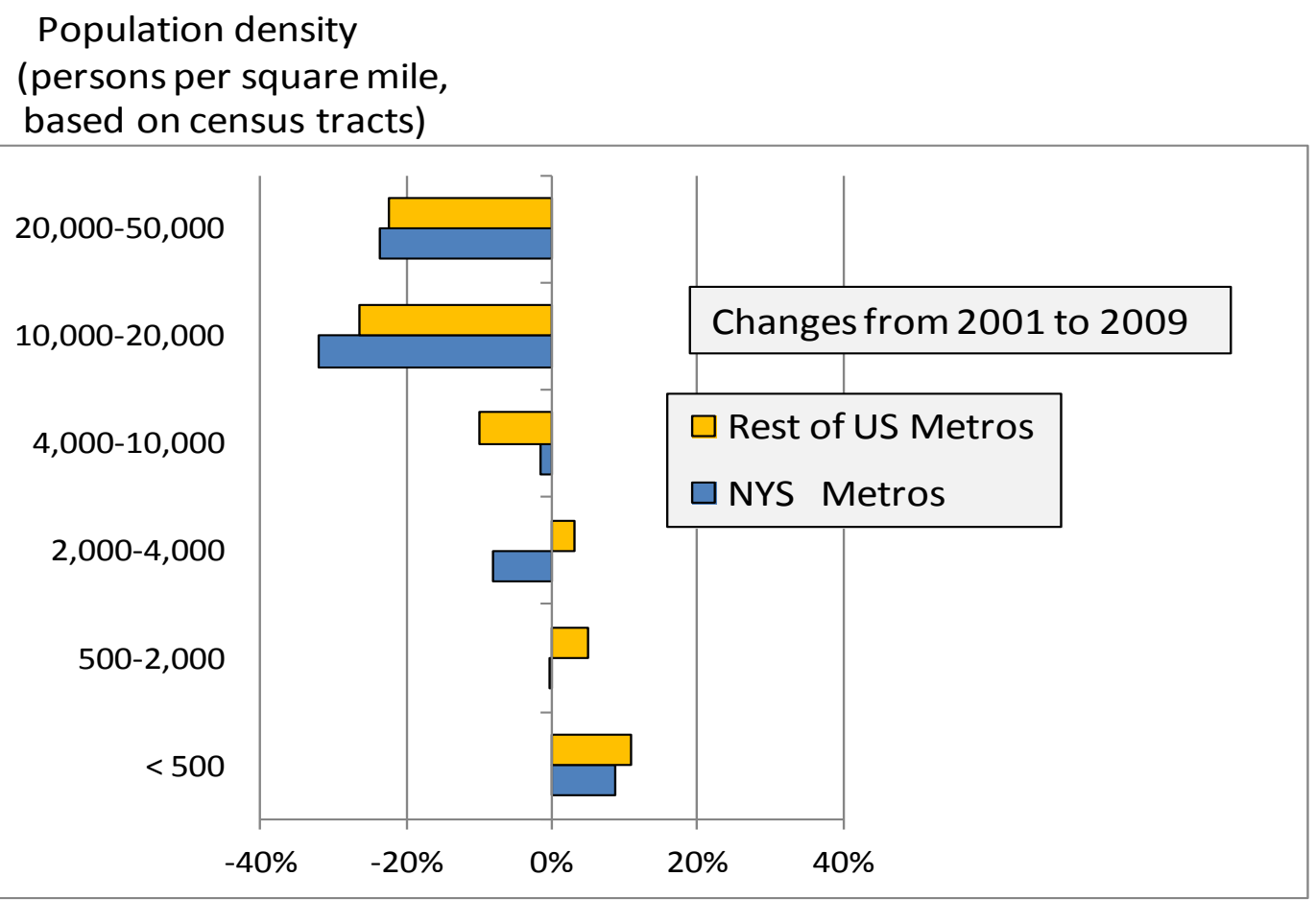

Population density

(persons per square mile, based on census tracts)

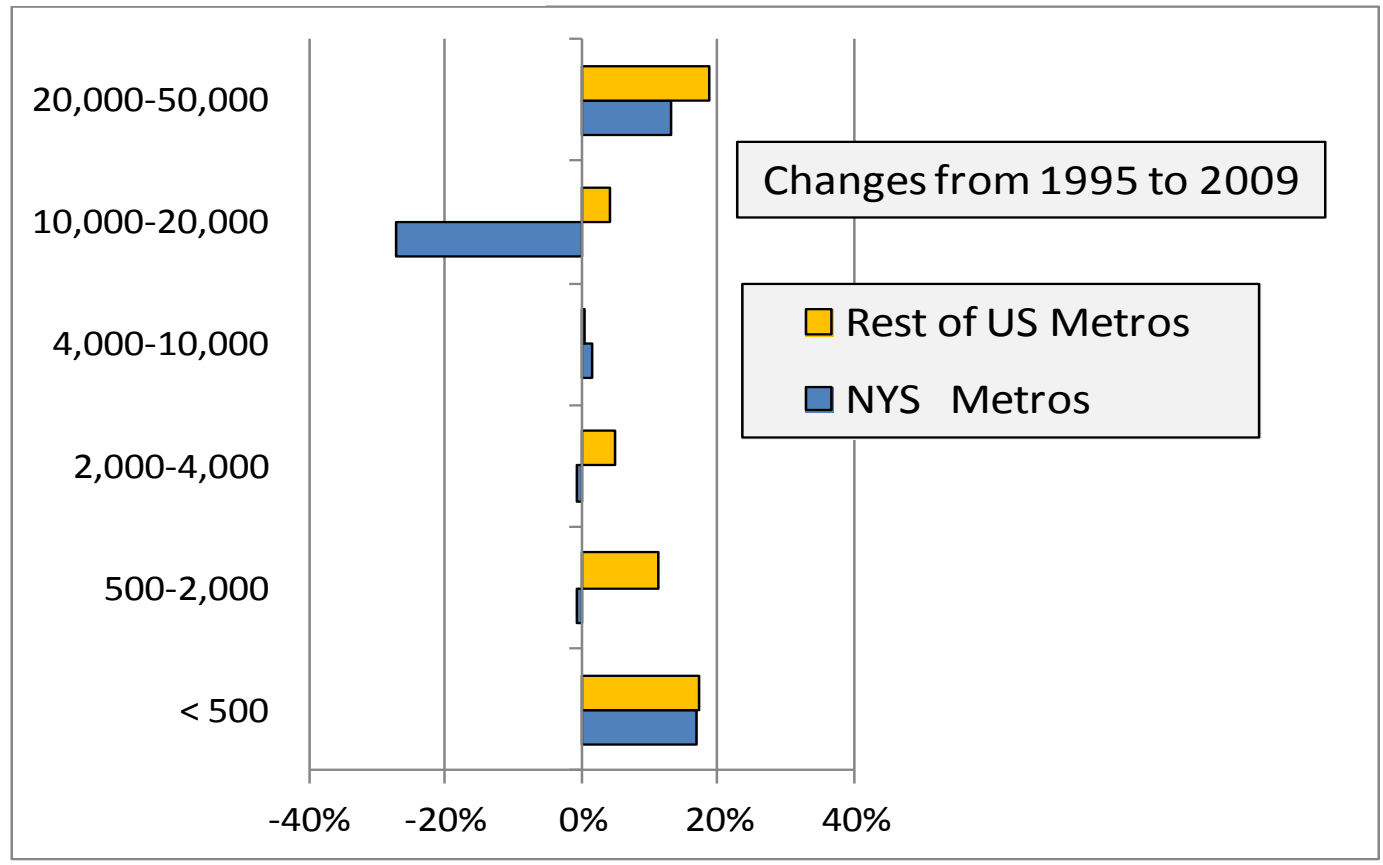

Figure 4.12 Percentage Differences in Trip Length from 2001 to 2009 and from 1995 to 2009: New York State Metros versus Metros Outside New York State. 

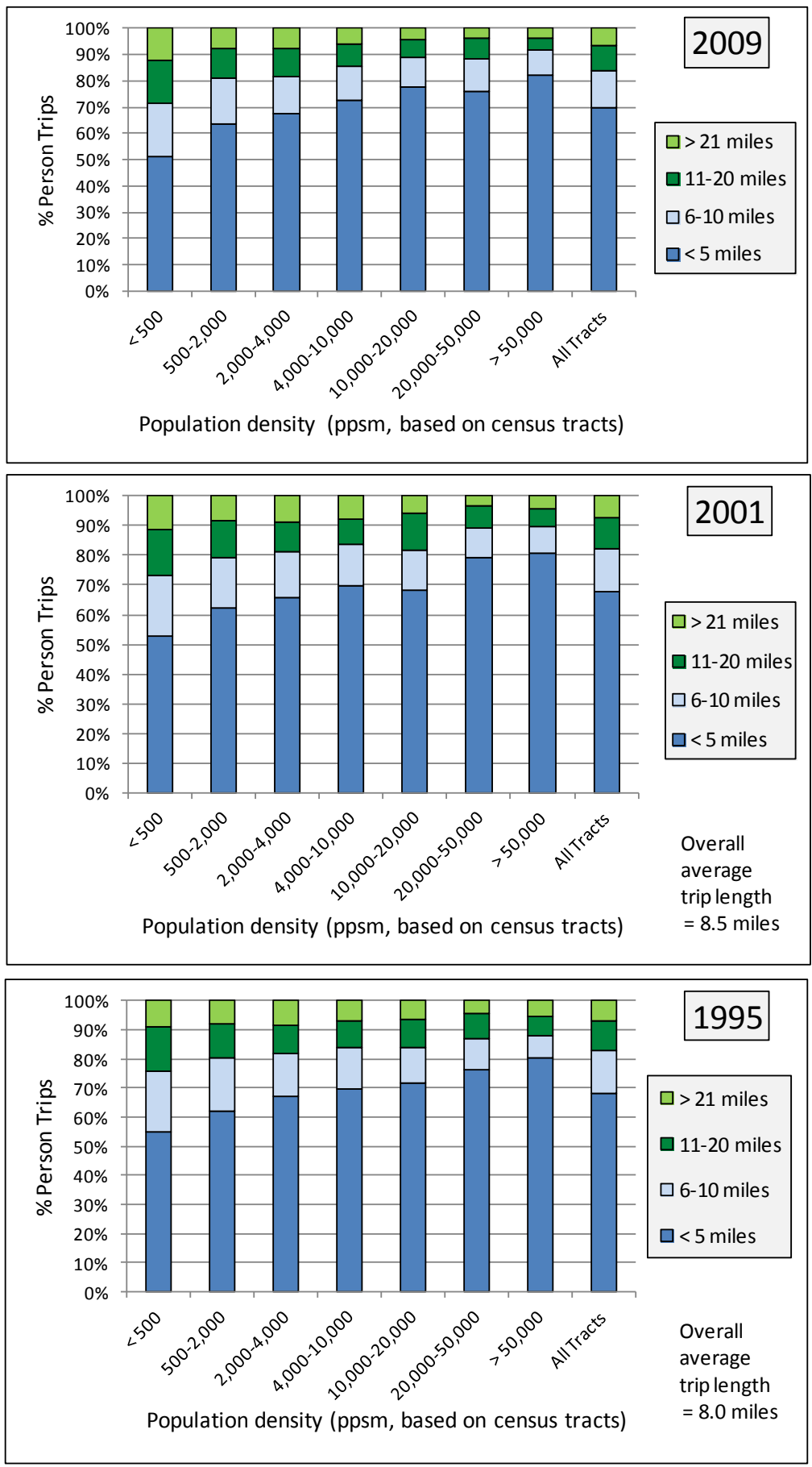

Figure 4.13 Distribution of Person Trips

by Trip Length and Population Density for New

York Metros. 


\subsubsection{PERSON MILES OF TRAVEL (PMT)}

In combination, daily trip frequencies and trip lengths define the average daily PMT. Figure 4.14 shows the resulting decline in average PMT with increasing urban population density, both inside and outside NYS. NYS metro area residents traveled fewer miles per day, on the average, in all density classes, with the exception of the most dense areas $(>50,000 \mathrm{ppsm})$ in 2009.

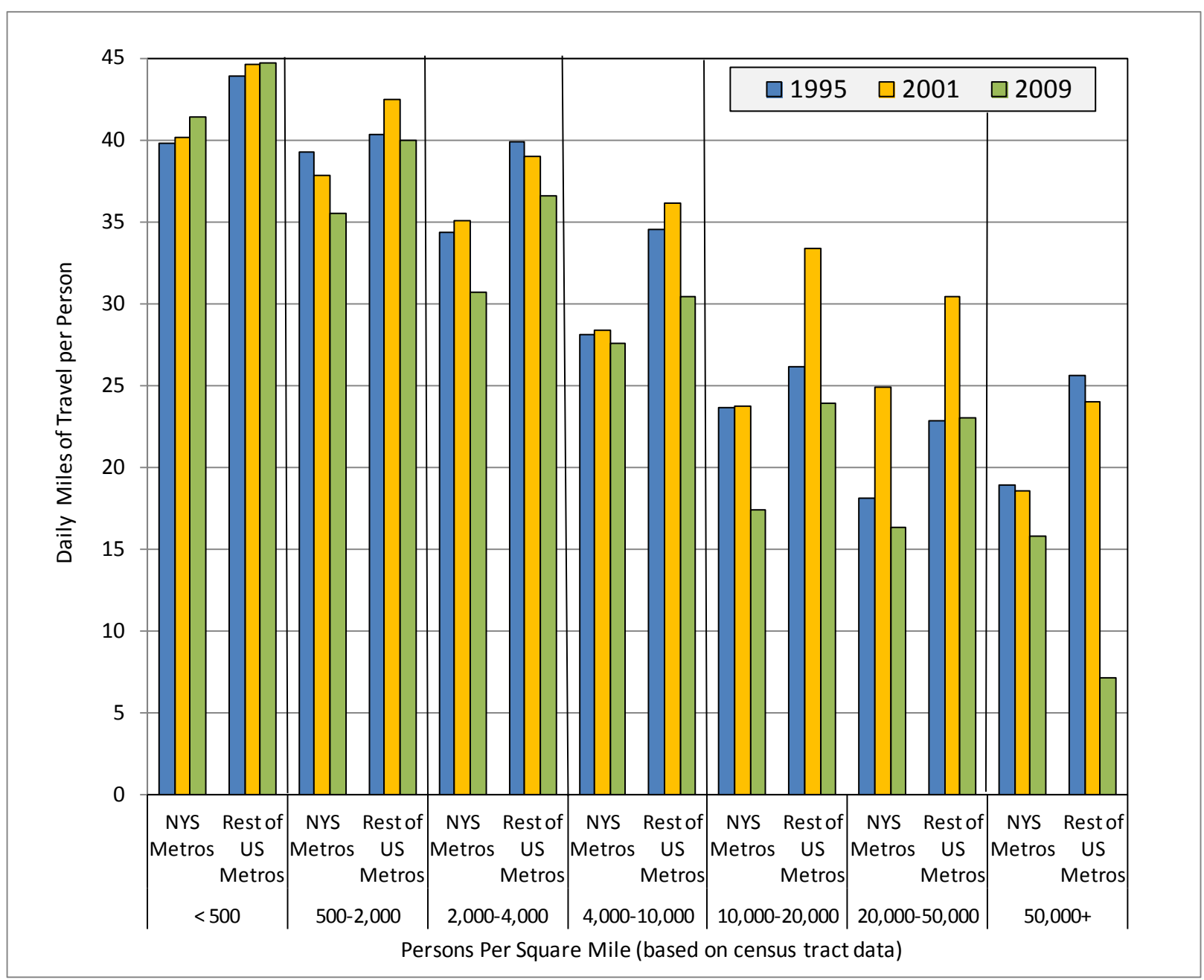

Figure 4.14 Daily Person Miles of Travel by Population Density in NYS and Rest of US Metro Areas for 1995, 2001, and 2009.

The very low average daily PMT for non-NYS metros (the result of both a low trip rate and low average trip length: Table 4.7) represents something of an anomaly here. 
Table 4.7 Personal Travel Statistics by Mode of Transportation and Population Density New York State Metros (NYS) vs. Metros Outside New York State (U.S.) in 2009

(population densities based on of census tracts)

\begin{tabular}{|c|c|c|c|c|c|c|c|c|c|c|c|c|c|c|}
\hline & \multicolumn{14}{|c|}{ 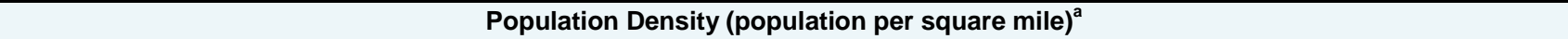 } \\
\hline & \multicolumn{2}{|c|}{$<500$} & \multicolumn{2}{|c|}{$500-2,000$} & \multicolumn{2}{|c|}{$2,000-4,000$} & \multicolumn{2}{|c|}{$4,000-10,000$} & \multicolumn{2}{|c|}{$10,000-20,000$} & \multicolumn{2}{|c|}{$20,000-50,000$} & \multicolumn{2}{|c|}{$50,000+$} \\
\hline & NYS & U.S. & NYS & U.S. & NYS & U.S. & NYS & U.S. & NYS & U.S. & NYS & U.S. & NYS & U.S. \\
\hline \multicolumn{15}{|c|}{ Person Trips per Person } \\
\hline TOTAL & 3.62 & 3.62 & 3.90 & 3.92 & 3.91 & 3.94 & 3.84 & 3.86 & 3.66 & 3.65 & 3.27 & 3.52 & 3.53 & 3.23 \\
\hline$\%$ SOV & $45.3 \%$ & $41.9 \%$ & $45.9 \%$ & $41.0 \%$ & $44.2 \%$ & $41.2 \%$ & $40.9 \%$ & $39.9 \%$ & $33.3 \%$ & $32.4 \%$ & $15.1 \%$ & $24.2 \%$ & $6.0 \%$ & $19.3 \%$ \\
\hline$\%$ MOV & $41.8 \%$ & $46.9 \%$ & $38.4 \%$ & $46.3 \%$ & $38.8 \%$ & $43.9 \%$ & $37.8 \%$ & $43.4 \%$ & $33.3 \%$ & $38.3 \%$ & $24.8 \%$ & $30.6 \%$ & $15.2 \%$ & $5.6 \%$ \\
\hline$\%$ Amtrak & $0.0 \% *$ & $0.0 \% *$ & $0.0 \% *$ & $0.0 \%$ & $0.0 \% *$ & $0.0 \%$ & & $0.0 \%$ & $0.1 \%$ & $0.1 \%$ & $1.1 \%$ & $0.1 \%^{*}$ & $0.2 \%$ & $0.4 \%$ * \\
\hline$\%$ Commuter Train & $0.1 \%$ & $0.0 \%$ & $0.4 \%$ & $0.1 \%$ & $0.6 \%$ & $0.1 \%$ & $0.6 \%$ & $0.2 \%$ & $0.6 \%$ & $0.1 \%$ & $1.9 \%$ & $1.1 \%$ & $1.7 \%$ & $0.6 \% *$ \\
\hline \% Subway/El Rail & $0.1 \%$ & $0.0 \%$ & $0.2 \%$ & $0.0 \%$ & $0.3 \%$ & $0.1 \%$ & $0.6 \%$ & $0.1 \%$ & $2.0 \%$ & $0.4 \%$ & $10.5 \%$ & $2.5 \%$ & $11.0 \%$ & $4.7 \%$ * \\
\hline$\%$ Other Public & $0.2 \%$ & $0.1 \%$ & $0.6 \%$ & $0.3 \%$ & $0.4 \%$ & $0.7 \%$ & $1.5 \%$ & $1.4 \%$ & $7.4 \%$ & $4.4 \%$ & $11.0 \%$ & $9.4 \%$ & $10.9 \%$ & $16.9 \%$ \\
\hline$\% W_{a l k}^{b}$ & $6.9 \%$ & $6.8 \%$ & $8.5 \%$ & $7.7 \%$ & $10.4 \%$ & $9.8 \%$ & $14.0 \%$ & $11.3 \%$ & $18.4 \%$ & $19.0 \%$ & $30.5 \%$ & $26.6 \%$ & $47.6 \%$ & $47.9 \%$ \\
\hline$\%$ Other & $5.5 \%$ & $4.1 \%$ & $5.9 \%$ & $4.5 \%$ & $5.1 \%$ & $4.1 \%$ & $4.6 \%$ & $3.4 \%$ & $4.4 \%$ & $5.1 \%$ & $4.9 \%$ & $5.4 \%$ & $7.3 \%$ & $4.7 \%$ \\
\hline$\%$ Unreported & $0.2 \%$ & $0.2 \%$ & $0.1 \%$ & $0.2 \%$ & $0.3 \%$ & $0.1 \%$ & $0.1 \%$ & $0.3 \%$ & $0.4 \%$ & $0.3 \%$ & $0.2 \%$ & $0.1 \%^{*}$ & $0.0 \% *$ & \\
\hline \multicolumn{15}{|c|}{ Person Miles Traveled (PMT) per Person } \\
\hline TOTAL & 41.34 & 44.67 & 35.52 & 39.94 & 30.67 & 36.58 & 27.54 & 30.40 & 17.33 & 23.93 & 16.29 & 23.01 & 15.75 & 7.10 \\
\hline$\%$ SOV & $43.4 \%$ & $41.5 \%$ & $41.8 \%$ & $39.3 \%$ & $43.7 \%$ & $36.2 \%$ & $37.1 \%$ & $38.1 \%$ & $37.8 \%$ & $38.2 \%$ & $16.2 \%$ & $34.4 \%$ & $11.6 \%$ & $38.7 \%$ \\
\hline$\%$ MOV & $47.9 \%$ & $51.5 \%$ & $45.1 \%$ & $45.5 \%$ & $40.2 \%$ & $52.2 \%$ & $37.4 \%$ & $47.5 \%$ & $38.5 \%$ & $46.6 \%$ & $43.4 \%$ & $38.3 \%$ & $44.5 \%$ & $7.3 \%$ \\
\hline$\%$ Amtrak & $0.0 \% *$ & $0.0 \% *$ & $0.1 \% *$ & $0.1 \%$ & $0.1 \% *$ & $0.1 \%$ & & $0.1 \%$ & $2.5 \%$ & $0.3 \%$ & $0.3 \%$ & $0.2 \%^{*}$ & $0.1 \% *$ & $0.2 \%$ * \\
\hline$\%$ Commuter Train & $0.4 \%$ & $0.0 \%$ & $1.4 \%$ & $0.1 \%$ & $2.6 \%$ & $0.3 \%$ & $1.8 \%$ & $0.2 \%$ & $2.0 \%$ & $0.2 \%$ & $1.6 \%$ & $11.4 \%$ & $3.3 \%$ & $4.5 \% *$ \\
\hline \% Subway/El Rail & $0.2 \%$ & $0.0 \%$ & $0.3 \%$ & $0.0 \%$ & $0.3 \%$ & $0.1 \%$ & $0.7 \%$ & $0.2 \%$ & $2.3 \%$ & $0.3 \%$ & $13.4 \%$ & $2.7 \%$ & $15.1 \%$ & $4.8 \%$ * \\
\hline$\%$ Other Public & $0.1 \%$ & $0.1 \%$ & $0.4 \%$ & $0.2 \%$ & $0.3 \%$ & $0.5 \%$ & $1.1 \%$ & $1.3 \%$ & $7.5 \%$ & $2.7 \%$ & $6.9 \%$ & $5.9 \%$ & $9.5 \%$ & $17.7 \%$ \\
\hline$\%$ Walk & $0.4 \%$ & $0.4 \%$ & $0.6 \%$ & $0.5 \%$ & $1.0 \%$ & $0.7 \%$ & $1.1 \%$ & $1.0 \%$ & $2.7 \%$ & $2.0 \%$ & $4.6 \%$ & $2.7 \%$ & $8.6 \%$ & $14.8 \%$ \\
\hline$\%$ Other & $7.5 \%$ & $6.5 \%$ & $10.2 \%$ & $14.2 \%$ & $11.4 \%$ & $9.8 \%$ & $20.9 \%$ & $11.5 \%$ & $6.7 \%$ & $9.5 \%$ & $13.2 \%$ & $4.3 \%$ & $7.3 \%$ & $12.0 \%$ \\
\hline$\%$ Unreported & $0.1 \%$ & $0.1 \%$ & $0.1 \%$ & $0.1 \%$ & $0.4 \%$ & $0.1 \%$ & $0.0 \% *$ & $0.2 \%$ & $0.1 \%$ & $0.1 \%$ & $0.5 \%$ & & & \\
\hline \multicolumn{15}{|c|}{ Person Trips per Person } \\
\hline Weekday & 3.42 & 3.19 & 3.50 & 3.68 & 3.73 & 3.75 & 3.41 & 3.60 & 3.62 & 3.45 & 3.14 & 3.07 & 3.30 & 4.16 \\
\hline Weekend & 3.69 & 3.81 & 4.07 & 4.01 & 4.00 & 4.01 & 3.96 & 3.97 & 3.67 & 3.72 & 3.33 & 3.71 & 3.62 & 3.10 \\
\hline \multicolumn{15}{|c|}{ Average Person Trip Length $^{d}$} \\
\hline & 11.58 & 12.50 & 9.35 & 10.38 & 7.95 & 9.49 & 7.33 & 8.07 & 4.98 & 6.92 & 5.86 & 6.92 & 4.93 & 2.59 \\
\hline
\end{tabular}

a All percentages may not add to $100 \%$ due to rounding. ${ }^{b}$ Multiple prompts in the 2001 and 2009 surveys for walk trips increased the number of such trips considerably.

"The mode "Other" includes commercial and private air, commuter/school/charter /city to city bus, water, taxi, limousine, airport shuttle, bicycle, and other non-specified vehicles.

${ }^{\mathrm{d}}$ Average trip length is calculated using only those records with trip mileage information present. $*=$ cells with large standard errors. Blank cells $=$ no survey responses. 
Table 4.8 Personal Travel Statistics by Mode of Transportation and Population Density

New York State Metros (NYS) vs. Metros Outside New York State (U.S.) in 2001

(population density of census tract)

\begin{tabular}{|c|c|c|c|c|c|c|c|c|c|c|c|c|c|c|}
\hline & \multicolumn{14}{|c|}{ Population Density (population per square mile) ${ }^{a}$} \\
\hline & \multicolumn{2}{|c|}{$<500$} & \multicolumn{2}{|c|}{$500-2,000$} & \multicolumn{2}{|c|}{$2,000-4,000$} & \multicolumn{2}{|c|}{$4,000-10,000$} & \multicolumn{2}{|c|}{$10,000-20,000$} & \multicolumn{2}{|c|}{$20,000-50,000$} & \multicolumn{2}{|c|}{$50,000+$} \\
\hline & NYS & U.S. & NYS & U.S. & NYS & U.S. & NYS & U.S. & NYS & U.S. & NYS & U.S. & NYS & U.S. \\
\hline \multicolumn{15}{|c|}{ Person Trips per Person } \\
\hline$\%$ SOV & $42.1 \%$ & $41.8 \%$ & $44.2 \%$ & $40.8 \%$ & $39.9 \%$ & $42.3 \%$ & $39.0 \%$ & $39.0 \%$ & $32.5 \%$ & $33.8 \%$ & $18.2 \%$ & $27.6 \%$ & $8.0 \%$ & $22.4 \%$ \\
\hline$\%$ MOV & $44.2 \%$ & $48.7 \%$ & $43.0 \%$ & $49.0 \%$ & $46.3 \%$ & $46.7 \%$ & $41.6 \%$ & $47.0 \%$ & $34.6 \%$ & $41.9 \%$ & $26.8 \%$ & $38.0 \%$ & $15.6 \%$ & $15.3 \%$ \\
\hline$\%$ Amtrak & $0.0 \%$ & $0 \% *$ & $0.1 \%$ & $0 \% *$ & $0.1 \%$ & $0.1 \%$ & $0.2 \%$ & $0.0 \%$ & $0.5 \%$ & $0.1 \% *$ & $0.3 \%$ & & $0.4 \%$ & \\
\hline$\%$ Commuter Train & $0.2 \%$ & $0.0 \%$ & $0.2 \%$ & $0.0 \%$ & $0.6 \%$ & $0.1 \%$ & $0.9 \%$ & $0.2 \%$ & $0.4 \%$ & $0.1 \%$ & $0.5 \%$ & $0.2 \%$ & $0.4 \%$ & \\
\hline \% Subway/El Rail & $0.4 \%$ & $0.0 \%$ & $0.3 \%$ & $0.1 \%$ & $0.5 \%$ & $0.1 \%$ & $0.8 \%$ & $0.2 \%$ & $4.8 \%$ & $0.8 \%$ & $10.0 \%$ & $1.7 \%$ & $16.1 \%$ & $5.0 \%$ \\
\hline$\%$ Other Public & $0.7 \%$ & $0.1 \%$ & $0.1 \%$ & $0.2 \%$ & $0.5 \%$ & $0.5 \%$ & $1.2 \%$ & $1.3 \%$ & $4.0 \%$ & $3.9 \%$ & $7.4 \%$ & $7.7 \%$ & $10.3 \%$ & $19.5 \%$ \\
\hline$\% W_{a l k}^{b}$ & $7.2 \%$ & $5.5 \%$ & $7.3 \%$ & $5.9 \%$ & $7.7 \%$ & $7.5 \%$ & $11.6 \%$ & $9.7 \%$ & $19.3 \%$ & $16.2 \%$ & $32.4 \%$ & $20.4 \%$ & $43.9 \%$ & $34.0 \%$ \\
\hline$\%$ Other & $5.1 \%$ & $3.8 \%$ & $4.6 \%$ & $3.8 \%$ & $4.4 \%$ & $2.6 \%$ & $4.7 \%$ & $2.6 \%$ & $3.7 \%$ & $3.4 \%$ & $4.3 \%$ & $4.3 \%$ & $5.2 \%$ & $3.8 \%$ \\
\hline$\%$ Unreported & $0.1 \%$ & $0.1 \%$ & $0.1 \%$ & $0.1 \%$ & $0.1 \%$ & $0.1 \%$ & $0.1 \%$ & $0.1 \%$ & $0.2 \%$ & $0.0 \%$ & $0.1 \%^{*}$ & $0.1 \%^{*}$ & $0.1 \% *$ & $0.1 \% *$ \\
\hline \multicolumn{15}{|c|}{ Person Miles Traveled (PMT) per Person } \\
\hline TOTAL & 40.12 & 44.64 & 37.78 & 42.47 & 35.05 & 39.00 & 28.31 & 36.08 & 23.75 & 33.39 & 24.84 & 30.37 & 18.51 & 24.00 \\
\hline$\%$ SOV & $42.5 \%$ & $40.3 \%$ & $41.5 \%$ & $38.5 \%$ & $39.7 \%$ & $39.6 \%$ & $36.8 \%$ & $36.6 \%$ & $31.4 \%$ & $27.9 \%$ & $16.3 \%$ & $24.5 \%$ & $13.0 \%$ & $22.8 \%$ \\
\hline$\%$ MOV & $49.3 \%$ & $53.7 \%$ & $44.8 \%$ & $49.6 \%$ & $49.0 \%$ & $50.7 \%$ & $47.4 \%$ & $49.2 \%$ & $47.9 \%$ & $41.8 \%$ & $20.9 \%$ & $42.7 \%$ & $29.4 \%$ & $58.0 \%$ \\
\hline$\%$ Commuter Train & $0.7 \%$ & $0.1 \%$ & $0.7 \%$ & $0.2 \%$ & $2.2 \%$ & $0.1 \%$ & $2.9 \%$ & $0.5 \%$ & $1.4 \%$ & $0.3 \%$ & $0.9 \%$ & $0.2 \%$ & $0.5 \%$ & \\
\hline \% Subway/El Rail & $0.5 \%$ & $0.0 \%$ & $0.3 \%$ & $0.2 \%$ & $0.5 \%$ & $0.1 \%$ & $1.5 \%$ & $0.2 \%$ & $6.9 \%$ & $0.7 \%$ & $9.8 \%$ & $1.1 \%$ & $18.2 \%$ & $3.6 \% *$ \\
\hline$\%$ Other Public & $0.6 \%$ & $0.1 \%$ & $0.2 \%$ & $0.2 \%$ & $0.4 \%$ & $0.4 \%$ & $1.0 \%$ & $1.0 \%$ & $3.5 \%$ & $2.3 \%$ & $4.1 \%$ & $3.9 \%$ & $6.5 \%$ & $12.0 \%$ \\
\hline \% Walk & $0.6 \%$ & $0.4 \%$ & $0.7 \%$ & $0.5 \%$ & $0.7 \%$ & $0.6 \%$ & $1.3 \%$ & $0.8 \%$ & $2.2 \%$ & $1.2 \%$ & $3.4 \%$ & $1.5 \%$ & $4.9 \%$ & $2.9 \%$ \\
\hline$\%$ Other & $5.2 \%$ & $5.4 \%$ & $11.4 \%$ & $10.7 \%$ & $7.1 \%$ & $6.3 \%$ & $6.8 \%$ & $11.6 \%$ & $5.7 \%$ & $25.4 \%$ & $44.5 \%$ & $26.2 \%$ & $24.1 \%$ & $0.7 \%$ \\
\hline$\%$ Unreported & $0.0 \%$ & $0.2 \%$ & $0.1 \%$ & $0.1 \%$ & $0.2 \% *$ & $2.2 \%$ & $1.8 \%$ & $0.1 \%$ & $0.2 \%$ & $0.0 \%$ & $0.0 \% *$ & $0.0 \% *$ & $1.9 \% *$ & $0 \% *$ \\
\hline \multicolumn{15}{|c|}{ Person Trips per Person } \\
\hline Weekday & 3.59 & 3.69 & 3.96 & 4.20 & 3.98 & 4.01 & 3.78 & 3.97 & 3.17 & 3.84 & 3.03 & 3.40 & 3.00 & 2.63 \\
\hline Weekend & 3.89 & 4.14 & 4.15 & 4.38 & 4.17 & 4.43 & 3.98 & 4.17 & 3.52 & 3.70 & 3.70 & 3.65 & 3.58 & 3.93 \\
\hline \multicolumn{15}{|c|}{ Average Person Trip Length ${ }^{d}$} \\
\hline & 10.66 & 11.27 & 9.36 & 9.90 & 8.65 & 9.21 & 7.45 & 8.96 & 7.34 & 9.40 & 7.68 & 8.91 & 6.22 & 7.75 \\
\hline
\end{tabular}

${ }^{a}$ All percentages may not add to $100 \%$ due to rounding.

${ }^{\mathrm{b}}$ Multiple prompts in the 2001 and 2009 surveys for walk trips increased the number of such trips considerably.

c The mode "Other" includes commercial and private air, commuter/school/charter /city to city bus, water, taxi, limousine, airport shuttle, bicycle, and other non-specified vehicles.

${ }^{\mathrm{d}}$ Average trip length is calculated using only those records with trip mileage information present. $*$ Cells with large standard errors. Blank cells $=$ no survey responses. 
Table 4.9 Personal Travel Statistics by Mode of Transportation and Population Density New York State Metros (NYS) vs. Metros Outside New York State (U.S.) in 1995

(population density of census tract)

\begin{tabular}{|c|c|c|c|c|c|c|c|c|c|c|c|c|c|c|}
\hline & \multicolumn{14}{|c|}{ Population Density (population per square mile) ${ }^{a}$} \\
\hline & \multicolumn{2}{|c|}{$<500$} & \multicolumn{2}{|c|}{$500-2,000$} & \multicolumn{2}{|c|}{$2,000-4,000$} & \multicolumn{2}{|c|}{$4,000-10,000$} & \multicolumn{2}{|c|}{$10,000-20,000$} & \multicolumn{2}{|c|}{$20,000-50,000$} & \multicolumn{2}{|c|}{$50,000+$} \\
\hline & NYS & U.S. & NYS & U.S. & NYS & U.S. & NYS & U.S. & NYS & U.S. & NYS & U.S. & NYS & U.S. \\
\hline \multicolumn{15}{|c|}{ Person Trips per Person } \\
\hline TOTAL & 4.06 & 4.17 & 4.24 & 4.36 & 4.34 & 4.45 & 4.01 & 4.36 & 3.62 & 4.03 & 3.76 & 4.09 & 3.46 & 3.50 \\
\hline$\%$ SOV & $43.1 \%$ & $43.4 \%$ & $41.7 \%$ & $42.9 \%$ & $46.8 \%$ & $44.3 \%$ & $39.7 \%$ & $42.0 \%$ & $32.0 \%$ & $36.7 \%$ & $18.4 \%$ & $23.2 \%$ & $7.2 \%$ & $25.4 \%$ \\
\hline$\%$ MOV & $44.6 \%$ & $47.0 \%$ & $45.0 \%$ & $46.8 \%$ & $39.4 \%$ & $44.3 \%$ & $42.1 \%$ & $44.0 \%$ & $37.0 \%$ & $38.5 \%$ & $23.1 \%$ & $34.0 \%$ & $16.2 \%$ & $20.0 \%$ \\
\hline$\%$ Amtrak & $0.0 \%$ & $0.2 \%$ & $0.0 \%$ & $0.0 \%$ & $0.2 \%$ & $0.0 \%$ & $0.0 \%$ & $0.0 \%$ & $0.0 \%$ & $0.0 \%$ & $0.3 \%$ & $0.0 \%$ & $0.0 \%$ & \\
\hline$\%$ Commuter Train & $0.0 \%$ & $0.0 \%$ & $0.0 \%$ & $0.0 \%$ & $0.0 \%$ & $0.0 \%$ & $0.0 \%$ & $0.0 \%$ & . & $0.0 \%$ & $0.0 \%$ & & $0.0 \%$ & \\
\hline \% Subway/El Rail & $0.2 \%$ & $0.0 \%$ & $0.5 \%$ & $0.0 \%$ & $0.7 \%$ & $0.2 \%$ & $0.7 \%$ & $0.2 \%$ & $0.8 \%$ & $0.5 \%$ & $1.9 \%$ & $0.5 \%$ & $3.5 \%$ & $0.6 \%$ \\
\hline$\%$ Other Public & $0.2 \%$ & $0.0 \%$ & $0.0 \%$ & $0.0 \%$ & $0.2 \%$ & $0.0 \%$ & $0.7 \%$ & $0.0 \%$ & $3.0 \%$ & $1.0 \%$ & $8.2 \%$ & $1.7 \%$ & $13.3 \%$ & $6.9 \%$ \\
\hline$\%$ Walk $^{\mathrm{b}}$ & $0.5 \%$ & $0.2 \%$ & $0.5 \%$ & $0.5 \%$ & $0.7 \%$ & $0.9 \%$ & $1.5 \%$ & $1.6 \%$ & $6.4 \%$ & $5.0 \%$ & $8.5 \%$ & $8.3 \%$ & $11.0 \%$ & $12.9 \%$ \\
\hline$\%$ Other & $3.9 \%$ & $2.4 \%$ & $4.5 \%$ & $3.0 \%$ & $4.1 \%$ & $4.7 \%$ & $7.2 \%$ & $6.2 \%$ & $12.4 \%$ & $11.7 \%$ & $30.3 \%$ & $22.7 \%$ & $36.1 \%$ & $28.9 \%$ \\
\hline$\%$ Unreported & $4.4 \%$ & $3.6 \%$ & $4.2 \%$ & $3.7 \%$ & $4.1 \%$ & $2.7 \%$ & $3.7 \%$ & $2.3 \%$ & $3.0 \%$ & $2.2 \%$ & $4.0 \%$ & $3.4 \%$ & $6.4 \%$ & $1.4 \%$ \\
\hline \multicolumn{15}{|c|}{ Person Miles Traveled (PMT) per Person } \\
\hline TOTAL & 39.75 & 43.90 & 39.25 & 40.28 & 34.31 & 39.89 & 28.12 & 34.49 & 23.60 & 26.13 & 18.05 & 22.84 & 18.93 & 25.59 \\
\hline$\%$ SOV & $42.4 \%$ & $42.7 \%$ & $37.1 \%$ & $41.4 \%$ & $43.7 \%$ & $38.4 \%$ & $38.9 \%$ & $41.1 \%$ & $34.1 \%$ & $40.1 \%$ & $26.1 \%$ & $31.8 \%$ & $12.8 \%$ & $16.0 \%$ \\
\hline$\%$ MOV & $48.3 \%$ & $52.0 \%$ & $55.6 \%$ & $51.0 \%$ & $47.4 \%$ & $49.4 \%$ & $48.3 \%$ & $49.0 \%$ & $48.9 \%$ & $44.4 \%$ & $36.4 \%$ & $47.0 \%$ & $38.4 \%$ & $68.4 \%$ \\
\hline$\%$ Amtrak & $0.0 \%$ & $0.1 \%$ & $0.0 \%$ & $0.0 \%$ & $0.3 \%$ & $0.4 \%$ & $0.0 \%$ & $0.1 \%$ & $0.0 \%$ & $0.0 \%$ & $0.4 \%$ & $0.0 \%$ & $0.1 \%$ & \\
\hline$\%$ Commuter Train & $1.8 \%$ & $0.0 \%$ & $0.1 \%$ & $0.0 \%$ & $0.0 \%$ & $0.1 \%$ & $0.4 \%$ & $0.0 \%$ & & $0.1 \%$ & & & $0.2 \%$ & \\
\hline \% Subway/El Rail & $0.7 \%$ & $0.1 \%$ & $1.5 \%$ & $0.2 \%$ & $2.7 \%$ & $0.5 \%$ & $3.3 \%$ & $0.4 \%$ & $2.2 \%$ & $0.7 \%$ & $3.0 \%$ & $0.6 \%$ & $7.4 \%$ & $1.5 \%$ \\
\hline$\%$ Other Public & $0.2 \%$ & $0.0 \%$ & $0.1 \%$ & $0.1 \%$ & $0.1 \%$ & $0.2 \%$ & $1.4 \%$ & $0.1 \%$ & $3.9 \%$ & $1.2 \%$ & $16.1 \%$ & $1.9 \%$ & $16.6 \%$ & $6.5 \%$ \\
\hline \% Walk & $1.3 \%$ & $0.3 \%$ & $0.9 \%$ & $0.4 \%$ & $1.1 \%$ & $2.1 \%$ & $2.9 \%$ & $1.4 \%$ & $6.9 \%$ & $8.3 \%$ & $9.3 \%$ & $8.8 \%$ & $10.7 \%$ & $3.7 \%$ \\
\hline$\%$ Other & $0.4 \%$ & $0.1 \%$ & $0.3 \%$ & $0.2 \%$ & $0.3 \%$ & $0.3 \%$ & $0.6 \%$ & $0.4 \%$ & $0.9 \%$ & $0.9 \%$ & $3.6 \%$ & $2.1 \%$ & $4.1 \%$ & $3.4 \%$ \\
\hline$\%$ Unreported & $4.0 \%$ & $3.9 \%$ & $3.5 \%$ & $5.9 \%$ & $3.3 \%$ & $6.8 \%$ & $2.8 \%$ & $6.6 \%$ & $2.1 \%$ & $2.8 \%$ & $4.4 \%$ & $7.5 \%$ & $8.9 \%$ & $0.2 \%$ \\
\hline \multicolumn{15}{|c|}{ Person Trips per Person } \\
\hline Weekday & 3.89 & 3.86 & 3.90 & 4.10 & 4.24 & 4.07 & 3.80 & 4.12 & 3.60 & 3.76 & 3.47 & 4.16 & 3.05 & 2.58 \\
\hline Weekend & 4.13 & 4.29 & 4.36 & 4.47 & 4.38 & 4.60 & 4.10 & 4.45 & 3.63 & 4.17 & 3.91 & 4.06 & 3.62 & 3.65 \\
\hline \multicolumn{15}{|c|}{ Average Person Trip Length ${ }^{c}$} \\
\hline & 9.91 & 10.66 & 9.41 & 9.33 & 8.02 & 9.06 & 7.23 & 8.05 & 6.85 & 6.64 & 5.18 & 5.83 & 5.95 & 7.31 \\
\hline
\end{tabular}

${ }_{b}^{a}$ All percentages may not add to $100 \%$ due to rounding.

${ }^{b}$ The mode "Other" includes commercial and private air, commuter/school/charter/city to city bus, water, taxi, limousine, airport shuttle, bicycle, and other non-specified vehicles.

${ }^{c}$ Average trip length is calculated using only those records with trip mileage information present. Blank cells = no survey responses. Standard errors were not computed for 1995 statistics. 


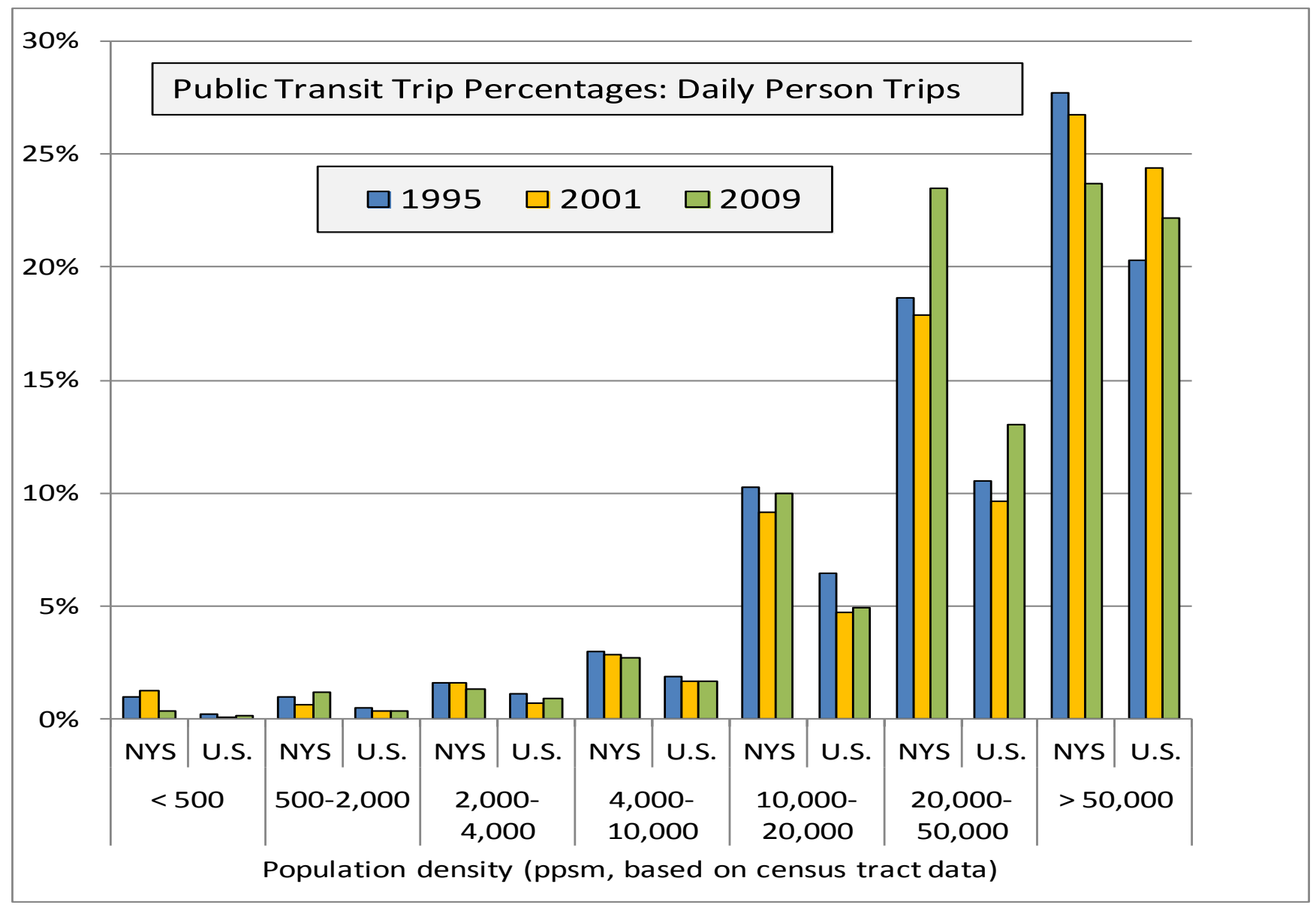

Figure 4.15 Public Transit Trip Percentages of Daily Person Trips by Population Density. 


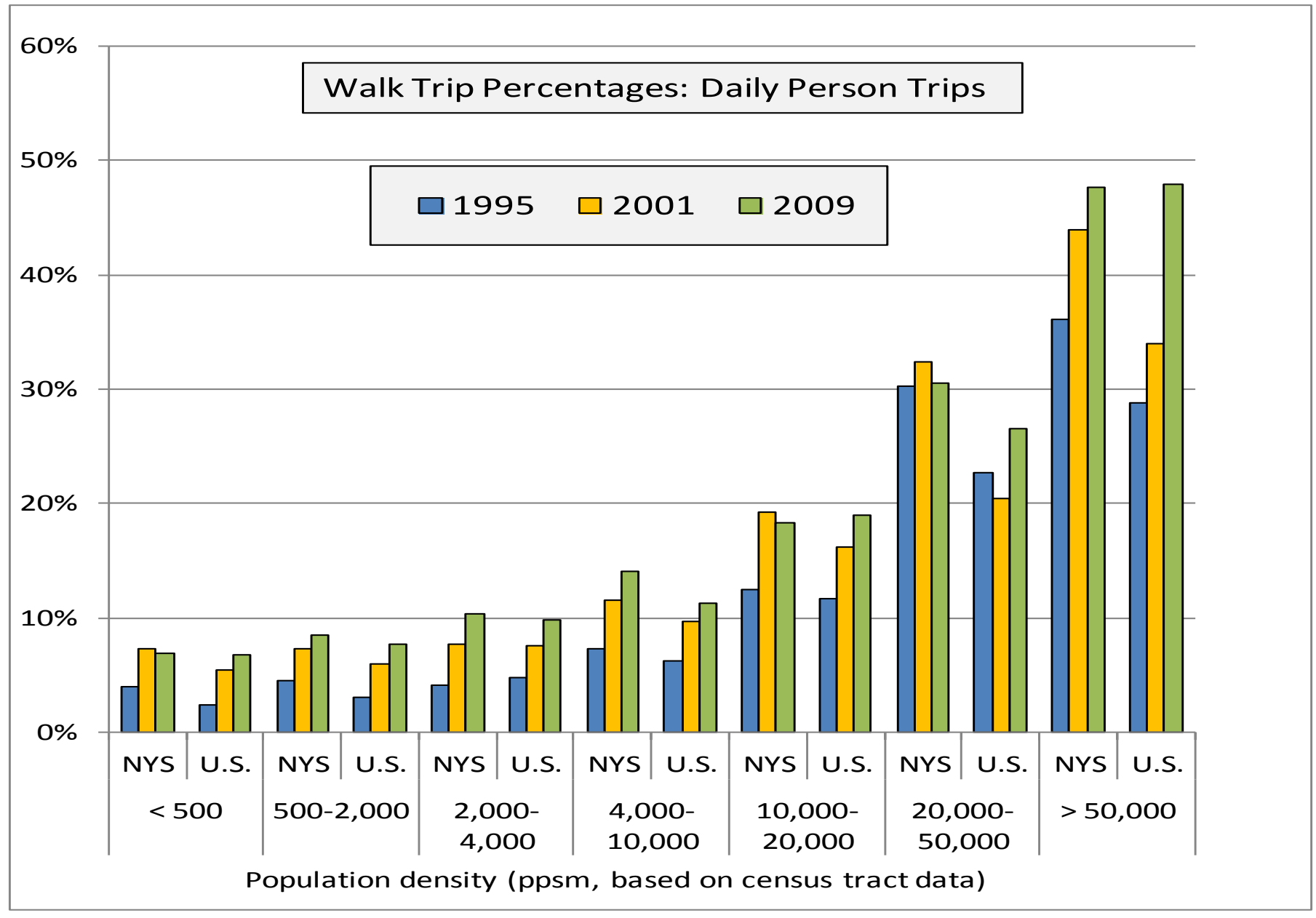

Figure 4.16 Walking Trip Percentages of Daily Person Trips by Population Density. 


\subsubsection{Public Transit, Walk, and Cycle Trips}

The percentage of trips taken in non-private vehicles (principally public transit and walking) also increases significantly with increasing population density (Tables 4.7, 4.8 and 4.9). Figures 4.15 and 4.16 show the percentages of daily person trips that are by public transit (commuter rail, elevated and subway trains and other, including bus transit) and walking, respectively, by residential density classes. Residents living in more densely populated areas are clearly much more likely to ride transit and/or walk to their trip destinations than those in low density areas.

When combined, based on results shown in Tables 4.3a-c, these transit and walk alternatives accounted for ten times the percentage of NYS metro area trips among 2009 travelers in the highest density class $(47.6 \%$ walk $+23.7 \%$ transit $=71.3 \%$ of person trips $)$ than they did in the lowest density class $(6.9 \%$ walk $+0.4 \%$ transit $=7.3 \%$ of person trips $)$. The metro areas in the rest of the nation in 2009 also display a similar result.

Figure 4.17 shows the number of minutes that urban household members spent waking daily, broken down by population density class. Again, the significant increase in walking activity among the higher residential density areas both inside and outside NYS is evident. The significant increases in walk and cycle minutes between 1995 and the two more recent surveys are also shown in Figure 4.17. As noted in Chapter 2 of this report, however, these could be an artifact of the improvements in the 2001 and 2009 surveys, where special prompting was carried out to better recall walk and bicycle trips.

Cycling (biking) trip activity patterns are much less obvious. When looked at either across these same seven population density classes, by inside versus outside NYS metro areas, or across all three surveys, most average daily cycle minutes per person were below one minute per day, with a range from less than 0.1 to 1.1 minutes per day.

\subsubsection{Travel by Zero-Vehicle Households}

As noted above, and as shown in Table 4.4, in metropolitan areas with more than 4,000 people per square mile, a noticeably greater proportion of NYS households are without a vehicle than are households elsewhere in the nation. Regardless of population density, those without a vehicle take fewer trips on average than those with a vehicle (see Appendix C.4). However, this difference in trip frequency narrows with population density, implying that having no access to a vehicle is less of a mobility constraint in highly populated areas than in less densely populated areas; reflecting the greater accessibility to public transit, to walk and cycle opportunities, and also to taxis, in more densely populated locations. 


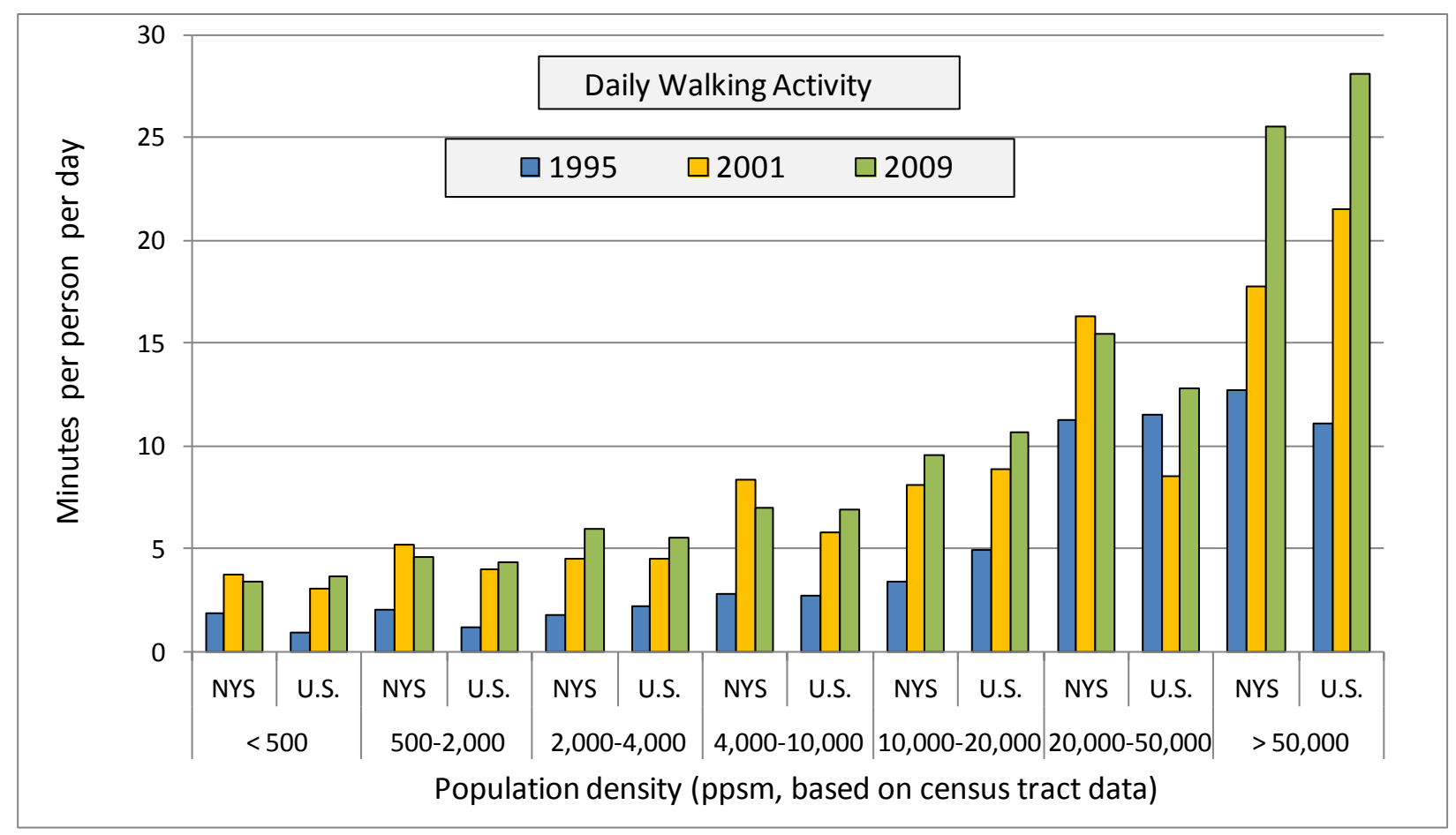

Figure 4.17 Average Minutes Spent on Walking Trips per Day by Population Density.

Figure 4.18 shows how daily person trip frequencies vary by population density class, both within NYS metro areas and in metro areas elsewhere in the nation. Within NYS metro areas the average trip rate increased with density, from 1.9 to almost 3.4 person trips per person per day in 2009. Outside NYS, households without a vehicle also become increasingly more mobile at increased densities. In 2009, this was reflected in an average daily trip rate of 2.2 trips per person in areas with less than 500 ppsm, rising consistently to a trip rate of around 4 trips per person at densities of $>50,000$ ppsm. However, this last figure of over 4 trips per day in 2009 is accompanied by standard errors of around 0.5 trips per day in both the 2001 and 2009 surveys. The much higher daily person trip rates for NYS households in the lowest density category in 1995, also shown in Figure 4.18 below, are less easy to explain. They are likely related to higher than average standard errors associated with both the 1995 and 2001 NHTS surveys (see Appendix C.4). 


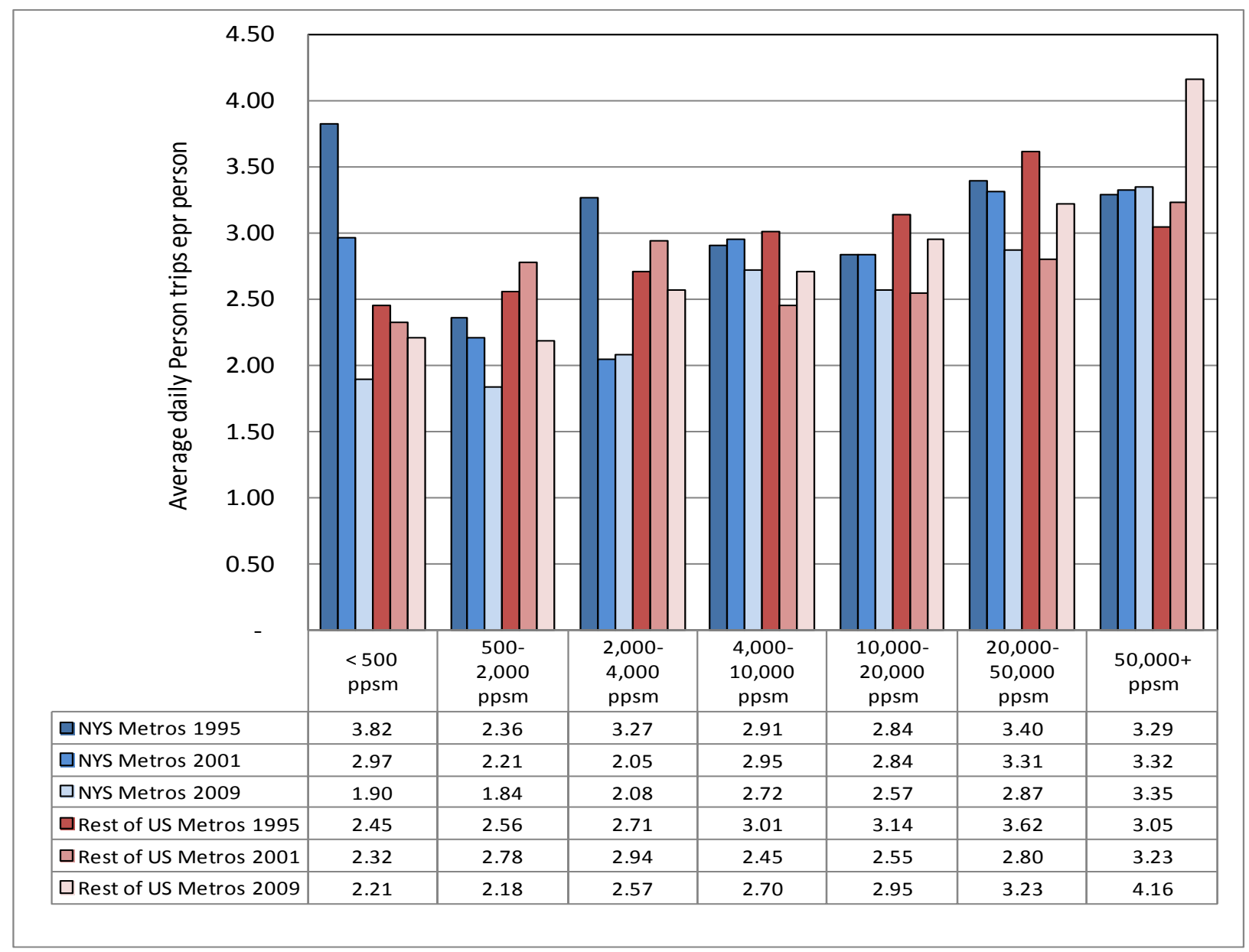

Figure 4.18 Average Daily Person Trips (in miles) of Individuals without a Vehicle New York State Metros vs. Metros Outside New York State by Population Density (persons per square mile, based on census tract data).

Note: Trip rate for metros outside NYS in > 50,000 ppsm class in 2009 is based on a relatively small sample size, as is the trip rate for NY metros in the <500 ppsm class in 1995.

As expected, individuals without a vehicle either walk or use public transit more frequently than those with a vehicle (Appendix C.4). This is true both inside and outside NYS. NYS residents who are without a vehicle and residing in population densities of less than 4,000 ppsm rely more on walking than do residents elsewhere in the country at similar densities. However, interpreting differences in public transit shares at these low densities is made difficult due to low sample sizes. As shown in Figures 4.19 and 4.20, for areas with densities over 50,000 ppsm, public transit and walk trips combined accounted for over $80 \%$ of person trips by these NYS households in 2001 and again in 2009. For those without a vehicle, walking was the most common mode of transportation in all density brackets in 2001 and 2009, both inside and outside NYS (Figures 4.16a and 4.16b). While a transit trip always implicitly includes walking (or occasionally, cycling), only a very small percentage of walking trips include public transit. 


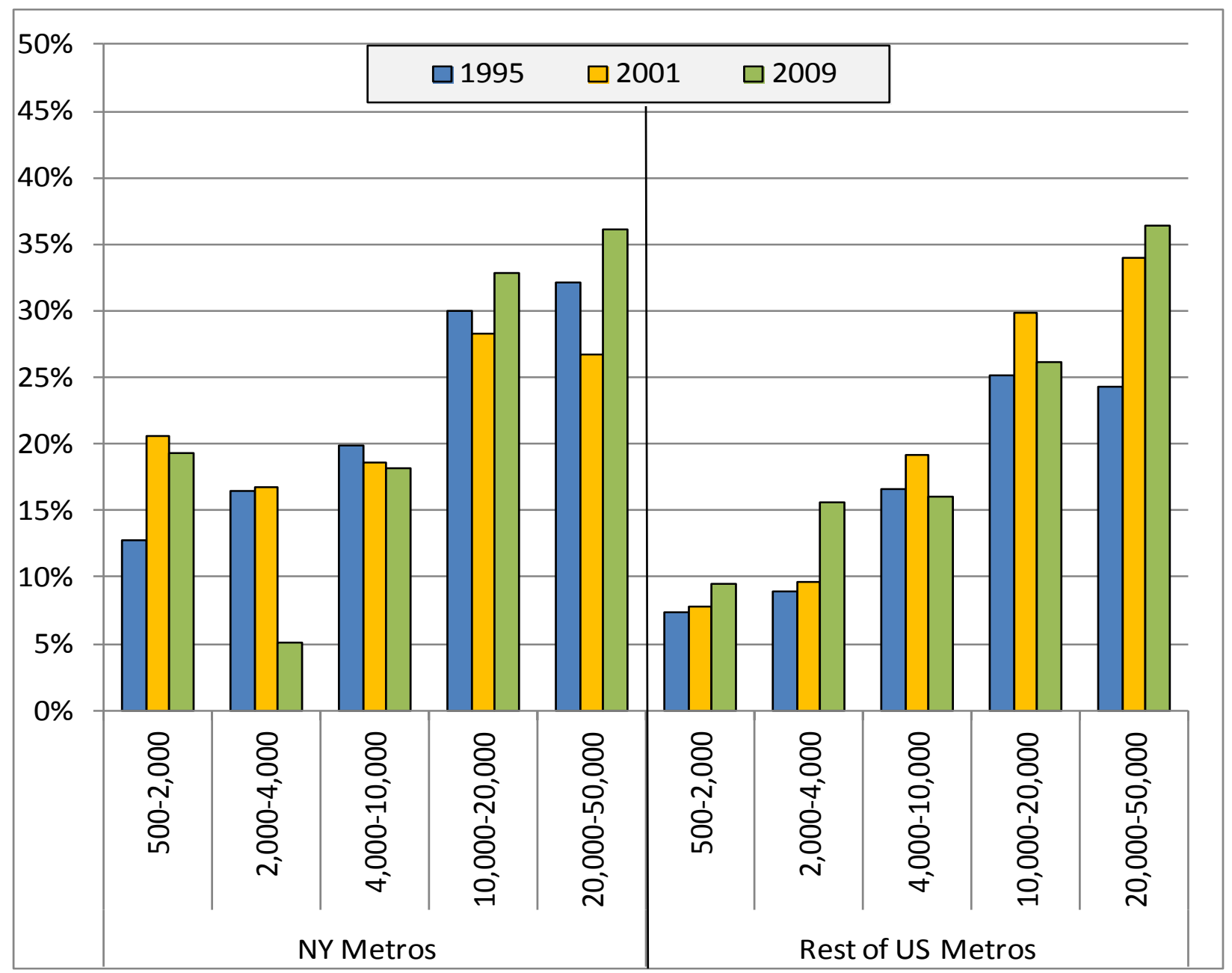

Figure 4.19 Percentage of Trips Taken by Public Transit by Those without a Vehicle, by Population Density in 1995, 2001, and 2009 (in persons per square mile, based on census tract data). 


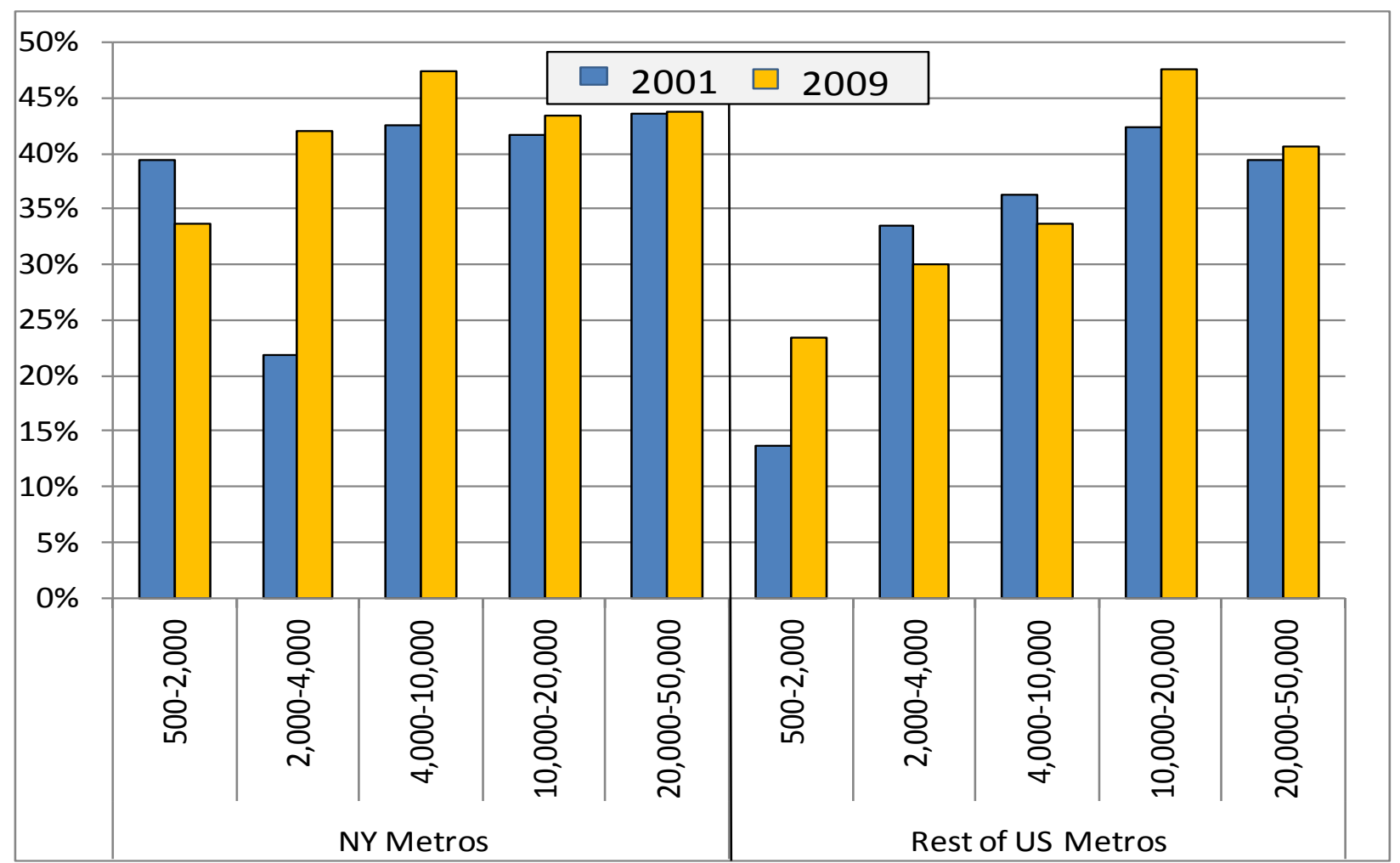

Figure 4.20 Percentage of Trips Taken by Walking by Those without a Vehicle, by Population Density in 2001 and 2009* (in persons per square mile, based on census tract data).

* Data from 1995 NHTS not compatible with later surveys.

Table 4.10 below shows the relationship between average trip length and population density for both NYS and out of state metro areas for 1995, 2001, and 2009, and for households both with and without access to a privately owned vehicle. Consistent with previous findings, those who do not own or have access to a vehicle take shorter trips than those who do. In 2009, trips taken by NYS residents living at densities $>50,000$ ppsm (mainly NYC) and who did not own a vehicle, were roughly half as long as those taken by their neighbors who did own a vehicle.

Among those metro area households who do own one or more vehicles, both in NYS and elsewhere in the nation, average trip length also tends to decrease with increasing population density: although an exception appears to exist in the very highest density areas associated with the NYS metros. (However, small sample sizes probably contribute to this result). Moreover, the differences in average trip distances between NYS residents with vehicles and those outside NYS with vehicles was quite small in 2009 when the standard errors in these estimates are considered (Table 4.10). 
Table 4.10 Average Person Trip Lengths (in miles) by Population Density and Vehicle Ownership in 1995, 2001, and 2009

\begin{tabular}{|c|c|c|c|c|c|c|c|c|c|c|c|c|c|c|}
\hline \multicolumn{15}{|c|}{ Population Density (persons per square mile, based on census tracts) } \\
\hline & \multicolumn{2}{|c|}{$<500$ ppsm } & \multicolumn{2}{|c|}{$\begin{array}{l}500-2,000 \\
\text { ppsm }\end{array}$} & \multicolumn{2}{|c|}{$\begin{array}{c}2,000-4,000 \\
\text { ppsm }\end{array}$} & \multicolumn{2}{|c|}{$\begin{array}{c}4,000-10,000 \\
\text { ppsm }\end{array}$} & \multicolumn{2}{|c|}{$\begin{array}{c}10,000-20,000 \\
\text { ppsm }\end{array}$} & \multicolumn{2}{|c|}{$\begin{array}{c}20,000-50,000 \\
\text { ppsm }\end{array}$} & \multicolumn{2}{|c|}{$50,000+$ ppsm } \\
\hline & $\begin{array}{c}\text { NY } \\
\text { State }\end{array}$ & U.S. & $\begin{array}{l}\text { NY } \\
\text { State }\end{array}$ & U.S. & $\begin{array}{c}\text { NY } \\
\text { State }\end{array}$ & U.S. & $\begin{array}{c}\text { NY } \\
\text { State }\end{array}$ & U.S. & $\begin{array}{c}\text { NY } \\
\text { State }\end{array}$ & U.S. & $\begin{array}{c}\text { NY } \\
\text { State }\end{array}$ & U.S. & $\begin{array}{c}\text { NY } \\
\text { State }\end{array}$ & U.S. \\
\hline \multicolumn{15}{|l|}{2009} \\
\hline All households & 11.58 & 12.50 & 9.35 & 10.38 & 7.95 & 9.49 & 7.33 & 8.07 & 4.98 & 6.92 & 5.86 & 6.92 & 4.93 & 2.59 \\
\hline $\begin{array}{l}\text { Zero Vehicle HHs } \\
\text { Non-Zero Vehicle }\end{array}$ & 5.87 & 8.51 & 3.01 & 6.31 & 6.56 & 5.33 & 2.62 & 4.41 & 3.62 & 2.84 & 2.76 & 4.05 & 3.32 & 1.46 \\
\hline $\mathrm{HHs}$ & 11.63 & 12.54 & 9.45 & 10.46 & 7.98 & 9.59 & 7.62 & 8.21 & 5.15 & 7.40 & 7.23 & 7.61 & 6.78 & 3.14 \\
\hline \multicolumn{15}{|l|}{2001} \\
\hline All households & 10.66 & 11.27 & 9.36 & 9.90 & 8.65 & 9.21 & 7.45 & 8.96 & 7.34 & 9.40 & 7.68 & 8.91 & 6.22 & 7.75 \\
\hline $\begin{array}{l}\text { Zero Vehicle HHs } \\
\text { Non-Zero Vehicle }\end{array}$ & 4.37 & 12.35 & 4.30 & 10.08 & 4.88 & 4.16 & 3.62 & 12.29 & 5.31 & 4.03 & 10.34 & 3.93 & 4.57 & 3.19 \\
\hline $\mathrm{HHs}$ & 10.77 & 11.26 & 9.40 & 9.90 & 8.72 & 9.31 & 7.64 & 8.87 & 7.64 & 9.80 & 6.38 & 9.77 & 7.88 & 11.37 \\
\hline \multicolumn{15}{|l|}{1995} \\
\hline All households & 9.91 & 10.66 & 9.41 & 9.33 & 8.02 & 9.06 & 7.23 & 8.05 & 6.85 & 6.64 & 5.18 & 5.83 & 5.95 & 7.31 \\
\hline $\begin{array}{l}\text { Zero Vehicle HHs } \\
\text { Non-Zero Vehicle }\end{array}$ & 6.72 & 7.08 & 3.58 & 7.25 & 4.78 & 4.85 & 6.13 & 4.40 & 5.38 & 4.09 & 3.69 & 3.63 & 5.49 & 1.95 \\
\hline $\mathrm{HHs}$ & 9.99 & 10.70 & 9.47 & 9.35 & 8.11 & 9.16 & 7.29 & 8.20 & 7.06 & 6.99 & 5.96 & 6.53 & 6.64 & 10.33 \\
\hline
\end{tabular}




\subsection{VEHICLE TRAVEL COMPARISONS}

\subsubsection{Driver Trip Rates}

Tables 4.11, 4.12 and 4.13 below show the effects of population density on vehicle trips and vehicle miles of travel per driver, as well as on average vehicle trip lengths and travel times, each further disaggregated by trip purpose. As with person trips (Table 4.7), the number of vehicle trips per day increases with population density, reaches its peak at just over 3 trips in areas with densities between two and four thousand people per square mile, then declines with increasing population density. A typical NYS metro area driver in the most densely populated areas takes about one vehicle trip a day. As also reported earlier in this chapter (Table 4.7), residents in these very high density areas, notably NYC, either walk, or ride public transit most of the time.

Figure 4.21 below shows these daily vehicle trip rates. While as a set the statistics shown in Tables 4.11, 4.12, 4.13 and Figure 4.21 indicate that population density plays a similar role with respect to vehicle trip frequencies and trip lengths both within and outside the state, some significant differences in driver trip rates between NYS metros and the metros in the rest of the country become apparent at population densities above 20,000 ppsm. This effect has carried throughout all three of the NHTS surveys. Figure 4.22 shows these differences, using the vehicle trip rate for metro areas in the rest of the US as the base for comparison. Most differences for metro areas with population densities below 20,000 ppsm are small or insignificant once standard errors of the estimates are taken into account.

Trip purpose shares show the usual consistency both inside and outside the state, with about half of all daily driving trips being made for family related and personal business reasons, followed by $25 \%$ for commuting to and from work and $20 \%$ for social and recreational purposes (Tables 4.11, 4.12 and 4.13). The only exception is for the very densest areas, where sample sizes are quite small. 
Table 4.11 Statistics on Daily Vehicle Travel by Population Density New York State Metros (NYS) vs. Metros Outside New York State (U.S.), 2009 (Population Density of Census Tract)

\begin{tabular}{|c|c|c|c|c|c|c|c|c|c|c|c|c|c|c|}
\hline & \multicolumn{14}{|c|}{ Population Density (population per square mile) ${ }^{a}$} \\
\hline & \multicolumn{2}{|c|}{$<500$} & \multicolumn{2}{|c|}{$500-2,000$} & \multicolumn{2}{|c|}{$2,000-4,000$} & \multicolumn{2}{|c|}{$4,000-10,000$} & \multicolumn{2}{|c|}{$10,000-20,000$} & \multicolumn{2}{|c|}{$20,000-50,000$} & \multicolumn{2}{|c|}{$50,000+$} \\
\hline & NYS & U.S. & NYS & U.S. & NYS & U.S. & NYS & U.S. & NYS & U.S. & NYS & U.S. & NYS & U.S. \\
\hline \multicolumn{15}{|l|}{ Vehicle Trips per Driver } \\
\hline TOTAL & 3.02 & 2.94 & 3.23 & 3.23 & 3.13 & 3.18 & 2.96 & 3.14 & 2.73 & 2.68 & 1.22 & 2.04 & 0.70 & 1.23 \\
\hline \% Earn a Living & $27.8 \%$ & $27.6 \%$ & $26.6 \%$ & $26.1 \%$ & $24.5 \%$ & $26.0 \%$ & $25.1 \%$ & $25.1 \%$ & $18.1 \%$ & $23.7 \%$ & $21.1 \%$ & $26.6 \%$ & $18.2 \%$ & $57.4 \%$ \\
\hline \% Family \& Personal Business & $47.1 \%$ & $45.4 \%$ & $46.5 \%$ & $46.6 \%$ & $48.0 \%$ & $46.6 \%$ & $48.2 \%$ & $47.1 \%$ & $54.9 \%$ & $48.7 \%$ & $57.0 \%$ & $49.6 \%$ & $53.2 \%$ & $23.2 \%$ \\
\hline$\%$ Civic, Educational \& Religious & $3.4 \%$ & $4.4 \%$ & $4.7 \%$ & $4.9 \%$ & $4.1 \%$ & $5.5 \%$ & $5.6 \%$ & $4.6 \%$ & $6.5 \%$ & $5.3 \%$ & $2.2 \%$ & $5.0 \%$ & $3.5 \%$ & $3.1 \% *$ \\
\hline \% Social \& Recreational & $20.6 \%$ & $21.4 \%$ & $20.9 \%$ & $21.2 \%$ & $22.4 \%$ & $20.9 \%$ & $20.2 \%$ & $22.0 \%$ & $20.0 \%$ & $21.4 \%$ & $17.1 \%$ & $17.7 \%$ & $23.8 \%$ & $16.0 \%$ \\
\hline$\%$ Other & $0.3 \%$ & $0.3 \%$ & $0.5 \%$ & $0.3 \%$ & $0.3 \%$ & $0.4 \%$ & $0.4 \%$ & $0.3 \%$ & $0.1 \% *$ & $0.2 \%$ & $0.2 \%$ & $0.0 \% *$ & $0.2 \% *$ & \\
\hline$\%$ Unreported & $0.8 \%$ & $1.0 \%$ & $0.9 \%$ & $0.9 \%$ & $0.7 \%$ & $0.8 \%$ & $0.6 \%$ & $1.0 \%$ & $0.4 \%$ & $0.8 \%$ & $2.4 \%$ & $1.1 \%$ & $1.2 \%$ & $0.2 \% *$ \\
\hline \multicolumn{15}{|c|}{ Vehicle Miles Traveled (VMT) per Driver } \\
\hline TOTAL & 34.06 & 36.60 & 29.69 & 31.46 & 24.41 & 27.99 & 19.72 & 24.01 & 14.76 & 20.22 & 7.10 & 17.29 & 7.24 & 4.85 \\
\hline \% Earn a Living & $36.6 \%$ & $35.5 \%$ & $34.6 \%$ & $35.8 \%$ & $37.5 \%$ & $33.9 \%$ & $37.5 \%$ & $35.1 \%$ & $29.5 \%$ & $36.5 \%$ & $27.9 \%$ & $35.3 \%$ & $18.6 \%$ & $67.5 \%$ \\
\hline \% Family \& Personal Business & $35.4 \%$ & $31.7 \%$ & $29.6 \%$ & $31.4 \%$ & $31.8 \%$ & $30.2 \%$ & $33.6 \%$ & $31.9 \%$ & $38.0 \%$ & $28.1 \%$ & $42.7 \%$ & $31.0 \%$ & $29.7 \%$ & $14.8 \%$ \\
\hline$\%$ Civic, Educational \& Religious & $2.8 \%$ & $3.6 \%$ & $3.3 \%$ & $4.0 \%$ & $4.3 \%$ & $4.4 \%$ & $4.6 \%$ & $4.1 \%$ & $4.0 \%$ & $5.4 \%$ & $1.1 \%$ & $12.9 \%$ & $2.7 \%$ & $0.4 \% *$ \\
\hline \% Social \& Recreational & $22.3 \%$ & $23.8 \%$ & $23.5 \%$ & $25.7 \%$ & $25.3 \%$ & $25.4 \%$ & $21.6 \%$ & $25.9 \%$ & $26.9 \%$ & $28.1 \%$ & $26.1 \%$ & $17.8 \%$ & $46.9 \%$ & $14.8 \%$ \\
\hline$\%$ Other & $0.6 \%$ & $0.5 \%$ & $0.6 \%$ & $0.7 \%$ & $0.3 \%$ & $0.8 \%$ & $0.4 \%$ & $0.6 \%$ & $0.2 \% *$ & $0.1 \%$ & $0.2 \%$ & $0.0 \% *$ & $0.3 \% *$ & \\
\hline$\%$ Unreported & $2.3 \%$ & $4.9 \%$ & $8.5 \%$ & $2.4 \%$ & $0.7 \%$ & $5.2 \%$ & $2.3 \%$ & $2.3 \%$ & $1.5 \%$ & $1.9 \%$ & $2.1 \%$ & $3.0 \%$ & $1.8 \%$ & $2.5 \% *$ \\
\hline \multicolumn{15}{|l|}{ Average Vehicle Trip Length (miles) ${ }^{b}$} \\
\hline & 11.42 & 12.57 & 9.31 & 9.85 & 7.88 & 8.93 & 6.73 & 7.76 & 5.53 & 7.77 & 6.34 & 8.79 & 10.64 & 4.00 \\
\hline \multicolumn{15}{|c|}{ Average Time Spend Driving in a POV in a Typical Day ${ }^{c}$ (minutes) } \\
\hline & 77.45 & 80.79 & 72.00 & 75.89 & 69.58 & 75.64 & 70.47 & 74.14 & 72.18 & 79.59 & 73.46 & 84.57 & 97.80 & 46.36 \\
\hline
\end{tabular}

\footnotetext{
${ }^{\text {a }}$ All percentages may not add to $100 \%$ due to rounding.

${ }^{\mathrm{b}}$ Average trip length is calculated using only those records with trip mileage information present.

${ }^{c}$ Average time spent driving includes persons who drove on travel-day only. It does not include any persons who did not take a trip on their travel day, nor does it include any driving done in a trip where public transit was used for part of that trip.
} 
Table 4.12 Statistics on Daily Vehicle Travel by Population Density New York State Metros (NYS) vs. Metros Outside New York State (U.S.), 2001 (Population Density of Census Tract)

\begin{tabular}{|c|c|c|c|c|c|c|c|c|c|c|c|c|c|c|}
\hline & \multicolumn{14}{|c|}{ Population Density (population per square mile) ${ }^{a}$} \\
\hline & \multicolumn{2}{|c|}{$<500$} & \multicolumn{2}{|c|}{$500-2,000$} & \multicolumn{2}{|c|}{$2,000-4,000$} & \multicolumn{2}{|c|}{$4,000-10,000$} & \multicolumn{2}{|c|}{$10,000-20,000$} & \multicolumn{2}{|c|}{$20,000-50,000$} & \multicolumn{2}{|c|}{$50,000+$} \\
\hline & NYS & U.S. & NYS & U.S. & NYS & U.S. & NYS & U.S. & NYS & U.S. & NYS & U.S. & NYS & U.S. \\
\hline \multicolumn{15}{|l|}{ Vehicle Trips per Driver } \\
\hline TOTAL & 3.10 & 3.35 & 3.39 & 3.56 & 3.33 & 3.61 & 3.21 & 3.37 & 2.47 & 2.93 & 1.99 & 2.51 & 1.03 & 1.83 \\
\hline$\%$ Earn a Living & $26.8 \%$ & $27.3 \%$ & $25.4 \%$ & $25.4 \%$ & $25.4 \%$ & $25.8 \%$ & $24.2 \%$ & $25.6 \%$ & $25.9 \%$ & $28.5 \%$ & $22.9 \%$ & $28.3 \%$ & $28.1 \%$ & $15.8 \%$ \\
\hline \% Family \& Personal Business & $47.4 \%$ & $47.5 \%$ & $48.8 \%$ & $48.5 \%$ & $48.6 \%$ & $48.2 \%$ & $49.6 \%$ & $48.9 \%$ & $47.9 \%$ & $45.8 \%$ & $55.2 \%$ & $43.9 \%$ & $44.6 \%$ & $60.4 \%$ \\
\hline \% Civic, Educational \& Religious & $3.9 \%$ & $4.9 \%$ & $4.2 \%$ & $4.7 \%$ & $3.5 \%$ & $5.0 \%$ & $4.9 \%$ & $4.7 \%$ & $5.6 \%$ & $4.0 \%$ & $3.8 \%$ & $4.9 \%$ & $2.6 \%$ & $0.5 \%$ \\
\hline \% Social \& Recreational & $21.2 \%$ & $19.7 \%$ & $20.9 \%$ & $20.9 \%$ & $22.0 \%$ & $20.4 \%$ & $20.4 \%$ & $20.3 \%$ & $20.0 \%$ & $21.1 \%$ & $16.2 \%$ & $22.5 \%$ & $24.0 \%$ & $20.5 \%$ \\
\hline$\%$ Other & $0.5 \%$ & $0.5 \%$ & $0.6 \%$ & $0.5 \%$ & $0.4 \%$ & $0.5 \%$ & $0.7 \%$ & $0.5 \%$ & $0.6 \%$ & $0.5 \%$ & $1.7 \%$ & $0.3 \%$ & $0.6 \%$ & \\
\hline$\%$ Unreported & $0.3 \%$ & $0.1 \%$ & $0.1 \%$ & $0.1 \%$ & $0.1 \%$ & $0.1 \%$ & $0.2 \%$ & $0.1 \%$ & $0.0 \% *$ & $0.1 \%$ & $0.2 \% *$ & $0.0 \%$ & $0.1 \% *$ & $2.8 \% *$ \\
\hline \multicolumn{15}{|c|}{ Vehicle Miles Traveled (VMT) per Driver } \\
\hline TOTAL & 33.70 & 37.90 & 30.22 & 33.77 & 28.76 & 31.99 & 23.12 & 29.25 & 19.46 & 23.15 & 12.21 & 20.16 & 10.08 & 12.06 \\
\hline \% Earn a Living & $36.2 \%$ & $37.7 \%$ & $36.2 \%$ & $34.8 \%$ & $38.3 \%$ & $34.4 \%$ & $35.6 \%$ & $36.2 \%$ & $32.7 \%$ & $37.3 \%$ & $32.8 \%$ & $31.9 \%$ & $32.2 \%$ & $39.1 \%$ \\
\hline \% Family \& Personal Business & $34.3 \%$ & $35.0 \%$ & $34.5 \%$ & $34.9 \%$ & $31.8 \%$ & $35.6 \%$ & $32.1 \%$ & $33.5 \%$ & $34.0 \%$ & $36.0 \%$ & $41.1 \%$ & $29.6 \%$ & $34.9 \%$ & $42.5 \%$ \\
\hline$\%$ Civic, Educational \& Religious & $2.9 \%$ & $4.1 \%$ & $3.4 \%$ & $3.7 \%$ & $3.0 \%$ & $3.6 \%$ & $3.5 \%$ & $3.5 \%$ & $6.0 \%$ & $3.6 \%$ & $2.4 \%$ & $5.0 \%$ & $2.1 \%$ & $0.8 \%$ \\
\hline \% Social \& Recreational & $25.6 \%$ & $22.3 \%$ & $24.3 \%$ & $25.3 \%$ & $26.3 \%$ & $25.4 \%$ & $28.0 \%$ & $26.1 \%$ & $26.4 \%$ & $22.4 \%$ & $22.7 \%$ & $32.9 \%$ & $30.0 \%$ & $14.2 \%$ \\
\hline$\%$ Other & $0.9 \%$ & $0.6 \%$ & $0.9 \%$ & $1.2 \%$ & $0.5 \%$ & $1.1 \%$ & $0.7 \%$ & $0.6 \%$ & $0.9 \%$ & $0.6 \%$ & $0.8 \%$ & $0.5 \%$ & $0.5 \%$ & \\
\hline$\%$ Unreported & $0.2 \%$ & $0.3 \%$ & $0.7 \%$ & $0.1 \%$ & $0.1 \%$ & $0.1 \%$ & $0.1 \%$ & $0.2 \%$ & $0.1 \% *$ & $0.1 \%$ & $0.2 \% *$ & $0.0 \%$ & $0.3 \% *$ & $3.4 \% *$ \\
\hline \multicolumn{15}{|l|}{ Average Vehicle Trip Length (miles) ${ }^{b}$} \\
\hline & 10.95 & 11.42 & 9.03 & 9.54 & 8.69 & 8.94 & 7.37 & 8.80 & 8.07 & 8.17 & 6.40 & 8.17 & 10.50 & 6.63 \\
\hline \multicolumn{15}{|c|}{ Average Time Spend Driving in a POV in a Typical Day ${ }^{\mathrm{c}}$ (minutes) } \\
\hline & 78.76 & 84.75 & 76.13 & 81.30 & 79.37 & 79.31 & 74.22 & 80.40 & 81.01 & 77.59 & 84.66 & 81.16 & 97.22 & 108.93 \\
\hline
\end{tabular}

a All percentages may not add to $100 \%$ due to rounding.

b Average trip length is calculated using only those records with trip mileage information present.

c Average time spent driving includes persons who drove on travel-day only. It does not include any persons who did not take a trip on their travel day, nor does it include any driving done in a trip where public transit was used for part of that trip. 
Table 4.13 Statistics on Daily Vehicle Travel by Population Density for New York State Metros (NYS) vs. Metros Outside New York State (U.S.), 1995 (Population Density of Census Tract)

\begin{tabular}{|c|c|c|c|c|c|c|c|c|c|c|c|c|c|c|}
\hline & \multicolumn{14}{|c|}{ Population Density (population per square mile) ${ }^{a}$} \\
\hline & \multicolumn{2}{|c|}{$<500$} & \multicolumn{2}{|c|}{$500-2,000$} & \multicolumn{2}{|c|}{$2,000-4,000$} & \multicolumn{2}{|c|}{$4,000-10,000$} & \multicolumn{2}{|c|}{$10,000-20,000$} & \multicolumn{2}{|c|}{$20,000-50,000$} & \multicolumn{2}{|c|}{$50,000+$} \\
\hline & NYS & U.S. & NYS & U.S. & NYS & U.S. & NYS & U.S. & NYS & U.S. & NYS & U.S. & NYS & U.S. \\
\hline \multicolumn{15}{|l|}{ Vehicle Trips per Driver } \\
\hline TOTAL & 3.39 & 3.53 & 3.47 & .65 & 3.67 & 3.77 & 3.31 & 3.58 & 2.80 & 3.23 & 1.95 & 2.69 & 1.07 & 1.79 \\
\hline \% Earn a Living & $27.9 \%$ & $28.2 \%$ & $26.2 \%$ & $27.2 \%$ & $24.5 \%$ & $27.9 \%$ & $26.1 \%$ & $26.5 \%$ & $28.5 \%$ & $25.7 \%$ & $22.6 \%$ & $26.8 \%$ & $31.8 \%$ & $29.1 \%$ \\
\hline \% Family \& Personal Business & $50.0 \%$ & $49.9 \%$ & $51.3 \%$ & $50.8 \%$ & $52.2 \%$ & $49.6 \%$ & $51.8 \%$ & $51.1 \%$ & $50.5 \%$ & $49.2 \%$ & $54.4 \%$ & $47.2 \%$ & $47.7 \%$ & $48.6 \%$ \\
\hline \% Civic, Educational \& Religious & $2.9 \%$ & $4.0 \%$ & $4.0 \%$ & $3.8 \%$ & $3.8 \%$ & $4.5 \%$ & $3.6 \%$ & $3.9 \%$ & $3.9 \%$ & $5.3 \%$ & $5.1 \%$ & $5.2 \%$ & $3.7 \%$ & \\
\hline \% Social \& Recreational & $18.8 \%$ & $17.9 \%$ & $18.4 \%$ & $18.1 \%$ & $19.6 \%$ & $18.0 \%$ & $18.5 \%$ & $18.4 \%$ & $17.1 \%$ & $19.8 \%$ & $17.9 \%$ & $20.8 \%$ & $16.8 \%$ & $22.3 \%$ \\
\hline$\%$ Other & $0.3 \%$ & $0.0 \%$ & $0.0 \%$ & $0.0 \%$ & $0.0 \%$ & $0.0 \%$ & $0.0 \%$ & $0.0 \%$ & $0.0 \%$ & $0.0 \%$ & $0.0 \%$ & & & \\
\hline$\%$ Unreported & 3.39 & 3.53 & 3.47 & 3.65 & 3.67 & 3.77 & 3.31 & 3.58 & 2.80 & 3.23 & 1.95 & 2.69 & 1.07 & 1.79 \\
\hline \multicolumn{15}{|c|}{ Vehicle Miles Traveled (VMT) per Driver } \\
\hline TOTAL & 33.21 & 37.19 & 32.04 & 33.74 & 28.89 & 31.19 & 23.22 & 28.28 & 20.81 & 23.04 & 13.37 & 20.65 & 12.12 & 20.35 \\
\hline \% Earn a Living & $38.8 \%$ & $39.7 \%$ & $35.5 \%$ & $38.7 \%$ & $37.2 \%$ & $38.4 \%$ & $41.2 \%$ & $36.6 \%$ & $36.9 \%$ & $34.4 \%$ & $35.4 \%$ & $34.7 \%$ & $34.9 \%$ & $16.6 \%$ \\
\hline \% Family \& Personal Business & $34.2 \%$ & $36.1 \%$ & $37.1 \%$ & $35.7 \%$ & $34.5 \%$ & $34.0 \%$ & $33.6 \%$ & $35.6 \%$ & $34.2 \%$ & $34.6 \%$ & $37.1 \%$ & $32.6 \%$ & $24.2 \%$ & $48.2 \%$ \\
\hline \% Civic, Educational \& Religious & $2.3 \%$ & $4.0 \%$ & $2.9 \%$ & $3.7 \%$ & $2.5 \%$ & $3.9 \%$ & $3.1 \%$ & $2.9 \%$ & $2.1 \%$ & $5.4 \%$ & $5.9 \%$ & $4.3 \%$ & $1.5 \%$ & \\
\hline \% Social \& Recreational & $24.0 \%$ & $20.1 \%$ & $24.4 \%$ & $21.5 \%$ & $25.8 \%$ & $23.6 \%$ & $22.0 \%$ & $24.7 \%$ & $26.4 \%$ & $25.6 \%$ & $21.6 \%$ & $28.3 \%$ & $39.4 \%$ & $35.2 \%$ \\
\hline$\%$ Other & $0.8 \%$ & $0.1 \%$ & $0.1 \%$ & $0.3 \%$ & $0.0 \%$ & $0.1 \%$ & $0.1 \%$ & $0.1 \%$ & $0.0 \%$ & $0.0 \%$ & $0.0 \%$ & & & \\
\hline$\%$ Unreported & 33.21 & 37.19 & 32.04 & 33.74 & 28.89 & 31.19 & 23.22 & 28.28 & 20.81 & 23.04 & 13.37 & 20.65 & 12.12 & 20.35 \\
\hline \multicolumn{15}{|l|}{ Average Vehicle Trip Length (miles) ${ }^{b}$} \\
\hline & 9.85 & 10.61 & 9.35 & 9.29 & 7.9 & 8.32 & 7.12 & 7.97 & 7.58 & 7.24 & 7.11 & 7.86 & 11.68 & 11.34 \\
\hline \multicolumn{15}{|c|}{ Average Time Spend Driving in a POV in a Typical Day ${ }^{\mathrm{c}}$ (minutes) } \\
\hline & 69.85 & 77.11 & 71.47 & 74 & 70.84 & 71.46 & 67.94 & 70.63 & 69.79 & 71.46 & 72.28 & 79.4 & 89.71 & 86.19 \\
\hline
\end{tabular}

a All percentages may not add to $100 \%$ due to rounding.

Average trip length is calculated using only those records with trip mileage information present.

c Average time spent driving includes persons who drove on travel-day only. It does not include any persons who did not take a trip on their travel day, nor does it include any driving done in a trip where public transit was used for part of that trip. 


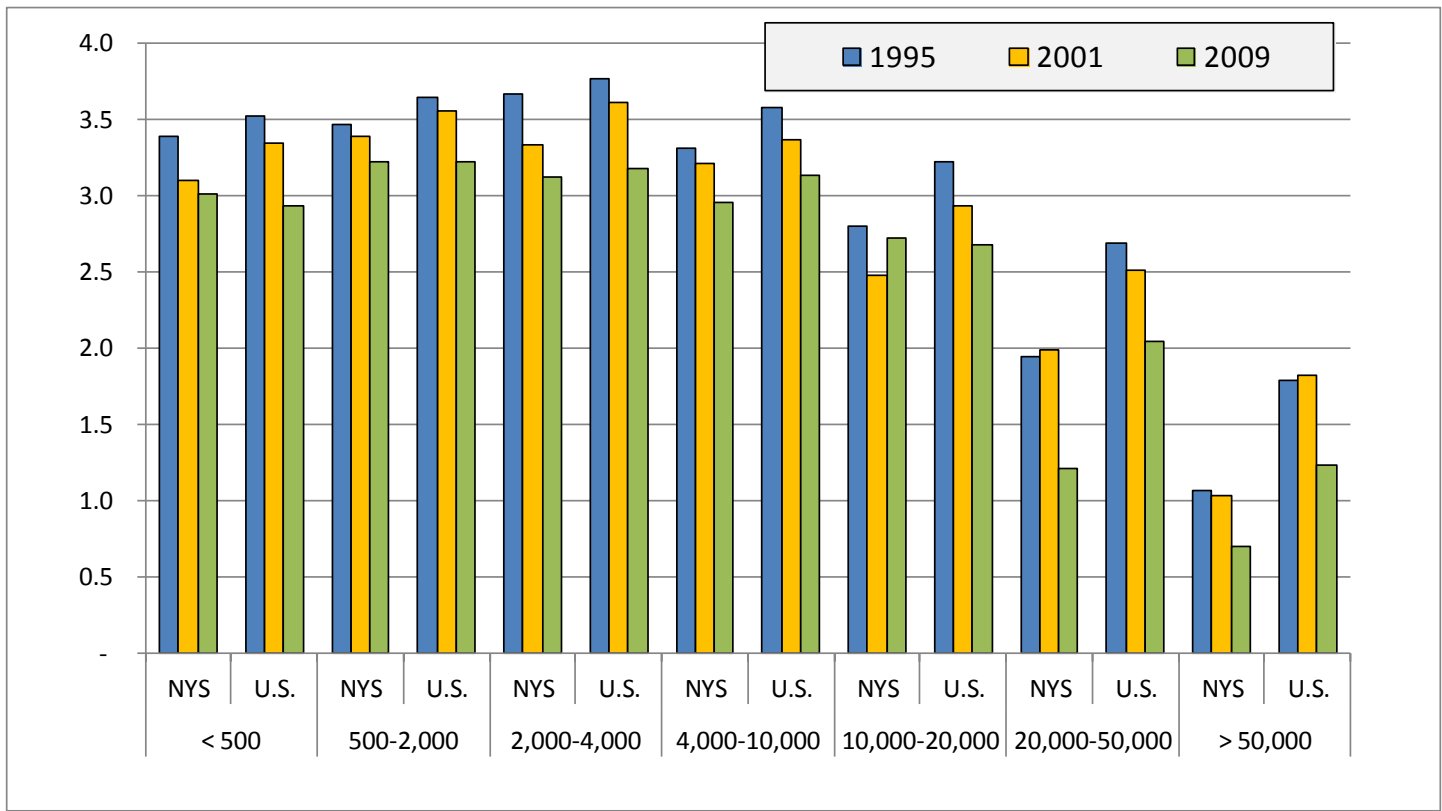

Figure 4.21 Daily Vehicle Trip Rates in 1995, 2001, and 2009, for New York Metros and Metros Outside New York State (persons per square mile, based on census tract data).

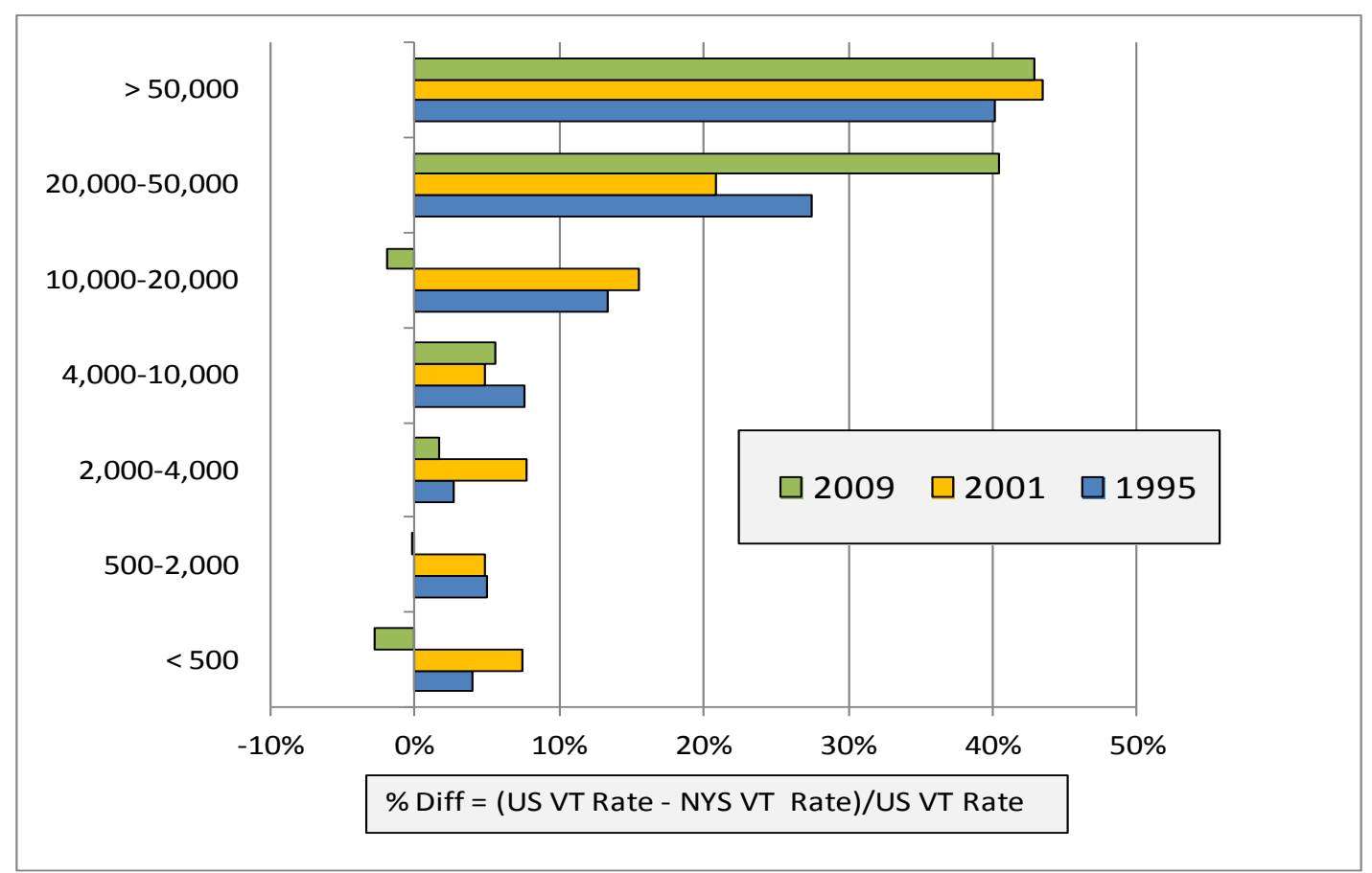

Figure 4.22 Percentage Differences in Daily Vehicle Trip (VT) Rates Between New York Metros and Metros Outside New York State (persons per square mile, based on census tract data) 
The percentage shares of vehicle trips and vehicle miles driven by trip purpose also remain very similar, no matter what the density class, and again both within and outside the state.

\subsubsection{Driving Distances and Times}

Average daily driving distances are graphed in Figure 4.23. With the exception of the highest density areas, trip lengths fall gradually with population density both inside and outside the state: dropping from around 11 miles per trip in low density areas to around 6 miles per trip in areas with densities in the range 20,000 to 50,000 ppsm within the NYS metros. In the very highest density areas of NYC, trip lengths climb to over 10 miles per trip in all three survey years (Tables 4.11, 4.12, 4.13 and Figure 4.23). This may be due to small sample sizes, but may also reflect the fact that these residents make longer trips when they drive, while carrying out the majority of their trip making activities by walk and public transit modes. A precipitous fall in average trip length is shown for metro areas outside NYS when 2009 is compared to 1995 and 2001. This result may be caused by a small sample size.

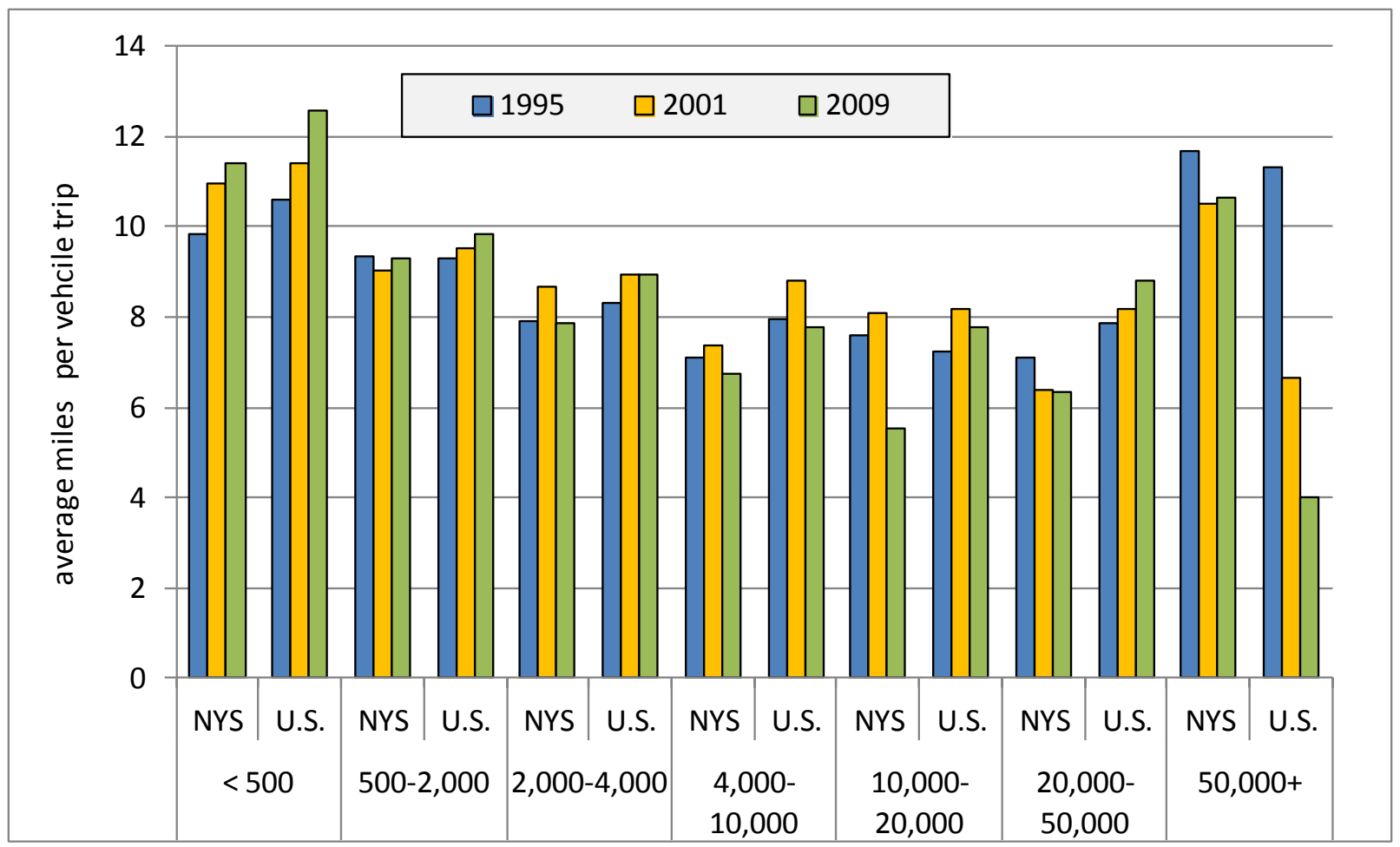

Figure 4.23 Average Driving Distances (in miles) for Drivers in New York Metros and for Metros Outside New York State, by Population Density (in persons per square mile, based on census tract data).

Figure 4.24 shows the distribution of minutes spent driving per day within both NYS and out of state metro areas. These driving times show only a limited amount of variability across density classes, until an increase in time spent on daily travel manifests itself in the 20,000 to 
50,000 ppsm class in metros outside of the state, and in the highest density class represented principally by NYC residents. As a result, the shorter average trip distances shown in Figure 4.23 for medium-high density areas do not show any correlation with reduced driving times. When coupled with the lower driving rates shown in Figure 4.21, this suggests that traffic congestion might be playing a significant role here in keeping daily in-vehicle travel times at similar levels across most densities. In the most densely populated areas both within and outside the state a driver typically spends one and one-half hours driving per day: and this situation has not changed significantly since 1995. Base on Figure 4.24, while daily driving times increased on the average between 1995 and 2001, they dropped back close to 1995 levels in 2009 in almost all except the highest density areas, in a similar manner both within and outside the state.

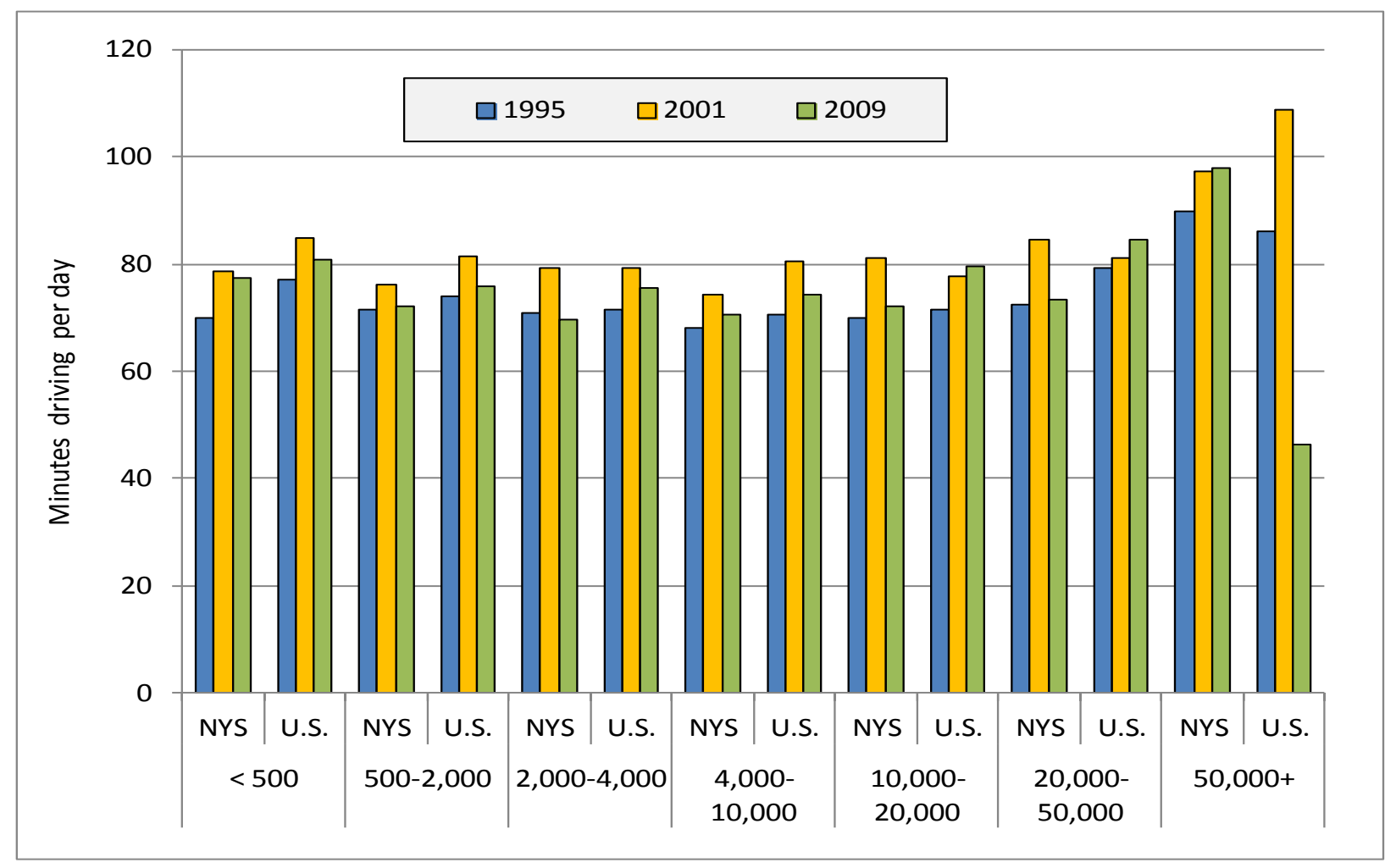

Figure 4.24 Average Driving Times (in minutes) for Drivers in New York Metros and Metros Outside New York State, by Population Density (in persons per square mile, based on census tract data).

Note: Minutes driving statistics are reported only for those persons who drove a vehicle on the travel day.

\subsubsection{Types and Ages of Vehicles Driven}

Figure 4.25 shows the distribution of in-use household vehicle fleet by vehicle type and density class, as reported by residents in the thirteen NYS metros and in the metro areas outside 
the state. Pickup trucks account for a larger share of POVs in the lowest density range of metro areas both inside and outside the state. However, at higher densities pickups are much less popular with NYS metro residents than elsewhere in the metro areas outside the state. Vans are more popular in the high density NYS metro areas than they are outside the state. Over time, the auto fleet percentage has been dropping since 1995 in favor of these other vehicle types, both within and outside the state, and across all density classes (Figure 4.26).

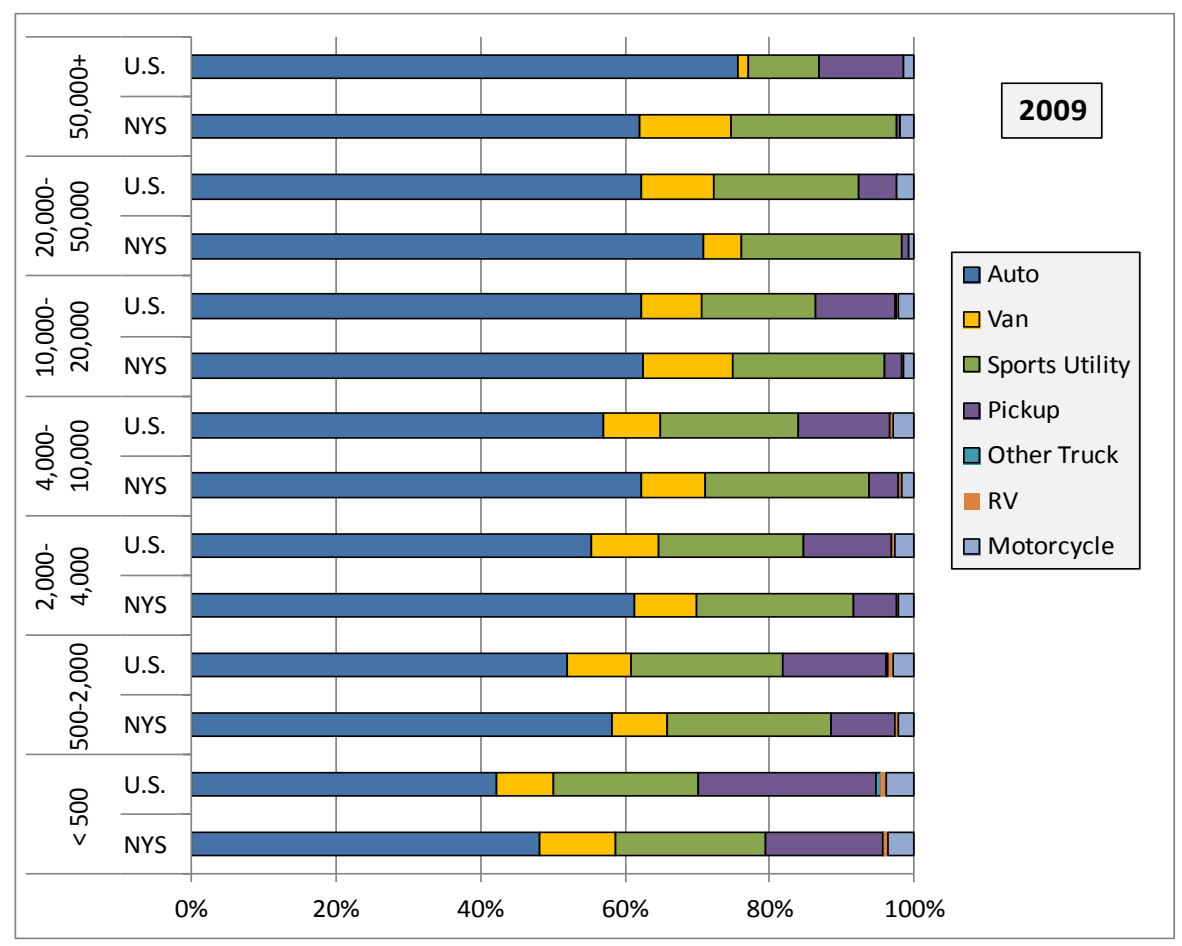


Figure 4.25 continued...

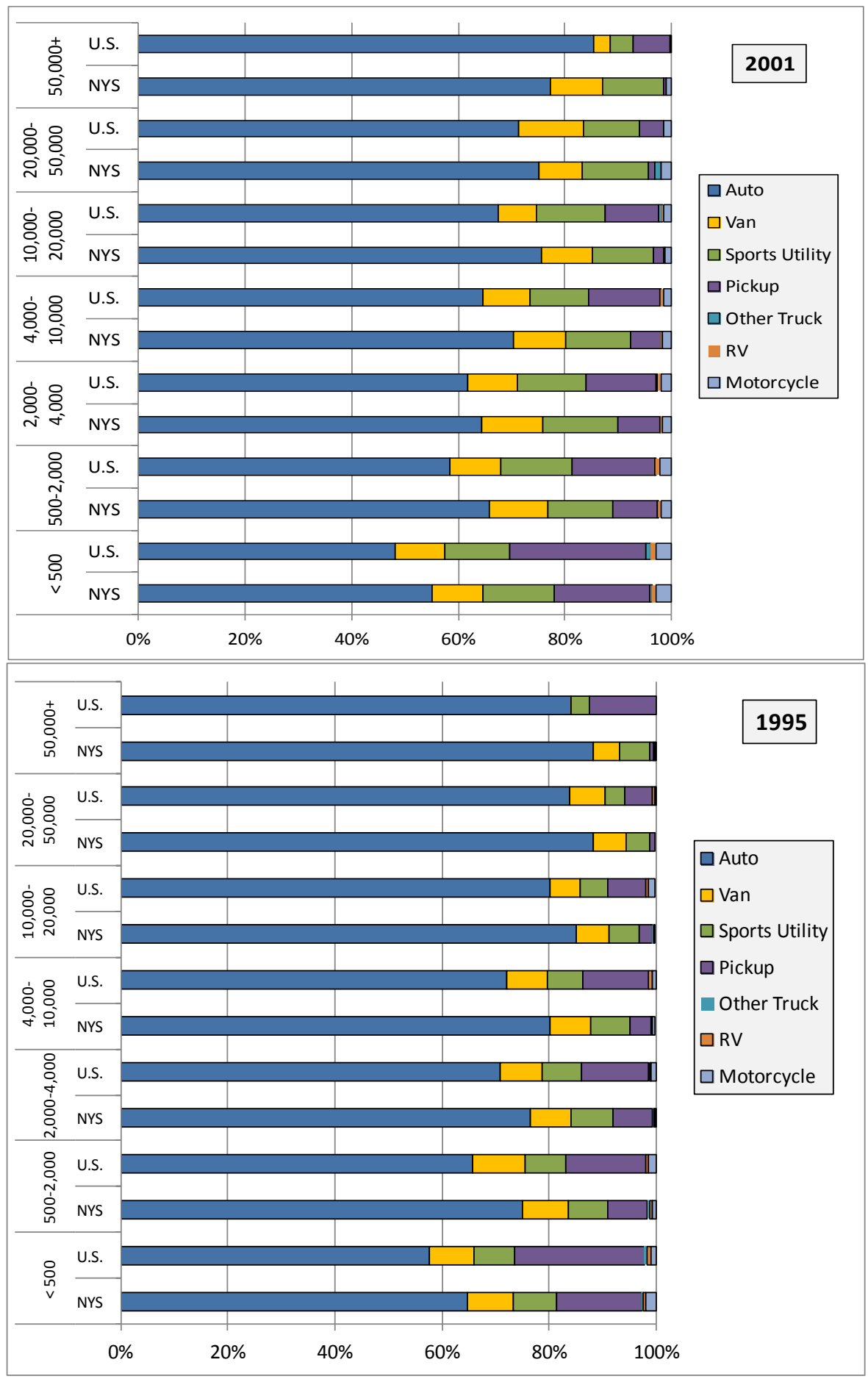

Figure 4.25 Household In-Use Vehicle Fleet Percentages, by Vehicle Type and Population Density (in persons per square mile, based on census tract data).

Note: $R V=$ recreational vehicle. 


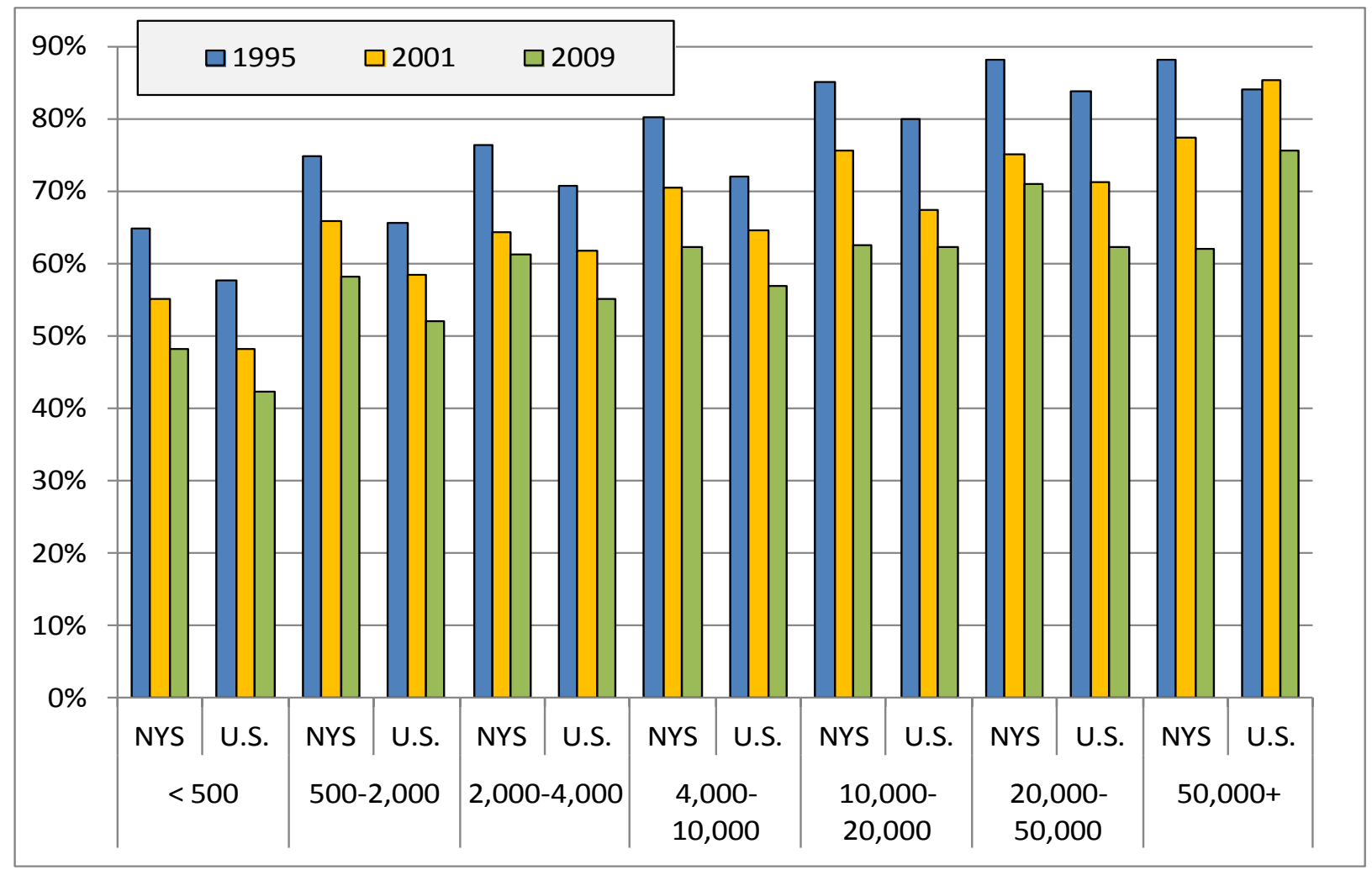

Figure 4.26 Temporal Trend in Auto Share by Population Density (persons per square mile, based on census tract data).

Figure 4.27 shows how the average and median age of household vehicles varies across population density classes for 2009. There is no clear trend in the data across density classes. On average, and for all density classes, household vehicle fleets within NYS metro areas are 1-2 years newer than those in metro areas outside the state. Figure 4.28 shows how average vehicle age has risen gradually in some density classes over the period 1995 to 2009, while staying essentially unchanged in others. Specifically, based on results shown in Figure 4.27, vehicles owned by households in the metro areas outside NYS with residential densities between 10,000 and 20,000 ppsm in 2009 have the highest average vehicle age, at 9.8 years (median age $=9$ years). NYS metro households in areas with 500 to 2,000 ppsm had the lowest average vehicle age at 7.3 years (median age $=6$ years). In 2009, the average vehicle age taken over all urban density ranges was 7.7 years for NYS metro area households, and 9.1 years for non-NYS metro households. Summary statistics supporting figures discussed in this part are presented in Appendix C.4 of this report. 


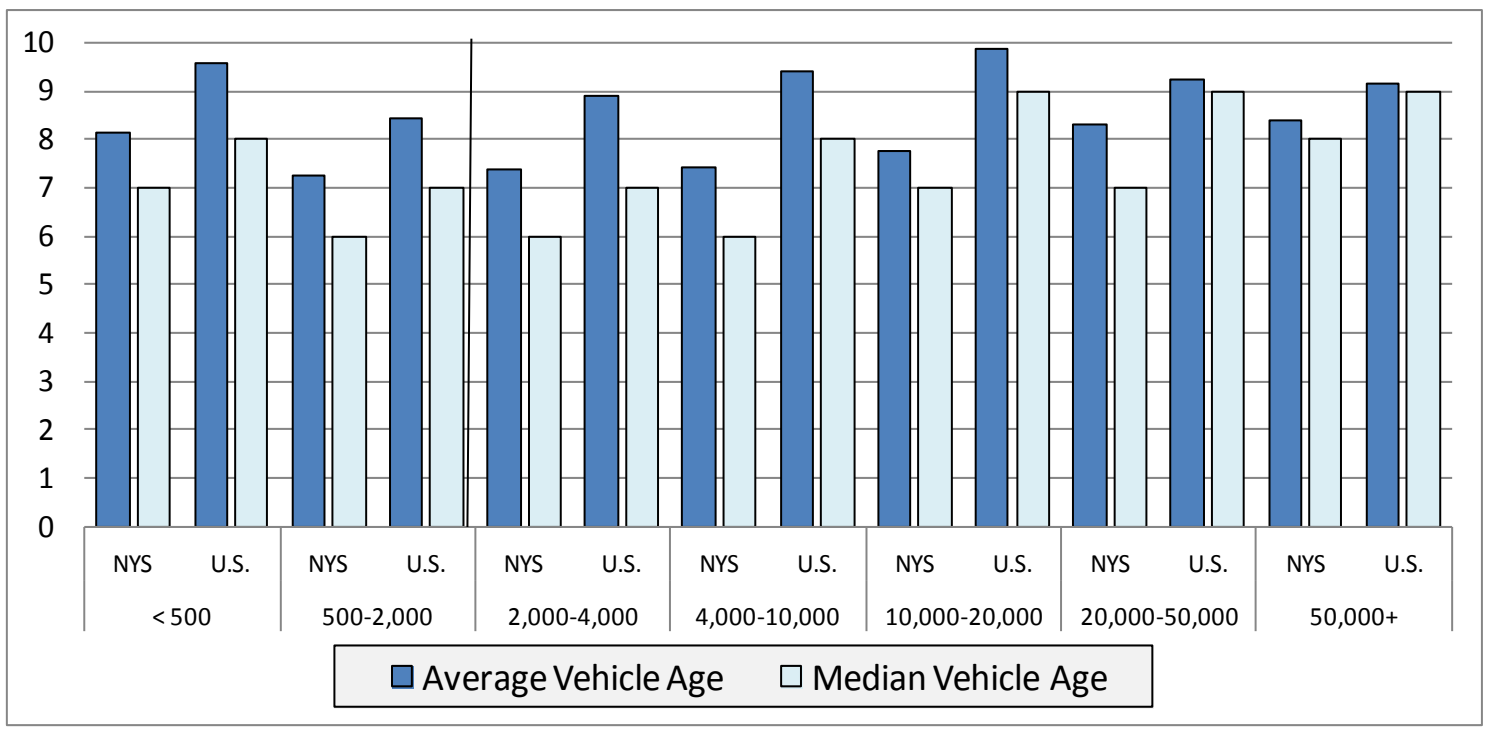

Figure 4.27 Variation in Age in Years of Privately Owned Household Vehicles with Population Residential Density in 2009 (persons per square mile, based on census tract data).

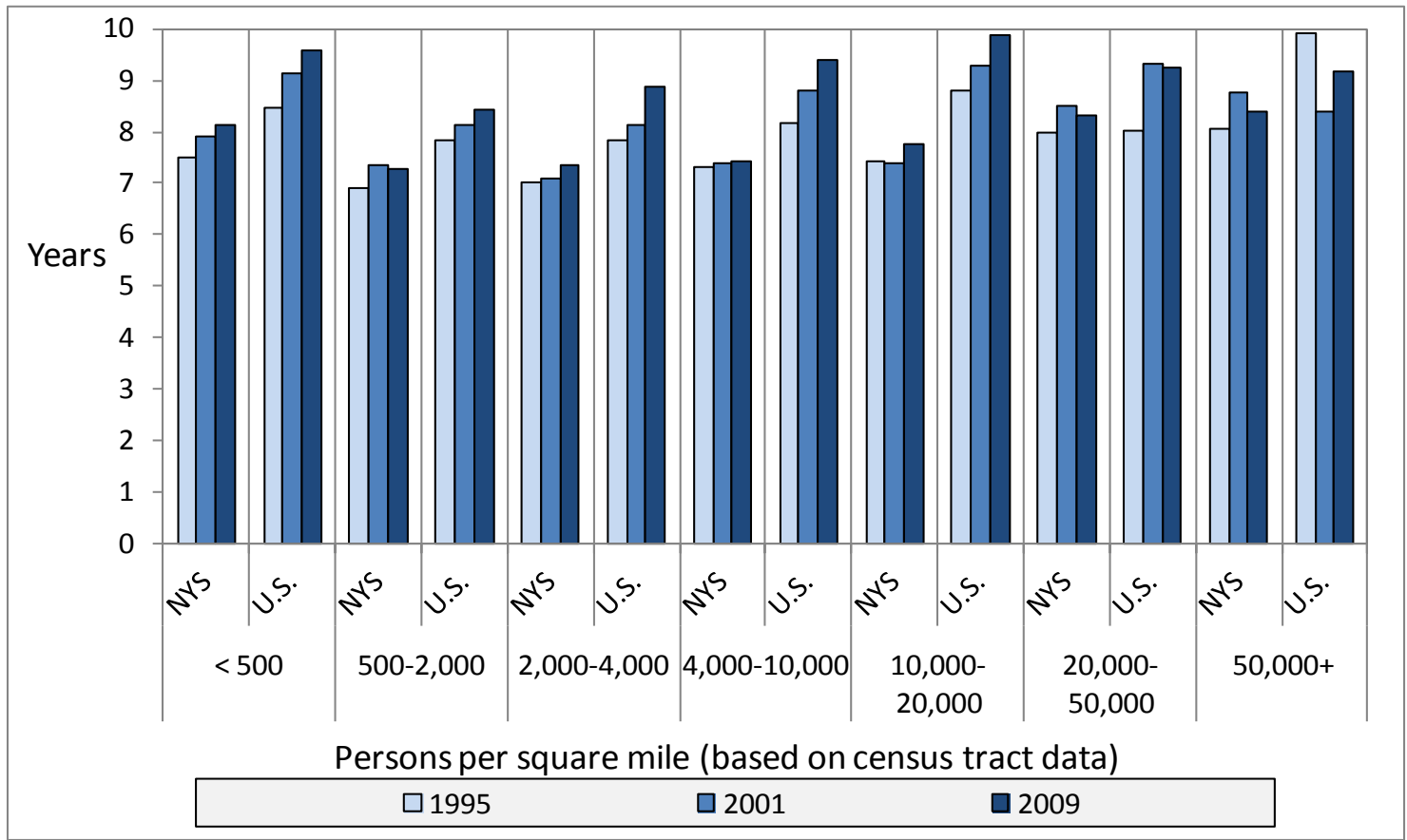

Figure 4.28 Trends in Average Age of Privately Owned Household Vehicles with Population Density for 1995, 2001, and 2009. 


\subsubsection{Greenhouse Gas Emissions Associated With Vehicle Travel}

As described in Chapters 2 and 3 of this report, NYS households on the average emit significantly fewer travel-generated carbon dioxide emissions annually than do residents in the rest of the nation. Figure 4.29 below shows estimated 2009 carbon dioxide (CO2) emissions for each of the seven population density classes used in this report, for both NYS and out of state metro areas. Due to the lower trip frequencies, shorter trip lengths, and shifts to walk and transit by travelers located in higher density areas, there is a steady decline in annual CO2 emissions per household with higher density residential location. Among both the NYS metros and metros in the rest of the nation, the averages of annual $\mathrm{CO} 2$ emissions in the highest density areas are at about $23 \%$ of the emission levels of the lowest density areas in 2009. NYS metro area average emissions rates are also seen to be consistently lower than average emissions rates per household in metro areas outside the state (recognizing that considerable variability may exist across different metro areas). ${ }^{14}$

Figure 4.30 compares CO2 emissions for the set of NYS metros in 2009 versus 2001. (The equivalent data sources for 1995 were not available for all modes of travel.) With the exception of the lowest density areas, average per household travel emissions in other density classes are all statistically lower in 2009, once standard errors are taken into account (see Appendix C.4). Overall, NYS metro area emissions rates are estimated to have come down from a household weighted average of 6.1 metric tons in 2001 to 5.6 metric tons in 2009.

${ }^{14}$ See Brown et al (2008) "Shrinking The Carbon Footprint of Metropolitan America" published by the Brookings Institution in Washington D.C. for a 2005 comparison of passenger and freight emissions per person and per metropolitan area domestic product for the nation's 100 largest metro areas, which also shows the New York City metropolitan area to be one of the lower per capita emitters in the country. 


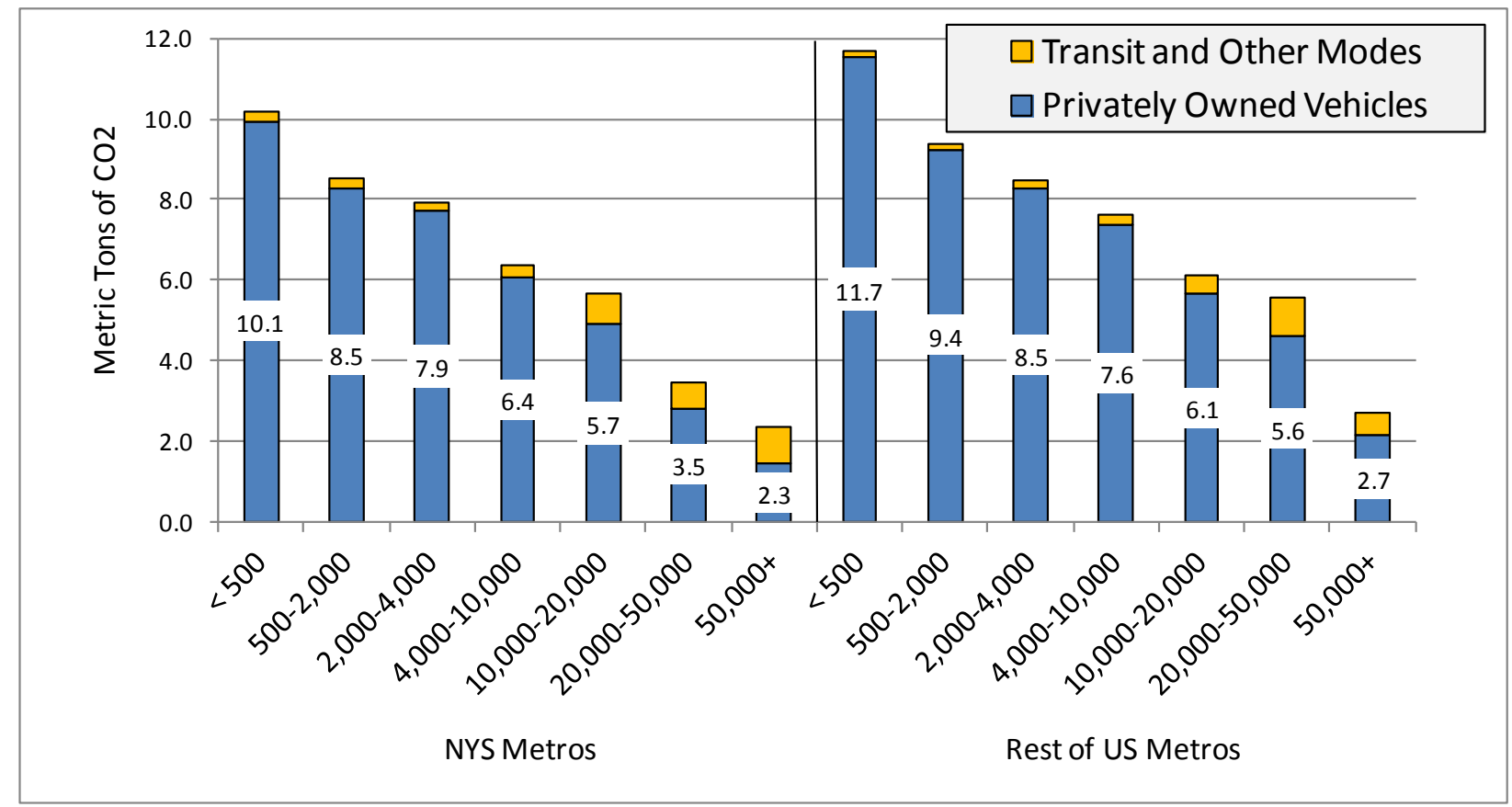

Figure 4.29 Average Annual Emissions of Carbon Dioxide (Metric Tons of CO2) from Household Travel in 2009 by Population Density (in persons per square mile, based on census tract data).

Note: Direct, vehicle operating emissions only, no "upstream" vehicle or fuel production or infrastructure provision related emissions are included. Air travel is excluded. The emissions rates used for each mode of travel are reported in Appendix D, and make use of US EPA recommended fuel use-to-CO2 emissions conversions, and emissions rate estimates derived from the Federal Transit Administration's rail, bus and ferry transit energy consumption database and average vehicle fuel efficiencies reported by or derived from Federal Highway Administration, American Bus Association, American School Bus Association, and the New York City Taxi and Limousine Commission estimates. Numbers on blue bars $=$ total POV plus Transit and Other Modes annual CO2 emissions. 


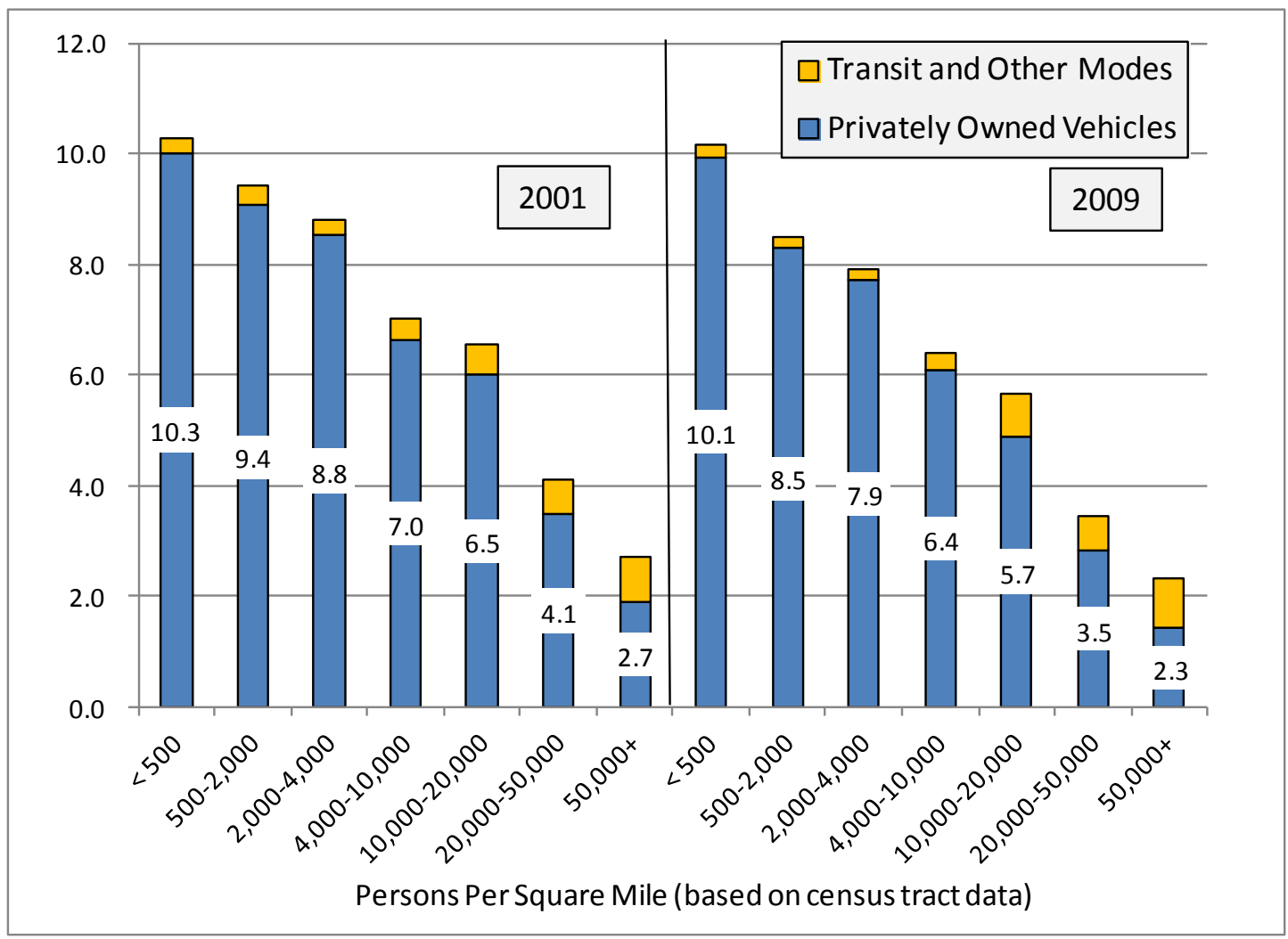

Figure 4.30 Estimated Average Annual Emissions of Carbon Dioxide (Metric Tons of CO2) from Household Travel for 2001 and 2009.

\subsection{COMMUTING COMPARISONS}

\subsubsection{Commute Modes}

Figures 4.31 and 4.32 show the modal shares associated with daily commuting trips within metro areas inside and outside NYS, respectively. While residential location does not significantly affect daily commute frequency, it does influence how people go to work and how long daily commutes take. While metro areas both inside and outside the state display a significant shift from private automobile trips to public transit trips with increasing population density, and noticeably so at densities over $20,000 \mathrm{ppsm}$, this shift is much more noticeable within NYS, principally due to the higher rates of transit ridership and also walk trips within the NYC metro area.

Within NYS POVs are responsible for over $80 \%$ of the commutes from metro areas with residential densities of less than 10,000 ppsm. This share drops to $70 \%$ at densities between 10,000 and 20,000 ppsm. At urban densities over 20,000 ppsm a major mode shift occurs, with walking and public transit commutes becoming the dominant means of travel to and from work (Figure 4.31). This pattern, due largely to commuting choices within the NYC metro area, has 
remained essentially the same since 1995. A similar pattern emerges from metro areas outside NYS. But both public transit and walking as commute modes are noticeably more significant within NYS metro areas with population densities above 4,000 ppsm than in the equivalent densities outside NYS (Figure 4.32). While in metro areas outside NYS two thirds of all commutes from areas with densities between 20,000 and 50,000 ppsm are made in POVs, only one third of commutes are by POV in NYS metro areas at these same high densities. Among the highest density areas of over 50,000 ppsm that were sampled outside the state in 2009 , some $44 \%$ of commuter trips still used private household vehicles. Within NYS (effectively households found within NYC), only some $16 \%$ of commutes are POV based at these very high population density areas: with public transit and walk trips accounting for three quarters of all daily commutes.

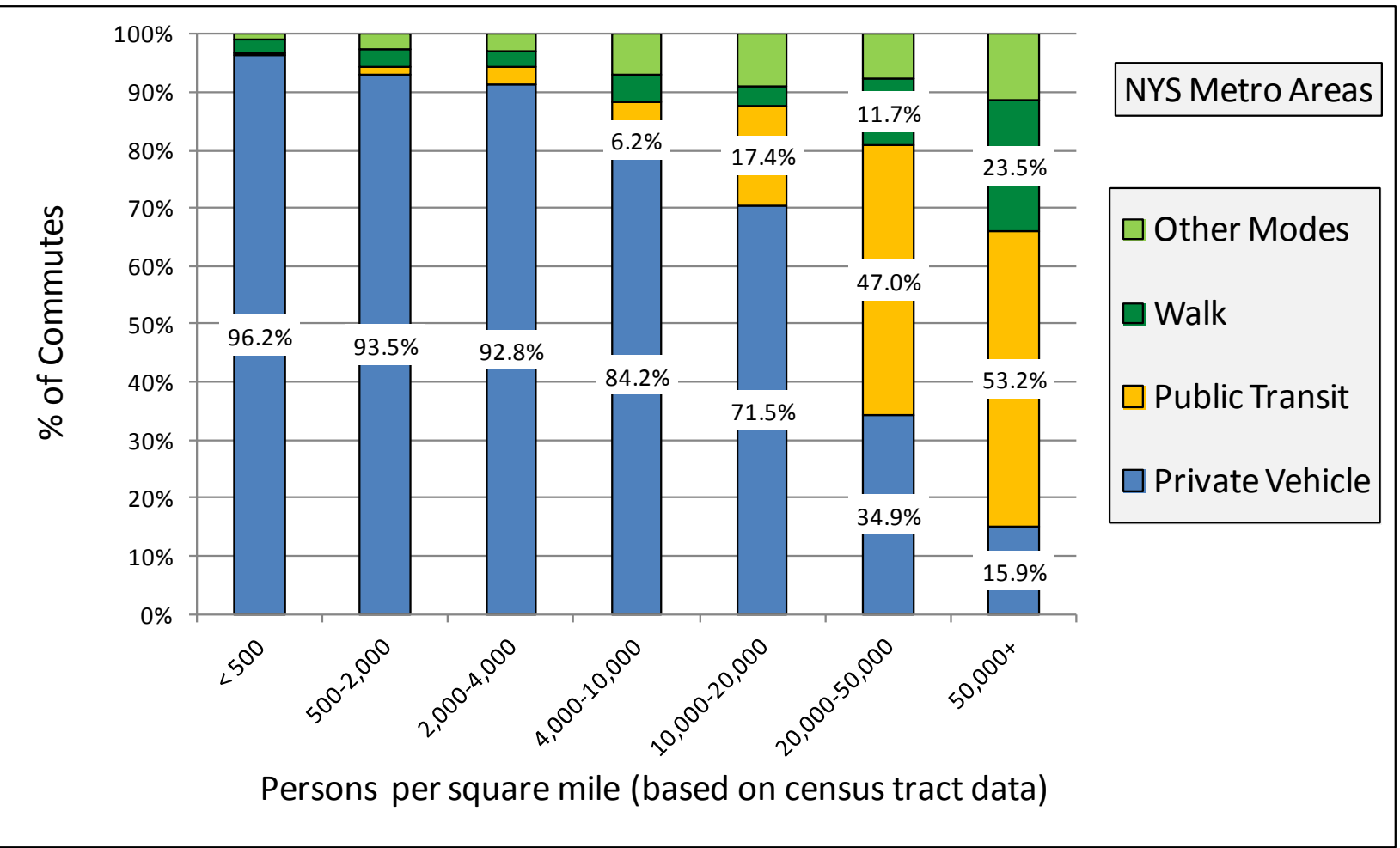

Figure 4.31 Commute Trips by Mode and Population Density for Households in NYS Metro Areas in 2009. 


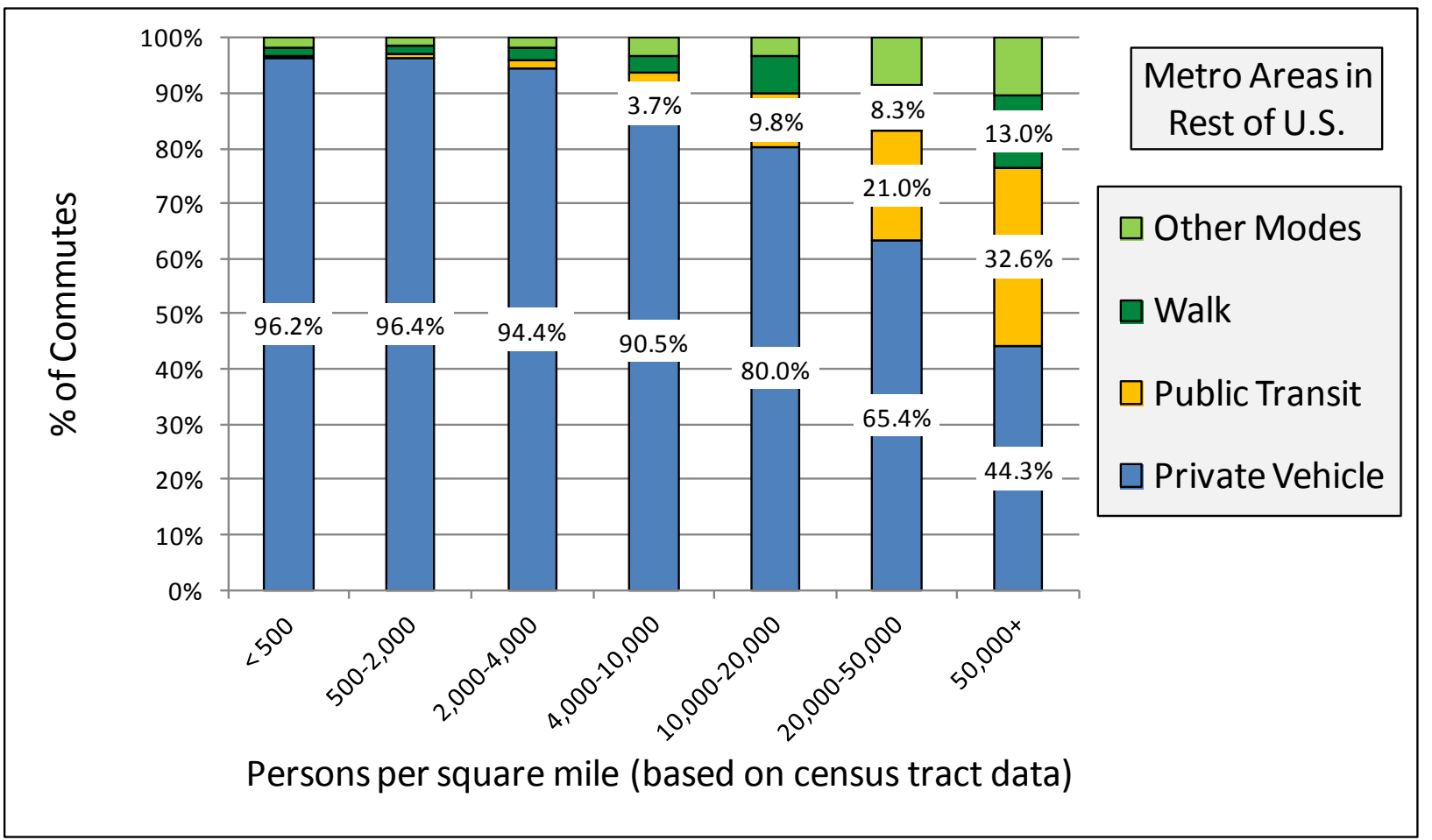

Figure 4.32 Commute Trips by Mode and Population Density for Households in Metro Areas Outside NYS in 2009.

Notes: Private Vehicle $=$ SOV (single occupancy vehicle) + MOV (multiple occupancy vehicle). The mode "Other" includes commercial and private air, school/charter/city to city buses, Amtrak, water modes, taxi, limousine, shuttle, bicycle and other nonspecified modes. Source: Appendix C.4.

\subsubsection{Commute Distances and Times}

Tables 4.14, 4.15, 4.16 and Figure 4.33 show how average daily commute trip lengths and travel times vary by residential densities, based on the 2009, 2001 and 1995 NHTS surveys. As shown in Figure 4.33, while commute distances decline steadily with population density in all three survey years, commute times trend slightly in the opposite direction, changing little at densities below 10,000 ppsm, but increasing noticeably at higher densities, in both the NYS metros and in metros in the rest of the nation. That is, traffic congestion leading to lower travel speeds and the use of usually slower door-to-door transit rides is impacting commutes significantly within higher density areas, despite the noticeably shorter trip lengths in these areas. More detailed statistics on commute distances and associate travel time can be found in Appendix C.4 of this report. 
Table 4.14 Daily Commute Statistics by Population Density Between New York State Metro Areas (NYS) vs. Metro Areas in the Rest of the United States (U.S.), 2009 (population density based on census tract data)

\begin{tabular}{|c|c|c|c|c|c|c|c|c|c|c|c|c|c|c|}
\hline & \multicolumn{14}{|c|}{ Population Density (population per square mile) ${ }^{a}$} \\
\hline & \multicolumn{2}{|c|}{$<500$} & \multicolumn{2}{|c|}{$500-2,000$} & \multicolumn{2}{|c|}{$2,000-4,000$} & \multicolumn{2}{|c|}{$4,000-10,000$} & \multicolumn{2}{|c|}{$10,000-20,000$} & \multicolumn{2}{|c|}{$20,000-50,000$} & \multicolumn{2}{|c|}{$50,000+$} \\
\hline & NYS & U.S. & NYS & U.S. & NYS & U.S. & NYS & U.S. & NYS & U.S. & NYS & U.S. & NYS & U.S. \\
\hline \multicolumn{15}{|c|}{ Average Commute Length ${ }^{\mathrm{a}}$ (miles) } \\
\hline Private Vehicle & 14.41 & 15.15 & 11.76 & 12.90 & 11.26 & 10.89 & 9.88 & 10.11 & 8.86 & 9.76 & 12.10 & 10.37 & 10.65 & 4.67 \\
\hline Public Transit & 20.97 & 6.13 & 18.45 & 14.34 & 26.42 & 17.24 & 14.58 & 11.14 & 12.22 & 5.94 & 7.92 & 8.23 & 7.57 & 4.64 \\
\hline Walk & 0.54 & 0.78 & 1.29 & 1.58 & 0.51 & 0.76 & 0.88 & 0.87 & 0.81 & 0.97 & 2.90 & 0.69 & 1.48 & 0.64 \\
\hline Other ${ }^{b}$ & 50.60 & 21.11 & 8.21 & 21.14 & 7.09 & 14.24 & 5.41 & 10.33 & 28.47 & 13.61 & 5.08 & 4.86 & 6.99 & $1.37^{\star}$ \\
\hline \multicolumn{15}{|c|}{ Commute Travel Time ${ }^{\mathrm{C}}$ (minutes) } \\
\hline Private Vehicle & 24.01 & 25.09 & 22.90 & 23.43 & 23.09 & 22.52 & 24.23 & 22.13 & 24.07 & 25.36 & 34.63 & 26.94 & 33.38 & 17.87 \\
\hline Public Transit & 61.30 & 50.57 & 53.61 & 51.20 & 69.24 & 70.79 & 55.86 & 51.74 & 63.68 & 49.45 & 52.18 & 53.79 & 49.49 & 37.20 \\
\hline Walk & 8.54 & 13.29 & 13.56 & 28.07 & 15.13 & 15.88 & 16.88 & 15.10 & 16.41 & 15.89 & 28.11 & 13.06 & 18.32 & 17.24 \\
\hline Other ${ }^{b}$ & 31.82 & 25.70 & 26.49 & 26.32 & 19.13 & 33.85 & 26.03 & 27.77 & 41.00 & 26.93 & 43.15 & 21.61 & 26.94 & $22.24^{*}$ \\
\hline \multicolumn{15}{|c|}{ Average Commute Speed ${ }^{\mathrm{C}}$} \\
\hline Private Vehicle & 36.01 & 36.22 & 30.82 & 33.02 & 29.25 & 29.01 & 24.47 & 27.41 & 22.08 & 23.09 & 20.97 & 23.08 & 19.13 & 15.66 \\
\hline \multicolumn{15}{|l|}{ Public Transit } \\
\hline Walk & 3.80 & 3.54 & 5.70 & 3.38 & 2.02 & 2.88 & 3.13 & 3.45 & 2.96 & 3.65 & 6.20 & 3.17 & 4.85 & 2.22 \\
\hline Other $^{b}$ & 95.40 & 49.29 & 18.60 & 48.21 & 22.24 & 25.24 & 12.47 & 22.31 & 41.67 & 30.33 & 7.06 & 13.48 & 15.57 & $3.69^{\star}$ \\
\hline
\end{tabular}

Note: An * after a number indicates a large standard error on the estimate.

${ }^{a}$ Average commute lengths are calculated using only those records with trip mileage information present.

b The mode "Other" includes Amtrak, airplane, taxi, bicycle, school bus, and other non-POV.

${ }^{\mathrm{c}}$ Average commute travel times and average commute speeds do not include time spent waiting for transportation. 
Table 4.15 Daily Commute Statistics by Population Density between New York State Metro Areas (NYS) vs. Metro Areas in the Rest of the Nation (U.S.), 2001 (population density based on census tract data)

\begin{tabular}{|c|c|c|c|c|c|c|c|c|c|c|c|c|c|c|}
\hline & \multicolumn{14}{|c|}{ Population Density (population per square mile) ${ }^{a}$} \\
\hline & \multicolumn{2}{|c|}{$<500$} & \multicolumn{2}{|c|}{$500-2,000$} & \multicolumn{2}{|c|}{$2,000-4,000$} & \multicolumn{2}{|c|}{$4,000-10,000$} & \multicolumn{2}{|c|}{$10,000-20,000$} & \multicolumn{2}{|c|}{$20,000-50,000$} & \multicolumn{2}{|c|}{$50,000+$} \\
\hline & NYS & U.S. & NYS & U.S. & NYS & U.S. & NYS & U.S. & NYS & U.S. & NYS & U.S. & NYS & U.S. \\
\hline \multicolumn{15}{|c|}{ Average Commute Length $^{\mathrm{a}}$ (miles) } \\
\hline Private Vehicle & 13.80 & 14.82 & 12.05 & 11.79 & 12.04 & 10.61 & 10.00 & 10.98 & 9.92 & 10.44 & 8.90 & 9.62 & 10.45 & 12.85 \\
\hline Public Transit & 19.98 & 22.56 & 29.95 & 23.18 & 27.01 & 14.78 & 21.93 & 12.83 & 13.95 & 9.21 & 11.04 & 6.14 & 7.72 & 9.15 \\
\hline Walk & 2.91 & 0.83 & 0.93 & 0.77 & 0.91 & 1.16 & 1.94 & 0.86 & 1.26 & 0.89 & 1.25 & 0.82 & 1.22 & $0.05^{\star}$ \\
\hline Other $^{b}$ & 47.27 & 102.60 & 24.74 & 100.65 & 12.69 & 86.44 & 14.08 & 72.59 & 11.04 & 31.46 & 7.43 & 3.01 & 6.80 & \\
\hline \multicolumn{15}{|c|}{ Commute Travel Time ${ }^{\mathrm{c}}$ (minutes) } \\
\hline Private Vehicle & 23.56 & 24.24 & 22.27 & 22.12 & 23.28 & 21.26 & 21.95 & 22.82 & 25.97 & 25.85 & 28.16 & 23.87 & 35.47 & 33.04 \\
\hline Public Transit & 57.97 & 106.73 & 74.46 & 61.73 & 71.18 & 56.27 & 77.46 & 59.50 & 71.98 & 48.40 & 58.02 & 43.85 & 51.14 & 54.67 \\
\hline Walk & 12.59 & 8.93 & 33.23 & 14.97 & 14.52 & 13.66 & 12.91 & 13.16 & 17.70 & 14.45 & 20.27 & 15.18 & 19.76 & $3.19^{*}$ \\
\hline Other ${ }^{b}$ & 67.52 & 74.27 & 52.86 & 58.37 & 32.74 & 56.92 & 53.63 & 38.34 & 42.48 & 40.41 & 32.43 & 32.08 & 37.50 & \\
\hline \multicolumn{15}{|c|}{ Average Commute Speed $^{c}$} \\
\hline Private Vehicle & 35.17 & 36.71 & 32.72 & 32.01 & 31.25 & 30.02 & 27.34 & 28.90 & 23.30 & 24.25 & 18.51 & 24.25 & 17.68 & 23.34 \\
\hline \multicolumn{15}{|l|}{ Public Transit } \\
\hline Walk & 7.09 & 5.48 & 1.40 & 2.47 & 3.77 & 3.06 & 6.78 & 3.72 & 3.14 & 3.09 & 3.14 & 2.65 & 3.15 & $0.90^{*}$ \\
\hline Other ${ }^{b}$ & 48.42 & 83.87 & 22.97 & 134.30 & 13.71 & 127.75 & 14.76 & 165.74 & 10.46 & 7.67 & 16.08 & 5.06 & 12.59 & \\
\hline
\end{tabular}

Note: An * after a number indicates a large standard error on the estimate.

\footnotetext{
${ }^{a}$ Average commute lengths are calculated using only those records with trip mileage information present.

b The mode "Other" includes Amtrak, airplane, taxi, bicycle, school bus, and other non-POV.

${ }^{\mathrm{c}}$ Average commute travel times and average commute speeds do not include time spent waiting for transportation.
} 
Table 4.16 Daily Commute Statistics by Population Density New York State Metro Areas (NYS) vs. Metro Areas in the Rest of the United States (U.S.), 1995 (population density based on census tract data)

\begin{tabular}{|c|c|c|c|c|c|c|c|c|c|c|c|c|c|c|}
\hline & \multicolumn{14}{|c|}{ Population Density (population per square mile) $^{a}$} \\
\hline & \multicolumn{2}{|c|}{$<500$} & \multicolumn{2}{|c|}{$500-2,000$} & \multicolumn{2}{|c|}{$2,000-4,000$} & \multicolumn{2}{|c|}{$4,000-10,000$} & \multicolumn{2}{|c|}{$10,000-20,000$} & \multicolumn{2}{|c|}{$20,000-50,000$} & \multicolumn{2}{|c|}{$50,000+$} \\
\hline & NYS & U.S. & NYS & U.S. & NYS & U.S. & NYS & U.S. & NYS & U.S. & NYS & U.S. & NYS & U.S. \\
\hline \multicolumn{15}{|c|}{ Average Commute Length ${ }^{\mathrm{a}}$ (miles) } \\
\hline Private Vehicle & 13.44 & 14.73 & 12.80 & 12.71 & 12.29 & 10.67 & 10.74 & 10.41 & 9.57 & 10.02 & 12.96 & 10.61 & 11.88 & 6.18 \\
\hline Public Transit & 38.32 & 38.67 & 35.01 & 20.24 & 27.13 & 20.44 & 20.86 & 11.24 & 12.97 & 8.32 & 12.99 & 8.72 & 8.89 & 5.36 \\
\hline Walk & 0.61 & 0.63 & 0.58 & 0.51 & 0.82 & 0.58 & 0.60 & 0.88 & 0.83 & 0.81 & 0.94 & 0.68 & 1.18 & 1.97 \\
\hline Other $^{\mathrm{b}}$ & 41.18 & 17.50 & 11.32 & 22.61 & 2.82 & 71.95 & 7.51 & 8.49 & 4.67 & 5.39 & 10.17 & 4.16 & 16.61 & 1.00 \\
\hline \multicolumn{15}{|c|}{ Commute Travel Time ${ }^{\mathrm{C}}$ (minutes) } \\
\hline Private Vehicle & 21.25 & 22.77 & 21.71 & 20.90 & 22.02 & 19.12 & 21.60 & 19.83 & 22.70 & 21.01 & 29.63 & 26.13 & 30.76 & 18.07 \\
\hline Public Transit & 55.72 & 67.45 & 60.88 & 48.73 & 60.38 & 46.46 & 50.32 & 39.15 & 46.31 & 33.28 & 49.94 & 36.85 & 39.39 & 35.84 \\
\hline Walk & 6.81 & 7.51 & 11.15 & 8.51 & 12.43 & 11.76 & 8.87 & 11.92 & 9.34 & 10.49 & 10.82 & 12.22 & 16.53 & 20.25 \\
\hline Other $^{b}$ & 37.95 & 56.84 & 35.40 & 24.83 & 11.80 & 36.82 & 24.93 & 39.77 & 23.33 & 19.48 & 29.48 & 52.54 & 23.23 & 5.00 \\
\hline \multicolumn{15}{|c|}{ Average Commute Speed $^{c}$} \\
\hline Private Vehicle & 37.94 & 38.81 & 35.37 & 36.46 & 33.48 & 33.47 & 29.84 & 31.50 & 25.30 & 28.61 & 26.25 & 24.36 & 23.17 & 20.51 \\
\hline Public Transit & 30.71 & 39.65 & 37.73 & 27.07 & 30.72 & 34.98 & 21.85 & 17.09 & 14.99 & 15.51 & 17.63 & 11.42 & 12.32 & 10.98 \\
\hline Walk & 5.35 & 5.01 & 3.13 & 3.60 & 3.98 & 2.94 & 4.09 & 4.41 & 5.35 & 4.66 & 5.18 & 3.33 & 4.27 & 5.84 \\
\hline Other $^{b}$ & 65.10 & 18.42 & 19.19 & 55.04 & 13.76 & 117.25 & 15.75 & 11.16 & 12.35 & 16.59 & 20.70 & 4.75 & 42.90 & 12.00 \\
\hline
\end{tabular}

Note: An * after a number indicates a large standard error on the estimate.

\footnotetext{
${ }^{a}$ Average commute lengths are calculated using only those records with trip mileage information present.

b The mode "Other" includes Amtrak, airplane, taxi, bicycle, school bus, and other non-POV.

${ }^{c}$ Average commute travel times and average commute speeds do not include time spent waiting for transportation.
} 


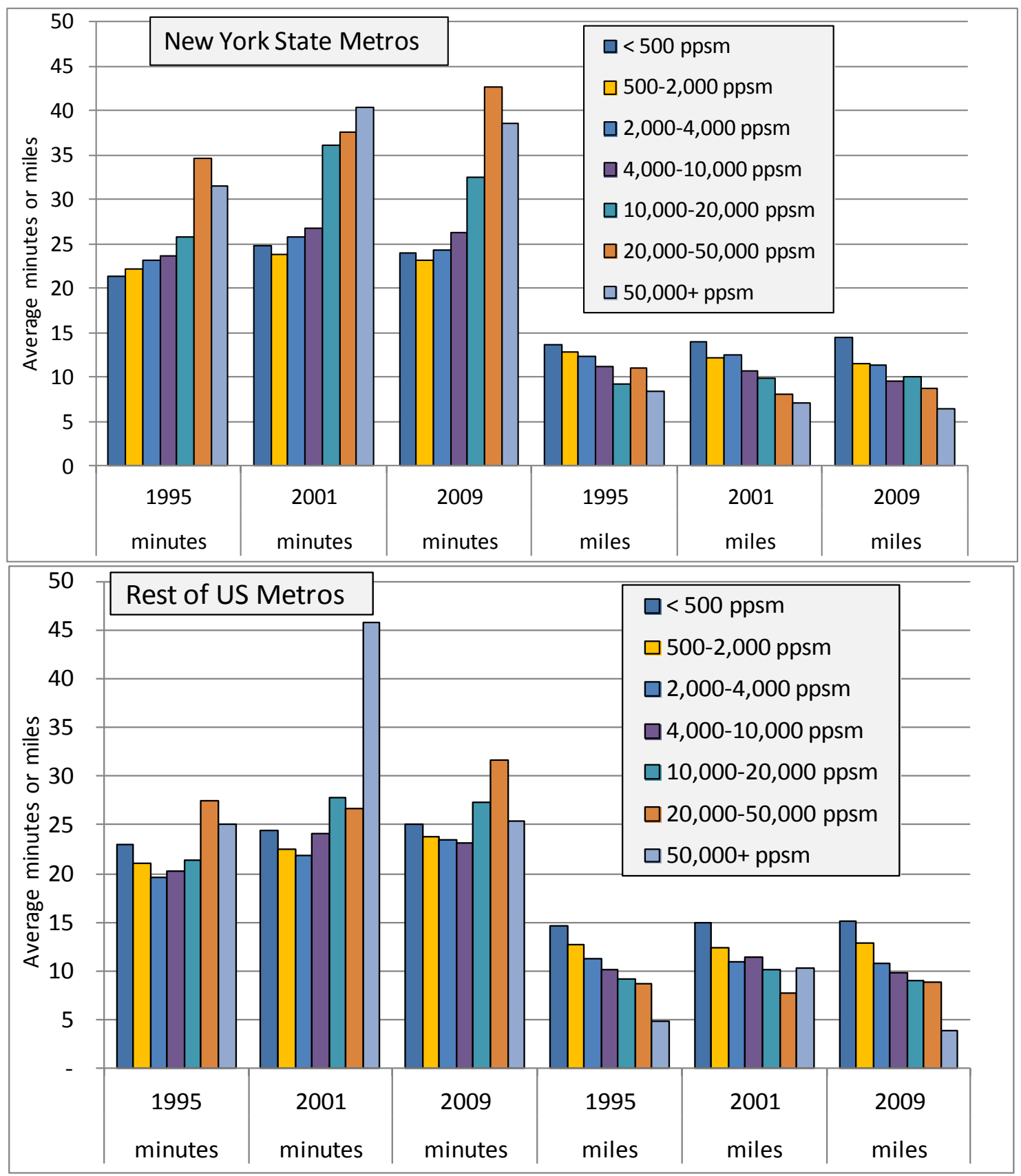

Figure 4.33 Trends in Commute Times and Distances: New York State Metros versus Rest of the United States Metro Areas Compared, by Population Density Class (persons per square mile, based on census tract data).

A frequently proposed solution to traffic congestion on our highways is a significant shift to public transit modes. A major challenge here is to make such trips more time competitive with auto travel in terms of travel times and convenience. Figure 4.34 shows the distribution of public transit commute distances and average commute travel times in 2009 for the 13 NYS metro 
areas. For comparison with conditions in the rest of the nation, the two right hand side bars in the figure show the average commute distance ( 12 miles) and average commute time (56 minutes) by public transit within metro areas outside the NYS. These statistics are based on averaging over all of out-of-state metro area commutes combined, i.e. averaged over all seven density classes of metros in the rest of the nation. Figure 4.35 below shows how these public transit average trip commute times within NYS metro areas have changed over time, for each of the seven population density classes used in this chapter. With the exception of trips made from the least densely populated areas, average commute times increased in 2001 and then fell back a little in 2009.

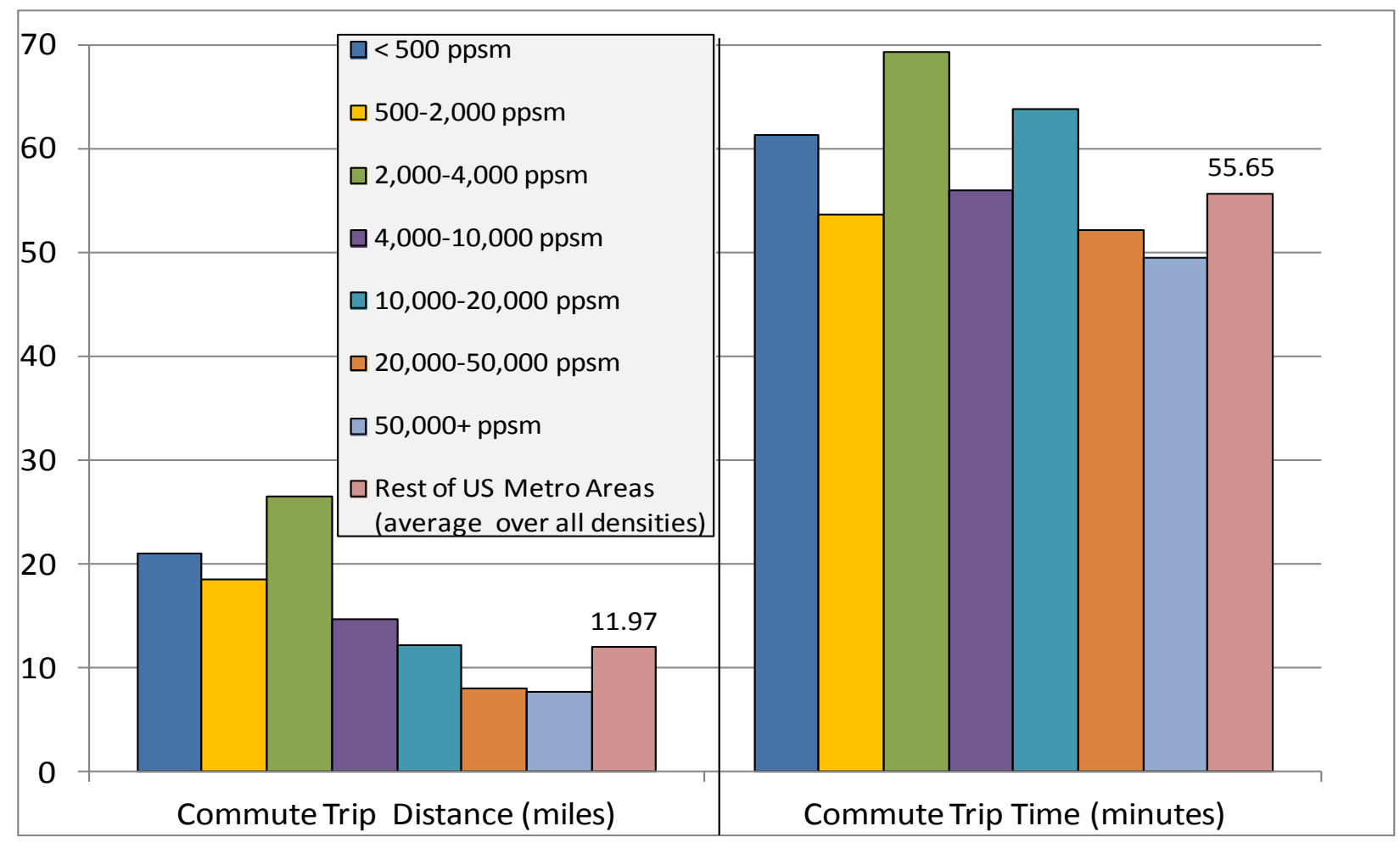

Figure 4.34 Metro Area Commute Trip Lengths and Times on Public Transit Broken Down by Population Density in 2009: (density in persons per square mile, based on census tract data). 


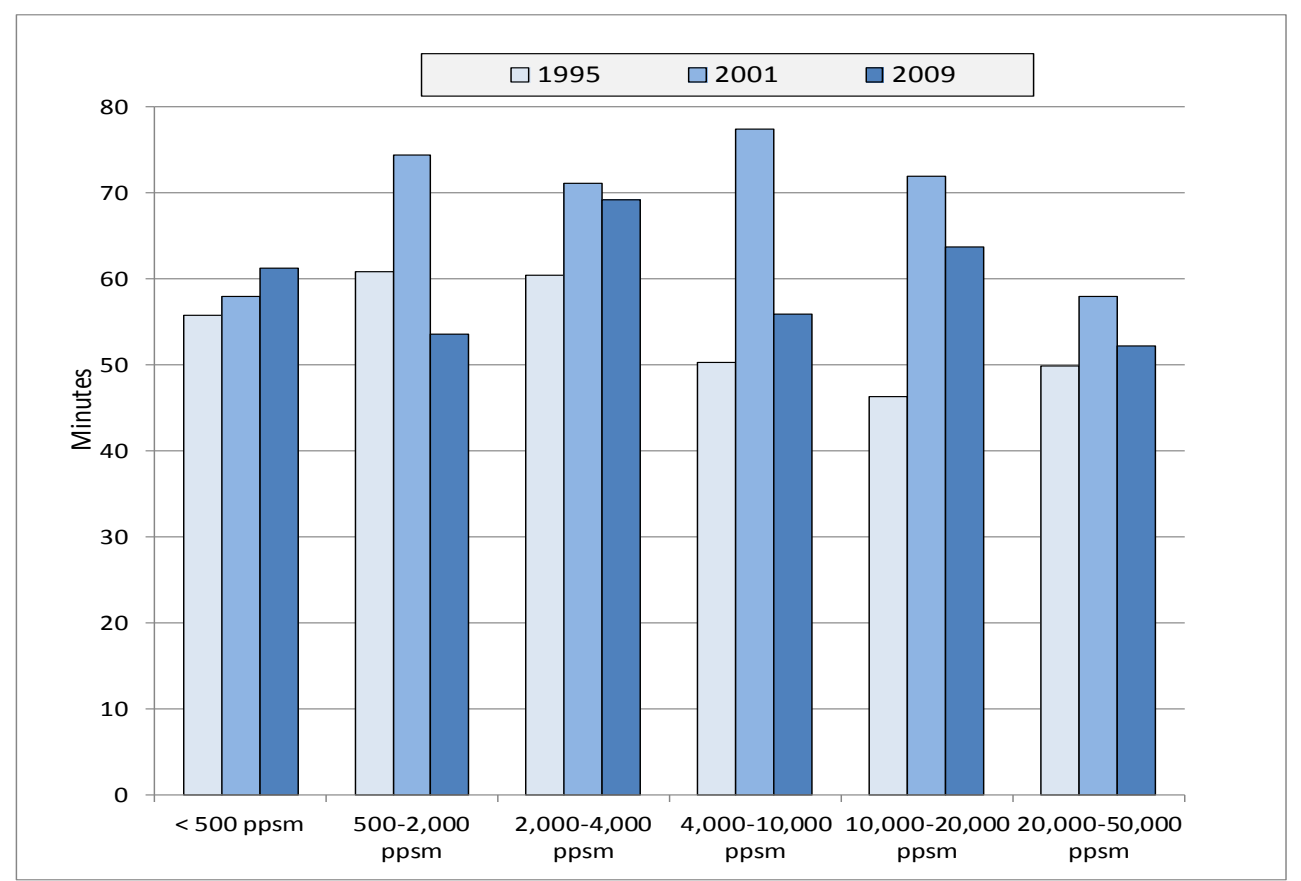

Figure 4.35 Average Daily Commute Trip Times by Public Transit in NYS Metro Areas in 1995, 2001, and 2009 by Population Density (in persons per square mile, based on census tract data).

Figure 4.36 shows the difference between private vehicle (i.e., auto) and public transit commute times in 2009 , as a percentage increase in the auto commute time for each population density class. The auto times are used here as the base for comparison (i.e. percentage increase $=$ $100 *[($ transit commute time - auto commute time)/auto commute time]). This figure suggests that differences in auto versus transit times are lower in higher density areas, possible as a result of greater congestion levels on highways in the denser areas (and also given the significant presence of rail transit in those areas).

Figure 4.37, based on the commuting time data shown in Tables 4.14, 4.15 and 4.16, shows these same 2009 percentage increases in metropolitan area averaged public transit versus auto commute times, compared with their 1995 and 2001 counterparts. Percentage differences in this figure are based on the same formulas used for Figure 4.36. Differences in transit versus private vehicle travel times are smallest in the highest density areas for all three years, both inside and outside the state. However, a significant reduction in the average commute time difference between the two modes appears to have taken place in the lowest density parts of the metro areas outside the state. 


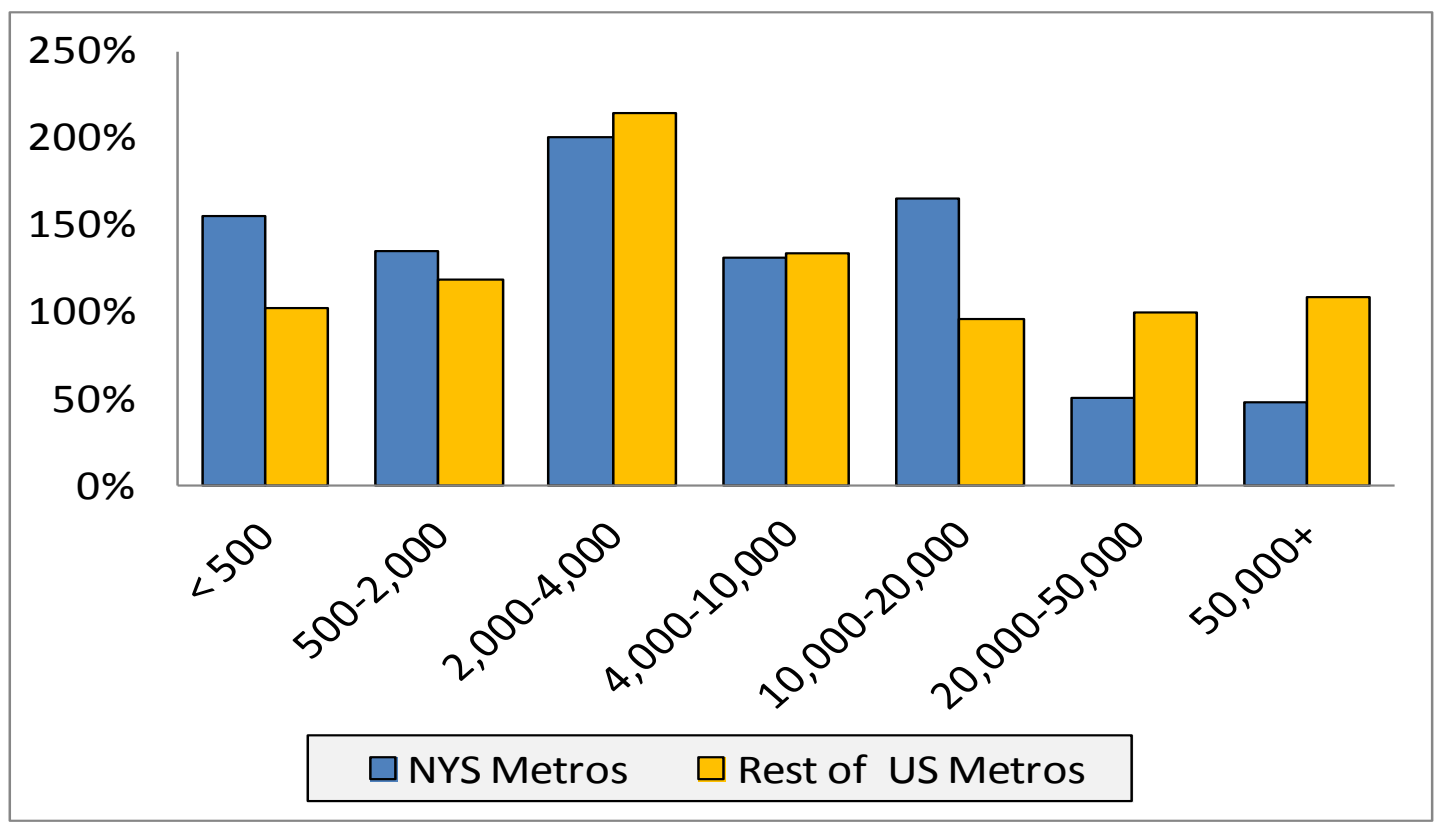

Figure 4.36 Percentage Increases in Commute Times: Public Transit versus Private Vehicle Trips in 2009, by Population Density 


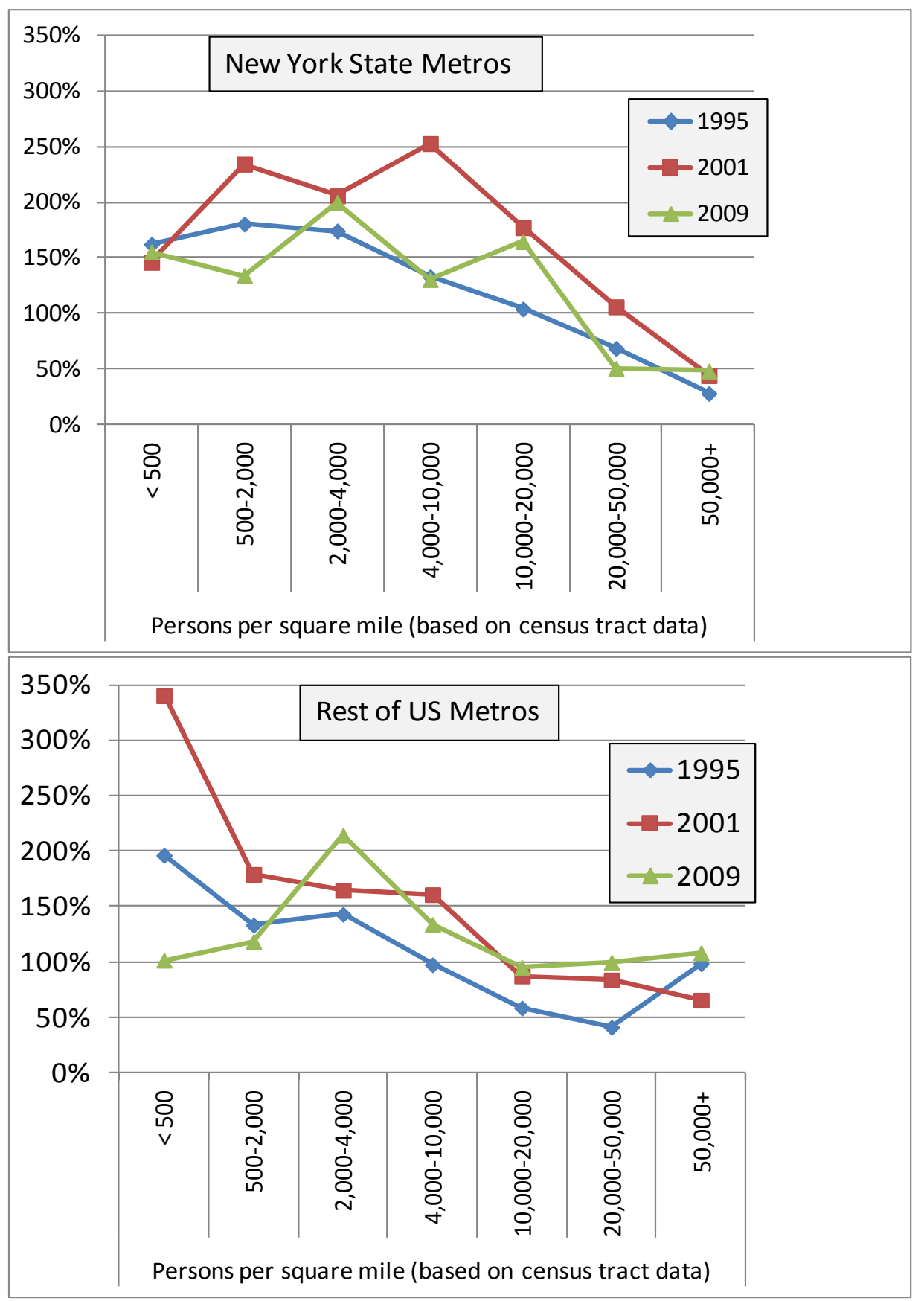

Figure 4.37 Temporal Trends in Commute Times (Percentage Differences) Between Public Transit and Private Vehicles, 1995, 2001, and 2009.

Finally, Figure 4.38 below provides another look at commuting patterns and trends, showing how person miles per person vary by density class and also over time. By combining the results of daily trip frequencies with average trip lengths, these average daily PMT per person statistics bring out not only the clear decline in daily commuting miles of travel with increased 
density, but also an apparent decline in commuting miles of travel between 1995 and 2009 in most density classes. While standard errors on the estimates (See Appendix C.4) suggest that this temporal decline is perhaps not quite as steep as it appears in Figure 4.38, a number of these differences are statistically significant. Also shown in Figure 4.38 is a similar trend over time towards fewer daily commuting miles in rural areas both inside and outside NYS (a topic picked up in Chapter 5 of this report).

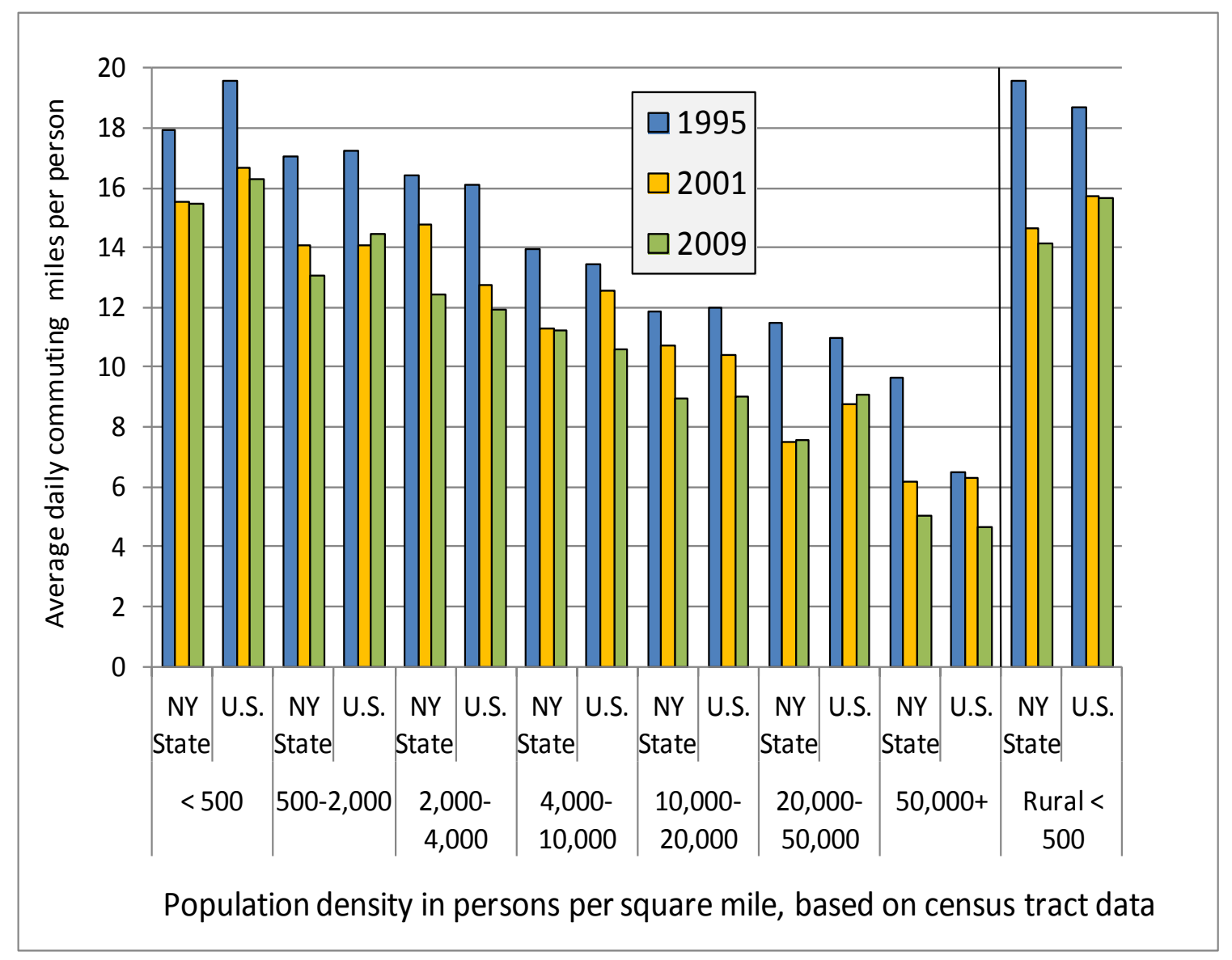

Figure 4.38 Commuting PMT* per Person by Density Class and Survey Year.

Note: $*$ PMT $=$ Person Miles of Travel, and here includes all modes used for commuting purposes.

\subsection{TRAVEL BY MANHATTAN RESIDENTS}

With roughly ninety percent of its households situated in populated areas with a tract density of more than 50,000 people per square mile, the question of whether Manhattan residents travel differently from Americans living in similarly dense urban areas elsewhere in the nation presents itself. This section explores this issue, and also considers how the travel behavior of Manhattan residents impacts the overall travel profile of NYS's 13 metro areas. 
Table 4.17 lists a number of household travel statistics for the island of Manhattan, comparing them to the same statistics for the households located a) in the rest of the 5 borough NYC metro area, and b) in metros outside NYS. The reader should note that statistics for these out of state, very high density metro area are based on a small sample size. ${ }^{15}$ Taking this and the associated standard errors of the estimates into account, some significant differences in Manhattan travel statistics are still evident. Beginning with vehicle ownership levels, approximately $77 \%$ of Manhattan households did not own a vehicle in 2009 (up from 69\% in 2001, and 74\% in 1995). This compares with $62 \%$ in the rest of NYC, and $27 \%$ in the non-NYS metros (which may be a low estimate; in 1995 and 2001 this value was around 48\%).

Despite this, more Manhattan residents considered themselves to be a driver than did their neighbors living elsewhere, at similar residential densities, in the rest of NYC: with the driver rate for Manhattan residents increasing from 57\% to 73\% since 1995 (Table 4.17 and Figure 4.39). Note that in the NHTS surveys, respondents were asked for their driver status (i.e., "Are you a driver?"), rather than license status. Therefore, the driver rates reported in this chapter refer to the percentage of NYS residents who state that they are drivers, and should not be compared directly to driver license rates maintained by the New York Department of Motor Vehicles. In all three regions represented in Table 4.17, male driver percentages remained significantly higher than female driver percentages, even though female driver percentages grew significantly between 1995 and 2009, in both Manhattan and in the rest of the NYC metro area.

${ }^{15}$ The 2009 NHTS, for example, yielded a sample of only 51 households in the $>50,000$ ppsm density range outside the NYS, including households in Los Angeles, San Francisco, Boston, Chicago, and Washington DC. 
Table 4.17 Household and Travel Characteristics of Manhattan, Other NYC Residents, and Residents Living in Very Dense Metro Areas, in 1995, 2001, and 2009 (based on census tracts with > 50,000 persons per square mile)

\begin{tabular}{|c|c|c|c|c|c|c|c|c|c|}
\hline & \multicolumn{3}{|c|}{1995} & \multicolumn{3}{|c|}{2001} & \multicolumn{3}{|c|}{2009} \\
\hline & Manhattan & $\begin{array}{c}\text { Rest of } \\
\text { NYC (Non- } \\
\text { Manhattan) }\end{array}$ & $\begin{array}{c}\text { Metros } \\
\text { in Rest } \\
\text { of US }\end{array}$ & Manhattan & $\begin{array}{c}\text { Rest of } \\
\text { NYC (Non- } \\
\text { Manhattan) }\end{array}$ & $\begin{array}{l}\text { Rest of } \\
\text { US }\end{array}$ & Manhattan & $\begin{array}{c}\text { Rest of } \\
\text { NYC (Non- } \\
\text { Manhattan) }\end{array}$ & $\begin{array}{l}\text { Metros in } \\
\text { Rest of } \\
\text { US }\end{array}$ \\
\hline Workers per Household & 1.13 & 1.11 & 1.18 & 1.15 & 1.33 & 1.11 & 1.22 & 1.28 & 1.75 \\
\hline Drivers per Household & 0.27 & 0.37 & 0.66 & 0.39 & 0.52 & 0.58 & 0.28 & 0.47 & 0.82 \\
\hline Vehicles per Driver & 0.27 & 0.41 & 0.60 & 0.39 & 0.48 & 0.62 & 0.21 & 0.30 & 0.54 \\
\hline \multicolumn{10}{|l|}{$\begin{array}{l}\text { Households by Household } \\
\text { Vehicles }\end{array}$} \\
\hline 0 vehicles & $73.5 \%$ & $64.4 \%$ & $47.1 \%$ & $68.7 \%$ & $56.8 \%$ & $49.1 \%$ & $77.4 \%$ & $62.3 \%$ & $27.0 \%$ \\
\hline 1 vehicle & $24.4 \%$ & $29.3 \%$ & $40.4 \%$ & $27.2 \%$ & $35.9 \%$ & $43.7 \%$ & $18.1 \%$ & $30.1 \%$ & $65.5 \%$ \\
\hline 2 vehicles & $2.1 \%$ & $5.8 \%$ & $12.1 \%$ & $3.1 \%$ & $6.5 \%$ & $6.9 \%$ & $3.7 \%$ & $6.5 \%$ & $6.2 \% *$ \\
\hline 3 vehicles & $0.1 \% *$ & $0.4 \% *$ & $0.44 \% *$ & $0.5 \% *$ & $0.6 \%$ & $0.3 \% *$ & $0.6 \%$ & $1.2 \% *$ & $1.4 \% *$ \\
\hline $4+$ vehicles & $0.1 \%^{*}$ & $0.1 \% *$ & $0.0 \% *$ & $0.5 \% *$ & $0.2 \% *$ & & $0.3 \% *$ & & \\
\hline TOTAL & $100.0 \%$ & $100.0 \%$ & $100.0 \%$ & $100.0 \%$ & $100.0 \%$ & $100.0 \%$ & $100.0 \%$ & $100.0 \%$ & $100.0 \%$ \\
\hline \multicolumn{10}{|l|}{ Driver Rate } \\
\hline$\%$ Drivers/All 16+ & $57.0 \%$ & $44.1 \%$ & $66.7 \%$ & $61.4 \%$ & $49.4 \%$ & $64.8 \%$ & $72.8 \%$ & $66.1 \%$ & $63.2 \%$ \\
\hline$\%$ Male Drivers/Males $16+$ & $67.8 \%$ & $62.7 \%$ & $74.7 \%$ & $73.3 \%$ & $63.4 \%$ & $67.3 \%$ & $80.1 \%$ & $75.0 \%$ & $74.8 \%$ \\
\hline$\%$ Female Drivers/Females 16+ & $47.4 \%$ & $30.3 \%$ & $55.6 \%$ & $51.0 \%$ & $37.4 \%$ & $58.5 \%$ & $66.6 \%$ & $58.2 \%$ & $43.3 \%$ \\
\hline \multicolumn{10}{|l|}{ Person Trips per Person } \\
\hline Person Trips per Person & 3.72 & 3.31 & 3.50 & 3.91 & 3.15 & 3.60 & 3.96 & 3.34 & 3.23 \\
\hline$\%$ POV & $16.1 \%$ & $28.4 \%$ & $45.4 \%$ & $17.8 \%$ & $27.1 \%$ & $37.8 \%$ & $18.4 \%$ & $22.7 \%$ & $24.8 \%$ \\
\hline$\%$ Public Transit & $28.2 \%$ & $27.2 \%$ & $20.3 \%$ & $24.7 \%$ & $28.2 \%$ & $24.4 \%$ & $19.5 \%$ & $28.0 \%$ & $23.9 \%$ \\
\hline$\%$ Walk & $41.4 \%$ & $32.6 \%$ & $28.9 \%$ & $50.8 \%$ & $39.8 \%$ & $34.0 \%$ & $54.1 \%$ & $44.3 \%$ & $47.9 \%$ \\
\hline$\%$ Other & $8.9 \%$ & $4.8 \%$ & $1.4 \%$ & $6.7 \%$ & $4.7 \%$ & $3.8 \%$ & $8.0 \%$ & $4.9 \%$ & $3.4 \%$ \\
\hline$\%$ Unreported & $5.4 \%$ & $7.0 \%$ & $4.0 \%$ & $0.1 \% *$ & $0.2 \% *$ & $0.1 \%{ }^{*}$ & & $0.0 \% *$ & \\
\hline \multicolumn{10}{|l|}{ Person Trips per Person } \\
\hline PMT per Person & 17.98 & 19.52 & 25.59 & 27.46 & 14.18 & 24.00 & 18.22 & 14.69 & 7.10 \\
\hline Average Trip Length & 5.10 & 6.54 & 7.31 & 7.59 & 5.32 & 7.75 & 4.84 & 4.98 & 2.59 \\
\hline \multicolumn{10}{|l|}{ Vehicle Trips per Driver } \\
\hline Vehicle Trips per Driver & 0.57 & 1.48 & 1.79 & 0.77 & 1.19 & 1.83 & 0.55 & 0.78 & 1.23 \\
\hline VMT per Driver & 7.11 & 16.29 & 20.35 & 11.66 & 9.10 & 12.06 & 8.29 & 6.70 & 4.85 \\
\hline
\end{tabular}

Note: $A^{*}$ next to a cell value indicates a large standard error of the estimate. 


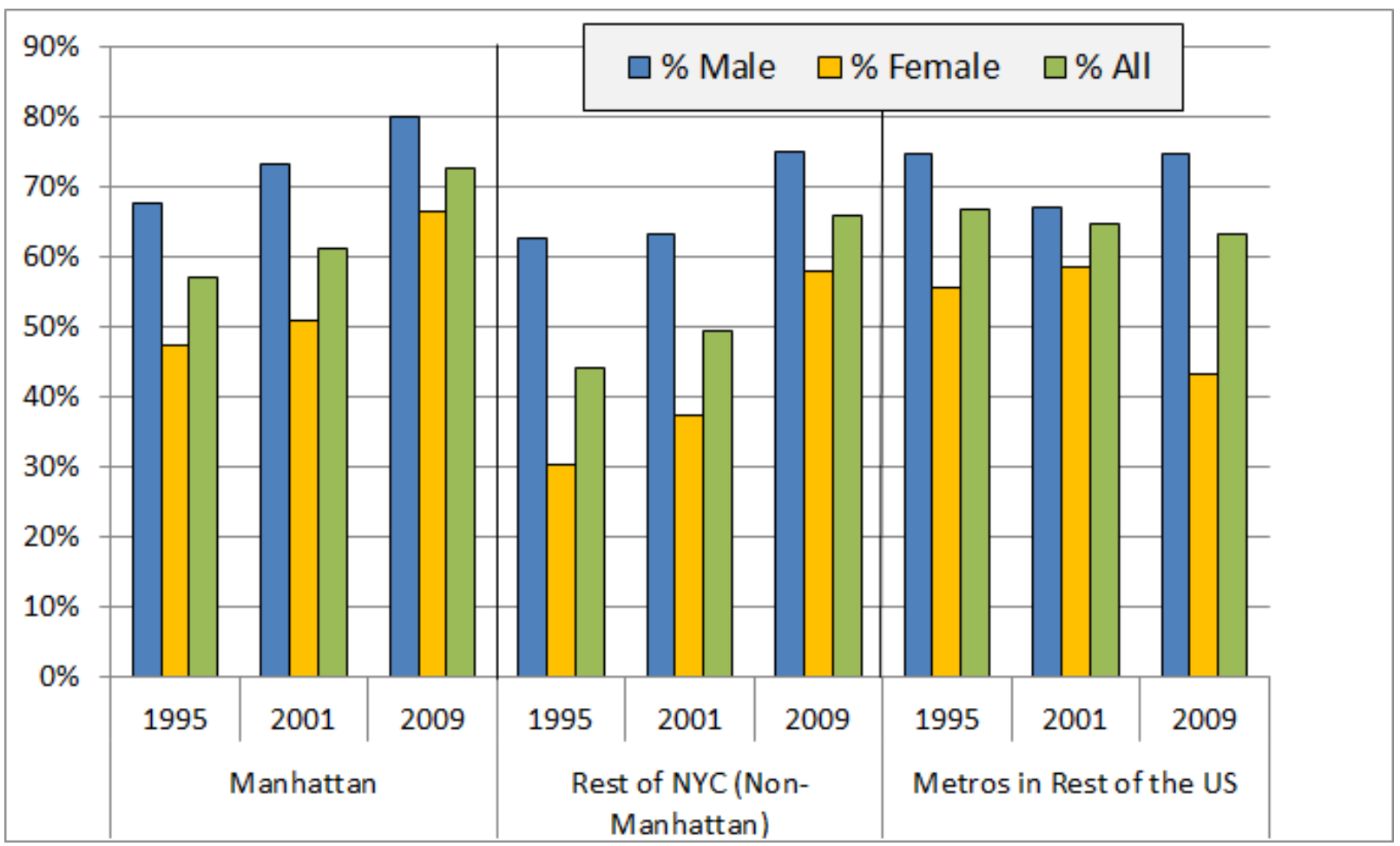

Figure 4.39 Driver Rates (Drivers per Adult >16 Years Old) for Those Living in Very Densely Populated Areas (areas with more than 50,000 people per square mile, based on census tract data).

In the very dense parts of the metro areas outside the state this upward trend in female driver rates is not evident. These rates start out much higher in 1995 and 2001 than in NYC, but appear to dip in 2009; although the standard errors here in 2001 and 2009 are quite large, on the order of $20 \%$. However, these higher Manhattan driver rates don't translate into more vehicle trips per driver, which are much lower in Manhattan than elsewhere: although average vehicle miles per driver statistics were comparable to those in other areas in 2001 and higher in 2009 (Table 4.17).

Manhattan residents make more person trips than others living in areas with similar population densities, either inside or outside NYS. Manhattan daily person trip rates were around 3.9 trips in 2001 and nearly 4.0 trips in 2009, up from 3.7 trips in 1995 (see Table 4.17). This compares to daily person trip rates of 3.2 to 3.6 elsewhere. This difference is largely the result of more walk and transit trips being taken by Manhattan residents. In both 2001 and 2009 Manhattan residents walked to their trip destinations over 50\% of the time, up slightly from 1995 when they walked for 4 in every 10 trips. In 1995 and 2001 these residents rode public transit about one quarter of the time, down slightly to 1 in 5 trips in 2009 (Figure 4.40), compensated for by taking more walking trips. Person trips by Manhattan residents in 2001 were much longer on average than in 1995, but fell back to around 5 miles per trip in 2009 (Table 4.17). 


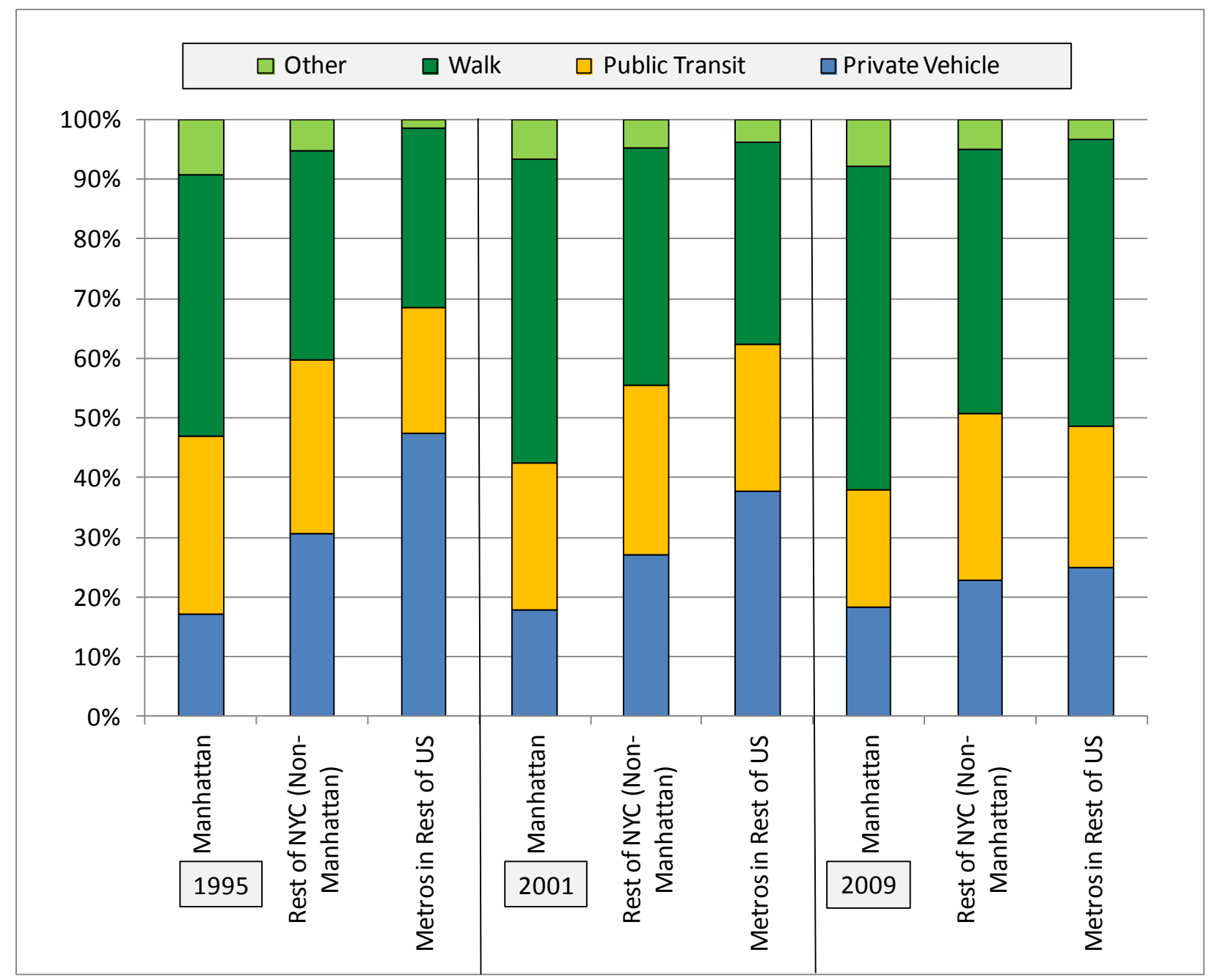

Figure 4.40 Mode Choices Made by Households Living in Very Densely Populated Areas in 1995, 2001, and 2009 (areas with more than 50,000 people per square mile, based on census tract data).

\subsection{SUMMARY}

Noting that the many comparisons drawn in this chapter are based on average responses within these two broad regional definitions, NYS's 13 metropolitan areas display both strong similarities as well as some significant differences in their travel statistics when compared with those for metropolitan areas in the rest of the country. It is also clear that differences in population density within metro areas both inside and outside of the state have a significant impact on household travel behavior. On average, residents in the most densely populated areas travel fewer miles per day as a result of shorter trips lengths as well slightly lower trip rates (Figure 4.14). 
People who live in high population density areas are also less likely to own or to drive a vehicle. This is true both inside and outside NYS. However, a key difference here between NYS metro area residents and those elsewhere is the much greater percentage of zero-vehicle owning households in NYC at the highest population densities: roughly 2 in every 3 households, versus fewer than 1 in 2 households out of state (Figure 4.5). Although it is true that the proportion of trips by public transit and walking increases significantly with population densities over 20,000 persons per square mile both inside and outside NYS, this rate of increase is much more pronounced in NYS than elsewhere in the nation: principally due to the high share of public transit, including rail transit trips associated with the NYC metro area. As a result, the densest residential areas in NYS report much lower private vehicle trip rates than elsewhere; and with this comes much lower fossil fuel consumption and associated greenhouse gas emissions. It is estimated that differences on the order of 4.3 to 1 in annual $\mathrm{CO} 2$ emissions per household exist between the most and least densely populated metropolitan areas, in both the state and in the rest of the nation (Figures 4.29 and 4.30).

However, taking public transit modes currently comes at a significant travel time premium for many urban travelers, both within and outside the state (Figure 4.36). While average commute distances drop significantly with an increase of population density, average commute travel times do not. This again is true both in NYS and in metropolitan areas elsewhere in the nation, and points to the continued problem of high levels of traffic congestion within our densest population centers, despite extensive use of non-automobile modes of travel to and from work (Figures 4.31, 4.32 and 4.33). 


\section{RURAL TRAVEL}

This chapter investigates whether rural travel in NYS differs from rural travel in the rest of the United States, and whether rural population densities have any bearing on the travel patterns of rural New Yorkers.

\subsection{DEFINITION OF "RURAL" FOR THIS CHAPTER}

In Chapter 4 of this report, metro area boundaries were used as a proxy to distinguish urban areas from rural areas within NYS. Outside NYS, this urban travel was defined as tripmaking by households located within the nation's many MSAs. However, comparing rural travel in NYS to rural travel elsewhere in the nation cannot simply make use of the remaining areas not covered by these metropolitan area boundaries. Given the geographic breakdowns and data definitions used in the NHTS surveys, non-NYS households can only be characterized by the size of the MSA in which they are located. This makes it difficult to identify rural households outside NYS for comparison purposes. In the two previous NYS Comparison Reports (Hu and Reuscher, 1999 and 2007), two different methods were explored for identifying a set of comparable "rural households" suitable for use both inside and outside NYS. The first option used the metro area boundary to identify rural households within the state, i.e. those households located outside metropolitan areas are treated as "rural." Using this approach, however, $27 \%$ of 1995 NYS households and 32\% of 2001 NYS households were found to be located outside the state's metro areas, yet were still found to lie within MSA areas of more than 500,000 people. As a result, of all non-metro households in NYS, only 65\% in 1995, and 61\% in 2001 were not located within MSAs: clearly suggesting that many NYS households located outside any of the state's metro areas are not really "rural": they are more likely to part of what is often termed the "suburban fringe". This obviously poses comparison problems with the assumption that rural households located outside NYS are simply those found outside the nation's MSAs.

Given the above finding, a second option was tried. This method uses the metro area boundaries in conjunction with the 1995 NPTS definition of rural households. "Rural households" are defined in the 1995 NPTS as those located within a census block group (a subdivision of a census tract) with a population density of less than 1,000 persons per square mile. Using this criterion, in both 1995 and 2001, some three-quarters of all NYS households located outside metro areas were characterized as rural households. Applying this same criterion to households located elsewhere in the nation yielded a similar distribution of households by population density to those within NYS, when compared at the individual block group level. Table 5.1 shows the resulting NYS versus rest of United States household distributions by population density for the households sampled in the latest, 2009 NHTS. In 2009, a higher percentage of NYS households fell in the lowest density strata, at $<100$ persons per square mile, than they did in the rest of the nation: but as a spatial set this option identifies rural households in 
as comparable a way as the data can support when considering households both inside and outside NYS.

Table 5.1 Distribution of Rural Households by Census Block Group's Population Density: New York State vs. Rest of the United States in 2009

\begin{tabular}{|c|c|c|c|c|c|c|}
\hline \multirow{3}{*}{ 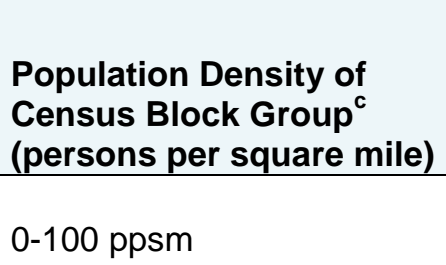 } & \multicolumn{3}{|c|}{ New York States ${ }^{a}$} & \multicolumn{3}{|c|}{ Rest of United States ${ }^{b}$} \\
\hline & \multirow{2}{*}{$\begin{array}{c}\begin{array}{c}\text { Sample } \\
\text { size }\end{array} \\
1,065\end{array}$} & \multicolumn{2}{|c|}{$\begin{array}{c}\text { Number of } \\
\text { Households } \\
\text { (thousands) }\end{array}$} & \multirow{2}{*}{$\begin{array}{c}\begin{array}{c}\text { Sample } \\
\text { size }\end{array} \\
10,996\end{array}$} & \multicolumn{2}{|c|}{$\begin{array}{c}\text { Number of } \\
\text { Households } \\
\text { (thousands) }\end{array}$} \\
\hline & & 319 & $(62.5 \%)$ & & 8,874 & (55.1\%) \\
\hline $100-500$ ppsm & 529 & 164 & (32.1\%) & 8,024 & 5,257 & $(32.6 \%)$ \\
\hline $500-1,000 \mathrm{ppsm}$ & 70 & 28 & $(5.4 \%)$ & 2,903 & 1,973 & $(12.3 \%)$ \\
\hline TOTAL & 1,664 & 511 & $(100.0 \%)$ & 21,923 & 16,103 & $(100.0 \%)$ \\
\hline
\end{tabular}

${ }^{a}$ NYS households outside metro areas and in areas with fewer than 1,000 persons per square mile in an individual block group level.

${ }^{\mathrm{b}}$ Non-NYS households outside MSAs and in areas with fewer than 1,000 persons per square mile in an individual block group level.

${ }^{\mathrm{c}}$ A block group is defined as a subdivision of a census tract that averages 1,000 to 1,100 people, and approximately 400-500 housing units.

In Chapter 4, urban households in NYS are compared to urban households outside NYS who reside in areas with similar population density. To facilitate comparing statistics across chapters, the analyses in this chapter continue to be categorized by the population density of census tracts. Unfortunately, when identifying rural households based on census tract population density only 32 NYS households in 1995, only 52 households in 2001, and only 33 households in 2009 were sampled from tracts with 500 to 2,000 people per square mile (see Table 5.2 below). Thus, this chapter presents statistics based on the survey data collected from only the 21,452 rural households (1,631 NYS households plus 19,821 households outside NYS) sampled from rural census tracts with fewer than 500 persons per square mile (ppsm). 
Table 5.2 Rural Household Distribution by Census Tract Population Density in the 2009 NHTS

\begin{tabular}{|c|c|c|c|c|c|c|}
\hline \multirow{3}{*}{$\begin{array}{l}\text { Population Density of } \\
\text { Census Tract } \\
\text { (persons per square mile) } \\
0-500 \text { ppsm }\end{array}$} & \multicolumn{3}{|c|}{ New York States } & \multicolumn{3}{|c|}{ Rest of United States } \\
\hline & \multirow{2}{*}{$\begin{array}{c}\begin{array}{c}\text { Sample } \\
\text { size }\end{array} \\
1,631\end{array}$} & \multicolumn{2}{|c|}{$\begin{array}{c}\text { Number of } \\
\text { Households } \\
\text { (thousands) }\end{array}$} & \multirow{2}{*}{$\begin{array}{c}\begin{array}{c}\text { Sample } \\
\text { size }\end{array} \\
19,821\end{array}$} & \multicolumn{2}{|c|}{$\begin{array}{c}\text { Number of } \\
\text { Households } \\
\text { (thousands) }\end{array}$} \\
\hline & & 497 & $(97.3 \%)$ & & 14,650 & $(91.0 \%)$ \\
\hline $500-2,000 \mathrm{ppsm}$ & 33 & 14 & $(2.7 \%)$ & 2,060 & 1,433 & $(8.9 \%)$ \\
\hline $2,000-4,000$ ppsm & 0 & 0 & $(0.0 \%)$ & 40 & 18 & $(0.1 \%)$ \\
\hline $4,000-10,000$ ppsm & 0 & 0 & $(0.0 \%)$ & 2 & 2 & $(0.0 \%)$ \\
\hline TOTAL & 1,664 & 511 & $(100.0 \%)$ & 21,923 & 16,103 & $(100.0 \%)$ \\
\hline
\end{tabular}

\subsection{PROFILE OF RURAL NEW YORK STATE HOUSEHOLDS BY POPULATION DENSITY}

On a per household basis, rural NYS households are similar to those households elsewhere with respect to the number of workers and number of drivers (Table 5.3). In 2009, a typical NYS rural household owned two vehicles, and had a vehicle available to each driver in the household. In the rest of the nation vehicle ownership was a little higher, at 2.3 vehicles per rural household and 1.2 vehicles per rural driver. This slightly lower level of vehicle ownership has persisted through all three NPTS/NHTS surveys. Only $4.8 \%$ of rural households in NYS reported not owning a vehicle in 2009. This is up from 3.2\% in 1995. In the rest of the US the percentage of zero-vehicle owning households has remained at a little over 4\% since 1995.

Vehicle ownership in rural households remained relatively stable between 2001 and 2009 in rural areas within and outside NYS; after an increase of approximately 0.2 vehicles per household in ownership between 1995 and 2001 (Table 5.3). As with households located in urban areas with fewer than 500 persons per square mile, about two-thirds of rural households own at least two vehicles (compare Table 5.3 with Table 4.4 from the previous chapter). In 2009 a smaller share of rural NYS households reported owning three or more vehicles than did rural households in the rest of the nation (22\% versus $36 \%$, Table 5.3), attributable largely to a reduction in the share of 3+ vehicle households in NYS since 2001 (from 29\% to 22\%). In 2009, about $93 \%$ of men and $90 \%$ of women in the rural areas of NYS reported driving a vehicle, with both percentages down about 3\% from 2001 (Table 5.3). As a result, rural area of NYS driver license percentages for both men and women were lower than their counterparts in the rest of the nation in 2009 for the first time since 1995: although the difference is only a marginal one. 
Table 5.3 Characteristics of Rural Households New York State (NYS) vs. Rest of the United States (US) (based on rural census tracts with $<500$ persons per square mile)

\begin{tabular}{|c|c|c|c|c|c|c|}
\hline & \multicolumn{2}{|c|}{1995} & \multicolumn{2}{|c|}{2001} & \multicolumn{2}{|c|}{2009} \\
\hline & NYS & $\begin{array}{c}\text { Rest of } \\
\text { US }\end{array}$ & NYS & $\begin{array}{c}\text { Rest of } \\
\text { US }\end{array}$ & NYS & $\begin{array}{c}\text { Rest of } \\
\text { US }\end{array}$ \\
\hline Workers per Household & 1.37 & 1.27 & 1.36 & 1.31 & 1.40 & 1.30 \\
\hline Drivers per Household & 1.94 & 1.83 & 1.89 & 1.85 & 1.99 & 1.96 \\
\hline Vehicles per Household & 1.80 & 2.01 & 2.08 & 2.25 & 1.97 & 2.31 \\
\hline Vehicles per Driver & 0.93 & 1.10 & 1.10 & 1.21 & 0.99 & 1.18 \\
\hline \multicolumn{7}{|c|}{ Distribution of Households by Number of Household Vehicles } \\
\hline ALL & $100 \%$ & $100 \%$ & $100 \%$ & $100 \%$ & $100 \%$ & $100 \%$ \\
\hline 0 vehicles & $3.18 \%$ & $4.26 \%$ & $4.93 \%$ & $4.50 \%$ & $4.81 \%$ & $4.10 \%$ \\
\hline 1 vehicle & $30.65 \%$ & $27.73 \%$ & $27.56 \%$ & $24.43 \%$ & $30.47 \%$ & $25.40 \%$ \\
\hline 2 vehicles & $44.51 \%$ & $41.37 \%$ & $38.66 \%$ & $37.80 \%$ & $42.58 \%$ & $34.42 \%$ \\
\hline 3 vehicles & $16.43 \%$ & $19.21 \%$ & $18.39 \%$ & $18.78 \%$ & $13.85 \%$ & $20.41 \%$ \\
\hline $4+$ vehicles & $5.22 \%$ & $7.43 \%$ & $10.45 \%$ & $14.49 \%$ & $8.28 \%$ & $15.66 \%$ \\
\hline \multicolumn{7}{|l|}{ Licensing Rate } \\
\hline$\%$ ALL Drivers/ALL 16+ & $92.00 \%$ & $91.63 \%$ & $94.07 \%$ & $93.41 \%$ & $90.70 \%$ & $92.36 \%$ \\
\hline$\%$ Male Drivers/Male 16+ & $94.30 \%$ & $94.50 \%$ & $95.77 \%$ & $95.68 \%$ & $91.64 \%$ & $93.56 \%$ \\
\hline$\%$ Female Drivers/Female $16+$ & $89.76 \%$ & $88.90 \%$ & $92.37 \%$ & $91.28 \%$ & $89.70 \%$ & $91.17 \%$ \\
\hline
\end{tabular}

Note: All percentages may not add to $100 \%$ due to rounding.

For both men and women, on average, rural NYS residents continued to drive fewer miles annually than their counterparts elsewhere in the United States (Figure 5.1). The difference in annual vehicle miles driven between men in NYS rural areas and men outside the State widened from $8 \%$ in 1995 to $15 \%$ in 2001 , but the gap narrowed again in 2009 to an $11 \%$ difference. 


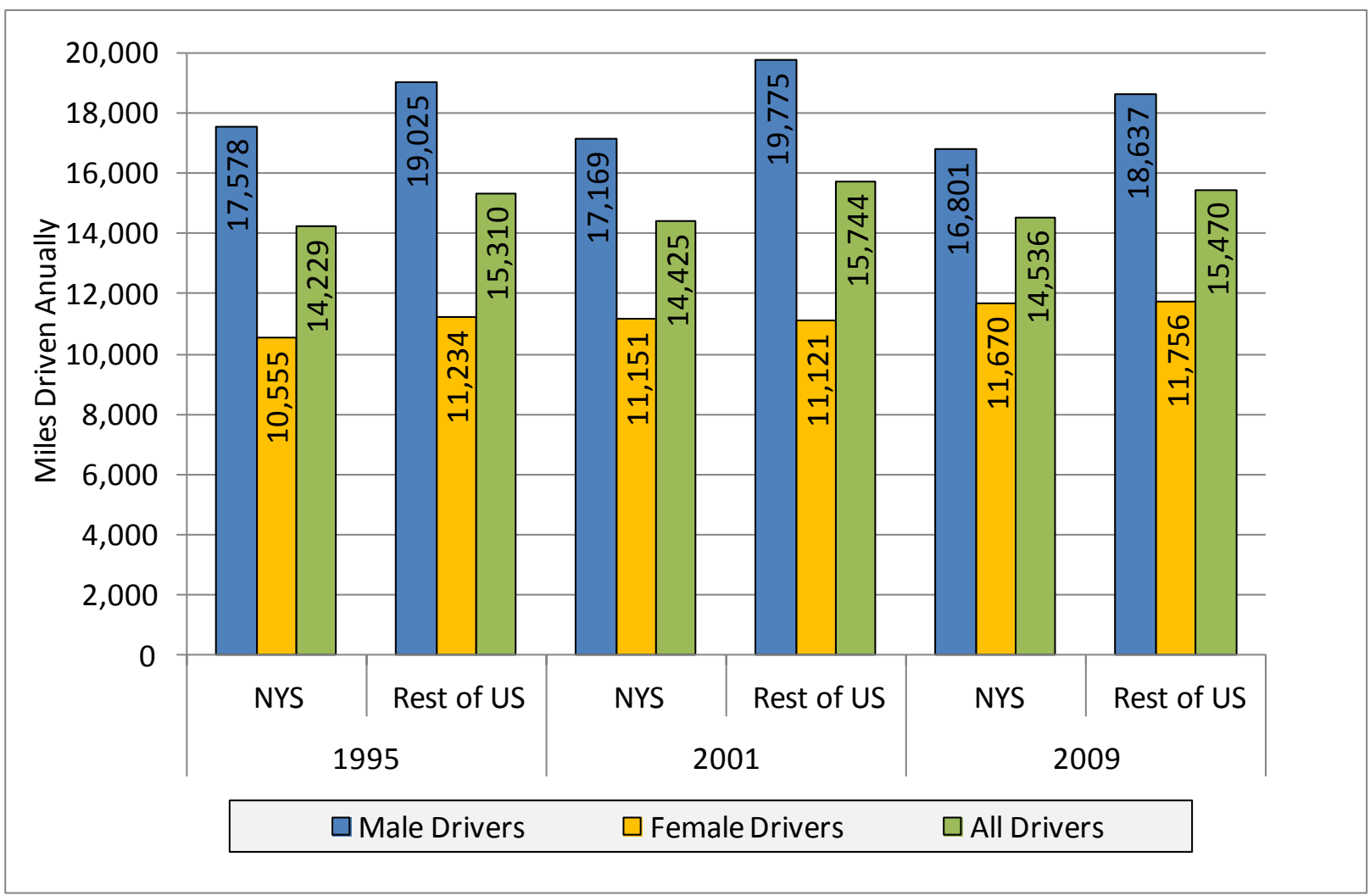

Figure 5.1 Average Annual Miles Driven* per Rural Driver New York State (NYS) vs. Rest of the United States (US) (based on census tracts of less than 500 people per square mile).

Note: Based on the self-reported VMT.

\subsection{PERSONAL TRAVEL COMPARISONS}

\subsubsection{Trip Frequencies, Trip Lengths and Travel Times}

In 2009 rural NYS residents took an average of 3.4 trips per day, at an average trip length of nearly 12 miles: producing about 40 miles of travel per person per day. This was down from an average of about 45 daily person miles of travel (PMT) in 2001 and 1995 (Table 5.4), due largely to a drop in daily trip frequency. Rural NYS residents traveled about $10 \%$ fewer miles per day on the average than rural households in the rest of the country in 2009 (based on PMTs shown in Table 5.4). The distribution of personal trips across both trip purposes and modes of travel are very similar between NYS and other rural areas (Table 5.4). Private automobile trips dominate daily rural travel in all three survey years, both inside and outside the state: with a slightly higher than '50/50' split in favor of multiple versus single occupant POVs across all three survey years, again both inside and outside NYS. Walking represented about $7 \%$ of all NYS rural household trips in both 2001 and 2009 (1995 percentages are much lower, but due in part to less effort being put into collecting these trips in that survey). Shifts in trip purpose 
specific shares have been small over the 14 year period covered by the three NPTS/NHTS surveys. Between them, personal and family business, plus social and recreational activities continue to account for some two-thirds of all rural trips, while work related trips account for around one quarter of all daily trip-making when measured by trip mileage.

Table 5.4 Personal Travel Statistics of Rural Households by Mode and Trip Purpose New York State (NYS) vs. in the Rest of the United States (US)

(Based on rural census tracts with $<500$ persons per square mile)

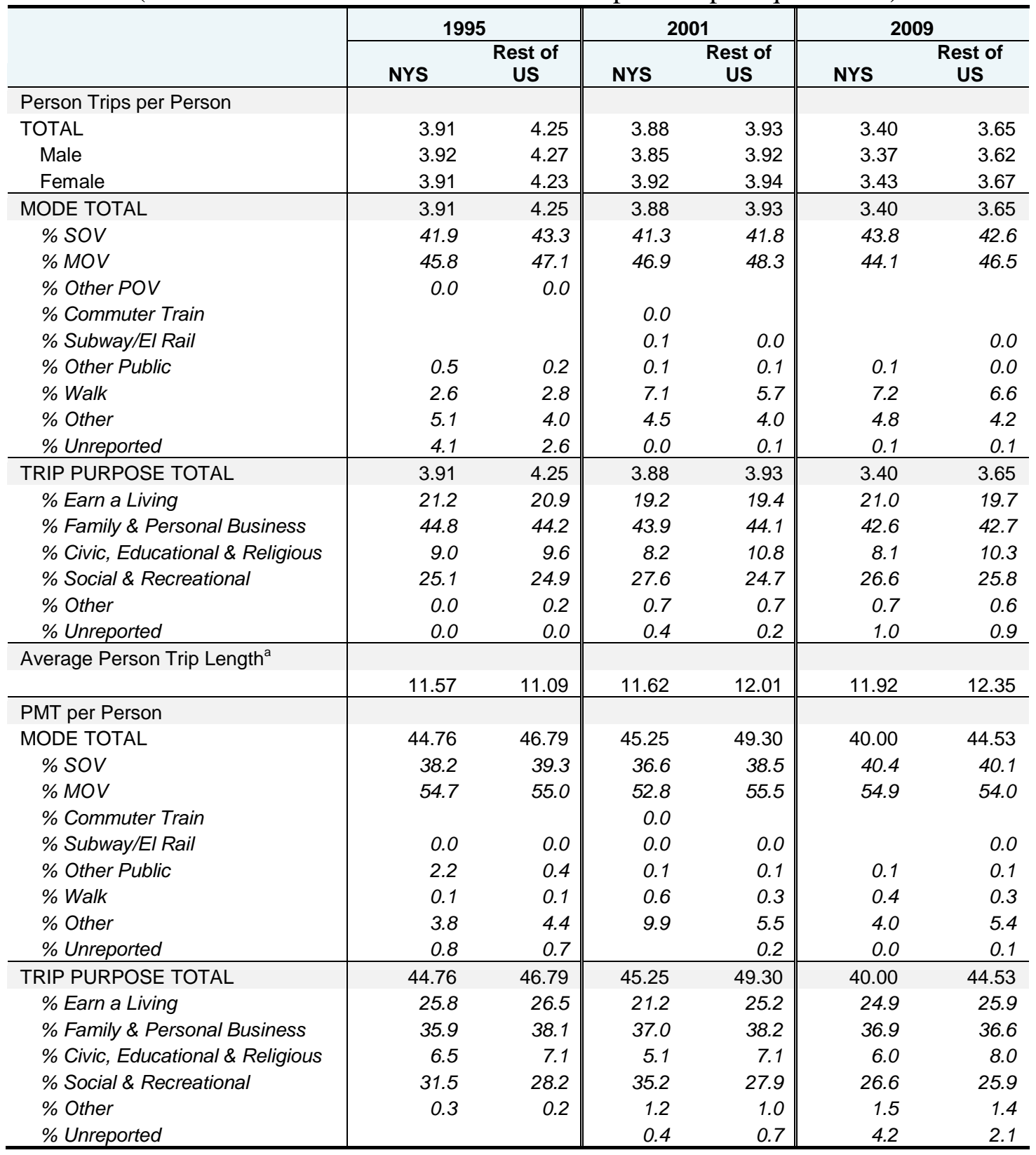

Notes: All percentages may not add to $100 \%$ due to rounding.

${ }^{\text {a }}$ Average trip length is calculated using only those records with trip mileage information present. "Other Public" refers largely to rural bus and/or vanpool services. 
Figure 5.2 offers a number of additional person trip frequency comparisons using statistics presented in Tables 5.4 and 4.3. First, it compares the values and temporal trends in both rural and low density ( $<500$ ppsm) urban trip frequencies from 1995 to 2009, indicating a similar gradual decline in all frequencies reported, both inside and outside NYS. It also shows the generally higher average trip frequencies found outside NYS, for both rural and low density urban areas. Compared to NYS residents in urban areas of similarly low density, residents in NYS rural areas took slightly fewer trips in 2009: while in the rest of the country there was no significant difference in these average person trip frequencies (of just over 3.6 trips per day).

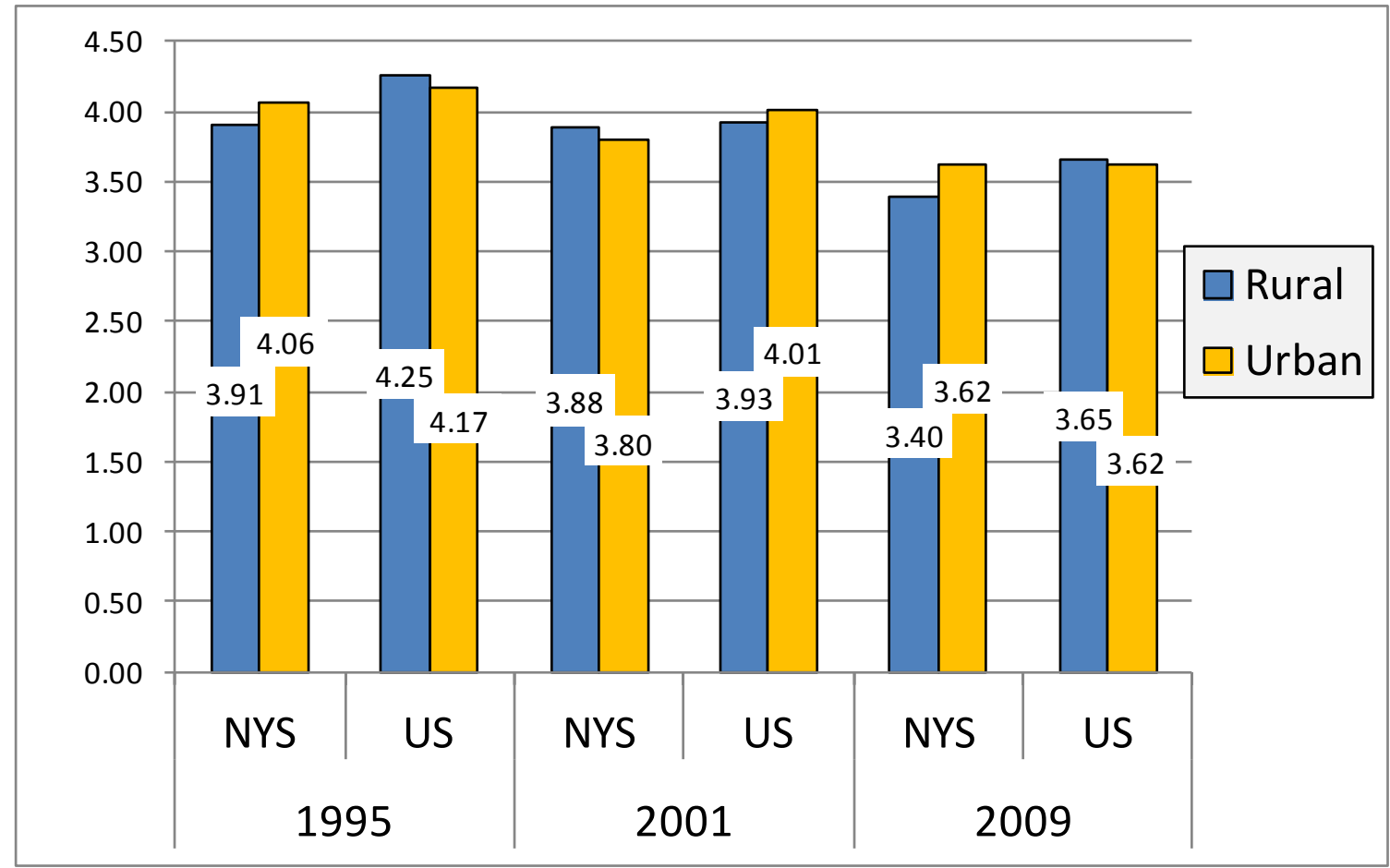

Figure 5.2 Average Daily Person Trips per Person for Households Located in Census Tracts with < 500 Persons per Square Mile: New York State (NYS) vs. Rest of the United States (US).

Similarly, Figure 5.3 shows a number of trip length comparisons. Residents in NYS rural areas take trips that are only slightly longer than NYS residents in urban areas of similar population density, at an average of 11.9 miles compared to 11.6 miles, respectively (by comparing statistics presented in Tables 5.4 and 4.3), but with a slightly lower daily trip frequency of 3.4 versus 3.6 trips. These differences in trip frequency and trip length even out, so that in 2009 rural NYS residents traveled an average of 40 miles per day versus 41 miles per day for low density urban area residents in the state (Tables 5.4 and 4.3). Based on standard errors of the estimates, however, the small increases in NYS trip length over time, as shown in Figure 5.3, are not statistically significant. 


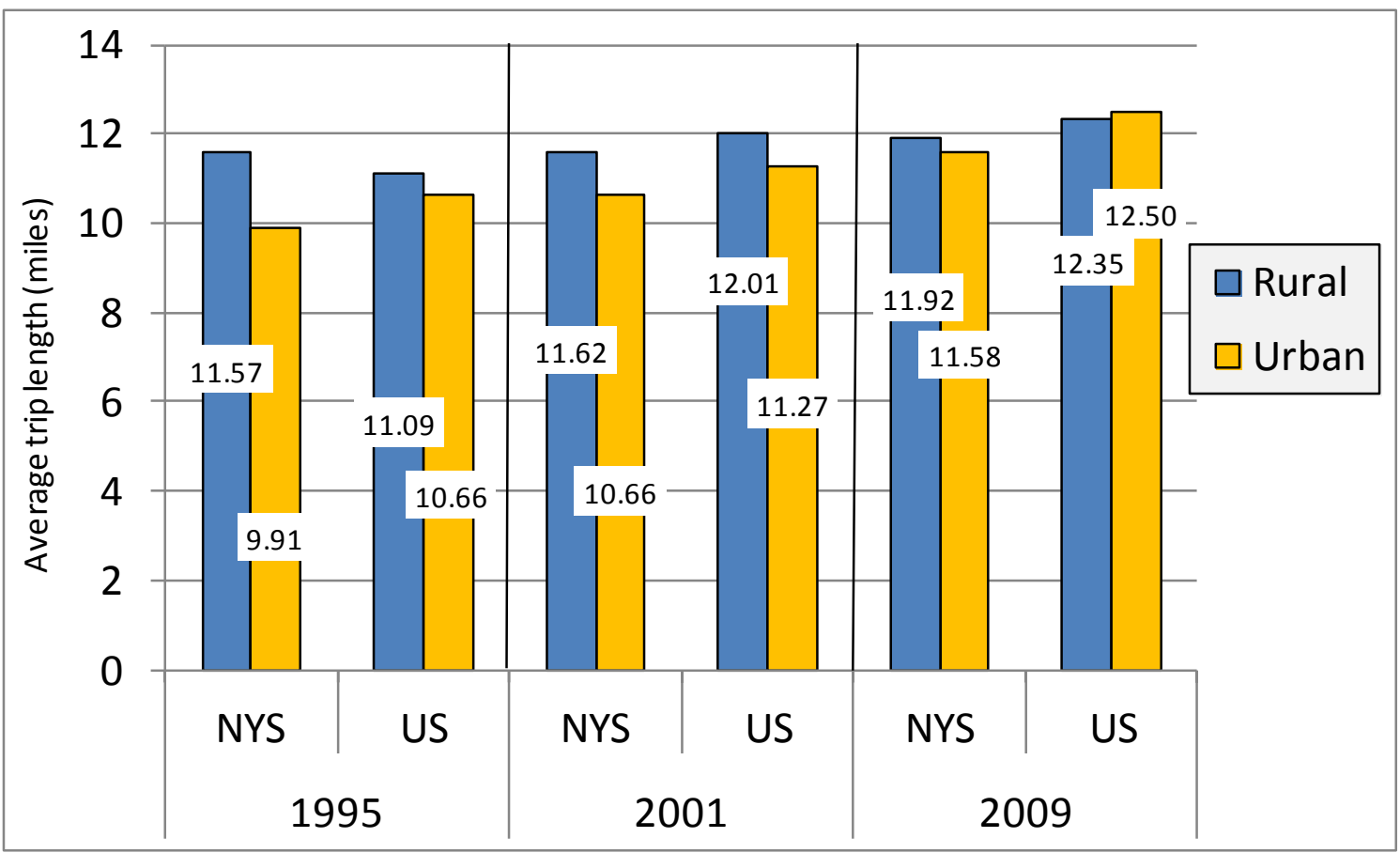

Figure 5.3 Average Person Trip Lengths for Households Located in Census Tracts with < 500 Persons per Square Mile: New York State (NYS) vs. Rest of the United States (US).

\subsubsection{Public Transit, Walk and Bike Trips}

As Table 5.4 shows, only a very small percentage of trips involve public transit in rural America, both within and outside the state. Most of these trips are by rural bus or vanpool services (referred to as "Other Public" trips in Table 5.4). Walking accounted for about $7 \%$ of all NYS rural area trips in 2009, compared to $6.6 \%$ in rural areas elsewhere. In both instances, this represents only some 3.3 minutes of walking activity per person per day both inside and outside the state: with one third of rural residents reporting that they did not walk anywhere "in the last week", down slightly since the 2001 NHTS survey (Table 5.5). Daily biking (cycling) activity levels are even lower. Less than one minute per person per day was devoted to biking in rural NYS in 2009 (but up from half a minute in 2001), with 0.6 minutes per day on average recorded for non-NYS rural area residents: and with only $10 \%$ on NYS rural area residents and $12 \%$ of rural residents elsewhere in the nation reporting at least one bike trip "in the last week" (Table 5.5). 
Table 5.5 Rural Area Per Person Walking and Biking Activity Statistics for 1995, 2001, and 2009 New York State (NYS) vs. Rest of the United States (US)

\begin{tabular}{|c|c|c|c|c|c|c|}
\hline & \multicolumn{2}{|c|}{1995} & \multicolumn{2}{|c|}{2001} & \multicolumn{2}{|c|}{2009} \\
\hline & NYS & $\begin{array}{l}\text { Rest } \\
\text { of } \\
\text { US }\end{array}$ & NYS & $\begin{array}{l}\text { Rest } \\
\text { of US }\end{array}$ & NYS & $\begin{array}{l}\text { Rest } \\
\text { of US }\end{array}$ \\
\hline Walk Trip Statistics & & & & & & \\
\hline $\begin{array}{l}\text { Percent Not Taking Walk Trips in the Last Week } \\
\text { Average Minutes Spent Walking per Day }\end{array}$ & $\stackrel{*}{*}$ & $\stackrel{*}{*}$ & $\begin{array}{r}29.3 \% \\
4.25\end{array}$ & $\begin{array}{r}34.0 \% \\
3.40\end{array}$ & $\begin{array}{r}33.3 \% \\
3.32\end{array}$ & $\begin{array}{r}33.0 \% \\
3.26\end{array}$ \\
\hline Bike Trip Statistics & & & & & & \\
\hline $\begin{array}{l}\text { Percent Not Taking Bike Trips in the Last Week } \\
\text { Average Minutes Spent Biking per Day }\end{array}$ & $\stackrel{*}{*}$ & $\begin{array}{c}* \\
0.32\end{array}$ & $\begin{array}{r}93.1 \% \\
0.53\end{array}$ & $\begin{array}{r}93.8 \% \\
0.43\end{array}$ & $\begin{array}{r}89.9 \% \\
0.86\end{array}$ & $\begin{array}{r}88.0 \% \\
0.59\end{array}$ \\
\hline
\end{tabular}

* Walk and Bike trip questions were not asked of persons under 16 years old in 2001, or at all in 1995.

\subsection{VEHICLE TRAVEL COMPARISONS}

\subsubsection{Driving Frequencies, Distances and Times}

Focusing on POV travel, rural drivers in NYS drove only marginally less frequently than their counterparts elsewhere in rural America in 2009, and also made marginally shorter trips (Table 5.6). The 2009 average POV trip lengths are 12.1 and 12.4 miles for rural drivers within and outside NYS, respectively (Table 5.6). Combining average trip lengths with average trip frequencies yields an average daily VMT total of 33.7 miles per NYS driver, versus a higher average of 36.3 miles per driver per day in the rest of the country. Since 2001 these differences between inside and outside of NYS VMT statistics have converged, with less difference between average frequencies and in particular between average trip lengths.

As also shown in Table 5.6, there is no noticeable difference between rural NYS households and similar households elsewhere as to why driving takes place, or in terms of how many miles is devoted to each trip purpose. About half of the daily driving trips are for family and personal business, less than thirty percent are for earning a living, and around twenty percent of trips involve social and recreational pursuits. 
Table 5.6 Vehicle Travel Statistics by Drivers in Rural Areas New York State (NYS) vs. Rest of the United States (US)

(Based on census tracts of less than 500 people per square mile.)

\begin{tabular}{|c|c|c|c|c|c|c|}
\hline & \multicolumn{2}{|c|}{1995} & \multicolumn{2}{|c|}{2001} & \multicolumn{2}{|c|}{2009} \\
\hline & NYS & $\begin{array}{l}\text { Rest of } \\
\text { US }\end{array}$ & NYS & $\begin{array}{l}\text { Rest of } \\
\text { US }\end{array}$ & NYS & $\begin{array}{l}\text { Rest of } \\
\text { US }\end{array}$ \\
\hline \multicolumn{7}{|l|}{ Vehicle Trips per Driver } \\
\hline TOTAL & 3.29 & 3.57 & 3.11 & 3.25 & 2.82 & 2.94 \\
\hline$\%$ Earn a Living & 30.1 & 28.3 & 27.7 & 26.9 & 28.8 & 26.8 \\
\hline \% Family \& Personal Business & 48.9 & 48.2 & 48.0 & 47.3 & 45.6 & 46.4 \\
\hline \% Civic, Educational \& Religious & 3.3 & 4.8 & 3.5 & 5.6 & 4.2 & 5.4 \\
\hline \% Social \& Recreational & 17.3 & 18.5 & 20.1 & 19.5 & 20.6 & 20.2 \\
\hline$\%$ Other & 0.0 & 0.0 & 0.4 & 0.5 & 0.1 & 0.2 \\
\hline$\%$ Unreported & 0.3 & 0.3 & 0.3 & 0.1 & 0.8 & 0.9 \\
\hline \multicolumn{7}{|l|}{ VMT per Driver } \\
\hline TOTAL & 37.84 & 38.31 & 34.94 & 40.51 & 33.73 & 36.30 \\
\hline \% Earn a Living & 36.5 & 37.1 & 33.2 & 34.5 & 34.2 & 34.2 \\
\hline$\%$ Family \& Personal Business & 37.5 & 36.5 & 37.6 & 38.1 & 38.1 & 37.2 \\
\hline \% Civic, Educational \& Religious & 3.4 & 4.6 & 3.0 & 4.0 & 4.0 & 5.9 \\
\hline \% Social \& Recreational & 22.2 & 21.7 & 24.9 & 22.5 & 20.9 & 20.3 \\
\hline$\%$ Other & 0.4 & 0.1 & 1.0 & 0.5 & 0.1 & 0.3 \\
\hline$\%$ Unreported & & & 0.2 & 0.5 & 2.8 & 2.1 \\
\hline \multicolumn{7}{|l|}{ Average Vehicle Trip Length ${ }^{\mathrm{a}}$} \\
\hline & 11.56 & 10.77 & 11.30 & 12.54 & 12.07 & 12.42 \\
\hline
\end{tabular}

Notes: All percentages may not add to $100 \%$ due to rounding.

${ }^{a}$ Average trip length is calculated using only those records with trip mileage information present.

Figure 5.4 shows that the distribution of one-way vehicle trip lengths is also similar for rural households both inside and outside NYS. In 2009 some $66 \%$ of NYS rural trips were less than 10 miles in length, while about $69 \%$ of trips were less than 10 miles in the rest of rural America. At the other end of the trip length spectrum, less than $8 \%$ of NYS trips were over 30 miles in 2009, while $8.4 \%$ of trips exceeded 30 miles in the rest of the nation. For all three survey years, and both inside and outside NYS, around half of all rural trips are less than 5 miles one-way: confirming the notion of a significant distance-decay effect in rural travel, consistent if a little less steep in its loss of trips with extra distance than in the urban areas reported in Chapter 4 (see Figure 4.13). Additional supporting statistics are provided in Appendix C.5 at the end of this report. 


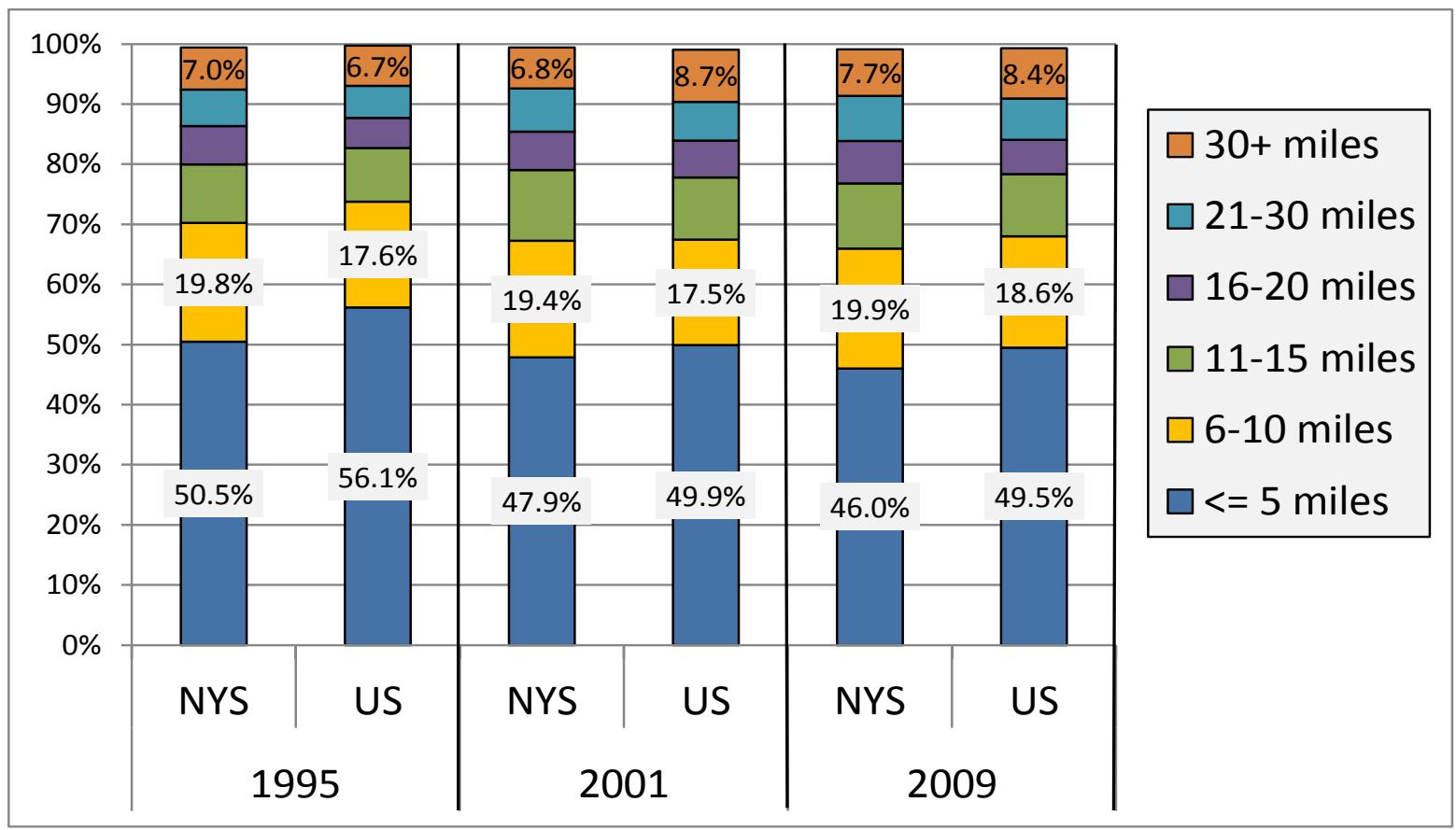

Figure 5.4 Distribution of Vehicle Trips in Rural Areas by Trip Length New York State (NYS) vs. Rest of the United States (US).* (based on census tracts of less than 500 people per square mile)

Note: *Columns don't sum to $100 \%$ due to small percentages of "unreported" distances.

\subsubsection{Types and Ages of Vehicles Driven}

Table 5.7 compares the distribution of privately owned household vehicles by vehicle type, for rural households located within versus outside NYS.

The major difference between rural households in NYS and rural households elsewhere in the country is a greater share outside the state for pickup trucks (Table 5.8). NYS households also display a slight preference for vans. Over time, the SUV share of rural household vehicles has grown noticeably and consistently both within and outside the state, from $7.1 \%$ in 1995 to $18.6 \%$ in 2009 within NYS and from $6.7 \%$ to $17.7 \%$ outside NYS. This shift mirrors that shown for the urban areas in NYS and elsewhere (cf. Figures 4.25 and 4.26), with most of the increases in SUV market share coming at the expense of the traditional automobile. Motorcycle share has also grown consistently over the years both inside and outside the state, from around $1 \%$ of vehicles owned in 1995 to $4.5 \%$ in NYS and $4.9 \%$ in the rest of the country in 2009 . Both the average and the median age of POVs in rural NYS was significantly lower than that in the rest of the nation in all three survey years, with the gap widening somewhat in 2009, at an average of 8.4 years in NYS versus 10.9 years in the rest of the United States (Table 5.7). These 2009 averages compare with the lower averages of 7.7 years for urban NYS household vehicles and 9.1 years for their urban area counterparts outside NYS (see Figures 4.27 and 4.28). 
Table 5.7 Types and Ages of Vehicles Used by Rural Households in New York State and in the Rest of the United States*

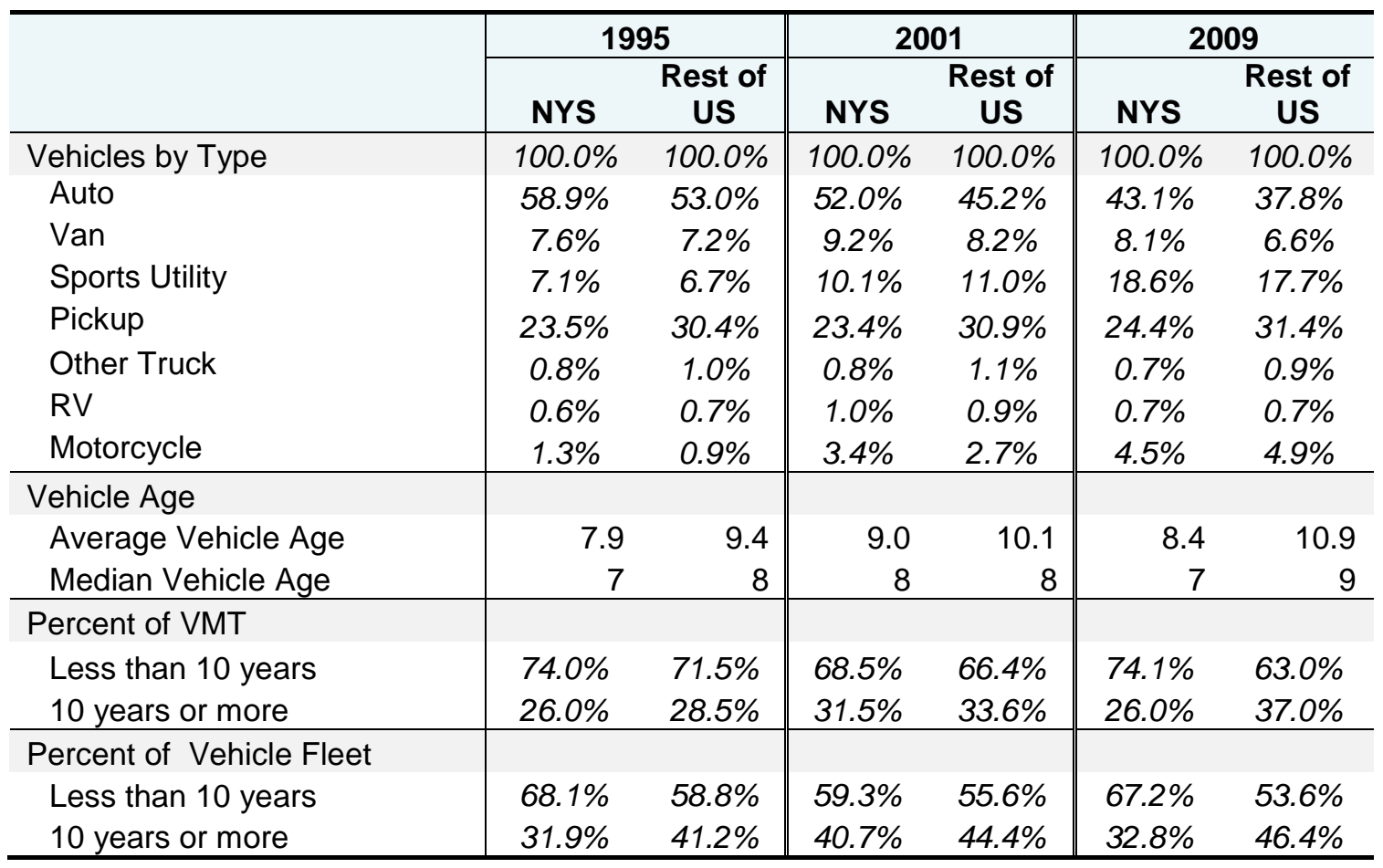

Notes: * Numbers reflect BESTMILE Estimates. Due to data being unavailable, self-reported annual miles were substituted for Rest of US 1995 estimates.

Table 5.8 Comparison of Average Annual Vehicle Miles of Travel by Vehicle Type for Rural Households in New York State and in the Rest of the United States

\begin{tabular}{l|cc||cc||cc}
\hline \multirow{2}{*}{} & \multicolumn{2}{c|}{1995} & \multicolumn{2}{c||}{ 2001 } & \multicolumn{2}{c}{ 2009 } \\
\cline { 2 - 7 } & NYS & $\begin{array}{c}\text { Rest of } \\
\text { US }\end{array}$ & NYS & $\begin{array}{c}\text { Rest } \\
\text { of US }\end{array}$ & NYS & $\begin{array}{c}\text { Rest of } \\
\text { US }\end{array}$ \\
\hline All Vehicles & 14,012 & 12,647 & 12,883 & 12,692 & 11,888 & 11,767 \\
Auto & 14,200 & 12,843 & 13,538 & 12,488 & 12,279 & 12,050 \\
Van & 17,173 & 15,881 & 13,759 & 13,844 & 14,465 & 7,923 \\
SUV & 14,515 & 12,389 & 15,690 & 15,184 & 13,479 & 13,324 \\
Pickup Truck & 13,164 & 11,629 & 11,592 & 12,464 & 11,504 & 11,517 \\
\hline
\end{tabular}

Notes: * Numbers reflect BESTMILE Estimates. Due to data being unavailable, selfreported annual miles were substituted for Rest of the US 1995 estimates.

In 2009 the average annual VMT per rural vehicle was very similar both inside and outside NYS, at around 11,800 miles per year (Table 5.8). When broken down by vehicle type, the only noticeable difference is the much higher mileage attributed to NYS vans $(14,466$ miles per year) versus rest of nation vans (7,923 miles per year). Once standard errors are accounted 
for, rural households in NYS used their vehicles only a little more in 2009 than did their urban counterparts within the state, and this applies to all vehicle types. Compared to the mileages reported in Chapter 3 of this report, these rural household estimates, while a little higher than the statewide averages either including or excluding New York City, also show a similar, gradual downward trend over time for autos, or when the mileages are averaged over all vehicle types. ${ }^{16}$

\subsubsection{Energy and Greenhouse Gas Emissions Associated With Vehicle Travel}

With slightly longer average trip lengths than their urban area counterparts, and given their heavier reliance on the private automobile for transportation, rural households are estimated to have emitted, on the average, more greenhouse gases in both 2001 and 2009 than did urban (defined by Chapter 4's metro area) households. Figure 5.5 shows these estimates for both NYS and the rest of the nation. Four different regional statistics are shown for 2001 and 2009: average rural household emissions, average urban household emissions for households located in census tracts with less than 500 ppsm, $\mathrm{CO} 2$ emissions averaged across all metro areas (i.e. taken over all metro area densities), and the average emissions for all households both inside and outside NYS. Comparable statistics are not available for 1995.

Based on the results shown in Figure 5.5, low density areas both inside and outside NYS emit significantly more emissions per household per year than do urban (metro) area households. It also appears that NYS rural residents reduced their annually averaged $\mathrm{CO} 2$ emissions from 11.4 to 10.0 metric tons between 2001 and 2009 - however, the standard error on the rural NYS 2001 estimate is quite large here, and less robust than its 2009 or urban area counterparts. Even so, rural NYS households produced fewer $\mathrm{CO} 2$ emissions on average than rural households elsewhere in the nation. In the rest of the country, in contrast, there appears to have been no significant decrease in rural household emissions, at just over 12 tons per household per year in 2009.

\footnotetext{
${ }^{16}$ For additional comparisons between these rural annual vehicle mileages and those associated with specific metropolitan urban densities within and outside NYS the reader is directed to Appendix C.4.
} 


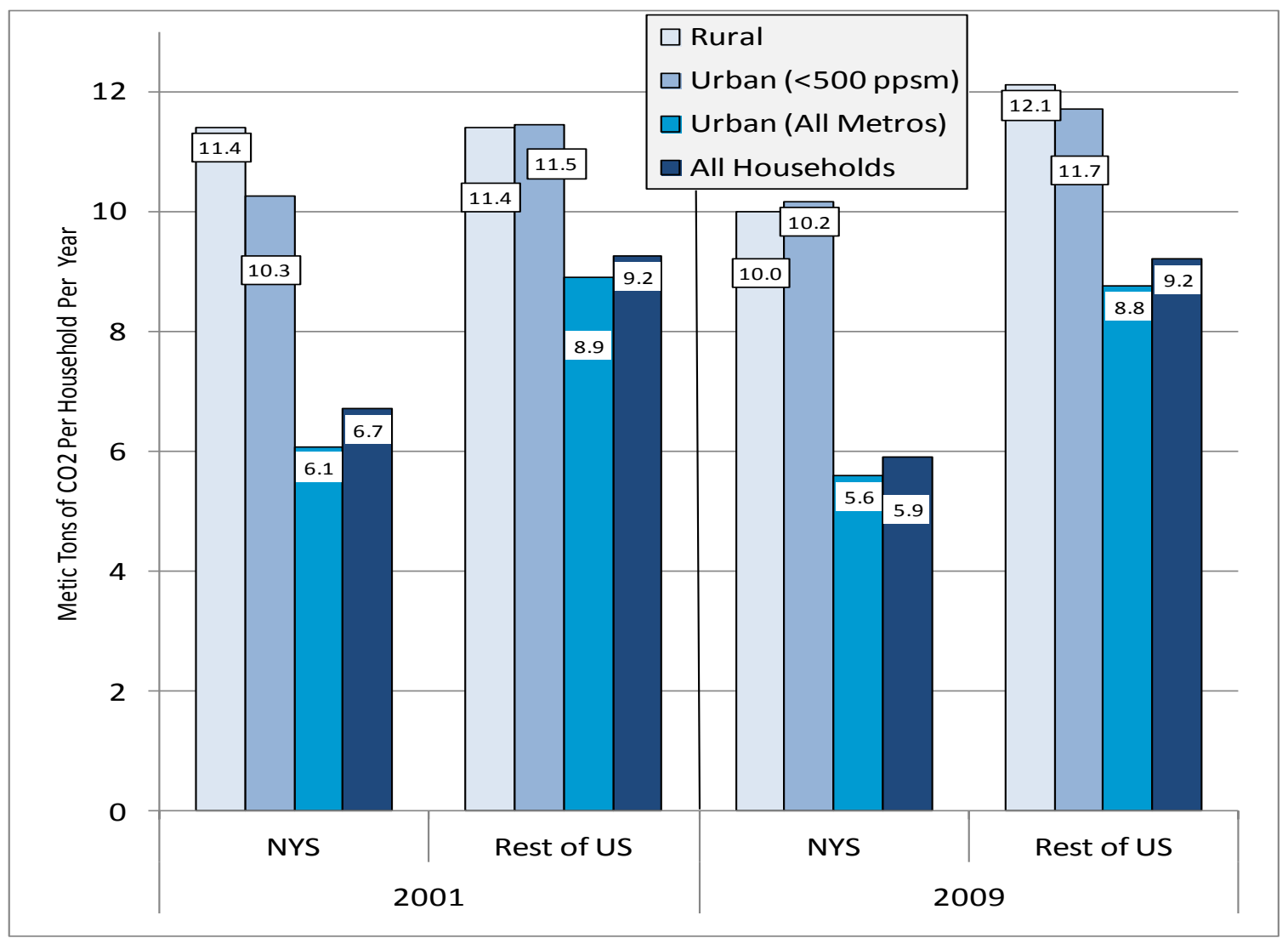

Figure 5.5 Comparison of Urban (Metro) and Rural Area Carbon Dioxide Emissions: Average Metric Tons of CO2 Emitted Per Household Per Year in 2001 and 2009.*

Note: * Direct, vehicle operating emissions only, no "upstream" vehicle or fuel production or infrastructure provision related emissions are included. Air travel is excluded. The emissions rates used for each NHTS mode of travel are reported in Appendix D, and make use of US EPA recommended fuel use to $\mathrm{CO} 2$ emissions conversions, and emissions rate estimates derived from the Federal Transit Administration's rail, bus and ferry transit energy consumption database, and average vehicle fuel efficiencies reported by or derived from Federal Highway Administration, American Bus Association, American School Bus Association, and the New York City Taxi and Limousine Commission estimates. See also results presented in Figure 2.14 and Figure 4.30.

\subsection{RURAL COMMUTING PATTERN COMPARISONS}

Table 5.9 shows the average daily commute trip frequencies and commuting trip length statistics for rural households, both within and outside NYS. 


\section{Table 5.9 Daily Commute Statistics in Rural Areas by Mode of Transportation: New York State (NYS) vs. Rest of the United States (US)}

(Based on census tracts of less than 500 people per square mile.)

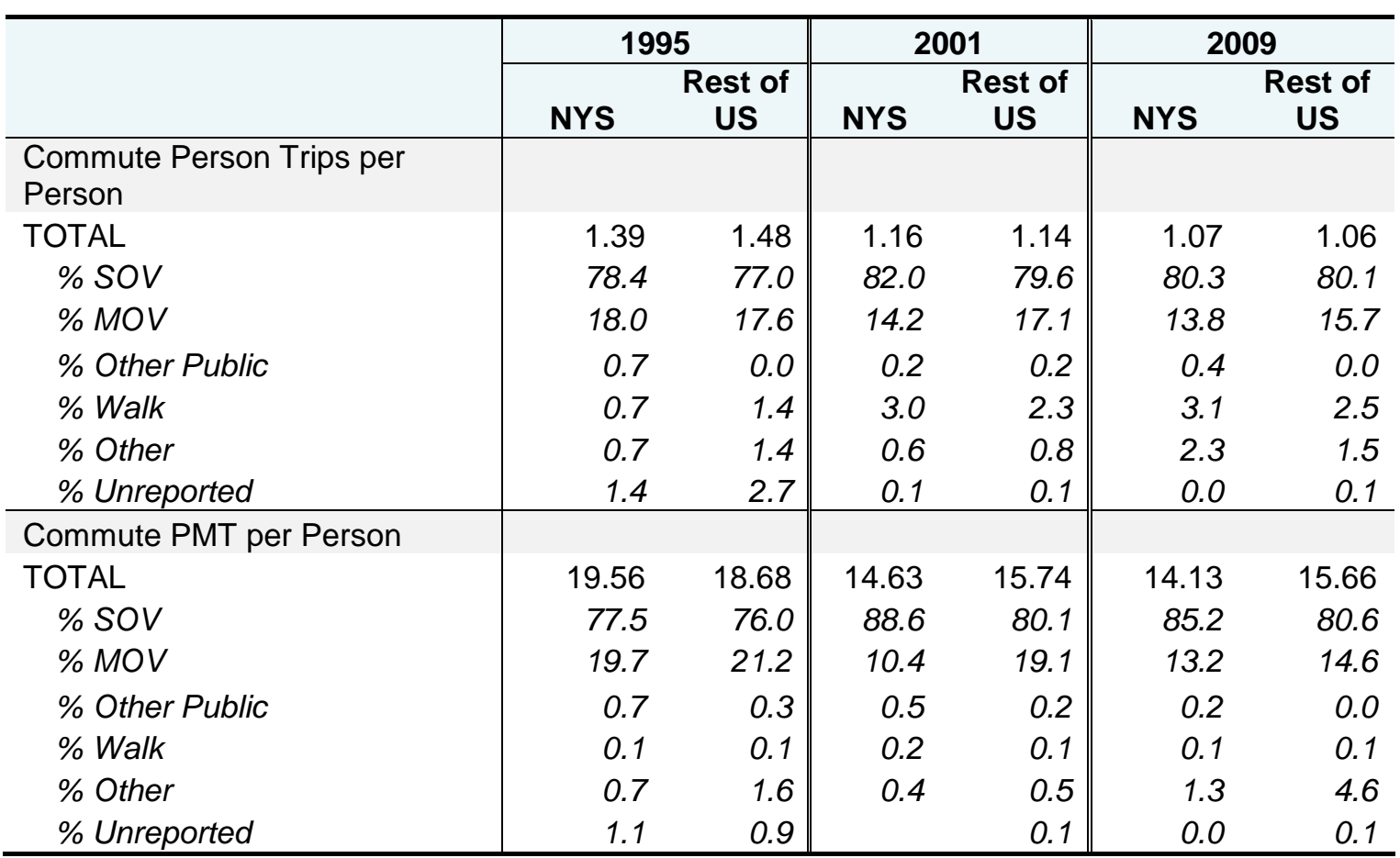

Notes: All percentages may not add to $100 \%$ due to rounding. SOV $=$ single occupancy vehicles. $\mathrm{MOV}=$ multiple occupancy vehicles. $\mathrm{SOV}+\mathrm{MOV}=$ total of $\mathrm{POV}=$ privately owned vehicles.

Compared to 1995 (around 1.4 trips), rural area commuters both inside and outside NYS took fewer daily work trips per person on the average in either 2001 (1.2 trips) or 2009 (1.1 trips). This also led to a reduction in average daily commuting miles per person, down from 19.6 miles per day in 1995 to 14.1 miles per day in 2009 for NYS rural commuters, and from 18.7 to 15.7 miles per day for rural commuters outside NYS. Recalling Figure 4.38 in Chapter 4 of this report, this temporal decline in daily commuting miles is similar to that shown for most urban areas of the state, including locations with higher population densities. Some $80 \%$ of these rural commutes were made in SOVs, both within and outside NYS. About 3.5\% of NYS commuters use walking and public transit to get to work, versus $2.5 \%$ in the rest of the nation in 2009 . This modal share difference is compensated by a slightly higher percentage of rural commuters outside NYS engaging in shared ride privately owned vehicle trips (i.e. \% MOVs in Table 5.9: see note below table).

Figure 5.6 shows rural commuting average trip length, average travel time, and average travel speed statistics. In 2009 the average commute time was around 22 minutes per one-way trip both inside and outside the state. In NYS, the average commute trip length in 2009, at 13.3 
miles, had increased since 2001 (at 12.6 miles), but was still lower than in 1995 (at 14.2 miles). With a decrease in average travel speed from just over $40 \mathrm{mph}$ to just over $36 \mathrm{mph}$, the average travel time for these commutes increased by about 1 minute in 2009 over 2001 and 1995 travel times. In the rest of the nation the average length of a rural commute also increased, from 12.7 miles in 1995 to 14.8 miles in 2009. With the 2009 and 1995 average speeds both just over 40 $\mathrm{mph}$, this produced an average trip time increase from 18.7 to 22.1 minutes, principally as a result of increased trip length.

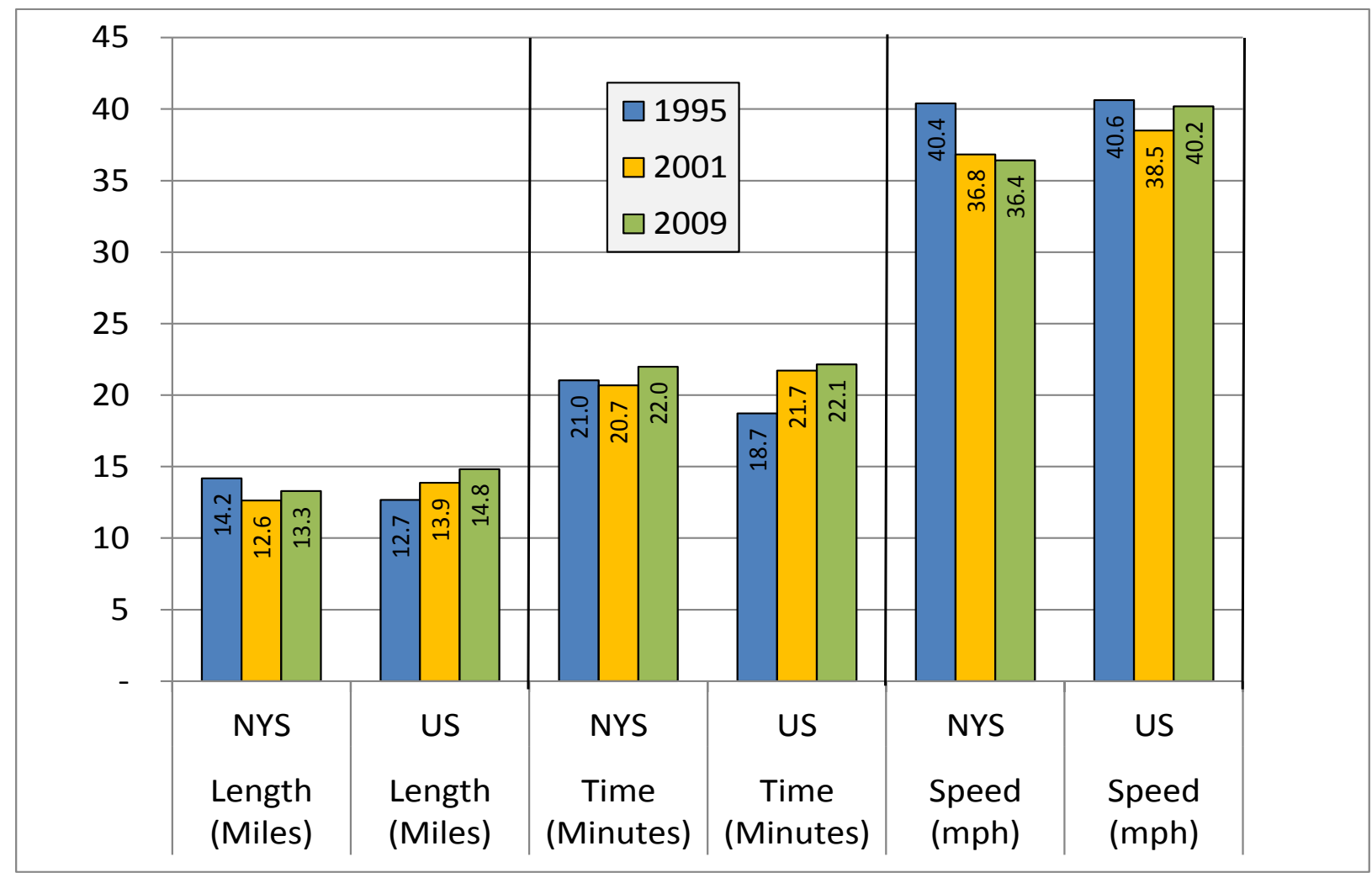

Figure 5.6 Daily Commute Patterns in Rural Areas New York State (NYS) vs. Outside New York State (US) (based on census tracts of less than 500 people per square mile)

\subsection{SUMMARY}

Noting that many individual statistics in this chapter are subject to very small sample sizes and resulting larger standard errors (see Appendix C.5), many similarities as well as a few differences are found to exist between NYS's rural household travel statistics and those for the rest of rural America. In 2009, as in 2001 and 1995, households in the rural areas of NYS owned, on the average, fewer vehicles than rural households elsewhere, and had fewer vehicles available per driver. Vehicle ownership patterns were also somewhat different for rural households inside versus outside NYS. While the proportion of zero-vehicle households has declined marginally at 
just over $4 \%$ in the rest of the nation in 2009, it has grown from $3.2 \%$ to $4.8 \%$ of rural households in NYS (Table 5.3). A larger percentage of rural households outside NYS also continue to own 3 or more vehicles when compared to rural NYS households. On average, drivers in NYS rural areas make marginally fewer and shorter trips than those in rural areas elsewhere, resulting in an average daily vehicle miles of travel of 33.7 for NYS rural area drivers versus 36.3 miles for rural drivers elsewhere in the nation (Table 5.6).

The average age of a vehicle owned by a rural household in NYS in 2009 was over two year higher than for rural households elsewhere in the nation. Rural NYS household vehicles are also on average half a year older than the vehicles owned by NYS households in the state's urban areas. These rural NYS households drive their vehicles a few more miles each year than NYS urban households, on the average. Carbon dioxide emissions associated with rural highway travel are found to be significantly higher than for their urban area counterparts, at an estimated 12.1 versus 9.2 metric tons of CO2 per household per year in 2009 (Figure 5.5); and also about $20 \%$ higher than the emissions from NYS households in similarly low density $(<500$ ppsm) urban areas; further confirming the strong relationship reported in Chapter 4 of this report between higher population density and lower per household mobile source greenhouse gas emissions. Most of this difference is attributable to the much higher share of public transit and walk trips taken by residents living in the nation's higher density urban locations. Finally, rural one-way commute times were around 22 minutes both inside and outside NYS in 2009, with average speeds in NYS declining by about $4 \mathrm{mph}$ to $36.4 \mathrm{mph}$ since 1995, while average rural highway speeds in the rest of rural America appear to have held steady at around $40 \mathrm{mph}$ (Figure 5.6). 


\section{COMPARISON OF TRAVEL PATTERNS AMONG NEW YORK STATE METROPOLITAN PLANNING AREAS}

Previous chapters of this report compare the travel patterns of NYS residents to those in the rest of the nation. This chapter examines travel patterns among the state's thirteen MPObased metropolitan areas: Albany; Binghamton; Buffalo; Elmira; Glens Falls; Ithaca; Kingston; the NYMTC area; Newburgh; Poughkeepsie; Rochester; Syracuse; and Utica-Rome (see Figure $6.1)$.

As already discussed in Chapter 4 of this report, each of these metropolitan areas is associated with a NYS MPO region. Since the NHTS sampling frame is comprised of the primary urban counties within which each MPO lies, an entire MPO area may not be represented by the survey in every case, so they are referred to here as metro areas or metros. Travel patterns are compared among NYS metros of similar size, and the NYMTC area is split into three separate geographic components: (1) Nassau and Suffolk; (2) the five counties of NYC (i.e. the Bronx, Kings, Queens, New York/Manhattan, and Richmond); and (3) Putnam, Rockland, and Westchester (P, R, \& W) counties. New York City is further broken down into New York county (i.e. Manhattan) and the rest of NYC. To make travel comparisons meaningful, these metro areas and their sub-components are grouped into U.S. Census defined MSA size categories; with the groupings of the original twelve metro areas remaining the same in 2009 as it was in the 2001 and 1995: and with the "new" Kingston metro area added to the 2009 statistics and falling into the smallest "Not in an MSA" size class (see Table 6.1). In particular, the small and medium sized metro areas, defined here as those with populations under 3 million persons, display a number of significant differences in their household travel statistics when compared to the larger, over 3 million person, metro areas centered on the NYC conurbation.

Figure 6.1 maps the population densities of areas in NYS according to the 2010 Census. Population density maps for the individual NYS add-on areas, allowing scrutiny of individual census tracts, can be found in Appendix B of this report. 


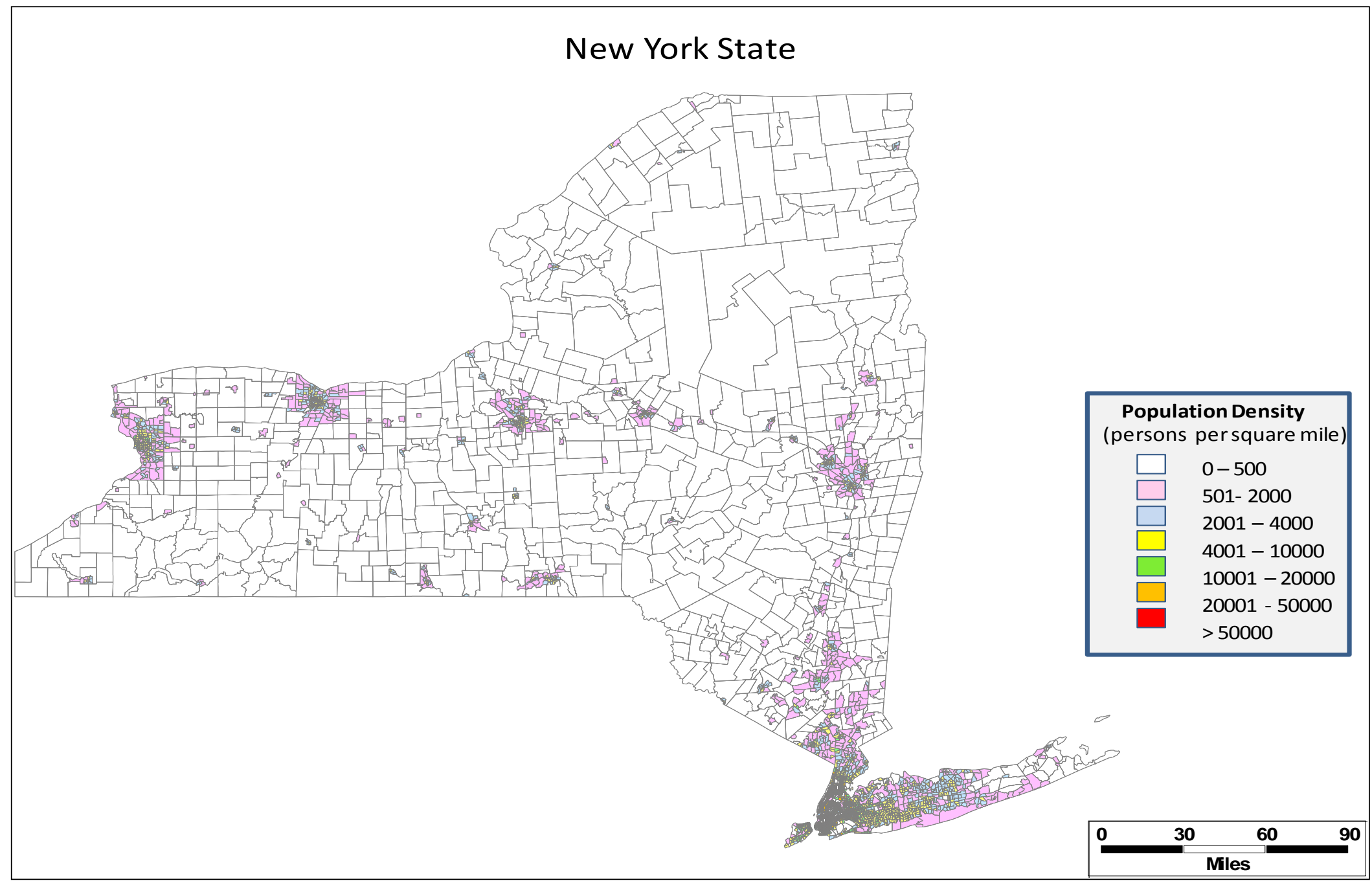

Figure 6.1 Population Densities by 2010 Census Tracts in New York State. 
Table 6.1 New York State MPO-Based Metro Areas Categorized by Population Size Class

\begin{tabular}{|c|l|}
\hline Population Size Category & NYS Metropolitan Areas \\
\hline Not in an MSA & $>$ Ithaca \\
& $>$ Kingston \\
\hline$<250,000$ & $>$ Elmira \\
& $>$ Glen Falls \\
\hline $250,000-499,999$ & $>$ Binghamton \\
& $>$ Utica-Rome \\
\hline \multirow{2}{*}{$500-999,999$} & $>$ Syracuse \\
\hline \multirow{2}{*}{1 to 2.9 million } & $>$ Buffalo \\
& $>$ Rochester \\
\hline \multirow{2}{*}{3 million } & $>$ Newburgh \\
& $>$ Poughkeepsie \\
& $>$ Nassau/Suffolk \\
& $>$ New York city (NYC's 5 counties; \\
& $>$ Bronx, Kings, Queens, New \\
& $>$ York/Manhattan, and Richmond) \\
&
\end{tabular}

\subsection{PROFILE OF NEW YORK STATE METRO AREA HOUSEHOLDS BY MSA SIZE}

\subsubsection{Workers Per Household, Vehicles Per Household, and Vehicles Per Driver}

More than seven out of ten metro area households within NYS were located in metros with a population of 3 million or more in 2009, with no major population shifts across MSA categories since 1995 (Figure 6.2). In 2009, the average number of workers per metro area household increased slightly from the levels in prior survey years in several metros, notably in Ithaca (Tables 6.2, 6.3 and 6.4). Vehicles per household fell back a little in some metros, closer to 1995 levels, while changing little from 2001 levels in other metros. Vehicles per driver in 2009 fell consistently across all metro areas to below 2001 levels, in all cases coming much closer to 1995 vehicle ownership levels of just under 1 vehicle per driver in 2009 in areas outside NYC. In NYC, it averaged 0.40 vehicles per driver in 2009, also down from an estimated 0.55 vehicles per driver in 2001. 


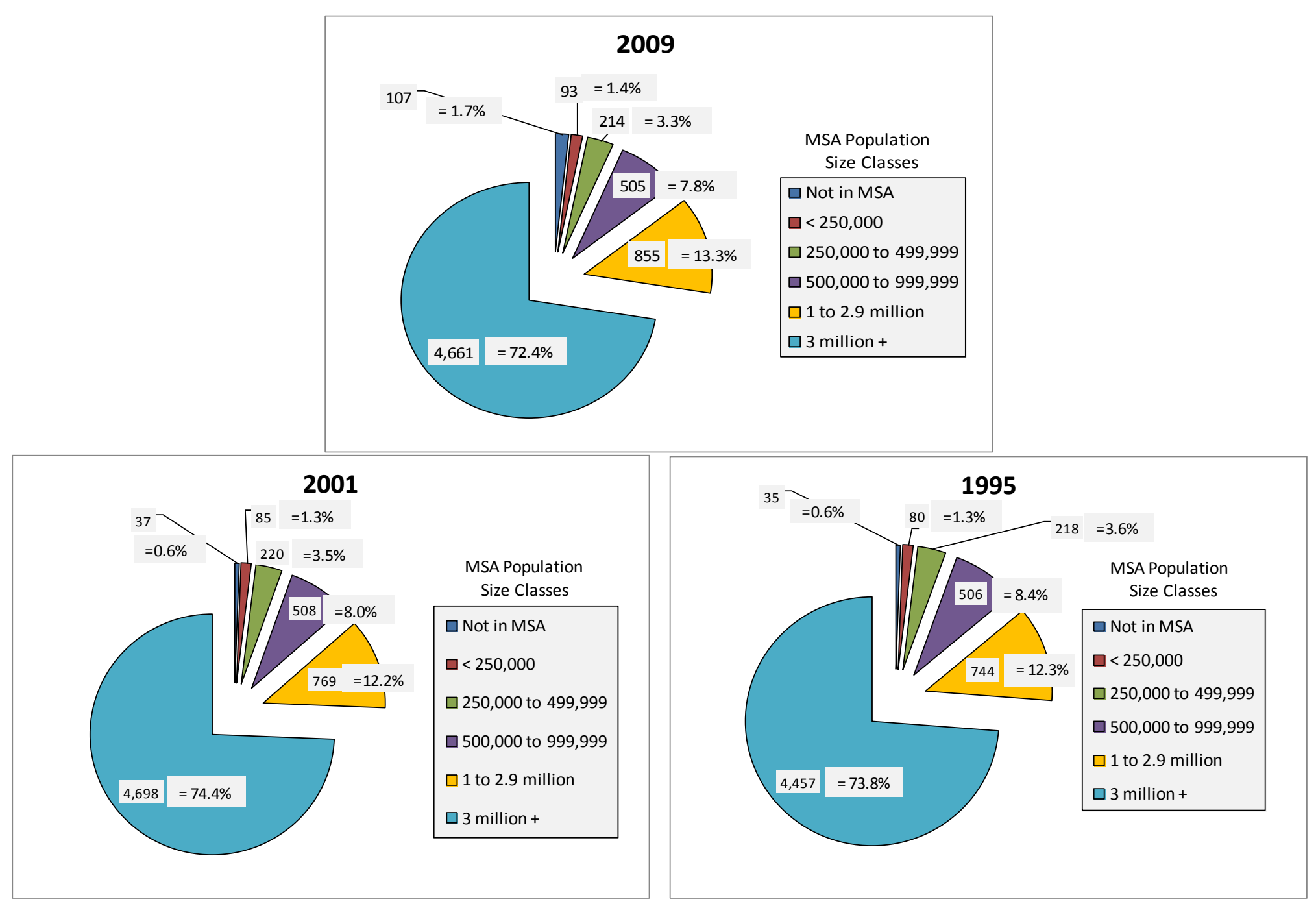

Figure 6.2 New York State Metro Area Households (000s) by MSA Size Class and Share.

Notes: The data include only NYS sampled households located within the 13 MPO-based metropolitan areas in the state. Data for the Kingston based MPO area are included in the 2009 results, but not in the results for 1995 or 2001, prior to the designation of this MPO area. 
Table 6.2 Household Characteristics and Vehicle Ownership Patterns for New York State Metro Areas by MSA Size in 2009

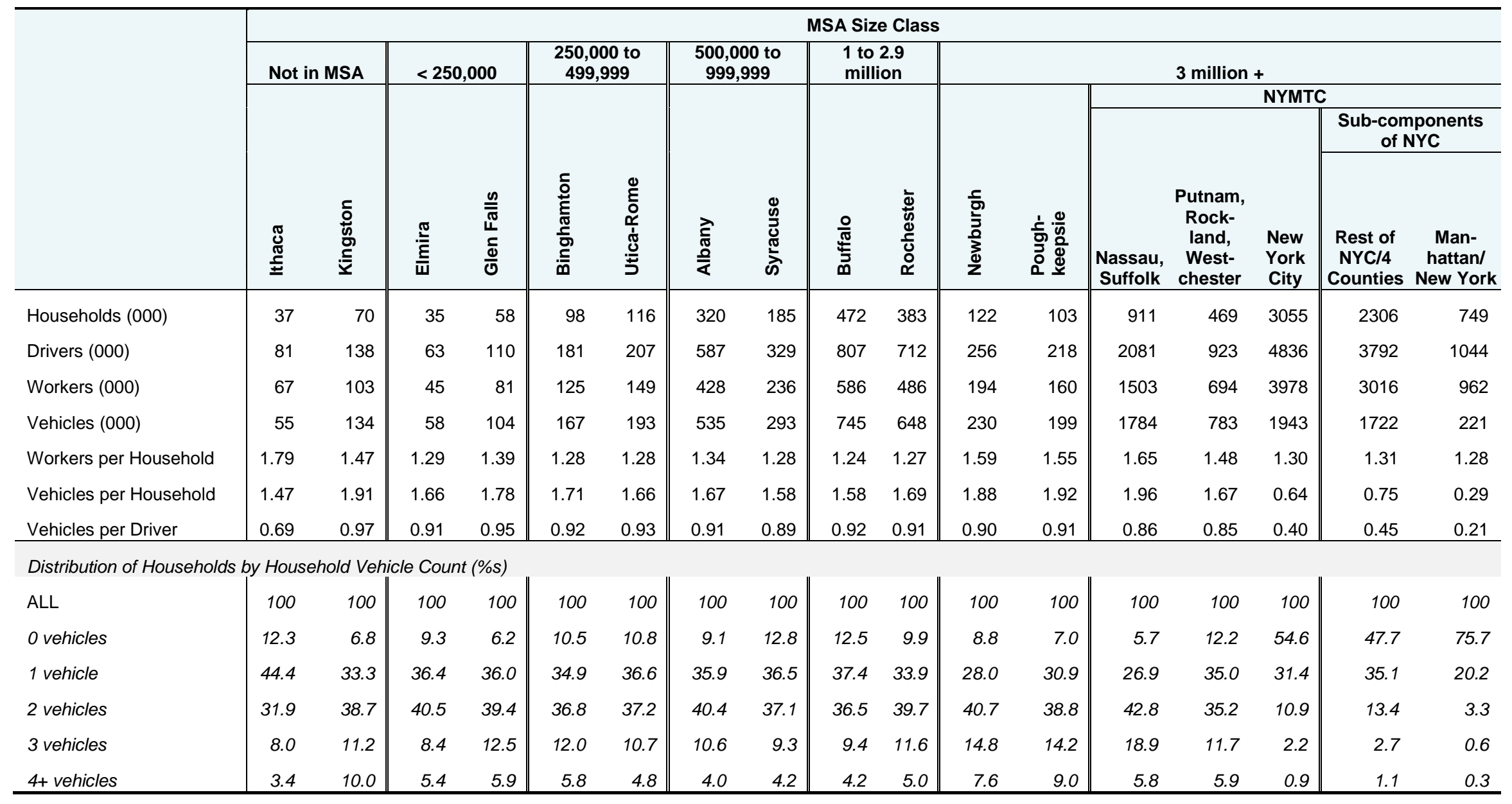

Note: All percentages may not add to $100 \%$ due to rounding. 
Table 6.3 Household Characteristics and Vehicle Ownership Patterns for New York State Metro Areas by MSA Size in 2001

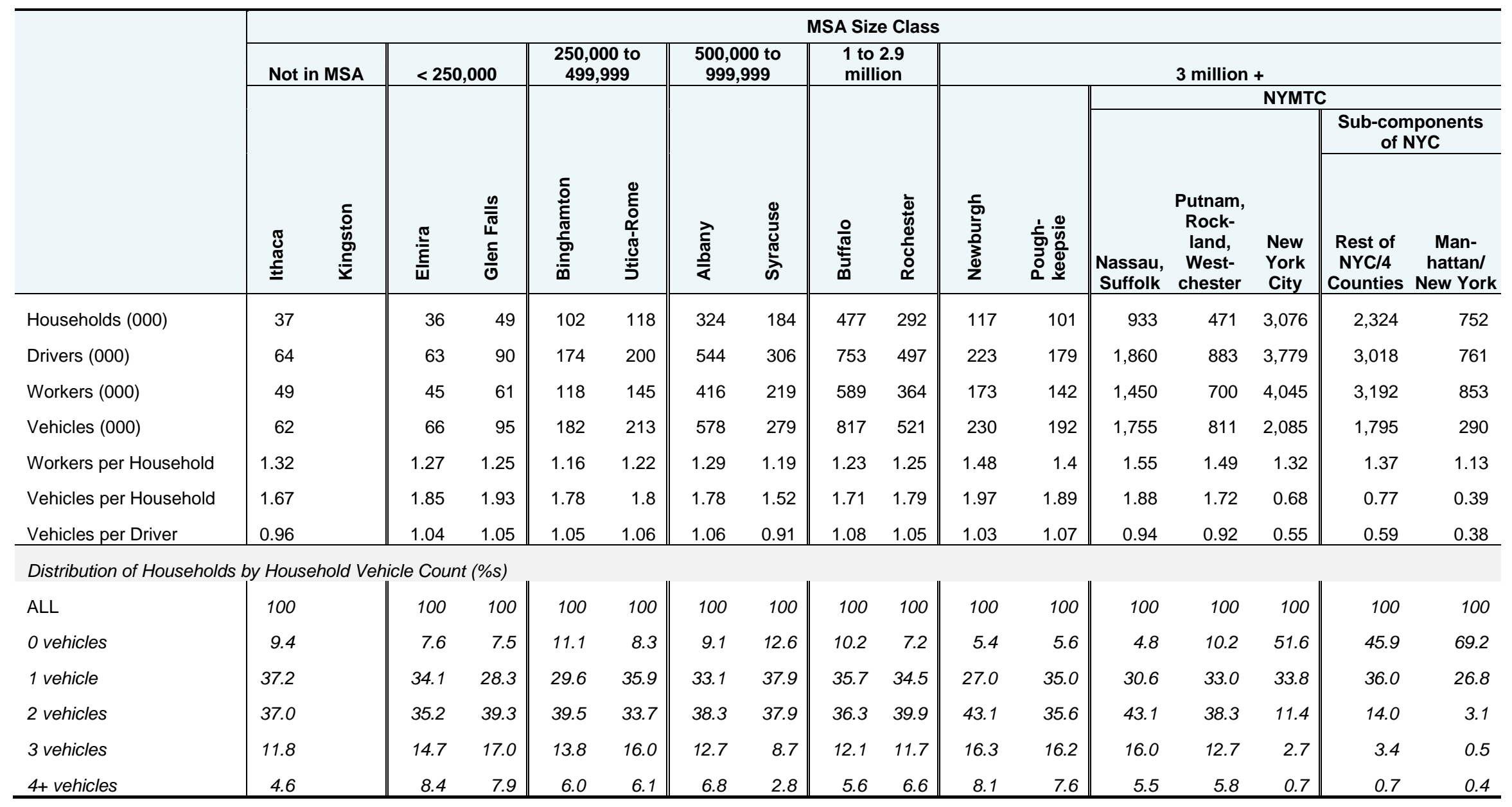

Notes: All percentages may not add to 100\% due to rounding. * Kingston area data were not separated out prior to 2009. 
Table 6.4 Household Characteristics and Vehicle Ownership Patterns for New York State Metro Areas by MSA Size in 1995

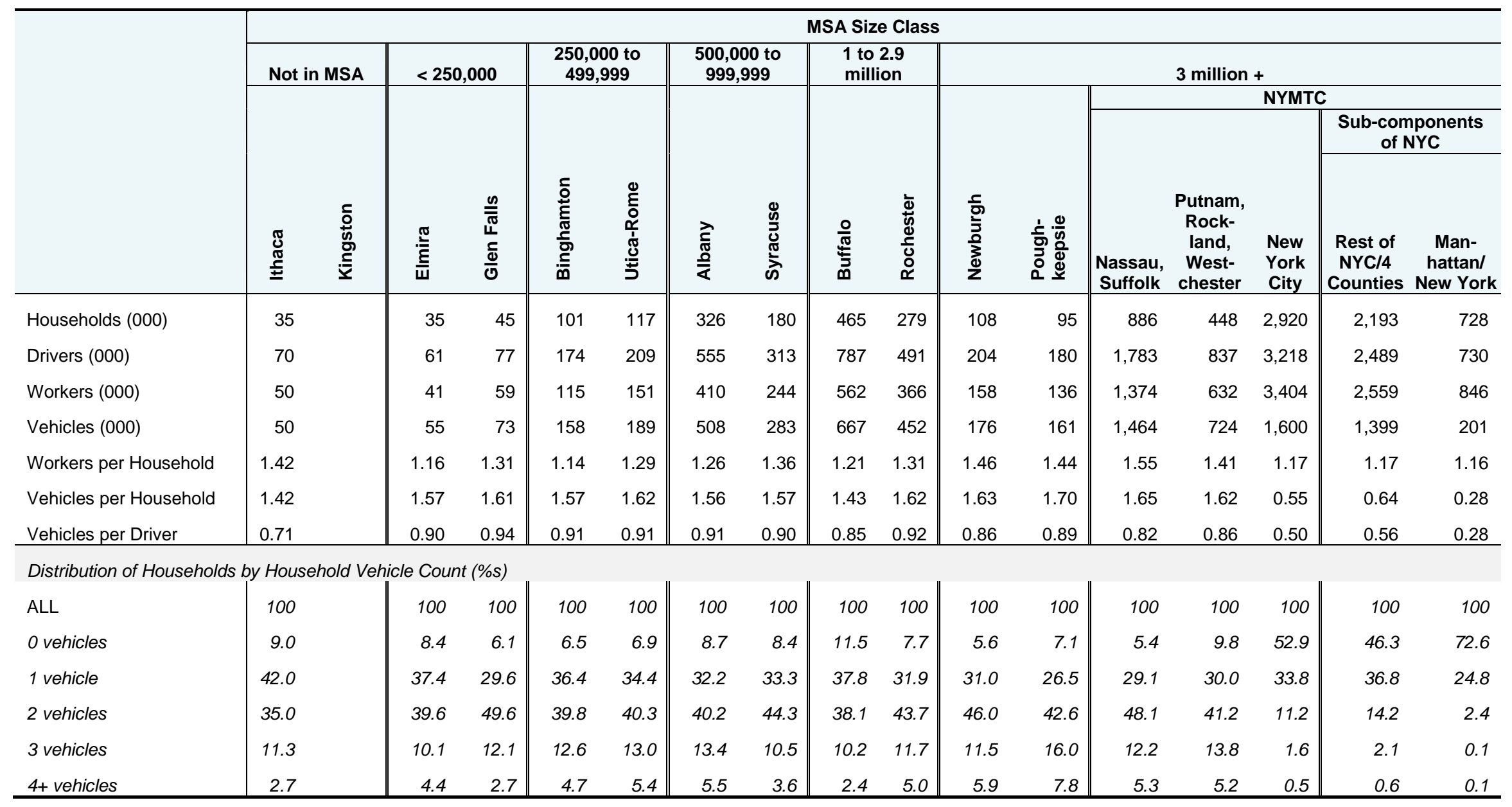

Notes: ${ }^{a}$ All percentages may not add to $100 \%$ due to rounding. * Kingston area data were not separated prior to 2009. 


\subsubsection{Vehicle Ownership}

With the exception of NYC, where about 1 in 2 households did not own a vehicle in all three survey years, zero-vehicle households accounted for from around 5\% (e.g., Nassau and Suffolk counties within the NYMTC in 2001) to over 12\% (e.g., Ithaca, Buffalo, and Syracuse in 2009) of households over this 14 year time period. The "new" Kingston metro area comes in near the lower end of this range, with just under 7\% zero-vehicle households in 2009.

The percentage of NYS households located in metro areas of under 3 million people, and reporting 3 or more vehicles per household (i.e. combining the 3 vehicles and 4 or more vehicles per household statistics from Tables 6.2, 6.3 and 6.4) varied from $11.4 \%$ (Ithaca) to $22.2 \%$ (Kingston) in 2009, both in the "Not in an MSA' category. Across the three survey years, these percentages have varied somewhat within individual metro areas, with a high of $24.9 \%$ for Glen Falls in 2001 and a low of $12.6 \%$ for Buffalo in 1995. Among the metros in the over 3 million person class, the Poughkeepsie region remained stable at between $23 \%$ and $24 \%$ of $3+$ vehicle households over the 14 year period, and the Putnam, Rockland, and Westchester area was stable at around $18 \%$ to $19 \%$; while the Newburgh and also Nassau/Suffolk metro areas saw increases in the percentage of $3+$ vehicle households from 1995 to 2001 from around $17 \%$ to $24 \%$, with these higher percentages largely retained in 2009.

Consistent with the findings in Chapter 3 of this report, households in NYC have considerably different vehicle ownership patterns than other metro area households in the state. In particular, $75 \%$ of Manhattan households reported not owning a vehicle in 2009, up from close to $70 \%$ in 2001 and 1995 (Tables 6.2, 6.3, and 6.4).

\subsubsection{Driving and Gender}

More than nine out of ten NYS men who are sixteen years or older reportedly drive. ${ }^{17}$ This is true for all NYS metro areas, with the exception of men living in NYC, where the ratio is closer to 4 in 5 men being drivers in 2009 (Figure 6.3). Women within the state are a little less likely to drive than men overall, no matter where they are located. However, this gap is narrowing and was closed in a number of metro areas in 2009 (e.g., Albany, Ithaca, UticaRome). In NYC, 2 in every 3 women reported being drivers in 2009, up significantly from around 50\% in 1995 and 2001 (Figure 6.4).

\footnotetext{
${ }^{17}$ Note that NHTS respondents were asked for their driver status (i.e. “Are you a driver?"), rather than license status. Therefore, the driver rates reported in this chapter refer to the percentage of New York residents who state that they are drivers, and should not be compared directly to driver license rates maintained by the New York Department of Motor Vehicles.
} 


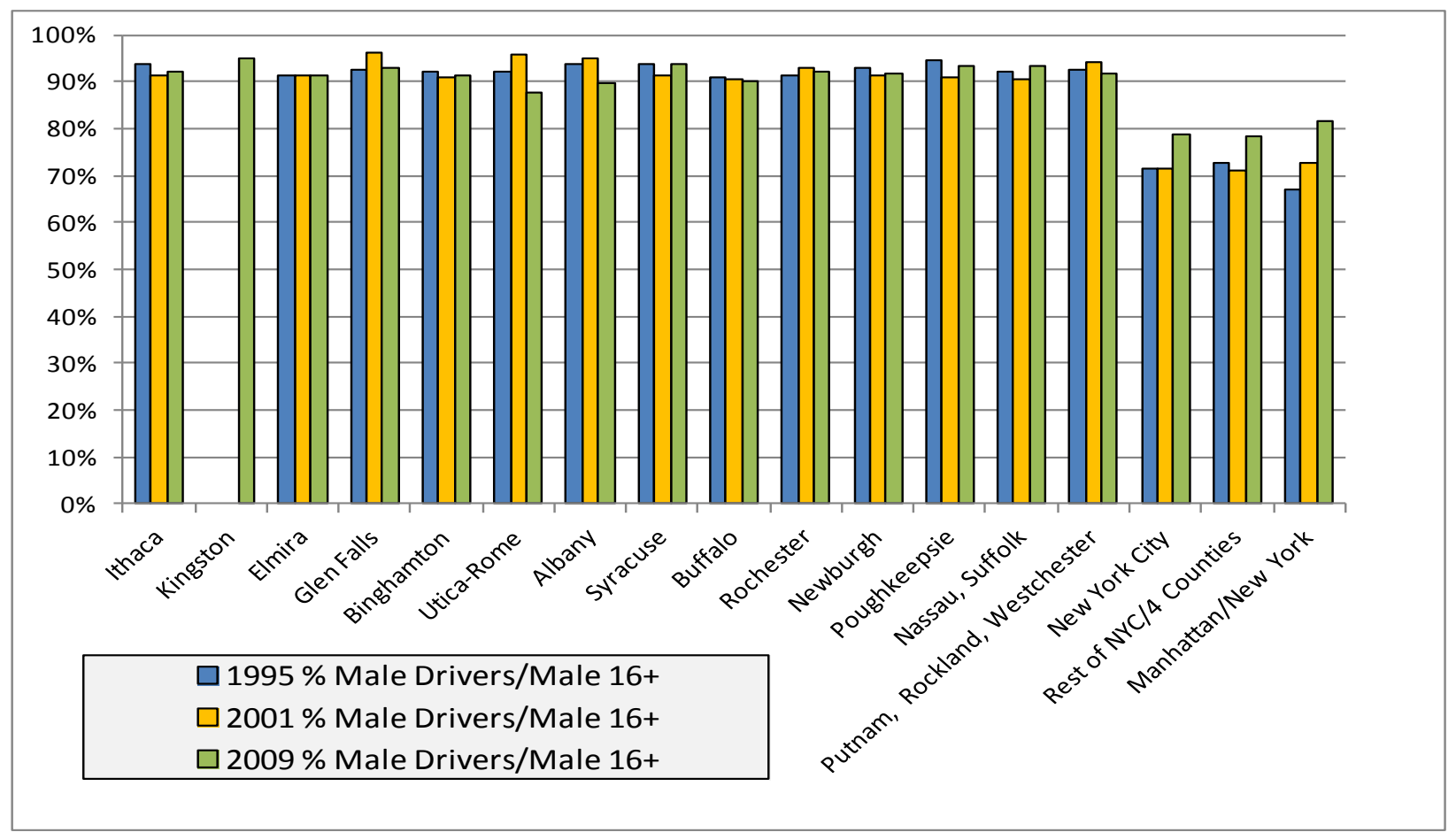

Figure 6.3 Percentage of Population Who Drive Categorized by Gender for New York State Metro Areas in 1995, 2001, and 2009: Male Drivers.

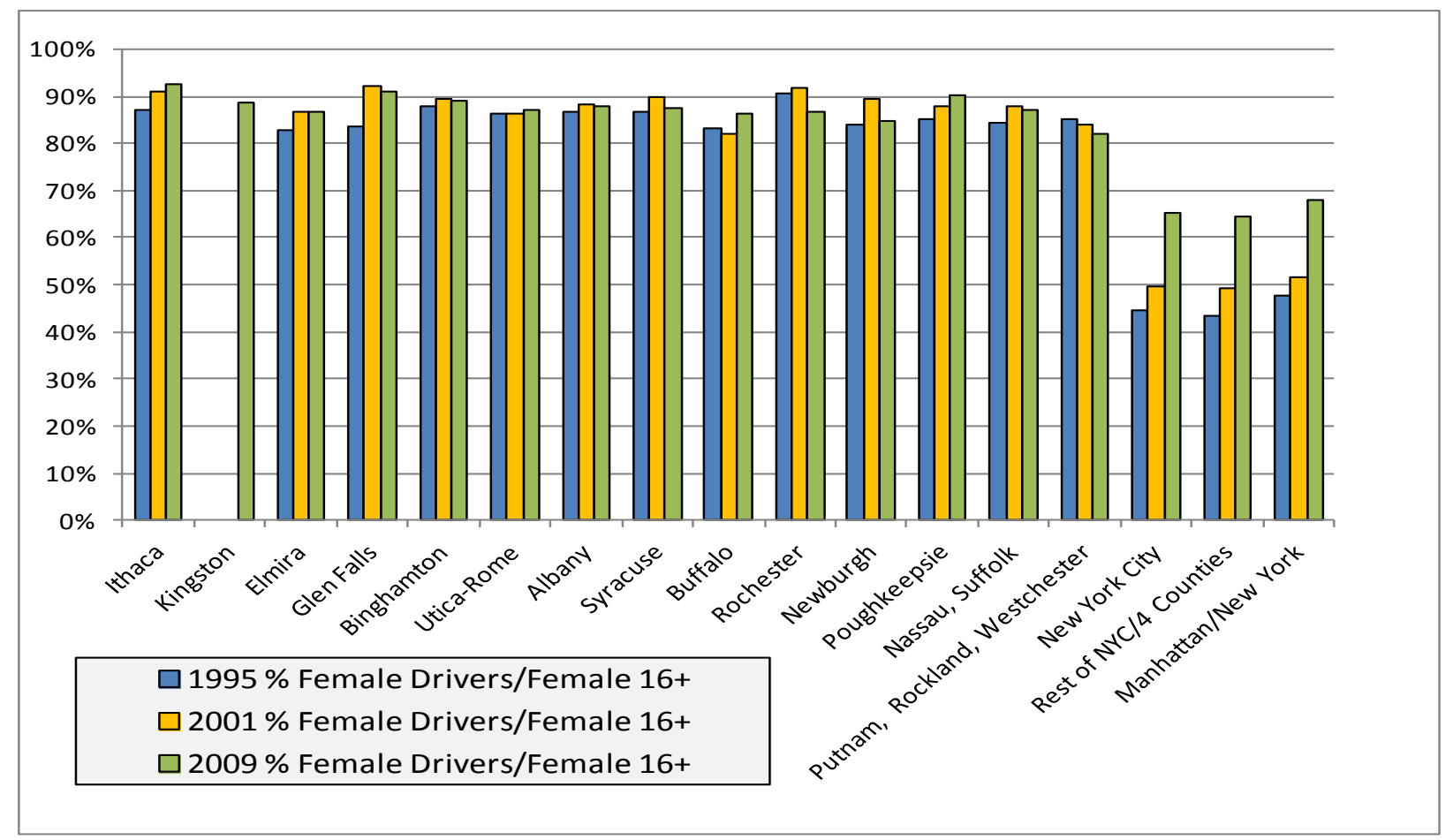

Figure 6.4 Percentage of Population Who Drive Categorized by Gender for New York State Metro Areas in 1995, 2001, and 2009: Female Drivers. 


\subsection{PERSONAL TRAVEL COMPARISONS}

\subsubsection{Trip Frequencies}

Tables 6.5, 6.6 and 6.7 contain a number of metro area-specific personal travel statistics. Consistent with the results presented in Chapter 4 of this report (Figures 4.9 and 4.10), these tables show a gradual decline in average daily person trip rates over time in most small and medium (defined here as less than 3 million population) metro areas within the state. Figure 6.5 below displays the average daily person trip rates. As shown in Figure 6.5, the exception is the Syracuse area, where trip rates have not fallen in 2009. In contrast, for areas with 3 million or more populations, person tripmaking increased in both Nassau and Suffolk counties and in Manhattan in 2009, where it reached 4 person trips per day, and remained stable in NYC as a whole at around 3.5 trips per person per day in all three NHTS surveys. In 2009, the lowest person trip rate was reported by the four non-Manhattan counties of NYC, at 3.3 trips per day. Based on statistics shown in Tables a-c, trip purpose shares show some but not a great deal of variation across metro areas either within or between each MSA size class, and remained relatively stable over time.

\subsubsection{Trip Lengths}

Figure 6.6 shows the trends in average trip lengths (distances in miles) across the various NYS metro areas for 1995, 2001, and 2009. While the Newburgh and Poughkeepsie metro areas show consistently longer trip distances, at around 11 miles per trip on average, the shortest trip distances are found in the NYC metro area, at around 5 miles per trip in 2009. Temporally, results are mixed: some metro areas have seen slight increases in average trip lengths, while others have seen small decreases or stayed essentially the same.

\subsubsection{Travel Modes}

Figures 6.7, 6.8, and 6.9 highlight patterns among the major modes of transportation used for personal travel in each survey year. Choice of mode is generally consistent across the state's small and medium-size metro areas, with private vehicle travel the dominant mode: although the Ithaca area has consistently reported a higher and over time increasing share of walk trips when compared to the other metro areas. In contrast, walking dominates tripmaking in the NYC region. This is especially true in Manhattan, where public transit ridership captures the second largest mode share after walking in all three NHTS surveys. Also of note, within NYC a decrease in Manhattan's public transit ridership share from 27\% in 1995 to $19 \%$ in 2009 was offset in part by a slight increase in public transit's share of trips in the other four NYC counties between 1995 and 2001. 
Table 6.5 Personal Travel Statistics New York State Metro Areas by MSA Size in 2009

\begin{tabular}{|c|c|c|c|c|c|c|c|c|c|c|c|c|c|c|c|c|c|}
\hline & \multicolumn{17}{|c|}{ MSA Size Class } \\
\hline & \multicolumn{2}{|c|}{ Not in MSA } & \multicolumn{2}{|c|}{$<250,000$} & \multicolumn{2}{|c|}{$\begin{array}{c}250,000 \text { to } \\
499,999\end{array}$} & \multicolumn{2}{|c|}{$\begin{array}{l}500,000 \text { to } \\
999,999\end{array}$} & \multicolumn{2}{|c|}{$\begin{array}{l}1 \text { to } 2.9 \\
\text { million }\end{array}$} & \multicolumn{7}{|c|}{3 million +} \\
\hline & \multirow[b]{3}{*}{$\begin{array}{l}\mathbb{8} \\
\stackrel{\mathbb{\Xi}}{ \pm} \\
\end{array}$} & \multirow[b]{3}{*}{ 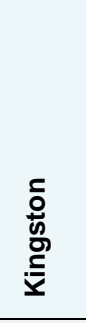 } & \multirow[b]{3}{*}{$\frac{\stackrel{\varpi}{\bar{E}}}{\underline{\underline{W}}}$} & \multirow[b]{3}{*}{$\begin{array}{l}\frac{\omega}{\bar{\sigma}} \\
\stackrel{c}{0} \\
\frac{c}{\omega}\end{array}$} & \multirow[b]{3}{*}{ 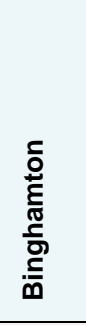 } & \multirow[b]{3}{*}{ 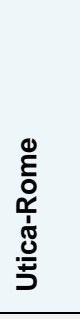 } & \multirow[b]{3}{*}{$\begin{array}{l}\text { D } \\
\frac{\mathbb{\pi}}{\mathbb{0}} \\
\frac{0}{\alpha}\end{array}$} & \multirow[b]{3}{*}{ 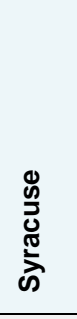 } & \multirow[b]{3}{*}{$\begin{array}{l}\frac{0}{\pi} \\
\stackrel{\pi}{5} \\
\bar{n}\end{array}$} & \multirow[b]{3}{*}{ 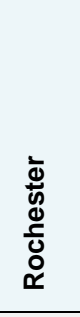 } & \multirow[b]{3}{*}{ 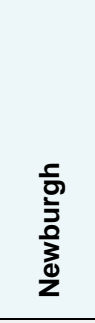 } & \multirow[b]{3}{*}{ 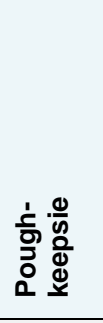 } & & & \multirow{3}{*}{\begin{tabular}{l|} 
NYMTC \\
\\
\\
\\
New \\
York \\
City
\end{tabular}} & & \\
\hline & & & & & & & & & & & & & \multirow{2}{*}{\multicolumn{2}{|c|}{$\begin{array}{c}\text { Putnam, } \\
\text { Rock- } \\
\text { land, } \\
\text { u, West- } \\
\text { k chester } \\
\end{array}$}} & & \multicolumn{2}{|c|}{\begin{tabular}{|c|}
$\begin{array}{c}\text { Sub-components } \\
\text { of NYC }\end{array}$ \\
\end{tabular}} \\
\hline & & & & & & & & & & & & & & & & $\begin{array}{l}\text { Rest of } \\
\text { NYC/4 } \\
\text { Counties }\end{array}$ & $\begin{array}{c}\text { Man- } \\
\text { hattan/ } \\
\text { New York }\end{array}$ \\
\hline \multicolumn{18}{|l|}{ Person Trips per Person } \\
\hline TOTAL & 3.73 & 3.81 & 3.99 & 3.90 & 3.84 & 3.66 & 3.68 & 4.04 & 3.60 & 3.75 & 3.57 & 3.69 & 4.00 & 3.86 & 3.46 & 3.31 & 4.04 \\
\hline Male & 3.58 & 3.77 & 3.82 & 3.79 & 3.94 & 3.54 & 3.73 & 4.08 & 3.56 & 3.79 & 3.50 & 3.66 & 3.94 & 3.88 & 3.46 & 3.26 & 4.28 \\
\hline Female & 3.89 & 3.84 & 4.14 & 4.01 & 3.74 & 3.77 & 3.63 & 4.00 & 3.64 & 3.71 & 3.63 & 3.71 & 4.05 & 3.84 & 3.45 & 3.35 & 3.82 \\
\hline \multicolumn{18}{|c|}{ Average Person Trip Length (miles) ${ }^{b}$} \\
\hline & 7.27 & 9.57 & 8.93 & 9.09 & 8.60 & 7.30 & 10.69 & 7.70 & 7.96 & 9.43 & 10.96 & 11.21 & 7.97 & 8.12 & 5.20 & 5.30 & 4.88 \\
\hline \multicolumn{18}{|l|}{ Person Trips per Person } \\
\hline TOTAL & 3.73 & 3.81 & 3.99 & 3.90 & 3.84 & 3.66 & 3.68 & 4.04 & 3.60 & 3.75 & 3.57 & 3.69 & 4.00 & 3.86 & 3.46 & 3.31 & 4.04 \\
\hline $\begin{array}{l}\% \text { Earn a Living } \\
\% \text { Family \& Personal }\end{array}$ & 22.4 & 18.5 & 17.0 & 21.2 & 18.7 & 18.1 & 20.7 & 18.1 & 20.5 & 19.2 & 20.1 & 18.2 & 19.4 & 18.2 & 16.6 & 16.8 & 16.0 \\
\hline $\begin{array}{l}\text { Business } \\
\% \text { Civic, Educational \& }\end{array}$ & 38.1 & 47.5 & 46.5 & 41.6 & 44.6 & 43.5 & 41.4 & 42.1 & 40.5 & 41.5 & 40.9 & 42.9 & 43.3 & 43.2 & 44.1 & 44.2 & 43.4 \\
\hline $\begin{array}{l}\text { Religious } \\
\% \text { Social \& }\end{array}$ & 6.9 & 8.7 & 8.5 & 7.0 & 9.1 & 9.0 & 9.0 & 8.7 & 8.9 & 10.5 & 13.0 & 9.6 & 9.6 & 10.1 & 9.6 & 10.9 & 5.4 \\
\hline Recreational & 29.6 & 24.1 & 26.0 & 28.7 & 26.5 & 28.5 & 27.2 & 29.5 & 28.9 & 27.4 & 24.1 & 27.7 & 25.3 & 26.8 & 27.3 & 25.8 & 32.4 \\
\hline$\%$ Other & 1.7 & 0.7 & 0.7 & 0.6 & 0.6 & 0.2 & 0.7 & 0.8 & 0.3 & 0.6 & 0.8 & 0.7 & 1.8 & 0.7 & 1.4 & 1.2 & 1.7 \\
\hline$\%$ Unreported & 1.3 & 0.6 & 1.3 & 0.9 & 0.6 & 0.8 & 1.2 & 0.8 & 0.8 & 0.8 & 1.1 & 1.0 & 0.7 & 0.9 & 1.0 & 1.0 & 1.1 \\
\hline \multicolumn{18}{|c|}{ Average Vehicle Occupancy ${ }^{c}$} \\
\hline & 1.61 & 1.48 & 1.76 & 1.51 & 1.55 & 1.59 & 1.62 & 1.78 & 1.54 & 1.83 & 1.51 & 1.60 & 1.51 & 1.59 & 1.92 & 1.83 & 2.25 \\
\hline
\end{tabular}

\footnotetext{
${ }^{a}$ All percentages may not add to $100 \%$ due to rounding.

${ }^{\mathrm{b}}$ Average trip length is calculated using only those records with trip mileage information present.

${ }^{c}$ Average Vehicle Occupancy $=$ Person miles (by Privately Owned Vehicles only) per vehicle mile.
} 
Table 6.6 Personal Travel Statistics New York State Metro Areas by MSA Size in 2001 ${ }^{\text {a }}$

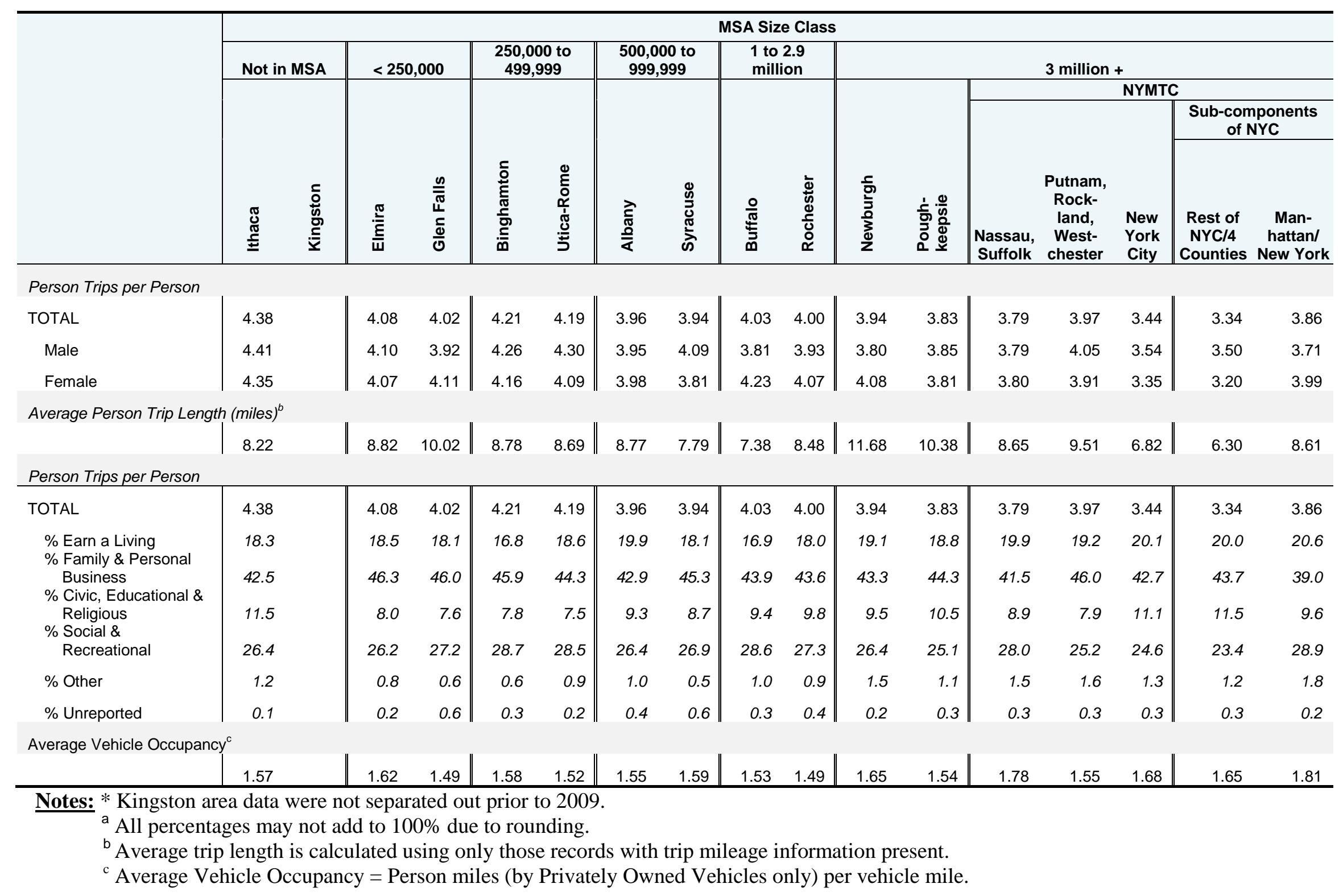


Table 6.7 Personal Travel Statistics New York State Metro Areas by MSA Size in 1995 $^{\mathrm{a}}$

\begin{tabular}{|c|c|c|c|c|c|c|c|c|c|c|c|c|c|c|c|c|c|}
\hline & \multicolumn{17}{|c|}{ MSA Size Class } \\
\hline & \multirow{4}{*}{\multicolumn{2}{|c|}{ 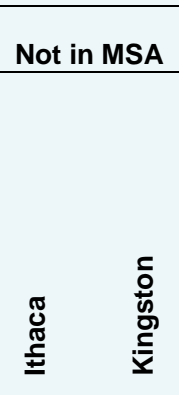 }} & \multicolumn{2}{|c|}{$<250,000$} & \multicolumn{2}{|c|}{$\begin{array}{c}250,000 \text { to } \\
499,999\end{array}$} & \multicolumn{2}{|c|}{$\begin{array}{c}500,000 \text { to } \\
999,999\end{array}$} & \multicolumn{2}{|c|}{$\begin{array}{l}1 \text { to } 2.9 \\
\text { million }\end{array}$} & \multicolumn{7}{|c|}{3 million +} \\
\hline & & & \multirow[b]{3}{*}{$\frac{\stackrel{\varpi}{\underline{E}}}{\bar{\Psi}}$} & \multirow[b]{3}{*}{$\begin{array}{l}\frac{0}{\bar{N}} \\
\stackrel{\leftarrow}{\sigma} \\
\frac{c}{\sigma}\end{array}$} & \multirow[b]{3}{*}{ 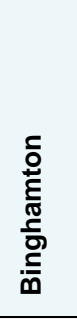 } & \multirow[b]{3}{*}{ 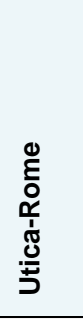 } & \multirow[b]{3}{*}{$\begin{array}{l}\stackrel{\lambda}{\frac{\pi}{\pi}} \\
\frac{0}{\bar{l}}\end{array}$} & \multirow[b]{3}{*}{ 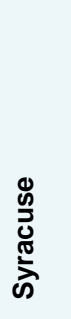 } & \multirow[b]{3}{*}{$\begin{array}{l}\frac{0}{\pi} \\
\frac{\pi}{5} \\
\overline{0}\end{array}$} & \multirow[b]{3}{*}{ 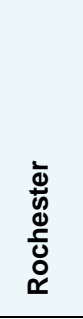 } & \multirow[b]{3}{*}{ 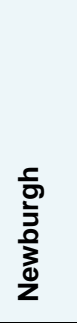 } & \multirow[b]{3}{*}{ 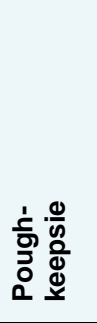 } & \multirow{3}{*}{\multicolumn{2}{|c|}{$\begin{array}{c}\text { Putnam, } \\
\text { Rock- } \\
\text { land, } \\
\text {, West- } \\
\text { k chester } \\
\end{array}$}} & \multicolumn{3}{|c|}{ NYMTC } \\
\hline & & & & & & & & & & & & & & & & $\begin{array}{r}\text { Sub-com } \\
\text { of } N \\
\end{array}$ & $\begin{array}{l}\text { nponents } \\
\text { NYC } \\
\end{array}$ \\
\hline & & & & & & & & & & & & & & & $\begin{array}{l}\text { New } \\
\text { York } \\
\text { City }\end{array}$ & $\begin{array}{c}\text { Rest of } \\
\text { NYC/4 } \\
\text { Counties }\end{array}$ & $\begin{array}{c}\text { Man- } \\
\text { hattan/ } \\
\text { New York }\end{array}$ \\
\hline \multicolumn{18}{|l|}{ Person Trips per Person } \\
\hline TOTAL & 4.38 & & 4.33 & 4.45 & 4.30 & 4.24 & 4.13 & 4.24 & 4.17 & 4.25 & 3.73 & 3.94 & 4.12 & 3.86 & 3.58 & 3.53 & 3.78 \\
\hline Male & 4.34 & & 4.40 & 4.42 & 4.40 & 4.37 & 4.18 & 4.32 & 4.25 & 4.26 & 3.66 & 4.01 & 4.18 & 3.76 & 3.63 & 3.56 & 3.91 \\
\hline Female & 4.41 & & 4.27 & 4.47 & 4.20 & 4.12 & 4.07 & 4.16 & 4.09 & 4.25 & 3.80 & 3.86 & 4.07 & 3.95 & 3.54 & 3.50 & 3.66 \\
\hline \multicolumn{18}{|c|}{ Average Person Trip Length (miles) ${ }^{b}$} \\
\hline & 7.24 & & 9.23 & 8.28 & 8.11 & 8.41 & 8.30 & 8.67 & 6.94 & 9.08 & 9.39 & 10.41 & 8.33 & 9.70 & 5.74 & 5.95 & 5.04 \\
\hline \multicolumn{18}{|l|}{ Person Trips per Person } \\
\hline TOTAL & 4.38 & & 4.33 & 4.45 & 4.30 & 4.24 & 4.13 & 4.24 & 4.17 & 4.25 & 3.73 & 3.94 & 4.12 & 3.86 & 3.58 & 3.53 & 3.78 \\
\hline $\begin{array}{l}\text { \% Earn a Living } \\
\% \text { Family \& Personal }\end{array}$ & 19.6 & & 17.8 & 21.6 & 17.0 & 20.3 & 19.7 & 20.5 & 19.2 & 20.2 & 23.1 & 21.4 & 18.7 & 23.3 & 19.6 & 19.0 & 21.2 \\
\hline $\begin{array}{l}\text { Business } \\
\% \text { Civic, Educational \& }\end{array}$ & 44.5 & & 49.0 & 44.8 & 46.7 & 46.0 & 45.5 & 47.5 & 47.4 & 46.0 & 45.3 & 47.8 & 47.6 & 41.3 & 45.8 & 46.9 & 42.4 \\
\hline $\begin{array}{l}\text { Religious } \\
\% \text { Social \& }\end{array}$ & 11.4 & & 7.9 & 9.5 & 9.1 & 8.7 & 7.5 & 7.5 & 7.2 & 8.0 & 9.1 & 7.6 & 9.0 & 9.3 & 10.6 & 11.4 & 7.4 \\
\hline Recreational & 24.2 & & 24.9 & 23.9 & 27.2 & 25.0 & 27.3 & 24.2 & 26.2 & 25.8 & 22.3 & 22.9 & 24.5 & 25.8 & 24.0 & 22.7 & 28.9 \\
\hline$\%$ Other & 0.2 & & 0.5 & 0.2 & 0.0 & 0.0 & 0.0 & 0.2 & 0.0 & 0.0 & 0.3 & 0.3 & 0.2 & 0.3 & 0.0 & 0.0 & 0.0 \\
\hline$\%$ Unreported & & & & & & & & & & & & & & & & & \\
\hline \multicolumn{18}{|c|}{ Average Vehicle Occupancy $^{c}$} \\
\hline & 1.44 & & 1.54 & 1.55 & 1.62 & 1.53 & 1.52 & 1.69 & 1.50 & 1.67 & 1.37 & 1.43 & 1.58 & 1.60 & 1.79 & 1.79 & 1.81 \\
\hline
\end{tabular}

Notes: * Kingston area data were not separated out prior to 2009.

a All percentages may not add to $100 \%$ due to rounding.

${ }^{\mathrm{b}}$ Average trip length is calculated using only those records with trip mileage information present.

${ }^{\mathrm{c}}$ Average Vehicle Occupancy $=$ Person miles (by Privately Owned Vehicles only) per vehicle mile. 


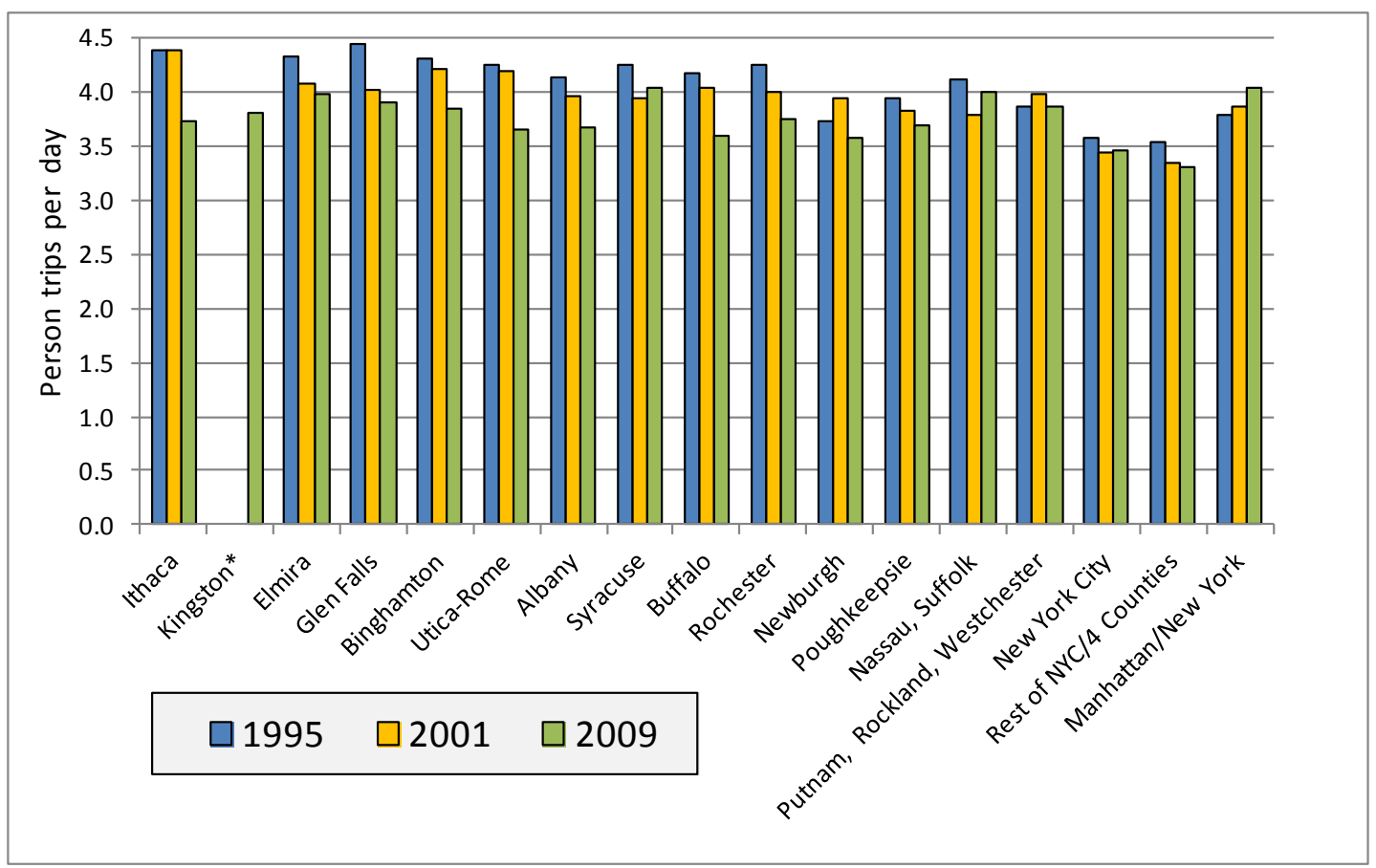

Figure 6.5 Average Daily Person Trips in New York Metro Areas in 1995, 2001, and 2009.

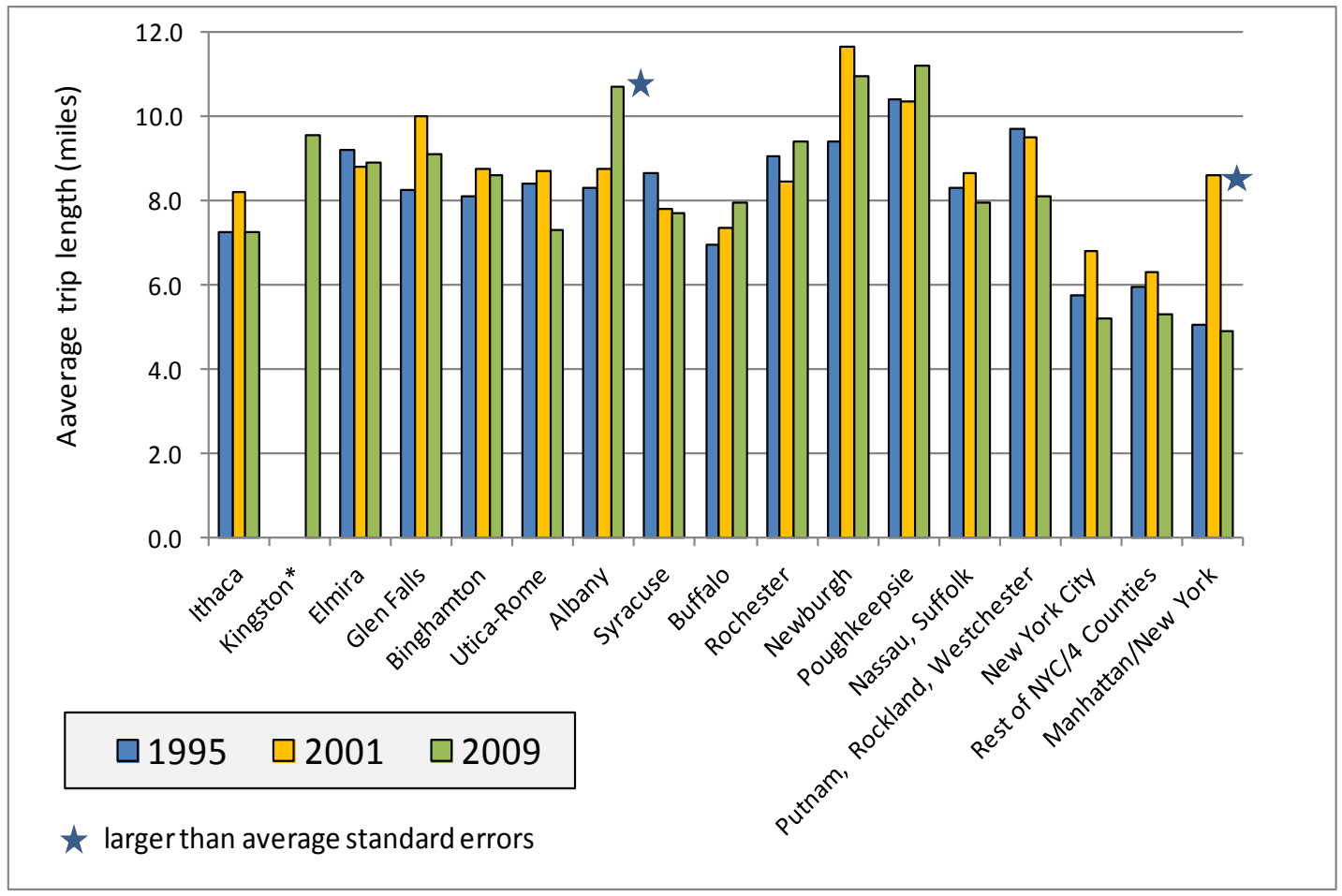

Figure 6.6 Average Person Trip Distances in New York Metro Areas in 1995, 2001, and 2009. 


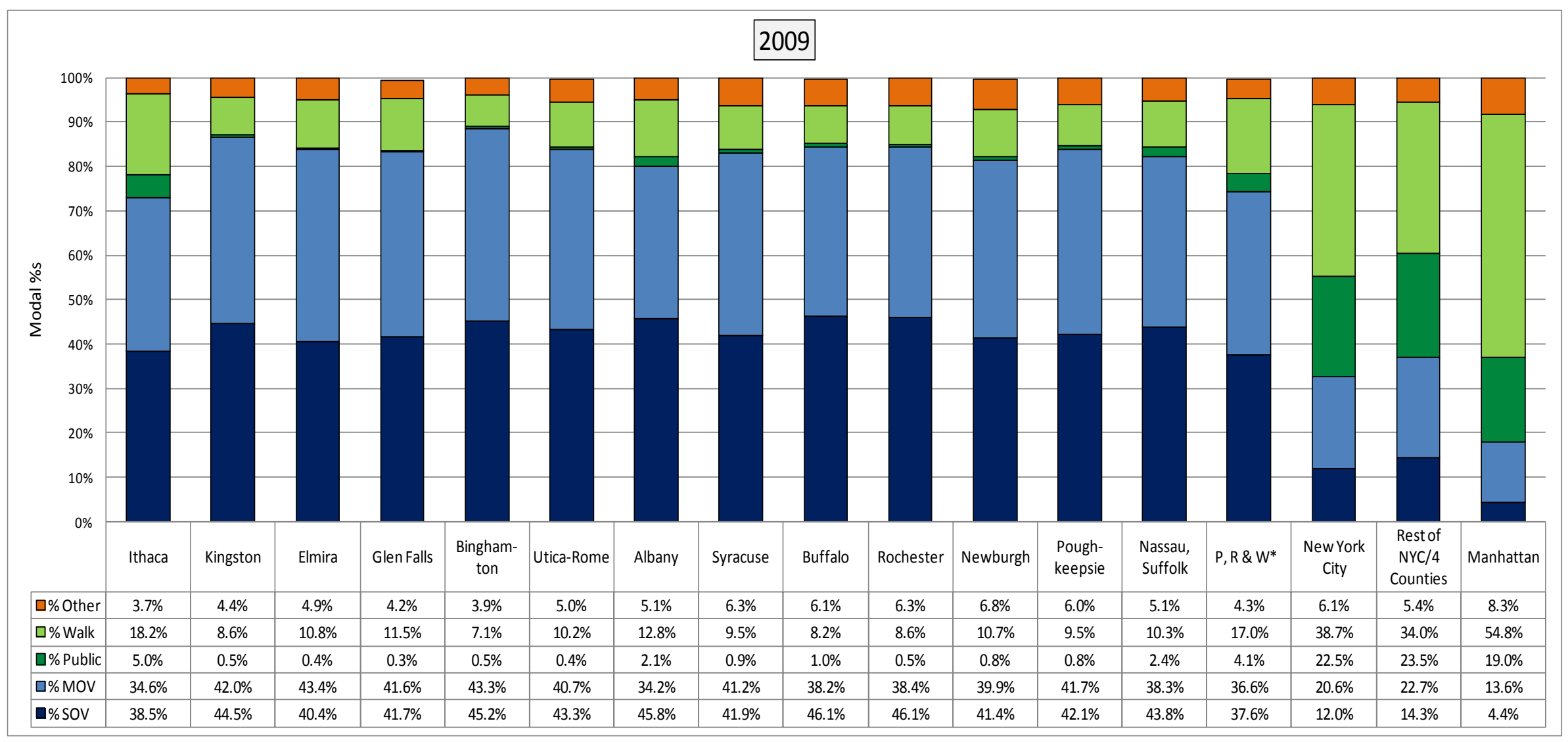

Figure 6.7 Daily Person Trips by Selected Modes: New York State Metro Areas in 2009.

Notes: ${ }^{\%}$ Public $=$ trips by Commuter rail, subway/elevated rail transit, and other public transit, mainly bus. The mode "Other" includes commercial and private air, commuter/school/charter /city to city bus, water, taxi, limousine, airport shuttle, bicycle, Amtrak and other non-specified vehicles. * P, R \& W = Putnam, Rockland and Westchester counties in the NYMYC region. * The Kingston metro area data was not separated out prior to 2009, and was in reported in Rest of State. Source: See Appendix C6. 


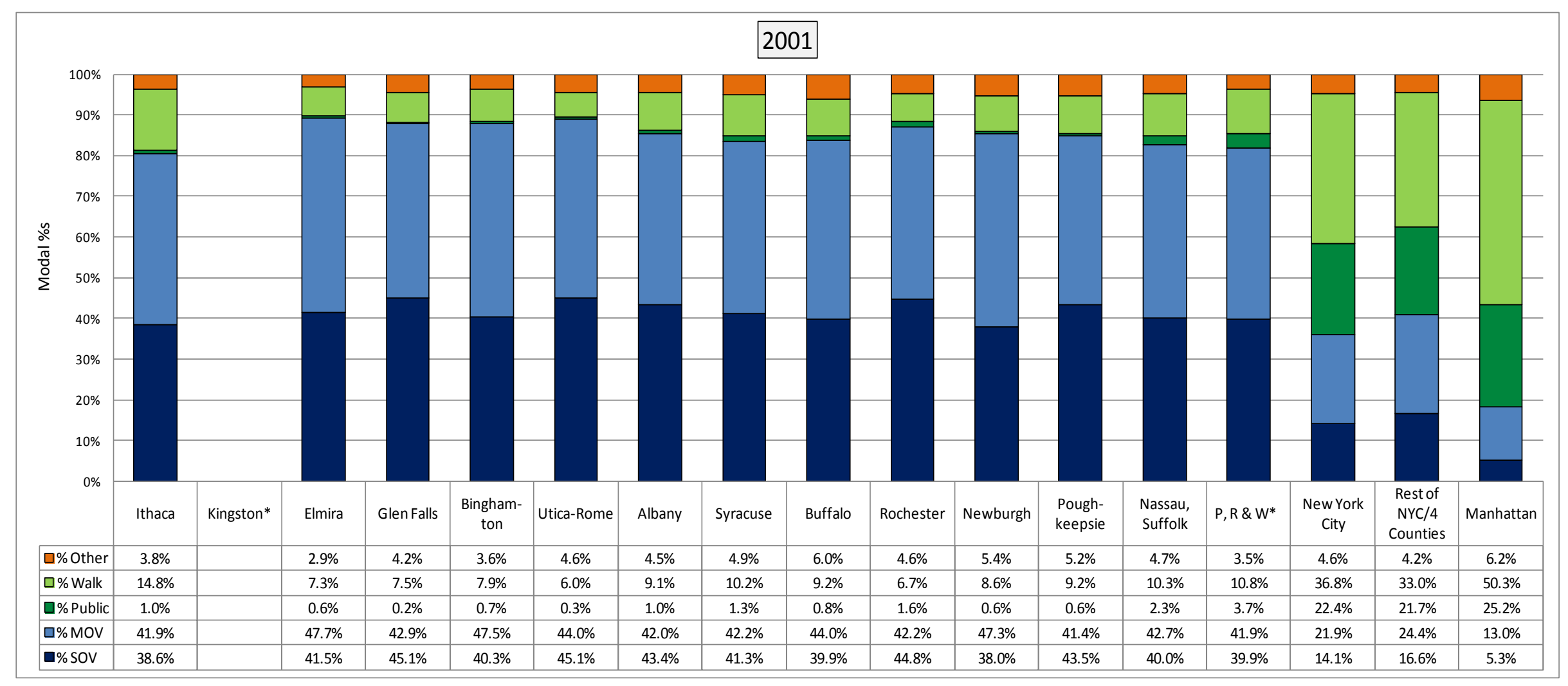

Figure 6.8 Daily Person Trips by Selected Modes: New York State Metro Areas in 2001

Notes: \% Public $=$ trips by Commuter rail, subway/elevated rail transit, and other public transit, mainly bus. The mode "Other" includes commercial and private air, commuter/school/charter/city to city bus, water, taxi, limousine, airport shuttle, bicycle, Amtrak and other non-specified vehicles. * P, R \& W = Putnam, Rockland and Westchester counties in the NYMYC region. * The Kingston metro area data was not separated out prior to 2009, and was in reported in Rest of State. Source: See Appendix C6. 


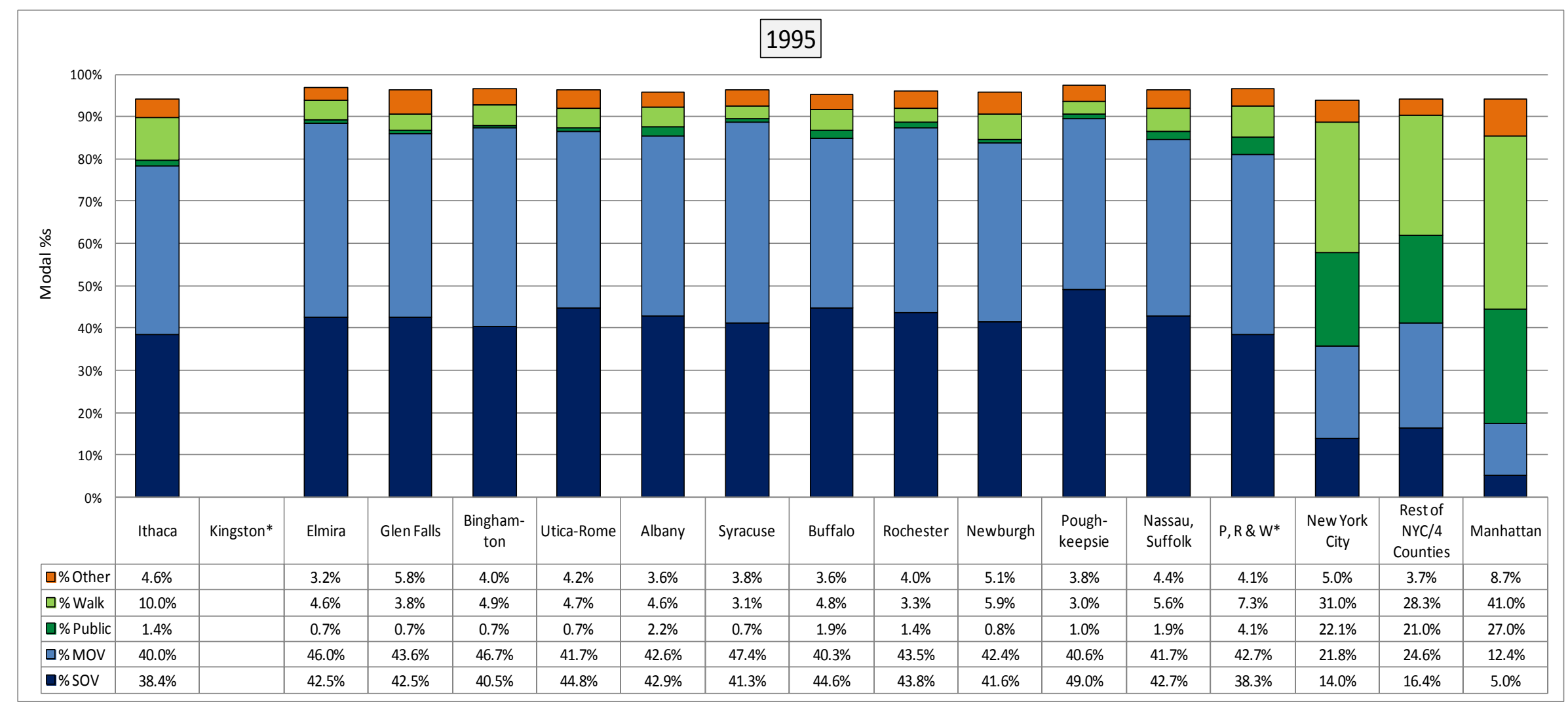

Figure 6.9 Daily Person Trips by Selected Modes: New York State Metro Areas in 1995.

Notes: ${ }^{\text {a }}$ All percentages may not add to $100 \%$ in 1995 due to unreported characteristics. ${ }^{\text {b }}$ Multiple prompts in the 2001 and 2009 surveys for walk trips increased the number of such trips considerably. ${ }^{\mathrm{c}}$ Public $=$ trips by Commuter rail, subway/elevated rail transit, and other public transit, mainly bus. ${ }^{\mathrm{d}}$ The mode "Other" includes commercial and private air, commuter/school/charter/city to city bus, water, taxi, limousine, airport shuttle, bicycle, Amtrak and other non-specified vehicles. * P, R \& W = Putnam, Rockland and Westchester counties in the NYMYC region. * The Kingston metro area data was not separated out prior to 2009, and was in reported in Rest of State. Source: See Appendix C6. 
Another difference between the non-NYC and NYC affiliated metro areas in the state is the roughly even split between single occupant vehicles (SOVs) and multiple occupant vehicles (MOVs) in the non-NYC metro areas, versus a roughly 3 to 2 split in favor of MOVs in NYC, including a better than 2 to 1 split in favor of MOVs over POVs in Manhattan: ratios that have remained stable across all three survey years. In contrast to NYC-affiliated metro areas, the large metro areas of Newburgh, Nassau/Suffolk, Putnam/Rockland/Westchester, and Poughkeepsie display similar modal share patterns to the state's smaller and medium sized metros. The modal shares of the state's most recently designated metro area centered on Kingston are very similar to other non NYC-affiliated metros in the state (Figure 6.6).

\subsubsection{Vehicle Occupancy Rates}

Also shown at the bottom of Tables 6.5, 6.6, and 6.7 are a set of metro area-specific average POV occupancy rates. These rates are defined as dividing the PMT in POVs by the POV VMT within each metro area. Looked at across the set of metro areas, these occupancy rates vary from a low of 1.3 to a high of 1.9 persons per vehicle, with the exception of Manhattan in 2009, where the rate tops out at 2.25 persons per vehicle (Table 6.5). Once the respective standard errors of these means are taken into account, in most cases differences of at least 0.4 persons per vehicle are required to claim a significant statistical difference, either between places or over time.

\subsubsection{Public Transit, Walk and Cycle Trips}

Table 6.8 compares two sets of walk and bike (cycle) statistics for each metro areaover all three NHTS surveys: (1) the percent of respondents who said they did not take a walk or a bike trip in the week prior to the survey day, and (2) the average minutes spent walking or biking per person per day. While 5 out of 6 residents of NYC report taking at least one walk trip in the past week, this ratio is down to $60-75 \%$ in the state's small and medium-sized metro areas. NYC residents walked an average of 20 minutes per day in 2009, compared to averages of around 5 minutes per day in most other metro areas, with the Ithaca, and also the Putnam/Rockland/ Westchester metro region falling somewhere in between these extremes, at close to 10 minutes per day. (It should be noted here that these daily per person averages include both those respondents who did and who did not report walking or biking as part of the NHTS surveys). An area-by-area comparison for 2001 produces very similar findings: although some metro area statistics increase while others decrease. Less than one in ten persons reported taking a bike trip in 2001, and while this ratio of those taking bike trips rose a little in 2009, all metro areas report less than $20 \%$ of persons using a bicycle at least once in the past week. Average minutes spent on a bike per person per day varies across metro areas and time periods, between less than 0.3 minutes per day up to 1.3 minutes per day in 2009 , but with no clear regional pattern once the standard errors on these means are accounted for. 
Table 6.8 Walking and Biking Trip Activity in NYS Metro Areas in 1995, 2001, and 2009

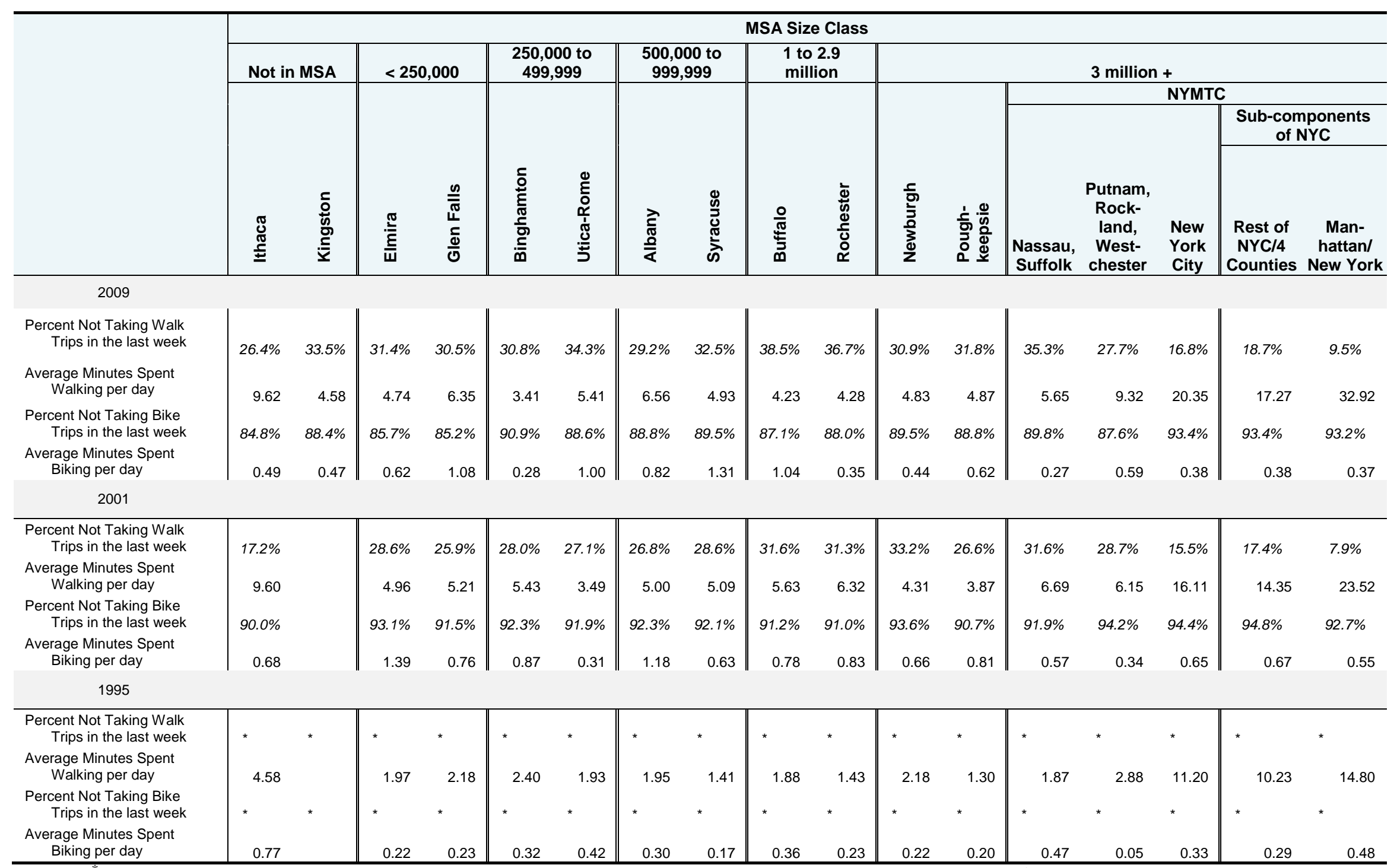

Notes: "Walk and bike trip questions were not asked of persons under 16 years old in 2001, or at all in $1995 .{ }^{a}$ The Kingston metro area data was not separated out prior to 2009 . 


\subsubsection{Travel by Zero-Vehicle Households}

As noted earlier, there is a definite difference between NYC-affiliated metros, where around 1 in 2 households have consistently reported owning no vehicles in 2009, versus other metro areas in the state, where zero-vehicle households represent between $5 \%$ and $13 \%$ of all households (Table 6.2). When examining the characteristics of these metro area-based, such as zero-vehicle household travel activities, it should be noted that comparisons are sometimes limited by small sample size. Although 1,501 households without a vehicle were successfully interviewed overall, with 912 of these in the NYMTC area, only 21, 28, and 29 such households were interviewed in Glens Falls, Poughkeepsie, and Kingston, respectively (Table 6.9). This disparity in sample sizes makes comparisons among MPOs less reliable. With this in mind, the rest of this section considers the area-specific travel characteristics of these zero-vehicle households.

\section{Table 6.9 Number of New York Households with Completed Interviews in 2009 NHTS, by Number of Vehicles}

\begin{tabular}{lccc}
\hline \multicolumn{1}{c}{ NYS Metro Area } & $\begin{array}{c}\text { Zero- } \\
\text { Vehicle } \\
\text { Households }\end{array}$ & $\begin{array}{c}\text { Non-Zero } \\
\text { Vehicle } \\
\text { Households }\end{array}$ & $\begin{array}{c}\text { All } \\
\text { Households }\end{array}$ \\
\hline Ithaca & 45 & 707 & 752 \\
Kingston & 29 & 712 & 741 \\
Elmira & 43 & 680 & 723 \\
Glen Falls & 21 & 489 & 510 \\
Binghamton & 37 & 596 & 633 \\
Utica-Rome & 54 & 669 & 723 \\
Albany & 81 & 1,453 & 1,534 \\
Syracuse & 34 & 706 & 740 \\
Buffalo & 36 & 629 & 665 \\
Rochester & 35 & 641 & 676 \\
Newburgh & 41 & 716 & 757 \\
Poughkeepsie & 28 & 756 & 784 \\
Nassau, Suffolk & 31 & 826 & 857 \\
New York City & 775 & 1,271 & 2,046 \\
Putnam, Rockland, & 106 & 1,785 & 1,891 \\
Westchester & 105 & 2,028 & 2,133 \\
Remainder of State & 1,501 & 14,664 & 16,165 \\
\hline Total for New York State & & & \\
\hline
\end{tabular}


Tables $6.10,6.11$ and 6.12 contain a number of travel statistics for zero-vehicle households in NYS metro areas, for survey years 2009, 2001 and 1995 respectively. As shown in Figures 6.10 and 6.11 the average number of trips and the average number of miles traveled per day (PMT) by people without a vehicle appear to vary considerably, across metro areas, both within and between MSA size classes, and also across the three survey years. However, large standard errors on many of these metro area-specific statistics make it difficult to pull out temporal or any other consistent trends in the data, other than a very general tendency towards higher trip frequencies among zero-vehicle households located in NYC. For further details on the standard errors associated with the averages reported in Table 6.10 and 6.11, the reader is directed to Appendix C.6 of this report. No standard errors were computed for the 1995 survey data.

Similarly, based on results presented in Tables 6.10, 6.11, and 6.12, the modal choices among people in metros who do not own a vehicle do not seem to follow any particular pattern. However, despite some large standard errors on some metro area statistics, there does appear to be some significant differences in the use on non-POV modes within the small and mediumsized metro areas.

As metropolitan size increases, the dependence on private vehicles begins to decline, and walking and public transit modes tend to become more prominent, as per the general household population. Almost half of the residents in NYC probably do not own a vehicle by choice and travel to places primarily by walking or by public transit (Table 6.10, 6.11 and 6.12). 


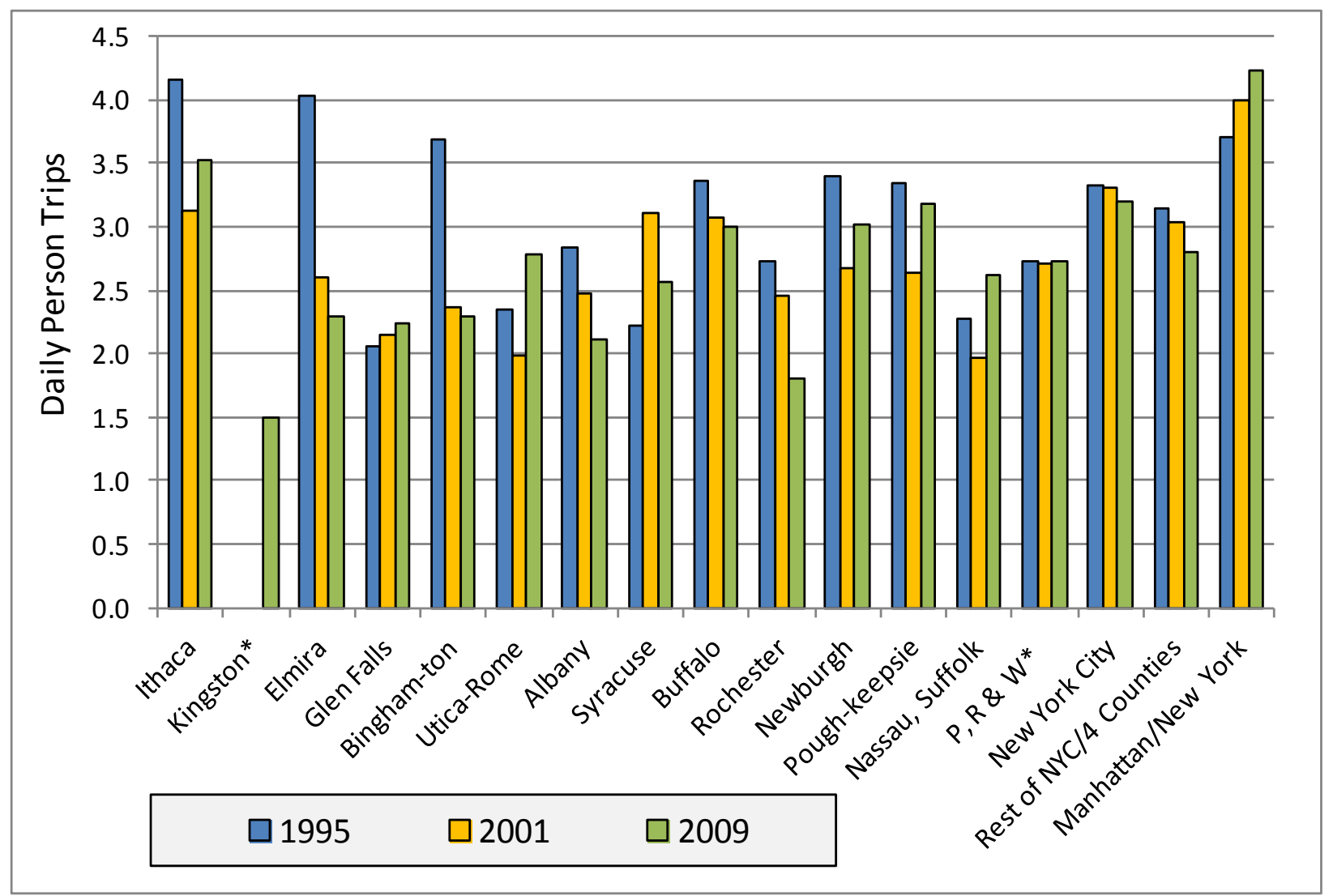

Figure 6.10 Personal Travel Trends of Zero-Vehicle Households in New York Metro Areas: Average Daily Person Trips.* 


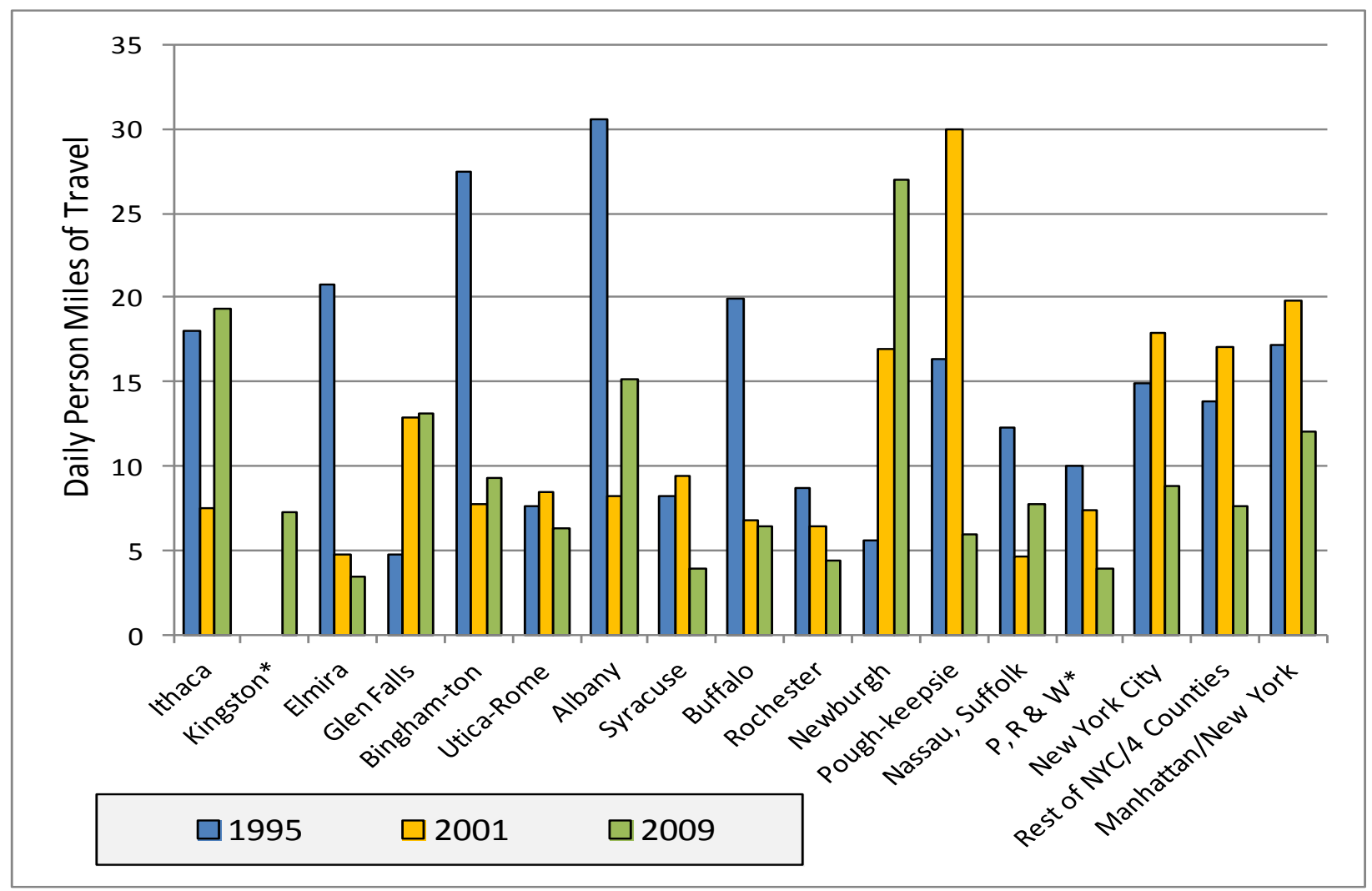

Figure 6.11 Personal Travel Trends of Zero-Vehicle Households in New York Metro Areas: Average Daily PMT.*

Notes: The PT and PMT statistics include a number of metro area/survey year specific results with significant standard errors and should be treated with caution. For details see Appendix C6.

* P,R \& W = Putnam, Rockland, Westchester counties. * The Kingston area data was not separated out prior to 2009. 
Table 6.10 Person Travel for Zero-Vehicle Households by Mode of Transportation New York State Metro Areas by MSA Size in $2009^{\mathrm{a}}$

\begin{tabular}{|c|c|c|c|c|c|c|c|c|c|c|c|c|c|c|c|c|c|}
\hline & \multicolumn{17}{|c|}{ MSA Size Class } \\
\hline & \multicolumn{2}{|c|}{ Not in MSA } & \multicolumn{2}{|c|}{$<250,000$} & \multicolumn{2}{|c|}{$\begin{array}{c}250,000 \text { to } \\
499,999\end{array}$} & \multicolumn{2}{|c|}{$\begin{array}{c}500,000 \text { to } \\
999,999\end{array}$} & \multicolumn{2}{|c|}{$\begin{array}{l}1 \text { to } 2.9 \\
\text { million }\end{array}$} & \multicolumn{7}{|c|}{3 million +} \\
\hline & \multirow[b]{3}{*}{ ֻٓ } & \multirow[b]{3}{*}{ 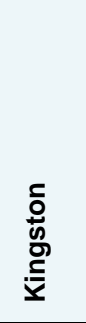 } & \multirow[b]{3}{*}{ 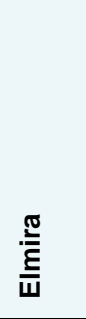 } & \multirow[b]{3}{*}{ 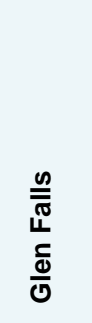 } & \multirow[b]{3}{*}{ 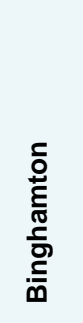 } & \multirow[b]{3}{*}{ 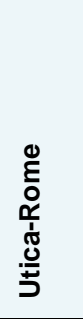 } & \multirow[b]{3}{*}{ 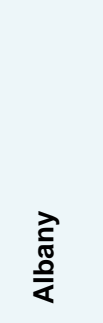 } & \multirow[b]{3}{*}{ 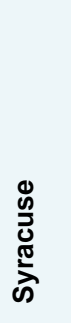 } & \multirow[b]{3}{*}{$\begin{array}{l}\frac{0}{\pi} \\
\frac{\pi}{5} \\
\overline{0}\end{array}$} & \multirow[b]{3}{*}{ 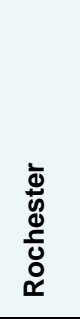 } & \multirow[b]{3}{*}{ 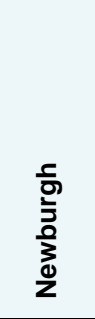 } & \multirow[b]{3}{*}{ 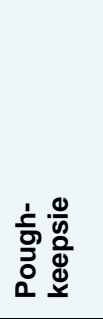 } & \multirow{3}{*}{\multicolumn{2}{|c|}{$\begin{array}{c}\text { Putnam, } \\
\text { Rock- } \\
\text { land, } \\
\text { u, West- } \\
\text { k chester } \\
\end{array}$}} & NYMTC & & \\
\hline & & & & & & & & & & & & & & & \multirow[b]{2}{*}{$\begin{array}{l}\text { New } \\
\text { York } \\
\text { City }\end{array}$} & \multicolumn{2}{|c|}{\begin{tabular}{|c|}
$\begin{array}{c}\text { Sub-components } \\
\text { of NYC }\end{array}$ \\
\end{tabular}} \\
\hline & & & & & & & & & & & & & & & & \begin{tabular}{|l} 
Rest of \\
NYC/4 \\
Counties
\end{tabular} & $\begin{array}{c}\text { Man- } \\
\text { hattan/ } \\
\text { New York }\end{array}$ \\
\hline \multicolumn{18}{|c|}{ Person Trips per Person } \\
\hline TOTAL & 3.53 & 1.49 & 2.30 & 2.24 & 2.29 & 2.79 & 2.12 & 2.57 & 3.00 & 1.80 & 3.03 & 3.18 & 2.61 & 2.72 & 3.20 & 2.81 & 4.24 \\
\hline$\%$ Private Vehicle & 12.1 & 27.1 & 16.2 & 52.5 & 26.3 & 20.5 & 21.8 & 9.9 & 28.1 & 34.5 & 13.3 & 32.5 & 18.1 & 17.5 & 7.4 & 7.9 & 6.5 \\
\hline$\%$ Public Transit & 27.2 & 16.5 & 9.1 & 1.5 & 14.7 & 11.2 & 32.4 & 16.2 & 17.1 & 12.6 & 5.3 & 9.2 & 29.1 & 23.5 & 32.5 & 37.5 & 23.7 \\
\hline \% Walk & 55.3 & 40.5 & 65.0 & 39.4 & 29.5 & 38.4 & 37.1 & 43.0 & 29.6 & 34.3 & 61.2 & 48.9 & 40.0 & 50.0 & 52.7 & 47.6 & 61.5 \\
\hline$\%$ Other & 5.2 & 15.9 & 9.6 & 6.6 & 29.5 & 24.0 & 8.8 & 25.3 & 25.2 & 18.7 & 20.2 & 9.4 & 9.2 & 8.9 & 7.3 & 6.8 & 8.3 \\
\hline$\%$ Unreported & 0.2 & & & & & 6.0 & & 5.5 & & & & & 3.7 & & 0.1 & 0.2 & \\
\hline \multicolumn{18}{|l|}{ PMT per Person } \\
\hline TOTAL & 19.29 & 7.24 & 3.48 & 13.18 & 9.33 & 6.34 & 15.20 & 3.92 & 6.47 & 4.39 & 27.00 & 5.92 & 7.73 & 3.98 & 8.88 & 7.66 & 12.08 \\
\hline$\%$ Private Vehicle & 54.6 & 66.9 & 35.2 & 90.5 & 59.6 & 28.3 & 38.5 & 22.6 & 35.2 & 76.3 & 42.1 & 54.7 & 26.7 & 21.7 & 20.1 & 15.8 & 27.2 \\
\hline$\%$ Public Transit & 36.6 & 10.7 & 14.6 & 2.1 & 17.6 & 24.4 & 55.5 & 32.1 & 25.6 & 9.2 & 41.6 & 18.7 & 40.0 & 44.7 & 55.7 & 60.1 & 48.2 \\
\hline \% Walk & 6.7 & 14.5 & 20.1 & 3.4 & 2.1 & 16.2 & 5.1 & 17.2 & 6.7 & 6.8 & 3.5 & 18.7 & 6.8 & 16.4 & 13.3 & 11.5 & 16.4 \\
\hline$\%$ Other & 1.8 & 7.9 & 30.1 & 4.0 & 20.8 & 21.1 & 0.9 & 16.2 & 32.6 & 7.6 & 12.9 & 7.9 & 5.9 & 17.3 & 10.9 & 12.5 & 8.2 \\
\hline$\%$ Unreported & 0.3 & & & & & 10.0 & & 12.0 & & & & & 20.6 & & 0.1 & 0.1 & \\
\hline
\end{tabular}

Note: ${ }^{\text {a }}$ All percentages may not add to $100 \%$ due to rounding. 
Table 6.11 Person Travel for Zero-Vehicle Households by Mode of Transportation New York State Metro Areas by MSA Size in $2001^{a}$

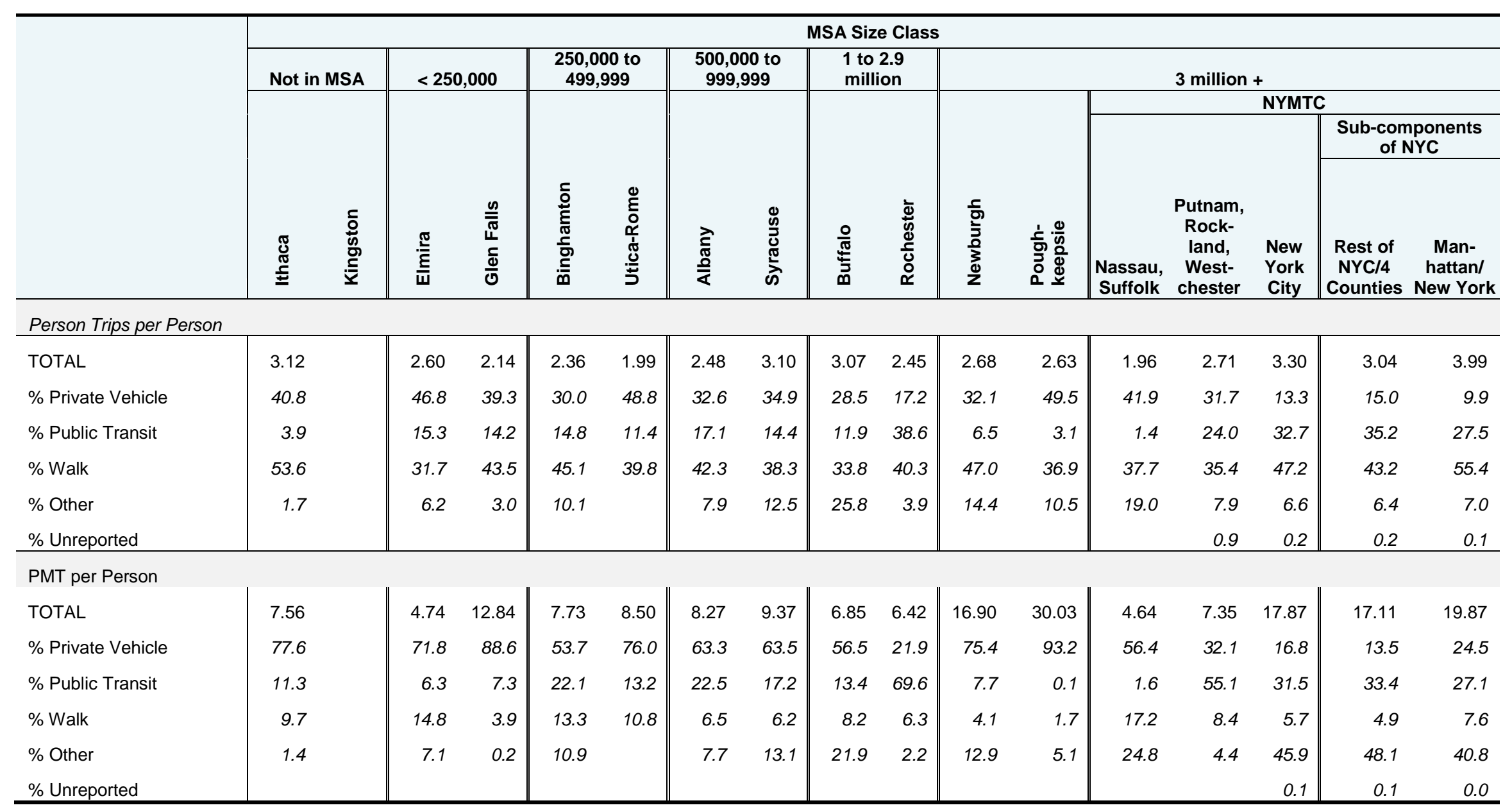

Notes: ${ }^{a}$ All percentages may not add to $100 \%$ due to rounding. * The Kingston area data was not separated out prior to 2009. 
Table 6.12 Person Travel for Zero-Vehicle Households by Mode of Transportation New York State Metro Areas by MSA Size in $1995^{\mathrm{a}}$

\begin{tabular}{|c|c|c|c|c|c|c|c|c|c|c|c|c|c|c|c|c|c|}
\hline & \multicolumn{17}{|c|}{ MSA Size Class } \\
\hline & \multicolumn{2}{|c|}{ Not in MSA } & \multicolumn{2}{|c|}{$<250,000$} & \multicolumn{2}{|c|}{$\begin{array}{c}250,000 \text { to } \\
499,999\end{array}$} & \multicolumn{2}{|c|}{$\begin{array}{c}500,000 \text { to } \\
999,999\end{array}$} & \multicolumn{2}{|c|}{$\begin{array}{l}1 \text { to } 2.9 \\
\text { million } \\
\end{array}$} & \multicolumn{7}{|c|}{3 million + } \\
\hline & \multirow[b]{3}{*}{$\begin{array}{l}\mathbb{8} \\
\stackrel{乛}{E} \\
\end{array}$} & \multirow[b]{3}{*}{ 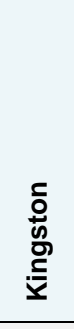 } & \multirow[b]{3}{*}{$\frac{\sqrt{\underline{L}}}{\underline{\underline{E}}}$} & \multirow[b]{3}{*}{$\begin{array}{l}\frac{\infty}{\bar{\sigma}} \\
\stackrel{5}{\sigma} \\
\frac{\Phi}{\sigma}\end{array}$} & \multirow[b]{3}{*}{ 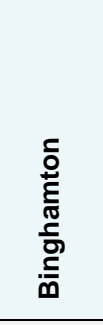 } & \multirow[b]{3}{*}{ 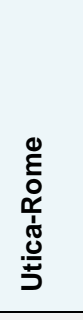 } & \multirow[b]{3}{*}{ 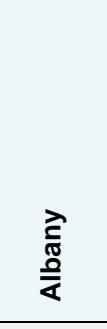 } & \multirow[b]{3}{*}{ 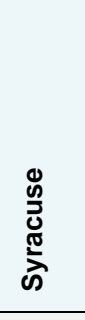 } & \multirow[b]{3}{*}{$\begin{array}{l}\frac{0}{0 \pi} \\
\stackrel{\pi}{5} \\
\bar{n}\end{array}$} & \multirow[b]{3}{*}{ 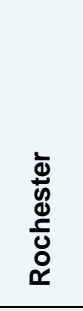 } & \multirow[b]{3}{*}{ 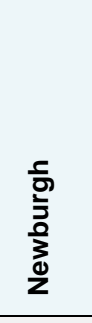 } & \multirow[b]{3}{*}{ 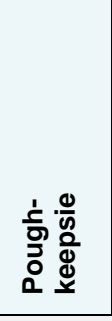 } & \multirow{3}{*}{\multicolumn{2}{|c|}{ 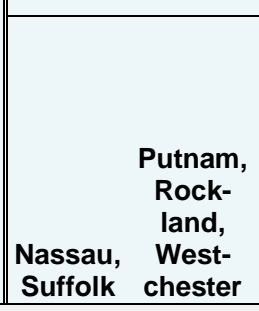 }} & NYMT & & \\
\hline & & & & & & & & & & & & & & & \multirow[b]{2}{*}{$\begin{array}{l}\text { New } \\
\text { York } \\
\text { City }\end{array}$} & \multicolumn{2}{|c|}{\begin{tabular}{|c|}
$\begin{array}{c}\text { Sub-components } \\
\text { of NYC }\end{array}$ \\
\end{tabular}} \\
\hline & & & & & & & & & & & & & & & & \begin{tabular}{||c} 
Rest of \\
NYC/4 \\
Counties \\
\end{tabular} & $\begin{array}{c}\text { Man- } \\
\text { hattan/ } \\
\text { New York }\end{array}$ \\
\hline \multicolumn{18}{|c|}{ Person Trips per Person } \\
\hline TOTAL & 4.16 & & 4.04 & 2.06 & 3.69 & 2.35 & 2.83 & 2.22 & 3.36 & 2.73 & 3.40 & 3.34 & 2.27 & 2.73 & 3.32 & 3.15 & 3.71 \\
\hline$\%$ Private Vehicle & 28.8 & & 57.7 & 32.5 & 43.6 & 36.2 & 48.1 & 52.7 & 40.8 & 35.2 & 26.5 & 52.4 & 37.4 & 21.2 & 11.4 & 13.0 & 8.6 \\
\hline$\%$ Public Transit & 9.4 & & 4.0 & 8.3 & 8.1 & 14.9 & 30.0 & 18.9 & 19.6 & 25.3 & 4.4 & 8.7 & 9.7 & 26.0 & 34.3 & 34.9 & 32.9 \\
\hline$\%$ Walk & 41.1 & & 20.0 & 12.6 & 30.4 & 26.4 & 15.5 & 17.1 & 16.7 & 19.0 & 53.2 & 21.0 & 26.4 & 21.6 & 41.6 & 40.0 & 44.7 \\
\hline$\%$ Other & 10.8 & & 10.4 & 41.3 & 11.4 & 12.8 & 3.5 & 2.3 & 6.5 & 11.0 & 10.6 & 15.9 & 11.5 & 17.6 & 6.3 & 5.1 & 8.1 \\
\hline$\%$ Unreported & 9.9 & & 7.9 & 5.3 & 6.5 & 9.8 & 2.8 & 9.0 & 16.4 & 9.5 & 5.3 & 2.1 & 15.0 & 13.6 & 6.3 & 7.0 & 5.7 \\
\hline \multicolumn{18}{|l|}{ PMT per Person } \\
\hline TOTAL & 18.02 & & 20.83 & 4.71 & 27.42 & 7.66 & 30.53 & 8.28 & 19.97 & 8.71 & 5.57 & 16.32 & 12.25 & 10.06 & 14.86 & 13.86 & 17.21 \\
\hline$\%$ Private Vehicle & 73.5 & & 92.2 & 56.5 & 89.4 & 62.5 & 76.7 & 80.4 & 80.8 & 37.4 & 74.9 & 74.9 & 87.3 & 15.7 & 33.4 & 33.8 & 32.5 \\
\hline$\%$ Public Transit & 15.7 & & 1.7 & 10.2 & 5.0 & 8.6 & 22.0 & 14.4 & 14.2 & 17.3 & 5.6 & 15.7 & 3.8 & 75.8 & 50.2 & 56.9 & 37.5 \\
\hline$\%$ Walk & 4.0 & & 2.1 & 30.8 & 3.6 & 10.4 & 0.6 & 2.2 & 2.4 & 42.6 & 4.7 & 5.1 & 4.8 & 4.9 & 9.8 & 3.0 & 22.5 \\
\hline$\%$ Other & 6.3 & & 2.4 & 1.9 & 1.9 & 5.4 & 0.6 & 2.9 & 2.0 & 2.2 & 14.9 & 4.1 & 3.1 & 3.0 & 5.8 & 5.3 & 6.7 \\
\hline$\%$ Unreported & 0.6 & & 1.7 & 0.6 & 0.1 & 13.1 & 0.1 & 0.1 & 0.7 & 0.5 & 0.0 & 0.1 & 1.0 & 0.6 & 0.9 & 0.9 & 0.9 \\
\hline
\end{tabular}

Notes: ${ }^{a}$ All percentages may not add to $100 \%$ due to rounding. * The Kingston area data was not separated out prior to 2009. 


\subsection{VEHICLE TRAVEL COMPARISONS}

\subsubsection{Driving Frequencies, Distances and Times}

Vehicle travel by residents in NYS metro areas varies more widely than it does for personal travel. In 2009, as shown in Table 6.13, all but one of the state's metro areas outside NYC had average daily vehicle trip frequencies at around 3 trips per day (except Ithaca at 2.4 trips per day), reflecting mostly marginal declines of 0.2 to 0.3 trips per day on the average since 2001, but in a few cases with larger and statistically significant declines between 1995 and 2009. NYC drivers, in contrast, drove an average of only 1.1 vehicle trips per day in 2009 , down from 1.6 trips per day in the two previous surveys, while Manhattan drivers drove less than 1 vehicle trip per day on average in all three survey years (Table 6.13 and Figure 6.12).

Table 6.13 Daily Vehicle Travel Statistics of New York State Metro Area Drivers by MSA Size in 1995, 2001, and 2009

\begin{tabular}{|c|c|c|c|c|c|c|c|c|c|}
\hline \multirow[b]{2}{*}{ MSA Size Class } & \multicolumn{3}{|c|}{ Daily Vehicle Trips per Driver } & \multicolumn{3}{|c|}{ Avg. Trip Length (miles) } & \multicolumn{3}{|c|}{ Daily VMT per Driver } \\
\hline & 2009 & 2001 & 1995 & 2009 & 2001 & 1995 & 2009 & 2001 & 1995 \\
\hline \multicolumn{10}{|l|}{ Not in MSA } \\
\hline Ithaca & 2.35 & 3.25 & 3.07 & 7.53 & 8.30 & 8.51 & 17.62 & 26.51 & 26.05 \\
\hline Kingston & 2.99 & ** & ** & 9.22 & ** & ** & 27.24 & ** & ** \\
\hline \multicolumn{10}{|l|}{$<250,000$} \\
\hline Elmira & 3.12 & 3.36 & 3.78 & 7.58 & 8.91 & 8.66 & 23.59 & 29.91 & 32.67 \\
\hline Glen Falls & 3.04 & 3.24 & 3.94 & 9.02 & 10.04 & 8.08 & 27.01 & 32.34 & 31.70 \\
\hline \multicolumn{10}{|l|}{250,000 to 499,999} \\
\hline Binghamton & 3.20 & 3.41 & 3.54 & 8.66 & 8.73 & 8.03 & 27.62 & 29.07 & 28.32 \\
\hline Utica-Rome & 3.08 & 3.63 & 3.59 & 8.13 & 8.64 & 8.57 & 24.93 & 31.31 & 30.63 \\
\hline \multicolumn{10}{|l|}{500,000 to 999,999} \\
\hline Albany & 2.95 & 3.27 & 3.30 & 9.17 & 8.75 & 7.95 & 26.89 & 28.22 & 26.05 \\
\hline Syracuse & 3.18 & 3.21 & 3.65 & 8.57 & 8.47 & 8.34 & 27.09 & 26.85 & 30.28 \\
\hline \multicolumn{10}{|l|}{1 to 2.9 million } \\
\hline Buffalo & 3.02 & 3.43 & 3.61 & 6.94 & 7.85 & 7.46 & 20.74 & 26.69 & 26.79 \\
\hline Rochester & 3.21 & 3.43 & 3.66 & 9.10 & 8.26 & 8.49 & 28.81 & 28.07 & 30.54 \\
\hline \multicolumn{10}{|l|}{3 million + } \\
\hline Newburgh & 2.97 & 3.32 & 3.14 & 11.98 & 12.08 & 10.79 & 35.07 & 39.93 & 33.68 \\
\hline Poughkeepsie & 2.95 & 3.35 & 3.55 & 11.76 & 9.85 & 10.54 & 34.08 & 32.66 & 37.23 \\
\hline \multicolumn{10}{|l|}{ NYMTC } \\
\hline Nassau, Suffolk & 3.18 & 3.07 & 3.45 & 7.89 & 8.59 & 7.98 & 24.83 & 25.73 & 27.12 \\
\hline Westchester & 2.90 & 3.17 & 3.05 & 8.70 & 9.40 & 9.58 & 24.72 & 29.16 & 28.63 \\
\hline $\begin{array}{l}\text { New York City } \\
\text { - Rest of NYC/4 }\end{array}$ & 1.13 & 1.57 & 1.67 & 7.55 & 7.91 & 8.54 & 8.13 & 11.86 & 13.86 \\
\hline Counties & 1.29 & 1.77 & 1.97 & 6.65 & 7.10 & 8.24 & 8.20 & 12.06 & 15.74 \\
\hline - Manhattan/New York & 0.53 & 0.75 & 0.66 & 15.48 & 15.59 & 11.45 & 7.89 & 11.10 & 7.45 \\
\hline
\end{tabular}

Note: ** Separate statistics were not gathered for the Kingston metro area before the 2009 survey. 

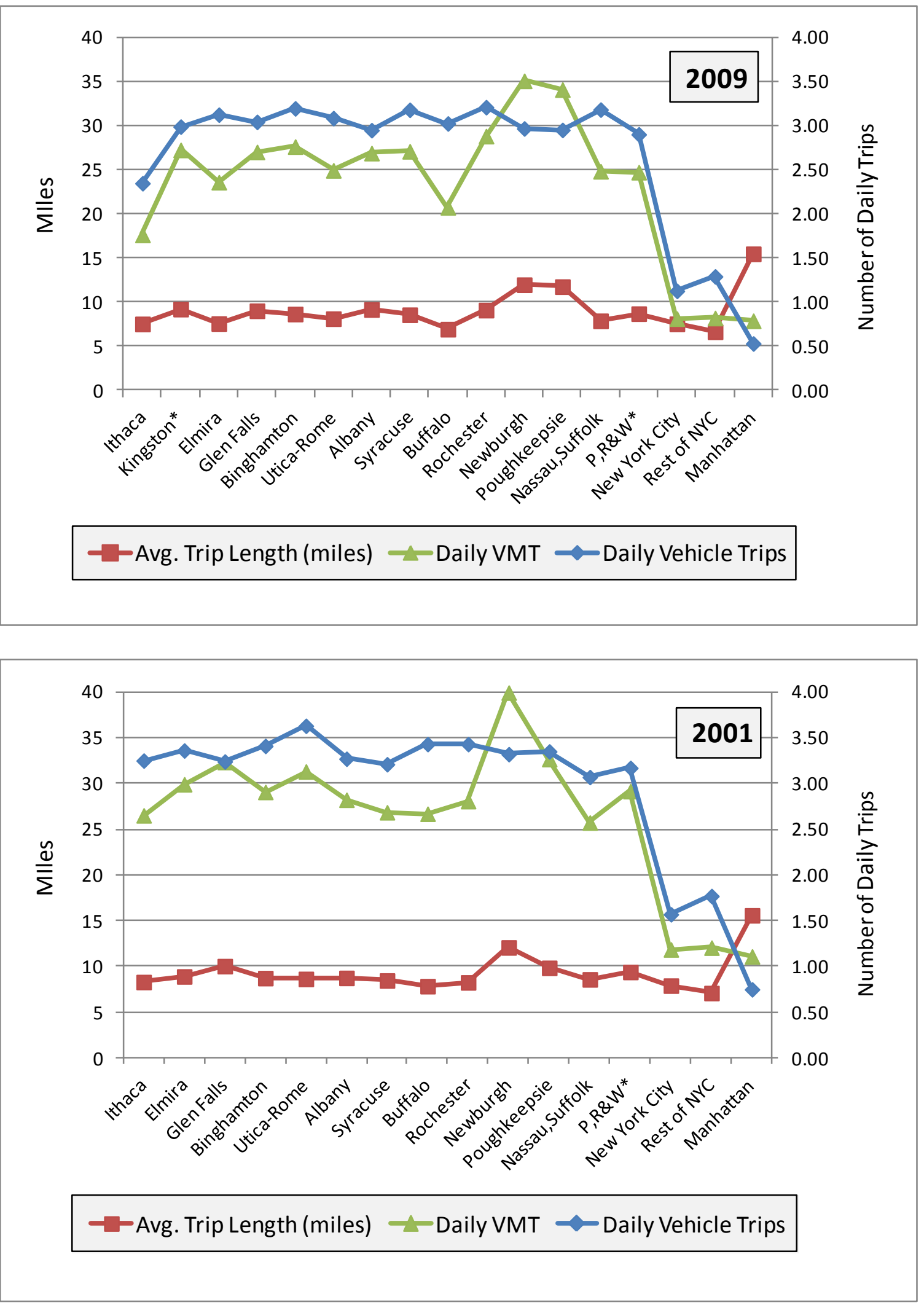
Figure 6.2 continued....

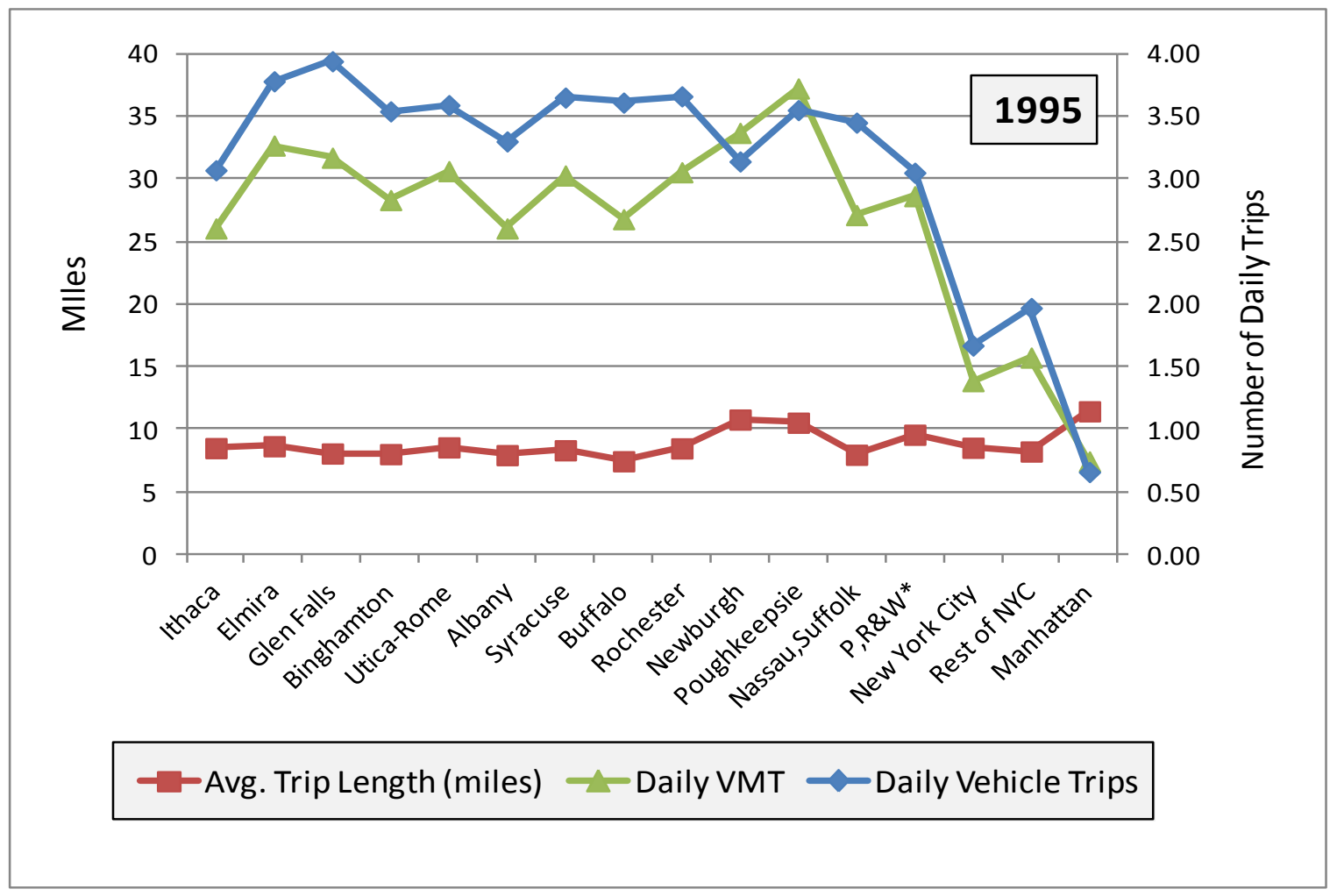

Figure 6.12 Vehicle Travel Statistics by New York State Metro Areas in 1995, 2001, and 2009.

Notes: * P, R \& W = Putnam, Rockland, Westchester counties. *The Kingston metro area was not separated out prior to 2009.

Most metro area specific average trip lengths remained similar to those in 2001, as did average daily VMT per driver for most metros once standard errors in the estimates are taken into account: although Glen Fall, Utica-Rome, and Buffalo daily VMT reductions are significant, as well as the reduction in Ithaca's daily VMT due to the 2001 to 2009 drop in its driving trip frequency. NYC driver VMT also fell between 2001 and 2009 from around 12 down to 8 miles of driving per day. This is around one third of the mileage covered by drivers in other NYS metro areas (Table 6.13 and Figure 6.12). Although Manhattan drivers drove the fewest number of trips and the least daily VMT, their vehicle trips continued to be the longest, on the average, among all metro areas in the state, at 15.5 miles per trip in both 2009 and 2001: more than 5 miles longer than any other metro area, with the exception of Newburgh and Poughkeepsie, both of which averaged just under 12 miles per trip in 2009 (Table 6.13 and Figure 6.12). 
Figure 6.13 shows the relationship between the daily VMT results shown in Figure 6.12 and the average amount of time spent in daily travel, for residents in each NYS metro area. Note that "Average Time Driving" refers here to the average daily time spent driving a POV based only on the responses of persons who reported driving on the sample travel day. Daily driving times vary from over 60 to just over 80 minutes per day in the state's small and medium sized metros, with times around 80 minutes per day in the larger metro areas. This increases to over 100 minutes per day for Manhattan residents in 2001 and 2009, despite their comparatively low daily VMT when compared to other metro areas in the state. Even allowing for much larger standard errors on these Manhattan averages, these travel times indicate the significant impact of urban traffic congestion on private vehicle tripmaking from, to, and/or within Manhattan.

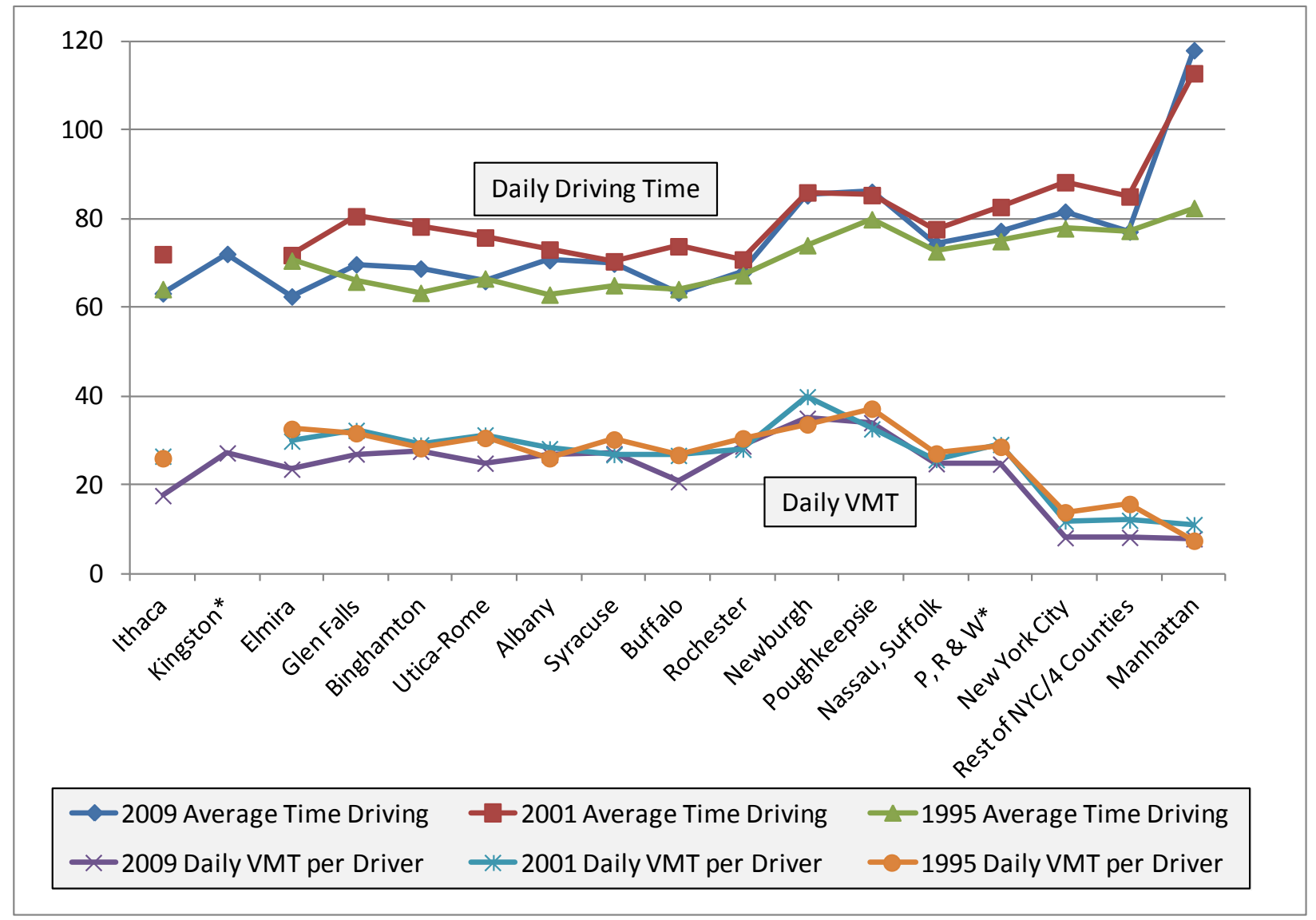

Figure 6.13 Average Time Driving a Private Vehicle and Daily VMT by New York State Metro Areas in 1995, 2001, and 2009

Notes: $* \mathrm{P}, \mathrm{R} \& \mathrm{~W}=$ Putnam, Rockland, Westchester. * The Kingston area data was not separated out prior to 2009. 
Tables 6.14, 6.15 and 6.16 show the distribution of vehicle (POV driver) trips, as well as driver VMT by major trip purpose. Figure 6.14 below shows the distribution of these vehicle trips by trip purpose and by metro area, for all three survey years. The pattern is generally consistent across metro areas. One exception to this is the apparent drop in the percent trips made for the purpose of earning a living in NYC, and notably in Manhattan: where the percentage drops from almost $26 \%$ in 1995 and 2001 to $18 \%$ in 2009 in NYC, and from $27 \%$ in 1995 and 31\% in 2001 down to 13\% in Manhattan. A similar shift did not occur elsewhere, where trips involved in earning a living account for between $20 \%$ and $30 \%$ of trips in the state's other metro areas. Both the 9/11/2001 terrorist attack on NYC and subsequently the economic recession of 2008-9 might have played a role here, but this would require further study.

Also shown in Tables 6.14, 6.15 and 6.16 are daily vehicle trip rates broken down by weekdays versus weekends. All three survey years report higher trip rates on the weekdays, for all metro areas outside NYC. Within NYC, the two rates are closer together, with the average weekend trip rate being higher than the weekday rate in Manhattan in 2009; and where the latter is reported to be a little lower than in previous survey years. 
Table 6.14 Daily Vehicle Travel Statistics for New York State Metro Area Drivers, by Trip Purpose and MSA Size in 2009a

\begin{tabular}{|c|c|c|c|c|c|c|c|c|c|c|c|c|c|c|c|c|c|}
\hline & \multicolumn{17}{|c|}{ MSA Size Class } \\
\hline & \multicolumn{2}{|c|}{ Not in MSA } & \multicolumn{2}{|c|}{$<250,000$} & \multicolumn{2}{|c|}{$\begin{array}{c}250,000 \text { to } \\
499,999\end{array}$} & \multicolumn{2}{|c|}{$\begin{array}{c}500,000 \text { to } \\
999,999\end{array}$} & \multicolumn{2}{|c|}{$\begin{array}{l}1 \text { to } 2.9 \\
\text { million }\end{array}$} & \multicolumn{7}{|c|}{3 million + } \\
\hline & \multirow[b]{3}{*}{ 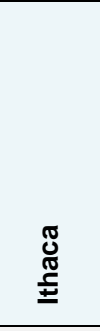 } & \multirow[b]{3}{*}{$\begin{array}{l}\text { 음 } \\
\frac{0}{0} \\
\frac{0}{x}\end{array}$} & \multirow[b]{3}{*}{ 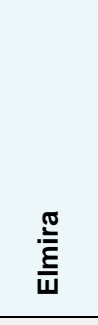 } & \multirow[b]{3}{*}{$\begin{array}{l}\frac{0}{\bar{\sigma}} \\
\stackrel{5}{\frac{\sigma}{\sigma}} \\
\frac{c}{\omega}\end{array}$} & \multirow[b]{3}{*}{ 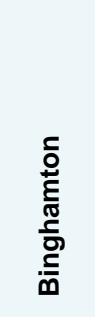 } & \multirow[b]{3}{*}{ 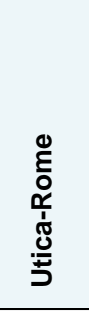 } & \multirow[b]{3}{*}{$\begin{array}{l}\text { 琣 } \\
\frac{0}{\alpha} \\
\frac{0}{\alpha}\end{array}$} & \multirow[b]{3}{*}{ 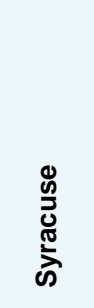 } & \multirow[b]{3}{*}{ 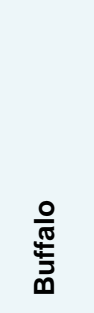 } & \multirow[b]{3}{*}{ 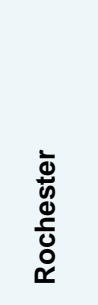 } & \multirow[b]{3}{*}{ 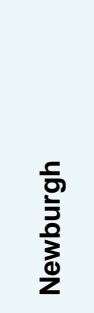 } & \multirow[b]{3}{*}{ 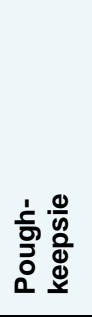 } & \multirow{3}{*}{\multicolumn{2}{|c|}{$\begin{array}{c}\text { Putnam, } \\
\text { Rock- } \\
\text { land, } \\
\text { West- } \\
\text { chester }\end{array}$}} & NYMT & & \\
\hline & & & & & & & & & & & & & & & \multirow[b]{2}{*}{$\begin{array}{l}\text { New } \\
\text { York } \\
\text { City }\end{array}$} & \multicolumn{2}{|c|}{$\begin{array}{l}\text { Sub-components } \\
\text { of NYC }\end{array}$} \\
\hline & & & & & & & & & & & & & & & & $\begin{array}{c}\text { Rest of } \\
\text { NYC/4 } \\
\text { Counties }\end{array}$ & $\begin{array}{c}\text { Man- } \\
\text { hattan/ } \\
\text { New York }\end{array}$ \\
\hline \multicolumn{18}{|c|}{ Daily Vehicle Trips per Driver } \\
\hline TOTAL & 2.35 & 2.99 & 3.12 & 3.04 & 3.20 & 3.08 & 2.95 & 3.18 & 3.02 & 3.21 & 2.97 & 2.95 & 3.18 & 2.90 & 1.13 & 1.29 & 0.53 \\
\hline $\begin{array}{l}\text { \% Earn a Living } \\
\text { \% Family \& Personal }\end{array}$ & $29.2 \%$ & $23.9 \%$ & $24.2 \%$ & $29.2 \%$ & $23.9 \%$ & $24.9 \%$ & $28.4 \%$ & $25.6 \%$ & $27.1 \%$ & $26.5 \%$ & $28.0 \%$ & $23.8 \%$ & $25.4 \%$ & $23.9 \%$ & $18.2 \%$ & $18.7 \%$ & $13.8 \%$ \\
\hline $\begin{array}{l}\text { Business } \\
\% \text { Civic, Educational \& }\end{array}$ & $42.7 \%$ & $52.8 \%$ & $50.9 \%$ & $44.0 \%$ & $48.2 \%$ & $46.7 \%$ & $46.0 \%$ & $46.9 \%$ & $46.6 \%$ & $45.2 \%$ & $48.1 \%$ & $47.7 \%$ & $48.5 \%$ & $49.9 \%$ & $55.5 \%$ & $56.3 \%$ & $47.8 \%$ \\
\hline Religious & $3.6 \%$ & $3.9 \%$ & $4.7 \%$ & $3.0 \%$ & $5.2 \%$ & $5.3 \%$ & $4.9 \%$ & $4.0 \%$ & $4.6 \%$ & $4.4 \%$ & $3.4 \%$ & $4.5 \%$ & $5.0 \%$ & $5.9 \%$ & $3.4 \%$ & $3.8 \%$ & $0.0 \%$ \\
\hline \% Social \& Recreational & $22.1 \%$ & $18.7 \%$ & $19.4 \%$ & $22.7 \%$ & $21.8 \%$ & $22.2 \%$ & $19.5 \%$ & $22.7 \%$ & $21.0 \%$ & $23.2 \%$ & $19.1 \%$ & $22.6 \%$ & $20.0 \%$ & $19.4 \%$ & $21.3 \%$ & $19.5 \%$ & $36.5 \%$ \\
\hline$\%$ Other & $1.0 \%$ & $0.2 \%$ & $0.1 \%$ & $0.3 \%$ & $0.3 \%$ & $0.0 \%$ & $0.2 \%$ & $0.1 \%$ & $0.1 \%$ & $0.1 \%$ & $0.5 \%$ & $0.3 \%$ & $0.6 \%$ & $0.3 \%$ & $0.2 \%$ & $0.2 \%$ & $0.4 \%$ \\
\hline \% Unreported & $1.4 \%$ & $0.5 \%$ & $0.7 \%$ & $0.9 \%$ & $0.6 \%$ & $1.0 \%$ & $1.0 \%$ & $0.8 \%$ & $0.7 \%$ & $0.7 \%$ & $0.8 \%$ & $1.1 \%$ & $0.5 \%$ & $0.6 \%$ & $1.5 \%$ & $1.5 \%$ & $1.6 \%$ \\
\hline TOTAL & 2.35 & 2.99 & 3.12 & 3.04 & 3.20 & 3.08 & 2.95 & 3.18 & 3.02 & 3.21 & 2.97 & 2.95 & 3.18 & 2.90 & 1.13 & 1.29 & 0.53 \\
\hline Weekday & 2.46 & 3.05 & 3.29 & 3.20 & 3.31 & 3.28 & 3.13 & 3.34 & 3.20 & 3.47 & 3.20 & 3.20 & 3.35 & 3.02 & 1.08 & 1.23 & 0.43 \\
\hline Weekend & 1.92 & 2.83 & 2.76 & 2.61 & 2.89 & 2.74 & 2.45 & 2.81 & 2.59 & 2.52 & 2.34 & 2.51 & 2.64 & 2.62 & 1.26 & 1.48 & 0.71 \\
\hline \multicolumn{18}{|l|}{ Daily VMT per Driver } \\
\hline TOTAL & 17.62 & 27.24 & 23.59 & 27.01 & 27.62 & 24.93 & 26.89 & 27.09 & 20.74 & 28.81 & 35.07 & 34.08 & 24.83 & 24.72 & 8.13 & 8.20 & 7.89 \\
\hline $\begin{array}{l}\% \text { Earn a Living } \\
\% \text { Family \& Personal }\end{array}$ & $35.6 \%$ & $34.8 \%$ & $28.1 \%$ & $42.0 \%$ & $31.8 \%$ & $30.4 \%$ & $35.9 \%$ & $33.8 \%$ & $32.7 \%$ & $29.6 \%$ & $44.4 \%$ & $34.1 \%$ & $39.6 \%$ & $37.3 \%$ & $24.1 \%$ & $25.3 \%$ & $19.6 \%$ \\
\hline $\begin{array}{l}\text { Business } \\
\% \text { Civic, Educational \& }\end{array}$ & $31.5 \%$ & $37.3 \%$ & $38.1 \%$ & $31.9 \%$ & $38.8 \%$ & $39.2 \%$ & $31.3 \%$ & $31.3 \%$ & $32.4 \%$ & $30.0 \%$ & $31.8 \%$ & $32.5 \%$ & $34.3 \%$ & $31.3 \%$ & $34.5 \%$ & $36.8 \%$ & $26.1 \%$ \\
\hline Religious & $3.2 \%$ & $3.5 \%$ & $5.3 \%$ & $1.8 \%$ & $4.3 \%$ & $3.5 \%$ & $4.7 \%$ & $3.5 \%$ & $4.5 \%$ & $3.0 \%$ & $2.0 \%$ & $2.8 \%$ & $3.7 \%$ & $4.6 \%$ & $2.3 \%$ & $2.9 \%$ & $0.0 \%$ \\
\hline$\%$ Social \& Recreational & $24.1 \%$ & $22.4 \%$ & $27.1 \%$ & $21.4 \%$ & $22.4 \%$ & $23.8 \%$ & $23.4 \%$ & $30.2 \%$ & $28.9 \%$ & $21.8 \%$ & $20.1 \%$ & $25.5 \%$ & $20.2 \%$ & $24.0 \%$ & $36.8 \%$ & $33.4 \%$ & $50.0 \%$ \\
\hline$\%$ Other & $1.6 \%$ & $0.1 \%$ & $0.1 \%$ & $1.1 \%$ & $0.8 \%$ & $0.0 \%$ & $0.4 \%$ & $0.1 \%$ & $0.2 \%$ & $0.3 \%$ & $0.4 \%$ & $0.7 \%$ & $0.6 \%$ & $0.5 \%$ & $0.4 \%$ & $0.3 \%$ & $0.0 \%$ \\
\hline$\%$ Unreported & $4.0 \%$ & $1.9 \%$ & $1.3 \%$ & $1.9 \%$ & $2.0 \%$ & $3.1 \%$ & $4.4 \%$ & $1.2 \%$ & $1.4 \%$ & $15.2 \%$ & $1.2 \%$ & $4.3 \%$ & $1.5 \%$ & $2.3 \%$ & $1.9 \%$ & $1.4 \%$ & $0.4 \%$ \\
\hline
\end{tabular}

Note: ${ }^{a}$ All percentages may not add to $100 \%$ due to rounding. 
Table 6.15 Daily Vehicle Travel Statistics for New York State Metro Area Drivers, by Trip Purpose and MSA Size in 2001

\begin{tabular}{|c|c|c|c|c|c|c|c|c|c|c|c|c|c|c|c|c|c|}
\hline & \multicolumn{17}{|c|}{ MSA Size Class } \\
\hline & \multirow[b]{4}{*}{ 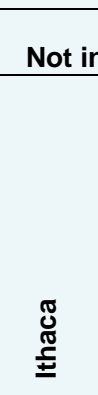 } & \multirow[b]{4}{*}{ 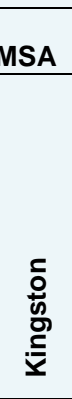 } & \multicolumn{2}{|c|}{$<250,000$} & \multicolumn{2}{|c|}{$\begin{array}{c}250,000 \text { to } \\
499,999\end{array}$} & \multicolumn{2}{|c|}{$\begin{array}{l}500,000 \text { to } \\
999,999\end{array}$} & \multicolumn{2}{|c|}{$\begin{array}{l}1 \text { to } 2.9 \\
\text { million }\end{array}$} & \multicolumn{7}{|c|}{3 million + } \\
\hline & & & \multirow[b]{3}{*}{$\frac{\stackrel{\pi}{\underline{\underline{E}}}}{\underline{\bar{W}}}$} & \multirow[b]{3}{*}{ 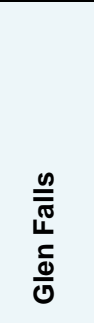 } & \multirow[b]{3}{*}{ 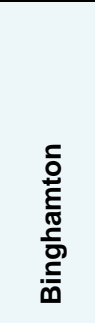 } & \multirow[b]{3}{*}{ 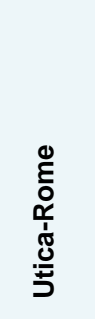 } & \multirow[b]{3}{*}{\begin{tabular}{l} 
\} $\\
{\frac{0}{\pi}} \\
{\frac{0}{4}}$ & \multirow[b]{3}{*}{ 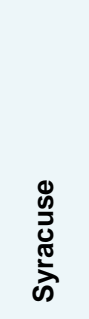 } & \multirow[b]{3}{*}{ 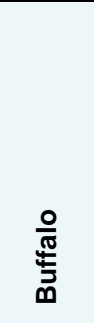 } & \multirow[b]{3}{*}{ 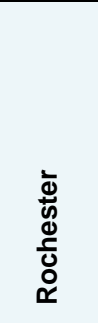 } & \multirow[b]{3}{*}{ 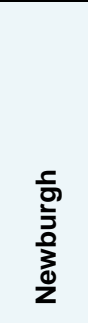 } & \multirow[b]{3}{*}{ 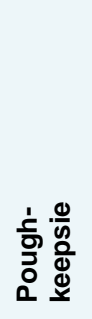 } & \multirow{3}{*}{\multicolumn{2}{|c|}{$\begin{array}{c}\text { Putnam, } \\
\text { Rock- } \\
\text { land, } \\
\text { West- } \\
\text { chester }\end{array}$}} & \multicolumn{3}{|c|}{ NYMTC } \\
\hline & & & & & & & & & & & & & & & & $\begin{array}{r}\text { Sub-com } \\
\text { of } 1\end{array}$ & $\begin{array}{l}\text { nponents } \\
\text { NYC }\end{array}$ \\
\hline & & & & & & & & & & & & & & & $\begin{array}{l}\text { New } \\
\text { York } \\
\text { City }\end{array}$ & \begin{tabular}{|c} 
Rest of \\
NYC $/ 4$ \\
Counties
\end{tabular} & $\begin{array}{c}\text { Man- } \\
\text { hattan/ } \\
\text { New York }\end{array}$ \\
\hline \multicolumn{18}{|c|}{ Daily Vehicle Trips per Driver } \\
\hline TOTAL & 3.25 & & 3.36 & 3.24 & 3.41 & 3.63 & 3.27 & 3.21 & 3.43 & 3.43 & 3.32 & 3.35 & 3.07 & 3.17 & 1.57 & 1.77 & 0.75 \\
\hline $\begin{array}{l}\text { \% Earn a Living } \\
\% \text { Family \& Personal }\end{array}$ & $24.3 \%$ & & $25.7 \%$ & $24.8 \%$ & $23.3 \%$ & $25.7 \%$ & $27.6 \%$ & $23.6 \%$ & $24.4 \%$ & $24.7 \%$ & $27.0 \%$ & $25.8 \%$ & $25.7 \%$ & $24.0 \%$ & $25.6 \%$ & $25.1 \%$ & $30.6 \%$ \\
\hline $\begin{array}{l}\text { Business } \\
\% \text { Civic, Educational \& }\end{array}$ & $47.9 \%$ & & $48.9 \%$ & $50.9 \%$ & $51.4 \%$ & $46.4 \%$ & $47.3 \%$ & $51.4 \%$ & $49.3 \%$ & $48.0 \%$ & $50.8 \%$ & $49.3 \%$ & $46.9 \%$ & $50.7 \%$ & $50.3 \%$ & $51.5 \%$ & $39.8 \%$ \\
\hline Religious & $6.1 \%$ & & $4.1 \%$ & $3.1 \%$ & $3.9 \%$ & $3.6 \%$ & $4.4 \%$ & $4.1 \%$ & $4.7 \%$ & $5.0 \%$ & $3.2 \%$ & $4.6 \%$ & $4.6 \%$ & $3.8 \%$ & $3.8 \%$ & $4.2 \%$ & $0.1 \%$ \\
\hline \% Social \& Recreational & $20.9 \%$ & & $20.8 \%$ & $20.4 \%$ & $21.1 \%$ & $23.6 \%$ & $20.0 \%$ & $20.4 \%$ & $21.2 \%$ & $22.0 \%$ & $18.2 \%$ & $19.5 \%$ & $21.9 \%$ & $20.8 \%$ & $19.1 \%$ & $18.1 \%$ & $28.6 \%$ \\
\hline$\%$ Other & $0.7 \%$ & & $0.3 \%$ & $0.4 \%$ & $0.2 \%$ & $0.6 \%$ & $0.6 \%$ & $0.3 \%$ & $0.5 \%$ & $0.3 \%$ & $0.7 \%$ & $0.7 \%$ & $0.8 \%$ & $0.5 \%$ & $1.0 \%$ & $1.1 \%$ & $0.9 \%$ \\
\hline$\%$ Unreported & $0.1 \%$ & & $0.2 \%$ & $0.4 \%$ & $0.2 \%$ & $0.1 \%$ & $0.2 \%$ & $0.2 \%$ & $0.0 \%$ & $0.0 \%$ & $0.1 \%$ & $0.1 \%$ & $0.2 \%$ & $0.3 \%$ & $0.1 \%$ & $0.1 \%$ & $0.0 \%$ \\
\hline TOTAL & 3.25 & & 3.36 & 3.24 & 3.41 & 3.63 & 3.27 & 3.21 & 3.43 & 3.43 & 3.32 & 3.35 & 3.07 & 3.17 & 1.57 & 1.77 & 0.75 \\
\hline Weekday & 3.55 & & 3.47 & 3.59 & 3.67 & 3.78 & 3.38 & 3.25 & 3.54 & 3.56 & 3.56 & 3.65 & 3.20 & 3.34 & 1.61 & 1.84 & 0.71 \\
\hline Weekend & 2.44 & & 3.07 & 2.42 & 2.71 & 3.29 & 2.91 & 3.09 & 3.15 & 3.03 & 2.76 & 2.52 & 2.76 & 2.80 & 1.47 & 1.62 & 0.85 \\
\hline \multicolumn{18}{|l|}{ Daily VMT per Driver } \\
\hline TOTAL & 26.51 & & 29.91 & 32.34 & 29.07 & 31.31 & 28.22 & 26.85 & 26.69 & 28.07 & 39.93 & 32.66 & 25.73 & 29.16 & 11.86 & 12.06 & 11.10 \\
\hline $\begin{array}{l}\text { \% Earn a Living } \\
\% \text { Family \& Personal }\end{array}$ & $29.2 \%$ & & $29.7 \%$ & $34.0 \%$ & $27.8 \%$ & $40.7 \%$ & $36.4 \%$ & $31.5 \%$ & $31.0 \%$ & $32.3 \%$ & $38.1 \%$ & $38.9 \%$ & $38.2 \%$ & $37.5 \%$ & $34.5 \%$ & $37.0 \%$ & $23.8 \%$ \\
\hline $\begin{array}{l}\text { Business } \\
\% \text { Civic, Educational \& }\end{array}$ & $39.6 \%$ & & $39.3 \%$ & $38.5 \%$ & $47.8 \%$ & $34.5 \%$ & $34.0 \%$ & $31.6 \%$ & $39.4 \%$ & $36.1 \%$ & $34.0 \%$ & $32.7 \%$ & $29.6 \%$ & $31.0 \%$ & $35.8 \%$ & $35.5 \%$ & $37.2 \%$ \\
\hline Religious & $5.9 \%$ & & $3.4 \%$ & $3.8 \%$ & $3.2 \%$ & $2.6 \%$ & $3.6 \%$ & $2.4 \%$ & $3.8 \%$ & $4.6 \%$ & $2.5 \%$ & $4.8 \%$ & $2.8 \%$ & $2.7 \%$ & $3.8 \%$ & $4.7 \%$ & $0.1 \%$ \\
\hline \% Social \& Recreational & $24.5 \%$ & & $26.3 \%$ & $22.4 \%$ & $20.9 \%$ & $20.9 \%$ & $24.5 \%$ & $34.0 \%$ & $25.2 \%$ & $24.8 \%$ & $22.4 \%$ & $22.5 \%$ & $28.9 \%$ & $27.8 \%$ & $25.1 \%$ & $22.0 \%$ & $38.4 \%$ \\
\hline$\%$ Other & $0.5 \%$ & & $0.7 \%$ & $0.8 \%$ & $0.2 \%$ & $1.0 \%$ & $0.9 \%$ & $0.4 \%$ & $0.6 \%$ & $1.0 \%$ & $2.8 \%$ & $1.1 \%$ & $0.5 \%$ & $0.8 \%$ & $0.6 \%$ & $0.6 \%$ & $0.5 \%$ \\
\hline$\%$ Unreported & $0.2 \%$ & & $0.5 \%$ & $0.6 \%$ & $0.1 \%$ & $0.4 \%$ & $0.5 \%$ & $0.1 \%$ & $0.0 \%$ & $1.3 \%$ & $0.2 \%$ & $0.0 \%$ & $0.1 \%$ & $0.2 \%$ & $0.2 \%$ & $0.3 \%$ & $0.0 \%$ \\
\hline
\end{tabular}}
\end{tabular}

Notes: ${ }^{a}$ All percentages may not add to $100 \%$ due to rounding. * The Kingston area data was not separated out prior to 2009. 
Table 6.16 Daily Vehicle Travel Statistics for New York State Metro Area Drivers, by Trip Purpose and MSA Size in 1995

\begin{tabular}{|c|c|c|c|c|c|c|c|c|c|c|c|c|c|c|c|c|c|}
\hline & \multicolumn{17}{|c|}{ MSA Size Class } \\
\hline & \multirow[b]{4}{*}{ 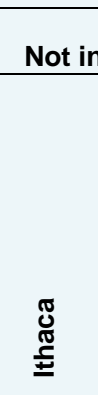 } & \multirow[b]{4}{*}{ 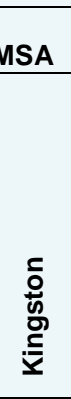 } & \multicolumn{2}{|c|}{$<250,000$} & \multicolumn{2}{|c|}{$\begin{array}{c}250,000 \text { to } \\
499,999\end{array}$} & \multicolumn{2}{|c|}{$\begin{array}{l}500,000 \text { to } \\
999,999\end{array}$} & \multicolumn{2}{|c|}{$\begin{array}{l}1 \text { to } 2.9 \\
\text { million }\end{array}$} & \multicolumn{7}{|c|}{3 million + } \\
\hline & & & \multirow[b]{3}{*}{$\frac{\sqrt[\pi]{\underline{\underline{E}}}}{\frac{\mathrm{E}}{\mathrm{W}}}$} & \multirow[b]{3}{*}{$\begin{array}{l}\frac{0}{\bar{\sigma}} \\
\stackrel{5}{0} \\
\frac{c}{\omega} \\
\end{array}$} & \multirow[b]{3}{*}{ 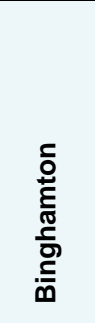 } & \multirow[b]{3}{*}{ 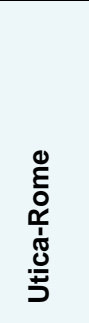 } & \multirow[b]{3}{*}{$\begin{array}{l}\underset{\mathbb{J}}{\frac{J}{\sigma}} \\
\frac{0}{\bar{\sigma}}\end{array}$} & \multirow[b]{3}{*}{ 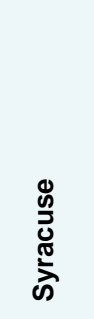 } & \multirow[b]{3}{*}{$\frac{0}{\frac{0}{10}}$} & \multirow[b]{3}{*}{ 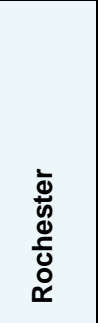 } & \multirow[b]{3}{*}{ 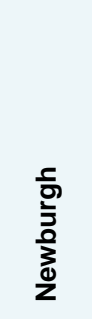 } & \multirow[b]{3}{*}{ 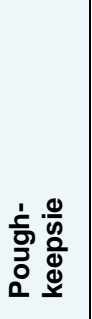 } & \multirow{3}{*}{\multicolumn{2}{|c|}{$\begin{array}{l}\text { Putnam, } \\
\text { Rock- } \\
\text { land, } \\
\text { West- } \\
\text { chester }\end{array}$}} & \multicolumn{3}{|c|}{ NYMTC } \\
\hline & & & & & & & & & & & & & & & & $\begin{array}{r}\text { Sub-com } \\
\text { of } N \\
\end{array}$ & $\begin{array}{l}\text { iponents } \\
\text { VYC }\end{array}$ \\
\hline & & & & & & & & & & & & & & & $\begin{array}{l}\text { New } \\
\text { York } \\
\text { City }\end{array}$ & $\begin{array}{c}\text { Rest of } \\
\text { NYC/4 } \\
\text { Counties }\end{array}$ & $\begin{array}{c}\text { Man- } \\
\text { hattan/ } \\
\text { New York }\end{array}$ \\
\hline \multicolumn{18}{|c|}{ Daily Vehicle Trips per Driver } \\
\hline TOTAL & 3.07 & & 3.78 & 3.94 & 3.54 & 3.59 & 3.30 & 3.65 & 3.61 & 3.66 & 3.14 & 3.55 & 3.45 & 3.05 & 1.67 & 1.97 & 0.66 \\
\hline $\begin{array}{l}\text { \% Earn a Living } \\
\% \text { Family \& Personal }\end{array}$ & $26.0 \%$ & & $25.9 \%$ & $30.5 \%$ & $23.2 \%$ & $27.3 \%$ & $26.6 \%$ & $28.2 \%$ & $26.0 \%$ & $27.7 \%$ & $30.4 \%$ & $26.5 \%$ & $24.1 \%$ & $30.8 \%$ & $25.7 \%$ & $25.4 \%$ & $27.3 \%$ \\
\hline $\begin{array}{l}\text { Business } \\
\% \text { Civic, Educational \& }\end{array}$ & $49.7 \%$ & & $51.6 \%$ & $50.0 \%$ & $51.3 \%$ & $50.1 \%$ & $49.8 \%$ & $49.9 \%$ & $51.2 \%$ & $50.7 \%$ & $51.4 \%$ & $51.8 \%$ & $53.5 \%$ & $47.2 \%$ & $52.7 \%$ & $53.3 \%$ & $45.5 \%$ \\
\hline Religious & $5.8 \%$ & & $3.4 \%$ & $2.5 \%$ & $4.5 \%$ & $3.9 \%$ & $3.9 \%$ & $3.3 \%$ & $2.8 \%$ & $3.3 \%$ & $3.5 \%$ & $3.4 \%$ & $4.1 \%$ & $3.3 \%$ & $4.2 \%$ & $4.6 \%$ & $3.0 \%$ \\
\hline$\%$ Social \& Recreational & $18.5 \%$ & & $18.8 \%$ & $17.0 \%$ & $21.0 \%$ & $18.7 \%$ & $19.3 \%$ & $18.6 \%$ & $19.9 \%$ & $18.4 \%$ & $14.7 \%$ & $18.3 \%$ & $18.3 \%$ & $18.7 \%$ & $17.4 \%$ & $16.8 \%$ & $24.2 \%$ \\
\hline$\%$ Other & $0.0 \%$ & & $0.3 \%$ & $0.0 \%$ & $0.0 \%$ & $0.0 \%$ & $0.3 \%$ & $0.0 \%$ & $0.0 \%$ & $0.0 \%$ & $0.0 \%$ & $0.0 \%$ & $0.0 \%$ & $0.0 \%$ & $0.0 \%$ & $0.0 \%$ & $0.0 \%$ \\
\hline$\%$ Unreported & $0.0 \%$ & & $0.0 \%$ & $0.0 \%$ & $0.0 \%$ & $0.0 \%$ & $0.0 \%$ & $0.0 \%$ & $0.0 \%$ & $0.0 \%$ & $0.0 \%$ & $0.0 \%$ & $0.0 \%$ & $0.0 \%$ & $0.0 \%$ & $0.0 \%$ & $0.0 \%$ \\
\hline TOTAL & 3.07 & & 3.78 & 3.94 & 3.54 & 3.59 & 3.30 & 3.65 & 3.61 & 3.66 & 3.14 & 3.55 & 3.45 & 3.05 & 1.67 & 1.97 & 0.66 \\
\hline Weekday & 3.18 & & 4.13 & 4.19 & 3.75 & 3.82 & 3.40 & 4.01 & 3.73 & 3.90 & 3.44 & 3.61 & 3.56 & 3.22 & 1.63 & 1.95 & 0.65 \\
\hline Weekend & 2.80 & & 2.87 & 3.23 & 3.01 & 2.95 & 3.02 & 2.82 & 3.25 & 3.10 & 2.49 & 3.38 & 3.18 & 2.60 & 1.76 & 2.00 & 0.71 \\
\hline \multicolumn{18}{|l|}{ Daily VMT per Driver } \\
\hline TOTAL & 26.05 & & 32.67 & 31.70 & 28.32 & 30.63 & 26.05 & 30.28 & 26.79 & 30.54 & 33.68 & 37.23 & 27.12 & 28.63 & 13.86 & 15.74 & 7.45 \\
\hline $\begin{array}{l}\text { \% Earn a Living } \\
\text { \% Family \& Personal }\end{array}$ & $35.7 \%$ & & $32.7 \%$ & $42.7 \%$ & $33.2 \%$ & $34.5 \%$ & $38.1 \%$ & $37.4 \%$ & $36.7 \%$ & $29.5 \%$ & $47.4 \%$ & $38.5 \%$ & $39.1 \%$ & $41.6 \%$ & $35.9 \%$ & $34.9 \%$ & $43.5 \%$ \\
\hline $\begin{array}{l}\text { Business } \\
\% \text { Civic, Educational \& }\end{array}$ & $36.7 \%$ & & $37.0 \%$ & $34.8 \%$ & $37.7 \%$ & $39.3 \%$ & $38.3 \%$ & $32.0 \%$ & $35.2 \%$ & $44.7 \%$ & $32.1 \%$ & $32.3 \%$ & $34.1 \%$ & $28.2 \%$ & $31.5 \%$ & $31.8 \%$ & $29.3 \%$ \\
\hline Religious & $3.5 \%$ & & $3.0 \%$ & $3.4 \%$ & $2.9 \%$ & $3.2 \%$ & $2.5 \%$ & $2.5 \%$ & $2.3 \%$ & $2.8 \%$ & $2.6 \%$ & $2.7 \%$ & $2.9 \%$ & $2.0 \%$ & $3.5 \%$ & $3.7 \%$ & $1.9 \%$ \\
\hline$\%$ Social \& Recreational & $24.1 \%$ & & $25.9 \%$ & $19.1 \%$ & $26.2 \%$ & $20.0 \%$ & $20.8 \%$ & $28.1 \%$ & $25.4 \%$ & $22.7 \%$ & $18.0 \%$ & $26.5 \%$ & $23.8 \%$ & $28.2 \%$ & $29.1 \%$ & $29.5 \%$ & $25.5 \%$ \\
\hline$\%$ Other & $0.0 \%$ & & $1.4 \%$ & $0.0 \%$ & $0.0 \%$ & $3.0 \%$ & $0.2 \%$ & $0.0 \%$ & $0.0 \%$ & $0.2 \%$ & $0.0 \%$ & $0.0 \%$ & $0.1 \%$ & $0.1 \%$ & $0.0 \%$ & $0.0 \%$ & $0.0 \%$ \\
\hline$\%$ Unreported & $0.0 \%$ & & $0.0 \%$ & $0.0 \%$ & $0.0 \%$ & $0.0 \%$ & $0.0 \%$ & $0.0 \%$ & $0.4 \%$ & $0.0 \%$ & $0.0 \%$ & $0.0 \%$ & $0.0 \%$ & $0.0 \%$ & $0.0 \%$ & $0.0 \%$ & $0.0 \%$ \\
\hline
\end{tabular}

Notes: ${ }^{a}$ All percentages may not add to $100 \%$ due to rounding. * The Kingston area data was not separated out prior to 2009. 


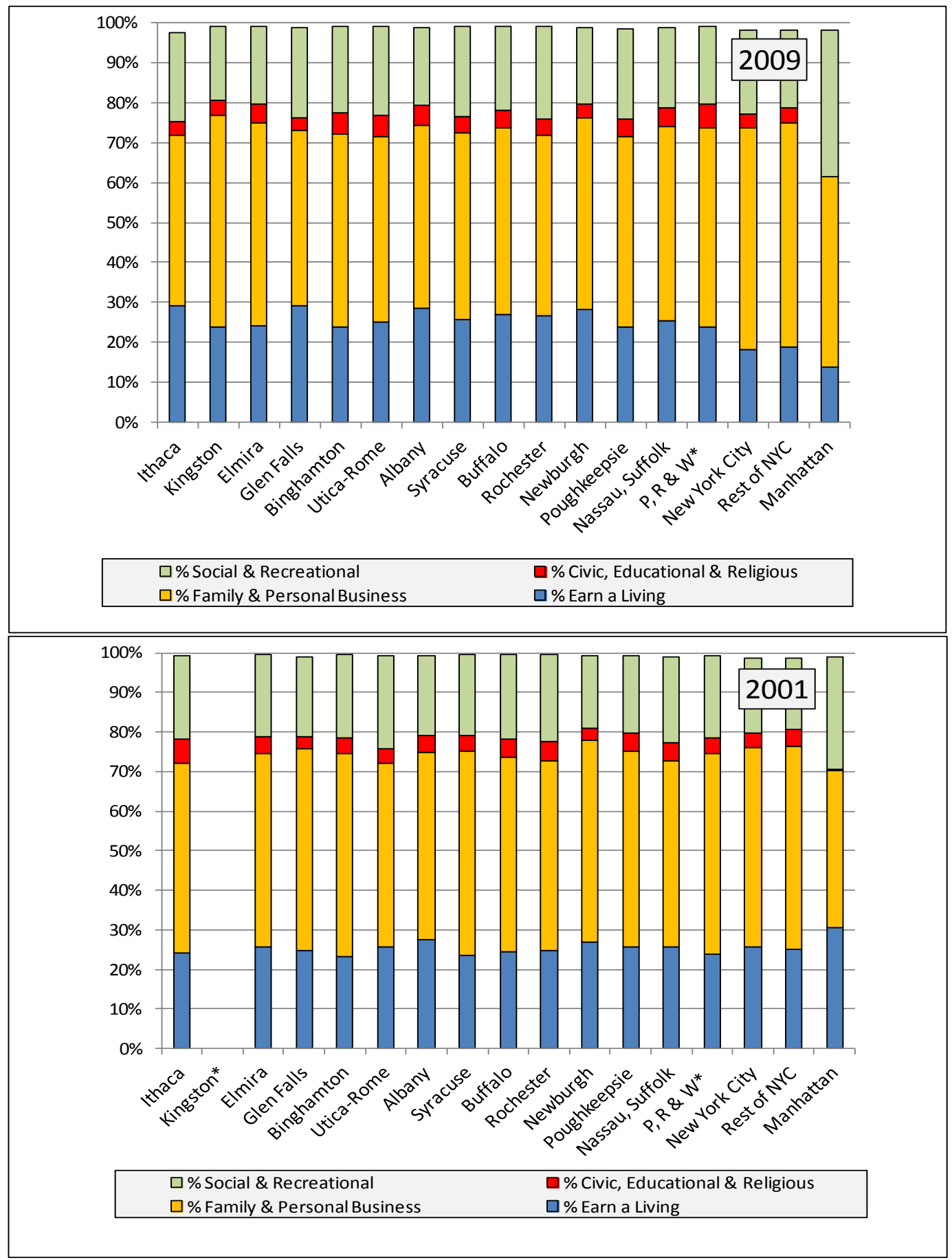


Figure 6.14 continued....

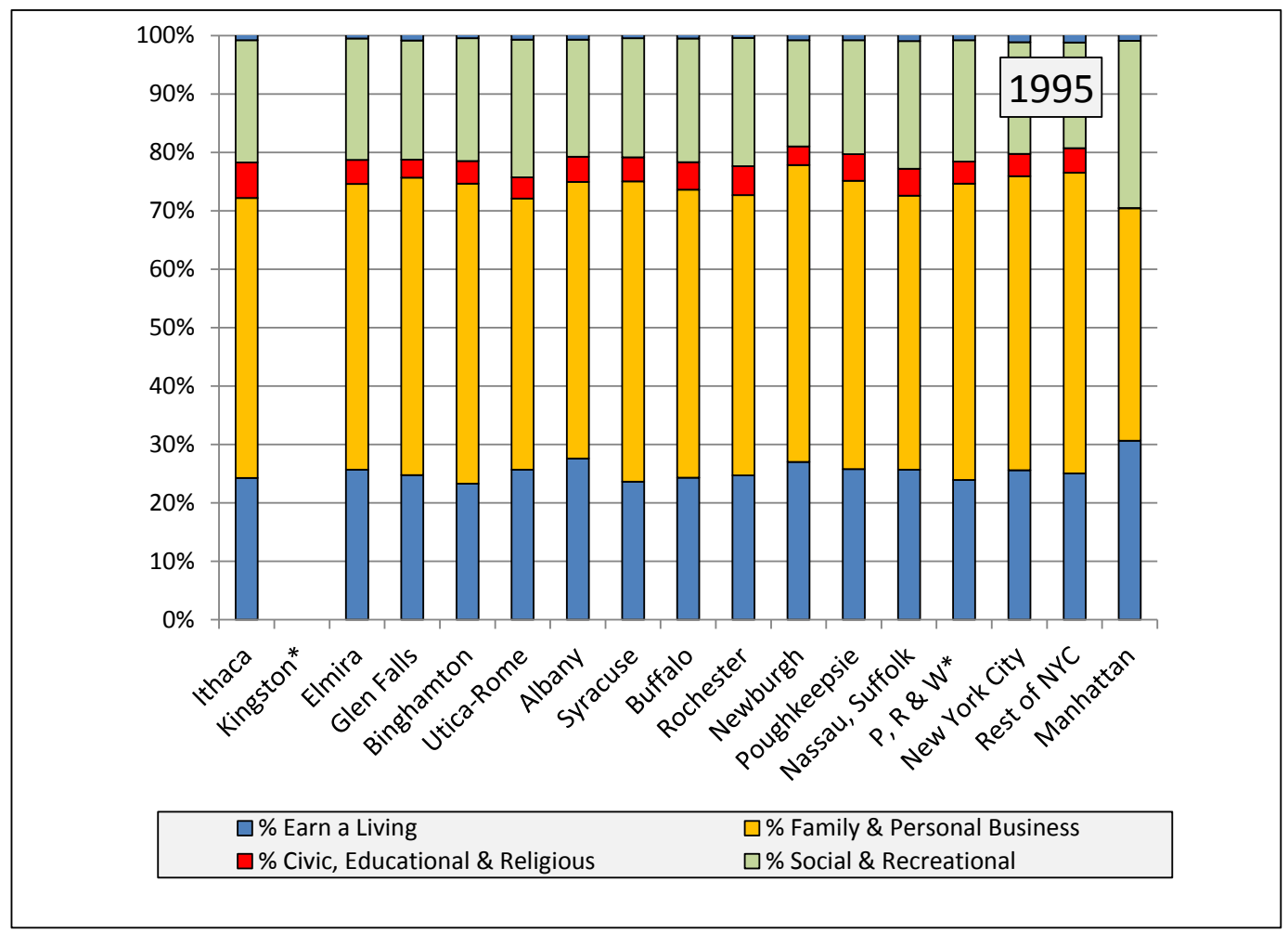

Figure 6.14 Distribution of Vehicle Trips by Household Trip Purpose in NYS Metro Areas in 1995, 2001, and 2009

Notes: Small percentages of "Other" and "Unreported" trip purposes not shown.

$* \mathrm{P}, \mathrm{R} \& \mathrm{~W}=$ Putnam, Rockland and Westchester. * The Kingston area data was not separated out prior to 2009.

\subsubsection{Types and Ages of Vehicles Driven}

Table 6.17 shows the distribution of in-use household vehicle fleet by vehicle type, as reported by residents in each NYS metro area. Vehicle type shares are reasonably consistent across metro areas. Two trends are evident: (1) a gradual shift over time within all metro areas to SUVs, largely at the expense of automobile shares - with increases between 1995 and 2009 ranging from $10 \%$ to $12 \%$ in small and medium sized metros, up to $17 \%$ in NYC; and (2) Pickup Trucks being significantly more popular in small and medium sized metros than in the NYMTC region. The lower part of Table 6.17 shows the average and medium age of vehicles in each metro area's in-use fleet of household vehicles in 2009. Syracuse, Putnam/Rockland/Westchester and Manhattan operate the youngest fleets and record a lower percentage of miles driven by vehicles 10 or more years old than do other metro areas. Ithaca, Kingston, Elmira, and Binghamton have the oldest fleets and the highest percentage of miles reported by older (10 or more years old) vehicles. 
Table 6.17 Household In-Use Vehicle Fleet Percentages for NYS Metro Areas, by Vehicle Types in 1995, 2001, and 2009, and Vehicle Age in $2009^{\mathrm{a}}$

\begin{tabular}{|c|c|c|c|c|c|c|c|c|c|c|c|c|c|c|c|c|c|}
\hline & \multicolumn{17}{|c|}{ MSA Size Class } \\
\hline & \multicolumn{2}{|c|}{ Not in MSA } & \multicolumn{2}{|c|}{$<250,000$} & \multicolumn{2}{|c|}{$\begin{array}{c}250,000 \text { to } \\
499,999\end{array}$} & \multicolumn{2}{|c|}{$\begin{array}{c}500,000 \text { to } \\
999,999\end{array}$} & \multicolumn{2}{|c|}{$\begin{array}{l}1 \text { to } 2.9 \\
\text { million }\end{array}$} & \multicolumn{7}{|c|}{3 million +} \\
\hline & \multirow[b]{3}{*}{ 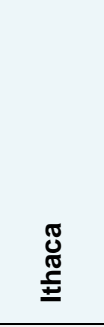 } & \multirow[b]{3}{*}{ 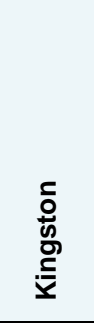 } & \multirow[b]{3}{*}{ 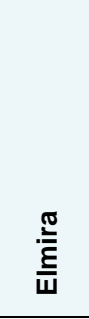 } & \multirow[b]{3}{*}{$\begin{array}{l}\frac{\infty}{\bar{\sigma}} \\
\stackrel{\leftarrow}{0} \\
\frac{c}{\sigma}\end{array}$} & \multirow[b]{3}{*}{ 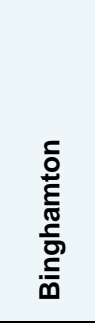 } & \multirow[b]{3}{*}{ 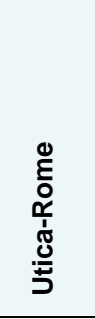 } & \multirow[b]{3}{*}{$\begin{array}{l}\underset{\mathbb{E}}{\pi} \\
\frac{0}{\alpha}\end{array}$} & \multirow[b]{3}{*}{ 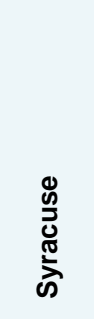 } & \multirow[b]{3}{*}{ 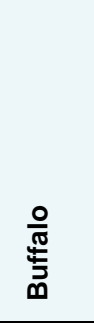 } & \multirow[b]{3}{*}{ 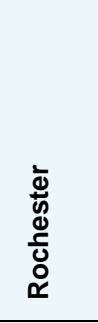 } & \multirow[b]{3}{*}{ 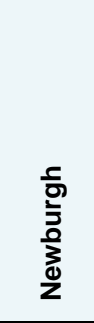 } & \multirow[b]{3}{*}{ 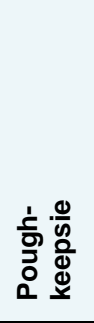 } & \multirow{3}{*}{\multicolumn{2}{|c|}{$\begin{array}{c}\text { Putnam, } \\
\text { Rock- } \\
\text { land, } \\
\text { u, West- } \\
\text { k chester } \\
\end{array}$}} & NYMT & & \\
\hline & & & & & & & & & & & & & & & \multirow[b]{2}{*}{$\begin{array}{l}\text { New } \\
\text { York } \\
\text { City }\end{array}$} & \multicolumn{2}{|c|}{\begin{tabular}{|c|}
$\begin{array}{c}\text { Sub-components } \\
\text { of NYC }\end{array}$ \\
\end{tabular}} \\
\hline & & & & & & & & & & & & & & & & \begin{tabular}{|c} 
Rest of \\
NYC/4 \\
Counties
\end{tabular} & $\begin{array}{c}\text { Man- } \\
\text { hattan/ } \\
\text { New York }\end{array}$ \\
\hline \multicolumn{18}{|l|}{2009 Vehicles by Type } \\
\hline Auto & $58.5 \%$ & $55.3 \%$ & $51.5 \%$ & $45.9 \%$ & $53.4 \%$ & $54.2 \%$ & $56.8 \%$ & $56.0 \%$ & $61.0 \%$ & $57.3 \%$ & $55.3 \%$ & $58.1 \%$ & $59.6 \%$ & $59.9 \%$ & $64.7 \%$ & $64.6 \%$ & $65.3 \%$ \\
\hline Van & $9.5 \%$ & $8.1 \%$ & $8.9 \%$ & $7.4 \%$ & $11.0 \%$ & $8.8 \%$ & $8.0 \%$ & $9.9 \%$ & $10.0 \%$ & $11.8 \%$ & $9.1 \%$ & $8.7 \%$ & $8.0 \%$ & $8.4 \%$ & $9.9 \%$ & $10.5 \%$ & $5.6 \%$ \\
\hline Sports Utility & $18.5 \%$ & $18.3 \%$ & $20.6 \%$ & $22.4 \%$ & $18.2 \%$ & $18.1 \%$ & $22.4 \%$ & $21.7 \%$ & $17.2 \%$ & $17.3 \%$ & $20.8 \%$ & $20.0 \%$ & $25.3 \%$ & $25.0 \%$ & $22.6 \%$ & $22.1 \%$ & $26.3 \%$ \\
\hline Pickup & $10.6 \%$ & $13.0 \%$ & $14.7 \%$ & $19.8 \%$ & $14.3 \%$ & $15.8 \%$ & $9.9 \%$ & $9.7 \%$ & $9.2 \%$ & $11.2 \%$ & $11.2 \%$ & $8.3 \%$ & $4.6 \%$ & $4.9 \%$ & $1.2 \%$ & $1.3 \%$ & $0.4 \%$ \\
\hline Motorcycle & $2.5 \%$ & $4.8 \%$ & $3.4 \%$ & $3.7 \%$ & $2.2 \%$ & $2.8 \%$ & $2.4 \%$ & $2.4 \%$ & $2.2 \%$ & $1.6 \%$ & $3.0 \%$ & $4.1 \%$ & $2.0 \%$ & $1.5 \%$ & $1.6 \%$ & $1.5 \%$ & $2.4 \%$ \\
\hline \multicolumn{18}{|l|}{2001 Vehicles by Type } \\
\hline Auto & $66.0 \%$ & * & $58.4 \%$ & $53.1 \%$ & $60.9 \%$ & $58.5 \%$ & $62.4 \%$ & $66.5 \%$ & $64.3 \%$ & $63.3 \%$ & $65.3 \%$ & $64.1 \%$ & $66.8 \%$ & $73.3 \%$ & $75.7 \%$ & $75.3 \%$ & $78.2 \%$ \\
\hline Van & $8.0 \%$ & * & $10.3 \%$ & $8.5 \%$ & $10.0 \%$ & $9.6 \%$ & $10.1 \%$ & $9.7 \%$ & $10.7 \%$ & $11.3 \%$ & $9.6 \%$ & $8.8 \%$ & $11.2 \%$ & $8.9 \%$ & $9.3 \%$ & $9.7 \%$ & $6.4 \%$ \\
\hline Sports Utility & $9.8 \%$ & * & $10.4 \%$ & $12.9 \%$ & $10.8 \%$ & $11.8 \%$ & $11.8 \%$ & $11.2 \%$ & $10.1 \%$ & $11.7 \%$ & $11.6 \%$ & $12.7 \%$ & $14.6 \%$ & $13.1 \%$ & $12.4 \%$ & $12.5 \%$ & $11.7 \%$ \\
\hline Pickup & $13.4 \%$ & * & $16.6 \%$ & $21.0 \%$ & $14.7 \%$ & $14.5 \%$ & $12.2 \%$ & $10.4 \%$ & $11.9 \%$ & $10.7 \%$ & $10.7 \%$ & $9.1 \%$ & $5.6 \%$ & $3.6 \%$ & $1.0 \%$ & $1.0 \%$ & $1.3 \%$ \\
\hline Motorcycle & $1.9 \%$ & * & $2.9 \%$ & $3.3 \%$ & $2.8 \%$ & $4.7 \%$ & $2.5 \%$ & $1.3 \%$ & $2.2 \%$ & $2.0 \%$ & $2.1 \%$ & $4.2 \%$ & $1.7 \%$ & $0.9 \%$ & $1.3 \%$ & $1.1 \%$ & $2.5 \%$ \\
\hline \multicolumn{18}{|l|}{1995 Vehicles by Type } \\
\hline Auto & $69.7 \%$ & * & $65.1 \%$ & $64.9 \%$ & $67.8 \%$ & $66.4 \%$ & $72.8 \%$ & $69.7 \%$ & $75.3 \%$ & $76.9 \%$ & $69.6 \%$ & $72.8 \%$ & $78.2 \%$ & $79.7 \%$ & $87.4 \%$ & $87.5 \%$ & $87.0 \%$ \\
\hline Van & $7.9 \%$ & * & $9.7 \%$ & $7.0 \%$ & $8.8 \%$ & $7.1 \%$ & $6.8 \%$ & $10.9 \%$ & $8.3 \%$ & $8.1 \%$ & $7.2 \%$ & $9.4 \%$ & $8.4 \%$ & $6.5 \%$ & $5.6 \%$ & $6.0 \%$ & $3.3 \%$ \\
\hline Sports Utility & $5.8 \%$ & * & $6.6 \%$ & $6.0 \%$ & $6.2 \%$ & $7.1 \%$ & $5.9 \%$ & $7.1 \%$ & $5.6 \%$ & $5.4 \%$ & $9.5 \%$ & $7.9 \%$ & $8.5 \%$ & $10.0 \%$ & $5.3 \%$ & $5.0 \%$ & $7.2 \%$ \\
\hline Pickup & $14.4 \%$ & * & $16.3 \%$ & $20.3 \%$ & $14.6 \%$ & $16.7 \%$ & $11.6 \%$ & $10.8 \%$ & $9.5 \%$ & $8.0 \%$ & $11.3 \%$ & $8.4 \%$ & $4.3 \%$ & $2.7 \%$ & $1.2 \%$ & $1.0 \%$ & $2.4 \%$ \\
\hline Motorcycle & $1.1 \%$ & * & $1.5 \%$ & $0.9 \%$ & $1.0 \%$ & $1.4 \%$ & $1.5 \%$ & $0.6 \%$ & $0.6 \%$ & $1.3 \%$ & $1.4 \%$ & $1.1 \%$ & $0.2 \%$ & $0.7 \%$ & $0.2 \%$ & $0.2 \%$ & $0.2 \%$ \\
\hline 2009 Vehicle Age Statistic & & & & & & & & & & & & & & & & & \\
\hline Average Vehicle Age & 8.75 & 8.83 & 8.65 & 7.90 & 9.04 & 7.71 & 7.72 & 7.01 & 7.62 & 7.91 & 7.73 & 7.64 & 7.40 & 7.16 & 7.98 & 8.09 & 7.08 \\
\hline Median Vehicle Age & 8.00 & 8.00 & 8.00 & 6.00 & 8.00 & 7.00 & 7.00 & 6.00 & 7.00 & 7.00 & 7.00 & 7.00 & 6.00 & 6.00 & 7.00 & 7.00 & 6.00 \\
\hline 2009 Vehicle Age Statistic & & & & & & & & & & & & & & & & & \\
\hline Less than 10 years & $68.5 \%$ & $68.3 \%$ & $70.9 \%$ & $75.0 \%$ & $67.9 \%$ & $74.2 \%$ & $76.7 \%$ & $81.9 \%$ & $77.5 \%$ & $72.5 \%$ & $78.8 \%$ & $78.5 \%$ & $77.1 \%$ & $76.1 \%$ & $71.1 \%$ & $70.0 \%$ & $78.8 \%$ \\
\hline 10 years or more & $31.5 \%$ & $31.7 \%$ & $29.1 \%$ & $25.0 \%$ & $32.1 \%$ & $25.8 \%$ & $23.3 \%$ & $18.1 \%$ & $22.5 \%$ & $27.5 \%$ & $21.2 \%$ & $21.5 \%$ & $22.9 \%$ & $23.9 \%$ & $28.9 \%$ & $30.0 \%$ & $21.2 \%$ \\
\hline
\end{tabular}

Notes: ${ }^{\text {a }}$ Percentages do not always add to $100 \%$ because of small percentages not reported for Other Trucks, Recreational Vehicles (RVs) and (in 1995$)$ for Other POVs. ${ }^{b}$ Numbers reflect BESTMILE Estimates. $*$ The Kingston area data was not separated out prior to 2009 . Sports Utility $=$ SUV in the text. 
Figure 6.15 shows the average annual miles that household vehicles were driven in each of the state's metro areas in 1995, 2001, and 2009. Of all the metro areas, household vehicles in Newburg and Poughkeepsie were driven the most on the average, in all three NHTS surveys, reporting over 12,000 annual miles per vehicle in 2009. NYC vehicles were driven the least in 2009 , at 9,400 miles per year. This difference is due largely to the reported reduction in nonManhattan based NYC vehicle mileages, which fell from an average of 12,500 miles per vehicle in 1995 to 11,600 miles per vehicle in 2001 and again to 9,400 miles per vehicle in 2009. Nassau/Suffolk and Buffalo households also reported significant mileage drops, notably between 2001 and 2009 (Figure 6.15).

\subsubsection{Greenhouse Gas Emissions Associated With Vehicle Travel}

Figure 6.16 below shows the estimated average annual, travel-induced emissions of $\mathrm{CO} 2$ per NYS household, in each of the state's metro areas and sub-areas. As described in Chapter 4 of this report, the state's most densely populated areas are estimated to have emitted less than one quarter of the CO2 emissions per household in 2009 than did households in the state's rural and more sparsely populated urban areas. While households in Kingston, Glen Falls, Newburgh and Poughkeepsie are estimated to have emitted a little over 9 metric tons of $\mathrm{CO} 2$ in that year, residents of NYC emitted about 3 metric tons, with Manhattan residents emitting less than 2 metric tons per year for personal travel purposes. The state's other metropolitan areas are estimated to have emitted between 7 and 8 tons of CO2 per household per year in 2009 .

Changes in these emissions rates over time proved difficult to quantify on a metro area specific level. The equivalent data sources for 1995 were not available for all modes of travel, while the 2001 data included many small size samples, resulting in large standard errors being associated with a number of metro area-specific means. 


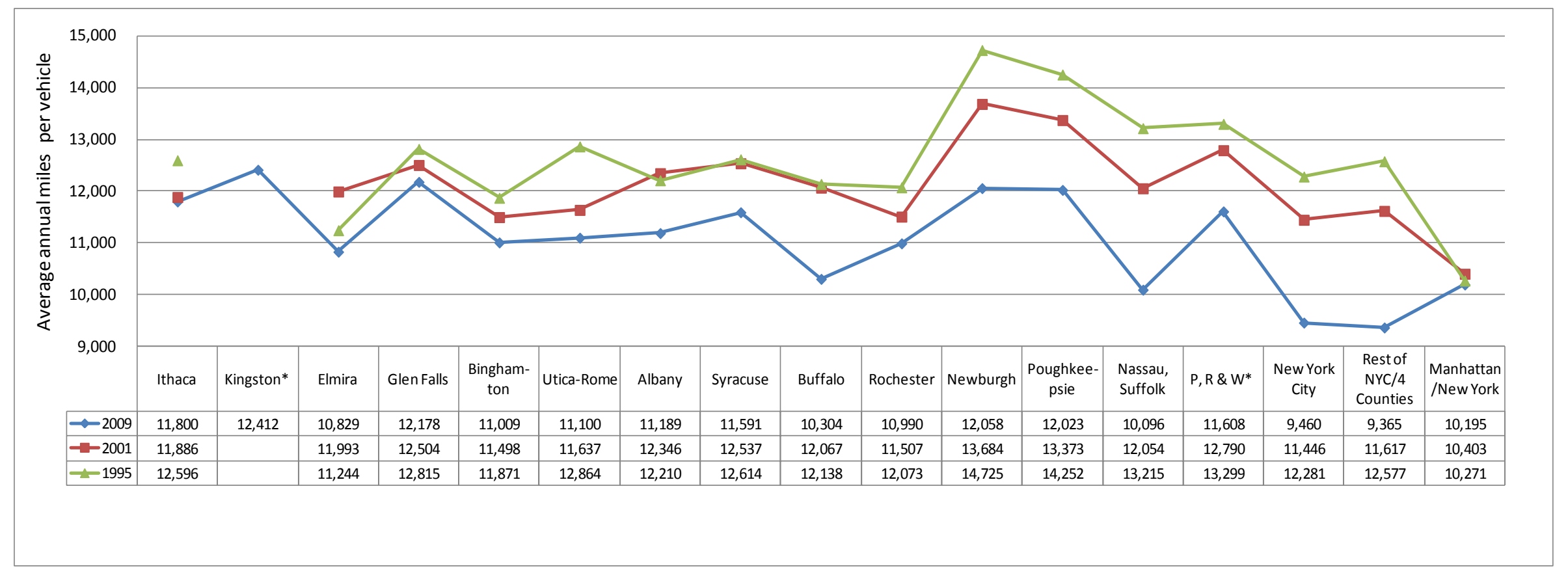

Figure 6.15 Annual Estimated Vehicle Mileages Driven by NYS Metro Areas, in 1995, 2201 and 2009.

Notes: ${ }^{\text {a }}$ Numbers reflect BESTMILE Estimates.* P, R \& W = Putnam, Rockland and Westchester counties.* Kingston area data was not separated out prior to 2009 . 


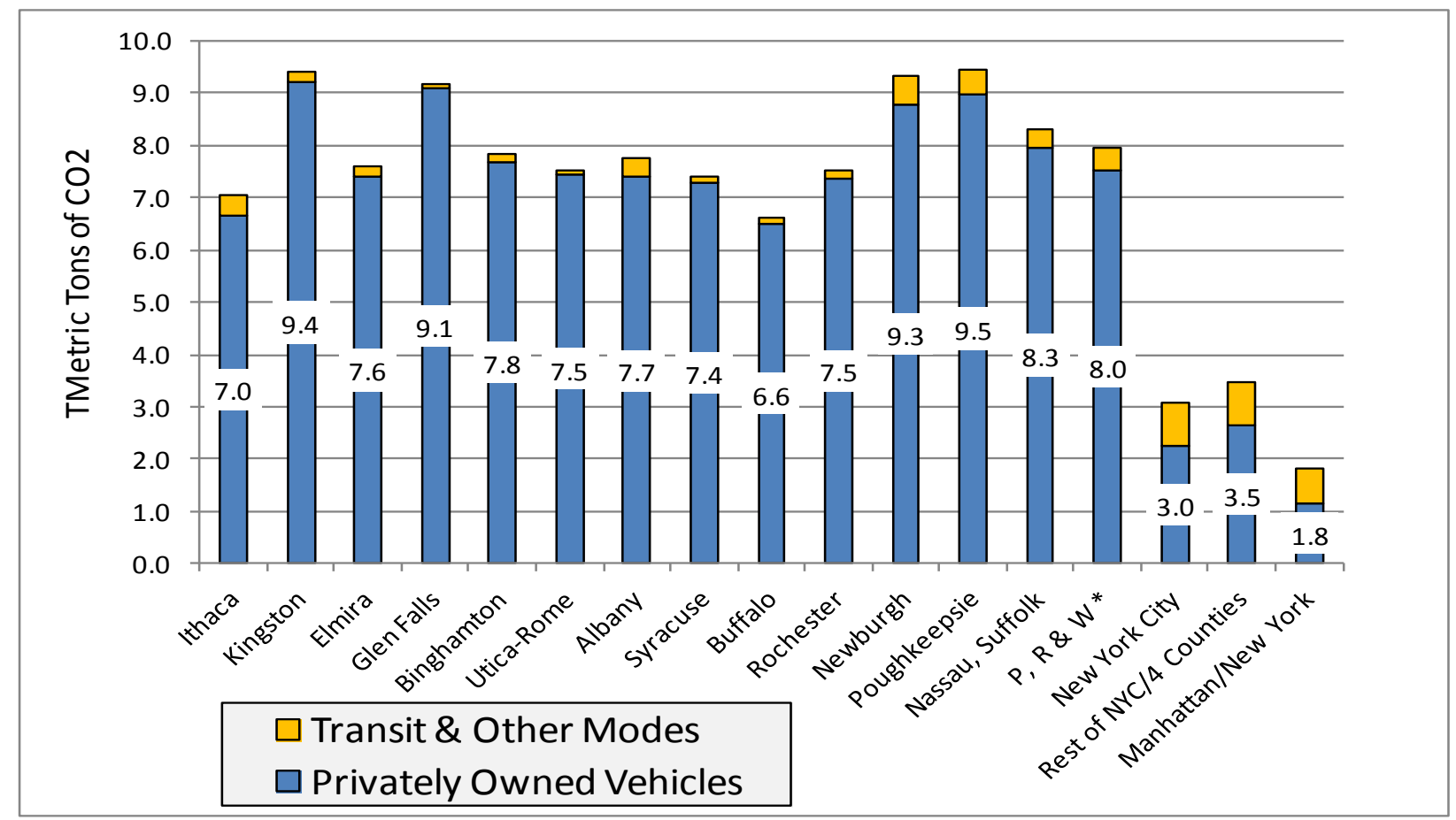

Figure 6.16 Average Annual Emissions of Carbon Dioxide (Metric Tons of CO2) from Household Travel by NYS Metro Area in 2009 by Private/Public Modes of Transportation.

Notes: Direct, vehicle operating emissions only, no "upstream" vehicle or fuel production or infrastructure provision related emissions are included. Air travel is excluded. The emissions rates used for each mode of travel are reported in Appendix D, and make use of US EPA recommended fuel use-to- $\mathrm{CO} 2$ emissions conversions, and emissions rate estimates derived from the Federal Transit Administration's rail, bus and ferry transit energy consumption database and average vehicle fuel efficiencies reported by or derived from Federal Highway Administration, American Bus Association, American School Bus Association, and the New York City Taxi and Limousine Commission estimates. Numbers on blue bars $=$ total POV plus Transit and Other Modes annual $\mathrm{CO} 2$ emissions. * P, R \& W = Putnam, Rockland and Westchester counties.

\subsection{COMMUTING COMPARISONS}

\subsubsection{Commuting Trip Frequencies and Miles of Travel by Mode}

Tables 6.18, 6.19, and 6.20 show the modal shares for NYS metro area-specific commuting trips, based on the 2009, 2001, and 1995 NHTS surveys respectively. Daily commute trip frequencies are consistently between 1.0 and 1.2 trips per worker across all of the state's metro areas in 2009 and 2001, down from average trip rates that exceeded 1.4 trips per worker per day in some metros in 1995. In contrast, and as expected given the range of geographies and population densities associated with this set of metro areas, daily person miles of commuting, including transit trips, varies a good deal more across metros: from a low around 6 miles per day 
in NYC (with the shortest trips in all three survey years) to a high of around 20 miles per day in Newburgh (with the longest trips in all three survey years). Also shown in Tables 6.18, 6.19, and 6.20 are metro area-specific commuting mode shares. As a set, these reflect patterns that are similar to total tripmaking within these metros, with the private vehicle trips accounting for over $90 \%$ of all commutes in non-NYMTC metropolitan regions, with the exception of Ithaca, where they accounted for $81 \%$ of commutes in 2009 and 1995 (but 89\% in 2001). Within the NYMTC area private vehicle travel also dominated, but fell in 2009 to under $77 \%$ in Putnam, Rockland and Westchester counties. In NYC, private vehicle trips accounted for only $28 \%$ of all commutes, second to a slightly higher share of subway and elevated transit line trips, and with walk and other public (largely bus) trips making up most of the remainder (Table 6.18).

Figure 6.17 below shows the relationship between one-way commuting distance and travel time for each of the state's metro areas. These results are similar to those for all daily vehicle travel shown in Figure 6.13 above. Although one-way commute distances for workers in NYC were about the same as those for workers in the state's small and medium-size metro areas, these NYC commuters spent almost twice as long in time traveling. In 2009 commute times ranged from 16 to 23 minutes in these smaller metros, versus 27 to over 43 minutes in metros of over 3 million people. The longest duration commutes here are those by non-Manhattan residents located in NYC, where commuting time has been consistently the highest across all three survey years: and where it has increased from an average of 35.5 minutes in 1995 to close to 43.5 minutes in 2009 - the significant jump due mainly between 1995 and 2001. 
Table 6.18 Commute Statistics by Mode of Transportation New York State Metro Areas by MSA Size in 2009

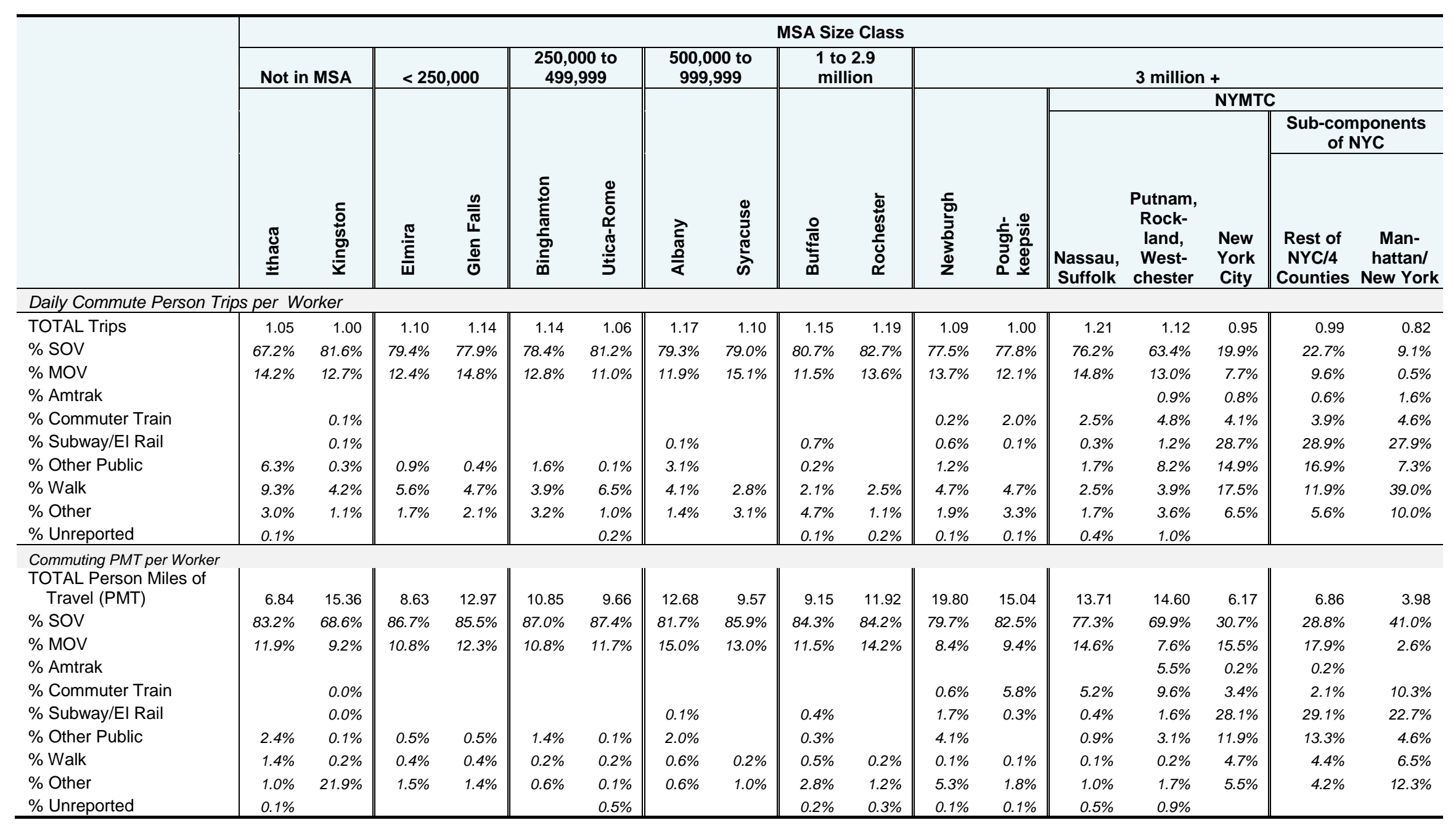

Note: ${ }^{\text {a }}$ All percentages may not add to $100 \%$ due to rounding. 
Table 6.19 Commute Statistics by Mode of Transportation New York State Metro Areas by MSA Size in 2001 ${ }^{\text {a }}$

\begin{tabular}{|c|c|c|c|c|c|c|c|c|c|c|c|c|c|c|c|c|c|}
\hline & \multicolumn{17}{|c|}{ MSA Size Class } \\
\hline & \multirow{4}{*}{\multicolumn{2}{|c|}{ 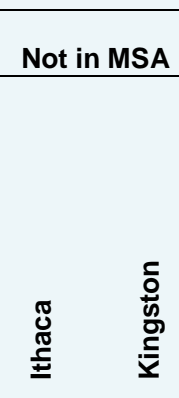 }} & \multicolumn{2}{|c|}{$<250,000$} & \multicolumn{2}{|c|}{$\begin{array}{c}250,000 \text { to } \\
499,999\end{array}$} & \multicolumn{2}{|c|}{$\begin{array}{c}500,000 \text { to } \\
999,999\end{array}$} & \multicolumn{2}{|c|}{$\begin{array}{l}1 \text { to } 2.9 \\
\text { million }\end{array}$} & \multicolumn{7}{|c|}{3 million + } \\
\hline & & & \multirow[b]{3}{*}{$\frac{\text { 플 }}{\underline{\underline{E}}}$} & \multirow[b]{3}{*}{$\begin{array}{l}\frac{\infty}{\bar{N}} \\
\frac{L}{\sigma} \\
\frac{c}{0}\end{array}$} & \multirow[b]{3}{*}{ 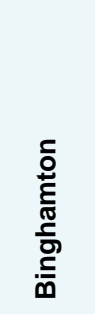 } & \multirow[b]{3}{*}{ 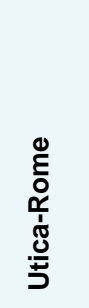 } & \multirow[b]{3}{*}{ 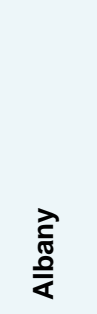 } & \multirow[b]{3}{*}{ 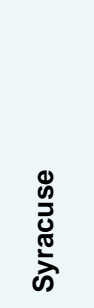 } & \multirow[b]{3}{*}{$\begin{array}{l}\frac{0}{\pi} \\
\stackrel{\pi}{ \pm} \\
\overline{0}\end{array}$} & \multirow[b]{3}{*}{ 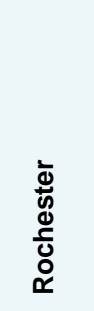 } & \multirow[b]{3}{*}{ 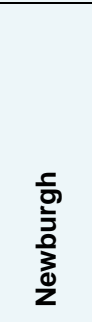 } & \multirow[b]{3}{*}{ 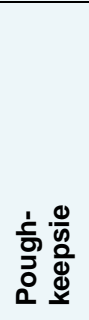 } & \multirow{3}{*}{\multicolumn{2}{|c|}{$\begin{array}{l}\text { Putnam, } \\
\text { Rock- } \\
\text { land, } \\
\text { West- } \\
\text { k chester }\end{array}$}} & \multicolumn{3}{|c|}{ NYMTC } \\
\hline & & & & & & & & & & & & & & & & $\begin{array}{r}\text { Sub-com } \\
\text { of } 1\end{array}$ & $\begin{array}{l}\text { nponents } \\
\text { VYC }\end{array}$ \\
\hline & & & & & & & & & & & & & & & $\begin{array}{l}\text { New } \\
\text { York } \\
\text { City } \\
\end{array}$ & \begin{tabular}{|c|} 
Rest of \\
NYC/4 \\
Counties \\
\end{tabular} & $\begin{array}{c}\text { Man- } \\
\text { hattan/ } \\
\text { New York }\end{array}$ \\
\hline \multicolumn{18}{|c|}{ Daily Commute Person Trips per Worker } \\
\hline TOTAL Trips & 1.09 & & 1.16 & 1.12 & 1.15 & 1.20 & 1.15 & 1.20 & 1.09 & 1.17 & 1.12 & 1.07 & 1.14 & 1.11 & 1.08 & 1.09 & 1.06 \\
\hline$\%$ SOV & $72.1 \%$ & & $81.7 \%$ & $79.6 \%$ & $77.2 \%$ & $79.6 \%$ & $79.5 \%$ & $74.5 \%$ & $81.5 \%$ & $82.6 \%$ & $77.3 \%$ & $80.8 \%$ & $71.2 \%$ & $67.4 \%$ & $25.0 \%$ & $29.4 \%$ & $8.0 \%$ \\
\hline$\% \mathrm{MOV}$ & $16.4 \%$ & & $14.3 \%$ & $16.9 \%$ & $16.6 \%$ & $17.6 \%$ & $13.9 \%$ & $14.3 \%$ & $14.0 \%$ & $12.3 \%$ & $15.1 \%$ & $12.2 \%$ & $14.7 \%$ & $14.8 \%$ & $9.7 \%$ & $10.1 \%$ & $7.9 \%$ \\
\hline$\%$ Amtrak & & & & $0.0 \%$ & & & $0.1 \%$ & & & & & $0.4 \%$ & $0.9 \%$ & $1.3 \%$ & $1.2 \%$ & $1.5 \%$ & $0.2 \%$ \\
\hline$\%$ Commuter Train & & & & $0.0 \%$ & & & & & & & $0.6 \%$ & $1.7 \%$ & $5.1 \%$ & $6.2 \%$ & $1.4 \%$ & $1.5 \%$ & $1.1 \%$ \\
\hline \% Subway/El Rail & & & & & & & $0.1 \%$ & & $0.1 \%$ & & $1.0 \%$ & $0.2 \%$ & $1.5 \%$ & $2.1 \%$ & $30.3 \%$ & $28.7 \%$ & $36.4 \%$ \\
\hline$\%$ Other Public & $2.0 \%$ & & $0.6 \%$ & $0.7 \%$ & $1.3 \%$ & $0.5 \%$ & $2.4 \%$ & $5.1 \%$ & $0.3 \%$ & $1.8 \%$ & $0.6 \%$ & $0.3 \%$ & $0.2 \%$ & $2.0 \%$ & $12.2 \%$ & $12.3 \%$ & $11.4 \%$ \\
\hline$\%$ Walk & $6.9 \%$ & & $1.7 \%$ & $1.8 \%$ & $4.6 \%$ & $2.4 \%$ & $3.3 \%$ & $4.0 \%$ & $3.5 \%$ & $2.5 \%$ & $3.1 \%$ & $2.3 \%$ & $4.6 \%$ & $3.7 \%$ & $16.0 \%$ & $13.1 \%$ & $27.4 \%$ \\
\hline$\%$ Other & $2.6 \%$ & & $1.8 \%$ & $0.5 \%$ & $0.4 \%$ & & $0.9 \%$ & $2.1 \%$ & $0.6 \%$ & $0.8 \%$ & $2.4 \%$ & $2.1 \%$ & $1.5 \%$ & $1.8 \%$ & $4.2 \%$ & $3.3 \%$ & $7.6 \%$ \\
\hline$\%$ Unreported & & & & $0.6 \%$ & & & & & & & & & $0.2 \%$ & $0.7 \%$ & $0.0 \%$ & $0.1 \%$ & \\
\hline \multicolumn{18}{|c|}{ Commuting PMT per Worker } \\
\hline $\begin{array}{l}\text { TOTAL Person Mile } \\
\text { Travel (PMT) }\end{array}$ & 8.37 & & 10.57 & 14.02 & 10.14 & 11.87 & 11.89 & 9.38 & 10.69 & 10.31 & 20.00 & 16.91 & 14.07 & 15.20 & 7.47 & 7.89 & 5.89 \\
\hline$\%$ SOV & $80.6 \%$ & & $83.6 \%$ & $79.0 \%$ & $82.5 \%$ & $80.4 \%$ & $83.7 \%$ & $86.3 \%$ & $82.7 \%$ & $88.3 \%$ & $74.2 \%$ & $77.3 \%$ & $68.8 \%$ & $67.4 \%$ & $33.6 \%$ & $37.3 \%$ & $15.0 \%$ \\
\hline$\% \mathrm{MOV}$ & $14.4 \%$ & & $14.4 \%$ & $18.3 \%$ & $15.1 \%$ & $18.8 \%$ & $12.9 \%$ & $10.3 \%$ & $16.3 \%$ & $10.8 \%$ & $13.1 \%$ & $10.1 \%$ & $12.7 \%$ & $12.4 \%$ & $13.1 \%$ & $10.7 \%$ & $24.8 \%$ \\
\hline$\%$ Amtrak & & & & $0.1 \%$ & & & $1.2 \%$ & & & & & $2.6 \%$ & $1.8 \%$ & $1.7 \%$ & $1.4 \%$ & $1.5 \%$ & $0.6 \%$ \\
\hline$\%$ Commuter Train & & & & $0.1 \%$ & & & & & & & $1.8 \%$ & $6.7 \%$ & $11.7 \%$ & $12.4 \%$ & $2.3 \%$ & $2.2 \%$ & $2.8 \%$ \\
\hline \% Subway/El Rail & & & & & & & $0.1 \%$ & & $0.1 \%$ & & $3.1 \%$ & $0.0 \%$ & $2.2 \%$ & $1.5 \%$ & $35.0 \%$ & $33.8 \%$ & $40.9 \%$ \\
\hline$\%$ Other Public & $1.9 \%$ & & $0.1 \%$ & $0.3 \%$ & $1.4 \%$ & $0.4 \%$ & $1.2 \%$ & $2.3 \%$ & $0.2 \%$ & $0.5 \%$ & $1.0 \%$ & $0.2 \%$ & $0.3 \%$ & $1.0 \%$ & $7.7 \%$ & $8.4 \%$ & $4.3 \%$ \\
\hline$\%$ Walk & $0.7 \%$ & & $0.2 \%$ & $0.2 \%$ & $0.5 \%$ & $0.4 \%$ & $0.3 \%$ & $0.2 \%$ & $0.5 \%$ & $0.3 \%$ & $0.1 \%$ & $0.8 \%$ & $0.5 \%$ & $0.4 \%$ & $2.8 \%$ & $2.2 \%$ & $6.2 \%$ \\
\hline$\%$ Other & $2.4 \%$ & & $1.7 \%$ & $0.9 \%$ & $0.5 \%$ & & $0.6 \%$ & $0.9 \%$ & $0.3 \%$ & $0.1 \%$ & $6.8 \%$ & $2.3 \%$ & $1.3 \%$ & $2.7 \%$ & $4.1 \%$ & $3.9 \%$ & $5.5 \%$ \\
\hline$\%$ Unreported & & & & $1.2 \%$ & & & & & & & & & $0.8 \%$ & $0.5 \%$ & $0.0 \%$ & $0.0 \%$ & \\
\hline
\end{tabular}

Note: ${ }^{\text {a }}$ All percentages may not add to $100 \%$ due to rounding. 
Table 6.20 Commute Statistics by Mode of Transportation New York State Metro Areas by MSA Size in 1995 ${ }^{a}$

\begin{tabular}{|c|c|c|c|c|c|c|c|c|c|c|c|c|c|c|c|c|c|}
\hline & \multicolumn{17}{|c|}{ MSA Size Class } \\
\hline & \multirow{4}{*}{\multicolumn{2}{|c|}{ 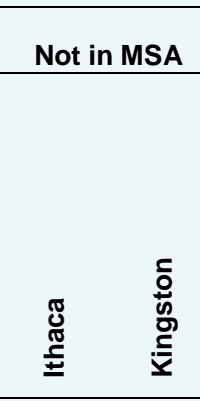 }} & \multicolumn{2}{|c|}{$<250,000$} & \multicolumn{2}{|c|}{$\begin{array}{c}250,000 \text { to } \\
499,999\end{array}$} & \multicolumn{2}{|c|}{$\begin{array}{l}500,000 \text { to } \\
999,999\end{array}$} & \multicolumn{2}{|c|}{$\begin{array}{l}1 \text { to } 2.9 \\
\text { million }\end{array}$} & \multicolumn{7}{|c|}{3 million +} \\
\hline & & & \multirow[b]{3}{*}{$\frac{\text { 를 }}{\underline{\underline{E}}}$} & \multirow[b]{3}{*}{$\begin{array}{l}\frac{\infty}{\bar{\sigma}} \\
\stackrel{5}{0} \\
\frac{c}{\sigma} \\
0\end{array}$} & \multirow[b]{3}{*}{ 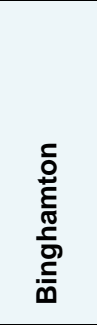 } & \multirow[b]{3}{*}{ 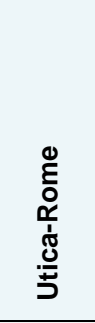 } & \multirow[b]{3}{*}{ 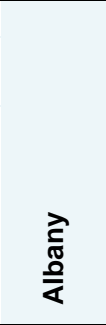 } & \multirow[b]{3}{*}{ 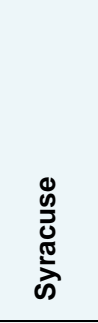 } & \multirow[b]{3}{*}{$\begin{array}{l}\frac{0}{\sqrt[N]{7}} \\
\frac{7}{5} \\
0\end{array}$} & \multirow[b]{3}{*}{ 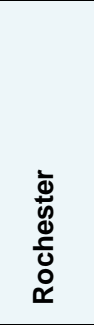 } & \multirow[b]{3}{*}{ 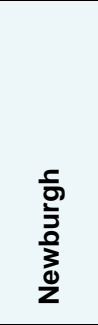 } & \multirow[b]{3}{*}{ 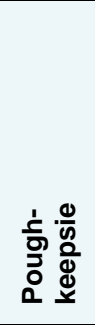 } & \multirow{3}{*}{\multicolumn{2}{|c|}{$\begin{array}{c}\text { Putnam, } \\
\text { Rock- } \\
\text { land, } \\
\text { u, West- } \\
\text { k chester } \\
\end{array}$}} & \multicolumn{3}{|c|}{ NYMTC } \\
\hline & & & & & & & & & & & & & & & & $\begin{array}{r}\text { Sub-com } \\
\text { of } 1\end{array}$ & $\begin{array}{l}\text { iponents } \\
\text { VYC }\end{array}$ \\
\hline & & & & & & & & & & & & & & & $\begin{array}{l}\text { New } \\
\text { York } \\
\text { City } \\
\end{array}$ & \begin{tabular}{|c} 
Rest of \\
NYC/4 \\
Counties
\end{tabular} & $\begin{array}{c}\text { Man- } \\
\text { hattan/ } \\
\text { New York }\end{array}$ \\
\hline \multicolumn{18}{|c|}{ Daily Commute Person Trips per Worker } \\
\hline TOTAL Trips & 1.41 & & 1.43 & 1.61 & 1.39 & 1.44 & 1.32 & 1.37 & 1.40 & 1.36 & 1.41 & 1.34 & 1.21 & 1.44 & 1.26 & 1.28 & 1.21 \\
\hline$\%$ SOV & $64.5 \%$ & & $81.8 \%$ & $74.5 \%$ & $71.2 \%$ & $76.4 \%$ & $77.3 \%$ & $78.8 \%$ & $77.9 \%$ & $81.6 \%$ & $73.0 \%$ & $78.4 \%$ & $71.9 \%$ & $68.8 \%$ & $25.4 \%$ & $29.7 \%$ & $9.1 \%$ \\
\hline$\% \mathrm{MOV}$ & $17.0 \%$ & & $13.3 \%$ & $19.3 \%$ & $19.4 \%$ & $17.4 \%$ & $12.9 \%$ & $16.1 \%$ & $12.9 \%$ & $11.8 \%$ & $17.0 \%$ & $14.9 \%$ & $14.0 \%$ & $14.6 \%$ & $9.5 \%$ & $10.2 \%$ & $5.8 \%$ \\
\hline$\%$ Other POV & & & & & & & & & & & & $0.0 \%$ & & & $0.0 \%$ & $0.0 \%$ & \\
\hline$\%$ Amtrak & & & & & & & & & & $0.0 \%$ & & & $0.0 \%$ & & & & \\
\hline$\%$ Commuter Train & & & & & & & $0.0 \%$ & & & & $0.7 \%$ & $0.7 \%$ & $5.0 \%$ & $5.6 \%$ & $5.6 \%$ & $5.5 \%$ & $5.8 \%$ \\
\hline \% Subway/El Rail & & & & & & & & & $0.0 \%$ & & $0.0 \%$ & $0.7 \%$ & $1.7 \%$ & $0.7 \%$ & $26.2 \%$ & $25.8 \%$ & $28.9 \%$ \\
\hline$\%$ Other Public & $1.4 \%$ & & $0.7 \%$ & $1.2 \%$ & $2.2 \%$ & $0.0 \%$ & $4.5 \%$ & $1.5 \%$ & $2.9 \%$ & $1.5 \%$ & $1.4 \%$ & $0.0 \%$ & $1.7 \%$ & $3.5 \%$ & $11.9 \%$ & $13.3 \%$ & $9.1 \%$ \\
\hline$\%$ Walk & $8.5 \%$ & & $2.8 \%$ & $1.9 \%$ & $3.6 \%$ & $1.4 \%$ & $2.3 \%$ & $1.5 \%$ & $2.9 \%$ & $1.5 \%$ & $2.1 \%$ & $2.2 \%$ & $2.5 \%$ & $3.5 \%$ & $13.5 \%$ & $8.6 \%$ & $26.4 \%$ \\
\hline$\%$ Other & $2.8 \%$ & & $0.0 \%$ & $1.9 \%$ & $0.7 \%$ & $2.1 \%$ & $0.0 \%$ & $0.0 \%$ & $1.4 \%$ & $1.5 \%$ & $1.4 \%$ & $2.2 \%$ & $1.7 \%$ & $0.7 \%$ & $5.6 \%$ & $3.1 \%$ & $10.7 \%$ \\
\hline$\%$ Unreported & $5.7 \%$ & & $1.4 \%$ & $1.2 \%$ & $2.9 \%$ & $2.8 \%$ & $3.0 \%$ & $2.2 \%$ & $2.1 \%$ & $2.2 \%$ & $4.3 \%$ & $0.7 \%$ & $1.7 \%$ & $2.8 \%$ & $2.4 \%$ & $3.9 \%$ & $4.1 \%$ \\
\hline \multicolumn{18}{|l|}{ Commuting PMT per Worker } \\
\hline $\begin{array}{l}\text { TOTAL Person Miles of } \\
\text { Travel (PMT) }\end{array}$ & 12.97 & & 14.34 & 16.42 & 15.01 & 15.00 & 13.67 & 15.08 & 13.50 & 12.01 & 22.54 & 19.74 & 16.07 & 18.41 & 10.70 & 11.42 & 8.52 \\
\hline$\%$ SOV & $76.9 \%$ & & $82.1 \%$ & $76.4 \%$ & $69.1 \%$ & $75.7 \%$ & $80.1 \%$ & $70.2 \%$ & $77.3 \%$ & $84.3 \%$ & $79.2 \%$ & $80.3 \%$ & $70.6 \%$ & $68.0 \%$ & $33.6 \%$ & $37.1 \%$ & $19.2 \%$ \\
\hline$\%$ MOV & $19.0 \%$ & & $17.0 \%$ & $14.6 \%$ & $28.5 \%$ & $21.9 \%$ & $14.9 \%$ & $29.0 \%$ & $19.3 \%$ & $12.8 \%$ & $12.9 \%$ & $12.9 \%$ & $11.0 \%$ & $11.1 \%$ & $13.7 \%$ & $13.3 \%$ & $15.5 \%$ \\
\hline$\%$ Other POV & & & & & & & & & & & & $0.1 \%$ & & & $0.2 \%$ & $0.3 \%$ & \\
\hline$\%$ Amtrak & & & & & & & & & & & & & $0.2 \%$ & & & & \\
\hline$\%$ Commuter Train & & & & & & & & & & & $2.1 \%$ & $4.0 \%$ & $13.2 \%$ & $14.2 \%$ & $6.6 \%$ & $6.2 \%$ & $8.7 \%$ \\
\hline$\%$ Subway/El Rail & & & & & & & & & $0.5 \%$ & & $0.0 \%$ & $0.8 \%$ & $2.6 \%$ & $1.1 \%$ & $26.2 \%$ & $27.7 \%$ & $20.2 \%$ \\
\hline$\%$ Other Public & $0.6 \%$ & & $0.1 \%$ & $5.2 \%$ & $1.0 \%$ & $0.1 \%$ & $3.7 \%$ & $0.5 \%$ & $1.9 \%$ & $0.6 \%$ & $4.2 \%$ & $0.6 \%$ & $0.9 \%$ & $2.1 \%$ & $9.2 \%$ & $10.4 \%$ & $4.1 \%$ \\
\hline$\%$ Walk & $0.8 \%$ & & $0.2 \%$ & $0.2 \%$ & $0.2 \%$ & $0.1 \%$ & $0.1 \%$ & $0.1 \%$ & $0.1 \%$ & $0.1 \%$ & $0.0 \%$ & $0.1 \%$ & $0.1 \%$ & $0.1 \%$ & $1.7 \%$ & $1.1 \%$ & $4.5 \%$ \\
\hline$\%$ Other & $1.2 \%$ & & $0.1 \%$ & $2.2 \%$ & $0.1 \%$ & $1.9 \%$ & $0.1 \%$ & & $0.4 \%$ & $1.8 \%$ & $0.9 \%$ & $1.2 \%$ & $0.5 \%$ & $2.5 \%$ & $8.1 \%$ & $3.4 \%$ & $27.2 \%$ \\
\hline \% Unreported & $1.4 \%$ & & $0.4 \%$ & $1.4 \%$ & $1.1 \%$ & $0.3 \%$ & $1.0 \%$ & $0.2 \%$ & $0.4 \%$ & $0.3 \%$ & $0.7 \%$ & $0.2 \%$ & $0.9 \%$ & $0.9 \%$ & $0.7 \%$ & $0.5 \%$ & $0.6 \%$ \\
\hline
\end{tabular}

Notes: ${ }^{a}$ All percentages may not add to $100 \%$ due to rounding. \% Other POV was only collected in 1995. 


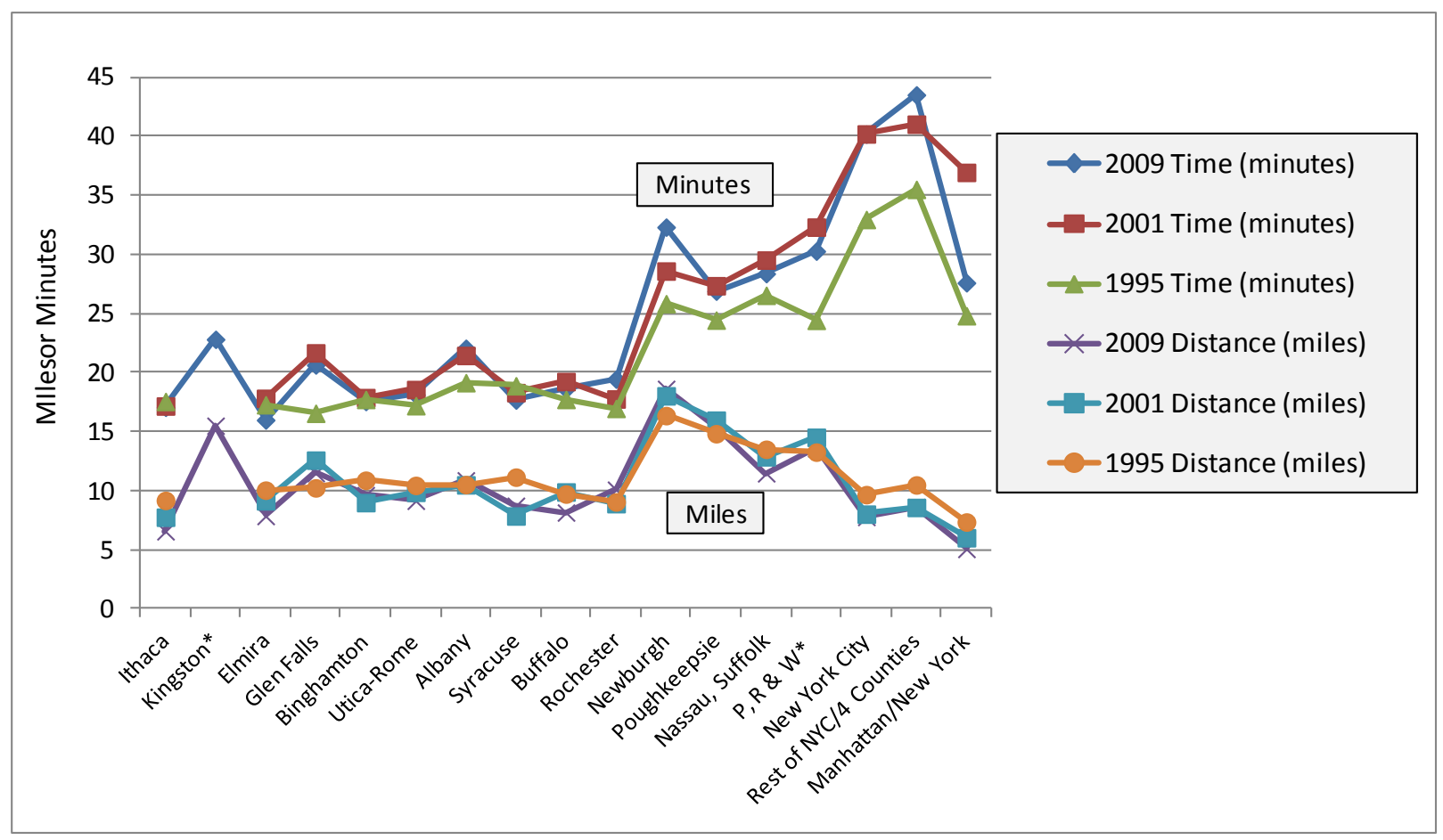

Figure 6.17 Average Commuting Distances and Travel Times for Individual NYS Metro Areas in 1995, 2001, and 2009.

Notes: $*$ P, R \& W = Putnam, Rockland and Westchester counties. *Kingston was not separated out prior to 2009.

\subsection{SUMMARY}

The travel characteristics observed in this chapter show some distinct patterns among NYS's MPO-served metro areas. Almost all comparisons suggest that NYS metro areas can be categorized into three distinctive groups, regardless of the size of the MSA within which each is located. The first group consists of New York/Manhattan, the second group consists of the remaining four counties of NYC, and the last group consists of all of the remaining metro areas, including the rest of the NYMTC MPO areas located outside NYC (i.e., the Nassau and Suffolk, and Putnam, Rockland, and Westchester county portions of the NYMTC). The second group has travel patterns that tend to fall somewhere between those of the first and the third groups. When data for New York/Manhattan residents are combined with those for the rest of the NYC, the unique travel characteristics of these Manhattan residents become obscured. Therefore, any comparisons in travel characteristics based on MPO boundaries should be made with caution.

Many of the differences between NYC counties and others in the state result from the striking differences in private vehicle ownership levels, with less than one in two NYC drivers and only 64\% of NYC households owning a vehicle in 2009: versus 9 out of 10 drivers owning a vehicle, and between 1.5 and 2 vehicles owned per household, on the average, in the state's other 
metro areas (Table 6.2). And this situation has changed very little over the past fourteen years covered by the three NHTS surveys. While households in metro areas outside NYC do not own a vehicle largely due to income constraints, many households in New York/Manhattan do not own a vehicle by choice. However, the statistics presented in this chapter suggest that the mobility of zero-vehicle households in New York/Manhattan is by no means deterred by the lack of a vehicle. While the private vehicle tripmaking rate of NYC residents was between one half and one third that in the state's other metro areas, and their daily VMT about half that of other metro areas (Table 6.13), most of their daily travel needs were met by walking or by public transit. As a result, their daily tripmaking rates remain consistent with those of vehicle-owning households when all modes of travel are considered (Tables 6.10, 6.11 and 6.12). This again indicates that owning a vehicle or being a driver in NYC was less important for meeting a household's mobility needs than anywhere else in NYS. The high levels of public transit usage within NYC replace a great deal of automobile use, and this plus greater use of walk trips results in significantly lower travel generated carbon dioxide emissions per household in NYC than elsewhere in the state (Figure 6.16). In contrast, the comparatively limited level of public transit ridership in the state's smaller and medium sized metro areas places a much greater reliance on the privately owned vehicle, be it an automobile or the increasingly popular SUV (Table 6.17). 


\section{SUMMARY}

This report is based on the 2009 NHTS, and is the third comparison report commissioned by NYSDOT. Several key questions were addressed through Chapters 2-6. The question of whether NYS residents are different from residents elsewhere in the nation with respect to personal mobility was discussed in Chapter 2. Chapter 3 answered the question of "to what extent do the travel patterns of NYC residents skew the overall travel statistics in the state?" Such impact proves to be substantial so Chapter 4 addressed how New York residents outside NYC travel differently from the rest of the nation. The remaining two Chapters, 5 and 6, in this report discussed the regional comparisons, including how the Metropolitan planning areas are different from each other in travel patterns and what trends are presented over time. A summary of findings from all chapters is included below. For ease of references, tables of most frequently used statistics are also summarized and presented in this chapter (Tables 7.1 and 7.2).

\subsection{EMPIRICAL FINDINGS}

\subsubsection{Sample Sizes and Weighted Sums}

For the state of New York, information was gathered for a total of 16,165 households, comprised of both add-on and national sample households in NYS. These households include 33,435 persons, 29,778 personal use vehicles, and 125,402 daily trips. The add-on sample households make it possible to develop statistically more robust trip rates and other travel statistics that can be applied at a more detailed geographic level within the state. Figure 7.1 shows the New York add-on sample areas.

The NHTS uses weights to expand the estimates derived from the sample data to the entire NYS population. Summary statistics for demographics and travel measures are presented in Tables 7.1 and 7.2 in weighted terms. These weights reflect the sample design and selection probabilities, over-sampling of certain strata, and adjustments necessary to compensate for survey non-response and non-coverage. The weights are multiplicative factors that must be applied to the variables in order to obtain valid estimates of population values. If the weights are not used, incorrect estimates will result. This is because un-weighted estimates only represent characteristics in the selected samples; they are not necessarily reflecting characteristics of the general population. For example, the overall average number of un-weighted daily sample person trips per household for the state of New York, according to the 2009 NHTS, is 7.8, whereas the overall number of weighted daily person trips per household is 9.3 (see Table 7.2). 


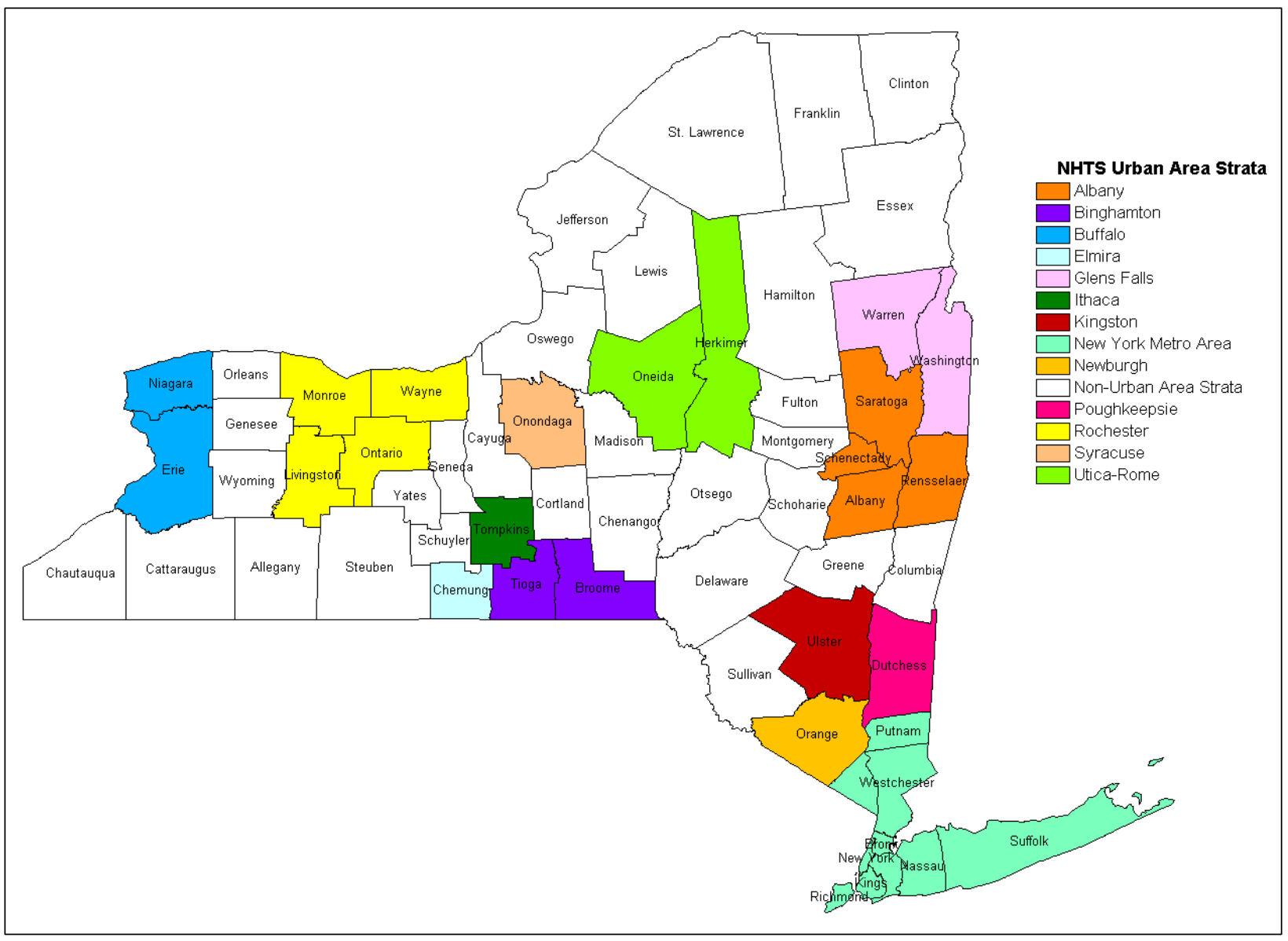

Figure 7.1 2009 NHTS New York Add-on Areas. 
Table 7.1 Summary Statistics on Demographic Characteristics based on 1995, 2001, and 2009 NPTS/NHTS for New York State and the Rest of the United States

\begin{tabular}{|c|c|c|c|c|c|c|}
\hline & \multicolumn{3}{|c|}{ New York State } & \multicolumn{3}{|c|}{ Rest of the United States } \\
\hline & 1995 NPTS & 2001 NHTS & 2009 NHTS & 1995 NPTS & 2001 NHTS & 2009 NHTS \\
\hline Households & $6,848,091$ & $7,183,208$ & $7,137,482$ & $92,858,005$ & $100,182,138$ & $105,963,848$ \\
\hline Person 5 Years or Older & $16,806,988$ & $17,394,393$ & $18,281,802$ & $224,868,012$ & $240,182,520$ & $264,772,070$ \\
\hline $5-15$ & $3,001,540$ & $2,805,630$ & $2,620,244$ & $40,090,427$ & $42,179,264$ & $42,104,086$ \\
\hline $16-19$ & 878,870 & 992,404 & $1,367,344$ & $13,195,492$ & $13,303,140$ & $18,046,333$ \\
\hline $20-34$ & $2,562,132$ & $3,810,147$ & $3,462,800$ & $55,102,487$ & $53,869,880$ & $47,380,739$ \\
\hline $35-54$ & $3,278,947$ & $5,486,605$ & $5,721,580$ & $68,330,367$ & $73,681,305$ & $86,057,563$ \\
\hline $55-64$ & 703,052 & $1,591,252$ & $2,502,163$ & $18,971,162$ & $22,536,612$ & $34,921,001$ \\
\hline 65 and over & $2,070,923$ & $2,305,198$ & $2,607,670$ & $29,178,077$ & $30,578,871$ & $36,262,348$ \\
\hline Not reported & - & 403,158 & - & - & $4,033,447$ & - \\
\hline Persons 5 Years or Older & $16,806,988$ & $17,394,393$ & $18,281,802$ & $224,868,012$ & $240,182,520$ & $264,772,070$ \\
\hline Male & $8,135,143$ & $8,284,292$ & $8,845,089$ & $109,500,857$ & $117,036,551$ & $130,411,972$ \\
\hline Female & $8,671,845$ & $9,110,101$ & $9,436,713$ & $115,367,155$ & $123,129,487$ & $134,360,098$ \\
\hline Drivers & $10,469,256$ & $11,167,231$ & $12,837,944$ & $165,861,154$ & $179,257,521$ & $199,471,054$ \\
\hline Male & $5,513,627$ & $5,729,689$ & $6,510,017$ & $82,966,036$ & $88,920,926$ & $100,302,575$ \\
\hline Female & $4,955,629$ & $5,437,541$ & $6,327,927$ & $82,895,118$ & $90,335,791$ & $99,168,479$ \\
\hline Workers & $8,774,635$ & $9,645,253$ & $9,759,446$ & $122,922,732$ & $135,626,865$ & $141,613,652$ \\
\hline Male & $4,702,897$ & $5,061,833$ & $5,112,346$ & $66,401,752$ & $73,202,538$ & $76,826,562$ \\
\hline Female & $4,071,739$ & $4,583,420$ & $4,647,099$ & $56,520,980$ & $62,423,880$ & $64,787,090$ \\
\hline Total Household Vehicles (000) & 7,922 & 9,545 & 9,144 & 168,145 & 193,041 & 202,357 \\
\hline
\end{tabular}

Notes: *excluding $0-4$ year olds; Sample errors can be magnified and lead to serious inaccuracies when weights are not used in tabulating the data. 
Table 7.2 Summary Statistics on Travel based on 1995, 2001, and 2009 NPTS/NHTS for New York State and the Rest of the United States

\begin{tabular}{|c|c|c|c|c|c|c|}
\hline & \multicolumn{3}{|c|}{ New York State } & \multicolumn{3}{|c|}{ Rest of the United States } \\
\hline & 1995 NPTS & 2001 NHTS & 2009 NHTS & 1995 NPTS & 2001 NHTS & 2009 NHTS \\
\hline Total Vehicle Trips $(000,000)$ & 11,023 & 10,886 & 10,877 & 218,723 & 222,144 & 222,973 \\
\hline Average Daily Vehicle Trips/Household & 4.4 & 4.2 & 4.2 & 6.5 & 6.1 & 5.8 \\
\hline Average Daily Vehicle Trips/Driver & 2.9 & 2.7 & 2.3 & 3.6 & 3.4 & 3.1 \\
\hline Average Vehicle Trip Length (miles) & 8.78 & 8.92 & 8.62 & 9.07 & 9.91 & 9.77 \\
\hline Total Vehicle Miles of Travel $(000,000)$ & 95,571 & 95,209 & 92,171 & $1,972,797$ & $2,179,560$ & $2,152,940$ \\
\hline Average Daily Vehicle Miles/Household & 38.2 & 36.3 & 35.4 & 58.2 & 59.6 & 55.7 \\
\hline Average Daily Vehicle Miles/Driver & 25.0 & 23.4 & 19.7 & 32.6 & 33.3 & 29.6 \\
\hline Average Vehicle Occupancy & 1.60 & 1.63 & 1.67 & 1.59 & 1.63 & 1.67 \\
\hline Total Person Trips $(000,000)^{*}$ & 23,810 & 23,705 & 24,281 & 355,120 & 360,704 & 367,742 \\
\hline Average Daily Person Trips/Household & 9.5 & 9.0 & 9.3 & 10.5 & 9.9 & 9.5 \\
\hline Average Daily Person Trips/Person & 3.9 & 3.7 & 3.6 & 4.3 & 4.1 & 3.8 \\
\hline Average Person Trip Length (miles) & 7.74 & 8.30 & 7.49 & 9.23 & 10.14 & 9.89 \\
\hline Total Person Miles of Travel $(000,000)^{*}$ & 177,072 & 186,685 & 171,875 & $3,234,049$ & $3,597,163$ & $3,560,916$ \\
\hline Average Daily Person Miles/Household & 70.8 & 71.2 & 66.0 & 95.4 & 98.4 & 92.1 \\
\hline Average Daily Person Miles/Person & 28.9 & 29.4 & 25.8 & 39.4 & 41.0 & 36.8 \\
\hline Average Daily Commute Person Trips/Worker & 1.31 & 1.12 & 1.06 & 1.40 & 1.15 & 1.11 \\
\hline Average Daily Commute Person Miles/Worker & 13.97 & 10.79 & 10.15 & 16.08 & 13.78 & 12.99 \\
\hline Transit Mode Share of Person Trips & $9.3 \%$ & $9.5 \%$ & $9.9 \%$ & $1.2 \%$ & $1.0 \%$ & $1.2 \%$ \\
\hline Transit Mode Share of Commute Trips & $18.3 \%$ & $20.1 \%$ & $19.6 \%$ & $2.9 \%$ & $2.5 \%$ & $2.3 \%$ \\
\hline
\end{tabular}

Notes: *excluding $0-4$ year olds; Sample errors can be magnified and lead to serious inaccuracies when weights are not used in tabulating the data. 


\subsubsection{Vehicle Ownership}

From a statewide perspective, personal travel in NYS and the rest of the nation differs in a number of significant ways. While less than $10 \%$ of households outside NYS are without a vehicle, over $25 \%$ of all NYS households have no vehicle (Figure 7.2). Many NYS households do not own a vehicle largely by choice ${ }^{18}$, whereas those elsewhere do not own a vehicle largely due to income constraints.

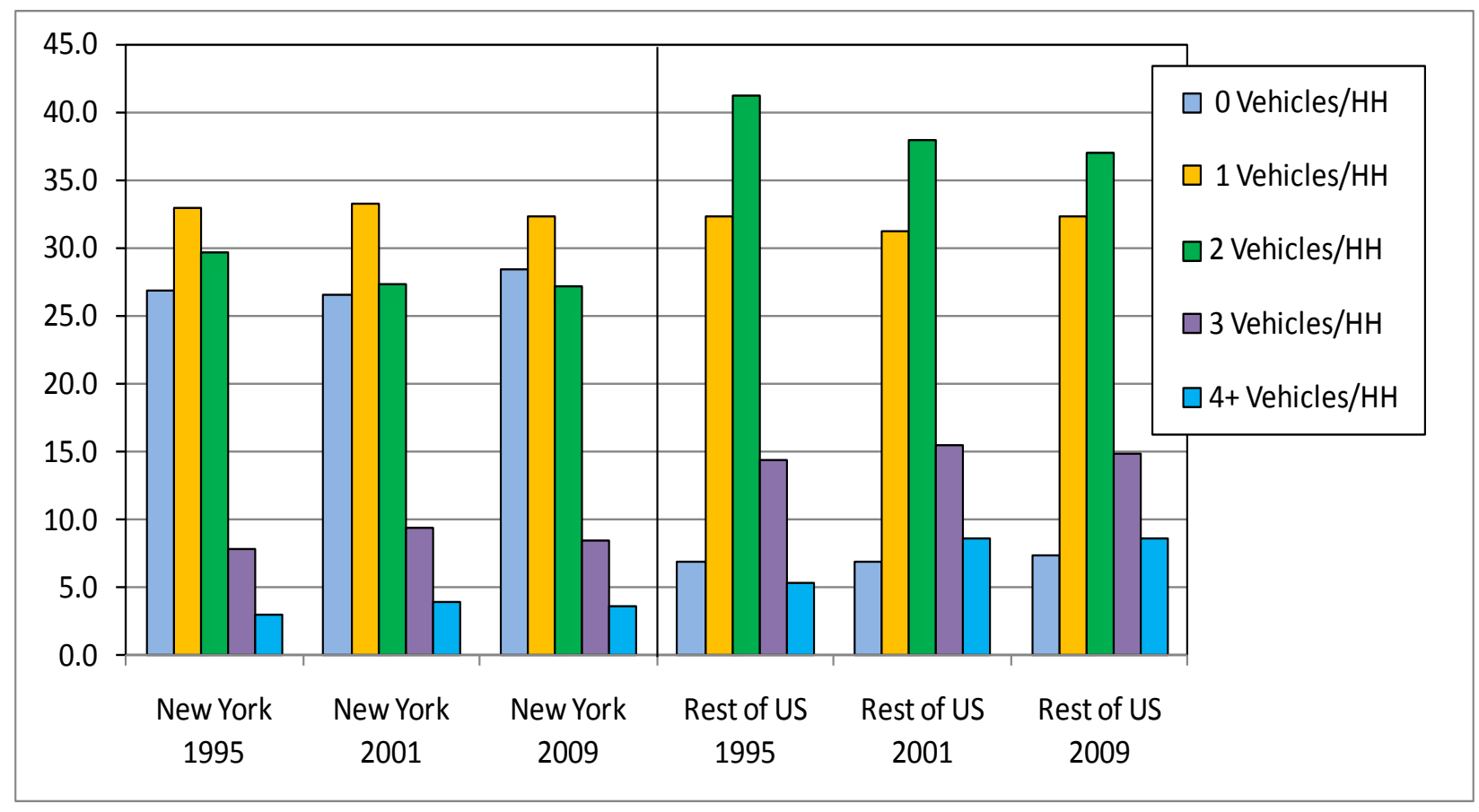

Figure 7.2 Distribution of Households Owning Vehicles in New York vs. Rest of the United States in 1995, 2001, and 2009

\subsubsection{Personal Mobility}

NYS residents consistently have taken fewer and shorter trips, and have driven considerably fewer miles than those in the rest of the United States over the three survey years (Figure 7.3). Specifically, NYS drivers traveled just under 20 miles daily, on the average, versus about 30 miles by drivers from the rest of the nation. The number of daily person trips per person and the daily VMT per driver show a gradual decline both across the state and across the rest of the nation, with a more noticeable decline in the daily VMT for both NYS and the rest of the nation between 2001 and 2009. On the other hand, average trip rates for residents of NYS and those in the rest of U.S. were closer to one another in 2009 than in previous survey years.

\footnotetext{
${ }^{18}$ While only 1 in 3 of these NYC households had an income under \$20,000 in 2009, 2 in 3 households were in these two lowest income classes in 2009 in both the rest of NYS and the rest of the nation
} 


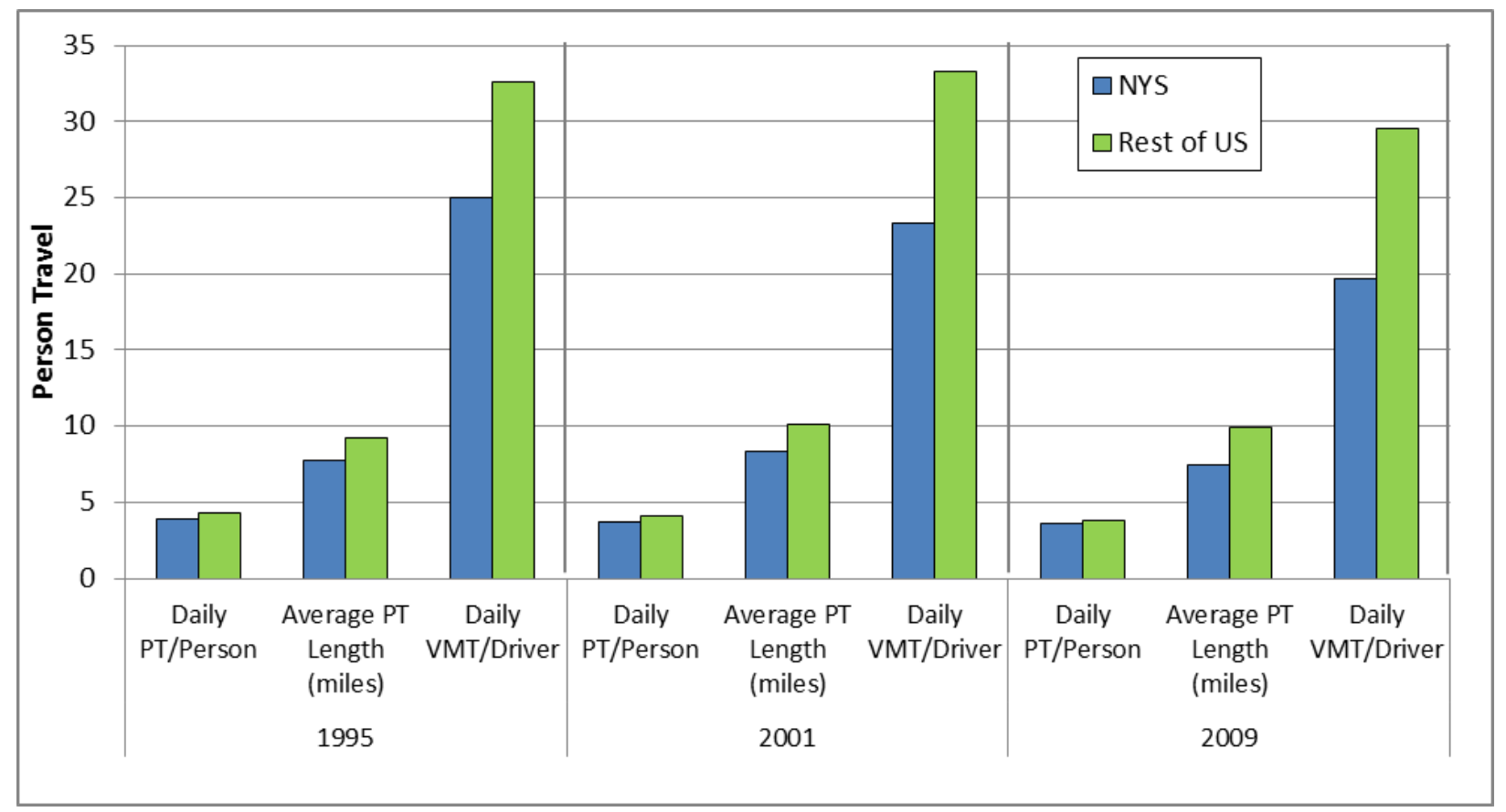

Figure 7.3 Personal Mobility Statistics in New York State vs. Rest of the

\section{United States.}

\subsubsection{Vehicular Travel}

In 2009, NYS drivers made an average of 2.3 trips daily, versus just over 3 trips daily by drivers in the rest of the nation. Both the median and average age of the household vehicle fleet is lower in NYS than elsewhere in that year. In 2009, 70\% of the NYS households' private vehicle fleet was made up of vehicles reported to be less than 10 years old. In the rest of the nation this percentage was $60 \%$. There is also a much lower share of pickup trucks reported in use by NYS households, at $8.6 \%$ of all NYS vehicles surveyed in 2009 , versus $18.3 \%$ in the rest of the nation.

\subsubsection{Impact of Not Owning a Vehicle on Mode Choice}

The relative popularity of walk trips in NYS, coupled with its transit options, renders a private vehicle unnecessary for many residents of the state. Privately owned household vehicles accounted for $79 \%$ of all NYS households' PMT in 2009, versus $89 \%$ in the rest of the United States. However, and due in large part to travelers in NYC, NYS residents on the average used public transit modes (notably rail and bus) significantly more than residents in the rest of the nation; about $10 \%$ vs. $1 \%$ respectively when measured in terms of the percentage of trips taken in 2009; or 6\% vs. 1\%, respectively if measured by PMT. Walk trips were also a much larger percentage of trips made in all three surveys, reaching $22 \%$ of total person trips in 2009 by NYS households, versus just under $10 \%$ in the rest of the nation. These walk trips accounted for $2.3 \%$ of all PMT in the state in 2009, three times the $0.7 \%$ share of PMT reported for the rest of the 
nation. Bike trip rates in NYS were similar to those in the rest of the country. In the same year, NYS residents reported an average of 12.3 minutes spent walking or (to a much lesser extent) cycling per day, which was double the 6.2 minutes per day average reported in the rest of the nation. In terms of commute person trips, NYS workers are eight times more likely to use public transit, and three times more likely to walk to work compared to workers in the rest of the nation. Combining these to non-auto modes, the percentage of total commute trips taken either by public transit or walking in New York State is almost six times that elsewhere, at $28 \%$ vs. 5\%.

\subsubsection{Energy Related CO2 Emissions Associated with Travel}

Significantly greater use of non-motorized forms of travel (walk and cycle) and of public transit modes, a significantly lower average tip length, and lower daily trip rates meant that New York households on average emitted far fewer carbon dioxide emissions annually from their daily travel activities than did households in the rest of the nation, in both 2001 and 2009 (Figure 7.4). ${ }^{19}$

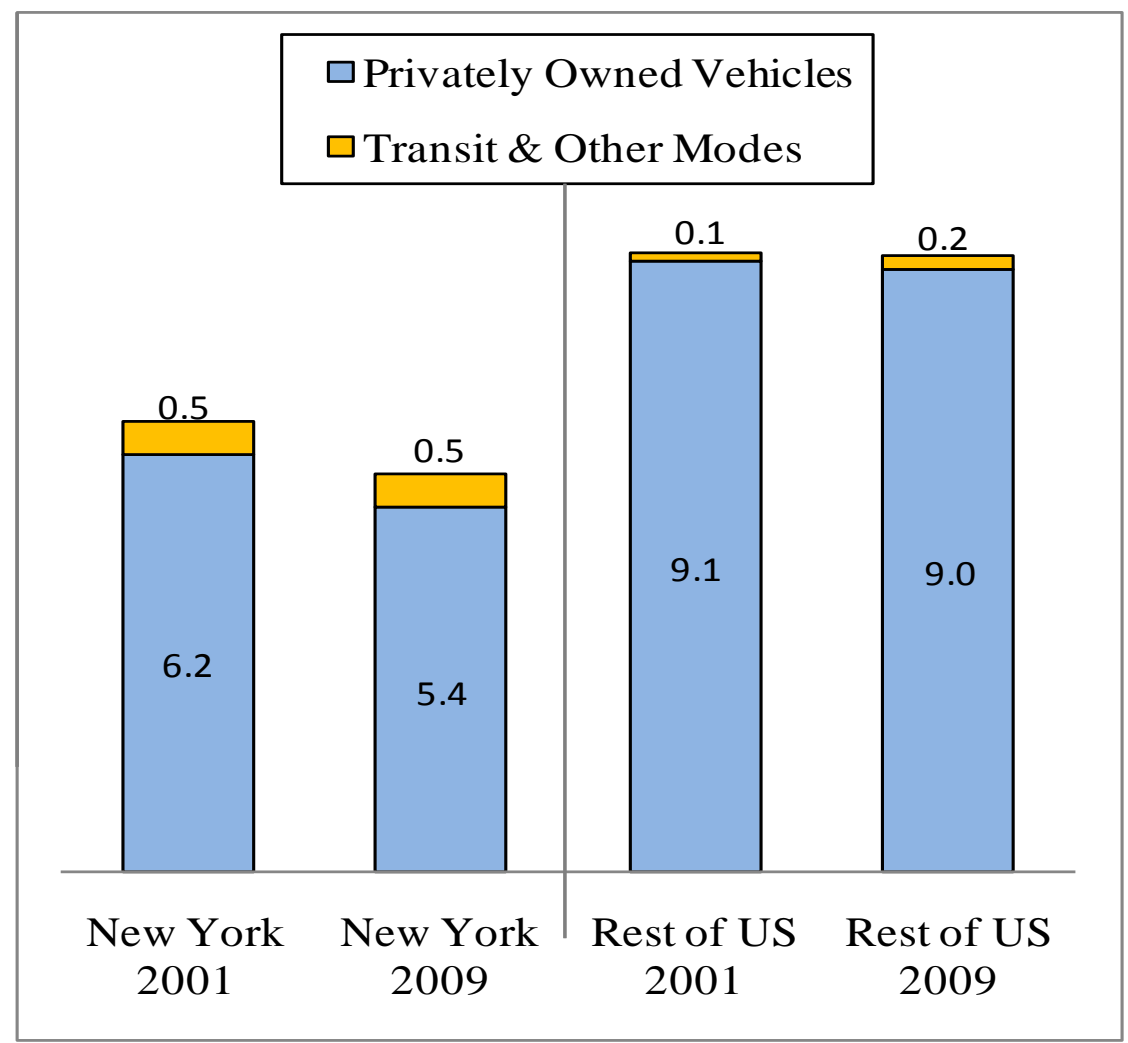

Figure 7.4 Annual Carbon Dioxide Emissions (Metric

Tons of CO2) from Travel per Household in 2001 and 2009:

New York State vs. Rest of the United States.

\footnotetext{
${ }^{19}$ Emissions data was not available in the 1995 NPTS.
} 


\subsection{THE INFLUENCE OF NEW YORK CITY ON THE STATE'S PERSONAL TRAVEL STATISTICS}

As expected, the travel patterns of NYC residents differ significantly in a number of ways from patterns found elsewhere in the state, as well as in the nation as a whole. Several of these differences are presented in the following subsections.

\subsubsection{Vehicle Ownership and Income}

Only $72 \%$ of NYC residents over the age of 16 held a driver's license in $2009(65 \%$ of women, $80 \%$ of men), versus $89 \%$ of residents in the rest of the state and also $89 \%$ in the rest of the nation. Households in the rest of NYS resemble households elsewhere in the United States in terms of vehicle ownership; with more than $90 \%$ of households owning at least one vehicle (Figure 7.5). Over half of NYC households do not own any vehicles in all three NPTS/NHTS survey years. NYC households are also far less likely on the average to own more than one vehicle than other NYS households, or households elsewhere. Outside NYC, about $58 \%$ of NYS households owned more than one vehicle in 2009. In the rest of the nation this number was $60 \%$ (Figure 7.5).

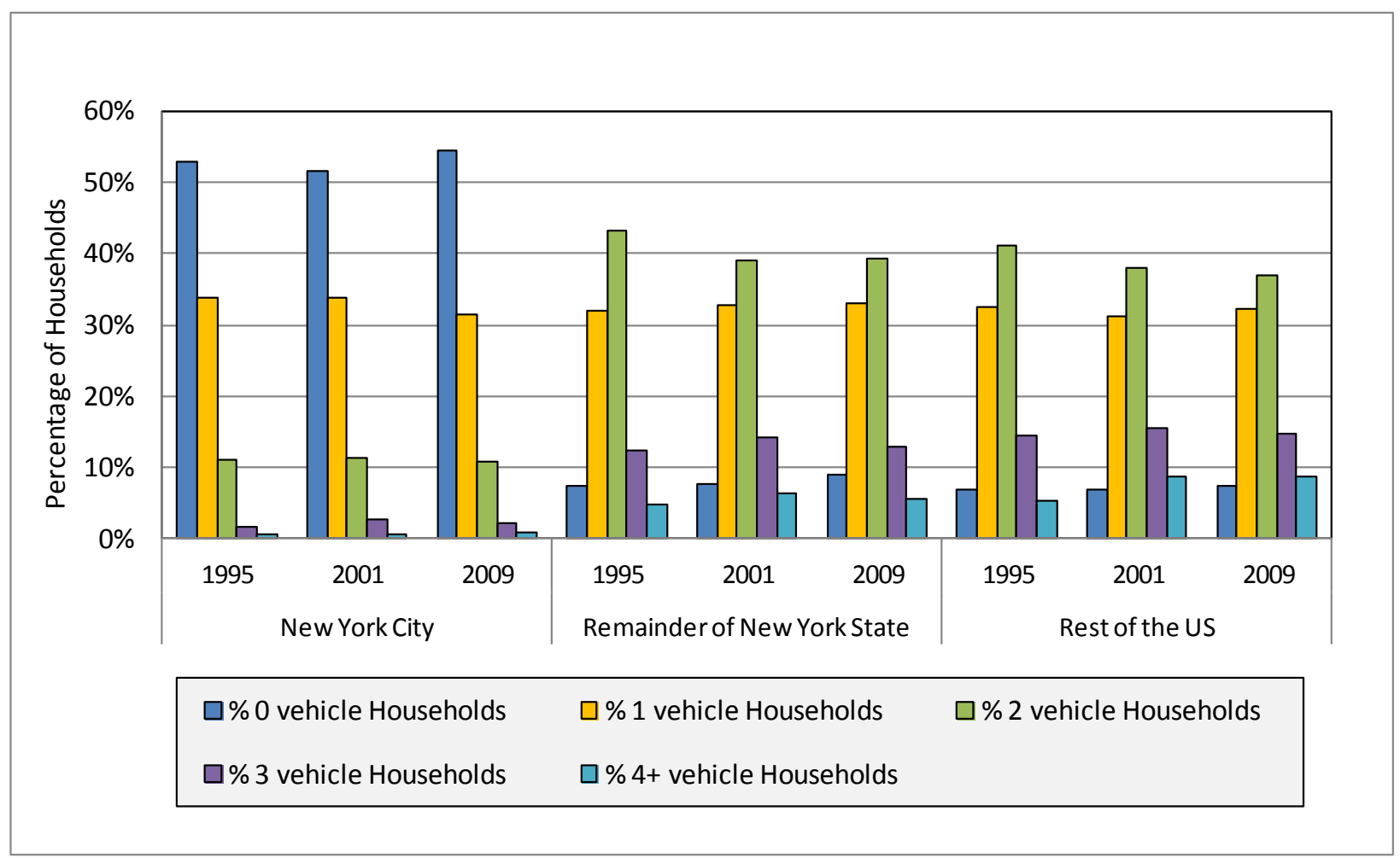

Figure 7.5 Distribution of Households by Number of Vehicles in 1995, 2001, and 2009. 
The income distribution of households without a vehicle is dramatically different in NYC. Approximately $60 \%$ of zero-vehicle households in the rest of the state and nation have incomes below $\$ 20,000$, while this proportion is only around one third for NYC. However, NYC households that do not own a vehicle are much more mobile than similar households in the rest of the state and nation, with daily person trip rates maintained by larger numbers of public transit and walk trips. As a result, while zero-vehicle owning households in the rest of the state and nation typically take roughly one third fewer person trips than the average household, this mobility gap is not evident for NYC households (Figure 7.6).

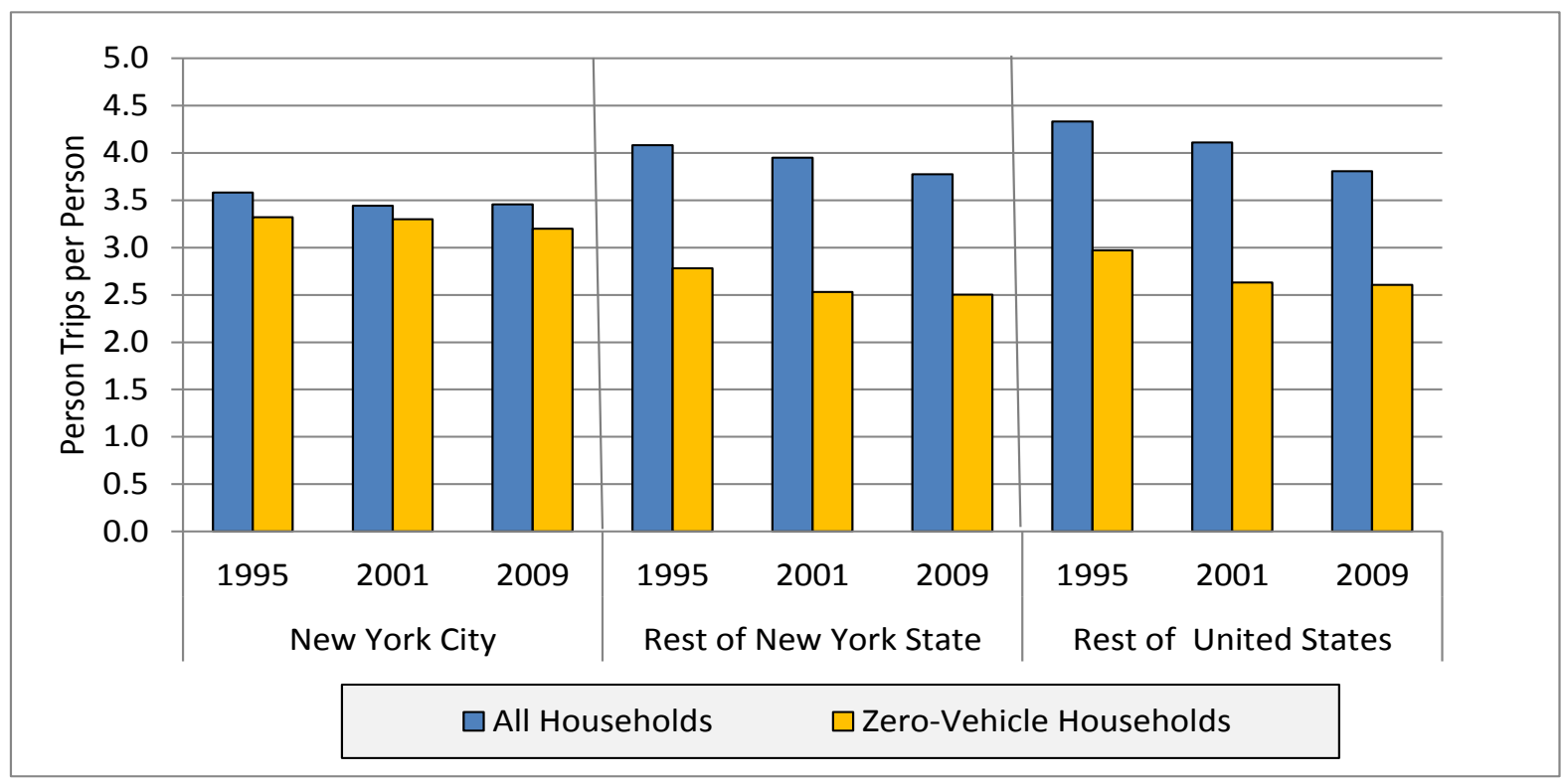

Figure 7.6 Effects of Not Owning a Vehicle on Daily Person Trips per Person.

\subsubsection{Trip Rates and Trip Distances}

On the average, NYC residents take fewer trips and significantly shorter trips than other NYS residents, or those located outside NYS (Figure 7.7). The difference in number of trips, however, has been narrowing over time. The distribution of trip purposes among NYC residents, even with the share of Family/Personal Business and Social/Recreation trips slightly increasing and Earning a Living trips slightly decreasing, is about the same as that in the rest of the country. 


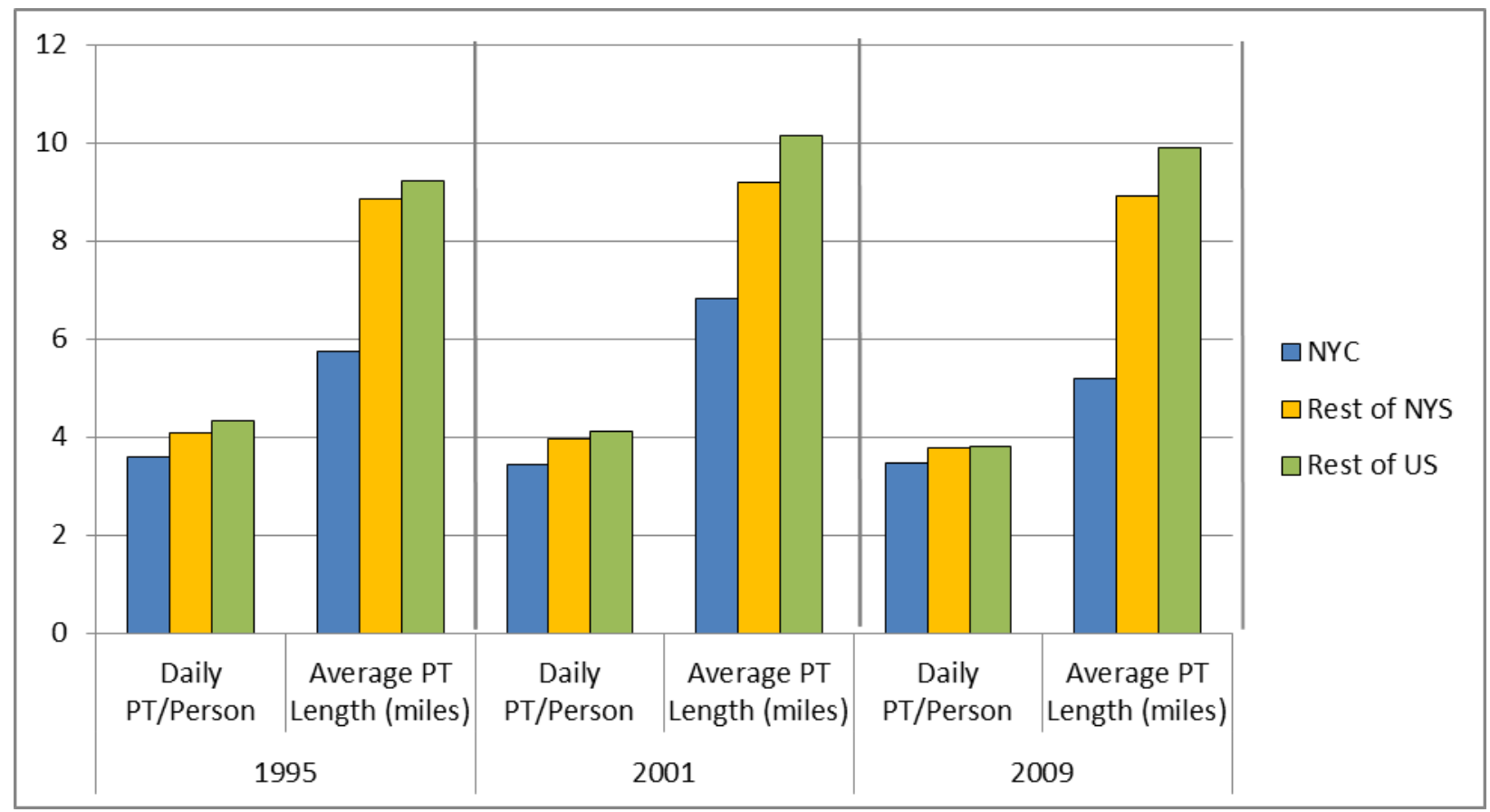

Figure 7.7 Daily Person Trips per Person and Average Trip Length (miles).

\subsubsection{Travel Mode}

Given the large proportion of zero-vehicle households within NYC, how NYC residents get to places is very different from that of households elsewhere. Residents of NYC are nearly four times more likely to walk to their destinations and twelve times more likely to use public transit than those in the rest of the state, with such differences even larger compared to those outside NYS (Figure 7.8).

\subsubsection{Carbon Dioxide Emissions}

As described earlier, NYS households on the average emit significantly fewer travel generated carbon dioxide emissions annually than do households in the rest of the nation. Figure 7.9 shows that much of this difference is also attributable to the travel characteristics of NYC households, who as reported above have shorter average trip distances, who walk a good deal more to activities, and who make much greater use of public transit modes for their daily travel needs. On average, NYC households in 2009 emitted less than $40 \%$ of the personal travel related $\mathrm{CO} 2$ emissions of households in the rest of the state, and only one third the emissions of households in the rest of the nation. Excluding NYC households, households in the rest of the state exhibit travel characteristics that are, for the most part, quite similar to those for the rest of the nation. 


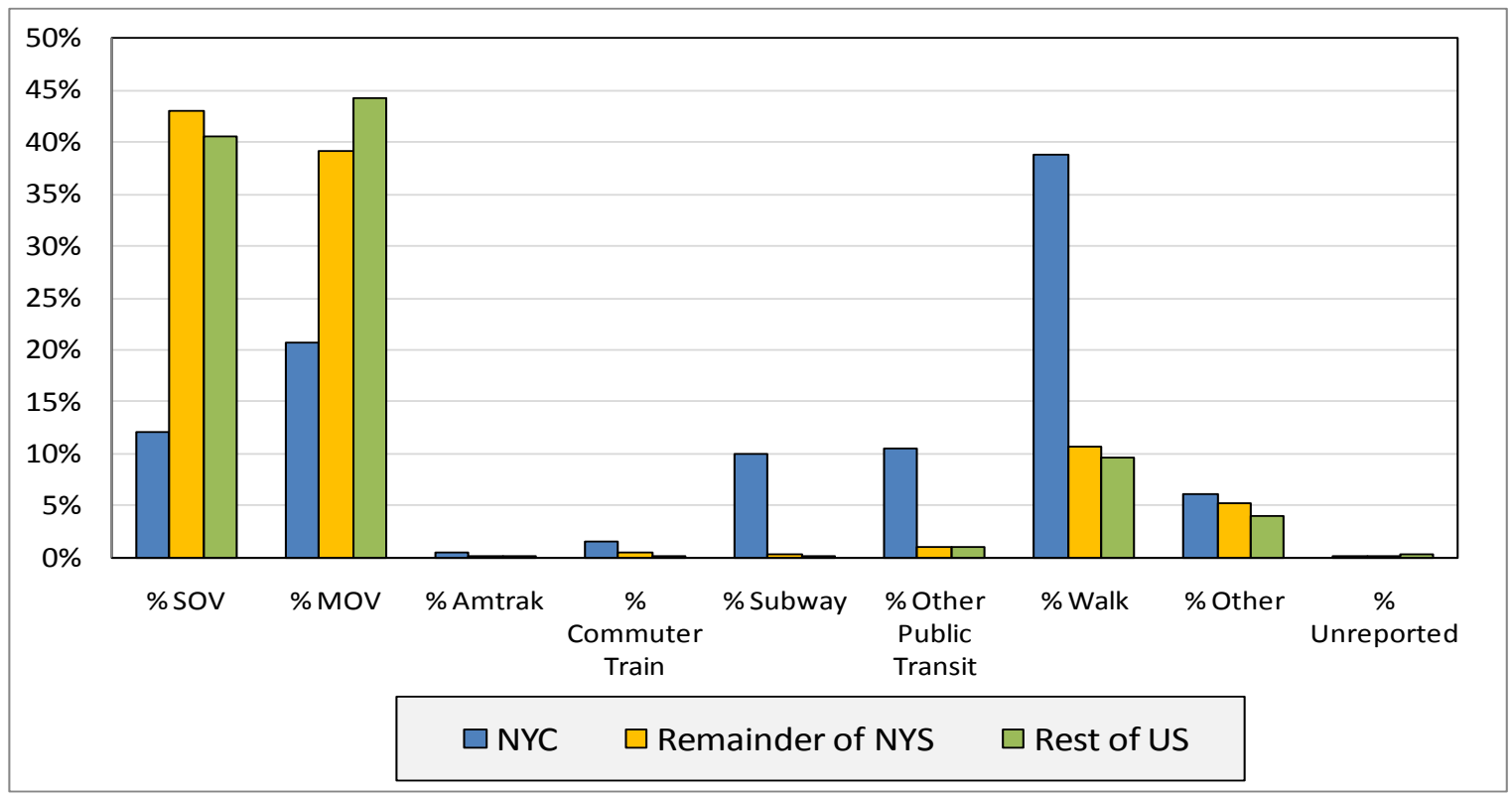

Figure 7.8 Person Trip Percentages by Selected Modes, New York City, Remainder of New York State, and Rest of the United States in 2009.

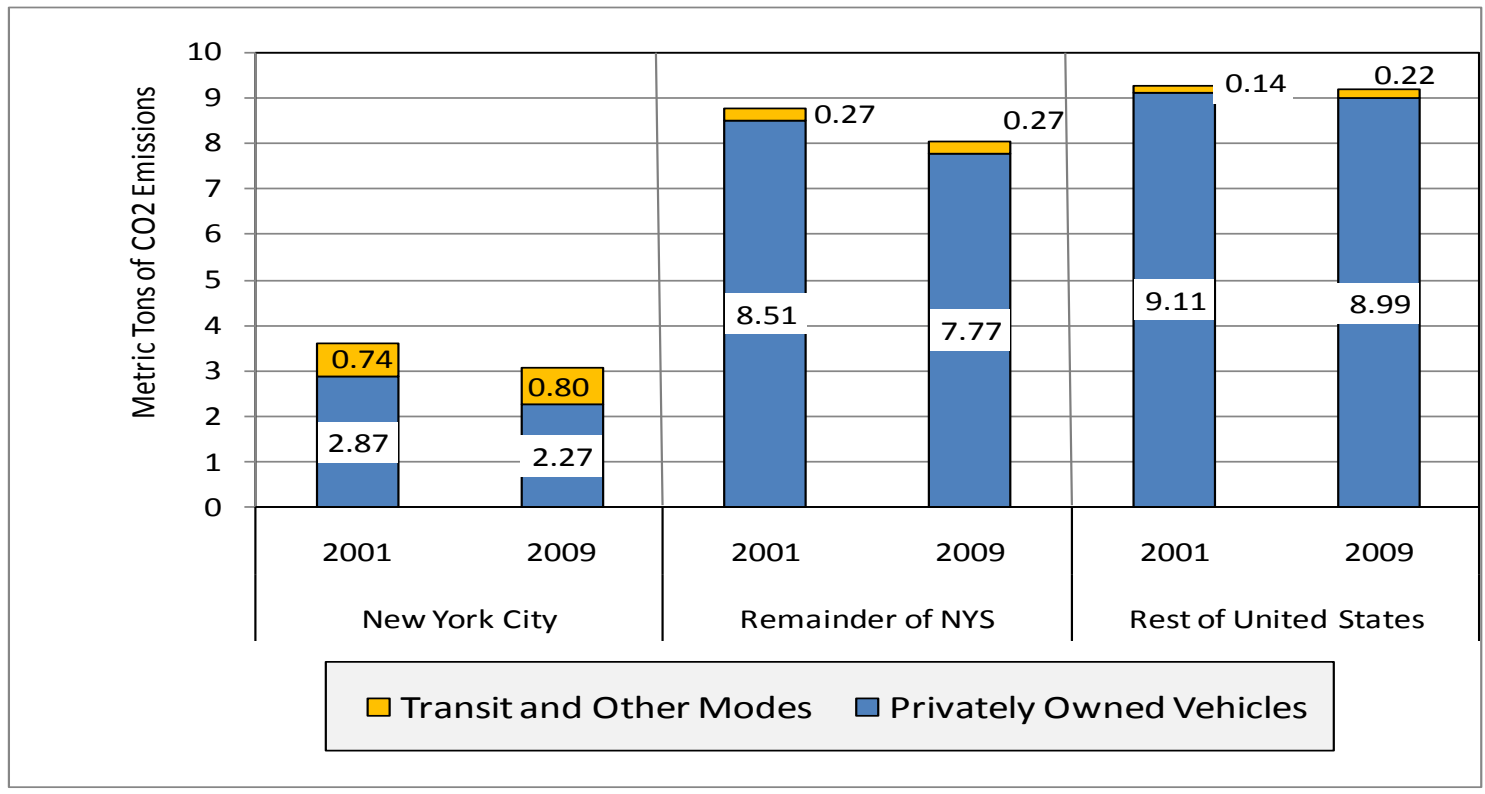

Figure 7.9 Average Annual Emissions of Carbon Dioxide (Metric Tons of CO2) from Household Travel* in 2001 and 2009.

Note: * Direct, vehicle operating emissions only, no "upstream" emissions associated with fuel or vehicle production or infrastructure supply included. 


\subsection{HOW PERSONAL TRAVEL STATISTICS VARY WITH URBAN POPULATION DENSITIES}

NYC residential and employment densities are much higher than those in most of the rest of the state and nation. This begs the question how such densities affect travel activity patterns, both within and outside the state. The percentage of households without a vehicle is, as we might expect, positively correlated with higher population density (Figure 7.10). Such relationships with density also exist between driver rates (which fall as density increases) and the availability of public transit (which rises as density increases).

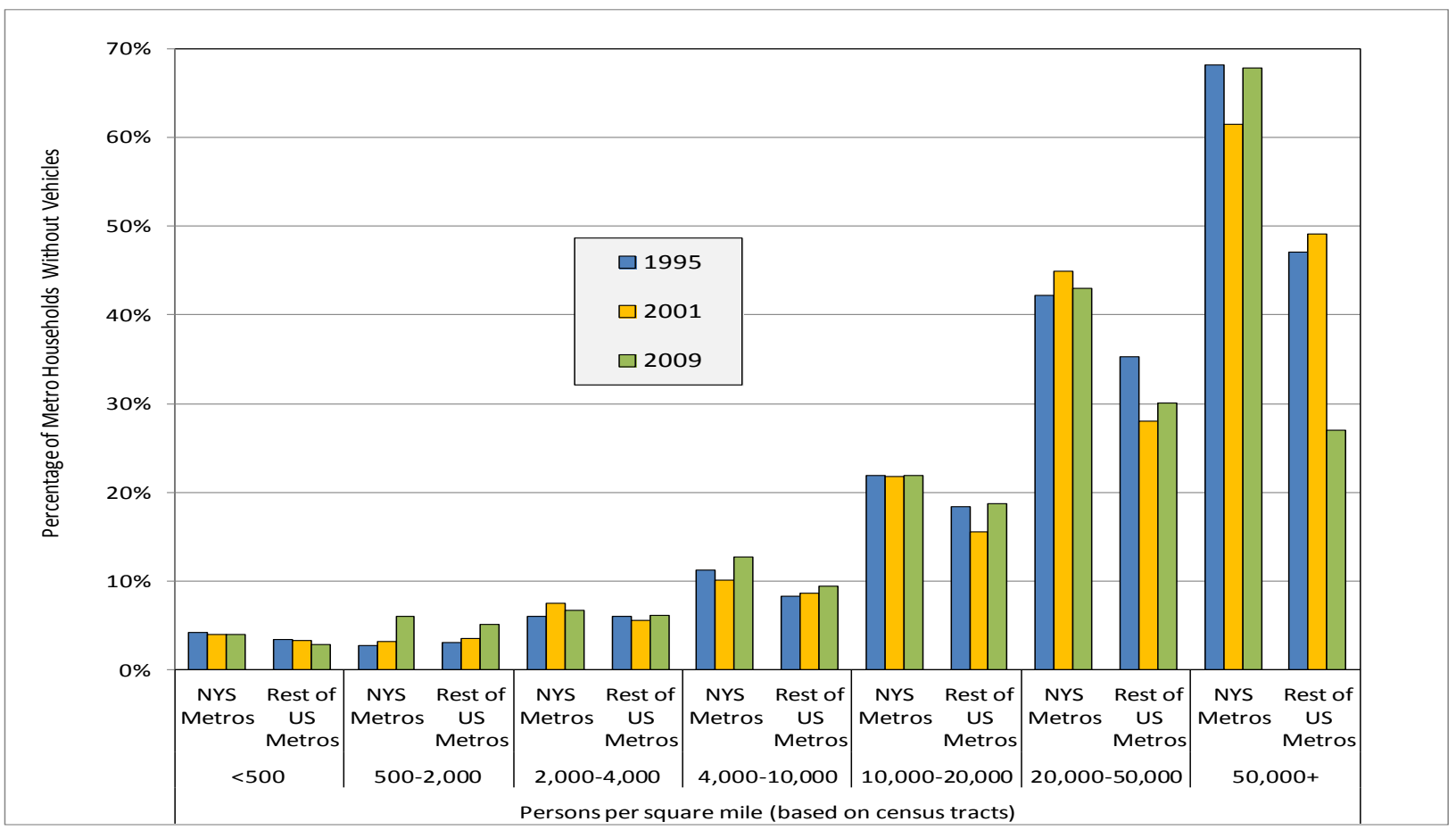

Figure 7.10 Percentages of Households Without a Vehicle Broken Down by Population Density, New York Metros vs. Metros Outside New York State.

Note: Differences in $\% \mathrm{~s}$ for the Rest of MSAs in US in the $>50,000$ ppsm class are based on small sample sizes and may be overstated.

\subsubsection{Trip Rates, Mode Choice and Population Density}

Figure 7.11 below shows the relationship between daily trip rate and population density first increasing, then declining as population density increases. Also of note is the reduced difference in 2009 between the generally higher 1995 and 2001 NYS person trip rates versus those in the rest of the United States, at most density levels. In terms of mode choice, public transit and walk modes accounted for ten times the percentage of NYS metro area trips among 2009 travelers in the highest density class $(47.6 \%$ walk $+23.7 \%$ transit $=71.3 \%$ of person trips $)$ 
than they did in the lowest density class $(6.9 \%$ walk $+0.4 \%$ transit $=7.3 \%$ of person trips $)$, with the metro areas in the rest of the nation in 2009 displaying a similar result (Figure 7.12).

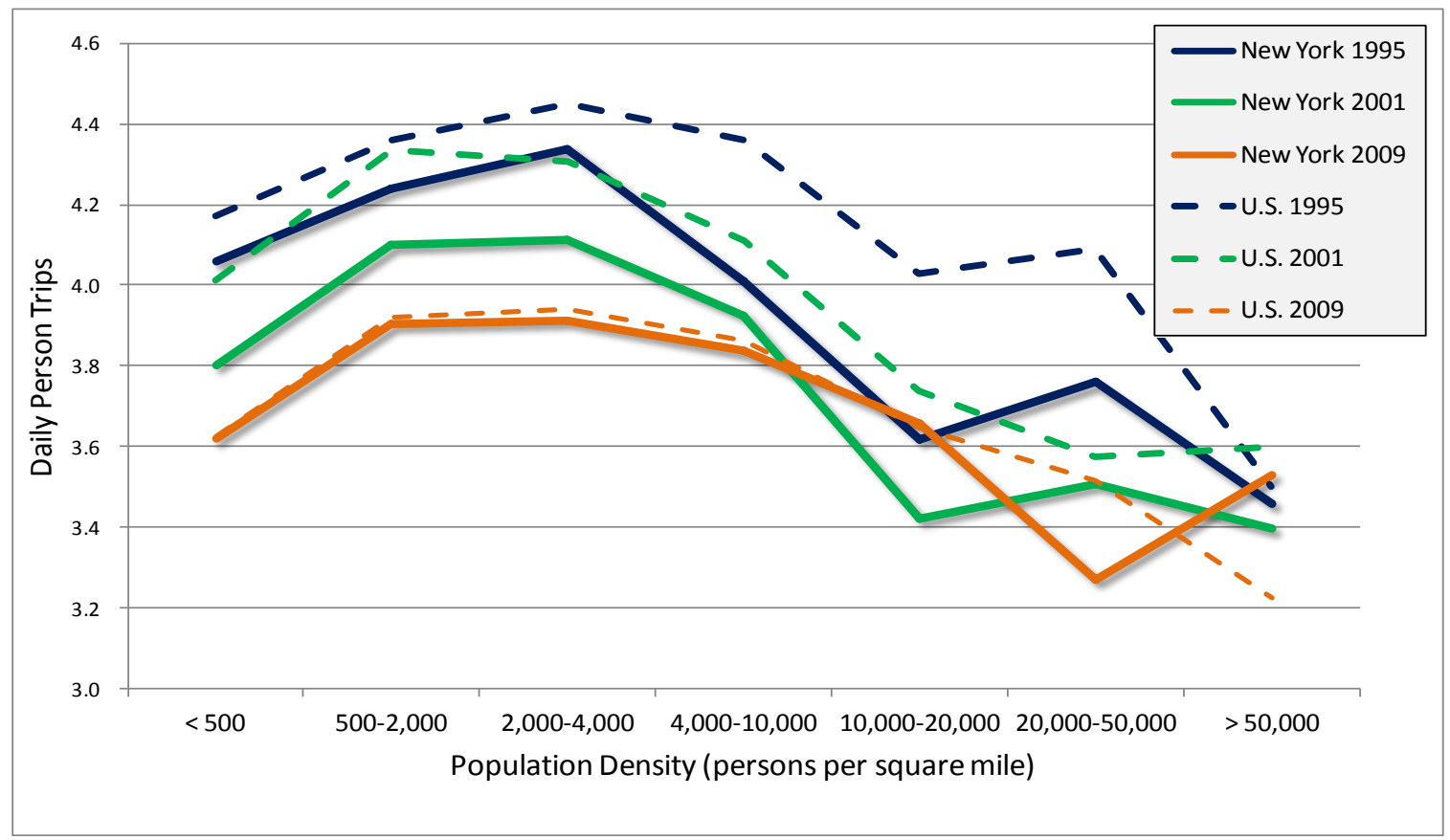

Figure 7.11 Daily Person Trips by Population Density: New York State Metros vs. Metros Found Outside New York State.

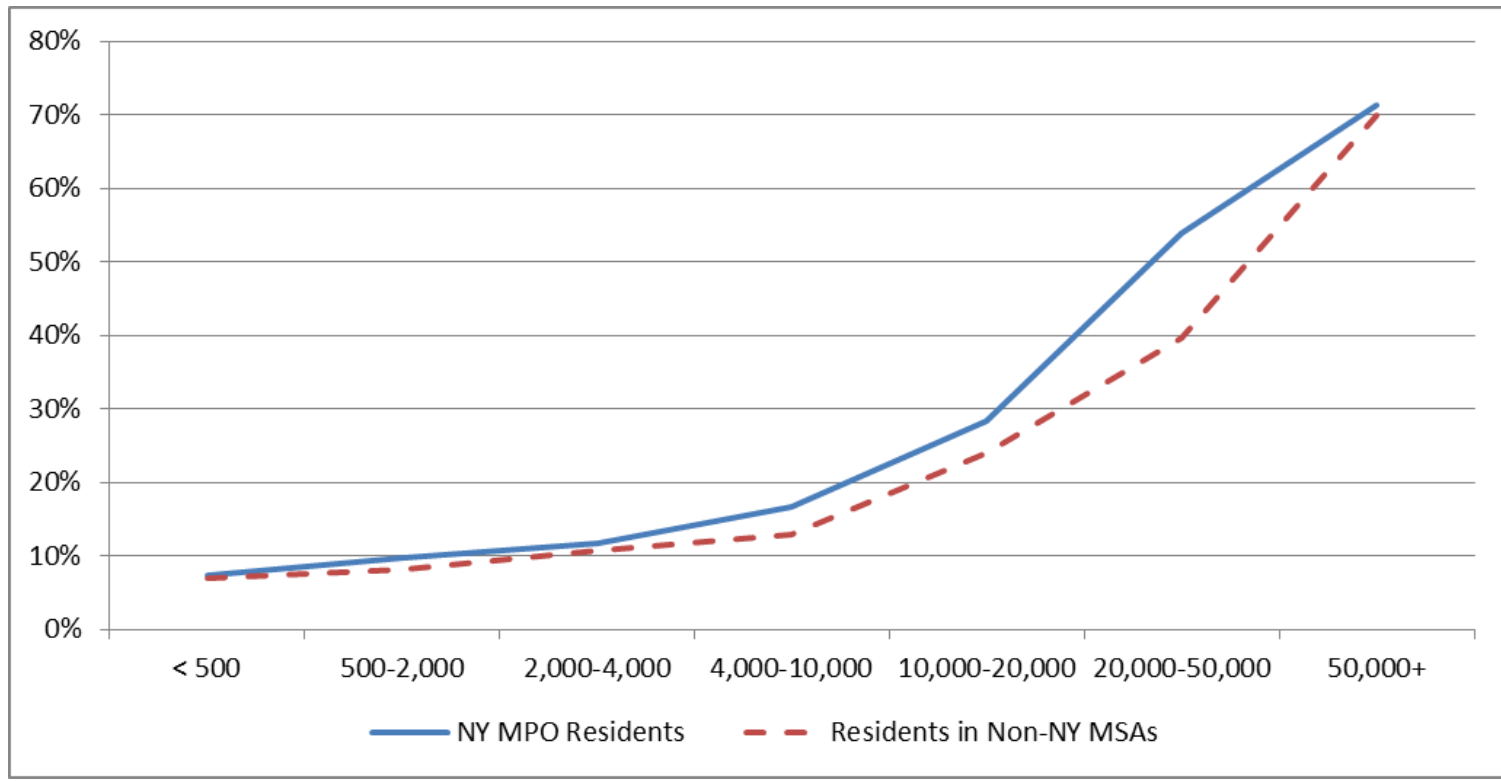

Figure 7.12 Combined Transit/Walk Share of Person Trips by Population Density, 2009 NHTS: New York State Metros vs. Metros Found Outside New York State. 
As shown in Figure 7.13 below, population density plays a similar role with respect to vehicle trip frequencies both within and outside the state. A typical NYS metro area driver in the most densely populated areas takes about one vehicle trip a day. As reported earlier, residents in these very high density areas, notably NYC, either walk or ride public transit most of the time.

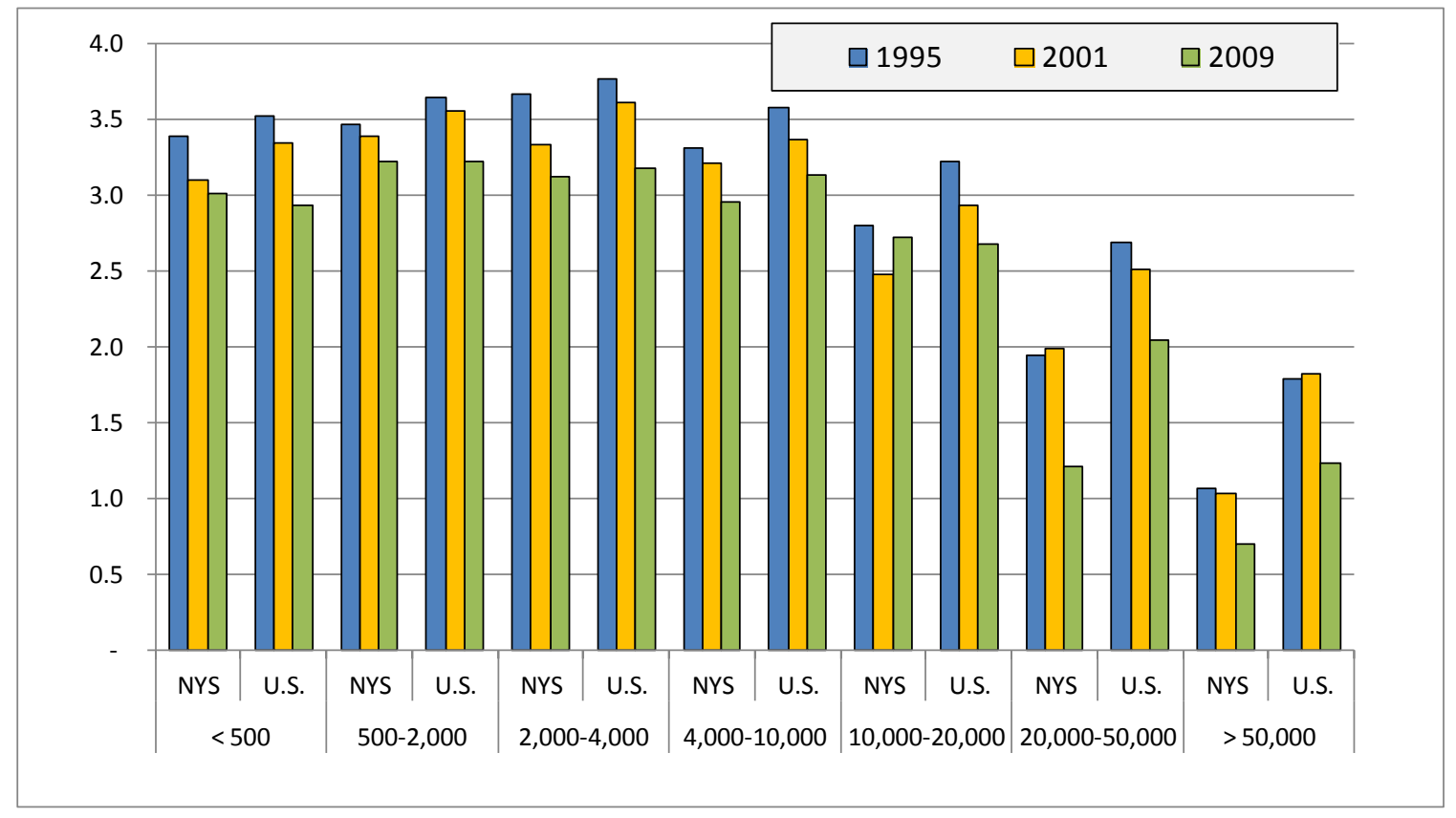

Figure 7.13 Daily Vehicle Trip Rates in 1995, 2001, and 2009: New York Metros and Metros Outside New York State by Population Density Class (persons per square mile).

\subsubsection{Commuting and Density}

Figures 7.14 and 7.15 below show the modal shares associated with daily commute to work trips within metro areas inside and outside NYS respectively. While metro areas both inside and outside the state display a significant shift from private automobile trips to public transit trips with increasing population density, and noticeably so at densities over 20,000 ppsm, this shift is much more noticeable within NYS, principally due to the higher rates of transit ridership and also walk trips within the NYC metro area. This pattern has remained essentially the same since 1995. Among the highest density areas of over 50,000 ppsm that were sampled outside the state in 2009 , some $44 \%$ of commuter trips still used private household vehicles. Within NYS (effectively households found within NYC) only some $16 \%$ of commutes are privately owned vehicle at these very high population densities: with public transit and walk trips accounting for three quarters of all commutes daily. 


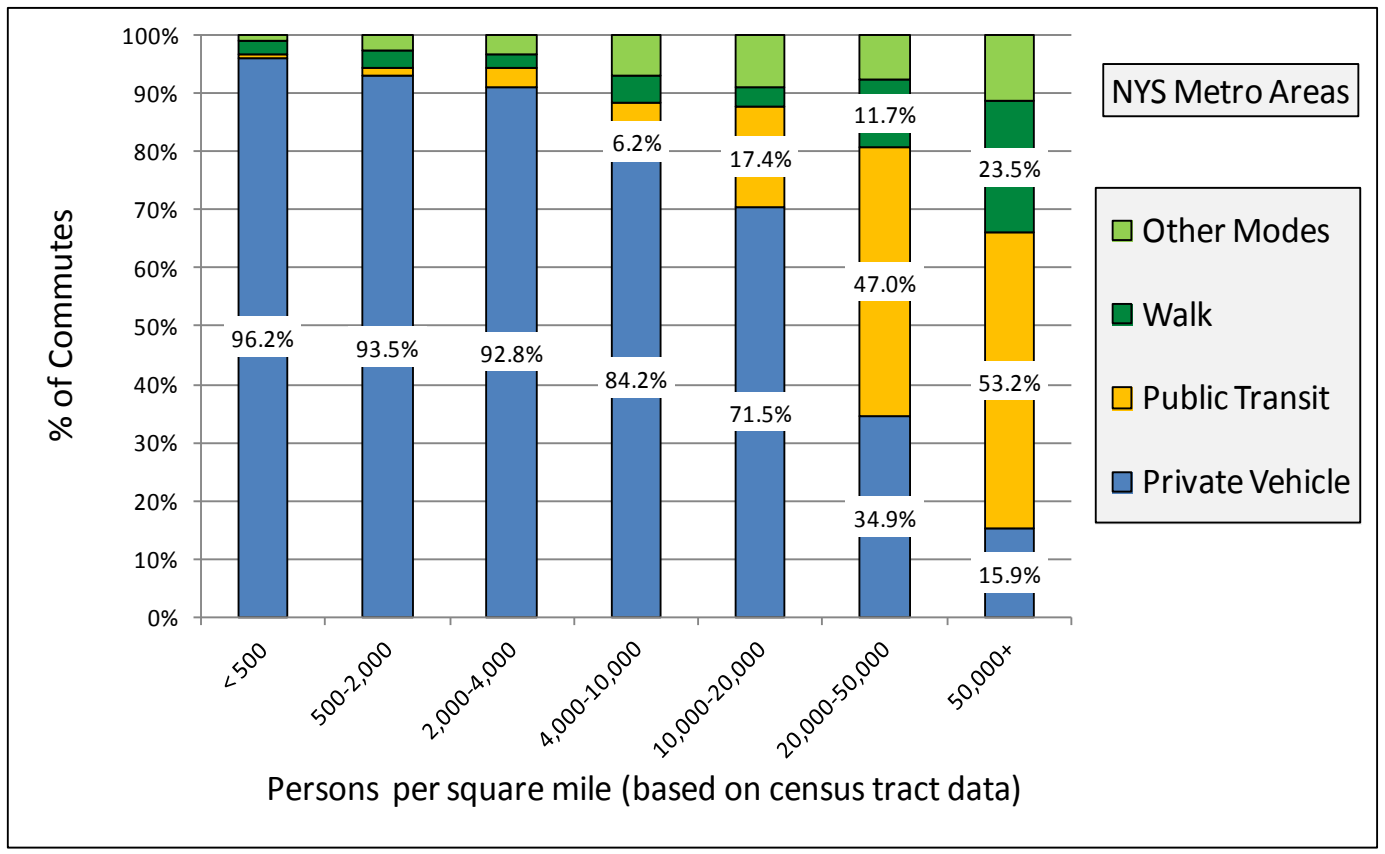

Figure 7.14 Commute Trips by Mode and Population Density for Households in NYS Metro Areas in 2009.

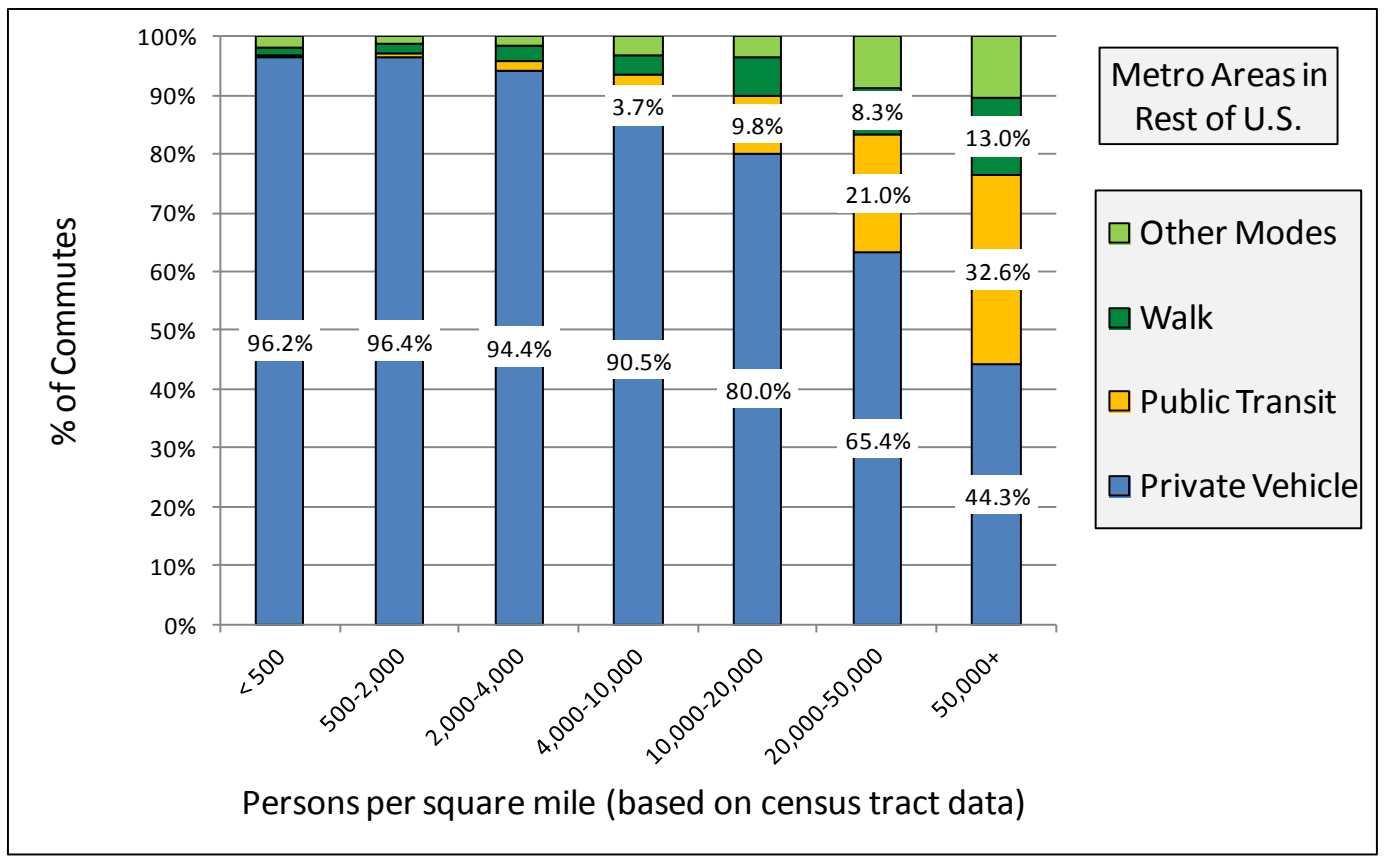

Figure 7.15 Commute Trips by Mode and Population Density for Households in Metro Areas Outside NYS in 2009.

Note: The mode "Other" includes commercial and private air, school/charter/city to city buses, Amtrak, water modes, taxi, limousine, shuttles, bicycle, and other non-specified modes. 


\subsubsection{Travel by Manhattan Households}

With roughly ninety percent of its households situated in populated areas with more than 50,000 people per square mile, the question of whether Manhattan residents travel differently from Americans living in similarly dense urban areas elsewhere in the nation presents itself. Some 77\% of Manhattan households did not own a vehicle in 2009 (up from 69\% in 2001, and closer to the $74 \%$ figure for 1995). This compares with $63 \%$ in the rest of NYC, and a $27 \%$ average in the non-NYS metros (which may be a low estimate: in 1995 and 2001 this value was around 48\%). Despite this, more Manhattan residents considered themselves to be a driver than did their neighbors living elsewhere, at similar residential densities, in the rest of NYC; with the driver rate for Manhattan residents increasing from 57\% to $73 \%$ since 1995. In terms of travel, Manhattan residents make more person trips than others living in areas with similar population densities, either inside or outside NYS. Daily person trip rates for Manhattan residents were around 3.9 trips in 2001 and 2009, up from 3.7 trips in 1995. This compares to daily person trip rates of 3.2 to 3.6 elsewhere. This difference is again largely due to more walk and transit trips being taken by Manhattan residents.

\subsubsection{Rural Household Travel Comparisons}

Many similarities, as well as a few differences, are found to exist between NYS's rural household travel statistics and those for the rest of rural America. On average, drivers in NYS rural areas make marginally fewer and shorter trips than those in rural areas elsewhere. The average age of a vehicle owned by a rural household in NYS in 2009 was over two years older than for rural households elsewhere in the nation. These rural NYS households drive their vehicles a few more miles each year than NYS urban households, on the average. Carbon dioxide emissions associated with rural highway travel are found to be significantly higher than for their urban area counterparts, and also about $20 \%$ higher than the emissions from NYS households in similarly low density (<500 ppsm) urban areas. Most of this difference is attributable to the much higher share of public transit and walk trips taken by residents living in the nation's higher density urban locations, with age and type of privately owned vehicle being used also playing a role. 


\subsubsection{MPO Specific Travel Characteristics}

Finally, we examined travel patterns among the state's thirteen MPO-based metropolitan areas: Albany; Binghamton; Buffalo; Elmira; Glens Falls; Ithaca; Kingston; the New York Metropolitan Transportation Council (NYMTC) area; Newburgh; Poughkeepsie; Rochester; Syracuse; and Utica-Rome (Figure 7.16).

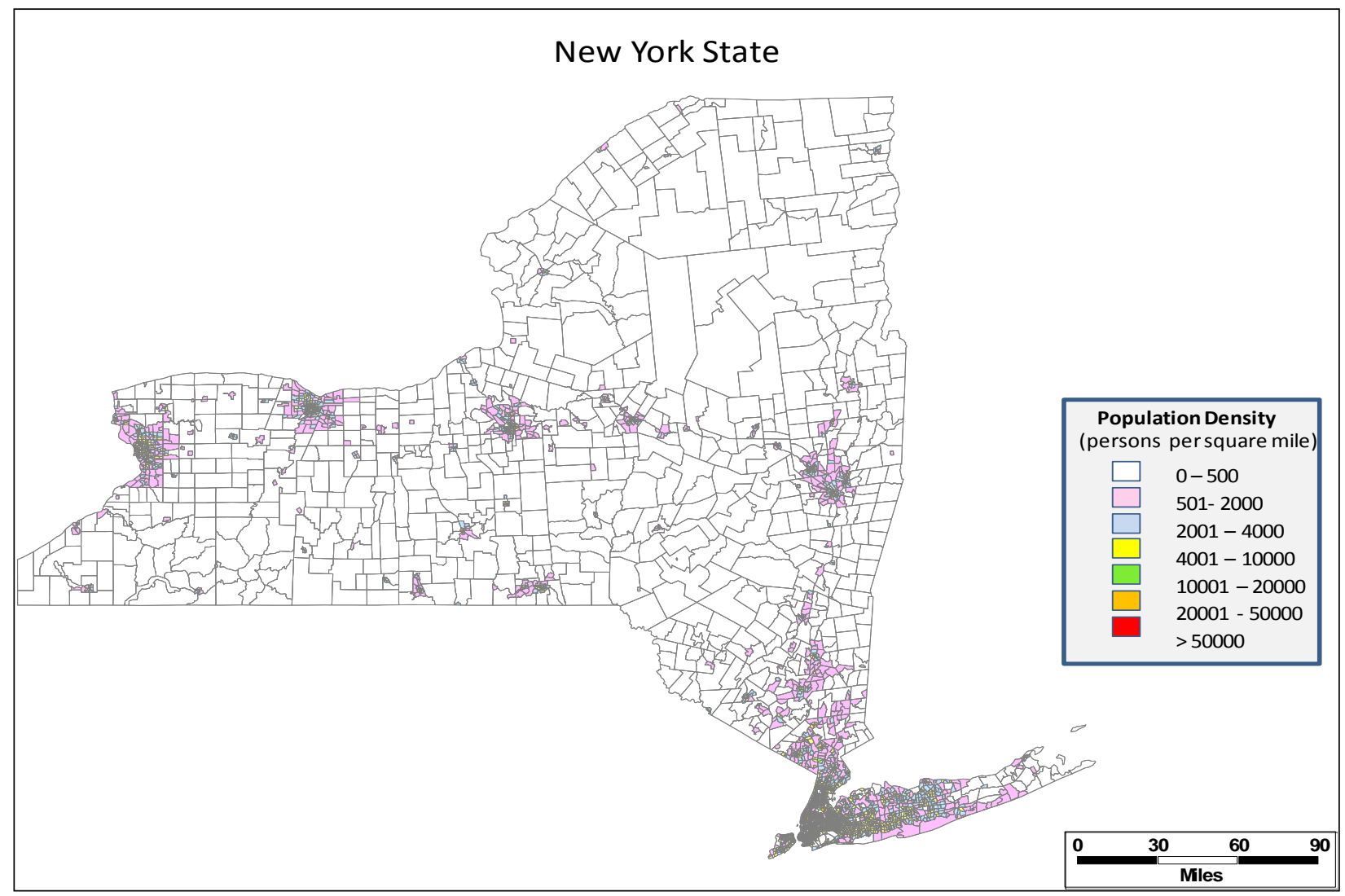

Figure 7.16 Population Densities by 2010 Census Tracts.

Some distinct patterns exist among NYS's MPO-served metropolitan areas. Almost all comparisons suggest that NYS metro areas can be categorized into three distinctive groups, regardless of the size of the MSA within which each is located. The first group consists of $\mathrm{NYC} / \mathrm{Manhattan}$, the second group consists of the remaining four counties of NYC, and the last group consists of all of the remaining metro areas, including the rest of the NYMTC MPO areas located outside NYC (i.e., the Nassau, Suffolk, Putnam, Rockland, and Westchester county portions of the NYMTC). The second group has travel patterns that tend to fall somewhere between those of the first and the third groups. When data for NYC/Manhattan residents are combined with those for the rest of the NYC, the unique travel characteristics of these Manhattan residents become obscured. Therefore, any comparisons in travel characteristics based on MPO boundaries should be made with caution. 


\subsection{CONCLUSION}

Many of the differences between NYC counties and others in the state result from the striking differences in private vehicle ownership levels, with less than one in two NYC drivers and only 64\% of NYC households owning a vehicle in 2009: versus 9 out of 10 drivers owning a vehicle, and between 1.5 and 2 vehicles owned per household, on the average, in the state's other metro areas. And this situation has changed very little over the past fourteen years covered by the three latest NPTS/NHTS surveys. While households in metro areas outside NYC do not own a vehicle largely due to income constraints, many households in NYC/Manhattan do not own a vehicle by choice. However, the statistics suggest that the mobility of zero-vehicle households in NYC/Manhattan is by no means deterred by the lack of a vehicle. While the private vehicle tripmaking rate of NYC residents was between one half and one third that in the state's other metro areas, and their daily VMT about half that of other metro areas, most of their daily travel needs were met by walking or by public transit. As a result, their daily trip-making rates remain consistent with those of vehicle-owning households when all modes of travel are considered. This again indicates that owning a vehicle or being a driver in NYC was less important for meeting a household's mobility needs than anywhere else in NYS (Figure 7.17). The high levels of public transit usage within NYC replace a great deal of automobile use, and this plus greater use of walk trips results in significantly lower travel generated carbon dioxide emissions per household in NYC than elsewhere in the state. In contrast, the comparatively limited level of public transit ridership in the state's smaller and medium sized metro areas places a much greater reliance on the privately owned vehicle, be it an automobile or the increasingly popular SUV. 


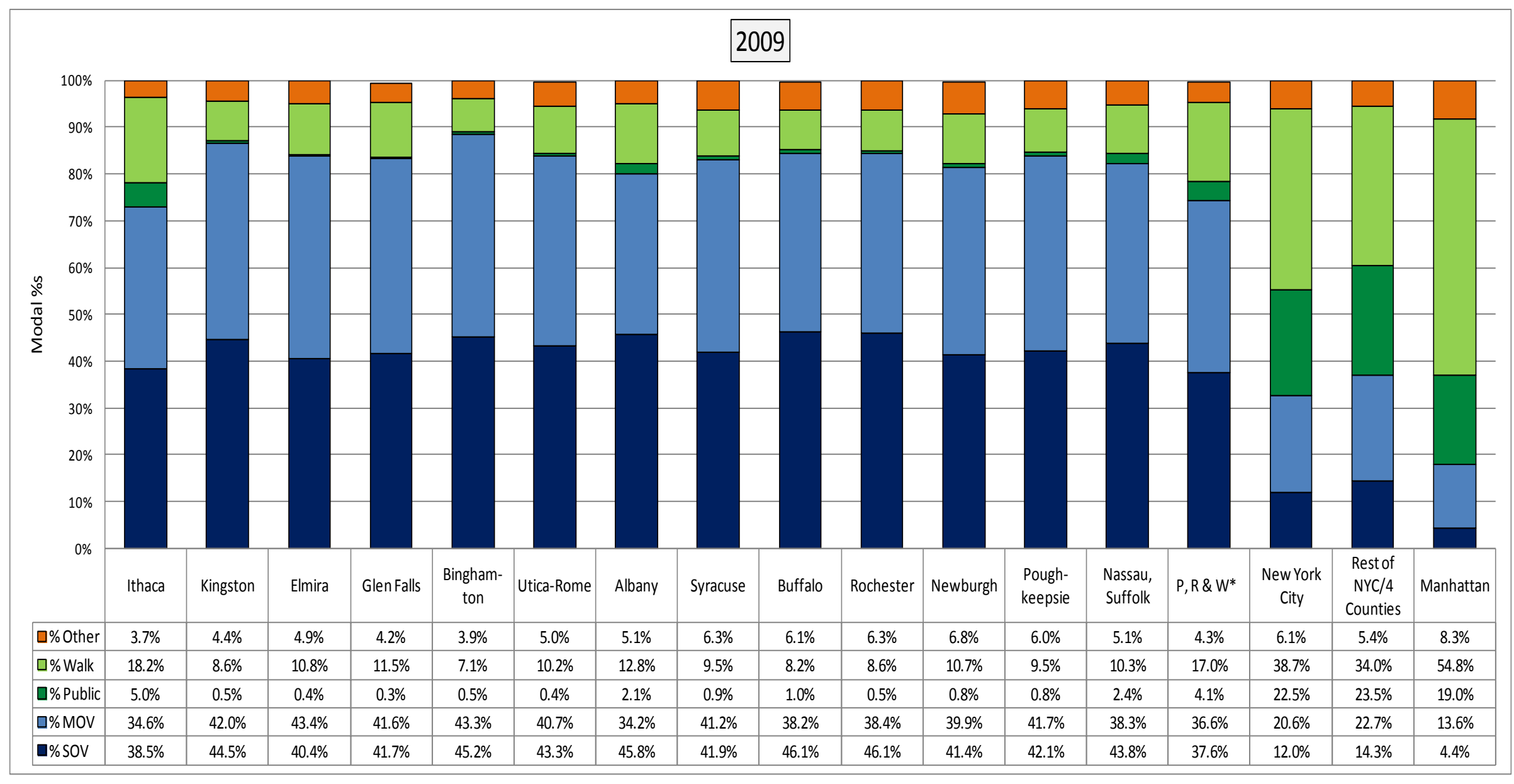

Figure 7.17 Daily Person Trips by Selected Modes for New York State Metro Areas in 2009.

Notes: ${ }^{\%}$ Public $=$ trips by Commuter rail, subway/elevated rail transit, and other public transit, mainly bus. The mode "Other" includes commercial and private air, commuter/school/charter/city to city bus, water, taxi, limousine, airport shuttle, bicycle, Amtrak and other non-specified vehicles. * P, $\mathrm{R} \& \mathrm{~W}=$ Putnam, Rockland and Westchester counties in the NYMYC region. 
FINAL 


\section{APPENDIX A: GLOSSARY OF TERMS}


This page intentionally left blank.

A - 2 


\section{APPENDIX A: GLOSSARY OF TERMS}

This glossary provides the most commonly used terms in the NHTS and definitions of those terms. These definitions are provided to assist the user in the interpretation of the NHTS data.

Adult

Block Group

Census Region and Division
For NHTS, this is defined as a person 18 years or older.

A subdivision of a Census tract that averages 1000 to 1100 people, and approximately 400-500 housing units. The source used for the 2009 NHTS was TeleAtlas MatchMaker (derived from Census 2000 definition).

The Census Bureau divides the states into four regions and nine divisions. Note that the divisions are wholly contained within a region, i.e., region lines do not split division lines. The regions and their component divisions are:

\section{Northeast Region:}

- New England Division: Connecticut, Maine, Massachusetts, New Hampshire, Rhode Island, Vermont

- Middle Atlantic Division: New Jersey, New York, Pennsylvania North Central Region:

- East North Central Division: Illinois, Indiana, Michigan, Ohio, Wisconsin

- West North Central Division: Iowa, Kansas, Minnesota, Missouri, Nebraska, North Dakota, South Dakota

\section{South Region:}

- South Atlantic Division: Delaware, Florida, Georgia, Maryland, North Carolina, South Carolina, Virginia, West Virginia

- East South Central Division: Alabama, Kentucky, Mississippi, Tennessee

- West South Central Division: Arkansas, Louisiana, Oklahoma, Texas

\section{West Region:}

- Mountain Division: Arizona, Colorado, Idaho, Montana, Nevada, New Mexico, Utah, Wyoming

- Pacific Division: Alaska, California, Hawaii, Oregon, Washington

Puerto Rico.

For the 2009 NHTS the source used for the 2000 Census Region was: http://www.census.gov/geo/www/cob/rg2000.html. The source used for the 2000 Census Division was: http://www.census.gov/geo/www/cob/dv2000.html. 


\section{Census Tract}

Child

\section{Consolidated \\ Metropolitan Statistical Area (CMSA)}

Destination

Driver

Employed

Education Level

Household
A small subdivision of a county, containing approximately 4,000 persons. Tracts can range in population from 2,500 to 8,000. The geographic size of the tract may vary considerably, depending on population density. Tracts were designed to be homogeneous in regard to population characteristics, economic status and living conditions when they were first delineated. Since the first tracts were delineated for the 1890 Census, today's tracts may be far from homogeneous. The source used for the 2009 NHTS was TeleAtlas MatchMaker (derived from Census 2000 definition).

A child is normally defined as a person under the age of 18 . An exception to this is for life cycle, where a child can be anyone through the age of 21 who is listed as a child to the household respondent.

A large metropolitan complex of 1 million or more population, containing two or more identifiable component parts designated as primary metropolitan statistical areas (PMSAs). For example, the New York-Northern New JerseyLong Island CMSA is composed of the following fourteen areas: Bridgeport, Danbury, Dutchess County, Jersey City, Middlesex-Somerset-Hunterdon, Monmouth-Ocean, Nassau-Suffolk, New Haven-Meriden, New York, Newark, Newburgh, Stamford-Norwalk, Trenton, Waterbury.

For travel day trips, the destination is the point at which there is a break in travel, except if the break is only to change vehicles or means of transport.

A driver is a person who operates a motorized vehicle. If more than one person drives on a single trip, the person who drives the most miles is classified as the principal driver.

A person is considered employed if (s)he worked for pay, either full time or part time, during the week before the interview. This includes persons who work at home or persons who have more than one job.

The number of years of regular schooling completed in graded public, private, or parochial schools, or in colleges, universities, or professional schools, whether day school or night school. Regular schooling advances a person toward an elementary or high school diploma, or a college, university, or professional school degree.

A group of persons whose usual place of residence is a specific housing unit; these persons may or may not be related to each other. The total of all U.S. households represents the total civilian non-institutionalized population. A household does not include group quarters (i.e., 10 or more persons living together, none of whom are related). 
Household Income

Household Members

Household Vehicle

Journey-to-Work Trips (Commute trips)

\section{Means of Transportation}

Household income is the money earned by all family members in a household, including those temporarily absent. Annual income consisted of the income earned 12 months preceding the interview. Household income includes monies from all sources, such as wages and salary, commissions, tips, cash bonuses, income from a business or farm, pensions, dividends, interest, unemployment or workmen's compensation, social security, veterans' payments, rent received from owned property (minus the operating costs), public assistance payments, regular gifts of money from friends or relatives not living in the household, alimony, child support, and other kinds of periodic money income other than earnings. Household income excludes in-kind income such as room and board, insurance payments, lump-sum inheritances, occasional gifts of money from persons not living in the same household, withdrawal of savings from banks, tax refunds, and the proceeds of the sale of one's house, car, or other personal property.

Household members include all people, whether present or temporarily absent, whose usual place of residence is in the sample unit. Household members also include people staying in the sample unit who have no other usual place of residence elsewhere.

A household vehicle is a motorized vehicle that is owned, leased, rented or company-owned and available to be used regularly by household members during the two-week travel period. Household vehicles include vehicles used solely for business purposes or business-owned vehicles, so long as they are driven home and can be used for the home to work trip, (e.g., taxicabs, police cars, etc.). Household vehicles include all vehicles that were owned or available for use by members of the household during the travel period, even though a vehicle may have been sold before the interview. Vehicles excluded from household vehicles are those which were not working and were not expected to be working within 60 days, and vehicles that were purchased or received after the designated travel day.

Includes travel to and from a place where one reports for work. Does not include any other work-related travel. Does not include any trips for persons who work at home.

A mode of travel used for going from one place (origin) to another (destination). A means of transportation includes private and public transit modes, as well as walking.

The following transportation modes, grouped by major mode, are included in the NHTS data.

Private Vehicle - a stipulation for being a private vehicle is that the vehicle is privately owned or operated.

1. Car. Includes cars and station wagons. Leased and rented cars are included if they are privately operated and not used for picking up passengers in return for fare. 
2. Van. Includes vans or minivans designed to carry 5 to 13 passengers, or to haul cargo.

3. Sport Utility Vehicle. Includes vehicles that are a hybrid of design elements from a van, a pickup truck and a station wagon. Examples include a Ford Explorer, Jeep Cherokee, or Nissan Pathfinder.

4. Pickup Truck. Includes vehicles with an enclosed cab that usually accommodates 2-3 passengers, and has an open cargo area in the rear. Late model pickups often have a back seat that allows for total seating of 4 -6 passengers. Pickup trucks usually have the same size of wheelbase as a full-size station wagon. This category also includes pickups with campers.

5. Other Truck: This category consists of all trucks other than pickup trucks (i.e., dump trucks, trailer trucks, etc.).

6. RV or Motor Home: An RV or motor home includes a self-powered recreational vehicle that is operated as a unit without being towed by another vehicle (e.g., a Winnebago motor home).

7. Motorcycle: This category includes large, medium, and small motorcycles and mopeds.

8. Golf Cart: This includes all electric or gas operated vehicles designed for use on a golf course, but whose use has recently extended to use within smaller, often gated, communities.

Public Transportation, as used in FHWA publications and analysis of NHTS data, typically includes the following that are indicated in bold below, mass transit bus, commuter bus, commuter train, subway/elevated rail, and streetcar/trolley.

Bus. This category includes:

9. mass transit systems, these are local public transit buses that are available to the general public,

10. commuter buses, these are buses used for short-distance public transport purposes (e.g., city bus or public bus),school buses, and

12. charter/tour buses, these are private buses operating on a fixed schedule between population centers, and

13. city to city buses, these are buses that run from one urban center to the other (e.g., Greyhound), and

14. shuttle buses, these are buses that shuttle passengers from one fixed place to another (e.g., airport shuttles).

Train: This category includes:

15. Amtrak/Intercity Train that run from one urban center to another,

16. Commuter trains and passenger trains

17. Subway and elevated rail (also known as rail rapid transit) is a high capacity system operated on a fixed rail or guide way system on a private right of way, and

18. Trolley/streetcars are vehicles that run on a fixed rail system powered by electricity obtained from an overhead power distribution system.

Other Modes

11. School Buses. 
Metropolitan

Planning Organization (MPO)

\author{
Metropolitan \\ Statistical Area \\ (MSA)
}

\section{Motorized Vehicle}

\section{New York City (NYC)}

\section{New York Metropolitan Transportation Council (NYMTC)}

\section{Occupancy}

\section{Occupancy Rate}

Origin
19. Taxi. Taxis include the use of a taxicab by a passenger for fare, including limousines. The taxi category does not include rental cars if they are privately operated.

20. Ferry. This includes travel by passenger line ferries.

21. Airplane. . Airplanes include commercial airplanes and smaller planes that are available for use by the general public in exchange for a fare. Private and corporate planes and helicopters are also included.

22. Bicycle: This category includes bicycles of all speeds and sizes that do not have a motor.

23. Walk: This category includes walking and jogging.

24. Special Transit for People with Disabilities. This includes things like "Dial-A-Ride"

97. Other. Includes any type of transportation not previously listed, (e.g. skate boards, roller blades, sailboats, cruise ships, etc).

A metropolitan planning organization devises solutions to regional transportation problems concerning land use, air quality, energy, economic development and commerce. Such an organization exists for every urban area with at least 50,000 residents. New York State has thirteen MPOs analyzed in this report: Albany; Binghamton; Buffalo; Elmira; Glens Falls; Ithaca; Kingston; the New York Metropolitan Transportation Council (NYMTC) area; Newburgh; Poughkeepsie; Rochester; Syracuse; and Utica-Rome.

Except in the New England States, a Metropolitan Statistical Area is a county or group of contiguous counties which contains at least one city of 50,000 inhabitants or more, or "twin cities" with a combined population of at least 50,000 . In addition, contiguous counties are included in an MSA if, according to certain criteria, they are socially and economically integrated with the central city. In the New England States, MSA's consist of towns and cities instead of counties. The source used for the 2009 NHTS was 1999 Metropolitan Areas: Cartographic Boundary Files. File ma99_99.shp from http://www.census.gov/geo/www/cob/ma1999.html.

Motorized vehicles are all vehicles that are licensed for highway driving. Snow mobiles and minibikes are specifically excluded.

New York City is defined in this report as the five county area: Bronx, Kings, Queens, New York (Manhattan), and Richmond.

The New York Metropolitan Transportation Council (NYMTC) encompasses includes the following three areas: (1) Nassau, Suffolk; (2) New York City, (which includes the following counties: Bronx, Kings, Queens, New York, and Richmond); and (3) Putnam, Rockland, and Westchester.

Occupancy is the number of persons, including driver and passenger(s) in a vehicle.

NHTS occupancy rates are generally defined as the mileage-weighted averages of the number of persons on a vehicle trip.

Origin is the starting point of a trip. 
Passenger

Person Miles of Travel (PMT)

Person Trip

Privately Owned Vehicle (POV)

Travel Day

Travel Day Trip

Travel Day Trip Purpose
For a specific trip, a passenger is any occupant of a motorized vehicle, other than the driver.

PMT is a primary measure of person travel. When one person travels one mile, one person mile of travel results. Where 2 or more persons travel together in the same vehicle, each person makes the same number of person miles as the vehicle miles. Therefore, four persons traveling 5 miles in the same vehicle results in 20 person miles $(4 \times 5=20)$.

A person trip is a trip by one or more persons in any mode of transportation. Each person is considered as making one person trip. For example, four persons traveling together in one auto are counted as four person trips.

A privately-owned vehicle or privately-operated vehicle. Either way, the intent here is that this is not a vehicle available to the public for a fee, such as a bus, subway, taxi, etc.

A travel day is a 24-hour period from 4:00 a.m. to 3:59 a.m. designated as the reference period for studying trips and travel by members of a sampled household.

A travel day trip is defined as any time the respondent went from one address to another by private motor vehicle, public transportation, bicycle, walking, or other means during the NHTS assigned reporting travel day. However, a separate trip is not counted in two instances:

1. When the sole purpose for the trip is to get to another vehicle or mode of transportation in order to continue to the destination.

2. Travel within a shopping center, mall or shopping areas of 4-5 blocks is to be considered as travel to one destination.

A trip purpose is the main reason that motivates a trip. There are 36 travel day trip purposes used in the 2009 NHTS.

Trip purposes were collected using a From-To approach. For each trip, the origin and destination are on the file in specific terms if reported by the respondent (e.g. from work to Bob's Beef Pit). The 36 trip reasons are defined below. The numbers in parentheses represent the value of WHYTO (trip purpose) in the dataset.

1. To Home (01). Represents a trip to the respondents' primary residence.

2. Go to Work (11). This is the first trip to the work location on travel day.

3. Return to Work (12). A trip to work that is not the first trip to the workplace on the travel day (e.g., returning to work after lunch).

4. Attend Business Meeting/Trip (13). Represents a work related trip whose purpose is to attend a business meeting.

5. Other Work Related (14). A work related trip whose purpose is not specified. 
6. Go to School as a Student (21). Represents a trip whose purpose is to go to school as a student.

7. Go to Religious Activity (22). Represents a trip whose purpose is to go to a place to attend a religious activity.

8. Go to Library, School Related (23). Represents a trip whose purpose is to go to the library as part of a school related activity.

Go to Daycare/Before or After School Care (24). Represents a trip

9. whose purpose is to attend day care or a supervised before or after school care program

10. Other School/Religious Activity (20). Represents school and religious activities that are not captured in WHYTO 21-24 above.

Medical/Dental Services (30). Represents a trip made to obtain

11. medical, dental, or mental health treatment, or other related professional services.

Buy Goods: groceries/clothing/hardware store (41). Represents a

12. shopping trip whose purpose is to purchase commodities for use or consumption elsewhere. This purpose also includes all shopping trips even if nothing is purchased.

Buy Services: video rentals/dry cleaning/post office/car service/bank

13. (42). This category includes the purchase of services other than medical/dental or other professional services.

14. Buy Gas (43). Represents a trip made specifically to get gas.

15. Shopping/Errands (40). Represents shopping and errand trips that are not captured in WHYTO 41-43 above.

16. Go to the Gym/Exercise/Play Sports (51). Represents a trip made for exercise, to engage in exercise or to participate in a sport.

Rest or Relaxation/Vacation (52). Represents a trip made for the

17. purpose of relaxing or taking a vacation, but does not include visiting family.

18. Visit Friends/Relatives (53). Represents the social/recreational trip whose purpose is to visit with family and friends.

Go out/Hang out: entertainment/theater/sports event/go to bar (54).

19. Represents trips whose purpose is entertainment related or hanging out with friends. Typically this event takes place in a public venue.

20. Visit Public Place: historical site/museum/park/library (55). Represents a trip purpose that is educational or enlightening.

21. Social/Recreational (50). This category includes social and recreational trips that are not captured in WHYTO 51-55 above. 
Use Professional Services: attorney/accountant (61). Represents a trip

22. made for to engage professional services other than for medical/dental purposes.

23. Attend Funeral/Wedding (62). Represents a trip whose purpose is to attend a funeral or a wedding.

24. Use Personal Services: grooming/haircut/nails (63). Represents a trip for personal services such as to get a massage or get a haircut.

25. Pet Care: walk the dog/vet visits (64).

Attend Meeting: PTA/home owner's association/local government

26. (65). Represents a trip purpose to attend a non-work related meeting, such as a community meeting

27. Family Personal Business/Obligations (60). Represents a trip for 13 personal business but is not captured in WHYTO 61-65 above.

28. Pickup Someone (71). Represents a trip whose purpose was to pick up a passenger.

Take and Wait (72). Represents a trip made to take someone to a

29. destination and then wait with or for them at the destination and then depart together.

30. Drop Someone Off (73). Represents a trip whose purpose was to drop off a passenger (but not wait for them).

Transport Someone (70). Represents trips with a passenger that are

31. related to picking up or dropping off someone but is not captured in WHYTO 71-73 above.

32. Social Event (81). Represents a trip whose purpose is to attend a social event but eating a meal is not a key component of the event.

33. Get/Eat Meal (82). Represents a trip whose primary purpose is to get and eat a meal.

34. Coffee/Ice Cream/Snacks (83). Represents a trip whose purpose is to get/eat a snack or drink, something less than a meal.

35. Meals (80). Represents a trip whose purpose is to eat or get a meal but is not captured in WHYTO 81-83 above.

36. Other (97). Represents a trip purpose not captured by any of the specific WHYTO categories described above. 
Urbanized Area

Vehicle

Vehicle Miles of Travel (VMT)

Vehicle Occupancy

Vehicle Trip

Vehicle Type

Weekday

Weekend
An urbanized area consists of the built up area surrounding a central core (or central city), with a population density of at least 1,000 persons per square mile. Urbanized areas do not follow jurisdictional boundaries thus it is common for the urbanized area boundary to divide a county. For the 2009 NHTS, Urban Areas were calculated two ways.

- Variable URBAN uses the 2000 Urbanized Areas: Cartographic Boundary Files. File ua00_d00.shp from http://www.census.gov/geo/www/cob/ua2000.html. Two codes are used: $0=$ Not in Urban Area, $1=$ in Urban Area

- Variable URBAN1 uses the 2000 Urbanized Areas: Cartographic Boundary Files. File ua00_d00.shp from http://www.census.gov/geo/www/cob/ua2000.html. Four codes are used: $0=$ Not in Urban Area, $1=$ in Urban Cluster, 2 = in Urban Area, $3=$ in area surrounded by urban areas.

In the 2009 NHTS, the term vehicle includes autos, passenger vans, sport utility vehicles, pickups and other light trucks, RV's, motorcycles and mopeds owned or available to the household.

VMT is a unit to measure vehicle travel made by a private vehicle, such as an automobile, van, pickup truck, or motorcycle. Each mile traveled is counted as one vehicle mile regardless of the number of persons in the vehicle.

Vehicle occupancy is the number of persons, including driver and passenger(s) in a vehicle; also includes persons who did not complete a whole trip. NHTS occupancy rates are generally calculated as person miles divided by vehicle miles.

A trip by a single privately-operated vehicle regardless of the number of persons in the vehicle.

For purposes of the 2009 NHTS, one of the following:

1. Automobile (including station wagon)

2. Van

3. Sport Utility Vehicle

4. Pickup Truck (including pickup with camper)

5. Other Truck

6. RV or Motor Home

7. Motorcycle

8. Other

Weekday is defined as Monday through Friday. In the previous comparison reports, it was defined as the time between 12:01 a.m. Monday and 6:00 p.m. Friday. This was modified to correctly estimate per person statistics.

Weekend is defined as Saturday and Sunday. See "Weekday" for more on the difference between previous reports. 
Work-Related Travel These are trips related to business activities except travel to the place of work: (WR) for example, a plumber drives to a wholesale dealer to purchase supplies for his business or a company executive travels from his office to another firm to attend a business meeting. Business, out-of-town trips, and professional conventions are also included.

Worker

See "Employed." 


\section{APPENDIX B: MAPS OF NEW YORK STATE AREAS}

B - 1 
This page intentionally left blank.

B - 2 


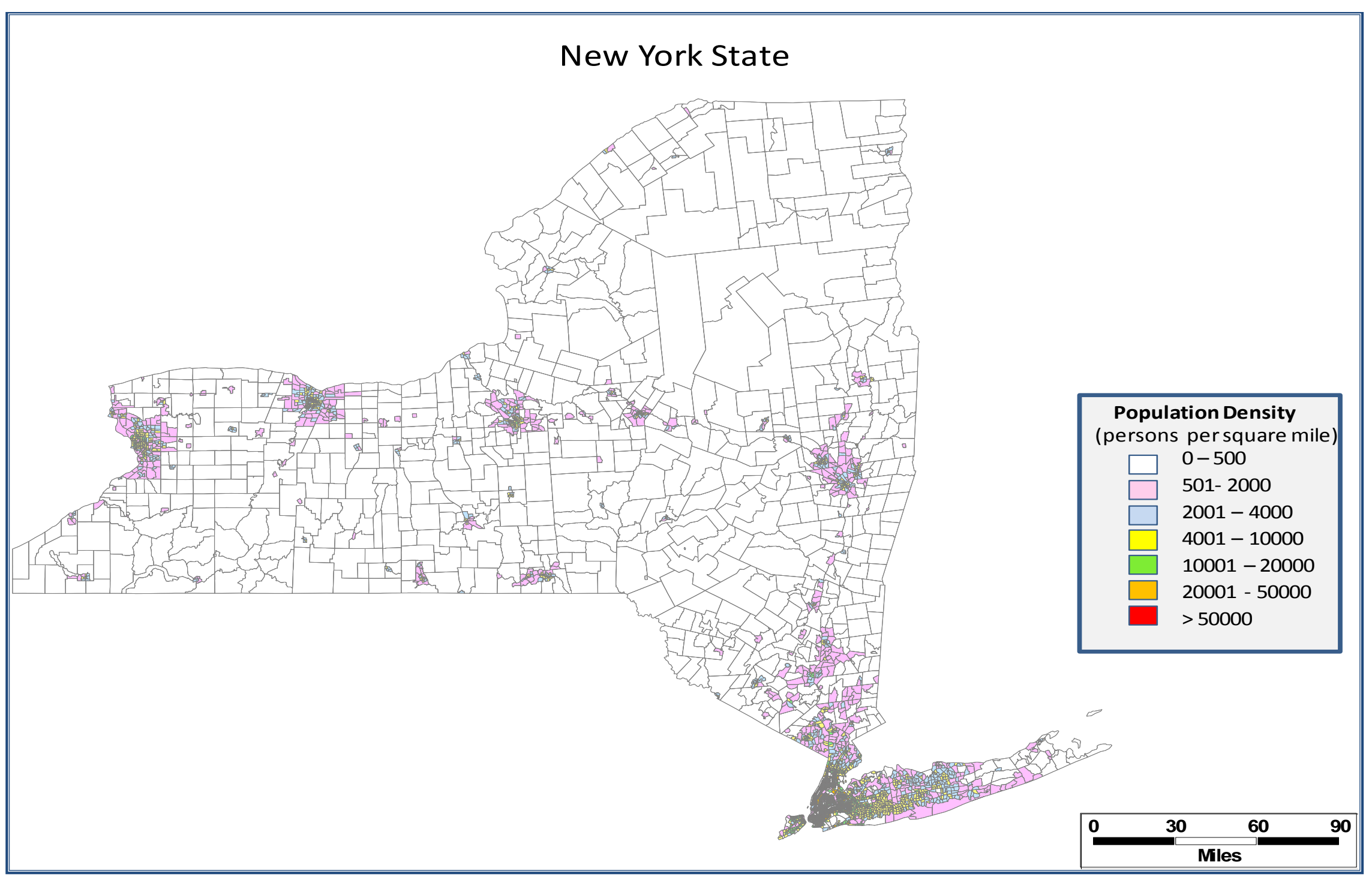




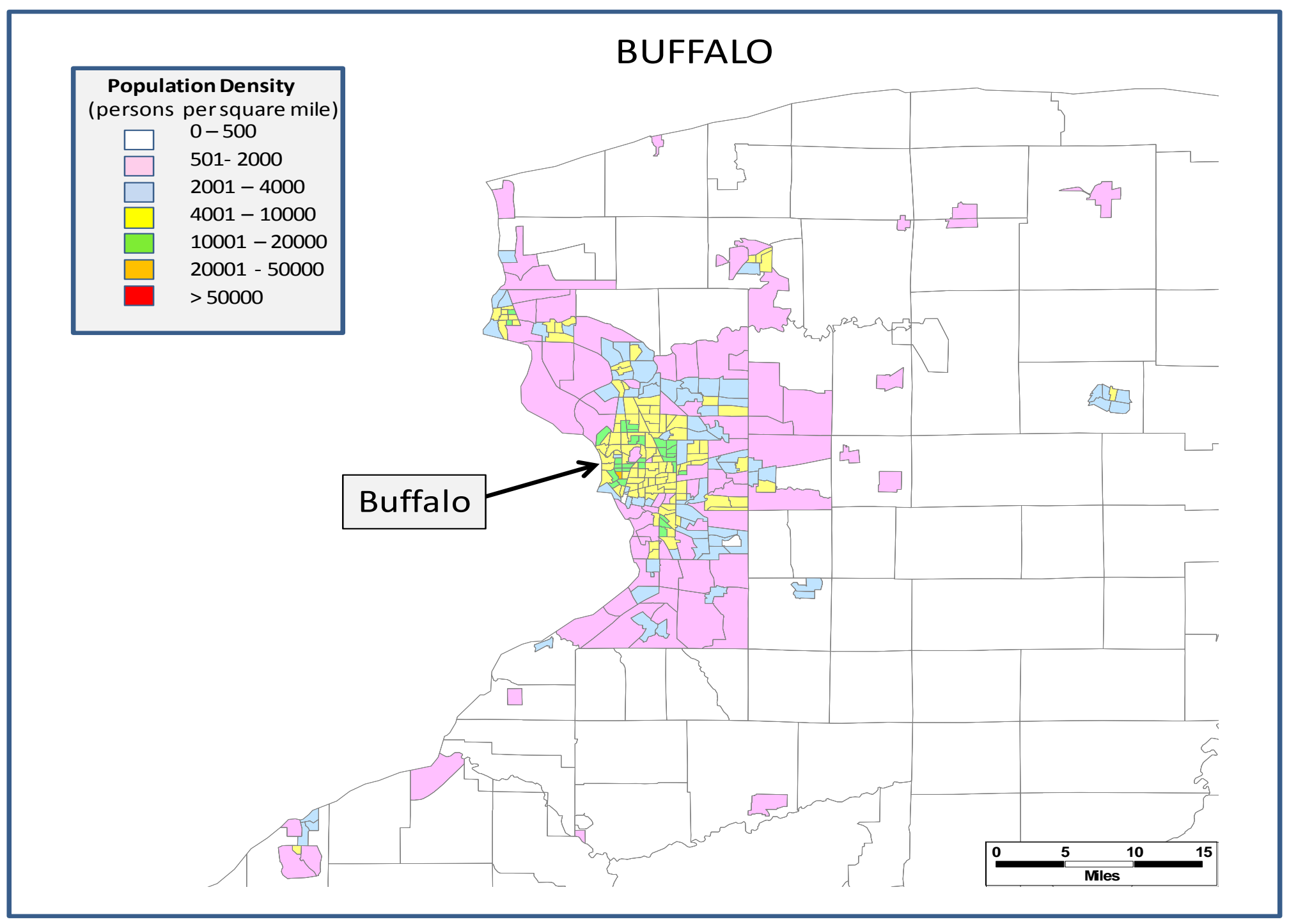




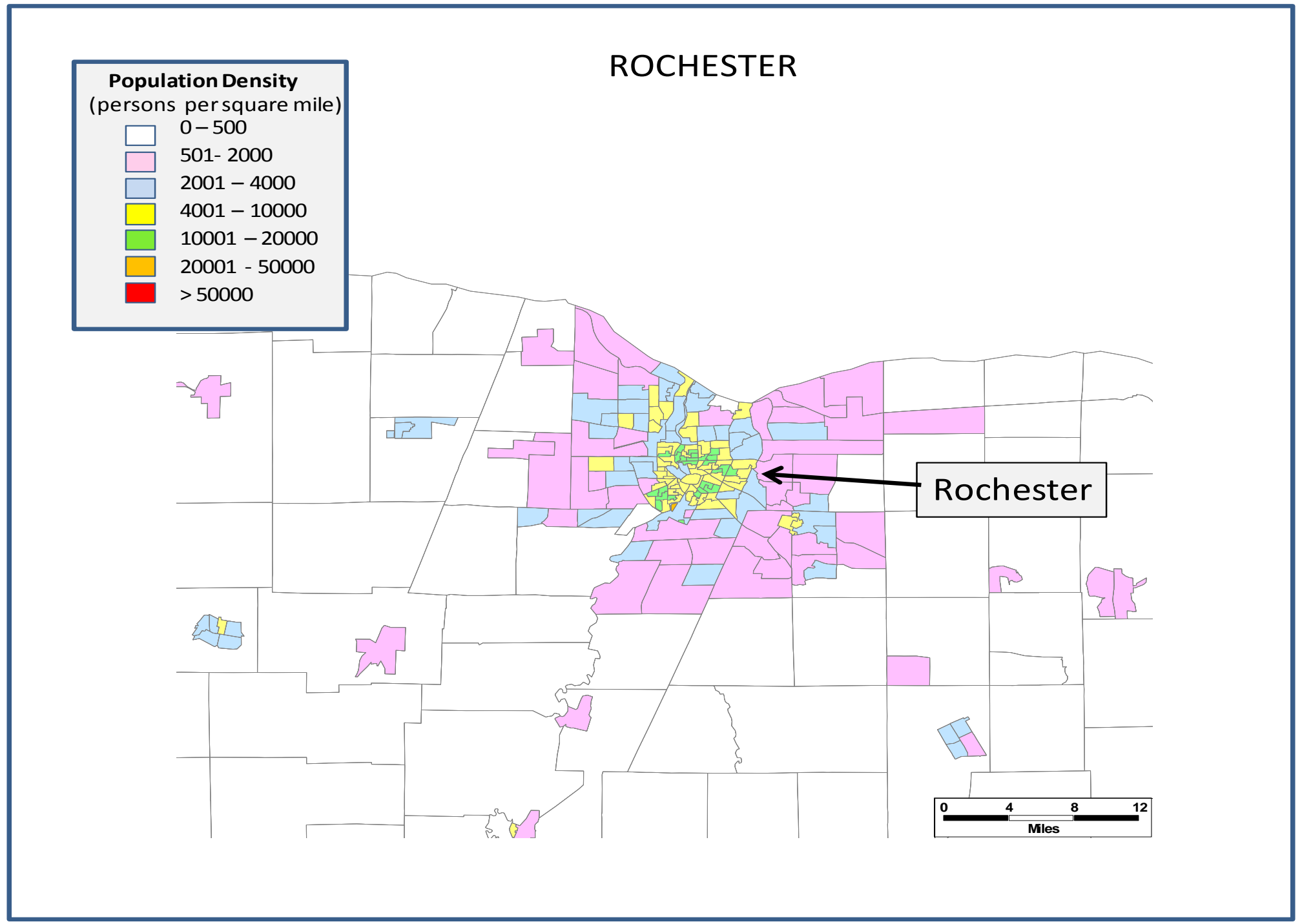




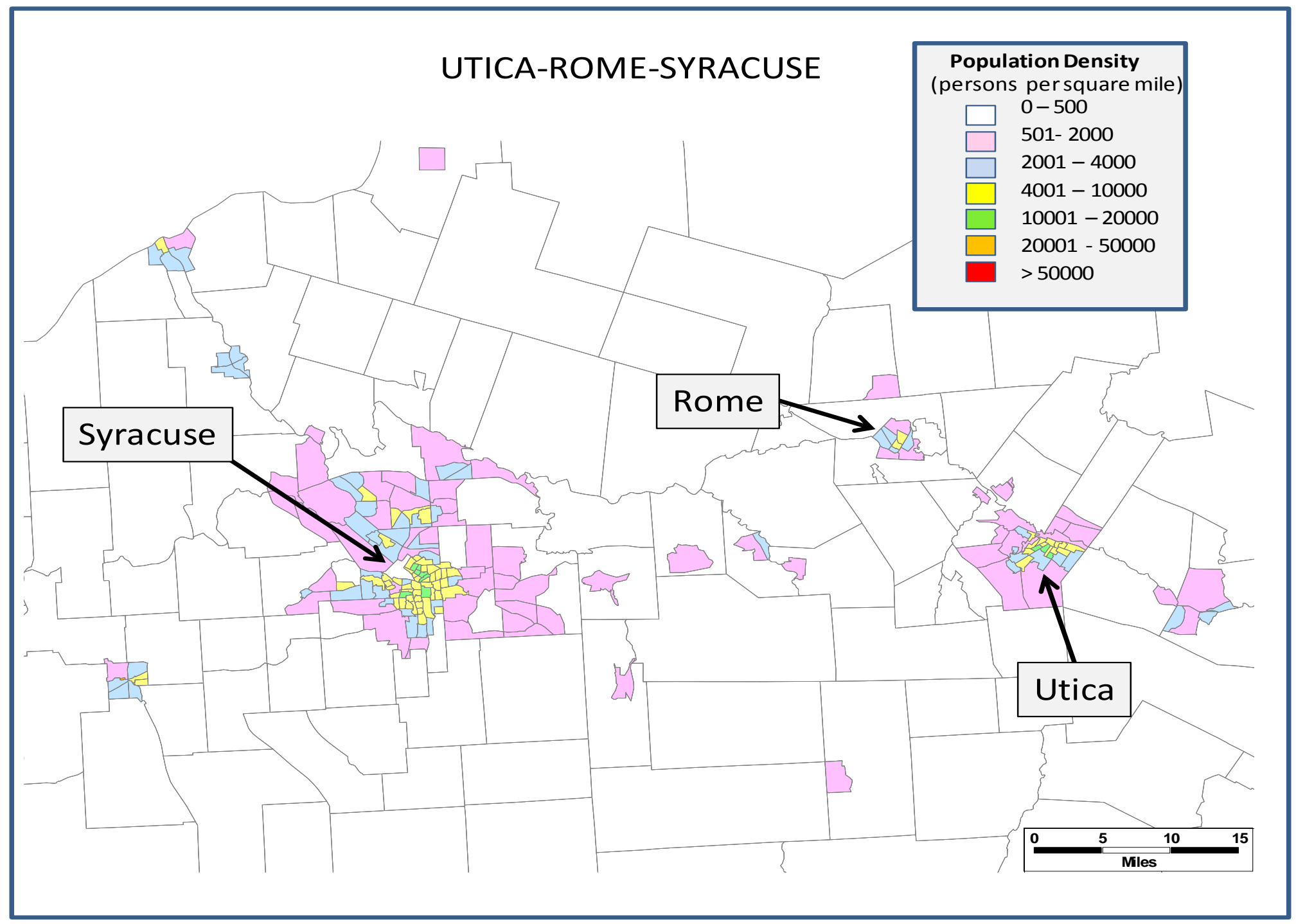




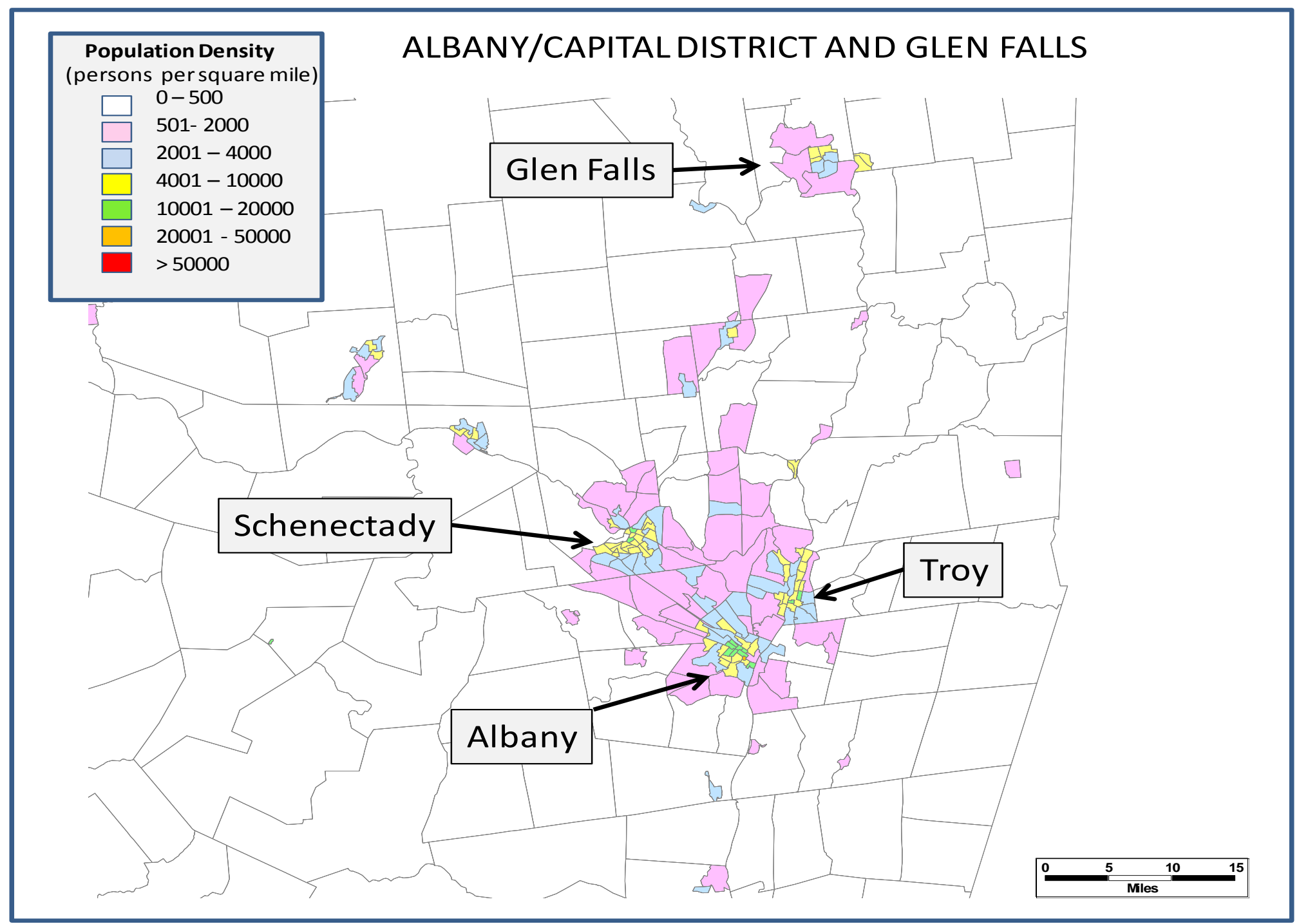




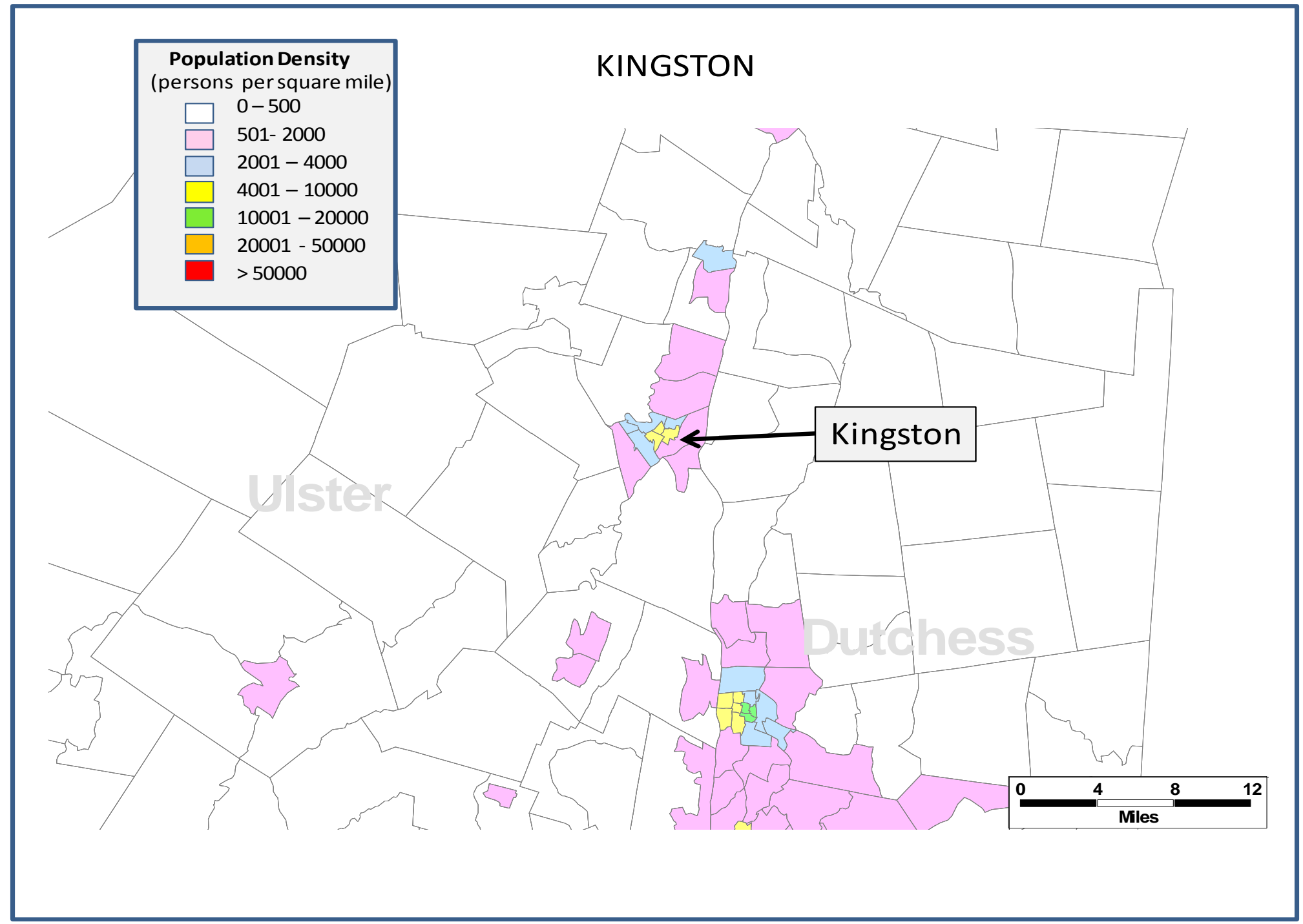




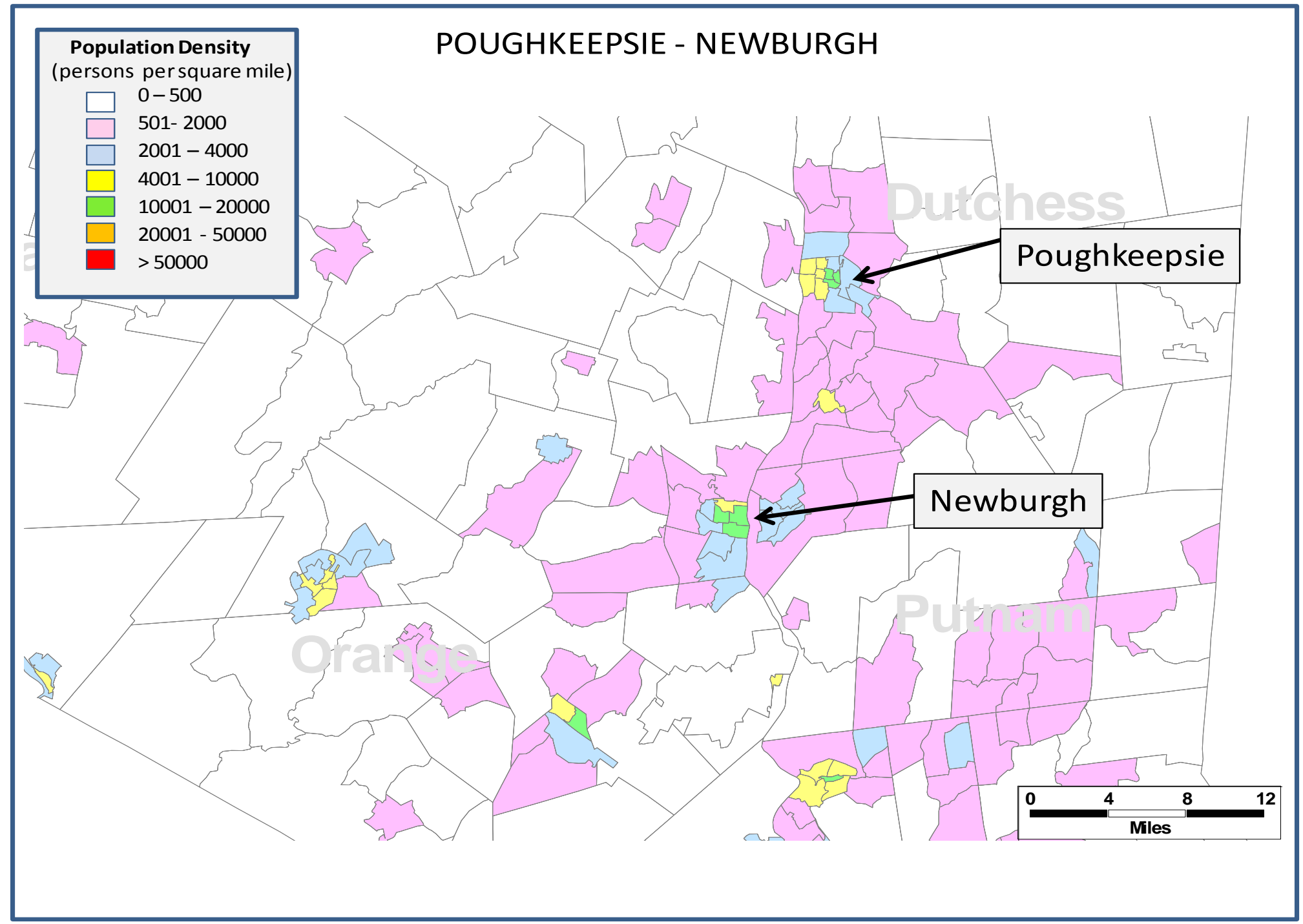




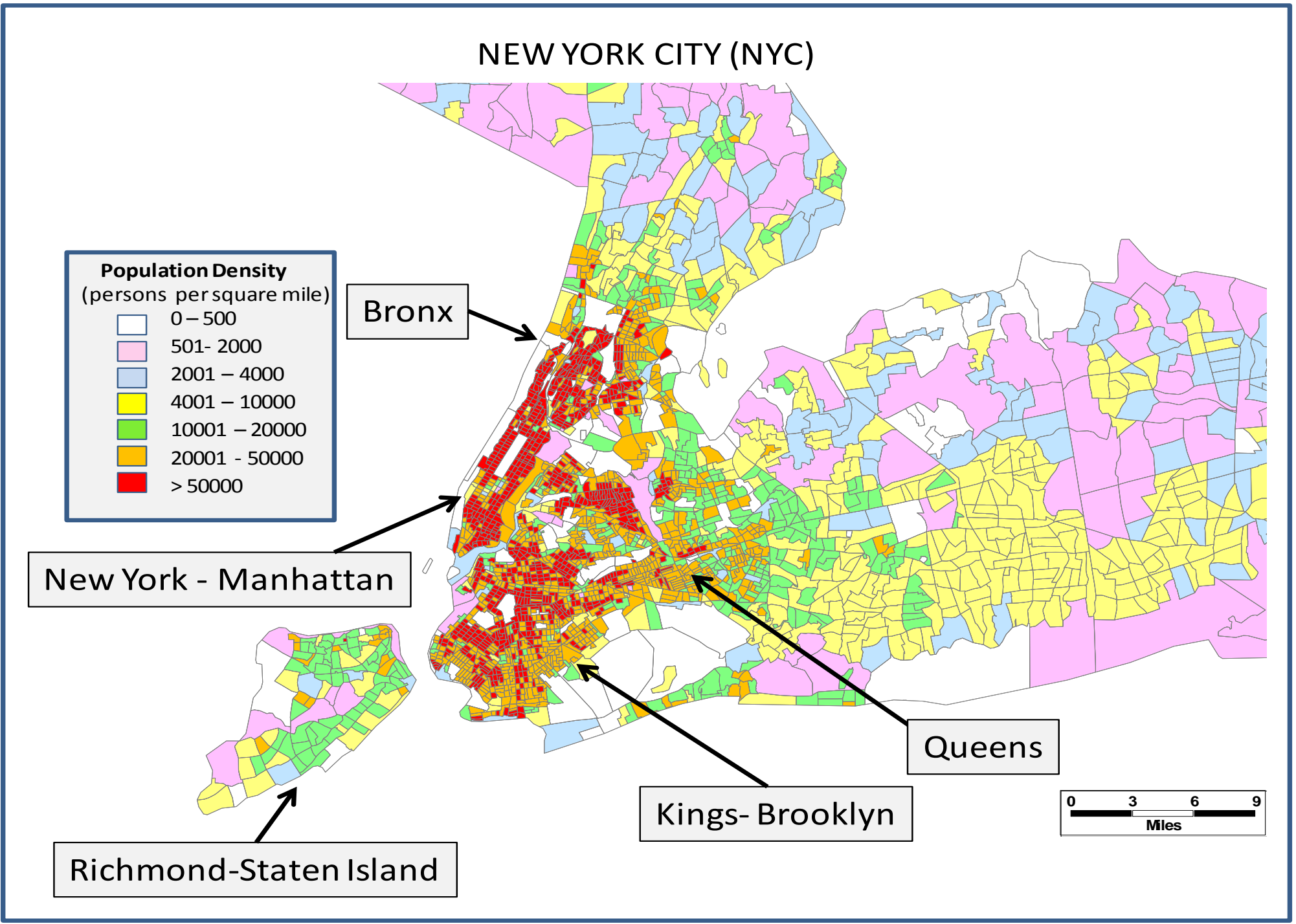




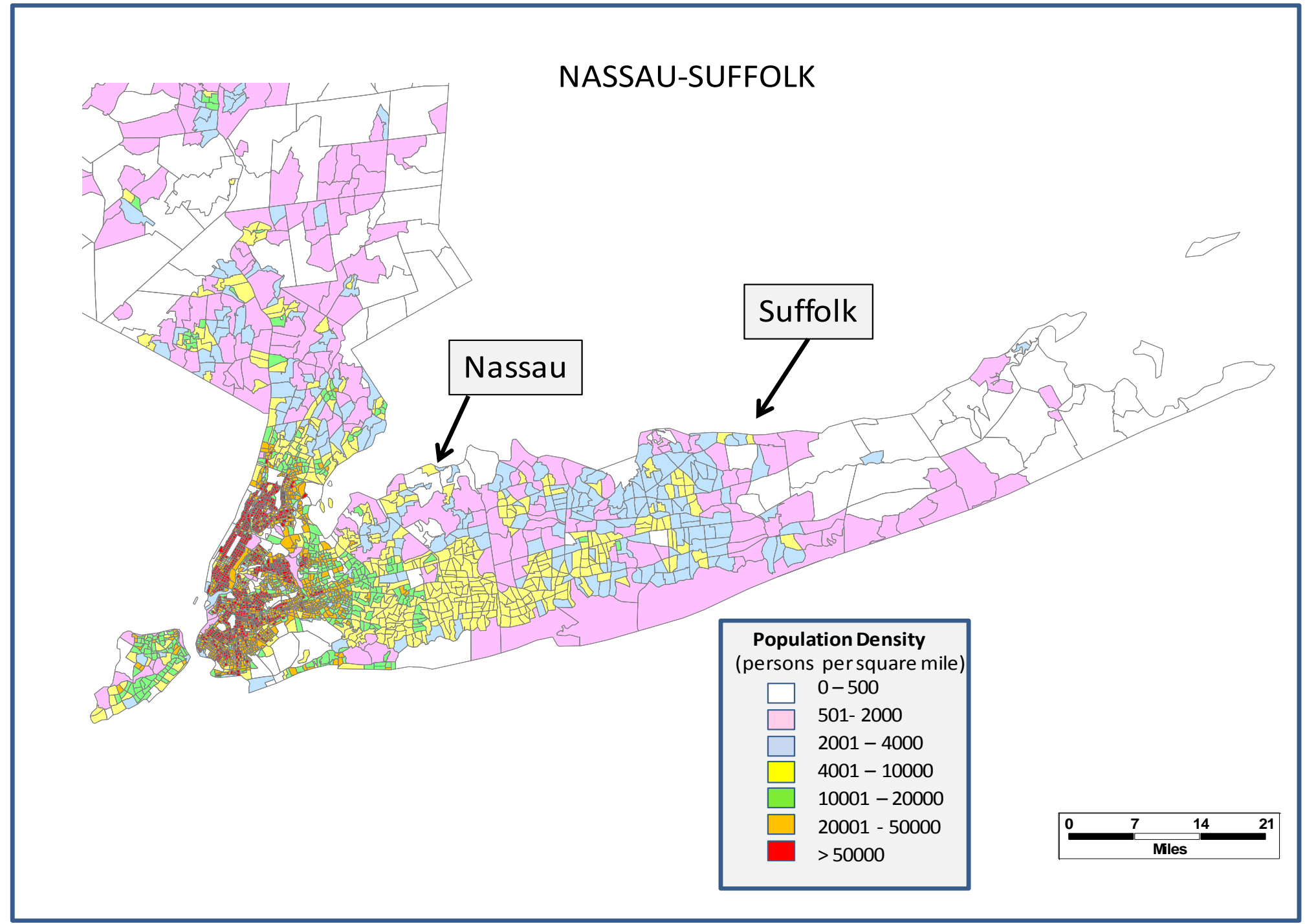




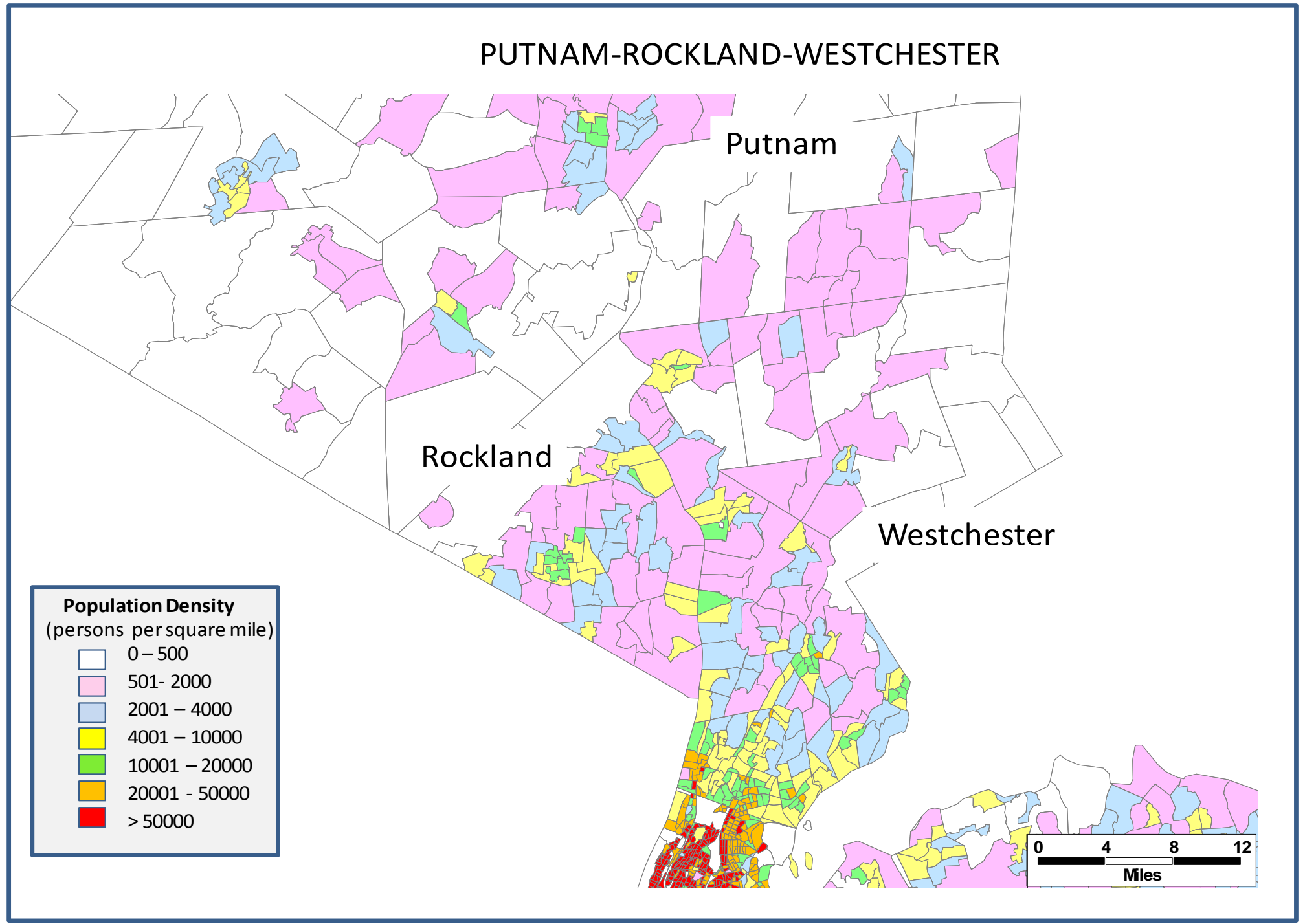


This page intentionally left blank.

C - 2 


\section{Accompanying Notes for Tables in Appendix C}

All totals could include some unreported characteristics.

Empty cells indicate no data available. Values of 0.0 indicate data available, but less than 0.1 .

$\square \quad$ A highlighted cell indicates a sample size of 5 or less.

$\square \quad$ Daily trip or mile-per-person rates include all persons 5 or older. This also includes persons not traveling on their travel day.

Weekday is defined as Monday through Friday, while Weekend is defined as Saturday and Sunday. This differs from past comparison reports, where Weekday was defined as the time between 12:01 a.m. Monday and 6:00 p.m. Friday and Weekend was defined as the time between 6:01 p.m. Friday and midnight Sunday. The 1995 and 2001 numbers in this report have been updated to reflect the new definition.

$\square \quad$ Number of workers includes those who work at home.

Commute trips do not include those who work at home.

All average trip lengths are calculated using only those records with trip mileage information present.

口 All calculations of average time spent driving do not include any persons who did not take a trip on their travel day. They also do not include any driving done in a segmented trip.

$\square \quad$ All calculations of average commute travel time do include time spent waiting for transportation.

All calculations of average commute speed do not include time spent waiting for transportation. They also do not include any segmented trips, which eliminates nearly all data points in 2001 statistics.

All calculations for the miles per hour (mph) are based on estimates of miles and minutes given by the respondent. Therefore, any mph estimate for walking that is greater than 5 might be attributable to self-reporting bias.

1995 numbers are based on the revised sample expansion factors where applicable (households and per household statistics). 
(Due to the large number of tables for Appendix $C$, they are not available in the Word version of this file. They can be viewed in the PDF or Excel files.) 


\section{APPENDIX C2. SUPPLEMENTAL TABLES FOR CHAPTER 2}


Chapter 2: Table 1

Comparison of NY State Data to the Rest of the United States

\begin{tabular}{|c|c|c|c|c|c|c|}
\hline \multirow[b]{3}{*}{ General Statistics } & \multicolumn{3}{|c|}{ New York State } & \multicolumn{3}{|c|}{ Remainder of U.S. } \\
\hline & 1995 & 2001 & 2009 & 1995 & 2001 & 2009 \\
\hline & & & & & & \\
\hline Households (000) & 6,848 & 7,183 & 7,137 & 92,858 & 100,182 & 105,964 \\
\hline Drivers (000) & 10,469 & 11,167 & 12,838 & 165,861 & 179,258 & 199,471 \\
\hline Workers (000) & 8,775 & 9,645 & 9,759 & 122,922 & 135,627 & 141,614 \\
\hline Vehicles (000) & 7,922 & 9,545 & 9,144 & 168,145 & 193,041 & 202,357 \\
\hline Workers per Household & 1.28 & 1.34 & 1.37 & 1.32 & 1.35 & 1.34 \\
\hline Vehicles per Household & 1.16 & 1.33 & 1.28 & 1.81 & 1.93 & 1.91 \\
\hline Vehicles per Driver & 0.76 & 0.85 & 0.71 & 1.01 & 1.08 & 1.01 \\
\hline Daily PMT per Person & 28.86 & 29.40 & 25.76 & 39.40 & 41.03 & 36.85 \\
\hline Daily VMT per Driver & 25.01 & 23.36 & 19.67 & 32.59 & 33.31 & 29.57 \\
\hline Daily Commute PMT per Worker & 13.97 & 10.79 & 10.15 & 16.08 & 13.78 & 12.99 \\
\hline \multicolumn{7}{|c|}{ Distribution of Households by Household Vehicle Count } \\
\hline ALL & $100 \%$ & $100 \%$ & $100 \%$ & $100 \%$ & $100 \%$ & $100 \%$ \\
\hline 0 vehicles & $26.8 \%$ & $26.5 \%$ & $28.5 \%$ & $6.9 \%$ & $6.8 \%$ & $7.4 \%$ \\
\hline 1 vehicle & $32.8 \%$ & $33.2 \%$ & $32.4 \%$ & $32.4 \%$ & $31.3 \%$ & $32.3 \%$ \\
\hline 2 vehicles & $29.7 \%$ & $27.2 \%$ & $27.1 \%$ & $41.1 \%$ & $37.9 \%$ & $36.9 \%$ \\
\hline 3 vehicles & $7.8 \%$ & $9.3 \%$ & $8.4 \%$ & $14.4 \%$ & $15.4 \%$ & $14.8 \%$ \\
\hline 4+ vehicles & $2.9 \%$ & $3.9 \%$ & $3.6 \%$ & $5.3 \%$ & $8.6 \%$ & $8.6 \%$ \\
\hline \multicolumn{7}{|c|}{ Distribution of Households by Household Income } \\
\hline ALL & $100 \%$ & $100 \%$ & $100 \%$ & $100 \%$ & $100 \%$ & $100 \%$ \\
\hline$<\$ 10,000$ Households & $5.5 \%$ & $7.3 \%$ & $7.8 \%$ & $4.9 \%$ & $6.6 \%$ & $7.7 \%$ \\
\hline$\$ 10$ to $\$ 20,000$ Households & $8.5 \%$ & $10.2 \%$ & $11.5 \%$ & $9.3 \%$ & $10.0 \%$ & $12.5 \%$ \\
\hline$\$ 20$ to $\$ 30,000$ Households & $10.2 \%$ & $9.2 \%$ & $10.2 \%$ & $10.6 \%$ & $9.7 \%$ & $11.6 \%$ \\
\hline$\$ 30$ to $\$ 40,000$ Households & $14.0 \%$ & $15.0 \%$ & $9.5 \%$ & $15.5 \%$ & $16.9 \%$ & $10.0 \%$ \\
\hline$\$ 40$ to $\$ 50,000$ Households & $3.9 \%$ & $4.3 \%$ & $8.8 \%$ & $4.3 \%$ & $5.1 \%$ & $8.9 \%$ \\
\hline$\$ 50$ to $\$ 60,000$ Households & $7.0 \%$ & $7.9 \%$ & $6.7 \%$ & $8.8 \%$ & $8.5 \%$ & $7.5 \%$ \\
\hline$\$ 60$ to $\$ 70,000$ Households & $7.2 \%$ & $6.1 \%$ & $5.9 \%$ & $7.6 \%$ & $6.7 \%$ & $6.0 \%$ \\
\hline$\$ 70$ to $\$ 80,000$ Households & $4.2 \%$ & $4.9 \%$ & $5.3 \%$ & $4.4 \%$ & $5.4 \%$ & $6.0 \%$ \\
\hline$\$ 80$ to $\$ 100,000$ Households & $7.9 \%$ & $8.4 \%$ & $7.4 \%$ & $8.0 \%$ & $8.7 \%$ & $7.6 \%$ \\
\hline$\$ 100,000+$ Households & $12.2 \%$ & $16.5 \%$ & $18.3 \%$ & $10.1 \%$ & $14.3 \%$ & $15.4 \%$ \\
\hline Unreported Households & $19.5 \%$ & $10.3 \%$ & $8.8 \%$ & $16.5 \%$ & $8.1 \%$ & $6.8 \%$ \\
\hline \multicolumn{7}{|l|}{ Licensing Rate } \\
\hline$\%$ Female Drivers/Female 16+ & $68.4 \%$ & $71.1 \%$ & $77.2 \%$ & $86.6 \%$ & $87.7 \%$ & $86.8 \%$ \\
\hline$\%$ Male Drivers/Male $16+$ & $84.1 \%$ & $83.5 \%$ & $86.4 \%$ & $93.2 \%$ & $93.3 \%$ & $91.6 \%$ \\
\hline
\end{tabular}


Chapter 2: Table 2

Comparison of NY State Data to the Rest of the United States

\begin{tabular}{|c|c|c|c|c|c|c|}
\hline \multirow{3}{*}{ Daily Person Trips per Person } & \multicolumn{3}{|c|}{ New York State } & \multicolumn{3}{|c|}{ Remainder of U.S. } \\
\hline & 1995 & 2001 & 2009 & 1995 & 2001 & 2009 \\
\hline & & & & & & \\
\hline TOTAL & 3.88 & 3.73 & 3.64 & 4.33 & 4.11 & 3.81 \\
\hline Male & 3.93 & 3.77 & 3.63 & 4.36 & 4.11 & 3.76 \\
\hline Female & 3.84 & 3.70 & 3.64 & 4.30 & 4.12 & 3.85 \\
\hline TOTAL & 3.88 & 3.73 & 3.64 & 4.33 & 4.11 & 3.81 \\
\hline $5-15$ years & 3.31 & 3.02 & 2.99 & 3.73 & 3.46 & 3.20 \\
\hline $16-19$ years & 3.76 & 3.53 & 3.32 & 4.69 & 4.19 & 3.54 \\
\hline 20-29 years & 4.02 & 3.76 & 3.38 & 4.60 & 4.24 & 3.75 \\
\hline $30-39$ years & 4.35 & 4.16 & 4.12 & 4.84 & 4.57 & 4.21 \\
\hline $40-49$ years & 4.39 & 4.35 & 4.35 & 4.83 & 4.67 & 4.33 \\
\hline $50-59$ years & 3.83 & 3.97 & 3.91 & 4.23 & 4.30 & 4.13 \\
\hline $60-64$ years & 3.80 & 3.88 & 4.03 & 4.16 & 4.12 & 3.90 \\
\hline $65+$ years & 3.29 & 3.18 & 2.96 & 3.44 & 3.43 & 3.22 \\
\hline Unreported & & 3.33 & & & 3.71 & \\
\hline TOTAL & 3.88 & 3.73 & 3.64 & 4.33 & 4.11 & 3.81 \\
\hline \% POV by Occupancy & $66.8 \%$ & $65.6 \%$ & $62.2 \%$ & $87.5 \%$ & $87.7 \%$ & $84.9 \%$ \\
\hline$\%$ SOV & $31.7 \%$ & $30.3 \%$ & $30.5 \%$ & $42.5 \%$ & $40.3 \%$ & $40.5 \%$ \\
\hline$\%$ MOV & $35.1 \%$ & $35.3 \%$ & $31.7 \%$ & $45.0 \%$ & $47.3 \%$ & $44.4 \%$ \\
\hline \% POV by Vehicle Type & $66.8 \%$ & $65.6 \%$ & $62.2 \%$ & $87.5 \%$ & $87.7 \%$ & $84.9 \%$ \\
\hline$\%$ Car & $50.7 \%$ & $42.9 \%$ & $36.3 \%$ & $59.2 \%$ & $50.1 \%$ & $44.8 \%$ \\
\hline$\%$ Van & $7.0 \%$ & $9.5 \%$ & $7.4 \%$ & $10.1 \%$ & $12.1 \%$ & $10.5 \%$ \\
\hline$\%$ SUV & $4.5 \%$ & $8.4 \%$ & $14.0 \%$ & $5.9 \%$ & $12.5 \%$ & $17.9 \%$ \\
\hline \% Pickup Truck & $4.3 \%$ & $4.4 \%$ & $4.0 \%$ & $11.8 \%$ & $12.3 \%$ & $10.7 \%$ \\
\hline$\%$ Other Truck & $0.5 \%$ & $0.3 \%$ & $0.3 \%$ & $0.6 \%$ & $0.5 \%$ & $0.5 \%$ \\
\hline$\% \mathrm{RV}$ & $0.0 \%$ & $0.0 \%$ & $0.1 \%$ & $0.0 \%$ & $0.0 \%$ & $0.0 \%$ \\
\hline$\%$ Motorcycle & $0.0 \%$ & $0.1 \%$ & $0.1 \%$ & $0.1 \%$ & $0.2 \%$ & $0.3 \%$ \\
\hline$\%$ Public Transit & $9.3 \%$ & $9.5 \%$ & $9.9 \%$ & $1.2 \%$ & $1.0 \%$ & $1.2 \%$ \\
\hline$\%$ Commuter Train & $1.3 \%$ & $0.4 \%$ & $0.9 \%$ & $0.0 \%$ & $0.1 \%$ & $0.1 \%$ \\
\hline \% Subway/Elevated Rail & $3.9 \%$ & $5.3 \%$ & $4.2 \%$ & $0.2 \%$ & $0.2 \%$ & $0.1 \%$ \\
\hline$\%$ Other Public & $4.1 \%$ & $3.8 \%$ & $4.8 \%$ & $0.9 \%$ & $0.8 \%$ & $1.0 \%$ \\
\hline$\%$ Amtrak & $0.0 \%$ & $0.2 \%$ & $0.2 \%$ & $0.0 \%$ & $0.0 \%$ & $0.0 \%$ \\
\hline$\%$ Walk & $14.7 \%$ & $20.0 \%$ & $22.0 \%$ & $4.8 \%$ & $7.9 \%$ & $9.7 \%$ \\
\hline$\%$ Other & $4.4 \%$ & $4.6 \%$ & $5.6 \%$ & $3.0 \%$ & $3.3 \%$ & $4.1 \%$ \\
\hline$\%$ Unreported & $4.9 \%$ & $0.1 \%$ & $0.1 \%$ & $3.5 \%$ & $0.1 \%$ & $0.2 \%$ \\
\hline TOTAL & 3.88 & 3.73 & 3.64 & 4.33 & 4.11 & 3.81 \\
\hline \% Earning a Living & $19.8 \%$ & $19.3 \%$ & $18.3 \%$ & $20.3 \%$ & $18.8 \%$ & $18.7 \%$ \\
\hline \% Family \& Personal Business & $45.9 \%$ & $43.3 \%$ & $43.2 \%$ & $45.7 \%$ & $43.9 \%$ & $42.4 \%$ \\
\hline \% Civic, Educational \& Religious & $9.3 \%$ & $9.7 \%$ & $9.5 \%$ & $8.8 \%$ & $9.8 \%$ & $9.6 \%$ \\
\hline \% Social \& Recreational & $25.0 \%$ & $26.2 \%$ & $27.0 \%$ & $24.9 \%$ & $26.6 \%$ & $27.5 \%$ \\
\hline$\%$ Other & $0.0 \%$ & $1.2 \%$ & $1.1 \%$ & $0.2 \%$ & $0.8 \%$ & $0.8 \%$ \\
\hline \% Unreported & & $0.3 \%$ & $0.9 \%$ & & $0.1 \%$ & $1.0 \%$ \\
\hline TOTAL & 3.88 & 3.73 & 3.64 & 4.33 & 4.11 & 3.81 \\
\hline Weekday & 4.00 & 3.85 & 3.74 & 4.46 & 4.21 & 3.92 \\
\hline Weekend & 3.61 & 3.46 & 3.37 & 3.99 & 3.89 & 3.52 \\
\hline TOTAL & 3.88 & 3.73 & 3.64 & 4.33 & 4.11 & 3.81 \\
\hline$\% 1-9 \min$ & $37.9 \%$ & $26.9 \%$ & $28.0 \%$ & $40.0 \%$ & $28.7 \%$ & $29.9 \%$ \\
\hline$\% 10-19 \min$ & $29.1 \%$ & $32.0 \%$ & $32.5 \%$ & $32.1 \%$ & $36.3 \%$ & $36.6 \%$ \\
\hline$\% 20-29 \min$ & $12.9 \%$ & $11.9 \%$ & $13.3 \%$ & $12.7 \%$ & $13.3 \%$ & $13.5 \%$ \\
\hline$\%$ 30-39 min & $7.5 \%$ & $10.4 \%$ & $11.3 \%$ & $6.2 \%$ & $9.8 \%$ & $9.8 \%$ \\
\hline$\%$ 40-49 min & $4.4 \%$ & $5.2 \%$ & $5.4 \%$ & $3.2 \%$ & $4.0 \%$ & $4.0 \%$ \\
\hline$\% 50+\min$ & $6.4 \%$ & $9.3 \%$ & $9.4 \%$ & $4.4 \%$ & $5.9 \%$ & $6.0 \%$ \\
\hline$\%$ Unreported & $1.8 \%$ & $4.3 \%$ & $0.3 \%$ & $1.4 \%$ & $1.9 \%$ & $0.3 \%$ \\
\hline TOTAL & 3.88 & 3.73 & 3.64 & 4.33 & 4.11 & 3.81 \\
\hline$\% 5$ or less miles & $66.0 \%$ & $65.0 \%$ & $66.5 \%$ & $62.6 \%$ & $59.6 \%$ & $60.8 \%$ \\
\hline$\%$ 6-10 miles & $13.4 \%$ & $13.1 \%$ & $12.9 \%$ & $15.9 \%$ & $17.0 \%$ & $16.4 \%$ \\
\hline$\% 11-15$ miles & $6.4 \%$ & $6.3 \%$ & $5.7 \%$ & $7.4 \%$ & $8.0 \%$ & $7.5 \%$ \\
\hline$\% 16-20$ miles & $3.4 \%$ & $3.5 \%$ & $3.2 \%$ & $3.9 \%$ & $4.4 \%$ & $4.1 \%$ \\
\hline$\%$ 21-30 miles & $3.4 \%$ & $3.3 \%$ & $2.9 \%$ & $3.9 \%$ & $4.3 \%$ & $4.2 \%$ \\
\hline$\% 31$ or more miles & $3.9 \%$ & $3.7 \%$ & $3.4 \%$ & $4.8 \%$ & $5.1 \%$ & $4.8 \%$ \\
\hline$\%$ Unreported & $3.6 \%$ & $5.1 \%$ & $5.5 \%$ & $1.4 \%$ & $1.7 \%$ & $2.1 \%$ \\
\hline
\end{tabular}


Chapter 2: Table 3

Comparison of NY State Data to the Rest of the United States

\begin{tabular}{|c|c|c|c|c|c|c|}
\hline \multirow[b]{3}{*}{ Daily PMT per Person } & \multicolumn{3}{|c|}{ New York State } & \multicolumn{3}{|c|}{ Remainder of U.S. } \\
\hline & 1995 & 2001 & 2009 & 1995 & 2001 & 2009 \\
\hline & & & & & & \\
\hline TOTAL & 28.86 & 29.40 & 25.76 & 39.40 & 41.03 & 36.85 \\
\hline \% POV by Occupancy & $82.7 \%$ & $74.8 \%$ & $78.9 \%$ & $91.5 \%$ & $88.9 \%$ & $88.8 \%$ \\
\hline$\%$ SOV & $34.5 \%$ & $31.8 \%$ & $34.5 \%$ & $40.4 \%$ & $37.6 \%$ & $39.0 \%$ \\
\hline$\% \mathrm{MOV}$ & $48.2 \%$ & $43.0 \%$ & $44.5 \%$ & $51.1 \%$ & $51.3 \%$ & $49.9 \%$ \\
\hline \% POV by Vehicle Type & $82.7 \%$ & $74.8 \%$ & $78.9 \%$ & $91.5 \%$ & $88.9 \%$ & $88.8 \%$ \\
\hline$\%$ Car & $58.8 \%$ & $47.0 \%$ & $44.4 \%$ & $57.5 \%$ & $47.7 \%$ & $44.4 \%$ \\
\hline$\% \operatorname{Van}$ & $10.6 \%$ & $9.7 \%$ & $8.5 \%$ & $10.4 \%$ & $11.9 \%$ & $10.3 \%$ \\
\hline$\%$ SUV & $6.1 \%$ & $10.1 \%$ & $19.0 \%$ & $7.1 \%$ & $12.8 \%$ & $19.7 \%$ \\
\hline \% Pickup Truck & $5.6 \%$ & $6.5 \%$ & $5.4 \%$ & $13.6 \%$ & $14.3 \%$ & $12.3 \%$ \\
\hline$\%$ Other Truck & $1.5 \%$ & $1.2 \%$ & $1.4 \%$ & $2.6 \%$ & $1.9 \%$ & $1.6 \%$ \\
\hline$\%$ RV & $0.1 \%$ & $0.1 \%$ & $0.0 \%$ & $0.2 \%$ & $0.1 \%$ & $0.1 \%$ \\
\hline$\%$ Motorcycle & $0.1 \%$ & $0.2 \%$ & $0.2 \%$ & $0.1 \%$ & $0.3 \%$ & $0.3 \%$ \\
\hline$\%$ Public Transit & $10.6 \%$ & $7.7 \%$ & $8.0 \%$ & $1.7 \%$ & $0.8 \%$ & $1.0 \%$ \\
\hline$\%$ Commuter Train & $2.5 \%$ & $1.1 \%$ & $1.6 \%$ & $0.3 \%$ & $0.2 \%$ & $0.3 \%$ \\
\hline \% Subway/Elevated Rail & $4.2 \%$ & $4.7 \%$ & $3.7 \%$ & $0.2 \%$ & $0.1 \%$ & $0.1 \%$ \\
\hline$\%$ Other Public & $3.9 \%$ & $2.0 \%$ & $2.7 \%$ & $1.3 \%$ & $0.5 \%$ & $0.6 \%$ \\
\hline$\%$ Amtrak & $0.3 \%$ & $0.6 \%$ & $0.2 \%$ & $0.0 \%$ & $0.1 \%$ & $0.1 \%$ \\
\hline$\%$ Walk & $1.2 \%$ & $1.8 \%$ & $2.3 \%$ & $0.3 \%$ & $0.6 \%$ & $0.7 \%$ \\
\hline$\%$ Other & $4.2 \%$ & $14.6 \%$ & $10.5 \%$ & $5.4 \%$ & $9.3 \%$ & $9.4 \%$ \\
\hline$\%$ Unreported & $0.9 \%$ & $0.6 \%$ & $0.1 \%$ & $1.0 \%$ & $0.5 \%$ & $0.1 \%$ \\
\hline TOTAL & 28.86 & 29.40 & 25.76 & 39.40 & 41.03 & 36.85 \\
\hline \% Earn a Living & $29.0 \%$ & $28.4 \%$ & $27.3 \%$ & $28.2 \%$ & $27.5 \%$ & $25.2 \%$ \\
\hline$\%$ Family \& Personal Business & $33.7 \%$ & $30.0 \%$ & $29.3 \%$ & $35.0 \%$ & $32.9 \%$ & $29.6 \%$ \\
\hline \% Civic, Educational \& Religious & $5.5 \%$ & $5.1 \%$ & $5.6 \%$ & $5.7 \%$ & $5.9 \%$ & $6.2 \%$ \\
\hline \% Social \& Recreational & $31.6 \%$ & $30.5 \%$ & $29.7 \%$ & $30.6 \%$ & $30.0 \%$ & $30.3 \%$ \\
\hline$\%$ Other & $0.2 \%$ & $4.5 \%$ & $4.4 \%$ & $0.4 \%$ & $3.4 \%$ & $5.0 \%$ \\
\hline$\%$ Unreported & & $1.4 \%$ & $3.8 \%$ & & $0.3 \%$ & $3.7 \%$ \\
\hline Average Person Trip Length & & & & & & \\
\hline TOTAL & 7.74 & 8.30 & 7.49 & 9.23 & 10.14 & 9.89 \\
\hline
\end{tabular}

$\mathrm{C}-8$ 
Chapter 2: Table 4

Comparison of NY State Data to the Rest of the United States

\begin{tabular}{|c|c|c|c|c|c|c|}
\hline & \multicolumn{3}{|c|}{ New York State } & \multicolumn{3}{|c|}{ Remainder of U.S. } \\
\hline & 1995 & 2001 & 2009 & 1995 & 2001 & 2009 \\
\hline \multicolumn{7}{|c|}{ Distribution of Zero-Vehicle Households by Household Income } \\
\hline TOTAL & $100 \%$ & $100 \%$ & $100 \%$ & $100 \%$ & $100 \%$ & $100 \%$ \\
\hline$<\$ 10,000$ Households & $13.8 \%$ & $18.1 \%$ & $19.0 \%$ & $24.3 \%$ & $34.5 \%$ & $35.8 \%$ \\
\hline$\$ 10$ to $\$ 20,000$ Households & $16.0 \%$ & $18.0 \%$ & $20.2 \%$ & $29.1 \%$ & $24.6 \%$ & $29.2 \%$ \\
\hline$\$ 20$ to $\$ 30,000$ Households & $13.6 \%$ & $12.3 \%$ & $11.1 \%$ & $13.4 \%$ & $11.6 \%$ & $10.1 \%$ \\
\hline$\$ 30$ to $\$ 40,000$ Households & $14.3 \%$ & $11.9 \%$ & $9.6 \%$ & $6.4 \%$ & $7.7 \%$ & $5.7 \%$ \\
\hline$\$ 40$ to $\$ 50,000$ Households & $3.5 \%$ & $3.0 \%$ & $6.6 \%$ & $1.1 \%$ & $1.7 \%$ & $3.4 \%$ \\
\hline$\$ 50$ to $\$ 60,000$ Households & $4.1 \%$ & $6.5 \%$ & $3.7 \%$ & $2.3 \%$ & $2.4 \%$ & $0.7 \%$ \\
\hline$\$ 60$ to $\$ 70,000$ Households & $4.4 \%$ & $2.8 \%$ & $4.0 \%$ & $1.4 \%$ & $0.8 \%$ & $0.4 \%$ \\
\hline$\$ 70$ to $\$ 80,000$ Households & $2.5 \%$ & $2.3 \%$ & $2.3 \%$ & $0.4 \%$ & $0.2 \%$ & $0.7 \%$ \\
\hline$\$ 80$ to $\$ 100,000$ Households & $1.9 \%$ & $2.4 \%$ & $4.3 \%$ & $0.4 \%$ & $0.5 \%$ & $0.4 \%$ \\
\hline$\$ 100,000+$ Households & $4.2 \%$ & $8.1 \%$ & $8.5 \%$ & $0.5 \%$ & $1.7 \%$ & $1.7 \%$ \\
\hline Unreported Households & $21.9 \%$ & $14.6 \%$ & $10.6 \%$ & $20.8 \%$ & $14.4 \%$ & $11.9 \%$ \\
\hline \multicolumn{7}{|c|}{ Zero-Vehicle Households - Daily Person Trips per Person } \\
\hline TOTAL & 3.24 & 3.21 & 3.09 & 2.97 & 2.63 & 2.61 \\
\hline$\%$ Private & $14.8 \%$ & $15.5 \%$ & $9.5 \%$ & $46.5 \%$ & $43.6 \%$ & $33.2 \%$ \\
\hline$\%$ Public & $32.1 \%$ & $30.8 \%$ & $30.8 \%$ & $14.5 \%$ & $16.7 \%$ & $17.6 \%$ \\
\hline$\%$ Walk & $39.2 \%$ & $46.1 \%$ & $51.4 \%$ & $24.6 \%$ & $31.9 \%$ & $34.2 \%$ \\
\hline$\%$ Other & $6.8 \%$ & $7.3 \%$ & $8.2 \%$ & $6.7 \%$ & $7.6 \%$ & $12.7 \%$ \\
\hline$\%$ Unreported & $7.1 \%$ & $0.2 \%$ & $0.2 \%$ & $7.7 \%$ & $0.1 \%$ & $2.2 \%$ \\
\hline \multicolumn{7}{|c|}{ Non-Zero-Vehicle Households - Daily Person Trips per Person } \\
\hline TOTAL & 4.07 & 3.87 & 3.80 & 4.4 & 4.18 & 3.87 \\
\hline$\%$ Private & $79.1 \%$ & $76.6 \%$ & $74.9 \%$ & $89.1 \%$ & $88.9 \%$ & $86.6 \%$ \\
\hline$\%$ Public & $3.9 \%$ & $5.0 \%$ & $5.6 \%$ & $0.7 \%$ & $0.7 \%$ & $0.8 \%$ \\
\hline$\%$ Walk & $8.9 \%$ & $14.2 \%$ & $14.9 \%$ & $3.0 \%$ & $7.2 \%$ & $8.8 \%$ \\
\hline$\%$ Other & $3.9 \%$ & $4.1 \%$ & $4.4 \%$ & $3.2 \%$ & $3.2 \%$ & $3.6 \%$ \\
\hline$\%$ Unreported & $4.2 \%$ & $0.1 \%$ & $0.1 \%$ & $4.1 \%$ & $0.1 \%$ & $0.1 \%$ \\
\hline \multicolumn{7}{|c|}{ Zero-Vehicle Households - Daily Person Trips per Person } \\
\hline TOTAL & 3.24 & 3.21 & 3.09 & 2.97 & 2.63 & 2.61 \\
\hline$<\$ 10,000$ & 2.89 & 2.78 & 2.41 & 2.57 & 2.45 & 2.43 \\
\hline$\$ 10$ to $\$ 20,000$ & 3.21 & 2.97 & 2.96 & 3.27 & 2.42 & 2.63 \\
\hline$\$ 20$ to $\$ 30,000$ & 3.45 & 3.15 & 3.18 & 3.59 & 3.25 & 3.23 \\
\hline$\$ 30$ to $\$ 40,000$ & 3.26 & 3.13 & 2.83 & 3.32 & 2.75 & 3.08 \\
\hline$\$ 40$ to $\$ 50,000$ & 3.38 & 3.88 & 2.77 & 3.85 & 2.54 & 3.22 \\
\hline$\$ 50$ to $\$ 60,000$ & 3.55 & 3.41 & 3.26 & 2.52 & 3.77 & 3.76 \\
\hline$\$ 60$ to $\$ 70,000$ & 4.19 & 4.31 & 4.58 & 2.62 & 3.94 & 3.32 \\
\hline$\$ 70$ to $\$ 80,000$ & 4.54 & 3.80 & 3.23 & 6.24 & 1.95 & 2.74 \\
\hline$\$ 80$ to $\$ 100,000$ & 3.49 & 4.44 & 3.74 & 8.10 & 3.79 & 3.88 \\
\hline$\$ 100,000_{+}$ & 4.16 & 4.43 & 4.79 & 4.23 & 4.13 & 3.77 \\
\hline
\end{tabular}


Chapter 2: Table 5

Comparison of NY State Data to the Rest of the United States

\begin{tabular}{|c|c|c|c|c|c|c|}
\hline \multirow{3}{*}{ Zero-Vehicle Households - Daily } & \multicolumn{3}{|c|}{ New York State } & \multicolumn{3}{|c|}{ Remainder of U.S. } \\
\hline & 1995 & 2001 & 2009 & 1995 & 2001 & 2009 \\
\hline & per Perso & & & & & \\
\hline TOTAL & 15.01 & 16.82 & 8.78 & 13.61 & 18.56 & 11.01 \\
\hline$\%$ Private & $39.4 \%$ & $20.0 \%$ & $23.5 \%$ & $68.7 \%$ & $56.6 \%$ & $57.4 \%$ \\
\hline$\%$ Public & $45.5 \%$ & $30.6 \%$ & $52.3 \%$ & $21.6 \%$ & $10.6 \%$ & $21.1 \%$ \\
\hline$\%$ Walk & $5.3 \%$ & $5.8 \%$ & $12.5 \%$ & $5.3 \%$ & $3.0 \%$ & $5.7 \%$ \\
\hline$\%$ Other & $9.0 \%$ & $43.6 \%$ & $11.2 \%$ & $3.0 \%$ & $29.6 \%$ & $11.9 \%$ \\
\hline$\%$ Unreported & $0.8 \%$ & $0.1 \%$ & $0.6 \%$ & $1.4 \%$ & $0.1 \%$ & $3.8 \%$ \\
\hline TOTAL & 15.01 & 16.82 & 8.78 & 13.61 & 18.56 & 11.01 \\
\hline$<\$ 10,000$ & 8.77 & 10.59 & 4.49 & 8.88 & 7.27 & 7.51 \\
\hline$\$ 10$ to $\$ 20,000$ & 17.45 & 9.19 & 5.60 & 16.73 & 12.79 & 11.36 \\
\hline$\$ 20$ to $\$ 30,000$ & 12.79 & 7.06 & 10.68 & 14.00 & 33.08 & 14.47 \\
\hline$\$ 30$ to $\$ 40,000$ & 16.83 & 15.89 & 9.83 & 18.34 & 20.37 & 15.75 \\
\hline$\$ 40$ to $\$ 50,000$ & 32.42 & 15.53 & 8.32 & 37.46 & 9.82 & 23.58 \\
\hline$\$ 50$ to $\$ 60,000$ & 13.28 & 13.92 & 4.58 & 6.74 & 166.25 & 10.34 \\
\hline$\$ 60$ to $\$ 70,000$ & 13.77 & 16.68 & 9.85 & 22.60 & 15.46 & 17.38 \\
\hline$\$ 70$ to $\$ 80,000$ & 11.68 & 31.10 & 13.06 & 17.07 & 2.99 & 19.36 \\
\hline$\$ 80$ to $\$ 100,000$ & 31.47 & 16.67 & 17.04 & 34.55 & 57.09 & 12.87 \\
\hline$\$ 100,000_{+}$ & 16.60 & 78.65 & 21.57 & 36.13 & 52.47 & 26.32 \\
\hline
\end{tabular}


Chapter 2: Table 6

Comparison of NY State Data to the Rest of the United States

\begin{tabular}{|c|c|c|c|c|c|c|}
\hline \multirow{3}{*}{ Daily Vehicle Trips per Driver } & \multicolumn{3}{|c|}{ New York State } & \multicolumn{3}{|c|}{ Remainder of U.S. } \\
\hline & 1995 & 2001 & 2009 & 1995 & 2001 & 2009 \\
\hline & 2.88 & 2.67 & 2.32 & 3.61 & 3.40 & 3.06 \\
\hline$\%$ Earning a Living & $26.7 \%$ & $25.5 \%$ & $24.7 \%$ & $27.4 \%$ & $26.2 \%$ & $26.1 \%$ \\
\hline \% Family \& Personal Business & $51.0 \%$ & $49.0 \%$ & $49.0 \%$ & $49.9 \%$ & $48.0 \%$ & $46.7 \%$ \\
\hline$\%$ Civic, Educational \& Religious & $3.8 \%$ & $4.1 \%$ & $4.5 \%$ & $4.2 \%$ & $4.9 \%$ & $4.9 \%$ \\
\hline \% Social \& Recreational & $18.4 \%$ & $20.6 \%$ & $20.8 \%$ & $18.3 \%$ & $20.3 \%$ & $21.1 \%$ \\
\hline$\%$ Other & $0.0 \%$ & $0.6 \%$ & $0.3 \%$ & $0.1 \%$ & $0.5 \%$ & $0.3 \%$ \\
\hline$\%$ Unreported & & $0.2 \%$ & $0.9 \%$ & & $0.1 \%$ & $0.9 \%$ \\
\hline TOTAL & 2.88 & 2.67 & 2.32 & 3.61 & 3.40 & 3.06 \\
\hline$\% 1-9 \min$ & $39.6 \%$ & $30.1 \%$ & $31.4 \%$ & $40.2 \%$ & $29.9 \%$ & $30.6 \%$ \\
\hline$\% 10-19 \min$ & $31.3 \%$ & $35.9 \%$ & $35.6 \%$ & $33.0 \%$ & $37.3 \%$ & $36.9 \%$ \\
\hline$\% 20-29 \min$ & $13.5 \%$ & $13.3 \%$ & $13.8 \%$ & $13.3 \%$ & $13.7 \%$ & $13.9 \%$ \\
\hline$\%$ 30-39 min & $6.3 \%$ & $9.9 \%$ & $9.6 \%$ & $6.4 \%$ & $9.5 \%$ & $9.4 \%$ \\
\hline$\%$ 40-49 min & $3.8 \%$ & $4.2 \%$ & $4.1 \%$ & $3.3 \%$ & $4.0 \%$ & $4.0 \%$ \\
\hline$\% 50+\min$ & $4.9 \%$ & $6.0 \%$ & $5.4 \%$ & $3.9 \%$ & $5.1 \%$ & $5.1 \%$ \\
\hline$\%$ Unreported & $0.6 \%$ & $0.6 \%$ & $0.2 \%$ & $0.0 \%$ & $0.6 \%$ & $0.2 \%$ \\
\hline TOTAL & 2.88 & 2.67 & 2.32 & 3.61 & 3.40 & 3.06 \\
\hline$\% 5$ or less miles & $60.4 \%$ & $59.3 \%$ & $60.2 \%$ & $60.1 \%$ & $56.3 \%$ & $56.7 \%$ \\
\hline$\% 6-10$ miles & $17.4 \%$ & $17.0 \%$ & $16.9 \%$ & $17.5 \%$ & $18.5 \%$ & $18.5 \%$ \\
\hline$\% 11-15$ miles & $8.3 \%$ & $8.4 \%$ & $7.9 \%$ & $8.3 \%$ & $9.1 \%$ & $8.8 \%$ \\
\hline$\% 16-20$ miles & $4.2 \%$ & $4.6 \%$ & $4.7 \%$ & $4.4 \%$ & $4.9 \%$ & $4.9 \%$ \\
\hline$\% 21-30$ miles & $4.2 \%$ & $4.3 \%$ & $4.3 \%$ & $4.4 \%$ & $4.9 \%$ & $4.9 \%$ \\
\hline$\% 31$ or more miles & $4.5 \%$ & $4.6 \%$ & $4.3 \%$ & $4.7 \%$ & $5.3 \%$ & $5.1 \%$ \\
\hline$\%$ Unreported & $1.0 \%$ & $1.9 \%$ & $1.7 \%$ & $0.6 \%$ & $1.0 \%$ & $1.2 \%$ \\
\hline TOTAL & 2.88 & 2.67 & 2.32 & 3.61 & 3.40 & 3.06 \\
\hline Weekday & 3.01 & 2.79 & 2.41 & 3.84 & 3.60 & 3.26 \\
\hline Weekend & 2.58 & 2.37 & 2.10 & 3.00 & 2.88 & 2.56 \\
\hline Daily VMT per Driver & & & & & & \\
\hline TOTAL & 25.01 & 23.36 & 19.67 & 32.59 & 33.31 & 29.57 \\
\hline$\%$ Earn a Living & $37.0 \%$ & $34.8 \%$ & $34.1 \%$ & $37.8 \%$ & $35.5 \%$ & $34.8 \%$ \\
\hline \% Family \& Personal Business & $35.1 \%$ & $34.8 \%$ & $34.0 \%$ & $35.5 \%$ & $35.3 \%$ & $32.7 \%$ \\
\hline$\%$ Civic, Educational \& Religious & $2.8 \%$ & $3.3 \%$ & $3.5 \%$ & $3.8 \%$ & $3.8 \%$ & $4.5 \%$ \\
\hline \% Social \& Recreational & $24.8 \%$ & $26.1 \%$ & $24.9 \%$ & $22.7 \%$ & $24.4 \%$ & $24.4 \%$ \\
\hline$\%$ Other & $0.2 \%$ & $0.8 \%$ & $0.4 \%$ & $0.1 \%$ & $0.8 \%$ & $0.6 \%$ \\
\hline$\%$ Unreported & & $0.3 \%$ & $3.2 \%$ & & $0.2 \%$ & $3.2 \%$ \\
\hline Average Vehicle Trip Length & & & & & & \\
\hline TOTAL & 8.78 & 8.92 & 8.62 & 9.07 & 9.91 & 9.77 \\
\hline \% Vehicle Trips/Person Trips & & & & & & \\
\hline TOTAL & 46.29 & 45.92 & 44.80 & 61.59 & 61.59 & 60.63 \\
\hline \% VMT/PMT & & & & & & \\
\hline TOTAL & 53.97 & 51.00 & 53.63 & 61.00 & 60.59 & 60.46 \\
\hline
\end{tabular}


Chapter 2: Table 7

Comparison of NY State Data to the Rest of the United States

\begin{tabular}{|c|c|c|c|c|c|c|}
\hline \multirow{3}{*}{$\begin{array}{l}\text { Daily Commute Trips per } \\
\text { Worker }\end{array}$} & \multicolumn{3}{|c|}{ New York State } & \multicolumn{3}{|c|}{ Remainder of U.S. } \\
\hline & 1995 & 2001 & 2009 & 1995 & 2001 & 2009 \\
\hline & & & & & & \\
\hline TOTAL & 1.31 & 1.12 & 1.06 & 1.40 & 1.15 & 1.11 \\
\hline \% POV by Occupancy & $69.5 \%$ & $67.9 \%$ & $67.6 \%$ & $92.1 \%$ & $94.1 \%$ & $93.0 \%$ \\
\hline$\%$ SOV & $56.5 \%$ & $55.3 \%$ & $56.0 \%$ & $75.7 \%$ & $77.7 \%$ & $78.4 \%$ \\
\hline$\% \mathrm{MOV}$ & $13.0 \%$ & $12.6 \%$ & $11.5 \%$ & $16.4 \%$ & $16.4 \%$ & $14.6 \%$ \\
\hline \% POV by Vehicle Type & $69.5 \%$ & $67.9 \%$ & $67.6 \%$ & $92.1 \%$ & $94.1 \%$ & $93.0 \%$ \\
\hline$\%$ Car & $51.1 \%$ & $44.7 \%$ & $39.6 \%$ & $59.2 \%$ & $53.6 \%$ & $52.2 \%$ \\
\hline$\%$ Van & $5.0 \%$ & $7.0 \%$ & $6.0 \%$ & $7.5 \%$ & $8.3 \%$ & $6.9 \%$ \\
\hline$\%$ SUV & $4.9 \%$ & $8.6 \%$ & $14.8 \%$ & $6.7 \%$ & $12.7 \%$ & $17.5 \%$ \\
\hline \% Pickup Truck & $7.1 \%$ & $7.1 \%$ & $6.5 \%$ & $17.5 \%$ & $18.6 \%$ & $15.1 \%$ \\
\hline$\%$ Other Truck & $0.9 \%$ & $0.3 \%$ & $0.4 \%$ & $1.2 \%$ & $0.5 \%$ & $0.6 \%$ \\
\hline$\% \mathrm{RV}$ & $0.0 \%$ & $0.0 \%$ & $0.0 \%$ & $0.0 \%$ & $0.0 \%$ & $0.0 \%$ \\
\hline$\%$ Motorcycle & $0.1 \%$ & $0.2 \%$ & $0.2 \%$ & $0.2 \%$ & $0.3 \%$ & $0.6 \%$ \\
\hline$\%$ Public Transit & $18.3 \%$ & $20.1 \%$ & $19.6 \%$ & $2.9 \%$ & $2.5 \%$ & $2.3 \%$ \\
\hline$\%$ Commuter Train & $3.1 \%$ & $1.8 \%$ & $2.3 \%$ & $0.7 \%$ & $0.3 \%$ & $0.3 \%$ \\
\hline$\%$ Subway/Elevated Rail & $9.9 \%$ & $12.8 \%$ & $10.6 \%$ & $0.7 \%$ & $0.5 \%$ & $0.3 \%$ \\
\hline$\%$ Other Public & $5.3 \%$ & $5.5 \%$ & $6.6 \%$ & $1.4 \%$ & $1.6 \%$ & $1.7 \%$ \\
\hline$\%$ Amtrak & $0.0 \%$ & $0.7 \%$ & $0.4 \%$ & $0.0 \%$ & $0.1 \%$ & $0.0 \%$ \\
\hline$\%$ Walk & $6.1 \%$ & $8.7 \%$ & $8.5 \%$ & $2.1 \%$ & $2.4 \%$ & $2.7 \%$ \\
\hline$\%$ Other & $2.3 \%$ & $2.4 \%$ & $3.9 \%$ & $1.4 \%$ & $0.9 \%$ & $1.8 \%$ \\
\hline$\%$ Unreported & $3.8 \%$ & $0.1 \%$ & $0.2 \%$ & $1.6 \%$ & $0.1 \%$ & $0.2 \%$ \\
\hline TOTAL & 1.31 & 1.12 & 1.06 & 1.40 & 1.15 & 1.11 \\
\hline$\% 1-6$ am & $4.5 \%$ & $4.9 \%$ & $4.6 \%$ & $5.7 \%$ & $6.2 \%$ & $6.3 \%$ \\
\hline$\% 6-9$ am & $29.3 \%$ & $30.9 \%$ & $30.5 \%$ & $28.6 \%$ & $30.1 \%$ & $30.0 \%$ \\
\hline$\% 9 \mathrm{am}-1 \mathrm{pm}$ & $12.0 \%$ & $11.0 \%$ & $11.1 \%$ & $12.9 \%$ & $11.5 \%$ & $11.6 \%$ \\
\hline$\% 1-4 \mathrm{pm}$ & $14.3 \%$ & $13.8 \%$ & $16.0 \%$ & $15.0 \%$ & $14.3 \%$ & $15.3 \%$ \\
\hline$\% 4-7 \mathrm{pm}$ & $25.6 \%$ & $26.2 \%$ & $24.0 \%$ & $26.4 \%$ & $25.5 \%$ & $26.2 \%$ \\
\hline$\% 7-10 \mathrm{pm}$ & $9.0 \%$ & $8.5 \%$ & $8.8 \%$ & $7.1 \%$ & $8.1 \%$ & $7.0 \%$ \\
\hline$\% 10 \mathrm{pm}-1 \mathrm{am}$ & $5.3 \%$ & $4.7 \%$ & $5.1 \%$ & $4.3 \%$ & $4.3 \%$ & $3.7 \%$ \\
\hline$\%$ Unreported & & $0.1 \%$ & & & $0.1 \%$ & $0.0 \%$ \\
\hline Daily Commute PMT per & & & & & & \\
\hline TOTAL & 13.97 & 10.79 & 10.15 & 16.08 & 13.78 & 12.99 \\
\hline$\%$ POV by Occupancy & $77.5 \%$ & $77.5 \%$ & $80.8 \%$ & $94.0 \%$ & $93.8 \%$ & $95.2 \%$ \\
\hline$\%$ SOV & $62.5 \%$ & $64.7 \%$ & $67.5 \%$ & $76.8 \%$ & $77.7 \%$ & $81.7 \%$ \\
\hline$\% \mathrm{MOV}$ & $15.0 \%$ & $12.8 \%$ & $13.3 \%$ & $17.2 \%$ & $16.1 \%$ & $13.5 \%$ \\
\hline \% POV by Vehicle Type & $77.5 \%$ & $77.5 \%$ & $80.8 \%$ & $94.0 \%$ & $93.8 \%$ & $95.2 \%$ \\
\hline$\%$ Car & $55.4 \%$ & $50.8 \%$ & $46.0 \%$ & $57.1 \%$ & $51.0 \%$ & $53.7 \%$ \\
\hline$\%$ Van & $5.4 \%$ & $7.3 \%$ & $6.2 \%$ & $7.1 \%$ & $7.8 \%$ & $6.3 \%$ \\
\hline$\%$ SUV & $5.5 \%$ & $9.6 \%$ & $17.9 \%$ & $7.0 \%$ & $12.5 \%$ & $16.3 \%$ \\
\hline \% Pickup Truck & $8.3 \%$ & $9.2 \%$ & $7.9 \%$ & $19.2 \%$ & $20.8 \%$ & $16.7 \%$ \\
\hline$\%$ Other Truck & $2.6 \%$ & $0.4 \%$ & $2.7 \%$ & $3.3 \%$ & $1.4 \%$ & $1.6 \%$ \\
\hline$\% \mathrm{RV}$ & $0.0 \%$ & $0.0 \%$ & $0.0 \%$ & $0.0 \%$ & $0.0 \%$ & $0.0 \%$ \\
\hline$\%$ Motorcycle & $0.1 \%$ & $0.2 \%$ & $0.1 \%$ & $0.2 \%$ & $0.3 \%$ & $0.6 \%$ \\
\hline$\%$ Public Transit & $17.9 \%$ & $18.0 \%$ & $14.2 \%$ & $2.6 \%$ & $2.1 \%$ & $1.7 \%$ \\
\hline$\%$ Commuter Train & $5.9 \%$ & $4.5 \%$ & $3.1 \%$ & $0.7 \%$ & $0.7 \%$ & $0.5 \%$ \\
\hline$\%$ Subway/Elevated Rail & $8.4 \%$ & $10.9 \%$ & $7.3 \%$ & $0.4 \%$ & $0.5 \%$ & $0.2 \%$ \\
\hline$\%$ Other Public & $3.7 \%$ & $2.7 \%$ & $3.8 \%$ & $1.5 \%$ & $1.0 \%$ & $1.1 \%$ \\
\hline$\%$ Amtrak & $0.0 \%$ & $1.0 \%$ & $0.6 \%$ & $0.1 \%$ & $0.3 \%$ & $0.0 \%$ \\
\hline$\%$ Walk & $0.6 \%$ & $1.1 \%$ & $1.3 \%$ & $0.1 \%$ & $0.2 \%$ & $0.2 \%$ \\
\hline$\%$ Other & $3.1 \%$ & $2.1 \%$ & $2.8 \%$ & $2.2 \%$ & $3.5 \%$ & $2.7 \%$ \\
\hline$\%$ Unreported & $0.7 \%$ & $0.2 \%$ & $0.2 \%$ & $0.9 \%$ & $0.1 \%$ & $0.2 \%$ \\
\hline TOTAL & 13.97 & 10.79 & 10.15 & 16.08 & 13.78 & 12.99 \\
\hline$\% 1-6$ am & $6.4 \%$ & $7.7 \%$ & $6.8 \%$ & $8.6 \%$ & $9.6 \%$ & $10.3 \%$ \\
\hline$\%$ 6-9 am & $30.8 \%$ & $33.0 \%$ & $33.3 \%$ & $29.0 \%$ & $31.9 \%$ & $31.5 \%$ \\
\hline$\% 9$ am-1 pm & $10.3 \%$ & $8.6 \%$ & $10.1 \%$ & $9.5 \%$ & $8.4 \%$ & $8.8 \%$ \\
\hline$\% 1-4 \mathrm{pm}$ & $13.6 \%$ & $12.9 \%$ & $14.0 \%$ & $14.6 \%$ & $13.1 \%$ & $13.6 \%$ \\
\hline$\%$ 4-7 pm & $26.1 \%$ & $25.9 \%$ & $23.9 \%$ & $26.5 \%$ & $24.2 \%$ & $25.9 \%$ \\
\hline$\% 7-10 \mathrm{pm}$ & $8.0 \%$ & $7.5 \%$ & $7.8 \%$ & $7.6 \%$ & $8.7 \%$ & $6.6 \%$ \\
\hline$\% 10 \mathrm{pm}-1 \mathrm{am}$ & $4.7 \%$ & $4.3 \%$ & $4.2 \%$ & $4.2 \%$ & $4.1 \%$ & $3.3 \%$ \\
\hline$\%$ Unreported & & $0.1 \%$ & & & $0.1 \%$ & $0.0 \%$ \\
\hline
\end{tabular}


Chapter 2: Table 8

Comparison of NY State Data to the Rest of the United States

\begin{tabular}{|c|c|c|c|c|c|c|}
\hline \multirow{3}{*}{ Average Commute Length, Travel } & \multicolumn{3}{|c|}{ New York State } & \multicolumn{3}{|c|}{ Remainder of U.S. } \\
\hline & 1995 & 2001 & 2009 & 1995 & 2001 & 2009 \\
\hline & \multicolumn{3}{|c|}{ Time, and Speed } & & & \\
\hline TOTAL & 11.29 & 10.39 & 10.25 & 11.65 & 12.22 & 11.89 \\
\hline POV & 12.15 & 11.31 & 11.61 & 11.82 & 12.13 & 12.11 \\
\hline Public & 12.60 & 11.32 & 9.04 & 13.00 & 11.94 & 10.71 \\
\hline \multicolumn{7}{|c|}{ Time (minutes) } \\
\hline TOTAL & 25.66 & 30.40 & 29.89 & 20.23 & 23.11 & 23.45 \\
\hline POV & 22.57 & 23.87 & 24.49 & 19.97 & 22.42 & 22.77 \\
\hline Public & 44.32 & 57.79 & 51.92 & 39.94 & 54.18 & 53.54 \\
\hline \multicolumn{7}{|c|}{ Miles per Hour } \\
\hline TOTAL & 28.83 & 26.40 & 26.08 & 35.00 & 32.82 & 31.54 \\
\hline POV & 32.28 & 28.49 & 28.45 & 35.53 & 32.51 & 31.92 \\
\hline Public & 15.82 & & & 21.10 & 29.46 & \\
\hline
\end{tabular}


Chapter 2: Table 9

Comparison of NY State Data to the Rest of the United States

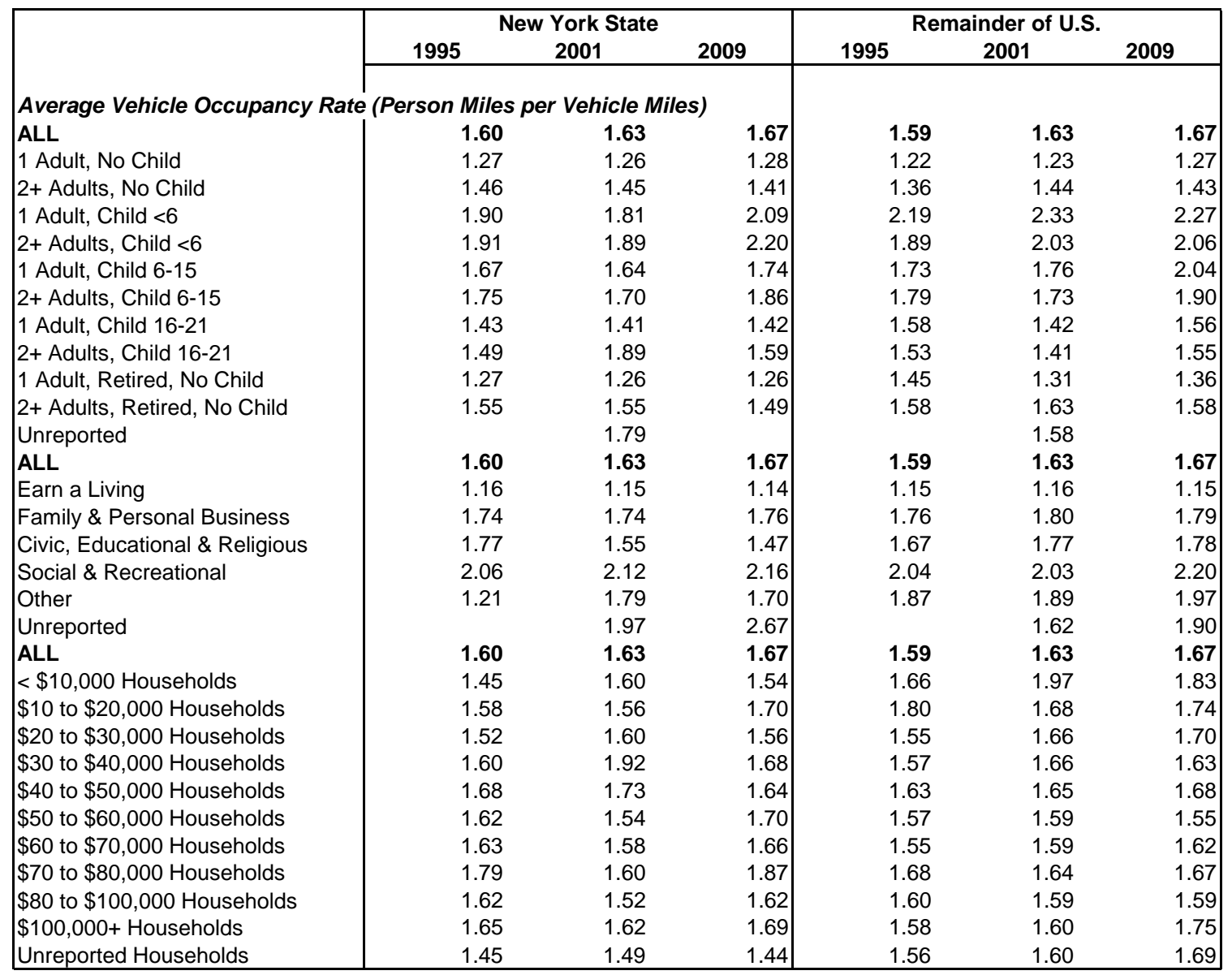


Chapter 2: Table 10

Comparison of NY State Data to the Rest of the United States

\begin{tabular}{|c|c|c|c|c|c|c|}
\hline & \multicolumn{3}{|c|}{ New York State } & \multicolumn{3}{|c|}{ Remainder of U.S. } \\
\hline & 1995 & 2001 & 2009 & 1995 & 2001 & 2009 \\
\hline \multicolumn{7}{|l|}{ Vehicles by Type } \\
\hline Auto & $100.0 \%$ & $100.0 \%$ & $100.0 \%$ & $100.0 \%$ & $100.0 \%$ & $100.0 \%$ \\
\hline Van & $75.4 \%$ & $66.0 \%$ & $58.0 \%$ & $64.7 \%$ & $56.4 \%$ & $49.7 \%$ \\
\hline Sports Utility & $7.4 \%$ & $9.9 \%$ & $9.1 \%$ & $8.0 \%$ & $9.0 \%$ & $8.2 \%$ \\
\hline Pickup & $6.9 \%$ & $12.0 \%$ & $21.5 \%$ & $7.0 \%$ & $12.1 \%$ & $19.4 \%$ \\
\hline Other Truck & $8.9 \%$ & $9.3 \%$ & $8.6 \%$ & $18.3 \%$ & $19.0 \%$ & $18.3 \%$ \\
\hline RV & $0.3 \%$ & $0.3 \%$ & $0.2 \%$ & $0.4 \%$ & $0.5 \%$ & $0.4 \%$ \\
\hline Motorcycle & $0.3 \%$ & $0.4 \%$ & $0.3 \%$ & $0.5 \%$ & $0.7 \%$ & $0.5 \%$ \\
\hline \multirow[t]{2}{*}{ Other POV } & $0.7 \%$ & $2.1 \%$ & $2.4 \%$ & $1.0 \%$ & $2.3 \%$ & $3.4 \%$ \\
\hline & $0.1 \%$ & * & & $0.1 \%$ & * & \\
\hline \multicolumn{7}{|c|}{ * Other POV not present in 2001 or 2009.} \\
\hline \multicolumn{7}{|l|}{ Age Statistics } \\
\hline Average Vehicle Age & 7.43 & 7.85 & 7.79 & 8.38 & 8.92 & 9.47 \\
\hline Median Vehicle Age & 7 & 7 & 7 & 7 & 7 & 8 \\
\hline \multicolumn{7}{|l|}{ Percent VMT* ${ }^{*}$} \\
\hline Less than $10 \mathrm{yrs}$ & $75.2 \%$ & $73.2 \%$ & $74.8 \%$ & $76.4 \%$ & $71.0 \%$ & $67.8 \%$ \\
\hline 10 yrs or more & $24.8 \%$ & $26.8 \%$ & $25.2 \%$ & $23.6 \%$ & $29.0 \%$ & $32.2 \%$ \\
\hline \multicolumn{7}{|l|}{ Percent Vehicle Fleet } \\
\hline Less than $10 \mathrm{yrs}$ & $71.6 \%$ & $66.5 \%$ & $69.3 \%$ & $66.0 \%$ & $62.6 \%$ & $60.7 \%$ \\
\hline 10 yrs or more & $28.4 \%$ & $33.5 \%$ & $30.7 \%$ & $34.0 \%$ & $37.5 \%$ & $39.3 \%$ \\
\hline Avg Fuel Consumption (gal/HH) & ** & 709 & 615 & ** & 1,036 & 1,020 \\
\hline Less than $10 \mathrm{yrs}$ & ** & $74.5 \%$ & $73.6 \%$ & ** & $71.3 \%$ & $66.3 \%$ \\
\hline 10 yrs or more & ** & $25.5 \%$ & $26.5 \%$ & ** & $28.7 \%$ & $33.7 \%$ \\
\hline Avg CO2 Emissions $(\mathrm{kg} / \mathrm{HH})$ & ** & 6,235 & 5,416 & ** & 9,106 & 8,985 \\
\hline Less than $10 \mathrm{yrs}$ & ** & $74.5 \%$ & $73.6 \%$ & ** & $71.3 \%$ & $66.3 \%$ \\
\hline 10 yrs or more & ** & $25.5 \%$ & $26.4 \%$ & ** & $28.7 \%$ & $33.7 \%$ \\
\hline
\end{tabular}


Chapter 2: Table 11

Comparison of NY State Data to the Rest of the United States

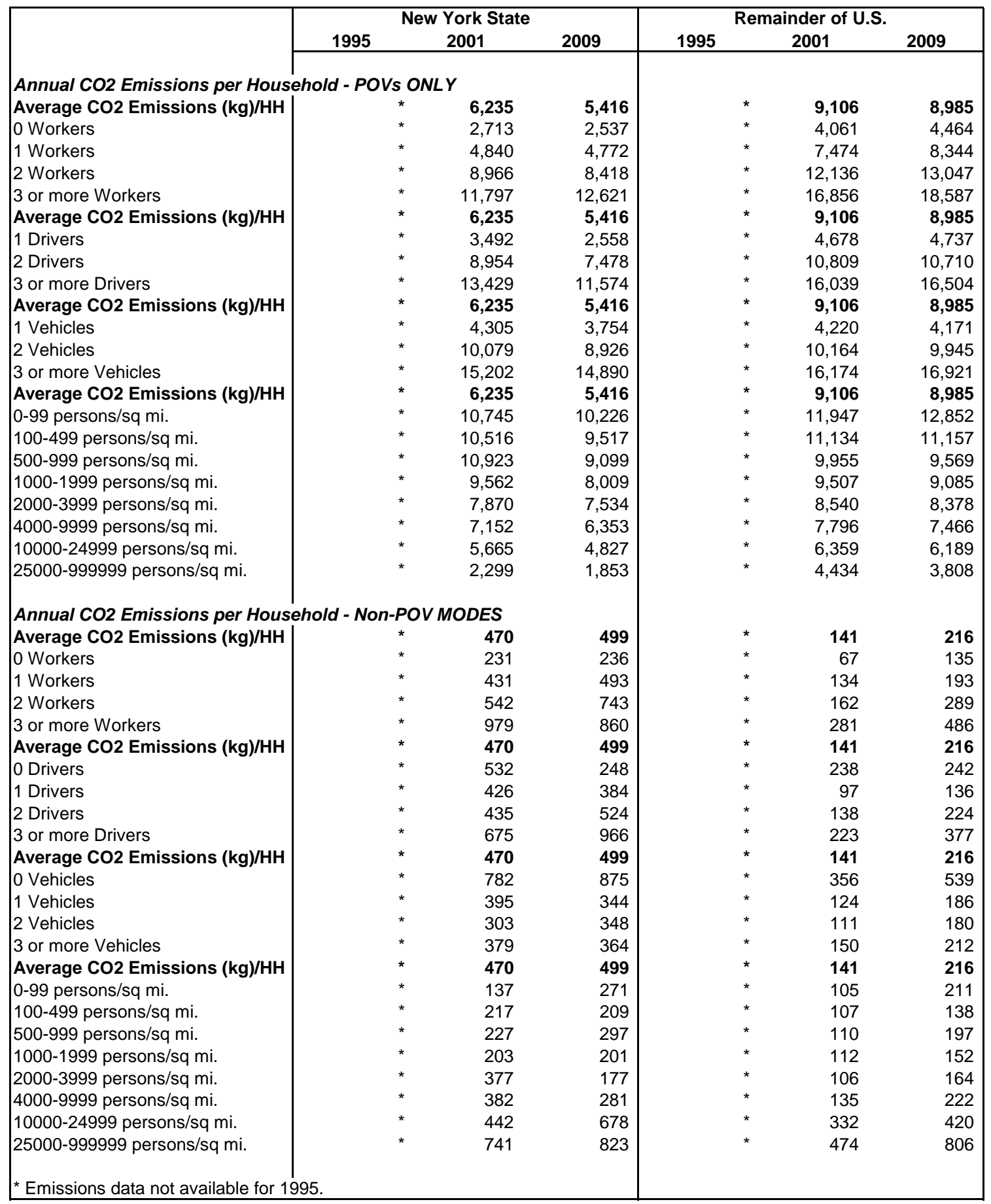


Chapter 2: Table 12

Comparison of NY State Data to the Rest of the United States

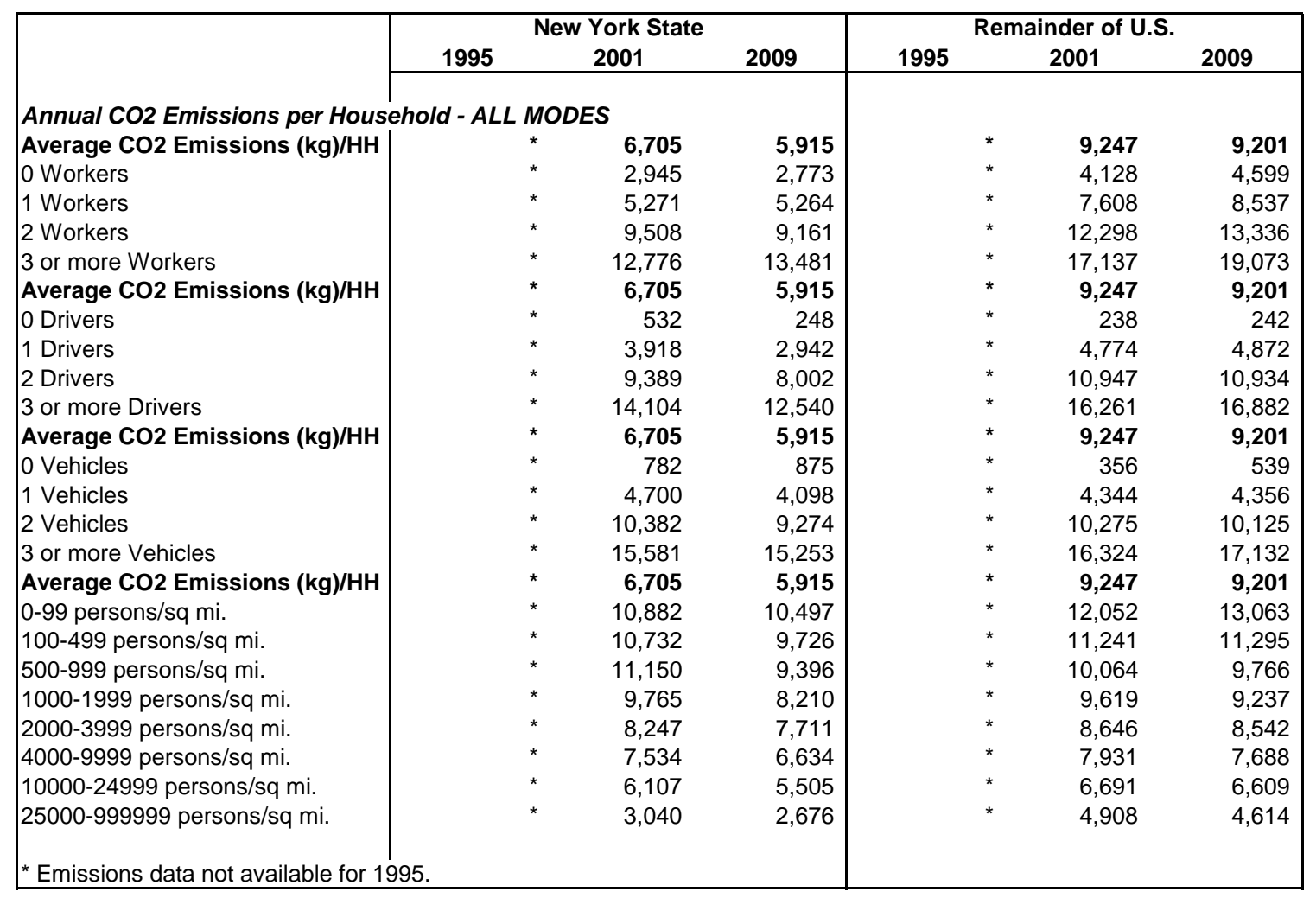


Chapter 2: Table 13

Comparison of NY State Data to the Rest of the United States

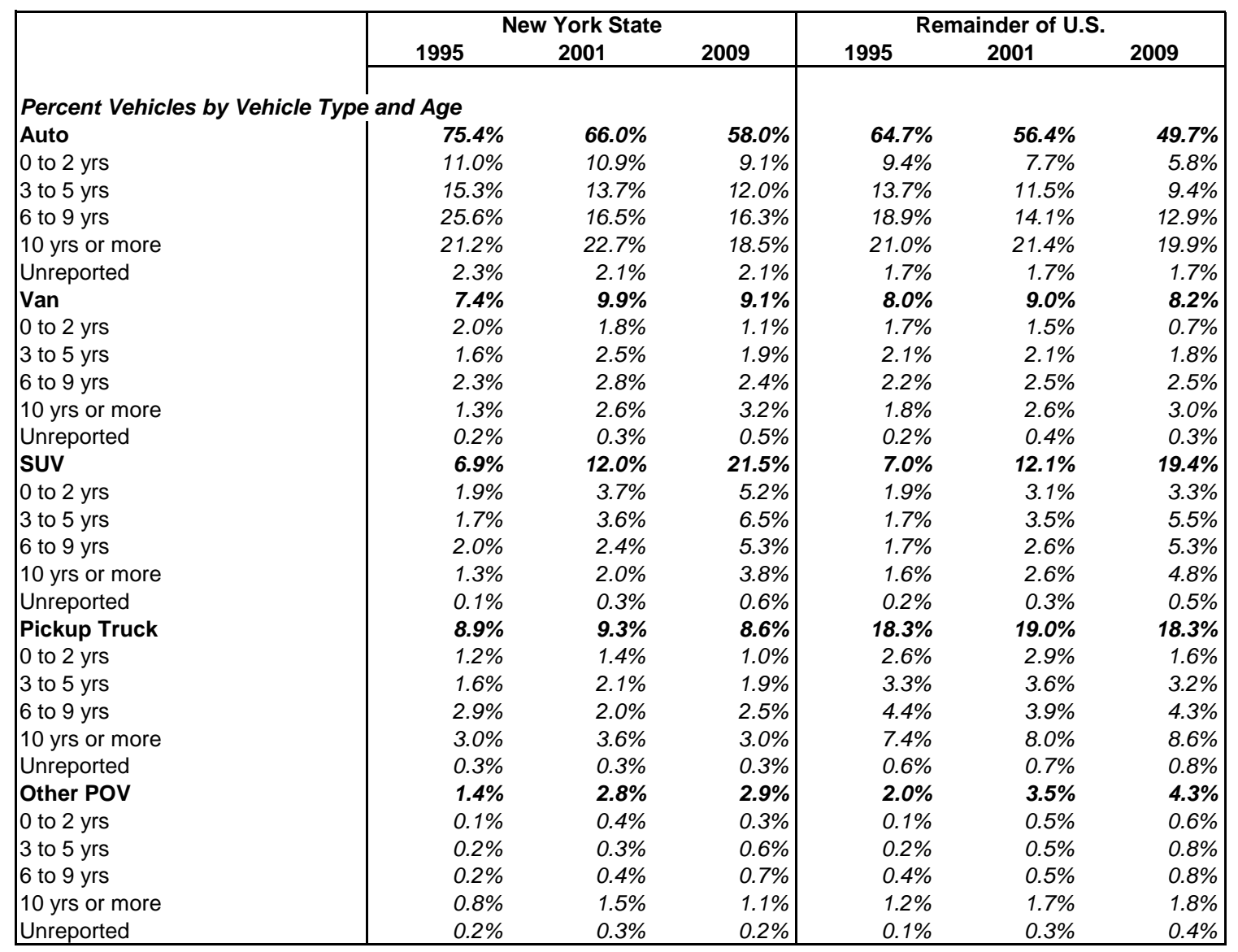


Chapter 2: Table 14

Comparison of NY State Data to the Rest of the United States

\begin{tabular}{|c|c|c|c|c|c|c|}
\hline & & York Stat & & & inder of $U$ & \\
\hline & 1995 & 2001 & 2009 & 1995 & 2001 & 2009 \\
\hline VMT/Vehicle by & & & & & & \\
\hline ALL VEHICLES & 12,843 & 12,144 & 10,707 & 12,268 & 12,019 & 11,314 \\
\hline 0 to 2 yrs & 14,976 & 13,474 & 12,424 & 16,225 & 14,701 & 14,216 \\
\hline 3 to $5 \mathrm{yrs}$ & 13,232 & 13,797 & 11,609 & 14,076 & 14,191 & 12,735 \\
\hline 6 to $9 \mathrm{yrs}$ & 12,608 & 12,614 & 10,910 & 12,665 & 12,512 & 11,754 \\
\hline 10 yrs or more & 11,300 & 9,857 & 8,872 & 8,748 & 9,360 & 9,319 \\
\hline Unreported & 15,289 & 12,247 & 10,366 & 11,975 & 10,925 & 11,143 \\
\hline Auto & 12,584 & 11,917 & 10,405 & 12,038 & 11,596 & 11,154 \\
\hline 0 to $2 \mathrm{yrs}$ & 14,597 & 13,137 & 11,914 & 15,524 & 14,054 & 14,230 \\
\hline 3 to $5 \mathrm{yrs}$ & 12,600 & 13,805 & 10,970 & 13,652 & 13,471 & 12,465 \\
\hline 6 to $9 \mathrm{yrs}$ & 12,458 & 11,975 & 10,641 & 12,387 & 12,028 & 11,336 \\
\hline 10 yrs or more & 11,331 & 10,115 & 9,059 & 8,928 & 9,433 & 9,477 \\
\hline Unreported & 15,779 & 12,081 & 10,503 & 11,369 & 11,292 & 11,425 \\
\hline Van & 15,225 & 13,593 & 11,269 & 14,278 & 13,400 & 12,587 \\
\hline 0 to 2 yrs & 16,121 & 15,273 & 13,652 & 17,759 & 15,862 & 15,495 \\
\hline 3 to $5 \mathrm{yrs}$ & 16,668 & 14,597 & 13,154 & 15,129 & 15,526 & 14,105 \\
\hline 6 to $9 \mathrm{yrs}$ & 14,172 & 13,559 & 12,202 & 13,313 & 13,597 & 13,389 \\
\hline 10 yrs or more & 14,309 & 10,759 & 8,599 & 10,685 & 10,274 & 10,119 \\
\hline Unreported & 12,728 & 18,916 & 11,335 & 17,465 & 11,547 & 14,513 \\
\hline SUV & 14,115 & 13,783 & 12,088 & 13,905 & 13,877 & 12,825 \\
\hline 0 to 2 yrs & 15,642 & 13,400 & 13,230 & 16,232 & 14,968 & 15,038 \\
\hline 3 to $5 \mathrm{yrs}$ & 14,305 & 14,336 & 12,609 & 14,567 & 15,235 & 13,672 \\
\hline 6 to $9 \mathrm{yrs}$ & 13,494 & 15,471 & 11,741 & 14,806 & 14,308 & 12,860 \\
\hline 10 yrs or more & 12,331 & 11,496 & 10,286 & 9,391 & 10,687 & 10,184 \\
\hline Unreported & 16,292 & 13,198 & 11,009 & 16,851 & 11,117 & 13,167 \\
\hline Pickup Truck & 13,082 & 12,226 & 11,189 & 12,078 & 12,465 & 11,329 \\
\hline 0 to 2 yrs & 15,660 & 15,606 & 14,283 & 17,640 & 16,552 & 15,068 \\
\hline 3 to $5 \mathrm{yrs}$ & 15,472 & 13,185 & 12,909 & 15,001 & 15,420 & 13,233 \\
\hline 6 to $9 \mathrm{yrs}$ & 12,521 & 14,536 & 11,761 & 12,862 & 12,888 & 12,016 \\
\hline 10 yrs or more & 11,274 & 9,258 & 8,698 & 8,348 & 9,536 & 9,544 \\
\hline Unreported & 13,069 & 9,057 & 10,959 & 11,984 & 11,879 & 11,759 \\
\hline Other POV & 6,245 & 3,285 & 2,682 & 7,626 & 5,094 & 3,459 \\
\hline 0 to 2 yrs & 13,331 & 5,005 & 4,591 & 18,632 & 7,612 & 5,078 \\
\hline 3 to $5 \mathrm{yrs}$ & 5,444 & 4,231 & 3,101 & 12,882 & 8,478 & 4,077 \\
\hline 6 to $9 \mathrm{yrs}$ & 7,282 & 3,790 & 2,605 & 10,827 & 7,350 & 4,198 \\
\hline 10 yrs or more & 3,207 & 2,186 & 1,797 & 4,726 & 3,101 & 2,470 \\
\hline Unreported & 14,421 & 5,589 & 3,535 & 4,394 & 2,189 & 2,666 \\
\hline
\end{tabular}


Chapter 2: Table 15

Comparison of NY State Data to the Rest of the United States

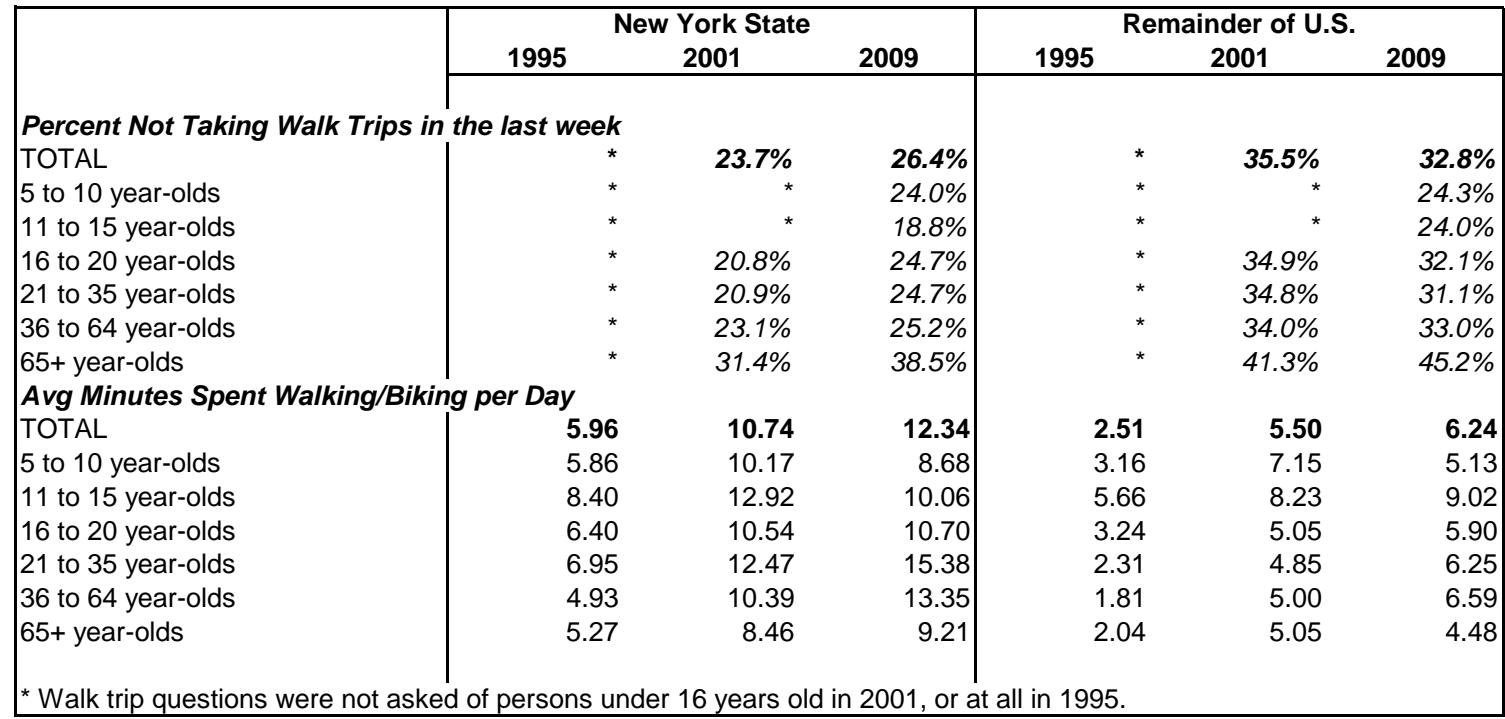


APPENDIX C2A. SUPPLEMENTAL TABLES FOR CHAPTER 2 STANDARD ERRORS 
Chapter 2: Table 1

Comparison of NY State Data to the Rest of the United States

STANDARD ERRORS

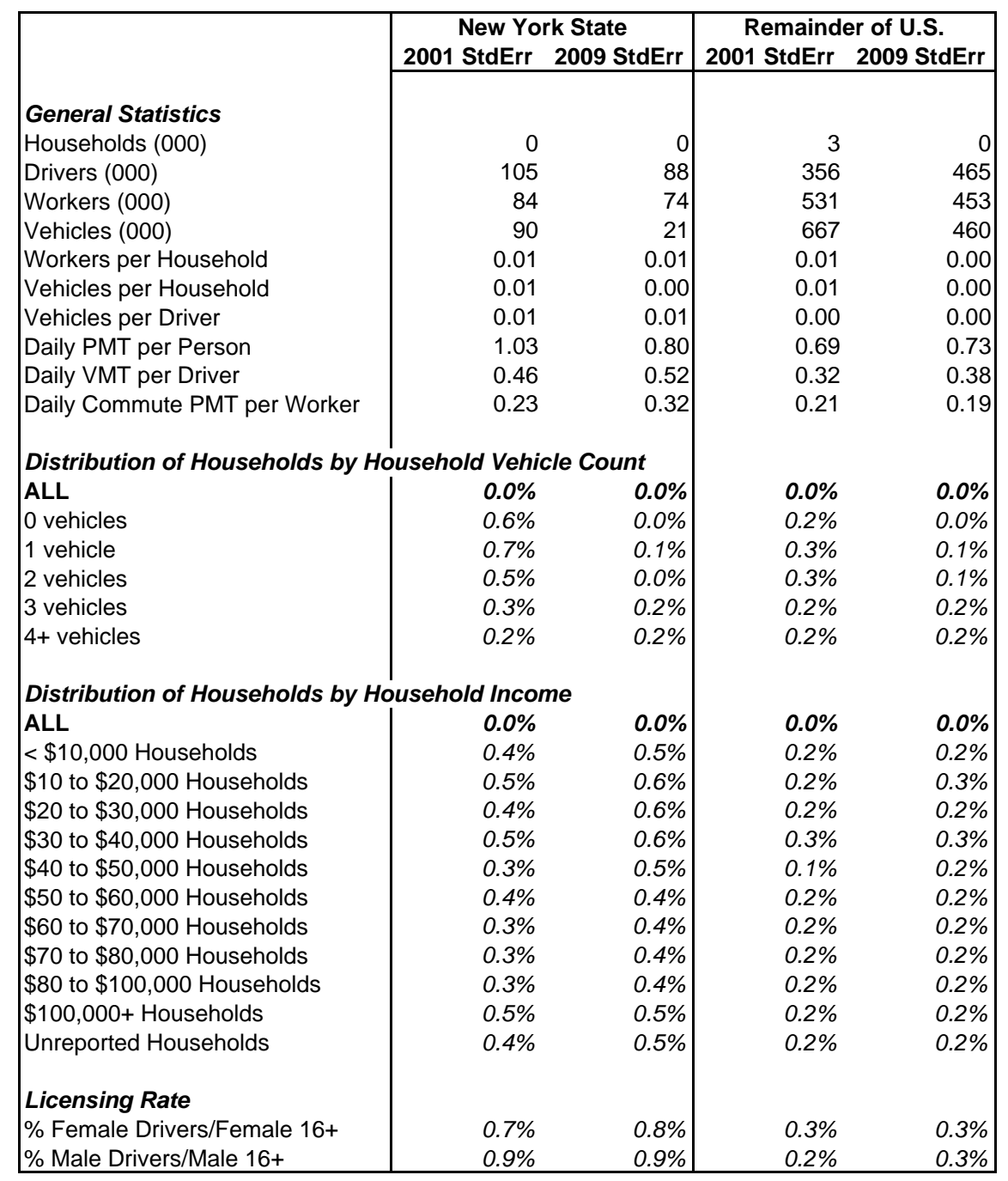


Chapter 2: Table 2

Comparison of NY State Data to the Rest of the United States

STANDARD ERRORS

\begin{tabular}{|c|c|c|c|c|}
\hline \multirow{3}{*}{ Daily Person Trips per Person } & \multicolumn{2}{|c|}{ New York State } & \multicolumn{2}{|c|}{ Remainder of U.S. } \\
\hline & 2001 StdErr & 2009 StdErr & 2001 StdErr & 2009 StdErr \\
\hline & & & & \\
\hline TOTAL & 0.03 & 0.04 & 0.02 & 0.02 \\
\hline Male & 0.04 & 0.04 & 0.02 & 0.02 \\
\hline Female & 0.04 & 0.05 & 0.02 & 0.02 \\
\hline TOTAL & 0.03 & 0.04 & 0.02 & 0.02 \\
\hline $5-15$ years & 0.06 & 0.07 & 0.03 & 0.04 \\
\hline $16-19$ years & 0.10 & 0.16 & 0.06 & 0.06 \\
\hline $20-29$ years & 0.09 & 0.14 & 0.04 & 0.05 \\
\hline 30-39 years & 0.07 & 0.12 & 0.04 & 0.05 \\
\hline $40-49$ years & 0.07 & 0.09 & 0.04 & 0.04 \\
\hline $50-59$ years & 0.07 & 0.09 & 0.04 & 0.05 \\
\hline $60-64$ years & 0.10 & 0.12 & 0.07 & 0.06 \\
\hline $65+$ years & 0.08 & 0.06 & 0.04 & 0.04 \\
\hline Unreported & 0.18 & & 0.11 & \\
\hline TOTAL & 0.03 & 0.04 & 0.02 & 0.02 \\
\hline$\%$ POV by Occupancy & & & & \\
\hline$\%$ SOV & $0.5 \%$ & $0.5 \%$ & $0.2 \%$ & $0.3 \%$ \\
\hline$\% \mathrm{MOV}$ & $0.5 \%$ & $0.7 \%$ & $0.2 \%$ & $0.3 \%$ \\
\hline$\%$ POV by Vehicle Type & & & & \\
\hline$\%$ Car & $0.6 \%$ & $0.7 \%$ & $0.4 \%$ & $0.4 \%$ \\
\hline$\%$ Van & $0.4 \%$ & $0.4 \%$ & $0.3 \%$ & $0.2 \%$ \\
\hline$\%$ SUV & $0.3 \%$ & $0.5 \%$ & $0.3 \%$ & $0.3 \%$ \\
\hline$\%$ Pickup Truck & $0.1 \%$ & $0.3 \%$ & $0.2 \%$ & $0.2 \%$ \\
\hline$\%$ Other Truck & $0.1 \%$ & $0.1 \%$ & $0.0 \%$ & $0.1 \%$ \\
\hline$\% \mathrm{RV}$ & $0.0 \%$ & $0.0 \%$ & $0.0 \%$ & $0.0 \%$ \\
\hline$\%$ Motorcycle & $0.0 \%$ & $0.0 \%$ & $0.0 \%$ & $0.0 \%$ \\
\hline$\%$ Public Transit & & & & \\
\hline$\%$ Commuter Train & $0.1 \%$ & $0.2 \%$ & $0.0 \%$ & $0.0 \%$ \\
\hline$\%$ Subway/Elevated Rail & $0.3 \%$ & $0.4 \%$ & $0.0 \%$ & $0.0 \%$ \\
\hline$\%$ Other Public & $0.2 \%$ & $0.4 \%$ & $0.0 \%$ & $0.1 \%$ \\
\hline$\%$ Amtrak & $0.0 \%$ & $0.1 \%$ & $0.0 \%$ & $0.0 \%$ \\
\hline$\%$ Walk & $0.5 \%$ & $0.7 \%$ & $0.1 \%$ & $0.2 \%$ \\
\hline$\%$ Other & $0.2 \%$ & $0.3 \%$ & $0.1 \%$ & $0.1 \%$ \\
\hline$\%$ Unreported & $0.0 \%$ & $0.0 \%$ & $0.0 \%$ & $0.0 \%$ \\
\hline TOTAL & 0.03 & 0.04 & 0.02 & 0.02 \\
\hline$\%$ Earning a Living & $0.3 \%$ & $0.4 \%$ & $0.2 \%$ & $0.2 \%$ \\
\hline$\%$ Family \& Personal Business & $0.4 \%$ & $0.5 \%$ & $0.2 \%$ & $0.2 \%$ \\
\hline$\%$ Civic, Educational \& Religious & $0.3 \%$ & $0.3 \%$ & $0.1 \%$ & $0.1 \%$ \\
\hline$\%$ Social \& Recreational & $0.3 \%$ & $0.5 \%$ & $0.2 \%$ & $0.2 \%$ \\
\hline$\%$ Other & $0.1 \%$ & $0.1 \%$ & $0.0 \%$ & $0.1 \%$ \\
\hline$\%$ Unreported & $0.0 \%$ & $0.1 \%$ & $0.0 \%$ & $0.0 \%$ \\
\hline TOTAL & 0.03 & 0.04 & 0.02 & 0.02 \\
\hline Weekday & 0.03 & 0.05 & 0.02 & 0.02 \\
\hline Weekend & 0.06 & 0.08 & 0.04 & 0.04 \\
\hline TOTAL & 0.03 & 0.04 & 0.02 & 0.02 \\
\hline$\% 1-9 \mathrm{~min}$ & $0.4 \%$ & $0.6 \%$ & $0.2 \%$ & $0.2 \%$ \\
\hline$\% 10-19 \min$ & $0.4 \%$ & $0.5 \%$ & $0.2 \%$ & $0.2 \%$ \\
\hline$\% 20-29 \min$ & $0.2 \%$ & $0.3 \%$ & $0.1 \%$ & $0.1 \%$ \\
\hline$\% 30-39 \min$ & $0.2 \%$ & $0.3 \%$ & $0.1 \%$ & $0.1 \%$ \\
\hline$\% 40-49 \min$ & $0.2 \%$ & $0.2 \%$ & $0.1 \%$ & $0.1 \%$ \\
\hline$\% 50+\min$ & $0.2 \%$ & $0.4 \%$ & $0.1 \%$ & $0.1 \%$ \\
\hline$\%$ Unreported & $0.2 \%$ & $0.1 \%$ & $0.1 \%$ & $0.0 \%$ \\
\hline TOTAL & 0.03 & 0.04 & 0.02 & 0.02 \\
\hline$\% 5$ or less miles & $0.4 \%$ & $0.6 \%$ & $0.2 \%$ & $0.3 \%$ \\
\hline$\%$ 6-10 miles & $0.3 \%$ & $0.3 \%$ & $0.2 \%$ & $0.2 \%$ \\
\hline$\% 11-15$ miles & $0.2 \%$ & $0.2 \%$ & $0.1 \%$ & $0.1 \%$ \\
\hline$\% 16-20$ miles & $0.1 \%$ & $0.2 \%$ & $0.1 \%$ & $0.1 \%$ \\
\hline$\%$ 21-30 miles & $0.1 \%$ & $0.1 \%$ & $0.1 \%$ & $0.1 \%$ \\
\hline$\% 31$ or more miles & $0.1 \%$ & $0.2 \%$ & $0.1 \%$ & $0.1 \%$ \\
\hline$\%$ Unreported & $0.3 \%$ & $0.5 \%$ & $0.1 \%$ & $0.1 \%$ \\
\hline
\end{tabular}


Chapter 2: Table 3

Comparison of NY State Data to the Rest of the United States

STANDARD ERRORS

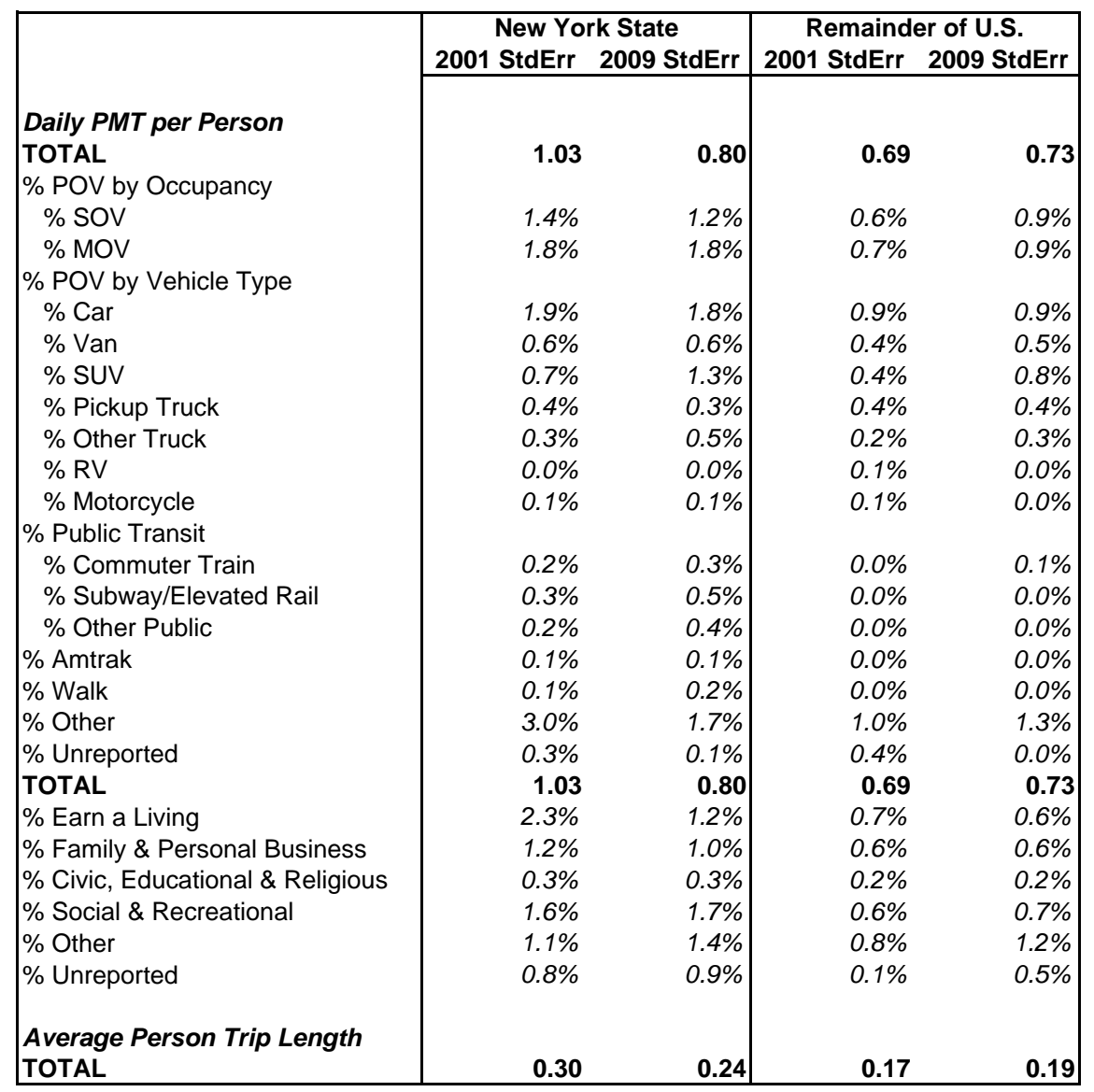


Chapter 2: Table 4

Comparison of NY State Data to the Rest of the United States

STANDARD ERRORS

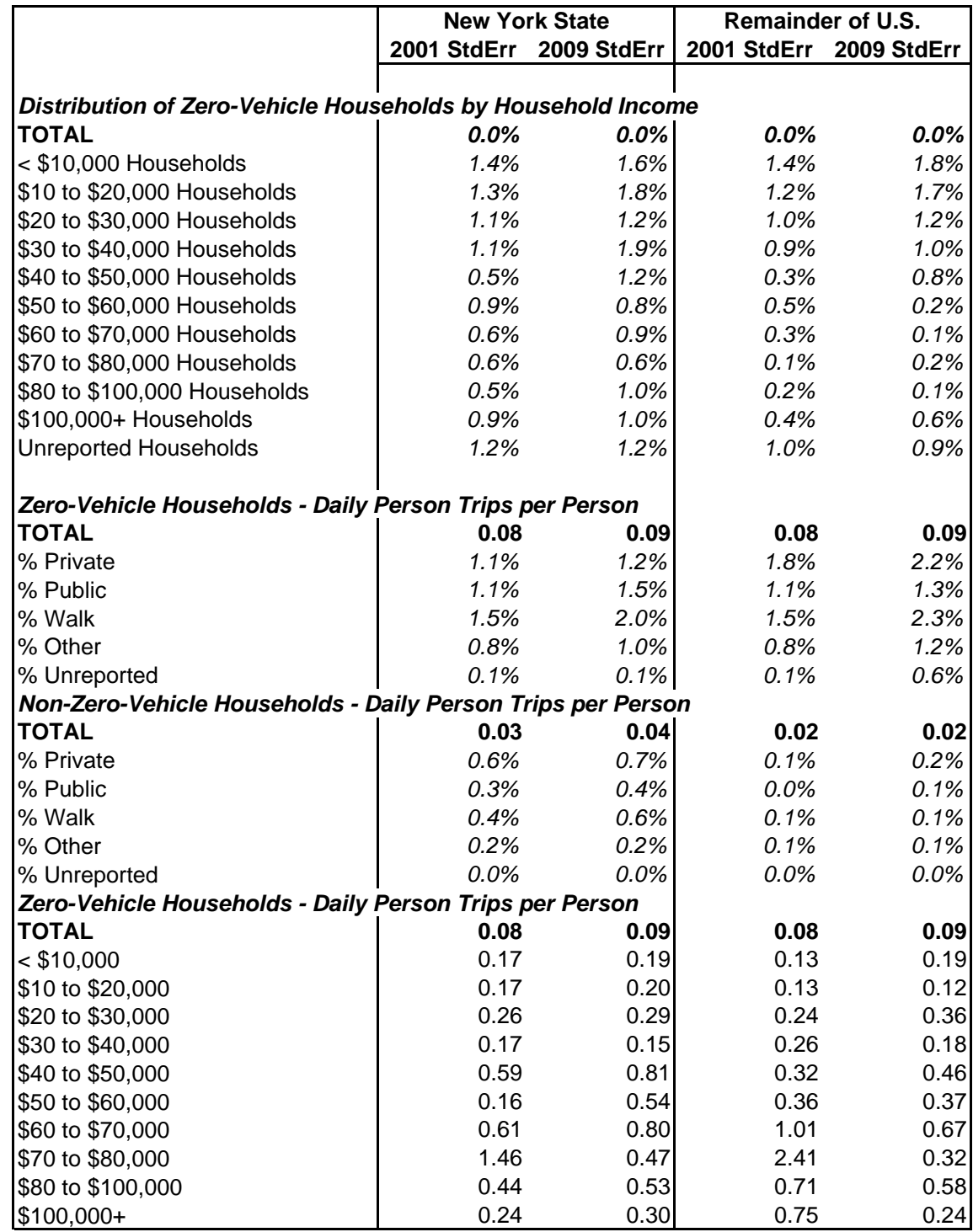


Chapter 2: Table 5

Comparison of NY State Data to the Rest of the United States

STANDARD ERRORS

\begin{tabular}{|l|rr|rr|}
\hline \multicolumn{4}{|c|}{} & \multicolumn{2}{|c|}{ New York State } & \multicolumn{2}{c|}{ Remainder of U.S. } \\
& 2001 StdErr & 2009 StdErr & 2001 StdErr & 2009 StdErr \\
\cline { 2 - 5 } Zero-Vehicle Households - Daily & PMT per Person & & \\
TOTAL & $\mathbf{4 . 2 2}$ & $\mathbf{0 . 7 7}$ & $\mathbf{3 . 3 7}$ & $\mathbf{1 . 0 0}$ \\
$\%$ Private & $6.9 \%$ & $4.0 \%$ & $12.2 \%$ & $4.2 \%$ \\
$\%$ Public & $10.1 \%$ & $5.3 \%$ & $2.5 \%$ & $3.1 \%$ \\
$\%$ Walk & $1.7 \%$ & $1.3 \%$ & $0.7 \%$ & $0.8 \%$ \\
$\%$ Other & $18.3 \%$ & $2.5 \%$ & $15.0 \%$ & $2.0 \%$ \\
$\%$ Unreported & $0.0 \%$ & $0.5 \%$ & $0.1 \%$ & $1.0 \%$ \\
TOTAL & 4.22 & $\mathbf{0 . 7 7}$ & 3.37 & $\mathbf{1 . 0 0}$ \\
$<\$ 10,000$ & 2.08 & 0.83 & 0.73 & 0.77 \\
$\$ 10$ to $\$ 20,000$ & 1.51 & 0.80 & 1.56 & 1.10 \\
$\$ 20$ to $\$ 30,000$ & 1.35 & 3.24 & 8.99 & 5.96 \\
$\$ 30$ to $\$ 40,000$ & 5.37 & 1.76 & 4.60 & 4.03 \\
$\$ 40$ to $\$ 50,000$ & 4.41 & 2.93 & 2.27 & 10.64 \\
$\$ 50$ to $\$ 60,000$ & 2.06 & 1.58 & 141.35 & 3.14 \\
$\$ 60$ to $\$ 70,000$ & 5.19 & 2.64 & 6.05 & 5.17 \\
$\$ 70$ to $\$ 80,000$ & 22.35 & 3.33 & 3.03 & 3.33 \\
$\$ 80$ to $\$ 100,000$ & 4.82 & 4.00 & 20.99 & 3.21 \\
$\$ 100,000+$ & 50.61 & 6.15 & 20.10 & 6.20 \\
\hline
\end{tabular}

C -26 
Chapter 2: Table 6

Comparison of NY State Data to the Rest of the United States

STANDARD ERRORS

\begin{tabular}{|c|c|c|c|c|}
\hline \multirow{3}{*}{ Daily Vehicle Trips per Driver } & \multicolumn{2}{|c|}{ New York State } & \multicolumn{2}{|c|}{ Remainder of U.S. } \\
\hline & 2001 StdErr & StdErr & 2001 StdErr & 2009 StdErr \\
\hline & & & & \\
\hline TOTAL & 0.03 & 0.04 & 0.02 & 0.02 \\
\hline$\%$ Earning a Living & $0.4 \%$ & $0.5 \%$ & $0.2 \%$ & $0.3 \%$ \\
\hline$\%$ Family \& Personal Business & $0.5 \%$ & $0.7 \%$ & $0.2 \%$ & $0.2 \%$ \\
\hline$\%$ Civic, Educational \& Religious & $0.2 \%$ & $0.2 \%$ & $0.1 \%$ & $0.1 \%$ \\
\hline$\%$ Social \& Recreational & $0.3 \%$ & $0.6 \%$ & $0.2 \%$ & $0.2 \%$ \\
\hline$\%$ Other & $0.1 \%$ & $0.0 \%$ & $0.0 \%$ & $0.0 \%$ \\
\hline$\%$ Unreported & $0.0 \%$ & $0.1 \%$ & $0.0 \%$ & $0.0 \%$ \\
\hline TOTAL & 0.03 & 0.04 & 0.02 & 0.02 \\
\hline$\% 1-9 \min$ & $0.5 \%$ & $0.5 \%$ & $0.2 \%$ & $0.2 \%$ \\
\hline$\% 10-19 \min$ & $0.4 \%$ & $0.5 \%$ & $0.2 \%$ & $0.3 \%$ \\
\hline$\% 20-29 \min$ & $0.2 \%$ & $0.4 \%$ & $0.1 \%$ & $0.2 \%$ \\
\hline$\% 30-39 \min$ & $0.2 \%$ & $0.3 \%$ & $0.1 \%$ & $0.1 \%$ \\
\hline$\% 40-49 \min$ & $0.2 \%$ & $0.2 \%$ & $0.1 \%$ & $0.1 \%$ \\
\hline$\% 50+\min$ & $0.2 \%$ & $0.3 \%$ & $0.1 \%$ & $0.1 \%$ \\
\hline$\%$ Unreported & $0.1 \%$ & $0.1 \%$ & $0.0 \%$ & $0.0 \%$ \\
\hline TOTAL & 0.03 & 0.04 & 0.02 & 0.02 \\
\hline$\% 5$ or less miles & $0.5 \%$ & $0.6 \%$ & $0.2 \%$ & $0.3 \%$ \\
\hline$\%$ 6-10 miles & $0.4 \%$ & $0.4 \%$ & $0.2 \%$ & $0.2 \%$ \\
\hline$\% 11-15$ miles & $0.3 \%$ & $0.3 \%$ & $0.1 \%$ & $0.1 \%$ \\
\hline$\% 16-20$ miles & $0.2 \%$ & $0.3 \%$ & $0.1 \%$ & $0.1 \%$ \\
\hline$\%$ 21-30 miles & $0.2 \%$ & $0.2 \%$ & $0.1 \%$ & $0.1 \%$ \\
\hline$\% 31$ or more miles & $0.2 \%$ & $0.2 \%$ & $0.1 \%$ & $0.1 \%$ \\
\hline$\%$ Unreported & $0.2 \%$ & $0.3 \%$ & $0.1 \%$ & $0.1 \%$ \\
\hline TOTAL & 0.03 & 0.04 & 0.02 & 0.02 \\
\hline Weekday & 0.04 & 0.05 & 0.02 & 0.02 \\
\hline Weekend & 0.05 & 0.07 & 0.03 & 0.03 \\
\hline Daily VMT per Driver & & & & \\
\hline TOTAL & 0.46 & 0.52 & 0.32 & 0.38 \\
\hline$\%$ Earn a Living & $0.9 \%$ & $1.1 \%$ & $0.4 \%$ & $0.6 \%$ \\
\hline$\%$ Family \& Personal Business & $0.7 \%$ & $1.0 \%$ & $0.4 \%$ & $0.4 \%$ \\
\hline$\%$ Civic, Educational \& Religious & $0.3 \%$ & $0.3 \%$ & $0.1 \%$ & $0.2 \%$ \\
\hline$\%$ Social \& Recreational & $0.9 \%$ & $1.4 \%$ & $0.5 \%$ & $0.5 \%$ \\
\hline$\%$ Other & $0.1 \%$ & $0.1 \%$ & $0.1 \%$ & $0.1 \%$ \\
\hline$\%$ Unreported & $0.1 \%$ & $1.0 \%$ & $0.1 \%$ & $0.5 \%$ \\
\hline Average Vehicle Trip Length & & & & \\
\hline TOTAL & 0.17 & 0.24 & 0.10 & 0.12 \\
\hline$\%$ Vehicle Trips/Person Trips & & & & \\
\hline TOTAL & 0.55 & 0.60 & 0.19 & 0.23 \\
\hline$\%$ VMT/PMT & & & & \\
\hline TOTAL & 1.92 & 1.30 & 0.79 & 1.05 \\
\hline
\end{tabular}


Chapter 2: Table 7

Comparison of NY State Data to the Rest of the United States

STANDARD ERRORS

\begin{tabular}{|c|c|c|c|c|}
\hline \multirow{3}{*}{$\begin{array}{l}\text { Daily Commute Trips per } \\
\text { Worker }\end{array}$} & \multicolumn{2}{|c|}{ New York State } & \multicolumn{2}{|c|}{ Remainder of U.S. } \\
\hline & 2001 StdErr & 2009 StdErr & 2001 StdErr & 2009 StdErr \\
\hline & & & & \\
\hline $\begin{array}{l}\text { TOTAL } \\
\% \text { POV by Occupancy }\end{array}$ & 0.02 & 0.02 & 0.01 & 0.01 \\
\hline$\%$ SOV & $1.0 \%$ & $1.3 \%$ & $0.4 \%$ & $0.4 \%$ \\
\hline$\% \mathrm{MOV}$ & $0.5 \%$ & $0.7 \%$ & $0.3 \%$ & $0.3 \%$ \\
\hline$\%$ POV by Vehicle Type & & & & \\
\hline$\%$ Car & $0.9 \%$ & $1.2 \%$ & $0.5 \%$ & $0.5 \%$ \\
\hline$\%$ Van & $0.5 \%$ & $0.4 \%$ & $0.2 \%$ & $0.3 \%$ \\
\hline$\%$ SUV & $0.5 \%$ & $0.6 \%$ & $0.3 \%$ & $0.4 \%$ \\
\hline$\%$ Pickup Truck & $0.3 \%$ & $0.3 \%$ & $0.3 \%$ & $0.3 \%$ \\
\hline$\%$ Other Truck & $0.1 \%$ & $0.1 \%$ & $0.1 \%$ & $0.1 \%$ \\
\hline$\% \mathrm{RV}$ & $0.0 \%$ & $0.0 \%$ & $0.0 \%$ & $0.0 \%$ \\
\hline$\%$ Motorcycle & $0.0 \%$ & $0.1 \%$ & $0.0 \%$ & $0.1 \%$ \\
\hline$\%$ Public Transit & & & & \\
\hline$\%$ Commuter Train & $0.3 \%$ & $0.5 \%$ & $0.1 \%$ & $0.1 \%$ \\
\hline$\%$ Subway/Elevated Rail & $0.7 \%$ & $1.0 \%$ & $0.1 \%$ & $0.1 \%$ \\
\hline$\%$ Other Public & $0.5 \%$ & $0.8 \%$ & $0.1 \%$ & $0.2 \%$ \\
\hline$\%$ Amtrak & $0.2 \%$ & $0.2 \%$ & $0.0 \%$ & $0.0 \%$ \\
\hline$\%$ Walk & $0.5 \%$ & $0.7 \%$ & $0.1 \%$ & $0.2 \%$ \\
\hline$\%$ Other & $0.3 \%$ & $0.4 \%$ & $0.1 \%$ & $0.2 \%$ \\
\hline$\%$ Unreported & $0.0 \%$ & $0.1 \%$ & $0.0 \%$ & $0.0 \%$ \\
\hline TOTAL & 0.02 & 0.02 & 0.01 & 0.01 \\
\hline$\% 1-6$ am & $0.3 \%$ & $0.4 \%$ & $0.1 \%$ & $0.1 \%$ \\
\hline$\%$ 6-9 am & $0.5 \%$ & $0.6 \%$ & $0.2 \%$ & $0.2 \%$ \\
\hline$\% 9$ am-1 pm & $0.4 \%$ & $0.5 \%$ & $0.2 \%$ & $0.2 \%$ \\
\hline$\% 1-4 \mathrm{pm}$ & $0.4 \%$ & $0.5 \%$ & $0.2 \%$ & $0.3 \%$ \\
\hline$\%$ 4-7 pm & $0.5 \%$ & $0.5 \%$ & $0.2 \%$ & $0.3 \%$ \\
\hline$\% 7-10 \mathrm{pm}$ & $0.4 \%$ & $0.4 \%$ & $0.2 \%$ & $0.2 \%$ \\
\hline$\% 10 \mathrm{pm}-1 \mathrm{am}$ & $0.3 \%$ & $0.4 \%$ & $0.1 \%$ & $0.2 \%$ \\
\hline$\%$ Unreported & $0.0 \%$ & & $0.0 \%$ & $0.0 \%$ \\
\hline Daily Commute PMT per Worker & & & & \\
\hline $\begin{array}{l}\text { TOTAL } \\
\% \text { POV by Occupancy }\end{array}$ & 0.23 & 0.32 & 0.21 & 0.19 \\
\hline$\%$ SOV & $1.4 \%$ & $1.8 \%$ & $1.1 \%$ & $0.8 \%$ \\
\hline$\%$ MOV & $0.7 \%$ & $1.2 \%$ & $0.6 \%$ & $0.5 \%$ \\
\hline$\%$ POV by Vehicle Type & & & & \\
\hline$\%$ Car & $1.2 \%$ & $1.5 \%$ & $0.9 \%$ & $0.7 \%$ \\
\hline$\%$ Van & $0.7 \%$ & $0.5 \%$ & $0.4 \%$ & $0.3 \%$ \\
\hline$\%$ SUV & $0.7 \%$ & $1.3 \%$ & $0.4 \%$ & $0.5 \%$ \\
\hline$\%$ Pickup Truck & $0.6 \%$ & $0.6 \%$ & $0.5 \%$ & $0.5 \%$ \\
\hline$\%$ Other Truck & $0.1 \%$ & $1.0 \%$ & $0.2 \%$ & $0.3 \%$ \\
\hline$\% \mathrm{RV}$ & $0.0 \%$ & $0.0 \%$ & $0.0 \%$ & $0.0 \%$ \\
\hline$\%$ Motorcycle & $0.0 \%$ & $0.0 \%$ & $0.1 \%$ & $0.1 \%$ \\
\hline$\%$ Public Transit & & & & \\
\hline$\%$ Commuter Train & $0.7 \%$ & $0.5 \%$ & $0.1 \%$ & $0.1 \%$ \\
\hline$\%$ Subway/Elevated Rail & $0.9 \%$ & $1.1 \%$ & $0.1 \%$ & $0.0 \%$ \\
\hline$\%$ Other Public & $0.4 \%$ & $0.8 \%$ & $0.1 \%$ & $0.2 \%$ \\
\hline$\%$ Amtrak & $0.2 \%$ & $0.5 \%$ & $0.2 \%$ & $0.0 \%$ \\
\hline$\%$ Walk & $0.1 \%$ & $0.3 \%$ & $0.0 \%$ & $0.0 \%$ \\
\hline$\%$ Other & $0.4 \%$ & $0.5 \%$ & $1.1 \%$ & $0.7 \%$ \\
\hline$\%$ Unreported & $0.1 \%$ & $0.1 \%$ & $0.0 \%$ & $0.0 \%$ \\
\hline TOTAL & 0.23 & 0.32 & 0.21 & 0.19 \\
\hline$\% 1-6 a m$ & $0.5 \%$ & $0.5 \%$ & $0.3 \%$ & $0.6 \%$ \\
\hline$\%$ 6-9 am & $0.7 \%$ & $0.7 \%$ & $0.6 \%$ & $0.5 \%$ \\
\hline$\% 9 \mathrm{am}-1 \mathrm{pm}$ & $0.6 \%$ & $0.9 \%$ & $0.3 \%$ & $0.4 \%$ \\
\hline$\% 1-4 \mathrm{pm}$ & $0.6 \%$ & $0.7 \%$ & $0.4 \%$ & $0.4 \%$ \\
\hline$\% 4-7 \mathrm{pm}$ & $0.7 \%$ & $0.7 \%$ & $0.5 \%$ & $0.5 \%$ \\
\hline$\% 7-10 \mathrm{pm}$ & $0.5 \%$ & $0.4 \%$ & $0.9 \%$ & $0.3 \%$ \\
\hline$\% 10 \mathrm{pm}-1 \mathrm{am}$ & $0.4 \%$ & $0.4 \%$ & $0.2 \%$ & $0.2 \%$ \\
\hline$\%$ Unreported & $0.0 \%$ & & $0.0 \%$ & $0.0 \%$ \\
\hline
\end{tabular}

C -28 


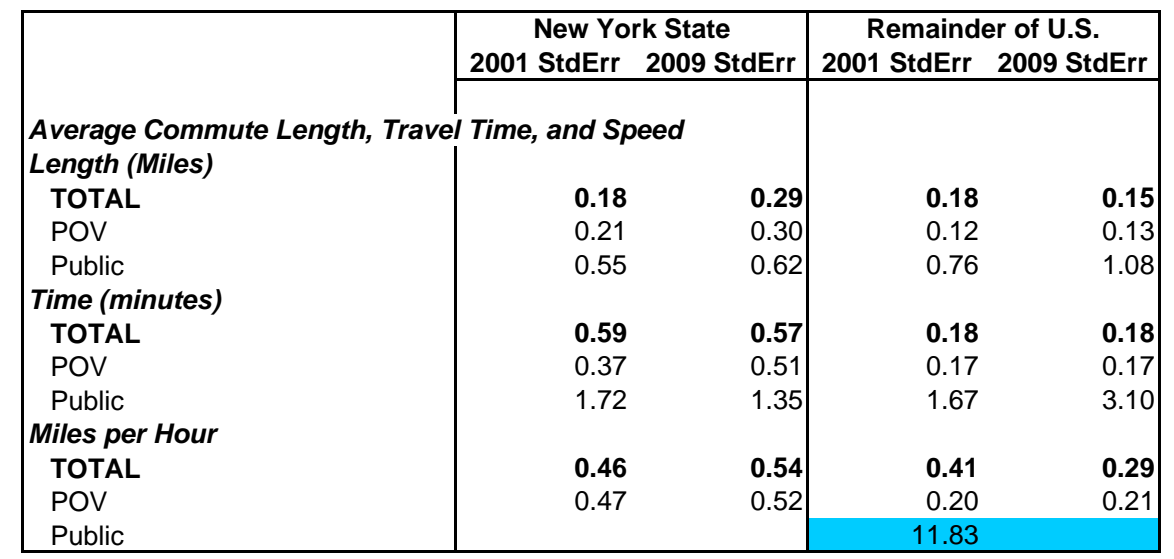


Chapter 2: Table 9

Comparison of NY State Data to the Rest of the United States

STANDARD ERRORS

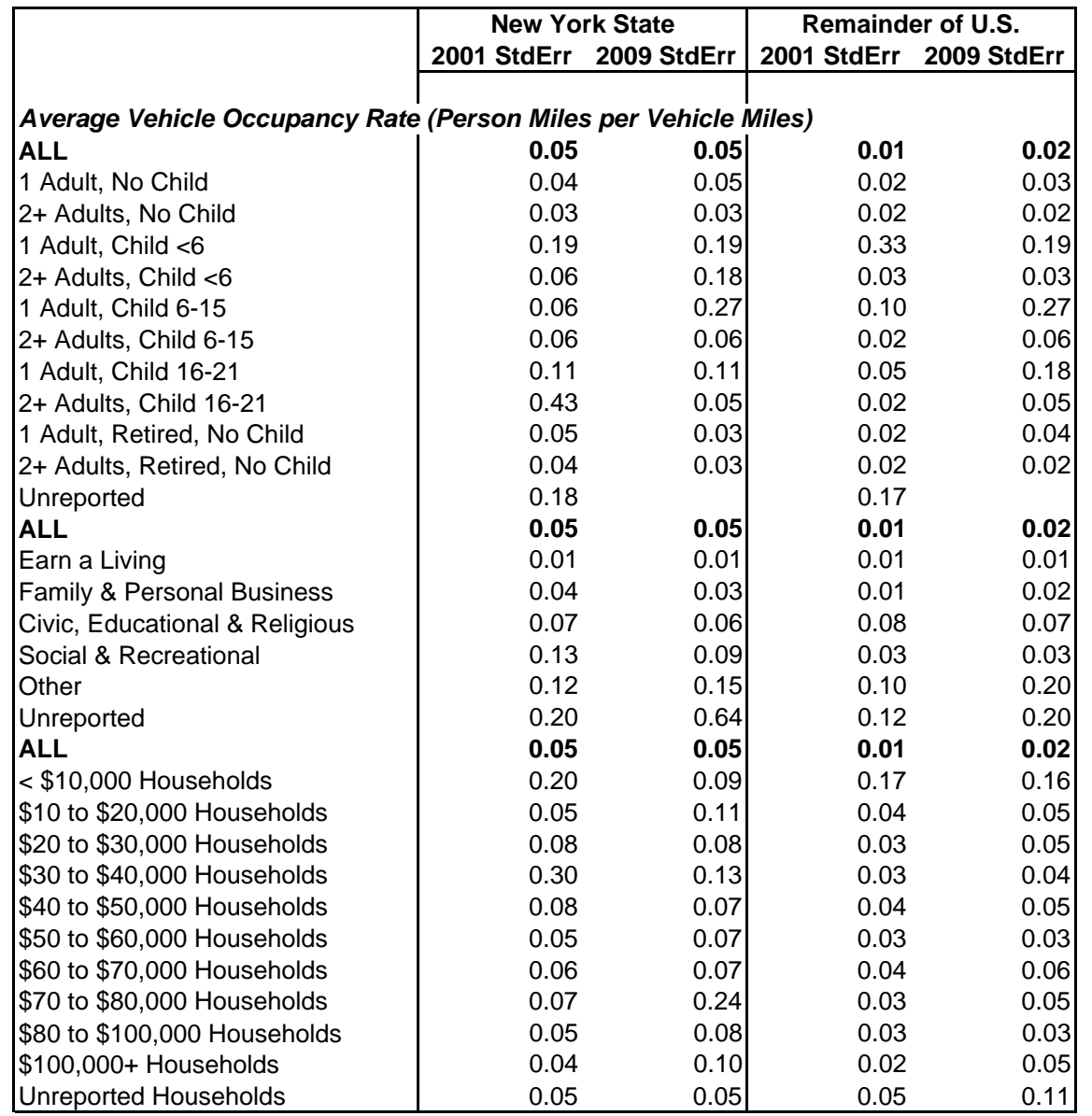


Chapter 2: Table 10

Comparison of NY State Data to the Rest of the United States

STANDARD ERRORS

\begin{tabular}{|c|c|c|c|c|}
\hline & \multicolumn{2}{|c|}{ New York State } & \multicolumn{2}{|c|}{ Remainder of U.S. } \\
\hline & 2001 StdErr & 2009 StdErr & 2001 StdErr & 2009 StdErr \\
\hline \multicolumn{5}{|l|}{ Vehicles by Type } \\
\hline Auto & $0.0 \%$ & $0.0 \%$ & $0.0 \%$ & $0.0 \%$ \\
\hline Van & $0.5 \%$ & $0.6 \%$ & $0.3 \%$ & $0.2 \%$ \\
\hline Sports Utility & $0.3 \%$ & $0.3 \%$ & $0.1 \%$ & $0.2 \%$ \\
\hline Pickup & $0.3 \%$ & $0.5 \%$ & $0.2 \%$ & $0.2 \%$ \\
\hline Other Truck & $0.2 \%$ & $0.2 \%$ & $0.2 \%$ & $0.2 \%$ \\
\hline RV & $0.1 \%$ & $0.0 \%$ & $0.0 \%$ & $0.0 \%$ \\
\hline Motorcycle & $0.0 \%$ & $0.0 \%$ & $0.0 \%$ & $0.0 \%$ \\
\hline Other POV & $\begin{array}{r}0.1 \% \\
*\end{array}$ & $\begin{array}{r}0.1 \% \\
*\end{array}$ & $\begin{array}{r}0.1 \% \\
*\end{array}$ & $0.1 \%$ \\
\hline \multicolumn{5}{|c|}{ * Other POV not present in 2001 or 2009.} \\
\hline Age Statistics & & & & \\
\hline le Age & 0.08 & 0.08 & 0.05 & 0.05 \\
\hline Median Vehicle Age & 0 & 0 & 0 & 0 \\
\hline Percent VMT* & & & & \\
\hline Less than 10 yrs & $0.7 \%$ & $0.6 \%$ & $1.7 \%$ & $0.4 \%$ \\
\hline 10 yrs or more & $0.7 \%$ & $0.6 \%$ & $1.7 \%$ & $0.4 \%$ \\
\hline Percent Vehicle Fleet & & & & \\
\hline Less than 10 yrs & $0.6 \%$ & $0.6 \%$ & $0.3 \%$ & $0.3 \%$ \\
\hline 10 yrs or more & $0.6 \%$ & $0.6 \%$ & $0.3 \%$ & $0.3 \%$ \\
\hline Avg Fuel Consumption (gal/HH) & 22 & 6 & 17 & 6 \\
\hline Less than 10 yrs & $3.4 \%$ & $0.6 \%$ & $1.5 \%$ & $0.4 \%$ \\
\hline 10 yrs or more & $3.4 \%$ & $0.6 \%$ & $1.5 \%$ & $0.4 \%$ \\
\hline Avg CO2 Emissions $(\mathrm{kg} / \mathrm{HH})$ & 191 & 54 & 147 & 54 \\
\hline Less than 10 yrs & $3.4 \%$ & $0.6 \%$ & $1.5 \%$ & $0.4 \%$ \\
\hline 10 yrs or more & $3.4 \%$ & $0.6 \%$ & $1.5 \%$ & $0.4 \%$ \\
\hline
\end{tabular}

C - 31 
Chapter 2: Table 11

Comparison of NY State Data to the Rest of the United States

STANDARD ERRORS

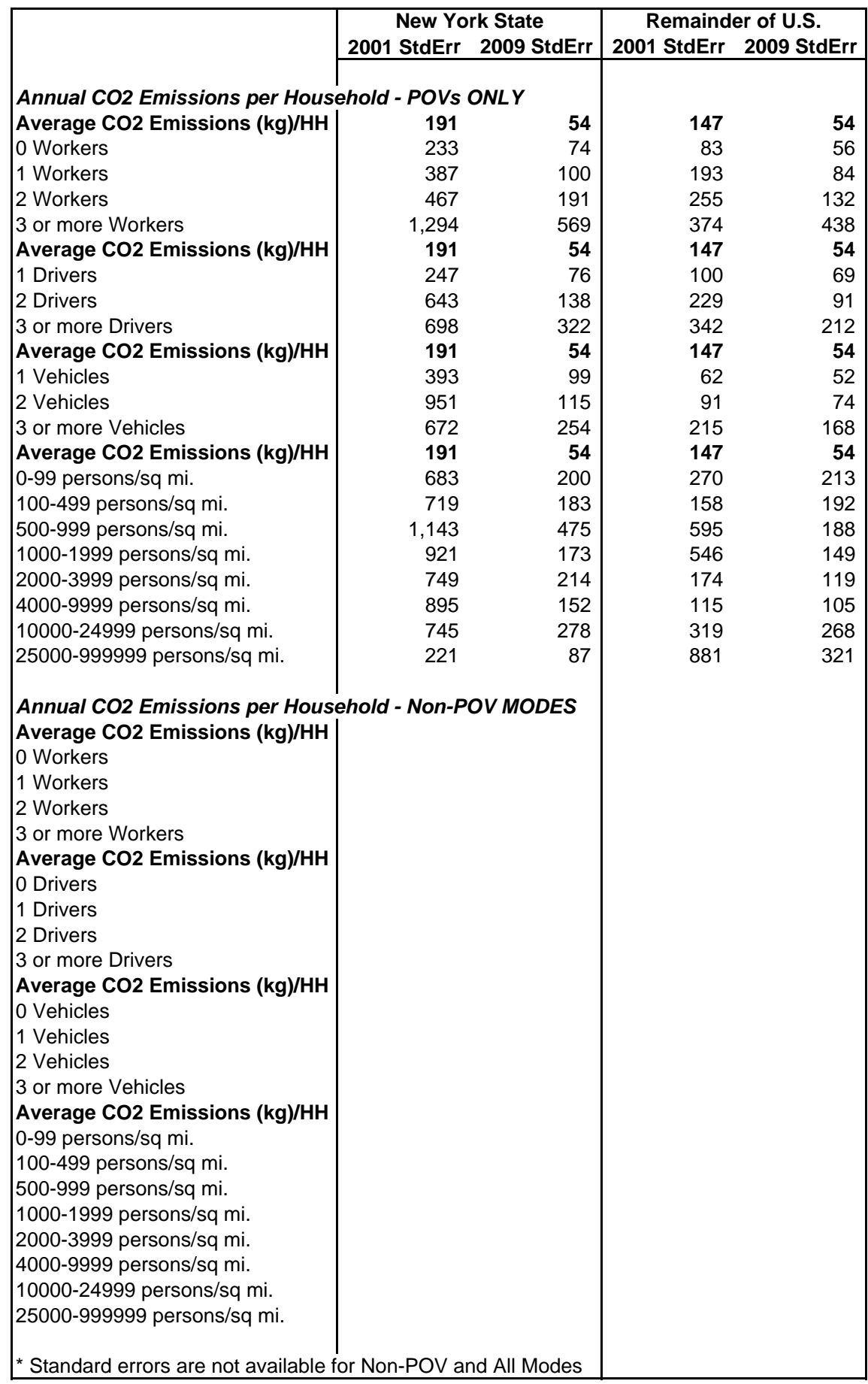


Chapter 2: Table 12

Comparison of NY State Data to the Rest of the United States

STANDARD ERRORS

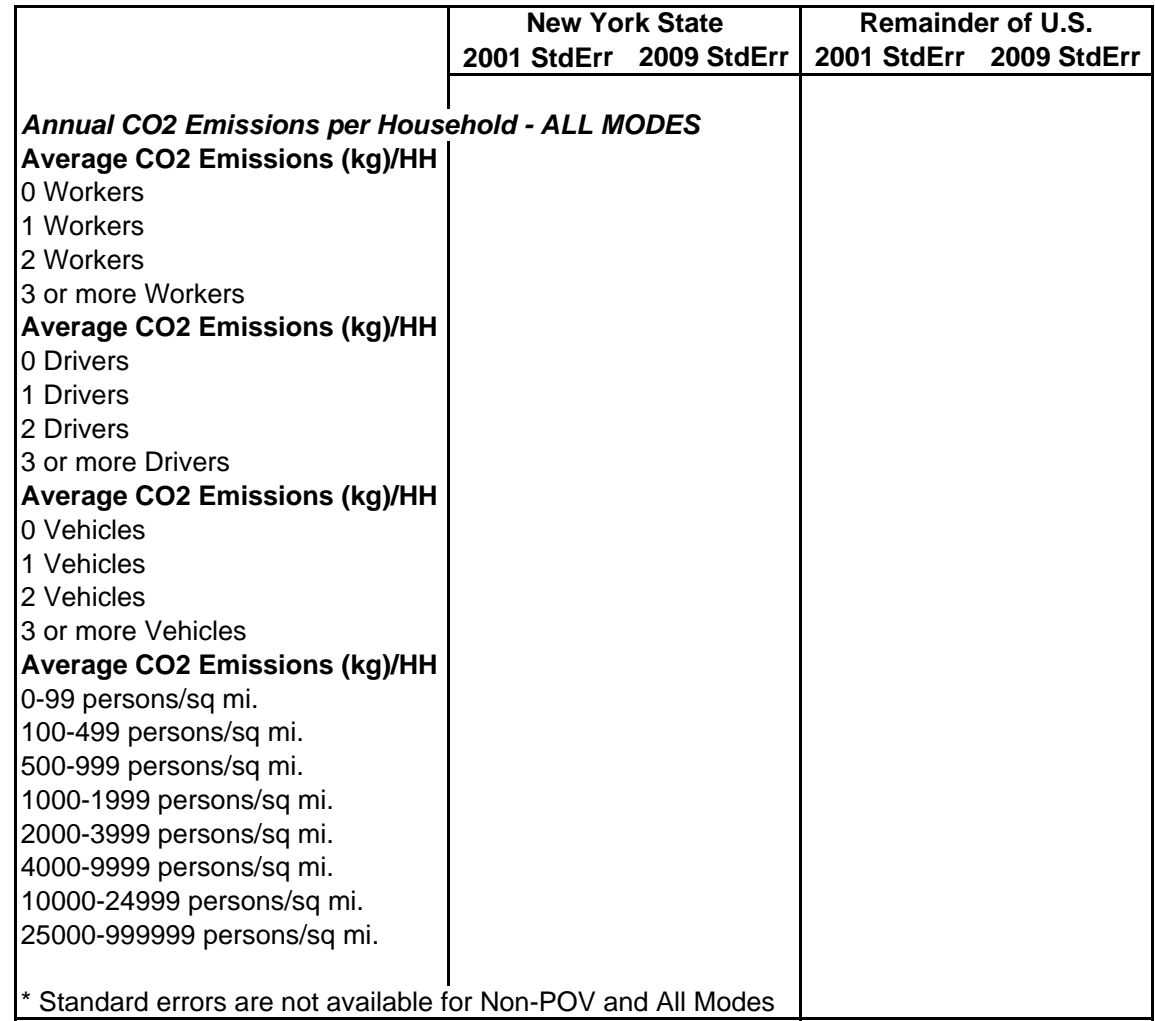


Chapter 2: Table 13

Comparison of NY State Data to the Rest of the United States

STANDARD ERRORS

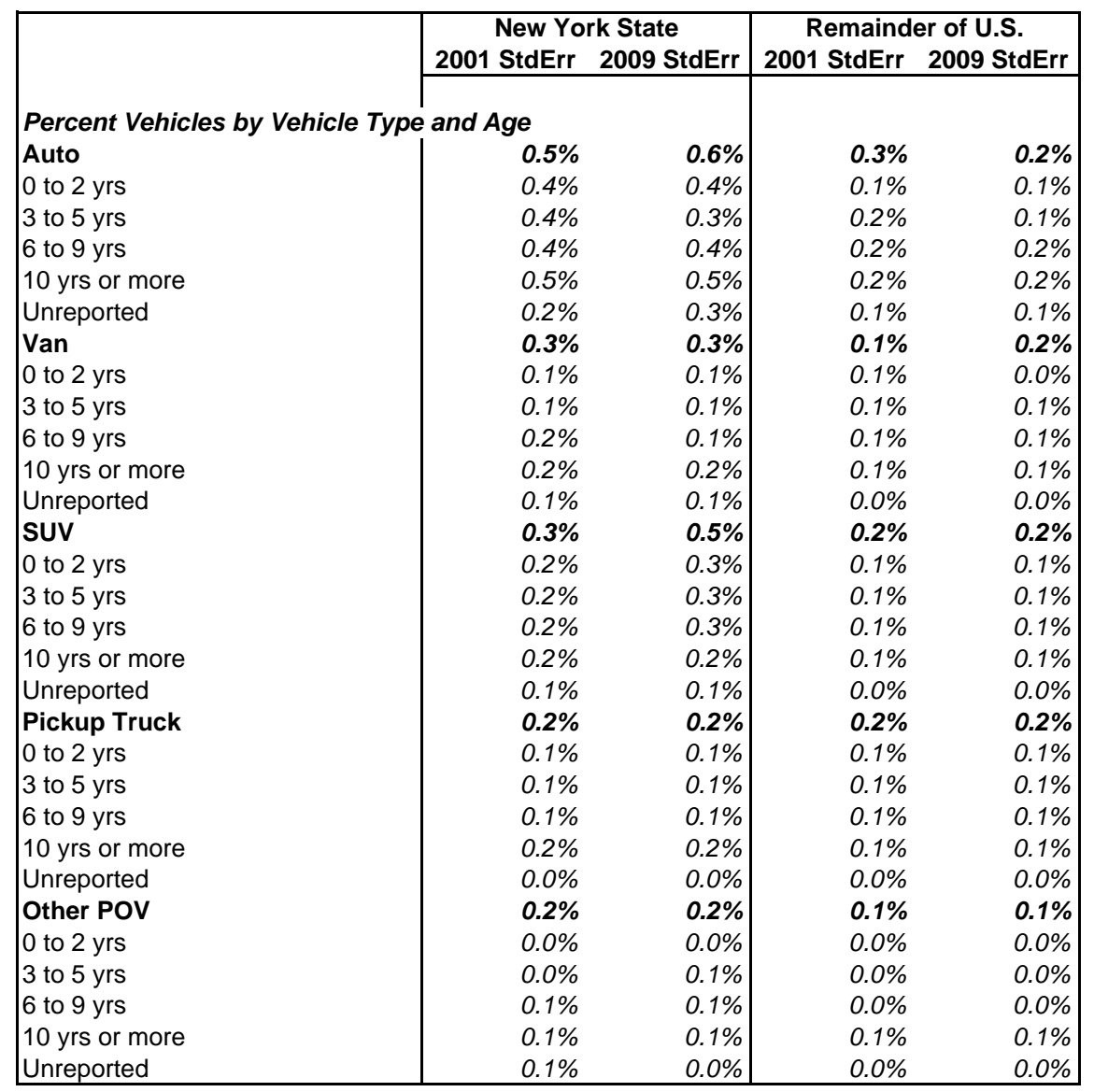


Chapter 2: Table 14

Comparison of NY State Data to the Rest of the United States

STANDARD ERRORS

\begin{tabular}{|c|c|c|c|c|}
\hline \multirow{3}{*}{ VMT/Vehicle by Vehicle Type anc } & \multicolumn{2}{|c|}{ New York State } & \multicolumn{2}{|c|}{ Remainder of U.S. } \\
\hline & \multicolumn{2}{|c|}{2001 StdErr 2009 StdErr } & \multicolumn{2}{|c|}{2001 StdErr 2009 StdErr } \\
\hline & Age & & & \\
\hline ALL VEHICLES & 130 & 103 & 81 & 60 \\
\hline 0 to 2 yrs & 268 & 297 & 152 & 217 \\
\hline 3 to 5 yrs & 277 & 207 & 425 & 91 \\
\hline 6 to 9 yrs & 211 & 185 & 185 & 113 \\
\hline 10 yrs or more & 243 & 199 & 192 & 79 \\
\hline Unreported & 731 & 680 & 483 & 286 \\
\hline Auto & 172 & 124 & 81 & 74 \\
\hline 0 to $2 \mathrm{yrs}$ & 314 & 272 & 205 & 321 \\
\hline 3 to $5 \mathrm{yrs}$ & 407 & 283 & 196 & 113 \\
\hline 6 to $9 \mathrm{yrs}$ & 232 & 235 & 198 & 133 \\
\hline 10 yrs or more & 319 & 237 & 228 & 111 \\
\hline Unreported & 891 & 1,187 & 455 & 488 \\
\hline Van & 418 & 356 & 359 & 265 \\
\hline 0 to $2 \mathrm{yrs}$ & 1,574 & 1,709 & 736 & 561 \\
\hline 3 to $5 \mathrm{yrs}$ & 595 & 424 & 1,832 & 358 \\
\hline 6 to $9 \mathrm{yrs}$ & 474 & 426 & 682 & 745 \\
\hline 10 yrs or more & 786 & 537 & 345 & 226 \\
\hline Unreported & 1,545 & 1,534 & 1,032 & 1,024 \\
\hline suv & 288 & 244 & 431 & 140 \\
\hline 0 to 2 yrs & 420 & 631 & 500 & 472 \\
\hline 3 to $5 \mathrm{yrs}$ & 466 & 385 & 324 & 181 \\
\hline 6 to $9 \mathrm{yrs}$ & 823 & 375 & 414 & 202 \\
\hline 10 yrs or more & 734 & 525 & 1,174 & 209 \\
\hline Unreported & 1,737 & 1,024 & 2,088 & 701 \\
\hline Pickup Truck & 292 & 292 & 237 & 131 \\
\hline 0 to $2 \mathrm{yrs}$ & 674 & 1,054 & 318 & 490 \\
\hline 3 to $5 \mathrm{yrs}$ & 389 & 723 & 1,048 & 258 \\
\hline 6 to $9 \mathrm{yrs}$ & 806 & 374 & 293 & 190 \\
\hline 10 yrs or more & 427 & 358 & 216 & 199 \\
\hline Unreported & 929 & 867 & 1,002 & 472 \\
\hline Other POV & 421 & 207 & 1,364 & 149 \\
\hline 0 to $2 \mathrm{yrs}$ & 1,141 & 742 & 7,311 & 565 \\
\hline 3 to $5 \mathrm{yrs}$ & 545 & 335 & 2,450 & 361 \\
\hline 6 to $9 \mathrm{yrs}$ & 901 & 362 & 1,538 & 422 \\
\hline 10 yrs or more & 281 & 243 & 443 & 197 \\
\hline Unreported & 5,594 & 1,517 & 579 & 333 \\
\hline
\end{tabular}


Chapter 2: Table 15

Comparison of NY State Data to the Rest of the United States

STANDARD ERRORS

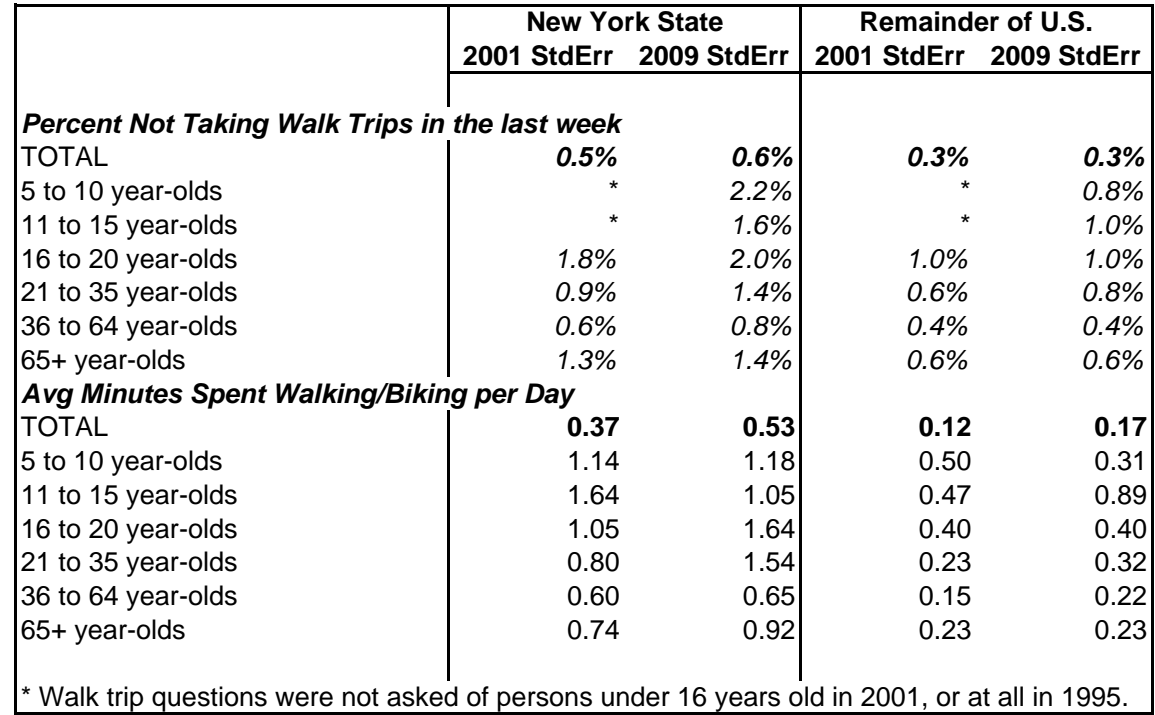

$$
\text { C - } 36
$$


APPENDIX C3. SUPPLEMENTAL TABLES FOR CHAPTER 3 
Chapter 3: Table 1

Influence of NY State Metropolitan Data on Overall NY Travel Patterns

\begin{tabular}{|c|c|c|c|c|c|c|c|c|c|}
\hline & \multicolumn{3}{|c|}{ New York City } & \multicolumn{3}{|c|}{ Remainder NY State } & \multicolumn{3}{|c|}{ Remainder of U.S. } \\
\hline & 1995 & 2001 & 2009 & 1995 & 2001 & 2009 & 1995 & 2001 & 2009 \\
\hline \multicolumn{10}{|l|}{ General Statistics } \\
\hline Households (000) & 2,920 & 3,076 & 3,055 & 3,928 & 4,108 & 4,082 & 92,858 & 100,182 & 105,964 \\
\hline Persons 5+ (000) & 6,792 & 7,439 & 7,788 & 10,015 & 9,955 & 10,494 & 224,868 & 240,182 & 264,772 \\
\hline Drivers $(000)$ & 3,218 & 3,779 & 4,836 & 7,251 & 7,388 & 8,002 & 165,861 & 179,258 & 199,471 \\
\hline Male Drivers (000) & 1,853 & 2,107 & 2,498 & 3,660 & 3,622 & 4,012 & 82,966 & 88,921 & 100,303 \\
\hline Female Drivers $(000)$ & 1,365 & 1,672 & 2,338 & 3,591 & 3,766 & 3,990 & 82,895 & 90,336 & 99,168 \\
\hline Workers $(000)$ & 3,404 & 4,045 & 3,978 & 5,371 & 5,601 & 5,781 & 122,922 & 135,627 & 141,614 \\
\hline Vehicles (000) & 1,600 & 2,085 & 1,943 & 6,322 & 7,461 & 7,201 & 168,145 & 193,041 & 202,357 \\
\hline 0-Vehicle Households (000) & 1,544 & 1,587 & 1,667 & 291 & 314 & 371 & 6,368 & 6,815 & 7,791 \\
\hline Workers per $\mathrm{HH}$ & 1.17 & 1.32 & 1.30 & 1.37 & 1.36 & 1.42 & 1.32 & 1.35 & 1.34 \\
\hline Vehicles per $\mathrm{HH}$ & 0.55 & 0.68 & 0.64 & 1.61 & 1.82 & 1.76 & 1.81 & 1.93 & 1.91 \\
\hline Vehicles per Dr & 0.50 & 0.55 & 0.40 & 0.87 & 1.01 & 0.90 & 1.01 & 1.08 & 1.01 \\
\hline \multicolumn{10}{|c|}{ Distribution of Households by Household Vehicle Count } \\
\hline ALL & $100 \%$ & $100 \%$ & $100.0 \%$ & $100 \%$ & $100 \%$ & $100.0 \%$ & $100 \%$ & $100 \%$ & $100.0 \%$ \\
\hline 0 vehicles & $52.9 \%$ & $51.6 \%$ & $54.5 \%$ & $7.4 \%$ & $7.6 \%$ & $9.1 \%$ & $6.9 \%$ & $6.8 \%$ & $7.4 \%$ \\
\hline 1 vehicle & $33.8 \%$ & $33.7 \%$ & $31.4 \%$ & $32.1 \%$ & $32.8 \%$ & $33.1 \%$ & $32.4 \%$ & $31.3 \%$ & $32.3 \%$ \\
\hline 2 vehicles & $11.2 \%$ & $11.3 \%$ & $10.9 \%$ & $43.3 \%$ & $39.0 \%$ & $39.2 \%$ & $41.1 \%$ & $37.9 \%$ & $36.9 \%$ \\
\hline 3 vehicles & $1.6 \%$ & $2.7 \%$ & $2.2 \%$ & $12.4 \%$ & $14.3 \%$ & $13.0 \%$ & $14.4 \%$ & $15.4 \%$ & $14.8 \%$ \\
\hline $4+$ vehicles & $0.5 \%$ & $0.7 \%$ & $0.9 \%$ & $4.7 \%$ & $6.3 \%$ & $5.6 \%$ & $5.3 \%$ & $8.6 \%$ & $8.6 \%$ \\
\hline \multicolumn{10}{|c|}{ Distribution of Households by Household Income } \\
\hline ALL & $100.0 \%$ & $100.0 \%$ & $100.0 \%$ & $100.0 \%$ & $100.0 \%$ & $100.0 \%$ & $100.0 \%$ & $100.0 \%$ & $100.0 \%$ \\
\hline$<\$ 10,000$ Households & $7.9 \%$ & $9.9 \%$ & $9.6 \%$ & $3.7 \%$ & $5.4 \%$ & $6.5 \%$ & $4.9 \%$ & $6.6 \%$ & $7.7 \%$ \\
\hline$\$ 10$ to $\$ 20,000$ Households & $9.2 \%$ & $11.2 \%$ & $12.0 \%$ & $7.9 \%$ & $9.4 \%$ & $11.1 \%$ & $9.3 \%$ & $10.0 \%$ & $12.5 \%$ \\
\hline$\$ 20$ to $\$ 30,000$ Households & $11.4 \%$ & $10.4 \%$ & $10.6 \%$ & $9.3 \%$ & $8.4 \%$ & $9.8 \%$ & $10.6 \%$ & $9.7 \%$ & $11.6 \%$ \\
\hline$\$ 30$ to $\$ 40,000$ Households & $14.6 \%$ & $14.2 \%$ & $9.6 \%$ & $13.5 \%$ & $15.6 \%$ & $9.4 \%$ & $15.5 \%$ & $16.9 \%$ & $10.0 \%$ \\
\hline$\$ 40$ to $\$ 50,000$ Households & $3.8 \%$ & $4.2 \%$ & $8.7 \%$ & $4.0 \%$ & $4.3 \%$ & $8.8 \%$ & $4.3 \%$ & $5.1 \%$ & $8.9 \%$ \\
\hline$\$ 50$ to $\$ 60,000$ Households & $6.1 \%$ & $7.2 \%$ & $5.4 \%$ & $7.7 \%$ & $8.5 \%$ & $7.7 \%$ & $8.8 \%$ & $8.5 \%$ & $7.5 \%$ \\
\hline$\$ 60$ to $\$ 70,000$ Households & $6.3 \%$ & $5.4 \%$ & $5.5 \%$ & $7.9 \%$ & $6.6 \%$ & $6.1 \%$ & $7.6 \%$ & $6.7 \%$ & $6.0 \%$ \\
\hline$\$ 70$ to $\$ 80,000$ Households & $3.5 \%$ & $4.8 \%$ & $5.0 \%$ & $4.7 \%$ & $5.0 \%$ & $5.5 \%$ & $4.4 \%$ & $5.4 \%$ & $6.0 \%$ \\
\hline$\$ 80,000-\$ 100,000$ Households & $6.4 \%$ & $6.3 \%$ & $7.4 \%$ & $9.0 \%$ & $9.9 \%$ & $7.4 \%$ & $8.0 \%$ & $8.7 \%$ & $7.6 \%$ \\
\hline$\$ 100,000+$ Households & $10.3 \%$ & $14.7 \%$ & $16.8 \%$ & $13.6 \%$ & $17.8 \%$ & $19.4 \%$ & $10.1 \%$ & $14.3 \%$ & $15.4 \%$ \\
\hline Unreported & $20.5 \%$ & $11.9 \%$ & $9.4 \%$ & $18.8 \%$ & $9.1 \%$ & $8.3 \%$ & $16.5 \%$ & $8.1 \%$ & $6.8 \%$ \\
\hline \multicolumn{10}{|l|}{ Licensing Rate } \\
\hline$\%$ Female Drivers/Female 16+ & $44.5 \%$ & $49.7 \%$ & $65.1 \%$ & $85.9 \%$ & $87.8 \%$ & $86.5 \%$ & $86.6 \%$ & $87.7 \%$ & $86.8 \%$ \\
\hline$\%$ Male Drivers/Male $16+$ & $71.4 \%$ & $71.5 \%$ & $78.9 \%$ & $92.4 \%$ & $92.5 \%$ & $91.7 \%$ & $93.2 \%$ & $93.3 \%$ & $91.6 \%$ \\
\hline
\end{tabular}


Chapter 3: Table 2

Influence of NY State Metropolitan Data on Overall NY Travel Patterns

\begin{tabular}{|c|c|c|c|c|c|c|c|c|c|}
\hline & \multicolumn{3}{|c|}{ New York City } & \multicolumn{3}{|c|}{ Remainder NY State } & \multicolumn{3}{|c|}{ Remainder of U.S. } \\
\hline & 1995 & 2001 & 2009 & 1995 & 2001 & 2009 & 1995 & 2001 & 2009 \\
\hline Daily Person Trips per Person & & & & & & & & & \\
\hline TOTAL & 3.58 & 3.44 & 3.46 & 4.08 & 3.95 & 3.78 & 4.33 & 4.11 & 3.81 \\
\hline Male & 3.63 & 3.54 & 3.46 & 4.12 & 3.93 & 3.76 & 4.36 & 4.11 & 3.76 \\
\hline Female & 3.54 & 3.35 & 3.45 & 4.05 & 3.97 & 3.79 & 4.30 & 4.12 & 3.85 \\
\hline TOTAL & 3.58 & 3.44 & 3.46 & 4.08 & 3.95 & 3.78 & 4.33 & 4.11 & 3.81 \\
\hline $5-15$ years & 3.09 & 2.71 & 2.76 & 3.44 & 3.21 & 3.17 & 3.73 & 3.46 & 3.20 \\
\hline $16-19$ years & 3.18 & 3.08 & 2.95 & 4.22 & 3.97 & 3.61 & 4.69 & 4.19 & 3.54 \\
\hline 20-34 years & 3.96 & 3.77 & 3.52 & 4.29 & 3.98 & 3.64 & 4.67 & 4.30 & 3.91 \\
\hline $35-54$ years & 3.84 & 3.89 & 4.04 & 4.55 & 4.47 & 4.32 & 4.75 & 4.64 & 4.27 \\
\hline $55-64$ years & 3.28 & 3.66 & 3.96 & 4.15 & 4.18 & 3.98 & 4.19 & 4.13 & 3.99 \\
\hline $65+$ years & 2.95 & 2.57 & 2.55 & 3.46 & 3.56 & 3.24 & 3.44 & 3.43 & 3.22 \\
\hline Unreported & & 3.03 & & & 3.61 & & & 3.71 & \\
\hline TOTAL & 3.58 & 3.44 & 3.46 & 4.08 & 3.95 & 3.78 & 4.33 & 4.11 & 3.81 \\
\hline$\%$ SOV & $14.0 \%$ & $14.1 \%$ & $12.0 \%$ & $42.4 \%$ & $40.8 \%$ & $43.1 \%$ & $42.5 \%$ & $40.3 \%$ & $40.5 \%$ \\
\hline$\% \mathrm{MOV}$ & $21.8 \%$ & $21.9 \%$ & $20.6 \%$ & $43.1 \%$ & $44.1 \%$ & $39.2 \%$ & $45.0 \%$ & $47.3 \%$ & $44.4 \%$ \\
\hline$\%$ Other POV & $0.0 \%$ & & & $0.0 \%$ & & & $0.0 \%$ & & \\
\hline$\%$ Amtrak & $0.0 \%$ & $0.4 \%$ & $0.4 \%$ & $0.0 \%$ & $0.1 \%$ & $0.0 \%$ & $0.0 \%$ & $0.0 \%$ & $0.0 \%$ \\
\hline$\%$ Commuter Train & $2.5 \%$ & $0.4 \%$ & $1.6 \%$ & $0.5 \%$ & $0.4 \%$ & $0.4 \%$ & $0.0 \%$ & $0.1 \%$ & $0.1 \%$ \\
\hline$\%$ Subway & $10.3 \%$ & $13.0 \%$ & $9.9 \%$ & $0.2 \%$ & $0.3 \%$ & $0.2 \%$ & $0.2 \%$ & $0.2 \%$ & $0.1 \%$ \\
\hline$\%$ Other Public Transit & $9.2 \%$ & $8.7 \%$ & $10.5 \%$ & $1.0 \%$ & $0.6 \%$ & $1.0 \%$ & $0.9 \%$ & $0.8 \%$ & $1.0 \%$ \\
\hline$\%$ Walk & $31.0 \%$ & $36.8 \%$ & $38.7 \%$ & $4.9 \%$ & $9.1 \%$ & $10.6 \%$ & $4.8 \%$ & $7.9 \%$ & $9.7 \%$ \\
\hline$\%$ Other & $5.0 \%$ & $4.6 \%$ & $6.1 \%$ & $4.2 \%$ & $4.6 \%$ & $5.2 \%$ & $3.0 \%$ & $3.3 \%$ & $4.1 \%$ \\
\hline$\%$ Unreported & $6.1 \%$ & $0.1 \%$ & $0.1 \%$ & $3.7 \%$ & $0.1 \%$ & $0.2 \%$ & $3.5 \%$ & $0.1 \%$ & $0.2 \%$ \\
\hline TOTAL & 3.58 & 3.44 & 3.46 & 4.08 & 3.95 & 3.78 & 4.33 & 4.11 & 3.81 \\
\hline$\%$ Earn a Living & $19.6 \%$ & $20.1 \%$ & $16.6 \%$ & $20.0 \%$ & $18.8 \%$ & $19.5 \%$ & $20.3 \%$ & $18.8 \%$ & $18.7 \%$ \\
\hline$\%$ Fam/Per Bus & $45.8 \%$ & $42.7 \%$ & $44.1 \%$ & $45.9 \%$ & $43.7 \%$ & $42.7 \%$ & $45.7 \%$ & $43.9 \%$ & $42.4 \%$ \\
\hline$\%$ Civ, Ed \& Rel & $10.6 \%$ & $11.1 \%$ & $9.6 \%$ & $8.5 \%$ & $8.8 \%$ & $9.4 \%$ & $8.8 \%$ & $9.8 \%$ & $9.6 \%$ \\
\hline$\%$ Social \& Recreational & $24.0 \%$ & $24.6 \%$ & $27.3 \%$ & $25.4 \%$ & $27.3 \%$ & $26.7 \%$ & $24.9 \%$ & $26.6 \%$ & $27.5 \%$ \\
\hline$\%$ Other & $0.0 \%$ & $1.3 \%$ & $1.3 \%$ & $0.2 \%$ & $1.1 \%$ & $0.9 \%$ & $0.2 \%$ & $0.8 \%$ & $0.8 \%$ \\
\hline$\%$ Unreported & & $0.3 \%$ & $1.0 \%$ & & $0.3 \%$ & $0.9 \%$ & & $0.1 \%$ & $1.0 \%$ \\
\hline TOTAL & 3.58 & 3.44 & 3.46 & 4.08 & 3.95 & 3.78 & 4.33 & 4.11 & 3.81 \\
\hline Weekday & 3.71 & 3.61 & 3.53 & 4.19 & 4.02 & 3.90 & 4.46 & 4.21 & 3.92 \\
\hline Weekend & 3.29 & 3.03 & 3.28 & 3.84 & 3.78 & 3.45 & 3.99 & 3.89 & 3.52 \\
\hline TOTAL & 3.58 & 3.44 & 3.46 & 4.08 & 3.95 & 3.78 & 4.33 & 4.11 & 3.81 \\
\hline$\% 1-9 \min$ & $32.7 \%$ & $21.6 \%$ & $21.8 \%$ & $40.9 \%$ & $30.4 \%$ & $32.1 \%$ & $40.0 \%$ & $28.7 \%$ & $29.9 \%$ \\
\hline$\% 10-19 \min$ & $26.0 \%$ & $27.9 \%$ & $28.3 \%$ & $31.1 \%$ & $34.6 \%$ & $35.3 \%$ & $32.1 \%$ & $36.3 \%$ & $36.6 \%$ \\
\hline$\% 20-29 \min$ & $13.1 \%$ & $10.3 \%$ & $12.7 \%$ & $12.5 \%$ & $13.0 \%$ & $13.6 \%$ & $12.7 \%$ & $13.3 \%$ & $13.5 \%$ \\
\hline$\%$ 30-39 min & $9.5 \%$ & $12.2 \%$ & $13.9 \%$ & $6.1 \%$ & $9.2 \%$ & $9.5 \%$ & $6.2 \%$ & $9.8 \%$ & $9.8 \%$ \\
\hline$\% 40-49 \min$ & $6.7 \%$ & $7.2 \%$ & $7.8 \%$ & $3.2 \%$ & $3.8 \%$ & $3.8 \%$ & $3.2 \%$ & $4.0 \%$ & $4.0 \%$ \\
\hline$\% 50+\min$ & $9.2 \%$ & $13.7 \%$ & $15.1 \%$ & $4.9 \%$ & $6.5 \%$ & $5.5 \%$ & $4.4 \%$ & $5.9 \%$ & $6.0 \%$ \\
\hline$\%$ Unreported & $2.8 \%$ & $7.0 \%$ & $0.4 \%$ & $1.2 \%$ & $2.5 \%$ & $0.2 \%$ & $1.4 \%$ & $1.9 \%$ & $0.3 \%$ \\
\hline TOTAL & 3.58 & 3.44 & 3.46 & 4.08 & 3.95 & 3.78 & 4.33 & 4.11 & 3.81 \\
\hline$\% 5$ or less miles & $72.1 \%$ & $70.2 \%$ & $71.6 \%$ & $62.3 \%$ & $61.7 \%$ & $63.0 \%$ & $62.6 \%$ & $59.6 \%$ & $60.8 \%$ \\
\hline$\%$ 6-10 miles & $8.7 \%$ & $9.2 \%$ & $9.1 \%$ & $16.2 \%$ & $15.6 \%$ & $15.4 \%$ & $15.9 \%$ & $17.0 \%$ & $16.4 \%$ \\
\hline$\% 11-15$ miles & $5.0 \%$ & $4.4 \%$ & $3.7 \%$ & $7.4 \%$ & $7.5 \%$ & $7.0 \%$ & $7.4 \%$ & $8.0 \%$ & $7.5 \%$ \\
\hline$\% 16-20$ miles & $2.2 \%$ & $2.6 \%$ & $1.8 \%$ & $3.9 \%$ & $4.1 \%$ & $4.2 \%$ & $3.9 \%$ & $4.4 \%$ & $4.1 \%$ \\
\hline$\% 21-30$ miles & $2.5 \%$ & $1.9 \%$ & $1.2 \%$ & $3.9 \%$ & $4.2 \%$ & $4.1 \%$ & $3.9 \%$ & $4.3 \%$ & $4.2 \%$ \\
\hline$\% 31$ or more miles & $2.2 \%$ & $1.9 \%$ & $2.2 \%$ & $4.7 \%$ & $5.0 \%$ & $4.2 \%$ & $4.9 \%$ & $5.1 \%$ & $4.8 \%$ \\
\hline$\%$ Unreported & $7.3 \%$ & $9.9 \%$ & $10.3 \%$ & $1.7 \%$ & $2.0 \%$ & $2.1 \%$ & $1.4 \%$ & $1.7 \%$ & $2.1 \%$ \\
\hline
\end{tabular}


Chapter 3: Table 3

Influence of NY State Metropolitan Data on Overall NY Travel Patterns

\begin{tabular}{|c|c|c|c|c|c|c|c|c|c|}
\hline & \multicolumn{3}{|c|}{ New York City } & \multicolumn{3}{|c|}{ Remainder NY State } & \multicolumn{3}{|c|}{ Remainder of U.S. } \\
\hline & 1995 & 2001 & 2009 & 1995 & 2001 & 2009 & 1995 & 2001 & 2009 \\
\hline \multicolumn{10}{|l|}{ Daily PMT per Person } \\
\hline TOTAL & 19.08 & 21.11 & 16.10 & 35.5 & 35.6 & 32.92 & 39.4 & 41.03 & 36.85 \\
\hline$\%$ SOV & $20.5 \%$ & $16.5 \%$ & $16.5 \%$ & $39.6 \%$ & $38.6 \%$ & $41.0 \%$ & $40.4 \%$ & $37.6 \%$ & $38.9 \%$ \\
\hline$\% \mathrm{MOV}$ & $38.9 \%$ & $28.2 \%$ & $43.3 \%$ & $51.5 \%$ & $49.5 \%$ & $44.9 \%$ & $51.1 \%$ & $51.3 \%$ & $49.9 \%$ \\
\hline$\%$ Other POV & $0.3 \%$ & & & $0.0 \%$ & & & $0.1 \%$ & & \\
\hline$\%$ Amtrak & $0.3 \%$ & $1.0 \%$ & $0.1 \%$ & $0.3 \%$ & $0.4 \%$ & $0.2 \%$ & $0.0 \%$ & $0.1 \%$ & $0.1 \%$ \\
\hline$\%$ Commuter Train & $5.0 \%$ & $0.6 \%$ & $2.4 \%$ & $1.6 \%$ & $1.3 \%$ & $1.3 \%$ & $0.3 \%$ & $0.2 \%$ & $0.3 \%$ \\
\hline$\%$ Subway & $14.8 \%$ & $14.2 \%$ & $13.3 \%$ & $0.3 \%$ & $0.4 \%$ & $0.2 \%$ & $0.2 \%$ & $0.1 \%$ & $0.1 \%$ \\
\hline$\%$ Other Public Transit & $9.2 \%$ & $5.4 \%$ & $8.3 \%$ & $2.0 \%$ & $0.4 \%$ & $0.6 \%$ & $1.3 \%$ & $0.5 \%$ & $0.6 \%$ \\
\hline$\%$ Walk & $3.5 \%$ & $3.9 \%$ & $6.5 \%$ & $0.3 \%$ & $0.8 \%$ & $0.8 \%$ & $0.3 \%$ & $0.6 \%$ & $0.7 \%$ \\
\hline$\%$ Other & $6.6 \%$ & $29.1 \%$ & $9.6 \%$ & $3.3 \%$ & $8.1 \%$ & $10.8 \%$ & $5.4 \%$ & $9.3 \%$ & $9.4 \%$ \\
\hline$\%$ Unreported & $0.8 \%$ & $0.9 \%$ & $0.1 \%$ & $1.0 \%$ & $0.4 \%$ & $0.2 \%$ & $1.0 \%$ & $0.5 \%$ & $0.1 \%$ \\
\hline TOTAL & 19.08 & 21.11 & 16.10 & 35.5 & 35.6 & 32.92 & 39.4 & 41.03 & 36.85 \\
\hline$\%$ Earn a Living & $31.2 \%$ & $34.2 \%$ & $29.3 \%$ & $28.2 \%$ & $25.9 \%$ & $26.5 \%$ & $28.2 \%$ & $27.5 \%$ & $25.2 \%$ \\
\hline$\%$ Fam/Per Bus & $32.2 \%$ & $23.6 \%$ & $27.5 \%$ & $34.2 \%$ & $32.9 \%$ & $30.0 \%$ & $35.0 \%$ & $32.9 \%$ & $29.6 \%$ \\
\hline$\%$ Civ, Ed \& Rel & $6.7 \%$ & $5.3 \%$ & $5.5 \%$ & $5.1 \%$ & $5.1 \%$ & $5.7 \%$ & $5.7 \%$ & $5.9 \%$ & $6.2 \%$ \\
\hline$\%$ Social \& Recreational & $30.0 \%$ & $24.3 \%$ & $34.2 \%$ & $32.2 \%$ & $33.3 \%$ & $28.0 \%$ & $30.6 \%$ & $30.0 \%$ & $30.3 \%$ \\
\hline$\%$ Other & $0.0 \%$ & $9.1 \%$ & $1.3 \%$ & $0.3 \%$ & $2.4 \%$ & $5.5 \%$ & $0.4 \%$ & $3.4 \%$ & $5.0 \%$ \\
\hline$\%$ Unreported & & $3.6 \%$ & $2.2 \%$ & & $0.5 \%$ & $4.4 \%$ & & $0.3 \%$ & $3.7 \%$ \\
\hline Average Person Trip Length & & & & & & & & & \\
\hline TOTAL & 5.74 & 6.82 & 5.20 & 8.86 & 9.18 & 8.91 & 9.23 & 10.14 & 9.89 \\
\hline
\end{tabular}


Chapter 3: Table 4

Influence of NY State Metropolitan Data on Overall NY Travel Patterns

\begin{tabular}{|c|c|c|c|c|c|c|c|c|c|}
\hline & \multicolumn{3}{|c|}{ New York City } & \multicolumn{3}{|c|}{ Remainder NY State } & \multicolumn{3}{|c|}{ Remainder of U.S. } \\
\hline & 1995 & 2001 & 2009 & 1995 & 2001 & 2009 & 1995 & 2001 & 2009 \\
\hline \multicolumn{10}{|c|}{ Distribution of Zero-Vehicle Households by Household Income } \\
\hline ALL & $100.0 \%$ & $100.0 \%$ & $100.0 \%$ & $100.0 \%$ & $100.0 \%$ & $100.0 \%$ & $100.0 \%$ & $100.0 \%$ & $100.0 \%$ \\
\hline$<\$ 10,000$ Households & $13.3 \%$ & $16.3 \%$ & $15.7 \%$ & $16.4 \%$ & $27.2 \%$ & $33.7 \%$ & $24.3 \%$ & $34.5 \%$ & $35.9 \%$ \\
\hline$\$ 10$ to $\$ 20,000$ Households & $14.2 \%$ & $15.6 \%$ & $17.6 \%$ & $26.0 \%$ & $30.1 \%$ & $32.0 \%$ & $29.1 \%$ & $24.6 \%$ & $29.2 \%$ \\
\hline$\$ 20$ to $\$ 30,000$ Households & $12.9 \%$ & $12.0 \%$ & $11.3 \%$ & $17.5 \%$ & $14.0 \%$ & $10.3 \%$ & $13.4 \%$ & $11.6 \%$ & $10.1 \%$ \\
\hline$\$ 30$ to $\$ 40,000$ Households & $14.9 \%$ & $12.5 \%$ & $10.4 \%$ & $10.8 \%$ & $8.9 \%$ & $6.3 \%$ & $6.4 \%$ & $7.7 \%$ & $5.7 \%$ \\
\hline$\$ 40$ to $\$ 50,000$ Households & $3.9 \%$ & $3.4 \%$ & $7.5 \%$ & $1.2 \%$ & $0.8 \%$ & $2.8 \%$ & $1.1 \%$ & $1.7 \%$ & $3.4 \%$ \\
\hline$\$ 50$ to $\$ 60,000$ Households & $4.7 \%$ & $7.6 \%$ & $4.4 \%$ & $0.7 \%$ & $1.0 \%$ & $0.6 \%$ & $2.3 \%$ & $2.4 \%$ & $0.7 \%$ \\
\hline$\$ 60$ to $\$ 70,000$ Households & $5.0 \%$ & $3.2 \%$ & $4.7 \%$ & $1.0 \%$ & $0.7 \%$ & $0.6 \%$ & $1.4 \%$ & $0.8 \%$ & $0.4 \%$ \\
\hline$\$ 70$ to $\$ 80,000$ Households & $2.8 \%$ & $2.7 \%$ & $2.7 \%$ & $0.6 \%$ & $0.3 \%$ & $0.3 \%$ & $0.4 \%$ & $0.2 \%$ & $0.7 \%$ \\
\hline$\$ 80,000-\$ 100,000$ Households & $2.3 \%$ & $2.8 \%$ & $5.3 \%$ & $0.2 \%$ & $0.6 \%$ & $0.2 \%$ & $0.4 \%$ & $0.5 \%$ & $0.4 \%$ \\
\hline$\$ 100,000+$ Households & $4.8 \%$ & $9.5 \%$ & $10.1 \%$ & $0.5 \%$ & $1.1 \%$ & $1.2 \%$ & $0.5 \%$ & $1.7 \%$ & $1.7 \%$ \\
\hline Unreported & $21.3 \%$ & $14.5 \%$ & $10.3 \%$ & $25.2 \%$ & $15.2 \%$ & $12.1 \%$ & $20.8 \%$ & $14.4 \%$ & $11.9 \%$ \\
\hline \multicolumn{10}{|c|}{ Zero-Vehicle Households - Daily Person Trips per Person } \\
\hline TOTAL & 3.32 & 3.30 & 3.20 & 2.78 & 2.53 & 2.50 & 2.97 & 2.63 & 2.61 \\
\hline$\%$ Private & $11.4 \%$ & $13.3 \%$ & $7.4 \%$ & $39.2 \%$ & $36.8 \%$ & $24.3 \%$ & $46.5 \%$ & $43.6 \%$ & $33.2 \%$ \\
\hline$\%$ Public & $34.3 \%$ & $32.7 \%$ & $32.5 \%$ & $16.9 \%$ & $13.5 \%$ & $18.5 \%$ & $14.5 \%$ & $16.7 \%$ & $17.6 \%$ \\
\hline$\%$ Walk & $41.6 \%$ & $47.2 \%$ & $52.7 \%$ & $21.2 \%$ & $35.8 \%$ & $41.8 \%$ & $24.6 \%$ & $31.9 \%$ & $34.2 \%$ \\
\hline$\%$ Other & $6.3 \%$ & $6.6 \%$ & $7.3 \%$ & $10.4 \%$ & $13.8 \%$ & $14.3 \%$ & $6.7 \%$ & $7.6 \%$ & $12.7 \%$ \\
\hline$\%$ Unreported & $6.3 \%$ & $0.2 \%$ & $0.1 \%$ & $12.2 \%$ & $0.2 \%$ & $1.2 \%$ & $7.7 \%$ & $0.1 \%$ & $2.2 \%$ \\
\hline TOTAL & 3.32 & 3.30 & 3.20 & 2.78 & 2.53 & 2.50 & 2.97 & 2.63 & 2.61 \\
\hline$<\$ 10,000$ & 2.96 & 2.83 & 2.46 & 2.50 & 2.53 & 2.27 & 2.57 & 2.45 & 2.43 \\
\hline$\$ 10$ to $\$ 20,000$ & 3.40 & 3.03 & 3.06 & 2.57 & 2.73 & 2.57 & 3.27 & 2.42 & 2.63 \\
\hline$\$ 20$ to $\$ 30,000$ & 3.56 & 3.31 & 3.20 & 2.91 & 2.12 & 3.08 & 3.59 & 3.25 & 3.23 \\
\hline$\$ 30$ to $\$ 40,000$ & 3.26 & 3.16 & 2.88 & 3.33 & 2.89 & 2.51 & 3.32 & 2.75 & 3.08 \\
\hline$\$ 40$ to $\$ 50,000$ & 3.31 & 3.93 & 2.76 & 4.61 & 2.70 & 2.97 & 3.85 & 2.54 & 3.22 \\
\hline$\$ 50$ to $\$ 60,000$ & 3.57 & 3.40 & 3.16 & 2.91 & 4.10 & 4.71 & 2.52 & 3.77 & 3.76 \\
\hline$\$ 60$ to $\$ 70,000$ & 4.22 & 4.42 & 4.61 & 3.72 & 1.22 & 3.41 & 2.62 & 3.94 & 3.32 \\
\hline$\$ 70$ to $\$ 80,000$ & 4.59 & 3.81 & 3.25 & 3.58 & 3.34 & 2.50 & 6.24 & 1.95 & 2.74 \\
\hline$\$ 80$ to $\$ 100,000$ & 3.36 & 4.39 & 3.74 & 8.00 & 5.19 & 4.00 & 8.10 & 3.79 & 3.88 \\
\hline$\$ 100,000+$ & 4.17 & 4.43 & 4.88 & 3.50 & 4.25 & 2.16 & 4.23 & 4.13 & 3.77 \\
\hline Unreported & 2.81 & 2.55 & 2.07 & 2.59 & 1.75 & 1.85 & 2.36 & 2.07 & 1.68 \\
\hline \multicolumn{10}{|c|}{ Zero-Vehicle Households - Daily PMT per Person } \\
\hline TOTAL & 14.86 & 17.87 & 8.88 & 15.98 & 9.15 & 8.26 & 13.61 & 18.56 & 11.01 \\
\hline$\%$ Private & $33.4 \%$ & $16.8 \%$ & $20.0 \%$ & $74.0 \%$ & $65.4 \%$ & $44.3 \%$ & $68.7 \%$ & $56.6 \%$ & $57.4 \%$ \\
\hline$\%$ Public & $50.2 \%$ & $31.5 \%$ & $55.6 \%$ & $18.6 \%$ & $17.3 \%$ & $31.8 \%$ & $21.6 \%$ & $10.6 \%$ & $21.1 \%$ \\
\hline$\%$ Walk & $5.8 \%$ & $5.7 \%$ & $13.3 \%$ & $2.1 \%$ & $6.4 \%$ & $7.2 \%$ & $5.3 \%$ & $3.0 \%$ & $5.7 \%$ \\
\hline$\%$ Other & $9.8 \%$ & $45.9 \%$ & $10.9 \%$ & $4.6 \%$ & $11.0 \%$ & $13.1 \%$ & $3.0 \%$ & $29.6 \%$ & $11.9 \%$ \\
\hline$\%$ Unreported & $0.9 \%$ & $0.1 \%$ & $0.1 \%$ & $0.7 \%$ & & $3.6 \%$ & $1.4 \%$ & $0.1 \%$ & $3.8 \%$ \\
\hline TOTAL & 14.86 & 17.87 & 8.88 & 15.98 & 9.15 & 8.26 & 13.61 & 18.56 & 11.01 \\
\hline$<\$ 10,000$ & 9.00 & 11.39 & 3.58 & 7.46 & 6.98 & 6.67 & 8.88 & 7.27 & 7.51 \\
\hline$\$ 10$ to $\$ 20,000$ & 20.07 & 9.01 & 4.75 & 8.58 & 9.99 & 9.01 & 16.73 & 12.79 & 11.36 \\
\hline$\$ 20$ to $\$ 30,000$ & 12.89 & 7.25 & 10.65 & 12.36 & 5.80 & 10.81 & 14.00 & 33.08 & 14.47 \\
\hline$\$ 30$ to $\$ 40,000$ & 16.47 & 16.12 & 10.23 & 20.02 & 13.84 & 6.95 & 18.34 & 20.37 & 15.75 \\
\hline$\$ 40$ to $\$ 50,000$ & 33.16 & 14.07 & 8.35 & 17.86 & 46.62 & 7.52 & 37.46 & 9.82 & 23.58 \\
\hline$\$ 50$ to $\$ 60,000$ & 12.69 & 13.91 & 4.26 & 31.34 & 14.31 & 9.26 & 6.74 & 166.25 & 10.34 \\
\hline$\$ 60$ to $\$ 70,000$ & 12.83 & 17.23 & 10.05 & 25.99 & 1.17 & 2.52 & 22.60 & 15.46 & 17.38 \\
\hline$\$ 70$ to $\$ 80,000$ & 11.04 & 29.83 & 12.95 & 23.80 & 61.28 & 18.49 & 17.07 & 2.99 & 19.36 \\
\hline$\$ 80$ to $\$ 100,000$ & 30.80 & 16.13 & 17.02 & 55.73 & 23.90 & 22.00 & 34.55 & 57.09 & 12.87 \\
\hline$\$ 100,000+$ & 14.70 & 79.77 & 21.67 & 175.81 & 14.13 & 18.85 & 36.13 & 52.47 & 26.32 \\
\hline Unreported & 11.37 & 5.65 & 2.40 & 26.55 & 3.98 & 6.93 & 10.42 & 7.35 & 8.87 \\
\hline
\end{tabular}


Chapter 3: Table 5

Influence of NY State Metropolitan Data on Overall NY Travel Patterns

\begin{tabular}{|c|c|c|c|c|c|c|c|c|c|}
\hline & \multicolumn{3}{|c|}{ New York City } & \multicolumn{3}{|c|}{ Remainder NY State } & \multicolumn{3}{|c|}{ Remainder of U.S. } \\
\hline & 1995 & 2001 & 2009 & 1995 & 2001 & 2009 & 1995 & 2001 & 2009 \\
\hline \multicolumn{10}{|c|}{ Daily Vehicle Trips per Driver } \\
\hline TOTAL & 1.67 & 1.57 & 1.13 & 3.42 & 3.23 & 3.04 & 3.61 & 3.40 & 3.06 \\
\hline$\%$ Earn a Living & $25.7 \%$ & $25.6 \%$ & $18.2 \%$ & $26.9 \%$ & $25.5 \%$ & $26.1 \%$ & $27.4 \%$ & $26.2 \%$ & $26.1 \%$ \\
\hline$\%$ Fam/Per Bus & $52.7 \%$ & $50.4 \%$ & $55.5 \%$ & $50.9 \%$ & $48.7 \%$ & $47.5 \%$ & $49.9 \%$ & $48.0 \%$ & $46.7 \%$ \\
\hline$\%$ Civ, Ed \& Rel & $4.2 \%$ & $3.8 \%$ & $3.4 \%$ & $3.5 \%$ & $4.2 \%$ & $4.7 \%$ & $4.2 \%$ & $4.9 \%$ & $4.9 \%$ \\
\hline$\%$ Social \& Recreational & $17.4 \%$ & $19.0 \%$ & $21.3 \%$ & $18.7 \%$ & $21.0 \%$ & $20.7 \%$ & $18.3 \%$ & $20.3 \%$ & $21.1 \%$ \\
\hline$\%$ Other & $0.0 \%$ & $1.0 \%$ & $0.2 \%$ & $0.0 \%$ & $0.5 \%$ & $0.3 \%$ & $0.1 \%$ & $0.5 \%$ & $0.3 \%$ \\
\hline$\%$ Unreported & & $0.1 \%$ & $1.5 \%$ & & $0.2 \%$ & $0.7 \%$ & & $0.1 \%$ & $0.9 \%$ \\
\hline TOTAL & 1.67 & 1.57 & 1.13 & 3.42 & 3.23 & 3.04 & 3.61 & 3.40 & 3.06 \\
\hline$\% 1-9 \min$ & $30.5 \%$ & $21.4 \%$ & $23.8 \%$ & $41.5 \%$ & $32.2 \%$ & $33.0 \%$ & $40.2 \%$ & $29.9 \%$ & $30.6 \%$ \\
\hline$\% 10-19 \mathrm{~min}$ & $28.7 \%$ & $35.1 \%$ & $33.0 \%$ & $31.9 \%$ & $36.1 \%$ & $36.1 \%$ & $33.0 \%$ & $37.3 \%$ & $36.9 \%$ \\
\hline$\% 20-29 \min$ & $15.6 \%$ & $13.0 \%$ & $15.1 \%$ & $13.2 \%$ & $13.4 \%$ & $13.5 \%$ & $13.3 \%$ & $13.7 \%$ & $13.9 \%$ \\
\hline$\% 30-39 \mathrm{~min}$ & $9.0 \%$ & $13.9 \%$ & $13.0 \%$ & $5.8 \%$ & $8.9 \%$ & $8.8 \%$ & $6.4 \%$ & $9.5 \%$ & $9.4 \%$ \\
\hline$\% 40-49 \mathrm{~min}$ & $7.2 \%$ & $6.5 \%$ & $6.3 \%$ & $2.9 \%$ & $3.6 \%$ & $3.7 \%$ & $3.3 \%$ & $4.0 \%$ & $4.0 \%$ \\
\hline$\% 50+\min$ & $8.4 \%$ & $9.6 \%$ & $8.3 \%$ & $4.1 \%$ & $5.1 \%$ & $4.8 \%$ & $3.9 \%$ & $5.1 \%$ & $5.1 \%$ \\
\hline$\%$ Unreported & $0.6 \%$ & $0.5 \%$ & $0.5 \%$ & $0.6 \%$ & $0.6 \%$ & $0.1 \%$ & $0.0 \%$ & $0.6 \%$ & $0.2 \%$ \\
\hline TOTAL & 1.67 & 1.57 & 1.13 & 3.42 & 3.23 & 3.04 & 3.61 & 3.40 & 3.06 \\
\hline$\% 5$ or less miles & $61.1 \%$ & $62.5 \%$ & $65.6 \%$ & $60.2 \%$ & $58.5 \%$ & $59.0 \%$ & $60.1 \%$ & $56.3 \%$ & $56.7 \%$ \\
\hline$\% 6-10$ miles & $15.0 \%$ & $15.2 \%$ & $13.4 \%$ & $17.8 \%$ & $17.4 \%$ & $17.7 \%$ & $17.5 \%$ & $18.5 \%$ & $18.5 \%$ \\
\hline$\% 11-15$ miles & $9.0 \%$ & $7.4 \%$ & $6.7 \%$ & $8.2 \%$ & $8.6 \%$ & $8.1 \%$ & $8.3 \%$ & $9.0 \%$ & $8.8 \%$ \\
\hline$\% 16-20$ miles & $3.6 \%$ & $3.9 \%$ & $4.0 \%$ & $4.4 \%$ & $4.7 \%$ & $4.9 \%$ & $4.4 \%$ & $4.9 \%$ & $4.9 \%$ \\
\hline$\% 21-30$ miles & $4.8 \%$ & $3.7 \%$ & $2.5 \%$ & $4.1 \%$ & $4.5 \%$ & $4.7 \%$ & $4.4 \%$ & $4.9 \%$ & $4.9 \%$ \\
\hline$\% 31$ or more miles & $3.6 \%$ & $3.0 \%$ & $3.3 \%$ & $4.4 \%$ & $4.9 \%$ & $4.5 \%$ & $4.7 \%$ & $5.3 \%$ & $5.1 \%$ \\
\hline$\%$ Unreported & $3.0 \%$ & $4.3 \%$ & $4.5 \%$ & $0.9 \%$ & $1.3 \%$ & $1.1 \%$ & $0.6 \%$ & $1.0 \%$ & $1.2 \%$ \\
\hline TOTAL & 1.67 & 1.57 & 1.13 & 3.42 & 3.23 & 3.04 & 3.61 & 3.40 & 3.06 \\
\hline Weekday & 1.63 & 1.61 & 1.08 & 3.61 & 3.39 & 3.22 & 3.84 & 3.60 & 3.26 \\
\hline Weekend & 1.76 & 1.47 & 1.26 & 2.95 & 2.85 & 2.58 & 3.00 & 2.88 & 2.56 \\
\hline \multicolumn{10}{|l|}{ Daily VMT per Driver } \\
\hline TOTAL & 13.86 & 11.86 & 8.13 & 29.96 & 29.24 & 26.64 & 32.59 & 33.31 & 29.57 \\
\hline$\%$ Earn a Living & $35.9 \%$ & $34.6 \%$ & $24.1 \%$ & $37.2 \%$ & $34.8 \%$ & $35.9 \%$ & $37.8 \%$ & $35.5 \%$ & $34.7 \%$ \\
\hline$\%$ Fam/Per Bus & $31.5 \%$ & $35.7 \%$ & $34.5 \%$ & $35.8 \%$ & $34.7 \%$ & $33.9 \%$ & $35.5 \%$ & $35.3 \%$ & $32.7 \%$ \\
\hline$\%$ Civ, Ed \& Rel & $3.5 \%$ & $3.9 \%$ & $2.3 \%$ & $2.7 \%$ & $3.2 \%$ & $3.7 \%$ & $3.8 \%$ & $3.8 \%$ & $4.4 \%$ \\
\hline$\%$ Social \& Recreational & $29.1 \%$ & $25.1 \%$ & $36.8 \%$ & $24.0 \%$ & $26.3 \%$ & $22.7 \%$ & $22.7 \%$ & $24.4 \%$ & $24.4 \%$ \\
\hline$\%$ Other & $0.0 \%$ & $0.6 \%$ & $0.4 \%$ & $0.2 \%$ & $0.9 \%$ & $0.4 \%$ & $0.1 \%$ & $0.8 \%$ & $0.6 \%$ \\
\hline$\%$ Unreported & & $0.2 \%$ & $1.9 \%$ & & $0.3 \%$ & $3.5 \%$ & & $0.2 \%$ & $3.2 \%$ \\
\hline \multicolumn{10}{|c|}{ Average Vehicle Trip Length } \\
\hline TOTAL & 8.54 & 7.91 & 7.55 & 8.84 & 9.16 & 8.85 & 9.07 & 9.91 & 9.77 \\
\hline \multicolumn{10}{|c|}{$\%$ Vehicle Trips/Person Trips } \\
\hline TOTAL & $22.1 \%$ & $23.2 \%$ & $20.3 \%$ & $60.7 \%$ & $60.7 \%$ & $61.5 \%$ & $61.6 \%$ & $61.6 \%$ & $60.6 \%$ \\
\hline$\%$ VMT/PMT & & & & & & & & & \\
\hline TOTAL & $34.4 \%$ & $28.6 \%$ & $31.4 \%$ & $61.1 \%$ & $61.0 \%$ & $61.7 \%$ & $61.0 \%$ & $60.6 \%$ & $60.5 \%$ \\
\hline
\end{tabular}


Chapter 3: Table 6

Influence of NY State Metropolitan Data on Overall NY Travel Patterns

\begin{tabular}{|c|c|c|c|c|c|c|c|c|c|}
\hline & \multicolumn{3}{|c|}{ New York City } & \multicolumn{3}{|c|}{ Remainder NY State } & \multicolumn{3}{|c|}{ Remainder of U.S. } \\
\hline & 1995 & 2001 & 2009 & 1995 & 2001 & 2009 & 1995 & 2001 & 2009 \\
\hline \multicolumn{10}{|l|}{ Daily Commute Trips per Worker } \\
\hline TOTAL & 1.26 & 1.08 & 0.95 & 1.34 & 1.14 & 1.14 & 1.40 & 1.15 & 1.11 \\
\hline$\%$ SOV & $25.4 \%$ & $25.0 \%$ & $19.9 \%$ & $75.4 \%$ & $76.1 \%$ & $76.7 \%$ & $75.7 \%$ & $77.7 \%$ & $78.4 \%$ \\
\hline$\% \mathrm{MOV}$ & $9.5 \%$ & $9.7 \%$ & $7.7 \%$ & $14.9 \%$ & $14.7 \%$ & $13.7 \%$ & $16.4 \%$ & $16.4 \%$ & $14.6 \%$ \\
\hline$\%$ Other POV & $0.0 \%$ & & & $0.0 \%$ & & & $0.0 \%$ & & \\
\hline$\%$ Amtrak & $0.0 \%$ & $1.2 \%$ & $0.8 \%$ & $0.0 \%$ & $0.4 \%$ & $0.1 \%$ & $0.0 \%$ & $0.1 \%$ & $0.0 \%$ \\
\hline$\%$ Commuter Train & $5.6 \%$ & $1.4 \%$ & $4.1 \%$ & $2.2 \%$ & $2.1 \%$ & $1.3 \%$ & $0.7 \%$ & $0.3 \%$ & $0.3 \%$ \\
\hline$\%$ Subway & $26.2 \%$ & $30.3 \%$ & $28.7 \%$ & $0.7 \%$ & $0.7 \%$ & $0.3 \%$ & $0.7 \%$ & $0.5 \%$ & $0.3 \%$ \\
\hline$\%$ Other Public Transit & $11.9 \%$ & $12.2 \%$ & $14.9 \%$ & $1.5 \%$ & $1.0 \%$ & $1.9 \%$ & $1.4 \%$ & $1.6 \%$ & $1.7 \%$ \\
\hline$\%$ Walk & $13.5 \%$ & $16.0 \%$ & $17.5 \%$ & $2.2 \%$ & $3.8 \%$ & $3.3 \%$ & $2.1 \%$ & $2.4 \%$ & $2.7 \%$ \\
\hline$\%$ Other & $5.6 \%$ & $4.2 \%$ & $6.5 \%$ & $1.5 \%$ & $1.2 \%$ & $2.3 \%$ & $1.4 \%$ & $0.9 \%$ & $1.8 \%$ \\
\hline$\%$ Unreported & $2.4 \%$ & $0.0 \%$ & & $1.5 \%$ & $0.2 \%$ & $0.2 \%$ & $1.6 \%$ & $0.1 \%$ & $0.2 \%$ \\
\hline TOTAL & 1.26 & 1.08 & 0.95 & 1.34 & 1.14 & 1.14 & 1.40 & 1.15 & 1.11 \\
\hline$\% 1-6$ am & $3.2 \%$ & $5.0 \%$ & $4.7 \%$ & $4.5 \%$ & $4.8 \%$ & $4.5 \%$ & $5.7 \%$ & $6.2 \%$ & $6.3 \%$ \\
\hline$\%$ 6-9 am & $31.7 \%$ & $31.4 \%$ & $31.4 \%$ & $28.4 \%$ & $30.5 \%$ & $30.0 \%$ & $28.6 \%$ & $30.1 \%$ & $30.0 \%$ \\
\hline$\% 9$ am-1 pm & $9.5 \%$ & $10.1 \%$ & $9.6 \%$ & $13.4 \%$ & $11.7 \%$ & $12.0 \%$ & $12.9 \%$ & $11.5 \%$ & $11.6 \%$ \\
\hline$\% 1-4 \mathrm{pm}$ & $11.9 \%$ & $11.0 \%$ & $14.1 \%$ & $16.4 \%$ & $15.6 \%$ & $17.0 \%$ & $15.0 \%$ & $14.3 \%$ & $15.3 \%$ \\
\hline$\%$ 4-7 pm & $26.2 \%$ & $26.9 \%$ & $22.7 \%$ & $25.4 \%$ & $25.7 \%$ & $24.7 \%$ & $26.4 \%$ & $25.5 \%$ & $26.1 \%$ \\
\hline$\% 7-10 \mathrm{pm}$ & $11.9 \%$ & $10.4 \%$ & $11.5 \%$ & $6.7 \%$ & $7.2 \%$ & $7.2 \%$ & $7.1 \%$ & $8.1 \%$ & $7.0 \%$ \\
\hline$\% 10 \mathrm{pm}-1 \mathrm{am}$ & $5.6 \%$ & $5.1 \%$ & $6.0 \%$ & $4.5 \%$ & $4.4 \%$ & $4.5 \%$ & $4.3 \%$ & $4.3 \%$ & $3.7 \%$ \\
\hline$\%$ Unreported & $0.0 \%$ & $0.1 \%$ & & $0.7 \%$ & $0.1 \%$ & & $0.0 \%$ & $0.1 \%$ & $0.0 \%$ \\
\hline \multicolumn{10}{|l|}{ Daily Commute PMT per Worker } \\
\hline TOTAL & 10.70 & 7.48 & 6.17 & 16.04 & 13.18 & 12.89 & 16.08 & 13.78 & 12.99 \\
\hline$\%$ SOV & $33.6 \%$ & $33.5 \%$ & $30.7 \%$ & $74.8 \%$ & $77.4 \%$ & $79.7 \%$ & $76.8 \%$ & $77.7 \%$ & $81.7 \%$ \\
\hline$\%$ MOV & $13.7 \%$ & $13.0 \%$ & $15.5 \%$ & $15.5 \%$ & $12.8 \%$ & $12.6 \%$ & $17.2 \%$ & $16.1 \%$ & $13.5 \%$ \\
\hline$\%$ Other POV & $0.2 \%$ & & & $0.0 \%$ & & & $0.1 \%$ & & \\
\hline$\%$ Amtrak & $0.0 \%$ & $1.4 \%$ & $0.2 \%$ & $0.1 \%$ & $0.9 \%$ & $0.8 \%$ & $0.1 \%$ & $0.3 \%$ & $0.0 \%$ \\
\hline$\%$ Commuter Train & $6.6 \%$ & $2.3 \%$ & $3.4 \%$ & $5.5 \%$ & $5.3 \%$ & $3.0 \%$ & $0.7 \%$ & $0.7 \%$ & $0.5 \%$ \\
\hline$\%$ Subway & $26.2 \%$ & $35.1 \%$ & $28.1 \%$ & $0.9 \%$ & $1.0 \%$ & $0.5 \%$ & $0.4 \%$ & $0.5 \%$ & $0.2 \%$ \\
\hline$\%$ Other Public Transit & $9.2 \%$ & $7.7 \%$ & $11.9 \%$ & $1.4 \%$ & $0.6 \%$ & $1.1 \%$ & $1.5 \%$ & $1.0 \%$ & $1.1 \%$ \\
\hline$\%$ Walk & $1.7 \%$ & $2.8 \%$ & $4.7 \%$ & $0.1 \%$ & $0.4 \%$ & $0.2 \%$ & $0.1 \%$ & $0.2 \%$ & $0.2 \%$ \\
\hline$\%$ Other & $8.1 \%$ & $4.1 \%$ & $5.5 \%$ & $0.9 \%$ & $1.3 \%$ & $1.9 \%$ & $2.2 \%$ & $3.5 \%$ & $2.7 \%$ \\
\hline$\%$ Unreported & $0.7 \%$ & $0.0 \%$ & & $0.9 \%$ & $0.3 \%$ & $0.3 \%$ & $0.9 \%$ & $0.1 \%$ & $0.2 \%$ \\
\hline TOTAL & 10.70 & 7.48 & 6.17 & 16.04 & 13.18 & 12.89 & 16.08 & 13.78 & 12.99 \\
\hline$\% 1-6 \mathrm{am}$ & $4.9 \%$ & $7.6 \%$ & $5.3 \%$ & $7.2 \%$ & $7.8 \%$ & $7.3 \%$ & $8.6 \%$ & $9.6 \%$ & $10.3 \%$ \\
\hline$\%$ 6-9 am & $32.8 \%$ & $33.1 \%$ & $32.8 \%$ & $29.9 \%$ & $33.0 \%$ & $33.4 \%$ & $29.0 \%$ & $31.9 \%$ & $31.5 \%$ \\
\hline$\% 9$ am-1 pm & $7.1 \%$ & $7.6 \%$ & $16.1 \%$ & $11.7 \%$ & $9.0 \%$ & $8.2 \%$ & $9.5 \%$ & $8.4 \%$ & $8.7 \%$ \\
\hline$\% 1-4 \mathrm{pm}$ & $10.8 \%$ & $9.6 \%$ & $9.6 \%$ & $14.8 \%$ & $14.3 \%$ & $15.4 \%$ & $14.6 \%$ & $13.1 \%$ & $13.6 \%$ \\
\hline$\%$ 4-7 pm & $27.8 \%$ & $27.7 \%$ & $22.0 \%$ & $25.3 \%$ & $25.1 \%$ & $24.6 \%$ & $26.5 \%$ & $24.2 \%$ & $25.9 \%$ \\
\hline$\% 7-10 \mathrm{pm}$ & $11.4 \%$ & $9.0 \%$ & $9.2 \%$ & $6.6 \%$ & $6.9 \%$ & $7.3 \%$ & $7.6 \%$ & $8.7 \%$ & $6.6 \%$ \\
\hline$\% 10 \mathrm{pm}-1 \mathrm{am}$ & $5.2 \%$ & $5.5 \%$ & $5.0 \%$ & $4.6 \%$ & $3.8 \%$ & $3.9 \%$ & $4.2 \%$ & $4.1 \%$ & $3.3 \%$ \\
\hline$\%$ Unreported & & $0.0 \%$ & & & $0.2 \%$ & & & $0.1 \%$ & $0.0 \%$ \\
\hline
\end{tabular}




\begin{tabular}{|c|c|c|c|c|c|c|c|c|c|}
\hline & \multicolumn{3}{|c|}{ New York City } & \multicolumn{3}{|c|}{ Remainder NY State } & \multicolumn{3}{|c|}{ Remainder of U.S. } \\
\hline & 1995 & 2001 & 2009 & 1995 & 2001 & 2009 & 1995 & 2001 & 2009 \\
\hline \multicolumn{10}{|c|}{$\begin{array}{l}\text { Average Commute Length, Travel Time, and Speed } \\
\text { Length (miles) }\end{array}$} \\
\hline TOTAL & 9.67 & 8.02 & 7.78 & 12.14 & 11.82 & 11.45 & 11.65 & 12.22 & 11.89 \\
\hline Private & 12.23 & 9.87 & 11.5152 & 12.13 & 11.67 & 11.6312 & 11.82 & 12.13 & 12.1136 \\
\hline Public & 10.43 & 9.33 & 7.9016 & 24.11 & 24.43 & 15.9096 & 13.00 & 11.94 & 10.712 \\
\hline \multicolumn{10}{|c|}{ Time (minutes) } \\
\hline TOTAL & 32.97 & 40.21 & 40.20 & 21.44 & 24.00 & 24.01 & 20.23 & 23.11 & 23.45 \\
\hline Private & 30.16 & 31.36 & 33.46 & 20.84 & 21.90 & 22.93 & 19.97 & 22.42 & 22.77 \\
\hline Public & 43.42 & 55.78 & 51.02 & 50.95 & 72.48 & 58.93 & 39.94 & 54.18 & 53.54 \\
\hline \multicolumn{10}{|c|}{ Miles per Hour } \\
\hline TOTAL & 19.69 & 15.8 & 15.79 & 34.09 & 31.19 & 29.86 & 35.00 & 32.82 & 31.54 \\
\hline Private & 24.32 & 18.82 & 20.65 & 34.92 & 32.07 & 30.43 & 35.53 & 32.51 & 31.92 \\
\hline Public & 14.32 & & & 26.97 & & & 21.10 & 29.46 & \\
\hline
\end{tabular}


Chapter 3: Table 8

Influence of NY State Metropolitan Data on Overall NY Travel Patterns

\begin{tabular}{|c|c|c|c|c|c|c|c|c|c|}
\hline & \multicolumn{3}{|c|}{ New York City } & \multicolumn{3}{|c|}{ Remainder NY State } & \multicolumn{3}{|c|}{ Remainder of U.S. } \\
\hline & 1995 & 2001 & 2009 & 1995 & 2001 & 2009 & 1995 & 2001 & 2009 \\
\hline \multicolumn{10}{|c|}{ Average Vehicle Occupancy Rate (Person Miles per Vehicle Mile) } \\
\hline ALL & 1.79 & 1.68 & 1.92 & 1.56 & 1.62 & 1.62 & 1.59 & 1.63 & 1.67 \\
\hline 1 Adult, No Child & 1.19 & 1.62 & 1.55 & 1.28 & 1.19 & 1.23 & 1.22 & 1.23 & 1.27 \\
\hline 2+ Adults, No Child & 1.70 & 1.66 & 1.58 & 1.40 & 1.40 & 1.38 & 1.36 & 1.44 & 1.43 \\
\hline 1 Adult, Child <6 & 1.91 & 1.89 & 1.67 & 1.90 & 1.80 & 2.13 & 2.19 & 2.33 & 2.27 \\
\hline $2+$ Adults, Child $<6$ & 2.16 & 1.70 & 2.76 & 1.85 & 1.94 & 2.06 & 1.89 & 2.03 & 2.06 \\
\hline 1 Adult, Child 6-15 & 1.80 & 1.76 & 1.32 & 1.59 & 1.63 & 1.90 & 1.73 & 1.76 & 2.04 \\
\hline 2+ Adults, Child 6-15 & 1.96 & 1.86 & 2.04 & 1.71 & 1.67 & 1.83 & 1.79 & 1.73 & 1.90 \\
\hline 1 Adult, Child 16-21 & 1.57 & 1.18 & 1.74 & 1.42 & 1.42 & 1.37 & 1.58 & 1.42 & 1.56 \\
\hline 2+ Adults, Child 16-21 & 1.89 & 1.44 & 1.79 & 1.44 & 1.96 & 1.57 & 1.53 & 1.41 & 1.55 \\
\hline 1 Adult, Retired, No Child & 1.37 & 1.30 & 1.34 & 1.25 & 1.25 & 1.24 & 1.45 & 1.31 & 1.36 \\
\hline 2+ Adults, Retired, No Child & 1.51 & 1.57 & 1.55 & 1.56 & 1.55 & 1.48 & 1.58 & 1.63 & 1.58 \\
\hline Unreported & & 1.79 & & & 1.79 & & & 1.58 & \\
\hline ALL & 1.79 & 1.68 & 1.92 & 1.56 & 1.62 & 1.62 & 1.59 & 1.63 & 1.67 \\
\hline Earn a Living & 1.32 & 1.26 & 1.22 & 1.12 & 1.13 & 1.13 & 1.15 & 1.16 & 1.15 \\
\hline Fam/Pers Bus & 1.84 & 1.86 & 1.90 & 1.72 & 1.72 & 1.73 & 1.76 & 1.80 & 1.79 \\
\hline Civ, Ed, \& Rel & 1.76 & 1.69 & 1.54 & 1.77 & 1.51 & 1.46 & 1.67 & 1.77 & 1.78 \\
\hline Soc and Rec & 2.31 & 1.99 & 2.42 & 2.00 & 2.14 & 2.08 & 2.04 & 2.03 & 2.20 \\
\hline Other & 1.89 & 1.84 & 1.59 & 1.21 & 1.78 & 1.72 & 1.87 & 1.89 & 1.97 \\
\hline Unreported & & 1.09 & 2.00 & & 2.12 & 2.74 & & 1.62 & 1.90 \\
\hline ALL & 1.79 & 1.68 & 1.92 & 1.56 & 1.62 & 1.62 & 1.59 & 1.63 & 1.67 \\
\hline$<\$ 10,000$ Households & 1.53 & 1.24 & 1.14 & 1.45 & 1.63 & 1.56 & 1.66 & 1.97 & 1.83 \\
\hline$\$ 10$ to $\$ 20,000$ Households & 2.43 & 1.58 & 2.28 & 1.43 & 1.56 & 1.60 & 1.8 & 1.68 & 1.74 \\
\hline$\$ 20$ to $\$ 30,000$ Households & 1.79 & 1.49 & 1.47 & 1.47 & 1.62 & 1.58 & 1.55 & 1.66 & 1.70 \\
\hline$\$ 30$ to $\$ 40,000$ Households & 1.79 & 1.88 & 1.99 & 1.56 & 1.93 & 1.63 & 1.57 & 1.66 & 1.63 \\
\hline$\$ 40$ to $\$ 50,000$ Households & 1.94 & 1.81 & 2.14 & 1.58 & 1.72 & 1.56 & 1.63 & 1.65 & 1.68 \\
\hline$\$ 50$ to $\$ 60,000$ Households & 1.68 & 1.87 & 1.94 & 1.61 & 1.47 & 1.67 & 1.57 & 1.59 & 1.55 \\
\hline$\$ 60$ to $\$ 70,000$ Households & 1.93 & 1.64 & 1.74 & 1.59 & 1.57 & 1.64 & 1.55 & 1.59 & 1.62 \\
\hline$\$ 70$ to $\$ 80,000$ Households & 2.99 & 1.54 & 2.33 & 1.52 & 1.61 & 1.66 & 1.68 & 1.64 & 1.67 \\
\hline$\$ 80$ to $\$ 100,000$ Households & 1.77 & 1.50 & 1.73 & 1.6 & 1.52 & 1.60 & 1.6 & 1.59 & 1.59 \\
\hline$\$ 100,000+$ Households & 1.52 & 1.74 & 1.84 & 1.68 & 1.59 & 1.66 & 1.58 & 1.60 & 1.75 \\
\hline Unreported Households & 1.42 & 1.42 & 1.31 & 1.46 & 1.50 & 1.45 & 1.56 & 1.60 & 1.69 \\
\hline
\end{tabular}


Chapter 3: Table 9

Influence of NY State Metropolitan Data on Overall NY Travel Patterns

\begin{tabular}{|c|c|c|c|c|c|c|c|c|c|}
\hline & \multicolumn{3}{|c|}{ New York City } & \multicolumn{3}{|c|}{ Remainder NY State } & \multicolumn{3}{|c|}{ Remainder of U.S. } \\
\hline & 1995 & 2001 & 2009 & 1995 & 2001 & 2009 & 1995 & 2001 & 2009 \\
\hline Vehicles by Type & $100.0 \%$ & $100.0 \%$ & $100.0 \%$ & $100.0 \%$ & $100.0 \%$ & $100.0 \%$ & $100.0 \%$ & $100.0 \%$ & $100.0 \%$ \\
\hline Auto & $87.4 \%$ & $75.7 \%$ & $64.7 \%$ & $72.3 \%$ & $63.2 \%$ & $56.2 \%$ & $64.7 \%$ & $56.4 \%$ & $49.7 \%$ \\
\hline Van & $5.6 \%$ & $9.3 \%$ & $9.9 \%$ & $7.8 \%$ & $10.1 \%$ & $8.9 \%$ & $8.0 \%$ & $9.0 \%$ & $8.2 \%$ \\
\hline Sports Utility & $5.3 \%$ & $12.4 \%$ & $22.6 \%$ & $7.3 \%$ & $11.9 \%$ & $21.1 \%$ & $7.0 \%$ & $12.1 \%$ & $19.4 \%$ \\
\hline Pickup & $1.2 \%$ & $1.0 \%$ & $1.2 \%$ & $10.8 \%$ & $11.6 \%$ & $10.6 \%$ & $18.3 \%$ & $19.0 \%$ & $18.3 \%$ \\
\hline Other Truck & $0.1 \%$ & $0.4 \%$ & $0.0 \%$ & $0.3 \%$ & $0.3 \%$ & $0.3 \%$ & $0.4 \%$ & $0.5 \%$ & $0.4 \%$ \\
\hline RV & $0.0 \%$ & $0.0 \%$ & $0.0 \%$ & $0.4 \%$ & $0.5 \%$ & $0.4 \%$ & $0.5 \%$ & $0.7 \%$ & $0.5 \%$ \\
\hline Motorcycle & $0.2 \%$ & $1.3 \%$ & $1.6 \%$ & $0.8 \%$ & $2.3 \%$ & $2.6 \%$ & $1.0 \%$ & $2.3 \%$ & $3.4 \%$ \\
\hline Other POV & $0.2 \%$ & * & & $0.1 \%$ & * & * & $0.1 \%$ & * & * \\
\hline * Other POV not present in 2001 o & & & & & & & & & \\
\hline Age Statistics & & & & & & & & & \\
\hline Average Vehicle Age & 7.82 & 8.18 & 7.98 & 7.33 & 7.76 & 7.74 & 8.38 & 8.92 & 9.47 \\
\hline Median Vehicle Age & 8 & 7 & 7 & 7 & 7 & 7 & 7 & 7 & 8 \\
\hline Percent VMT* & & & & & & & & & \\
\hline Less than $10 \mathrm{yrs}$ & $70.6 \%$ & $69.3 \%$ & $71.1 \%$ & $76.2 \%$ & $74.2 \%$ & $75.6 \%$ & $76.4 \%$ & $71.0 \%$ & $67.8 \%$ \\
\hline 10 yrs or more & $29.4 \%$ & $30.7 \%$ & $28.9 \%$ & $23.8 \%$ & $25.8 \%$ & $24.4 \%$ & $23.6 \%$ & $29.0 \%$ & $32.2 \%$ \\
\hline Percent Vehicle Fleet & & & & & & & & & \\
\hline Less than 10 yrs & $68.6 \%$ & $61.3 \%$ & $64.9 \%$ & $72.4 \%$ & $68.0 \%$ & $70.5 \%$ & $66.0 \%$ & $62.6 \%$ & $60.7 \%$ \\
\hline 10 yrs or more & $31.5 \%$ & $38.7 \%$ & $35.1 \%$ & $27.6 \%$ & $32.0 \%$ & $29.5 \%$ & $34.0 \%$ & $37.5 \%$ & $39.3 \%$ \\
\hline Avg Fuel Consumption (gal/HH) & ** & 325 & 258 & ** & 968 & 883 & ** & 1,036 & 1,020 \\
\hline Less than $10 \mathrm{yrs}$ & ** & $70.8 \%$ & $69.9 \%$ & ** & $75.4 \%$ & $74.3 \%$ & ** & $71.3 \%$ & $66.3 \%$ \\
\hline 10 yrs or more & ** & $29.2 \%$ & $30.1 \%$ & ** & $24.6 \%$ & $25.7 \%$ & ** & $28.7 \%$ & $33.7 \%$ \\
\hline Avg CO2 Emissions (kg/HH) & ** & 2,866 & 2,265 & ** & 8,508 & 7,774 & ** & 9,106 & 8,985 \\
\hline Less than $10 \mathrm{yrs}$ & ** & $70.8 \%$ & $70.0 \%$ & ** & $75.4 \%$ & $74.3 \%$ & ** & $71.3 \%$ & $66.3 \%$ \\
\hline 10 yrs or more & ** & $29.2 \%$ & $30.0 \%$ & ** & $24.6 \%$ & $25.7 \%$ & ** & $28.7 \%$ & $33.7 \%$ \\
\hline
\end{tabular}


Chapter 3: Table 10

Influence of NY State Metropolitan Data on Overall NY Travel Patterns

\begin{tabular}{|c|c|c|c|c|c|c|c|c|c|}
\hline & \multicolumn{3}{|c|}{ New York City } & \multicolumn{3}{|c|}{ Remainder NY State } & \multicolumn{3}{|c|}{ Remainder of U.S. } \\
\hline & 1995 & 2001 & 2009 & 1995 & 2001 & 2009 & 1995 & 2001 & 2009 \\
\hline \multicolumn{10}{|c|}{ Annual CO2 Emissions per Household - POVs ONLY } \\
\hline Average $\mathrm{CO} 2$ Emissions $(\mathrm{kg}) / \mathrm{HH}$ & ** & 2,866 & 2,265 & ** & 8,508 & 7,774 & ** & 9,106 & 8,985 \\
\hline 0 Workers & ** & 1,284 & 953 & ** & 3,596 & 3,774 & ** & 4,061 & 4,464 \\
\hline 1 Workers & ** & 2,193 & 2,039 & ** & 7,143 & 7,103 & ** & 7,474 & 8,344 \\
\hline 2 Workers & ** & 3,762 & 3,894 & ** & 11,825 & 11,242 & ** & 12,136 & 13,047 \\
\hline 3 or more Workers & ** & 7,816 & 6,054 & ** & 14,075 & 15,406 & ** & 16,856 & 18,587 \\
\hline Average CO2 Emissions (kg)/HH & ** & 2,866 & 2,265 & ** & 8,508 & 7,774 & ** & 9,106 & 8,985 \\
\hline 1 Drivers & ** & 2,349 & 1,224 & ** & 4,439 & 3,938 & ** & 4,678 & 4,737 \\
\hline 2 Drivers & ** & 4,836 & 3,713 & ** & 10,457 & 9,309 & ** & 10,809 & 10,710 \\
\hline 3 or more Drivers & ** & 10,140 & 6,196 & ** & 14,444 & 14,115 & ** & 16,039 & 16,504 \\
\hline Average $\mathrm{CO} 2$ Emissions $(\mathrm{kg}) / \mathrm{HH}$ & ** & 2,866 & 2,265 & ** & 8,508 & 7,774 & ** & 9,106 & 8,985 \\
\hline 1 Vehicles & ** & 4,288 & 3,536 & ** & 4,317 & 3,908 & ** & 4,220 & 4,171 \\
\hline 2 Vehicles & ** & 7,682 & 7,215 & ** & 10,506 & 9,283 & ** & 10,164 & 9,945 \\
\hline 3 or more Vehicles & ** & 16,987 & 11,823 & ** & 15,026 & 15,272 & ** & 16,174 & 16,921 \\
\hline Average CO2 Emissions (kg)/HH & ** & 2,866 & 2,265 & ** & 8,508 & 7,774 & ** & 9,106 & $\mathbf{8 , 9 8 5}$ \\
\hline 0-99 persons/sq mi. & ** & 4,597 & & ** & 10,797 & 10,289 & ** & 11,947 & 12,852 \\
\hline 100-499 persons/sq mi. & ** & 3,884 & & ** & 10,731 & 9,543 & ** & 11,134 & 11,157 \\
\hline 500-999 persons/sq mi. & ** & & 8,304 & ** & 10,923 & 9,102 & ** & 9,955 & 9,569 \\
\hline $1000-1999$ persons/sq mi. & ** & 7,300 & 1,282 & ** & 9,570 & 8,044 & ** & 9,507 & 9,085 \\
\hline 2000-3999 persons/sq mi. & ** & 6,084 & 6,815 & ** & 7,891 & 7,548 & ** & 8,540 & 8,378 \\
\hline 4000-9999 persons/sq mi. & ** & 5,429 & 4,836 & ** & 7,246 & 6,469 & ** & 7,796 & 7,466 \\
\hline 10000-24999 persons/sq mi. & ** & 6,714 & 4,764 & ** & 4,835 & 4,894 & ** & 6,359 & 6,189 \\
\hline 25000-999999 persons/sq mi. & ** & 2,292 & 1,802 & ** & 2,566 & 3,992 & ** & 4,434 & 3,808 \\
\hline \multicolumn{10}{|c|}{ Annual CO2 Emissions per Household - Non-POV MODES } \\
\hline Average CO2 Emissions (kg)/HH & ** & 737 & 804 & ** & 270 & 271 & ** & 141 & 216 \\
\hline 0 Workers & ** & 397 & 394 & ** & 104 & 112 & ** & 67 & 135 \\
\hline 1 Workers & ** & 648 & 751 & ** & 235 & 272 & ** & 134 & 193 \\
\hline 2 Workers & ** & 892 & 1,373 & ** & 331 & 350 & ** & 162 & 289 \\
\hline 3 or more Workers & ** & 1,572 & 1,421 & ** & 575 & 622 & ** & 281 & 486 \\
\hline Average CO2 Emissions (kg)/HH & ** & 737 & 804 & ** & 270 & 271 & ** & 141 & 216 \\
\hline 0 Drivers & ** & 578 & 319 & ** & 354 & 102 & ** & 238 & 242 \\
\hline 1 Drivers & ** & 700 & 597 & ** & 160 & 164 & ** & 97 & 136 \\
\hline 2 Drivers & ** & 861 & 1,025 & ** & 264 & 280 & ** & 138 & 224 \\
\hline 3 or more Drivers & ** & 1,153 & 1,875 & $* *$ & 522 & 537 & ** & 223 & 377 \\
\hline Average CO2 Emissions (kg)/HH & ** & 737 & 804 & ** & 270 & 271 & ** & 141 & 216 \\
\hline 0 Vehicles & ** & 862 & 927 & ** & 374 & 644 & ** & 356 & 539 \\
\hline 1 Vehicles & ** & 608 & 678 & ** & 231 & 107 & ** & 124 & 186 \\
\hline 2 Vehicles & ** & 553 & 573 & $\star *$ & 248 & 301 & ** & 111 & 180 \\
\hline 3 or more Vehicles & ** & 720 & 747 & ** & 337 & 316 & ** & 150 & 212 \\
\hline Average CO2 Emissions (kg)/HH & ** & 737 & 804 & ** & 270 & 271 & ** & 141 & 216 \\
\hline 0-99 persons/sq mi. & ** & 820 & 121 & ** & 125 & 272 & ** & 105 & 211 \\
\hline 100-499 persons/sq mi. & ** & 844 & & ** & 206 & 209 & ** & 107 & 138 \\
\hline 500-999 persons/sq mi. & ** & & & ** & 227 & 298 & ** & 110 & 197 \\
\hline 1000-1999 persons/sq mi. & ** & 59 & 263 & ** & 204 & 200 & ** & 112 & 152 \\
\hline 2000-3999 persons/sq mi. & ** & 1,287 & 329 & ** & 354 & 174 & ** & 106 & 164 \\
\hline 4000-9999 persons/sq mi. & ** & 755 & 592 & ** & 354 & 258 & ** & 135 & 222 \\
\hline 10000-24999 persons/sq mi. & ** & 637 & 824 & ** & 250 & 523 & ** & 332 & 420 \\
\hline 25000-999999 persons/sq mi. & $* *$ & 749 & 813 & ** & 387 & 1,257 & ** & 474 & 806 \\
\hline
\end{tabular}


Chapter 3: Table 11

Influence of NY State Metropolitan Data on Overall NY Travel Patterns

\begin{tabular}{|c|c|c|c|c|c|c|c|c|c|}
\hline & \multicolumn{3}{|c|}{ New York City } & \multicolumn{3}{|c|}{ Remainder NY State } & \multicolumn{3}{|c|}{ Remainder of U.S. } \\
\hline & 1995 & 2001 & 2009 & 1995 & 2001 & 2009 & 1995 & 2001 & 2009 \\
\hline \multicolumn{10}{|c|}{ Annual CO2 Emissions per Household - ALL MODES } \\
\hline Average $\mathrm{CO} 2$ Emissions (kg)/HH & ** & 3,603 & 3,070 & ** & 8,779 & 8,045 & ** & 9,247 & 9,201 \\
\hline 0 Workers & ** & 1,681 & 1,347 & ** & 3,700 & 3,886 & ** & 4,128 & 4,599 \\
\hline 1 Workers & ** & 2,841 & 2,790 & ** & 7,378 & 7,375 & ** & 7,608 & 8,537 \\
\hline 2 Workers & ** & 4,654 & 5,267 & ** & 12,156 & 11,592 & ** & 12,298 & 13,336 \\
\hline 3 or more Workers & ** & 9,388 & 7,475 & ** & 14,650 & 16,027 & ** & 17,137 & 19,073 \\
\hline Average CO2 Emissions $(\mathrm{kg}) / \mathrm{HH}$ & ** & 3,603 & 3,070 & ** & 8,779 & 8,045 & ** & 9,247 & 9,201 \\
\hline 0 Drivers & ** & 578 & 319 & ** & 354 & 102 & ** & 238 & 242 \\
\hline 1 Drivers & ** & 3,049 & 1,821 & ** & 4,600 & 4,102 & ** & 4,774 & 4,872 \\
\hline 2 Drivers & ** & 5,697 & 4,738 & ** & 10,721 & 9,589 & ** & 10,947 & 10,934 \\
\hline 3 or more Drivers & ** & 11,293 & 8,071 & ** & 14,966 & 14,652 & ** & 16,261 & 16,882 \\
\hline Average CO2 Emissions (kg)/HH & ** & 3,603 & 3,070 & ** & 8,779 & 8,045 & ** & 9,247 & 9,201 \\
\hline 0 Vehicles & ** & 862 & 927 & ** & 374 & 644 & ** & 356 & 539 \\
\hline 1 Vehicles & ** & 4,896 & 4,214 & ** & 4,548 & 4,016 & ** & 4,344 & 4,356 \\
\hline 2 Vehicles & ** & 8,235 & 7,789 & ** & 10,754 & 9,584 & ** & 10,275 & 10,125 \\
\hline 3 or more Vehicles & ** & 17,707 & 12,569 & ** & 15,364 & 15,588 & ** & 16,324 & 17,132 \\
\hline Average CO2 Emissions (kg)/HH & ** & 3,603 & 3,070 & ** & 8,779 & 8,045 & ** & 9,247 & 9,201 \\
\hline 0-99 persons/sq mi. & ** & 5,417 & 121 & ** & 10,922 & 10,561 & ** & 12,052 & 13,063 \\
\hline 100-499 persons/sq mi. & ** & 4,728 & & ** & 10,937 & 9,753 & ** & 11,241 & 11,295 \\
\hline 500-999 persons/sq mi. & ** & & 8,304 & ** & 11,150 & 9,400 & ** & 10,064 & 9,766 \\
\hline 1000-1999 persons/sq mi. & ** & 7,358 & 1,545 & ** & 9,774 & 8,244 & ** & 9,619 & 9,237 \\
\hline 2000-3999 persons/sq mi. & ** & 7,370 & 7,144 & ** & 8,245 & 7,721 & ** & 8,646 & 8,542 \\
\hline 4000-9999 persons/sq mi. & ** & 6,184 & 5,428 & ** & 7,600 & 6,726 & ** & 7,931 & 7,688 \\
\hline $10000-24999$ persons/sq mi. & ** & 7,351 & 5,589 & ** & 5,085 & 5,416 & ** & 6,691 & 6,609 \\
\hline 25000-999999 persons/sq mi. & ** & 3,041 & 2,615 & ** & 2,954 & 5,249 & ** & 4,908 & 4,614 \\
\hline
\end{tabular}


Chapter 3: Table 12

Influence of NY State Metropolitan Data on Overall NY Travel Patterns

\begin{tabular}{|c|c|c|c|c|c|c|c|c|c|}
\hline & \multicolumn{3}{|c|}{ New York City } & \multicolumn{3}{|c|}{ Remainder NY State } & \multicolumn{3}{|c|}{ Remainder of U.S. } \\
\hline & 1995 & 2001 & 2009 & 1995 & 2001 & 2009 & 1995 & 2001 & 2009 \\
\hline \multicolumn{10}{|c|}{ Percent Vehicles by Vehicle Type and Age } \\
\hline Auto & $87.4 \%$ & $75.7 \%$ & $64.7 \%$ & $72.3 \%$ & $63.2 \%$ & $56.2 \%$ & $64.7 \%$ & $56.4 \%$ & $49.7 \%$ \\
\hline 0 to 2 yrs & $10.5 \%$ & $11.4 \%$ & $11.0 \%$ & $11.2 \%$ & $10.8 \%$ & $8.6 \%$ & $9.4 \%$ & $7.7 \%$ & $5.8 \%$ \\
\hline 3 to 5 yrs & $11.8 \%$ & $13.9 \%$ & $11.2 \%$ & $16.2 \%$ & $13.6 \%$ & $12.2 \%$ & $13.7 \%$ & $11.5 \%$ & $9.4 \%$ \\
\hline 6 to 9 yrs & $33.9 \%$ & $17.1 \%$ & $16.5 \%$ & $23.5 \%$ & $16.4 \%$ & $16.2 \%$ & $18.9 \%$ & $14.1 \%$ & $12.9 \%$ \\
\hline 10 yrs or more & $27.1 \%$ & $29.4 \%$ & $22.6 \%$ & $19.7 \%$ & $20.8 \%$ & $17.4 \%$ & $21.0 \%$ & $21.4 \%$ & $19.8 \%$ \\
\hline Unreported & $4.2 \%$ & $3.8 \%$ & $3.4 \%$ & $1.8 \%$ & $1.6 \%$ & $1.7 \%$ & $1.7 \%$ & $1.7 \%$ & $1.7 \%$ \\
\hline Van & $5.6 \%$ & $9.3 \%$ & $9.9 \%$ & $7.8 \%$ & $10.1 \%$ & $8.9 \%$ & $8.0 \%$ & $9.0 \%$ & $8.2 \%$ \\
\hline 0 to 2 yrs & $0.9 \%$ & $1.5 \%$ & $1.6 \%$ & $2.3 \%$ & $1.9 \%$ & $1.0 \%$ & $1.7 \%$ & $1.5 \%$ & $0.7 \%$ \\
\hline 3 to 5 yrs & $1.2 \%$ & $1.6 \%$ & $1.3 \%$ & $1.7 \%$ & $2.7 \%$ & $2.1 \%$ & $2.1 \%$ & $2.1 \%$ & $1.8 \%$ \\
\hline 6 to 9 yrs & $1.8 \%$ & $2.4 \%$ & $1.1 \%$ & $2.4 \%$ & $2.9 \%$ & $2.8 \%$ & $2.2 \%$ & $2.5 \%$ & $2.5 \%$ \\
\hline 10 yrs or more & $1.3 \%$ & $3.2 \%$ & $5.1 \%$ & $1.3 \%$ & $2.4 \%$ & $2.7 \%$ & $1.8 \%$ & $2.6 \%$ & $3.0 \%$ \\
\hline Unreported & $0.4 \%$ & $0.6 \%$ & $0.9 \%$ & $0.2 \%$ & $0.3 \%$ & $0.3 \%$ & $0.2 \%$ & $0.4 \%$ & $0.3 \%$ \\
\hline suv & $5.3 \%$ & $12.4 \%$ & $22.6 \%$ & $7.3 \%$ & $11.9 \%$ & $21.1 \%$ & $7.0 \%$ & $12.1 \%$ & $19.4 \%$ \\
\hline 0 to 2 yrs & $1.4 \%$ & $4.3 \%$ & $5.0 \%$ & $2.0 \%$ & $3.5 \%$ & $5.3 \%$ & $1.9 \%$ & $3.1 \%$ & $3.3 \%$ \\
\hline 3 to $5 \mathrm{yrs}$ & $1.4 \%$ & $2.8 \%$ & $6.5 \%$ & $1.7 \%$ & $3.8 \%$ & $6.5 \%$ & $1.7 \%$ & $3.5 \%$ & $5.5 \%$ \\
\hline 6 to 9 yrs & $1.7 \%$ & $2.1 \%$ & $5.7 \%$ & $2.0 \%$ & $2.5 \%$ & $5.2 \%$ & $1.7 \%$ & $2.6 \%$ & $5.3 \%$ \\
\hline 10 yrs or more & $0.7 \%$ & $2.5 \%$ & $4.2 \%$ & $1.4 \%$ & $1.9 \%$ & $3.6 \%$ & $1.6 \%$ & $2.6 \%$ & $4.7 \%$ \\
\hline Unreported & & $0.6 \%$ & $1.1 \%$ & $0.2 \%$ & $0.3 \%$ & $0.5 \%$ & $0.2 \%$ & $0.3 \%$ & $0.5 \%$ \\
\hline Pickup Truck & $1.2 \%$ & $1.0 \%$ & $1.2 \%$ & $10.8 \%$ & $11.6 \%$ & $10.6 \%$ & $18.3 \%$ & $19.0 \%$ & $18.3 \%$ \\
\hline 0 to 2 yrs & $0.0 \%$ & $0.3 \%$ & $0.1 \%$ & $1.5 \%$ & $1.7 \%$ & $1.2 \%$ & $2.6 \%$ & $2.9 \%$ & $1.6 \%$ \\
\hline 3 to 5 yrs & $0.1 \%$ & $0.1 \%$ & $0.2 \%$ & $2.0 \%$ & $2.7 \%$ & $2.3 \%$ & $3.3 \%$ & $3.6 \%$ & $3.1 \%$ \\
\hline 6 to $9 \mathrm{yrs}$ & $0.4 \%$ & $0.1 \%$ & $0.4 \%$ & $3.5 \%$ & $2.5 \%$ & $3.0 \%$ & $4.4 \%$ & $3.9 \%$ & $4.2 \%$ \\
\hline 10 yrs or more & $0.6 \%$ & $0.5 \%$ & $0.5 \%$ & $3.6 \%$ & $4.4 \%$ & $3.7 \%$ & $7.4 \%$ & $8.0 \%$ & $8.6 \%$ \\
\hline Unreported & $0.1 \%$ & $0.0 \%$ & $0.0 \%$ & $0.3 \%$ & $0.3 \%$ & $0.4 \%$ & $0.6 \%$ & $0.7 \%$ & $0.8 \%$ \\
\hline Other POV & $0.5 \%$ & $1.7 \%$ & $1.7 \%$ & $1.7 \%$ & $3.1 \%$ & $3.2 \%$ & $2.0 \%$ & $3.5 \%$ & $4.3 \%$ \\
\hline 0 to 2 yrs & $0.1 \%$ & $0.2 \%$ & $0.2 \%$ & $0.1 \%$ & $0.4 \%$ & $0.4 \%$ & $0.1 \%$ & $0.5 \%$ & $0.6 \%$ \\
\hline 3 to 5 yrs & $0.0 \%$ & $0.1 \%$ & $0.1 \%$ & $0.2 \%$ & $0.4 \%$ & $0.7 \%$ & $0.2 \%$ & $0.5 \%$ & $0.8 \%$ \\
\hline 6 to $9 \mathrm{yrs}$ & $0.1 \%$ & $0.1 \%$ & $0.5 \%$ & $0.3 \%$ & $0.4 \%$ & $0.7 \%$ & $0.4 \%$ & $0.5 \%$ & $0.8 \%$ \\
\hline 10 yrs or more & $0.1 \%$ & $0.9 \%$ & $0.8 \%$ & $0.9 \%$ & $1.6 \%$ & $1.2 \%$ & $1.2 \%$ & $1.7 \%$ & $1.8 \%$ \\
\hline Unreported & $0.3 \%$ & $0.4 \%$ & $0.0 \%$ & $0.1 \%$ & $0.2 \%$ & $0.3 \%$ & $0.1 \%$ & $0.3 \%$ & $0.4 \%$ \\
\hline
\end{tabular}


Chapter 3: Table 13

Influence of NY State Metropolitan Data on Overall NY Travel Patterns

\begin{tabular}{|c|c|c|c|c|c|c|c|c|c|}
\hline & \multicolumn{3}{|c|}{ New York City } & \multicolumn{3}{|c|}{ Remainder NY State } & \multicolumn{3}{|c|}{ Remainder of U.S. } \\
\hline & 1995 & 2001 & 2009 & 1995 & 2001 & 2009 & 1995 & 2001 & 2009 \\
\hline \multicolumn{10}{|c|}{ VMT/Vehicle by Vehicle Type and Age } \\
\hline ALL VEHICLES & 12,281 & 11,446 & 9,460 & 12,982 & 12,338 & 11,033 & 12,268 & 12,019 & 11,314 \\
\hline 0 to 2 yrs & 13,182 & 12,583 & 10,500 & 15,314 & 13,712 & 12,977 & 16,225 & 14,701 & 14,216 \\
\hline 3 to 5 yrs & 11,965 & 13,799 & 9,871 & 13,445 & 13,796 & 11,981 & 14,076 & 14,191 & 12,735 \\
\hline 6 to $9 \mathrm{yrs}$ & 12,014 & 12,177 & 10,348 & 12,786 & 12,722 & 11,040 & 12,665 & 12,512 & 11,754 \\
\hline 10 yrs or more & 11,591 & 9,178 & 7,876 & 11,221 & 10,080 & 9,173 & 8,748 & 9,360 & 9,319 \\
\hline Unreported & 17,519 & 11,854 & 10,228 & 14,300 & 12,443 & 10,423 & 11,975 & 10,925 & 11,143 \\
\hline Auto & 11,851 & 11,003 & 9,529 & 12,802 & 12,220 & 10,665 & 12,038 & 11,596 & 11,154 \\
\hline 0 to 2 yrs & 12,685 & 11,992 & 10,065 & 15,047 & 13,471 & 12,522 & 15,524 & 14,054 & 14,230 \\
\hline 3 to $5 \mathrm{yrs}$ & 11,287 & 14,235 & 8,898 & 12,841 & 13,681 & 11,471 & 13,652 & 13,471 & 12,465 \\
\hline 6 to 9 yrs & 11,809 & 11,264 & 10,836 & 12,693 & 12,183 & 10,588 & 12,387 & 12,028 & 11,336 \\
\hline 10 yrs or more & 11,079 & 8,861 & 8,383 & 11,415 & 10,610 & 9,282 & 8,928 & 9,433 & 9,477 \\
\hline Unreported & 17,117 & 11,407 & 11,254 & 15,074 & 12,448 & 10,153 & 11,369 & 11,292 & 11,425 \\
\hline Van & 13,754 & 14,728 & 7,991 & 15,486 & 13,307 & 12,237 & 14,278 & 13,400 & 12,587 \\
\hline 0 to 2 yrs & 16,147 & 19,632 & 8,130 & 16,118 & 14,270 & 15,848 & 17,759 & 15,862 & 15,495 \\
\hline 3 to $5 \mathrm{yrs}$ & 16,790 & 12,969 & 11,890 & 16,647 & 14,863 & 13,365 & 15,129 & 15,526 & 14,105 \\
\hline 6 to 9 yrs & 11,453 & 14,718 & 10,315 & 14,660 & 13,292 & 12,389 & 13,313 & 13,597 & 13,389 \\
\hline 10 yrs or more & 13,181 & 12,594 & 6,385 & 14,606 & 10,086 & 9,737 & 10,685 & 10,274 & 10,119 \\
\hline Unreported & 10,471 & 18,233 & 8,453 & 13,897 & 19,268 & 13,635 & 17,465 & 11,547 & 14,513 \\
\hline suv & 14,430 & 13,108 & 10,475 & 14,059 & 13,972 & 12,552 & 13,905 & 13,877 & 12,825 \\
\hline 0 to 2 yrs & 15,654 & 11,628 & 12,190 & 15,640 & 13,982 & 13,505 & 16,232 & 14,968 & 15,038 \\
\hline 3 to $5 \mathrm{yrs}$ & 12,665 & 12,296 & 11,150 & 14,654 & 14,753 & 12,992 & 14,567 & 15,235 & 13,672 \\
\hline 6 to $9 \mathrm{yrs}$ & 14,108 & 17,161 & 9,786 & 13,367 & 15,062 & 12,329 & 14,806 & 14,308 & 12,860 \\
\hline 10 yrs or more & 16,341 & 12,325 & 8,577 & 11,803 & 11,217 & 10,829 & 9,391 & 10,687 & 10,184 \\
\hline Unreported & & 15,521 & 9,457 & 16,292 & 11,579 & 11,770 & 16,851 & 11,117 & 13,167 \\
\hline Pickup Truck & 23,811 & 9,597 & 9,467 & 12,786 & 12,291 & 11,242 & 12,078 & 12,465 & 11,329 \\
\hline 0 to $2 \mathrm{yrs}$ & 7,307 & 16,542 & 22,178 & 15,709 & 15,564 & 14,145 & 17,640 & 16,552 & 15,068 \\
\hline 3 to 5 yrs & 32,249 & 6,833 & 12,504 & 15,312 & 13,240 & 12,917 & 15,001 & 15,420 & 13,233 \\
\hline 6 to $9 \mathrm{yrs}$ & 24,383 & 6,792 & 8,505 & 12,169 & 14,660 & 11,884 & 12,862 & 12,888 & 12,016 \\
\hline 10 yrs or more & 25,434 & 7,071 & 7,422 & 10,688 & 9,330 & 8,742 & 8,348 & 9,536 & 9,544 \\
\hline Unreported & 7,722 & 11,516 & 6,107 & 13,446 & 9,044 & 11,121 & 11,984 & 11,879 & 11,759 \\
\hline Other POV & 19,874 & 1,182 & 1,270 & 5,110 & 3,626 & 2,885 & 7,626 & 5,094 & 3,459 \\
\hline 0 to 2 yrs & 1,714 & 1,944 & 3,665 & 14,622 & 5,379 & 4,765 & 18,632 & 7,612 & 5,078 \\
\hline 3 to $5 \mathrm{yrs}$ & 6,000 & 2,500 & 1,777 & 5,407 & 4,238 & 3,144 & 12,882 & 8,478 & 4,077 \\
\hline 6 to $9 \mathrm{yrs}$ & 4,751 & 6,000 & 1,386 & 7,507 & 3,717 & 2,809 & 10,827 & 7,350 & 4,198 \\
\hline 10 yrs or more & 3,811 & 1,042 & 479 & 3,197 & 2,406 & 2,060 & 4,726 & 3,101 & 2,470 \\
\hline Unreported & 35,246 & 632 & 171 & 3,218 & 9,504 & 3,613 & 4,394 & 2,189 & 2,666 \\
\hline
\end{tabular}


Chapter 3: Table 14

Influence of NY State Metropolitan Data on Overall NY Travel Patterns

\begin{tabular}{|c|c|c|c|c|c|c|c|c|c|}
\hline & \multicolumn{3}{|c|}{ New York City } & \multicolumn{3}{|c|}{ Remainder NY State } & \multicolumn{3}{|c|}{ Remainder of U.S. } \\
\hline & 1995 & 2001 & 2009 & 1995 & 2001 & 2009 & 1995 & 2001 & 2009 \\
\hline \multicolumn{10}{|c|}{ Percent Not Taking Walk Trips in the last week } \\
\hline TOTAL & * & $15.5 \%$ & $16.8 \%$ & * & $29.9 \%$ & $33.4 \%$ & * & $35.5 \%$ & $32.8 \%$ \\
\hline 5 to 10 year-olds & * & * & $18.6 \%$ & * & * & $27.2 \%$ & * & * & $24.3 \%$ \\
\hline 11 to 15 year-olds & * & * & $11.5 \%$ & * & * & $24.6 \%$ & * & * & $24.0 \%$ \\
\hline 16 to 20 year-olds & * & $13.2 \%$ & $21.2 \%$ & * & $28.7 \%$ & $27.3 \%$ & * & $34.9 \%$ & $32.1 \%$ \\
\hline 21 to 35 year-olds & * & $11.6 \%$ & $12.5 \%$ & * & $29.8 \%$ & $36.6 \%$ & * & $34.8 \%$ & $31.1 \%$ \\
\hline 36 to 64 year-olds & * & $16.1 \%$ & $15.9 \%$ & * & $27.9 \%$ & $31.4 \%$ & * & $34.0 \%$ & $33.0 \%$ \\
\hline $65+$ year-olds & * & $23.8 \%$ & $26.2 \%$ & * & $36.1 \%$ & $46.6 \%$ & * & $41.3 \%$ & $45.2 \%$ \\
\hline \multicolumn{10}{|c|}{ Avg Minutes Spent Walking per Day } \\
\hline TOTAL & 11.2 & 16.11 & 20.35 & 1.88 & 5.61 & 5.51 & 2.08 & 4.71 & 5.47 \\
\hline 5 to 10 year-olds & 11.13 & 14.79 & 14.49 & 1.86 & 4.13 & 3.71 & 2.50 & 4.89 & 3.89 \\
\hline 11 to 15 year-olds & 15.59 & 13.18 & 14.10 & 3.17 & 8.58 & 5.33 & 4.32 & 6.18 & 7.43 \\
\hline 16 to 20 year-olds & 9.98 & 14.14 & 17.68 & 2.85 & 6.47 & 4.72 & 2.71 & 4.35 & 5.19 \\
\hline 21 to 35 year-olds & 11.97 & 19.24 & 23.79 & 1.39 & 5.02 & 5.85 & 1.91 & 4.42 & 5.66 \\
\hline 36 to 64 year-olds & 9.94 & 15.91 & 22.38 & 1.61 & 6.01 & 6.35 & 1.51 & 4.44 & 5.82 \\
\hline $65+$ year-olds & 11.11 & 14.17 & 16.62 & 2.31 & 4.44 & 4.03 & 1.98 & 4.79 & 4.10 \\
\hline \multicolumn{10}{|c|}{ Percent Not Taking Bike Trips in the last week } \\
\hline TOTAL & * & $94.4 \%$ & $93.4 \%$ & * & $92.2 \%$ & $88.9 \%$ & * & $92.6 \%$ & $87.2 \%$ \\
\hline 5 to 10 year-olds & * & * & $79.7 \%$ & * & * & $58.6 \%$ & * & * & $50.3 \%$ \\
\hline 11 to 15 year-olds & * & * & $92.7 \%$ & * & * & $70.0 \%$ & * & * & $68.6 \%$ \\
\hline 16 to 20 year-olds & * & $88.5 \%$ & $95.3 \%$ & * & $84.8 \%$ & $88.0 \%$ & * & $87.4 \%$ & $88.9 \%$ \\
\hline 21 to 35 year-olds & * & $92.8 \%$ & $89.7 \%$ & * & $91.5 \%$ & $92.7 \%$ & * & $91.2 \%$ & $91.7 \%$ \\
\hline 36 to 64 year-olds & * & $95.3 \%$ & $95.5 \%$ & * & $92.1 \%$ & $92.6 \%$ & * & $93.2 \%$ & $92.1 \%$ \\
\hline $65+$ year-olds & * & $99.0 \%$ & $98.2 \%$ & * & $96.4 \%$ & $98.0 \%$ & * & $96.3 \%$ & $97.0 \%$ \\
\hline \multicolumn{10}{|c|}{ Avg Minutes Spent Biking per Day } \\
\hline TOTAL & 0.33 & 0.65 & 0.38 & 0.31 & 0.64 & 0.61 & 0.43 & 0.79 & 0.78 \\
\hline 5 to 10 year-olds & 0.10 & 2.04 & 0.19 & 0.37 & 1.44 & 0.96 & 0.67 & 2.25 & 1.24 \\
\hline 11 to 15 year-olds & 0.21 & 2.92 & 0.02 & 1.47 & 2.60 & 1.47 & 1.34 & 2.05 & 1.59 \\
\hline 16 to 20 year-olds & 0.59 & 0.08 & 0.14 & 0.31 & 0.26 & 0.74 & 0.54 & 0.70 & 0.71 \\
\hline 21 to 35 year-olds & 0.54 & 0.54 & 0.42 & 0.29 & 0.37 & 0.73 & 0.39 & 0.44 & 0.59 \\
\hline 36 to 64 year-olds & 0.26 & 0.40 & 0.57 & 0.16 & 0.34 & 0.49 & 0.30 & 0.56 & 0.77 \\
\hline $65+$ year-olds & & 0.05 & 0.15 & 0.04 & 0.47 & 0.18 & 0.05 & 0.26 & 0.38 \\
\hline \multicolumn{10}{|c|}{ Avg Minutes Spent Walking/Biking per Day } \\
\hline TOTAL & 11.52 & 16.76 & 20.73 & 2.19 & 6.25 & 6.12 & 2.51 & 5.50 & 6.24 \\
\hline 5 to 10 year-olds & 11.23 & 16.83 & 14.68 & 2.22 & 5.57 & 4.67 & 3.16 & 7.15 & 5.13 \\
\hline 11 to 15 year-olds & 15.80 & 16.09 & 14.12 & 4.64 & 11.18 & 6.80 & 5.66 & 8.23 & 9.02 \\
\hline 16 to 20 year-olds & 10.57 & 14.22 & 17.82 & 3.16 & 6.72 & 5.46 & 3.24 & 5.05 & 5.90 \\
\hline 21 to 35 year-olds & 12.51 & 19.78 & 24.22 & 1.68 & 5.39 & 6.58 & 2.31 & 4.85 & 6.25 \\
\hline 36 to 64 year-olds & 10.20 & 16.31 & 22.95 & 1.76 & 6.35 & 6.84 & 1.81 & 5.00 & 6.59 \\
\hline $65+$ year-olds & 11.11 & 14.22 & 16.77 & 2.35 & 4.90 & 4.21 & 2.04 & 5.05 & 4.48 \\
\hline
\end{tabular}


APPENDIX C3A. SUPPLEMENTAL TABLES FOR CHAPTER 3 STANDARD ERRORS 
Chapter 3: Table 1

Influence of NY State Metropolitan Data on Overall NY Travel Patterns

STANDARD ERRORS

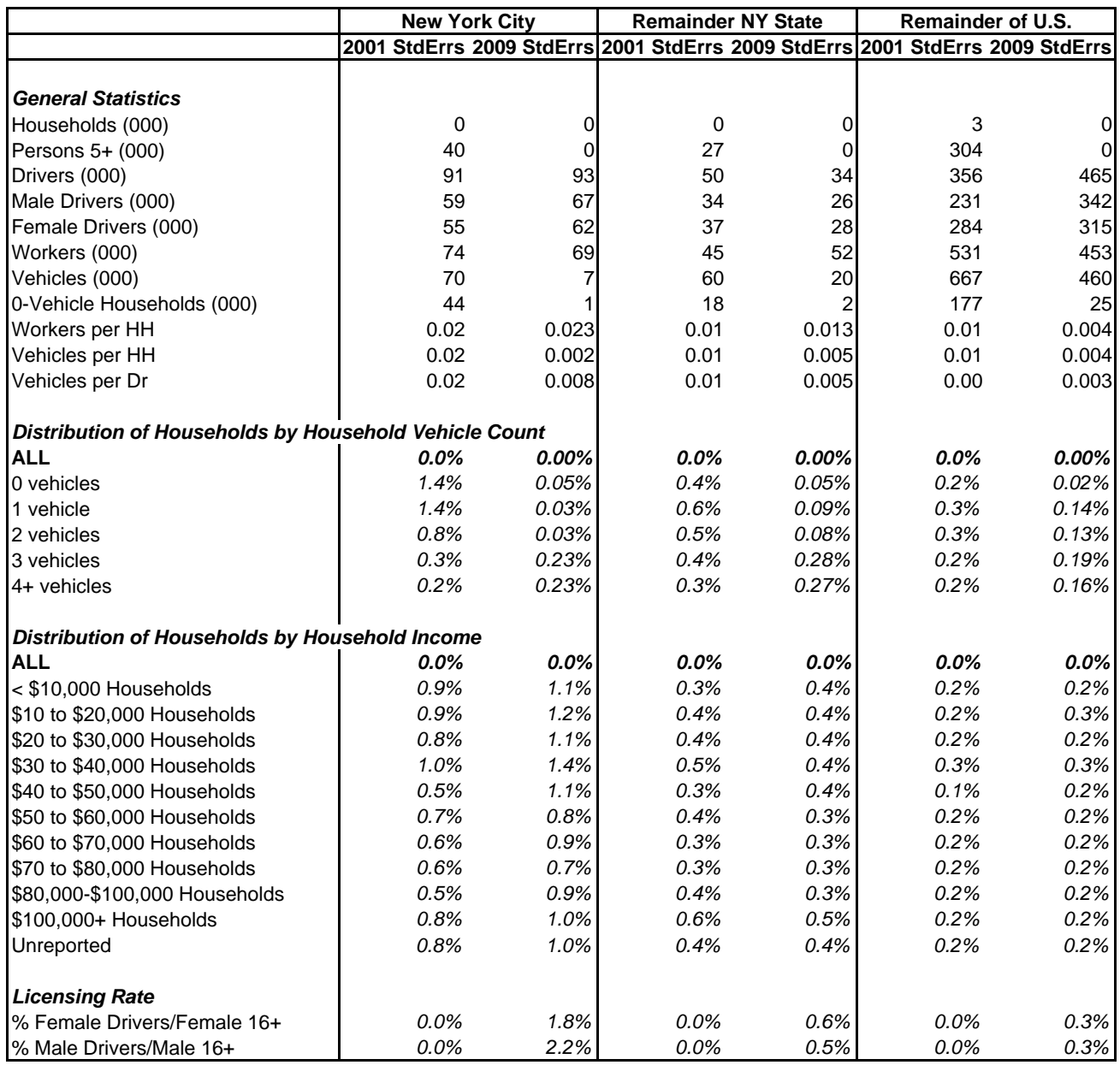


Chapter 3: Table 2

Influence of NY State Metropolitan Data on Overall NY Travel Patterns

STANDARD ERRORS

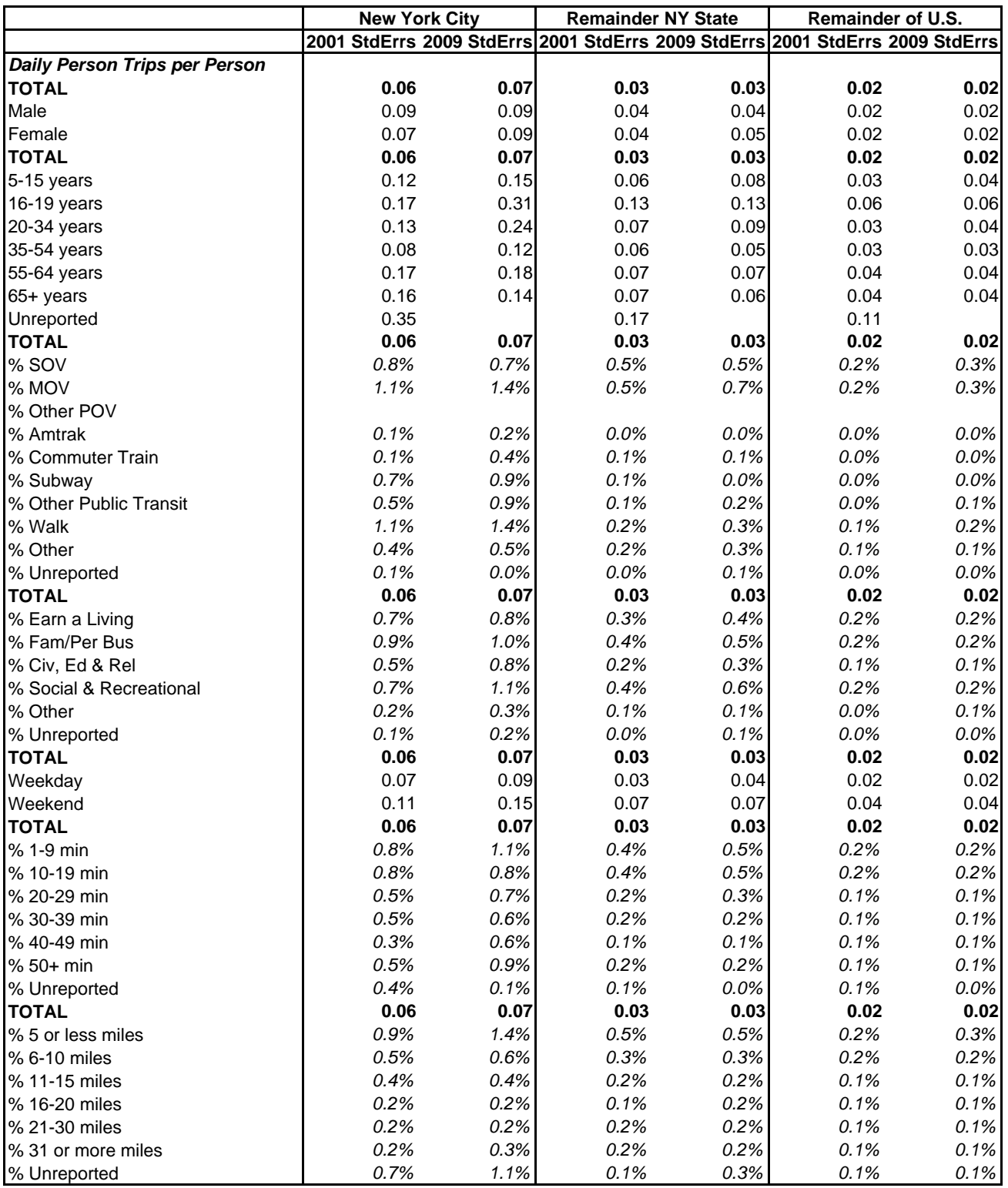


Chapter 3: Table 3

Influence of NY State Metropolitan Data on Overall NY Travel Patterns

STANDARD ERRORS

\begin{tabular}{|c|c|c|c|c|c|c|}
\hline & New Yo & & Remainde & State & Remainde & \\
\hline & 2001 StdErrs & tdErrs & 2001 StdErrs & StdErrs & 2001 StdErrs & tdErrs \\
\hline Daily PMT per Person & & & & & & \\
\hline TOTAL & 2.31 & 1.24 & 0.71 & 1.11 & 0.69 & 0.73 \\
\hline$\%$ sov & $2.5 \%$ & $1.9 \%$ & $1.0 \%$ & $1.3 \%$ & $0.6 \%$ & $0.9 \%$ \\
\hline$\%$ MOV & $3.8 \%$ & $4.9 \%$ & $1.2 \%$ & $1.6 \%$ & $0.7 \%$ & $0.9 \%$ \\
\hline$\%$ Other POV & & & & & & \\
\hline$\%$ Amtrak & $0.4 \%$ & $0.1 \%$ & $0.1 \%$ & $0.2 \%$ & $0.0 \%$ & $0.0 \%$ \\
\hline$\%$ Commuter Train & $0.2 \%$ & $0.8 \%$ & $0.2 \%$ & $0.2 \%$ & $0.0 \%$ & $0.1 \%$ \\
\hline$\%$ Subway & $1.9 \%$ & $1.8 \%$ & $0.1 \%$ & $0.1 \%$ & $0.0 \%$ & $0.0 \%$ \\
\hline$\%$ Other Public Transit & $0.9 \%$ & $1.6 \%$ & $0.1 \%$ & $0.1 \%$ & $0.0 \%$ & $0.0 \%$ \\
\hline$\%$ Walk & $0.4 \%$ & $0.7 \%$ & $0.1 \%$ & $0.0 \%$ & $0.0 \%$ & $0.0 \%$ \\
\hline$\%$ Other & $8.4 \%$ & $2.4 \%$ & $1.4 \%$ & $2.2 \%$ & $1.0 \%$ & $1.3 \%$ \\
\hline$\%$ Unreported & $0.9 \%$ & $0.0 \%$ & $0.3 \%$ & $0.1 \%$ & $0.4 \%$ & $0.0 \%$ \\
\hline TOTAL & 2.31 & 1.24 & 0.71 & 1.11 & 0.69 & 0.73 \\
\hline$\%$ Earn a Living & $7.2 \%$ & $3.7 \%$ & $0.8 \%$ & $1.0 \%$ & $0.7 \%$ & $0.6 \%$ \\
\hline$\%$ Fam/Per Bus & $2.9 \%$ & $2.8 \%$ & $0.8 \%$ & $1.0 \%$ & $0.6 \%$ & $0.6 \%$ \\
\hline$\%$ Civ, Ed \& Rel & $0.8 \%$ & $0.9 \%$ & $0.3 \%$ & $0.3 \%$ & $0.2 \%$ & $0.2 \%$ \\
\hline$\%$ Social \& Recreational & $4.1 \%$ & $5.1 \%$ & $1.2 \%$ & $1.3 \%$ & $0.6 \%$ & $0.7 \%$ \\
\hline$\%$ Other & $3.4 \%$ & $0.4 \%$ & $0.4 \%$ & $1.9 \%$ & $0.8 \%$ & $1.2 \%$ \\
\hline$\%$ Unreported & $2.6 \%$ & $0.9 \%$ & $0.1 \%$ & $1.2 \%$ & $0.1 \%$ & $0.5 \%$ \\
\hline Average Person Trip Length & & & & & & \\
\hline TOTAL & 0.76 & 0.41 & 0.19 & 0.30 & 0.17 & 0.19 \\
\hline
\end{tabular}


Chapter 3: Table 4

Influence of NY State Metropolitan Data on Overall NY Travel Patterns

STANDARD ERRORS

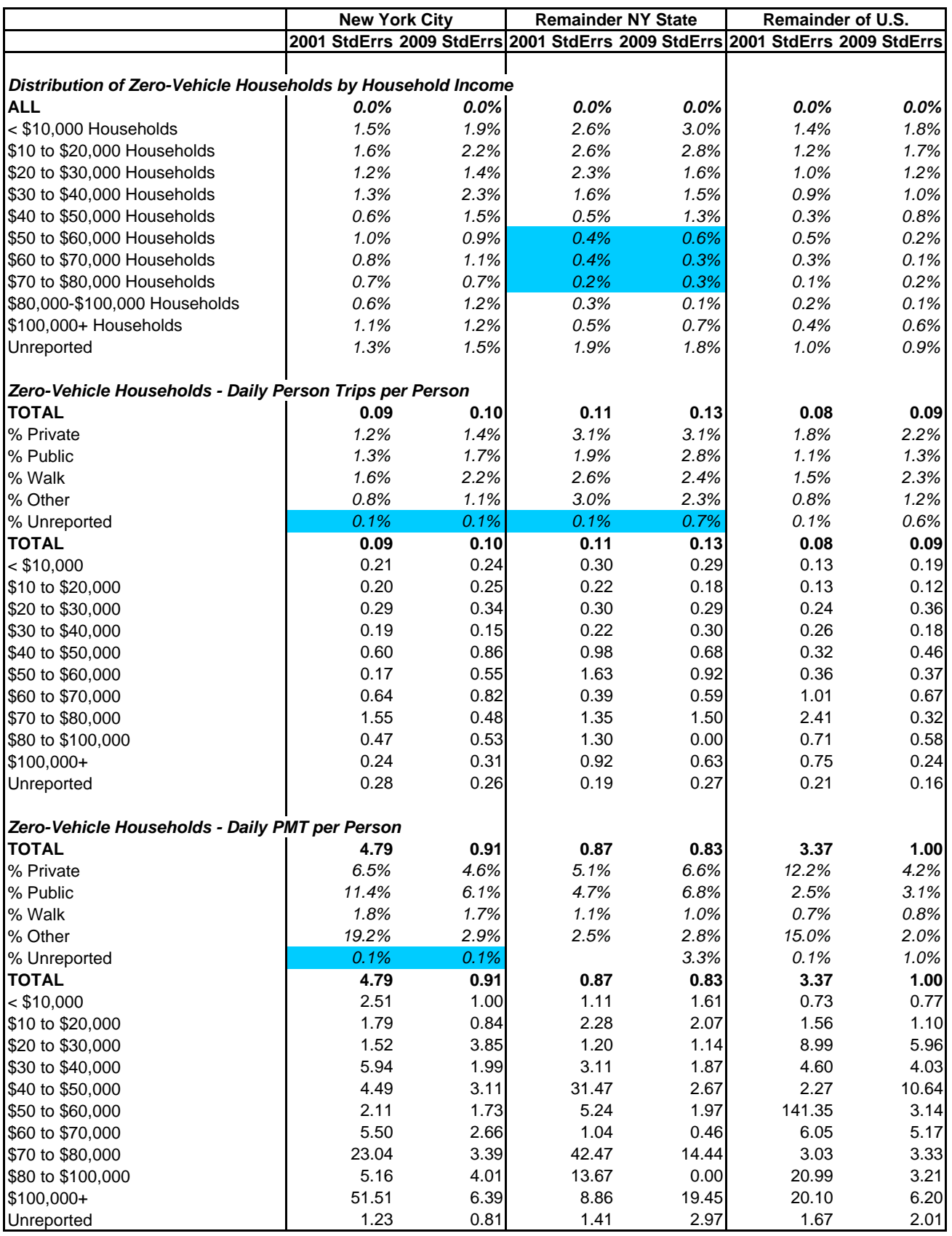


Chapter 3: Table 5

Influence of NY State Metropolitan Data on Overall NY Travel Patterns

STANDARD ERRORS

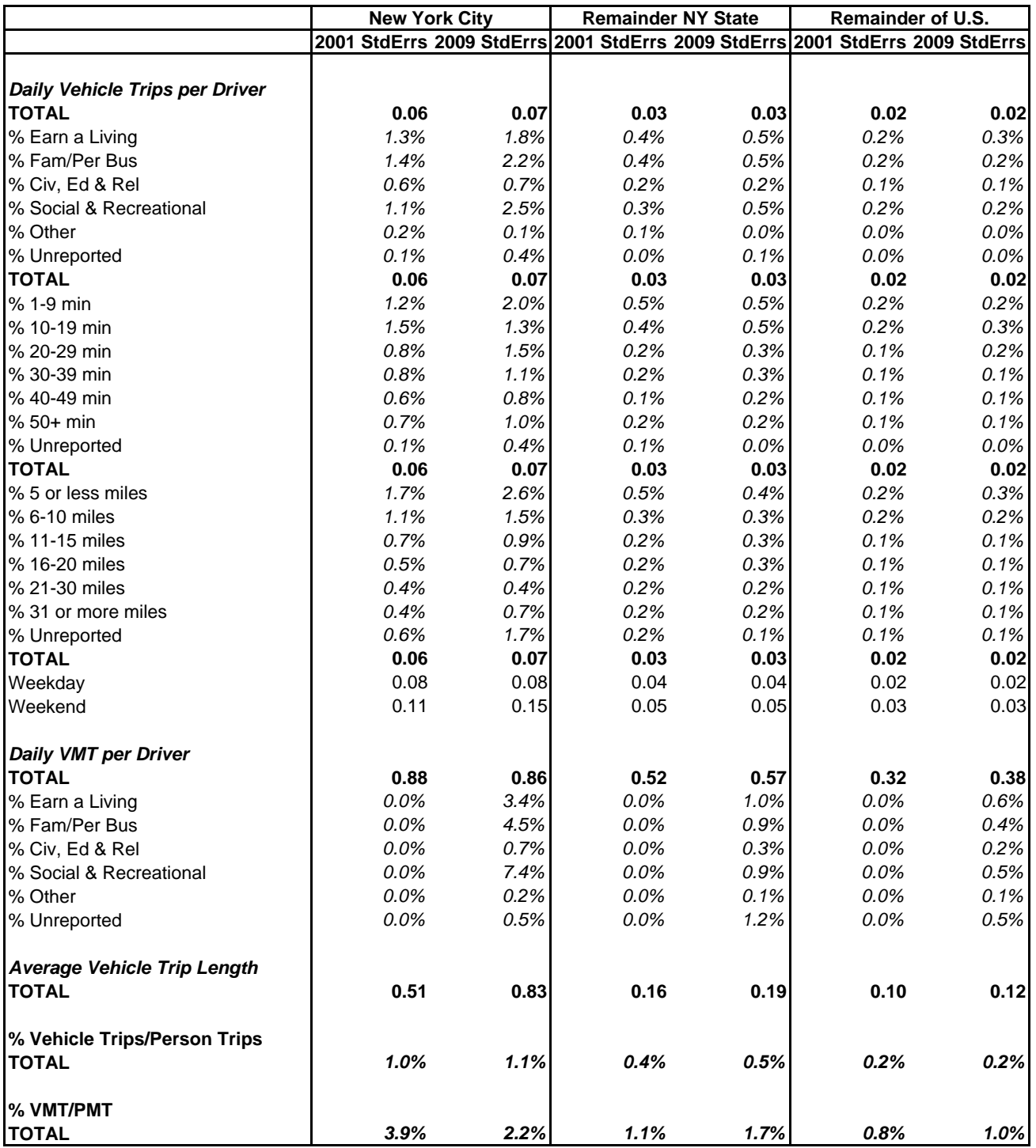


Chapter 3: Table 6

Influence of NY State Metropolitan Data on Overall NY Travel Patterns

STANDARD ERRORS

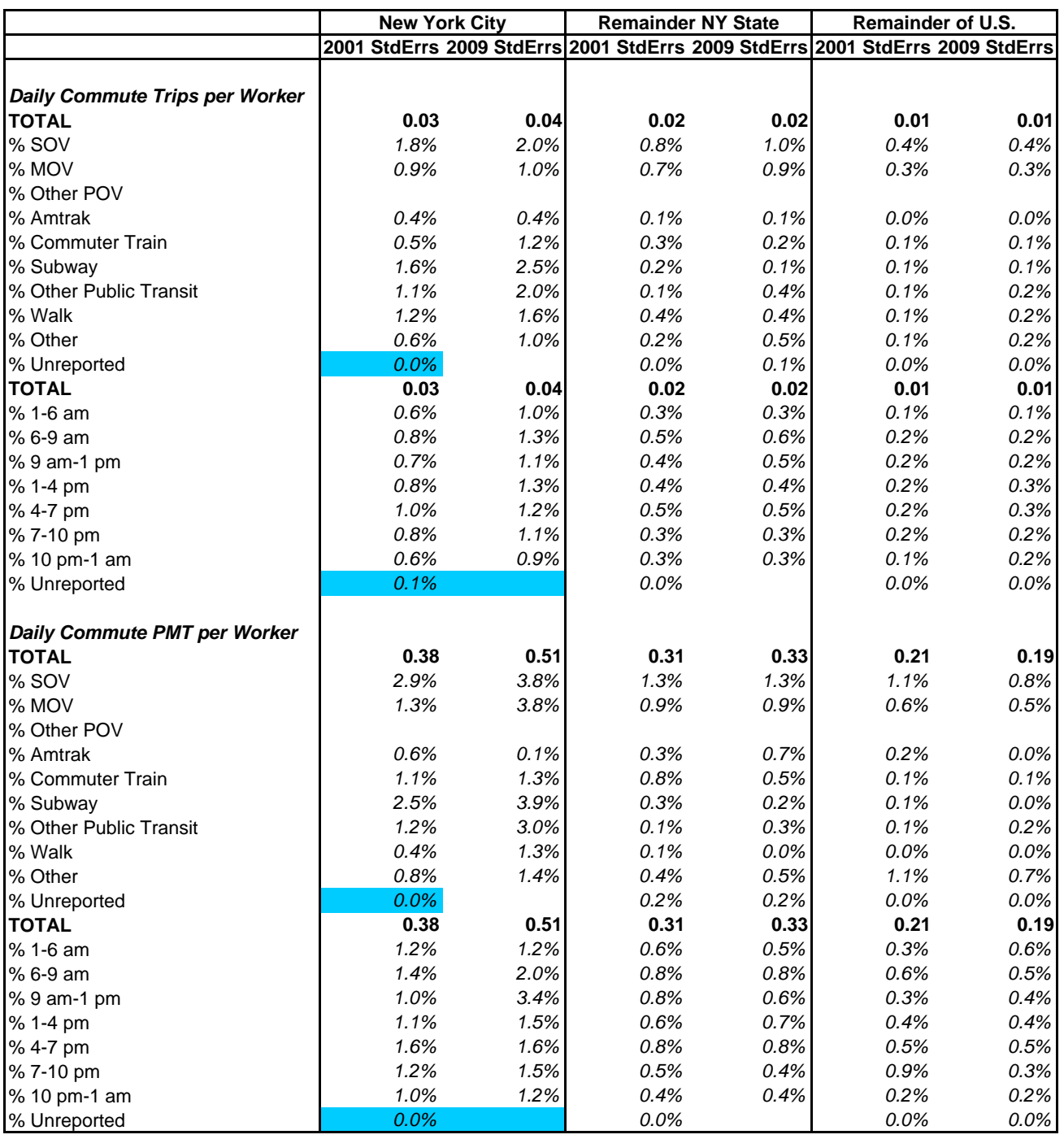


Chapter 3: Table 7

Influence of NY State Metropolitan Data on Overall NY Travel Patterns

STANDARD ERRORS

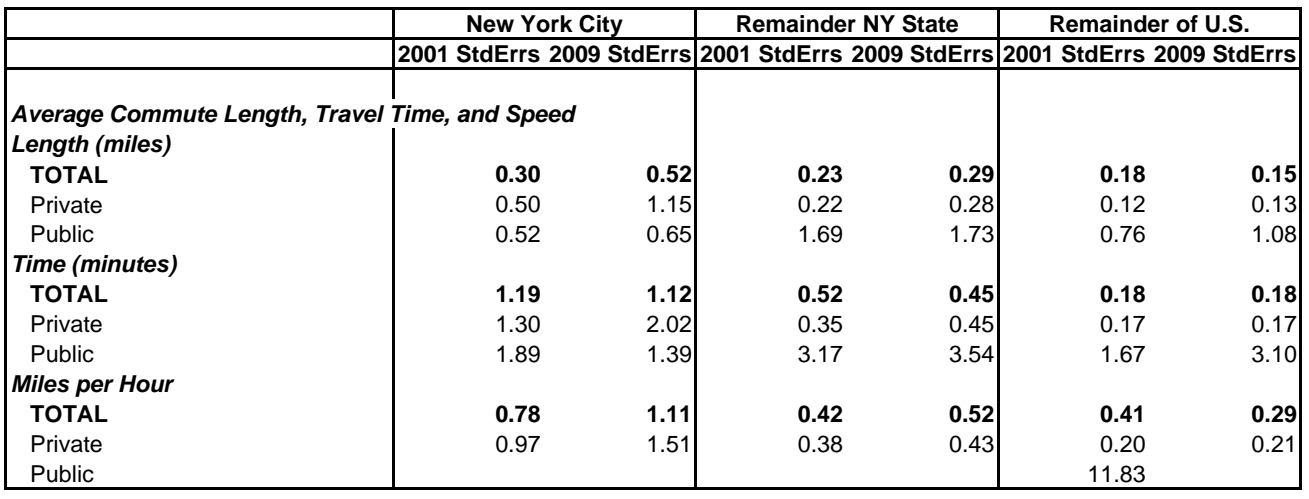

C -59 
Chapter 3: Table 8

Influence of NY State Metropolitan Data on Overall NY Travel Patterns

STANDARD ERRORS

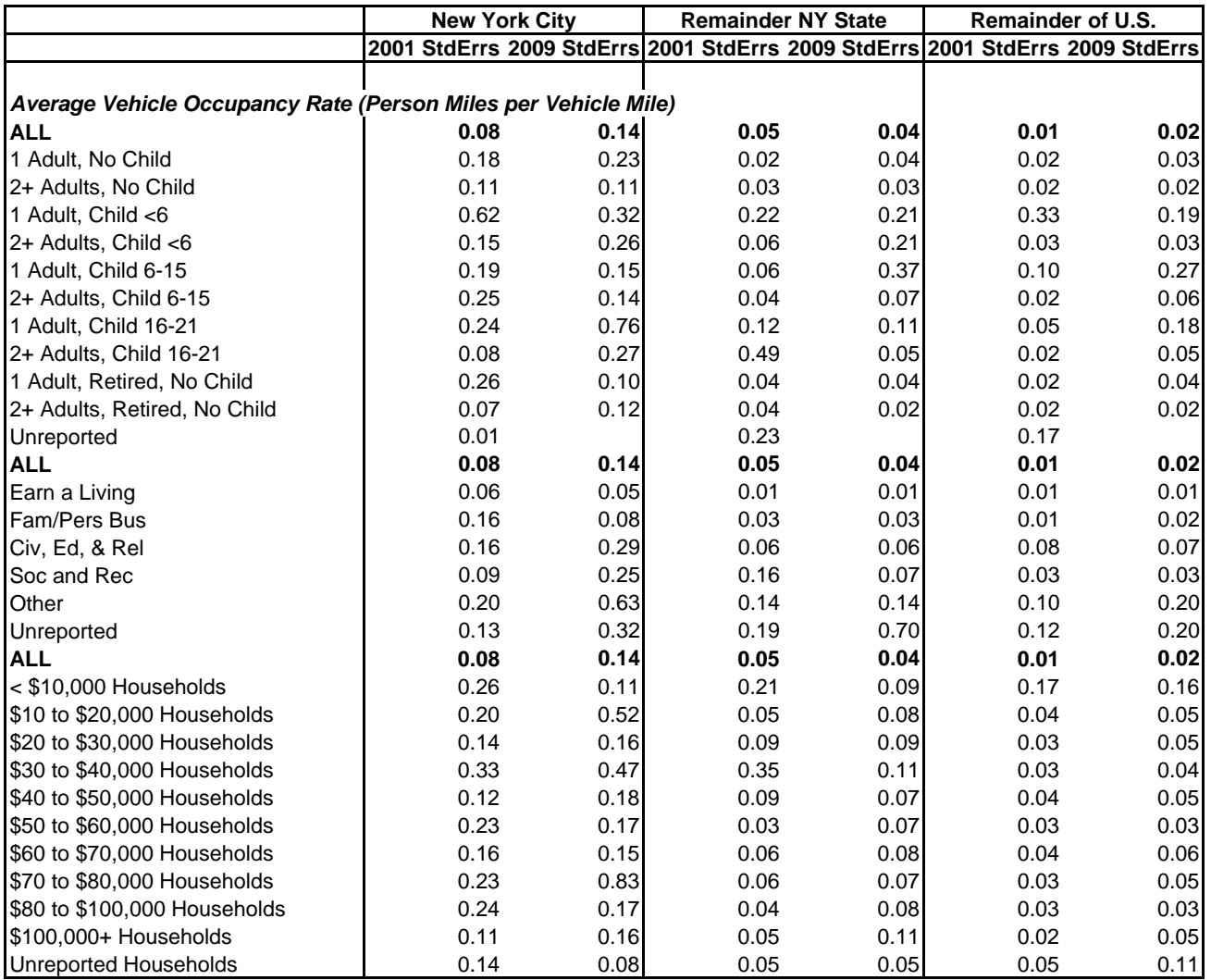




\begin{tabular}{|c|c|c|c|c|c|c|}
\hline & New Yo & & Remainde & tate & Remainde & \\
\hline & 2001 StdErrs & StdErrs & 2001 StdErrs & tdErrs & 2001 StdErrs & tdErrs \\
\hline Vehicles by Type & $0.0 \%$ & $0.0 \%$ & $0.0 \%$ & $0.0 \%$ & $0.0 \%$ & $0.0 \%$ \\
\hline Auto & $3.4 \%$ & $2.1 \%$ & $3.1 \%$ & $0.6 \%$ & $0.3 \%$ & $0.2 \%$ \\
\hline Van & $1.0 \%$ & $1.3 \%$ & $0.6 \%$ & $0.3 \%$ & $0.1 \%$ & $0.2 \%$ \\
\hline Sports Utility & $1.1 \%$ & $1.6 \%$ & $0.7 \%$ & $0.4 \%$ & $0.2 \%$ & $0.2 \%$ \\
\hline Pickup & $0.2 \%$ & $0.3 \%$ & $0.6 \%$ & $0.3 \%$ & $0.2 \%$ & $0.2 \%$ \\
\hline Other Truck & $0.3 \%$ & $0.0 \%$ & $0.0 \%$ & $0.0 \%$ & $0.0 \%$ & $0.0 \%$ \\
\hline RV & $0.0 \%$ & $0.0 \%$ & $0.1 \%$ & $0.1 \%$ & $0.0 \%$ & $0.0 \%$ \\
\hline Motorcycle & $0.3 \%$ & $0.4 \%$ & $0.2 \%$ & $0.2 \%$ & $0.1 \%$ & $0.1 \%$ \\
\hline Other POV & * & & * & & * & \\
\hline * Other POV not present in 2001 o & 009. & & & & & \\
\hline Age Statistics & & & & & & \\
\hline Average Vehicle Age & 0.23 & 0.27 & 0.07 & 0.07 & 0.05 & 0.05 \\
\hline Median Vehicle Age & 0 & 0 & 0 & 0 & 0 & 0 \\
\hline Percent VMT* & & & & & & \\
\hline Less than $10 \mathrm{yrs}$ & $2.4 \%$ & $2.1 \%$ & $0.7 \%$ & $0.7 \%$ & $1.7 \%$ & $0.4 \%$ \\
\hline 10 yrs or more & $2.4 \%$ & $2.1 \%$ & $0.7 \%$ & $0.7 \%$ & $1.7 \%$ & $0.4 \%$ \\
\hline Percent Vehicle Fleet & & & & & & \\
\hline Less than $10 \mathrm{yrs}$ & $1.6 \%$ & $2.2 \%$ & $0.5 \%$ & $0.5 \%$ & $0.3 \%$ & $0.3 \%$ \\
\hline 10 yrs or more & $1.6 \%$ & $2.2 \%$ & $0.5 \%$ & $0.5 \%$ & $0.3 \%$ & $0.3 \%$ \\
\hline Avg Fuel Consumption (gal/HH) & 30 & 8 & 31 & 9 & 17 & 6 \\
\hline Less than $10 \mathrm{yrs}$ & $4.5 \%$ & $2.2 \%$ & $3.7 \%$ & $0.6 \%$ & $1.5 \%$ & $0.4 \%$ \\
\hline 10 yrs or more & $4.5 \%$ & $2.2 \%$ & $3.7 \%$ & $0.6 \%$ & $1.5 \%$ & $0.4 \%$ \\
\hline Avg CO2 Emissions ( $\mathrm{kg} / \mathrm{HH})$ & 269 & 68 & 275 & 78 & 147 & 54 \\
\hline Less than $10 \mathrm{yrs}$ & $4.5 \%$ & $2.2 \%$ & $3.7 \%$ & $0.6 \%$ & $1.5 \%$ & $0.4 \%$ \\
\hline 10 yrs or more & $4.5 \%$ & $2.2 \%$ & $3.7 \%$ & $0.6 \%$ & $1.5 \%$ & $0.4 \%$ \\
\hline
\end{tabular}


Chapter 3: Table 10

Influence of NY State Metropolitan Data on Overall NY Travel Patterns

STANDARD ERRORS

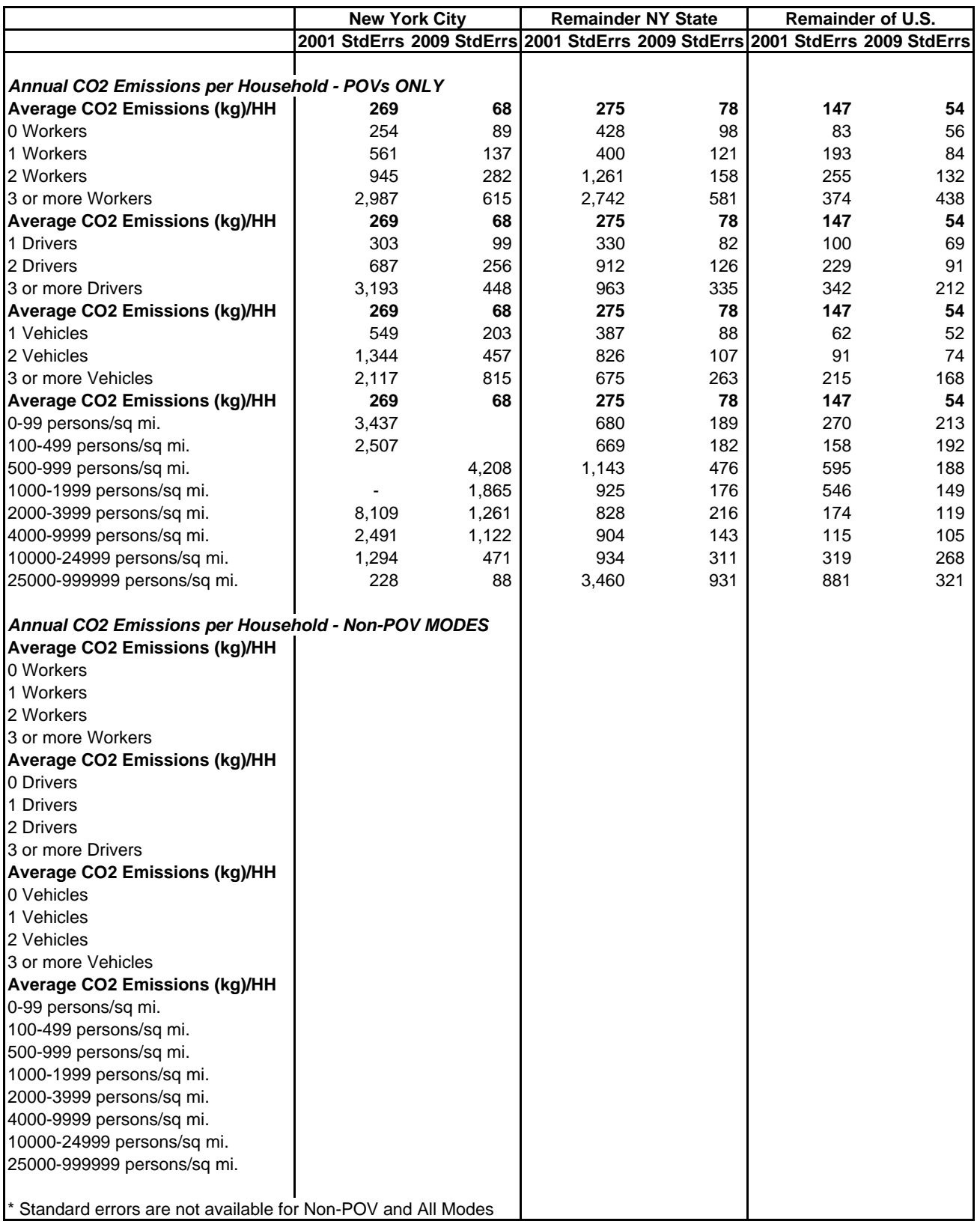


Chapter 3: Table 11

Influence of NY State Metropolitan Data on Overall NY Travel Patterns

STANDARD ERRORS

\begin{tabular}{|c|c|c|c|}
\hline & New York City & Remainder NY State & Remainder of U.S. \\
\hline & 2001 StdErrs 2009 StdErrs & 2001 StdErrs 2009 StdErrs & 2001 StdErrs 2009 StdErrs \\
\hline \multicolumn{4}{|c|}{ Annual CO2 Emissions per Household - ALL MODES } \\
\hline \multirow{2}{*}{\multicolumn{4}{|c|}{ Average CO2 Emissions $(\mathrm{kg}) / \mathrm{HH}$}} \\
\hline \multicolumn{2}{|l|}{$\begin{array}{l}0 \text { Workers } \\
1 \text { Workers }\end{array}$} & & \\
\hline \\
\hline & & & \\
\hline \multicolumn{4}{|l|}{3 or more Workers } \\
\hline \multirow{2}{*}{\multicolumn{4}{|c|}{ Average CO2 Emissions $(\mathbf{k g}) / \mathrm{HH}$}} \\
\hline \multirow{2}{*}{\multicolumn{4}{|c|}{1 Drivers }} \\
\hline & & & \\
\hline \multicolumn{4}{|l|}{2 Drivers } \\
\hline \multirow{2}{*}{\multicolumn{4}{|c|}{$\begin{array}{l}3 \text { or more Drivers } \\
\text { Average CO2 Emissions }(\mathrm{kg}) / \mathrm{HH}\end{array}$}} \\
\hline & & & \\
\hline \multicolumn{4}{|l|}{0 Vehicles } \\
\hline \multicolumn{4}{|l|}{1 Vehicles } \\
\hline \multicolumn{4}{|l|}{$\begin{array}{l}2 \text { Vehicles } \\
3 \text { or more Vehicles }\end{array}$} \\
\hline \multirow{2}{*}{\multicolumn{4}{|c|}{ Average $\mathrm{CO} 2$ Emissions $(\mathrm{kg}) / \mathrm{HH}$}} \\
\hline & & & \\
\hline \multicolumn{4}{|l|}{$\begin{array}{l}0-99 \text { persons/sq } \mathrm{mi} \\
100-499 \mathrm{persons} / \mathrm{sq} \mathrm{mi}\end{array}$} \\
\hline \multirow{2}{*}{\multicolumn{4}{|c|}{$\begin{array}{l}500-999 \mathrm{persons} / \mathrm{sq} \mathrm{mi} . \\
1000-1999 \text { persons/sq mi. }\end{array}$}} \\
\hline & & & \\
\hline \multicolumn{4}{|l|}{ 2000-3999 persons/sq mi. } \\
\hline \multicolumn{4}{|l|}{$\begin{array}{l}\text { 4000-9999 persons/sq mi. } \\
10000-24999 \text { persons/sq mi. }\end{array}$} \\
\hline $25000-999999 \mathrm{persons} / \mathrm{sq} \mathrm{mi}$. & & & \\
\hline * Standard errors are not available & Non-POV and All Modes & & \\
\hline
\end{tabular}

C -63 
Chapter 3: Table 12

Influence of NY State Metropolitan Data on Overall NY Travel Patterns

STANDARD ERRORS

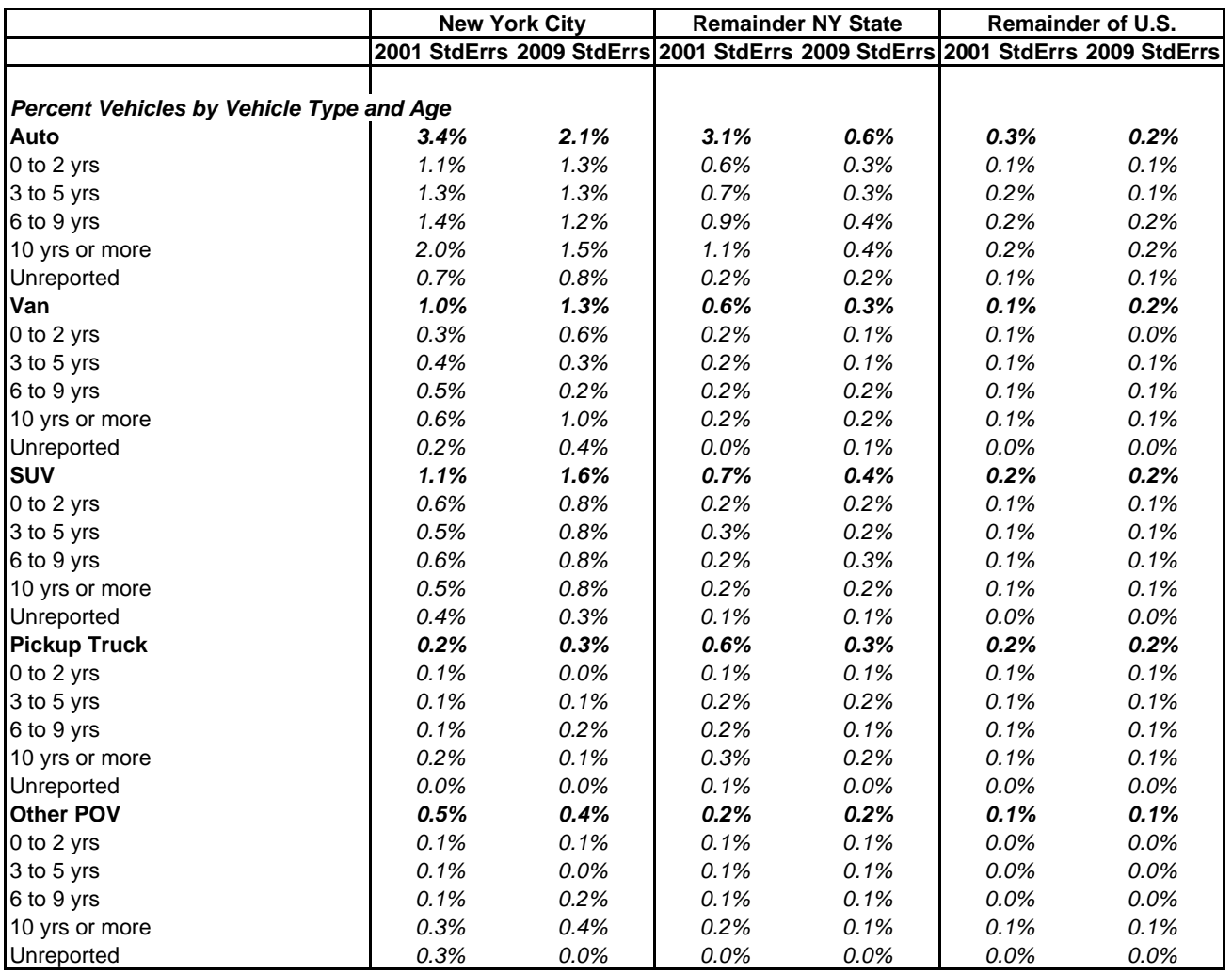


Chapter 3: Table 13

Influence of NY State Metropolitan Data on Overall NY Travel Patterns

STANDARD ERRORS

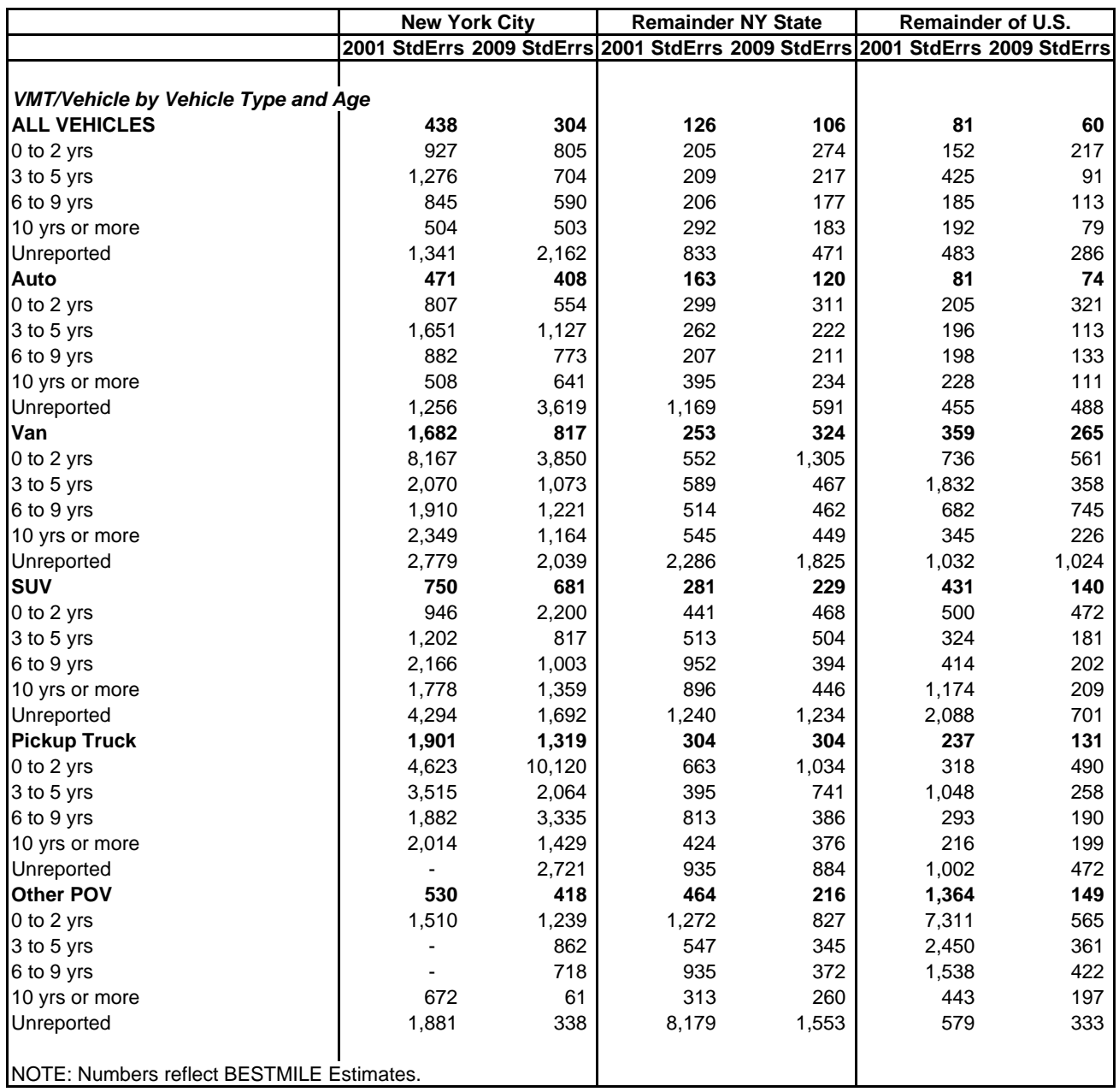

C -65 


\begin{tabular}{|c|c|c|c|c|c|c|}
\hline & New & City & Remain & Y State & Rema & ff U.S. \\
\hline & $2001 \mathrm{StdEr}$ & 09 StdErrs & $2001 \mathrm{StdE}$ & 09 StdErrs & 2001 StdE & 09 StdErrs \\
\hline Percent Not Takin & he last weel & & & & & \\
\hline TOTAL & $0.9 \%$ & $1.1 \%$ & $0.5 \%$ & $0.6 \%$ & $0.3 \%$ & $0.3 \%$ \\
\hline 5 to 10 year-olds & * & $4.4 \%$ & * & $2.4 \%$ & * & $0.8 \%$ \\
\hline 11 to 15 year-olds & * & $2.4 \%$ & * & $2.3 \%$ & * & $1.0 \%$ \\
\hline 16 to 20 year-olds & $2.8 \%$ & $3.9 \%$ & $2.3 \%$ & $2.0 \%$ & $1.0 \%$ & $1.0 \%$ \\
\hline 21 to 35 year-olds & $1.3 \%$ & $2.0 \%$ & $1.2 \%$ & $1.7 \%$ & $0.6 \%$ & $0.8 \%$ \\
\hline 36 to 64 year-olds & $1.1 \%$ & $1.5 \%$ & $0.7 \%$ & $0.8 \%$ & $0.4 \%$ & $0.4 \%$ \\
\hline $65+$ year-olds & $2.7 \%$ & $2.6 \%$ & $1.3 \%$ & $1.5 \%$ & $0.6 \%$ & $0.6 \%$ \\
\hline Avg Minutes Spen & & & & & & \\
\hline TOTAL & 0.69 & 1.15 & 0.43 & 0.19 & 0.10 & 0.16 \\
\hline 5 to 10 year-olds & 1.53 & 3.02 & 0.75 & 0.62 & 0.42 & 0.28 \\
\hline 11 to 15 year-olds & 1.70 & 2.23 & 1.88 & 0.64 & 0.41 & 0.86 \\
\hline 16 to 20 year-olds & 1.71 & 3.56 & 1.05 & 0.67 & 0.37 & 0.38 \\
\hline 21 to 35 year-olds & 1.45 & 3.06 & 0.55 & 0.50 & 0.19 & 0.30 \\
\hline 36 to 64 year-olds & 0.91 & 1.39 & 0.94 & 0.32 & 0.12 & 0.20 \\
\hline $65+$ year-olds & 1.61 & 2.21 & 0.37 & 0.33 & 0.23 & 0.22 \\
\hline Percent Not Takin & last weeh & & & & & \\
\hline TOTAL & $0.5 \%$ & $0.8 \%$ & $0.3 \%$ & $0.4 \%$ & $0.2 \%$ & $0.2 \%$ \\
\hline 5 to 10 year-olds & * & $4.1 \%$ & * & $2.4 \%$ & * & $1.0 \%$ \\
\hline 11 to 15 year-olds & * & $2.6 \%$ & * & $2.2 \%$ & * & $1.0 \%$ \\
\hline 16 to 20 year-olds & $2.7 \%$ & $2.2 \%$ & $1.8 \%$ & $1.5 \%$ & $0.7 \%$ & $0.7 \%$ \\
\hline 21 to 35 year-olds & $1.1 \%$ & $2.3 \%$ & $0.7 \%$ & $1.0 \%$ & $0.3 \%$ & $0.4 \%$ \\
\hline 36 to 64 year-olds & $0.7 \%$ & $0.9 \%$ & $0.4 \%$ & $0.5 \%$ & $0.2 \%$ & $0.2 \%$ \\
\hline $65+$ year-olds & $0.5 \%$ & $0.7 \%$ & $0.5 \%$ & $0.3 \%$ & $0.3 \%$ & $0.2 \%$ \\
\hline Avg Minutes Spen & & & & & & \\
\hline TOTAL & 0.23 & 0.18 & 0.08 & 0.07 & 0.06 & 0.04 \\
\hline 5 to 10 year-olds & 1.73 & 0.28 & 0.24 & 0.32 & 0.26 & 0.15 \\
\hline 11 to 15 year-olds & 2.51 & 0.01 & 0.45 & 0.28 & 0.27 & 0.19 \\
\hline 16 to 20 year-olds & 0.06 & 0.10 & 0.09 & 0.27 & 0.14 & 0.13 \\
\hline 21 to 35 year-olds & 0.26 & 0.44 & 0.08 & 0.24 & 0.08 & 0.11 \\
\hline 36 to 64 year-olds & 0.13 & 0.37 & 0.07 & 0.08 & 0.08 & 0.07 \\
\hline $65+$ year-olds & 0.05 & 0.10 & 0.21 & 0.09 & 0.06 & 0.09 \\
\hline Avg Minutes Spen & per Day & & & & & \\
\hline TOTAL & 0.72 & 1.17 & 0.43 & 0.22 & 0.12 & 0.17 \\
\hline 5 to 10 year-olds & 2.46 & 2.94 & 0.79 & 0.73 & 0.50 & 0.31 \\
\hline 11 to 15 year-olds & 3.02 & 2.23 & 1.95 & 0.70 & 0.47 & 0.89 \\
\hline 16 to 20 year-olds & 1.70 & 3.55 & 1.04 & 0.74 & 0.40 & 0.40 \\
\hline 21 to 35 year-olds & 1.45 & 3.08 & 0.55 & 0.59 & 0.23 & 0.32 \\
\hline 36 to 64 year-olds & 0.92 & 1.48 & 0.94 & 0.34 & 0.15 & 0.22 \\
\hline $65+$ year-olds & 1.61 & 2.22 & 0.44 & 0.34 & 0.23 & 0.23 \\
\hline
\end{tabular}




\section{APPENDIX C4. SUPPLEMENTAL TABLES FOR CHAPTER 4}




\begin{tabular}{|c|c|c|c|c|c|c|c|c|c|c|c|c|c|c|}
\hline \multicolumn{15}{|c|}{ Population Density (census tract) } \\
\hline & \multicolumn{2}{|c|}{$<500$} & \multicolumn{2}{|c|}{$500-2,000$} & \multicolumn{2}{|c|}{$2,000-4,000$} & \multicolumn{2}{|c|}{$4,000-10,000$} & \multicolumn{2}{|c|}{$10,000-20,000$} & \multicolumn{2}{|c|}{$20,000-50,000$} & \multicolumn{2}{|c|}{$50,000+$} \\
\hline & NY State & U.S. & NY State & U.S. & NY State & U.S. & NY State & U.S. & NY State & U.S. & NY State & U.S. & NY State & U.S. \\
\hline \multicolumn{15}{|l|}{ General Statistics } \\
\hline Households (000) & 633 & 14,480 & 822 & 19,448 & 710 & 19,717 & 1,032 & 22,496 & 522 & 5,711 & 926 & 2,430 & 1,790 & 133 \\
\hline Persons (000) & 1,669 & 37,767 & 2,144 & 49,723 & 1,811 & 48,836 & 2,671 & 55,685 & 1,426 & 14,066 & 2,414 & 6,359 & 4,435 & 353 \\
\hline Drivers (000) & 1,305 & 29,537 & 1,648 & 37,589 & 1,435 & 37,111 & 1,995 & 40,858 & 954 & 9,497 & 1,565 & 4,039 & 2,626 & 201 \\
\hline Workers (000) & 966 & 20,656 & 1,194 & 26,899 & 1,025 & 26,172 & 1,441 & 30,365 & 711 & 6,896 & 1,252 & 3,214 & 2,248 & 233 \\
\hline Vehicles (000) & 1,308 & 32,975 & 1,529 & 38,087 & 1,298 & 36,018 & 1,595 & 38,342 & 681 & 7,733 & 745 & 2,702 & 713 & 109 \\
\hline Workers per Household & 1.53 & 1.43 & 1.45 & 1.38 & 1.44 & 1.33 & 1.40 & 1.35 & 1.36 & 1.21 & 1.35 & 1.32 & 1.26 & 1.75 \\
\hline Vehicles per Household & 2.07 & 2.28 & 1.86 & 1.96 & 1.83 & 1.83 & 1.55 & 1.70 & 1.30 & 1.35 & 0.80 & 1.11 & 0.40 & 0.82 \\
\hline Vehicles per Driver & 1.00 & 1.12 & 0.93 & 1.01 & 0.90 & 0.97 & 0.80 & 0.94 & 0.71 & 0.81 & 0.48 & 0.67 & 0.27 & 0.54 \\
\hline \multicolumn{15}{|c|}{ Distribution of Households by Household Vehicle Count } \\
\hline ALL & $100.0 \%$ & $100.0 \%$ & $100.0 \%$ & $100.0 \%$ & $100.0 \%$ & $100.0 \%$ & $100.0 \%$ & $100.0 \%$ & $100.0 \%$ & $100.0 \%$ & $100.0 \%$ & $100.0 \%$ & $100.0 \%$ & $100.0 \%$ \\
\hline 0 vehicles & $4.0 \%$ & $2.8 \%$ & $6.1 \%$ & $5.1 \%$ & $6.7 \%$ & $6.2 \%$ & $12.7 \%$ & $9.4 \%$ & $21.9 \%$ & $18.8 \%$ & $43.1 \%$ & $30.1 \%$ & $67.9 \%$ & $27.0 \%$ \\
\hline 1 vehicle & $25.5 \%$ & $24.4 \%$ & $32.0 \%$ & $28.9 \%$ & $30.8 \%$ & $35.2 \%$ & $39.5 \%$ & $37.3 \%$ & $40.1 \%$ & $43.6 \%$ & $38.4 \%$ & $40.1 \%$ & $25.6 \%$ & $65.5 \%$ \\
\hline 2 vehicles & $44.6 \%$ & $39.1 \%$ & $41.8 \%$ & $42.8 \%$ & $43.5 \%$ & $38.6 \%$ & $32.8 \%$ & $36.1 \%$ & $28.0 \%$ & $26.9 \%$ & $15.0 \%$ & $23.0 \%$ & $5.4 \%$ & $6.2 \%$ \\
\hline 3 vehicles & $16.9 \%$ & $19.6 \%$ & $13.7 \%$ & $15.7 \%$ & $13.8 \%$ & $13.6 \%$ & $11.7 \%$ & $11.4 \%$ & $6.9 \%$ & $7.2 \%$ & $2.3 \%$ & $5.1 \%$ & $1.0 \%$ & $1.4 \%$ \\
\hline $4+$ vehicles & $9.0 \%$ & $14.1 \%$ & $6.4 \%$ & $7.6 \%$ & $5.2 \%$ & $6.4 \%$ & $3.3 \%$ & $5.8 \%$ & $3.1 \%$ & $3.5 \%$ & $1.3 \%$ & $1.8 \%$ & $0.1 \%$ & \\
\hline \multicolumn{15}{|c|}{ Distribution of Households by Household Income } \\
\hline ALL & $100.0 \%$ & $100.0 \%$ & $100.0 \%$ & $100.0 \%$ & $100.0 \%$ & $100.0 \%$ & $100.0 \%$ & $100.0 \%$ & $100.0 \%$ & $100.0 \%$ & $100.0 \%$ & $100.0 \%$ & $100.0 \%$ & $100.0 \%$ \\
\hline$<\$ 10,000$ & $5.1 \%$ & $5.6 \%$ & $3.8 \%$ & $6.5 \%$ & $3.8 \%$ & $6.1 \%$ & $9.0 \%$ & $7.5 \%$ & $6.4 \%$ & $11.4 \%$ & $10.2 \%$ & $14.0 \%$ & $10.6 \%$ & $6.8 \%$ \\
\hline$\$ 10$ to $\$ 20,000$ & $8.8 \%$ & $11.8 \%$ & $7.3 \%$ & $8.7 \%$ & $8.2 \%$ & $10.8 \%$ & $11.8 \%$ & $12.7 \%$ & $14.0 \%$ & $19.4 \%$ & $10.4 \%$ & $16.6 \%$ & $13.8 \%$ & $33.3 \%$ \\
\hline$\$ 20$ to $\$ 30,000$ & $10.0 \%$ & $11.0 \%$ & $9.4 \%$ & $9.8 \%$ & $7.7 \%$ & $10.5 \%$ & $9.0 \%$ & $12.0 \%$ & $16.4 \%$ & $14.1 \%$ & $8.3 \%$ & $13.9 \%$ & $10.2 \%$ & $5.2 \%$ \\
\hline$\$ 30$ to $\$ 40,000$ & $9.9 \%$ & $10.3 \%$ & $7.7 \%$ & $8.1 \%$ & $7.9 \%$ & $9.4 \%$ & $8.4 \%$ & $11.0 \%$ & $8.9 \%$ & $9.0 \%$ & $10.0 \%$ & $9.8 \%$ & $10.2 \%$ & $2.6 \%$ \\
\hline$\$ 40$ to $\$ 50,000$ & $8.8 \%$ & $8.7 \%$ & $8.6 \%$ & $9.3 \%$ & $8.2 \%$ & $8.2 \%$ & $7.7 \%$ & $7.7 \%$ & $6.8 \%$ & $7.3 \%$ & $9.7 \%$ & $6.1 \%$ & $9.0 \%$ & $2.2 \%$ \\
\hline$\$ 50$ to $\$ 60,000$ & $9.1 \%$ & $7.8 \%$ & $7.6 \%$ & $6.9 \%$ & $7.3 \%$ & $7.7 \%$ & $6.8 \%$ & $7.9 \%$ & $5.4 \%$ & $7.2 \%$ & $6.7 \%$ & $5.7 \%$ & $4.8 \%$ & $9.9 \%$ \\
\hline$\$ 60$ to $\$ 70,000$ & $5.7 \%$ & $6.7 \%$ & $7.0 \%$ & $5.7 \%$ & $7.1 \%$ & $6.4 \%$ & $5.8 \%$ & $5.8 \%$ & $5.7 \%$ & $4.1 \%$ & $5.5 \%$ & $6.7 \%$ & $4.9 \%$ & $7.4 \%$ \\
\hline$\$ 70$ to $\$ 80,000$ & $7.0 \%$ & $6.3 \%$ & $5.6 \%$ & $7.1 \%$ & $5.3 \%$ & $6.2 \%$ & $5.6 \%$ & $6.0 \%$ & $4.5 \%$ & $3.6 \%$ & $3.5 \%$ & $3.5 \%$ & $5.5 \%$ & $3.1 \%$ \\
\hline$\$ 80$ to $\$ 100,000$ & $8.5 \%$ & $9.2 \%$ & $8.6 \%$ & $10.1 \%$ & $9.4 \%$ & $7.9 \%$ & $5.6 \%$ & $6.9 \%$ & $9.7 \%$ & $5.5 \%$ & $9.5 \%$ & $5.3 \%$ & $5.4 \%$ & $5.5 \%$ \\
\hline$\$ 100,000+$ & $19.7 \%$ & $16.0 \%$ & $26.2 \%$ & $21.8 \%$ & $24.9 \%$ & $18.8 \%$ & $21.1 \%$ & $15.2 \%$ & $14.5 \%$ & $10.7 \%$ & $15.4 \%$ & $10.9 \%$ & $16.6 \%$ & $16.5 \%$ \\
\hline Unreported & $7.5 \%$ & $6.5 \%$ & $8.4 \%$ & $6.1 \%$ & $10.2 \%$ & $8.0 \%$ & $9.1 \%$ & $7.4 \%$ & $7.8 \%$ & $7.9 \%$ & $10.9 \%$ & $7.4 \%$ & $9.1 \%$ & $7.6 \%$ \\
\hline Licensing Rate & $92.2 \%$ & $92.4 \%$ & $90.2 \%$ & $91.7 \%$ & $92.0 \%$ & $90.3 \%$ & $86.7 \%$ & $86.2 \%$ & $79.7 \%$ & $79.9 \%$ & $74.2 \%$ & $73.5 \%$ & $68.2 \%$ & $63.2 \%$ \\
\hline$\%$ Male Drivers/Male $16+$ & $95.4 \%$ & $93.2 \%$ & $92.1 \%$ & $93.9 \%$ & $94.9 \%$ & $91.8 \%$ & $90.4 \%$ & $88.9 \%$ & $82.3 \%$ & $88.8 \%$ & $80.5 \%$ & $83.3 \%$ & $76.6 \%$ & $74.8 \%$ \\
\hline$\%$ Female Drivers/Female $16+$ & $89.3 \%$ & $91.7 \%$ & $88.3 \%$ & $89.6 \%$ & $89.0 \%$ & $88.9 \%$ & $83.5 \%$ & $83.7 \%$ & $77.4 \%$ & $72.0 \%$ & $68.6 \%$ & $64.7 \%$ & $60.9 \%$ & $43.3 \%$ \\
\hline
\end{tabular}




\begin{tabular}{|c|c|c|c|c|c|c|c|c|c|c|c|c|c|c|}
\hline \multicolumn{15}{|c|}{ Population Density (census tract) } \\
\hline & \multicolumn{2}{|c|}{$<500$} & \multicolumn{2}{|c|}{$500-2,000$} & \multicolumn{2}{|c|}{$2,000-4,000$} & \multicolumn{2}{|c|}{$4,000-10,000$} & \multicolumn{2}{|c|}{$10,000-20,000$} & \multicolumn{2}{|c|}{$20,000-50,000$} & \multicolumn{2}{|c|}{$50,000+$} \\
\hline & NY State & U.S. & NY State & U.S. & NY State & U.S. & NY State & U.S. & NY State & U.S. & NY State & U.S. & NY State & U.S. \\
\hline \multicolumn{15}{|l|}{ General Statistics } \\
\hline Households (000) & 530 & 14,822 & 738 & 16,982 & 664 & 17,629 & 1,028 & 21,548 & 635 & 5,893 & 1,002 & 2,380 & 1,720 & 197 \\
\hline Drivers (000) & 1,054 & 29,465 & 1,407 & 32,376 & 1,192 & 30,924 & 1,784 & 36,802 & 1,087 & 9,186 & 1,279 & 3,167 & 1,812 & 186 \\
\hline Workers $(000)$ & 756 & 21,649 & 1,046 & 23,984 & 882 & 23,327 & 1,428 & 29,077 & 953 & 8,259 & 1,280 & 3,021 & 2,170 & 218 \\
\hline Vehicles $(000)$ & 1,105 & 33,747 & 1,445 & 34,350 & 1,174 & 32,594 & 1,707 & 36,814 & 868 & 8,560 & 779 & 2,645 & 806 & 115 \\
\hline Workers per Household & 1.42 & 1.46 & 1.42 & 1.41 & 1.33 & 1.32 & 1.39 & 1.35 & 1.50 & 1.40 & 1.28 & 1.27 & 1.26 & 1.11 \\
\hline Vehicles per Household & 2.08 & 2.28 & 1.96 & 2.02 & 1.77 & 1.85 & 1.66 & 1.71 & 1.37 & 1.45 & 0.78 & 1.11 & 0.47 & 0.58 \\
\hline Vehicles per Driver & 1.05 & 1.15 & 1.03 & 1.06 & 0.98 & 1.05 & 0.96 & 1.00 & 0.80 & 0.93 & 0.61 & 0.84 & 0.44 & 0.62 \\
\hline \multicolumn{15}{|c|}{ Distribution of Households by Household Vehicle Count } \\
\hline ALL & $100.0 \%$ & $100.0 \%$ & $100.0 \%$ & $100.0 \%$ & $100.0 \%$ & $100.0 \%$ & $100.0 \%$ & $100.0 \%$ & $100.0 \%$ & $100.0 \%$ & $100.0 \%$ & $100.0 \%$ & $100.0 \%$ & $100.0 \%$ \\
\hline 0 vehicles & $4.0 \%$ & $3.3 \%$ & $3.2 \%$ & $3.5 \%$ & $7.5 \%$ & $5.6 \%$ & $10.2 \%$ & $8.7 \%$ & $21.8 \%$ & $15.6 \%$ & $45.0 \%$ & $28.0 \%$ & $61.5 \%$ & $49.1 \%$ \\
\hline 1 vehicle & $24.0 \%$ & $22.9 \%$ & $30.2 \%$ & $28.4 \%$ & $33.7 \%$ & $33.9 \%$ & $35.6 \%$ & $37.1 \%$ & $38.2 \%$ & $41.7 \%$ & $36.6 \%$ & $42.2 \%$ & $32.5 \%$ & $43.7 \%$ \\
\hline 2 vehicles & $45.0 \%$ & $39.9 \%$ & $44.1 \%$ & $43.1 \%$ & $40.7 \%$ & $39.2 \%$ & $37.4 \%$ & $36.6 \%$ & $26.5 \%$ & $30.1 \%$ & $15.2 \%$ & $22.6 \%$ & $5.2 \%$ & $6.9 \%$ \\
\hline 3 vehicles & $18.0 \%$ & $20.1 \%$ & $15.9 \%$ & $16.4 \%$ & $12.9 \%$ & $15.3 \%$ & $12.6 \%$ & $12.4 \%$ & $10.2 \%$ & $8.4 \%$ & $2.5 \%$ & $5.5 \%$ & $0.6 \%$ & $0.3 \%$ \\
\hline $4+$ vehicles & $9.0 \%$ & $13.8 \%$ & $6.7 \%$ & $8.6 \%$ & $5.3 \%$ & $6.0 \%$ & $4.3 \%$ & $5.2 \%$ & $3.3 \%$ & $4.2 \%$ & $0.8 \%$ & $1.8 \%$ & $0.3 \%$ & \\
\hline \multicolumn{15}{|c|}{ Distribution of Households by Household Income } \\
\hline ALL & $100.0 \%$ & $100.0 \%$ & $99.9 \%$ & $100.0 \%$ & $100.0 \%$ & $100.0 \%$ & $100.0 \%$ & $100.0 \%$ & $100.0 \%$ & $100.0 \%$ & $100.0 \%$ & $100.0 \%$ & $100.0 \%$ & $100.0 \%$ \\
\hline$<\$ 10,000$ & $3.4 \%$ & $4.7 \%$ & $3.1 \%$ & $4.4 \%$ & $4.4 \%$ & $5.0 \%$ & $5.7 \%$ & $7.6 \%$ & $9.1 \%$ & $10.6 \%$ & $9.7 \%$ & $10.0 \%$ & $10.8 \%$ & $10.7 \%$ \\
\hline$\$ 10$ to $\$ 20,000$ & $8.1 \%$ & $9.3 \%$ & $5.5 \%$ & $6.9 \%$ & $7.9 \%$ & $8.2 \%$ & $9.6 \%$ & $9.5 \%$ & $10.0 \%$ & $12.5 \%$ & $11.7 \%$ & $15.5 \%$ & $11.8 \%$ & $19.4 \%$ \\
\hline$\$ 20$ to $\$ 30,000$ & $6.7 \%$ & $9.4 \%$ & $6.4 \%$ & $7.5 \%$ & $7.6 \%$ & $9.1 \%$ & $6.5 \%$ & $9.7 \%$ & $7.9 \%$ & $10.2 \%$ & $11.4 \%$ & $10.2 \%$ & $11.4 \%$ & $19.2 \%$ \\
\hline$\$ 30$ to $\$ 40,000$ & $16.3 \%$ & $16.8 \%$ & $11.2 \%$ & $14.4 \%$ & $13.7 \%$ & $15.7 \%$ & $14.4 \%$ & $17.2 \%$ & $16.1 \%$ & $15.8 \%$ & $15.8 \%$ & $21.1 \%$ & $13.5 \%$ & $9.9 \%$ \\
\hline$\$ 40$ to $\$ 50,000$ & $5.3 \%$ & $5.0 \%$ & $4.0 \%$ & $4.7 \%$ & $3.6 \%$ & $4.5 \%$ & $3.8 \%$ & $5.0 \%$ & $3.8 \%$ & $4.6 \%$ & $4.0 \%$ & $8.3 \%$ & $4.0 \%$ & $5.2 \%$ \\
\hline$\$ 50$ to $\$ 60,000$ & $9.5 \%$ & $8.6 \%$ & $8.3 \%$ & $9.3 \%$ & $5.7 \%$ & $7.9 \%$ & $9.3 \%$ & $8.1 \%$ & $8.3 \%$ & $7.6 \%$ & $7.3 \%$ & $5.2 \%$ & $6.7 \%$ & $3.8 \%$ \\
\hline$\$ 60$ to $\$ 70,000$ & $6.7 \%$ & $7.1 \%$ & $7.1 \%$ & $6.3 \%$ & $5.4 \%$ & $7.3 \%$ & $7.2 \%$ & $7.0 \%$ & $5.4 \%$ & $6.0 \%$ & $6.8 \%$ & $4.1 \%$ & $4.7 \%$ & $3.8 \%$ \\
\hline$\$ 70$ to $\$ 80,000$ & $6.3 \%$ & $6.4 \%$ & $6.8 \%$ & $6.3 \%$ & $4.1 \%$ & $5.3 \%$ & $4.1 \%$ & $5.2 \%$ & $6.0 \%$ & $4.2 \%$ & $2.5 \%$ & $1.5 \%$ & $5.6 \%$ & $1.7 \%$ \\
\hline$\$ 80$ to $\$ 100,000$ & $10.2 \%$ & $9.8 \%$ & $13.8 \%$ & $10.9 \%$ & $11.5 \%$ & $10.8 \%$ & $10.3 \%$ & $8.3 \%$ & $8.2 \%$ & $6.6 \%$ & $5.9 \%$ & $5.5 \%$ & $5.2 \%$ & $8.6 \%$ \\
\hline$\$ 100,000+$ & $20.1 \%$ & $15.7 \%$ & $24.8 \%$ & $21.1 \%$ & $25.5 \%$ & $17.3 \%$ & $18.6 \%$ & $13.7 \%$ & $17.2 \%$ & $12.9 \%$ & $12.0 \%$ & $9.4 \%$ & $14.3 \%$ & $12.7 \%$ \\
\hline Unreported & $7.2 \%$ & $7.3 \%$ & $9.0 \%$ & $8.2 \%$ & $10.8 \%$ & $8.9 \%$ & $10.5 \%$ & $8.6 \%$ & $8.0 \%$ & $9.1 \%$ & $12.9 \%$ & $9.3 \%$ & $12.1 \%$ & $4.9 \%$ \\
\hline Licensing Ra & $93.6 \%$ & $93.2 \%$ & $93.8 \%$ & $93.6 \%$ & $91.2 \%$ & $91.2 \%$ & $86.5 \%$ & $88.1 \%$ & $76.4 \%$ & $79.2 \%$ & $63.7 \%$ & $72.5 \%$ & $53.3 \%$ & $64.8 \%$ \\
\hline$\%$ Male Drivers/Male 16+ & $94.2 \%$ & $95.4 \%$ & $95.8 \%$ & $95.1 \%$ & $95.3 \%$ & $93.7 \%$ & $89.2 \%$ & $91.7 \%$ & $82.1 \%$ & $86.5 \%$ & $74.0 \%$ & $80.6 \%$ & $66.7 \%$ & $67.3 \%$ \\
\hline$\%$ Female Drivers/Female 16+ & $93.0 \%$ & $91.1 \%$ & $92.0 \%$ & $92.1 \%$ & $87.5 \%$ & $89.0 \%$ & $84.1 \%$ & $84.8 \%$ & $71.2 \%$ & $72.3 \%$ & $54.1 \%$ & $65.2 \%$ & $41.9 \%$ & $58.5 \%$ \\
\hline
\end{tabular}




\begin{tabular}{|c|c|c|c|c|c|c|c|c|c|c|c|c|c|c|}
\hline \multicolumn{15}{|c|}{ Population Density (census tract) } \\
\hline & \multicolumn{2}{|c|}{$<500$} & \multicolumn{2}{|c|}{$500-2,000$} & \multicolumn{2}{|c|}{$2,000-4,000$} & \multicolumn{2}{|c|}{$4,000-10,000$} & \multicolumn{2}{|c|}{$10,000-20,000$} & \multicolumn{2}{|c|}{$20,000-50,000$} & \multicolumn{2}{|c|}{$50,000+$} \\
\hline & NY State & U.S. & NY State & U.S. & NY State & U.S. & NY State & U.S. & NY State & U.S. & NY State & U.S. & NY State & U.S. \\
\hline \multicolumn{15}{|l|}{ General Statistics } \\
\hline Households (000) & 568 & 14,723 & 727 & 15,721 & 601 & 15,126 & 994 & 19,726 & 617 & 5,230 & 978 & 1,962 & 1,528 & 83 \\
\hline Drivers (000) & 1,076 & 28,148 & 1,422 & 29,804 & 1,141 & 27,253 & 1,781 & 34,019 & 903 & 7,741 & 1,174 & 2,387 & 1,428 & 92 \\
\hline Workers $(000)$ & 796 & 20,355 & 1,007 & 22,007 & 834 & 20,532 & 1,397 & 26,000 & 792 & 6,189 & 1,137 & 2,337 & 1,713 & 98 \\
\hline Vehicles (000) & 995 & 30,649 & 1,283 & 30,706 & 971 & 27,071 & 1,444 & 32,278 & 664 & 6,772 & 679 & 1,767 & 496 & 55 \\
\hline Workers per Household & 1.40 & 1.38 & 1.39 & 1.40 & 1.39 & 1.36 & 1.41 & 1.32 & 1.28 & 1.18 & 1.16 & 1.19 & 1.12 & 1.18 \\
\hline Vehicles per Household & 1.75 & 2.08 & 1.76 & 1.95 & 1.62 & 1.79 & 1.45 & 1.64 & 1.08 & 1.29 & 0.69 & 0.90 & 0.32 & 0.66 \\
\hline Vehicles per Driver & 0.92 & 1.09 & 0.90 & 1.03 & 0.85 & 0.99 & 0.81 & 0.95 & 0.73 & 0.87 & 0.58 & 0.74 & 0.35 & 0.60 \\
\hline \multicolumn{15}{|c|}{ Distribution of Households by Household Vehicle Count } \\
\hline ALL & $100 \%$ & $100 \%$ & $100 \%$ & $100 \%$ & $100 \%$ & $100 \%$ & $100 \%$ & $100 \%$ & $100 \%$ & $100 \%$ & $100 \%$ & $100 \%$ & $100 \%$ & $100 \%$ \\
\hline 0 vehicles & $4.2 \%$ & $3.4 \%$ & $2.8 \%$ & $3.2 \%$ & $6.1 \%$ & $6.1 \%$ & $11.3 \%$ & $8.3 \%$ & $21.9 \%$ & $18.5 \%$ & $42.2 \%$ & $35.3 \%$ & $68.2 \%$ & $47.1 \%$ \\
\hline 1 vehicle & $26.8 \%$ & $23.1 \%$ & $28.1 \%$ & $28.8 \%$ & $32.1 \%$ & $33.7 \%$ & $36.1 \%$ & $38.6 \%$ & $43.0 \%$ & $45.1 \%$ & $39.2 \%$ & $43.9 \%$ & $27.2 \%$ & $40.4 \%$ \\
\hline 2 vehicles & $48.1 \%$ & $46.4 \%$ & $48.8 \%$ & $46.4 \%$ & $43.4 \%$ & $42.3 \%$ & $39.5 \%$ & $38.6 \%$ & $28.5 \%$ & $28.0 \%$ & $15.2 \%$ & $16.6 \%$ & $4.3 \%$ & $12.1 \%$ \\
\hline 3 vehicles & $15.5 \%$ & $19.6 \%$ & $14.1 \%$ & $16.0 \%$ & $13.8 \%$ & $12.8 \%$ & $8.8 \%$ & $11.0 \%$ & $5.4 \%$ & $6.4 \%$ & $2.9 \%$ & $3.9 \%$ & $0.3 \%$ & $0.4 \%$ \\
\hline 4+ vehicles & $5.4 \%$ & $7.5 \%$ & $6.3 \%$ & $5.7 \%$ & $4.6 \%$ & $5.1 \%$ & $4.4 \%$ & $3.5 \%$ & $1.1 \%$ & $2.1 \%$ & $0.6 \%$ & $0.3 \%$ & $0.1 \%$ & $0.0 \%$ \\
\hline \multicolumn{15}{|c|}{ Distribution of Households by Household Income } \\
\hline ALL & $100.0 \%$ & $100.0 \%$ & $100.0 \%$ & $100.0 \%$ & $100.0 \%$ & $100.0 \%$ & $100.0 \%$ & $100.0 \%$ & $100.0 \%$ & $100.0 \%$ & $100.0 \%$ & $100.0 \%$ & $100.0 \%$ & $100.0 \%$ \\
\hline$<\$ 10,0$ & $2.7 \%$ & $3.8 \%$ & $1.4 \%$ & $3.6 \%$ & $2.3 \%$ & $4.4 \%$ & $3.7 \%$ & $4.4 \%$ & $4.7 \%$ & $6.1 \%$ & $5.5 \%$ & $11.6 \%$ & $11.1 \%$ & $13.3 \%$ \\
\hline$\$ 10$ to $\$ 20,000$ & $6.0 \%$ & $7.5 \%$ & $5.6 \%$ & $6.5 \%$ & $5.8 \%$ & $7.5 \%$ & $7.4 \%$ & $9.6 \%$ & $8.5 \%$ & $12.3 \%$ & $8.8 \%$ & $16.1 \%$ & $10.8 \%$ & $16.6 \%$ \\
\hline$\$ 20$ to $\$$ & $9.9 \%$ & $9.5 \%$ & $5.8 \%$ & $8.2 \%$ & $9.5 \%$ & $9.7 \%$ & $9.6 \%$ & $9.9 \%$ & $9.5 \%$ & $13.3 \%$ & $11.2 \%$ & $10.4 \%$ & $12.0 \%$ & $17.3 \%$ \\
\hline$\$ 30$ to $\$ 40,000$ & $13.2 \%$ & $15.8 \%$ & $11.8 \%$ & $13.4 \%$ & $11.1 \%$ & $13.9 \%$ & $12.7 \%$ & $15.9 \%$ & $11.4 \%$ & $17.1 \%$ & $16.3 \%$ & $14.3 \%$ & $14.3 \%$ & $10.2 \%$ \\
\hline$\$ 40$ to & $4.2 \%$ & $4.2 \%$ & $2.5 \%$ & $3.7 \%$ & $4.3 \%$ & $3.9 \%$ & $3.6 \%$ & $4.5 \%$ & $3.3 \%$ & $3.3 \%$ & $3.7 \%$ & $4.0 \%$ & $4.2 \%$ & \\
\hline$\$ 50$ to $\$ 60,000$ & $8.1 \%$ & $8.8 \%$ & $7.8 \%$ & $9.2 \%$ & $7.1 \%$ & $8.5 \%$ & $7.1 \%$ & $9.3 \%$ & $5.0 \%$ & $8.1 \%$ & $7.4 \%$ & $6.1 \%$ & $5.8 \%$ & $13.4 \%$ \\
\hline$\$ 60$ to & $7.6 \%$ & $8.4 \%$ & $8.2 \%$ & $8.1 \%$ & & $7.3 \%$ & $8.1 \%$ & $8.1 \%$ & 8.50 & $6.3 \%$ & $8.5 \%$ & $3.2 \%$ & $4.3 \%$ & $0.6 \%$ \\
\hline$\$ 70$ to & $4.8 \%$ & $5.0 \%$ & $6.0 \%$ & $5.6 \%$ & $6.6 \%$ & $5.0 \%$ & $3.5 \%$ & $4.4 \%$ & $3.2 \%$ & $3.2 \%$ & $4.9 \%$ & $2.5 \%$ & $2.5 \%$ & \\
\hline$\$ 80$ to $\$$ & $9.9 \%$ & $9.8 \%$ & $9.9 \%$ & $10.9 \%$ & $11.9 \%$ & $9.1 \%$ & $9.1 \%$ & $7.8 \%$ & $12.6 \%$ & $6.2 \%$ & $5.5 \%$ & $5.2 \%$ & $4.5 \%$ & $8.8 \%$ \\
\hline$\$ 100,00$ & $13.9 \%$ & $11.1 \%$ & $20.0 \%$ & $14.3 \%$ & $16.5 \%$ & $14.2 \%$ & $14.9 \%$ & $9.8 \%$ & $11.7 \%$ & $6.7 \%$ & $8.1 \%$ & $7.5 \%$ & $10.7 \%$ & $9.7 \%$ \\
\hline Unreported & $19.7 \%$ & $16.1 \%$ & $21.0 \%$ & $16.6 \%$ & $17.5 \%$ & $16.5 \%$ & $20.4 \%$ & $16.3 \%$ & $21.6 \%$ & $17.5 \%$ & $20.0 \%$ & $19.1 \%$ & $19.6 \%$ & $10.0 \%$ \\
\hline \multicolumn{15}{|l|}{ Licensing Rate } \\
\hline$\%$ Male Drivers/Male & $94.7 \%$ & $95.8 \%$ & $95.4 \%$ & $95.2 \%$ & $94.0 \%$ & $93.4 \%$ & $90.4 \%$ & $92.0 \%$ & $82.2 \%$ & $85.0 \%$ & $75.3 \%$ & $73.4 \%$ & $64.8 \%$ & $74.7 \%$ \\
\hline$\%$ Female Drivers/Female 16+ & $89.7 \%$ & $91.0 \%$ & $90.4 \%$ & $91.2 \%$ & $88.7 \%$ & $86.9 \%$ & $80.3 \%$ & $84.2 \%$ & $64.7 \%$ & $71.0 \%$ & $49.2 \%$ & $58.7 \%$ & $36.6 \%$ & $55.6 \%$ \\
\hline
\end{tabular}




\begin{tabular}{|c|c|c|c|c|c|c|c|c|c|c|c|c|c|c|}
\hline \multicolumn{15}{|c|}{ Population Density (census tract) } \\
\hline & \multicolumn{2}{|c|}{$<500$} & \multicolumn{2}{|c|}{$500-2,000$} & \multicolumn{2}{|c|}{$2,000-4,000$} & \multicolumn{2}{|c|}{$4,000-10,000$} & \multicolumn{2}{|c|}{$10,000-20,000$} & \multicolumn{2}{|c|}{$20,000-50,000$} & \multicolumn{2}{|c|}{$50,000+$} \\
\hline & NY State & U.S. & NY State & U.S. & NY State & U.S. & NY State & U.S. & NY State & U.S. & NY State & U.S. & NY State & U.S. \\
\hline Daily Person Trips per Person & & & & & & & & & & & & & & \\
\hline TOTAL & 3.62 & 3.62 & 3.90 & 3.92 & 3.91 & 3.94 & 3.84 & 3.86 & 3.66 & 3.65 & 3.27 & 3.52 & 3.53 & 3.23 \\
\hline Male & 3.58 & 3.54 & 3.81 & 3.84 & 4.03 & 3.82 & 3.82 & 3.86 & 3.64 & 3.61 & 3.28 & 3.73 & 3.52 & 3.09 \\
\hline Female & 3.66 & 3.71 & 3.99 & 3.99 & 3.79 & 4.06 & 3.85 & 3.87 & 3.67 & 3.68 & 3.27 & 3.33 & 3.54 & 3.43 \\
\hline TOTAL & 3.62 & 3.62 & 3.90 & 3.92 & 3.91 & 3.94 & 3.84 & 3.86 & 3.66 & 3.65 & 3.27 & 3.52 & 3.53 & 3.23 \\
\hline $5-15$ years & 2.96 & 3.03 & 3.35 & 3.34 & 3.21 & 3.25 & 3.39 & 3.27 & 2.91 & 2.84 & 2.52 & 2.68 & 2.88 & 2.21 \\
\hline $16-19$ years & 3.55 & 3.31 & 3.60 & 3.54 & 3.80 & 3.85 & 3.69 & 3.60 & 3.11 & 3.45 & 3.17 & 2.63 & 2.91 & 3.46 \\
\hline 20-34 years & 3.46 & 3.59 & 3.83 & 4.01 & 3.44 & 3.93 & 3.65 & 4.09 & 3.77 & 3.93 & 3.28 & 3.68 & 3.68 & 2.98 \\
\hline $35-54$ years & 4.07 & 4.06 & 4.42 & 4.38 & 4.57 & 4.46 & 4.36 & 4.36 & 4.63 & 4.29 & 3.71 & 4.18 & 4.12 & 4.20 \\
\hline $55-64$ years & 3.83 & 3.74 & 4.28 & 4.09 & 4.09 & 4.19 & 3.90 & 3.90 & 3.64 & 3.77 & 4.10 & 3.59 & 3.93 & 2.24 \\
\hline $65+$ years & 3.22 & 3.34 & 3.25 & 3.40 & 3.41 & 3.38 & 3.44 & 3.13 & 2.57 & 2.58 & 2.39 & 2.69 & 2.50 & 2.64 \\
\hline TOTAL & 3.62 & 3.62 & 3.90 & 3.92 & 3.91 & 3.94 & 3.84 & 3.86 & 3.66 & 3.65 & 3.27 & 3.52 & 3.53 & 3.23 \\
\hline$\%$ POV & $87.1 \%$ & $88.8 \%$ & $84.3 \%$ & $87.3 \%$ & $83.0 \%$ & $85.1 \%$ & $78.7 \%$ & $83.4 \%$ & $66.7 \%$ & $70.7 \%$ & $39.8 \%$ & $54.8 \%$ & $21.2 \%$ & $24.8 \%$ \\
\hline$\%$ Public & $0.4 \%$ & $0.2 \%$ & $1.2 \%$ & $0.4 \%$ & $1.3 \%$ & $1.1 \%$ & $3.1 \%$ & $1.9 \%$ & $10.8 \%$ & $5.6 \%$ & $24.3 \%$ & $13.6 \%$ & $25.2 \%$ & $23.9 \%$ \\
\hline$\%$ Walk & $6.9 \%$ & $6.8 \%$ & $8.5 \%$ & $7.7 \%$ & $10.4 \%$ & $9.8 \%$ & $14.0 \%$ & $11.3 \%$ & $18.4 \%$ & $19.0 \%$ & $30.5 \%$ & $26.6 \%$ & $47.6 \%$ & $47.9 \%$ \\
\hline$\%$ Other & $5.4 \%$ & $4.1 \%$ & $5.8 \%$ & $4.4 \%$ & $5.1 \%$ & $3.9 \%$ & $4.2 \%$ & $3.2 \%$ & $3.8 \%$ & $4.4 \%$ & $5.2 \%$ & $5.0 \%$ & $6.0 \%$ & $3.4 \%$ \\
\hline$\%$ Unreported & $0.2 \%$ & $0.2 \%$ & $0.1 \%$ & $0.2 \%$ & $0.3 \%$ & $0.1 \%$ & $0.1 \%$ & $0.3 \%$ & $0.4 \%$ & $0.3 \%$ & $0.2 \%$ & $0.1 \%$ & $0.0 \%$ & \\
\hline TOTAL & 3.62 & $\begin{array}{r}3.62 \\
\end{array}$ & 3.90 & $\begin{array}{r}3.92 \\
\end{array}$ & 3.91 & $\begin{array}{r}3.94 \\
\end{array}$ & 3.84 & 3.86 & 3.66 & $\begin{array}{r}3.65 \\
\end{array}$ & 3.27 & 3.52 & 3.53 & 3.23 \\
\hline$\%$ SOV & $45.3 \%$ & $41.9 \%$ & $45.9 \%$ & $41.0 \%$ & $44.2 \%$ & $41.2 \%$ & $40.9 \%$ & $39.9 \%$ & $33.3 \%$ & $32.4 \%$ & $15.1 \%$ & $24.2 \%$ & $6.0 \%$ & $19.3 \%$ \\
\hline$\%$ MOV & $41.8 \%$ & $46.9 \%$ & $38.4 \%$ & $46.3 \%$ & $38.8 \%$ & $43.9 \%$ & $37.8 \%$ & $43.4 \%$ & $33.3 \%$ & $38.3 \%$ & $24.8 \%$ & $30.6 \%$ & $15.2 \%$ & $5.6 \%$ \\
\hline$\%$ Amtrak & $0.0 \%$ & $0.0 \%$ & $0.0 \%$ & $0.0 \%$ & $0.0 \%$ & $0.0 \%$ & & $0.0 \%$ & $0.1 \%$ & $0.1 \%$ & $1.1 \%$ & $0.1 \%$ & $0.2 \%$ & $0.4 \%$ \\
\hline$\%$ Commuter Train & $0.1 \%$ & $0.0 \%$ & $0.4 \%$ & $0.1 \%$ & $0.6 \%$ & $0.1 \%$ & $0.6 \%$ & $0.2 \%$ & $0.6 \%$ & $0.1 \%$ & $1.9 \%$ & $1.1 \%$ & $1.7 \%$ & $0.6 \%$ \\
\hline$\%$ Subway/El Rail & $0.1 \%$ & $0.0 \%$ & $0.2 \%$ & $0.0 \%$ & $0.3 \%$ & $0.1 \%$ & $0.6 \%$ & $0.1 \%$ & $2.0 \%$ & $0.4 \%$ & $10.5 \%$ & $2.5 \%$ & $11.0 \%$ & $4.7 \%$ \\
\hline$\%$ Other Public & $0.2 \%$ & $0.1 \%$ & $0.6 \%$ & $0.3 \%$ & $0.4 \%$ & $0.7 \%$ & $1.5 \%$ & $1.4 \%$ & $7.4 \%$ & $4.4 \%$ & $11.0 \%$ & $9.4 \%$ & $10.9 \%$ & $16.9 \%$ \\
\hline$\%$ Walk & $6.9 \%$ & $6.8 \%$ & $8.5 \%$ & $7.7 \%$ & $10.4 \%$ & $9.8 \%$ & $14.0 \%$ & $11.3 \%$ & $18.4 \%$ & $19.0 \%$ & $30.5 \%$ & $26.6 \%$ & $47.6 \%$ & $47.9 \%$ \\
\hline$\%$ Other & $5.5 \%$ & $4.1 \%$ & $5.9 \%$ & $4.5 \%$ & $5.1 \%$ & $4.1 \%$ & $4.6 \%$ & $3.4 \%$ & $4.4 \%$ & $5.1 \%$ & $4.9 \%$ & $5.4 \%$ & $7.3 \%$ & $4.7 \%$ \\
\hline$\%$ Unreported & $0.2 \%$ & $0.2 \%$ & $0.1 \%$ & $0.2 \%$ & $0.3 \%$ & $0.1 \%$ & $0.1 \%$ & $0.3 \%$ & $0.4 \%$ & $0.3 \%$ & $0.2 \%$ & $0.1 \%$ & $0.0 \%$ & \\
\hline TOTAL & 3.62 & 3.62 & 3.90 & 3.92 & 3.91 & 3.94 & 3.84 & 3.86 & 3.66 & 3.65 & 3.27 & 3.52 & 3.53 & 3.23 \\
\hline$\%$ Earn a Living & $20.4 \%$ & $20.1 \%$ & $19.5 \%$ & $18.3 \%$ & $18.2 \%$ & $18.1 \%$ & $18.9 \%$ & $18.2 \%$ & $14.9 \%$ & $16.7 \%$ & $19.0 \%$ & $18.8 \%$ & $16.6 \%$ & $30.5 \%$ \\
\hline$\%$ Family \& Personal Business & $42.7 \%$ & $41.3 \%$ & $41.2 \%$ & $41.8 \%$ & $42.0 \%$ & $42.4 \%$ & $44.4 \%$ & $42.8 \%$ & $44.8 \%$ & $44.3 \%$ & $44.9 \%$ & $41.8 \%$ & $42.9 \%$ & $30.6 \%$ \\
\hline$\%$ Civic, Educational \& Religious & $8.8 \%$ & $9.0 \%$ & $9.6 \%$ & $10.1 \%$ & $8.3 \%$ & $9.8 \%$ & $9.4 \%$ & $9.2 \%$ & $14.3 \%$ & $10.7 \%$ & $8.3 \%$ & $11.4 \%$ & $9.7 \%$ & $3.9 \%$ \\
\hline$\%$ Social \& Recreational & $26.6 \%$ & $27.9 \%$ & $27.7 \%$ & $28.2 \%$ & $29.7 \%$ & $27.8 \%$ & $25.6 \%$ & $28.1 \%$ & $23.7 \%$ & $27.0 \%$ & $24.9 \%$ & $24.9 \%$ & $28.6 \%$ & $28.4 \%$ \\
\hline$\%$ Other & $0.7 \%$ & $0.7 \%$ & $1.2 \%$ & $0.7 \%$ & $1.1 \%$ & $1.0 \%$ & $0.9 \%$ & $0.9 \%$ & $1.5 \%$ & $0.6 \%$ & $0.9 \%$ & $1.9 \%$ & $1.5 \%$ & \\
\hline$\%$ Unreported & $0.8 \%$ & $1.0 \%$ & $0.9 \%$ & $0.9 \%$ & $0.7 \%$ & $1.0 \%$ & $0.9 \%$ & $1.0 \%$ & $0.8 \%$ & $0.7 \%$ & $1.9 \%$ & $1.2 \%$ & $0.7 \%$ & $6.7 \%$ \\
\hline TOTAL & 3.62 & 3.62 & 3.90 & 3.92 & 3.91 & 3.94 & 3.84 & 3.86 & 3.66 & 3.65 & 3.27 & 3.52 & 3.53 & 3.23 \\
\hline Weekend & 3.42 & 3.19 & 3.50 & 3.68 & 3.73 & 3.75 & 3.41 & 3.60 & 3.62 & 3.45 & 3.14 & 3.07 & 3.30 & 4.16 \\
\hline Weekday & 3.69 & 3.81 & 4.07 & 4.01 & 4.00 & 4.01 & 3.96 & 3.97 & 3.67 & 3.72 & 3.33 & 3.71 & 3.62 & 3.10 \\
\hline
\end{tabular}




\begin{tabular}{|c|c|c|c|c|c|c|c|c|c|c|c|c|c|c|}
\hline \multicolumn{15}{|c|}{ Population Density (census tract) } \\
\hline & \multicolumn{2}{|c|}{$\begin{array}{c}<00 \\
x_{S}\end{array}$} & \multicolumn{2}{|c|}{$500-2,000$} & \multicolumn{2}{|c|}{$2,000-4,000$} & \multicolumn{2}{|c|}{$4,000-10,000$} & \multicolumn{2}{|c|}{$10,000-20,000$} & \multicolumn{2}{|c|}{$20,000-50,000$} & \multicolumn{2}{|c|}{$50,000+$} \\
\hline & NY State & U.S. & NY State & U.S. & NY State & U.S. & NY State & U.S. & NY State & U.S. & NY State & U.S. & NY State & U.S. \\
\hline Daily Person Trips per Person & & & & & & & & & & & & & & \\
\hline TOTAL & 3.80 & 4.01 & 4.10 & 4.33 & 4.11 & 4.31 & 3.93 & 4.11 & 3.42 & 3.74 & 3.51 & 3.57 & 3.40 & 3.60 \\
\hline Male & 3.74 & 4.01 & 4.05 & 4.30 & 4.06 & 4.25 & 3.90 & 4.09 & 3.46 & 3.87 & 3.76 & 3.82 & 3.46 & 3.84 \\
\hline Female & 3.86 & 4.01 & 4.14 & 4.37 & 4.16 & 4.36 & 3.95 & 4.13 & 3.39 & 3.61 & 3.28 & 3.35 & 3.34 & 2.98 \\
\hline TOTAL & 3.80 & 4.01 & 4.10 & 4.33 & 4.11 & 4.31 & 3.93 & 4.11 & 3.42 & 3.74 & 3.51 & 3.57 & 3.40 & 3.60 \\
\hline $0-4$ years & 2.84 & 3.12 & 2.78 & 3.53 & 2.83 & 3.35 & 2.44 & 3.05 & 2.31 & 2.94 & 2.84 & 3.30 & 2.72 & \\
\hline $5-15$ years & 3.07 & 3.42 & 3.27 & 3.74 & 3.47 & 3.45 & 3.00 & 3.43 & 2.71 & 3.06 & 2.83 & 3.15 & 2.63 & 0.84 \\
\hline $16-19$ years & 3.44 & 4.04 & 4.13 & 4.52 & 4.23 & 4.38 & 3.88 & 4.11 & 3.13 & 3.31 & 3.49 & 3.58 & 2.83 & 2.00 \\
\hline $20-34$ years & 3.79 & 4.28 & 4.14 & 4.53 & 4.04 & 4.48 & 3.98 & 4.28 & 3.66 & 4.00 & 3.73 & 3.86 & 3.85 & 3.87 \\
\hline $35-54$ years & 4.25 & 4.42 & 4.62 & 4.79 & 4.40 & 4.93 & 4.52 & 4.67 & 4.02 & 4.25 & 4.17 & 4.15 & 3.72 & 3.15 \\
\hline $55-64$ years & 3.99 & 4.08 & 4.36 & 4.36 & 4.51 & 4.31 & 4.12 & 4.09 & 3.11 & 3.61 & 4.23 & 3.60 & 3.46 & 4.89 \\
\hline $65+$ years & 3.65 & 3.37 & 3.61 & 3.70 & 4.05 & 3.64 & 3.60 & 3.41 & 2.73 & 2.75 & 2.33 & 2.07 & 2.67 & 1.14 \\
\hline Unreported & 3.83 & 3.36 & 3.88 & 3.62 & 4.16 & 3.94 & 3.28 & 3.86 & 3.64 & 4.03 & 2.66 & 2.06 & 2.98 & 3.46 \\
\hline TOTAL & 3.80 & 4.01 & 4.10 & 4.33 & 4.11 & 4.31 & 3.93 & 4.11 & 3.42 & 3.74 & 3.51 & 3.57 & 3.40 & 3.60 \\
\hline$\% \mathrm{POV}$ & $86.4 \%$ & $90.5 \%$ & $87.3 \%$ & $89.8 \%$ & $86.2 \%$ & $89.0 \%$ & $80.6 \%$ & $86.0 \%$ & $67.1 \%$ & $75.7 \%$ & $45.1 \%$ & $65.6 \%$ & $23.6 \%$ & $37.8 \%$ \\
\hline$\%$ Public & $1.3 \%$ & $0.1 \%$ & $0.7 \%$ & $0.4 \%$ & $1.6 \%$ & $0.8 \%$ & $3.0 \%$ & $1.7 \%$ & $9.3 \%$ & $4.9 \%$ & $18.2 \%$ & $9.8 \%$ & $26.9 \%$ & $24.4 \%$ \\
\hline$\%$ Walk & $7.2 \%$ & $5.5 \%$ & $7.3 \%$ & $5.9 \%$ & $7.7 \%$ & $7.5 \%$ & $11.6 \%$ & $9.7 \%$ & $19.3 \%$ & $16.2 \%$ & $32.4 \%$ & $20.4 \%$ & $43.9 \%$ & $34.0 \%$ \\
\hline$\%$ Other & $5.0 \%$ & $3.8 \%$ & $4.6 \%$ & $3.7 \%$ & $4.4 \%$ & $2.6 \%$ & $4.7 \%$ & $2.6 \%$ & $4.1 \%$ & $3.3 \%$ & $4.3 \%$ & $4.1 \%$ & $5.5 \%$ & $3.8 \%$ \\
\hline$\%$ Unreported & $0.1 \%$ & $0.1 \%$ & $0.1 \%$ & $0.1 \%$ & $0.1 \%$ & $0.1 \%$ & $0.1 \%$ & $0.1 \%$ & $0.2 \%$ & $0.0 \%$ & $0.1 \%$ & $0.1 \%$ & $0.1 \%$ & $0.1 \%$ \\
\hline TOTAL & 3.80 & 4.01 & 4.10 & 4.33 & 4.11 & 4.31 & 3.93 & 4.11 & 3.42 & 3.74 & 3.51 & 3.57 & 3.40 & 3.60 \\
\hline$\%$ SOV & $42.1 \%$ & $41.8 \%$ & $44.2 \%$ & $40.8 \%$ & $39.9 \%$ & $42.3 \%$ & $39.0 \%$ & $39.0 \%$ & $32.5 \%$ & $33.8 \%$ & $18.2 \%$ & $27.6 \%$ & $8.0 \%$ & $22.4 \%$ \\
\hline$\%$ MOV & $44.2 \%$ & $48.7 \%$ & $43.0 \%$ & $49.0 \%$ & $46.3 \%$ & $46.7 \%$ & $41.6 \%$ & $47.0 \%$ & $34.6 \%$ & $41.9 \%$ & $26.8 \%$ & $38.0 \%$ & $15.6 \%$ & $15.3 \%$ \\
\hline$\%$ Amtrak & $0.0 \%$ & $0.0 \%$ & $0.1 \%$ & $0.0 \%$ & $0.1 \%$ & $0.1 \%$ & $0.2 \%$ & $0.0 \%$ & $0.5 \%$ & $0.1 \%$ & $0.3 \%$ & & $0.4 \%$ & \\
\hline$\%$ Commuter Train & $0.2 \%$ & $0.0 \%$ & $0.2 \%$ & $0.0 \%$ & $0.6 \%$ & $0.1 \%$ & $0.9 \%$ & $0.2 \%$ & $0.4 \%$ & $0.1 \%$ & $0.5 \%$ & $0.2 \%$ & $0.4 \%$ & \\
\hline \% Subway/El Rail & $0.4 \%$ & $0.0 \%$ & $0.3 \%$ & $0.1 \%$ & $0.5 \%$ & $0.1 \%$ & $0.8 \%$ & $0.2 \%$ & $4.8 \%$ & $0.8 \%$ & $10.0 \%$ & $1.7 \%$ & $16.1 \%$ & $5.0 \%$ \\
\hline$\%$ Other Public & $0.7 \%$ & $0.1 \%$ & $0.1 \%$ & $0.2 \%$ & $0.5 \%$ & $0.5 \%$ & $1.2 \%$ & $1.3 \%$ & $4.0 \%$ & $3.9 \%$ & $7.4 \%$ & $7.7 \%$ & $10.3 \%$ & $19.5 \%$ \\
\hline$\%$ Walk & $7.2 \%$ & $5.5 \%$ & $7.3 \%$ & $5.9 \%$ & $7.7 \%$ & $7.5 \%$ & $11.6 \%$ & $9.7 \%$ & $19.3 \%$ & $16.2 \%$ & $32.4 \%$ & $20.4 \%$ & $43.9 \%$ & $34.0 \%$ \\
\hline$\%$ Other & $5.1 \%$ & $3.8 \%$ & $4.6 \%$ & $3.8 \%$ & $4.4 \%$ & $2.6 \%$ & $4.7 \%$ & $2.6 \%$ & $3.7 \%$ & $3.4 \%$ & $4.3 \%$ & $4.3 \%$ & $5.2 \%$ & $3.8 \%$ \\
\hline$\%$ Unreported & $0.1 \%$ & $0.1 \%$ & $0.1 \%$ & $0.1 \%$ & $0.1 \%$ & $0.1 \%$ & $0.1 \%$ & $0.1 \%$ & $0.2 \%$ & $0.0 \%$ & $0.1 \%$ & $0.1 \%$ & $0.1 \%$ & $0.1 \%$ \\
\hline TOTAL & 3.80 & 4.01 & 4.10 & 4.33 & 4.11 & 4.31 & 3.93 & 4.11 & 3.42 & 3.74 & 3.51 & 3.57 & 3.40 & 3.60 \\
\hline \% Earn a Living & $19.0 \%$ & $19.2 \%$ & $18.8 \%$ & $17.9 \%$ & $18.8 \%$ & $18.6 \%$ & $18.3 \%$ & $18.7 \%$ & $22.4 \%$ & $20.6 \%$ & $19.2 \%$ & $22.3 \%$ & $19.9 \%$ & $15.1 \%$ \\
\hline$\%$ Family \& Personal Business & $42.3 \%$ & $43.5 \%$ & $43.2 \%$ & $43.5 \%$ & $44.4 \%$ & $44.0 \%$ & $44.7 \%$ & $44.7 \%$ & $40.1 \%$ & $43.1 \%$ & $45.8 \%$ & $41.6 \%$ & $41.3 \%$ & $50.1 \%$ \\
\hline$\%$ Civic, Educational \& Religious & $9.0 \%$ & $10.4 \%$ & $8.3 \%$ & $9.6 \%$ & $7.6 \%$ & $9.4 \%$ & $9.8 \%$ & $9.4 \%$ & $11.5 \%$ & $8.8 \%$ & $10.5 \%$ & $9.9 \%$ & $11.2 \%$ & $6.4 \%$ \\
\hline \% Social \& Recreational & $28.3 \%$ & $26.0 \%$ & $28.2 \%$ & $28.0 \%$ & $28.3 \%$ & $27.0 \%$ & $25.2 \%$ & $26.4 \%$ & $24.3 \%$ & $26.6 \%$ & $22.4 \%$ & $25.0 \%$ & $26.5 \%$ & $26.5 \%$ \\
\hline$\%$ Other & $1.0 \%$ & $0.8 \%$ & $1.1 \%$ & $0.9 \%$ & $0.7 \%$ & $0.9 \%$ & $1.6 \%$ & $0.7 \%$ & $1.6 \%$ & $0.8 \%$ & $1.7 \%$ & $1.2 \%$ & $1.0 \%$ & $0.0 \%$ \\
\hline$\%$ Unreported & $0.3 \%$ & $0.1 \%$ & $0.3 \%$ & $0.1 \%$ & $0.2 \%$ & $0.1 \%$ & $0.4 \%$ & $0.1 \%$ & $0.1 \%$ & $0.2 \%$ & $0.5 \%$ & $0.0 \%$ & $0.2 \%$ & $2.1 \%$ \\
\hline TOTAL & 3.80 & 4.01 & 4.10 & 4.33 & 4.11 & 4.31 & 3.93 & 4.11 & 3.42 & 3.74 & 3.51 & 3.57 & 3.40 & 3.60 \\
\hline Weekend & 3.59 & 3.69 & 3.96 & 4.20 & 3.98 & 4.01 & 3.78 & 3.97 & 3.17 & 3.84 & 3.03 & 3.40 & 3.00 & 2.63 \\
\hline Weekday & 3.89 & 4.14 & 4.15 & 4.38 & 4.17 & 4.43 & 3.98 & 4.17 & 3.52 & 3.70 & 3.70 & 3.65 & 3.58 & 3.93 \\
\hline
\end{tabular}




\begin{tabular}{|c|c|c|c|c|c|c|c|c|c|c|c|c|c|c|}
\hline \multicolumn{15}{|c|}{ Population Density (census tract) } \\
\hline & \multicolumn{2}{|c|}{$<500$} & \multicolumn{2}{|c|}{$500-2,000$} & \multicolumn{2}{|c|}{$2,000-4,000$} & \multicolumn{2}{|c|}{$4,000-10,000$} & \multicolumn{2}{|c|}{$10,000-20,000$} & \multicolumn{2}{|c|}{$20,000-50,000$} & \multicolumn{2}{|c|}{$50,000+$} \\
\hline & NY State & U.S. & NY State & U.S. & NY State & U.S. & NY State & U.S. & NY State & U.S. & NY State & U.S. & NY State & U.S. \\
\hline \multicolumn{15}{|l|}{ Daily Person Trips per Person } \\
\hline TOTAL & 4.06 & 4.17 & 4.24 & 4.36 & 4.34 & 4.45 & 4.01 & 4.36 & 3.62 & 4.03 & 3.76 & 4.09 & 3.46 & 3.50 \\
\hline Male & 4.07 & 4.18 & 4.24 & 4.39 & 4.44 & 4.49 & 4.09 & 4.38 & 3.60 & 4.08 & 3.71 & 4.47 & 3.55 & 3.26 \\
\hline Female & 4.06 & 4.15 & 4.25 & 4.33 & 4.24 & 4.42 & 3.93 & 4.33 & 3.63 & 3.99 & 3.82 & 3.78 & 3.38 & 3.83 \\
\hline TOTAL & 4.06 & 4.17 & 4.24 & 4.36 & 4.34 & 4.45 & 4.01 & 4.36 & 3.62 & 4.03 & 3.76 & 4.09 & 3.46 & 3.50 \\
\hline $5-15$ years & 3.62 & 3.58 & 3.72 & 3.76 & 3.37 & 3.74 & 3.38 & 3.86 & 2.96 & 3.14 & 3.19 & 3.13 & 3.03 & 2.00 \\
\hline $16-19$ years & 4.16 & 4.74 & 4.43 & 4.82 & 4.47 & 4.79 & 4.31 & 4.48 & 3.23 & 4.19 & 3.38 & 4.35 & 3.01 & \\
\hline 20-34 years & 3.95 & 4.55 & 4.28 & 4.57 & 4.50 & 4.85 & 4.38 & 4.69 & 4.01 & 4.55 & 4.03 & 4.43 & 3.93 & 3.80 \\
\hline $35-54$ years & 4.49 & 4.51 & 4.68 & 4.89 & 4.77 & 4.84 & 4.49 & 4.68 & 4.11 & 4.31 & 4.13 & 4.60 & 3.62 & 4.15 \\
\hline $55-64$ years & 4.18 & 4.18 & 4.65 & 4.17 & 4.63 & 4.44 & 3.70 & 4.21 & 3.59 & 3.92 & 3.22 & 4.24 & 3.06 & \\
\hline $65+$ years & 3.60 & 3.21 & 3.58 & 3.47 & 3.99 & 3.57 & 3.19 & 3.57 & 2.85 & 3.21 & 3.55 & 2.80 & 2.42 & 3.34 \\
\hline TOTAL & 4.06 & 4.17 & 4.24 & 4.36 & 4.34 & 4.45 & 4.01 & 4.36 & 3.62 & 4.03 & 3.76 & 4.09 & 3.46 & 3.50 \\
\hline$\%$ POV & $87.7 \%$ & $90.6 \%$ & $86.8 \%$ & $89.7 \%$ & $86.4 \%$ & $88.5 \%$ & $81.8 \%$ & $86.0 \%$ & $69.1 \%$ & $75.2 \%$ & $41.8 \%$ & $57.2 \%$ & $23.4 \%$ & $45.4 \%$ \\
\hline$\%$ Public & $1.0 \%$ & $0.2 \%$ & $0.9 \%$ & $0.5 \%$ & $1.6 \%$ & $1.1 \%$ & $3.0 \%$ & $1.8 \%$ & $10.2 \%$ & $6.5 \%$ & $18.6 \%$ & $10.5 \%$ & $27.7 \%$ & $20.3 \%$ \\
\hline$\%$ Walk & $3.9 \%$ & $2.4 \%$ & $4.5 \%$ & $3.0 \%$ & $4.1 \%$ & $4.7 \%$ & $7.2 \%$ & $6.2 \%$ & $12.4 \%$ & $11.7 \%$ & $30.3 \%$ & $22.7 \%$ & $36.1 \%$ & $28.9 \%$ \\
\hline$\%$ Other & $4.4 \%$ & $3.6 \%$ & $4.2 \%$ & $3.7 \%$ & $4.1 \%$ & $2.7 \%$ & $3.7 \%$ & $2.3 \%$ & $3.0 \%$ & $2.2 \%$ & $4.0 \%$ & $3.4 \%$ & $6.4 \%$ & $1.4 \%$ \\
\hline$\%$ Unreported & $3.0 \%$ & $3.1 \%$ & $3.5 \%$ & $3.2 \%$ & $3.7 \%$ & $2.9 \%$ & $4.2 \%$ & $3.7 \%$ & $5.2 \%$ & $4.5 \%$ & $5.3 \%$ & $6.1 \%$ & $6.4 \%$ & $4.0 \%$ \\
\hline TOTAL & 4.06 & 4.17 & 4.24 & 4.36 & 4.34 & 4.45 & 4.01 & 4.36 & 3.62 & 4.03 & 3.76 & 4.09 & 3.46 & 3.50 \\
\hline$\%$ SOV & $43.1 \%$ & $43.4 \%$ & $41.7 \%$ & $42.9 \%$ & $46.8 \%$ & $44.3 \%$ & $39.7 \%$ & $42.0 \%$ & $32.0 \%$ & $36.7 \%$ & $18.4 \%$ & $23.2 \%$ & $7.2 \%$ & $25.4 \%$ \\
\hline$\% \mathrm{MOV}$ & $44.6 \%$ & $47.0 \%$ & $45.0 \%$ & $46.8 \%$ & $39.4 \%$ & $44.3 \%$ & $42.1 \%$ & $44.0 \%$ & $37.0 \%$ & $38.5 \%$ & $23.1 \%$ & $34.0 \%$ & $16.2 \%$ & $20.0 \%$ \\
\hline$\%$ Other POV & $0.0 \%$ & $0.2 \%$ & $0.0 \%$ & $0.0 \%$ & $0.2 \%$ & $0.0 \%$ & $0.0 \%$ & $0.0 \%$ & $0.0 \%$ & $0.0 \%$ & $0.3 \%$ & $0.0 \%$ & $0.0 \%$ & \\
\hline$\%$ Amtrak & $0.0 \%$ & $0.0 \%$ & $0.0 \%$ & $0.0 \%$ & $0.0 \%$ & $0.0 \%$ & $0.0 \%$ & $0.0 \%$ & & $0.0 \%$ & $0.0 \%$ & & $0.0 \%$ & \\
\hline$\%$ Commuter Train & $0.2 \%$ & $0.0 \%$ & $0.5 \%$ & $0.0 \%$ & $0.7 \%$ & $0.2 \%$ & $0.7 \%$ & $0.2 \%$ & $0.8 \%$ & $0.5 \%$ & $1.9 \%$ & $0.5 \%$ & $3.5 \%$ & $0.6 \%$ \\
\hline$\%$ Subway/El Rail & $0.2 \%$ & $0.0 \%$ & $0.0 \%$ & $0.0 \%$ & $0.2 \%$ & $0.0 \%$ & $0.7 \%$ & $0.0 \%$ & $3.0 \%$ & $1.0 \%$ & $8.2 \%$ & $1.7 \%$ & $13.3 \%$ & $6.9 \%$ \\
\hline$\%$ Other Public & $0.5 \%$ & $0.2 \%$ & $0.5 \%$ & $0.5 \%$ & $0.7 \%$ & $0.9 \%$ & $1.5 \%$ & $1.6 \%$ & $6.4 \%$ & $5.0 \%$ & $8.5 \%$ & $8.3 \%$ & $11.0 \%$ & $12.9 \%$ \\
\hline$\%$ Walk & $3.9 \%$ & $2.4 \%$ & $4.5 \%$ & $3.0 \%$ & $4.1 \%$ & $4.7 \%$ & $7.2 \%$ & $6.2 \%$ & $12.4 \%$ & $11.7 \%$ & $30.3 \%$ & $22.7 \%$ & $36.1 \%$ & $28.9 \%$ \\
\hline$\%$ Other & $4.4 \%$ & $3.6 \%$ & $4.2 \%$ & $3.7 \%$ & $4.1 \%$ & $2.7 \%$ & $3.7 \%$ & $2.3 \%$ & $3.0 \%$ & $2.2 \%$ & $4.0 \%$ & $3.4 \%$ & $6.4 \%$ & $1.4 \%$ \\
\hline$\%$ Unreported & $3.0 \%$ & $3.1 \%$ & $3.5 \%$ & $3.2 \%$ & $3.7 \%$ & $2.9 \%$ & $4.2 \%$ & $3.7 \%$ & $5.2 \%$ & $4.5 \%$ & $5.3 \%$ & $6.1 \%$ & $6.4 \%$ & $4.0 \%$ \\
\hline TOTAL & 4.06 & 4.17 & 4.24 & 4.36 & 4.34 & 4.45 & 4.01 & 4.36 & 3.62 & 4.03 & 3.76 & 4.09 & 3.46 & 3.50 \\
\hline$\%$ Earn a Living & $20.4 \%$ & $20.7 \%$ & $19.1 \%$ & $19.7 \%$ & $19.3 \%$ & $20.9 \%$ & $20.1 \%$ & $20.0 \%$ & $22.3 \%$ & $19.8 \%$ & $17.8 \%$ & $19.1 \%$ & $20.6 \%$ & $29.1 \%$ \\
\hline$\%$ Family \& Pers & $45.7 \%$ & $45.9 \%$ & $45.0 \%$ & $45.5 \%$ & $47.4 \%$ & $45.4 \%$ & $46.9 \%$ & $47.2 \%$ & $46.6 \%$ & $45.0 \%$ & $47.7 \%$ & $46.6 \%$ & $43.8 \%$ & $35.0 \%$ \\
\hline \% Civic, Educational \& Religious & $7.9 \%$ & $8.7 \%$ & $8.5 \%$ & $9.2 \%$ & $8.0 \%$ & $8.5 \%$ & $9.0 \%$ & $8.0 \%$ & $9.1 \%$ & $10.1 \%$ & $10.6 \%$ & $9.3 \%$ & $10.7 \%$ & $6.6 \%$ \\
\hline$\%$ Social \& Recreational & $25.8 \%$ & $24.8 \%$ & $27.4 \%$ & $25.4 \%$ & $25.1 \%$ & $24.9 \%$ & $24.1 \%$ & $24.5 \%$ & $22.0 \%$ & $24.8 \%$ & $23.9 \%$ & $25.0 \%$ & $24.9 \%$ & $29.3 \%$ \\
\hline$\%$ Other & $0.2 \%$ & $0.0 \%$ & $0.0 \%$ & $0.2 \%$ & $0.2 \%$ & $0.2 \%$ & $0.0 \%$ & $0.2 \%$ & $0.0 \%$ & $0.2 \%$ & $0.0 \%$ & $0.0 \%$ & $0.0 \%$ & \\
\hline TOTAL & 4.06 & 4.17 & 4.24 & 4.36 & 4.34 & 4.45 & 4.01 & 4.36 & 3.62 & 4.03 & 3.76 & 4.09 & 3.46 & 3.50 \\
\hline Weekend & 3.89 & 3.86 & 3.90 & 4.10 & 4.24 & 4.07 & 3.80 & 4.12 & 3.60 & 3.76 & 3.47 & 4.16 & 3.05 & 2.58 \\
\hline Weekday & 4.13 & 4.29 & 4.36 & 4.47 & 4.38 & 4.60 & 4.10 & 4.45 & 3.63 & 4.17 & 3.91 & 4.06 & 3.62 & 3.65 \\
\hline
\end{tabular}




\begin{tabular}{|c|c|c|c|c|c|c|c|c|c|c|c|c|c|c|}
\hline \multicolumn{15}{|c|}{ Population Density (census tract) } \\
\hline & \multicolumn{2}{|c|}{$<500$} & \multicolumn{2}{|c|}{$500-2,000$} & \multicolumn{2}{|c|}{$2,000-4,000$} & \multicolumn{2}{|c|}{$4,000-10,000$} & \multicolumn{2}{|c|}{$10,000-20,000$} & \multicolumn{2}{|c|}{$20,000-50,000$} & \multicolumn{2}{|c|}{$50,000+$} \\
\hline & NY State & U.S. & NY State & U.S. & NY State & U.S. & NY State & U.S. & NY State & U.S. & NY State & U.S. & NY State & U.S. \\
\hline \multicolumn{15}{|l|}{ Daily Person Trips per Person } \\
\hline TOTAL & 3.62 & 3.62 & 3.90 & 3.92 & 3.91 & 3.94 & 3.84 & 3.86 & 3.66 & 3.65 & 3.27 & 3.52 & 3.53 & 3.23 \\
\hline$\% 1-9 \min$ & $30.1 \%$ & $26.6 \%$ & $31.6 \%$ & $29.9 \%$ & $32.8 \%$ & $29.9 \%$ & $33.3 \%$ & $29.4 \%$ & $29.3 \%$ & $25.7 \%$ & $18.6 \%$ & $22.8 \%$ & $21.8 \%$ & $15.2 \%$ \\
\hline$\% 10-19$ min & $32.5 \%$ & $34.8 \%$ & $37.6 \%$ & $37.8 \%$ & $36.1 \%$ & $38.3 \%$ & $35.0 \%$ & $37.8 \%$ & $32.9 \%$ & $36.6 \%$ & $27.8 \%$ & $33.4 \%$ & $28.1 \%$ & $33.8 \%$ \\
\hline$\% 20-29 \min$ & $15.3 \%$ & $15.1 \%$ & $13.9 \%$ & $13.7 \%$ & $13.7 \%$ & $13.8 \%$ & $13.3 \%$ & $14.2 \%$ & $14.2 \%$ & $13.9 \%$ & $12.9 \%$ & $13.7 \%$ & $12.3 \%$ & $13.5 \%$ \\
\hline$\% 30-39 \mathrm{~min}$ & $11.1 \%$ & $11.8 \%$ & $8.7 \%$ & $9.3 \%$ & $8.8 \%$ & $8.9 \%$ & $9.0 \%$ & $9.4 \%$ & $12.0 \%$ & $12.1 \%$ & $14.3 \%$ & $13.6 \%$ & $13.9 \%$ & $27.3 \%$ \\
\hline$\% 40-49$ min & $4.7 \%$ & $5.0 \%$ & $3.2 \%$ & $3.6 \%$ & $3.2 \%$ & $3.5 \%$ & $3.6 \%$ & $3.7 \%$ & $4.3 \%$ & $4.3 \%$ & $8.3 \%$ & $5.3 \%$ & $8.4 \%$ & $2.1 \%$ \\
\hline$\% 50+\min$ & $6.2 \%$ & $6.4 \%$ & $4.8 \%$ & $5.5 \%$ & $5.3 \%$ & $5.3 \%$ & $5.6 \%$ & $5.2 \%$ & $7.2 \%$ & $7.3 \%$ & $17.2 \%$ & $10.8 \%$ & $15.5 \%$ & $7.9 \%$ \\
\hline$\%$ Unreported & $0.1 \%$ & $0.3 \%$ & $0.2 \%$ & $0.2 \%$ & $0.2 \%$ & $0.2 \%$ & $0.2 \%$ & $0.3 \%$ & $0.3 \%$ & $0.1 \%$ & $0.8 \%$ & $0.5 \%$ & $0.1 \%$ & $0.2 \%$ \\
\hline TOTAL & 3.62 & 3.62 & 3.90 & 3.92 & 3.91 & 3.94 & 3.84 & 3.86 & 3.66 & 3.65 & 3.27 & 3.52 & 3.53 & 3.23 \\
\hline$\% 5$ or less miles & $50.7 \%$ & $48.6 \%$ & $61.8 \%$ & $59.7 \%$ & $66.5 \%$ & $64.1 \%$ & $71.2 \%$ & $65.8 \%$ & $74.0 \%$ & $70.9 \%$ & $64.5 \%$ & $70.2 \%$ & $74.3 \%$ & $77.7 \%$ \\
\hline$\%$ 6-10 miles & $19.7 \%$ & $20.1 \%$ & $17.0 \%$ & $17.8 \%$ & $14.0 \%$ & $16.0 \%$ & $12.7 \%$ & $15.4 \%$ & $10.6 \%$ & $12.0 \%$ & $10.2 \%$ & $11.8 \%$ & $8.6 \%$ & $2.9 \%$ \\
\hline$\% 11-15$ miles & $10.4 \%$ & $10.8 \%$ & $7.0 \%$ & $7.6 \%$ & $7.3 \%$ & $6.8 \%$ & $4.5 \%$ & $6.5 \%$ & $4.3 \%$ & $4.6 \%$ & $3.8 \%$ & $5.9 \%$ & $3.4 \%$ & $2.1 \%$ \\
\hline$\% 16-20$ miles & $5.9 \%$ & $6.5 \%$ & $4.0 \%$ & $4.1 \%$ & $3.2 \%$ & $3.5 \%$ & $3.7 \%$ & $3.5 \%$ & $2.4 \%$ & $2.3 \%$ & $3.1 \%$ & $1.9 \%$ & $1.0 \%$ & $0.7 \%$ \\
\hline$\% 21-30$ miles & $5.8 \%$ & $5.9 \%$ & $3.5 \%$ & $4.5 \%$ & $3.7 \%$ & $3.6 \%$ & $3.2 \%$ & $3.3 \%$ & $1.9 \%$ & $2.2 \%$ & $1.1 \%$ & $1.9 \%$ & $0.9 \%$ & $1.3 \%$ \\
\hline$\% 31$ or more miles & $6.0 \%$ & $6.7 \%$ & $4.0 \%$ & $4.6 \%$ & $3.9 \%$ & $3.9 \%$ & $2.7 \%$ & $3.0 \%$ & $1.9 \%$ & $2.9 \%$ & $2.0 \%$ & $3.0 \%$ & $2.3 \%$ & $0.4 \%$ \\
\hline$\%$ Unreported & $1.4 \%$ & $1.4 \%$ & $2.8 \%$ & $1.8 \%$ & $1.4 \%$ & $2.2 \%$ & $2.0 \%$ & $2.5 \%$ & $4.9 \%$ & $5.1 \%$ & $15.2 \%$ & $5.4 \%$ & $9.5 \%$ & $15.0 \%$ \\
\hline \multicolumn{15}{|l|}{ Daily PMT per Person } \\
\hline TOTAL & 41.34 & 44.67 & 35.52 & 39.94 & 30.67 & 36.58 & 27.54 & 30.40 & 17.33 & 23.93 & 16.29 & 23.01 & 15.75 & 7.10 \\
\hline$\%$ POV & $91.3 \%$ & $93.0 \%$ & $86.9 \%$ & $84.8 \%$ & $83.9 \%$ & $88.4 \%$ & $74.5 \%$ & $85.6 \%$ & $76.3 \%$ & $84.9 \%$ & $59.6 \%$ & $72.7 \%$ & $56.1 \%$ & $46.0 \%$ \\
\hline$\%$ Public & $0.7 \%$ & $0.2 \%$ & $2.1 \%$ & $0.4 \%$ & $3.2 \%$ & $1.1 \%$ & $4.0 \%$ & $1.8 \%$ & $15.0 \%$ & $3.6 \%$ & $22.8 \%$ & $20.4 \%$ & $28.4 \%$ & $29.1 \%$ \\
\hline$\%$ Walk & $0.4 \%$ & $0.4 \%$ & $0.6 \%$ & $0.5 \%$ & $1.0 \%$ & $0.7 \%$ & $1.1 \%$ & $1.0 \%$ & $2.7 \%$ & $2.0 \%$ & $4.6 \%$ & $2.7 \%$ & $8.6 \%$ & $14.8 \%$ \\
\hline$\%$ Other & $7.5 \%$ & $6.4 \%$ & $10.3 \%$ & $14.2 \%$ & $11.5 \%$ & $9.6 \%$ & $20.4 \%$ & $11.4 \%$ & $6.0 \%$ & $9.5 \%$ & $12.5 \%$ & $4.2 \%$ & $6.9 \%$ & $10.1 \%$ \\
\hline$\%$ Unreported & $0.1 \%$ & $0.1 \%$ & $0.1 \%$ & $0.1 \%$ & $0.4 \%$ & $0.1 \%$ & $0.0 \%$ & $0.2 \%$ & $0.1 \%$ & $0.1 \%$ & $0.5 \%$ & & & \\
\hline TOTAL & 41.34 & 44.67 & 35.52 & 39.94 & 30.67 & 36.58 & 27.54 & 30.40 & 17.33 & 23.93 & 16.29 & 23.01 & 15.75 & 7.10 \\
\hline$\%$ SOV & $43.4 \%$ & $41.5 \%$ & $41.8 \%$ & $39.3 \%$ & $43.7 \%$ & $36.2 \%$ & $37.1 \%$ & $38.1 \%$ & $37.8 \%$ & $38.2 \%$ & $16.2 \%$ & $34.4 \%$ & $11.6 \%$ & $38.7 \%$ \\
\hline$\%$ MOV & $47.9 \%$ & $51.5 \%$ & $45.1 \%$ & $45.5 \%$ & $40.2 \%$ & $52.2 \%$ & $37.4 \%$ & $47.5 \%$ & $38.5 \%$ & $46.6 \%$ & $43.4 \%$ & $38.3 \%$ & $44.5 \%$ & $7.3 \%$ \\
\hline$\%$ Amtrak & $0.0 \%$ & $0.0 \%$ & $0.1 \%$ & $0.1 \%$ & $0.1 \%$ & $0.1 \%$ & & $0.1 \%$ & $2.5 \%$ & $0.3 \%$ & $0.3 \%$ & $0.2 \%$ & $0.1 \%$ & $0.2 \%$ \\
\hline$\%$ Commuter Train & $0.4 \%$ & $0.0 \%$ & $1.4 \%$ & $0.1 \%$ & $2.6 \%$ & $0.3 \%$ & $1.8 \%$ & $0.2 \%$ & $2.0 \%$ & $0.2 \%$ & $1.6 \%$ & $11.4 \%$ & $3.3 \%$ & $4.5 \%$ \\
\hline$\%$ Subway/El Rail & $0.2 \%$ & $0.0 \%$ & $0.3 \%$ & $0.0 \%$ & $0.3 \%$ & $0.1 \%$ & $0.7 \%$ & $0.2 \%$ & $2.3 \%$ & $0.3 \%$ & $13.4 \%$ & $2.7 \%$ & $15.1 \%$ & $4.8 \%$ \\
\hline$\%$ Other Public & $0.1 \%$ & $0.1 \%$ & $0.4 \%$ & $0.2 \%$ & $0.3 \%$ & $0.5 \%$ & $1.1 \%$ & $1.3 \%$ & $7.5 \%$ & $2.7 \%$ & $6.9 \%$ & $5.9 \%$ & $9.5 \%$ & $17.7 \%$ \\
\hline$\%$ Walk & $0.4 \%$ & $0.4 \%$ & $0.6 \%$ & $0.5 \%$ & $1.0 \%$ & $0.7 \%$ & $1.1 \%$ & $1.0 \%$ & $2.7 \%$ & $2.0 \%$ & $4.6 \%$ & $2.7 \%$ & $8.6 \%$ & $14.8 \%$ \\
\hline$\%$ Other & $7.5 \%$ & $6.5 \%$ & $10.2 \%$ & $14.2 \%$ & $11.4 \%$ & $9.8 \%$ & $20.9 \%$ & $11.5 \%$ & $6.7 \%$ & $9.5 \%$ & $13.2 \%$ & $4.3 \%$ & $7.3 \%$ & $12.0 \%$ \\
\hline$\%$ Unreported & $0.1 \%$ & $0.1 \%$ & $0.1 \%$ & $0.1 \%$ & $0.4 \%$ & $0.1 \%$ & $0.0 \%$ & $0.2 \%$ & $0.1 \%$ & $0.1 \%$ & $0.5 \%$ & & & \\
\hline TOTAL & 41.34 & 44.67 & 35.52 & 39.94 & 30.67 & 36.58 & 27.54 & 30.40 & 17.33 & 23.93 & 16.29 & 23.01 & 15.75 & 7.10 \\
\hline$\%$ Earn a Living & $27.2 \%$ & $27.7 \%$ & $26.8 \%$ & $24.9 \%$ & $27.6 \%$ & $23.1 \%$ & $25.4 \%$ & $25.0 \%$ & $28.2 \%$ & $24.8 \%$ & $41.4 \%$ & $23.7 \%$ & $23.0 \%$ & $48.8 \%$ \\
\hline$\%$ Family \& Pers & $32.5 \%$ & $30.6 \%$ & $26.7 \%$ & $27.1 \%$ & $26.8 \%$ & $26.1 \%$ & $27.0 \%$ & $27.4 \%$ & $31.1 \%$ & $25.9 \%$ & $28.1 \%$ & $24.1 \%$ & $26.8 \%$ & $15.9 \%$ \\
\hline$\%$ Civic, Educational \& Religious & $6.3 \%$ & $5.9 \%$ & $5.4 \%$ & $5.9 \%$ & $5.1 \%$ & $5.7 \%$ & $5.1 \%$ & $5.8 \%$ & $8.4 \%$ & $6.4 \%$ & $5.2 \%$ & $10.3 \%$ & $5.3 \%$ & $9.8 \%$ \\
\hline$\%$ Social \& Recreational & $28.5 \%$ & $29.5 \%$ & $29.4 \%$ & $28.9 \%$ & $35.4 \%$ & $33.0 \%$ & $22.6 \%$ & $32.6 \%$ & $27.3 \%$ & $38.7 \%$ & $24.1 \%$ & $25.9 \%$ & $40.9 \%$ & $24.5 \%$ \\
\hline$\%$ Other & $3.4 \%$ & $2.5 \%$ & $4.8 \%$ & $10.6 \%$ & $4.4 \%$ & $4.9 \%$ & $12.6 \%$ & $5.8 \%$ & $3.6 \%$ & $2.7 \%$ & $0.3 \%$ & $5.0 \%$ & $1.1 \%$ & \\
\hline$\%$ Unreported & $2.1 \%$ & $3.8 \%$ & $7.1 \%$ & $2.6 \%$ & $0.7 \%$ & $7.2 \%$ & $7.3 \%$ & $3.3 \%$ & $1.4 \%$ & $1.5 \%$ & $1.0 \%$ & $11.0 \%$ & $3.0 \%$ & $1.0 \%$ \\
\hline \multicolumn{15}{|l|}{ Average } \\
\hline TOTAL & 11.58 & 12.50 & 9.35 & 10.38 & 7.95 & 9.49 & 7.33 & 8.07 & 4.98 & 6.92 & 5.86 & 6.92 & 4.93 & 2.59 \\
\hline
\end{tabular}




\begin{tabular}{|c|c|c|c|c|c|c|c|c|c|c|c|c|c|c|}
\hline \multicolumn{15}{|c|}{ Population Density (census tract) } \\
\hline & \multicolumn{2}{|c|}{$<500$} & \multicolumn{2}{|c|}{$500-2,000$} & \multicolumn{2}{|c|}{$2,000-4,000$} & \multicolumn{2}{|c|}{$4,000-10,000$} & \multicolumn{2}{|c|}{$10,000-20,000$} & \multicolumn{2}{|c|}{$20,000-50,000$} & \multicolumn{2}{|c|}{$50,000+$} \\
\hline & NY State & U.S. & NY State & U.S. & NY State & U.S. & NY State & U.S. & NY State & U.S. & NY State & U.S. & NY State & U.S. \\
\hline \multicolumn{15}{|l|}{ Daily Person Trips per Person } \\
\hline TOTAL & 3.80 & 4.01 & 4.10 & 4.33 & 4.11 & 4.31 & 3.93 & 4.11 & 3.42 & 3.74 & 3.51 & 3.57 & 3.40 & 3.60 \\
\hline$\% 1-9 \min$ & $27.6 \%$ & $26.1 \%$ & $29.8 \%$ & $28.3 \%$ & $31.2 \%$ & $29.5 \%$ & $31.1 \%$ & $28.3 \%$ & $22.7 \%$ & $23.1 \%$ & $23.1 \%$ & $20.3 \%$ & $20.6 \%$ & $18.0 \%$ \\
\hline$\% 10-19 \min$ & $33.5 \%$ & $35.5 \%$ & $37.0 \%$ & $38.1 \%$ & $35.5 \%$ & $38.0 \%$ & $34.1 \%$ & $37.2 \%$ & $33.0 \%$ & $35.7 \%$ & $30.5 \%$ & $33.8 \%$ & $25.8 \%$ & $22.6 \%$ \\
\hline$\% 20-29 \min$ & $14.8 \%$ & $14.8 \%$ & $13.7 \%$ & $13.8 \%$ & $12.0 \%$ & $13.3 \%$ & $12.5 \%$ & $13.6 \%$ & $12.1 \%$ & $13.0 \%$ & $9.5 \%$ & $12.8 \%$ & $10.5 \%$ & $14.6 \%$ \\
\hline$\%$ 30-39 min & $11.3 \%$ & $11.4 \%$ & $8.2 \%$ & $9.3 \%$ & $8.9 \%$ & $8.8 \%$ & $8.3 \%$ & $9.8 \%$ & $11.3 \%$ & $11.6 \%$ & $11.7 \%$ & $15.1 \%$ & $12.9 \%$ & $20.0 \%$ \\
\hline$\% 40-49 \min$ & $4.4 \%$ & $4.6 \%$ & $3.6 \%$ & $3.9 \%$ & $3.5 \%$ & $3.6 \%$ & $3.4 \%$ & $3.7 \%$ & $4.6 \%$ & $4.8 \%$ & $6.6 \%$ & $5.1 \%$ & $8.2 \%$ & $5.5 \%$ \\
\hline$\% 50+\min$ & $6.2 \%$ & $6.1 \%$ & $6.0 \%$ & $5.1 \%$ & $6.6 \%$ & $5.0 \%$ & $7.4 \%$ & $5.3 \%$ & $11.6 \%$ & $8.5 \%$ & $13.1 \%$ & $8.5 \%$ & $13.6 \%$ & $10.9 \%$ \\
\hline \% Unreported & $2.2 \%$ & $1.5 \%$ & $1.6 \%$ & $1.6 \%$ & $2.4 \%$ & $1.8 \%$ & $3.2 \%$ & $2.0 \%$ & $4.6 \%$ & $3.4 \%$ & $5.6 \%$ & $4.4 \%$ & $8.4 \%$ & $8.4 \%$ \\
\hline TOTAL & 3.80 & 4.01 & 4.10 & 4.33 & 4.11 & 4.31 & 3.93 & 4.11 & 3.42 & 3.74 & 3.51 & 3.57 & 3.40 & 3.60 \\
\hline$\% 5$ or less miles & $52.1 \%$ & $49.2 \%$ & $61.5 \%$ & $58.5 \%$ & $64.6 \%$ & $62.5 \%$ & $67.7 \%$ & $64.0 \%$ & $64.7 \%$ & $64.3 \%$ & $72.9 \%$ & $65.9 \%$ & $70.7 \%$ & $68.5 \%$ \\
\hline$\%$ 6-10 miles & $20.5 \%$ & $20.5 \%$ & $16.7 \%$ & $18.9 \%$ & $15.4 \%$ & $16.7 \%$ & $13.3 \%$ & $15.9 \%$ & $12.6 \%$ & $13.7 \%$ & $9.1 \%$ & $13.0 \%$ & $8.0 \%$ & $6.2 \%$ \\
\hline$\% 11-15$ miles & $9.5 \%$ & $10.7 \%$ & $7.6 \%$ & $8.3 \%$ & $6.5 \%$ & $7.0 \%$ & $5.5 \%$ & $6.9 \%$ & $8.4 \%$ & $6.7 \%$ & $4.2 \%$ & $5.5 \%$ & $3.2 \%$ & $3.6 \%$ \\
\hline$\% 16-20$ miles & $5.9 \%$ & $6.1 \%$ & $4.4 \%$ & $4.1 \%$ & $3.4 \%$ & $3.8 \%$ & $2.8 \%$ & $3.6 \%$ & $3.6 \%$ & $3.2 \%$ & $2.7 \%$ & $3.9 \%$ & $2.0 \%$ & $4.2 \%$ \\
\hline$\% 21-30$ miles & $5.4 \%$ & $5.9 \%$ & $3.4 \%$ & $4.2 \%$ & $3.7 \%$ & $3.8 \%$ & $3.7 \%$ & $3.1 \%$ & $2.7 \%$ & $3.3 \%$ & $1.7 \%$ & $3.2 \%$ & $1.8 \%$ & $1.0 \%$ \\
\hline$\% 31$ or more miles & $5.6 \%$ & $6.1 \%$ & $4.9 \%$ & $4.6 \%$ & $5.0 \%$ & $4.0 \%$ & $3.9 \%$ & $3.8 \%$ & $2.6 \%$ & $3.5 \%$ & $1.6 \%$ & $3.5 \%$ & $1.9 \%$ & $2.2 \%$ \\
\hline \% Unreported & $1.0 \%$ & $1.5 \%$ & $1.6 \%$ & $1.5 \%$ & $1.5 \%$ & $2.2 \%$ & $3.2 \%$ & $2.6 \%$ & $5.4 \%$ & $5.4 \%$ & $7.8 \%$ & $5.1 \%$ & $12.4 \%$ & $14.4 \%$ \\
\hline \multicolumn{15}{|l|}{ Daily PMT per Person } \\
\hline TOTAL & 40.12 & 44.64 & 37.78 & 42.47 & 35.05 & 39.00 & 28.31 & 36.08 & 23.75 & 33.39 & 24.84 & 30.37 & 18.51 & 24.00 \\
\hline$\%$ POV & $91.8 \%$ & $93.9 \%$ & $86.2 \%$ & $88.2 \%$ & $88.8 \%$ & $90.3 \%$ & $84.2 \%$ & $85.8 \%$ & $79.2 \%$ & $69.7 \%$ & $37.2 \%$ & $67.1 \%$ & $42.4 \%$ & $80.8 \%$ \\
\hline$\%$ Public & $1.9 \%$ & $0.2 \%$ & $1.4 \%$ & $0.6 \%$ & $3.3 \%$ & $0.7 \%$ & $5.5 \%$ & $1.6 \%$ & $12.3 \%$ & $3.3 \%$ & $15.2 \%$ & $5.9 \%$ & $25.3 \%$ & $15.6 \%$ \\
\hline$\%$ Walk & $0.6 \%$ & $0.4 \%$ & $0.7 \%$ & $0.5 \%$ & $0.7 \%$ & $0.6 \%$ & $1.3 \%$ & $0.8 \%$ & $2.2 \%$ & $1.2 \%$ & $3.4 \%$ & $1.5 \%$ & $4.9 \%$ & $2.9 \%$ \\
\hline$\%$ Other & $5.7 \%$ & $5.4 \%$ & $11.6 \%$ & $10.7 \%$ & $7.1 \%$ & $6.3 \%$ & $7.2 \%$ & $11.7 \%$ & $6.1 \%$ & $25.8 \%$ & $44.3 \%$ & $25.5 \%$ & $25.6 \%$ & $0.7 \%$ \\
\hline$\%$ Unreported & $0.0 \%$ & $0.2 \%$ & $0.1 \%$ & $0.1 \%$ & $0.2 \%$ & $2.2 \%$ & $1.8 \%$ & $0.1 \%$ & $0.2 \%$ & $0.0 \%$ & $0.0 \%$ & $0.0 \%$ & $1.9 \%$ & $0.0 \%$ \\
\hline TOTAL & 40.12 & 44.64 & 37.78 & 42.47 & 35.05 & 39.00 & 28.31 & 36.08 & 23.75 & 33.39 & 24.84 & 30.37 & 18.51 & 24.00 \\
\hline$\%$ SOV & $42.5 \%$ & $40.3 \%$ & $41.5 \%$ & $38.5 \%$ & $39.7 \%$ & $39.6 \%$ & $36.8 \%$ & $36.6 \%$ & $31.4 \%$ & $27.9 \%$ & $16.3 \%$ & $24.5 \%$ & $13.0 \%$ & $22.8 \%$ \\
\hline$\%$ MOV & $49.3 \%$ & $53.7 \%$ & $44.8 \%$ & $49.6 \%$ & $49.0 \%$ & $50.7 \%$ & $47.4 \%$ & $49.2 \%$ & $47.9 \%$ & $41.8 \%$ & $20.9 \%$ & $42.7 \%$ & $29.4 \%$ & $58.0 \%$ \\
\hline$\%$ Amtrak & $0.6 \%$ & $0.0 \%$ & $0.4 \%$ & $0.0 \%$ & $0.2 \%$ & $0.0 \%$ & $0.6 \%$ & $0.2 \%$ & $0.9 \%$ & $0.4 \%$ & $0.2 \%$ & & $1.7 \%$ & \\
\hline \% Commuter Train & $0.7 \%$ & $0.1 \%$ & $0.7 \%$ & $0.2 \%$ & $2.2 \%$ & $0.1 \%$ & $2.9 \%$ & $0.5 \%$ & $1.4 \%$ & $0.3 \%$ & $0.9 \%$ & $0.2 \%$ & $0.5 \%$ & \\
\hline \% Subway/El Rail & $0.5 \%$ & $0.0 \%$ & $0.3 \%$ & $0.2 \%$ & $0.5 \%$ & $0.1 \%$ & $1.5 \%$ & $0.2 \%$ & $6.9 \%$ & $0.7 \%$ & $9.8 \%$ & $1.1 \%$ & $18.2 \%$ & $3.6 \%$ \\
\hline \% Other Public & $0.6 \%$ & $0.1 \%$ & $0.2 \%$ & $0.2 \%$ & $0.4 \%$ & $0.4 \%$ & $1.0 \%$ & $1.0 \%$ & $3.5 \%$ & $2.3 \%$ & $4.1 \%$ & $3.9 \%$ & $6.5 \%$ & $12.0 \%$ \\
\hline$\%$ Walk & $0.6 \%$ & $0.4 \%$ & $0.7 \%$ & $0.5 \%$ & $0.7 \%$ & $0.6 \%$ & $1.3 \%$ & $0.8 \%$ & $2.2 \%$ & $1.2 \%$ & $3.4 \%$ & $1.5 \%$ & $4.9 \%$ & $2.9 \%$ \\
\hline$\%$ Other & $5.2 \%$ & $5.4 \%$ & $11.4 \%$ & $10.7 \%$ & $7.1 \%$ & $6.3 \%$ & $6.8 \%$ & $11.6 \%$ & $5.7 \%$ & $25.4 \%$ & $44.5 \%$ & $26.2 \%$ & $24.1 \%$ & $0.7 \%$ \\
\hline$\%$ Unreported & $0.0 \%$ & $0.2 \%$ & $0.1 \%$ & $0.1 \%$ & $0.2 \%$ & $2.2 \%$ & $1.8 \%$ & $0.1 \%$ & $0.2 \%$ & $0.0 \%$ & $0.0 \%$ & $0.0 \%$ & $1.9 \%$ & $0.0 \%$ \\
\hline TOTAL & 40.12 & 44.64 & 37.78 & 42.47 & 35.05 & 39.00 & 28.31 & 36.08 & 23.75 & 33.39 & 24.84 & 30.37 & 18.51 & 24.00 \\
\hline$\%$ Earn a Living & $0.3 \%$ & $0.3 \%$ & $0.3 \%$ & $0.3 \%$ & $0.3 \%$ & $0.3 \%$ & $0.3 \%$ & $0.3 \%$ & $0.3 \%$ & $0.4 \%$ & $0.5 \%$ & $0.2 \%$ & $0.2 \%$ & $0.2 \%$ \\
\hline$\%$ Family \& Pers & $0.3 \%$ & $0.3 \%$ & $0.3 \%$ & $0.3 \%$ & $0.3 \%$ & $0.3 \%$ & $0.3 \%$ & $0.3 \%$ & $0.3 \%$ & $0.3 \%$ & $0.2 \%$ & $0.2 \%$ & $0.2 \%$ & $0.2 \%$ \\
\hline$\%$ Civic, Educational \& Religious & $0.1 \%$ & $0.1 \%$ & $0.1 \%$ & $0.1 \%$ & $0.0 \%$ & $0.1 \%$ & $0.0 \%$ & $0.0 \%$ & $0.1 \%$ & $0.0 \%$ & $0.0 \%$ & $0.0 \%$ & $0.0 \%$ & $0.0 \%$ \\
\hline \% Social \& Recreational & $0.3 \%$ & $0.3 \%$ & $0.3 \%$ & $0.3 \%$ & $0.3 \%$ & $0.3 \%$ & $0.3 \%$ & $0.3 \%$ & $0.3 \%$ & $0.3 \%$ & $0.1 \%$ & $0.3 \%$ & $0.3 \%$ & $0.6 \%$ \\
\hline$\%$ Other & $0.0 \%$ & $0.0 \%$ & $0.0 \%$ & $0.0 \%$ & $0.0 \%$ & $0.1 \%$ & $0.0 \%$ & $0.0 \%$ & $0.0 \%$ & $0.0 \%$ & $0.1 \%$ & $0.2 \%$ & $0.1 \%$ & $0.0 \%$ \\
\hline$\%$ Unreported & $0.0 \%$ & $0.0 \%$ & $0.0 \%$ & $0.0 \%$ & $0.0 \%$ & $0.0 \%$ & $0.0 \%$ & $0.0 \%$ & $0.0 \%$ & $0.0 \%$ & $0.1 \%$ & $0.0 \%$ & $0.0 \%$ & $0.0 \%$ \\
\hline \multicolumn{15}{|l|}{ Average Person Trip Length } \\
\hline TOTAL & 10.66 & 11.27 & 9.36 & 9.90 & 8.65 & 9.21 & 7.45 & 8.96 & 7.34 & 9.40 & 7.68 & 8.91 & 6.22 & 7.75 \\
\hline
\end{tabular}




\begin{tabular}{|c|c|c|c|c|c|c|c|c|c|c|c|c|c|c|}
\hline \multicolumn{15}{|c|}{ Population Density (census tract) } \\
\hline & \multicolumn{2}{|c|}{$<500$} & \multicolumn{2}{|c|}{$500-2,000$} & \multicolumn{2}{|c|}{$2,000-4,000$} & \multicolumn{2}{|c|}{$4,000-10,000$} & \multicolumn{2}{|c|}{$10,000-20,000$} & \multicolumn{2}{|c|}{$20,000-50,000$} & \multicolumn{2}{|c|}{$50,000+$} \\
\hline & NY State & U.S. & NY State & U.S. & NY State & U.S. & NY State & U.S. & NY State & U.S. & NY State & U.S. & NY State & U.S. \\
\hline \multicolumn{15}{|l|}{ Daily Person Trips per Person } \\
\hline TOTAL & 4.06 & 4.17 & 4.24 & 4.36 & 4.34 & 4.45 & 4.01 & 4.36 & 3.62 & 4.03 & 3.76 & 4.09 & 3.46 & 3.50 \\
\hline$\% 1-9 \min$ & $39.2 \%$ & $36.0 \%$ & $40.3 \%$ & $39.2 \%$ & $41.9 \%$ & $40.4 \%$ & $40.4 \%$ & $40.1 \%$ & $37.3 \%$ & $35.5 \%$ & $33.5 \%$ & $31.3 \%$ & $31.5 \%$ & $34.9 \%$ \\
\hline$\% 10-19 \min$ & $30.8 \%$ & $32.1 \%$ & $32.1 \%$ & $33.7 \%$ & $31.6 \%$ & $33.0 \%$ & $31.7 \%$ & $32.8 \%$ & $29.8 \%$ & $33.5 \%$ & $26.6 \%$ & $32.5 \%$ & $25.1 \%$ & $25.7 \%$ \\
\hline$\% 20-29 \min$ & $13.8 \%$ & $14.6 \%$ & $13.7 \%$ & $12.8 \%$ & $12.2 \%$ & $12.8 \%$ & $12.0 \%$ & $13.1 \%$ & $11.9 \%$ & $13.9 \%$ & $13.6 \%$ & $14.7 \%$ & $13.6 \%$ & $13.4 \%$ \\
\hline$\% 30-39 \mathrm{~min}$ & $7.6 \%$ & $7.4 \%$ & $6.1 \%$ & $6.0 \%$ & $5.3 \%$ & $5.8 \%$ & $5.7 \%$ & $6.2 \%$ & $6.6 \%$ & $8.4 \%$ & $8.5 \%$ & $9.0 \%$ & $10.4 \%$ & $9.4 \%$ \\
\hline$\% 40-49$ min & $3.2 \%$ & $3.8 \%$ & $2.6 \%$ & $3.4 \%$ & $2.8 \%$ & $2.7 \%$ & $3.2 \%$ & $3.0 \%$ & $4.1 \%$ & $3.7 \%$ & $5.9 \%$ & $5.4 \%$ & $7.5 \%$ & $7.7 \%$ \\
\hline$\% 50+\min$ & $4.2 \%$ & $4.8 \%$ & $4.5 \%$ & $3.9 \%$ & $4.8 \%$ & $4.0 \%$ & $5.2 \%$ & $3.7 \%$ & $8.0 \%$ & $4.2 \%$ & $9.3 \%$ & $5.4 \%$ & $8.7 \%$ & $6.3 \%$ \\
\hline$\%$ Unreported & $1.2 \%$ & $1.2 \%$ & $0.7 \%$ & $0.9 \%$ & $1.4 \%$ & $1.1 \%$ & $1.7 \%$ & $1.1 \%$ & $2.2 \%$ & $0.7 \%$ & $2.7 \%$ & $1.7 \%$ & $3.2 \%$ & $2.6 \%$ \\
\hline TOTAL & 4.06 & 4.17 & 4.24 & 4.36 & 4.34 & 4.45 & 4.01 & 4.36 & 3.62 & 4.03 & 3.76 & 4.09 & 3.46 & 3.50 \\
\hline$\% 5$ or less miles & $54.2 \%$ & $52.5 \%$ & $61.1 \%$ & $61.0 \%$ & $66.4 \%$ & $65.4 \%$ & $67.6 \%$ & $67.4 \%$ & $68.2 \%$ & $69.2 \%$ & $70.7 \%$ & $72.1 \%$ & $73.7 \%$ & $77.1 \%$ \\
\hline$\%$ 6-10 miles & $20.7 \%$ & $19.7 \%$ & $17.7 \%$ & $17.9 \%$ & $14.5 \%$ & $15.7 \%$ & $13.7 \%$ & $14.7 \%$ & $11.6 \%$ & $13.4 \%$ & $9.6 \%$ & $11.2 \%$ & $7.2 \%$ & $12.0 \%$ \\
\hline$\% 11-15$ miles & $9.6 \%$ & $10.1 \%$ & $8.0 \%$ & $7.6 \%$ & $6.5 \%$ & $6.7 \%$ & $6.0 \%$ & $6.4 \%$ & $5.8 \%$ & $6.2 \%$ & $5.1 \%$ & $4.6 \%$ & $4.3 \%$ & $3.4 \%$ \\
\hline$\% 16-20$ miles & $5.4 \%$ & $5.8 \%$ & $3.8 \%$ & $3.9 \%$ & $3.0 \%$ & $3.6 \%$ & $3.0 \%$ & $3.4 \%$ & $3.0 \%$ & $3.0 \%$ & $3.2 \%$ & $2.4 \%$ & $1.7 \%$ & $2.9 \%$ \\
\hline$\% 21-30$ miles & $4.4 \%$ & $5.3 \%$ & $3.3 \%$ & $3.9 \%$ & $3.7 \%$ & $3.4 \%$ & $3.2 \%$ & $3.0 \%$ & $3.6 \%$ & $3.0 \%$ & $2.1 \%$ & $2.4 \%$ & $2.3 \%$ & $1.7 \%$ \\
\hline$\% 31$ or more miles & $4.4 \%$ & $5.8 \%$ & $4.5 \%$ & $4.8 \%$ & $4.6 \%$ & $4.0 \%$ & $3.5 \%$ & $3.4 \%$ & $2.8 \%$ & $2.7 \%$ & $1.9 \%$ & $2.7 \%$ & $2.6 \%$ & $3.1 \%$ \\
\hline$\%$ Unreported & $1.2 \%$ & $0.8 \%$ & $1.7 \%$ & $0.9 \%$ & $1.4 \%$ & $1.1 \%$ & $3.0 \%$ & $1.6 \%$ & $5.0 \%$ & $2.5 \%$ & $7.4 \%$ & $4.4 \%$ & $8.1 \%$ & \\
\hline \multicolumn{15}{|l|}{ Daily PMT per Person } \\
\hline TOTAL & 39.75 & 43.90 & 39.25 & 40.28 & 34.31 & 39.89 & 28.12 & 34.49 & 23.60 & 26.13 & 18.05 & 22.84 & 18.93 & 25.59 \\
\hline$\% \mathrm{POV}$ & $90.8 \%$ & $94.7 \%$ & $92.7 \%$ & $92.5 \%$ & $91.3 \%$ & $88.2 \%$ & $87.3 \%$ & $90.1 \%$ & $83.0 \%$ & $84.5 \%$ & $63.0 \%$ & $78.8 \%$ & $51.2 \%$ & $84.4 \%$ \\
\hline$\%$ Public & $2.2 \%$ & $0.5 \%$ & $2.5 \%$ & $0.7 \%$ & $3.9 \%$ & $2.8 \%$ & $7.6 \%$ & $2.0 \%$ & $13.1 \%$ & $10.2 \%$ & $28.4 \%$ & $11.3 \%$ & $34.7 \%$ & $11.8 \%$ \\
\hline$\%$ Walk & $0.4 \%$ & $0.1 \%$ & $0.3 \%$ & $0.2 \%$ & $0.3 \%$ & $0.3 \%$ & $0.6 \%$ & $0.4 \%$ & $0.9 \%$ & $0.9 \%$ & $3.6 \%$ & $2.1 \%$ & $4.1 \%$ & $3.4 \%$ \\
\hline$\%$ Other & $5.8 \%$ & $4.0 \%$ & $3.6 \%$ & $5.9 \%$ & $3.3 \%$ & $6.9 \%$ & $3.2 \%$ & $6.6 \%$ & $2.1 \%$ & $2.9 \%$ & $4.4 \%$ & $7.5 \%$ & $9.1 \%$ & $0.2 \%$ \\
\hline$\%$ Unreported & $0.8 \%$ & $0.8 \%$ & $0.8 \%$ & $0.7 \%$ & $1.1 \%$ & $1.8 \%$ & $1.4 \%$ & $0.9 \%$ & $1.0 \%$ & $1.5 \%$ & $0.7 \%$ & $0.3 \%$ & $0.9 \%$ & $0.2 \%$ \\
\hline TOTAL & 39.75 & 43.90 & 39.25 & 40.28 & 34.31 & 39.89 & 28.12 & 34.49 & 23.60 & 26.13 & 18.05 & 22.84 & 18.93 & 25.59 \\
\hline$\%$ sov & $42.4 \%$ & $42.7 \%$ & $37.1 \%$ & $41.4 \%$ & $43.7 \%$ & $38.4 \%$ & $38.9 \%$ & $41.1 \%$ & $34.1 \%$ & $40.1 \%$ & $26.1 \%$ & $31.8 \%$ & $12.8 \%$ & $16.0 \%$ \\
\hline$\%$ MOV & $48.3 \%$ & $52.0 \%$ & $55.6 \%$ & $51.0 \%$ & $47.4 \%$ & $49.4 \%$ & $48.3 \%$ & $49.0 \%$ & $48.9 \%$ & $44.4 \%$ & $36.4 \%$ & $47.0 \%$ & $38.4 \%$ & $68.4 \%$ \\
\hline$\%$ Other POV & $0.0 \%$ & $0.1 \%$ & $0.0 \%$ & $0.0 \%$ & $0.3 \%$ & $0.4 \%$ & $0.0 \%$ & $0.1 \%$ & $0.0 \%$ & $0.0 \%$ & $0.4 \%$ & $0.0 \%$ & $0.1 \%$ & \\
\hline$\%$ Amtrak & $1.8 \%$ & $0.0 \%$ & $0.1 \%$ & $0.0 \%$ & $0.0 \%$ & $0.1 \%$ & $0.4 \%$ & $0.0 \%$ & & $0.1 \%$ & & & $0.2 \%$ & \\
\hline$\%$ Commuter Train & $0.7 \%$ & $0.1 \%$ & $1.5 \%$ & $0.2 \%$ & $2.7 \%$ & $0.5 \%$ & $3.3 \%$ & $0.4 \%$ & $2.2 \%$ & $0.7 \%$ & $3.0 \%$ & $0.6 \%$ & $7.4 \%$ & $1.5 \%$ \\
\hline \% Subway/El Rail & $0.2 \%$ & $0.0 \%$ & $0.1 \%$ & $0.1 \%$ & $0.1 \%$ & $0.2 \%$ & $1.4 \%$ & $0.1 \%$ & $3.9 \%$ & $1.2 \%$ & $16.1 \%$ & $1.9 \%$ & $16.6 \%$ & $6.5 \%$ \\
\hline$\%$ Other Public & $1.3 \%$ & $0.3 \%$ & $0.9 \%$ & $0.4 \%$ & $1.1 \%$ & $2.1 \%$ & $2.9 \%$ & $1.4 \%$ & $6.9 \%$ & $8.3 \%$ & $9.3 \%$ & $8.8 \%$ & $10.7 \%$ & $3.7 \%$ \\
\hline$\%$ Walk & $0.4 \%$ & $0.1 \%$ & $0.3 \%$ & $0.2 \%$ & 0.3 & $0.3 \%$ & $0.6 \%$ & $0.4 \%$ & $0.9 \%$ & $0.9 \%$ & $3.6 \%$ & $2.1 \%$ & $4.1 \%$ & $3.4 \%$ \\
\hline$\%$ Other & $4.0 \%$ & $3.9 \%$ & $3.5 \%$ & $5.9 \%$ & 3.3 & $6.8 \%$ & $2.8 \%$ & $6.6 \%$ & $2.1 \%$ & $2.8 \%$ & $4.4 \%$ & $7.5 \%$ & $8.9 \%$ & $0.2 \%$ \\
\hline$\%$ Unreported & $0.8 \%$ & $0.8 \%$ & $0.8 \%$ & $0.7 \%$ & $1.1 \%$ & $1.8 \%$ & $1.4 \%$ & $0.9 \%$ & $1.0 \%$ & $1.5 \%$ & $0.7 \%$ & $0.3 \%$ & $0.9 \%$ & $0.2 \%$ \\
\hline TOTAL & 39.75 & 43.9 & 39.25 & 40.28 & 34.31 & 39.89 & 28.12 & 34.49 & 23.6 & 26.13 & 18.05 & 22.84 & 18.93 & 25.59 \\
\hline \% Earn a Living & $29.5 \%$ & $29.0 \%$ & $27.0 \%$ & $29.2 \%$ & $30.7 \%$ & $30.1 \%$ & $31.1 \%$ & $27.7 \%$ & $29.8 \%$ & $26.9 \%$ & $35.6 \%$ & $28.9 \%$ & $28.0 \%$ & $18.5 \%$ \\
\hline$\%$ Fam/l & $33.2 \%$ & $34.7 \%$ & $34.8 \%$ & $35.7 \%$ & $35.0 \%$ & $31.8 \%$ & $31.8 \%$ & $34.8 \%$ & $31.9 \%$ & $34.0 \%$ & $32.4 \%$ & $29.9 \%$ & $31.2 \%$ & $29.0 \%$ \\
\hline$\%$ Civ, Ed, \& Rel & $5.2 \%$ & $6.2 \%$ & $4.5 \%$ & $6.3 \%$ & $4.5 \%$ & $5.3 \%$ & $6.3 \%$ & $4.2 \%$ & $5.2 \%$ & $7.4 \%$ & $6.1 \%$ & $5.0 \%$ & $6.3 \%$ & $2.8 \%$ \\
\hline$\%$ Soc and Rec & $31.5 \%$ & $30.0 \%$ & $33.6 \%$ & $28.3 \%$ & $29.5 \%$ & $32.6 \%$ & $30.7 \%$ & $32.9 \%$ & $32.8 \%$ & $31.6 \%$ & $25.9 \%$ & $36.2 \%$ & $34.5 \%$ & $49.7 \%$ \\
\hline$\%$ Other & $0.7 \%$ & $0.1 \%$ & $0.2 \%$ & $0.6 \%$ & $0.3 \%$ & $0.3 \%$ & $0.1 \%$ & $0.1 \%$ & $0.0 \%$ & $0.0 \%$ & $0.0 \%$ & $0.0 \%$ & $0.0 \%$ & \\
\hline$\%$ Unreported & $0.0 \%$ & $0.0 \%$ & $0.0 \%$ & $0.0 \%$ & & $0.0 \%$ & $0.0 \%$ & $0.2 \%$ & $0.3 \%$ & & & & & \\
\hline Aver & & & & & & & & & & & & & & \\
\hline TOTAL & 9.91 & 10.66 & 9.41 & 9.33 & 8.02 & 9.06 & 7.23 & 8.05 & 6.85 & 6.64 & 5.18 & 5.83 & 5.95 & 7.31 \\
\hline
\end{tabular}




\begin{tabular}{|c|c|c|c|c|c|c|c|c|c|c|c|c|c|c|}
\hline \multicolumn{15}{|c|}{ Population Density (census tract) } \\
\hline & \multicolumn{2}{|c|}{$<500$} & \multicolumn{2}{|c|}{$500-2,000$} & \multicolumn{2}{|c|}{$2,000-4,000$} & \multicolumn{2}{|c|}{$4,000-10,000$} & \multicolumn{2}{|c|}{$10,000-20,000$} & \multicolumn{2}{|c|}{$20,000-50,000$} & \multicolumn{2}{|c|}{$50,000+$} \\
\hline & NY State & U.S. & NY State & U.S. & NY State & U.S. & NY State & U.S. & NY State & U.S. & NY State & U.S. & NY State & U.S. \\
\hline \multicolumn{15}{|c|}{ Distribution of Zero-Vehicle Households by Household Income } \\
\hline ALL & $100 \%$ & $100 \%$ & $100 \%$ & $100 \%$ & $100 \%$ & $100 \%$ & $100 \%$ & $100 \%$ & $100 \%$ & $100 \%$ & $100 \%$ & $100 \%$ & $100 \%$ & $100 \%$ \\
\hline$<\$ 10,000$ & $28.4 \%$ & $30.8 \%$ & $37.8 \%$ & $46.1 \%$ & $29.1 \%$ & $30.0 \%$ & $33.9 \%$ & $35.7 \%$ & $16.3 \%$ & $29.1 \%$ & $20.1 \%$ & $24.6 \%$ & $14.9 \%$ & $12.6 \%$ \\
\hline$\$ 10$ to $\$ 20,000$ & $20.7 \%$ & $39.0 \%$ & $26.1 \%$ & $22.8 \%$ & $33.5 \%$ & $30.6 \%$ & $30.6 \%$ & $27.6 \%$ & $28.5 \%$ & $35.1 \%$ & $17.1 \%$ & $24.7 \%$ & $18.1 \%$ & $38.4 \%$ \\
\hline$\$ 20$ to $\$ 30,000$ & $10.3 \%$ & $8.7 \%$ & $14.1 \%$ & $10.0 \%$ & $14.8 \%$ & $11.2 \%$ & $8.1 \%$ & $9.5 \%$ & $21.9 \%$ & $10.7 \%$ & $10.1 \%$ & $20.6 \%$ & $10.5 \%$ & $6.2 \%$ \\
\hline$\$ 30$ to $\$ 40,000$ & $11.4 \%$ & $2.1 \%$ & $6.7 \%$ & $3.0 \%$ & $5.5 \%$ & $5.0 \%$ & $6.5 \%$ & $6.7 \%$ & $8.9 \%$ & $4.5 \%$ & $14.3 \%$ & $14.1 \%$ & $9.0 \%$ & $5.0 \%$ \\
\hline$\$ 40$ to $\$ 50,000$ & & $0.7 \%$ & $1.9 \%$ & $4.6 \%$ & $2.6 \%$ & $3.8 \%$ & $3.1 \%$ & $4.7 \%$ & $0.5 \%$ & $0.9 \%$ & $8.6 \%$ & $7.4 \%$ & $7.7 \%$ & $3.1 \%$ \\
\hline$\$ 50$ to $\$ 60,000$ & & $0.3 \%$ & & $0.1 \%$ & & $1.7 \%$ & $1.3 \%$ & $0.4 \%$ & $1.8 \%$ & $0.3 \%$ & $3.3 \%$ & $1.5 \%$ & $4.8 \%$ & $9.9 \%$ \\
\hline$\$ 60$ to $\$ 70,000$ & $0.9 \%$ & $0.5 \%$ & $2.1 \%$ & $0.1 \%$ & & $0.5 \%$ & $0.6 \%$ & $0.6 \%$ & $0.2 \%$ & $0.4 \%$ & $5.1 \%$ & $0.3 \%$ & $4.7 \%$ & $11.2 \%$ \\
\hline$\$ 70$ to $\$ 80,000$ & & $1.9 \%$ & $2.1 \%$ & $2.5 \%$ & & $0.1 \%$ & & $0.3 \%$ & $1.1 \%$ & $0.4 \%$ & $1.9 \%$ & $0.8 \%$ & $3.0 \%$ & \\
\hline$\$ 80$ to $\$ 100,000$ & & $0.1 \%$ & & $0.1 \%$ & $1.5 \%$ & $0.2 \%$ & $1.2 \%$ & $0.3 \%$ & $7.6 \%$ & $1.2 \%$ & $2.6 \%$ & $0.7 \%$ & $5.5 \%$ & \\
\hline$\$ 100,000+$ & $1.2 \%$ & $4.7 \%$ & $0.6 \%$ & $0.7 \%$ & $3.0 \%$ & $0.6 \%$ & $1.9 \%$ & $1.3 \%$ & $1.5 \%$ & $3.6 \%$ & $4.7 \%$ & $3.1 \%$ & $12.2 \%$ & $2.2 \%$ \\
\hline Unreported & $27.1 \%$ & $11.4 \%$ & $8.6 \%$ & $10.2 \%$ & $10.0 \%$ & $16.5 \%$ & $12.8 \%$ & $13.0 \%$ & $11.7 \%$ & $14.0 \%$ & $12.2 \%$ & $2.3 \%$ & $9.6 \%$ & $11.5 \%$ \\
\hline \multicolumn{15}{|c|}{ Zero-Vehicle Households - Daily Person Trips per Person } \\
\hline TOTAL & 1.90 & 2.21 & 1.84 & 2.18 & 2.08 & 2.57 & 2.72 & 2.70 & 2.57 & 2.95 & 2.87 & 3.23 & 3.35 & 4.16 \\
\hline$\%$ Private & $53.3 \%$ & $54.2 \%$ & $33.2 \%$ & $54.6 \%$ & $19.5 \%$ & $36.8 \%$ & $20.9 \%$ & $32.5 \%$ & $13.1 \%$ & $16.5 \%$ & $14.4 \%$ & $10.9 \%$ & $5.4 \%$ & $3.1 \%$ \\
\hline$\%$ Public & $6.3 \%$ & $6.6 \%$ & $19.3 \%$ & $9.6 \%$ & $5.1 \%$ & $15.6 \%$ & $18.2 \%$ & $16.0 \%$ & $32.8 \%$ & $26.1 \%$ & $36.1 \%$ & $36.4 \%$ & $31.3 \%$ & $22.1 \%$ \\
\hline$\%$ Walk & $16.9 \%$ & $24.0 \%$ & $33.7 \%$ & $23.3 \%$ & $42.0 \%$ & $30.1 \%$ & $47.4 \%$ & $33.7 \%$ & $43.4 \%$ & $47.5 \%$ & $43.7 \%$ & $40.5 \%$ & $55.3 \%$ & $65.7 \%$ \\
\hline$\%$ Other & $16.6 \%$ & $14.0 \%$ & $13.8 \%$ & $10.9 \%$ & $21.9 \%$ & $13.9 \%$ & $13.5 \%$ & $13.9 \%$ & $9.2 \%$ & $9.0 \%$ & $5.8 \%$ & $12.0 \%$ & $8.0 \%$ & $9.1 \%$ \\
\hline$\%$ Unreported & $6.9 \%$ & $1.4 \%$ & & $1.7 \%$ & $11.5 \%$ & $3.6 \%$ & & $3.9 \%$ & $1.5 \%$ & $0.9 \%$ & & $0.2 \%$ & $0.0 \%$ & \\
\hline TOTAL & 1.90 & 2.21 & 1.84 & 2.18 & 2.08 & 2.57 & 2.72 & 2.70 & 2.57 & 2.95 & 2.87 & 3.23 & 3.35 & 4.16 \\
\hline$<\$ 10,000$ & 2.04 & 1.89 & 1.69 & 1.93 & 2.04 & 2.40 & 2.10 & 2.79 & 2.47 & 3.31 & 3.03 & 2.38 & 2.29 & 2.65 \\
\hline$\$ 10$ to $\$ 20,000$ & 2.28 & 2.39 & 2.72 & 2.13 & 1.35 & 3.03 & 3.01 & 2.61 & 2.59 & 2.94 & 1.82 & 2.63 & 3.45 & 3.59 \\
\hline$\$ 20$ to $\$ 30,000$ & 0.42 & 2.51 & 1.62 & 2.95 & 3.76 & 1.89 & 3.51 & 2.81 & 2.31 & 3.05 & 3.98 & 5.47 & 3.12 & 7.98 \\
\hline$\$ 30$ to $\$ 40,000$ & 1.87 & 2.70 & 1.13 & 2.60 & 2.71 & 3.67 & 3.86 & 3.31 & 2.68 & 2.38 & 2.27 & 3.06 & 3.01 & \\
\hline$\$ 40$ to $\$ 50,000$ & & 3.13 & 2.66 & 0.60 & 2.32 & 1.29 & 4.98 & 3.88 & 2.16 & 2.53 & 3.37 & 4.47 & 2.52 & 8.00 \\
\hline$\$ 50$ to $\$ 60,000$ & & 2.39 & & 4.81 & & 4.58 & 3.92 & 2.30 & 0.65 & 4.87 & 2.96 & 2.37 & 3.32 & 3.09 \\
\hline$\$ 60$ to $\$ 70,000$ & 4.00 & 2.42 & & 1.79 & & 1.14 & 2.38 & 2.71 & 3.00 & 3.83 & 5.25 & 4.01 & 4.40 & 8.00 \\
\hline$\$ 70$ to $\$ 80,000$ & & 2.35 & 2.50 & 3.00 & & 2.42 & & 2.98 & 2.00 & 2.71 & 4.09 & 2.63 & 3.11 & \\
\hline$\$ 80$ to $\$ 100,000$ & & 3.35 & & 4.41 & 4.00 & 4.51 & 2.00 & 3.35 & 3.84 & 3.41 & 4.77 & 5.65 & 3.61 & \\
\hline$\$ 100,000+$ & 1.10 & 2.03 & 3.03 & 3.86 & 2.73 & 3.07 & 2.72 & 4.34 & 1.04 & 3.72 & 3.32 & 4.02 & 5.07 & 7.23 \\
\hline Unreported & 1.93 & 1.63 & 0.56 & 2.40 & 0.69 & 2.00 & 1.72 & 1.37 & 2.36 & 1.56 & 1.61 & 1.35 & 2.51 & 2.30 \\
\hline \multicolumn{15}{|c|}{ Zero-Vehicle Households - Daily PMT per Person } \\
\hline TOTAL & 10.95 & 18.10 & 5.24 & 12.80 & 12.81 & 12.25 & 6.70 & 10.35 & 8.01 & 7.53 & 6.50 & 11.78 & 9.73 & 5.62 \\
\hline$\%$ Private & $68.8 \%$ & $80.4 \%$ & $54.3 \%$ & $71.5 \%$ & $58.7 \%$ & $51.9 \%$ & $23.9 \%$ & $49.5 \%$ & $25.3 \%$ & $33.2 \%$ & $14.6 \%$ & $42.8 \%$ & $21.7 \%$ & $0.4 \%$ \\
\hline$\%$ Public & $14.7 \%$ & $5.3 \%$ & $29.0 \%$ & $10.9 \%$ & $4.1 \%$ & $23.9 \%$ & $50.2 \%$ & $22.7 \%$ & $50.1 \%$ & $38.7 \%$ & $69.1 \%$ & $45.2 \%$ & $52.7 \%$ & $20.8 \%$ \\
\hline$\%$ Walk & $2.1 \%$ & $1.6 \%$ & $6.4 \%$ & $3.8 \%$ & $5.0 \%$ & $4.1 \%$ & $11.0 \%$ & $6.9 \%$ & $9.2 \%$ & $14.2 \%$ & $12.0 \%$ & $5.7 \%$ & $13.6 \%$ & $25.7 \%$ \\
\hline$\%$ Other & $10.4 \%$ & $11.2 \%$ & $10.4 \%$ & $11.3 \%$ & $8.7 \%$ & $11.3 \%$ & $14.9 \%$ & $15.2 \%$ & $14.0 \%$ & $12.5 \%$ & $4.3 \%$ & $6.4 \%$ & $12.0 \%$ & $53.1 \%$ \\
\hline$\%$ Unreported & $4.1 \%$ & $1.5 \%$ & & $2.5 \%$ & $23.6 \%$ & $8.9 \%$ & & $5.7 \%$ & $1.4 \%$ & $1.3 \%$ & & & & \\
\hline
\end{tabular}




\begin{tabular}{|c|c|c|c|c|c|c|c|c|c|c|c|c|c|c|}
\hline \multicolumn{15}{|c|}{ Population Density (census tract) } \\
\hline & \multicolumn{2}{|c|}{$<500$} & \multicolumn{2}{|c|}{$500-2,000$} & \multicolumn{2}{|c|}{$2,000-4,000$} & \multicolumn{2}{|c|}{$4,000-10,000$} & \multicolumn{2}{|c|}{$10,000-20,000$} & \multicolumn{2}{|c|}{$20,000-50,000$} & \multicolumn{2}{|c|}{$50,000+$} \\
\hline & NY State & U.S. & NY State & U.S. & NY State & U.S. & NY State & U.S. & NY State & U.S. & NY State & U.S. & NY State & U.S. \\
\hline \multicolumn{15}{|c|}{ Distribution of Zero-Vehicle Households by Household Income } \\
\hline ALL & $100.0 \%$ & $100.0 \%$ & $100.0 \%$ & $100.0 \%$ & $100.0 \%$ & $100.0 \%$ & $100.0 \%$ & $100.0 \%$ & $100.0 \%$ & $100.0 \%$ & $100.0 \%$ & $100.0 \%$ & $100.0 \%$ & $100.0 \%$ \\
\hline$<\$ 10,000$ & $24.7 \%$ & $35.3 \%$ & $18.5 \%$ & $31.5 \%$ & $29.5 \%$ & $35.8 \%$ & $27.0 \%$ & $34.9 \%$ & $21.1 \%$ & $35.9 \%$ & $17.5 \%$ & $22.7 \%$ & $16.0 \%$ & $9.1 \%$ \\
\hline$\$ 10$ to $\$ 20,000$ & $31.4 \%$ & $25.3 \%$ & $25.5 \%$ & $20.7 \%$ & $21.2 \%$ & $22.2 \%$ & $33.2 \%$ & $22.7 \%$ & $22.6 \%$ & $25.3 \%$ & $15.5 \%$ & $23.0 \%$ & $15.4 \%$ & $39.1 \%$ \\
\hline$\$ 20$ to $\$ 30,000$ & $3.4 \%$ & $6.5 \%$ & $13.4 \%$ & $16.2 \%$ & $22.5 \%$ & $12.3 \%$ & $12.3 \%$ & $14.8 \%$ & $8.7 \%$ & $10.9 \%$ & $16.2 \%$ & $6.5 \%$ & $10.6 \%$ & $31.6 \%$ \\
\hline$\$ 30$ to $\$ 40,000$ & $3.7 \%$ & $5.3 \%$ & $4.2 \%$ & $7.6 \%$ & $4.7 \%$ & $2.8 \%$ & $8.6 \%$ & $7.8 \%$ & $14.0 \%$ & $9.8 \%$ & $12.3 \%$ & $19.6 \%$ & $12.7 \%$ & $10.4 \%$ \\
\hline$\$ 40$ to $\$ 50,000$ & $9.0 \%$ & $1.5 \%$ & $10.5 \%$ & $1.0 \%$ & & $1.9 \%$ & $1.7 \%$ & $1.2 \%$ & $0.9 \%$ & $1.5 \%$ & $4.7 \%$ & $5.4 \%$ & $2.6 \%$ & $6.1 \%$ \\
\hline$\$ 50$ to $\$ 60,000$ & $2.0 \%$ & $2.1 \%$ & $0.7 \%$ & $1.4 \%$ & $3.9 \%$ & $1.6 \%$ & $1.9 \%$ & $2.7 \%$ & $9.5 \%$ & $3.8 \%$ & $4.6 \%$ & $3.5 \%$ & $8.0 \%$ & \\
\hline$\$ 60$ to $\$ 70,000$ & $0.4 \%$ & $0.9 \%$ & $2.7 \%$ & $0.5 \%$ & & $1.1 \%$ & $0.9 \%$ & $0.9 \%$ & $4.1 \%$ & $0.2 \%$ & $3.7 \%$ & $1.7 \%$ & $2.8 \%$ & \\
\hline$\$ 70$ to $\$ 80,000$ & $0.3 \%$ & $0.0 \%$ & & $0.0 \%$ & $0.3 \%$ & $0.1 \%$ & & $0.2 \%$ & $0.8 \%$ & $0.1 \%$ & $0.8 \%$ & $0.0 \%$ & $3.6 \%$ & $3.0 \%$ \\
\hline$\$ 80$ to $\$ 100,000$ & $7.5 \%$ & $1.1 \%$ & $0.6 \%$ & $0.6 \%$ & & $0.6 \%$ & $0.8 \%$ & $0.2 \%$ & $2.0 \%$ & $0.4 \%$ & $0.6 \%$ & $1.0 \%$ & $3.5 \%$ & \\
\hline$\$ 100,000_{+}$ & $7.1 \%$ & $4.1 \%$ & $1.1 \%$ & $2.6 \%$ & & $1.1 \%$ & $0.5 \%$ & $0.9 \%$ & $3.7 \%$ & $1.5 \%$ & $5.2 \%$ & $5.9 \%$ & $11.6 \%$ & \\
\hline Unreported & $10.5 \%$ & $18.0 \%$ & $22.9 \%$ & $17.9 \%$ & $18.1 \%$ & $20.5 \%$ & $13.2 \%$ & $13.8 \%$ & $12.4 \%$ & $10.8 \%$ & $19.0 \%$ & $10.9 \%$ & $13.2 \%$ & $0.7 \%$ \\
\hline \multicolumn{15}{|c|}{ Zero-Vehicle Households - Daily Person Trips per Person } \\
\hline TOTAL & 2.97 & 2.32 & 2.21 & 2.78 & 2.05 & 2.94 & 2.95 & 2.45 & 2.84 & 2.55 & 3.31 & 2.80 & 3.32 & 3.23 \\
\hline$\%$ Private & $14.3 \%$ & $79.6 \%$ & $35.9 \%$ & $74.1 \%$ & $45.3 \%$ & $51.1 \%$ & $25.1 \%$ & $36.2 \%$ & $21.9 \%$ & $20.2 \%$ & $23.0 \%$ & $18.5 \%$ & $9.1 \%$ & $0.1 \%$ \\
\hline$\%$ Public & $33.8 \%$ & $0.3 \%$ & $20.6 \%$ & $7.8 \%$ & $16.7 \%$ & $9.6 \%$ & $18.6 \%$ & $19.1 \%$ & $28.3 \%$ & $29.9 \%$ & $26.7 \%$ & $33.9 \%$ & $34.8 \%$ & $46.7 \%$ \\
\hline$\%$ Walk & $46.0 \%$ & $15.4 \%$ & $39.5 \%$ & $13.6 \%$ & $21.9 \%$ & $33.5 \%$ & $42.5 \%$ & $36.3 \%$ & $41.7 \%$ & $42.3 \%$ & $43.6 \%$ & $39.3 \%$ & $49.1 \%$ & $47.4 \%$ \\
\hline$\%$ Other & $6.0 \%$ & $4.4 \%$ & $4.1 \%$ & $4.4 \%$ & $16.1 \%$ & $5.8 \%$ & $13.8 \%$ & $8.3 \%$ & $8.2 \%$ & $7.7 \%$ & $6.5 \%$ & $8.3 \%$ & $6.7 \%$ & $5.7 \%$ \\
\hline$\%$ Unreported & & $0.3 \%$ & & $0.1 \%$ & & & $0.0 \%$ & $0.1 \%$ & & $0.0 \%$ & $0.2 \%$ & & $0.3 \%$ & $0.0 \%$ \\
\hline TOTAL & 2.97 & 2.32 & 2.21 & 2.78 & 2.05 & 2.94 & 2.95 & 2.45 & 2.84 & 2.55 & 3.31 & 2.80 & 3.32 & 3.23 \\
\hline$<\$ 10,000$ & 3.64 & 1.47 & 1.51 & 2.65 & 1.98 & 2.78 & 3.46 & 2.31 & 2.90 & 2.92 & 2.69 & 2.13 & 2.84 & 3.50 \\
\hline$\$ 10$ to $\$ 20,000$ & 1.21 & 2.73 & 1.42 & 2.88 & 2.96 & 2.61 & 3.22 & 2.32 & 2.05 & 2.47 & 3.26 & 2.43 & 3.08 & 2.12 \\
\hline$\$ 20$ to $\$ 30,000$ & 2.07 & 2.22 & 2.85 & 3.21 & 0.73 & 3.90 & 2.79 & 2.85 & 2.20 & 2.67 & 3.64 & 3.51 & 3.18 & 3.51 \\
\hline$\$ 30$ to $\$ 40,000$ & 2.10 & 2.08 & 3.13 & 4.15 & 3.70 & 4.02 & 2.28 & 2.30 & 2.63 & 2.32 & 2.73 & 2.78 & 3.49 & 2.02 \\
\hline$\$ 40$ to $\$ 50,000$ & & 5.00 & 6.00 & 0.10 & & 3.16 & 3.27 & 1.83 & 3.64 & 1.71 & 4.44 & 4.09 & 3.68 & 3.91 \\
\hline$\$ 50$ to $\$ 60,000$ & 5.57 & 4.34 & & 1.86 & 5.62 & 4.20 & 2.89 & 3.81 & 3.31 & 3.47 & 4.77 & 3.35 & 3.00 & \\
\hline$\$ 60$ to $\$ 70,000$ & 2.45 & 6.29 & 0.57 & 5.00 & & 5.84 & 2.00 & 2.91 & 5.51 & 4.36 & 5.12 & 2.51 & 3.40 & \\
\hline$\$ 70$ to $\$ 80,000$ & 5.00 & 2.94 & & 0.47 & 1.95 & & & & 3.64 & 6.35 & 3.90 & & 3.83 & 8.00 \\
\hline$\$ 80$ to $\$ 100,000$ & 4.02 & 4.29 & 1.18 & 0.27 & & 5.29 & 5.13 & 1.92 & 3.92 & 3.08 & 5.56 & 1.98 & 4.45 & \\
\hline$\$ 100,000_{+}$ & 5.96 & 4.09 & 4.32 & 3.66 & & 2.28 & 4.05 & 5.02 & 2.47 & 3.83 & 4.45 & 4.02 & 4.45 & \\
\hline Unreported & 1.46 & 2.09 & 1.73 & 1.50 & 1.81 & 2.03 & 2.12 & 2.14 & 2.20 & 1.71 & 2.22 & 2.90 & 2.72 & 4.11 \\
\hline \multicolumn{15}{|c|}{ Zero-Vehicle Households - Daily PMT per Person } \\
\hline TOTAL & 12.63 & 27.14 & 9.08 & 25.56 & 8.04 & 11.21 & 9.26 & 26.90 & 12.51 & 8.72 & 30.29 & 9.56 & 12.97 & 7.55 \\
\hline$\%$ Private & $33.7 \%$ & $97.3 \%$ & $44.7 \%$ & $80.0 \%$ & $62.7 \%$ & $83.3 \%$ & $48.0 \%$ & $24.6 \%$ & $28.0 \%$ & $51.7 \%$ & $10.8 \%$ & $32.6 \%$ & $22.2 \%$ & $0.6 \%$ \\
\hline$\%$ Public & $48.7 \%$ & $0.3 \%$ & $41.1 \%$ & $4.7 \%$ & $18.0 \%$ & $8.3 \%$ & $33.8 \%$ & $8.4 \%$ & $45.9 \%$ & $31.6 \%$ & $13.8 \%$ & $53.1 \%$ & $45.6 \%$ & $85.9 \%$ \\
\hline$\%$ Walk & $14.7 \%$ & $0.7 \%$ & $5.3 \%$ & $0.6 \%$ & $4.8 \%$ & $5.6 \%$ & $8.3 \%$ & $2.2 \%$ & $6.7 \%$ & $7.7 \%$ & $3.8 \%$ & $9.6 \%$ & $7.5 \%$ & $10.6 \%$ \\
\hline$\%$ Other & $2.9 \%$ & $1.7 \%$ & $9.0 \%$ & $14.7 \%$ & $14.4 \%$ & $2.7 \%$ & $9.9 \%$ & $64.7 \%$ & $19.4 \%$ & $9.1 \%$ & $71.6 \%$ & $4.7 \%$ & $24.7 \%$ & $3.0 \%$ \\
\hline$\%$ Unreported & & & & $0.0 \%$ & & & & $0.0 \%$ & & $0.0 \%$ & & & $0.1 \%$ & $0.0 \%$ \\
\hline
\end{tabular}




\begin{tabular}{|c|c|c|c|c|c|c|c|c|c|c|c|c|c|c|}
\hline \multicolumn{15}{|c|}{ Population Density (census tract) } \\
\hline & \multicolumn{2}{|c|}{$<500$} & \multicolumn{2}{|c|}{$500-2,000$} & \multicolumn{2}{|c|}{$2,000-4,000$} & \multicolumn{2}{|c|}{$4,000-10,000$} & \multicolumn{2}{|c|}{$10,000-20,000$} & \multicolumn{2}{|c|}{$20,000-50,000$} & \multicolumn{2}{|c|}{$50,000+$} \\
\hline & NY State & U.S. & NY State & U.S. & NY State & U.S. & NY State & U.S. & NY State & U.S. & NY State & U.S. & NY State & U.S. \\
\hline \multicolumn{15}{|c|}{ ouseholds by Household Income } \\
\hline ALL & $100.0 \%$ & $100.0 \%$ & $100.0 \%$ & $100.0 \%$ & $100.0 \%$ & $100.0 \%$ & $100.0 \%$ & $100.0 \%$ & $100.0 \%$ & $100.0 \%$ & $100.0 \%$ & $100.0 \%$ & $100.0 \%$ & $100.0 \%$ \\
\hline$<\$ 10,000$ & $14.8 \%$ & $29.9 \%$ & $23.7 \%$ & $24.2 \%$ & $19.0 \%$ & $28.8 \%$ & $12.1 \%$ & $23.9 \%$ & $13.7 \%$ & $15.5 \%$ & $10.3 \%$ & $23.1 \%$ & $14.7 \%$ & $12.7 \%$ \\
\hline$\$ 10$ to $\$ 20,000$ & $12.9 \%$ & $43.8 \%$ & $18.4 \%$ & $26.6 \%$ & $26.3 \%$ & $23.7 \%$ & $23.7 \%$ & $31.0 \%$ & $17.3 \%$ & $32.5 \%$ & $15.9 \%$ & $22.3 \%$ & $14.1 \%$ & $16.0 \%$ \\
\hline$\$ 20$ to $\$ 30,000$ & $11.0 \%$ & $8.0 \%$ & $10.7 \%$ & $10.4 \%$ & $22.6 \%$ & $19.6 \%$ & $20.4 \%$ & $11.4 \%$ & $9.6 \%$ & $20.8 \%$ & $13.7 \%$ & $15.0 \%$ & $13.1 \%$ & $31.8 \%$ \\
\hline$\$ 30$ to $\$ 40,000$ & $10.8 \%$ & $0.1 \%$ & $11.1 \%$ & $4.8 \%$ & $5.1 \%$ & $4.2 \%$ & $14.2 \%$ & $7.1 \%$ & $16.3 \%$ & $9.9 \%$ & $17.9 \%$ & $11.7 \%$ & $13.5 \%$ & $2.2 \%$ \\
\hline$\$ 40$ to $\$ 50,000$ & & $1.0 \%$ & & $5.3 \%$ & $2.0 \%$ & $0.0 \%$ & $0.7 \%$ & $1.1 \%$ & $2.4 \%$ & $0.8 \%$ & $1.3 \%$ & $1.2 \%$ & $5.1 \%$ & \\
\hline$\$ 50$ to $\$ 60,000$ & $0.1 \%$ & & $0.5 \%$ & $0.7 \%$ & & $1.3 \%$ & $1.9 \%$ & $4.4 \%$ & $2.3 \%$ & $0.6 \%$ & $5.1 \%$ & $4.4 \%$ & $4.5 \%$ & $4.7 \%$ \\
\hline$\$ 60$ to $\$ 70,000$ & & $2.0 \%$ & $3.2 \%$ & $0.2 \%$ & $2.4 \%$ & $0.4 \%$ & $1.5 \%$ & $2.1 \%$ & $5.4 \%$ & $2.2 \%$ & $5.7 \%$ & $1.4 \%$ & $4.4 \%$ & \\
\hline$\$ 70$ to $\$ 80,000$ & & & & $0.0 \%$ & $3.9 \%$ & & & $0.7 \%$ & $0.1 \%$ & $0.7 \%$ & $5.1 \%$ & & $2.1 \%$ & \\
\hline$\$ 80$ to $\$ 100,000$ & $2.3 \%$ & & & $2.0 \%$ & & & $0.4 \%$ & $0.6 \%$ & $0.2 \%$ & & $1.3 \%$ & $0.8 \%$ & $2.7 \%$ & \\
\hline$\$ 100,000+$ & $5.2 \%$ & $0.4 \%$ & $1.4 \%$ & $0.8 \%$ & $1.9 \%$ & & & $0.1 \%$ & $2.5 \%$ & $0.4 \%$ & $3.4 \%$ & $0.4 \%$ & $5.4 \%$ & $16.0 \%$ \\
\hline Unreported & $42.7 \%$ & $14.9 \%$ & $31.0 \%$ & $24.9 \%$ & $16.7 \%$ & $22.0 \%$ & $25.2 \%$ & $17.6 \%$ & $30.2 \%$ & $16.6 \%$ & $20.4 \%$ & $19.6 \%$ & $20.4 \%$ & $16.6 \%$ \\
\hline \multicolumn{15}{|c|}{ son Trips per Person } \\
\hline TOTAL & 3.82 & 2.45 & 2.36 & 2.56 & 3.27 & 2.71 & 2.91 & 3.01 & 2.84 & 3.14 & 3.40 & 3.62 & 3.29 & 3.05 \\
\hline$\%$ Private & $34.6 \%$ & $71.4 \%$ & $33.1 \%$ & $68.8 \%$ & $42.5 \%$ & $60.9 \%$ & $34.7 \%$ & $40.2 \%$ & $31.0 \%$ & $30.9 \%$ & $13.5 \%$ & $24.3 \%$ & $9.7 \%$ & $5.6 \%$ \\
\hline$\%$ Public & $13.4 \%$ & $1.2 \%$ & $12.7 \%$ & $7.4 \%$ & $16.5 \%$ & $8.9 \%$ & $19.9 \%$ & $16.6 \%$ & $29.9 \%$ & $25.2 \%$ & $32.1 \%$ & $24.3 \%$ & $35.3 \%$ & $42.0 \%$ \\
\hline$\%$ Walk & $8.6 \%$ & $12.7 \%$ & $8.1 \%$ & $9.4 \%$ & $7.3 \%$ & $8.9 \%$ & $13.4 \%$ & $6.0 \%$ & $6.0 \%$ & $8.3 \%$ & $5.0 \%$ & $4.4 \%$ & $7.0 \%$ & $1.6 \%$ \\
\hline$\%$ Other & $32.7 \%$ & $10.2 \%$ & $30.1 \%$ & $6.6 \%$ & $19.9 \%$ & $16.6 \%$ & $24.7 \%$ & $29.6 \%$ & $22.9 \%$ & $27.7 \%$ & $42.9 \%$ & $37.6 \%$ & $41.6 \%$ & $43.3 \%$ \\
\hline$\%$ Unreported & $10.7 \%$ & $4.5 \%$ & $16.1 \%$ & $7.8 \%$ & $13.8 \%$ & $4.8 \%$ & $7.2 \%$ & $7.6 \%$ & $10.2 \%$ & $8.0 \%$ & $6.5 \%$ & $9.4 \%$ & $6.4 \%$ & $7.5 \%$ \\
\hline TOTAL & 3.82 & 2.45 & 2.36 & 2.56 & 3.27 & 2.71 & 2.91 & 3.01 & 2.84 & 3.14 & 3.40 & 3.62 & 3.29 & 3.05 \\
\hline$<\$ 10,000$ & 2.57 & 1.95 & 1.26 & 1.34 & 3.41 & 2.00 & 2.21 & 2.46 & 2.99 & 3.50 & 2.66 & 3.65 & 3.08 & 3.00 \\
\hline$\$ 10$ to & 3.49 & 2.65 & 3.35 & 2.57 & 2.84 & 4.03 & 3.07 & 3.37 & 1.79 & 3.31 & 3.62 & 3.37 & 3.27 & 1.18 \\
\hline$\$ 20$ to $\$ 30,000$ & 3.80 & 3.19 & 2.81 & 2.40 & 2.84 & 2.99 & 2.81 & 3.77 & 3.50 & 4.28 & 4.00 & 4.11 & 3.34 & 3.30 \\
\hline$\$ 30$ to $\$ 40,0$ & 2.54 & 6.25 & 3.21 & 5.52 & 5.80 & 2.98 & 3.54 & 3.04 & 3.6 & 2.20 & 2.87 & 5.01 & 3.41 & 4.00 \\
\hline$\$ 40$ to & & 5.79 & & 1.93 & 6.80 & 4.00 & 3.70 & 3.83 & 3.8 & 7.01 & 5.71 & 3.60 & 2.92 & \\
\hline$\$ 50$ to & 4.03 & & 3.00 & 6.07 & & 1.02 & 3.14 & 2.53 & 2.46 & 3.31 & 3.53 & 2.77 & 3.63 & 7.00 \\
\hline$\$ 60$ to $\$$ & & 3.77 & 2.00 & 4.55 & 5.00 & 7.00 & 2.92 & 2.35 & 5.10 & 1.93 & 2.86 & 2.86 & 4.76 & \\
\hline$\$ 70$ to & & & & 1.78 & 3.65 & & & 6.23 & 2.00 & 9.48 & 4.79 & & 4.34 & \\
\hline$\$ 80$ to & 4.88 & & & 10.14 & & & 3.54 & 5.69 & 4.04 & & 1.95 & 6.32 & 3.71 & \\
\hline$\$ 100,000+$ & 5.00 & 2.00 & 2.00 & 3.72 & 6.00 & & & 4.77 & 1.30 & 3.50 & 4.87 & 2.76 & 4.11 & 3.69 \\
\hline Unreported & 4.38 & 1.10 & 0.98 & 2.49 & 2.08 & 2.24 & 2.68 & 2.60 & 2.38 & 2.05 & 3.04 & 3.07 & 2.75 & 3.65 \\
\hline \multicolumn{15}{|c|}{ olds - Daily PMT per Person } \\
\hline TOTAL & 24.75 & 16.36 & 8.21 & 17.54 & 14.22 & 12.72 & 16.69 & 12.51 & 13.71 & 12.16 & 11.17 & 11.74 & 16.31 & 5.97 \\
\hline$\%$ Priv & $61.5 \%$ & $89.0 \%$ & $71.0 \%$ & $88.8 \%$ & $57.9 \%$ & $66.0 \%$ & $59.9 \%$ & $70.2 \%$ & $64.8 \%$ & $32.3 \%$ & $19.5 \%$ & $42.2 \%$ & $37.0 \%$ & $16.9 \%$ \\
\hline$\%$ Public & $25.5 \%$ & $2.4 \%$ & $14.6 \%$ & $6.0 \%$ & $22.7 \%$ & $18.7 \%$ & $20.4 \%$ & $20.8 \%$ & $27.1 \%$ & $54.2 \%$ & $69.3 \%$ & $44.2 \%$ & $46.2 \%$ & $66.3 \%$ \\
\hline$\% \mathrm{Wa}$ & $5.8 \%$ & $0.9 \%$ & $5.8 \%$ & $0.8 \%$ & $3.0 \%$ & $1.8 \%$ & $2.6 \%$ & $4.1 \%$ & $2.8 \%$ & $4.3 \%$ & $7.1 \%$ & $6.6 \%$ & $5.5 \%$ & $14.9 \%$ \\
\hline$\% \mathrm{O}$ & $\%$ & $6.8 \%$ & $6.5 \%$ & $4.0 \%$ & $15.5 \%$ & $12.7 \%$ & $16.8 \%$ & $3.9 \%$ & $5.0 \%$ & $4.9 \%$ & $3.1 \%$ & $5.9 \%$ & $10.6 \%$ & $0.8 \%$ \\
\hline$\%$ Unreported & $5.3 \%$ & $0.9 \%$ & $2.1 \%$ & $0.3 \%$ & $0.8 \%$ & $0.9 \%$ & $0.4 \%$ & $1.0 \%$ & $0.4 \%$ & $4.3 \%$ & $1.0 \%$ & $1.1 \%$ & $0.7 \%$ & $1.0 \%$ \\
\hline
\end{tabular}




\begin{tabular}{|c|c|c|c|c|c|c|c|c|c|c|c|c|c|c|}
\hline \multicolumn{15}{|c|}{ Population Density (census tract) } \\
\hline & \multicolumn{2}{|c|}{$<500$} & \multicolumn{2}{|c|}{$500-2,000$} & \multicolumn{2}{|c|}{$2,000-4,000$} & \multicolumn{2}{|c|}{$4,000-10,000$} & \multicolumn{2}{|c|}{$10,000-20,000$} & \multicolumn{2}{|c|}{$20,000-50,000$} & \multicolumn{2}{|c|}{$50,000+$} \\
\hline & NY State & U.S. & NY State & U.S. & NY State & U.S. & NY State & U.S. & NY State & U.S. & NY State & U.S. & NY State & U.S. \\
\hline \multicolumn{15}{|c|}{ Zero-Vehicle Households - Daily PMT per Person } \\
\hline TOTAL & 10.95 & 18.10 & 5.24 & 12.80 & 12.81 & 12.25 & 6.70 & 10.35 & 8.01 & 7.53 & 6.50 & 11.78 & 9.73 & 5.62 \\
\hline$<\$ 10,000$ & 6.63 & 14.38 & 4.98 & 5.61 & 16.26 & 8.31 & 3.72 & 9.13 & 4.40 & 5.88 & 6.12 & 4.01 & 2.57 & 1.14 \\
\hline$\$ 10$ to $\$ 20,000$ & 13.77 & 12.53 & 6.25 & 14.79 & 4.37 & 12.31 & 6.43 & 9.88 & 11.31 & 10.51 & 2.82 & 11.00 & 5.34 & 7.37 \\
\hline$\$ 20$ to $\$ 30,000$ & 1.65 & 27.24 & 8.18 & 39.08 & 4.19 & 5.97 & 15.51 & 7.67 & 5.25 & 6.64 & 10.87 & 10.61 & 11.86 & 9.55 \\
\hline$\$ 30$ to $\$ 40,000$ & 39.24 & 49.53 & 0.65 & 16.66 & 13.18 & 32.77 & 7.42 & 14.63 & 9.70 & 7.37 & 9.58 & 4.20 & 10.20 & \\
\hline$\$ 40$ to $\$ 50,000$ & & 15.03 & 8.92 & 4.86 & 17.39 & 3.92 & 8.02 & 18.15 & 10.53 & 6.62 & 9.85 & 65.83 & 7.69 & 4.83 \\
\hline$\$ 50$ to $\$ 60,000$ & & 3.26 & & 26.08 & & 10.67 & 7.54 & 5.32 & 3.55 & 9.72 & 2.66 & 2.88 & 4.91 & 3.05 \\
\hline$\$ 60$ to $\$ 70,000$ & 2.00 & 29.72 & & 15.94 & & 56.62 & 32.58 & 9.45 & 78.00 & 2.07 & 14.67 & 15.95 & 8.22 & 5.72 \\
\hline$\$ 70$ to $\$ 80,000$ & & 24.15 & 18.49 & 12.92 & & 3.11 & & 15.44 & 10.00 & 5.91 & 2.34 & 20.66 & 14.91 & \\
\hline$\$ 80$ to $\$ 100,000$ & & 72.40 & & 44.13 & 22.00 & 29.41 & 2.00 & 10.56 & 14.77 & 4.94 & 23.44 & 7.20 & 17.10 & \\
\hline$\$ 100,000+$ & 3.55 & 23.58 & 2.41 & 26.06 & 40.83 & 18.26 & 6.64 & 33.65 & 0.23 & 16.94 & 3.24 & 38.28 & 23.77 & 3.16 \\
\hline Unreported & 6.93 & 5.46 & 0.22 & 6.00 & 1.29 & 14.65 & 9.41 & 8.97 & 4.45 & 1.47 & 0.83 & 0.66 & 3.75 & 0.51 \\
\hline \multicolumn{15}{|c|}{ Non-Zero-Vehicle Households - Daily Person Trips per Person } \\
\hline TOTAL & 3.65 & 3.65 & 3.98 & 3.98 & 3.97 & 3.99 & 3.94 & 3.94 & 3.89 & 3.76 & 3.50 & 3.60 & 3.78 & 2.94 \\
\hline$\%$ Private & $87.4 \%$ & $89.2 \%$ & $85.1 \%$ & $88.0 \%$ & $84.1 \%$ & $86.2 \%$ & $82.5 \%$ & $85.6 \%$ & $74.2 \%$ & $77.5 \%$ & $51.6 \%$ & $66.0 \%$ & $40.8 \%$ & $34.2 \%$ \\
\hline$\%$ Public & $0.4 \%$ & $0.1 \%$ & $0.9 \%$ & $0.3 \%$ & $1.3 \%$ & $0.7 \%$ & $2.1 \%$ & $1.3 \%$ & $7.7 \%$ & $3.1 \%$ & $18.9 \%$ & $7.8 \%$ & $17.6 \%$ & $24.6 \%$ \\
\hline$\%$ Walk & $6.8 \%$ & $6.6 \%$ & $8.1 \%$ & $7.4 \%$ & $9.8 \%$ & $9.3 \%$ & $11.8 \%$ & $10.3 \%$ & $14.8 \%$ & $15.4 \%$ & $24.4 \%$ & $23.0 \%$ & $38.1 \%$ & $40.3 \%$ \\
\hline$\%$ Other & $5.3 \%$ & $4.0 \%$ & $5.7 \%$ & $4.3 \%$ & $4.8 \%$ & $3.7 \%$ & $3.6 \%$ & $2.8 \%$ & $3.0 \%$ & $3.8 \%$ & $4.9 \%$ & $3.2 \%$ & $3.5 \%$ & $1.0 \%$ \\
\hline$\%$ Unreported & $0.1 \%$ & $0.2 \%$ & $0.1 \%$ & $0.1 \%$ & $0.1 \%$ & $0.1 \%$ & $0.1 \%$ & $0.1 \%$ & $0.3 \%$ & $0.2 \%$ & $0.3 \%$ & $0.1 \%$ & & \\
\hline \multicolumn{15}{|c|}{ - Daily PMT per Person } \\
\hline TOTAL & 41.80 & 45.15 & 36.56 & 40.97 & 31.27 & 37.49 & 29.52 & 31.65 & 19.32 & 26.55 & 21.78 & 26.21 & 24.14 & 7.55 \\
\hline$\%$ Private & $91.4 \%$ & $93.1 \%$ & $87.1 \%$ & $84.9 \%$ & $84.3 \%$ & $88.9 \%$ & $75.5 \%$ & $86.3 \%$ & $80.8 \%$ & $87.2 \%$ & $67.1 \%$ & $76.6 \%$ & $75.5 \%$ & $56.3 \%$ \\
\hline \% Public & $0.7 \%$ & $0.1 \%$ & $1.9 \%$ & $0.3 \%$ & $3.2 \%$ & $0.9 \%$ & $3.0 \%$ & $1.4 \%$ & $11.9 \%$ & $2.0 \%$ & $15.1 \%$ & $17.2 \%$ & $14.7 \%$ & $30.9 \%$ \\
\hline$\%$ Walk & $0.4 \%$ & $0.4 \%$ & $0.6 \%$ & $0.5 \%$ & $0.9 \%$ & $0.7 \%$ & $0.9 \%$ & $0.9 \%$ & $2.1 \%$ & $1.4 \%$ & $3.3 \%$ & $2.3 \%$ & $5.7 \%$ & $12.4 \%$ \\
\hline$\%$ Other & $7.5 \%$ & $6.4 \%$ & $10.3 \%$ & $14.2 \%$ & $11.5 \%$ & $9.6 \%$ & $20.5 \%$ & $11.3 \%$ & $5.3 \%$ & $9.4 \%$ & $13.9 \%$ & $3.9 \%$ & $4.1 \%$ & $0.4 \%$ \\
\hline$\%$ Unreported & $0.1 \%$ & $0.1 \%$ & $0.1 \%$ & $0.1 \%$ & $0.1 \%$ & $0.0 \%$ & $0.0 \%$ & $0.1 \%$ & $0.0 \%$ & $0.1 \%$ & $0.6 \%$ & & & \\
\hline \multicolumn{15}{|c|}{ Average Person Trip Length } \\
\hline ALL & 11.58 & 12.50 & 9.35 & 10.38 & 7.95 & 9.49 & 7.33 & 8.07 & 4.98 & 6.92 & 5.86 & 6.92 & 4.93 & 2.59 \\
\hline Zero Vehicle HHs & 5.87 & 8.51 & 3.01 & 6.31 & 6.56 & 5.33 & 2.62 & 4.41 & 3.62 & 2.84 & 2.76 & 4.05 & 3.32 & 1.46 \\
\hline Non-Zero Vehicle HHs & 11.63 & 12.54 & 9.45 & 10.46 & 7.98 & 9.59 & 7.62 & 8.21 & 5.15 & 7.40 & 7.23 & 7.61 & 6.78 & 3.14 \\
\hline
\end{tabular}




\begin{tabular}{|c|c|c|c|c|c|c|c|c|c|c|c|c|c|c|}
\hline \multicolumn{15}{|c|}{ Population Density (census tract) } \\
\hline & \multicolumn{2}{|c|}{$<500$} & \multicolumn{2}{|c|}{$500-2,000$} & \multicolumn{2}{|c|}{$2,000-4,000$} & \multicolumn{2}{|c|}{$4,000-10,000$} & \multicolumn{2}{|c|}{$10,000-20,000$} & \multicolumn{2}{|c|}{$20,000-50,000$} & \multicolumn{2}{|c|}{$50,000+$} \\
\hline & NY State & U.S. & NY State & U.S. & NY State & U.S. & NY State & U.S. & NY State & U.S. & NY State & U.S. & NY State & U.S. \\
\hline \multicolumn{15}{|c|}{ Zero-Vehicle Households - Daily PMT per Person } \\
\hline TOTAL & 12.63 & 27.14 & 9.08 & 25.56 & 8.04 & 11.21 & 9.26 & 26.90 & 12.51 & 8.72 & 30.29 & 9.56 & 12.97 & 7.55 \\
\hline $\mid<\$ 10,000$ & 16.84 & 7.45 & 6.70 & 9.91 & 5.79 & 6.75 & 8.86 & 7.14 & 6.82 & 4.68 & 9.34 & 8.38 & 12.23 & 4.03 \\
\hline$\$ 10$ to $\$ 20,000$ & 7.01 & 45.63 & 2.45 & 24.25 & 7.20 & 7.42 & 10.42 & 8.27 & 14.83 & 6.61 & 5.39 & 8.46 & 8.81 & 0.97 \\
\hline$\$ 20$ to $\$ 30,000$ & 6.90 & 50.83 & 7.05 & 46.85 & 2.84 & 14.77 & 6.89 & 43.25 & 7.12 & 12.89 & 5.53 & 8.04 & 8.20 & 11.47 \\
\hline$\$ 30$ to $\$ 40,000$ & 20.17 & 16.17 & 12.81 & 33.09 & 18.32 & 19.68 & 16.77 & 18.13 & 5.91 & 22.63 & 14.39 & 11.38 & 17.61 & 7.60 \\
\hline$\$ 40$ to $\$ 50,000$ & & 21.00 & 24.78 & 0.47 & & 9.01 & 4.56 & 6.21 & 72.54 & 4.22 & 27.21 & 13.83 & 7.48 & 6.17 \\
\hline$\$ 50$ to $\$ 60,000$ & 30.57 & 137.84 & & 33.92 & 27.08 & 35.62 & 7.81 & 476.86 & 18.80 & 17.21 & 8.49 & 17.27 & 13.81 & \\
\hline$\$ 60$ to $\$ 70,000$ & 1.61 & 55.78 & & 44.00 & & 13.08 & & 9.80 & 14.13 & 13.24 & 19.72 & 13.80 & 15.48 & \\
\hline$\$ 70$ to $\$ 80,000$ & 10.00 & 34.24 & & 0.10 & 107.07 & & & & 23.03 & 33.74 & 7.80 & & 31.11 & 7.33 \\
\hline$\$ 80$ to $\$ 100,000$ & 16.09 & 51.94 & 23.54 & 0.44 & & 130.11 & 8.98 & 3.98 & 13.48 & 16.59 & 32.01 & 9.96 & 15.76 & \\
\hline$\$ 100,000_{+}$ & 13.32 & 44.63 & 47.20 & 104.24 & & 12.61 & 7.80 & 77.66 & 10.21 & 4.45 & 359.98 & 13.91 & 19.35 & \\
\hline Unreported & 8.96 & 11.72 & 9.02 & 8.69 & 1.09 & 8.85 & 3.23 & 6.60 & 8.42 & 2.26 & 5.18 & 3.83 & 5.91 & 5.00 \\
\hline \multicolumn{15}{|c|}{ Non-Zero-Vehicle Households - Daily Person Trips per Person } \\
\hline TOTAL & 3.82 & 4.04 & 4.12 & 4.36 & 4.22 & 4.35 & 4.00 & 4.20 & 3.55 & 3.89 & 3.62 & 3.77 & 3.48 & 4.10 \\
\hline$\%$ Private & $87.6 \%$ & $90.7 \%$ & $87.6 \%$ & $90.0 \%$ & $87.2 \%$ & $89.9 \%$ & $83.8 \%$ & $87.5 \%$ & $74.8 \%$ & $80.3 \%$ & $56.6 \%$ & $74.7 \%$ & $38.9 \%$ & $78.2 \%$ \\
\hline$\%$ Public & $0.8 \%$ & $0.1 \%$ & $0.6 \%$ & $0.3 \%$ & $1.3 \%$ & $0.6 \%$ & $2.1 \%$ & $1.2 \%$ & $6.0 \%$ & $2.8 \%$ & $13.7 \%$ & $5.1 \%$ & $18.6 \%$ & $0.5 \%$ \\
\hline$\%$ Walk & $6.6 \%$ & $5.4 \%$ & $7.1 \%$ & $5.8 \%$ & $7.4 \%$ & $7.0 \%$ & $9.8 \%$ & $8.9 \%$ & $15.5 \%$ & $14.0 \%$ & $26.5 \%$ & $16.8 \%$ & $38.3 \%$ & $19.6 \%$ \\
\hline$\%$ Other & $5.0 \%$ & $3.8 \%$ & $4.6 \%$ & $3.7 \%$ & $4.1 \%$ & $2.5 \%$ & $4.2 \%$ & $2.4 \%$ & $3.4 \%$ & $2.9 \%$ & $3.1 \%$ & $3.3 \%$ & $4.2 \%$ & $1.7 \%$ \\
\hline$\%$ Unreported & $0.1 \%$ & $0.1 \%$ & $0.1 \%$ & $0.1 \%$ & $0.1 \%$ & $0.1 \%$ & $0.1 \%$ & $0.1 \%$ & $0.2 \%$ & $0.0 \%$ & $0.1 \%$ & $0.1 \%$ & $0.0 \%$ & $0.1 \%$ \\
\hline \multicolumn{15}{|c|}{ Non-Zero-Vehicle Households - Daily PMT per Person } \\
\hline TOTAL & 40.74 & 44.99 & 38.20 & 42.80 & 36.39 & 39.88 & 29.78 & 36.57 & 26.16 & 36.54 & 21.73 & 35.78 & 24.66 & 46.47 \\
\hline$\%$ Private & $92.2 \%$ & $93.9 \%$ & $86.4 \%$ & $88.2 \%$ & $89.0 \%$ & $90.3 \%$ & $85.0 \%$ & $88.2 \%$ & $84.5 \%$ & $70.3 \%$ & $58.2 \%$ & $69.5 \%$ & $54.1 \%$ & $98.6 \%$ \\
\hline$\%$ Public & $1.6 \%$ & $0.1 \%$ & $1.3 \%$ & $0.6 \%$ & $3.1 \%$ & $0.6 \%$ & $4.8 \%$ & $1.4 \%$ & $8.9 \%$ & $2.4 \%$ & $16.3 \%$ & $2.6 \%$ & $13.4 \%$ & $0.0 \%$ \\
\hline$\%$ Walk & $0.5 \%$ & $0.4 \%$ & $0.6 \%$ & $0.5 \%$ & $0.7 \%$ & $0.5 \%$ & $1.2 \%$ & $0.7 \%$ & $1.7 \%$ & $1.0 \%$ & $3.0 \%$ & $0.9 \%$ & $3.4 \%$ & $1.1 \%$ \\
\hline$\%$ Other & $5.7 \%$ & $5.5 \%$ & $11.6 \%$ & $10.6 \%$ & $7.0 \%$ & $6.3 \%$ & $7.1 \%$ & $9.6 \%$ & $4.7 \%$ & $26.3 \%$ & $22.5 \%$ & $27.0 \%$ & $26.2 \%$ & $0.2 \%$ \\
\hline$\%$ Unreported & $0.0 \%$ & $0.2 \%$ & $0.1 \%$ & $0.1 \%$ & $0.2 \%$ & $2.3 \%$ & $1.9 \%$ & $0.1 \%$ & $0.2 \%$ & $0.0 \%$ & $0.0 \%$ & $0.0 \%$ & $2.9 \%$ & $0.0 \%$ \\
\hline \multicolumn{15}{|c|}{ Average Person Trip Length } \\
\hline ALL & 10.66 & 11.27 & 9.36 & 9.90 & 8.65 & 9.21 & 7.45 & 8.96 & 7.34 & 9.40 & 7.68 & 8.91 & 6.22 & 7.75 \\
\hline Zero Vehicle HHs & 4.37 & 12.35 & 4.30 & 10.08 & 4.88 & 4.16 & 3.62 & 12.29 & 5.31 & 4.03 & 10.34 & 3.93 & 4.57 & 3.19 \\
\hline Non-Zero Vehicle HHs & 10.77 & 11.26 & 9.40 & 9.90 & 8.72 & 9.31 & 7.64 & 8.87 & 7.64 & 9.80 & 6.38 & 9.77 & 7.88 & 11.37 \\
\hline
\end{tabular}




\begin{tabular}{|c|c|c|c|c|c|c|c|c|c|c|c|c|c|c|}
\hline \multicolumn{15}{|c|}{ Population Density (census tract) } \\
\hline & \multicolumn{2}{|c|}{$<500$} & \multirow{2}{*}{\multicolumn{2}{|c|}{\begin{tabular}{c}
\multicolumn{2}{c}{$500-2,000$} \\
NY State U.S.
\end{tabular}}} & \multicolumn{2}{|c|}{$2,000-4,000$} & \multicolumn{2}{|c|}{$4,000-10,000$} & \multicolumn{2}{|c|}{$10,000-20,000$} & \multicolumn{2}{|c|}{$20,000-50,000$} & \multicolumn{2}{|c|}{$50,000+$} \\
\hline & NY State & U.S. & NY State & & NY State & U.S. & NY State & U.S. & NY State & U.S. & NY State & U.S. & NY State & U.S. \\
\hline \multicolumn{15}{|c|}{ Zero-Vehicle Households - Daily PMT per Person } \\
\hline TOTAL & 24.75 & 16.36 & 8.21 & 17.54 & 14.22 & 12.72 & 16.69 & 12.51 & 13.71 & 12.16 & 11.17 & 11.74 & 16.31 & 5.97 \\
\hline$<\$ 10,000$ & 11.46 & 7.29 & 8.74 & 7.83 & 13.12 & 7.67 & 6.62 & 6.26 & 7.34 & 9.93 & 6.14 & 6.03 & 9.92 & 14.00 \\
\hline$\$ 10$ to $\$ 20,000$ & 10.75 & 14.64 & 7.97 & 11.92 & 11.73 & 16.51 & 13.00 & 21.62 & 7.50 & 16.19 & 8.64 & 10.29 & 23.49 & 2.21 \\
\hline$\$ 20$ to $\$ 30,000$ & 22.26 & 27.33 & 10.20 & 12.84 & 10.57 & 15.39 & 17.92 & 9.65 & 6.86 & 17.45 & 11.59 & 15.20 & 13.67 & 9.14 \\
\hline$\$ 30$ to $\$ 40,000$ & 22.36 & 23.32 & 3.97 & 22.66 & 26.52 & 30.55 & 31.76 & 13.73 & 16.45 & 6.71 & 16.25 & 35.05 & 16.04 & 5.11 \\
\hline$\$ 40$ to $\$ 50,000$ & & 18.87 & & 92.73 & 77.97 & 106.00 & 7.32 & 3.46 & 16.68 & 13.04 & 11.46 & 29.72 & 36.79 & \\
\hline$\$ 50$ to $\$ 60,000$ & 45.32 & & 261.00 & 16.97 & & 3.66 & 16.74 & 6.69 & 58.55 & 6.81 & 10.02 & 10.01 & 10.75 & 5.30 \\
\hline$\$ 60$ to $\$ 70,000$ & & 72.80 & 64.00 & 18.01 & 28.67 & 72.39 & 19.72 & 9.24 & 9.50 & 3.96 & 4.22 & 6.13 & 17.17 & \\
\hline$\$ 70$ to $\$ 80,000$ & & & & 17.10 & 26.27 & & & 13.90 & 2.00 & 28.82 & 13.31 & & 8.18 & \\
\hline$\$ 80$ to $\$ 100,000$ & 5.85 & & & 54.72 & & & 449.66 & 17.08 & 40.51 & & 17.61 & 11.19 & 26.41 & \\
\hline$\$ 100,000+$ & 226.86 & 90.00 & 28.00 & 68.32 & 2.96 & & & 75.01 & 5.82 & 16.88 & 12.05 & 1.85 & 15.76 & 5.95 \\
\hline Unreported & 18.13 & 8.09 & 1.07 & 12.00 & 4.48 & 9.44 & 4.89 & 8.15 & 18.09 & 7.83 & 11.49 & 8.08 & 13.19 & 2.67 \\
\hline \multicolumn{15}{|c|}{ Non-Zero-Vehicle Households - Daily Person Trips per Person } \\
\hline TOTAL & 4.07 & 4.21 & 4.28 & 4.40 & 4.38 & 4.53 & 4.10 & 4.44 & 3.77 & 4.20 & 4.00 & 4.28 & 3.75 & 3.81 \\
\hline$\%$ Private & $88.9 \%$ & $91.0 \%$ & $87.4 \%$ & $90.0 \%$ & $87.9 \%$ & $89.2 \%$ & $84.9 \%$ & $88.1 \%$ & $75.1 \%$ & $81.2 \%$ & $57.5 \%$ & $68.5 \%$ & $44.3 \%$ & $67.7 \%$ \\
\hline$\%$ Public & $0.7 \%$ & $0.2 \%$ & $0.9 \%$ & $0.5 \%$ & $0.9 \%$ & $0.9 \%$ & $2.2 \%$ & $1.1 \%$ & $7.2 \%$ & $3.6 \%$ & $11.0 \%$ & $5.8 \%$ & $16.0 \%$ & $8.4 \%$ \\
\hline$\%$ Walk & $3.2 \%$ & $2.1 \%$ & $4.2 \%$ & $3.0 \%$ & $3.7 \%$ & $4.4 \%$ & $6.3 \%$ & $5.2 \%$ & $10.9 \%$ & $9.3 \%$ & $23.3 \%$ & $17.5 \%$ & $27.5 \%$ & $21.0 \%$ \\
\hline$\%$ Other & $4.4 \%$ & $3.6 \%$ & $4.2 \%$ & $3.6 \%$ & $4.1 \%$ & $2.6 \%$ & $3.2 \%$ & $2.0 \%$ & $2.4 \%$ & $1.4 \%$ & $3.5 \%$ & $3.0 \%$ & $5.6 \%$ & $1.3 \%$ \\
\hline$\%$ Unreported & $2.7 \%$ & $3.1 \%$ & $3.3 \%$ & $3.0 \%$ & $3.4 \%$ & $2.9 \%$ & $3.4 \%$ & $3.6 \%$ & $4.5 \%$ & $4.5 \%$ & $4.8 \%$ & $5.1 \%$ & $6.7 \%$ & $1.6 \%$ \\
\hline \multicolumn{15}{|c|}{ Non-Zero-Vehicle Households - Daily PMT per Person } \\
\hline TOTAL & 40.17 & 44.53 & 39.89 & 40.74 & 35.12 & 41.04 & 29.10 & 35.88 & 25.54 & 28.71 & 22.56 & 27.37 & 23.46 & 39.41 \\
\hline$\%$ Private & $91.3 \%$ & $94.7 \%$ & $92.8 \%$ & $92.5 \%$ & $91.9 \%$ & $88.5 \%$ & $88.6 \%$ & $90.5 \%$ & $84.9 \%$ & $88.6 \%$ & $77.1 \%$ & $85.2 \%$ & $68.4 \%$ & $91.6 \%$ \\
\hline$\%$ Public & $1.8 \%$ & $0.4 \%$ & $2.5 \%$ & $0.7 \%$ & $3.6 \%$ & $2.6 \%$ & $6.9 \%$ & $1.6 \%$ & $11.6 \%$ & $6.8 \%$ & $15.2 \%$ & $5.5 \%$ & $20.7 \%$ & $6.0 \%$ \\
\hline$\%$ Walk & $0.3 \%$ & $0.1 \%$ & $0.3 \%$ & $0.2 \%$ & $0.3 \%$ & $0.3 \%$ & $0.4 \%$ & $0.3 \%$ & $0.7 \%$ & $0.7 \%$ & $2.5 \%$ & $1.2 \%$ & $2.3 \%$ & $2.2 \%$ \\
\hline$\%$ Other & $5.9 \%$ & $4.0 \%$ & $3.6 \%$ & $5.9 \%$ & $3.1 \%$ & $6.8 \%$ & $2.5 \%$ & $6.7 \%$ & $1.8 \%$ & $2.7 \%$ & $4.7 \%$ & $7.8 \%$ & $7.4 \%$ & $0.1 \%$ \\
\hline$\%$ Unreported & $0.7 \%$ & $0.8 \%$ & $0.9 \%$ & $0.7 \%$ & $1.1 \%$ & $1.8 \%$ & $1.5 \%$ & $0.8 \%$ & $1.0 \%$ & $1.2 \%$ & $0.5 \%$ & $0.2 \%$ & $1.1 \%$ & $0.1 \%$ \\
\hline \multicolumn{15}{|l|}{ Average Person Trip } \\
\hline & 9.91 & 10.66 & 9.41 & 9.33 & 8.02 & 9.06 & 7.23 & 8.05 & 6.85 & 6.64 & 5.18 & 5.83 & 5.95 & 7.31 \\
\hline Zero Ve & 6.72 & 7.08 & 3.58 & 7.25 & 4.78 & 4.85 & 6.13 & 4.40 & 5.38 & 4.09 & 3.69 & 3.63 & 5.49 & 1.95 \\
\hline Non-Zero Vehicle HHs & 9.99 & 10.70 & 9.47 & 9.35 & 8.11 & 9.16 & 7.29 & 8.20 & 7.06 & 6.99 & 5.96 & 6.53 & 6.64 & 10.33 \\
\hline
\end{tabular}




\begin{tabular}{|c|c|c|c|c|c|c|c|c|c|c|c|c|c|c|}
\hline \multicolumn{15}{|c|}{ Population Density (census tract) } \\
\hline & \multicolumn{2}{|c|}{$<500$} & \multicolumn{2}{|c|}{$500-2,000$} & \multicolumn{2}{|c|}{$2,000-4,000$} & \multicolumn{2}{|c|}{$4,000-10,000$} & \multicolumn{2}{|c|}{$10,000-20,000$} & \multicolumn{2}{|c|}{$20,000-50,000$} & \multicolumn{2}{|c|}{$50,000+$} \\
\hline & NY State & U.S. & NY State & U.S. & NY State & U.S. & NY State & U.S. & NY State & U.S. & NY State & U.S. & NY State & U.S. \\
\hline $\begin{array}{l}\text { Daily Vehicle Trips per Driver } \\
\text { TOTAL }\end{array}$ & 3.02 & 2.94 & 3.23 & 3.23 & 3.13 & 3.18 & 296 & 314 & 273 & 268 & 122 & 204 & & 123 \\
\hline$\%$ Earn a Living & $\begin{array}{r}3.02 \\
27.8 \%\end{array}$ & $\begin{array}{r}2.64 \\
27.6 \%\end{array}$ & $26.6 \%$ & $\begin{array}{r}5.25 \\
26.1 \%\end{array}$ & $24.5 \%$ & $26.0 \%$ & $25.1 \%$ & $\begin{array}{r}5.14 \\
25.1 \%\end{array}$ & $\begin{array}{r}2.13 \\
18.1 \%\end{array}$ & $\begin{array}{r}2.68 \\
23.7 \%\end{array}$ & $\begin{array}{r}1.22 \\
21.1 \%\end{array}$ & $\begin{array}{r}2.04 \\
26.6 \%\end{array}$ & $18.2 \%$ & $\begin{array}{r}1.23 \\
57.4 \%\end{array}$ \\
\hline$\%$ Family \& Personal Business & $47.1 \%$ & $45.4 \%$ & $46.5 \%$ & $46.6 \%$ & $48.0 \%$ & $46.6 \%$ & $48.2 \%$ & $47.1 \%$ & $54.9 \%$ & $48.7 \%$ & $57.0 \%$ & $49.6 \%$ & $53.2 \%$ & $23.2 \%$ \\
\hline$\%$ Civic, Educational \& Religious & $3.4 \%$ & $4.4 \%$ & $4.7 \%$ & $4.9 \%$ & $4.1 \%$ & $5.5 \%$ & $5.6 \%$ & $4.6 \%$ & $6.5 \%$ & $5.3 \%$ & $2.2 \%$ & $5.0 \%$ & $3.5 \%$ & $3.1 \%$ \\
\hline \% Social \& Recreational & $20.6 \%$ & $21.4 \%$ & $20.9 \%$ & $21.2 \%$ & $22.4 \%$ & $20.9 \%$ & $20.2 \%$ & $22.0 \%$ & $20.0 \%$ & $21.4 \%$ & $17.1 \%$ & $17.7 \%$ & $23.8 \%$ & $16.0 \%$ \\
\hline$\%$ Other & $0.3 \%$ & $0.3 \%$ & $0.5 \%$ & $0.3 \%$ & $0.3 \%$ & $0.4 \%$ & $0.4 \%$ & $0.3 \%$ & $0.1 \%$ & $0.2 \%$ & $0.2 \%$ & $0.0 \%$ & $0.2 \%$ & \\
\hline$\%$ Unreported & $0.8 \%$ & $1.0 \%$ & $0.9 \%$ & $0.9 \%$ & $0.7 \%$ & $0.8 \%$ & $0.6 \%$ & $1.0 \%$ & $0.4 \%$ & $0.8 \%$ & $2.4 \%$ & $1.1 \%$ & $1.2 \%$ & $0.2 \%$ \\
\hline TOTAL & 3.02 & 2.94 & 3.23 & 3.23 & 3.13 & 3.18 & 2.96 & 3.14 & 2.73 & 2.68 & 1.22 & 2.04 & 0.70 & 1.23 \\
\hline Weekend & 2.49 & 2.32 & 2.71 & 2.69 & 2.83 & 2.74 & 2.35 & 2.62 & 2.58 & 2.47 & 1.27 & 1.68 & 0.91 & 2.14 \\
\hline Weekday & 3.21 & 3.19 & 3.44 & 3.44 & 3.26 & 3.34 & 3.15 & 3.35 & 2.80 & 2.76 & 1.20 & 2.17 & 0.63 & 1.10 \\
\hline TOTAL & 3.02 & 2.94 & 3.23 & 3.23 & 3.13 & 3.18 & 2.96 & 3.14 & 2.73 & 2.68 & 1.22 & 2.04 & 0.70 & 1.23 \\
\hline$\% 1-9 \mathrm{~min}$ & $30.6 \%$ & $26.5 \%$ & $33.0 \%$ & $30.0 \%$ & $34.0 \%$ & $30.2 \%$ & $33.5 \%$ & $29.8 \%$ & $31.9 \%$ & $27.1 \%$ & $23.2 \%$ & $22.4 \%$ & $17.0 \%$ & $14.7 \%$ \\
\hline$\% 10-19 \mathrm{~min}$ & $33.4 \%$ & $34.9 \%$ & $37.2 \%$ & $37.8 \%$ & $37.4 \%$ & $39.0 \%$ & $37.3 \%$ & $38.3 \%$ & $36.0 \%$ & $36.7 \%$ & $33.3 \%$ & $33.5 \%$ & $31.9 \%$ & $49.8 \%$ \\
\hline$\%$ 20-29 min & $15.3 \%$ & $16.0 \%$ & $13.9 \%$ & $13.9 \%$ & $12.3 \%$ & $13.8 \%$ & $12.3 \%$ & $14.8 \%$ & $13.8 \%$ & $15.2 \%$ & $17.6 \%$ & $17.9 \%$ & $16.2 \%$ & $21.1 \%$ \\
\hline$\%$ 30-39 min & $10.5 \%$ & $11.4 \%$ & $8.2 \%$ & $9.3 \%$ & $7.6 \%$ & $8.7 \%$ & $8.7 \%$ & $9.3 \%$ & $11.0 \%$ & $11.1 \%$ & $11.1 \%$ & $13.5 \%$ & $14.3 \%$ & $7.4 \%$ \\
\hline$\%$ 40-49 min & $4.3 \%$ & $5.2 \%$ & $3.2 \%$ & $3.9 \%$ & $3.4 \%$ & $3.7 \%$ & $3.7 \%$ & $3.5 \%$ & $3.8 \%$ & $4.0 \%$ & $6.2 \%$ & $5.1 \%$ & $7.9 \%$ & $1.8 \%$ \\
\hline$\% 50+\min$ & $5.8 \%$ & $5.8 \%$ & $4.3 \%$ & $5.0 \%$ & $4.9 \%$ & $4.6 \%$ & $4.3 \%$ & $4.0 \%$ & $3.4 \%$ & $5.9 \%$ & $7.8 \%$ & $7.6 \%$ & $12.7 \%$ & $5.3 \%$ \\
\hline$\%$ Unreported & $0.1 \%$ & $0.2 \%$ & $0.2 \%$ & $0.2 \%$ & $0.3 \%$ & $0.1 \%$ & $0.2 \%$ & $0.3 \%$ & $0.1 \%$ & $0.1 \%$ & $0.8 \%$ & $0.0 \%$ & $0.1 \%$ & \\
\hline TOTAL & 3.02 & 2.94 & 3.23 & 3.23 & 3.13 & 3.18 & 2.96 & 3.14 & 2.73 & 2.68 & 1.22 & 2.04 & 0.70 & 1.23 \\
\hline$\% 5$ or less & $46.8 \%$ & $44.5 \%$ & $58.8 \%$ & $55.3 \%$ & $62.8 \%$ & $60.1 \%$ & $66.9 \%$ & $61.9 \%$ & $72.0 \%$ & $65.7 \%$ & $62.0 \%$ & $60.4 \%$ & $62.2 \%$ & $78.7 \%$ \\
\hline$\%$ 6-10 miles & $22.0 \%$ & $21.7 \%$ & $18.5 \%$ & $20.0 \%$ & $16.3 \%$ & $18.1 \%$ & $15.1 \%$ & $17.7 \%$ & $13.7 \%$ & $15.2 \%$ & $15.7 \%$ & $16.5 \%$ & $12.8 \%$ & $9.1 \%$ \\
\hline$\% 11-15$ miles & $11.0 \%$ & $12.1 \%$ & $8.3 \%$ & $9.0 \%$ & $7.9 \%$ & $8.1 \%$ & $5.7 \%$ & $7.8 \%$ & $4.9 \%$ & $6.6 \%$ & $6.5 \%$ & $6.6 \%$ & $9.4 \%$ & $6.9 \%$ \\
\hline$\% 16-2$ & $6.5 \%$ & $7.2 \%$ & $4.9 \%$ & $4.8 \%$ & $3.6 \%$ & $4.4 \%$ & $4.7 \%$ & $4.3 \%$ & $3.0 \%$ & $3.0 \%$ & $4.0 \%$ & $3.2 \%$ & $4.1 \%$ & $0.4 \%$ \\
\hline$\% 21-30$ miles & $6.4 \%$ & $6.9 \%$ & $4.3 \%$ & $5.1 \%$ & $4.2 \%$ & $4.1 \%$ & $3.7 \%$ & $3.9 \%$ & $2.3 \%$ & $3.2 \%$ & $1.7 \%$ & $4.1 \%$ & $2.5 \%$ & $2.6 \%$ \\
\hline$\% 31$ or $\mathrm{m}$ & $6.2 \%$ & $6.9 \%$ & $4.0 \%$ & $4.8 \%$ & $4.4 \%$ & $3.9 \%$ & $2.8 \%$ & $3.1 \%$ & $2.0 \%$ & $3.5 \%$ & $2.2 \%$ & $5.5 \%$ & $5.9 \%$ & $0.6 \%$ \\
\hline$\%$ Unreported & $1.1 \%$ & $0.8 \%$ & $1.2 \%$ & $1.0 \%$ & $0.9 \%$ & $1.3 \%$ & $1.1 \%$ & $1.4 \%$ & $2.2 \%$ & $2.8 \%$ & $8.0 \%$ & $3.7 \%$ & $3.2 \%$ & $1.6 \%$ \\
\hline Daily VM & & & & & & & & & & & & & & \\
\hline TOTAL & 34.06 & 36.60 & 29.69 & 31.46 & 24.41 & 27.99 & 19.72 & 24.01 & 14.76 & 20.22 & 7.10 & 17.29 & 7.24 & 4.85 \\
\hline$\%$ Earn a & $36.6 \%$ & $35.5 \%$ & $34.6 \%$ & $35.8 \%$ & $37.5 \%$ & $33.9 \%$ & $37.5 \%$ & $35.1 \%$ & $29.5 \%$ & $36.5 \%$ & $27.9 \%$ & $35.3 \%$ & $18.6 \%$ & $67.5 \%$ \\
\hline$\%$ Family \& Personal Business & $35.4 \%$ & $31.7 \%$ & $29.6 \%$ & $31.4 \%$ & $31.8 \%$ & $30.2 \%$ & $33.6 \%$ & $31.9 \%$ & $38.0 \%$ & $28.1 \%$ & $42.7 \%$ & $31.0 \%$ & $29.7 \%$ & $14.8 \%$ \\
\hline$\%$ Civic, Education & $2.8 \%$ & $3.6 \%$ & $3.3 \%$ & $4.0 \%$ & $4.3 \%$ & $4.4 \%$ & $4.6 \%$ & $4.1 \%$ & $4.0 \%$ & $5.4 \%$ & $1.1 \%$ & $12.9 \%$ & $2.7 \%$ & $0.4 \%$ \\
\hline$\%$ Social \& Recreational & $22.3 \%$ & $23.8 \%$ & $23.5 \%$ & $25.7 \%$ & $25.3 \%$ & $25.4 \%$ & $21.6 \%$ & $25.9 \%$ & $26.9 \%$ & $28.1 \%$ & $26.1 \%$ & $17.8 \%$ & $46.9 \%$ & $14.8 \%$ \\
\hline$\%$ Other & $0.6 \%$ & $0.5 \%$ & $0.6 \%$ & $0.7 \%$ & $0.3 \%$ & $0.8 \%$ & $0.4 \%$ & $0.6 \%$ & $0.2 \%$ & $0.1 \%$ & $0.2 \%$ & $0.0 \%$ & $0.3 \%$ & \\
\hline$\%$ Unreported & $2.3 \%$ & $4.9 \%$ & $8.5 \%$ & $2.4 \%$ & $0.7 \%$ & $5.2 \%$ & $2.3 \%$ & $2.3 \%$ & $1.5 \%$ & $1.9 \%$ & $2.1 \%$ & $3.0 \%$ & $1.8 \%$ & $2.5 \%$ \\
\hline ehicle & & & & & & & & & & & & & & \\
\hline TOTAL & 11.42 & 12.57 & 9.31 & 9.85 & 7.88 & 8.93 & 6.73 & 7.76 & 5.53 & 7.77 & 6.34 & 8.79 & 10.64 & 4.00 \\
\hline Ave & rav & & & & & & & & & & & & & \\
\hline TOTAL & 77.45 & 80.79 & 72.00 & 75.89 & 69.58 & 75.64 & 70.47 & 74.14 & 72.18 & 79.59 & 73.46 & 84.57 & 97.80 & 46.36 \\
\hline
\end{tabular}




\begin{tabular}{|c|c|c|c|c|c|c|c|c|c|c|c|c|c|c|}
\hline \multicolumn{15}{|c|}{ Population Density (census tract) } \\
\hline & \multicolumn{2}{|c|}{$<500$} & \multicolumn{2}{|c|}{$500-2,000$} & \multicolumn{2}{|c|}{$2,000-4,000$} & \multicolumn{2}{|c|}{$4,000-10,000$} & \multicolumn{2}{|c|}{$10,000-20,000$} & \multicolumn{2}{|c|}{$20,000-50,000$} & \multicolumn{2}{|c|}{$50,000+$} \\
\hline & NY State & U.S. & NY State & U.S. & NY State & U.S. & NY State & U.S. & NY State & U.S. & NY State & U.S. & NY State & U.S. \\
\hline \multicolumn{15}{|l|}{ Daily Vehicle Trips per Driver } \\
\hline TOTAL & 3.10 & 3.35 & 3.39 & 3.56 & 3.33 & 3.61 & 3.21 & 3.37 & 2.47 & 2.93 & 1.99 & 2.51 & 1.03 & 1.83 \\
\hline$\%$ Earn a Living & $26.8 \%$ & $27.3 \%$ & $25.4 \%$ & $25.4 \%$ & $25.4 \%$ & $25.8 \%$ & $24.2 \%$ & $25.6 \%$ & $25.9 \%$ & $28.5 \%$ & $22.9 \%$ & $28.3 \%$ & $28.1 \%$ & $15.8 \%$ \\
\hline$\%$ Family \& Personal Business & $47.4 \%$ & $47.5 \%$ & $48.8 \%$ & $48.5 \%$ & $48.6 \%$ & $48.2 \%$ & $49.6 \%$ & $48.9 \%$ & $47.9 \%$ & $45.8 \%$ & $55.2 \%$ & $43.9 \%$ & $44.6 \%$ & $60.4 \%$ \\
\hline$\%$ Civic, Educational \& Religious & $3.9 \%$ & $4.9 \%$ & $4.2 \%$ & $4.7 \%$ & $3.5 \%$ & $5.0 \%$ & $4.9 \%$ & $4.7 \%$ & $5.6 \%$ & $4.0 \%$ & $3.8 \%$ & $4.9 \%$ & $2.6 \%$ & $0.5 \%$ \\
\hline$\%$ Social \& Recreational & $21.2 \%$ & $19.7 \%$ & $20.9 \%$ & $20.9 \%$ & $22.0 \%$ & $20.4 \%$ & $20.4 \%$ & $20.3 \%$ & $20.0 \%$ & $21.1 \%$ & $16.2 \%$ & $22.5 \%$ & $24.0 \%$ & $20.5 \%$ \\
\hline$\%$ Other & $0.5 \%$ & $0.5 \%$ & $0.6 \%$ & $0.5 \%$ & $0.4 \%$ & $0.5 \%$ & $0.7 \%$ & $0.5 \%$ & $0.6 \%$ & $0.5 \%$ & $1.7 \%$ & $0.3 \%$ & $0.6 \%$ & \\
\hline$\%$ Unreported & $0.3 \%$ & $0.1 \%$ & $0.1 \%$ & $0.1 \%$ & $0.1 \%$ & $0.1 \%$ & $0.2 \%$ & $0.1 \%$ & $0.0 \%$ & $0.1 \%$ & $0.2 \%$ & $0.0 \%$ & $0.1 \%$ & $2.8 \%$ \\
\hline TOTAL & 3.10 & 3.35 & 3.39 & 3.56 & 3.33 & 3.61 & 3.21 & 3.37 & 2.47 & 2.93 & 1.99 & 2.51 & 1.03 & 1.83 \\
\hline Weekend & 2.59 & 2.73 & 2.99 & 3.03 & 3.01 & 3.03 & 2.90 & 2.94 & 2.28 & 2.91 & 2.02 & 2.61 & 0.99 & 1.42 \\
\hline Weekday & 3.29 & 3.60 & 3.55 & 3.76 & 3.45 & 3.85 & 3.33 & 3.56 & 2.55 & 2.94 & 1.98 & 2.48 & 1.05 & 2.02 \\
\hline TOTAL & 3.10 & 3.35 & 3.39 & 3.56 & 3.33 & 3.61 & 3.21 & 3.37 & 2.47 & 2.93 & 1.99 & 2.51 & 1.03 & 1.83 \\
\hline$\% 1-9$ min & $28.3 \%$ & $26.9 \%$ & $31.0 \%$ & $29.1 \%$ & $32.8 \%$ & $30.2 \%$ & $34.2 \%$ & $28.9 \%$ & $24.8 \%$ & $25.3 \%$ & $24.3 \%$ & $21.1 \%$ & $13.8 \%$ & $21.1 \%$ \\
\hline$\% 10-19 \min$ & $35.7 \%$ & $36.2 \%$ & $38.3 \%$ & $38.6 \%$ & $36.8 \%$ & $39.1 \%$ & $36.0 \%$ & $38.2 \%$ & $37.0 \%$ & $37.8 \%$ & $38.6 \%$ & $37.7 \%$ & $31.8 \%$ & $32.1 \%$ \\
\hline$\%$ 20-29 min & $15.4 \%$ & $15.1 \%$ & $13.7 \%$ & $14.1 \%$ & $12.7 \%$ & $13.7 \%$ & $13.2 \%$ & $14.6 \%$ & $13.7 \%$ & $14.1 \%$ & $11.7 \%$ & $14.0 \%$ & $14.7 \%$ & $19.0 \%$ \\
\hline$\% 30-39 \mathrm{~min}$ & $10.7 \%$ & $11.0 \%$ & $8.3 \%$ & $9.1 \%$ & $8.5 \%$ & $8.5 \%$ & $7.7 \%$ & $9.8 \%$ & $11.5 \%$ & $11.5 \%$ & $12.5 \%$ & $15.2 \%$ & $17.9 \%$ & $11.2 \%$ \\
\hline$\% 40-49$ min & $4.1 \%$ & $4.6 \%$ & $3.5 \%$ & $3.9 \%$ & $3.2 \%$ & $3.7 \%$ & $3.2 \%$ & $3.6 \%$ & $5.1 \%$ & $5.1 \%$ & $5.4 \%$ & $5.5 \%$ & $8.2 \%$ & $8.7 \%$ \\
\hline$\% 50+\min$ & $5.0 \%$ & $5.7 \%$ & $4.7 \%$ & $4.6 \%$ & $5.4 \%$ & $4.2 \%$ & $5.1 \%$ & $4.4 \%$ & $7.3 \%$ & $5.7 \%$ & $6.9 \%$ & $6.0 \%$ & $13.5 \%$ & $8.0 \%$ \\
\hline$\%$ Unreported & $0.7 \%$ & $0.5 \%$ & $0.5 \%$ & $0.6 \%$ & $0.7 \%$ & $0.6 \%$ & $0.6 \%$ & $0.5 \%$ & $0.6 \%$ & $0.6 \%$ & $0.5 \%$ & $0.5 \%$ & $0.3 \%$ & \\
\hline TOTAL & 3.10 & 3.35 & 3.39 & 3.56 & 3.33 & 3.61 & 3.21 & 3.37 & 2.47 & 2.93 & 1.99 & 2.51 & 1.03 & 1.83 \\
\hline$\% 5$ or less miles & $48.3 \%$ & $46.1 \%$ & $58.1 \%$ & $55.8 \%$ & $61.8 \%$ & $59.5 \%$ & $65.7 \%$ & $60.0 \%$ & $61.4 \%$ & $58.3 \%$ & $68.1 \%$ & $58.9 \%$ & $55.8 \%$ & $68.6 \%$ \\
\hline$\%$ 6-10 miles & $21.7 \%$ & $21.5 \%$ & $18.2 \%$ & $19.8 \%$ & $17.2 \%$ & $18.5 \%$ & $15.2 \%$ & $17.9 \%$ & $15.6 \%$ & $17.1 \%$ & $14.2 \%$ & $17.3 \%$ & $16.8 \%$ & $12.4 \%$ \\
\hline$\% 11-15$ miles & $10.8 \%$ & $11.6 \%$ & $9.0 \%$ & $9.2 \%$ & $7.5 \%$ & $8.0 \%$ & $6.4 \%$ & $8.2 \%$ & $10.4 \%$ & $8.5 \%$ & $5.4 \%$ & $7.4 \%$ & $7.1 \%$ & $3.5 \%$ \\
\hline$\% 16-20$ miles & $6.9 \%$ & $6.7 \%$ & $4.9 \%$ & $4.7 \%$ & $4.2 \%$ & $4.1 \%$ & $3.2 \%$ & $4.2 \%$ & $4.3 \%$ & $4.2 \%$ & $3.2 \%$ & $5.8 \%$ & $3.8 \%$ & $8.9 \%$ \\
\hline$\% 21-30$ miles & $6.0 \%$ & $6.5 \%$ & $3.9 \%$ & $4.7 \%$ & $3.8 \%$ & $4.3 \%$ & $3.6 \%$ & $3.9 \%$ & $3.2 \%$ & $4.4 \%$ & $2.5 \%$ & $4.3 \%$ & $5.0 \%$ & $3.3 \%$ \\
\hline$\% 31$ or more miles & $5.7 \%$ & $6.4 \%$ & $4.7 \%$ & $4.8 \%$ & $4.9 \%$ & $4.0 \%$ & $3.8 \%$ & $3.9 \%$ & $2.7 \%$ & $4.0 \%$ & $2.6 \%$ & $4.0 \%$ & $4.6 \%$ & $2.3 \%$ \\
\hline$\%$ Unreported & $0.7 \%$ & $1.1 \%$ & $1.3 \%$ & $1.0 \%$ & $0.7 \%$ & $1.5 \%$ & $2.3 \%$ & $1.9 \%$ & $2.5 \%$ & $3.6 \%$ & $4.1 \%$ & $2.2 \%$ & $7.0 \%$ & $1.1 \%$ \\
\hline \multicolumn{15}{|l|}{ Daily VMT per Driver } \\
\hline TOTAL & 33.70 & 37.90 & 30.22 & 33.77 & 28.76 & 31.99 & 23.12 & 29.25 & 19.46 & 23.15 & 12.21 & 20.16 & 10.08 & 12.06 \\
\hline$\%$ Earn a Living & $36.2 \%$ & $37.7 \%$ & $36.2 \%$ & $34.8 \%$ & $38.3 \%$ & $34.4 \%$ & $35.6 \%$ & $36.2 \%$ & $32.7 \%$ & $37.3 \%$ & $32.8 \%$ & $31.9 \%$ & $32.2 \%$ & $39.1 \%$ \\
\hline$\%$ Family \& Personal Business & $34.3 \%$ & $35.0 \%$ & $34.5 \%$ & $34.9 \%$ & $31.8 \%$ & $35.6 \%$ & $32.1 \%$ & $33.5 \%$ & $34.0 \%$ & $36.0 \%$ & $41.1 \%$ & $29.6 \%$ & $34.9 \%$ & $42.5 \%$ \\
\hline$\%$ Civic, Educational \& Religious & $2.9 \%$ & $4.1 \%$ & $3.4 \%$ & $3.7 \%$ & $3.0 \%$ & $3.6 \%$ & $3.5 \%$ & $3.5 \%$ & $6.0 \%$ & $3.6 \%$ & $2.4 \%$ & $5.0 \%$ & $2.1 \%$ & $0.8 \%$ \\
\hline$\%$ Social \& Recreational & $25.6 \%$ & $22.3 \%$ & $24.3 \%$ & $25.3 \%$ & $26.3 \%$ & $25.4 \%$ & $28.0 \%$ & $26.1 \%$ & $26.4 \%$ & $22.4 \%$ & $22.7 \%$ & $32.9 \%$ & $30.0 \%$ & $14.2 \%$ \\
\hline$\%$ Other & $0.9 \%$ & $0.6 \%$ & $0.9 \%$ & $1.2 \%$ & $0.5 \%$ & $1.1 \%$ & $0.7 \%$ & $0.6 \%$ & $0.9 \%$ & $0.6 \%$ & $0.8 \%$ & $0.5 \%$ & $0.5 \%$ & \\
\hline$\%$ Unreported & $0.2 \%$ & $0.3 \%$ & $0.7 \%$ & $0.1 \%$ & $0.1 \%$ & $0.1 \%$ & $0.1 \%$ & $0.2 \%$ & $0.1 \%$ & $0.1 \%$ & $0.2 \%$ & $0.0 \%$ & $0.3 \%$ & $3.4 \%$ \\
\hline Average Vehicle Trip $L$ & & & & & & & & & & & & & & \\
\hline TOTAL & 10.95 & 11.42 & 9.03 & 9.54 & 8.69 & 8.94 & 7.37 & 8.80 & 8.07 & 8.17 & 6.40 & 8.17 & 10.50 & 6.63 \\
\hline \multicolumn{15}{|l|}{ Average Time Driving a POV (per } \\
\hline TOTAL & 78.76 & 84.75 & 76.13 & 81.30 & 79.37 & 79.31 & 74.22 & 80.40 & 81.01 & 77.59 & 84.66 & 81.16 & 97.22 & 108.93 \\
\hline
\end{tabular}




\begin{tabular}{|c|c|c|c|c|c|c|c|c|c|c|c|c|c|c|}
\hline \multicolumn{15}{|c|}{ Population Density (census tract) } \\
\hline & \multicolumn{2}{|c|}{$<500$} & \multicolumn{2}{|c|}{$500-2,000$} & \multicolumn{2}{|c|}{$2,000-4,000$} & \multicolumn{2}{|c|}{$4,000-10,000$} & \multicolumn{2}{|c|}{$10,000-20,000$} & \multicolumn{2}{|c|}{$20,000-50,000$} & \multicolumn{2}{|c|}{$50,000+$} \\
\hline & NY State & U.S. & NY State & U.S. & NY State & U.S. & NY State & U.S. & NY State & U.S. & NY State & U.S. & NY State & U.S. \\
\hline \multicolumn{15}{|l|}{ Daily Vehicle Trips per Driver } \\
\hline TOTAL & 3.39 & 3.53 & 3.47 & 3.65 & 3.67 & 3.77 & 3.31 & 3.58 & 2.80 & 3.23 & 1.95 & 2.69 & 1.07 & 1.79 \\
\hline$\%$ Earn a Living & $27.9 \%$ & $28.2 \%$ & $26.2 \%$ & $27.2 \%$ & $24.5 \%$ & $27.9 \%$ & $26.1 \%$ & $26.5 \%$ & $28.5 \%$ & $25.7 \%$ & $22.6 \%$ & $26.8 \%$ & $31.8 \%$ & $29.1 \%$ \\
\hline$\%$ Family \& Personal Business & $50.0 \%$ & $49.9 \%$ & $51.3 \%$ & $50.8 \%$ & $52.2 \%$ & $49.6 \%$ & $51.8 \%$ & $51.1 \%$ & $50.5 \%$ & $49.2 \%$ & $54.4 \%$ & $47.2 \%$ & $47.7 \%$ & $48.6 \%$ \\
\hline$\%$ Civic, Educationa & $2.9 \%$ & $4.0 \%$ & $4.0 \%$ & $3.8 \%$ & $3.8 \%$ & $4.5 \%$ & $3.6 \%$ & $3.9 \%$ & $3.9 \%$ & $5.3 \%$ & $5.1 \%$ & $5.2 \%$ & $3.7 \%$ & \\
\hline$\%$ Social \& Recreational & $18.8 \%$ & $17.9 \%$ & $18.4 \%$ & $18.1 \%$ & $19.6 \%$ & $18.0 \%$ & $18.5 \%$ & $18.4 \%$ & $17.1 \%$ & $19.8 \%$ & $17.9 \%$ & $20.8 \%$ & $16.8 \%$ & $22.3 \%$ \\
\hline$\%$ Other & $0.3 \%$ & $0.0 \%$ & $0.0 \%$ & $0.0 \%$ & $0.0 \%$ & $0.0 \%$ & $0.0 \%$ & $0.0 \%$ & $0.0 \%$ & $0.0 \%$ & $0.0 \%$ & & & \\
\hline TOTAL & 3.39 & 3.53 & 3.47 & 3.65 & 3.67 & 3.77 & 3.31 & 3.58 & 2.80 & 3.23 & 1.95 & 2.69 & 1.07 & 1.79 \\
\hline Weekend & 2.93 & 2.87 & 3.00 & 3.02 & 3.27 & 3.18 & 2.94 & 3.09 & 2.87 & 2.89 & 1.94 & 2.87 & 1.11 & 0.35 \\
\hline Weekday & 3.57 & 3.78 & 3.64 & 3.89 & 3.83 & 3.96 & 3.46 & 3.77 & 2.77 & 3.40 & 1.95 & 2.61 & 1.06 & 1.98 \\
\hline TOTAL & 3.39 & 3.53 & 3.47 & 3.65 & 3.67 & 3.77 & 3.31 & 3.58 & 2.80 & 3.23 & 1.95 & 2.69 & 1.07 & 1.79 \\
\hline$\% 1-9 \min$ & $39.8 \%$ & $35.4 \%$ & $39.2 \%$ & $38.6 \%$ & $42.8 \%$ & $40.6 \%$ & $42.6 \%$ & $39.4 \%$ & $37.1 \%$ & $34.4 \%$ & $31.8 \%$ & $28.6 \%$ & $23.4 \%$ & $40.6 \%$ \\
\hline$\% 10-19 \mathrm{~min}$ & $31.3 \%$ & $32.9 \%$ & $33.4 \%$ & $34.2 \%$ & $31.6 \%$ & $33.7 \%$ & $32.0 \%$ & $33.5 \%$ & $33.6 \%$ & $35.3 \%$ & $30.3 \%$ & $33.1 \%$ & $23.4 \%$ & $24.4 \%$ \\
\hline$\% 20-29 \mathrm{~min}$ & $14.5 \%$ & $15.3 \%$ & $14.1 \%$ & $13.4 \%$ & $13.1 \%$ & $13.3 \%$ & $12.7 \%$ & $14.0 \%$ & $13.6 \%$ & $14.9 \%$ & $16.4 \%$ & $17.5 \%$ & $18.7 \%$ & $18.3 \%$ \\
\hline$\%$ 30-39 min & $7.1 \%$ & $7.6 \%$ & $5.8 \%$ & $6.3 \%$ & $5.7 \%$ & $5.8 \%$ & $5.1 \%$ & $6.1 \%$ & $5.4 \%$ & $8.4 \%$ & $8.7 \%$ & $9.7 \%$ & $10.3 \%$ & $6.7 \%$ \\
\hline$\% 40-49 \min$ & $3.2 \%$ & $3.7 \%$ & $3.2 \%$ & $3.6 \%$ & $2.7 \%$ & $2.9 \%$ & $.7 \%$ & $3.1 \%$ & $4.3 \%$ & $3.4 \%$ & $6.2 \%$ & $5.6 \%$ & $10.3 \%$ & \\
\hline$\% 50+\min$ & $3.8 \%$ & $4.5 \%$ & $4.0 \%$ & $3.6 \%$ & $4.1 \%$ & $3.2 \%$ & $4.2 \%$ & $3.4 \%$ & $5.7 \%$ & $3.4 \%$ & $6.2 \%$ & $5.2 \%$ & $13.1 \%$ & $10.0 \%$ \\
\hline$\%$ Unreported & $0.3 \%$ & $0.6 \%$ & $0.3 \%$ & $0.3 \%$ & $0.0 \%$ & $0.5 \%$ & $0.6 \%$ & $0.6 \%$ & $0.4 \%$ & $0.3 \%$ & $0.5 \%$ & $0.4 \%$ & $0.9 \%$ & \\
\hline TOTAL & 3.39 & 3.53 & 3.47 & 3.65 & 3.67 & 3.77 & 3.31 & 3.58 & 2.80 & 3.23 & 1.95 & 2.69 & 1.07 & 1.79 \\
\hline$\% 5$ or less miles & $51.6 \%$ & $50.1 \%$ & $57.6 \%$ & $58.6 \%$ & $65.4 \%$ & $63.4 \%$ & $65.9 \%$ & $63.7 \%$ & $63.9 \%$ & $64.1 \%$ & $62.6 \%$ & $59.9 \%$ & $55.1 \%$ & $62.8 \%$ \\
\hline$\%$ 6-10 mile & $21.5 \%$ & $20.4 \%$ & $19.6 \%$ & $18.9 \%$ & $15.5 \%$ & $17.2 \%$ & $15.7 \%$ & $17.0 \%$ & $15.4 \%$ & $16.7 \%$ & $14.9 \%$ & $18.6 \%$ & $16.8 \%$ & $16.1 \%$ \\
\hline$\% 11-$ & $10.6 \%$ & $11.3 \%$ & $8.9 \%$ & $8.5 \%$ & $6.8 \%$ & $7.4 \%$ & $6.9 \%$ & $7.5 \%$ & $7.5 \%$ & $7.4 \%$ & $7.7 \%$ & $8.2 \%$ & $11.2 \%$ & $8.3 \%$ \\
\hline$\% 16-20$ miles & $6.2 \%$ & $5.9 \%$ & $4.3 \%$ & $4.4 \%$ & $3.5 \%$ & $4.2 \%$ & $3.3 \%$ & $3.9 \%$ & $3.9 \%$ & $3.7 \%$ & $4.6 \%$ & $4.1 \%$ & $1.9 \%$ & $5.0 \%$ \\
\hline$\% 21-$ & $5.0 \%$ & $5.9 \%$ & $3.7 \%$ & $4.7 \%$ & $4.1 \%$ & $3.7 \%$ & $3.3 \%$ & $3.4 \%$ & $4.3 \%$ & $3.7 \%$ & $3.6 \%$ & $4.1 \%$ & $6.5 \%$ & $2.8 \%$ \\
\hline$\% 31$ & $4.4 \%$ & $5.7 \%$ & $4.6 \%$ & $4.7 \%$ & $4.4 \%$ & $3.7 \%$ & $3.0 \%$ & $3.6 \%$ & $2.9 \%$ & $2.8 \%$ & $2.6 \%$ & $3.3 \%$ & $5.6 \%$ & $5.0 \%$ \\
\hline$\%$ Unreported & $0.6 \%$ & $0.6 \%$ & $1.2 \%$ & $0.3 \%$ & $0.3 \%$ & $0.3 \%$ & $1.8 \%$ & $0.8 \%$ & $2.1 \%$ & $1.5 \%$ & $4.1 \%$ & $1.9 \%$ & $2.8 \%$ & $0.0 \%$ \\
\hline \multicolumn{15}{|l|}{ Daily VM } \\
\hline TOTAL & 33.21 & 37.19 & 32.04 & 33.74 & 28.89 & 31.19 & 23.22 & 28.28 & 20.81 & 23.04 & 13.37 & 20.65 & 12.12 & 20.35 \\
\hline \% Earn a Living & $38.8 \%$ & $39.7 \%$ & $35.5 \%$ & $38.7 \%$ & $37.2 \%$ & $38.4 \%$ & $41.2 \%$ & $36.6 \%$ & $36.9 \%$ & $34.4 \%$ & $35.4 \%$ & $34.7 \%$ & $34.9 \%$ & $16.6 \%$ \\
\hline$\%$ Family \& & $34.2 \%$ & $36.1 \%$ & $37.1 \%$ & $35.7 \%$ & $34.5 \%$ & $34.0 \%$ & $33.6 \%$ & $35.6 \%$ & $34.2 \%$ & $34.6 \%$ & $37.1 \%$ & $32.6 \%$ & $24.2 \%$ & $48.2 \%$ \\
\hline \% Civic, Educational \& Religious & $2.3 \%$ & $4.0 \%$ & $2.9 \%$ & $3.7 \%$ & $2.5 \%$ & $3.9 \%$ & $3.1 \%$ & $2.9 \%$ & $2.1 \%$ & $5.4 \%$ & $5.9 \%$ & $4.3 \%$ & $1.5 \%$ & \\
\hline \% Social \& Recreational & $24.0 \%$ & $20.1 \%$ & $24.4 \%$ & $21.5 \%$ & $25.8 \%$ & $23.6 \%$ & $22.0 \%$ & $24.7 \%$ & $26.4 \%$ & $25.6 \%$ & $21.6 \%$ & $28.3 \%$ & $39.4 \%$ & $35.2 \%$ \\
\hline$\%$ Other & $0.8 \%$ & $0.1 \%$ & $0.1 \%$ & $0.3 \%$ & $0.0 \%$ & $0.1 \%$ & $0.1 \%$ & $0.1 \%$ & $0.0 \%$ & $0.0 \%$ & $0.0 \%$ & & & \\
\hline$\%$ Unreported & $0.0 \%$ & $0.0 \%$ & $0.0 \%$ & $0.0 \%$ & & $0.0 \%$ & $0.0 \%$ & $0.0 \%$ & $0.5 \%$ & & & & & \\
\hline \multicolumn{15}{|l|}{ Average Vehicle Trip Length } \\
\hline TOTAL & 9.85 & 10.61 & 9.35 & 9.29 & 7.90 & 8.32 & 7.12 & 7.97 & 7.58 & 7.24 & 7.11 & 7.86 & 11.68 & 11.34 \\
\hline \multicolumn{15}{|c|}{ ons who drove on travel day only) } \\
\hline 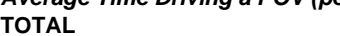 & 69.85 & 77.11 & 71.47 & 74.00 & 70.84 & 71.46 & 67.94 & 70.63 & 69.79 & 71.46 & 72.28 & 79.40 & 89.71 & 86.19 \\
\hline
\end{tabular}




\begin{tabular}{|c|c|c|c|c|c|c|c|c|c|c|c|c|c|c|}
\hline \multicolumn{15}{|c|}{ Population Density (census tract) } \\
\hline & \multicolumn{2}{|c|}{$<500$} & \multicolumn{2}{|c|}{$500-2,000$} & \multicolumn{2}{|c|}{$2,000-4,000$} & \multicolumn{2}{|c|}{$4,000-10,000$} & \multicolumn{2}{|c|}{$10,000-20,000$} & \multicolumn{2}{|c|}{$20,000-50,000$} & \multicolumn{2}{|c|}{$50,000+$} \\
\hline & NY State & U.S. & NY State & U.S. & NY State & U.S. & NY State & U.S. & NY State & U.S. & NY State & U.S. & NY State & U.S. \\
\hline \multicolumn{15}{|c|}{ Daily Commute Person Trips per Person } \\
\hline TOTAL & 1.08 & 1.09 & 1.15 & 1.14 & 1.10 & 1.12 & 1.20 & 1.10 & 0.94 & 1.08 & 1.06 & 1.12 & 0.93 & 1.26 \\
\hline$\%$ SOV & $83.7 \%$ & $80.5 \%$ & $82.2 \%$ & $82.4 \%$ & $82.5 \%$ & $81.4 \%$ & $69.4 \%$ & $75.8 \%$ & $50.0 \%$ & $62.4 \%$ & $23.5 \%$ & $51.1 \%$ & $11.6 \%$ & $44.2 \%$ \\
\hline$\%$ MOV & $12.5 \%$ & $15.7 \%$ & $11.3 \%$ & $13.9 \%$ & $10.3 \%$ & $13.0 \%$ & $14.7 \%$ & $14.7 \%$ & $21.6 \%$ & $17.6 \%$ & $11.4 \%$ & $14.3 \%$ & $4.3 \%$ & $0.1 \%$ \\
\hline$\%$ Amtrak & & $0.0 \%$ & & $0.0 \%$ & & $0.0 \%$ & & $0.0 \%$ & $0.9 \%$ & $0.2 \%$ & $1.4 \%$ & $0.3 \%$ & $0.6 \%$ & $1.7 \%$ \\
\hline$\%$ Commuter Train & $0.1 \%$ & $0.0 \%$ & $0.6 \%$ & $0.2 \%$ & $2.3 \%$ & $0.2 \%$ & $2.3 \%$ & $0.7 \%$ & $2.3 \%$ & $0.3 \%$ & $3.3 \%$ & $4.1 \%$ & $5.1 \%$ & $2.2 \%$ \\
\hline \% Subway/El Rail & $0.1 \%$ & $0.0 \%$ & $0.2 \%$ & $0.0 \%$ & $0.2 \%$ & $0.1 \%$ & $1.8 \%$ & $0.3 \%$ & $2.2 \%$ & $1.1 \%$ & $27.8 \%$ & $5.3 \%$ & $32.6 \%$ & $16.0 \%$ \\
\hline$\%$ Other Public & $0.4 \%$ & $0.6 \%$ & $0.8 \%$ & $0.6 \%$ & $0.7 \%$ & $1.2 \%$ & $2.1 \%$ & $2.7 \%$ & $13.0 \%$ & $8.4 \%$ & $16.0 \%$ & $11.6 \%$ & $15.6 \%$ & $14.4 \%$ \\
\hline$\%$ Walk & $2.3 \%$ & $1.2 \%$ & $2.8 \%$ & $1.6 \%$ & $2.6 \%$ & $2.4 \%$ & $4.8 \%$ & $3.3 \%$ & $3.3 \%$ & $6.5 \%$ & $11.7 \%$ & $8.3 \%$ & $23.5 \%$ & $13.0 \%$ \\
\hline$\%$ Other & $0.8 \%$ & $1.9 \%$ & $2.1 \%$ & $1.1 \%$ & $0.9 \%$ & $1.5 \%$ & $4.9 \%$ & $2.4 \%$ & $6.9 \%$ & $3.0 \%$ & $4.5 \%$ & $4.9 \%$ & $6.8 \%$ & $8.4 \%$ \\
\hline$\%$ Unreported & $0.2 \%$ & $0.1 \%$ & & $0.2 \%$ & $0.6 \%$ & $0.1 \%$ & & $0.2 \%$ & & $0.5 \%$ & $0.6 \%$ & $0.2 \%$ & & \\
\hline TOTAL & 1.08 & 1.09 & 1.15 & 1.14 & 1.10 & 1.12 & 1.20 & 1.10 & 0.94 & 1.08 & 1.06 & 1.12 & 0.93 & 1.26 \\
\hline$\% 1-6 \mathrm{am}$ & $4.9 \%$ & $7.3 \%$ & $4.2 \%$ & $6.0 \%$ & $3.9 \%$ & $5.4 \%$ & $3.7 \%$ & $5.5 \%$ & $3.8 \%$ & $6.9 \%$ & $5.7 \%$ & $7.7 \%$ & $3.8 \%$ & $5.9 \%$ \\
\hline$\%$ 6-9 am & $32.2 \%$ & $30.2 \%$ & $29.6 \%$ & $29.9 \%$ & $28.0 \%$ & $30.3 \%$ & $30.4 \%$ & $30.3 \%$ & $31.7 \%$ & $31.2 \%$ & $30.3 \%$ & $31.3 \%$ & $32.0 \%$ & $21.9 \%$ \\
\hline$\% 9 \mathrm{am}-1 \mathrm{pm}$ & $9.8 \%$ & $9.9 \%$ & $13.1 \%$ & $12.0 \%$ & $11.2 \%$ & $12.0 \%$ & $12.1 \%$ & $11.5 \%$ & $9.3 \%$ & $9.6 \%$ & $8.6 \%$ & $8.1 \%$ & $10.9 \%$ & $15.5 \%$ \\
\hline$\% 1-4 \mathrm{pm}$ & $16.5 \%$ & $15.8 \%$ & $14.6 \%$ & $15.1 \%$ & $18.8 \%$ & $13.9 \%$ & $17.6 \%$ & $15.2 \%$ & $20.2 \%$ & $15.2 \%$ & $15.6 \%$ & $14.9 \%$ & $11.2 \%$ & $13.8 \%$ \\
\hline$\% 4-7 \mathrm{pm}$ & $25.9 \%$ & $26.1 \%$ & $25.7 \%$ & $26.9 \%$ & $24.0 \%$ & $27.1 \%$ & $25.5 \%$ & $27.1 \%$ & $22.5 \%$ & $24.6 \%$ & $23.1 \%$ & $22.0 \%$ & $22.4 \%$ & $17.9 \%$ \\
\hline$\% 7-10 \mathrm{pm}$ & $6.0 \%$ & $6.9 \%$ & $8.8 \%$ & $6.8 \%$ & $8.7 \%$ & $7.5 \%$ & $6.2 \%$ & $6.8 \%$ & $7.3 \%$ & $8.1 \%$ & $9.4 \%$ & $10.2 \%$ & $14.0 \%$ & $6.7 \%$ \\
\hline$\% 10 \mathrm{pm}-1 \mathrm{am}$ & $4.7 \%$ & $3.8 \%$ & $4.1 \%$ & $3.3 \%$ & $5.3 \%$ & $3.8 \%$ & $4.5 \%$ & $3.6 \%$ & $5.2 \%$ & $4.3 \%$ & $7.2 \%$ & $5.9 \%$ & $5.7 \%$ & $18.4 \%$ \\
\hline$\%$ Unreported & & & & $0.0 \%$ & & & & & & & & & & \\
\hline \multicolumn{15}{|c|}{ Daily Commute PMT per Person } \\
\hline TOTAL & 15.46 & 16.27 & 13.07 & 14.43 & 12.43 & 11.94 & 11.23 & 10.62 & 8.97 & 9.05 & 7.57 & 9.06 & 5.04 & 4.68 \\
\hline$\%$ SOV & $84.3 \%$ & $81.9 \%$ & $85.4 \%$ & $83.7 \%$ & $80.5 \%$ & $83.9 \%$ & $73.8 \%$ & $80.7 \%$ & $50.7 \%$ & $77.9 \%$ & $25.7 \%$ & $67.2 \%$ & $24.1 \%$ & $55.4 \%$ \\
\hline$\%$ MOV & $11.7 \%$ & $15.0 \%$ & $10.4 \%$ & $13.4 \%$ & $11.1 \%$ & $11.4 \%$ & $14.0 \%$ & $12.3 \%$ & $15.1 \%$ & $11.8 \%$ & $29.0 \%$ & $11.7 \%$ & $5.2 \%$ & $0.2 \%$ \\
\hline$\%$ Amtrak & & $0.0 \%$ & & $0.0 \%$ & & $0.0 \%$ & & $0.0 \%$ & $8.4 \%$ & $0.8 \%$ & $0.8 \%$ & $0.3 \%$ & & $0.5 \%$ \\
\hline \multirow{2}{*}{$\begin{array}{l}\text { \% Commuter Train } \\
\% \text { Subway/EI Rail }\end{array}$} & $0.4 \%$ & $0.0 \%$ & $1.8 \%$ & $0.4 \%$ & $6.1 \%$ & $0.7 \%$ & $4.8 \%$ & $0.9 \%$ & $4.5 \%$ & $0.3 \%$ & $4.4 \%$ & $4.7 \%$ & $3.9 \%$ & $10.4 \%$ \\
\hline & $0.2 \%$ & $0.0 \%$ & $0.5 \%$ & $0.0 \%$ & $0.3 \%$ & $0.2 \%$ & $2.5 \%$ & $0.3 \%$ & $1.2 \%$ & $0.7 \%$ & $25.8 \%$ & $3.7 \%$ & $37.0 \%$ & $8.6 \%$ \\
\hline$\%$ Other Public & $0.3 \%$ & $0.2 \%$ & $0.2 \%$ & $0.2 \%$ & $0.6 \%$ & $1.4 \%$ & $1.1 \%$ & $2.7 \%$ & $11.6 \%$ & $4.0 \%$ & $7.1 \%$ & $9.3 \%$ & $17.8 \%$ & $17.8 \%$ \\
\hline$\%$ Walk & $0.1 \%$ & $0.1 \%$ & $0.3 \%$ & $0.2 \%$ & $0.1 \%$ & $0.2 \%$ & $0.5 \%$ & $0.3 \%$ & $0.2 \%$ & $0.7 \%$ & $4.6 \%$ & $0.7 \%$ & $6.2 \%$ & $2.2 \%$ \\
\hline$\%$ Other & $2.8 \%$ & $2.7 \%$ & $1.5 \%$ & $1.8 \%$ & $0.6 \%$ & $2.2 \%$ & $3.4 \%$ & $2.5 \%$ & $8.3 \%$ & $3.5 \%$ & $1.8 \%$ & $2.4 \%$ & $5.9 \%$ & $4.8 \%$ \\
\hline$\%$ Unreported & $0.3 \%$ & $0.1 \%$ & & $0.3 \%$ & $0.8 \%$ & $0.1 \%$ & & $0.3 \%$ & & $0.3 \%$ & $0.9 \%$ & & & \\
\hline TOTAL & 15.46 & 16.27 & 13.07 & 14.43 & 12.43 & 11.94 & 11.23 & 10.62 & 8.97 & 9.05 & 7.57 & 9.06 & 5.04 & 4.68 \\
\hline$\% 1-6$ an & $8.3 \%$ & $9.9 \%$ & $5.0 \%$ & $9.3 \%$ & $7.2 \%$ & $8.5 \%$ & $7.1 \%$ & $7.9 \%$ & $5.2 \%$ & $10.5 \%$ & $4.0 \%$ & $16.8 \%$ & $5.6 \%$ & $19.9 \%$ \\
\hline$\% 6-9 \mathrm{am}$ & $34.3 \%$ & $31.8 \%$ & $32.7 \%$ & $31.6 \%$ & $32.5 \%$ & $33.5 \%$ & $34.4 \%$ & $34.1 \%$ & $38.8 \%$ & $31.4 \%$ & $24.7 \%$ & $28.2 \%$ & $38.7 \%$ & $27.1 \%$ \\
\hline$\% 9 \mathrm{am}-1 \mathrm{pm}$ & $6.3 \%$ & $7.4 \%$ & $10.3 \%$ & $9.0 \%$ & $8.0 \%$ & $9.3 \%$ & $8.4 \%$ & $8.6 \%$ & $7.1 \%$ & $8.2 \%$ & $25.2 \%$ & $5.1 \%$ & $11.9 \%$ & $9.9 \%$ \\
\hline$\% 1-4 \mathrm{pm}$ & $14.2 \%$ & $13.5 \%$ & $13.2 \%$ & $14.2 \%$ & $18.6 \%$ & $12.4 \%$ & $15.2 \%$ & $13.2 \%$ & $10.5 \%$ & $13.8 \%$ & $13.4 \%$ & $10.7 \%$ & $4.6 \%$ & $10.7 \%$ \\
\hline$\% 4-7 \mathrm{pm}$ & $27.1 \%$ & $26.3 \%$ & $26.6 \%$ & $27.0 \%$ & $20.0 \%$ & $26.5 \%$ & $24.6 \%$ & $27.1 \%$ & $21.0 \%$ & $24.6 \%$ & $17.9 \%$ & $16.5 \%$ & $25.1 \%$ & $17.4 \%$ \\
\hline$\% 7-10 \mathrm{pm}$ & $5.5 \%$ & $6.9 \%$ & $7.7 \%$ & $6.1 \%$ & $9.7 \%$ & $7.1 \%$ & $6.9 \%$ & $5.9 \%$ & $13.0 \%$ & $7.6 \%$ & $6.5 \%$ & $13.6 \%$ & $11.5 \%$ & $4.8 \%$ \\
\hline$\% 10 \mathrm{pm}-1 \mathrm{am}$ & $4.3 \%$ & $4.1 \%$ & $4.7 \%$ & $2.8 \%$ & $4.0 \%$ & $2.8 \%$ & $3.3 \%$ & $3.3 \%$ & $4.4 \%$ & $3.9 \%$ & $8.2 \%$ & $9.2 \%$ & $2.7 \%$ & $10.2 \%$ \\
\hline$\%$ Unreported & & & & $0.0 \%$ & & & & & & & & & & \\
\hline
\end{tabular}




\begin{tabular}{|c|c|c|c|c|c|c|c|c|c|c|c|c|c|c|}
\hline \multicolumn{15}{|c|}{ Population Density (census tract) } \\
\hline & \multicolumn{2}{|c|}{$<500$} & \multicolumn{2}{|c|}{$500-2,000$} & \multicolumn{2}{|c|}{$2,000-4,000$} & \multicolumn{2}{|c|}{$4,000-10,000$} & \multicolumn{2}{|c|}{$10,000-20,000$} & \multicolumn{2}{|c|}{$20,000-50,000$} & \multicolumn{2}{|c|}{$50,000+$} \\
\hline & NY State & U.S. & NY State & U.S. & NY State & U.S. & NY State & U.S. & NY State & U.S. & NY State & U.S. & NY State & U.S. \\
\hline Daily Commute Pe & & & & & & & & & & & & & & \\
\hline TOTAL & 1.12 & 1.13 & 1.16 & 1.15 & 1.20 & 1.18 & 1.09 & 1.13 & 1.19 & 1.11 & 1.05 & 1.20 & 1.05 & 0.62 \\
\hline$\%$ SOV & $80.3 \%$ & $81.3 \%$ & $81.1 \%$ & $81.2 \%$ & $73.8 \%$ & $81.1 \%$ & $71.2 \%$ & $73.6 \%$ & $50.1 \%$ & $65.0 \%$ & $33.6 \%$ & $47.2 \%$ & $13.8 \%$ & $27.0 \%$ \\
\hline$\%$ MOV & $13.8 \%$ & $16.7 \%$ & $12.9 \%$ & $16.0 \%$ & $15.7 \%$ & $14.7 \%$ & $13.2 \%$ & $17.6 \%$ & $14.1 \%$ & $17.0 \%$ & $9.5 \%$ & $18.9 \%$ & $9.7 \%$ & $6.6 \%$ \\
\hline$\%$ Amtrak & $0.1 \%$ & & $0.2 \%$ & $0.0 \%$ & $0.1 \%$ & $0.1 \%$ & $0.9 \%$ & $0.1 \%$ & $2.0 \%$ & $0.3 \%$ & $0.7 \%$ & & $1.3 \%$ & \\
\hline$\%$ Commuter Train & $0.7 \%$ & $0.1 \%$ & $1.0 \%$ & $0.2 \%$ & $3.0 \%$ & $0.3 \%$ & $4.5 \%$ & $0.9 \%$ & $1.6 \%$ & $0.3 \%$ & $3.2 \%$ & $1.1 \%$ & $0.8 \%$ & \\
\hline \% Subway/El Rail & $1.8 \%$ & $0.0 \%$ & $0.4 \%$ & $0.3 \%$ & $1.4 \%$ & $0.3 \%$ & $2.8 \%$ & $0.5 \%$ & $12.5 \%$ & $3.1 \%$ & $23.8 \%$ & $4.8 \%$ & $36.4 \%$ & $24.6 \%$ \\
\hline \% Other Public & $0.3 \%$ & $0.1 \%$ & $0.4 \%$ & $0.3 \%$ & $1.0 \%$ & $1.1 \%$ & $1.7 \%$ & $2.8 \%$ & $8.1 \%$ & $7.5 \%$ & $9.2 \%$ & $12.4 \%$ & $14.5 \%$ & $41.3 \%$ \\
\hline$\%$ Walk & $2.1 \%$ & $1.3 \%$ & $2.9 \%$ & $1.1 \%$ & $3.4 \%$ & $1.8 \%$ & $4.3 \%$ & $3.3 \%$ & $8.8 \%$ & $5.3 \%$ & $16.2 \%$ & $10.4 \%$ & $18.3 \%$ & $0.5 \%$ \\
\hline$\%$ Other & $0.8 \%$ & $0.4 \%$ & $1.0 \%$ & $0.7 \%$ & $1.3 \%$ & $0.6 \%$ & $1.4 \%$ & $1.1 \%$ & $2.3 \%$ & $1.6 \%$ & $3.7 \%$ & $4.9 \%$ & $5.2 \%$ & \\
\hline$\%$ Unreported & $0.0 \%$ & $0.2 \%$ & & $0.1 \%$ & $0.2 \%$ & $0.0 \%$ & $0.1 \%$ & $0.1 \%$ & $0.5 \%$ & $0.0 \%$ & $0.0 \%$ & $0.3 \%$ & & \\
\hline TOTAL & 1.12 & 1.13 & 1.16 & 1.15 & 1.20 & 1.18 & 1.09 & 1.13 & 1.19 & 1.11 & 1.05 & 1.20 & 1.05 & 0.62 \\
\hline$\% 1-6 \mathrm{am}$ & $5.6 \%$ & $6.7 \%$ & $4.1 \%$ & $5.4 \%$ & $4.2 \%$ & $5.5 \%$ & $4.3 \%$ & $6.2 \%$ & $5.3 \%$ & $6.3 \%$ & $5.1 \%$ & $7.3 \%$ & $4.4 \%$ & $0.0 \%$ \\
\hline$\% 6-9$ am & $32.2 \%$ & $30.6 \%$ & $31.1 \%$ & $30.8 \%$ & $30.1 \%$ & $30.4 \%$ & $30.8 \%$ & $30.2 \%$ & $29.9 \%$ & $29.9 \%$ & $33.4 \%$ & $30.6 \%$ & $30.4 \%$ & $40.2 \%$ \\
\hline$\% 9 \mathrm{am}-1 \mathrm{pm}$ & $9.9 \%$ & $10.7 \%$ & $11.7 \%$ & $12.2 \%$ & $12.3 \%$ & $12.0 \%$ & $10.7 \%$ & $11.1 \%$ & $10.4 \%$ & $8.5 \%$ & $10.0 \%$ & $8.6 \%$ & $11.2 \%$ & $1.4 \%$ \\
\hline$\% 1-4 \mathrm{pm}$ & $15.1 \%$ & $13.8 \%$ & $15.2 \%$ & $13.4 \%$ & $16.2 \%$ & $14.3 \%$ & $14.1 \%$ & $14.8 \%$ & $13.0 \%$ & $14.0 \%$ & $12.4 \%$ & $15.7 \%$ & $10.0 \%$ & $5.8 \%$ \\
\hline$\%$ 4-7 pm & $24.9 \%$ & $25.6 \%$ & $25.6 \%$ & $26.2 \%$ & $25.4 \%$ & $25.3 \%$ & $28.5 \%$ & $25.6 \%$ & $27.7 \%$ & $26.0 \%$ & $23.6 \%$ & $25.5 \%$ & $28.1 \%$ & $44.5 \%$ \\
\hline$\% 7-10 \mathrm{pm}$ & $7.7 \%$ & $8.2 \%$ & $7.6 \%$ & $8.4 \%$ & $8.3 \%$ & $8.6 \%$ & $7.1 \%$ & $7.6 \%$ & $6.3 \%$ & $8.6 \%$ & $11.1 \%$ & $6.6 \%$ & $11.5 \%$ & $7.1 \%$ \\
\hline$\% 10 \mathrm{pm}-1 \mathrm{am}$ & $4.5 \%$ & $4.3 \%$ & $4.7 \%$ & $3.7 \%$ & $3.5 \%$ & $3.8 \%$ & $4.5 \%$ & $4.4 \%$ & $7.0 \%$ & $6.5 \%$ & $4.5 \%$ & $5.8 \%$ & $4.5 \%$ & $1.0 \%$ \\
\hline \% Unreported & $0.1 \%$ & $0.1 \%$ & & $0.0 \%$ & & $0.1 \%$ & $0.1 \%$ & $0.1 \%$ & $0.5 \%$ & $0.1 \%$ & & & & \\
\hline Daily Commute PM & & & & & & & & & & & & & & \\
\hline TOTAL & 15.53 & 16.66 & 14.06 & 14.09 & 14.74 & 12.74 & 11.28 & 12.55 & 10.75 & 10.41 & 7.51 & 8.74 & 6.18 & 6.31 \\
\hline$\%$ sOV & $78.6 \%$ & $81.1 \%$ & $82.0 \%$ & $78.2 \%$ & $70.2 \%$ & $79.2 \%$ & $70.2 \%$ & $72.3 \%$ & $53.2 \%$ & $70.4 \%$ & $42.5 \%$ & $54.4 \%$ & $20.2 \%$ & $31.7 \%$ \\
\hline$\%$ MOV & $14.2 \%$ & $16.0 \%$ & $11.1 \%$ & $14.8 \%$ & $16.8 \%$ & $13.9 \%$ & $9.4 \%$ & $16.5 \%$ & $13.8 \%$ & $15.1 \%$ & $7.9 \%$ & $30.4 \%$ & $18.2 \%$ & $9.8 \%$ \\
\hline$\%$ Amtrak & $0.7 \%$ & & $0.9 \%$ & $0.1 \%$ & $0.6 \%$ & $0.1 \%$ & $1.8 \%$ & $0.7 \%$ & $2.8 \%$ & $2.3 \%$ & $0.9 \%$ & & $1.1 \%$ & \\
\hline$\%$ Commuter Train & $2.7 \%$ & $0.2 \%$ & $2.8 \%$ & $0.7 \%$ & $8.2 \%$ & $0.3 \%$ & $10.6 \%$ & $2.0 \%$ & $4.4 \%$ & $1.5 \%$ & $5.7 \%$ & $1.0 \%$ & $1.0 \%$ & \\
\hline \% Subway/El Rail & $1.0 \%$ & $0.0 \%$ & $0.9 \%$ & $0.4 \%$ & $1.0 \%$ & $0.4 \%$ & $4.3 \%$ & $0.5 \%$ & $17.0 \%$ & $3.2 \%$ & $30.4 \%$ & $4.2 \%$ & $41.5 \%$ & $20.3 \%$ \\
\hline$\%$ Other Public & $0.2 \%$ & $0.1 \%$ & $0.4 \%$ & $0.3 \%$ & $0.8 \%$ & $1.0 \%$ & $1.0 \%$ & $1.8 \%$ & $5.4 \%$ & $4.8 \%$ & $5.9 \%$ & $7.0 \%$ & $9.3 \%$ & $38.2 \%$ \\
\hline$\%$ Walk & $0.4 \%$ & $0.1 \%$ & $0.2 \%$ & $0.1 \%$ & $0.2 \%$ & $0.2 \%$ & $0.8 \%$ & $0.3 \%$ & $1.2 \%$ & $0.5 \%$ & $2.7 \%$ & $1.2 \%$ & $3.6 \%$ & $0.0 \%$ \\
\hline$\%$ Other & $2.0 \%$ & $2.1 \%$ & $1.7 \%$ & $5.3 \%$ & $1.5 \%$ & $4.8 \%$ & $1.4 \%$ & $6.0 \%$ & $2.0 \%$ & $2.4 \%$ & $4.0 \%$ & $1.8 \%$ & $5.0 \%$ & \\
\hline$\%$ Unreported & $0.1 \%$ & $0.4 \%$ & & $0.1 \%$ & $0.8 \%$ & $0.0 \%$ & $0.5 \%$ & $0.1 \%$ & $0.2 \%$ & $0.0 \%$ & $0.1 \%$ & & & \\
\hline TOTAL & 15.53 & 16.66 & 14.06 & 14.09 & 14.74 & 12.74 & 11.28 & 12.55 & 10.75 & 10.41 & 7.51 & 8.74 & 6.18 & 6.31 \\
\hline$\% 1-6$ am & $7.6 \%$ & $9.8 \%$ & $5.9 \%$ & $7.6 \%$ & $9.1 \%$ & $7.3 \%$ & $8.0 \%$ & $9.4 \%$ & $9.0 \%$ & $8.3 \%$ & $6.5 \%$ & $17.6 \%$ & $5.6 \%$ & $0.0 \%$ \\
\hline$\%$ 6-9 am & $34.3 \%$ & $32.2 \%$ & $35.2 \%$ & $35.6 \%$ & $32.5 \%$ & $35.0 \%$ & $31.0 \%$ & $30.9 \%$ & $32.5 \%$ & $28.8 \%$ & $34.0 \%$ & $27.5 \%$ & $32.8 \%$ & $46.8 \%$ \\
\hline$\% 9$ am-1 pm & $6.6 \%$ & $7.8 \%$ & $8.3 \%$ & $8.7 \%$ & $9.0 \%$ & $9.5 \%$ & $10.8 \%$ & $8.0 \%$ & $8.4 \%$ & $7.8 \%$ & $8.0 \%$ & $7.5 \%$ & $8.8 \%$ & $0.7 \%$ \\
\hline$\% 1-4 \mathrm{pm}$ & $14.2 \%$ & $13.2 \%$ & $14.7 \%$ & $11.7 \%$ & $15.3 \%$ & $12.7 \%$ & $11.4 \%$ & $12.5 \%$ & $11.9 \%$ & $16.2 \%$ & $10.6 \%$ & $14.6 \%$ & $8.1 \%$ & $2.5 \%$ \\
\hline$\%$ 4-7 pm & $25.6 \%$ & $25.2 \%$ & $24.2 \%$ & $24.1 \%$ & $24.6 \%$ & $23.9 \%$ & $27.8 \%$ & $24.1 \%$ & $25.9 \%$ & $23.2 \%$ & $21.5 \%$ & $22.9 \%$ & $31.4 \%$ & $46.7 \%$ \\
\hline$\% 7-10 \mathrm{pm}$ & $7.2 \%$ & $7.8 \%$ & $7.8 \%$ & $8.9 \%$ & $7.1 \%$ & $8.0 \%$ & $6.5 \%$ & $11.0 \%$ & $5.2 \%$ & $9.4 \%$ & $14.0 \%$ & $5.3 \%$ & $9.0 \%$ & $3.1 \%$ \\
\hline$\% 10 \mathrm{pm}-1 \mathrm{am}$ & $4.4 \%$ & $3.9 \%$ & $4.0 \%$ & $3.4 \%$ & $2.5 \%$ & $3.5 \%$ & $4.0 \%$ & $4.2 \%$ & $7.1 \%$ & $6.3 \%$ & $5.5 \%$ & $4.6 \%$ & $4.3 \%$ & $0.2 \%$ \\
\hline$\%$ Unreported & $0.0 \%$ & $0.2 \%$ & & $0.0 \%$ & & $0.1 \%$ & $0.6 \%$ & $0.0 \%$ & $0.0 \%$ & & & & & \\
\hline
\end{tabular}




\begin{tabular}{|c|c|c|c|c|c|c|c|c|c|c|c|c|c|c|}
\hline \multicolumn{15}{|c|}{ Population Density (census tract) } \\
\hline & \multicolumn{2}{|c|}{$\begin{array}{c}<500 \\
<1\end{array}$} & \multicolumn{2}{|c|}{$500-2,000$} & \multicolumn{2}{|c|}{$2,000-4,000$} & \multicolumn{2}{|c|}{$4,000-10,000$} & \multicolumn{2}{|c|}{$10,000-20,000$} & \multicolumn{2}{|c|}{$20,000-50,000$} & \multicolumn{2}{|c|}{$50,000+$} \\
\hline & NY State & U.S. & NY State & U.s. & NY State & U.S. & NY State & U.S. & NY State & U.S. & NY State & U.S. & NY State & U.S. \\
\hline \multicolumn{15}{|c|}{ Daily Commute Person $T$} \\
\hline TOTAL & 1.32 & 1.35 & 1.34 & 1.36 & 1.34 & 1.44 & 1.29 & 1.36 & 1.37 & 1.35 & 1.19 & 1.36 & 1.32 & 1.34 \\
\hline$\%$ sov & $78.2 \%$ & $79.3 \%$ & $78.2 \%$ & $80.0 \%$ & $78.9 \%$ & $77.2 \%$ & $67.7 \%$ & $73.2 \%$ & $50.7 \%$ & $63.7 \%$ & $32.2 \%$ & $46.3 \%$ & $16.0 \%$ & $30.1 \%$ \\
\hline$\% \mathrm{MOV}$ & $15.8 \%$ & $17.0 \%$ & $14.3 \%$ & $15.6 \%$ & $11.3 \%$ & $15.2 \%$ & $14.6 \%$ & $16.7 \%$ & $15.9 \%$ & $15.6 \%$ & $9.3 \%$ & $12.7 \%$ & $6.9 \%$ & $5.1 \%$ \\
\hline$\%$ Other POV & & $0.0 \%$ & $0.0 \%$ & $0.0 \%$ & $0.0 \%$ & $0.0 \%$ & $0.0 \%$ & $0.0 \%$ & & & & & $0.0 \%$ & \\
\hline$\%$ Amtrak & & $0.0 \%$ & & $0.0 \%$ & $0.0 \%$ & $0.0 \%$ & $0.0 \%$ & $0.0 \%$ & & & & & & \\
\hline$\%$ Commuter Train & $0.8 \%$ & $0.0 \%$ & $1.5 \%$ & $0.0 \%$ & $2.3 \%$ & $0.7 \%$ & $3.8 \%$ & $0.7 \%$ & $2.2 \%$ & $1.5 \%$ & $5.9 \%$ & $1.5 \%$ & $6.9 \%$ & $2.2 \%$ \\
\hline \% Subway/El Rail & $0.0 \%$ & $0.0 \%$ & $0.0 \%$ & $0.0 \%$ & $0.0 \%$ & $0.7 \%$ & $2.3 \%$ & $0.7 \%$ & $8.0 \%$ & $3.0 \%$ & $23.7 \%$ & $4.5 \%$ & $31.3 \%$ & $14.0 \%$ \\
\hline$\%$ Other Public & $0.8 \%$ & $0.0 \%$ & $0.8 \%$ & $0.7 \%$ & $1.5 \%$ & $1.4 \%$ & $3.8 \%$ & $2.9 \%$ & $9.4 \%$ & $6.7 \%$ & $11.9 \%$ & $17.9 \%$ & $13.0 \%$ & $25.0 \%$ \\
\hline$\%$ Walk & $0.8 \%$ & $0.7 \%$ & $1.5 \%$ & $0.7 \%$ & $1.5 \%$ & $1.4 \%$ & $3.8 \%$ & $2.9 \%$ & $7.2 \%$ & $4.4 \%$ & $10.2 \%$ & $11.2 \%$ & $16.8 \%$ & $21.3 \%$ \\
\hline$\%$ Other & $0.8 \%$ & $0.7 \%$ & $1.5 \%$ & $1.5 \%$ & $1.5 \%$ & $1.4 \%$ & $1.5 \%$ & $0.7 \%$ & $3.6 \%$ & $1.5 \%$ & $3.4 \%$ & $3.0 \%$ & $6.1 \%$ & $2.2 \%$ \\
\hline$\%$ Unreported & $3.0 \%$ & $2.2 \%$ & $2.3 \%$ & $1.5 \%$ & $3.0 \%$ & $2.1 \%$ & $2.3 \%$ & $2.2 \%$ & $2.9 \%$ & $3.7 \%$ & $3.4 \%$ & $3.0 \%$ & $3.1 \%$ & $0.0 \%$ \\
\hline TOTAL & 1.32 & 1.35 & 1.34 & 1.36 & 1.34 & 1.44 & 1.29 & 1.36 & 1.37 & 1.35 & 1.19 & 1.36 & 1.32 & 1.34 \\
\hline$\% 1-6 \mathrm{am}$ & $4.5 \%$ & $5.9 \%$ & $3.7 \%$ & $5.1 \%$ & $4.5 \%$ & $4.8 \%$ & $4.7 \%$ & $5.9 \%$ & $3.6 \%$ & $6.7 \%$ & $3.3 \%$ & $4.4 \%$ & $3.8 \%$ & $2.2 \%$ \\
\hline$\% 6-9$ am & $30.1 \%$ & $29.6 \%$ & $29.9 \%$ & $28.7 \%$ & $28.6 \%$ & $28.3 \%$ & $28.1 \%$ & $28.7 \%$ & $31.2 \%$ & $28.9 \%$ & $33.3 \%$ & $28.7 \%$ & $30.3 \%$ & $40.3 \%$ \\
\hline$\% 9 \mathrm{am}-1 \mathrm{pm}$ & $12.8 \%$ & $11.9 \%$ & $13.4 \%$ & $12.5 \%$ & $14.3 \%$ & $13.1 \%$ & $13.3 \%$ & $12.5 \%$ & $11.6 \%$ & $11.1 \%$ & $8.3 \%$ & $13.2 \%$ & $10.6 \%$ & $10.4 \%$ \\
\hline$\% 1-4 \mathrm{pm}$ & $14.3 \%$ & $14.8 \%$ & $14.9 \%$ & $15.4 \%$ & $13.5 \%$ & $13.8 \%$ & $16.4 \%$ & $14.7 \%$ & $18.1 \%$ & $15.6 \%$ & $12.5 \%$ & $12.5 \%$ & $10.6 \%$ & $5.2 \%$ \\
\hline$\% 4-7 \mathrm{pm}$ & $27.8 \%$ & $27.4 \%$ & $26.9 \%$ & $27.2 \%$ & $25.6 \%$ & $27.6 \%$ & $25.8 \%$ & $26.5 \%$ & $21.7 \%$ & $23.0 \%$ & $26.7 \%$ & $26.5 \%$ & $26.5 \%$ & $29.9 \%$ \\
\hline$\% 7-10 \mathrm{pm}$ & $6.8 \%$ & $6.7 \%$ & $6.7 \%$ & $6.6 \%$ & $9.0 \%$ & $7.6 \%$ & $7.0 \%$ & $7.4 \%$ & $8.7 \%$ & $8.9 \%$ & $8.3 \%$ & $10.3 \%$ & $13.6 \%$ & $3.7 \%$ \\
\hline$\% 10 \mathrm{pm}-1 \mathrm{am}$ & $3.8 \%$ & $3.7 \%$ & $4.5 \%$ & $4.4 \%$ & $4.5 \%$ & $4.8 \%$ & $4.7 \%$ & $4.4 \%$ & $5.1 \%$ & $5.9 \%$ & $7.5 \%$ & $4.4 \%$ & $4.5 \%$ & $8.2 \%$ \\
\hline \multicolumn{15}{|c|}{ Daily Commute PMT p } \\
\hline TOTAL & 17.92 & 19.56 & 17.07 & 17.21 & 16.40 & 16.07 & 13.92 & 13.47 & 11.84 & 12.01 & 11.47 & 10.97 & 9.65 & 6.49 \\
\hline$\%$ SOV & $77.7 \%$ & $80.0 \%$ & $73.4 \%$ & $77.0 \%$ & $74.4 \%$ & $75.4 \%$ & $69.5 \%$ & $77.9 \%$ & $60.7 \%$ & $69.4 \%$ & $37.2 \%$ & $60.6 \%$ & $23.1 \%$ & $42.5 \%$ \\
\hline$\%$ MOV & $15.6 \%$ & $17.1 \%$ & $18.7 \%$ & $17.7 \%$ & $14.5 \%$ & $13.1 \%$ & $10.9 \%$ & $16.1 \%$ & $11.1 \%$ & $18.6 \%$ & $15.7 \%$ & $12.8 \%$ & $12.8 \%$ & $2.6 \%$ \\
\hline$\%$ Other POV & & $0.1 \%$ & $0.0 \%$ & $0.0 \%$ & $0.6 \%$ & $0.2 \%$ & & $0.1 \%$ & & & & & & \\
\hline$\%$ Amtrak & & $0.0 \%$ & & $0.1 \%$ & & $0.0 \%$ & $0.2 \%$ & $0.1 \%$ & & & & & & \\
\hline$\%$ Commu & $2.3 \%$ & $0.1 \%$ & $4.8 \%$ & $0.8 \%$ & $7.6 \%$ & $1.4 \%$ & $10.9 \%$ & $1.3 \%$ & $6.2 \%$ & $2.1 \%$ & $3.9 \%$ & $1.7 \%$ & $10.7 \%$ & $8.6 \%$ \\
\hline$\%$ Sub & $0.1 \%$ & $0.1 \%$ & $0.2 \%$ & $0.1 \%$ & $0.4 \%$ & $0.6 \%$ & $4.2 \%$ & $0.5 \%$ & $10.0 \%$ & $2.2 \%$ & $30.0 \%$ & $3.8 \%$ & $27.4 \%$ & $24.9 \%$ \\
\hline$\%$ Other Public & $0.9 \%$ & $0.8 \%$ & $1.2 \%$ & 0.6 & $0.7 \%$ & $1.5 \%$ & $2.8 \%$ & $2.2 \%$ & $8.1 \%$ & $5.5 \%$ & $8.3 \%$ & $18.8 \%$ & $9.5 \%$ & $12.1 \%$ \\
\hline$\%$ Walk & $0.1 \%$ & $0.1 \%$ & $0.1 \%$ & $0.1 \%$ & $0.1 \%$ & $0.1 \%$ & $0.2 \%$ & $0.2 \%$ & $0.7 \%$ & $0.4 \%$ & $1.0 \%$ & $0.9 \%$ & $2.7 \%$ & $8.8 \%$ \\
\hline$\%$ Other & $2.1 \%$ & $0.9 \%$ & $1.0 \%$ & $2.8 \%$ & $0.2 \%$ & $6.8 \%$ & $1.1 \%$ & $0.4 \%$ & $1.8 \%$ & $0.8 \%$ & $3.7 \%$ & $1.2 \%$ & $13.6 \%$ & $0.5 \%$ \\
\hline$\%$ Unreported & $1.2 \%$ & $1.0 \%$ & $0.5 \%$ & 0.90 & $1.3 \%$ & $1.0 \%$ & $0.3 \%$ & $1.0 \%$ & $1.4 \%$ & $1.0 \%$ & $0.2 \%$ & $0.2 \%$ & $0.2 \%$ & \\
\hline TOTAL & 17.92 & 19.56 & 17.07 & 17.21 & 16.40 & 16.07 & 13.92 & 13.47 & 11.84 & 12.01 & 11.47 & 10.97 & 9.65 & 6.49 \\
\hline$\% 1-6$ ar & $5.6 \%$ & $10.7 \%$ & $6.7 \%$ & $7.7 \%$ & 8.6 & $6.3 \%$ & $7.1 \%$ & $8.2 \%$ & $4.1 \%$ & $8.1 \%$ & $4.2 \%$ & $8.7 \%$ & $5.0 \%$ & $0.2 \%$ \\
\hline$\% 6-9$ am & $31.5 \%$ & $29.1 \%$ & $30.7 \%$ & $30.0 \%$ & $29.5 \%$ & $30.7 \%$ & $31.2 \%$ & $28.7 \%$ & $32.0 \%$ & $31.4 \%$ & $35.8 \%$ & $27.7 \%$ & $30.6 \%$ & $36.9 \%$ \\
\hline$\% 9 \mathrm{am}-1 \mathrm{pm}$ & $10.3 \%$ & $7.6 \%$ & $14.1 \%$ & $10.5 \%$ & $12.9 \%$ & $9.8 \%$ & $10.9 \%$ & $9.3 \%$ & $9.5 \%$ & $9.9 \%$ & $5.4 \%$ & $16.0 \%$ & $7.9 \%$ & $11.2 \%$ \\
\hline$\% 1-4 \mathrm{pm}$ & $14.1 \%$ & $14.9 \%$ & $13.2 \%$ & $14.2 \%$ & $12.6 \%$ & $13.2 \%$ & $14.4 \%$ & $14.6 \%$ & $18.7 \%$ & $15.4 \%$ & $9.6 \%$ & $8.1 \%$ & $9.3 \%$ & $7.1 \%$ \\
\hline$\% 4-7 \mathrm{pm}$ & $28.1 \%$ & $27.9 \%$ & $24.9 \%$ & $25.7 \%$ & $22.8 \%$ & $27.4 \%$ & $26.4 \%$ & $27.4 \%$ & $22.4 \%$ & $20.5 \%$ & $24.9 \%$ & $24.2 \%$ & $32.4 \%$ & $27.2 \%$ \\
\hline$\% 7-10 p$ & $6.2 \%$ & 6.6 & $6.6 \%$ & $7.4 \%$ & $9.2 \%$ & $8.4 \%$ & $5.6 \%$ & $7.3 \%$ & $4.9 \%$ & $8.3 \%$ & $14.8 \%$ & $9.8 \%$ & $11.0 \%$ & $8.9 \%$ \\
\hline$\% 10 \mathrm{pm}-1 \mathrm{am}$ & $4.1 \%$ & $3.2 \%$ & $3.8 \%$ & $4.6 \%$ & $4.4 \%$ & $4.3 \%$ & $4.4 \%$ & $4.4 \%$ & $8.4 \%$ & $6.4 \%$ & $5.3 \%$ & $5.5 \%$ & $4.0 \%$ & $8.4 \%$ \\
\hline
\end{tabular}




\begin{tabular}{|c|c|c|c|c|c|c|c|c|c|c|c|c|c|c|}
\hline \multicolumn{15}{|c|}{ Population Density (census tract) } \\
\hline & \multicolumn{2}{|c|}{$<500$} & \multirow{2}{*}{\multicolumn{2}{|c|}{$500-2,000$}} & \multicolumn{2}{|c|}{$2,000-4,000$} & \multicolumn{2}{|c|}{$4,000-10,000$} & \multicolumn{2}{|c|}{$10,000-20,000$} & \multicolumn{2}{|c|}{$20,000-50,000$} & \multicolumn{2}{|c|}{$50,000+$} \\
\hline & NY State & U.S. & & U.S. & NY State & U.S. & NY State & U.S. & NY State & U.S. & NY State & U.S. & NY State & U.S. \\
\hline \multicolumn{15}{|c|}{$\begin{array}{l}\text { Average Commute Length, Travel Time, and Speed } \\
\text { Length (miles) }\end{array}$} \\
\hline TOTAL & 14.42 & 15.03 & 11.51 & 12.81 & 11.42 & 10.82 & 9.57 & 9.88 & 10.10 & 8.95 & 8.82 & 8.85 & 6.45 & 3.94 \\
\hline Private & 14.41 & 15.15 & 11.76 & 12.90 & 11.26 & 10.89 & 9.88 & 10.11 & 8.86 & 9.76 & 12.10 & 10.37 & 10.65 & 4.67 \\
\hline Public & 20.97 & 6.13 & 18.45 & 14.34 & 26.42 & 17.24 & 14.58 & 11.14 & 12.22 & 5.94 & 7.92 & 8.23 & 7.57 & 4.64 \\
\hline Walk & 0.54 & 0.78 & 1.29 & 1.58 & 0.51 & 0.76 & 0.88 & 0.87 & 0.81 & 0.97 & 2.90 & 0.69 & 1.48 & 0.64 \\
\hline Other & 50.60 & 21.11 & 8.21 & 21.14 & 7.09 & 14.24 & 5.41 & 10.33 & 28.47 & 13.61 & 5.08 & 4.86 & 6.99 & 1.37 \\
\hline \multicolumn{15}{|c|}{ Time (minutes) } \\
\hline TOTAL & 23.95 & 25.12 & 23.22 & 23.83 & 24.34 & 23.38 & 26.24 & 23.21 & 32.59 & 27.27 & 42.70 & 31.67 & 38.55 & 25.33 \\
\hline Private & 24.01 & 25.09 & 22.90 & 23.43 & 23.09 & 22.52 & 24.23 & 22.13 & 24.07 & 25.36 & 34.63 & 26.94 & 33.38 & 17.87 \\
\hline Public & 61.30 & 50.57 & 53.61 & 51.20 & 69.24 & 70.79 & 55.86 & 51.74 & 63.68 & 49.45 & 52.18 & 53.79 & 49.49 & 37.20 \\
\hline Walk & 8.54 & 13.29 & 13.56 & 28.07 & 15.13 & 15.88 & 16.88 & 15.10 & 16.41 & 15.89 & 28.11 & 13.06 & 18.32 & 17.24 \\
\hline Other & 31.82 & 25.70 & 26.49 & 26.32 & 19.13 & 33.85 & 26.03 & 27.77 & 41.00 & 26.93 & 43.15 & 21.61 & 26.94 & 22.24 \\
\hline \multicolumn{15}{|c|}{ Miles per Hour } \\
\hline TOTAL & 36.38 & 36.23 & 30.13 & 32.60 & 28.77 & 28.52 & 23.16 & 26.76 & 23.26 & 22.35 & 16.89 & 21.34 & 12.90 & 11.85 \\
\hline Private & 36.01 & 36.22 & 30.82 & 33.02 & 29.25 & 29.01 & 24.47 & 27.41 & 22.08 & 23.09 & 20.97 & 23.08 & 19.13 & 15.66 \\
\hline Public & & & & & & & & & & & & & & \\
\hline Walk & 3.80 & 3.54 & 5.70 & 3.38 & 2.02 & 2.88 & 3.13 & 3.45 & 2.96 & 3.65 & 6.20 & 3.17 & 4.85 & 2.22 \\
\hline Other & 95.40 & 49.29 & 18.60 & 48.21 & 22.24 & 25.24 & 12.47 & 22.31 & 41.67 & 30.33 & 7.06 & 13.48 & 15.57 & 3.69 \\
\hline
\end{tabular}




\begin{tabular}{|c|c|c|c|c|c|c|c|c|c|c|c|c|c|c|}
\hline \multicolumn{15}{|c|}{ Population Density (census tract) } \\
\hline & \multicolumn{2}{|c|}{$<500$} & \multicolumn{2}{|c|}{$500-2,000$} & \multicolumn{2}{|c|}{$2,000-4,000$} & \multicolumn{2}{|c|}{$4,000-10,000$} & \multicolumn{2}{|c|}{$10,000-20,000$} & \multicolumn{2}{|c|}{$20,000-50,000$} & \multicolumn{2}{|c|}{$50,000+$} \\
\hline & NY State & U.S. & NY State & U.S. & NY State & U.S. & NY State & U.S. & NY State & U.S. & NY State & U.S. & NY State & U.S. \\
\hline \multirow{2}{*}{\multicolumn{15}{|c|}{$\begin{array}{l}\text { Average Commute Length, Travel Time, and Speed } \\
\text { Length (miles) }\end{array}$}} \\
\hline & & & & & & & & & & & & & & \\
\hline TOTAL & 14.00 & 14.96 & 12.19 & 12.33 & 12.52 & 10.97 & 10.75 & 11.35 & 9.94 & 10.06 & 8.16 & 7.78 & 7.03 & 10.34 \\
\hline Private & 13.80 & 14.82 & 12.05 & 11.79 & 12.04 & 10.61 & 10.00 & 10.98 & 9.92 & 10.44 & 8.90 & 9.62 & 10.45 & 12.85 \\
\hline Public & 19.98 & 22.56 & 29.95 & 23.18 & 27.01 & 14.78 & 21.93 & 12.83 & 13.95 & 9.21 & 11.04 & 6.14 & 7.72 & 9.15 \\
\hline Walk & 2.91 & 0.83 & 0.93 & 0.77 & 0.91 & 1.16 & 1.94 & 0.86 & 1.26 & 0.89 & 1.25 & 0.82 & 1.22 & 0.05 \\
\hline Other & 47.27 & 102.60 & 24.74 & 100.65 & 12.69 & 86.44 & 14.08 & 72.59 & 11.04 & 31.46 & 7.43 & 3.01 & 6.80 & \\
\hline \multicolumn{15}{|c|}{ Time (minutes) } \\
\hline TOTAL & 24.79 & 24.41 & 23.77 & 22.48 & 25.86 & 21.92 & 26.86 & 24.04 & 36.13 & 27.84 & 37.67 & 26.67 & 40.46 & 45.74 \\
\hline Private & 23.56 & 24.24 & 22.27 & 22.12 & 23.28 & 21.26 & 21.95 & 22.82 & 25.97 & 25.85 & 28.16 & 23.87 & 35.47 & 33.04 \\
\hline Public & 57.97 & 106.73 & 74.46 & 61.73 & 71.18 & 56.27 & 77.46 & 59.50 & 71.98 & 48.40 & 58.02 & 43.85 & 51.14 & 54.67 \\
\hline Walk & 12.59 & 8.93 & 33.23 & 14.97 & 14.52 & 13.66 & 12.91 & 13.16 & 17.70 & 14.45 & 20.27 & 15.18 & 19.76 & 3.19 \\
\hline Other & 67.52 & 74.27 & 52.86 & 58.37 & 32.74 & 56.92 & 53.63 & 38.34 & 42.48 & 40.41 & 32.43 & 32.08 & 37.50 & \\
\hline \multicolumn{15}{|c|}{ Miles per Hour } \\
\hline TOTAL & 34.96 & 36.86 & 31.40 & 33.06 & 30.64 & 30.88 & 26.78 & 29.87 & 21.35 & 23.40 & 16.01 & 21.48 & 13.85 & 23.31 \\
\hline Private & 35.17 & 36.71 & 32.72 & 32.01 & 31.25 & 30.02 & 27.34 & 28.90 & 23.30 & 24.25 & 18.51 & 24.25 & 17.68 & 23.34 \\
\hline Public & & & & & & 34.29 & & 18.04 & & & & & & \\
\hline Walk & 7.09 & 5.48 & 1.40 & 2.47 & 3.77 & 3.06 & 6.78 & 3.72 & 3.14 & 3.09 & 3.14 & 2.65 & 3.15 & 0.90 \\
\hline Other & 48.42 & 83.87 & 22.97 & 134.30 & 13.71 & 127.75 & 14.76 & 165.74 & 10.46 & 7.67 & 16.08 & 5.06 & 12.59 & \\
\hline
\end{tabular}




\begin{tabular}{|c|c|c|c|c|c|c|c|c|c|c|c|c|c|c|}
\hline \multicolumn{15}{|c|}{ Population Density (census tract) } \\
\hline & \multicolumn{2}{|c|}{$<500$} & \multicolumn{2}{|c|}{\begin{tabular}{c}
\multicolumn{5}{c}{$500-2,000$} \\
UY State
\end{tabular}} & \multicolumn{2}{|c|}{$2,000-4,000$} & \multicolumn{2}{|c|}{$4,000-10,000$} & \multicolumn{2}{|c|}{$10,000-20,000$} & \multicolumn{2}{|c|}{$20,000-50,000$} & \multicolumn{2}{|c|}{$50,000+$} \\
\hline & NY State & U.S. & NY State & U.S. & NY State & U.S. & NY State & U.S. & NY State & U.S. & NY State & U.S. & NY State & U.S. \\
\hline \multicolumn{15}{|c|}{$\begin{array}{l}\text { Average Commute Length, Travel Time, and Speed } \\
\text { Length (miles) }\end{array}$} \\
\hline TOTAL & 13.66 & 14.64 & 12.92 & 12.77 & 12.38 & 11.27 & 11.12 & 10.07 & 9.17 & 9.11 & 11.02 & 8.60 & 8.49 & 4.84 \\
\hline Private & 13.44 & 14.73 & 12.80 & 12.71 & 12.29 & 10.67 & 10.74 & 10.41 & 9.57 & 10.02 & 12.96 & 10.61 & 11.88 & 6.18 \\
\hline Public & 38.32 & 38.67 & 35.01 & 20.24 & 27.13 & 20.44 & 20.86 & 11.24 & 12.97 & 8.32 & 12.99 & 8.72 & 8.89 & 5.36 \\
\hline Walk & 0.61 & 0.63 & 0.58 & 0.51 & 0.82 & 0.58 & 0.60 & 0.88 & 0.83 & 0.81 & 0.94 & 0.68 & 1.18 & 1.97 \\
\hline Other & 41.18 & 17.50 & 11.32 & 22.61 & 2.82 & 71.95 & 7.51 & 8.49 & 4.67 & 5.39 & 10.17 & 4.16 & 16.61 & 1.00 \\
\hline \multicolumn{15}{|c|}{ Time (minutes) } \\
\hline TOTAL & 21.39 & 23.01 & 22.24 & 21.03 & 23.13 & 19.54 & 23.60 & 20.29 & 25.75 & 21.44 & 34.64 & 27.43 & 31.55 & 24.99 \\
\hline Private & 21.25 & 22.77 & 21.71 & 20.90 & 22.02 & 19.12 & 21.60 & 19.83 & 22.70 & 21.01 & 29.63 & 26.13 & 30.76 & 18.07 \\
\hline Public & 55.72 & 67.45 & 60.88 & 48.73 & 60.38 & 46.46 & 50.32 & 39.15 & 46.31 & 33.28 & 49.94 & 36.85 & 39.39 & 35.84 \\
\hline Walk & 6.81 & 7.51 & 11.15 & 8.51 & 12.43 & 11.76 & 8.87 & 11.92 & 9.34 & 10.49 & 10.82 & 12.22 & 16.53 & 20.25 \\
\hline Other & 37.95 & 56.84 & 35.40 & 24.83 & 11.80 & 36.82 & 24.93 & 39.77 & 23.33 & 19.48 & 29.48 & 52.54 & 23.23 & 5.00 \\
\hline \multicolumn{15}{|c|}{ Miles per Hour } \\
\hline TOTAL & 37.98 & 38.22 & 34.71 & 36.53 & 32.72 & 34.88 & 28.40 & 30.35 & 22.02 & 26.66 & 22.13 & 19.86 & 17.79 & 13.50 \\
\hline Private & 37.94 & 38.81 & 35.37 & 36.46 & 33.48 & 33.47 & 29.84 & 31.50 & 25.30 & 28.61 & 26.25 & 24.36 & 23.17 & 20.51 \\
\hline Public & 30.71 & 39.65 & 37.73 & 27.07 & 30.72 & 34.98 & 21.85 & 17.09 & 14.99 & 15.51 & 17.63 & 11.42 & 12.32 & 10.98 \\
\hline Walk & 5.35 & 5.01 & 3.13 & 3.60 & 3.98 & 2.94 & 4.09 & 4.41 & 5.35 & 4.66 & 5.18 & 3.33 & 4.27 & 5.84 \\
\hline Other & 65.10 & 18.42 & 19.19 & 55.04 & 13.76 & 117.25 & 15.75 & 11.16 & 12.35 & 16.59 & 20.70 & 4.75 & 42.90 & 12.00 \\
\hline
\end{tabular}




\begin{tabular}{|c|c|c|c|c|c|c|c|c|c|c|c|c|c|c|}
\hline \multicolumn{15}{|c|}{ Population Density (census tract) } \\
\hline & \multicolumn{2}{|c|}{ 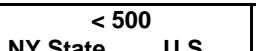 } & \multicolumn{2}{|c|}{$500-2,000$} & \multicolumn{2}{|c|}{$2,000-4,000$} & \multicolumn{2}{|c|}{$4,000-10,000$} & \multicolumn{2}{|c|}{$10,000-20,000$} & \multicolumn{2}{|c|}{$20,000-50,000$} & \multicolumn{2}{|c|}{$50,000+$} \\
\hline & NY State & U.S. & NY State & U.S. & NY State & U.S. & NY State & U.S. & NY State & U.S. & NY State & U.S. & NY State & U.S. \\
\hline \multicolumn{15}{|c|}{ Average Vehicle Occupancy (Person Miles per Vehicle Mile) } \\
\hline ALL & 1.60 & 1.63 & 1.66 & 1.64 & 1.50 & 1.78 & 1.58 & 1.68 & 1.57 & 1.66 & 1.78 & 1.62 & 2.21 & 1.14 \\
\hline 1 Adult, No Child & 1.18 & 1.19 & 1.23 & 1.33 & 1.09 & 1.31 & 1.08 & 1.23 & 1.06 & 1.24 & 1.59 & 1.29 & 1.92 & 1.22 \\
\hline 2+ Adults, No Child & 1.46 & 1.41 & 1.37 & 1.33 & 1.36 & 1.50 & 1.25 & 1.50 & 1.60 & 1.36 & 1.42 & 1.23 & 1.77 & 1.22 \\
\hline 1 Adult, Child $<6$ & 1.50 & 2.29 & 2.88 & 1.94 & 2.30 & 1.99 & 2.31 & 3.02 & 2.11 & 2.00 & 1.00 & 5.36 & 2.00 & \\
\hline 2+ Adults, Child $<6$ & 1.69 & 2.13 & 2.53 & 1.92 & 1.94 & 2.02 & 1.67 & 2.19 & 1.74 & 2.14 & 2.96 & 1.76 & 3.06 & 1.00 \\
\hline 1 Adult, Child 6-15 & 1.52 & 1.81 & 1.43 & 2.88 & 1.36 & 1.77 & 1.77 & 1.72 & 1.43 & 1.61 & 1.04 & 1.51 & 1.12 & \\
\hline 2+ Adults, Child 6-15 & 1.90 & 1.74 & 1.57 & 1.83 & 1.62 & 2.19 & 2.22 & 1.85 & 1.72 & 2.54 & 1.69 & 1.81 & 2.45 & 1.10 \\
\hline 1 Adult, Child 16-21 & 1.54 & 1.35 & 1.67 & 1.31 & 1.55 & 2.00 & 1.20 & 1.57 & 1.00 & 1.16 & 1.77 & 1.57 & 1.00 & \\
\hline 2+ Adults, Child 16-21 & 1.53 & 1.43 & 1.57 & 1.41 & 1.46 & 1.71 & 1.52 & 1.50 & 1.36 & 1.46 & 2.24 & 3.15 & 1.77 & \\
\hline 1 Adult, Retired, No Child & 1.45 & 1.25 & 1.12 & 1.29 & 1.16 & 1.30 & 1.27 & 1.44 & 1.21 & 1.18 & 1.55 & 1.03 & 1.13 & 1.10 \\
\hline $\begin{array}{l}\text { 2+ Adults, Retired, No Child } \\
\text { Unreported }\end{array}$ & 1.46 & 1.56 & 1.44 & 1.66 & 1.50 & 1.57 & 1.46 & 1.56 & 1.46 & 1.33 & 1.66 & 1.34 & 1.51 & 1.06 \\
\hline ALL & 1.60 & 1.63 & 1.66 & 1.64 & 1.50 & 1.78 & 1.58 & 1.68 & 1.57 & 1.66 & 1.78 & 1.62 & 2.21 & 1.14 \\
\hline Earn a Living & 1.10 & 1.16 & 1.13 & 1.15 & 1.13 & 1.13 & 1.13 & 1.18 & 1.23 & 1.13 & 1.29 & 1.06 & 1.19 & 1.04 \\
\hline Family \& Personal Business & 1.77 & 1.81 & 1.61 & 1.76 & 1.58 & 1.79 & 1.71 & 1.79 & 1.58 & 1.72 & 1.78 & 2.27 & 2.18 & 1.29 \\
\hline Civic, Educational \& Religious & 1.70 & 1.74 & 1.50 & 1.76 & 1.16 & 1.67 & 1.40 & 1.83 & 1.26 & 1.36 & 1.78 & 1.28 & 1.65 & 1.75 \\
\hline Social \& Recreational & 2.17 & 2.13 & 1.90 & 2.12 & 2.01 & 2.45 & 2.12 & 2.19 & 2.00 & 2.36 & 2.32 & 1.97 & 2.65 & 1.44 \\
\hline Other & 1.85 & 2.08 & 1.42 & 2.43 & 2.00 & 1.29 & 1.88 & 2.33 & 4.15 & 1.39 & 1.29 & 1.69 & 1.00 & \\
\hline Unreported & 1.18 & 1.36 & 3.36 & 1.88 & 1.82 & 2.91 & 2.18 & 1.56 & 1.17 & 1.32 & 1.70 & 1.04 & 2.62 & 1.00 \\
\hline ALL & 1.60 & 1.63 & 1.66 & 1.64 & 1.50 & 1.78 & 1.58 & 1.68 & 1.57 & 1.66 & 1.78 & 1.62 & 2.21 & 1.14 \\
\hline$<\$ 10,000$ & 1.68 & 1.60 & 1.57 & 2.51 & 1.66 & 1.70 & 1.53 & 1.66 & 1.32 & 1.58 & 1.01 & 1.31 & 1.13 & 1.00 \\
\hline$\$ 10$ to $\$ 20,000$ & 1.46 & 1.95 & 1.63 & 1.68 & 1.22 & 1.60 & 1.60 & 1.73 & 1.68 & 1.62 & 1.79 & 1.44 & 2.72 & 1.00 \\
\hline$\$ 20$ to $\$ 30,000$ & 1.78 & 1.75 & 1.34 & 1.78 & 1.40 & 1.59 & 1.54 & 1.67 & 1.43 & 1.62 & 1.26 & 1.73 & 1.58 & 1.00 \\
\hline$\$ 30$ to $\$ 40,000$ & 1.44 & 1.62 & 1.53 & 1.55 & 1.46 & 1.56 & 1.24 & 1.85 & 1.67 & 1.82 & 1.43 & 1.32 & 2.32 & 1.44 \\
\hline$\$ 40$ to $\$ 50,000$ & 1.36 & 1.70 & 1.39 & 1.70 & 1.28 & 1.58 & 1.76 & 1.53 & 1.50 & 1.38 & 1.50 & 2.07 & 2.38 & 1.00 \\
\hline$\$ 50$ to $\$ 60,000$ & 1.60 & 1.52 & 1.57 & 1.62 & 1.73 & 1.48 & 1.63 & 1.62 & 1.49 & 1.43 & 1.93 & 1.26 & 2.28 & 1.00 \\
\hline$\$ 60$ to $\$ 70,000$ & 1.46 & 1.53 & 1.63 & 1.60 & 1.54 & 1.63 & 1.63 & 1.56 & 2.03 & 2.32 & 1.67 & 1.37 & 1.37 & 2.00 \\
\hline$\$ 70$ to $\$ 80,000$ & 1.87 & 1.56 & 1.54 & 1.69 & 1.62 & 1.78 & 1.45 & 1.69 & 1.50 & 1.37 & 1.60 & 1.19 & 2.64 & 1.88 \\
\hline$\$ 80$ to $\$ 100,000$ & 1.54 & 1.57 & 1.76 & 1.51 & 1.67 & 1.67 & 1.41 & 1.52 & 1.49 & 1.67 & 1.85 & 3.10 & 1.26 & 1.00 \\
\hline$\$ 100,000+$ & 1.64 & 1.66 & 1.82 & 1.61 & 1.49 & 2.07 & 1.64 & 1.68 & 1.53 & 1.67 & 1.99 & 1.63 & 1.99 & 1.19 \\
\hline Unreported & 1.67 & 1.38 & 1.36 & 1.70 & 1.31 & 1.75 & 1.51 & 2.03 & 1.34 & 1.21 & 1.58 & 1.41 & 1.22 & 1.00 \\
\hline
\end{tabular}




\begin{tabular}{|c|c|c|c|c|c|c|c|c|c|c|c|c|c|c|}
\hline \multicolumn{15}{|c|}{ Population Density (census tract) } \\
\hline & \multicolumn{2}{|c|}{$<500$} & \multicolumn{2}{|c|}{$500-2,000$} & \multicolumn{2}{|c|}{$2,000-4,000$} & \multicolumn{2}{|c|}{$4,000-10,000$} & \multicolumn{2}{|c|}{$10,000-20,000$} & \multicolumn{2}{|c|}{$20,000-50,000$} & \multicolumn{2}{|c|}{$50,000+$} \\
\hline & NY State & U.S. & NY State & U.S. & NY State & U.S. & NY State & U.S. & NY State & U.S. & NY State & U.S. & NY State & U.S. \\
\hline \multicolumn{15}{|c|}{ Average Vehicle Occupancy (Person Miles per Vehicle Mile) } \\
\hline ALL & 1.52 & 1.62 & 1.52 & 1.63 & 1.61 & 1.60 & 1.58 & 1.62 & 2.06 & 1.64 & 1.70 & 1.74 & 1.68 & 1.19 \\
\hline 1 Adult, No Child & 1.15 & 1.18 & 1.19 & 1.27 & 1.20 & 1.25 & 1.15 & 1.21 & 1.42 & 1.26 & 1.29 & 1.06 & 1.78 & 1.09 \\
\hline 2+ Adults, No Child & 1.36 & 1.37 & 1.38 & 1.47 & 1.40 & 1.38 & 1.39 & 1.41 & 1.44 & 1.54 & 1.64 & 1.49 & 1.78 & 1.20 \\
\hline 1 Adult, Child $<6$ & 1.51 & 1.97 & 1.64 & 1.97 & 1.55 & 2.14 & 1.43 & 1.71 & 2.05 & 1.86 & 1.19 & 2.87 & 2.45 & 1.05 \\
\hline 2+ Adults, Child $<6$ & 1.92 & 2.02 & 1.94 & 2.10 & 2.03 & 2.03 & 2.01 & 2.02 & 1.95 & 1.92 & 1.59 & 2.77 & 1.64 & 1.52 \\
\hline 1 Adult, Child 6-15 & 1.84 & 1.57 & 1.58 & 1.64 & 1.74 & 1.89 & 1.79 & 1.77 & 1.24 & 1.72 & 1.62 & 1.30 & 1.53 & \\
\hline 2+ Adults, Child 6-15 & 1.59 & 1.77 & 1.64 & 1.63 & 1.75 & 1.59 & 1.52 & 1.76 & 1.70 & 1.78 & 2.07 & 1.92 & 1.57 & 1.07 \\
\hline 1 Adult, Child 16-21 & 1.19 & 1.32 & 1.34 & 1.36 & 1.25 & 1.62 & 1.31 & 1.40 & 1.63 & 1.25 & 1.36 & 1.29 & 1.00 & 1.38 \\
\hline 2+ Adults, Child 16-21 & 1.38 & 1.38 & 1.40 & 1.39 & 1.41 & 1.48 & 1.48 & 1.48 & 4.23 & 1.49 & 1.51 & 2.07 & 1.34 & \\
\hline 1 Adult, Retired, No Child & 1.14 & 1.34 & 1.34 & 1.32 & 1.18 & 1.31 & 1.28 & 1.26 & 1.07 & 1.37 & 1.71 & 1.41 & 1.08 & 1.28 \\
\hline 2+ Adults, Retired, No Child & 1.58 & 1.64 & 1.44 & 1.60 & 1.46 & 1.66 & 1.66 & 1.61 & 1.47 & 1.59 & 1.65 & 1.40 & 1.62 & 1.63 \\
\hline Unreported & & 1.25 & 1.01 & 1.84 & 1.00 & 3.05 & 1.94 & 1.70 & 1.55 & 1.93 & & & & \\
\hline ALL & 1.52 & 1.62 & 1.52 & 1.63 & 1.61 & 1.60 & 1.58 & 1.62 & 2.06 & 1.64 & 1.70 & 1.74 & 1.68 & 1.19 \\
\hline Earn a Living & 1.11 & 1.17 & 1.11 & 1.13 & 1.20 & 1.15 & 1.09 & 1.16 & 1.24 & 1.11 & 1.18 & 1.16 & 1.29 & 1.14 \\
\hline Family \& Personal Business & 1.69 & 1.79 & 1.60 & 1.76 & 1.70 & 1.71 & 1.78 & 1.84 & 1.80 & 1.84 & 1.89 & 2.16 & 1.92 & 1.14 \\
\hline Civic, Educational \& Religious & 1.65 & 1.79 & 1.67 & 2.05 & 1.60 & 1.67 & 1.52 & 1.65 & 1.53 & 1.41 & 1.33 & 2.30 & 1.70 & 1.79 \\
\hline Social \& Recreational & 1.84 & 2.06 & 1.99 & 2.04 & 2.10 & 2.02 & 1.99 & 1.96 & 3.52 & 2.26 & 2.10 & 1.83 & 1.84 & 1.49 \\
\hline Other & 2.22 & 1.91 & 1.78 & 1.97 & 1.50 & 2.07 & 1.23 & 1.51 & 1.98 & 1.82 & 2.45 & 1.32 & 1.30 & \\
\hline Unreported & 1.26 & 1.81 & 2.11 & 1.34 & 2.72 & 2.05 & 2.14 & 1.48 & 1.31 & 1.04 & 1.00 & 1.14 & 1.00 & 1.00 \\
\hline ALL & 1.52 & 1.62 & 1.52 & 1.63 & 1.61 & 1.60 & 1.58 & 1.62 & 2.06 & 1.64 & 1.70 & 1.74 & 1.68 & 1.19 \\
\hline$<\$ 10,000$ & 1.31 & 1.72 & 1.42 & 2.05 & 1.35 & 1.50 & 1.38 & 2.06 & 1.50 & 1.55 & 1.03 & 1.65 & 1.11 & 1.00 \\
\hline$\$ 10$ to $\$ 20,000$ & 1.44 & 1.69 & 1.63 & 1.52 & 1.48 & 1.46 & 1.85 & 1.73 & 1.24 & 1.79 & 1.26 & 1.51 & 1.89 & \\
\hline$\$ 20$ to $\$ 30,000$ & 1.48 & 1.61 & 1.35 & 1.62 & 1.46 & 1.47 & 1.69 & 1.70 & 1.38 & 1.86 & 1.87 & 3.37 & 1.32 & 1.32 \\
\hline$\$ 30$ to $\$ 40,000$ & 1.57 & 1.58 & 1.48 & 1.79 & 1.31 & 1.71 & 1.71 & 1.56 & 4.15 & 1.86 & 2.05 & 1.63 & 1.52 & 1.33 \\
\hline$\$ 40$ to $\$ 50,000$ & 1.49 & 1.60 & 1.60 & 1.49 & 1.53 & 1.73 & 2.17 & 1.71 & 1.73 & 1.89 & 1.73 & 1.49 & 1.51 & 1.00 \\
\hline$\$ 50$ to $\$ 60,000$ & 1.62 & 1.62 & 1.48 & 1.64 & 1.56 & 1.49 & 1.34 & 1.62 & 1.55 & 1.62 & 1.54 & 1.16 & 1.93 & 1.54 \\
\hline$\$ 60$ to $\$ 70,000$ & 1.54 & 1.72 & 1.55 & 1.54 & 1.64 & 1.50 & 1.72 & 1.61 & 1.30 & 1.42 & 1.63 & 1.38 & 1.57 & 1.31 \\
\hline$\$ 70$ to $\$ 80,000$ & 1.46 & 1.84 & 1.56 & 1.60 & 1.79 & 1.57 & 1.58 & 1.60 & 1.64 & 2.00 & 1.34 & 1.22 & 1.75 & 1.67 \\
\hline$\$ 80$ to $\$ 100,000$ & 1.53 & 1.57 & 1.59 & 1.60 & 1.61 & 1.63 & 1.37 & 1.60 & 1.38 & 1.24 & 1.56 & 1.37 & 1.50 & 1.01 \\
\hline$\$ 100,000_{+}$ & 1.52 & 1.56 & 1.49 & 1.60 & 1.70 & 1.61 & 1.55 & 1.60 & 1.58 & 1.45 & 1.70 & 1.56 & 1.94 & 1.24 \\
\hline Unreported & 1.43 & 1.49 & 1.55 & 1.68 & 1.52 & 1.67 & 1.50 & 1.42 & 1.79 & 1.81 & 1.61 & 1.51 & 1.16 & 1.10 \\
\hline
\end{tabular}




\begin{tabular}{|c|c|c|c|c|c|c|c|c|c|c|c|c|c|c|}
\hline \multicolumn{15}{|c|}{ Population Density (census tract) } \\
\hline & \multirow{2}{*}{\multicolumn{2}{|c|}{$\begin{array}{c}<500 \\
\text { SY State }\end{array}$}} & \multicolumn{2}{|c|}{$500-2,000$} & \multicolumn{2}{|c|}{$2,000-4,000$} & \multirow{2}{*}{\multicolumn{2}{|c|}{$4,000-10,000$}} & \multicolumn{2}{|c|}{$10,000-20,000$} & \multicolumn{2}{|c|}{$20,000-50,000$} & \multicolumn{2}{|c|}{$50,000+$} \\
\hline & & & NY State & U.S. & NY State & U.S. & & U.S. & NY State & U.S. & NY State & U.S. & NY State & U.S. \\
\hline \multicolumn{15}{|c|}{ Average Vehicle Occupancy (Person Miles per Vehicle Mile) } \\
\hline ALL & 1.50 & 1.56 & 1.62 & 1.59 & 1.53 & 1.62 & 1.58 & 1.55 & 1.70 & 1.57 & 1.54 & 1.66 & 2.05 & 1.74 \\
\hline 1 Adult, No Child & 1.22 & 1.14 & 1.51 & 1.25 & 1.08 & 1.29 & 1.31 & 1.19 & 1.17 & 1.40 & 1.10 & 1.21 & 1.20 & 1.45 \\
\hline $2+$ Adults, No Child & 1.36 & 1.34 & 1.38 & 1.31 & 1.49 & 1.40 & 1.32 & 1.32 & 1.50 & 1.29 & 1.62 & 1.45 & 2.01 & 1.79 \\
\hline 1 Adult, Child $<6$ & 1.62 & 1.48 & 2.57 & 1.67 & 1.34 & 4.11 & 2.12 & 1.74 & 2.88 & 1.81 & 1.41 & & 1.36 & \\
\hline $2+$ Adults, Child $<6$ & 1.69 & 1.79 & 2.00 & 1.91 & 1.74 & 1.88 & 1.91 & 1.89 & 1.97 & 1.87 & 1.67 & 1.80 & 2.54 & 1.00 \\
\hline 1 Adult, Child 6-15 & 1.75 & 1.51 & 1.39 & 1.66 & 1.35 & 2.17 & 1.55 & 1.57 & 2.96 & 1.52 & 1.27 & 2.42 & 2.30 & \\
\hline 2+ Adults, Child 6-15 & 1.67 & 1.83 & 1.64 & 1.74 & 1.85 & 1.80 & 1.78 & 1.84 & 1.94 & 1.84 & 1.90 & 2.15 & 2.06 & 1.57 \\
\hline 1 Adult, Child 16-21 & 1.07 & 1.67 & 1.80 & 1.55 & 1.21 & 1.94 & 1.51 & 1.42 & 1.55 & 1.06 & & 2.51 & 1.47 & \\
\hline 2+ Adults, Child 16-21 & 1.37 & 1.37 & 1.40 & 1.44 & 1.19 & 1.49 & 1.63 & 1.63 & 1.69 & 1.29 & 1.31 & 2.42 & 2.47 & \\
\hline 1 Adult, Retired, No Child & 1.19 & 1.29 & 1.06 & 1.82 & 1.20 & 1.42 & 1.15 & 1.20 & 1.44 & 1.32 & 1.41 & 1.02 & 1.50 & \\
\hline 2+ Adults, Retired, No Child & 1.46 & 1.50 & 1.66 & 1.61 & 1.49 & 1.49 & 1.58 & 1.54 & 1.69 & 2.02 & 1.43 & 2.20 & 1.73 & 2.00 \\
\hline ALL & 1.50 & 1.56 & 1.62 & 1.59 & 1.53 & 1.62 & 1.58 & 1.55 & 1.70 & 1.57 & 1.54 & 1.66 & 2.05 & 1.74 \\
\hline Earn a Living & 1.12 & 1.15 & 1.19 & 1.15 & 1.07 & 1.14 & 1.11 & 1.14 & 1.14 & 1.13 & 1.11 & 1.07 & 1.63 & 1.04 \\
\hline Family \& Personal Business & 1.63 & 1.70 & 1.72 & 1.76 & 1.70 & 1.80 & 1.75 & 1.71 & 1.86 & 1.74 & 1.64 & 2.04 & 2.04 & 1.88 \\
\hline Civic, Educational \& Religious & 1.56 & 1.64 & 1.47 & 1.58 & 1.53 & 1.56 & 2.55 & 1.64 & 1.59 & 2.07 & 1.38 & 1.83 & 1.91 & \\
\hline Social \& Recreational & 1.92 & 2.10 & 2.11 & 2.10 & 1.98 & 2.17 & 2.04 & 1.93 & 2.32 & 1.81 & 2.11 & 1.92 & 2.43 & 1.86 \\
\hline Other & 1.19 & 2.18 & 1.99 & 1.93 & 3.00 & 1.49 & 1.08 & 1.58 & 2.00 & 2.09 & 1.00 & & & \\
\hline ALL & 1.50 & 1.56 & 1.62 & 1.59 & 1.53 & 1.62 & 1.58 & 1.55 & 1.70 & 1.57 & 1.54 & 1.66 & 2.05 & 1.74 \\
\hline $\mid<\$ 10,000$ & 1.46 & 1.33 & 1.64 & 1.53 & 1.12 & 2.22 & 1.54 & 1.36 & 1.47 & 1.25 & 1.49 & 2.33 & 1.54 & 1.00 \\
\hline$\$ 10$ to $\$ 20,000$ & 1.30 & 1.50 & 1.63 & 2.13 & 1.31 & 2.23 & 1.38 & 1.73 & 1.29 & 2.08 & 1.71 & 1.72 & 2.63 & \\
\hline$\$ 20$ to $\$ 30,000$ & 1.44 & 1.50 & 1.28 & 1.72 & 1.34 & 1.36 & 1.32 & 1.63 & 1.38 & 1.74 & 1.65 & 1.38 & 2.21 & 1.10 \\
\hline$\$ 30$ to $\$ 40,000$ & 1.44 & 1.60 & 1.67 & 1.56 & 1.42 & 1.48 & 1.59 & 1.59 & 1.91 & 1.64 & 1.44 & 1.81 & 1.98 & 1.45 \\
\hline$\$ 40$ to $\$ 50,000$ & 1.42 & 1.50 & 1.50 & 1.67 & 1.33 & 2.06 & 1.76 & 1.31 & 1.48 & 1.71 & 1.52 & 1.58 & 1.95 & \\
\hline$\$ 50$ to $\$ 60,000$ & 1.67 & 1.62 & 1.73 & 1.43 & 1.63 & 1.59 & 1.61 & 1.47 & 1.92 & 1.43 & 1.64 & 1.94 & 1.30 & 1.33 \\
\hline$\$ 60$ to $\$ 70,000$ & 1.48 & 1.50 & 1.65 & 1.50 & 1.31 & 1.55 & 1.66 & 1.51 & 1.85 & 1.39 & 2.02 & 2.31 & 1.64 & \\
\hline$\$ 70$ to $\$ 80,000$ & 1.38 & 1.52 & 1.57 & 1.75 & 1.63 & 1.88 & 1.31 & 1.61 & 2.23 & 1.49 & 1.56 & 1.10 & 3.58 & \\
\hline$\$ 80$ to $\$ 100,000$ & 1.73 & 1.69 & 1.59 & 1.65 & 1.49 & 1.50 & 1.63 & 1.52 & 1.78 & 1.60 & 1.85 & 1.61 & 2.05 & 1.97 \\
\hline$\$ 100,000_{+}$ & 1.45 & 1.55 & 1.77 & 1.55 & 1.84 & 1.60 & 1.74 & 1.52 & 1.57 & 1.43 & 1.31 & 1.38 & 1.65 & 1.00 \\
\hline Unreported & 1.44 & 1.50 & 1.49 & 1.56 & 1.40 & 1.62 & 1.41 & 1.66 & 1.61 & 1.41 & 1.36 & 1.50 & 1.32 & \\
\hline
\end{tabular}




\begin{tabular}{|c|c|c|c|c|c|c|c|c|c|c|c|c|c|c|}
\hline \multicolumn{15}{|c|}{ Population Density (census tract) } \\
\hline & \multicolumn{2}{|c|}{$<500$} & \multicolumn{2}{|c|}{$500-2,000$} & \multicolumn{2}{|c|}{$2,000-4,000$} & \multicolumn{2}{|c|}{$4,000-10,000$} & \multicolumn{2}{|c|}{$10,000-20,000$} & \multicolumn{2}{|c|}{$20,000-50,000$} & \multicolumn{2}{|c|}{$50,000+$} \\
\hline & NY State & U.S. & NY State & U.S. & NY State & U.S. & NY State & U.S. & NY State & U.S. & NY State & U.S. & NY State & U.S. \\
\hline Vehicles by Type & $100.0 \%$ & $100.0 \%$ & $100.0 \%$ & $100.0 \%$ & $100.0 \%$ & $100.0 \%$ & $100.0 \%$ & $100.0 \%$ & $100.0 \%$ & $0.0 \%$ & $0.0 \%$ & $0.0 \%$ & $0.0 \%$ & $0.0 \%$ \\
\hline Auto & $48.1 \%$ & $42.2 \%$ & $58.1 \%$ & $52.0 \%$ & $61.3 \%$ & $55.2 \%$ & $62.3 \%$ & $56.9 \%$ & $62.4 \%$ & $62.3 \%$ & $70.9 \%$ & $62.2 \%$ & $62.1 \%$ & $75.6 \%$ \\
\hline Van & $10.6 \%$ & $7.9 \%$ & $7.8 \%$ & $8.8 \%$ & $8.6 \%$ & $9.4 \%$ & $8.9 \%$ & $8.0 \%$ & $12.4 \%$ & $8.3 \%$ & $5.3 \%$ & $10.1 \%$ & $12.6 \%$ & $1.4 \%$ \\
\hline Sports Utility & $20.8 \%$ & $19.9 \%$ & $22.7 \%$ & $21.1 \%$ & $21.6 \%$ & $20.0 \%$ & $22.6 \%$ & $19.2 \%$ & $21.1 \%$ & $15.8 \%$ & $22.2 \%$ & $19.9 \%$ & $23.0 \%$ & $9.9 \%$ \\
\hline Pickup & $16.1 \%$ & $24.8 \%$ & $8.8 \%$ & $14.3 \%$ & $6.0 \%$ & $12.2 \%$ & $4.2 \%$ & $12.5 \%$ & $2.5 \%$ & $11.1 \%$ & $0.9 \%$ & $5.3 \%$ & $0.3 \%$ & $11.6 \%$ \\
\hline Other Truck & $0.3 \%$ & $0.7 \%$ & $0.2 \%$ & $0.3 \%$ & $0.2 \%$ & $0.2 \%$ & $0.1 \%$ & $0.2 \%$ & $0.1 \%$ & $0.2 \%$ & & $0.0 \%$ & & \\
\hline RV & $0.6 \%$ & $0.8 \%$ & $0.3 \%$ & $0.5 \%$ & $0.1 \%$ & $0.4 \%$ & $0.2 \%$ & $0.3 \%$ & $0.0 \%$ & $0.2 \%$ & & $0.0 \%$ & & \\
\hline $\begin{array}{l}\text { Motorcycle } \\
\text { Other POV }\end{array}$ & $\begin{array}{r}3.5 \% \\
\text { * }\end{array}$ & $3.8 \%$ & $2.2 \%$ & $3.0 \%$ & $2.1 \%$ & $2.7 \%$ & $\begin{aligned} & 1.7 \% \\
& *\end{aligned}$ & $3.0 \%$ & $1.5 \%$ & $2.1 \%$ & $0.8 \%$ & $2.4 \%$ & $2.0 \%$ & $1.5 \%$ \\
\hline \multicolumn{15}{|c|}{ * Other POV not present in 2001 or 2009.} \\
\hline \multicolumn{15}{|l|}{ Age Statistics } \\
\hline Average Vehicle Age & 8.13 & 9.59 & 7.26 & 8.42 & 7.37 & 8.88 & 7.42 & 9.41 & 7.77 & 9.86 & 8.31 & 9.26 & 8.39 & 9.17 \\
\hline Median Vehicle Age & 7 & & 6 & 7 & 6 & 7 & 6 & 8 & 7 & 9 & 7 & 9 & 8 & \\
\hline \multicolumn{15}{|l|}{ Percent VMT* } \\
\hline Less than $10 \mathrm{yrs}$ & $74.7 \%$ & $69.6 \%$ & $78.9 \%$ & $72.8 \%$ & $76.4 \%$ & $70.0 \%$ & $76.5 \%$ & $66.5 \%$ & $75.6 \%$ & $61.8 \%$ & $63.8 \%$ & $64.1 \%$ & $69.3 \%$ & $50.0 \%$ \\
\hline $10 \mathrm{yrs}$ or more & $25.3 \%$ & $30.4 \%$ & $21.1 \%$ & $27.2 \%$ & $23.6 \%$ & $30.0 \%$ & $23.6 \%$ & $33.5 \%$ & $24.4 \%$ & $38.2 \%$ & $36.2 \%$ & $35.9 \%$ & $30.7 \%$ & $50.0 \%$ \\
\hline \multicolumn{15}{|l|}{ Percent Vehicle Fleet } \\
\hline Less than $10 \mathrm{yrs}$ & $68.7 \%$ & $60.5 \%$ & $74.2 \%$ & $66.8 \%$ & $72.7 \%$ & $64.0 \%$ & $71.1 \%$ & $60.0 \%$ & $68.0 \%$ & $56.3 \%$ & $62.0 \%$ & $58.9 \%$ & $62.0 \%$ & $66.6 \%$ \\
\hline $10 \mathrm{yrs}$ or more & $31.3 \%$ & $39.5 \%$ & $25.8 \%$ & $33.2 \%$ & $27.3 \%$ & $36.0 \%$ & $28.9 \%$ & $40.0 \%$ & $32.0 \%$ & $43.7 \%$ & $38.0 \%$ & $41.1 \%$ & $38.0 \%$ & $33.4 \%$ \\
\hline Avg Fuel Consumption (gal/HH) & 1,130 & 1,306 & 942 & 1,049 & 876 & 940 & 691 & 839 & 557 & 642 & 321 & 526 & 163 & 244 \\
\hline Less than $10 \mathrm{yrs}$ & $73.2 \%$ & $67.8 \%$ & $77.8 \%$ & $71.6 \%$ & $75.9 \%$ & $69.2 \%$ & $75.0 \%$ & $64.9 \%$ & $74.5 \%$ & $59.7 \%$ & $62.6 \%$ & $63.1 \%$ & $67.9 \%$ & $52.7 \%$ \\
\hline $10 \mathrm{yrs}$ or more & $26.8 \%$ & $32.2 \%$ & $22.2 \%$ & $28.4 \%$ & $24.2 \%$ & $30.9 \%$ & $25.0 \%$ & $35.1 \%$ & $25.5 \%$ & $40.4 \%$ & $37.4 \%$ & $36.9 \%$ & $32.1 \%$ & $47.3 \%$ \\
\hline Avg CO2 Emissions $(\mathrm{kg} / \mathrm{HH})$ & 9,952 & 11,523 & 8,292 & 9,235 & 7,719 & 8,277 & 6,077 & 7,381 & 4,895 & 5,648 & 2,820 & 4,621 & 1,430 & 2,147 \\
\hline Less than $10 \mathrm{yrs}$ & $73.2 \%$ & $67.8 \%$ & $77.8 \%$ & $71.6 \%$ & $75.9 \%$ & $69.2 \%$ & $75.0 \%$ & $64.9 \%$ & $74.5 \%$ & $59.7 \%$ & $62.6 \%$ & $63.1 \%$ & $67.9 \%$ & $52.7 \%$ \\
\hline $10 \mathrm{yrs}$ or more & $26.8 \%$ & $32.2 \%$ & $22.2 \%$ & $28.4 \%$ & $24.2 \%$ & $30.9 \%$ & $25.0 \%$ & $35.1 \%$ & $25.5 \%$ & $40.4 \%$ & $37.4 \%$ & $36.9 \%$ & $32.1 \%$ & $47.3 \%$ \\
\hline${ }^{*}$ Numbers reflect B & & & & & & & & & & & & & & \\
\hline
\end{tabular}




\begin{tabular}{|c|c|c|c|c|c|c|c|c|c|c|c|c|c|c|}
\hline \multicolumn{15}{|c|}{ Population Density (census tract) } \\
\hline & \multicolumn{2}{|c|}{$<500$} & \multicolumn{2}{|c|}{$500-2,000$} & \multicolumn{2}{|c|}{$2,000-4,000$} & \multicolumn{2}{|c|}{$4,000-10,000$} & \multicolumn{2}{|c|}{$10,000-20,000$} & \multicolumn{2}{|c|}{$20,000-50,000$} & \multicolumn{2}{|c|}{$50,000+$} \\
\hline & NY State & U.S. & NY State & U.S. & NY State & U.S. & NY State & U.S. & NY State & U.S. & NY State & U.S. & NY State & U.S. \\
\hline Vehicles by Type & $100.0 \%$ & $100.0 \%$ & $100.0 \%$ & $100.0 \%$ & $100.0 \%$ & $100.0 \%$ & $100.0 \%$ & $100.0 \%$ & $100.0 \%$ & $0.0 \%$ & $0.0 \%$ & $0.0 \%$ & $0.0 \%$ & $0.0 \%$ \\
\hline Auto & $55.0 \%$ & $48.2 \%$ & $65.9 \%$ & $58.4 \%$ & $64.3 \%$ & $61.8 \%$ & $70.4 \%$ & $64.7 \%$ & $75.6 \%$ & $67.5 \%$ & $75.2 \%$ & $71.2 \%$ & $77.4 \%$ & $85.4 \%$ \\
\hline Van & $9.6 \%$ & $9.3 \%$ & $10.8 \%$ & $9.7 \%$ & $11.5 \%$ & $9.2 \%$ & $9.8 \%$ & $8.8 \%$ & $9.5 \%$ & $7.2 \%$ & $8.1 \%$ & $12.2 \%$ & $9.8 \%$ & $3.2 \%$ \\
\hline Sports Utility & $13.5 \%$ & $12.3 \%$ & $12.1 \%$ & $13.4 \%$ & $14.0 \%$ & $12.9 \%$ & $12.2 \%$ & $11.1 \%$ & $11.5 \%$ & $12.9 \%$ & $12.3 \%$ & $10.7 \%$ & $11.4 \%$ & $4.2 \%$ \\
\hline Pickup & $17.8 \%$ & $25.5 \%$ & $8.5 \%$ & $15.4 \%$ & $8.0 \%$ & $13.3 \%$ & $5.6 \%$ & $13.3 \%$ & $1.9 \%$ & $10.1 \%$ & $1.4 \%$ & $4.5 \%$ & $0.6 \%$ & $7.0 \%$ \\
\hline Other Truck & $0.5 \%$ & $0.8 \%$ & $0.2 \%$ & $0.3 \%$ & $0.1 \%$ & $0.2 \%$ & $0.0 \%$ & $0.3 \%$ & $0.1 \%$ & $0.6 \%$ & $1.1 \%$ & $0.0 \%$ & & \\
\hline RV & $0.7 \%$ & $1.0 \%$ & $0.5 \%$ & $0.7 \%$ & $0.5 \%$ & $0.6 \%$ & $0.2 \%$ & $0.5 \%$ & $0.1 \%$ & $0.3 \%$ & & $0.0 \%$ & & \\
\hline Motorcycle & $2.9 \%$ & $2.9 \%$ & $1.9 \%$ & $2.3 \%$ & $1.7 \%$ & $2.0 \%$ & $1.8 \%$ & $1.5 \%$ & $1.2 \%$ & $1.5 \%$ & $1.9 \%$ & $1.4 \%$ & $0.9 \%$ & $0.3 \%$ \\
\hline Other POV & & & & & & & & & & & & & & \\
\hline \multicolumn{15}{|c|}{ * Other POV not present in 2001 or 2009.} \\
\hline \multicolumn{15}{|l|}{ Age Statistics } \\
\hline Average Vehicle Age & 7.92 & 9.12 & 7.36 & 8.11 & 7.10 & 8.14 & 7.40 & 8.78 & 7.38 & 9.28 & 8.51 & 9.30 & 8.76 & 8.38 \\
\hline Median Vehicle Age & 7 & 7 & 6 & 6 & 6 & 7 & 6 & 7 & 6 & 8 & 8 & 8 & 8 & 8 \\
\hline \multicolumn{15}{|l|}{ Percent VMT* } \\
\hline Less than $10 \mathrm{yrs}$ & $74.7 \%$ & $73.0 \%$ & $78.6 \%$ & $75.8 \%$ & $76.6 \%$ & $74.1 \%$ & $74.0 \%$ & $70.5 \%$ & $76.5 \%$ & $60.5 \%$ & $67.9 \%$ & $65.5 \%$ & $63.0 \%$ & $63.7 \%$ \\
\hline $10 \mathrm{yrs}$ or more & $25.3 \%$ & $27.0 \%$ & $21.5 \%$ & $24.2 \%$ & $23.4 \%$ & $25.9 \%$ & $26.0 \%$ & $29.5 \%$ & $23.5 \%$ & $39.5 \%$ & $32.1 \%$ & $34.5 \%$ & $37.0 \%$ & $36.3 \%$ \\
\hline \multicolumn{15}{|l|}{ Percent Vehicle Fleet } \\
\hline Less than $10 \mathrm{yrs}$ & $67.5 \%$ & $62.1 \%$ & $71.3 \%$ & $68.1 \%$ & $71.9 \%$ & $67.7 \%$ & $70.3 \%$ & $62.6 \%$ & $69.4 \%$ & $57.8 \%$ & $56.9 \%$ & $56.8 \%$ & $57.0 \%$ & $65.0 \%$ \\
\hline $10 \mathrm{yrs}$ or more & $32.6 \%$ & $37.9 \%$ & $28.7 \%$ & $32.0 \%$ & $28.1 \%$ & $32.4 \%$ & $29.7 \%$ & $37.4 \%$ & $30.6 \%$ & $42.2 \%$ & $43.1 \%$ & $43.3 \%$ & $43.0 \%$ & $35.0 \%$ \\
\hline Avg Fuel Consumption (gal//HH) & 1,141 & 1,293 & 1,032 & 1,109 & 972 & 964 & 755 & 857 & 685 & 741 & 395 & 517 & 219 & 375 \\
\hline Less than $10 \mathrm{yrs}$ & $77.2 \%$ & $73.5 \%$ & $78.6 \%$ & $76.0 \%$ & $83.2 \%$ & $73.9 \%$ & $76.5 \%$ & $70.3 \%$ & $79.3 \%$ & $61.0 \%$ & $67.5 \%$ & $65.6 \%$ & $63.9 \%$ & $62.4 \%$ \\
\hline 10 yrs or more & $22.8 \%$ & $26.5 \%$ & $21.4 \%$ & $24.0 \%$ & $16.8 \%$ & $26.1 \%$ & $23.5 \%$ & $29.7 \%$ & $20.7 \%$ & $39.0 \%$ & $32.5 \%$ & $34.5 \%$ & $36.1 \%$ & $37.6 \%$ \\
\hline Avg CO2 Emissions $(\mathrm{kg} / \mathrm{HH})$ & 10,024 & 11,366 & 9,068 & 9,753 & 8,542 & 8,470 & 6,639 & 7,535 & 6,016 & 6,518 & 3,496 & 4,545 & 1,920 & 3,298 \\
\hline Less than $10 \mathrm{yrs}$ & $77.2 \%$ & $73.5 \%$ & $78.6 \%$ & $76.0 \%$ & $83.2 \%$ & $73.9 \%$ & $76.5 \%$ & $70.3 \%$ & $79.3 \%$ & $61.0 \%$ & $67.5 \%$ & $65.6 \%$ & $63.9 \%$ & $62.4 \%$ \\
\hline $10 \mathrm{yrs}$ or more & $22.8 \%$ & $26.5 \%$ & $21.4 \%$ & $24.0 \%$ & $16.8 \%$ & $26.1 \%$ & $23.5 \%$ & $29.7 \%$ & $20.7 \%$ & $39.0 \%$ & $32.5 \%$ & $34.5 \%$ & $36.1 \%$ & $37.6 \%$ \\
\hline${ }^{*}$ Numbers re & & & & & & & & & & & & & & \\
\hline
\end{tabular}




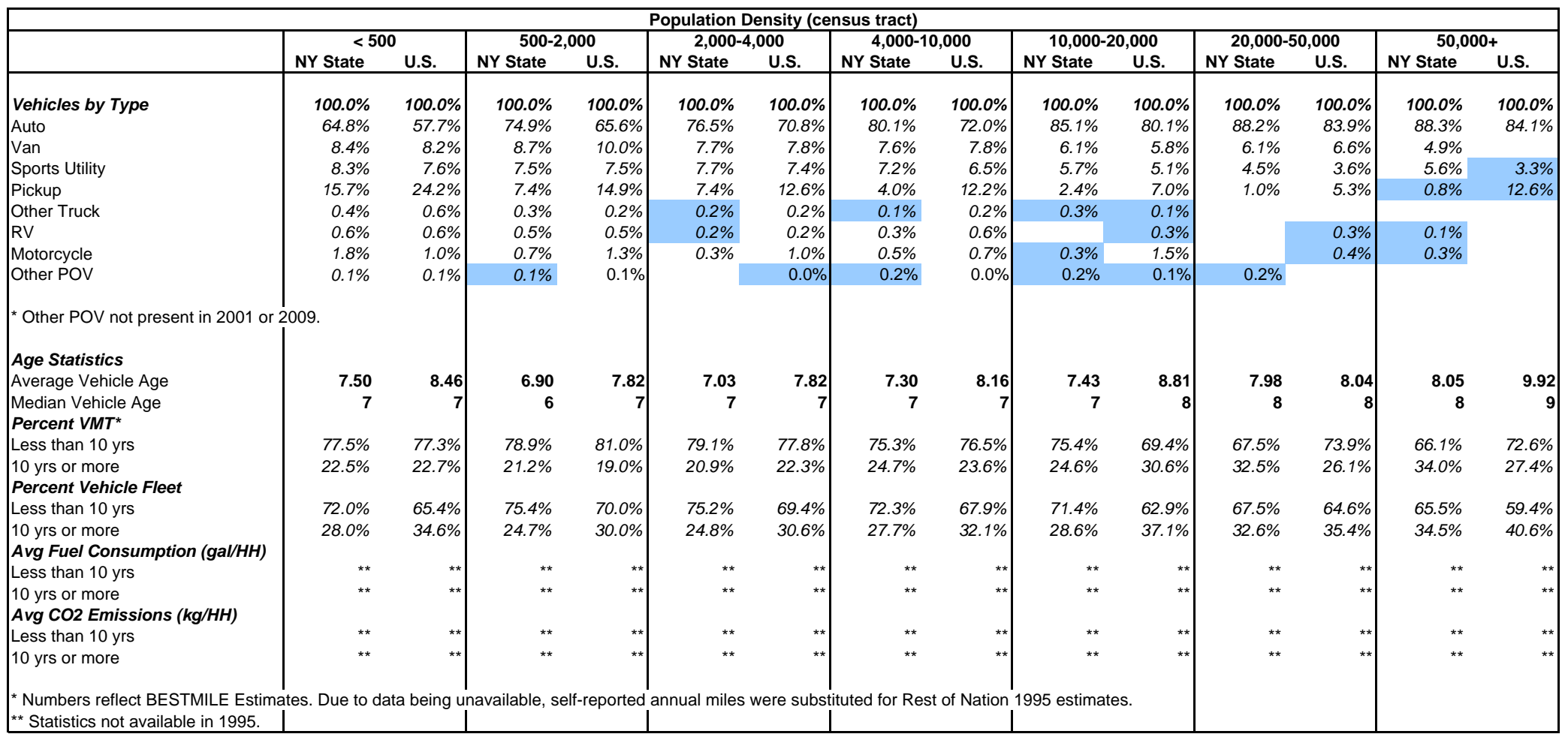


Chapter 4: Table 11

Urban Travel and Population Density 2009 NHTS

\begin{tabular}{|c|c|c|c|c|c|c|c|c|c|c|c|c|c|c|}
\hline \multicolumn{15}{|c|}{ Population Density (census tract) } \\
\hline & \multicolumn{2}{|c|}{$<500$} & \multicolumn{2}{|c|}{$500-2,000$} & \multicolumn{2}{|c|}{$2,000-4,000$} & \multicolumn{2}{|c|}{$4,000-10,000$} & \multicolumn{2}{|c|}{$10,000-20,000$} & \multicolumn{2}{|c|}{$20,000-50,000$} & \multicolumn{2}{|c|}{$50,000+$} \\
\hline & NY State & U.S. & NY State & U.S. & NY State & U.S. & NY State & U.S. & NY State & U.S. & NY State & U.S. & NY State & U.S. \\
\hline \multicolumn{15}{|c|}{ Annual CO2 Emissions per Household - POVs ONLY } \\
\hline Average $\mathrm{CO} 2 \mathrm{Emissions}(\mathrm{kg}) / \mathrm{HH}$ & 9,952 & 11,523 & 8,292 & 9,235 & 7,719 & 8,277 & 6,077 & 7,381 & 4,895 & 5,648 & 2,820 & 4,621 & 1,430 & 2,147 \\
\hline 0 Workers & 5,399 & 6,240 & 4,050 & 4,637 & 3,837 & 3,949 & 2,766 & 3,395 & 2,590 & 2,600 & 1,141 & 1,606 & 513 & 1,589 \\
\hline 1 Workers & 8,885 & 10,332 & 7,637 & 8,675 & 7,000 & 7,844 & 5,563 & 6,821 & 4,993 & 5,398 & 2,752 & 4,256 & 1,183 & 2,501 \\
\hline 2 Workers & 13,188 & 15,691 & 11,261 & 12,643 & 11,090 & 12,021 & 9,328 & 11,089 & 5,950 & 9,575 & 5,277 & 8,512 & 2,889 & 1,829 \\
\hline 3 or more Workers & 17,075 & 21,660 & 15,848 & 17,485 & 14,169 & 16,652 & 13,834 & 15,658 & 13,350 & 15,859 & 4,969 & 9,995 & 4,211 & 5,077 \\
\hline Average $\mathrm{CO} 2$ Emissions $(\mathrm{kg}) / \mathrm{HH}$ & 9,952 & 11,523 & 8,292 & 9,235 & 7,719 & 8,277 & 6,077 & 7,381 & 4,895 & 5,648 & 2,820 & 4,621 & 1,430 & 2,147 \\
\hline 1 Drivers & 5,010 & 5,697 & 3,775 & 4,929 & 3,754 & 4,740 & 3,244 & 4,175 & 2,667 & 3,265 & 1,736 & 2,247 & 856 & 2,066 \\
\hline 2 Drivers & 11,176 & 12,415 & 9,666 & 10,563 & 9,247 & 9,613 & 7,199 & 9,324 & 6,271 & 7,809 & 4,347 & 8,065 & 2,639 & 3,278 \\
\hline 3 or more Drivers & 15,567 & 18,945 & 14,807 & 16,092 & 13,053 & 15,050 & 12,679 & 14,042 & 10,515 & 12,927 & 6,391 & 9,847 & 3,932 & 3,500 \\
\hline Average $\mathrm{CO} 2$ Emissions $(\mathrm{kg}) / \mathrm{HH}$ & 9,952 & 11,523 & 8,292 & 9,235 & 7,719 & 8,277 & 6,077 & 7,381 & 4,895 & 5,648 & 2,820 & 4,621 & 1,430 & 2,147 \\
\hline 1 Vehicles & 4,492 & 4,746 & 3,907 & 4,181 & 3,684 & 4,090 & 3,521 & 3,852 & 3,460 & 3,673 & 3,485 & 3,632 & 3,802 & 2,813 \\
\hline 2 Vehicles & 10,294 & 10,945 & 9,355 & 10,132 & 8,932 & 9,664 & 8,257 & 8,943 & 7,938 & 8,903 & 7,112 & 9,917 & 6,544 & 3,465 \\
\hline 3 or more Vehicles & 16,300 & 18,070 & 15,541 & 15,870 & 14,244 & 15,554 & 13,234 & 15,783 & 12,860 & 15,386 & 11,695 & 12,905 & 9,232 & 6,612 \\
\hline \multicolumn{15}{|c|}{ Annual CO2 Emissions per Household - Non-POV MODES } \\
\hline Average $\mathrm{CO} 2$ Emissions $(\mathrm{kg}) / \mathrm{HH}$ & 219 & 182 & 225 & 140 & 215 & 188 & 309 & 234 & 762 & 453 & 649 & 958 & 894 & 559 \\
\hline 0 Workers & 66 & 76 & 104 & 91 & 76 & 141 & 115 & 173 & 139 & 314 & 401 & 388 & 447 & 468 \\
\hline 1 Workers & 173 & 139 & 210 & 114 & 183 & 171 & 326 & 188 & 873 & 605 & 564 & 578 & 823 & 820 \\
\hline 2 Workers & 256 & 282 & 312 & 167 & 239 & 247 & 499 & 309 & 1,208 & 298 & 965 & 2,099 & 1,548 & 295 \\
\hline 3 or more Workers & 922 & 439 & 424 & 480 & 799 & 293 & 460 & 619 & 1,468 & 528 & 1,549 & 4,174 & 1,616 & 1,229 \\
\hline Average $\mathrm{CO} 2$ Emissions $(\mathrm{kg}) / \mathrm{HH}$ & 219 & 182 & 225 & 140 & 215 & 188 & 309 & 234 & 762 & 453 & 649 & 958 & 894 & 559 \\
\hline 0 Drivers & 43 & 91 & 97 & 202 & 35 & 173 & 83 & 305 & 451 & 261 & 118 & 760 & 360 & 765 \\
\hline 1 Drivers & 32 & 106 & 71 & 77 & 86 & 101 & 175 & 169 & 849 & 267 & 389 & 451 & 656 & 426 \\
\hline 2 Drivers & 295 & 189 & 224 & 145 & 184 & 225 & 389 & 186 & 697 & 659 & 939 & 1,503 & 1,179 & 565 \\
\hline 3 or more Drivers & 298 & 286 & 554 & 241 & 613 & 279 & 503 & 562 & 973 & 700 & 1,554 & 1,983 & 2,605 & 1,484 \\
\hline Average $\mathrm{CO} 2$ Emissions $(\mathrm{kg}) / \mathrm{HH}$ & 219 & 182 & 225 & 140 & 215 & 188 & 309 & 234 & 762 & 453 & 649 & 958 & 894 & 559 \\
\hline 0 Vehicles & 446 & 383 & 309 & 452 & 110 & 479 & 631 & 614 & 1,060 & 685 & 690 & 951 & 1,016 & 585 \\
\hline 1 Veh & 90 & 79 & 54 & 72 & 121 & 142 & 112 & 174 & 775 & 546 & 568 & 1,102 & 655 & 507 \\
\hline 2 Vehicles & 290 & 240 & 217 & 136 & 235 & 189 & 407 & 141 & 492 & 227 & 737 & 795 & 589 & 1,120 \\
\hline 3 or more Vehicles & 189 & 172 & 490 & 162 & 362 & 174 & 340 & 349 & 814 & 239 & 651 & 690 & 461 & \\
\hline \multicolumn{15}{|c|}{ Annual CO2 Emissions per Household - ALL MODES } \\
\hline Average CO2 Emissions $(\mathrm{kg}) / \mathrm{HH}$ & 10,171 & 11,705 & 8,518 & 9,375 & 7,934 & 8,465 & 6,386 & 7,614 & 5,657 & 6,101 & 3,469 & 5,578 & 2,324 & 2,706 \\
\hline 0 Workers & 5,465 & 6,316 & 4,154 & 4,728 & 3,913 & 4,089 & 2,881 & 3,568 & 2,728 & 2,913 & 1,542 & 1,993 & 960 & 2,057 \\
\hline 1 Workers & 9,058 & 10,471 & 7,846 & 8,789 & 7,183 & 8,016 & 5,890 & 7,009 & 5,866 & 6,003 & 3,316 & 4,834 & 2,006 & 3,321 \\
\hline 2 Workers & 13,444 & 15,973 & 11,573 & 12,810 & 11,330 & 12,267 & 9,827 & 11,398 & 7,158 & 9,872 & 6,242 & 10,611 & 4,437 & 2,124 \\
\hline 3 or more Workers & 17,997 & 22,098 & 16,271 & 17,965 & 14,968 & 16,944 & 14,294 & 16,276 & 14,819 & 16,387 & 6,518 & 14,169 & 5,827 & 6,306 \\
\hline Average $\mathrm{CO} 2$ Emissions $(\mathrm{kg}) / \mathrm{HH}$ & 10,171 & 11,705 & 8,518 & 9,375 & 7,934 & 8,465 & 6,386 & 7,614 & 5,657 & 6,101 & 3,469 & 5,578 & 2,324 & 2,706 \\
\hline 0 Drivers & 43 & 91 & 97 & 202 & 35 & 173 & 83 & 305 & 451 & 261 & 118 & 760 & 360 & 765 \\
\hline 1 Drivers & 5,042 & 5,803 & 3,846 & 5,006 & 3,840 & 4,840 & 3,418 & 4,344 & 3,516 & 3,531 & 2,125 & 2,697 & 1,512 & 2,492 \\
\hline 2 Drivers & 11,471 & 12,604 & 9,891 & 10,707 & 9,431 & 9,839 & 7,588 & 9,510 & 6,969 & 8,468 & 5,286 & 9,568 & 3,818 & 3,843 \\
\hline 3 or more Drivers & 15,865 & 19,231 & 15,361 & 16,332 & 13,666 & 15,329 & 13,182 & 14,604 & 11,488 & 13,627 & 7,944 & 11,830 & 6,537 & 4,984 \\
\hline Average $\mathrm{CO} 2$ Emissions $(\mathrm{kg}) / \mathrm{HH}$ & 10,171 & 11,705 & 8,518 & 9,375 & 7,934 & 8,465 & 6,386 & 7,614 & 5,657 & 6,101 & 3,469 & 5,578 & 2,324 & 2,706 \\
\hline 0 Vehicles & 446 & 383 & 309 & 452 & 110 & 479 & 631 & 614 & 1,060 & 685 & 690 & 951 & 1,016 & 585 \\
\hline 1 Vehicles & 4,582 & 4,825 & 3,961 & 4,253 & 3,805 & 4,233 & 3,634 & 4,026 & 4,235 & 4,219 & 4,053 & 4,734 & 4,456 & 3,320 \\
\hline 2 Vehicles & 10,584 & 11,185 & 9,573 & 10,268 & 9,166 & 9,853 & 8,663 & 9,085 & 8,430 & 9,129 & 7,849 & 10,712 & 7,133 & 4,585 \\
\hline 3 or more Vehicles & 16,489 & 18,242 & 16,030 & 16,032 & 14,606 & 15,728 & 13,573 & 16,132 & 13,674 & 15,625 & 12,345 & 13,595 & 9,693 & 6,612 \\
\hline
\end{tabular}


Chapter 4: Table 11

Urban Travel and Population Density 2001 NHTS

\begin{tabular}{|c|c|c|c|c|c|c|c|c|c|c|c|c|c|c|}
\hline \multicolumn{15}{|c|}{ Population Density (census tract) } \\
\hline & \multicolumn{2}{|c|}{$<500$} & \multicolumn{2}{|c|}{$500-2,000$} & \multicolumn{2}{|c|}{$2,000-4,000$} & \multicolumn{2}{|c|}{$4,000-10,000$} & \multicolumn{2}{|c|}{$10,000-20,000$} & \multicolumn{2}{|c|}{$20,000-50,000$} & \multicolumn{2}{|c|}{$50,000+$} \\
\hline & NY State & U.S. & NY State & U.S. & NY State & U.S. & NY State & U.S. & NY State & U.S. & NY State & U.S. & NY State & U.S. \\
\hline \multicolumn{15}{|c|}{ Annual CO2 Emissions per Household - POVs ONLY } \\
\hline Average $\mathrm{CO} 2$ Emissions $(\mathrm{kg}) / \mathrm{HH}$ & 10,024 & 11,366 & 9,068 & 9,753 & 8,542 & 8,470 & 6,639 & 7,535 & 6,016 & 6,518 & 3,496 & 4,545 & 1,920 & 3,298 \\
\hline 0 Workers & 5,645 & 5,342 & 3,786 & 4,306 & 3,633 & 3,496 & 1,814 & 2,900 & 2,094 & 2,108 & 1,381 & 1,885 & 1,145 & 399 \\
\hline 1 Workers & 9,392 & 9,153 & 7,830 & 8,342 & 6,598 & 7,127 & 5,224 & 6,096 & 6,332 & 5,003 & 2,938 & 3,649 & 1,230 & 5,577 \\
\hline 2 Workers & 12,324 & 14,377 & 11,675 & 12,401 & 12,810 & 11,606 & 8,756 & 10,349 & 8,734 & 8,695 & 4,639 & 6,326 & 2,599 & 4,715 \\
\hline 3 or more Workers & 17,667 & 19,990 & 16,839 & 17,585 & 13,498 & 15,120 & 12,259 & 14,485 & 7,953 & 13,421 & 7,700 & 9,782 & 6,720 & \\
\hline Average $\mathrm{CO} 2$ Emissions $(\mathrm{kg}) / \mathrm{HH}$ & 10,024 & 11,366 & 9,068 & 9,753 & 8,542 & $\mathbf{8 , 4 7 0}$ & 6,639 & 7,535 & 6,016 & 6,518 & 3,496 & 4,545 & 1,920 & 3,298 \\
\hline 1 Drivers & 7,737 & 5,407 & 4,080 & 4,893 & 4,746 & 4,375 & 3,470 & 4,305 & 3,026 & 3,882 & 2,590 & 3,019 & 2,068 & 4,179 \\
\hline 2 Drivers & 11,111 & 12,258 & 10,745 & 10,856 & 10,586 & 10,199 & 8,090 & 9,235 & 6,619 & 8,668 & 5,705 & 7,917 & 3,834 & 5,333 \\
\hline 3 or more Drivers & 12,633 & 18,629 & 14,909 & 16,730 & 12,814 & 14,804 & 12,953 & 13,766 & 13,407 & 13,417 & 9,897 & 7,463 & 6,705 & \\
\hline Average $\mathrm{CO} 2$ Emissions $(\mathrm{kg}) / \mathrm{HH}$ & 10,024 & 11,366 & 9,068 & 9,753 & 8,542 & $\mathbf{8 , 4 7 0}$ & 6,639 & 7,535 & 6,016 & 6,518 & 3,496 & 4,545 & 1,920 & 3,298 \\
\hline 1 Vehicles & 6,432 & 4,352 & 3,972 & 4,361 & 4,888 & 4,172 & 3,434 & 4,014 & 3,289 & 4,095 & 4,437 & 3,537 & 4,294 & 5,733 \\
\hline 2 Vehicles & 11,738 & 11,291 & 10,721 & 10,590 & 10,000 & 9,722 & 8,520 & 9,114 & 9,507 & 8,955 & 7,669 & 9,486 & 6,400 & 7,201 \\
\hline 3 or more Vehicles & 12,750 & 17,253 & 14,837 & 15,894 & 13,594 & 14,886 & 14,392 & 14,805 & 14,197 & 16,294 & 20,220 & 11,482 & 15,985 & \\
\hline \multicolumn{15}{|c|}{ Annual CO2 Emissions per Household - Non-POV MODES } \\
\hline Average $\mathrm{CO} 2$ Emissions $(\mathrm{kg}) / \mathrm{HH}$ & 244 & 89 & 365 & 132 & 260 & 80 & 368 & 164 & 528 & 339 & 630 & 520 & 784 & 602 \\
\hline 0 Workers & 27 & 15 & 178 & 49 & 34 & 38 & 219 & 81 & 239 & 123 & 299 & 509 & 441 & 4 \\
\hline 1 Workers & 322 & 83 & 329 & 107 & 253 & 79 & 244 & 161 & 442 & 228 & 734 & 539 & 601 & 172 \\
\hline 2 Workers & 261 & 117 & 228 & 163 & 397 & 94 & 529 & 171 & 598 & 533 & 533 & 469 & 1,128 & 187 \\
\hline 3 or more Workers & 473 & 158 & 1,355 & 288 & 398 & 148 & 582 & 369 & 1,059 & 574 & 1,304 & 611 & 1,700 & 4,440 \\
\hline Average $\mathrm{CO} 2$ Emissions $(\mathrm{kg}) / \mathrm{HH}$ & 244 & 89 & 365 & 132 & 260 & 80 & 368 & 164 & 528 & 339 & 630 & 520 & 784 & 602 \\
\hline 0 Drivers & 57 & 24 & 137 & 138 & 709 & 110 & 560 & 238 & 357 & 387 & 322 & 761 & 678 & 102 \\
\hline 1 Drivers & 210 & 41 & 151 & 73 & 74 & 53 & 288 & 132 & 537 & 258 & 711 & 274 & 643 & 158 \\
\hline 2 Drivers & 227 & 99 & 311 & 125 & 302 & 80 & 345 & 151 & 469 & 397 & 612 & 694 & 1,124 & 54 \\
\hline 3 or more Drivers & 414 & 139 & 1,046 & 266 & 397 & 145 & 564 & 271 & 757 & 377 & 1,257 & 540 & 1,165 & 9,760 \\
\hline Average $\mathrm{CO} 2$ Emissions $(\mathrm{kg}) / \mathrm{HH}$ & 244 & 89 & 365 & 132 & 260 & 80 & 368 & 164 & 528 & 339 & 630 & 520 & 784 & 602 \\
\hline 0 Vehicles & 554 & 73 & 304 & 204 & 551 & 144 & 580 & 358 & 733 & 558 & 691 & 774 & 900 & 1,191 \\
\hline 1 Vehicles & 176 & 79 & 238 & 72 & 168 & 64 & 353 & 167 & 609 & 320 & 589 & 293 & 564 & 37 \\
\hline 2 Vehicles & 225 & 89 & 328 & 100 & 264 & 81 & 331 & 108 & 272 & 314 & 580 & 724 & 659 & 12 \\
\hline 3 or more Vehicles & 291 & 99 & 616 & 244 & 300 & 89 & 352 & 178 & 472 & 192 & 477 & 227 & 1,544 & \\
\hline \multicolumn{15}{|c|}{ Annual CO2 Emissions per Household - ALL MODES } \\
\hline Average $\mathrm{CO} 2$ Emissions $(\mathrm{kg}) / \mathrm{HH}$ & 10,269 & 11,456 & 9,433 & 9,884 & 8,802 & 8,551 & 7,007 & 7,699 & 6,544 & 6,857 & 4,126 & 5,065 & 2,705 & 3,899 \\
\hline 0 Workers & 5,673 & 5,358 & 3,964 & 4,355 & 3,667 & 3,535 & 2,033 & 2,980 & 2,333 & 2,230 & 1,680 & 2,394 & 1,586 & 403 \\
\hline 1 Workers & 9,714 & 9,236 & 8,158 & 8,450 & 6,851 & 7,205 & 5,468 & 6,257 & 6,774 & 5,231 & 3,672 & 4,188 & 1,831 & 5,749 \\
\hline 2 Workers & 12,585 & 14,495 & 11,903 & 12,564 & 13,207 & 11,700 & 9,285 & 10,520 & 9,332 & 9,229 & 5,172 & 6,796 & 3,726 & 4,902 \\
\hline 3 or more Workers & 18,140 & 20,148 & 18,193 & 17,873 & 13,896 & 15,269 & 12,841 & 14,854 & 9,012 & 13,995 & 9,004 & 10,393 & 8,420 & 4,440 \\
\hline Average $\mathrm{CO} 2$ Emissions $(\mathrm{kg}) / \mathrm{HH}$ & 10,269 & 11,456 & 9,433 & $\mathbf{9 , 8 8 4}$ & 8,802 & 8,551 & 7,007 & 7,699 & 6,544 & 6,857 & 4,126 & 5,065 & 2,705 & 3,899 \\
\hline 0 Drivers & 57 & 24 & 137 & 138 & 709 & 110 & 560 & 238 & 357 & 387 & 322 & 761 & 678 & 102 \\
\hline 1 Drivers & 7,946 & 5,448 & 4,231 & 4,966 & 4,820 & 4,428 & 3,757 & 4,437 & 3,563 & 4,140 & 3,301 & 3,293 & 2,712 & 4,336 \\
\hline 2 Drivers & 11,338 & 12,357 & 11,056 & 10,982 & 10,889 & 10,279 & 8,434 & 9,386 & 7,089 & 9,065 & 6,317 & 8,611 & 4,959 & 5,387 \\
\hline 3 or more Drivers & 13,046 & 18,769 & 15,955 & 16,996 & 13,211 & 14,949 & 13,517 & 14,037 & 14,164 & 13,795 & 11,153 & 8,003 & 7,870 & 9,760 \\
\hline Average $\mathrm{CO} 2$ Emissions $(\mathrm{kg}) / \mathrm{HH}$ & 10,269 & 11,456 & 9,433 & $\mathbf{9 , 8 8 4}$ & 8,802 & 8,551 & 7,007 & 7,699 & 6,544 & 6,857 & 4,126 & 5,065 & 2,705 & 3,899 \\
\hline 0 Vehicles & 554 & 73 & 304 & 204 & 551 & 144 & 580 & 358 & 733 & 558 & 691 & 774 & 900 & 1,191 \\
\hline 1 Vehicles & 6,608 & 4,431 & 4,210 & 4,433 & 5,056 & 4,236 & 3,787 & 4,181 & 3,898 & 4,415 & 5,026 & 3,830 & 4,858 & 5,770 \\
\hline 2 Vehicles & 11,964 & 11,380 & 11,049 & 10,689 & 10,265 & 9,803 & 8,850 & 9,222 & 9,779 & 9,269 & 8,249 & 10,210 & 7,060 & 7,213 \\
\hline 3 or more Vehicles & 13,041 & 17,351 & 15,453 & 16,139 & 13,894 & 14,975 & 14,744 & 14,983 & 14,669 & 16,486 & 20,697 & 11,710 & 17,529 & \\
\hline
\end{tabular}




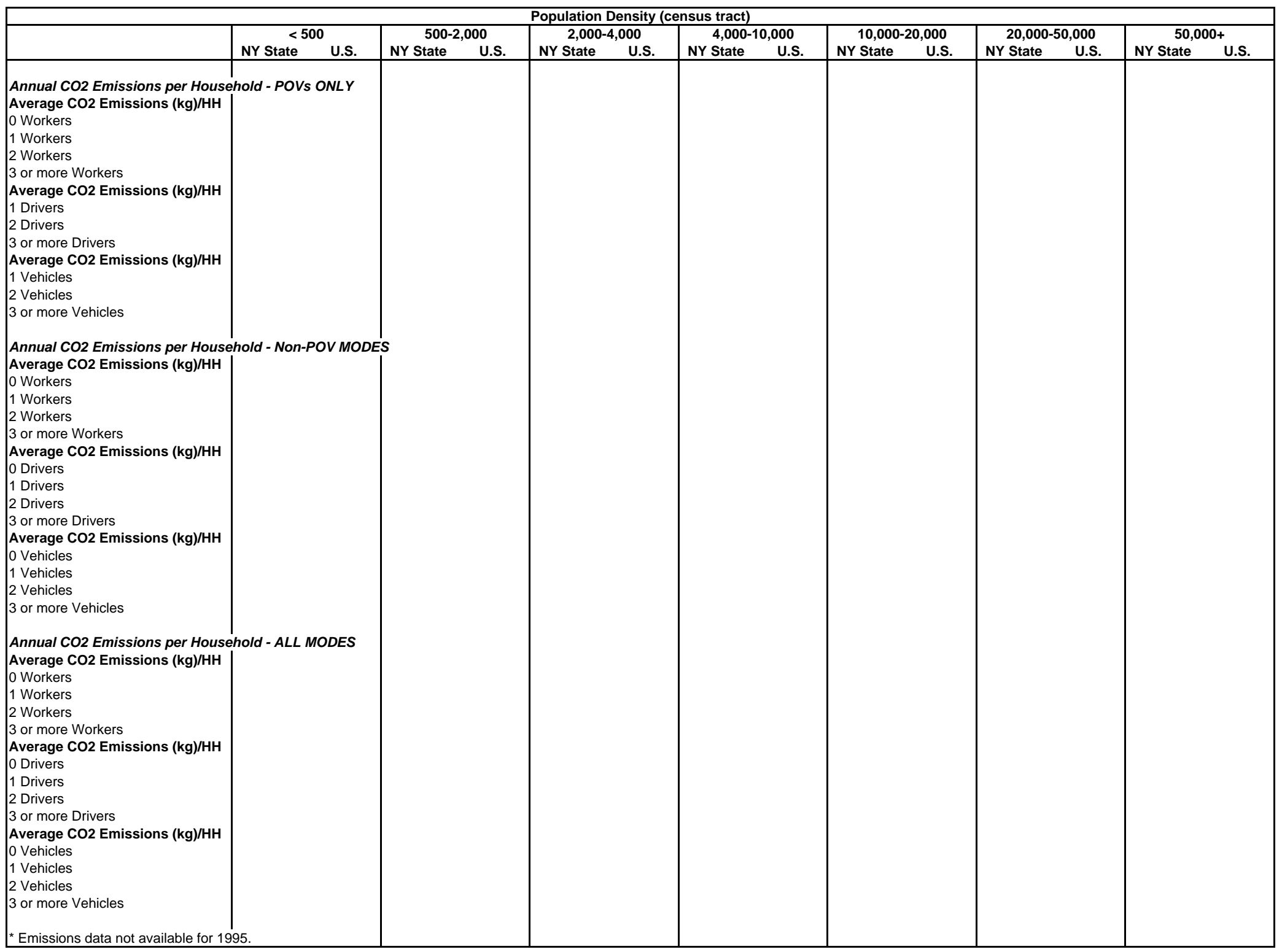




\begin{tabular}{|c|c|c|c|c|c|c|c|c|c|c|c|c|c|c|}
\hline \multicolumn{15}{|c|}{ Population Density (census tract) } \\
\hline & \multicolumn{2}{|c|}{$<500$} & \multicolumn{2}{|c|}{$500-2,000$} & \multicolumn{2}{|c|}{$2,000-4,000$} & \multicolumn{2}{|c|}{$4,000-10,000$} & \multicolumn{2}{|c|}{$10,000-20,000$} & \multicolumn{2}{|c|}{$20,000-50,000$} & \multicolumn{2}{|c|}{$50,000+$} \\
\hline & NY State & U.S. & NY State & U.S. & NY State & U.S. & NY State & U.S. & NY State & U.S. & NY State & U.S. & NY State & U.S. \\
\hline \multicolumn{15}{|c|}{ Percent Vehicles by Vehicle Type and Age } \\
\hline Auto & $48.1 \%$ & $42.2 \%$ & $58.1 \%$ & $52.0 \%$ & $61.3 \%$ & $55.2 \%$ & $62.3 \%$ & $56.9 \%$ & $62.4 \%$ & $62.3 \%$ & $70.9 \%$ & $62.2 \%$ & $62.1 \%$ & $75.6 \%$ \\
\hline 0 to $2 \mathrm{yrs}$ & $7.1 \%$ & $5.1 \%$ & $9.9 \%$ & $7.2 \%$ & $10.4 \%$ & $6.6 \%$ & $9.5 \%$ & $6.3 \%$ & $10.1 \%$ & $7.4 \%$ & $13.3 \%$ & $7.0 \%$ & $7.3 \%$ & $7.1 \%$ \\
\hline 3 to $5 \mathrm{yrs}$ & $10.1 \%$ & $7.9 \%$ & $12.9 \%$ & $11.1 \%$ & $12.9 \%$ & $11.4 \%$ & $13.6 \%$ & $10.3 \%$ & $13.0 \%$ & $9.1 \%$ & $11.9 \%$ & $8.2 \%$ & $9.9 \%$ & $9.2 \%$ \\
\hline 6 to $9 \mathrm{yrs}$ & $14.2 \%$ & $11.2 \%$ & $17.3 \%$ & $13.6 \%$ & $16.7 \%$ & $14.3 \%$ & $18.1 \%$ & $15.2 \%$ & $17.2 \%$ & $15.4 \%$ & $14.9 \%$ & $16.1 \%$ & $18.3 \%$ & $32.6 \%$ \\
\hline $10 \mathrm{yrs}$ or more & $15.2 \%$ & $16.4 \%$ & $16.7 \%$ & $18.5 \%$ & $18.8 \%$ & $21.3 \%$ & $19.1 \%$ & $23.2 \%$ & $19.4 \%$ & $26.3 \%$ & $27.2 \%$ & $27.2 \%$ & $22.2 \%$ & $26.6 \%$ \\
\hline Unreported & $1.4 \%$ & $1.6 \%$ & $1.3 \%$ & $1.6 \%$ & $2.5 \%$ & $1.5 \%$ & $2.1 \%$ & $1.9 \%$ & $2.7 \%$ & $4.1 \%$ & $3.6 \%$ & $3.8 \%$ & $4.4 \%$ & \\
\hline Van & $10.6 \%$ & $7.9 \%$ & $7.8 \%$ & $8.8 \%$ & $8.6 \%$ & $9.4 \%$ & $8.9 \%$ & $8.0 \%$ & $12.4 \%$ & $8.3 \%$ & $5.3 \%$ & $10.1 \%$ & $12.6 \%$ & $1.4 \%$ \\
\hline 0 to $2 \mathrm{yrs}$ & $0.9 \%$ & $0.7 \%$ & $1.0 \%$ & $0.8 \%$ & $1.0 \%$ & $0.7 \%$ & $1.8 \%$ & $0.6 \%$ & $1.1 \%$ & $0.4 \%$ & $0.6 \%$ & $0.7 \%$ & $1.9 \%$ & \\
\hline 3 to $5 \mathrm{yrs}$ & $2.6 \%$ & $1.8 \%$ & $1.9 \%$ & $2.2 \%$ & $2.1 \%$ & $2.4 \%$ & $1.8 \%$ & $1.4 \%$ & $1.6 \%$ & $1.0 \%$ & $1.4 \%$ & $3.7 \%$ & $1.2 \%$ & \\
\hline 6 to $9 \mathrm{yrs}$ & $3.7 \%$ & $2.3 \%$ & $2.7 \%$ & $2.8 \%$ & $2.7 \%$ & $2.8 \%$ & $2.3 \%$ & $2.4 \%$ & $2.5 \%$ & $2.6 \%$ & $0.9 \%$ & $2.3 \%$ & $0.4 \%$ & \\
\hline $10 \mathrm{yrs}$ or more & $3.1 \%$ & $2.8 \%$ & $2.0 \%$ & $2.7 \%$ & $2.4 \%$ & $3.1 \%$ & $2.7 \%$ & $3.3 \%$ & $6.9 \%$ & $3.7 \%$ & $1.6 \%$ & $2.3 \%$ & $7.6 \%$ & $1.4 \%$ \\
\hline Unreported & $0.2 \%$ & $0.4 \%$ & $0.3 \%$ & $0.3 \%$ & $0.5 \%$ & $0.4 \%$ & $0.4 \%$ & $0.3 \%$ & $0.3 \%$ & $0.6 \%$ & $0.9 \%$ & $1.1 \%$ & $1.5 \%$ & \\
\hline suv & $20.8 \%$ & $19.9 \%$ & $22.7 \%$ & $21.1 \%$ & $21.6 \%$ & $20.0 \%$ & $22.6 \%$ & $19.2 \%$ & $21.1 \%$ & $15.8 \%$ & $22.2 \%$ & $19.9 \%$ & $23.0 \%$ & $9.9 \%$ \\
\hline 0 to $2 \mathrm{yrs}$ & $4.3 \%$ & $3.2 \%$ & $6.5 \%$ & $4.4 \%$ & $6.1 \%$ & $3.8 \%$ & $6.6 \%$ & $3.2 \%$ & $4.6 \%$ & $2.8 \%$ & $4.0 \%$ & $2.4 \%$ & $4.5 \%$ & $2.6 \%$ \\
\hline 3 to $5 \mathrm{yrs}$ & $6.8 \%$ & $5.7 \%$ & $7.3 \%$ & $6.9 \%$ & $6.2 \%$ & $5.9 \%$ & $6.5 \%$ & $5.2 \%$ & $7.4 \%$ & $4.0 \%$ & $6.3 \%$ & $6.2 \%$ & $6.1 \%$ & \\
\hline 6 to $9 \mathrm{yrs}$ & $5.0 \%$ & $5.6 \%$ & $5.3 \%$ & $5.6 \%$ & $6.3 \%$ & $5.6 \%$ & $5.0 \%$ & $5.3 \%$ & $5.1 \%$ & $3.6 \%$ & $5.1 \%$ & $3.9 \%$ & $6.7 \%$ & $1.9 \%$ \\
\hline $10 \mathrm{yrs}$ or more & $4.1 \%$ & $5.1 \%$ & $3.2 \%$ & $3.8 \%$ & $2.7 \%$ & $4.3 \%$ & $4.0 \%$ & $4.9 \%$ & $2.9 \%$ & $4.1 \%$ & $6.0 \%$ & $6.7 \%$ & $4.3 \%$ & $5.4 \%$ \\
\hline Unreported & $0.6 \%$ & $0.4 \%$ & $0.4 \%$ & $0.4 \%$ & $0.3 \%$ & $0.4 \%$ & $0.5 \%$ & $0.7 \%$ & $1.1 \%$ & $1.4 \%$ & $0.9 \%$ & $0.8 \%$ & $1.3 \%$ & \\
\hline Pickup Truck & $16.1 \%$ & $24.8 \%$ & $8.8 \%$ & $14.3 \%$ & $6.0 \%$ & $12.2 \%$ & $4.2 \%$ & $12.5 \%$ & $2.5 \%$ & $11.1 \%$ & $0.9 \%$ & $5.3 \%$ & $0.3 \%$ & $11.6 \%$ \\
\hline 0 to $2 \mathrm{yrs}$ & $1.7 \%$ & $2.1 \%$ & $1.0 \%$ & $1.4 \%$ & $1.0 \%$ & $1.3 \%$ & $0.4 \%$ & $1.0 \%$ & $0.5 \%$ & $0.6 \%$ & & $0.5 \%$ & & \\
\hline 3 to $5 \mathrm{yrs}$ & $3.3 \%$ & $4.2 \%$ & $2.5 \%$ & $2.8 \%$ & $1.8 \%$ & $2.4 \%$ & $0.8 \%$ & $2.3 \%$ & $0.3 \%$ & $1.7 \%$ & & $1.4 \%$ & $0.2 \%$ & \\
\hline 6 to $9 \mathrm{yrs}$ & $4.6 \%$ & $5.6 \%$ & $2.6 \%$ & $3.7 \%$ & $1.3 \%$ & $3.2 \%$ & $1.3 \%$ & $3.0 \%$ & $1.0 \%$ & $2.2 \%$ & $0.0 \%$ & $0.9 \%$ & & $11.6 \%$ \\
\hline $10 \mathrm{yrs}$ or more & $5.7 \%$ & $11.7 \%$ & $2.5 \%$ & $5.8 \%$ & $1.8 \%$ & $4.8 \%$ & $1.6 \%$ & $5.7 \%$ & $0.5 \%$ & $5.3 \%$ & $0.8 \%$ & $1.9 \%$ & $0.2 \%$ & \\
\hline Unreported & $0.9 \%$ & $1.1 \%$ & $0.2 \%$ & $0.5 \%$ & $0.2 \%$ & $0.5 \%$ & $0.1 \%$ & $0.5 \%$ & $0.2 \%$ & $1.4 \%$ & & $0.6 \%$ & & \\
\hline Other POV & $4.4 \%$ & $5.2 \%$ & $2.6 \%$ & $3.8 \%$ & $2.5 \%$ & $3.2 \%$ & $2.1 \%$ & $3.4 \%$ & $1.6 \%$ & $2.6 \%$ & $0.8 \%$ & $2.4 \%$ & $2.0 \%$ & $1.5 \%$ \\
\hline 0 to $2 \mathrm{yrs}$ & $0.5 \%$ & $0.8 \%$ & $0.4 \%$ & $0.6 \%$ & $0.2 \%$ & $0.5 \%$ & $0.2 \%$ & $0.5 \%$ & & $0.5 \%$ & $0.2 \%$ & $0.0 \%$ & $0.4 \%$ & $1.5 \%$ \\
\hline 3 to $5 \mathrm{yrs}$ & $0.6 \%$ & $1.1 \%$ & $0.5 \%$ & $0.8 \%$ & $0.8 \%$ & $0.6 \%$ & $0.4 \%$ & $0.7 \%$ & $0.2 \%$ & $0.5 \%$ & & $0.1 \%$ & $0.1 \%$ & \\
\hline 6 to $9 \mathrm{yrs}$ & $1.0 \%$ & $1.1 \%$ & $0.6 \%$ & $0.7 \%$ & $0.8 \%$ & $0.5 \%$ & $0.8 \%$ & $0.5 \%$ & $0.3 \%$ & $0.4 \%$ & $0.2 \%$ & $1.9 \%$ & $0.6 \%$ & \\
\hline $10 \mathrm{yrs}$ or more & $2.0 \%$ & $2.0 \%$ & $0.8 \%$ & $1.3 \%$ & $0.6 \%$ & $1.2 \%$ & $0.5 \%$ & $1.4 \%$ & $0.9 \%$ & $1.1 \%$ & $0.4 \%$ & $0.4 \%$ & $0.9 \%$ & \\
\hline Unreported & $0.4 \%$ & $0.3 \%$ & $0.2 \%$ & $0.4 \%$ & $0.1 \%$ & $0.5 \%$ & $0.2 \%$ & $0.3 \%$ & $0.2 \%$ & $0.1 \%$ & & $0.1 \%$ & & \\
\hline
\end{tabular}




\begin{tabular}{|c|c|c|c|c|c|c|c|c|c|c|c|c|c|c|}
\hline \multicolumn{15}{|c|}{ Population Density (census tract) } \\
\hline & \multicolumn{2}{|c|}{$<500$} & \multicolumn{2}{|c|}{$500-2,000$} & \multicolumn{2}{|c|}{$2,000-4,000$} & \multicolumn{2}{|c|}{$4,000-10,000$} & \multicolumn{2}{|c|}{$10,000-20,000$} & \multicolumn{2}{|c|}{$20,000-50,000$} & \multicolumn{2}{|c|}{$50,000+$} \\
\hline & NY State & U.S. & NY State & U.S. & NY State & U.S. & NY State & U.S. & NY State & U.S. & NY State & U.S. & NY State & U.S. \\
\hline \multicolumn{15}{|c|}{ Percent Vehicles by Vehicle Type and Age } \\
\hline Auto & $55.0 \%$ & $48.2 \%$ & $65.9 \%$ & $58.4 \%$ & $64.3 \%$ & $61.8 \%$ & $70.4 \%$ & $64.7 \%$ & $75.6 \%$ & $67.5 \%$ & $75.2 \%$ & $71.2 \%$ & $77.4 \%$ & $85.4 \%$ \\
\hline 0 to $2 \mathrm{yrs}$ & $9.4 \%$ & $6.6 \%$ & $12.4 \%$ & $9.4 \%$ & $13.3 \%$ & $9.2 \%$ & $13.1 \%$ & $9.4 \%$ & $12.1 \%$ & $7.9 \%$ & $10.2 \%$ & $9.9 \%$ & $10.9 \%$ & $16.3 \%$ \\
\hline 3 to $5 \mathrm{yrs}$ & $12.1 \%$ & $9.2 \%$ & $15.2 \%$ & $13.5 \%$ & $14.4 \%$ & $13.7 \%$ & $14.9 \%$ & $13.0 \%$ & $16.9 \%$ & $12.1 \%$ & $12.9 \%$ & $10.0 \%$ & $13.0 \%$ & $11.9 \%$ \\
\hline 6 to $9 \mathrm{yrs}$ & $14.2 \%$ & $12.1 \%$ & $17.5 \%$ & $14.5 \%$ & $14.2 \%$ & $16.9 \%$ & $18.3 \%$ & $15.4 \%$ & $19.3 \%$ & $14.3 \%$ & $15.8 \%$ & $17.7 \%$ & $17.1 \%$ & $22.6 \%$ \\
\hline $10 \mathrm{yrs}$ or more & $18.0 \%$ & $18.7 \%$ & $19.3 \%$ & $19.5 \%$ & $20.8 \%$ & $20.5 \%$ & $22.0 \%$ & $25.0 \%$ & $24.7 \%$ & $29.7 \%$ & $31.2 \%$ & $29.1 \%$ & $33.0 \%$ & $34.2 \%$ \\
\hline Unreported & $1.2 \%$ & $1.5 \%$ & $1.6 \%$ & $1.5 \%$ & $1.6 \%$ & $1.6 \%$ & $2.1 \%$ & $1.9 \%$ & $2.6 \%$ & $3.4 \%$ & $5.1 \%$ & $4.6 \%$ & $3.5 \%$ & $0.4 \%$ \\
\hline Van & $9.6 \%$ & $9.3 \%$ & $10.8 \%$ & $9.7 \%$ & $11.5 \%$ & $9.2 \%$ & $9.8 \%$ & $8.8 \%$ & $9.5 \%$ & $7.2 \%$ & $8.1 \%$ & $12.2 \%$ & $9.8 \%$ & $3.2 \%$ \\
\hline 0 to $2 \mathrm{yrs}$ & $1.8 \%$ & $1.9 \%$ & $1.9 \%$ & $1.8 \%$ & $2.7 \%$ & $1.6 \%$ & $2.0 \%$ & $1.3 \%$ & $1.6 \%$ & $1.0 \%$ & $1.7 \%$ & $1.5 \%$ & $1.0 \%$ & $0.2 \%$ \\
\hline 3 to $5 \mathrm{yrs}$ & $2.8 \%$ & $2.1 \%$ & $2.6 \%$ & $2.5 \%$ & $3.8 \%$ & $2.6 \%$ & $2.6 \%$ & $1.9 \%$ & $2.2 \%$ & $1.1 \%$ & $0.6 \%$ & $1.4 \%$ & $2.2 \%$ & $2.4 \%$ \\
\hline 6 to $9 \mathrm{yrs}$ & $2.5 \%$ & $2.6 \%$ & $3.5 \%$ & $2.7 \%$ & $2.8 \%$ & $2.5 \%$ & $2.8 \%$ & $2.4 \%$ & $3.0 \%$ & $1.8 \%$ & $1.7 \%$ & $2.7 \%$ & $1.7 \%$ & $0.1 \%$ \\
\hline 10 yrs or more & $2.3 \%$ & $2.4 \%$ & $2.7 \%$ & $2.3 \%$ & $2.1 \%$ & $2.2 \%$ & $2.0 \%$ & $2.7 \%$ & $2.6 \%$ & $2.6 \%$ & $3.4 \%$ & $4.4 \%$ & $4.2 \%$ & $0.1 \%$ \\
\hline Unreported & $0.2 \%$ & $0.4 \%$ & $0.2 \%$ & $0.3 \%$ & $0.1 \%$ & $0.3 \%$ & $0.4 \%$ & $0.5 \%$ & $0.1 \%$ & $0.8 \%$ & $0.7 \%$ & $2.2 \%$ & $0.8 \%$ & $0.4 \%$ \\
\hline suv & $13.5 \%$ & $12.3 \%$ & $12.1 \%$ & $13.4 \%$ & $14.0 \%$ & $12.9 \%$ & $12.2 \%$ & $11.1 \%$ & $11.5 \%$ & $12.9 \%$ & $12.3 \%$ & $10.7 \%$ & $11.4 \%$ & $4.2 \%$ \\
\hline 0 to $2 \mathrm{yrs}$ & $4.0 \%$ & $2.8 \%$ & $4.3 \%$ & $3.9 \%$ & $5.6 \%$ & $3.7 \%$ & $3.3 \%$ & $3.0 \%$ & $4.6 \%$ & $4.2 \%$ & $4.0 \%$ & $2.3 \%$ & $3.1 \%$ & $0.1 \%$ \\
\hline 3 to $5 \mathrm{yrs}$ & $3.7 \%$ & $3.8 \%$ & $3.4 \%$ & $4.1 \%$ & $4.8 \%$ & $4.1 \%$ & $4.8 \%$ & $3.1 \%$ & $2.9 \%$ & $3.6 \%$ & $1.8 \%$ & $2.8 \%$ & $2.9 \%$ & $4.1 \%$ \\
\hline 6 to $9 \mathrm{yrs}$ & $2.9 \%$ & $2.6 \%$ & $2.6 \%$ & $2.9 \%$ & $1.8 \%$ & $2.5 \%$ & $2.5 \%$ & $2.3 \%$ & $2.7 \%$ & $2.3 \%$ & $2.3 \%$ & $1.8 \%$ & $2.2 \%$ & \\
\hline $10 \mathrm{yrs}$ or more & $2.8 \%$ & $2.8 \%$ & $1.6 \%$ & $2.2 \%$ & $1.3 \%$ & $2.3 \%$ & $1.4 \%$ & $2.3 \%$ & $1.3 \%$ & $2.7 \%$ & $2.8 \%$ & $3.0 \%$ & $3.0 \%$ & \\
\hline Unreported & $0.2 \%$ & $0.3 \%$ & $0.3 \%$ & $0.3 \%$ & $0.5 \%$ & $0.3 \%$ & $0.3 \%$ & $0.4 \%$ & $0.1 \%$ & $0.1 \%$ & $1.4 \%$ & $0.9 \%$ & $0.2 \%$ & \\
\hline Pickup Truck & $17.8 \%$ & $25.5 \%$ & $8.5 \%$ & $15.4 \%$ & $8.0 \%$ & $13.3 \%$ & $5.6 \%$ & $13.3 \%$ & $1.9 \%$ & $10.1 \%$ & $1.4 \%$ & $4.5 \%$ & $0.6 \%$ & $7.0 \%$ \\
\hline 0 to $2 \mathrm{yrs}$ & $3.1 \%$ & $4.1 \%$ & $1.5 \%$ & $2.5 \%$ & $1.2 \%$ & $2.4 \%$ & $0.6 \%$ & $2.4 \%$ & $0.2 \%$ & $1.5 \%$ & $0.4 \%$ & $0.4 \%$ & $0.2 \%$ & $0.1 \%$ \\
\hline 3 to $5 \mathrm{yrs}$ & $4.5 \%$ & $4.8 \%$ & $1.9 \%$ & $3.4 \%$ & $2.0 \%$ & $2.7 \%$ & $1.3 \%$ & $2.6 \%$ & $0.6 \%$ & $1.9 \%$ & & $0.7 \%$ & $0.1 \%$ & $6.5 \%$ \\
\hline 6 to $9 \mathrm{yrs}$ & $3.2 \%$ & $5.3 \%$ & $1.9 \%$ & $3.2 \%$ & $2.5 \%$ & $2.5 \%$ & $1.2 \%$ & $2.6 \%$ & $0.4 \%$ & $2.2 \%$ & $0.2 \%$ & $0.3 \%$ & $0.1 \%$ & $0.1 \%$ \\
\hline $10 \mathrm{yrs}$ or more & $6.2 \%$ & $10.4 \%$ & $3.2 \%$ & $5.8 \%$ & $2.0 \%$ & $5.1 \%$ & $2.4 \%$ & $5.1 \%$ & $0.6 \%$ & $4.0 \%$ & $0.8 \%$ & $2.0 \%$ & $0.1 \%$ & $0.2 \%$ \\
\hline Unreported & $0.7 \%$ & $1.0 \%$ & $0.1 \%$ & $0.5 \%$ & $0.3 \%$ & $0.6 \%$ & $0.1 \%$ & $0.5 \%$ & $0.2 \%$ & $0.4 \%$ & & $1.1 \%$ & & \\
\hline Other POV & $4.2 \%$ & $4.7 \%$ & $2.6 \%$ & $3.2 \%$ & $2.2 \%$ & $2.8 \%$ & $2.0 \%$ & $2.2 \%$ & $1.5 \%$ & $2.4 \%$ & $3.1 \%$ & $1.4 \%$ & $0.9 \%$ & $0.3 \%$ \\
\hline 0 to $2 \mathrm{yrs}$ & $0.4 \%$ & $0.6 \%$ & $0.6 \%$ & $0.4 \%$ & $0.1 \%$ & $0.5 \%$ & $0.3 \%$ & $0.3 \%$ & $0.1 \%$ & $0.4 \%$ & $0.3 \%$ & $0.0 \%$ & $0.1 \%$ & \\
\hline 3 to $5 \mathrm{yrs}$ & $0.5 \%$ & $0.8 \%$ & $0.3 \%$ & $0.4 \%$ & $0.5 \%$ & $0.6 \%$ & $0.2 \%$ & $0.4 \%$ & $0.4 \%$ & $0.2 \%$ & $0.2 \%$ & $0.1 \%$ & & \\
\hline 6 to $9 \mathrm{yrs}$ & $0.5 \%$ & $0.7 \%$ & $0.3 \%$ & $0.8 \%$ & $0.4 \%$ & $0.3 \%$ & $0.4 \%$ & $0.2 \%$ & $0.4 \%$ & $0.5 \%$ & $0.2 \%$ & $0.3 \%$ & & \\
\hline 10 yrs or more & $2.2 \%$ & $2.1 \%$ & $1.3 \%$ & $1.2 \%$ & $1.1 \%$ & $1.2 \%$ & $1.0 \%$ & $1.1 \%$ & $0.5 \%$ & $1.1 \%$ & $1.4 \%$ & $1.0 \%$ & $0.8 \%$ & $0.3 \%$ \\
\hline Unreported & $0.6 \%$ & $0.5 \%$ & $0.2 \%$ & $0.3 \%$ & $0.0 \%$ & $0.2 \%$ & $0.1 \%$ & $0.2 \%$ & $0.1 \%$ & $0.2 \%$ & $1.0 \%$ & $0.0 \%$ & & \\
\hline
\end{tabular}




\begin{tabular}{|c|c|c|c|c|c|c|c|c|c|c|c|c|c|c|}
\hline \multicolumn{15}{|c|}{ Population Density (census tract) } \\
\hline & \multicolumn{2}{|c|}{$<500$} & \multirow{2}{*}{\multicolumn{2}{|c|}{$500-2,000$}} & \multicolumn{2}{|c|}{$2,000-4,000$} & \multicolumn{2}{|c|}{$4,000-10,000$} & \multicolumn{2}{|c|}{$10,000-20,000$} & \multicolumn{2}{|c|}{$20,000-50,000$} & \multicolumn{2}{|c|}{$50,000+$} \\
\hline & NY State & U.S. & & U.S. & NY State & U.S. & NY State & U.S. & NY State & U.S. & NY State & U.S. & NY State & U.S. \\
\hline \multicolumn{15}{|c|}{ Percent Vehicles by Vehicle Type and Age } \\
\hline Auto & $64.8 \%$ & $57.7 \%$ & $74.9 \%$ & $65.6 \%$ & $76.5 \%$ & $70.8 \%$ & $80.1 \%$ & $72.0 \%$ & $85.1 \%$ & $80.1 \%$ & $88.2 \%$ & $83.9 \%$ & $88.3 \%$ & $84.1 \%$ \\
\hline 0 to $2 \mathrm{yrs}$ & $8.8 \%$ & $8.3 \%$ & $13.6 \%$ & $11.2 \%$ & $12.2 \%$ & $11.2 \%$ & $13.1 \%$ & $10.7 \%$ & $10.4 \%$ & $10.2 \%$ & $10.1 \%$ & $10.7 \%$ & $10.0 \%$ & $3.6 \%$ \\
\hline 3 to $5 \mathrm{yrs}$ & $16.1 \%$ & $12.0 \%$ & $17.4 \%$ & $14.6 \%$ & $17.7 \%$ & $16.2 \%$ & $17.3 \%$ & $14.8 \%$ & $15.2 \%$ & $15.2 \%$ & $9.2 \%$ & $16.8 \%$ & $11.0 \%$ & $10.2 \%$ \\
\hline 6 to $9 \mathrm{yrs}$ & $21.0 \%$ & $16.9 \%$ & $24.0 \%$ & $19.1 \%$ & $25.8 \%$ & $20.3 \%$ & $24.5 \%$ & $22.0 \%$ & $33.1 \%$ & $22.4 \%$ & $36.1 \%$ & $24.9 \%$ & $31.1 \%$ & $29.7 \%$ \\
\hline 10 yrs or more & $17.5 \%$ & $19.1 \%$ & $18.3 \%$ & $19.3 \%$ & $19.1 \%$ & $21.6 \%$ & $22.5 \%$ & $22.6 \%$ & $24.4 \%$ & $29.4 \%$ & $28.7 \%$ & $29.6 \%$ & $29.7 \%$ & $40.6 \%$ \\
\hline Unreported & $1.5 \%$ & $1.4 \%$ & $1.6 \%$ & $1.5 \%$ & $1.8 \%$ & $1.6 \%$ & $2.8 \%$ & $2.0 \%$ & $2.1 \%$ & $2.9 \%$ & $4.0 \%$ & $1.8 \%$ & $6.5 \%$ & \\
\hline Van & $8.4 \%$ & $8.2 \%$ & $8.7 \%$ & $10.0 \%$ & $7.7 \%$ & $7.8 \%$ & $7.6 \%$ & $7.8 \%$ & $6.1 \%$ & $5.8 \%$ & $6.1 \%$ & $6.6 \%$ & $4.9 \%$ & \\
\hline 0 to $2 \mathrm{yrs}$ & $2.3 \%$ & $1.7 \%$ & $3.0 \%$ & $2.4 \%$ & $2.6 \%$ & $1.8 \%$ & $2.0 \%$ & $1.9 \%$ & $1.4 \%$ & $0.6 \%$ & $0.9 \%$ & $0.7 \%$ & $0.4 \%$ & \\
\hline 3 to 5 yrs & $2.3 \%$ & $2.2 \%$ & $2.0 \%$ & $2.6 \%$ & $1.8 \%$ & $2.1 \%$ & $1.2 \%$ & $1.8 \%$ & $1.1 \%$ & $1.0 \%$ & $1.2 \%$ & $0.8 \%$ & $1.0 \%$ & \\
\hline 6 to $9 \mathrm{yrs}$ & $2.3 \%$ & $2.4 \%$ & $2.2 \%$ & $2.8 \%$ & $1.9 \%$ & $2.1 \%$ & $2.9 \%$ & $2.0 \%$ & $2.0 \%$ & $1.8 \%$ & $2.5 \%$ & $2.1 \%$ & $1.7 \%$ & \\
\hline 10 yrs or more & $1.3 \%$ & $1.8 \%$ & $1.2 \%$ & $1.9 \%$ & $1.4 \%$ & $1.6 \%$ & $1.3 \%$ & $1.9 \%$ & $1.4 \%$ & $2.1 \%$ & $1.4 \%$ & $2.8 \%$ & $1.1 \%$ & \\
\hline Unreported & $0.2 \%$ & $0.2 \%$ & $0.2 \%$ & $0.2 \%$ & $0.1 \%$ & $0.2 \%$ & $0.3 \%$ & $0.2 \%$ & $0.2 \%$ & $0.4 \%$ & $0.1 \%$ & $0.2 \%$ & $0.8 \%$ & \\
\hline suv & $8.3 \%$ & $7.6 \%$ & $7.5 \%$ & $7.5 \%$ & $7.7 \%$ & $7.4 \%$ & $7.2 \%$ & $6.5 \%$ & $5.7 \%$ & $5.1 \%$ & $4.5 \%$ & $3.6 \%$ & $5.6 \%$ & $3.3 \%$ \\
\hline 0 to $2 \mathrm{yrs}$ & $2.9 \%$ & $2.1 \%$ & $2.1 \%$ & $2.3 \%$ & $2.9 \%$ & $2.1 \%$ & $1.5 \%$ & $1.8 \%$ & $2.3 \%$ & $1.5 \%$ & $0.8 \%$ & $1.4 \%$ & $1.1 \%$ & $3.3 \%$ \\
\hline 3 to 5 yrs & $1.3 \%$ & $1.8 \%$ & $1.7 \%$ & $2.0 \%$ & $1.5 \%$ & $1.9 \%$ & $2.0 \%$ & $1.6 \%$ & $1.5 \%$ & $1.5 \%$ & $0.8 \%$ & $0.5 \%$ & $2.7 \%$ & \\
\hline 6 to $9 \mathrm{yrs}$ & $2.6 \%$ & $1.7 \%$ & $2.2 \%$ & $1.5 \%$ & $2.0 \%$ & $1.8 \%$ & $2.2 \%$ & $1.9 \%$ & $0.9 \%$ & $1.4 \%$ & $2.3 \%$ & $0.6 \%$ & $1.0 \%$ & \\
\hline $10 \mathrm{yrs}$ or more & $1.4 \%$ & $1.8 \%$ & $1.3 \%$ & $1.5 \%$ & $1.3 \%$ & $1.4 \%$ & $1.3 \%$ & $1.1 \%$ & $0.8 \%$ & $0.5 \%$ & $0.6 \%$ & $0.8 \%$ & $0.9 \%$ & \\
\hline Unreported & $0.1 \%$ & $0.2 \%$ & $0.1 \%$ & $0.2 \%$ & $0.0 \%$ & $0.1 \%$ & $0.2 \%$ & $0.1 \%$ & $0.2 \%$ & $0.3 \%$ & & $0.3 \%$ & & \\
\hline Pickup Truck & $15.7 \%$ & $24.2 \%$ & $7.4 \%$ & $14.9 \%$ & $7.4 \%$ & $12.6 \%$ & $4.0 \%$ & $12.2 \%$ & $2.4 \%$ & $7.0 \%$ & $1.0 \%$ & $5.3 \%$ & $0.8 \%$ & $12.6 \%$ \\
\hline 0 to $2 \mathrm{yrs}$ & $2.4 \%$ & $3.6 \%$ & $1.2 \%$ & $2.1 \%$ & $0.9 \%$ & $2.3 \%$ & $0.4 \%$ & $2.1 \%$ & $0.3 \%$ & $0.7 \%$ & $0.3 \%$ & $0.5 \%$ & & $0.7 \%$ \\
\hline 3 to $5 \mathrm{yrs}$ & $3.1 \%$ & $4.1 \%$ & $1.1 \%$ & $3.2 \%$ & $1.6 \%$ & $2.5 \%$ & $1.0 \%$ & $2.5 \%$ & $0.5 \%$ & $1.2 \%$ & $0.1 \%$ & $1.1 \%$ & & \\
\hline 6 to $9 \mathrm{yrs}$ & $4.9 \%$ & $6.1 \%$ & $2.5 \%$ & $3.8 \%$ & $2.3 \%$ & $2.8 \%$ & $1.2 \%$ & $2.8 \%$ & $0.6 \%$ & $2.0 \%$ & $0.3 \%$ & $2.0 \%$ & $0.6 \%$ & $11.9 \%$ \\
\hline $10 \mathrm{yrs}$ or more & $5.2 \%$ & $9.8 \%$ & $2.3 \%$ & $5.4 \%$ & $2.0 \%$ & $4.5 \%$ & $1.3 \%$ & $4.5 \%$ & $1.0 \%$ & $2.9 \%$ & $0.2 \%$ & $0.8 \%$ & $0.1 \%$ & \\
\hline Unreported & $0.1 \%$ & $0.8 \%$ & $0.3 \%$ & $0.4 \%$ & $0.6 \%$ & $0.5 \%$ & $0.1 \%$ & $0.4 \%$ & $0.1 \%$ & $0.2 \%$ & $0.1 \%$ & $0.8 \%$ & $0.1 \%$ & \\
\hline Other POV & $2.8 \%$ & $2.2 \%$ & $1.6 \%$ & $2.1 \%$ & $0.7 \%$ & $1.4 \%$ & $1.1 \%$ & $1.6 \%$ & $0.8 \%$ & $2.0 \%$ & $0.2 \%$ & $0.6 \%$ & $0.4 \%$ & \\
\hline 0 to $2 \mathrm{yrs}$ & $0.2 \%$ & $0.1 \%$ & $0.1 \%$ & $0.2 \%$ & $0.2 \%$ & $0.2 \%$ & $0.1 \%$ & $0.1 \%$ & $0.2 \%$ & $0.3 \%$ & & $0.0 \%$ & & \\
\hline 3 to $5 \mathrm{yrs}$ & $0.3 \%$ & $0.2 \%$ & $0.2 \%$ & $0.3 \%$ & $0.1 \%$ & $0.2 \%$ & $0.0 \%$ & $0.2 \%$ & & $0.7 \%$ & & & $0.1 \%$ & \\
\hline 6 to $9 \mathrm{yrs}$ & $0.4 \%$ & $0.5 \%$ & $0.3 \%$ & $0.5 \%$ & $0.1 \%$ & $0.2 \%$ & $0.3 \%$ & $0.3 \%$ & & $0.0 \%$ & $0.2 \%$ & $0.3 \%$ & & \\
\hline 10 yrs or more & $1.8 \%$ & $1.3 \%$ & $1.0 \%$ & $1.1 \%$ & $0.4 \%$ & $0.8 \%$ & $0.4 \%$ & $1.0 \%$ & $0.1 \%$ & $0.9 \%$ & & $0.4 \%$ & $0.1 \%$ & \\
\hline Unreported & $0.1 \%$ & $0.1 \%$ & $0.1 \%$ & $0.1 \%$ & & $0.1 \%$ & $0.2 \%$ & $0.1 \%$ & $0.5 \%$ & $0.1 \%$ & & & $0.2 \%$ & \\
\hline
\end{tabular}




\begin{tabular}{|c|c|c|c|c|c|c|c|c|c|c|c|c|c|c|}
\hline \multicolumn{15}{|c|}{ Population Density (census tract) } \\
\hline & \multicolumn{2}{|c|}{$<500$} & \multicolumn{2}{|c|}{$500-2,000$} & \multicolumn{2}{|c|}{$2,000-4,000$} & \multicolumn{2}{|c|}{$4,000-10,000$} & \multicolumn{2}{|c|}{$10,000-20,000$} & \multicolumn{2}{|c|}{$20,000-50,000$} & \multicolumn{2}{|c|}{$50,000+$} \\
\hline & NY State & U.S. & NY State & U.S. & NY State & U.S. & NY State & U.S. & NY State & U.S. & NY State & U.S. & NY State & U.S. \\
\hline \multicolumn{15}{|c|}{ VMT/Vehicle by Vehicle Type and Age } \\
\hline ALL VEHICLES & 11,836 & 11,787 & 11,179 & 11,492 & 10,657 & 11,165 & 10,041 & 10,691 & 9,803 & 10,889 & 9,473 & 11,218 & 9,566 & 7,237 \\
\hline 0 to $2 \mathrm{yrs}$ & 14,732 & 16,082 & 13,126 & 13,595 & 11,709 & 13,566 & 12,106 & 13,397 & 11,269 & 13,674 & 8,994 & 12,900 & 11,110 & 6,817 \\
\hline 3 to 5 yrs & 13,134 & 13,614 & 12,066 & 12,597 & 11,468 & 12,466 & 10,274 & 11,867 & 12,661 & 12,306 & 8,485 & 10,778 & 10,217 & 7,994 \\
\hline 6 to $9 \mathrm{yrs}$ & 11,740 & 12,237 & 10,951 & 11,696 & 10,545 & 11,418 & 10,361 & 11,001 & 9,482 & 10,958 & 11,218 & 11,934 & 10,300 & 4,509 \\
\hline $10 \mathrm{yrs}$ or more & 9,608 & 9,139 & 9,216 & 9,457 & 9,236 & 9,388 & 8,269 & 9,008 & 7,509 & 9,427 & 8,827 & 10,329 & 8,040 & 11,046 \\
\hline Unreported & 11,042 & 11,567 & 9,750 & 12,507 & 11,159 & 9,403 & 9,193 & 11,043 & 7,389 & 11,311 & 12,740 & 12,115 & 9,270 & \\
\hline Auto & 11,797 & 11,855 & 10,907 & 11,315 & 10,149 & 10,853 & 9,677 & 10,452 & 9,252 & 10,911 & 9,463 & 10,420 & $\mathbf{9 , 5 3 7}$ & 7,488 \\
\hline 0 to $2 \mathrm{yrs}$ & 14,427 & 16,195 & 13,451 & 13,509 & 11,151 & 13,212 & 11,345 & 14,099 & 9,218 & 14,839 & 9,510 & 8,420 & 9,475 & 10,500 \\
\hline 3 to $5 \mathrm{yrs}$ & 12,320 & 13,707 & 11,699 & 12,356 & 11,168 & 12,047 & 10,223 & 11,191 & 11,358 & 12,480 & 7,711 & 10,661 & 8,237 & 7,994 \\
\hline 6 to $9 \mathrm{yrs}$ & 11,863 & 12,181 & 10,666 & 11,117 & 9,638 & 10,744 & 10,073 & 10,612 & 9,348 & 10,887 & 12,113 & 11,756 & 10,429 & 3,130 \\
\hline $10 \mathrm{yrs}$ or more & 10,143 & 9,377 & 9,058 & 9,839 & 9,336 & 9,606 & 8,125 & 8,917 & 8,108 & 9,540 & 8,441 & 10,201 & 8,984 & 11,841 \\
\hline Unreported & 11,818 & 11,822 & 10,502 & 13,112 & 10,279 & 10,072 & 9,069 & 11,919 & 6,255 & 8,872 & 12,397 & 8,978 & 12,303 & \\
\hline Van & 12,594 & 12,598 & 12,251 & 12,667 & 11,711 & 12,450 & 10,793 & 11,310 & 8,970 & 11,386 & 11,316 & 15,502 & 7,936 & 12,929 \\
\hline 0 to $2 \mathrm{yrs}$ & 14,456 & 15,048 & 14,717 & 15,812 & 11,789 & 16,671 & 13,776 & 13,569 & 13,754 & 9,533 & 15,875 & 8,814 & 9,626 & 14,759 \\
\hline 3 to 5 yrs & 14,985 & 15,372 & 13,452 & 13,811 & 11,890 & 13,681 & 11,344 & 12,888 & 13,181 & 15,260 & 13,893 & 13,622 & 10,791 & 13,937 \\
\hline 6 to $9 \mathrm{yrs}$ & 12,182 & 12,671 & 11,886 & 12,591 & 12,912 & 12,969 & 11,474 & 11,977 & 10,126 & 10,958 & 9,317 & 28,798 & 6,660 & 14,279 \\
\hline 10 yrs or more & 10,687 & 10,358 & 10,219 & 10,308 & 8,919 & 9,804 & 8,341 & 9,520 & 6,683 & 11,098 & 7,367 & 9,300 & 7,604 & 9,713 \\
\hline Unreported & 10,364 & 11,437 & 13,397 & 16,886 & 17,801 & 14,611 & 7,394 & 13,466 & 28,680 & 10,066 & 14,030 & 10,043 & 5,894 & 16,852 \\
\hline suv & 13,534 & 13,802 & 12,562 & 12,920 & 12,272 & 12,361 & 11,180 & 12,076 & 12,685 & 12,306 & 9,409 & 12,559 & 11,233 & 5,325 \\
\hline 0 to $2 \mathrm{yrs}$ & 15,933 & 18,055 & 13,118 & 14,262 & 12,993 & 13,806 & 12,564 & 13,634 & 15,321 & 13,068 & 7,180 & 27,951 & 14,687 & 1,669 \\
\hline 3 to $5 \mathrm{yrs}$ & 14,184 & 14,922 & 12,757 & 13,297 & 12,750 & 13,619 & 10,501 & 12,969 & 14,881 & 12,184 & 8,633 & 9,805 & 13,561 & \\
\hline 6 to $9 \mathrm{yrs}$ & 12,822 & 13,873 & 12,862 & 13,241 & 12,374 & 12,586 & 11,276 & 12,076 & 10,549 & 11,837 & 8,996 & 8,026 & 10,896 & 4,766 \\
\hline 10 yrs or more & 10,972 & 9,694 & 10,645 & 10,165 & 9,779 & 9,356 & 9,986 & 10,012 & 8,089 & 11,047 & 11,668 & 10,036 & 6,292 & 7,318 \\
\hline Unreported & 12,666 & 14,436 & 11,329 & 13,656 & 8,720 & 9,170 & 11,729 & 12,646 & 7,695 & 16,490 & 12,725 & 29,309 & 5,557 & \\
\hline Pickup Truck & 11,705 & 11,372 & 10,931 & 11,300 & 11,092 & 11,504 & 11,508 & 11,415 & 8,168 & 9,968 & 7,800 & 11,596 & 8,593 & 8,047 \\
\hline 0 to $2 \mathrm{yrs}$ & 16,446 & 15,806 & 12,483 & 14,497 & 10,934 & 15,691 & 19,258 & 13,583 & 10,102 & 12,804 & & 10,150 & & \\
\hline 3 to 5 yrs & 13,414 & 13,341 & 12,614 & 13,277 & 11,027 & 12,256 & 12,448 & 14,189 & 14,612 & 12,215 & & 8,195 & 10,735 & \\
\hline 6 to $9 \mathrm{yrs}$ & 11,753 & 12,185 & 9,915 & 12,399 & 13,055 & 12,068 & 13,294 & 11,482 & 6,842 & 11,473 & 27,591 & 10,993 & & 8,047 \\
\hline $10 \mathrm{yrs}$ or more & 9,243 & 9,368 & 9,956 & 8,826 & 9,716 & 9,623 & 7,485 & 9,966 & 6,048 & 7,561 & 7,029 & 15,637 & 6,245 & \\
\hline Unreported & 12,303 & 12,321 & 6,345 & 11,656 & 11,766 & 11,279 & 12,316 & 10,260 & 8,293 & 13,336 & & 8,458 & & \\
\hline Other POV & 2,688 & 3,970 & 2,492 & 3,557 & 3,826 & 3,440 & 1,867 & 2,346 & 1,023 & 3,595 & 1,105 & 2,079 & 1,821 & 1,700 \\
\hline 0 to 2 yrs & 4,179 & 8,810 & 3,651 & 4,463 & 3,976 & 3,802 & 5,457 & 3,033 & & 3,553 & 1,000 & 250 & 5,256 & 1,700 \\
\hline 3 to $5 \mathrm{yrs}$ & 4,580 & 4,136 & 2,932 & 4,186 & 5,288 & 4,664 & 344 & 2,573 & 199 & 3,492 & & 7,262 & 2,600 & \\
\hline 6 to $9 \mathrm{yrs}$ & 2,602 & 3,492 & 2,503 & 3,126 & 2,968 & 3,752 & 2,287 & 3,853 & 1,471 & 2,378 & 6,000 & 1,425 & 1,888 & \\
\hline 10 yrs or more & 2,026 & 2,264 & 1,866 & 2,580 & 3,515 & 3,406 & 1,606 & 1,551 & 532 & 4,048 & 567 & 2,769 & 350 & \\
\hline Unreported & 1,303 & 2,794 & 1,564 & 4,982 & 2,365 & 1,310 & 705 & 1,671 & 2,946 & 3,634 & & 17,700 & & \\
\hline${ }^{*}$ Numbers refle & & & & & & & & & & & & & & \\
\hline
\end{tabular}




\begin{tabular}{|c|c|c|c|c|c|c|c|c|c|c|c|c|c|c|}
\hline \multicolumn{15}{|c|}{ Population Density (census tract) } \\
\hline & \multicolumn{2}{|c|}{$<500$} & \multicolumn{2}{|c|}{$500-2,000$} & \multicolumn{2}{|c|}{$2,000-4,000$} & \multicolumn{2}{|c|}{$4,000-10,000$} & \multicolumn{2}{|c|}{$10,000-20,000$} & \multicolumn{2}{|c|}{$20,000-50,000$} & \multicolumn{2}{|c|}{$50,000+$} \\
\hline & NY State & U.S. & NY State & U.S. & NY State & U.S. & NY State & U.S. & NY State & U.S. & NY State & U.S. & NY State & U.S. \\
\hline VMT/Vehicle by Vehicle Type and Age & & & & & & & & & & & & & & \\
\hline ALL VEHICLES & 13,069 & 12,521 & 12,308 & 12,192 & 11,762 & 11,503 & 11,685 & 11,427 & 12,095 & 12,041 & 11,687 & 11,325 & 11,525 & 12,816 \\
\hline 0 to $2 \mathrm{yrs}$ & 15,453 & 16,457 & 14,002 & 14,549 & 12,370 & 13,537 & 12,473 & 14,019 & 13,445 & 11,870 & 11,813 & 14,484 & 12,486 & 14,081 \\
\hline 3 to $5 \mathrm{yrs}$ & 14,366 & 14,900 & 14,154 & 14,018 & 13,213 & 12,824 & 12,587 & 13,615 & 12,393 & 13,824 & 17,617 & 13,159 & 12,845 & 12,569 \\
\hline 6 to $9 \mathrm{yrs}$ & 13,441 & 13,403 & 12,405 & 12,570 & 11,759 & 11,860 & 11,460 & 11,611 & 13,840 & 11,935 & 12,405 & 11,219 & 12,773 & 11,248 \\
\hline 10 yrs or more & 10,289 & 9,031 & 9,379 & 9,209 & 9,984 & 9,203 & 10,269 & 8,993 & 9,492 & 11,355 & 8,857 & 9,149 & 9,847 & 13,323 \\
\hline Unreported & 13,806 & 10,721 & 12,027 & 11,661 & 10,501 & 10,715 & 14,937 & 10,527 & 11,432 & 11,422 & 11,857 & 12,761 & 12,727 & \\
\hline Auto & 12,934 & 12,205 & 12,229 & 12,006 & 11,440 & 10,901 & 11,395 & 10,908 & 11,546 & 11,705 & 11,681 & 11,037 & 11,024 & 13,239 \\
\hline 0 to $2 \mathrm{yrs}$ & 14,733 & 16,498 & 14,243 & 14,247 & 12,266 & 12,942 & 12,110 & 13,193 & 11,568 & 10,823 & 11,643 & 13,251 & 12,809 & 14,081 \\
\hline 3 to $5 \mathrm{yrs}$ & 14,687 & 13,988 & 13,728 & 13,548 & 12,691 & 12,229 & 12,204 & 13,119 & 12,629 & 13,380 & 18,505 & 13,134 & 13,188 & 15,594 \\
\hline 6 to $9 \mathrm{yrs}$ & 13,303 & 13,033 & 12,126 & 12,384 & 10,201 & 11,267 & 11,287 & 11,232 & 12,640 & 12,167 & 11,000 & 10,940 & 12,559 & 11,248 \\
\hline $10 \mathrm{yrs}$ or more & 10,460 & 9,351 & 9,810 & 9,569 & 10,855 & 8,908 & 10,488 & 8,695 & 9,913 & 10,980 & 9,256 & 9,098 & 8,696 & 13,323 \\
\hline Unreported & 13,266 & 11,236 & 12,362 & 12,748 & 11,828 & 9,650 & 11,755 & 11,065 & 11,481 & 11,884 & 11,614 & 14,130 & 12,268 & \\
\hline Van & 15,745 & 14,508 & 13,196 & 13,466 & 12,389 & 13,351 & 12,765 & 12,615 & 16,424 & 10,803 & 11,965 & 11,734 & 13,185 & 2,536 \\
\hline 0 to $2 \mathrm{yrs}$ & 16,479 & 15,852 & 14,459 & 15,806 & 11,832 & 14,905 & 13,521 & 16,864 & 31,699 & 13,313 & 12,639 & 12,840 & 9,386 & \\
\hline 3 to $5 \mathrm{yrs}$ & 15,613 & 17,949 & 16,165 & 15,413 & 15,112 & 14,398 & 13,017 & 12,998 & 16,004 & 9,498 & 14,456 & 22,142 & 9,348 & 2,536 \\
\hline 6 to $9 \mathrm{yrs}$ & 15,927 & 15,374 & 12,218 & 12,841 & 12,059 & 13,866 & 11,431 & 12,417 & 15,836 & 11,518 & 15,264 & 11,983 & 11,565 & \\
\hline $10 \mathrm{yrs}$ or more & 15,356 & 10,300 & 10,454 & 10,343 & 8,905 & 10,248 & 9,243 & 10,826 & 7,580 & 10,343 & 7,880 & 9,463 & 16,274 & \\
\hline Unreported & 12,310 & 10,457 & 12,282 & 12,819 & 10,311 & 13,504 & 31,114 & 10,132 & 15,310 & 9,155 & 18,646 & 7,659 & 17,728 & \\
\hline suv & 13,570 & 14,283 & 13,815 & 13,303 & 12,571 & 13,674 & 13,743 & 13,567 & 12,613 & 14,372 & 14,152 & 12,168 & 14,215 & 13,845 \\
\hline 0 to $2 \mathrm{yrs}$ & 15,830 & 16,903 & 13,967 & 14,780 & 12,149 & 13,904 & 13,438 & 14,489 & 11,883 & 12,998 & 12,360 & 15,723 & 11,800 & \\
\hline 3 to $5 \mathrm{yrs}$ & 14,377 & 16,130 & 15,900 & 14,507 & 14,024 & 14,354 & 14,225 & 14,623 & 9,780 & 18,158 & 12,467 & 11,529 & 14,461 & 13,845 \\
\hline 6 to $9 \mathrm{yrs}$ & 14,128 & 15,227 & 13,488 & 12,493 & 14,194 & 15,241 & 13,768 & 13,564 & 19,240 & 11,072 & 20,571 & 13,187 & 15,894 & \\
\hline 10 yrs or more & 8,843 & 8,098 & 9,556 & 10,254 & 8,052 & 10,753 & 12,274 & 11,566 & 7,703 & 14,050 & 9,489 & 9,147 & 15,698 & \\
\hline Unreported & 12,579 & 12,928 & 12,179 & 8,978 & 8,897 & 11,462 & 16,247 & 10,945 & 11,505 & & 16,993 & 11,866 & 6,499 & \\
\hline Pickup Truck & 13,279 & 12,838 & 11,898 & 12,515 & 13,717 & 12,268 & 11,526 & 12,169 & 12,273 & 13,486 & 8,793 & 14,221 & 14,672 & 11,020 \\
\hline 0 to $2 \mathrm{yrs}$ & 17,742 & 17,836 & 13,998 & 15,759 & 15,162 & 15,878 & 14,365 & 15,061 & 14,563 & 13,511 & 12,120 & 46,632 & 27,023 & \\
\hline 3 to $5 \mathrm{yrs}$ & 13,580 & 15,717 & 12,926 & 15,346 & 13,622 & 13,550 & 12,033 & 15,700 & 8,966 & 12,881 & & 6,184 & 5,020 & 11,020 \\
\hline 6 to $9 \mathrm{yrs}$ & 12,832 & 12,931 & 14,806 & 14,361 & 19,302 & 10,662 & 13,262 & 11,840 & 22,308 & 12,800 & 8,167 & 9,053 & 5,743 & \\
\hline $10 \mathrm{yrs}$ or more & 11,197 & 9,462 & 8,535 & 8,406 & 7,026 & 10,840 & 9,765 & 9,448 & 9,150 & 14,201 & 7,281 & 11,223 & 18,509 & \\
\hline Unreported & 11,199 & 12,464 & 12,844 & 12,473 & 7,220 & 13,067 & 9,255 & 11,374 & 9,393 & 12,857 & & 14,757 & & \\
\hline Other POV & 4,851 & 4,350 & 3,691 & 3,475 & 4,546 & 3,700 & 2,698 & 6,441 & 4,277 & 7,040 & 1,212 & 3,483 & 1,211 & \\
\hline 0 to $2 \mathrm{yrs}$ & 3,994 & 6,070 & 6,583 & 5,114 & 24,283 & 5,584 & 4,520 & 15,637 & 2,000 & 11,726 & 504 & & 4,500 & \\
\hline 3 to $5 \mathrm{yrs}$ & 4,747 & 5,048 & 5,562 & 2,931 & 3,709 & 3,758 & 2,045 & 11,278 & 4,740 & 2,235 & & & & \\
\hline 6 to $9 \mathrm{yrs}$ & 3,496 & 7,650 & 4,957 & 5,802 & 6,506 & 8,434 & 1,115 & 5,900 & 10,000 & 5,077 & 6,000 & & & \\
\hline $10 \mathrm{yrs}$ or more & 2,275 & 3,119 & 1,759 & 2,301 & 2,903 & 1,715 & 3,426 & 2,532 & 684 & 6,711 & 1,324 & 3,483 & 722 & \\
\hline Unreported & 22,143 & 1,823 & 1,378 & 1,804 & 1,862 & 7,331 & 1,763 & 1,154 & & & 597 & & & \\
\hline${ }^{*}$ Numbers reflect $B$ & & & & & & & & & & & & & & \\
\hline
\end{tabular}




\begin{tabular}{|c|c|c|c|c|c|c|c|c|c|c|c|c|c|c|}
\hline \multicolumn{15}{|c|}{ Population Density (census tract) } \\
\hline & \multicolumn{2}{|c|}{$<500$} & \multicolumn{2}{|c|}{$500-2,000$} & \multicolumn{2}{|c|}{$2,000-4,000$} & \multicolumn{2}{|c|}{$4,000-10,000$} & \multicolumn{2}{|c|}{$10,000-20,000$} & \multicolumn{2}{|c|}{$20,000-50,000$} & \multicolumn{2}{|c|}{$50,000+$} \\
\hline & NY State & U.S. & NY State & U.S. & NY State & U.S. & NY State & U.S. & NY State & U.S. & NY State & U.S. & NY State & U.S. \\
\hline \multicolumn{15}{|c|}{ VMT/Vehicle by Vehicle Type and Age } \\
\hline ALL VEHICLES & 13,424 & 13,120 & 13,148 & 12,491 & 12,664 & 12,059 & 12,448 & 11,303 & 12,186 & 11,935 & 11,857 & 12,371 & 12,775 & 9,357 \\
\hline 0 to $2 \mathrm{yrs}$ & 16,853 & 18,421 & 15,349 & 16,387 & 14,229 & 15,378 & 14,501 & 13,919 & 14,148 & 14,475 & 12,329 & 15,590 & 13,542 & 25,002 \\
\hline 3 to $5 \mathrm{yrs}$ & 14,126 & 15,497 & 14,028 & 14,040 & 13,069 & 13,198 & 11,613 & 12,913 & 12,959 & 11,528 & 12,107 & 11,628 & 10,794 & 9,720 \\
\hline 6 to $9 \mathrm{yrs}$ & 13,328 & 13,634 & 12,160 & 12,776 & 12,884 & 12,087 & 13,042 & 11,542 & 11,687 & 12,620 & 11,316 & 15,128 & 12,495 & 9,427 \\
\hline 10 yrs or more & 10,904 & 8,740 & 11,299 & 8,265 & 10,686 & 9,022 & 11,079 & 8,504 & 10,396 & 10,534 & 12,575 & 9,427 & 12,180 & 6,273 \\
\hline Unreported & 12,472 & 11,285 & 18,074 & 13,724 & 13,519 & 12,912 & 12,652 & 11,263 & 20,407 & 12,029 & 10,092 & 7,904 & 20,366 & \\
\hline Auto & 13,550 & 13,115 & 13,271 & 12,029 & 12,180 & 11,576 & 12,075 & 11,135 & 11,793 & 12,042 & 11,495 & 12,594 & 12,348 & 7,993 \\
\hline 0 to $2 \mathrm{yrs}$ & 17,179 & 17,798 & 15,397 & 16,132 & 13,628 & 13,968 & 13,895 & 13,927 & 14,023 & 14,669 & 12,477 & 16,385 & 11,886 & 18,000 \\
\hline 3 to $5 \mathrm{yrs}$ & 13,460 & 15,538 & 14,110 & 13,457 & 12,295 & 12,721 & 11,090 & 12,758 & 11,817 & 11,719 & 11,818 & 11,360 & 9,887 & 9,720 \\
\hline 6 to $9 \mathrm{yrs}$ & 13,696 & 13,360 & 12,300 & 12,190 & 12,813 & 11,887 & 12,473 & 11,190 & 11,675 & 12,494 & 11,371 & 15,984 & 11,800 & 8,578 \\
\hline 10 yrs or more & 11,671 & 9,222 & 11,429 & 8,064 & 10,161 & 9,012 & 11,182 & 8,642 & 10,562 & 10,735 & 11,370 & 9,530 & 12,149 & 6,273 \\
\hline Unreported & 13,194 & 10,332 & 21,460 & 13,002 & 13,655 & 12,244 & 13,348 & 9,299 & 16,819 & 12,545 & 10,181 & 5,319 & 22,576 & \\
\hline Van & 14,972 & 15,338 & 14,481 & 14,309 & 17,357 & 13,672 & 15,440 & 12,819 & 13,162 & 13,219 & 10,224 & 13,895 & 17,474 & \\
\hline 0 to $2 \mathrm{yrs}$ & 15,617 & 21,601 & 15,857 & 15,738 & 16,116 & 18,752 & 14,834 & 15,119 & 15,374 & 17,696 & 8,467 & 20,795 & 40,204 & \\
\hline 3 to $5 \mathrm{yrs}$ & 17,206 & 15,125 & 14,482 & 15,987 & 20,978 & 13,632 & 15,045 & 13,421 & 18,401 & 16,020 & 8,911 & 13,511 & 24,685 & \\
\hline 6 to $9 \mathrm{yrs}$ & 14,018 & 14,096 & 14,313 & 14,706 & 14,296 & 12,752 & 16,894 & 11,844 & 12,221 & 11,309 & 6,485 & 6,942 & 14,337 & \\
\hline $10 \mathrm{yrs}$ or more & 12,309 & 11,385 & 11,725 & 9,012 & 19,071 & 9,224 & 13,511 & 9,970 & 9,115 & 12,209 & \multirow[t]{2}{*}{18,335} & 24,725 & 11,905 & \\
\hline Unreported & 10,646 & 14,159 & 11,748 & 14,877 & 15,430 & 10,343 & 14,902 & 28,264 & 6,593 & 10,000 & & 15,000 & 11,431 & \\
\hline suv & 14,339 & 15,064 & 13,803 & 15,174 & 13,333 & 14,770 & 13,447 & 12,693 & 15,680 & 11,807 & 16,755 & 10,182 & 12,939 & 35,000 \\
\hline 0 to $2 \mathrm{yrs}$ & 17,529 & 18,242 & 13,630 & 17,789 & 14,183 & 17,277 & 17,082 & 13,749 & 14,656 & 12,408 & 16,857 & 5,376 & 19,689 & 35,000 \\
\hline 3 to $5 \mathrm{yrs}$ & 14,661 & 14,935 & 15,141 & 15,165 & 14,257 & 15,749 & 11,583 & 12,880 & 20,664 & 12,543 & 15,608 & 16,957 & 9,469 & \\
\hline 6 to $9 \mathrm{yrs}$ & 12,259 & 17,053 & 11,421 & 14,629 & 11,635 & 14,264 & 15,513 & 14,246 & 9,972 & 12,919 & 15,612 & 12,645 & 14,680 & \\
\hline $10 \mathrm{yrs}$ or more & 11,273 & 8,871 & 16,836 & 11,235 & 12,874 & 10,548 & 9,116 & 8,299 & 14,504 & 6,294 & 22,342 & 7,817 & 13,256 & \\
\hline Unreported & 8,475 & 32,645 & 10,411 & 22,009 & 16,130 & 12,577 & 8,961 & 9,431 & 16,608 & 8,815 & & & & \\
\hline Pickup Truck & 13,459 & 12,214 & 11,277 & 13,071 & 12,764 & 12,682 & 13,846 & 11,338 & 10,376 & 12,223 & 31,012 & 10,528 & 33,731 & 11,621 \\
\hline 0 to $2 \mathrm{yrs}$ & 17,068 & 18,869 & 15,792 & 17,550 & 18,384 & 17,222 & 17,800 & 13,216 & 16,513 & 16,563 & 8,512 & 38 & & 13,000 \\
\hline 3 to $5 \mathrm{yrs}$ & 16,048 & 16,269 & 11,102 & 15,047 & 11,661 & 14,435 & 17,639 & 13,402 & 13,192 & 9,170 & 49,966 & 11,235 & & \\
\hline 6 to $9 \mathrm{yrs}$ & 12,598 & 12,666 & 10,351 & 14,389 & 13,980 & 12,660 & 11,998 & 12,514 & 12,888 & 14,921 & 12,277 & 14,137 & 41,396 & 11,543 \\
\hline $10 \mathrm{yrs}$ or more & 11,026 & 7,994 & 10,281 & 9,041 & 9,785 & 8,997 & 11,607 & 8,490 & 6,143 & 10,883 & 110,724 & 1,138 & 19,777 & \\
\hline Unreported & 13,459 & 10,084 & 8,968 & 13,242 & 12,788 & 16,177 & 14,401 & 13,451 & 7,783 & 12,110 & 7,080 & 11,729 & 8,739 & \\
\hline Other POV & 2,741 & 8,315 & 5,055 & 4,313 & 5,093 & 7,725 & 6,744 & 5,375 & 28,366 & 3,360 & 5,000 & 484 & 3,787 & \\
\hline 0 to $2 \mathrm{yrs}$ & 2,996 & 8,295 & 29,511 & 7,605 & 7,690 & 20,152 & 33,108 & 4,333 & 2,420 & 5,964 & \multirow{5}{*}{5,000} & 600 & & \\
\hline 3 to $5 \mathrm{yrs}$ & 5,887 & 5,770 & 5,999 & 7,747 & 15,000 & 7,180 & 7,000 & 15,064 & & 2,227 & & \multirow{4}{*}{$\begin{array}{r}1,000 \\
125\end{array}$} & \multicolumn{2}{|l|}{6,000} \\
\hline 6 to $9 \mathrm{yrs}$ & 4,581 & 19,773 & 5,526 & 4,377 & 3,427 & 1,773 & 4,678 & 7,969 & & 6,378 & & & & \\
\hline \multirow{2}{*}{$\begin{array}{l}10 \text { yrs or more } \\
\text { Unreported }\end{array}$} & 1,801 & 3,846 & 3,143 & 2,955 & \multirow[t]{2}{*}{2,103} & 6,422 & 2,031 & 3,421 & 1,538 & 3,612 & & & \multirow{2}{*}{\multicolumn{2}{|c|}{$\begin{array}{l}2,000 \\
3,000\end{array}$}} \\
\hline & 1,023 & 2,781 & 2,325 & 3,627 & & 4,174 & 3,264 & 7,659 & 46,667 & 5,000 & & & & \\
\hline
\end{tabular}




\begin{tabular}{|c|c|c|c|c|c|c|c|c|c|c|c|c|c|c|}
\hline \multicolumn{15}{|c|}{ Population Density (census tract) } \\
\hline & \multirow{2}{*}{\multicolumn{2}{|c|}{$\begin{array}{c}<500 \\
\text { NY State }\end{array}$}} & \multicolumn{2}{|c|}{$500-2,000$} & \multicolumn{2}{|c|}{$2,000-4,000$} & \multicolumn{2}{|c|}{$4,000-10,000$} & \multicolumn{2}{|c|}{$10,000-20,000$} & \multicolumn{2}{|c|}{$20,000-50,000$} & \multicolumn{2}{|c|}{$50,000+$} \\
\hline & & & NY State & U.S. & NY State & U.S. & NY State & U.S. & NY State & U.S. & NY State & U.S. & NY State & U.S. \\
\hline \multicolumn{15}{|c|}{ Percent Not Taking Walk Trips in the last week } \\
\hline TOTAL & $34.0 \%$ & $33.5 \%$ & $33.7 \%$ & $33.0 \%$ & $34.0 \%$ & $33.0 \%$ & $33.4 \%$ & $33.1 \%$ & $26.4 \%$ & $30.7 \%$ & $20.7 \%$ & $27.3 \%$ & $12.7 \%$ & $18.4 \%$ \\
\hline 5 to 10 year-olds & $29.7 \%$ & $27.0 \%$ & $24.5 \%$ & $24.7 \%$ & $24.6 \%$ & $22.0 \%$ & $28.2 \%$ & $24.6 \%$ & $17.2 \%$ & $22.9 \%$ & $22.1 \%$ & $16.0 \%$ & $18.4 \%$ & \\
\hline 11 to 15 year-olds & $26.7 \%$ & $24.3 \%$ & $27.8 \%$ & $26.0 \%$ & $26.9 \%$ & $23.3 \%$ & $21.1 \%$ & $23.7 \%$ & $20.0 \%$ & $21.0 \%$ & $14.4 \%$ & $11.8 \%$ & $8.0 \%$ & $41.0 \%$ \\
\hline 16 to 20 year-olds & $34.8 \%$ & $32.4 \%$ & $28.6 \%$ & $35.3 \%$ & $30.3 \%$ & $33.5 \%$ & $23.4 \%$ & $31.1 \%$ & $15.6 \%$ & $26.3 \%$ & $14.4 \%$ & $34.1 \%$ & $23.6 \%$ & $17.4 \%$ \\
\hline 21 to 35 year-olds & $38.0 \%$ & $35.4 \%$ & $33.6 \%$ & $30.4 \%$ & $44.0 \%$ & $33.0 \%$ & $37.5 \%$ & $29.5 \%$ & $19.0 \%$ & $26.0 \%$ & $17.4 \%$ & $24.3 \%$ & $9.1 \%$ & $30.1 \%$ \\
\hline 36 to 64 year-olds & $31.1 \%$ & $33.1 \%$ & $32.6 \%$ & $33.6 \%$ & $30.4 \%$ & $32.6 \%$ & $31.2 \%$ & $33.8 \%$ & $32.8 \%$ & $32.2 \%$ & $21.8 \%$ & $25.8 \%$ & $9.4 \%$ & $8.8 \%$ \\
\hline 65+ year-olds & $45.4 \%$ & $43.0 \%$ & $47.8 \%$ & $43.8 \%$ & $46.0 \%$ & $46.6 \%$ & $46.8 \%$ & $46.9 \%$ & $37.1 \%$ & $45.5 \%$ & $28.0 \%$ & $48.5 \%$ & $23.4 \%$ & $13.3 \%$ \\
\hline \multicolumn{15}{|c|}{ Avg Minutes Spent Walking per Day } \\
\hline TOTAL & 3.39 & 3.68 & 4.66 & 4.36 & 6.00 & 5.58 & 6.98 & 6.95 & 9.58 & 10.72 & 15.43 & 12.78 & 25.58 & 28.10 \\
\hline 5 to 10 year-olds & 1.73 & 2.20 & 1.74 & 2.24 & 5.20 & 3.97 & 6.79 & 5.36 & 10.82 & 9.51 & 18.20 & 20.30 & 13.11 & 29.89 \\
\hline 11 to 15 year-olds & 3.55 & 3.88 & 5.31 & 5.23 & 3.27 & 7.40 & 7.14 & 13.64 & 6.10 & 11.95 & 10.58 & 11.37 & 19.59 & 16.76 \\
\hline 16 to 20 year-olds & 1.97 & 3.35 & 3.95 & 6.29 & 5.41 & 5.10 & 6.29 & 5.87 & 9.53 & 10.94 & 12.91 & 8.05 & 22.65 & 20.28 \\
\hline 21 to 35 year-olds & 3.27 & 2.49 & 5.86 & 3.88 & 5.13 & 5.20 & 6.92 & 6.53 & 14.24 & 15.69 & 20.22 & 14.19 & 26.82 & 27.63 \\
\hline 36 to 64 year-olds & 4.23 & 4.64 & 5.27 & 4.63 & 7.21 & 6.19 & 7.70 & 7.06 & 8.21 & 9.63 & 14.70 & 13.04 & 30.34 & 34.59 \\
\hline $65+$ year-olds & 2.47 & 3.01 & 3.10 & 3.94 & 4.97 & 4.25 & 5.48 & 5.17 & 7.86 & 6.49 & 14.50 & 9.57 & 19.92 & 17.49 \\
\hline \multicolumn{15}{|c|}{ Percent Not Taking Bike Trips in the last week } \\
\hline TOTAL & $88.3 \%$ & $86.9 \%$ & $86.5 \%$ & $85.6 \%$ & $89.0 \%$ & $87.0 \%$ & $90.9 \%$ & $87.8 \%$ & $92.0 \%$ & $88.7 \%$ & $94.2 \%$ & $89.4 \%$ & $92.4 \%$ & $89.5 \%$ \\
\hline 5 to 10 year-olds & $52.0 \%$ & $43.1 \%$ & $60.3 \%$ & $48.5 \%$ & $50.6 \%$ & $51.2 \%$ & $66.4 \%$ & $55.0 \%$ & $65.5 \%$ & $63.1 \%$ & $92.7 \%$ & $70.9 \%$ & $76.0 \%$ & $26.5 \%$ \\
\hline 11 to 15 year-olds & $74.2 \%$ & $63.2 \%$ & $64.2 \%$ & $68.2 \%$ & $69.9 \%$ & $69.2 \%$ & $76.1 \%$ & $74.0 \%$ & $85.9 \%$ & $79.0 \%$ & $86.8 \%$ & $64.0 \%$ & $93.7 \%$ & $100.0 \%$ \\
\hline 16 to 20 year-olds & $89.7 \%$ & $91.4 \%$ & $82.1 \%$ & $89.1 \%$ & $91.6 \%$ & $88.4 \%$ & $89.1 \%$ & $88.6 \%$ & $93.4 \%$ & $83.8 \%$ & $98.3 \%$ & $93.3 \%$ & $93.6 \%$ & $91.6 \%$ \\
\hline 21 to 35 year-olds & $92.4 \%$ & $92.2 \%$ & $89.6 \%$ & $91.9 \%$ & $94.8 \%$ & $92.1 \%$ & $93.0 \%$ & $91.2 \%$ & $91.9 \%$ & $90.8 \%$ & $87.5 \%$ & $88.4 \%$ & $90.3 \%$ & $95.6 \%$ \\
\hline 36 to 64 year-olds & $92.0 \%$ & $93.2 \%$ & $90.6 \%$ & $90.9 \%$ & $92.6 \%$ & $91.6 \%$ & $93.9 \%$ & $91.3 \%$ & $96.5 \%$ & $92.7 \%$ & $97.0 \%$ & $93.5 \%$ & $93.7 \%$ & $92.1 \%$ \\
\hline 65 + year-olds & $97.5 \%$ & $96.9 \%$ & $98.0 \%$ & $96.4 \%$ & $97.4 \%$ & $96.2 \%$ & $98.3 \%$ & $97.5 \%$ & $98.2 \%$ & $96.8 \%$ & $96.9 \%$ & $99.2 \%$ & $99.3 \%$ & $100.0 \%$ \\
\hline \multicolumn{15}{|c|}{ Avg Minutes Spent Biking per Day } \\
\hline TOTAL & 0.45 & 0.56 & 0.77 & 0.76 & 0.52 & 0.85 & 0.61 & 1.05 & 0.30 & 0.78 & 0.08 & 0.80 & 0.55 & 0.37 \\
\hline 5 to 10 year & 0.28 & 1.01 & 0.73 & 1.51 & 1.81 & 1.10 & 0.84 & 1.36 & 0.41 & 0.62 & 0.80 & 0.11 & & \\
\hline 11 to 15 year-olds & 0.97 & 1.19 & 1.46 & 1.33 & 0.92 & 2.89 & 1.13 & 1.02 & 0.89 & 1.44 & \multirow{5}{*}{0.10} & 0.21 & & \\
\hline 16 to 20 year-olds & 1.41 & 0.58 & 0.92 & 0.86 & 0.09 & 1.05 & 1.15 & 0.71 & 0.28 & 1.11 & & 0.15 & 0.15 & 2.53 \\
\hline 21 to 35 year-olds & 0.07 & 0.35 & 2.25 & 0.43 & 0.29 & 0.40 & 0.27 & 1.19 & & 0.61 & & 1.36 & 0.68 & \\
\hline 36 to 64 year-olds & 0.35 & 0.44 & 0.33 & 0.68 & 0.55 & 0.72 & 0.65 & 1.24 & 0.27 & 0.89 & & 1.04 & 0.85 & \\
\hline $65+$ year-olds & 0.33 & 0.56 & 0.10 & 0.43 & 0.09 & 0.37 & 0.33 & 0.26 & 0.43 & 0.30 & & 0.05 & 0.15 & \\
\hline \multicolumn{15}{|c|}{ Avg Minutes Spent Walking/Biking per Day } \\
\hline TOTAL & 3.84 & 4.23 & 5.43 & 5.12 & 6.52 & 6.43 & 7.59 & 8.00 & 9.88 & 11.50 & 15.51 & 13.59 & 26.12 & 28.47 \\
\hline 5 to 10 year-olds & 2.01 & 3.21 & 2.47 & 3.74 & 7.02 & 5.07 & 7.64 & 6.73 & 11.22 & 10.13 & 19.00 & 20.41 & 13.11 & 29.89 \\
\hline 11 to 15 year-olds & 4.51 & 5.07 & 6.77 & 6.56 & 4.18 & 10.29 & 8.28 & 14.66 & 6.98 & 13.40 & 10.58 & 11.59 & 19.59 & 16.76 \\
\hline 16 to 20 year-olds & 3.38 & 3.93 & 4.88 & 7.15 & 5.49 & 6.15 & 7.44 & 6.57 & 9.81 & 12.04 & 12.91 & 8.19 & 22.80 & 22.81 \\
\hline 21 to 35 year-olds & 3.34 & 2.84 & 8.11 & 4.31 & 5.42 & 5.60 & 7.19 & 7.73 & 14.24 & 16.30 & 20.22 & 15.56 & 27.50 & 27.63 \\
\hline 36 to 64 year-olds & 4.58 & 5.08 & 5.60 & 5.31 & 7.75 & 6.90 & 8.35 & 8.30 & 8.48 & 10.52 & 14.80 & 14.08 & 31.19 & 34.59 \\
\hline $65+$ year-olds & 2.80 & 3.58 & 3.20 & 4.37 & 5.06 & 4.62 & 5.81 & 5.42 & 8.30 & 6.79 & 14.50 & 9.62 & 20.07 & 17.49 \\
\hline
\end{tabular}




\begin{tabular}{|c|c|c|c|c|c|c|c|c|c|c|c|c|c|c|}
\hline \multicolumn{15}{|c|}{ Population Density (census tract) } \\
\hline & \multicolumn{2}{|c|}{$\begin{array}{c}<500 \\
x^{2}\end{array}$} & \multicolumn{2}{|c|}{$500-2,000$} & \multicolumn{2}{|c|}{$2,000-4,000$} & \multicolumn{2}{|c|}{$4,000-10,000$} & \multicolumn{2}{|c|}{$10,000-20,000$} & \multicolumn{2}{|c|}{$20,000-50,000$} & \multicolumn{2}{|c|}{$50,000+$} \\
\hline & NY State & U.S. & NY State & U.S. & NY State & U.S. & NY State & U.S. & NY State & U.S. & NY State & U.S. & NY State & U.S. \\
\hline \multicolumn{15}{|c|}{ Percent Not Taking Walk Trips in the last week } \\
\hline TOTAL & $27.1 \%$ & $36.3 \%$ & $28.9 \%$ & $36.4 \%$ & $29.4 \%$ & $36.8 \%$ & $31.2 \%$ & $36.1 \%$ & $27.0 \%$ & $30.4 \%$ & $17.9 \%$ & $26.1 \%$ & $12.3 \%$ & $13.4 \%$ \\
\hline 5 to 10 year-olds & & & & & & & & & & & * & & * & \\
\hline 11 to 15 year-olds & * & & * & * & * & & * & * & * & * & * & * & * & * \\
\hline 16 to 20 year-olds & $29.2 \%$ & $38.3 \%$ & $32.4 \%$ & $36.9 \%$ & $35.3 \%$ & $34.8 \%$ & $18.0 \%$ & $33.5 \%$ & $17.9 \%$ & $30.6 \%$ & $7.7 \%$ & $23.9 \%$ & $16.7 \%$ & $100.0 \%$ \\
\hline 21 to 35 year-olds & $25.8 \%$ & $35.1 \%$ & $30.4 \%$ & $37.4 \%$ & $27.7 \%$ & $36.2 \%$ & $31.5 \%$ & $35.7 \%$ & $25.3 \%$ & $28.0 \%$ & $17.3 \%$ & $24.2 \%$ & $7.6 \%$ & $4.5 \%$ \\
\hline 36 to 64 year-olds & $26.6 \%$ & $34.7 \%$ & $26.0 \%$ & $34.5 \%$ & $25.5 \%$ & $36.3 \%$ & $30.9 \%$ & $35.0 \%$ & $25.6 \%$ & $29.8 \%$ & $18.3 \%$ & $21.7 \%$ & $13.2 \%$ & $25.9 \%$ \\
\hline $65+$ year-olds & $29.3 \%$ & $42.1 \%$ & $33.8 \%$ & $41.9 \%$ & $38.6 \%$ & $40.8 \%$ & $36.3 \%$ & $41.8 \%$ & $43.0 \%$ & $41.9 \%$ & $23.2 \%$ & $44.7 \%$ & $16.6 \%$ & $16.3 \%$ \\
\hline \multicolumn{15}{|c|}{ Avg Minutes Spent Walking per Day } \\
\hline TOTAL & 3.76 & 3.05 & 5.19 & 4.05 & 4.56 & 4.55 & 8.34 & 5.83 & 8.14 & 8.93 & 16.31 & 8.59 & 17.76 & 21.58 \\
\hline 5 to 10 year-olds & 2.34 & 3.22 & 5.93 & 2.88 & 2.16 & 3.75 & 6.14 & 7.19 & 11.53 & 14.92 & 12.31 & 9.86 & 16.89 & 3.80 \\
\hline 11 to 15 year-olds & 3.35 & 3.47 & 5.92 & 4.68 & 7.08 & 5.86 & 13.71 & 10.12 & 14.01 & 9.97 & 16.35 & 14.77 & 13.06 & 1.25 \\
\hline 16 to 20 year-olds & 0.93 & 1.58 & 3.67 & 2.76 & 6.39 & 5.19 & 8.29 & 6.16 & 14.57 & 8.48 & 14.24 & 8.50 & 13.35 & 49.00 \\
\hline 21 to 35 year-olds & 3.42 & 2.65 & 4.32 & 3.04 & 3.38 & 4.20 & 6.56 & 5.58 & 4.76 & 8.36 & 21.53 & 8.46 & 21.05 & 27.56 \\
\hline 36 to 64 year-olds & 4.95 & 3.26 & 5.77 & 4.34 & 4.81 & 4.12 & 10.17 & 4.87 & 6.74 & 7.59 & 15.88 & 7.84 & 17.80 & 18.80 \\
\hline $65+$ year-olds & 3.23 & 3.48 & 4.57 & 5.15 & 5.51 & 4.84 & 5.10 & 5.39 & 8.67 & 5.67 & 12.08 & 7.88 & 17.03 & 4.28 \\
\hline \multicolumn{15}{|c|}{ Percent Not Taking Bike Trips in the last week } \\
\hline TOTAL & $93.3 \%$ & $93.1 \%$ & $91.5 \%$ & $91.9 \%$ & $90.1 \%$ & $92.6 \%$ & $92.2 \%$ & $92.2 \%$ & $94.1 \%$ & $92.3 \%$ & $94.1 \%$ & $91.9 \%$ & $95.1 \%$ & $91.6 \%$ \\
\hline 5 to 10 year-olds & * & & * & & * & & * & & * & & * & * & * & * \\
\hline 11 to 15 year-olds & * & & * & * & * & * & * & * & * & * & * & * & * & * \\
\hline 16 to 20 year-olds & $86.2 \%$ & $91.0 \%$ & $86.7 \%$ & $88.4 \%$ & $86.2 \%$ & $87.5 \%$ & $77.1 \%$ & $86.8 \%$ & $91.5 \%$ & $83.7 \%$ & $81.4 \%$ & $83.0 \%$ & $91.4 \%$ & $100.0 \%$ \\
\hline 21 to 35 year-olds & $92.0 \%$ & $91.6 \%$ & $91.5 \%$ & $92.3 \%$ & $89.2 \%$ & $91.1 \%$ & $91.7 \%$ & $90.7 \%$ & $92.3 \%$ & $90.4 \%$ & $90.8 \%$ & $87.7 \%$ & $94.0 \%$ & $79.5 \%$ \\
\hline 36 to 64 year-olds & $93.5 \%$ & $93.5 \%$ & $90.7 \%$ & $91.4 \%$ & $89.2 \%$ & $93.4 \%$ & $92.1 \%$ & $92.8 \%$ & $94.2 \%$ & $94.5 \%$ & $97.0 \%$ & $96.1 \%$ & $95.6 \%$ & $100.0 \%$ \\
\hline $65+$ year-olds & $96.6 \%$ & $95.4 \%$ & $95.5 \%$ & $95.4 \%$ & $93.7 \%$ & $95.8 \%$ & $98.1 \%$ & $96.5 \%$ & $99.1 \%$ & $96.9 \%$ & $98.8 \%$ & $98.0 \%$ & $99.1 \%$ & $100.0 \%$ \\
\hline \multicolumn{15}{|c|}{ Avg Minutes Spent Biking per Day } \\
\hline TOTAL & 0.59 & 0.78 & 0.66 & 1.13 & 1.06 & 0.72 & 0.48 & 0.82 & 0.89 & 0.62 & 0.91 & 1.07 & 0.38 & 1.02 \\
\hline 5 to 10 year-olds & 1.95 & 3.33 & 1.99 & 2.63 & 1.48 & 1.99 & 0.94 & 1.86 & 8.79 & 1.80 & 0.44 & 0.05 & 0.30 & \\
\hline 11 to 15 year-olds & 2.76 & 2.13 & 3.03 & 2.60 & 1.86 & 2.41 & 2.10 & 2.06 & 0.35 & 0.88 & 8.51 & 1.65 & 0.79 & \\
\hline 16 to 20 year-olds & 0.12 & 0.25 & 0.17 & 1.13 & 0.15 & 0.47 & 0.11 & 1.08 & 0.31 & 0.57 & 0.02 & 3.74 & 0.08 & \\
\hline 21 to 35 year-olds & 0.39 & 0.16 & 0.03 & 0.75 & 0.86 & 0.28 & 0.28 & 0.51 & 0.50 & 0.50 & 1.02 & 1.43 & 0.38 & 2.67 \\
\hline 36 to 64 year-olds & 0.16 & 0.48 & 0.30 & 0.84 & 1.13 & 0.58 & 0.15 & 0.69 & 0.11 & 0.41 & 0.33 & 0.53 & 0.54 & \\
\hline $65+$ year-olds & 0.15 & 0.12 & 0.61 & 0.55 & 0.85 & 0.26 & 0.79 & 0.10 & & 0.68 & 0.13 & 1.24 & & \\
\hline \multicolumn{15}{|c|}{ Avg Minutes Spent Walking/Biking per Day } \\
\hline TOTAL & 4.35 & 3.83 & 5.85 & 5.18 & 5.62 & 5.26 & 8.82 & 6.65 & 9.03 & 9.55 & 17.22 & 9.66 & 18.14 & 22.60 \\
\hline 5 to 10 yea & 4.29 & 6.54 & 7.93 & 5.51 & 3.64 & 5.73 & 7.08 & 9.05 & 20.32 & 16.72 & 12.75 & 9.90 & 17.19 & 3.80 \\
\hline 11 to 15 year-olds & 6.11 & 5.60 & 8.95 & 7.28 & 8.94 & 8.26 & 15.81 & 12.17 & 14.36 & 10.85 & 24.86 & 16.42 & 13.85 & 1.25 \\
\hline 16 to 20 year-olds & 1.05 & 1.84 & 3.84 & 3.89 & 6.54 & 5.67 & 8.41 & 7.24 & 14.88 & 9.06 & 14.26 & 12.24 & 13.43 & 49.00 \\
\hline 21 to 35 year-olds & 3.81 & 2.81 & 4.34 & 3.79 & 4.24 & 4.49 & 6.84 & 6.09 & 5.26 & 8.86 & 22.56 & 9.88 & 21.43 & 30.23 \\
\hline 36 to 64 year-olds & 5.11 & 3.74 & 6.07 & 5.18 & 5.94 & 4.71 & 10.32 & 5.56 & 6.85 & 8.00 & 16.21 & 8.37 & 18.34 & 18.80 \\
\hline $65+$ year-olds & 3.38 & 3.59 & 5.18 & 5.70 & 6.36 & 5.10 & 5.89 & 5.49 & 8.67 & 6.35 & 12.21 & 9.12 & 17.03 & 4.28 \\
\hline
\end{tabular}




\begin{tabular}{|c|c|c|c|c|c|c|c|c|c|c|c|c|c|c|}
\hline \multicolumn{15}{|c|}{ Population Density (census tract) } \\
\hline & \multicolumn{2}{|c|}{$<500$} & \multicolumn{2}{|c|}{$500-2,000$} & \multicolumn{2}{|c|}{$2,000-4,000$} & \multicolumn{2}{|c|}{$4,000-10,000$} & \multicolumn{2}{|c|}{$10,000-20,000$} & \multicolumn{2}{|c|}{$20,000-50,000$} & \multicolumn{2}{|c|}{$50,000+$} \\
\hline & NY State & U.S. & NY State & U.S. & NY State & U.S. & NY State & U.s. & NY State & U.S. & NY State & U.S. & NY State & U.s. \\
\hline \multicolumn{15}{|c|}{ Percent Not Taking Walk Trips in the last week } \\
\hline TOTAL & & * & * & * & * & 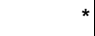 & * & * & * & * & * & * & * & \\
\hline 5 to 10 year-olds & * & * & * & * & * & * & * & * & * & * & * & * & * & \\
\hline 11 to 15 year-olds & * & * & * & * & * & * & * & * & * & * & * & * & * & * \\
\hline 16 to 20 year-olds & * & * & * & * & * & * & * & * & * & * & * & * & * & \\
\hline 21 to 35 year-olds & * & * & * & * & * & * & * & * & * & * & * & * & * & \\
\hline 36 to 64 year-olds & * & * & * & * & * & * & * & * & * & * & * & * & * & \\
\hline $65+$ year-olds & * & * & * & * & * & * & * & * & * & * & * & * & * & \\
\hline \multicolumn{15}{|c|}{ Avg Minutes Spent Walking per Day } \\
\hline TOTAL & 1.89 & 0.92 & 2.02 & 1.19 & 1.83 & 2.21 & 2.84 & 2.77 & 3.43 & 4.95 & 11.26 & 11.55 & 12.77 & 11.11 \\
\hline 5 to 10 year-olds & 1.04 & 1.30 & 1.86 & 1.42 & 1.43 & 3.29 & 2.33 & 3.77 & 2.65 & 4.89 & 12.87 & 8.70 & 12.58 & \\
\hline 11 to 15 year-olds & 6.22 & 1.91 & 2.93 & 2.78 & 3.93 & 5.32 & 5.77 & 5.28 & 2.90 & 14.88 & 14.34 & 10.77 & 16.88 & \\
\hline 16 to 20 year-olds & 0.86 & 0.87 & 2.69 & 1.90 & 4.49 & 2.86 & 3.33 & 4.23 & 3.67 & 5.29 & 12.84 & 13.74 & 10.18 & \\
\hline 21 to 35 year-olds & 0.45 & 0.65 & 1.46 & 0.56 & 0.90 & 1.88 & 3.30 & 2.42 & 3.69 & 5.08 & 10.43 & 11.60 & 13.88 & 18.00 \\
\hline 36 to 64 year-olds & 2.29 & 0.69 & 1.78 & 0.94 & 1.49 & 1.61 & 2.10 & 1.98 & 3.21 & 3.76 & 9.29 & 12.81 & 12.04 & 5.99 \\
\hline $65+$ year-olds & 1.02 & 1.15 & 2.75 & 1.46 & 2.64 & 1.51 & 2.36 & 2.83 & 4.21 & 3.15 & 15.29 & 9.22 & 10.06 & 5.50 \\
\hline \multicolumn{15}{|c|}{ Percent Not Taking Bike Trips in the last week } \\
\hline TOTAL & * & * & * & * & * & * & * & * & * & * & * & * & * & \\
\hline 5 to 10 year-olds & * & * & * & * & * & * & * & * & * & * & * & * & * & \\
\hline 11 to 15 year-olds & * & * & * & * & * & * & * & * & * & * & * & * & * & \\
\hline 16 to 20 year-olds & * & * & * & * & * & * & * & * & * & * & * & * & * & \\
\hline 21 to 35 year-olds & * & * & * & * & * & * & * & * & * & * & * & * & * & \\
\hline 36 to 64 year-olds & * & * & * & * & * & * & * & * & * & * & * & * & * & \\
\hline $65+$ year-olds & * & * & * & * & * & * & * & * & * & * & * & * & * & \\
\hline \multicolumn{15}{|c|}{ Avg Minutes Spent Biking per Day } \\
\hline TOTAL & 0.27 & 0.47 & 0.20 & 0.38 & 0.26 & 0.43 & 0.49 & 0.52 & 0.15 & 0.47 & 0.16 & 0.60 & 0.48 & \\
\hline 5 to 10 year-olds & 0.29 & 0.29 & 0.29 & 0.35 & 0.23 & 0.88 & 0.63 & 1.22 & 0.07 & 0.04 & & 0.24 & 0.18 & \\
\hline 11 to 15 year-olds & 1.37 & 1.11 & 1.06 & 1.46 & 2.21 & 1.24 & 1.95 & 1.61 & 0.62 & 0.94 & 0.10 & 1.37 & 0.26 & \\
\hline 16 to 20 year-olds & 0.52 & 0.17 & 0.35 & 0.70 & 0.06 & 0.75 & 0.39 & 0.32 & 0.24 & 0.53 & 1.21 & 4.98 & 0.34 & \\
\hline 21 to 35 year-olds & 0.06 & 0.23 & 0.25 & 0.22 & 0.16 & 0.42 & 0.57 & 0.67 & 0.12 & 0.91 & 0.14 & 0.41 & 0.88 & \\
\hline 36 to 64 year-olds & 0.18 & 0.70 & 0.01 & 0.27 & 0.02 & 0.20 & 0.26 & 0.19 & 0.16 & 0.26 & 0.11 & 0.03 & 0.35 & \\
\hline $65+$ year-olds & & 0.00 & 0.01 & 0.12 & 0.21 & 0.10 & 0.04 & 0.08 & & & & & & \\
\hline \multicolumn{15}{|c|}{ Avg Minutes Spent Walking/Biking per Day } \\
\hline TOTAL & 2.16 & 1.40 & 2.22 & 1.57 & 2.09 & 2.63 & 3.34 & 3.29 & 3.58 & 5.42 & 11.42 & 12.15 & 13.25 & 11.11 \\
\hline 5 to 10 year-olds & 1.33 & 1.59 & 2.15 & 1.78 & 1.66 & 4.18 & 2.96 & 4.99 & 2.72 & 4.93 & 12.87 & 8.93 & 12.76 & \\
\hline 11 to 15 year-olds & 7.60 & 3.02 & 3.99 & 4.24 & 6.14 & 6.56 & 7.72 & 6.90 & 3.53 & 15.82 & 14.43 & 12.14 & 17.15 & \\
\hline 16 to 20 year-olds & 1.38 & 1.04 & 3.04 & 2.60 & 4.55 & 3.62 & 3.72 & 4.54 & 3.91 & 5.81 & 14.05 & 18.72 & 10.52 & \\
\hline 21 to 35 year-olds & 0.51 & 0.89 & 1.71 & 0.78 & 1.06 & 2.30 & 3.87 & 3.09 & 3.81 & 6.00 & 10.57 & 12.01 & 14.76 & 18.00 \\
\hline 36 to 64 year-olds & 2.46 & 1.39 & 1.80 & 1.21 & 1.51 & 1.81 & 2.36 & 2.17 & 3.37 & 4.02 & 9.40 & 12.84 & 12.39 & 5.99 \\
\hline $65+$ year-olds & 1.02 & 1.15 & 2.76 & 1.58 & 2.86 & 1.61 & 2.40 & 2.91 & 4.21 & 3.15 & 15.29 & 9.22 & 10.06 & 5.50 \\
\hline
\end{tabular}


APPENDIX C4A. SUPPLEMENTAL TABLES FOR CHAPTER 4 STANDARD ERRORS 
Chapter 4: Table 1

Urban Travel and Population Density 2009 NHTS

STANDARD ERRORS

\begin{tabular}{|c|c|c|c|c|c|c|c|c|c|c|c|c|c|c|}
\hline \multicolumn{15}{|c|}{ Population Density (census tract) } \\
\hline & \multicolumn{2}{|c|}{$<500$} & \multicolumn{2}{|c|}{$500-2,000$} & \multicolumn{2}{|c|}{$2,000-4,000$} & \multicolumn{2}{|c|}{$4,000-10,000$} & \multicolumn{2}{|c|}{$10,000-20,000$} & \multicolumn{2}{|c|}{$20,000-50,000$} & \multicolumn{2}{|c|}{$50,000+$} \\
\hline & NY State & U.S. & NY State & U.S. & NY State & U.S. & NY State & U.S. & NY State & U.S. & NY State & U.S. & NY State & U.S. \\
\hline \multicolumn{15}{|l|}{ General Statistics } \\
\hline Households (000) & 12 & 261 & 21 & 296 & 21 & 304 & 28 & 297 & 32 & 200 & 49 & 152 & 42 & 21 \\
\hline Persons (000) & 51 & 753 & 75 & 836 & 69 & 914 & 97 & 822 & 98 & 499 & 146 & 498 & 147 & 63 \\
\hline Drivers $(000)$ & 31 & 564 & 58 & 644 & 53 & 709 & 75 & 616 & 58 & 346 & 95 & 309 & 104 & 39 \\
\hline Workers (000) & 29 & 484 & 45 & 552 & 45 & 595 & 65 & 536 & 63 & 303 & 96 & 319 & 93 & 41 \\
\hline Vehicles (000) & 27 & 665 & 45 & 647 & 44 & 592 & 47 & 593 & 41 & 246 & 49 & 261 & 46 & 20 \\
\hline Workers per Household & 0.03 & 0.03 & 0.03 & 0.02 & 0.04 & 0.02 & 0.04 & 0.02 & 0.07 & 0.04 & 0.08 & 0.09 & 0.04 & 0.23 \\
\hline Vehicles per Household & 0.03 & 0.02 & 0.03 & 0.02 & 0.04 & 0.02 & 0.03 & 0.02 & 0.06 & 0.03 & 0.05 & 0.07 & 0.02 & 0.08 \\
\hline Vehicles per Driver & 0.01 & 0.01 & 0.02 & 0.01 & 0.02 & 0.01 & 0.02 & 0.01 & 0.03 & 0.02 & 0.04 & 0.04 & 0.02 & 0.11 \\
\hline \multicolumn{15}{|c|}{ Distribution of Households by Household Vehicle Count } \\
\hline ALL & $0.0 \%$ & $0.0 \%$ & $0.0 \%$ & $0.0 \%$ & $0.0 \%$ & $0.0 \%$ & $0.0 \%$ & $0.0 \%$ & $0.0 \%$ & $0.0 \%$ & $0.0 \%$ & $0.0 \%$ & $0.0 \%$ & $0.0 \%$ \\
\hline 0 vehicles & $0.7 \%$ & $0.4 \%$ & $0.6 \%$ & $0.4 \%$ & $0.9 \%$ & $0.5 \%$ & $0.9 \%$ & $0.4 \%$ & $3.1 \%$ & $1.3 \%$ & $3.1 \%$ & $2.6 \%$ & $1.7 \%$ & $6.3 \%$ \\
\hline 1 vehicle & $1.1 \%$ & $0.8 \%$ & $1.3 \%$ & $0.8 \%$ & $1.5 \%$ & $0.9 \%$ & $1.4 \%$ & $0.8 \%$ & $3.8 \%$ & $1.5 \%$ & $2.7 \%$ & $2.9 \%$ & $1.5 \%$ & $6.7 \%$ \\
\hline 2 vehicles & $1.2 \%$ & $0.9 \%$ & $1.2 \%$ & $0.9 \%$ & $1.7 \%$ & $0.8 \%$ & $1.0 \%$ & $0.6 \%$ & $2.3 \%$ & $1.4 \%$ & $1.4 \%$ & $2.2 \%$ & $0.7 \%$ & $2.9 \%$ \\
\hline 3 vehicles & $0.7 \%$ & $0.6 \%$ & $0.8 \%$ & $0.6 \%$ & $1.3 \%$ & $0.6 \%$ & $0.9 \%$ & $0.5 \%$ & $1.3 \%$ & $0.6 \%$ & $0.7 \%$ & $1.6 \%$ & $0.4 \%$ & $1.2 \%$ \\
\hline $4+$ vehicles & $0.6 \%$ & $0.6 \%$ & $0.6 \%$ & $0.4 \%$ & $0.9 \%$ & $0.4 \%$ & $0.6 \%$ & $0.3 \%$ & $0.8 \%$ & $0.4 \%$ & $0.8 \%$ & $1.0 \%$ & $0.1 \%$ & \\
\hline \multicolumn{15}{|c|}{ Distribution of Households by Household Income } \\
\hline ALL & $0.0 \%$ & $0.0 \%$ & $0.0 \%$ & $0.0 \%$ & $0.0 \%$ & $0.0 \%$ & $0.0 \%$ & $0.0 \%$ & $0.0 \%$ & $0.0 \%$ & $0.0 \%$ & $0.0 \%$ & $0.0 \%$ & $0.0 \%$ \\
\hline$<\$ 10,000$ & $0.7 \%$ & $0.6 \%$ & $0.4 \%$ & $0.5 \%$ & $0.7 \%$ & $0.5 \%$ & $1.4 \%$ & $0.5 \%$ & $1.4 \%$ & $1.2 \%$ & $2.2 \%$ & $2.7 \%$ & $1.5 \%$ & $2.8 \%$ \\
\hline$\$ 10$ to $\$ 20,000$ & $0.9 \%$ & $0.7 \%$ & $0.8 \%$ & $0.4 \%$ & $0.9 \%$ & $0.7 \%$ & $1.1 \%$ & $0.6 \%$ & $2.0 \%$ & $1.7 \%$ & $1.4 \%$ & $2.8 \%$ & $2.0 \%$ & $12.5 \%$ \\
\hline$\$ 20$ to $\$ 30,000$ & $0.6 \%$ & $0.5 \%$ & $0.9 \%$ & $0.6 \%$ & $1.2 \%$ & $0.5 \%$ & $1.1 \%$ & $0.6 \%$ & $3.0 \%$ & $1.4 \%$ & $1.7 \%$ & $2.7 \%$ & $1.5 \%$ & $3.0 \%$ \\
\hline$\$ 30$ to $\$ 40,000$ & $0.9 \%$ & $0.5 \%$ & $0.8 \%$ & $0.4 \%$ & $0.9 \%$ & $0.5 \%$ & $1.0 \%$ & $0.6 \%$ & $1.5 \%$ & $1.0 \%$ & $3.2 \%$ & $2.3 \%$ & $1.3 \%$ & $2.0 \%$ \\
\hline$\$ 40$ to $\$ 50,000$ & $0.6 \%$ & $0.5 \%$ & $1.1 \%$ & $0.6 \%$ & $1.0 \%$ & $0.5 \%$ & $1.1 \%$ & $0.4 \%$ & $1.3 \%$ & $1.1 \%$ & $1.8 \%$ & $1.3 \%$ & $1.5 \%$ & $1.4 \%$ \\
\hline$\$ 50$ to $\$ 60,000$ & $0.8 \%$ & $0.5 \%$ & $0.6 \%$ & $0.4 \%$ & $0.9 \%$ & $0.5 \%$ & $1.0 \%$ & $0.4 \%$ & $1.1 \%$ & $1.1 \%$ & $1.9 \%$ & $1.2 \%$ & $1.0 \%$ & $6.0 \%$ \\
\hline$\$ 60$ to $\$ 70,000$ & $0.6 \%$ & $0.4 \%$ & $0.9 \%$ & $0.4 \%$ & $0.9 \%$ & $0.4 \%$ & $1.0 \%$ & $0.4 \%$ & $2.0 \%$ & $0.7 \%$ & $1.5 \%$ & $2.2 \%$ & $1.0 \%$ & $3.8 \%$ \\
\hline$\$ 70$ to $\$ 80,000$ & $0.7 \%$ & $0.5 \%$ & $0.6 \%$ & $0.4 \%$ & $0.7 \%$ & $0.5 \%$ & $0.9 \%$ & $0.4 \%$ & $0.9 \%$ & $0.5 \%$ & $0.9 \%$ & $1.2 \%$ & $1.1 \%$ & $2.1 \%$ \\
\hline$\$ 80$ to $\$ 100,000$ & $0.5 \%$ & $0.6 \%$ & $0.7 \%$ & $0.5 \%$ & $1.1 \%$ & $0.4 \%$ & $0.7 \%$ & $0.4 \%$ & $2.0 \%$ & $0.5 \%$ & $1.9 \%$ & $1.1 \%$ & $1.2 \%$ & $4.1 \%$ \\
\hline$\$ 100,000_{+}$ & $1.0 \%$ & $0.7 \%$ & $1.3 \%$ & $0.6 \%$ & $1.7 \%$ & $0.5 \%$ & $1.3 \%$ & $0.5 \%$ & $2.1 \%$ & $1.1 \%$ & $2.1 \%$ & $1.5 \%$ & $1.3 \%$ & $10.1 \%$ \\
\hline Unreported & $0.7 \%$ & $0.5 \%$ & $0.7 \%$ & $0.3 \%$ & $1.0 \%$ & $0.4 \%$ & $1.2 \%$ & $0.5 \%$ & $1.0 \%$ & $1.0 \%$ & $1.6 \%$ & $2.1 \%$ & $1.5 \%$ & $3.5 \%$ \\
\hline Licensing Rat & $0.7 \%$ & $0.5 \%$ & $1.0 \%$ & $0.4 \%$ & $0.7 \%$ & $0.7 \%$ & $1.2 \%$ & $0.5 \%$ & $2.2 \%$ & $1.4 \%$ & $2.3 \%$ & $2.3 \%$ & $1.9 \%$ & $10.3 \%$ \\
\hline$\%$ Male Drivers/Male 16+ & $0.7 \%$ & $0.7 \%$ & $1.5 \%$ & $0.6 \%$ & $0.7 \%$ & $1.0 \%$ & $1.2 \%$ & $0.6 \%$ & $3.7 \%$ & $1.3 \%$ & $4.2 \%$ & $4.0 \%$ & $2.6 \%$ & $8.0 \%$ \\
\hline$\%$ Female Drivers/Female 16+ & $1.2 \%$ & $0.7 \%$ & $1.0 \%$ & $0.7 \%$ & $1.1 \%$ & $0.6 \%$ & $1.7 \%$ & $0.7 \%$ & $2.1 \%$ & $2.1 \%$ & $3.4 \%$ & $2.8 \%$ & $2.8 \%$ & $17.1 \%$ \\
\hline
\end{tabular}


Chapter 4: Table 1

Urban Travel and Population Density

2001 NHTS

STANDARD ERRORS

\begin{tabular}{|c|c|c|c|c|c|c|c|c|c|c|c|c|c|c|}
\hline \multicolumn{15}{|c|}{ Population Density (census tract) } \\
\hline & \multicolumn{2}{|c|}{$<500$} & \multicolumn{2}{|c|}{$500-2,000$} & \multicolumn{2}{|c|}{$2,000-4,000$} & \multicolumn{2}{|c|}{$4,000-10,000$} & \multicolumn{2}{|c|}{$10,000-20,000$} & \multicolumn{2}{|c|}{$20,000-50,000$} & \multicolumn{2}{|c|}{$50,000+$} \\
\hline & NY State & U.S. & NY State & U.S. & NY State & U.S. & NY State & U.S. & NY State & U.S. & NY State & U.S. & NY State & U.S. \\
\hline General Statistics & & & & & & & & & & & & & & \\
\hline Households & 14 & 214 & 21 & 197 & 20 & 220 & 24 & 259 & 28 & 182 & 36 & 111 & 35 & 36 \\
\hline Drivers (000) & 29 & 498 & 44 & 436 & 42 & 507 & 58 & 471 & 61 & 333 & 66 & 171 & 81 & 48 \\
\hline Workers $(000)$ & 25 & 426 & 37 & 370 & 39 & 434 & 50 & 443 & 56 & 314 & 73 & 183 & 80 & 51 \\
\hline Vehicles (000) & 32 & 567 & 47 & 475 & 45 & 515 & 50 & 522 & 49 & 324 & 46 & 168 & 52 & 29 \\
\hline Workers per Household & 0.03 & 0.02 & 0.03 & 0.02 & 0.04 & 0.02 & 0.04 & 0.02 & 0.06 & 0.04 & 0.05 & 0.06 & 0.03 & 0.25 \\
\hline Vehicles per Household & 0.03 & 0.02 & 0.03 & 0.02 & 0.04 & 0.01 & 0.03 & 0.02 & 0.05 & 0.03 & 0.04 & 0.05 & 0.03 & 0.12 \\
\hline Vehicles per Driver & 0.02 & 0.01 & 0.02 & 0.01 & 0.02 & 0.01 & 0.02 & 0.01 & 0.03 & 0.02 & 0.03 & 0.04 & 0.02 & 0.16 \\
\hline \multicolumn{15}{|c|}{ Distribution of Households by Household Vehicle Count } \\
\hline ALL & $0.0 \%$ & $0.0 \%$ & $0.0 \%$ & $0.0 \%$ & $0.0 \%$ & $0.0 \%$ & $0.0 \%$ & $0.0 \%$ & $0.0 \%$ & $0.0 \%$ & $0.0 \%$ & $0.0 \%$ & $0.0 \%$ & $0.0 \%$ \\
\hline 0 vehicles & $0.7 \%$ & $0.4 \%$ & $0.6 \%$ & $0.4 \%$ & $1.1 \%$ & $0.4 \%$ & $1.0 \%$ & $0.5 \%$ & $2.3 \%$ & $1.2 \%$ & $2.5 \%$ & $2.4 \%$ & $1.8 \%$ & $9.8 \%$ \\
\hline 1 vehicle & $1.4 \%$ & $0.7 \%$ & $1.4 \%$ & $0.7 \%$ & $2.0 \%$ & $0.8 \%$ & $1.5 \%$ & $0.8 \%$ & $2.0 \%$ & $1.8 \%$ & $2.1 \%$ & $2.7 \%$ & $1.7 \%$ & $9.3 \%$ \\
\hline 2 vehicles & $1.4 \%$ & $0.7 \%$ & $1.5 \%$ & $0.8 \%$ & $1.8 \%$ & $0.8 \%$ & $1.2 \%$ & $0.8 \%$ & $1.9 \%$ & $1.6 \%$ & $1.7 \%$ & $2.3 \%$ & $1.0 \%$ & $4.7 \%$ \\
\hline 3 vehicles & $1.0 \%$ & $0.7 \%$ & $1.0 \%$ & $0.6 \%$ & $1.2 \%$ & $0.6 \%$ & $1.0 \%$ & $0.5 \%$ & $1.4 \%$ & $1.0 \%$ & $0.6 \%$ & $1.2 \%$ & $0.2 \%$ & $0.2 \%$ \\
\hline $4+$ vehicles & $0.8 \%$ & $0.5 \%$ & $0.7 \%$ & $0.5 \%$ & $0.7 \%$ & $0.3 \%$ & $0.7 \%$ & $0.3 \%$ & $0.7 \%$ & $0.7 \%$ & $0.3 \%$ & $0.7 \%$ & $0.2 \%$ & \\
\hline \multicolumn{15}{|c|}{ Distribution of Households by Household Income } \\
\hline ALL & $0.0 \%$ & $0.0 \%$ & $0.0 \%$ & $0.0 \%$ & $0.0 \%$ & $0.0 \%$ & $0.0 \%$ & $0.0 \%$ & $0.0 \%$ & $0.0 \%$ & $0.0 \%$ & $0.0 \%$ & $0.0 \%$ & $0.0 \%$ \\
\hline$<\$ 10,000$ & $0.5 \%$ & $0.4 \%$ & $0.6 \%$ & $0.4 \%$ & $0.7 \%$ & $0.4 \%$ & $0.7 \%$ & $0.5 \%$ & $1.3 \%$ & $0.9 \%$ & $1.6 \%$ & $1.6 \%$ & $1.3 \%$ & $7.2 \%$ \\
\hline$\$ 10$ to $\$ 20,000$ & $0.9 \%$ & $0.5 \%$ & $0.6 \%$ & $0.4 \%$ & $1.0 \%$ & $0.5 \%$ & $1.0 \%$ & $0.5 \%$ & $1.5 \%$ & $1.2 \%$ & $1.8 \%$ & $2.0 \%$ & $1.3 \%$ & $8.0 \%$ \\
\hline$\$ 20$ to $\$ 30,000$ & $0.7 \%$ & $0.5 \%$ & $0.7 \%$ & $0.4 \%$ & $1.0 \%$ & $0.5 \%$ & $0.7 \%$ & $0.5 \%$ & $1.2 \%$ & $0.9 \%$ & $1.6 \%$ & $1.6 \%$ & $1.1 \%$ & $9.0 \%$ \\
\hline$\$ 30$ to $\$ 40,000$ & $1.1 \%$ & $0.6 \%$ & $0.8 \%$ & $0.5 \%$ & $1.2 \%$ & $0.6 \%$ & $1.0 \%$ & $0.6 \%$ & $1.7 \%$ & $1.1 \%$ & $1.9 \%$ & $1.9 \%$ & $1.4 \%$ & $6.2 \%$ \\
\hline$\$ 40$ to $\$ 50,000$ & $0.6 \%$ & $0.4 \%$ & $0.6 \%$ & $0.4 \%$ & $0.6 \%$ & $0.3 \%$ & $0.6 \%$ & $0.3 \%$ & $1.1 \%$ & $0.7 \%$ & $0.8 \%$ & $1.7 \%$ & $0.6 \%$ & $3.2 \%$ \\
\hline$\$ 50$ to $\$ 60,000$ & $1.0 \%$ & $0.5 \%$ & $0.8 \%$ & $0.5 \%$ & $0.7 \%$ & $0.5 \%$ & $1.0 \%$ & $0.4 \%$ & $1.7 \%$ & $0.9 \%$ & $1.1 \%$ & $1.2 \%$ & $0.9 \%$ & $3.5 \%$ \\
\hline$\$ 60$ to $\$ 70,000$ & $0.7 \%$ & $0.5 \%$ & $0.7 \%$ & $0.4 \%$ & $0.9 \%$ & $0.5 \%$ & $0.7 \%$ & $0.4 \%$ & $1.1 \%$ & $0.8 \%$ & $1.2 \%$ & $1.2 \%$ & $0.9 \%$ & $2.7 \%$ \\
\hline$\$ 70$ to $\$ 80,000$ & $0.6 \%$ & $0.4 \%$ & $0.6 \%$ & $0.4 \%$ & $0.6 \%$ & $0.4 \%$ & $0.6 \%$ & $0.4 \%$ & $1.1 \%$ & $0.8 \%$ & $0.7 \%$ & $0.6 \%$ & $1.0 \%$ & $1.5 \%$ \\
\hline$\$ 80$ to $\$ 100,000$ & $0.8 \%$ & $0.6 \%$ & $1.0 \%$ & $0.5 \%$ & $1.4 \%$ & $0.5 \%$ & $0.9 \%$ & $0.4 \%$ & $1.4 \%$ & $0.7 \%$ & $0.9 \%$ & $1.1 \%$ & $0.8 \%$ & $1.7 \%$ \\
\hline$\$ 100,000+$ & $1.3 \%$ & $0.6 \%$ & $1.3 \%$ & $0.6 \%$ & $1.7 \%$ & $0.5 \%$ & $1.3 \%$ & $0.6 \%$ & $1.7 \%$ & $1.2 \%$ & $1.6 \%$ & $1.5 \%$ & $1.1 \%$ & $7.1 \%$ \\
\hline Unreported & $0.6 \%$ & $0.4 \%$ & $0.7 \%$ & $0.5 \%$ & $1.1 \%$ & $0.5 \%$ & $0.9 \%$ & $0.5 \%$ & $1.0 \%$ & $0.8 \%$ & $1.5 \%$ & $1.1 \%$ & $1.1 \%$ & $4.4 \%$ \\
\hline Licensir & $0.7 \%$ & $0.4 \%$ & $0.5 \%$ & $0.4 \%$ & $0.9 \%$ & $0.3 \%$ & $1.0 \%$ & $0.4 \%$ & $2.0 \%$ & $1.1 \%$ & $2.0 \%$ & $2.3 \%$ & $1.8 \%$ & $8.0 \%$ \\
\hline$\%$ Male Drivers/Male 16+ & $0.8 \%$ & $0.4 \%$ & $0.6 \%$ & $0.5 \%$ & $1.0 \%$ & $0.5 \%$ & $1.2 \%$ & $0.5 \%$ & $2.7 \%$ & $1.4 \%$ & $2.8 \%$ & $2.8 \%$ & $2.7 \%$ & $7.2 \%$ \\
\hline$\%$ Female Drivers/Female 16+ & $1.0 \%$ & $0.6 \%$ & $0.8 \%$ & $0.5 \%$ & $1.2 \%$ & $0.6 \%$ & $1.4 \%$ & $0.7 \%$ & $3.4 \%$ & $1.5 \%$ & $2.6 \%$ & $2.8 \%$ & $2.1 \%$ & $21.1 \%$ \\
\hline
\end{tabular}


Chapter 4: Table 2

Urban Travel and Population Density

2009 NHTS

STANDARD ERRORS

\begin{tabular}{|c|c|c|c|c|c|c|c|c|c|c|c|c|c|c|}
\hline \multicolumn{15}{|c|}{ Population Density (census tract) } \\
\hline & \multirow{2}{*}{\multicolumn{2}{|c|}{$\begin{array}{c}<500 \\
\end{array}$}} & \multicolumn{2}{|c|}{$500-2,000$} & \multicolumn{2}{|c|}{$2,000-4,000$} & \multicolumn{2}{|c|}{$4,000-10,000$} & \multicolumn{2}{|c|}{$10,000-20,000$} & \multicolumn{2}{|c|}{$20,000-50,000$} & \multicolumn{2}{|c|}{$50,000+$} \\
\hline & & U.S. & NY State & U.S. & NY State & U.S. & NY State & U.S. & NY State & U.S. & NY State & U.S. & NY State & U.S. \\
\hline Daily Person Trips per Person & & & & & & & & & & & & & & \\
\hline TOTAL & 0.07 & 0.05 & 0.09 & 0.04 & 0.09 & 0.05 & 0.07 & 0.04 & 0.14 & 0.07 & 0.13 & 0.21 & 0.12 & 0.41 \\
\hline Male & 0.08 & 0.06 & 0.09 & 0.04 & 0.10 & 0.06 & 0.09 & 0.05 & 0.21 & 0.09 & 0.19 & 0.21 & 0.14 & 0.36 \\
\hline Female & 0.10 & 0.05 & 0.11 & 0.05 & 0.10 & 0.06 & 0.11 & 0.05 & 0.19 & 0.11 & 0.16 & 0.26 & 0.15 & 0.54 \\
\hline TOTAL & 0.07 & 0.05 & 0.09 & 0.04 & 0.09 & 0.05 & 0.07 & 0.04 & 0.14 & 0.07 & 0.13 & 0.21 & 0.12 & 0.41 \\
\hline $5-15$ years & 0.12 & 0.08 & 0.17 & 0.09 & 0.20 & 0.10 & 0.29 & 0.09 & 0.22 & 0.09 & 0.21 & 0.30 & 0.22 & 0.39 \\
\hline $16-19$ years & 0.22 & 0.14 & 0.35 & 0.10 & 0.25 & 0.21 & 0.29 & 0.13 & 0.37 & 0.26 & 0.69 & 0.51 & 0.34 & 0.70 \\
\hline 20-34 years & 0.12 & 0.10 & 0.28 & 0.10 & 0.18 & 0.10 & 0.19 & 0.09 & 0.35 & 0.19 & 0.33 & 0.42 & 0.34 & 0.45 \\
\hline $35-54$ years & 0.10 & 0.07 & 0.12 & 0.06 & 0.14 & 0.08 & 0.13 & 0.06 & 0.25 & 0.11 & 0.23 & 0.25 & 0.16 & 0.35 \\
\hline 55-64 years & 0.11 & 0.08 & 0.18 & 0.09 & 0.20 & 0.08 & 0.17 & 0.09 & 0.31 & 0.18 & 0.34 & 0.26 & 0.29 & 0.64 \\
\hline $65+$ years & 0.22 & 0.09 & 0.10 & 0.09 & 0.14 & 0.09 & 0.16 & 0.07 & 0.23 & 0.14 & 0.19 & 0.43 & 0.23 & 0.66 \\
\hline TOTAL & 0.07 & 0.05 & 0.09 & 0.04 & 0.09 & 0.05 & 0.07 & 0.04 & 0.14 & 0.07 & 0.13 & 0.21 & 0.12 & 0.41 \\
\hline$\%$ POV & $0.7 \%$ & $0.4 \%$ & $0.7 \%$ & $0.4 \%$ & $0.9 \%$ & $0.5 \%$ & $1.2 \%$ & $0.5 \%$ & $2.7 \%$ & $1.5 \%$ & $3.5 \%$ & $4.4 \%$ & $1.8 \%$ & $6.8 \%$ \\
\hline$\%$ Public & $0.1 \%$ & $0.1 \%$ & $0.2 \%$ & $0.1 \%$ & $0.3 \%$ & $0.2 \%$ & $0.5 \%$ & $0.2 \%$ & $2.4 \%$ & $0.7 \%$ & $2.2 \%$ & $1.7 \%$ & $1.6 \%$ & $2.7 \%$ \\
\hline$\%$ Walk & $0.4 \%$ & $0.4 \%$ & $0.4 \%$ & $0.3 \%$ & $0.7 \%$ & $0.4 \%$ & $0.9 \%$ & $0.4 \%$ & $1.9 \%$ & $1.3 \%$ & $2.7 \%$ & $3.3 \%$ & $1.8 \%$ & $6.5 \%$ \\
\hline$\%$ Other & $0.7 \%$ & $0.3 \%$ & $0.6 \%$ & $0.2 \%$ & $0.6 \%$ & $0.2 \%$ & $0.5 \%$ & $0.2 \%$ & $0.6 \%$ & $0.7 \%$ & $0.7 \%$ & $1.0 \%$ & $0.8 \%$ & $1.4 \%$ \\
\hline$\%$ Unreported & $0.1 \%$ & $0.1 \%$ & $0.1 \%$ & $0.0 \%$ & $0.2 \%$ & $0.0 \%$ & $0.0 \%$ & $0.1 \%$ & $0.3 \%$ & $0.1 \%$ & $0.2 \%$ & $0.1 \%$ & $0.0 \%$ & \\
\hline TOTAL & 0.07 & 0.05 & 0.09 & 0.04 & 0.09 & 0.05 & 0.07 & 0.04 & 0.14 & 0.07 & 0.13 & 0.21 & 0.12 & 0.41 \\
\hline$\%$ SOV & $1.2 \%$ & $0.7 \%$ & $1.1 \%$ & $0.6 \%$ & $1.4 \%$ & $0.7 \%$ & $1.6 \%$ & $0.7 \%$ & $2.2 \%$ & $1.0 \%$ & $1.7 \%$ & $2.7 \%$ & $0.7 \%$ & $6.1 \%$ \\
\hline$\%$ MOV & $1.5 \%$ & $0.8 \%$ & $1.1 \%$ & $0.7 \%$ & $1.3 \%$ & $0.7 \%$ & $2.1 \%$ & $0.7 \%$ & $2.7 \%$ & $1.3 \%$ & $2.9 \%$ & $3.1 \%$ & $1.6 \%$ & $1.9 \%$ \\
\hline$\%$ Amtrak & $0.0 \%$ & $0.0 \%$ & $0.0 \%$ & $0.0 \%$ & $0.0 \%$ & $0.0 \%$ & & $0.0 \%$ & $0.1 \%$ & $0.0 \%$ & $0.4 \%$ & $0.1 \%$ & $0.1 \%$ & $0.4 \%$ \\
\hline$\%$ Commuter Train & $0.0 \%$ & $0.0 \%$ & $0.1 \%$ & $0.0 \%$ & $0.2 \%$ & $0.0 \%$ & $0.2 \%$ & $0.0 \%$ & $0.3 \%$ & $0.0 \%$ & $1.1 \%$ & $0.4 \%$ & $0.5 \%$ & $0.5 \%$ \\
\hline$\%$ Subway/El Rail & $0.1 \%$ & $0.0 \%$ & $0.1 \%$ & $0.0 \%$ & $0.1 \%$ & $0.1 \%$ & $0.2 \%$ & $0.0 \%$ & $1.0 \%$ & $0.1 \%$ & $1.9 \%$ & $0.8 \%$ & $1.1 \%$ & $4.5 \%$ \\
\hline$\%$ Other Public & $0.1 \%$ & $0.1 \%$ & $0.1 \%$ & $0.1 \%$ & $0.1 \%$ & $0.1 \%$ & $0.4 \%$ & $0.1 \%$ & $1.6 \%$ & $0.7 \%$ & $1.3 \%$ & $1.4 \%$ & $1.3 \%$ & $4.8 \%$ \\
\hline$\%$ Walk & $0.4 \%$ & $0.4 \%$ & $0.4 \%$ & $0.3 \%$ & $0.7 \%$ & $0.4 \%$ & $0.9 \%$ & $0.4 \%$ & $1.9 \%$ & $1.3 \%$ & $2.7 \%$ & $3.3 \%$ & $1.8 \%$ & $6.5 \%$ \\
\hline$\%$ Other & $0.7 \%$ & $0.3 \%$ & $0.6 \%$ & $0.2 \%$ & $0.6 \%$ & $0.2 \%$ & $0.6 \%$ & $0.2 \%$ & $0.7 \%$ & $0.8 \%$ & $0.7 \%$ & $0.9 \%$ & $0.9 \%$ & $1.4 \%$ \\
\hline$\%$ Unreported & $0.1 \%$ & $0.1 \%$ & $0.1 \%$ & $0.0 \%$ & $0.2 \%$ & $0.0 \%$ & $0.0 \%$ & $0.1 \%$ & $0.3 \%$ & $0.1 \%$ & $0.2 \%$ & $0.1 \%$ & $0.0 \%$ & \\
\hline TOTAL & 0.07 & 0.05 & 0.09 & 0.04 & 0.09 & 0.05 & 0.07 & 0.04 & 0.14 & 0.07 & 0.13 & 0.21 & 0.12 & 0.41 \\
\hline$\%$ Earn a Living & $0.7 \%$ & $0.5 \%$ & $0.7 \%$ & $0.4 \%$ & $1.0 \%$ & $0.4 \%$ & $1.0 \%$ & $0.4 \%$ & $1.6 \%$ & $0.7 \%$ & $1.7 \%$ & $1.4 \%$ & $1.0 \%$ & $3.3 \%$ \\
\hline$\%$ Family \& Personal Business & $0.9 \%$ & $0.6 \%$ & $0.8 \%$ & $0.5 \%$ & $1.2 \%$ & $0.6 \%$ & $1.3 \%$ & $0.5 \%$ & $2.3 \%$ & $1.2 \%$ & $2.1 \%$ & $1.4 \%$ & $1.6 \%$ & $8.7 \%$ \\
\hline$\%$ Civic, Educational \& Religious & $0.7 \%$ & $0.3 \%$ & $0.6 \%$ & $0.3 \%$ & $0.7 \%$ & $0.4 \%$ & $0.7 \%$ & $0.3 \%$ & $1.8 \%$ & $0.8 \%$ & $1.1 \%$ & $2.2 \%$ & $1.2 \%$ & $1.7 \%$ \\
\hline$\%$ Social \& Recreational & $0.8 \%$ & $0.6 \%$ & $0.8 \%$ & $0.5 \%$ & $1.3 \%$ & $0.5 \%$ & $1.2 \%$ & $0.5 \%$ & $3.5 \%$ & $1.1 \%$ & $2.2 \%$ & $2.0 \%$ & $1.5 \%$ & $4.4 \%$ \\
\hline$\%$ Other & $0.1 \%$ & $0.1 \%$ & $0.4 \%$ & $0.1 \%$ & $0.2 \%$ & $0.1 \%$ & $0.2 \%$ & $0.1 \%$ & $0.5 \%$ & $0.2 \%$ & $0.2 \%$ & $1.0 \%$ & $0.5 \%$ & \\
\hline$\%$ Unreported & $0.1 \%$ & $0.1 \%$ & $0.1 \%$ & $0.1 \%$ & $0.2 \%$ & $0.1 \%$ & $0.1 \%$ & $0.1 \%$ & $0.2 \%$ & $0.1 \%$ & $0.5 \%$ & $0.2 \%$ & $0.1 \%$ & $4.0 \%$ \\
\hline TOTAL & 0.07 & 0.05 & 0.09 & 0.04 & 0.09 & 0.05 & 0.07 & 0.04 & 0.14 & 0.07 & 0.13 & 0.21 & 0.12 & 0.41 \\
\hline Weekend & 0.10 & 0.07 & 0.13 & 0.07 & 0.14 & 0.11 & 0.21 & 0.08 & 0.34 & 0.12 & 0.30 & 0.41 & 0.25 & 0.65 \\
\hline Weekday & 0.09 & 0.06 & 0.09 & 0.04 & 0.10 & 0.05 & 0.09 & 0.05 & 0.13 & 0.09 & 0.14 & 0.19 & 0.13 & 0.44 \\
\hline
\end{tabular}


Chapter 4: Table 2

Urban Travel and Population Density

2001 NHTS

STANDARD ERRORS

\begin{tabular}{|c|c|c|c|c|c|c|c|c|c|c|c|c|c|c|}
\hline \multicolumn{15}{|c|}{ Population Density (census tract) } \\
\hline & \multicolumn{2}{|c|}{$\begin{array}{c}<500 \\
<Y \text { State }\end{array}$} & \multicolumn{2}{|c|}{$500-2,000$} & \multicolumn{2}{|c|}{$2,000-4,000$} & \multicolumn{2}{|c|}{$4,000-10,000$} & \multicolumn{2}{|c|}{$10,000-20,000$} & \multicolumn{2}{|c|}{$20,000-50,000$} & \multicolumn{2}{|c|}{$50,000+$} \\
\hline & NY State & U.S. & NY State & U.S. & NY State & U.S. & NY State & U.S. & NY State & U.S. & NY State & U.S. & NY State & U.S. \\
\hline Daily Person Trips per Person & & & & & & & & & & & & & & \\
\hline TOTAL & 0.05 & 0.05 & 0.07 & 0.04 & 0.10 & 0.04 & 0.08 & 0.04 & 0.09 & 0.08 & 0.11 & 0.10 & 0.08 & 0.38 \\
\hline Male & 0.07 & 0.05 & 0.09 & 0.05 & 0.12 & 0.05 & 0.11 & 0.05 & 0.12 & 0.10 & 0.17 & 0.13 & 0.10 & 0.46 \\
\hline Female & 0.07 & 0.05 & 0.09 & 0.05 & 0.13 & 0.05 & 0.10 & 0.05 & 0.12 & 0.10 & 0.13 & 0.13 & 0.10 & 0.56 \\
\hline \begin{tabular}{|l} 
TOTAL \\
$0-4$ years
\end{tabular} & 0.05 & 0.05 & 0.07 & 0.04 & 0.10 & 0.04 & 0.08 & 0.04 & 0.09 & 0.08 & 0.11 & 0.10 & 0.08 & 0.38 \\
\hline $5-15$ years & 0.10 & 0.08 & 0.15 & 0.09 & 0.24 & 0.07 & 0.13 & 0.08 & 0.18 & 0.17 & 0.24 & 0.28 & 0.14 & 0.58 \\
\hline $16-19$ years & 0.17 & 0.14 & 0.19 & 0.15 & 0.45 & 0.18 & 0.36 & 0.13 & 0.33 & 0.21 & 0.27 & 0.63 & 0.23 & 1.99 \\
\hline 20-34 years & 0.15 & 0.10 & 0.12 & 0.08 & 0.18 & 0.09 & 0.19 & 0.07 & 0.20 & 0.11 & 0.23 & 0.16 & 0.17 & 0.49 \\
\hline $35-54$ years & 0.09 & 0.07 & 0.14 & 0.06 & 0.17 & 0.07 & 0.11 & 0.06 & 0.14 & 0.13 & 0.18 & 0.18 & 0.12 & 0.97 \\
\hline $55-64$ years & 0.13 & 0.10 & 0.16 & 0.10 & 0.21 & 0.10 & 0.18 & 0.10 & 0.23 & 0.24 & 0.37 & 0.34 & 0.20 & 1.03 \\
\hline $65+$ years & 0.17 & 0.09 & 0.14 & 0.09 & 0.21 & 0.10 & 0.18 & 0.09 & 0.29 & 0.22 & 0.23 & 0.23 & 0.20 & 4.11 \\
\hline Unreported & 0.28 & 0.25 & 0.28 & 0.30 & 0.54 & 0.30 & 0.44 & 0.28 & 0.55 & 0.50 & 0.63 & 0.34 & 0.54 & 0.47 \\
\hline TOTAL & 0.05 & 0.05 & 0.07 & 0.04 & 0.10 & 0.04 & 0.08 & 0.04 & 0.09 & 0.08 & 0.11 & 0.10 & 0.08 & 0.38 \\
\hline$\%$ POV & $0.9 \%$ & $0.4 \%$ & $0.7 \%$ & $0.4 \%$ & $0.9 \%$ & $0.3 \%$ & $1.0 \%$ & $0.4 \%$ & $2.5 \%$ & $1.1 \%$ & $2.0 \%$ & $2.2 \%$ & $1.7 \%$ & $11.7 \%$ \\
\hline$\%$ Public & $0.3 \%$ & $0.0 \%$ & $0.2 \%$ & $0.1 \%$ & $0.3 \%$ & $0.1 \%$ & $0.3 \%$ & $0.1 \%$ & $1.1 \%$ & $0.4 \%$ & $1.4 \%$ & $0.9 \%$ & $1.1 \%$ & $8.3 \%$ \\
\hline$\%$ Walk & $0.7 \%$ & $0.3 \%$ & $0.5 \%$ & $0.3 \%$ & $0.6 \%$ & $0.3 \%$ & $0.7 \%$ & $0.3 \%$ & $1.7 \%$ & $0.9 \%$ & $1.7 \%$ & $1.7 \%$ & $1.5 \%$ & $6.3 \%$ \\
\hline$\%$ Other & $0.5 \%$ & $0.2 \%$ & $0.3 \%$ & $0.2 \%$ & $0.5 \%$ & $0.2 \%$ & $0.5 \%$ & $0.2 \%$ & $0.5 \%$ & $0.4 \%$ & $0.9 \%$ & $0.7 \%$ & $0.5 \%$ & $3.0 \%$ \\
\hline$\%$ Unreported & $0.0 \%$ & $0.0 \%$ & $0.0 \%$ & $0.0 \%$ & $0.0 \%$ & $0.0 \%$ & $0.0 \%$ & $0.0 \%$ & $0.1 \%$ & $0.0 \%$ & $0.1 \%$ & $0.1 \%$ & $0.1 \%$ & $0.0 \%$ \\
\hline TOTAL & 0.05 & 0.05 & 0.07 & 0.04 & 0.10 & 0.04 & 0.08 & 0.04 & 0.09 & 0.08 & 0.11 & 0.10 & 0.08 & 0.38 \\
\hline$\%$ SOV & $1.1 \%$ & $0.6 \%$ & $0.9 \%$ & $0.6 \%$ & $1.5 \%$ & $0.6 \%$ & $1.1 \%$ & $0.6 \%$ & $1.9 \%$ & $1.2 \%$ & $1.3 \%$ & $1.6 \%$ & $0.9 \%$ & $8.5 \%$ \\
\hline$\%$ MOV & $1.1 \%$ & $0.6 \%$ & $1.1 \%$ & $0.6 \%$ & $1.5 \%$ & $0.6 \%$ & $1.1 \%$ & $0.6 \%$ & $2.0 \%$ & $1.3 \%$ & $1.7 \%$ & $2.2 \%$ & $1.6 \%$ & $5.1 \%$ \\
\hline$\%$ Amtrak & $0.0 \%$ & $0.0 \%$ & $0.1 \%$ & $0.0 \%$ & $0.0 \%$ & $0.1 \%$ & $0.1 \%$ & $0.0 \%$ & $0.2 \%$ & $0.0 \%$ & $0.2 \%$ & & $0.1 \%$ & \\
\hline$\%$ Commuter Train & $0.1 \%$ & $0.0 \%$ & $0.1 \%$ & $0.0 \%$ & $0.2 \%$ & $0.0 \%$ & $0.2 \%$ & $0.0 \%$ & $0.1 \%$ & $0.0 \%$ & $0.2 \%$ & $0.1 \%$ & $0.1 \%$ & \\
\hline$\%$ Subway/El Rail & $0.2 \%$ & $0.0 \%$ & $0.2 \%$ & $0.0 \%$ & $0.1 \%$ & $0.0 \%$ & $0.2 \%$ & $0.0 \%$ & $0.9 \%$ & $0.2 \%$ & $1.1 \%$ & $0.3 \%$ & $1.0 \%$ & $2.4 \%$ \\
\hline$\%$ Other Public & $0.2 \%$ & $0.0 \%$ & $0.0 \%$ & $0.1 \%$ & $0.1 \%$ & $0.1 \%$ & $0.3 \%$ & $0.1 \%$ & $0.6 \%$ & $0.4 \%$ & $0.8 \%$ & $0.8 \%$ & $0.7 \%$ & $6.1 \%$ \\
\hline$\%$ Walk & $0.7 \%$ & $0.3 \%$ & $0.5 \%$ & $0.3 \%$ & $0.6 \%$ & $0.3 \%$ & $0.7 \%$ & $0.3 \%$ & $1.7 \%$ & $0.9 \%$ & $1.7 \%$ & $1.7 \%$ & $1.5 \%$ & $6.3 \%$ \\
\hline$\%$ Other & $0.5 \%$ & $0.2 \%$ & $0.3 \%$ & $0.2 \%$ & $0.5 \%$ & $0.2 \%$ & $0.5 \%$ & $0.2 \%$ & $0.5 \%$ & $0.4 \%$ & $0.9 \%$ & $0.7 \%$ & $0.5 \%$ & $3.0 \%$ \\
\hline$\%$ Unreported & $0.0 \%$ & $0.0 \%$ & $0.0 \%$ & $0.0 \%$ & $0.0 \%$ & $0.0 \%$ & $0.0 \%$ & $0.0 \%$ & $0.1 \%$ & $0.0 \%$ & $0.1 \%$ & $0.1 \%$ & $0.1 \%$ & $0.0 \%$ \\
\hline TOTAL & 0.05 & 0.05 & 0.07 & 0.04 & 0.10 & 0.04 & 0.08 & 0.04 & 0.09 & 0.08 & 0.11 & 0.10 & 0.08 & 0.38 \\
\hline$\%$ Earn a Living & $0.6 \%$ & $0.4 \%$ & $0.7 \%$ & $0.3 \%$ & $1.0 \%$ & $0.4 \%$ & $0.7 \%$ & $0.4 \%$ & $1.2 \%$ & $0.8 \%$ & $1.2 \%$ & $1.3 \%$ & $1.1 \%$ & $3.8 \%$ \\
\hline$\%$ Family \& Personal Business & $0.8 \%$ & $0.5 \%$ & $0.9 \%$ & $0.4 \%$ & $1.1 \%$ & $0.5 \%$ & $0.9 \%$ & $0.4 \%$ & $1.4 \%$ & $1.1 \%$ & $1.6 \%$ & $1.4 \%$ & $1.3 \%$ & $6.4 \%$ \\
\hline$\%$ Civic, Educational \& Religious & $0.6 \%$ & $0.3 \%$ & $0.5 \%$ & $0.3 \%$ & $0.6 \%$ & $0.3 \%$ & $0.6 \%$ & $0.3 \%$ & $1.1 \%$ & $0.6 \%$ & $1.0 \%$ & $1.0 \%$ & $0.8 \%$ & $4.0 \%$ \\
\hline$\%$ Social \& Recreational & $0.9 \%$ & $0.5 \%$ & $1.0 \%$ & $0.5 \%$ & $0.9 \%$ & $0.5 \%$ & $0.8 \%$ & $0.4 \%$ & $1.3 \%$ & $1.1 \%$ & $1.1 \%$ & $1.5 \%$ & $1.2 \%$ & $7.8 \%$ \\
\hline$\%$ Other & $0.2 \%$ & $0.1 \%$ & $0.2 \%$ & $0.1 \%$ & $0.1 \%$ & $0.1 \%$ & $0.3 \%$ & $0.1 \%$ & $0.3 \%$ & $0.1 \%$ & $0.4 \%$ & $0.5 \%$ & $0.2 \%$ & $0.0 \%$ \\
\hline$\%$ Unreported & $0.1 \%$ & $0.0 \%$ & $0.1 \%$ & $0.0 \%$ & $0.1 \%$ & $0.0 \%$ & $0.1 \%$ & $0.0 \%$ & $0.1 \%$ & $0.1 \%$ & $0.1 \%$ & $0.0 \%$ & $0.1 \%$ & $1.3 \%$ \\
\hline TOTAL & 0.05 & 0.05 & 0.07 & 0.04 & 0.10 & 0.04 & 0.08 & 0.04 & 0.09 & 0.08 & 0.11 & 0.10 & 0.08 & 0.38 \\
\hline Weekend & 0.10 & 0.08 & 0.16 & 0.09 & 0.23 & 0.08 & 0.19 & 0.08 & 0.17 & 0.19 & 0.16 & 0.23 & 0.17 & 0.53 \\
\hline Weekday & 0.06 & 0.05 & 0.08 & 0.04 & 0.11 & 0.05 & 0.09 & 0.04 & 0.11 & 0.08 & 0.15 & 0.12 & 0.09 & 0.45 \\
\hline
\end{tabular}


Chapter 4: Table 3

Urban Travel and Population Density

2009 NHTS

STANDARD ERRORS

\begin{tabular}{|c|c|c|c|c|c|c|c|c|c|c|c|c|c|c|}
\hline \multicolumn{15}{|c|}{ Population Density (census tract) } \\
\hline & \multicolumn{2}{|c|}{$<500$} & \multicolumn{2}{|c|}{$500-2,000$} & \multicolumn{2}{|c|}{$2,000-4,000$} & \multicolumn{2}{|c|}{$4,000-10,000$} & \multicolumn{2}{|c|}{$10,000-20,000$} & \multicolumn{2}{|c|}{$20,000-50,000$} & \multicolumn{2}{|c|}{$50,000+$} \\
\hline & NY State & U.S. & NY State & U.S. & NY State & U.S. & NY State & U.S. & NY State & U.S. & NY State & U.S. & NY State & U.S. \\
\hline \multicolumn{15}{|l|}{ Daily Person Trips per Person } \\
\hline$\% 1-9 \min$ & $1.2 \%$ & $0.6 \%$ & $0.9 \%$ & $0.6 \%$ & $1.1 \%$ & $0.6 \%$ & $1.5 \%$ & $0.5 \%$ & $2.0 \%$ & $1.1 \%$ & $2.3 \%$ & $2.1 \%$ & $1.2 \%$ & $2.7 \%$ \\
\hline$\% 10-19 \min$ & $0.8 \%$ & $0.5 \%$ & $0.9 \%$ & $0.5 \%$ & $0.9 \%$ & $0.6 \%$ & $1.4 \%$ & $0.5 \%$ & $1.4 \%$ & $1.0 \%$ & $1.6 \%$ & $2.3 \%$ & $1.2 \%$ & $4.6 \%$ \\
\hline$\%$ 20-29 min & $0.9 \%$ & $0.4 \%$ & $0.7 \%$ & $0.3 \%$ & $0.6 \%$ & $0.3 \%$ & $0.8 \%$ & $0.3 \%$ & $1.6 \%$ & $0.7 \%$ & $1.1 \%$ & $1.1 \%$ & $1.0 \%$ & $2.0 \%$ \\
\hline$\% 30-39 \mathrm{~min}$ & $0.6 \%$ & $0.3 \%$ & $0.5 \%$ & $0.3 \%$ & $0.6 \%$ & $0.3 \%$ & $0.7 \%$ & $0.3 \%$ & $1.5 \%$ & $0.6 \%$ & $1.4 \%$ & $1.4 \%$ & $0.9 \%$ & $4.0 \%$ \\
\hline$\% 40-49 \min$ & $0.2 \%$ & $0.2 \%$ & $0.3 \%$ & $0.2 \%$ & $0.3 \%$ & $0.2 \%$ & $0.4 \%$ & $0.2 \%$ & $0.6 \%$ & $0.4 \%$ & $1.1 \%$ & $0.9 \%$ & $0.8 \%$ & $0.8 \%$ \\
\hline$\% 50+\min$ & $0.4 \%$ & $0.3 \%$ & $0.4 \%$ & $0.3 \%$ & $0.5 \%$ & $0.3 \%$ & $0.5 \%$ & $0.3 \%$ & $1.1 \%$ & $0.6 \%$ & $1.8 \%$ & $1.3 \%$ & $1.2 \%$ & $2.2 \%$ \\
\hline$\%$ Unreported & $0.0 \%$ & $0.1 \%$ & $0.1 \%$ & $0.1 \%$ & $0.1 \%$ & $0.0 \%$ & $0.1 \%$ & $0.1 \%$ & $0.2 \%$ & $0.0 \%$ & $0.5 \%$ & $0.2 \%$ & $0.1 \%$ & $0.2 \%$ \\
\hline TOTAL & 0.07 & 0.05 & 0.09 & 0.04 & 0.09 & 0.05 & 0.07 & 0.04 & 0.14 & 0.07 & 0.13 & 0.21 & 0.12 & 0.41 \\
\hline$\% 5$ or less miles & $1.1 \%$ & $0.7 \%$ & $1.2 \%$ & $0.6 \%$ & $1.0 \%$ & $0.6 \%$ & $1.2 \%$ & $0.6 \%$ & $1.9 \%$ & $1.1 \%$ & $3.0 \%$ & $2.5 \%$ & $1.7 \%$ & $8.4 \%$ \\
\hline$\% 6-10$ miles & $0.6 \%$ & $0.5 \%$ & $0.6 \%$ & $0.4 \%$ & $0.7 \%$ & $0.4 \%$ & $0.7 \%$ & $0.4 \%$ & $1.2 \%$ & $0.7 \%$ & $1.2 \%$ & $1.5 \%$ & $0.9 \%$ & $1.7 \%$ \\
\hline$\% 11-15$ miles & $0.7 \%$ & $0.4 \%$ & $0.5 \%$ & $0.2 \%$ & $0.5 \%$ & $0.2 \%$ & $0.4 \%$ & $0.2 \%$ & $0.6 \%$ & $0.4 \%$ & $0.9 \%$ & $1.0 \%$ & $0.5 \%$ & $1.0 \%$ \\
\hline$\% 16-20$ miles & $0.4 \%$ & $0.3 \%$ & $0.4 \%$ & $0.2 \%$ & $0.3 \%$ & $0.2 \%$ & $0.5 \%$ & $0.2 \%$ & $0.9 \%$ & $0.2 \%$ & $0.6 \%$ & $0.3 \%$ & $0.2 \%$ & $0.5 \%$ \\
\hline$\% 21-30$ miles & $0.4 \%$ & $0.2 \%$ & $0.3 \%$ & $0.3 \%$ & $0.4 \%$ & $0.3 \%$ & $0.4 \%$ & $0.2 \%$ & $0.4 \%$ & $0.2 \%$ & $0.3 \%$ & $0.6 \%$ & $0.2 \%$ & $0.9 \%$ \\
\hline$\% 31$ or more miles & $0.4 \%$ & $0.3 \%$ & $0.4 \%$ & $0.3 \%$ & $0.4 \%$ & $0.2 \%$ & $0.5 \%$ & $0.2 \%$ & $0.4 \%$ & $0.4 \%$ & $0.6 \%$ & $1.1 \%$ & $0.5 \%$ & $0.3 \%$ \\
\hline$\%$ Unreported & $0.2 \%$ & $0.2 \%$ & $1.2 \%$ & $0.2 \%$ & $0.3 \%$ & $0.2 \%$ & $0.3 \%$ & $0.2 \%$ & $1.4 \%$ & $0.5 \%$ & $2.6 \%$ & $1.0 \%$ & $1.0 \%$ & $8.0 \%$ \\
\hline \multicolumn{15}{|l|}{ Daily PMT per Person } \\
\hline TOTAL & 1.58 & 1.41 & 2.20 & 2.65 & 2.03 & 1.96 & 2.88 & 1.09 & 1.12 & 2.08 & 2.07 & 3.29 & 2.10 & 1.67 \\
\hline$\%$ POV & $1.6 \%$ & $1.2 \%$ & $3.2 \%$ & $4.8 \%$ & $5.2 \%$ & $2.1 \%$ & $7.5 \%$ & $2.1 \%$ & $3.6 \%$ & $2.9 \%$ & $6.6 \%$ & $8.2 \%$ & $6.4 \%$ & $12.2 \%$ \\
\hline$\%$ Public & $0.2 \%$ & $0.1 \%$ & $0.6 \%$ & $0.1 \%$ & $0.8 \%$ & $0.3 \%$ & $0.8 \%$ & $0.2 \%$ & $2.8 \%$ & $0.6 \%$ & $3.8 \%$ & $8.2 \%$ & $5.0 \%$ & $8.9 \%$ \\
\hline$\%$ Walk & $0.0 \%$ & $0.0 \%$ & $0.1 \%$ & $0.0 \%$ & $0.1 \%$ & $0.1 \%$ & $0.2 \%$ & $0.1 \%$ & $0.4 \%$ & $0.3 \%$ & $1.0 \%$ & $0.8 \%$ & $1.6 \%$ & $6.7 \%$ \\
\hline$\%$ Other & $1.6 \%$ & $1.2 \%$ & $3.3 \%$ & $4.9 \%$ & $5.4 \%$ & $2.1 \%$ & $7.9 \%$ & $2.2 \%$ & $2.2 \%$ & $2.9 \%$ & $6.4 \%$ & $1.7 \%$ & $1.8 \%$ & $9.2 \%$ \\
\hline$\%$ Unreported & $0.0 \%$ & $0.0 \%$ & $0.0 \%$ & $0.0 \%$ & $0.3 \%$ & $0.1 \%$ & $0.0 \%$ & $0.1 \%$ & $0.1 \%$ & $0.1 \%$ & $0.5 \%$ & & & \\
\hline TOTAL & 1.58 & 1.41 & 2.20 & 2.65 & 2.03 & 1.96 & 2.88 & 1.09 & 1.12 & 2.08 & 2.07 & 3.29 & 2.10 & 1.67 \\
\hline$\%$ sov & $1.9 \%$ & $1.6 \%$ & $2.9 \%$ & $2.7 \%$ & $3.6 \%$ & $2.1 \%$ & $4.4 \%$ & $1.5 \%$ & $3.1 \%$ & $4.0 \%$ & $2.4 \%$ & $7.5 \%$ & $2.6 \%$ & $10.8 \%$ \\
\hline$\%$ MOV & $2.1 \%$ & $1.8 \%$ & $3.4 \%$ & $2.7 \%$ & $3.5 \%$ & $2.6 \%$ & $4.6 \%$ & $1.7 \%$ & $3.9 \%$ & $4.9 \%$ & $6.9 \%$ & $7.3 \%$ & $7.8 \%$ & $3.7 \%$ \\
\hline$\%$ Amtrak & $0.0 \%$ & $0.0 \%$ & $0.1 \%$ & $0.0 \%$ & $0.1 \%$ & $0.0 \%$ & & $0.0 \%$ & $2.0 \%$ & $0.3 \%$ & $0.1 \%$ & $0.1 \%$ & $0.1 \%$ & $0.2 \%$ \\
\hline$\%$ Commuter Train & $0.1 \%$ & $0.0 \%$ & $0.6 \%$ & $0.0 \%$ & $0.8 \%$ & $0.1 \%$ & $0.5 \%$ & $0.1 \%$ & $1.0 \%$ & $0.1 \%$ & $0.5 \%$ & $8.6 \%$ & $1.4 \%$ & $3.7 \%$ \\
\hline$\%$ Subway/El Rail & $0.1 \%$ & $0.0 \%$ & $0.1 \%$ & $0.0 \%$ & $0.1 \%$ & $0.0 \%$ & $0.4 \%$ & $0.1 \%$ & $1.1 \%$ & $0.1 \%$ & $2.9 \%$ & $1.0 \%$ & $3.0 \%$ & $4.1 \%$ \\
\hline$\%$ Other Public & $0.1 \%$ & $0.0 \%$ & $0.1 \%$ & $0.1 \%$ & $0.1 \%$ & $0.1 \%$ & $0.2 \%$ & $0.2 \%$ & $1.5 \%$ & $0.5 \%$ & $1.8 \%$ & $1.6 \%$ & $2.7 \%$ & $9.0 \%$ \\
\hline$\%$ Walk & $0.0 \%$ & $0.0 \%$ & $0.1 \%$ & $0.0 \%$ & $0.1 \%$ & $0.1 \%$ & $0.2 \%$ & $0.1 \%$ & $0.4 \%$ & $0.3 \%$ & $1.0 \%$ & $0.8 \%$ & $1.6 \%$ & $6.7 \%$ \\
\hline$\%$ Other & $1.6 \%$ & $1.2 \%$ & $3.2 \%$ & $4.9 \%$ & $5.4 \%$ & $2.1 \%$ & $7.9 \%$ & $2.1 \%$ & $1.8 \%$ & $2.9 \%$ & $6.5 \%$ & $1.8 \%$ & $1.8 \%$ & $9.1 \%$ \\
\hline$\%$ Unreported & $0.0 \%$ & $0.0 \%$ & $0.0 \%$ & $0.0 \%$ & $0.3 \%$ & $0.1 \%$ & $0.0 \%$ & $0.1 \%$ & $0.1 \%$ & $0.1 \%$ & $0.5 \%$ & & & \\
\hline TOTAL & 1.58 & 1.41 & 2.20 & 2.65 & 2.03 & 1.96 & 2.88 & 1.09 & 1.12 & 2.08 & 2.07 & 3.29 & 2.10 & 1.67 \\
\hline$\%$ Earn a Living & $1.6 \%$ & $1.5 \%$ & $2.9 \%$ & $1.8 \%$ & $2.7 \%$ & $1.4 \%$ & $2.9 \%$ & $1.3 \%$ & $2.9 \%$ & $3.0 \%$ & $7.0 \%$ & $4.0 \%$ & $4.1 \%$ & $7.8 \%$ \\
\hline$\%$ Family \& Pers & $1.4 \%$ & $1.4 \%$ & $1.9 \%$ & $1.9 \%$ & $2.2 \%$ & $1.3 \%$ & $3.8 \%$ & $1.1 \%$ & $2.6 \%$ & $2.9 \%$ & $3.8 \%$ & $3.7 \%$ & $4.7 \%$ & $4.1 \%$ \\
\hline$\%$ Civic, Educational \& Religious & $0.6 \%$ & $0.4 \%$ & $0.5 \%$ & $0.5 \%$ & $0.8 \%$ & $0.4 \%$ & $1.0 \%$ & $0.5 \%$ & $1.4 \%$ & $1.0 \%$ & $1.0 \%$ & $5.7 \%$ & $1.4 \%$ & $9.3 \%$ \\
\hline$\%$ Social \& Recreational & $1.6 \%$ & $1.7 \%$ & $3.0 \%$ & $1.9 \%$ & $4.5 \%$ & $2.0 \%$ & $3.1 \%$ & $2.1 \%$ & $4.1 \%$ & $5.5 \%$ & $5.0 \%$ & $5.1 \%$ & $8.1 \%$ & $5.7 \%$ \\
\hline$\%$ Other & $1.5 \%$ & $0.8 \%$ & $1.7 \%$ & $5.1 \%$ & $3.1 \%$ & $0.9 \%$ & $8.1 \%$ & $1.5 \%$ & $1.4 \%$ & $1.4 \%$ & $0.1 \%$ & $2.1 \%$ & $0.5 \%$ & \\
\hline$\%$ Unreported & $0.4 \%$ & $1.6 \%$ & $3.5 \%$ & $0.5 \%$ & $0.2 \%$ & $1.9 \%$ & $4.3 \%$ & $0.5 \%$ & $0.5 \%$ & $0.3 \%$ & $0.4 \%$ & $8.6 \%$ & $1.5 \%$ & $0.9 \%$ \\
\hline Average Person Trip & & & & & & & & & & & & & & \\
\hline TOTAL & 0.40 & 0.42 & 0.55 & 0.70 & 0.52 & 0.51 & 0.78 & 0.28 & 0.30 & 0.63 & 0.85 & 1.02 & 0.66 & 0.44 \\
\hline
\end{tabular}


Chapter 4: Table 3

Urban Travel and Population Density

2001 NHTS

STANDARD ERRORS

\begin{tabular}{|c|c|c|c|c|c|c|c|c|c|c|c|c|c|c|}
\hline \multicolumn{15}{|c|}{ Population Density (census tract) } \\
\hline & \multirow{2}{*}{\multicolumn{2}{|c|}{\begin{tabular}{ll}
\multicolumn{2}{c}{$<500$} \\
NY State & U.S.
\end{tabular}}} & \multicolumn{2}{|c|}{$500-2,000$} & \multicolumn{2}{|c|}{$2,000-4,000$} & \multicolumn{2}{|c|}{$4,000-10,000$} & \multicolumn{2}{|c|}{$10,000-20,000$} & \multicolumn{2}{|c|}{$20,000-50,000$} & \multicolumn{2}{|c|}{$50,000+$} \\
\hline & & U.S. & NY State & U.S. & NY State & U.S. & NY State & U.S. & NY State & U.S. & NY State & U.S. & NY State & U.S. \\
\hline Daily Person Trips per Person & & & & & & & & & & & & & & \\
\hline $\begin{array}{l}\text { TOTAL } \\
\% 1-9 \min \end{array}$ & $\begin{array}{r}0.05 \\
0.8 \%\end{array}$ & $\begin{array}{r}0.05 \\
0.5 \%\end{array}$ & $\begin{array}{r}0.07 \\
0.9 \%\end{array}$ & $\begin{array}{r}0.04 \\
0.5 \%\end{array}$ & $\begin{array}{r}0.10 \\
1.0 \%\end{array}$ & $\begin{array}{r}0.04 \\
0.5 \%\end{array}$ & $\begin{array}{r}0.08 \\
1.0 \%\end{array}$ & $\begin{array}{r}\mathbf{0 . 0 4} \\
0.5 \%\end{array}$ & $\begin{array}{r}\mathbf{0 . 0 9} \\
1.3 \%\end{array}$ & $\begin{array}{r}0.08 \\
0.8 \%\end{array}$ & $\begin{array}{r}\mathbf{0 . 1 1} \\
1.6 \%\end{array}$ & $\begin{array}{r}\mathbf{0 . 1 0} \\
1.5 \%\end{array}$ & $\begin{array}{r}\mathbf{0 . 0 8} \\
1.0 \%\end{array}$ & $\begin{array}{r}0.38 \\
5.2 \%\end{array}$ \\
\hline$\% 10-19 \min$ & $0.8 \%$ & $0.5 \%$ & $0.8 \%$ & $0.5 \%$ & $1.0 \%$ & $0.5 \%$ & $0.9 \%$ & $0.4 \%$ & $1.3 \%$ & $0.8 \%$ & $1.9 \%$ & $1.3 \%$ & $0.8 \%$ & $3.4 \%$ \\
\hline$\% 20-29 \min$ & $0.6 \%$ & $0.3 \%$ & $0.5 \%$ & $0.3 \%$ & $0.6 \%$ & $0.3 \%$ & $0.6 \%$ & $0.3 \%$ & $0.8 \%$ & $0.6 \%$ & $1.0 \%$ & $1.1 \%$ & $0.5 \%$ & $5.6 \%$ \\
\hline$\% 30-39 \min$ & $0.5 \%$ & $0.3 \%$ & $0.4 \%$ & $0.3 \%$ & $0.7 \%$ & $0.3 \%$ & $0.5 \%$ & $0.2 \%$ & $0.7 \%$ & $0.6 \%$ & $0.8 \%$ & $1.1 \%$ & $0.6 \%$ & $2.4 \%$ \\
\hline$\% 40-49 \min$ & $0.3 \%$ & $0.2 \%$ & $0.3 \%$ & $0.2 \%$ & $0.5 \%$ & $0.2 \%$ & $0.3 \%$ & $0.2 \%$ & $0.5 \%$ & $0.4 \%$ & $0.6 \%$ & $0.5 \%$ & $0.6 \%$ & $2.7 \%$ \\
\hline$\% 50+\min$ & $0.4 \%$ & $0.2 \%$ & $0.4 \%$ & $0.2 \%$ & $0.5 \%$ & $0.2 \%$ & $0.5 \%$ & $0.2 \%$ & $1.2 \%$ & $0.5 \%$ & $1.0 \%$ & $0.7 \%$ & $0.7 \%$ & $3.7 \%$ \\
\hline$\%$ Unreported & $0.3 \%$ & $0.1 \%$ & $0.2 \%$ & $0.2 \%$ & $0.3 \%$ & $0.1 \%$ & $0.3 \%$ & $0.1 \%$ & $0.5 \%$ & $0.3 \%$ & $0.6 \%$ & $0.7 \%$ & $0.6 \%$ & $1.9 \%$ \\
\hline TOTAL & 0.05 & 0.05 & 0.07 & 0.04 & 0.10 & 0.04 & 0.08 & 0.04 & 0.09 & 0.08 & 0.11 & 0.10 & 0.08 & 0.38 \\
\hline$\% 5$ or less miles & $0.9 \%$ & $0.6 \%$ & $0.9 \%$ & $0.6 \%$ & $1.0 \%$ & $0.5 \%$ & $1.1 \%$ & $0.6 \%$ & $1.7 \%$ & $1.3 \%$ & $1.6 \%$ & $1.6 \%$ & $1.2 \%$ & $5.2 \%$ \\
\hline$\% 6-10$ miles & $0.7 \%$ & $0.4 \%$ & $0.7 \%$ & $0.4 \%$ & $0.9 \%$ & $0.4 \%$ & $0.6 \%$ & $0.4 \%$ & $0.9 \%$ & $0.7 \%$ & $0.9 \%$ & $1.1 \%$ & $0.6 \%$ & $1.9 \%$ \\
\hline$\% 11-15$ miles & $0.5 \%$ & $0.3 \%$ & $0.4 \%$ & $0.2 \%$ & $0.5 \%$ & $0.3 \%$ & $0.4 \%$ & $0.2 \%$ & $1.1 \%$ & $0.6 \%$ & $0.6 \%$ & $0.7 \%$ & $0.4 \%$ & $2.5 \%$ \\
\hline$\% 16-20$ miles & $0.3 \%$ & $0.2 \%$ & $0.3 \%$ & $0.2 \%$ & $0.4 \%$ & $0.2 \%$ & $0.3 \%$ & $0.2 \%$ & $0.5 \%$ & $0.3 \%$ & $0.5 \%$ & $0.6 \%$ & $0.3 \%$ & $2.6 \%$ \\
\hline$\%$ 21-30 miles & $0.4 \%$ & $0.3 \%$ & $0.3 \%$ & $0.2 \%$ & $0.4 \%$ & $0.2 \%$ & $0.4 \%$ & $0.2 \%$ & $0.4 \%$ & $0.4 \%$ & $0.3 \%$ & $0.7 \%$ & $0.2 \%$ & $1.0 \%$ \\
\hline$\% 31$ or more miles & $0.4 \%$ & $0.2 \%$ & $0.4 \%$ & $0.2 \%$ & $0.5 \%$ & $0.2 \%$ & $0.3 \%$ & $0.2 \%$ & $0.6 \%$ & $0.3 \%$ & $0.3 \%$ & $0.5 \%$ & $0.2 \%$ & $1.8 \%$ \\
\hline$\%$ Unreported & $0.2 \%$ & $0.2 \%$ & $0.2 \%$ & $0.1 \%$ & $0.3 \%$ & $0.2 \%$ & $0.4 \%$ & $0.2 \%$ & $1.3 \%$ & $0.9 \%$ & $1.1 \%$ & $0.8 \%$ & $1.1 \%$ & $3.1 \%$ \\
\hline Daily PMT per Per & & & & & & & & & & & & & & \\
\hline TOTAL & 1.26 & 1.03 & 1.57 & 1.07 & 1.84 & 1.42 & 1.47 & 1.45 & 2.30 & 4.55 & 6.51 & 4.56 & 1.96 & 11.95 \\
\hline$\%$ POV & $1.1 \%$ & $0.9 \%$ & $2.2 \%$ & $1.9 \%$ & $2.6 \%$ & $2.8 \%$ & $2.5 \%$ & $3.0 \%$ & $3.4 \%$ & $10.0 \%$ & $12.9 \%$ & $10.8 \%$ & $5.9 \%$ & $22.9 \%$ \\
\hline$\%$ Public & $0.4 \%$ & $0.1 \%$ & $0.3 \%$ & $0.1 \%$ & $0.9 \%$ & $0.1 \%$ & $0.8 \%$ & $0.2 \%$ & $2.5 \%$ & $0.6 \%$ & $5.2 \%$ & $1.2 \%$ & $3.3 \%$ & $20.3 \%$ \\
\hline$\%$ Walk & $0.1 \%$ & $0.0 \%$ & $0.1 \%$ & $0.0 \%$ & $0.1 \%$ & $0.0 \%$ & $0.2 \%$ & $0.1 \%$ & $0.5 \%$ & $0.2 \%$ & $1.2 \%$ & $0.3 \%$ & $0.7 \%$ & $2.9 \%$ \\
\hline$\%$ Other & $1.0 \%$ & $0.9 \%$ & $2.3 \%$ & $1.9 \%$ & $2.6 \%$ & $1.4 \%$ & $2.3 \%$ & $3.1 \%$ & $1.8 \%$ & $10.6 \%$ & $18.8 \%$ & $11.8 \%$ & $8.0 \%$ & $0.9 \%$ \\
\hline$\%$ Unreported & $0.0 \%$ & $0.1 \%$ & $0.1 \%$ & $0.1 \%$ & $0.2 \%$ & $2.2 \%$ & $1.6 \%$ & $0.0 \%$ & $0.1 \%$ & $0.0 \%$ & $0.0 \%$ & $0.0 \%$ & $1.9 \%$ & $0.0 \%$ \\
\hline TOTAL & 1.26 & 1.03 & 1.57 & 1.07 & 1.84 & 1.42 & 1.47 & 1.45 & 2.30 & 4.55 & 6.51 & 4.56 & 1.96 & 11.95 \\
\hline$\%$ sov & $1.5 \%$ & $1.1 \%$ & $2.0 \%$ & $1.1 \%$ & $2.8 \%$ & $1.8 \%$ & $2.2 \%$ & $1.5 \%$ & $4.4 \%$ & $4.0 \%$ & $5.9 \%$ & $4.5 \%$ & $2.9 \%$ & $24.0 \%$ \\
\hline$\%$ MOV & $1.8 \%$ & $1.2 \%$ & $1.8 \%$ & $1.4 \%$ & $2.9 \%$ & $1.9 \%$ & $2.2 \%$ & $2.2 \%$ & $6.7 \%$ & $6.7 \%$ & $7.3 \%$ & $7.7 \%$ & $4.7 \%$ & $41.7 \%$ \\
\hline$\%$ Amtrak & $0.4 \%$ & $0.0 \%$ & $0.3 \%$ & $0.0 \%$ & $0.1 \%$ & $0.0 \%$ & $0.3 \%$ & $0.1 \%$ & $0.4 \%$ & $0.4 \%$ & $0.2 \%$ & & $0.9 \%$ & \\
\hline$\%$ Commuter Train & $0.2 \%$ & $0.0 \%$ & $0.2 \%$ & $0.1 \%$ & $0.7 \%$ & $0.0 \%$ & $0.6 \%$ & $0.1 \%$ & $0.7 \%$ & $0.3 \%$ & $0.6 \%$ & $0.1 \%$ & $0.2 \%$ & \\
\hline$\%$ Subway/El Rail & $0.2 \%$ & $0.0 \%$ & $0.1 \%$ & $0.1 \%$ & $0.2 \%$ & $0.1 \%$ & $0.4 \%$ & $0.0 \%$ & $2.0 \%$ & $0.2 \%$ & $3.3 \%$ & $0.3 \%$ & $2.5 \%$ & $4.9 \%$ \\
\hline$\%$ Other Public & $0.2 \%$ & $0.0 \%$ & $0.1 \%$ & $0.1 \%$ & $0.1 \%$ & $0.1 \%$ & $0.3 \%$ & $0.2 \%$ & $0.9 \%$ & $0.5 \%$ & $1.6 \%$ & $0.8 \%$ & $1.2 \%$ & $15.4 \%$ \\
\hline$\%$ Walk & $0.1 \%$ & $0.0 \%$ & $0.1 \%$ & $0.0 \%$ & $0.1 \%$ & $0.0 \%$ & $0.2 \%$ & $0.1 \%$ & $0.5 \%$ & $0.2 \%$ & $1.2 \%$ & $0.3 \%$ & $0.7 \%$ & $2.9 \%$ \\
\hline$\%$ Other & $1.0 \%$ & $0.9 \%$ & $2.3 \%$ & $1.9 \%$ & $2.6 \%$ & $1.4 \%$ & $2.3 \%$ & $3.1 \%$ & $1.8 \%$ & $10.7 \%$ & $18.8 \%$ & $11.7 \%$ & $8.1 \%$ & $0.9 \%$ \\
\hline$\%$ Unreported & $0.0 \%$ & $0.1 \%$ & $0.1 \%$ & $0.1 \%$ & $0.2 \%$ & $2.2 \%$ & $1.6 \%$ & $0.0 \%$ & $0.1 \%$ & $0.0 \%$ & $0.0 \%$ & $0.0 \%$ & $1.9 \%$ & $0.0 \%$ \\
\hline TOTAL & 1.26 & 1.03 & 1.57 & 1.07 & 1.84 & 1.42 & 1.47 & 1.45 & 2.30 & 4.55 & 6.51 & 4.56 & 1.96 & 11.95 \\
\hline$\%$ Earn a Living & $0.0 \%$ & $0.0 \%$ & $0.0 \%$ & $0.0 \%$ & $0.0 \%$ & $0.0 \%$ & $0.0 \%$ & $0.0 \%$ & $0.0 \%$ & $0.1 \%$ & $0.2 \%$ & $0.1 \%$ & $0.0 \%$ & $0.2 \%$ \\
\hline$\%$ Family \& Pers & $0.0 \%$ & $0.0 \%$ & $0.0 \%$ & $0.0 \%$ & $0.0 \%$ & $0.0 \%$ & $0.0 \%$ & $0.0 \%$ & $0.0 \%$ & $0.0 \%$ & $0.1 \%$ & $0.0 \%$ & $0.0 \%$ & $0.2 \%$ \\
\hline$\%$ Civic, Educational \& Religious & $0.0 \%$ & $0.0 \%$ & $0.0 \%$ & $0.0 \%$ & $0.0 \%$ & $0.0 \%$ & $0.0 \%$ & $0.0 \%$ & $0.0 \%$ & $0.0 \%$ & $0.0 \%$ & $0.0 \%$ & $0.0 \%$ & $0.0 \%$ \\
\hline$\%$ Social \& Recreational & $0.0 \%$ & $0.0 \%$ & $0.0 \%$ & $0.0 \%$ & $0.0 \%$ & $0.0 \%$ & $0.0 \%$ & $0.0 \%$ & $0.0 \%$ & $0.0 \%$ & $0.0 \%$ & $0.1 \%$ & $0.1 \%$ & $0.4 \%$ \\
\hline$\%$ Other & $0.0 \%$ & $0.0 \%$ & $0.0 \%$ & $0.0 \%$ & $0.0 \%$ & $0.0 \%$ & $0.0 \%$ & $0.0 \%$ & $0.0 \%$ & $0.0 \%$ & $0.1 \%$ & $0.1 \%$ & $0.1 \%$ & $0.0 \%$ \\
\hline$\%$ Unreported & $0.0 \%$ & $0.0 \%$ & $0.0 \%$ & $0.0 \%$ & $0.0 \%$ & $0.0 \%$ & $0.0 \%$ & $0.0 \%$ & $0.0 \%$ & $0.0 \%$ & $0.1 \%$ & $0.0 \%$ & $0.0 \%$ & $0.0 \%$ \\
\hline $\begin{array}{l}\text { Average Person Trip Le } \\
\text { TOTAL }\end{array}$ & 0.36 & 0.25 & 0.35 & 0.26 & 0.46 & 0.33 & 0.37 & 0.37 & 0.74 & 1.28 & 2.03 & 1.30 & 0.67 & 3.9 \\
\hline
\end{tabular}


Chapter 4: Table 4

Urban Travel and Population Density

2009 NHTS

STANDARD ERRORS

\begin{tabular}{|c|c|c|c|c|c|c|c|c|c|c|c|c|c|c|}
\hline \multicolumn{15}{|c|}{ Population Density (census tract) } \\
\hline & \multicolumn{2}{|c|}{ NY State $^{<500}$ U.S. } & \multicolumn{2}{|c|}{$500-2,000$} & \multicolumn{2}{|c|}{$2,000-4,000$} & \multicolumn{2}{|c|}{$4,000-10,000$} & \multicolumn{2}{|c|}{$10,000-20,000$} & \multicolumn{2}{|c|}{$20,000-50,000$} & \multicolumn{2}{|c|}{$50,000+$} \\
\hline & NY State & U.S. & NY State & U.S. & NY State & U.S. & NY State & U.S. & NY State & U.S. & NY State & U.S. & NY State & U.S. \\
\hline \multicolumn{15}{|c|}{ Distribution of Zero-Vehicle Households by Household Income } \\
\hline ALL & $0.0 \%$ & $0.0 \%$ & $0.0 \%$ & $0.0 \%$ & $0.0 \%$ & $0.0 \%$ & $0.0 \%$ & $0.0 \%$ & $0.0 \%$ & $0.0 \%$ & $0.0 \%$ & $0.0 \%$ & $0.0 \%$ & $0.0 \%$ \\
\hline$<\$ 10,000$ & $8.9 \%$ & $6.2 \%$ & $5.3 \%$ & $4.3 \%$ & $5.9 \%$ & $4.6 \%$ & $6.4 \%$ & $3.3 \%$ & $4.9 \%$ & $4.7 \%$ & $5.4 \%$ & $6.9 \%$ & $2.1 \%$ & $7.0 \%$ \\
\hline$\$ 10$ to $\$ 20,000$ & $7.0 \%$ & $8.4 \%$ & $4.8 \%$ & $3.9 \%$ & $6.3 \%$ & $4.2 \%$ & $6.3 \%$ & $3.0 \%$ & $5.1 \%$ & $5.3 \%$ & $3.0 \%$ & $6.7 \%$ & $2.6 \%$ & $11.5 \%$ \\
\hline$\$ 20$ to $\$ 30,000$ & $6.6 \%$ & $3.0 \%$ & $3.7 \%$ & $2.9 \%$ & $4.2 \%$ & $2.9 \%$ & $2.0 \%$ & $1.7 \%$ & $8.3 \%$ & $2.5 \%$ & $3.0 \%$ & $7.5 \%$ & $1.5 \%$ & $6.0 \%$ \\
\hline$\$ 30$ to $\$ 40,000$ & $6.3 \%$ & $0.9 \%$ & $4.6 \%$ & $0.8 \%$ & $2.0 \%$ & $3.2 \%$ & $2.3 \%$ & $1.5 \%$ & $3.1 \%$ & $1.9 \%$ & $6.4 \%$ & $7.4 \%$ & $1.6 \%$ & $5.3 \%$ \\
\hline$\$ 40$ to $\$ 50,000$ & & $0.4 \%$ & $0.9 \%$ & $3.6 \%$ & $1.7 \%$ & $1.5 \%$ & $2.6 \%$ & $1.8 \%$ & $0.3 \%$ & $0.4 \%$ & $3.0 \%$ & $3.1 \%$ & $1.7 \%$ & $3.6 \%$ \\
\hline$\$ 50$ to $\$ 60,000$ & & $0.2 \%$ & & $0.1 \%$ & & $0.6 \%$ & $1.6 \%$ & $0.2 \%$ & $1.1 \%$ & $0.2 \%$ & $1.6 \%$ & $0.6 \%$ & $1.2 \%$ & $7.8 \%$ \\
\hline$\$ 60$ to $\$ 70,000$ & $0.7 \%$ & $0.3 \%$ & $1.8 \%$ & $0.0 \%$ & & $0.3 \%$ & $0.5 \%$ & $0.2 \%$ & $0.4 \%$ & $0.4 \%$ & $2.5 \%$ & $0.2 \%$ & $1.4 \%$ & $9.9 \%$ \\
\hline$\$ 70$ to $\$ 80,000$ & & $1.9 \%$ & $2.1 \%$ & $2.0 \%$ & & $0.1 \%$ & & $0.1 \%$ & $1.1 \%$ & $0.3 \%$ & $1.1 \%$ & $0.4 \%$ & $0.9 \%$ & \\
\hline$\$ 80$ to $\$ 100,000$ & & $0.1 \%$ & & $0.1 \%$ & $0.7 \%$ & $0.1 \%$ & $0.7 \%$ & $0.2 \%$ & $6.6 \%$ & $0.8 \%$ & $1.3 \%$ & $0.3 \%$ & $1.6 \%$ & \\
\hline$\$ 100,000+$ & $0.8 \%$ & $3.4 \%$ & $0.5 \%$ & $0.4 \%$ & $3.1 \%$ & $0.3 \%$ & $1.2 \%$ & $0.7 \%$ & $1.6 \%$ & $4.0 \%$ & $2.0 \%$ & $1.7 \%$ & $1.6 \%$ & $2.7 \%$ \\
\hline Unreported & $6.9 \%$ & $3.3 \%$ & $2.2 \%$ & $2.0 \%$ & $3.9 \%$ & $3.0 \%$ & $4.1 \%$ & $1.9 \%$ & $3.6 \%$ & $2.9 \%$ & $2.4 \%$ & $0.6 \%$ & $1.8 \%$ & $6.4 \%$ \\
\hline \multicolumn{15}{|c|}{ Zero-Vehicle Households - Daily Person Trips per Person } \\
\hline TOTAL & 0.32 & 0.21 & 0.29 & 0.18 & 0.23 & 0.18 & 0.26 & 0.17 & 0.28 & 0.27 & 0.25 & 0.48 & 0.14 & 0.47 \\
\hline$\%$ Private & $9.7 \%$ & $7.4 \%$ & $7.7 \%$ & $7.8 \%$ & $4.5 \%$ & $4.9 \%$ & $5.1 \%$ & $4.0 \%$ & $5.6 \%$ & $2.4 \%$ & $5.3 \%$ & $3.7 \%$ & $1.1 \%$ & $2.1 \%$ \\
\hline$\%$ Public & $4.6 \%$ & $4.7 \%$ & $5.4 \%$ & $2.4 \%$ & $2.4 \%$ & $3.7 \%$ & $3.3 \%$ & $2.4 \%$ & $12.1 \%$ & $5.2 \%$ & $4.7 \%$ & $3.7 \%$ & $2.2 \%$ & $5.0 \%$ \\
\hline$\%$ Walk & $6.4 \%$ & $5.1 \%$ & $4.6 \%$ & $5.2 \%$ & $8.3 \%$ & $2.7 \%$ & $3.8 \%$ & $5.1 \%$ & $10.6 \%$ & $6.6 \%$ & $5.7 \%$ & $5.3 \%$ & $2.2 \%$ & $5.6 \%$ \\
\hline$\%$ Other & $6.4 \%$ & $3.2 \%$ & $4.2 \%$ & $2.8 \%$ & $9.0 \%$ & $2.6 \%$ & $2.4 \%$ & $2.7 \%$ & $2.8 \%$ & $2.6 \%$ & $1.8 \%$ & $2.6 \%$ & $1.3 \%$ & $3.7 \%$ \\
\hline$\%$ Unreported & $7.1 \%$ & $0.7 \%$ & & $0.8 \%$ & $8.1 \%$ & $1.5 \%$ & & $2.2 \%$ & $1.2 \%$ & $0.4 \%$ & & $0.2 \%$ & $0.0 \%$ & \\
\hline TOTAL & 0.32 & 0.21 & 0.29 & 0.18 & 0.23 & 0.18 & 0.26 & 0.17 & 0.28 & 0.27 & 0.25 & 0.48 & 0.14 & 0.47 \\
\hline$<\$ 10,000$ & 0.62 & 0.25 & 0.52 & 0.25 & 0.48 & 0.35 & 0.58 & 0.38 & 0.68 & 0.69 & 0.35 & 0.90 & 0.28 & 0.34 \\
\hline$\$ 10$ to $\$ 20,000$ & 0.54 & 0.51 & 0.51 & 0.25 & 0.41 & 0.32 & 0.36 & 0.23 & 0.40 & 0.39 & 0.23 & 0.28 & 0.26 & 0.37 \\
\hline$\$ 20$ to $\$ 30,000$ & 0.49 & 0.73 & 0.60 & 0.14 & 1.04 & 0.50 & 0.33 & 0.40 & 0.71 & 0.54 & 0.72 & 0.59 & 0.43 & 0.04 \\
\hline$\$ 30$ to $\$ 40,000$ & 1.10 & 0.39 & 0.55 & 0.71 & 0.26 & 0.47 & 0.37 & 0.43 & 0.34 & 0.32 & 0.22 & 0.25 & 0.18 & \\
\hline$\$ 40$ to $\$ 50,000$ & & 1.25 & 0.81 & 1.11 & 0.89 & 0.43 & 2.76 & 0.59 & 0.35 & 0.57 & 0.37 & 0.28 & 1.19 & 0.00 \\
\hline$\$ 50$ to $\$ 60,000$ & & 0.86 & & 2.11 & & 0.65 & 0.36 & 1.80 & 0.77 & 0.43 & 2.15 & 0.40 & 0.33 & 0.91 \\
\hline$\$ 60$ to $\$ 70,000$ & 0.00 & 0.09 & & 0.65 & & 0.54 & 1.68 & 0.76 & 2.99 & 0.27 & 3.30 & 3.30 & 1.07 & 0.00 \\
\hline$\$ 70$ to $\$ 80,000$ & & 1.62 & 1.50 & 0.07 & & 2.37 & & 0.79 & 1.99 & 0.30 & 0.31 & 0.25 & 0.56 & \\
\hline$\$ 80$ to $\$ 100,000$ & & 0.18 & & 0.57 & 0.00 & 0.55 & 0.00 & 0.77 & 0.70 & 1.59 & 1.96 & 0.34 & 0.72 & \\
\hline$\$ 100,000+$ & 1.45 & 0.06 & 3.02 & 0.71 & 2.72 & 0.56 & 1.06 & 0.22 & 1.04 & 1.29 & 0.61 & 0.25 & 0.35 & 7.19 \\
\hline Unreported & 0.58 & 0.67 & 0.27 & 1.14 & 0.38 & 0.31 & 0.73 & 0.21 & 0.86 & 0.42 & 0.35 & 0.40 & 0.34 & 1.00 \\
\hline \multicolumn{15}{|c|}{ Zero-Vehicle Households - Daily PMT per Person } \\
\hline TOTAL & 3.18 & 2.60 & 1.32 & 5.52 & 5.53 & 2.15 & 1.06 & 1.19 & 1.68 & 1.05 & 0.99 & 4.07 & 1.24 & 2.58 \\
\hline$\%$ Private & $10.7 \%$ & $7.1 \%$ & $10.9 \%$ & $14.6 \%$ & $24.0 \%$ & $11.7 \%$ & $5.4 \%$ & $6.3 \%$ & $13.3 \%$ & $9.4 \%$ & $7.8 \%$ & $13.8 \%$ & $5.6 \%$ & $0.6 \%$ \\
\hline$\%$ Public & $10.9 \%$ & $3.6 \%$ & $9.7 \%$ & $3.0 \%$ & $3.7 \%$ & $13.5 \%$ & $8.0 \%$ & $4.7 \%$ & $14.2 \%$ & $8.9 \%$ & $8.1 \%$ & $11.4 \%$ & $7.4 \%$ & $18.6 \%$ \\
\hline$\%$ Walk & $1.0 \%$ & $0.6 \%$ & $2.1 \%$ & $1.1 \%$ & $3.4 \%$ & $0.9 \%$ & $2.2 \%$ & $2.1 \%$ & $4.3 \%$ & $4.3 \%$ & $2.8 \%$ & $2.6 \%$ & $2.0 \%$ & $22.9 \%$ \\
\hline$\%$ Other & $5.1 \%$ & $5.5 \%$ & $3.6 \%$ & $11.2 \%$ & $6.9 \%$ & $3.7 \%$ & $4.8 \%$ & $3.7 \%$ & $6.7 \%$ & $5.8 \%$ & $1.5 \%$ & $2.5 \%$ & $3.5 \%$ & $41.2 \%$ \\
\hline$\%$ Unreported & $4.2 \%$ & $0.8 \%$ & & $2.5 \%$ & $24.6 \%$ & $3.9 \%$ & & $3.0 \%$ & $1.1 \%$ & $0.7 \%$ & & & & \\
\hline
\end{tabular}


Chapter 4: Table 4

Urban Travel and Population Density

2001 NHTS

STANDARD ERRORS

\begin{tabular}{|c|c|c|c|c|c|c|c|c|c|c|c|c|c|c|}
\hline \multicolumn{15}{|c|}{ Population Density (census tract) } \\
\hline & \multicolumn{2}{|c|}{$<500$} & \multicolumn{2}{|c|}{$500-2,000$} & \multicolumn{2}{|c|}{$2,000-4,000$} & \multicolumn{2}{|c|}{$4,000-10,000$} & \multicolumn{2}{|c|}{$10,000-20,000$} & \multicolumn{2}{|c|}{$20,000-50,000$} & \multicolumn{2}{|c|}{$50,000+$} \\
\hline & NY State & U.S. & NY State & U.S. & NY State & U.S. & NY State & U.S. & NY State & U.S. & NY State & U.S. & NY State & U.S. \\
\hline \multicolumn{15}{|c|}{ Distribution of Zero-Vehicle Households by Household Income } \\
\hline ALL & $0.0 \%$ & $0.0 \%$ & $0.0 \%$ & $0.0 \%$ & $0.0 \%$ & $0.0 \%$ & $0.0 \%$ & $0.0 \%$ & $0.0 \%$ & $0.0 \%$ & $0.0 \%$ & $0.0 \%$ & $0.0 \%$ & $0.0 \%$ \\
\hline$<\$ 10,000$ & $8.5 \%$ & $5.2 \%$ & $5.1 \%$ & $4.9 \%$ & $6.6 \%$ & $3.9 \%$ & $4.7 \%$ & $3.2 \%$ & $4.5 \%$ & $4.1 \%$ & $3.2 \%$ & $4.2 \%$ & $1.9 \%$ & $9.5 \%$ \\
\hline$\$ 10$ to $\$ 20,000$ & $9.8 \%$ & $5.2 \%$ & $7.2 \%$ & $3.6 \%$ & $6.1 \%$ & $3.4 \%$ & $4.6 \%$ & $2.1 \%$ & $5.1 \%$ & $3.9 \%$ & $3.2 \%$ & $3.7 \%$ & $1.8 \%$ & $16.0 \%$ \\
\hline$\$ 20$ to $\$ 30,000$ & $1.7 \%$ & $3.1 \%$ & $4.5 \%$ & $3.9 \%$ & $9.2 \%$ & $3.0 \%$ & $3.0 \%$ & $2.0 \%$ & $2.6 \%$ & $2.5 \%$ & $2.9 \%$ & $2.2 \%$ & $1.4 \%$ & $16.7 \%$ \\
\hline$\$ 30$ to $\$ 40,000$ & $2.4 \%$ & $1.8 \%$ & $2.0 \%$ & $2.1 \%$ & $2.3 \%$ & $1.1 \%$ & $2.7 \%$ & $1.7 \%$ & $3.8 \%$ & $2.4 \%$ & $2.7 \%$ & $4.4 \%$ & $1.6 \%$ & $10.7 \%$ \\
\hline$\$ 40$ to $\$ 50,000$ & $9.0 \%$ & $1.5 \%$ & $10.7 \%$ & $0.7 \%$ & & $1.2 \%$ & $1.2 \%$ & $0.2 \%$ & $0.9 \%$ & $1.0 \%$ & $1.3 \%$ & $2.3 \%$ & $0.7 \%$ & $4.8 \%$ \\
\hline$\$ 50$ to $\$ 60,000$ & $1.6 \%$ & $1.1 \%$ & $0.8 \%$ & $0.8 \%$ & $2.7 \%$ & $0.8 \%$ & $1.1 \%$ & $1.1 \%$ & $5.1 \%$ & $1.6 \%$ & $1.2 \%$ & $1.8 \%$ & $1.3 \%$ & \\
\hline$\$ 60$ to $\$ 70,000$ & $0.4 \%$ & $0.9 \%$ & $2.3 \%$ & $0.5 \%$ & & $1.0 \%$ & $0.9 \%$ & $0.6 \%$ & $2.3 \%$ & $0.2 \%$ & $1.2 \%$ & $1.3 \%$ & $1.0 \%$ & \\
\hline$\$ 70$ to $\$ 80,000$ & $0.4 \%$ & $0.0 \%$ & & $0.0 \%$ & $0.3 \%$ & $0.1 \%$ & & $0.2 \%$ & $0.5 \%$ & $0.0 \%$ & $0.6 \%$ & $0.0 \%$ & $1.0 \%$ & $3.1 \%$ \\
\hline$\$ 80$ to $\$ 100,000$ & $7.7 \%$ & $0.8 \%$ & $0.6 \%$ & $0.5 \%$ & & $0.4 \%$ & $0.6 \%$ & $0.2 \%$ & $1.4 \%$ & $0.3 \%$ & $0.4 \%$ & $1.0 \%$ & $0.8 \%$ & \\
\hline$\$ 100,000+$ & $5.9 \%$ & $1.8 \%$ & $1.0 \%$ & $1.7 \%$ & & $0.6 \%$ & $0.4 \%$ & $0.7 \%$ & $2.0 \%$ & $1.1 \%$ & $1.7 \%$ & $3.0 \%$ & $1.6 \%$ & \\
\hline Unreported & $4.8 \%$ & $3.6 \%$ & $7.9 \%$ & $4.1 \%$ & $6.1 \%$ & $3.4 \%$ & $2.8 \%$ & $2.0 \%$ & $2.9 \%$ & $2.1 \%$ & $2.7 \%$ & $2.2 \%$ & $1.5 \%$ & $0.5 \%$ \\
\hline \multicolumn{15}{|c|}{ Zero-Vehicle Households - Daily Person Trips per Person } \\
\hline TOTAL & 0.65 & 0.23 & 0.36 & 0.24 & 0.34 & 0.26 & 0.23 & 0.16 & 0.23 & 0.18 & 0.20 & 0.21 & 0.10 & 0.53 \\
\hline$\%$ Private & $9.0 \%$ & $4.5 \%$ & $11.3 \%$ & $6.0 \%$ & $10.1 \%$ & $7.0 \%$ & $4.3 \%$ & $3.7 \%$ & $4.5 \%$ & $2.9 \%$ & $3.0 \%$ & $3.8 \%$ & $1.3 \%$ & $0.1 \%$ \\
\hline$\%$ Public & $8.7 \%$ & $0.3 \%$ & $9.9 \%$ & $2.6 \%$ & $5.8 \%$ & $2.3 \%$ & $3.6 \%$ & $2.5 \%$ & $4.3 \%$ & $3.3 \%$ & $2.2 \%$ & $4.2 \%$ & $1.7 \%$ & $10.3 \%$ \\
\hline$\%$ Walk & $9.6 \%$ & $4.5 \%$ & $5.5 \%$ & $3.2 \%$ & $6.5 \%$ & $5.2 \%$ & $4.6 \%$ & $2.9 \%$ & $6.1 \%$ & $4.7 \%$ & $4.0 \%$ & $6.0 \%$ & $1.9 \%$ & $7.7 \%$ \\
\hline$\%$ Other & $4.3 \%$ & $1.8 \%$ & $2.9 \%$ & $1.7 \%$ & $9.2 \%$ & $1.9 \%$ & $5.8 \%$ & $1.6 \%$ & $1.8 \%$ & $2.1 \%$ & $2.2 \%$ & $2.7 \%$ & $0.9 \%$ & $6.0 \%$ \\
\hline$\%$ Unreported & & $0.3 \%$ & & $0.1 \%$ & & & $0.0 \%$ & $0.2 \%$ & & $0.0 \%$ & $0.1 \%$ & & $0.2 \%$ & $0.0 \%$ \\
\hline TOTAL & 0.65 & 0.23 & 0.36 & 0.24 & 0.34 & 0.26 & 0.23 & 0.16 & 0.23 & 0.18 & 0.20 & 0.21 & 0.10 & 0.53 \\
\hline$<\$ 10,000$ & 2.46 & 0.30 & 0.65 & 0.47 & 0.76 & 0.44 & 0.52 & 0.20 & 0.83 & 0.48 & 0.41 & 0.29 & 0.26 & 0.49 \\
\hline$\$ 10$ to $\$ 20,000$ & 0.57 & 0.55 & 0.56 & 0.71 & 0.91 & 0.35 & 0.39 & 0.31 & 0.34 & 0.32 & 0.31 & 0.51 & 0.25 & 1.19 \\
\hline$\$ 20$ to $\$ 30,000$ & 0.61 & 0.90 & 0.54 & 0.40 & 0.32 & 1.13 & 0.63 & 0.45 & 0.31 & 0.42 & 0.56 & 0.85 & 0.28 & 0.96 \\
\hline$\$ 30$ to $\$ 40,000$ & 0.10 & 1.08 & 1.05 & 0.83 & 0.66 & 0.43 & 0.98 & 0.54 & 0.47 & 0.43 & 0.34 & 0.59 & 0.22 & 0.27 \\
\hline$\$ 40$ to $\$ 50,000$ & & 4.97 & 5.97 & 0.33 & & 0.68 & 0.77 & 0.18 & 0.65 & 0.69 & 1.85 & 0.50 & 0.55 & 2.16 \\
\hline$\$ 50$ to $\$ 60,000$ & 2.38 & 1.46 & & 0.86 & 3.18 & 1.49 & 1.35 & 0.88 & 0.67 & 1.00 & 0.24 & 0.68 & 0.21 & \\
\hline$\$ 60$ to $\$ 70,000$ & 2.43 & 4.27 & 1.54 & 4.97 & & 3.87 & 1.99 & 0.17 & 2.80 & 0.68 & 1.52 & 1.21 & 0.42 & \\
\hline$\$ 70$ to $\$ 80,000$ & 4.97 & 2.93 & & 1.60 & 1.94 & & & & 2.47 & 3.40 & 1.53 & & 1.67 & 7.96 \\
\hline$\$ 80$ to $\$ 100,000$ & 4.00 & 2.66 & 1.17 & 3.36 & & 1.90 & 0.76 & 0.69 & 0.13 & 0.31 & 0.91 & 0.14 & 0.65 & \\
\hline$\$ 100,000+$ & 0.17 & 0.72 & 1.48 & 1.79 & & 0.23 & 0.13 & 7.64 & 2.41 & 2.07 & 0.63 & 0.02 & 0.27 & \\
\hline Unreported & 0.29 & 0.73 & 0.71 & 1.01 & 0.59 & 0.76 & 0.24 & 0.33 & 0.61 & 0.21 & 0.63 & 1.03 & 0.31 & 1.42 \\
\hline \multicolumn{15}{|c|}{ Zero-Vehicle Households - Daily PMT per Person } \\
\hline TOTAL & 2.85 & 4.30 & 2.68 & 5.13 & 2.74 & 1.81 & 1.49 & 12.81 & 2.83 & 2.04 & 17.55 & 1.59 & 1.67 & 5.51 \\
\hline$\%$ Private & $19.6 \%$ & $1.3 \%$ & $9.7 \%$ & $13.8 \%$ & $17.5 \%$ & $4.2 \%$ & $10.2 \%$ & $21.3 \%$ & $8.5 \%$ & $14.0 \%$ & $13.9 \%$ & $9.2 \%$ & $4.3 \%$ & $2.1 \%$ \\
\hline$\%$ Public & $16.5 \%$ & $0.3 \%$ & $15.8 \%$ & $2.1 \%$ & $9.8 \%$ & $2.7 \%$ & $10.8 \%$ & $7.2 \%$ & $9.2 \%$ & $10.1 \%$ & $17.4 \%$ & $8.4 \%$ & $6.5 \%$ & $39.6 \%$ \\
\hline$\%$ Walk & $8.0 \%$ & $0.3 \%$ & $2.5 \%$ & $0.2 \%$ & $2.9 \%$ & $1.6 \%$ & $1.5 \%$ & $1.8 \%$ & $2.9 \%$ & $2.5 \%$ & $4.9 \%$ & $3.1 \%$ & $1.2 \%$ & $27.5 \%$ \\
\hline$\%$ Other & $2.6 \%$ & $1.2 \%$ & $8.0 \%$ & $14.4 \%$ & $11.5 \%$ & $0.9 \%$ & $3.3 \%$ & $29.7 \%$ & $14.1 \%$ & $3.6 \%$ & $35.8 \%$ & $2.8 \%$ & $9.2 \%$ & $10.3 \%$ \\
\hline$\%$ Unreported & & & & $0.0 \%$ & & & & $0.0 \%$ & & $0.0 \%$ & & & $0.1 \%$ & $0.0 \%$ \\
\hline
\end{tabular}




\begin{tabular}{|c|c|c|c|c|c|c|c|c|c|c|c|c|c|c|}
\hline \multicolumn{15}{|c|}{ Population Density (census tract) } \\
\hline & \multicolumn{2}{|c|}{$<500$} & \multicolumn{2}{|c|}{$500-2,000$} & \multicolumn{2}{|c|}{$2,000-4,000$} & \multicolumn{2}{|c|}{$4,000-10,000$} & \multicolumn{2}{|c|}{$10,000-20,000$} & \multicolumn{2}{|c|}{$20,000-50,000$} & \multicolumn{2}{|c|}{$50,000+$} \\
\hline & NY State & U.S. & NY State & U.S. & NY State & U.S. & NY State & U.S. & NY State & U.S. & NY State & U.S. & NY State & U.S. \\
\hline \multicolumn{15}{|c|}{ Zero-Vehicle Households - Daily PMT per Person } \\
\hline TOTAL & 3.18 & 2.60 & 1.32 & 5.52 & 5.53 & 2.15 & 1.06 & 1.19 & 1.68 & 1.05 & 0.99 & 4.07 & 1.24 & 2.58 \\
\hline$<\$ 10,000$ & 2.63 & 5.39 & 1.82 & 1.48 & 16.13 & 1.92 & 1.17 & 1.83 & 2.19 & 1.06 & 2.63 & 1.72 & 0.66 & 0.65 \\
\hline$\$ 10$ to $\$ 20,000$ & 4.87 & 2.39 & 2.36 & 6.81 & 1.94 & 2.56 & 1.36 & 1.17 & 5.14 & 2.61 & 1.30 & 2.55 & 0.89 & 5.10 \\
\hline$\$ 20$ to $\$ 30,000$ & 1.92 & 12.18 & 4.17 & 26.87 & 1.03 & 1.64 & 1.96 & 1.55 & 2.48 & 1.32 & 1.88 & 5.11 & 6.18 & 0.01 \\
\hline$\$ 30$ to $\$ 40,000$ & 34.54 & 23.95 & 0.54 & 7.71 & 3.75 & 17.17 & 4.84 & 3.56 & 2.17 & 2.36 & 4.12 & 4.41 & 2.09 & \\
\hline$\$ 40$ to $\$ 50,000$ & & 4.16 & 3.70 & 9.26 & 6.63 & 1.62 & 5.08 & 12.49 & 3.66 & 2.86 & 3.31 & 23.57 & 4.29 & 0.00 \\
\hline$\$ 50$ to $\$ 60,000$ & & 1.48 & & 20.67 & & 3.57 & 0.63 & 4.32 & 4.17 & 2.47 & 1.83 & 1.34 & 2.17 & 0.06 \\
\hline$\$ 60$ to $\$ 70,000$ & 0.00 & 19.76 & & 10.66 & & 51.20 & 33.00 & 2.17 & 77.61 & 1.17 & 13.10 & 6.93 & 2.20 & 0.00 \\
\hline$\$ 70$ to $\$ 80,000$ & & 49.39 & 14.44 & 0.21 & & 11.41 & & 4.54 & 9.95 & 4.25 & 5.17 & 2.73 & 3.86 & \\
\hline$\$ 80$ to $\$ 100,000$ & & 41.21 & & 11.16 & 0.00 & 11.03 & 0.00 & 7.95 & 11.41 & 2.73 & 7.54 & 1.12 & 5.53 & \\
\hline$\$ 100,000+$ & 4.7 & 0.5 & 2.4 & 7.1 & 40.6 & 7.7 & 2.6 & 1.8 & 0.2 & 11.1 & 1.1 & 24.3 & 7.2 & 3.1 \\
\hline Unreported & 2.74 & 1.77 & 0.15 & 2.65 & 0.90 & 5.35 & 9.37 & 5.00 & 2.33 & 0.56 & 0.32 & 0.27 & 1.23 & 0.22 \\
\hline \multicolumn{15}{|c|}{ Non-Zero-Vehicle Households - Daily Person Trips per Person } \\
\hline TOTAL & 0.07 & 0.05 & 0.09 & 0.04 & 0.09 & 0.05 & 0.07 & 0.04 & 0.15 & 0.08 & 0.16 & 0.20 & 0.18 & 0.47 \\
\hline$\%$ Private & $0.7 \%$ & $0.4 \%$ & $0.7 \%$ & $0.4 \%$ & $0.9 \%$ & $0.5 \%$ & $1.1 \%$ & $0.4 \%$ & $2.4 \%$ & $1.2 \%$ & $3.3 \%$ & $4.2 \%$ & $3.1 \%$ & $9.7 \%$ \\
\hline$\%$ Public & $0.1 \%$ & $0.1 \%$ & $0.2 \%$ & $0.0 \%$ & $0.3 \%$ & $0.1 \%$ & $0.5 \%$ & $0.1 \%$ & $1.7 \%$ & $0.4 \%$ & $2.4 \%$ & $1.6 \%$ & $1.9 \%$ & $3.1 \%$ \\
\hline$\%$ Walk & $0.4 \%$ & $0.4 \%$ & $0.4 \%$ & $0.3 \%$ & $0.7 \%$ & $0.4 \%$ & $1.0 \%$ & $0.3 \%$ & $1.8 \%$ & $0.9 \%$ & $2.5 \%$ & $3.7 \%$ & $2.8 \%$ & $9.1 \%$ \\
\hline$\%$ Other & $0.7 \%$ & $0.3 \%$ & $0.6 \%$ & $0.2 \%$ & $0.6 \%$ & $0.2 \%$ & $0.5 \%$ & $0.1 \%$ & $0.6 \%$ & $0.8 \%$ & $0.7 \%$ & $0.6 \%$ & $0.7 \%$ & $0.7 \%$ \\
\hline$\%$ Unreported & $0.1 \%$ & $0.1 \%$ & $0.1 \%$ & $0.0 \%$ & $0.1 \%$ & $0.0 \%$ & $0.0 \%$ & $0.0 \%$ & $0.3 \%$ & $0.1 \%$ & $0.3 \%$ & $0.1 \%$ & & \\
\hline \multicolumn{15}{|c|}{ Non-Zero-Vehicle Households - Daily PMT per Person } \\
\hline TOTAL & 1.60 & 1.42 & 2.26 & 2.75 & 2.08 & 2.01 & 3.13 & 1.13 & 1.18 & 2.34 & 3.16 & 4.10 & 4.67 & 2.16 \\
\hline$\%$ Private & $1.6 \%$ & $1.2 \%$ & $3.2 \%$ & $4.9 \%$ & $5.3 \%$ & $2.1 \%$ & $7.8 \%$ & $2.1 \%$ & $3.6 \%$ & $3.0 \%$ & $7.3 \%$ & $9.4 \%$ & $6.0 \%$ & $13.9 \%$ \\
\hline$\%$ Public & $0.2 \%$ & $0.0 \%$ & $0.6 \%$ & $0.1 \%$ & $0.8 \%$ & $0.2 \%$ & $0.7 \%$ & $0.2 \%$ & $2.5 \%$ & $0.3 \%$ & $2.9 \%$ & $9.4 \%$ & $3.9 \%$ & $10.4 \%$ \\
\hline$\%$ Walk & $0.0 \%$ & $0.0 \%$ & $0.1 \%$ & $0.0 \%$ & $0.1 \%$ & $0.1 \%$ & $0.1 \%$ & $0.1 \%$ & $0.4 \%$ & $0.2 \%$ & $1.0 \%$ & $0.8 \%$ & $1.9 \%$ & $8.1 \%$ \\
\hline$\%$ Other & $1.6 \%$ & $1.2 \%$ & $3.3 \%$ & $4.9 \%$ & $5.5 \%$ & $2.1 \%$ & $8.1 \%$ & $2.2 \%$ & $2.3 \%$ & $3.0 \%$ & $7.4 \%$ & $1.9 \%$ & $2.0 \%$ & $0.3 \%$ \\
\hline$\%$ Unreported & $0.0 \%$ & $0.0 \%$ & $0.0 \%$ & $0.0 \%$ & $0.1 \%$ & $0.0 \%$ & $0.0 \%$ & $0.0 \%$ & $0.0 \%$ & $0.0 \%$ & $0.5 \%$ & & & \\
\hline \multicolumn{15}{|c|}{ Average Person Trip Leng } \\
\hline ALL & 0.40 & 0.42 & 0.55 & 0.70 & 0.52 & 0.51 & 0.78 & 0.28 & 0.30 & 0.63 & 0.85 & 1.02 & 0.66 & 0.44 \\
\hline Zero V & 1.60 & 1.09 & 0.63 & 2.52 & 2.62 & 0.76 & 0.36 & 0.52 & 0.78 & 0.43 & 0.40 & 1.35 & 0.41 & 0.67 \\
\hline Non-Zero Vehicle HHs & 0.41 & 0.43 & 0.56 & 0.71 & 0.53 & 0.51 & 0.83 & 0.29 & 0.31 & 0.68 & 1.17 & 1.18 & 1.32 & 0.65 \\
\hline
\end{tabular}


Chapter 4: Table 5

Urban Travel and Population Density

2001 NHTS

STANDARD ERRORS

\begin{tabular}{|c|c|c|c|c|c|c|c|c|c|c|c|c|c|c|}
\hline \multicolumn{15}{|c|}{ Population Density (census tract) } \\
\hline & \multicolumn{2}{|c|}{$<500$} & \multicolumn{2}{|c|}{$500-2,000$} & \multicolumn{2}{|c|}{$2,000-4,000$} & \multicolumn{2}{|c|}{$4,000-10,000$} & \multicolumn{2}{|c|}{$10,000-20,000$} & \multicolumn{2}{|c|}{$20,000-50,000$} & \multicolumn{2}{|c|}{$50,000+$} \\
\hline & NY State & U.S. & NY State & U.S. & NY State & U.S. & NY State & U.S. & NY State & U.S. & NY State & U.S. & NY State & U.S. \\
\hline \multicolumn{15}{|c|}{ Zero-Vehicle Households - Daily PMT per Person } \\
\hline TOTAL & 2.85 & 4.30 & 2.68 & 5.13 & 2.74 & 1.81 & 1.49 & 12.81 & 2.83 & 2.04 & 17.55 & 1.59 & 1.67 & 5.51 \\
\hline$<\$ 10,000$ & 13.52 & 2.58 & 4.20 & 4.83 & 3.71 & 1.82 & 2.19 & 1.58 & 3.97 & 1.08 & 3.95 & 3.84 & 3.36 & 64.64 \\
\hline$\$ 10$ to $\$ 20,000$ & 5.61 & 14.24 & 1.05 & 10.14 & 3.96 & 2.04 & 2.44 & 2.21 & 8.30 & 0.97 & 1.21 & 4.62 & 1.91 & 0.66 \\
\hline$\$ 20$ to $\$ 30,000$ & 4.90 & 38.65 & 2.65 & 7.70 & 1.32 & 4.17 & 2.98 & 34.47 & 4.21 & 6.20 & 1.93 & 2.40 & 2.25 & 10.51 \\
\hline$\$ 30$ to $\$ 40,000$ & 49.89 & 10.66 & 7.26 & 14.06 & 11.80 & 10.96 & 7.69 & 9.03 & 2.31 & 14.05 & 3.52 & 4.21 & 9.41 & 6.21 \\
\hline$\$ 40$ to $\$ 50,000$ & & 20.89 & 24.65 & 1.52 & & 4.59 & 10.06 & 2.72 & 65.73 & 5.28 & 13.35 & 7.68 & 1.98 & 6.98 \\
\hline$\$ 50$ to $\$ 60,000$ & 15.39 & 94.77 & & 32.59 & 3.25 & 29.35 & 6.87 & 507.17 & 11.17 & 7.63 & 0.74 & 7.33 & 2.05 & \\
\hline$\$ 60$ to $\$ 70,000$ & 1.60 & 35.10 & & 43.78 & & 10.17 & & 0.85 & 21.39 & 2.93 & 16.92 & 9.78 & 3.09 & \\
\hline$\$ 70$ to $\$ 80,000$ & 9.95 & 34.06 & & 0.35 & 106.54 & & & & 7.67 & 26.63 & 4.41 & & 24.79 & 7.30 \\
\hline$\$ 80$ to $\$ 100,000$ & 16.01 & 8.45 & 23.44 & 5.41 & & 124.05 & 4.37 & 2.00 & 13.00 & 12.63 & 80.98 & 17.97 & 7.05 & \\
\hline$\$ 100,000+$ & 8.62 & 6.12 & 57.28 & 120.55 & & 11.82 & 9.39 & 134.21 & 10.03 & 4.25 & 299.36 & 1.05 & 3.13 & \\
\hline Unreported & 9.24 & 5.29 & 5.64 & 8.49 & 0.60 & 4.54 & 0.89 & 2.50 & 5.08 & 1.58 & 1.98 & 1.28 & 1.82 & 0.00 \\
\hline \multicolumn{15}{|c|}{ Non-Zero-Vehicle Households - Daily Person Trips per Person } \\
\hline TOTAL & 0.05 & 0.05 & 0.08 & 0.04 & 0.10 & 0.04 & 0.09 & 0.04 & 0.10 & 0.09 & 0.14 & 0.11 & 0.11 & 0.62 \\
\hline$\%$ Private & $0.7 \%$ & $0.4 \%$ & $0.7 \%$ & $0.4 \%$ & $0.8 \%$ & $0.3 \%$ & $0.9 \%$ & $0.4 \%$ & $2.5 \%$ & $1.0 \%$ & $2.1 \%$ & $1.8 \%$ & $2.8 \%$ & $8.8 \%$ \\
\hline$\%$ Public & $0.1 \%$ & $0.0 \%$ & $0.1 \%$ & $0.1 \%$ & $0.2 \%$ & $0.1 \%$ & $0.3 \%$ & $0.1 \%$ & $0.9 \%$ & $0.3 \%$ & $1.6 \%$ & $0.7 \%$ & $1.7 \%$ & $0.4 \%$ \\
\hline$\%$ Walk & $0.5 \%$ & $0.3 \%$ & $0.5 \%$ & $0.3 \%$ & $0.6 \%$ & $0.3 \%$ & $0.7 \%$ & $0.3 \%$ & $1.8 \%$ & $0.8 \%$ & $1.6 \%$ & $1.5 \%$ & $2.2 \%$ & $7.9 \%$ \\
\hline$\%$ Other & $0.5 \%$ & $0.2 \%$ & $0.3 \%$ & $0.2 \%$ & $0.5 \%$ & $0.2 \%$ & $0.4 \%$ & $0.1 \%$ & $0.6 \%$ & $0.4 \%$ & $0.6 \%$ & $0.6 \%$ & $0.6 \%$ & $1.6 \%$ \\
\hline$\%$ Unreported & $0.0 \%$ & $0.0 \%$ & $0.0 \%$ & $0.0 \%$ & $0.0 \%$ & $0.0 \%$ & $0.0 \%$ & $0.0 \%$ & $0.1 \%$ & $0.0 \%$ & $0.1 \%$ & $0.1 \%$ & $0.0 \%$ & $0.1 \%$ \\
\hline \multicolumn{15}{|c|}{ Non-Zero-Vehicle Households - Daily PMT per Person } \\
\hline TOTAL & 1.26 & 1.03 & 1.60 & 1.10 & 1.94 & 1.46 & 1.56 & 1.36 & 2.77 & 5.16 & 2.73 & 5.61 & 3.83 & 27.79 \\
\hline$\%$ Privat & $1.1 \%$ & $0.9 \%$ & $2.2 \%$ & $1.9 \%$ & $2.6 \%$ & $2.8 \%$ & $2.6 \%$ & $2.8 \%$ & $2.8 \%$ & $10.4 \%$ & $7.1 \%$ & $12.0 \%$ & $10.0 \%$ & $2.2 \%$ \\
\hline$\%$ Public & $0.3 \%$ & $0.1 \%$ & $0.3 \%$ & $0.1 \%$ & $0.9 \%$ & $0.1 \%$ & $0.7 \%$ & $0.2 \%$ & $2.2 \%$ & $0.5 \%$ & $3.0 \%$ & $0.5 \%$ & $2.7 \%$ & $0.1 \%$ \\
\hline$\%$ Walk & $0.1 \%$ & $0.0 \%$ & $0.1 \%$ & $0.0 \%$ & $0.1 \%$ & $0.0 \%$ & $0.2 \%$ & $0.0 \%$ & $0.5 \%$ & $0.2 \%$ & $0.4 \%$ & $0.2 \%$ & $0.7 \%$ & $1.8 \%$ \\
\hline$\%$ Other & $1.0 \%$ & $0.9 \%$ & $2.3 \%$ & $1.9 \%$ & $2.7 \%$ & $1.4 \%$ & $2.3 \%$ & $2.8 \%$ & $1.3 \%$ & $10.9 \%$ & $9.1 \%$ & $12.5 \%$ & $12.0 \%$ & $0.4 \%$ \\
\hline$\%$ Unreported & $0.0 \%$ & $0.1 \%$ & $0.1 \%$ & $0.1 \%$ & $0.2 \%$ & $2.2 \%$ & $1.6 \%$ & $0.0 \%$ & $0.1 \%$ & $0.0 \%$ & $0.0 \%$ & $0.0 \%$ & $3.0 \%$ & $0.0 \%$ \\
\hline Average Person Trip & & & & & & & & & & & & & & \\
\hline ALL & 0.36 & 0.25 & 0.35 & 0.26 & 0.46 & 0.33 & 0.37 & 0.37 & 0.74 & 1.28 & 2.03 & 1.30 & 0.67 & 3.95 \\
\hline Zero Vehicle HHs & 0.90 & 1.58 & 0.97 & 1.64 & 1.46 & 0.66 & 0.55 & 5.72 & 1.04 & 0.92 & 6.08 & 0.60 & 0.58 & 2.10 \\
\hline Non-Zero Vehicle HHs & 0.36 & 0.25 & 0.36 & 0.27 & 0.47 & 0.33 & 0.38 & 0.34 & 0.83 & 1.37 & 0.80 & 1.50 & 1.25 & 7.15 \\
\hline
\end{tabular}


Chapter 4: Table 6

Urban Travel and Population Density

2009 NHTS

STANDARD ERRORS

\begin{tabular}{|c|c|c|c|c|c|c|c|c|c|c|c|c|c|c|}
\hline \multicolumn{15}{|c|}{ Population Density (census tract) } \\
\hline & \multicolumn{2}{|c|}{$<500$} & \multicolumn{2}{|c|}{$500-2,000$} & \multicolumn{2}{|c|}{$2,000-4,000$} & \multicolumn{2}{|c|}{$4,000-10,000$} & \multicolumn{2}{|c|}{$10,000-20,000$} & \multicolumn{2}{|c|}{$20,000-50,000$} & \multicolumn{2}{|c|}{$50,000+$} \\
\hline & NY State & U.S. & NY State & U.S. & NY State & U.S. & NY State & U.S. & NY State & U.S. & NY State & U.S. & NY State & U.S. \\
\hline $\begin{array}{l}\text { Daily Vehicle Trips per Driver } \\
\text { TOTAL }\end{array}$ & 0.06 & 0.04 & 0.06 & 0.04 & 0.09 & 0.04 & 0.08 & 0.04 & 0.16 & 0.09 & 0.13 & 0.20 & 0.07 & 0.44 \\
\hline$\%$ Earn a Living & $0.9 \%$ & $0.7 \%$ & $0.9 \%$ & $0.5 \%$ & $1.3 \%$ & $0.6 \%$ & $1.2 \%$ & $0.5 \%$ & $2.4 \%$ & $1.0 \%$ & $2.9 \%$ & $2.4 \%$ & $2.8 \%$ & $9.4 \%$ \\
\hline$\%$ Family \& Personal Business & $0.9 \%$ & $0.6 \%$ & $1.0 \%$ & $0.6 \%$ & $1.3 \%$ & $0.6 \%$ & $1.5 \%$ & $0.6 \%$ & $3.6 \%$ & $1.4 \%$ & $3.3 \%$ & $1.7 \%$ & $3.7 \%$ & $6.1 \%$ \\
\hline$\%$ Civic, Educational \& Religious & $0.3 \%$ & $0.3 \%$ & $0.5 \%$ & $0.2 \%$ & $0.5 \%$ & $0.4 \%$ & $0.8 \%$ & $0.3 \%$ & $1.3 \%$ & $0.8 \%$ & $0.6 \%$ & $2.8 \%$ & $1.5 \%$ & $1.8 \%$ \\
\hline$\%$ Social \& Recreational & $0.7 \%$ & $0.5 \%$ & $0.8 \%$ & $0.4 \%$ & $1.2 \%$ & $0.4 \%$ & $1.2 \%$ & $0.4 \%$ & $3.8 \%$ & $1.2 \%$ & $2.0 \%$ & $2.1 \%$ & $4.0 \%$ & $5.9 \%$ \\
\hline$\%$ Other & $0.1 \%$ & $0.1 \%$ & $0.2 \%$ & $0.0 \%$ & $0.1 \%$ & $0.1 \%$ & $0.1 \%$ & $0.1 \%$ & $0.1 \%$ & $0.1 \%$ & $0.2 \%$ & $0.0 \%$ & $0.2 \%$ & \\
\hline$\%$ Unreported & $0.1 \%$ & $0.1 \%$ & $0.2 \%$ & $0.1 \%$ & $0.2 \%$ & $0.1 \%$ & $0.2 \%$ & $0.1 \%$ & $0.1 \%$ & $0.1 \%$ & $1.1 \%$ & $0.5 \%$ & $0.4 \%$ & $0.2 \%$ \\
\hline TOTAL & 0.06 & 0.04 & 0.06 & 0.04 & 0.09 & 0.04 & 0.08 & 0.04 & 0.16 & 0.09 & 0.13 & 0.20 & 0.07 & 0.44 \\
\hline Weekend & 0.08 & 0.06 & 0.10 & 0.05 & 0.14 & 0.09 & 0.14 & 0.07 & 0.25 & 0.12 & 0.27 & 0.19 & 0.17 & 0.76 \\
\hline Weekday & 0.07 & 0.05 & 0.08 & 0.04 & 0.11 & 0.05 & 0.09 & 0.04 & 0.21 & 0.11 & 0.14 & 0.24 & 0.09 & 0.47 \\
\hline TOTAL & 0.06 & 0.04 & 0.06 & 0.04 & 0.09 & 0.04 & 0.08 & 0.04 & 0.16 & 0.09 & 0.13 & 0.20 & 0.07 & 0.44 \\
\hline$\% 1-9 \min$ & $1.1 \%$ & $0.6 \%$ & $1.0 \%$ & $0.6 \%$ & $1.2 \%$ & $0.6 \%$ & $1.5 \%$ & $0.5 \%$ & $2.4 \%$ & $1.1 \%$ & $3.4 \%$ & $1.9 \%$ & $2.8 \%$ & $5.6 \%$ \\
\hline$\% 10-19 \min$ & $0.8 \%$ & $0.6 \%$ & $0.9 \%$ & $0.4 \%$ & $1.1 \%$ & $0.6 \%$ & $1.4 \%$ & $0.5 \%$ & $1.7 \%$ & $0.9 \%$ & $2.7 \%$ & $2.4 \%$ & $2.6 \%$ & $12.6 \%$ \\
\hline$\%$ 20-29 min & $0.8 \%$ & $0.5 \%$ & $0.7 \%$ & $0.4 \%$ & $0.6 \%$ & $0.3 \%$ & $0.7 \%$ & $0.4 \%$ & $1.6 \%$ & $0.9 \%$ & $2.0 \%$ & $2.2 \%$ & $4.5 \%$ & $6.7 \%$ \\
\hline$\% 30-39 \mathrm{~min}$ & $0.5 \%$ & $0.4 \%$ & $0.6 \%$ & $0.3 \%$ & $0.7 \%$ & $0.3 \%$ & $0.8 \%$ & $0.3 \%$ & $1.4 \%$ & $0.7 \%$ & $1.7 \%$ & $2.8 \%$ & $2.6 \%$ & $3.1 \%$ \\
\hline$\% 40-49 \mathrm{~min}$ & $0.3 \%$ & $0.3 \%$ & $0.3 \%$ & $0.2 \%$ & $0.4 \%$ & $0.2 \%$ & $0.5 \%$ & $0.2 \%$ & $0.7 \%$ & $0.4 \%$ & $1.4 \%$ & $1.2 \%$ & $1.6 \%$ & $1.2 \%$ \\
\hline$\% 50+\min$ & $0.4 \%$ & $0.2 \%$ & $0.4 \%$ & $0.2 \%$ & $0.5 \%$ & $0.2 \%$ & $0.5 \%$ & $0.2 \%$ & $0.7 \%$ & $0.6 \%$ & $1.7 \%$ & $1.1 \%$ & $2.5 \%$ & $3.0 \%$ \\
\hline$\%$ Unreported & $0.0 \%$ & $0.1 \%$ & $0.1 \%$ & $0.1 \%$ & $0.2 \%$ & $0.0 \%$ & $0.2 \%$ & $0.1 \%$ & $0.1 \%$ & $0.0 \%$ & $0.8 \%$ & $0.0 \%$ & $0.1 \%$ & \\
\hline TOTAL & 0.06 & 0.04 & 0.06 & 0.04 & 0.09 & 0.04 & 0.08 & 0.04 & 0.16 & 0.09 & 0.13 & 0.20 & 0.07 & 0.44 \\
\hline$\% 5$ or les & $1.0 \%$ & $0.7 \%$ & $1.1 \%$ & $0.6 \%$ & $1.2 \%$ & $0.6 \%$ & $1.5 \%$ & $0.7 \%$ & $2.3 \%$ & $1.3 \%$ & $4.2 \%$ & $2.4 \%$ & $5.0 \%$ & $6.3 \%$ \\
\hline$\%$ 6-10 miles & $0.7 \%$ & $0.5 \%$ & $0.7 \%$ & $0.4 \%$ & $0.9 \%$ & $0.4 \%$ & $0.8 \%$ & $0.4 \%$ & $1.8 \%$ & $0.8 \%$ & $2.4 \%$ & $2.1 \%$ & $2.7 \%$ & $4.8 \%$ \\
\hline$\% 11-15$ miles & $0.6 \%$ & $0.4 \%$ & $0.6 \%$ & $0.3 \%$ & $0.7 \%$ & $0.3 \%$ & $0.5 \%$ & $0.3 \%$ & $1.0 \%$ & $0.6 \%$ & $1.5 \%$ & $0.9 \%$ & $2.2 \%$ & $3.5 \%$ \\
\hline$\% 16-20$ miles & $0.4 \%$ & $0.3 \%$ & $0.6 \%$ & $0.2 \%$ & $0.4 \%$ & $0.2 \%$ & $0.7 \%$ & $0.2 \%$ & $1.1 \%$ & $0.3 \%$ & $1.0 \%$ & $0.7 \%$ & $1.2 \%$ & $0.3 \%$ \\
\hline$\% 21-30$ miles & $0.4 \%$ & $0.3 \%$ & $0.4 \%$ & $0.3 \%$ & $0.5 \%$ & $0.2 \%$ & $0.5 \%$ & $0.2 \%$ & $0.5 \%$ & $0.3 \%$ & $0.5 \%$ & $1.4 \%$ & $0.8 \%$ & $2.6 \%$ \\
\hline$\% 31$ or more miles & $0.4 \%$ & $0.3 \%$ & $0.4 \%$ & $0.3 \%$ & $0.5 \%$ & $0.2 \%$ & $0.6 \%$ & $0.2 \%$ & $0.6 \%$ & $0.4 \%$ & $0.7 \%$ & $2.7 \%$ & $1.5 \%$ & $0.5 \%$ \\
\hline$\%$ Unreported & $0.2 \%$ & $0.1 \%$ & $0.4 \%$ & $0.1 \%$ & $0.2 \%$ & $0.2 \%$ & $0.4 \%$ & $0.1 \%$ & $1.1 \%$ & $0.5 \%$ & $4.3 \%$ & $1.8 \%$ & $1.1 \%$ & $1.3 \%$ \\
\hline \multicolumn{15}{|l|}{ Daily } \\
\hline TOTAL & 1.18 & 1.31 & 1.91 & 0.80 & 1.04 & 1.01 & 1.06 & 0.51 & 1.14 & 1.37 & 0.88 & 3.23 & 1.62 & 1.66 \\
\hline$\%$ Earn & $1.6 \%$ & $1.5 \%$ & $2.7 \%$ & $1.2 \%$ & $2.6 \%$ & $1.5 \%$ & $2.2 \%$ & $1.1 \%$ & $3.2 \%$ & $3.7 \%$ & $4.5 \%$ & $6.2 \%$ & $6.0 \%$ & $7.4 \%$ \\
\hline$\%$ Family \& Personal Business & $1.5 \%$ & $1.4 \%$ & $2.2 \%$ & $1.0 \%$ & $1.7 \%$ & $1.0 \%$ & $2.4 \%$ & $0.8 \%$ & $3.5 \%$ & $2.4 \%$ & $4.0 \%$ & $5.7 \%$ & $8.3 \%$ & $6.5 \%$ \\
\hline$\%$ Civic, Educational \& Religious & $0.3 \%$ & $0.4 \%$ & $0.4 \%$ & $0.3 \%$ & $1.0 \%$ & $0.3 \%$ & $1.2 \%$ & $0.4 \%$ & $0.8 \%$ & $1.0 \%$ & $0.4 \%$ & $11.3 \%$ & $1.5 \%$ & $0.3 \%$ \\
\hline$\%$ Social \& Recreational & $1.3 \%$ & $1.5 \%$ & $2.5 \%$ & $1.4 \%$ & $2.5 \%$ & $1.3 \%$ & $2.4 \%$ & $1.3 \%$ & $4.1 \%$ & $3.9 \%$ & $4.2 \%$ & $4.9 \%$ & $13.8 \%$ & $6.4 \%$ \\
\hline$\%$ Other & $0.3 \%$ & $0.2 \%$ & $0.2 \%$ & $0.2 \%$ & $0.1 \%$ & $0.2 \%$ & $0.1 \%$ & $0.1 \%$ & $0.1 \%$ & $0.1 \%$ & $0.1 \%$ & $0.0 \%$ & $0.3 \%$ & \\
\hline$\%$ Unreported & $0.4 \%$ & $2.4 \%$ & $5.2 \%$ & $0.4 \%$ & $0.2 \%$ & $1.4 \%$ & $0.9 \%$ & $0.3 \%$ & $0.6 \%$ & $0.4 \%$ & $1.2 \%$ & $2.1 \%$ & $0.9 \%$ & $2.1 \%$ \\
\hline $\begin{array}{l}\text { Average Vehicle Trip Length } \\
\text { TOTAL }\end{array}$ & 0.35 & 0.45 & 0.59 & 0.24 & 0.27 & 0.33 & 0.35 & 0.16 & 0.39 & 0.54 & 0.60 & 1.04 & 2.28 & 0.89 \\
\hline \multicolumn{15}{|c|}{ ns who drove on travel day only) } \\
\hline TOTAL & 1.88 & 1.17 & 1.85 & 0.98 & 1.73 & 1.05 & 2.67 & 1.02 & 3.81 & 2.94 & 3.80 & 6.03 & 10.54 & 8.78 \\
\hline
\end{tabular}


Chapter 4: Table 6

Urban Travel and Population Density

2001 NHTS

STANDARD ERRORS

\begin{tabular}{|c|c|c|c|c|c|c|c|c|c|c|c|c|c|c|}
\hline \multicolumn{15}{|c|}{ Population Density (census tract) } \\
\hline & \multirow{2}{*}{\multicolumn{2}{|c|}{ NY State $^{<500}$ U.S. }} & \multicolumn{2}{|c|}{$500-2,000$} & \multicolumn{2}{|c|}{$2,000-4,000$} & \multicolumn{2}{|c|}{$4,000-10,000$} & \multicolumn{2}{|c|}{$10,000-20,000$} & \multicolumn{2}{|c|}{$20,000-50,000$} & \multicolumn{2}{|c|}{$50,000+$} \\
\hline & & U.S. & NY State & U.S. & NY State & U.S. & NY State & U.S. & NY State & U.S. & NY State & U.S. & NY State & U.S. \\
\hline $\begin{array}{l}\text { Daily Vehicle Trips per Driver } \\
\text { TOTAL }\end{array}$ & 0.00 & 0.04 & 0.07 & $0.04]$ & 009 & 0.04 & 009 & 0.04 & 0.12 & 0.07 & 013 & 0.11 & 0.08 & 068 \\
\hline$\%$ Earn a Living & $0.8 \%$ & $0.5 \%$ & $0.9 \%$ & $0.4 \%$ & $1.3 \%$ & $0.5 \%$ & $1.0 \%$ & $0.5 \%$ & $1.6 \%$ & $1.0 \%$ & $2.1 \%$ & $1.8 \%$ & $3.0 \%$ & $\begin{array}{r}0.68 \\
7.2 \%\end{array}$ \\
\hline$\%$ Family \& Personal Business & $0.9 \%$ & $0.5 \%$ & $1.1 \%$ & $0.5 \%$ & $1.2 \%$ & $0.5 \%$ & $1.1 \%$ & $0.5 \%$ & $1.7 \%$ & $1.3 \%$ & $2.2 \%$ & $1.9 \%$ & $3.2 \%$ & $13.2 \%$ \\
\hline$\%$ Civic, Educational \& Religious & $0.4 \%$ & $0.2 \%$ & $0.4 \%$ & $0.2 \%$ & $0.4 \%$ & $0.3 \%$ & $0.4 \%$ & $0.2 \%$ & $0.8 \%$ & $0.4 \%$ & $0.9 \%$ & $0.8 \%$ & $1.1 \%$ & $0.4 \%$ \\
\hline$\%$ Social \& Recreational & $0.7 \%$ & $0.4 \%$ & $0.7 \%$ & $0.4 \%$ & $0.8 \%$ & $0.4 \%$ & $0.7 \%$ & $0.4 \%$ & $1.4 \%$ & $0.9 \%$ & $1.4 \%$ & $1.8 \%$ & $2.5 \%$ & $9.3 \%$ \\
\hline$\%$ Other & $0.1 \%$ & $0.1 \%$ & $0.1 \%$ & $0.1 \%$ & $0.1 \%$ & $0.1 \%$ & $0.1 \%$ & $0.1 \%$ & $0.2 \%$ & $0.1 \%$ & $0.4 \%$ & $0.2 \%$ & $0.2 \%$ & \\
\hline$\%$ Unreported & $0.1 \%$ & $0.0 \%$ & $0.0 \%$ & $0.0 \%$ & $0.1 \%$ & $0.0 \%$ & $0.1 \%$ & $0.0 \%$ & $0.0 \%$ & $0.1 \%$ & $0.1 \%$ & $0.0 \%$ & $0.1 \%$ & $3.0 \%$ \\
\hline TOTAL & 0.06 & 0.04 & 0.07 & 0.04 & 0.09 & 0.04 & 0.09 & 0.04 & 0.12 & 0.07 & 0.13 & 0.11 & 0.08 & 0.68 \\
\hline Weekend & 0.07 & 0.06 & 0.16 & 0.07 & 0.15 & 0.07 & 0.17 & 0.07 & 0.17 & 0.15 & 0.19 & 0.22 & 0.15 & 1.03 \\
\hline Weekday & 0.08 & 0.05 & 0.07 & 0.04 & 0.11 & 0.05 & 0.10 & 0.04 & 0.13 & 0.08 & 0.16 & 0.12 & 0.08 & 0.98 \\
\hline TOTAL & 0.06 & 0.04 & 0.07 & 0.04 & 0.09 & 0.04 & 0.09 & 0.04 & 0.12 & 0.07 & 0.13 & 0.11 & 0.08 & 0.68 \\
\hline$\% 1-9 \min$ & $0.7 \%$ & $0.5 \%$ & $0.9 \%$ & $0.5 \%$ & $1.1 \%$ & $0.5 \%$ & $1.2 \%$ & $0.5 \%$ & $1.7 \%$ & $1.0 \%$ & $2.3 \%$ & $1.8 \%$ & $1.6 \%$ & $12.7 \%$ \\
\hline$\% 10-19 \mathrm{~min}$ & $0.8 \%$ & $0.5 \%$ & $0.9 \%$ & $0.5 \%$ & $1.2 \%$ & $0.5 \%$ & $1.0 \%$ & $0.5 \%$ & $1.6 \%$ & $1.0 \%$ & $2.5 \%$ & $1.7 \%$ & $2.0 \%$ & $9.4 \%$ \\
\hline$\%$ 20-29 min & $0.5 \%$ & $0.3 \%$ & $0.5 \%$ & $0.3 \%$ & $0.6 \%$ & $0.3 \%$ & $0.7 \%$ & $0.3 \%$ & $1.0 \%$ & $0.6 \%$ & $1.4 \%$ & $1.3 \%$ & $1.7 \%$ & $5.1 \%$ \\
\hline$\% 30-39 \mathrm{~min}$ & $0.5 \%$ & $0.3 \%$ & $0.5 \%$ & $0.3 \%$ & $0.5 \%$ & $0.3 \%$ & $0.5 \%$ & $0.3 \%$ & $0.9 \%$ & $0.7 \%$ & $1.2 \%$ & $1.4 \%$ & $1.7 \%$ & $5.2 \%$ \\
\hline$\% 40-49 \mathrm{~min}$ & $0.3 \%$ & $0.2 \%$ & $0.3 \%$ & $0.2 \%$ & $0.4 \%$ & $0.2 \%$ & $0.3 \%$ & $0.2 \%$ & $0.7 \%$ & $0.5 \%$ & $0.8 \%$ & $0.8 \%$ & $1.1 \%$ & $8.9 \%$ \\
\hline$\% 50+\min$ & $0.4 \%$ & $0.2 \%$ & $0.4 \%$ & $0.2 \%$ & $0.4 \%$ & $0.2 \%$ & $0.5 \%$ & $0.2 \%$ & $1.0 \%$ & $0.5 \%$ & $1.0 \%$ & $0.8 \%$ & $1.4 \%$ & $5.7 \%$ \\
\hline$\%$ Unreported & $0.1 \%$ & $0.1 \%$ & $0.2 \%$ & $0.1 \%$ & $0.2 \%$ & $0.1 \%$ & $0.2 \%$ & $0.1 \%$ & $0.2 \%$ & $0.2 \%$ & $0.2 \%$ & $0.2 \%$ & $0.2 \%$ & \\
\hline TOTAL & 0.06 & 0.04 & 0.07 & 0.04 & 0.09 & 0.04 & 0.09 & 0.04 & 0.12 & 0.07 & 0.13 & 0.11 & 0.08 & 0.68 \\
\hline$\% 5$ or less miles & $0.9 \%$ & $0.6 \%$ & $0.9 \%$ & $0.5 \%$ & $1.0 \%$ & $0.6 \%$ & $1.3 \%$ & $0.6 \%$ & $1.6 \%$ & $1.5 \%$ & $2.8 \%$ & $2.3 \%$ & $2.6 \%$ & $14.9 \%$ \\
\hline$\%$ 6-10 miles & $0.7 \%$ & $0.4 \%$ & $0.7 \%$ & $0.4 \%$ & $0.8 \%$ & $0.4 \%$ & $0.7 \%$ & $0.4 \%$ & $1.1 \%$ & $0.9 \%$ & $1.7 \%$ & $1.7 \%$ & $2.0 \%$ & $5.1 \%$ \\
\hline$\% 11-15$ miles & $0.5 \%$ & $0.3 \%$ & $0.5 \%$ & $0.2 \%$ & $0.6 \%$ & $0.3 \%$ & $0.4 \%$ & $0.3 \%$ & $1.3 \%$ & $0.7 \%$ & $1.0 \%$ & $1.3 \%$ & $1.1 \%$ & $2.9 \%$ \\
\hline$\% 16-20$ & $0.4 \%$ & $0.2 \%$ & $0.4 \%$ & $0.2 \%$ & $0.4 \%$ & $0.2 \%$ & $0.4 \%$ & $0.2 \%$ & $0.7 \%$ & $0.4 \%$ & $0.7 \%$ & $0.9 \%$ & $0.7 \%$ & $8.8 \%$ \\
\hline$\% 21-30$ miles & $0.4 \%$ & $0.2 \%$ & $0.3 \%$ & $0.2 \%$ & $0.4 \%$ & $0.2 \%$ & $0.4 \%$ & $0.2 \%$ & $0.5 \%$ & $0.5 \%$ & $0.6 \%$ & $1.0 \%$ & $0.7 \%$ & $3.7 \%$ \\
\hline$\% 31$ or more miles & $0.4 \%$ & $0.3 \%$ & $0.4 \%$ & $0.2 \%$ & $0.5 \%$ & $0.2 \%$ & $0.4 \%$ & $0.2 \%$ & $0.6 \%$ & $0.4 \%$ & $0.7 \%$ & $0.7 \%$ & $0.9 \%$ & $2.4 \%$ \\
\hline$\%$ Unreported & $0.1 \%$ & $0.1 \%$ & $0.3 \%$ & $0.1 \%$ & $0.2 \%$ & $0.1 \%$ & $0.6 \%$ & $0.2 \%$ & $0.6 \%$ & $0.8 \%$ & $0.9 \%$ & $0.6 \%$ & $1.4 \%$ & $0.5 \%$ \\
\hline Daily VM & & & & & & & & & & & & & & \\
\hline TOTAL & 1.05 & 0.68 & 0.96 & 0.67 & 1.37 & 0.69 & 1.12 & 0.69 & 1.88 & 1.14 & 1.43 & 1.44 & 1.31 & 5.52 \\
\hline$\%$ Earn & $1.7 \%$ & $1.1 \%$ & $1.6 \%$ & $0.9 \%$ & $2.2 \%$ & $1.2 \%$ & $2.3 \%$ & $1.0 \%$ & $4.6 \%$ & $2.1 \%$ & $4.9 \%$ & $3.5 \%$ & $5.3 \%$ & $19.0 \%$ \\
\hline$\%$ Family \& Personal Business & $1.3 \%$ & $1.0 \%$ & $1.7 \%$ & $0.8 \%$ & $1.9 \%$ & $1.3 \%$ & $1.7 \%$ & $1.0 \%$ & $2.5 \%$ & $2.3 \%$ & $3.8 \%$ & $2.5 \%$ & $5.2 \%$ & $11.7 \%$ \\
\hline$\%$ Civic, Educational \& Religious & $0.3 \%$ & $0.3 \%$ & $0.4 \%$ & $0.3 \%$ & $0.6 \%$ & $0.3 \%$ & $0.5 \%$ & $0.2 \%$ & $2.4 \%$ & $0.6 \%$ & $0.8 \%$ & $1.1 \%$ & $1.5 \%$ & $0.9 \%$ \\
\hline$\%$ Social \& Recreational & $1.9 \%$ & $0.9 \%$ & $1.3 \%$ & $1.1 \%$ & $2.1 \%$ & $1.2 \%$ & $2.4 \%$ & $1.3 \%$ & $3.9 \%$ & $1.5 \%$ & $3.4 \%$ & $4.3 \%$ & $6.6 \%$ & $6.0 \%$ \\
\hline$\%$ Other & $0.3 \%$ & $0.1 \%$ & $0.3 \%$ & $0.3 \%$ & $0.1 \%$ & $0.2 \%$ & $0.2 \%$ & $0.1 \%$ & $0.5 \%$ & $0.3 \%$ & $0.2 \%$ & $0.3 \%$ & $0.3 \%$ & \\
\hline$\%$ Unreported & $0.1 \%$ & $0.2 \%$ & $0.4 \%$ & $0.0 \%$ & $0.1 \%$ & $0.0 \%$ & $0.0 \%$ & $0.1 \%$ & $0.1 \%$ & $0.1 \%$ & $0.2 \%$ & $0.0 \%$ & $0.3 \%$ & $3.5 \%$ \\
\hline $\begin{array}{l}\text { Average Vehicle Trip Length } \\
\text { TOTAL }\end{array}$ & 0.33 & 0.22 & 0.28 & 0.18 & 0.37 & 0.18 & 0.34 & 0.21 & 0.75 & 0.34 & 0.72 & 0.52 & 1.22 & 2.03 \\
\hline & & & & & & & & & & & & & & \\
\hline TOTAL & 1.46 & 1.05 & 1.76 & 1.01 & 2.23 & 0.96 & 2.12 & 1.10 & 3.74 & 1.85 & 4.37 & 3.41 & 5.31 & 43.22 \\
\hline
\end{tabular}


Chapter 4: Table 7

Urban Travel and Population Density

2009 NHTS

STANDARD ERRORS

\begin{tabular}{|c|c|c|c|c|c|c|c|c|c|c|c|c|c|c|}
\hline \multicolumn{15}{|c|}{ Population Density (census tract) } \\
\hline & \multicolumn{2}{|c|}{$<500$} & \multicolumn{2}{|c|}{$500-2,000$} & \multicolumn{2}{|c|}{$2,000-4,000$} & \multicolumn{2}{|c|}{$4,000-10,000$} & \multicolumn{2}{|c|}{$10,000-20,000$} & \multicolumn{2}{|c|}{$20,000-50,000$} & \multicolumn{2}{|c|}{$50,000+$} \\
\hline & NY State & U.S. & NY State & U.s. & NY State & u.s. & NY State & U.S. & NY State & U.S. & NY State & U.S. & NY State & U.S. \\
\hline \multicolumn{15}{|c|}{ Daily Commute Person Trips per Person } \\
\hline TOTAL & 0.03 & 0.02 & 0.03 & 0.02 & 0.05 & 0.02 & 0.04 & 0.02 & 0.09 & 0.05 & 0.09 & 0.08 & 0.06 & 0.10 \\
\hline$\%$ SOV & $1.4 \%$ & $1.4 \%$ & $1.8 \%$ & $0.9 \%$ & $1.9 \%$ & $0.9 \%$ & $2.8 \%$ & $1.0 \%$ & $4.2 \%$ & $2.6 \%$ & $3.3 \%$ & $4.0 \%$ & $2.9 \%$ & $17.8 \%$ \\
\hline$\%$ MOV & $1.2 \%$ & $1.3 \%$ & $1.4 \%$ & $0.7 \%$ & $1.4 \%$ & $0.7 \%$ & $2.3 \%$ & $0.7 \%$ & $4.9 \%$ & $1.7 \%$ & $2.7 \%$ & $2.6 \%$ & $1.0 \%$ & $0.1 \%$ \\
\hline$\%$ Amtrak & & $0.0 \%$ & & $0.0 \%$ & & $0.0 \%$ & & $0.0 \%$ & $0.8 \%$ & $0.2 \%$ & $0.8 \%$ & $0.4 \%$ & $0.6 \%$ & $1.5 \%$ \\
\hline$\%$ Commuter Train & $0.1 \%$ & $0.0 \%$ & $0.2 \%$ & $0.1 \%$ & $0.9 \%$ & $0.2 \%$ & $0.6 \%$ & $0.3 \%$ & $1.1 \%$ & $0.1 \%$ & $1.2 \%$ & $1.7 \%$ & $2.1 \%$ & $1.8 \%$ \\
\hline$\%$ Subway/El Rail & $0.1 \%$ & $0.0 \%$ & $0.1 \%$ & $0.0 \%$ & $0.1 \%$ & $0.1 \%$ & $0.8 \%$ & $0.1 \%$ & $1.0 \%$ & $0.3 \%$ & $4.1 \%$ & $2.1 \%$ & $3.6 \%$ & $17.6 \%$ \\
\hline$\%$ Other Public & $0.4 \%$ & $0.3 \%$ & $0.5 \%$ & $0.3 \%$ & $0.2 \%$ & $0.3 \%$ & $1.4 \%$ & $0.4 \%$ & $2.7 \%$ & $1.6 \%$ & $3.1 \%$ & $2.3 \%$ & $3.2 \%$ & $5.3 \%$ \\
\hline$\%$ Walk & $0.5 \%$ & $0.3 \%$ & $0.6 \%$ & $0.2 \%$ & $0.6 \%$ & $0.4 \%$ & $1.2 \%$ & $0.4 \%$ & $0.9 \%$ & $1.5 \%$ & $2.6 \%$ & $2.6 \%$ & $2.8 \%$ & $5.6 \%$ \\
\hline$\%$ Other & $0.3 \%$ & $0.5 \%$ & $0.6 \%$ & $0.3 \%$ & $0.3 \%$ & $0.3 \%$ & $1.7 \%$ & $0.4 \%$ & $1.9 \%$ & $0.6 \%$ & $1.5 \%$ & $1.5 \%$ & $1.5 \%$ & $3.5 \%$ \\
\hline$\%$ Unreported & $0.1 \%$ & $0.1 \%$ & & $0.1 \%$ & $0.6 \%$ & $0.0 \%$ & & $0.1 \%$ & & $0.3 \%$ & $0.6 \%$ & $0.2 \%$ & & \\
\hline TOTAL & 0.03 & 0.02 & 0.03 & 0.02 & 0.05 & 0.02 & 0.04 & 0.02 & 0.09 & 0.05 & 0.09 & 0.08 & 0.06 & 0.10 \\
\hline$\% 1-6 \mathrm{am}$ & $0.6 \%$ & $0.5 \%$ & $0.6 \%$ & $0.4 \%$ & $0.6 \%$ & $0.3 \%$ & $0.7 \%$ & $0.3 \%$ & $0.9 \%$ & $0.9 \%$ & $1.7 \%$ & $1.8 \%$ & $1.4 \%$ & $2.8 \%$ \\
\hline$\%$ 6-9 am & $1.1 \%$ & $0.7 \%$ & $1.2 \%$ & $0.6 \%$ & $1.6 \%$ & $0.7 \%$ & $1.4 \%$ & $0.6 \%$ & $1.9 \%$ & $1.3 \%$ & $2.2 \%$ & $1.6 \%$ & $1.7 \%$ & $8.9 \%$ \\
\hline$\% 9 \mathrm{am}-1 \mathrm{pm}$ & $0.7 \%$ & $0.6 \%$ & $1.0 \%$ & $0.5 \%$ & $1.1 \%$ & $0.5 \%$ & $1.1 \%$ & $0.5 \%$ & $1.1 \%$ & $0.9 \%$ & $1.9 \%$ & $1.3 \%$ & $1.7 \%$ & $8.4 \%$ \\
\hline$\% 1-4 \mathrm{pm}$ & $1.0 \%$ & $0.6 \%$ & $0.9 \%$ & $0.6 \%$ & $1.3 \%$ & $0.6 \%$ & $1.5 \%$ & $0.6 \%$ & $2.1 \%$ & $1.0 \%$ & $2.2 \%$ & $2.8 \%$ & $1.8 \%$ & $4.2 \%$ \\
\hline$\%$ 4-7 pm & $1.1 \%$ & $0.9 \%$ & $1.1 \%$ & $0.6 \%$ & $1.4 \%$ & $0.7 \%$ & $1.5 \%$ & $0.6 \%$ & $2.4 \%$ & $1.0 \%$ & $2.1 \%$ & $2.4 \%$ & $2.0 \%$ & $9.0 \%$ \\
\hline$\%$ 7-10 pm & $0.6 \%$ & $0.5 \%$ & $0.8 \%$ & $0.4 \%$ & $1.0 \%$ & $0.4 \%$ & $0.8 \%$ & $0.5 \%$ & $1.5 \%$ & $0.9 \%$ & $1.4 \%$ & $2.1 \%$ & $1.8 \%$ & $2.5 \%$ \\
\hline$\% 10 \mathrm{pm}-1 \mathrm{am}$ & $1.0 \%$ & $0.4 \%$ & $0.9 \%$ & $0.3 \%$ & $0.9 \%$ & $0.3 \%$ & $0.8 \%$ & $0.3 \%$ & $1.4 \%$ & $1.0 \%$ & $1.6 \%$ & $2.1 \%$ & $1.2 \%$ & $8.4 \%$ \\
\hline$\%$ Unreported & & & & $0.0 \%$ & & & & & & & & & & \\
\hline \multicolumn{15}{|c|}{ Daily Commute PMT per Person } \\
\hline TOTAL & 0.57 & 0.50 & 0.55 & 0.54 & 0.98 & 0.35 & 0.65 & 0.28 & 1.17 & 0.53 & 1.19 & 1.16 & 0.64 & 1.19 \\
\hline$\%$ sov & $2.6 \%$ & $1.6 \%$ & $2.3 \%$ & $1.6 \%$ & $3.3 \%$ & $1.4 \%$ & $3.4 \%$ & $1.1 \%$ & $6.4 \%$ & $2.9 \%$ & $5.2 \%$ & $5.1 \%$ & $6.7 \%$ & $13.7 \%$ \\
\hline$\%$ MOV & $1.7 \%$ & $1.5 \%$ & $2.4 \%$ & $1.3 \%$ & $2.5 \%$ & $0.8 \%$ & $3.2 \%$ & $0.7 \%$ & $3.9 \%$ & $1.3 \%$ & $7.8 \%$ & $2.7 \%$ & $1.2 \%$ & $0.2 \%$ \\
\hline$\%$ Amtrak & & $0.0 \%$ & & $0.0 \%$ & & $0.0 \%$ & & $0.0 \%$ & $6.8 \%$ & $0.9 \%$ & $0.4 \%$ & $0.4 \%$ & & $0.5 \%$ \\
\hline$\%$ Commuter Train & $0.2 \%$ & $0.0 \%$ & $0.6 \%$ & $0.2 \%$ & $2.3 \%$ & $0.6 \%$ & $1.1 \%$ & $0.3 \%$ & $2.8 \%$ & $0.1 \%$ & $1.7 \%$ & $2.4 \%$ & $2.2 \%$ & $6.8 \%$ \\
\hline$\%$ Subway/El Rail & $0.2 \%$ & $0.0 \%$ & $0.4 \%$ & $0.0 \%$ & $0.1 \%$ & $0.1 \%$ & $1.6 \%$ & $0.2 \%$ & $0.4 \%$ & $0.3 \%$ & $5.6 \%$ & $2.0 \%$ & $6.0 \%$ & $9.7 \%$ \\
\hline$\%$ Other Public & $0.2 \%$ & $0.1 \%$ & $0.1 \%$ & $0.1 \%$ & $0.3 \%$ & $0.5 \%$ & $0.5 \%$ & $0.5 \%$ & $2.8 \%$ & $0.7 \%$ & $2.3 \%$ & $2.6 \%$ & $6.3 \%$ & $10.8 \%$ \\
\hline$\%$ Walk & $0.0 \%$ & $0.0 \%$ & $0.1 \%$ & $0.1 \%$ & $0.0 \%$ & $0.1 \%$ & $0.1 \%$ & $0.0 \%$ & $0.1 \%$ & $0.2 \%$ & $3.1 \%$ & $0.3 \%$ & $1.6 \%$ & $1.3 \%$ \\
\hline$\%$ Other & $2.0 \%$ & $0.7 \%$ & $0.5 \%$ & $0.8 \%$ & $0.3 \%$ & $0.7 \%$ & $1.1 \%$ & $0.6 \%$ & $2.8 \%$ & $2.4 \%$ & $0.6 \%$ & $0.9 \%$ & $2.3 \%$ & $3.8 \%$ \\
\hline$\%$ Unreported & $0.1 \%$ & $0.1 \%$ & & $0.2 \%$ & $0.8 \%$ & $0.1 \%$ & & $0.1 \%$ & & $0.1 \%$ & $1.0 \%$ & & & \\
\hline TOTAL & 0.57 & 0.50 & 0.55 & 0.54 & 0.98 & 0.35 & 0.65 & 0.28 & 1.17 & 0.53 & 1.19 & 1.16 & 0.64 & 1.19 \\
\hline$\% 1-6 \mathrm{am}$ & $1.2 \%$ & $0.8 \%$ & $0.8 \%$ & $0.7 \%$ & $1.6 \%$ & $0.7 \%$ & $1.5 \%$ & $0.6 \%$ & $1.7 \%$ & $1.2 \%$ & $1.1 \%$ & $4.2 \%$ & $2.2 \%$ & $10.0 \%$ \\
\hline$\%$ 6-9 am & $1.8 \%$ & $1.0 \%$ & $1.9 \%$ & $1.2 \%$ & $2.7 \%$ & $1.1 \%$ & $2.2 \%$ & $0.7 \%$ & $2.8 \%$ & $1.9 \%$ & $3.4 \%$ & $4.0 \%$ & $2.3 \%$ & $8.5 \%$ \\
\hline$\% 9 \mathrm{am}-1 \mathrm{pm}$ & $0.8 \%$ & $0.7 \%$ & $1.3 \%$ & $0.6 \%$ & $1.3 \%$ & $0.8 \%$ & $1.7 \%$ & $0.5 \%$ & $1.9 \%$ & $1.1 \%$ & $7.1 \%$ & $1.3 \%$ & $3.4 \%$ & $6.9 \%$ \\
\hline$\% 1-4 \mathrm{pm}$ & $1.2 \%$ & $0.8 \%$ & $1.4 \%$ & $1.1 \%$ & $2.2 \%$ & $0.8 \%$ & $2.1 \%$ & $0.8 \%$ & $1.9 \%$ & $1.3 \%$ & $3.1 \%$ & $3.3 \%$ & $1.3 \%$ & $3.6 \%$ \\
\hline$\%$ 4-7 pm & $1.6 \%$ & $1.1 \%$ & $1.5 \%$ & $1.5 \%$ & $2.1 \%$ & $0.9 \%$ & $2.0 \%$ & $0.8 \%$ & $2.6 \%$ & $2.2 \%$ & $2.7 \%$ & $3.1 \%$ & $2.8 \%$ & $6.1 \%$ \\
\hline$\%$ 7-10 pm & $0.7 \%$ & $0.6 \%$ & $0.7 \%$ & $0.5 \%$ & $2.1 \%$ & $0.6 \%$ & $1.3 \%$ & $0.4 \%$ & $3.4 \%$ & $1.3 \%$ & $1.5 \%$ & $4.0 \%$ & $2.6 \%$ & $3.2 \%$ \\
\hline$\% 10 \mathrm{pm}-1 \mathrm{am}$ & $0.8 \%$ & $0.7 \%$ & $1.2 \%$ & $0.3 \%$ & $1.0 \%$ & $0.3 \%$ & $0.6 \%$ & $0.4 \%$ & $1.8 \%$ & $1.0 \%$ & $2.8 \%$ & $6.6 \%$ & $1.1 \%$ & $4.0 \%$ \\
\hline$\%$ Unreported & & & & $0.0 \%$ & & & & & & & & & & \\
\hline
\end{tabular}


Chapter 4: Table 7

Urban Travel and Population Density

2001 NHTS

STANDARD ERRORS

\begin{tabular}{|c|c|c|c|c|c|c|c|c|c|c|c|c|c|c|}
\hline \multicolumn{15}{|c|}{ Population Density (census tract) } \\
\hline & \multicolumn{2}{|c|}{$<500$} & \multicolumn{2}{|c|}{$500-2,000$} & \multicolumn{2}{|c|}{$2,000-4,000$} & \multicolumn{2}{|c|}{$4,000-10,000$} & \multicolumn{2}{|c|}{$10,000-20,000$} & \multicolumn{2}{|c|}{$20,000-50,000$} & \multicolumn{2}{|c|}{$50,000+$} \\
\hline & NY State & U.S. & NY State & U.S. & NY State & U.S. & NY State & U.S. & NY State & U.S. & NY State & U.S. & NY State & U.S. \\
\hline \multicolumn{15}{|c|}{ Daily Commute Person Trips per Person } \\
\hline TOTAL & 0.03 & 0.02 & 0.04 & 0.02 & 0.05 & 0.02 & 0.04 & 0.02 & 0.06 & 0.03 & 0.06 & 0.05 & 0.05 & 0.18 \\
\hline$\%$ SOV & $2.2 \%$ & $0.8 \%$ & $1.9 \%$ & $0.7 \%$ & $2.3 \%$ & $0.9 \%$ & $1.6 \%$ & $0.9 \%$ & $3.8 \%$ & $2.0 \%$ & $3.0 \%$ & $3.3 \%$ & $2.2 \%$ & $19.3 \%$ \\
\hline$\%$ MOV & $1.3 \%$ & $0.8 \%$ & $1.9 \%$ & $0.7 \%$ & $1.7 \%$ & $0.8 \%$ & $1.5 \%$ & $0.8 \%$ & $1.9 \%$ & $1.5 \%$ & $1.4 \%$ & $2.2 \%$ & $1.4 \%$ & $6.0 \%$ \\
\hline$\%$ Amtrak & $0.1 \%$ & & $0.1 \%$ & $0.0 \%$ & $0.1 \%$ & $0.1 \%$ & $0.5 \%$ & $0.0 \%$ & $0.8 \%$ & $0.2 \%$ & $0.5 \%$ & & $0.5 \%$ & \\
\hline$\%$ Commuter Train & $0.3 \%$ & $0.0 \%$ & $0.3 \%$ & $0.1 \%$ & $0.9 \%$ & $0.2 \%$ & $0.9 \%$ & $0.2 \%$ & $0.5 \%$ & $0.2 \%$ & $1.3 \%$ & $0.5 \%$ & $0.3 \%$ & \\
\hline$\%$ Subway/El Rail & $1.3 \%$ & $0.0 \%$ & $0.2 \%$ & $0.2 \%$ & $0.7 \%$ & $0.1 \%$ & $0.9 \%$ & $0.2 \%$ & $2.5 \%$ & $0.9 \%$ & $3.0 \%$ & $0.7 \%$ & $2.3 \%$ & $22.5 \%$ \\
\hline$\%$ Other Public & $0.1 \%$ & $0.1 \%$ & $0.1 \%$ & $0.1 \%$ & $0.3 \%$ & $0.3 \%$ & $0.4 \%$ & $0.4 \%$ & $1.6 \%$ & $1.0 \%$ & $1.7 \%$ & $1.8 \%$ & $1.7 \%$ & $12.7 \%$ \\
\hline$\%$ Walk & $0.6 \%$ & $0.2 \%$ & $0.7 \%$ & $0.2 \%$ & $0.9 \%$ & $0.3 \%$ & $0.8 \%$ & $0.4 \%$ & $1.6 \%$ & $1.1 \%$ & $2.2 \%$ & $2.4 \%$ & $1.8 \%$ & $0.4 \%$ \\
\hline$\%$ Other & $0.3 \%$ & $0.1 \%$ & $0.3 \%$ & $0.1 \%$ & $0.5 \%$ & $0.2 \%$ & $0.4 \%$ & $0.2 \%$ & $0.6 \%$ & $0.4 \%$ & $1.1 \%$ & $2.3 \%$ & $0.9 \%$ & \\
\hline$\%$ Unreported & $0.0 \%$ & $0.1 \%$ & & $0.1 \%$ & $0.2 \%$ & $0.0 \%$ & $0.1 \%$ & $0.0 \%$ & $0.2 \%$ & $0.0 \%$ & $0.0 \%$ & $0.3 \%$ & & \\
\hline TOTAL & 0.03 & 0.02 & 0.04 & 0.02 & 0.05 & 0.02 & 0.04 & 0.02 & 0.06 & 0.03 & 0.06 & 0.05 & 0.05 & 0.18 \\
\hline$\% 1-6 \mathrm{am}$ & $0.6 \%$ & $0.4 \%$ & $0.6 \%$ & $0.3 \%$ & $0.6 \%$ & $0.3 \%$ & $0.7 \%$ & $0.3 \%$ & $1.0 \%$ & $0.8 \%$ & $1.2 \%$ & $1.3 \%$ & $0.8 \%$ & $0.0 \%$ \\
\hline$\% 6-9 \mathrm{am}$ & $0.8 \%$ & $0.5 \%$ & $1.0 \%$ & $0.5 \%$ & $1.3 \%$ & $0.5 \%$ & $1.1 \%$ & $0.5 \%$ & $1.5 \%$ & $1.1 \%$ & $1.6 \%$ & $1.5 \%$ & $1.1 \%$ & $8.2 \%$ \\
\hline$\% 9 \mathrm{am}-1 \mathrm{pm}$ & $0.8 \%$ & $0.4 \%$ & $0.8 \%$ & $0.5 \%$ & $1.5 \%$ & $0.5 \%$ & $0.8 \%$ & $0.4 \%$ & $1.2 \%$ & $0.9 \%$ & $1.7 \%$ & $1.1 \%$ & $1.0 \%$ & $1.1 \%$ \\
\hline$\% 1-4 \mathrm{pm}$ & $0.8 \%$ & $0.6 \%$ & $1.0 \%$ & $0.4 \%$ & $1.4 \%$ & $0.5 \%$ & $0.9 \%$ & $0.5 \%$ & $1.4 \%$ & $1.1 \%$ & $1.6 \%$ & $1.5 \%$ & $1.1 \%$ & $5.9 \%$ \\
\hline$\% 4-7 \mathrm{pm}$ & $0.7 \%$ & $0.6 \%$ & $0.9 \%$ & $0.6 \%$ & $1.2 \%$ & $0.5 \%$ & $1.0 \%$ & $0.5 \%$ & $1.8 \%$ & $1.1 \%$ & $1.6 \%$ & $1.7 \%$ & $1.4 \%$ & $7.4 \%$ \\
\hline$\% 7-10 \mathrm{pm}$ & $0.7 \%$ & $0.4 \%$ & $0.6 \%$ & $0.4 \%$ & $0.9 \%$ & $0.4 \%$ & $0.7 \%$ & $0.4 \%$ & $1.0 \%$ & $0.8 \%$ & $1.5 \%$ & $1.1 \%$ & $1.2 \%$ & $6.6 \%$ \\
\hline$\% 10 \mathrm{pm}-1 \mathrm{am}$ & $0.6 \%$ & $0.4 \%$ & $0.9 \%$ & $0.3 \%$ & $0.5 \%$ & $0.3 \%$ & $0.6 \%$ & $0.3 \%$ & $1.1 \%$ & $0.7 \%$ & $1.0 \%$ & $0.8 \%$ & $0.8 \%$ & $0.9 \%$ \\
\hline$\%$ Unreported & $0.1 \%$ & $0.1 \%$ & & $0.0 \%$ & & $0.1 \%$ & $0.0 \%$ & $0.0 \%$ & $0.4 \%$ & $0.1 \%$ & & & & \\
\hline \multicolumn{15}{|c|}{ Daily Commute PMT per Person } \\
\hline TOTAL & 0.57 & 0.49 & 0.57 & 0.61 & 0.96 & 0.39 & 0.67 & 0.64 & 1.14 & 0.67 & 0.76 & 1.17 & 0.40 & 2.64 \\
\hline$\%$ SOV & $2.4 \%$ & $1.4 \%$ & $2.1 \%$ & $3.4 \%$ & $4.6 \%$ & $1.3 \%$ & $3.2 \%$ & $3.8 \%$ & $4.5 \%$ & $3.6 \%$ & $5.4 \%$ & $7.9 \%$ & $3.5 \%$ & $33.4 \%$ \\
\hline$\%$ MOV & $2.1 \%$ & $1.3 \%$ & $1.9 \%$ & $1.3 \%$ & $3.6 \%$ & $1.2 \%$ & $1.8 \%$ & $1.3 \%$ & $3.0 \%$ & $3.0 \%$ & $2.0 \%$ & $8.8 \%$ & $2.2 \%$ & $13.2 \%$ \\
\hline$\%$ Amtrak & $0.4 \%$ & & $0.5 \%$ & $0.1 \%$ & $0.5 \%$ & $0.1 \%$ & $1.0 \%$ & $0.6 \%$ & $1.4 \%$ & $2.3 \%$ & $0.9 \%$ & & $0.7 \%$ & \\
\hline$\%$ Commuter Train & $1.0 \%$ & $0.1 \%$ & $0.7 \%$ & $0.3 \%$ & $2.5 \%$ & $0.2 \%$ & $2.2 \%$ & $0.5 \%$ & $2.0 \%$ & $1.3 \%$ & $3.4 \%$ & $0.6 \%$ & $0.5 \%$ & \\
\hline$\%$ Subway/El Rail & $0.7 \%$ & $0.0 \%$ & $0.5 \%$ & $0.3 \%$ & $0.7 \%$ & $0.3 \%$ & $1.3 \%$ & $0.2 \%$ & $5.3 \%$ & $1.0 \%$ & $5.1 \%$ & $0.8 \%$ & $3.4 \%$ & $20.6 \%$ \\
\hline$\%$ Other Public & $0.1 \%$ & $0.1 \%$ & $0.2 \%$ & $0.1 \%$ & $0.4 \%$ & $0.3 \%$ & $0.4 \%$ & $0.4 \%$ & $1.5 \%$ & $1.0 \%$ & $1.7 \%$ & $1.7 \%$ & $2.1 \%$ & $23.9 \%$ \\
\hline$\%$ Walk & $0.3 \%$ & $0.0 \%$ & $0.1 \%$ & $0.0 \%$ & $0.1 \%$ & $0.1 \%$ & $0.3 \%$ & $0.1 \%$ & $0.3 \%$ & $0.2 \%$ & $0.9 \%$ & $0.4 \%$ & $0.7 \%$ & $0.0 \%$ \\
\hline$\%$ Other & $1.2 \%$ & $1.0 \%$ & $0.7 \%$ & $4.0 \%$ & $1.2 \%$ & $0.6 \%$ & $0.6 \%$ & $4.4 \%$ & $0.5 \%$ & $2.0 \%$ & $1.4 \%$ & $1.0 \%$ & $1.3 \%$ & \\
\hline$\%$ Unreported & $0.1 \%$ & $0.2 \%$ & & $0.0 \%$ & $0.6 \%$ & $0.0 \%$ & $0.6 \%$ & $0.0 \%$ & $0.2 \%$ & $0.0 \%$ & $0.1 \%$ & & & \\
\hline TOTAL & 0.57 & 0.49 & 0.57 & 0.61 & 0.96 & 0.39 & 0.67 & 0.64 & 1.14 & 0.67 & 0.76 & 1.17 & 0.40 & 2.64 \\
\hline$\% 1-6 \mathrm{am}$ & $0.8 \%$ & $0.8 \%$ & $1.0 \%$ & $0.7 \%$ & $2.0 \%$ & $0.6 \%$ & $1.6 \%$ & $0.9 \%$ & $2.4 \%$ & $1.3 \%$ & $1.7 \%$ & $9.9 \%$ & $1.4 \%$ & $0.0 \%$ \\
\hline$\% 6-9 \mathrm{am}$ & $1.6 \%$ & $1.1 \%$ & $1.3 \%$ & $2.8 \%$ & $2.8 \%$ & $1.0 \%$ & $2.3 \%$ & $1.7 \%$ & $2.3 \%$ & $2.0 \%$ & $2.4 \%$ & $4.1 \%$ & $2.0 \%$ & $18.0 \%$ \\
\hline$\% 9 \mathrm{am}-1 \mathrm{pm}$ & $0.8 \%$ & $0.6 \%$ & $1.0 \%$ & $0.6 \%$ & $1.6 \%$ & $0.8 \%$ & $2.8 \%$ & $0.8 \%$ & $2.2 \%$ & $1.1 \%$ & $1.9 \%$ & $2.0 \%$ & $1.5 \%$ & $0.9 \%$ \\
\hline$\%$ & $1.2 \%$ & $0.9 \%$ & $1.4 \%$ & $0.8 \%$ & $2.1 \%$ & $0.8 \%$ & $1.3 \%$ & $0.7 \%$ & $2.2 \%$ & $2.6 \%$ & $2.6 \%$ & $2.3 \%$ & $1.5 \%$ & $3.1 \%$ \\
\hline$\%$ 4-7 pm & $1.0 \%$ & $1.0 \%$ & $1.4 \%$ & $1.3 \%$ & $1.9 \%$ & $0.9 \%$ & $1.7 \%$ & $1.6 \%$ & $3.1 \%$ & $2.1 \%$ & $2.7 \%$ & $3.6 \%$ & $2.3 \%$ & $13.3 \%$ \\
\hline$\%$ 7-10 pm & $0.7 \%$ & $0.6 \%$ & $1.0 \%$ & $0.9 \%$ & $1.2 \%$ & $1.0 \%$ & $1.2 \%$ & $4.1 \%$ & $1.4 \%$ & $1.7 \%$ & $3.0 \%$ & $1.6 \%$ & $1.8 \%$ & $3.6 \%$ \\
\hline$\% 10 \mathrm{pm}-1 \mathrm{am}$ & $0.7 \%$ & $0.5 \%$ & $0.8 \%$ & $0.4 \%$ & $0.5 \%$ & $0.4 \%$ & $0.8 \%$ & $0.6 \%$ & $2.1 \%$ & $1.6 \%$ & $1.8 \%$ & $1.4 \%$ & $1.1 \%$ & $0.2 \%$ \\
\hline$\%$ Unreported & $0.0 \%$ & $0.2 \%$ & & $0.0 \%$ & & $0.0 \%$ & $0.0 \%$ & $0.0 \%$ & $0.0 \%$ & & & & & \\
\hline
\end{tabular}


Chapter 4: Table 8

Urban Travel and Population Density

2009 NHTS

STANDARD ERRORS

\begin{tabular}{|c|c|c|c|c|c|c|c|c|c|c|c|c|c|c|}
\hline \multicolumn{15}{|c|}{ Population Density (census tract) } \\
\hline & \multicolumn{2}{|c|}{$<500$} & \multicolumn{2}{|c|}{$500-2,000$} & \multicolumn{2}{|c|}{$2,000-4,000$} & \multicolumn{2}{|c|}{$4,000-10,000$} & \multicolumn{2}{|c|}{$10,000-20,000$} & \multicolumn{2}{|c|}{$20,000-50,000$} & \multicolumn{2}{|c|}{$50,000+$} \\
\hline & NY State & U.S. & NY State & U.S. & NY State & U.S. & NY State & U.S. & NY State & U.S. & NY State & U.S. & NY State & U.S. \\
\hline \multicolumn{15}{|c|}{$\begin{array}{l}\text { Average Commute Length, Travel Time, and Speed } \\
\text { Length (miles) }\end{array}$} \\
\hline TOTAL & 0.50 & 0.35 & 0.42 & 0.41 & 0.75 & 0.24 & 0.57 & 0.22 & 1.07 & 0.50 & 1.15 & 0.84 & 0.64 & 0.95 \\
\hline Private & 0.46 & 0.33 & 0.45 & 0.42 & 0.78 & 0.24 & 0.59 & 0.24 & 0.87 & 0.47 & 2.16 & 1.12 & 2.32 & 1.64 \\
\hline Public & 8.71 & 2.05 & 7.69 & 4.72 & 2.97 & 4.51 & 2.01 & 1.14 & 2.04 & 1.08 & 1.22 & 1.26 & 0.79 & 3.11 \\
\hline Walk & 0.06 & 0.13 & 0.51 & 0.89 & 0.05 & 0.24 & 0.19 & 0.11 & 0.20 & 0.18 & 1.76 & 0.07 & 0.35 & 0.09 \\
\hline Other & 39.52 & 6.07 & 2.98 & 11.32 & 2.16 & 3.36 & 1.64 & 2.13 & 13.58 & 8.10 & 2.03 & 1.14 & 2.89 & 0.41 \\
\hline \multicolumn{15}{|c|}{ Time (minutes) } \\
\hline TOTAL & 0.63 & 0.46 & 0.82 & 0.47 & 1.26 & 0.53 & 1.00 & 0.39 & 1.94 & 1.05 & 1.85 & 1.58 & 1.78 & 3.14 \\
\hline Private & 0.65 & 0.46 & 0.88 & 0.48 & 1.27 & 0.42 & 1.08 & 0.37 & 1.73 & 0.98 & 3.23 & 1.78 & 4.55 & 3.85 \\
\hline Public & 7.30 & 11.14 & 11.26 & 16.36 & 5.37 & 18.85 & 5.16 & 3.22 & 3.74 & 5.07 & 2.98 & 3.41 & 1.58 & 11.85 \\
\hline Walk & 1.53 & 2.44 & 2.08 & 9.83 & 3.28 & 2.09 & 2.94 & 1.56 & 3.35 & 2.01 & 7.89 & 0.88 & 1.54 & 3.60 \\
\hline Other & 6.17 & 4.20 & 5.92 & 4.87 & 2.82 & 4.10 & 4.85 & 2.87 & 8.90 & 5.04 & 8.54 & 3.27 & 5.14 & 3.06 \\
\hline \multicolumn{15}{|c|}{ Miles per Hour } \\
\hline TOTAL & 0.82 & 0.50 & 0.86 & 0.64 & 0.65 & 0.37 & 0.98 & 0.37 & 2.34 & 0.92 & 2.27 & 1.73 & 1.85 & 2.67 \\
\hline Private & 0.51 & 0.43 & 0.95 & 0.61 & 0.64 & 0.36 & 1.00 & 0.35 & 1.22 & 0.82 & 2.35 & 1.75 & 3.38 & 2.67 \\
\hline \multicolumn{15}{|l|}{ Public } \\
\hline Walk & 0.66 & 0.65 & 1.47 & 2.27 & 0.35 & 0.80 & 0.98 & 0.32 & 0.85 & 0.72 & 2.57 & 0.27 & 0.87 & 0.19 \\
\hline Other & 54.18 & 9.88 & 4.78 & 24.17 & 5.41 & 4.12 & 2.34 & 4.00 & 20.07 & 12.28 & 4.05 & 1.69 & 5.76 & 1.46 \\
\hline
\end{tabular}


Chapter 4: Table 8

Urban Travel and Population Density

2001 NHTS

STANDARD ERRORS

\begin{tabular}{|c|c|c|c|c|c|c|c|c|c|c|c|c|c|c|}
\hline \multicolumn{15}{|c|}{ Population Density (census tract) } \\
\hline & \multicolumn{2}{|c|}{$<500$} & \multicolumn{2}{|c|}{$500-2,000$} & \multicolumn{2}{|c|}{$2,000-4,000$} & \multicolumn{2}{|c|}{$4,000-10,000$} & \multicolumn{2}{|c|}{$10,000-20,000$} & \multicolumn{2}{|c|}{$20,000-50,000$} & \multicolumn{2}{|c|}{$50,000+$} \\
\hline & NY State & U.S. & NY State & U.S. & NY State & U.S. & NY State & U.S. & NY State & U.S. & NY State & U.S. & NY State & U.S. \\
\hline \multicolumn{15}{|c|}{$\begin{array}{l}\text { Average Commute Length, Travel Time, and Speed } \\
\text { Length (miles) }\end{array}$} \\
\hline TOTAL & 0.41 & 0.36 & 0.38 & 0.50 & 0.68 & 0.26 & 0.58 & 0.57 & 0.75 & 0.53 & 0.72 & 0.99 & 0.36 & 2.66 \\
\hline Private & 0.37 & 0.32 & 0.39 & 0.25 & 0.63 & 0.27 & 0.63 & 0.25 & 0.74 & 0.51 & 1.06 & 1.34 & 0.86 & 4.45 \\
\hline Public & 9.71 & 27.94 & 3.62 & 4.01 & 3.89 & 2.04 & 2.15 & 1.31 & 2.32 & 1.44 & 1.14 & 0.60 & 0.57 & 6.02 \\
\hline Walk & 1.64 & 0.07 & 0.24 & 0.14 & 0.39 & 0.27 & 0.56 & 0.18 & 0.28 & 0.22 & 0.36 & 0.17 & 0.18 & 0.08 \\
\hline Other & 29.23 & 52.71 & 9.75 & 80.74 & 6.58 & 27.84 & 3.17 & 50.88 & 1.06 & 20.63 & 1.56 & 1.15 & 1.37 & \\
\hline \multicolumn{15}{|c|}{ Time (minutes) } \\
\hline TOTAL & 0.66 & 0.44 & 0.88 & 0.36 & 1.23 & 0.37 & 1.39 & 0.39 & 1.92 & 1.12 & 1.56 & 1.30 & 1.92 & 7.38 \\
\hline Private & 0.54 & 0.41 & 0.61 & 0.38 & 0.93 & 0.37 & 1.03 & 0.38 & 1.31 & 1.11 & 1.97 & 1.32 & 2.89 & 7.55 \\
\hline Public & 13.61 & 25.22 & 3.62 & 4.65 & 5.37 & 4.11 & 6.32 & 3.48 & 4.11 & 3.60 & 2.77 & 2.50 & 2.82 & 5.53 \\
\hline Walk & 2.84 & 1.03 & 23.39 & 2.55 & 4.76 & 1.97 & 2.02 & 0.89 & 3.45 & 1.94 & 3.06 & 1.78 & 1.71 & 3.23 \\
\hline Other & 23.61 & 26.40 & 20.07 & 20.18 & 13.26 & 11.33 & 12.38 & 5.88 & 3.86 & 19.55 & 3.12 & 12.04 & 5.03 & \\
\hline \multicolumn{15}{|c|}{ Miles per Hour } \\
\hline TOTAL & 0.55 & 0.49 & 1.11 & 1.24 & 1.03 & 0.43 & 1.01 & 1.47 & 1.24 & 1.07 & 1.83 & 2.41 & 0.93 & 6.71 \\
\hline Private & 0.50 & 0.35 & 0.60 & 0.42 & 1.03 & 0.43 & 1.03 & 0.44 & 1.24 & 1.13 & 2.10 & 2.56 & 1.47 & 6.72 \\
\hline Public & & & & & & 0.00 & & 3.83 & & & & & & \\
\hline Walk & 3.89 & 0.60 & 3.69 & 0.33 & 1.99 & 0.56 & 2.54 & 0.79 & 0.56 & 0.40 & 0.62 & 0.29 & 0.18 & 0.93 \\
\hline Other & 34.67 & 46.47 & 5.36 & 95.15 & 4.46 & 16.70 & 2.64 & 137.94 & 4.02 & 1.00 & 3.59 & 1.52 & 2.93 & \\
\hline
\end{tabular}


Chapter 4: Table 9

Urban Travel and Population Density

2009 NHTS

STANDARD ERRORS

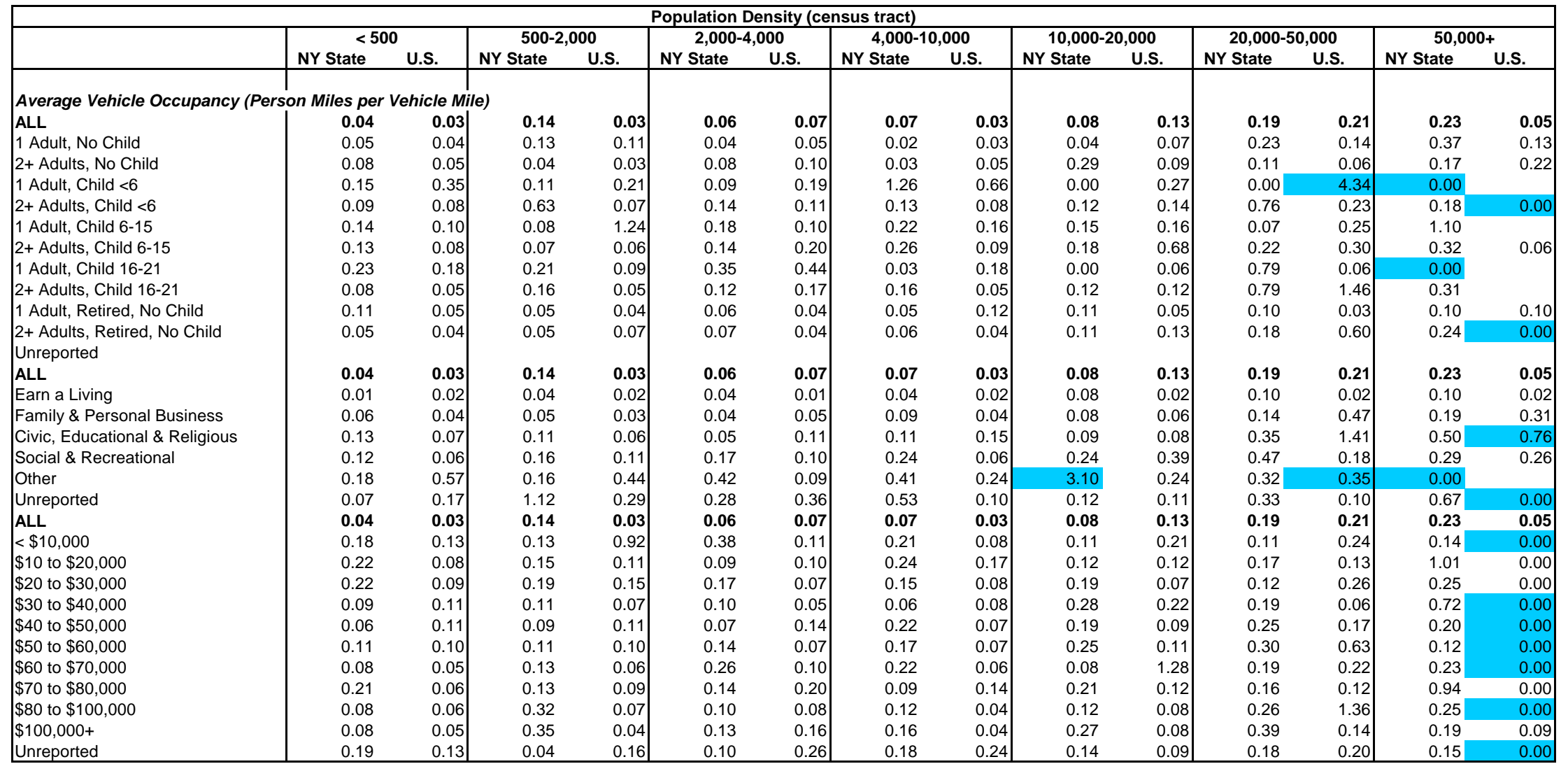


Chapter 4: Table 9

Urban Travel and Population Density

2001 NHTS

STANDARD ERRORS

\begin{tabular}{|c|c|c|c|c|c|c|c|c|c|c|c|c|c|c|}
\hline \multicolumn{15}{|c|}{ Population Density (census tract) } \\
\hline & \multicolumn{2}{|c|}{$<500$} & \multicolumn{2}{|c|}{$500-2,000$} & \multicolumn{2}{|c|}{$2,000-4,000$} & \multicolumn{2}{|c|}{$4,000-10,000$} & \multicolumn{2}{|c|}{$10,000-20,000$} & \multicolumn{2}{|c|}{$20,000-50,000$} & \multicolumn{2}{|c|}{$50,000+$} \\
\hline & NY State & U.S. & NY State & U.S. & NY State & U.S. & NY State & U.S. & NY State & U.S. & NY State & U.S. & NY State & U.S. \\
\hline \multicolumn{15}{|c|}{ Average Vehicle Occupancy (Person Miles per Vehicle Mile) } \\
\hline ALL & 0.02 & 0.02 & 0.03 & 0.03 & 0.06 & 0.03 & 0.04 & 0.02 & 0.51 & 0.05 & 0.10 & 0.07 & 0.12 & 0.08 \\
\hline 1 Adult, No Child & 0.06 & 0.04 & 0.09 & 0.09 & 0.07 & 0.06 & 0.04 & 0.02 & 0.12 & 0.09 & 0.12 & 0.03 & 0.26 & 0.22 \\
\hline 2+ Adults, No Child & 0.04 & 0.03 & 0.04 & 0.07 & 0.09 & 0.04 & 0.08 & 0.03 & 0.10 & 0.10 & 0.15 & 0.08 & 0.20 & 0.25 \\
\hline 1 Adult, Child <6 & 0.18 & 0.16 & 0.16 & 0.21 & 0.33 & 0.30 & 0.14 & 0.13 & 0.41 & 0.53 & 0.84 & 1.22 & 1.50 & 1.94 \\
\hline 2+ Adults, Child <6 & 0.09 & 0.08 & 0.14 & 0.11 & 0.17 & 0.09 & 0.13 & 0.07 & 0.17 & 0.09 & 0.17 & 0.32 & 0.32 & 0.10 \\
\hline 1 Adult, Child 6-15 & 0.17 & 0.11 & 0.15 & 0.12 & 0.25 & 0.16 & 0.14 & 0.27 & 0.23 & 0.22 & 0.34 & 0.10 & 0.26 & \\
\hline 2+ Adults, Child 6-15 & 0.07 & 0.05 & 0.07 & 0.04 & 0.18 & 0.04 & 0.07 & 0.07 & 0.19 & 0.14 & 0.40 & 0.20 & 0.17 & 0.23 \\
\hline 1 Adult, Child 16-21 & 0.05 & 0.09 & 0.10 & 0.08 & 0.25 & 0.15 & 0.17 & 0.12 & 0.49 & 0.15 & 0.36 & 0.32 & 0.00 & 0.00 \\
\hline 2+ Adults, Child 16-21 & 0.08 & 0.05 & 0.08 & 0.04 & 0.07 & 0.06 & 0.08 & 0.08 & 2.82 & 0.22 & 0.14 & 0.21 & 0.16 & \\
\hline 1 Adult, Retired, No Child & 0.05 & 0.06 & 0.11 & 0.06 & 0.06 & 0.06 & 0.08 & 0.05 & 0.04 & 0.13 & 0.77 & 0.11 & 0.07 & 0.57 \\
\hline 2+ Adults, Retired, No Child & 0.05 & 0.05 & 0.06 & 0.05 & 0.10 & 0.06 & 0.15 & 0.04 & 0.09 & 0.10 & 0.13 & 0.17 & 0.18 & 0.41 \\
\hline Unreported & & 0.13 & 0.01 & 0.41 & 0.00 & 1.27 & 0.68 & 0.14 & 0.17 & 0.00 & & & & \\
\hline ALL & 0.02 & 0.02 & 0.03 & 0.03 & 0.06 & 0.03 & 0.04 & 0.02 & 0.51 & 0.05 & 0.10 & 0.07 & 0.12 & 0.08 \\
\hline Earn a Living & 0.02 & 0.02 & 0.02 & 0.01 & 0.06 & 0.02 & 0.02 & 0.01 & 0.08 & 0.02 & 0.04 & 0.06 & 0.09 & 0.16 \\
\hline Family \& Personal Business & 0.04 & 0.03 & 0.04 & 0.03 & 0.07 & 0.04 & 0.07 & 0.03 & 0.18 & 0.07 & 0.22 & 0.12 & 0.22 & 0.12 \\
\hline Civic, Educational \& Religious & 0.18 & 0.09 & 0.15 & 0.37 & 0.18 & 0.11 & 0.14 & 0.09 & 0.30 & 0.13 & 0.17 & 0.22 & 0.60 & 0.78 \\
\hline Social \& Recreational & 0.08 & 0.05 & 0.09 & 0.09 & 0.16 & 0.06 & 0.06 & 0.06 & 1.57 & 0.13 & 0.20 & 0.12 & 0.12 & 0.13 \\
\hline Other & 0.76 & 0.22 & 0.29 & 0.25 & 0.16 & 0.23 & 0.14 & 0.12 & 1.48 & 0.19 & 0.46 & 0.37 & 0.36 & \\
\hline Unreported & 0.14 & 0.08 & 0.29 & 0.23 & 1.68 & 0.40 & 0.63 & 0.23 & 0.43 & 0.06 & 0.00 & 1.04 & 0.00 & 0.00 \\
\hline ALL & 0.02 & 0.02 & 0.03 & 0.03 & 0.06 & 0.03 & 0.04 & 0.02 & 0.51 & 0.05 & 0.10 & 0.07 & 0.12 & 0.08 \\
\hline$<\$ 10,000$ & 0.11 & 0.21 & 0.19 & 0.40 & 0.14 & 0.13 & 0.15 & 0.14 & 0.24 & 0.13 & 0.12 & 0.21 & 0.43 & 0.00 \\
\hline$\$ 10$ to $\$ 20,000$ & 0.08 & 0.09 & 0.13 & 0.10 & 0.20 & 0.07 & 0.19 & 0.15 & 0.09 & 0.23 & 0.18 & 0.17 & 0.36 & \\
\hline$\$ 20$ to $\$ 30,000$ & 0.13 & 0.08 & 0.08 & 0.10 & 0.11 & 0.07 & 0.15 & 0.11 & 0.12 & 0.13 & 0.19 & 0.41 & 0.23 & 0.84 \\
\hline$\$ 30$ to $\$ 40,000$ & 0.09 & 0.05 & 0.06 & 0.19 & 0.07 & 0.09 & 0.11 & 0.04 & 2.38 & 0.15 & 0.61 & 0.14 & 0.12 & 0.27 \\
\hline$\$ 40$ to $\$ 50,000$ & 0.09 & 0.11 & 0.19 & 0.06 & 0.11 & 0.09 & 0.37 & 0.10 & 0.14 & 0.26 & 0.27 & 0.19 & 0.29 & 0.00 \\
\hline$\$ 50$ to $\$ 60,000$ & 0.07 & 0.06 & 0.06 & 0.08 & 0.27 & 0.04 & 0.07 & 0.08 & 0.17 & 0.20 & 0.15 & 0.14 & 0.38 & 0.69 \\
\hline$\$ 60$ to $\$ 70,000$ & 0.09 & 0.12 & 0.13 & 0.07 & 0.16 & 0.07 & 0.19 & 0.05 & 0.12 & 0.11 & 0.24 & 0.19 & 0.26 & 0.08 \\
\hline$\$ 70$ to $\$ 80,000$ & 0.05 & 0.10 & 0.08 & 0.06 & 0.24 & 0.08 & 0.14 & 0.08 & 0.24 & 0.24 & 0.22 & 0.10 & 0.46 & 0.23 \\
\hline$\$ 80$ to $\$ 100,000$ & 0.09 & 0.05 & 0.09 & 0.06 & 0.14 & 0.07 & 0.06 & 0.08 & 0.16 & 0.06 & 0.17 & 0.14 & 0.54 & 0.17 \\
\hline$\$ 100,000+$ & 0.04 & 0.04 & 0.07 & 0.06 & 0.12 & 0.05 & 0.08 & 0.05 & 0.10 & 0.04 & 0.16 & 0.11 & 0.26 & 0.15 \\
\hline Unreported & 0.11 & 0.08 & 0.13 & 0.12 & 0.14 & 0.13 & 0.11 & 0.11 & 0.37 & 0.30 & 0.32 & 0.19 & 0.15 & 0.29 \\
\hline
\end{tabular}


Chapter 4: Table 10

Urban Travel and Population Density

2009 NHTS

STANDARD ERRORS

\begin{tabular}{|c|c|c|c|c|c|c|c|c|c|c|c|c|c|c|}
\hline \multicolumn{15}{|c|}{ Population Density (census tract) } \\
\hline & \multicolumn{2}{|c|}{$<500$} & \multicolumn{2}{|c|}{$500-2,000$} & \multicolumn{2}{|c|}{$2,000-4,000$} & \multicolumn{2}{|c|}{$4,000-10,000$} & \multicolumn{2}{|c|}{$10,000-20,000$} & \multicolumn{2}{|c|}{$20,000-50,000$} & \multicolumn{2}{|c|}{$50,000+$} \\
\hline & NY State & U.S. & NY State & U.S. & NY State & U.S. & NY State & U.S. & NY State & U.S. & NY State & U.S. & NY State & U.S. \\
\hline Vehicles by Type & $0.0 \%$ & $0.0 \%$ & $0.0 \%$ & $0.0 \%$ & $0.0 \%$ & $0.0 \%$ & $0.0 \%$ & $0.0 \%$ & $0.0 \%$ & $0.0 \%$ & $0.0 \%$ & $0.0 \%$ & $0.0 \%$ & $0.0 \%$ \\
\hline Auto & $0.8 \%$ & $0.6 \%$ & $1.1 \%$ & $0.6 \%$ & $1.5 \%$ & $0.6 \%$ & $1.8 \%$ & $0.6 \%$ & $3.0 \%$ & $1.2 \%$ & $3.4 \%$ & $3.1 \%$ & $3.7 \%$ & $12.2 \%$ \\
\hline Van & $0.6 \%$ & $0.3 \%$ & $0.4 \%$ & $0.3 \%$ & $0.7 \%$ & $0.4 \%$ & $1.2 \%$ & $0.4 \%$ & $2.5 \%$ & $0.7 \%$ & $1.2 \%$ & $1.9 \%$ & $2.4 \%$ & $1.3 \%$ \\
\hline Sports Utility & $0.7 \%$ & $0.4 \%$ & $0.8 \%$ & $0.4 \%$ & $1.1 \%$ & $0.5 \%$ & $1.3 \%$ & $0.4 \%$ & $2.1 \%$ & $1.0 \%$ & $2.8 \%$ & $2.1 \%$ & $3.1 \%$ & $4.0 \%$ \\
\hline Pickup & $0.6 \%$ & $0.5 \%$ & $0.8 \%$ & $0.4 \%$ & $0.6 \%$ & $0.4 \%$ & $0.5 \%$ & $0.3 \%$ & $0.7 \%$ & $0.7 \%$ & $0.4 \%$ & $0.9 \%$ & $0.1 \%$ & $11.5 \%$ \\
\hline Other Truck & $0.1 \%$ & $0.2 \%$ & $0.1 \%$ & $0.1 \%$ & $0.1 \%$ & $0.1 \%$ & $0.1 \%$ & $0.0 \%$ & $0.1 \%$ & $0.1 \%$ & & $0.0 \%$ & & \\
\hline RV & $0.2 \%$ & $0.1 \%$ & $0.1 \%$ & $0.1 \%$ & $0.0 \%$ & $0.1 \%$ & $0.2 \%$ & $0.0 \%$ & $0.0 \%$ & $0.1 \%$ & & $0.0 \%$ & & \\
\hline Motorcycle & $0.3 \%$ & $0.2 \%$ & $0.3 \%$ & $0.2 \%$ & $0.5 \%$ & $0.2 \%$ & $0.4 \%$ & $0.3 \%$ & $0.4 \%$ & $0.4 \%$ & $0.5 \%$ & $1.8 \%$ & $0.9 \%$ & $1.6 \%$ \\
\hline Other POV & & & & & & & & & & & & & & \\
\hline \multicolumn{15}{|c|}{ * Other POV not present in 2001 or 2009.} \\
\hline \multicolumn{15}{|l|}{ Age Statistics } \\
\hline Average Vehicle Age & 0.11 & 0.11 & 0.15 & 0.10 & 0.18 & 0.10 & 0.17 & 0.10 & 0.30 & 0.20 & 0.42 & 0.38 & 0.51 & 0.70 \\
\hline Median Vehicle Age & 0 & 0 & 0 & 0 & 0 & 0 & 1 & 0 & 0 & 0 & 5 & 4 & 0 & \\
\hline \multicolumn{15}{|l|}{ Percent VMT* } \\
\hline Less than $10 \mathrm{yrs}$ & $1.0 \%$ & $0.8 \%$ & $1.2 \%$ & $0.9 \%$ & $1.6 \%$ & $0.9 \%$ & $1.9 \%$ & $0.9 \%$ & $2.6 \%$ & $1.9 \%$ & $4.0 \%$ & $4.0 \%$ & $3.9 \%$ & $15.4 \%$ \\
\hline 10 yrs or more & $1.0 \%$ & $0.8 \%$ & $1.2 \%$ & $0.9 \%$ & $1.6 \%$ & $0.9 \%$ & $1.9 \%$ & $0.9 \%$ & $2.6 \%$ & $1.9 \%$ & $4.0 \%$ & $4.0 \%$ & $3.9 \%$ & $15.4 \%$ \\
\hline \multicolumn{15}{|l|}{ Percent Vehicle Fleet } \\
\hline Less than $10 \mathrm{yrs}$ & $0.8 \%$ & $0.7 \%$ & $1.1 \%$ & $0.7 \%$ & $1.4 \%$ & $0.6 \%$ & $1.4 \%$ & $0.8 \%$ & $2.7 \%$ & $1.5 \%$ & $3.2 \%$ & $3.6 \%$ & $4.5 \%$ & $9.8 \%$ \\
\hline $10 \mathrm{yrs}$ or more & $0.8 \%$ & $0.7 \%$ & $1.1 \%$ & $0.7 \%$ & $1.4 \%$ & $0.6 \%$ & $1.4 \%$ & $0.8 \%$ & $2.7 \%$ & $1.5 \%$ & $3.2 \%$ & $3.6 \%$ & $4.5 \%$ & $9.8 \%$ \\
\hline Avg Fuel Consumption (gal/HH) & 18 & 21 & 26 & 12 & 23 & 14 & 20 & 16 & 42 & 24 & 22 & 44 & 12 & 55 \\
\hline Less than $10 \mathrm{yrs}$ & $1.0 \%$ & $0.9 \%$ & $1.3 \%$ & $0.9 \%$ & $1.5 \%$ & $0.8 \%$ & $1.7 \%$ & $1.0 \%$ & $2.8 \%$ & $1.8 \%$ & $3.7 \%$ & $4.2 \%$ & $3.9 \%$ & $16.0 \%$ \\
\hline $10 \mathrm{yrs}$ or more & $1.0 \%$ & $0.9 \%$ & $1.3 \%$ & $0.9 \%$ & $1.5 \%$ & $0.8 \%$ & $1.7 \%$ & $1.0 \%$ & $2.8 \%$ & $1.8 \%$ & $3.7 \%$ & $4.2 \%$ & $3.9 \%$ & $16.0 \%$ \\
\hline Avg CO2 Emissions (kg/HH) & 156 & 191 & 228 & 106 & 203 & 126 & 174 & 143 & 371 & 215 & 196 & 387 & 102 & 488 \\
\hline Less than $10 \mathrm{yrs}$ & $1.0 \%$ & $0.9 \%$ & $1.3 \%$ & $0.9 \%$ & $1.5 \%$ & $0.8 \%$ & $1.7 \%$ & $1.0 \%$ & $2.8 \%$ & $1.8 \%$ & $3.7 \%$ & $4.2 \%$ & $3.9 \%$ & $16.0 \%$ \\
\hline $10 \mathrm{yrs}$ or more & $1.0 \%$ & $0.9 \%$ & $1.3 \%$ & $0.9 \%$ & $1.5 \%$ & $0.8 \%$ & $1.7 \%$ & $1.0 \%$ & $2.8 \%$ & $1.8 \%$ & $3.7 \%$ & $4.2 \%$ & $3.9 \%$ & $16.0 \%$ \\
\hline Numbers reflect BESTMILE Es & & & & & & & & & & & & & & \\
\hline
\end{tabular}


Chapter 4: Table 10

Urban Travel and Population Density

2001 NHTS

STANDARD ERRORS

\begin{tabular}{|c|c|c|c|c|c|c|c|c|c|c|c|c|c|c|}
\hline \multicolumn{15}{|c|}{ Population Density (census tract) } \\
\hline & \multicolumn{2}{|c|}{$\begin{array}{c}\text { NY State }^{<500} \text { U.S. } \\
\text { N }\end{array}$} & \multicolumn{2}{|c|}{$500-2,000$} & \multicolumn{2}{|c|}{$2,000-4,000$} & \multicolumn{2}{|c|}{$4,000-10,000$} & \multicolumn{2}{|c|}{$10,000-20,000$} & \multicolumn{2}{|c|}{$20,000-50,000$} & \multicolumn{2}{|c|}{$50,000+$} \\
\hline & NY State & U.S. & NY State & U.S. & NY State & U.S. & NY State & U.S. & NY State & U.S. & NY State & U.S. & NY State & U.S. \\
\hline Vehicles by Type & $0.0 \%$ & $0.0 \%$ & $0.0 \%$ & $0.0 \%$ & $0.0 \%$ & $0.0 \%$ & $0.0 \%$ & $0.0 \%$ & $0.0 \%$ & $0.0 \%$ & $0.0 \%$ & $0.0 \%$ & $0.0 \%$ & $0.0 \%$ \\
\hline Auto & $4.3 \%$ & $0.6 \%$ & $2.6 \%$ & $0.5 \%$ & $1.4 \%$ & $0.6 \%$ & $2.6 \%$ & $0.6 \%$ & $3.3 \%$ & $1.2 \%$ & $2.4 \%$ & $2.4 \%$ & $6.4 \%$ & $8.0 \%$ \\
\hline Van & $0.9 \%$ & $0.4 \%$ & $0.7 \%$ & $0.3 \%$ & $1.0 \%$ & $0.3 \%$ & $0.7 \%$ & $0.3 \%$ & $1.1 \%$ & $0.7 \%$ & $1.5 \%$ & $1.8 \%$ & $1.7 \%$ & $2.4 \%$ \\
\hline Sports Utility & $1.2 \%$ & $0.4 \%$ & $0.7 \%$ & $0.4 \%$ & $1.3 \%$ & $0.4 \%$ & $1.1 \%$ & $0.4 \%$ & $1.3 \%$ & $1.0 \%$ & $1.7 \%$ & $1.7 \%$ & $1.9 \%$ & $4.1 \%$ \\
\hline Pickup & $1.5 \%$ & $0.4 \%$ & $0.7 \%$ & $0.4 \%$ & $0.8 \%$ & $0.4 \%$ & $0.6 \%$ & $0.4 \%$ & $0.4 \%$ & $0.8 \%$ & $0.5 \%$ & $0.9 \%$ & $0.3 \%$ & $6.8 \%$ \\
\hline Other Truck & $0.1 \%$ & $0.1 \%$ & $0.1 \%$ & $0.1 \%$ & $0.0 \%$ & $0.1 \%$ & $0.0 \%$ & $0.1 \%$ & $0.1 \%$ & $0.2 \%$ & $0.9 \%$ & $0.0 \%$ & & \\
\hline RV & $0.2 \%$ & $0.1 \%$ & $0.2 \%$ & $0.1 \%$ & $0.2 \%$ & $0.1 \%$ & $0.1 \%$ & $0.1 \%$ & $0.1 \%$ & $0.1 \%$ & & $0.0 \%$ & & \\
\hline Motorcycle & $0.4 \%$ & $0.2 \%$ & $0.2 \%$ & $0.2 \%$ & $0.4 \%$ & $0.2 \%$ & $0.3 \%$ & $0.1 \%$ & $0.4 \%$ & $0.3 \%$ & $0.6 \%$ & $0.7 \%$ & $0.7 \%$ & $0.3 \%$ \\
\hline Other POV & & & & & 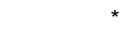 & & * & & & & & & & \\
\hline \multicolumn{15}{|c|}{ * Other POV not present in 2001 or 2009.} \\
\hline \multicolumn{15}{|l|}{ Age Statistics } \\
\hline Average Vehicle Age & 0.15 & 0.10 & 0.14 & 0.10 & 0.21 & 0.10 & 0.14 & 0.11 & 0.22 & 0.22 & 0.30 & 0.42 & 0.54 & 1.42 \\
\hline Median Vehicle Age & 0 & 0 & 0 & 5 & 2 & 0 & 0 & 0 & 0 & 0 & 0 & 1 & 0 & 7 \\
\hline \multicolumn{15}{|l|}{ Percent VMT* } \\
\hline Less than $10 \mathrm{yrs}$ & $1.2 \%$ & $0.8 \%$ & $1.0 \%$ & $0.7 \%$ & $2.5 \%$ & $0.8 \%$ & $1.6 \%$ & $2.8 \%$ & $2.1 \%$ & $10.1 \%$ & $4.3 \%$ & $7.6 \%$ & $3.6 \%$ & $42.6 \%$ \\
\hline 10 yrs or more & $1.2 \%$ & $0.8 \%$ & $1.0 \%$ & $0.7 \%$ & $2.5 \%$ & $0.8 \%$ & $1.6 \%$ & $2.8 \%$ & $2.1 \%$ & $10.1 \%$ & $4.3 \%$ & $7.6 \%$ & $3.6 \%$ & $42.6 \%$ \\
\hline \multicolumn{15}{|l|}{ Percent Vehicle Fleet } \\
\hline Less than $10 \mathrm{yrs}$ & $1.1 \%$ & $0.6 \%$ & $1.1 \%$ & $0.6 \%$ & $1.5 \%$ & $0.7 \%$ & $1.0 \%$ & $0.7 \%$ & $2.1 \%$ & $1.6 \%$ & $2.7 \%$ & $3.0 \%$ & $2.9 \%$ & $12.2 \%$ \\
\hline $10 \mathrm{yrs}$ or more & $1.1 \%$ & $0.6 \%$ & $1.1 \%$ & $0.6 \%$ & $1.5 \%$ & $0.7 \%$ & $1.0 \%$ & $0.7 \%$ & $2.1 \%$ & $1.6 \%$ & $2.7 \%$ & $3.0 \%$ & $2.9 \%$ & $12.2 \%$ \\
\hline Avg Fuel Consumption (gal/HH) & 234 & 23 & 149 & 38 & 153 & 17 & 57 & 15 & 107 & 38 & 73 & 53 & 27 & 134 \\
\hline Less than $10 \mathrm{yrs}$ & $3.7 \%$ & $0.8 \%$ & $7.1 \%$ & $0.7 \%$ & $5.2 \%$ & $0.8 \%$ & $4.6 \%$ & $2.6 \%$ & $7.8 \%$ & $9.9 \%$ & $10.6 \%$ & $8.7 \%$ & $9.3 \%$ & $46.1 \%$ \\
\hline $10 \mathrm{yrs}$ or more & $3.7 \%$ & $0.8 \%$ & $7.1 \%$ & $0.7 \%$ & $5.2 \%$ & $0.8 \%$ & $4.6 \%$ & $2.6 \%$ & $7.8 \%$ & $9.9 \%$ & $10.6 \%$ & $8.7 \%$ & $9.3 \%$ & $46.1 \%$ \\
\hline Avg CO2 Emissions $(\mathrm{kg} / \mathrm{HH})$ & 2,057 & 199 & 1,308 & 327 & 1,349 & 146 & 500 & 135 & 944 & 329 & 649 & 468 & 239 & 1,179 \\
\hline Less than $10 \mathrm{yrs}$ & $3.7 \%$ & $0.8 \%$ & $7.1 \%$ & $0.7 \%$ & $5.2 \%$ & $0.8 \%$ & $4.6 \%$ & $2.6 \%$ & $7.8 \%$ & $9.9 \%$ & $10.6 \%$ & $8.7 \%$ & $9.3 \%$ & $46.1 \%$ \\
\hline $10 \mathrm{yrs}$ or more & $3.7 \%$ & $0.8 \%$ & $7.1 \%$ & $0.7 \%$ & $5.2 \%$ & $0.8 \%$ & $4.6 \%$ & $2.6 \%$ & $7.8 \%$ & $9.9 \%$ & $10.6 \%$ & $8.7 \%$ & $9.3 \%$ & $46.1 \%$ \\
\hline${ }^{\star}$ Numbers refle & & & & & & & & & & & & & & \\
\hline
\end{tabular}


Chapter 4: Table 11

Urban Travel and Population Density

2009 NHTS

STANDARD ERRORS

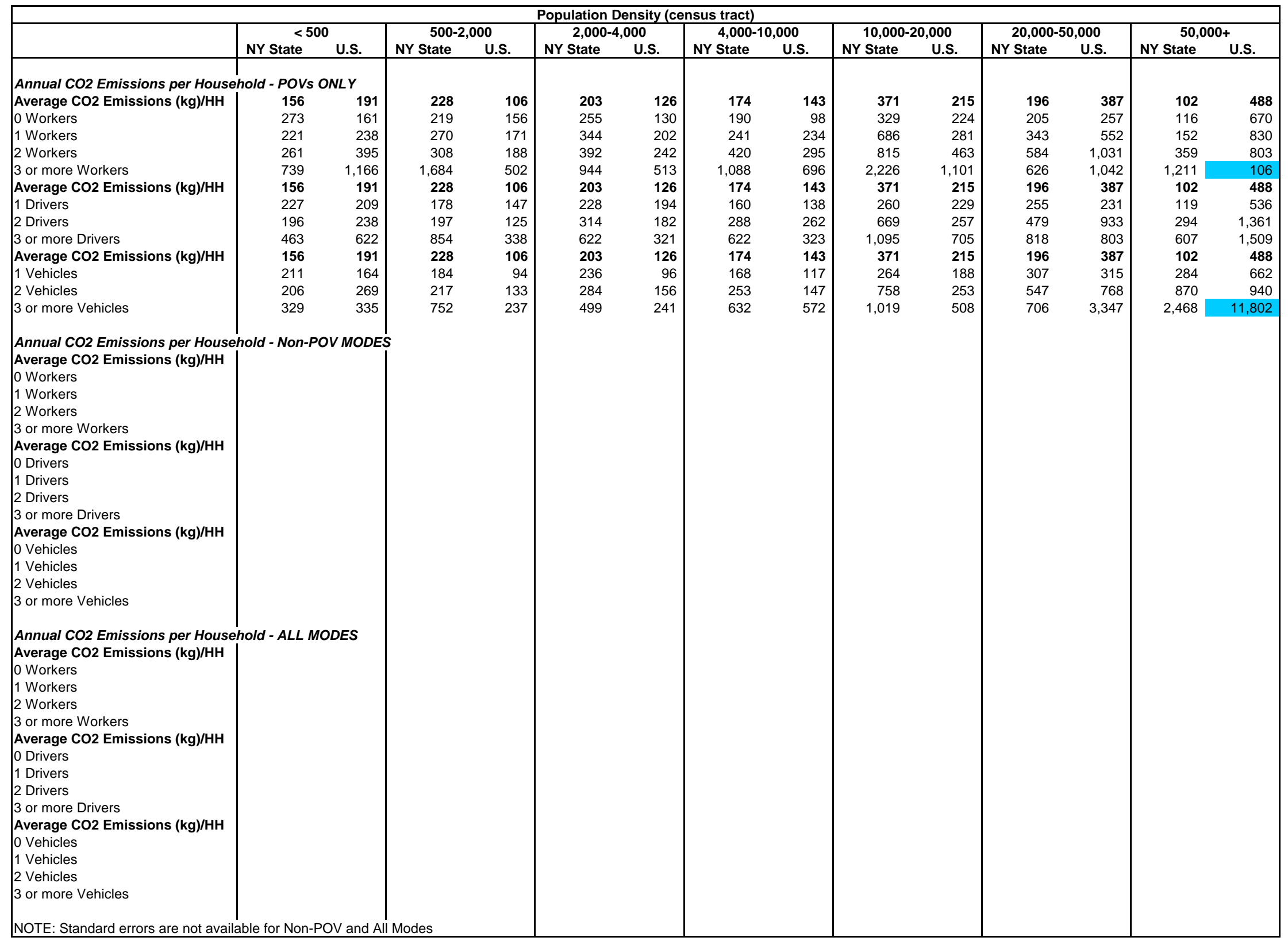


Chapter 4: Table 11

Urban Travel and Population Density

2001 NHTS

STANDARD ERRORS

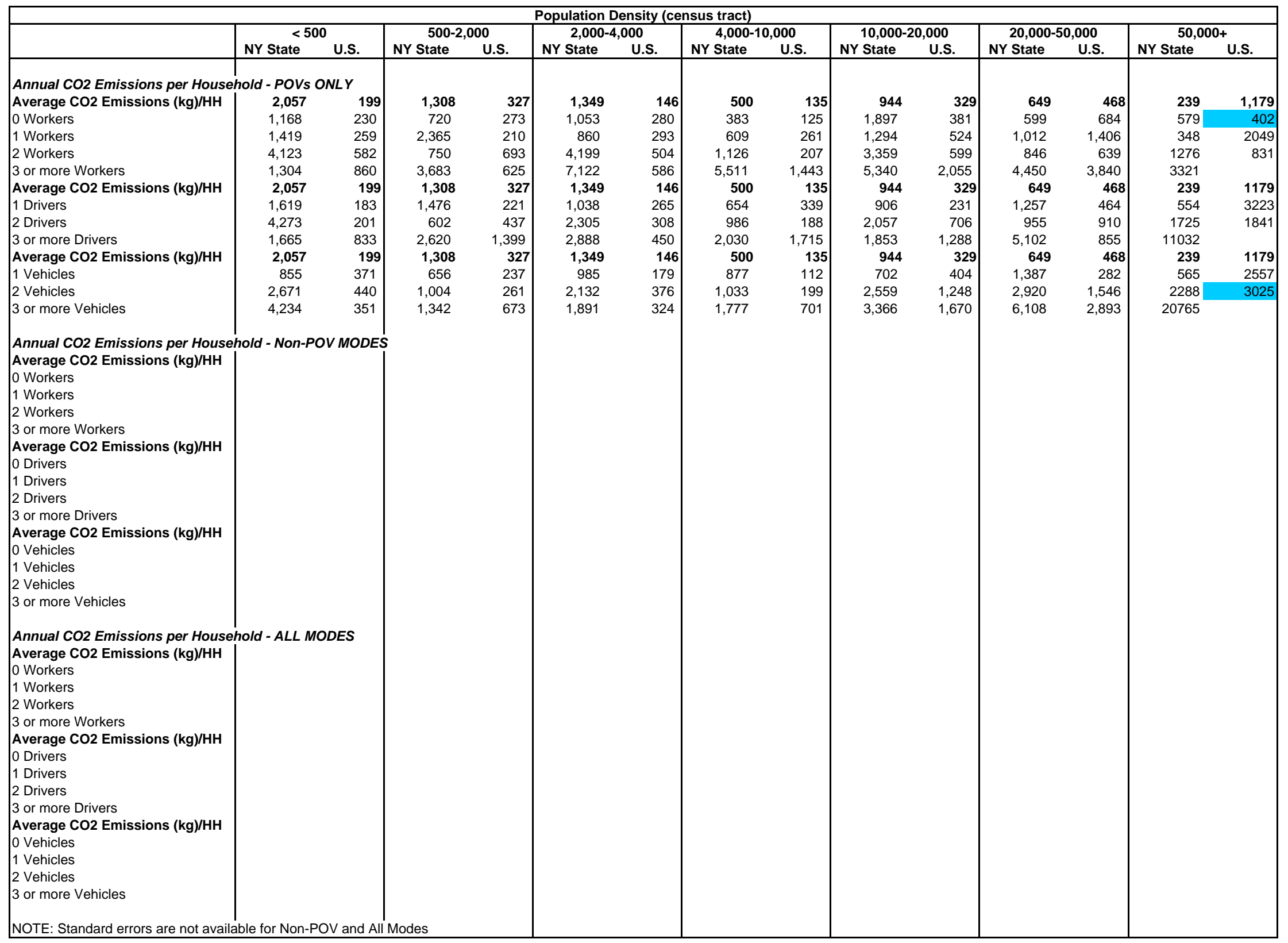


Chapter 4: Table 12

Urban Travel and Population Density

2009 NHTS

STANDARD ERRORS

\begin{tabular}{|c|c|c|c|c|c|c|c|c|c|c|c|c|c|c|}
\hline \multicolumn{15}{|c|}{ Population Density (census tract) } \\
\hline & \multicolumn{2}{|c|}{$<500$} & \multicolumn{2}{|c|}{$\begin{array}{c}500-2,000 \\
Y \text { State }\end{array}$} & \multicolumn{2}{|c|}{$2,000-4,000$} & \multicolumn{2}{|c|}{$4,000-10,000$} & \multicolumn{2}{|c|}{$10,000-20,000$} & \multicolumn{2}{|c|}{$20,000-50,000$} & \multicolumn{2}{|c|}{$50,000+$} \\
\hline & NY State & U.S. & NY State & U.S. & NY State & U.S. & NY State & U.S. & NY State & U.S. & NY State & U.S. & NY State & U.S. \\
\hline \multicolumn{15}{|c|}{ Percent Vehicles by } \\
\hline Auto & $0.8 \%$ & $0.6 \%$ & $1.1 \%$ & $0.6 \%$ & $1.5 \%$ & $0.6 \%$ & $1.8 \%$ & $0.6 \%$ & $3.0 \%$ & $1.2 \%$ & $3.4 \%$ & $3.1 \%$ & $3.7 \%$ & $12.2 \%$ \\
\hline 0 to $2 \mathrm{yrs}$ & $0.4 \%$ & $0.2 \%$ & $0.6 \%$ & $0.3 \%$ & $0.9 \%$ & $0.3 \%$ & $0.6 \%$ & $0.3 \%$ & $1.2 \%$ & $0.9 \%$ & $2.8 \%$ & $2.5 \%$ & $1.4 \%$ & $3.8 \%$ \\
\hline 3 to $5 \mathrm{yrs}$ & $0.4 \%$ & $0.3 \%$ & $0.6 \%$ & $0.3 \%$ & $0.9 \%$ & $0.4 \%$ & $0.9 \%$ & $0.4 \%$ & $2.1 \%$ & $0.6 \%$ & $2.3 \%$ & $1.1 \%$ & $2.8 \%$ & $4.2 \%$ \\
\hline 6 to $9 \mathrm{yrs}$ & $0.6 \%$ & $0.4 \%$ & $0.9 \%$ & $0.3 \%$ & $1.2 \%$ & $0.4 \%$ & $1.0 \%$ & $0.4 \%$ & $1.6 \%$ & $1.2 \%$ & $2.1 \%$ & $2.4 \%$ & $2.9 \%$ & $14.9 \%$ \\
\hline 10 yrs or more & $0.6 \%$ & $0.5 \%$ & $0.8 \%$ & $0.5 \%$ & $1.3 \%$ & $0.5 \%$ & $1.3 \%$ & $0.6 \%$ & $1.8 \%$ & $1.3 \%$ & $2.9 \%$ & $2.4 \%$ & $3.2 \%$ & $7.8 \%$ \\
\hline Unreported & $0.3 \%$ & $0.2 \%$ & $0.2 \%$ & $0.2 \%$ & $1.1 \%$ & $0.2 \%$ & $0.5 \%$ & $0.2 \%$ & $0.8 \%$ & $0.8 \%$ & $1.5 \%$ & $1.4 \%$ & $1.4 \%$ & \\
\hline Van & $0.6 \%$ & $0.3 \%$ & $0.4 \%$ & $0.3 \%$ & $0.7 \%$ & $0.4 \%$ & $1.2 \%$ & $0.4 \%$ & $2.5 \%$ & $0.7 \%$ & $1.2 \%$ & $1.9 \%$ & $2.4 \%$ & $1.3 \%$ \\
\hline 0 to $2 \mathrm{yrs}$ & $0.2 \%$ & $0.1 \%$ & $0.2 \%$ & $0.1 \%$ & $0.3 \%$ & $0.1 \%$ & $0.7 \%$ & $0.1 \%$ & $0.5 \%$ & $0.1 \%$ & $0.2 \%$ & $0.3 \%$ & $0.8 \%$ & \\
\hline 3 to $5 \mathrm{yrs}$ & $0.3 \%$ & $0.1 \%$ & $0.2 \%$ & $0.2 \%$ & $0.3 \%$ & $0.2 \%$ & $0.4 \%$ & $0.1 \%$ & $0.4 \%$ & $0.2 \%$ & $0.5 \%$ & $1.7 \%$ & $0.6 \%$ & \\
\hline 6 to $9 \mathrm{yrs}$ & $0.4 \%$ & $0.2 \%$ & $0.3 \%$ & $0.2 \%$ & $0.5 \%$ & $0.2 \%$ & $0.4 \%$ & $0.2 \%$ & $0.6 \%$ & $0.6 \%$ & $0.2 \%$ & $0.8 \%$ & $0.2 \%$ & \\
\hline 10 yrs or more & $0.3 \%$ & $0.2 \%$ & $0.2 \%$ & $0.2 \%$ & $0.4 \%$ & $0.2 \%$ & $0.5 \%$ & $0.3 \%$ & $2.4 \%$ & $0.3 \%$ & $0.8 \%$ & $0.5 \%$ & $1.6 \%$ & $1.3 \%$ \\
\hline Unreported & $0.1 \%$ & $0.1 \%$ & $0.1 \%$ & $0.1 \%$ & $0.2 \%$ & $0.1 \%$ & $0.2 \%$ & $0.1 \%$ & $0.2 \%$ & $0.1 \%$ & $0.7 \%$ & $0.3 \%$ & $0.8 \%$ & \\
\hline Suv & $0.7 \%$ & $0.4 \%$ & $0.8 \%$ & $0.4 \%$ & $1.1 \%$ & $0.5 \%$ & $1.3 \%$ & $0.4 \%$ & $2.1 \%$ & $1.0 \%$ & $2.8 \%$ & $2.1 \%$ & $3.1 \%$ & $4.0 \%$ \\
\hline 0 to $2 \mathrm{yrs}$ & $0.3 \%$ & $0.2 \%$ & $0.6 \%$ & $0.3 \%$ & $0.7 \%$ & $0.2 \%$ & $0.9 \%$ & $0.2 \%$ & $1.3 \%$ & $0.6 \%$ & $0.9 \%$ & $0.9 \%$ & $1.3 \%$ & $2.4 \%$ \\
\hline 3 to $5 \mathrm{yrs}$ & $0.4 \%$ & $0.3 \%$ & $0.5 \%$ & $0.3 \%$ & $0.7 \%$ & $0.3 \%$ & $0.6 \%$ & $0.3 \%$ & $1.4 \%$ & $0.4 \%$ & $1.2 \%$ & $2.1 \%$ & $1.6 \%$ & \\
\hline 6 to $9 \mathrm{yrs}$ & $0.3 \%$ & $0.3 \%$ & $0.4 \%$ & $0.3 \%$ & $0.6 \%$ & $0.3 \%$ & $0.7 \%$ & $0.3 \%$ & $0.9 \%$ & $0.3 \%$ & $1.2 \%$ & $1.2 \%$ & $2.0 \%$ & $1.3 \%$ \\
\hline 10 yrs or more & $0.3 \%$ & $0.3 \%$ & $0.5 \%$ & $0.2 \%$ & $0.5 \%$ & $0.3 \%$ & $0.5 \%$ & $0.3 \%$ & $0.7 \%$ & $0.5 \%$ & $1.6 \%$ & $2.0 \%$ & $1.4 \%$ & $3.4 \%$ \\
\hline Unreported & $0.3 \%$ & $0.1 \%$ & $0.1 \%$ & $0.1 \%$ & $0.1 \%$ & $0.1 \%$ & $0.1 \%$ & $0.1 \%$ & $0.6 \%$ & $0.5 \%$ & $0.5 \%$ & $0.3 \%$ & $0.5 \%$ & \\
\hline Pickup Truck & $0.6 \%$ & $0.5 \%$ & $0.8 \%$ & $0.4 \%$ & $0.6 \%$ & $0.4 \%$ & $0.5 \%$ & $0.3 \%$ & $0.7 \%$ & $0.7 \%$ & $0.4 \%$ & $0.9 \%$ & $0.1 \%$ & $11.5 \%$ \\
\hline 0 to $2 \mathrm{yrs}$ & $0.2 \%$ & $0.2 \%$ & $0.2 \%$ & $0.1 \%$ & $0.3 \%$ & $0.1 \%$ & $0.2 \%$ & $0.1 \%$ & $0.4 \%$ & $0.1 \%$ & & $0.2 \%$ & & \\
\hline 3 to $5 \mathrm{yrs}$ & $0.3 \%$ & $0.2 \%$ & $0.5 \%$ & $0.2 \%$ & $0.4 \%$ & $0.2 \%$ & $0.2 \%$ & $0.1 \%$ & $0.1 \%$ & $0.3 \%$ & & $0.6 \%$ & $0.1 \%$ & \\
\hline 6 to $9 \mathrm{yrs}$ & $0.3 \%$ & $0.3 \%$ & $0.3 \%$ & $0.2 \%$ & $0.2 \%$ & $0.2 \%$ & $0.3 \%$ & $0.2 \%$ & $0.6 \%$ & $0.2 \%$ & $0.0 \%$ & $0.3 \%$ & & $11.5 \%$ \\
\hline 10 yrs or more & $0.4 \%$ & $0.4 \%$ & $0.5 \%$ & $0.3 \%$ & $0.3 \%$ & $0.2 \%$ & $0.3 \%$ & $0.2 \%$ & $0.3 \%$ & $0.6 \%$ & $0.4 \%$ & $0.5 \%$ & $0.1 \%$ & \\
\hline Unreported & $0.2 \%$ & $0.2 \%$ & $0.1 \%$ & $0.1 \%$ & $0.1 \%$ & $0.1 \%$ & $0.0 \%$ & $0.1 \%$ & $0.1 \%$ & $0.3 \%$ & & $0.3 \%$ & & \\
\hline Other POV & $0.4 \%$ & $0.3 \%$ & $0.3 \%$ & $0.2 \%$ & $0.5 \%$ & $0.2 \%$ & $0.4 \%$ & $0.3 \%$ & $0.4 \%$ & $0.4 \%$ & $0.5 \%$ & $1.8 \%$ & $0.9 \%$ & $1.6 \%$ \\
\hline 0 to $2 \mathrm{yrs}$ & $0.1 \%$ & $0.1 \%$ & $0.1 \%$ & $0.1 \%$ & $0.1 \%$ & $0.1 \%$ & $0.1 \%$ & $0.1 \%$ & & $0.3 \%$ & $0.2 \%$ & $0.0 \%$ & $0.2 \%$ & $1.6 \%$ \\
\hline 3 to $5 \mathrm{yrs}$ & $0.1 \%$ & $0.1 \%$ & $0.1 \%$ & $0.1 \%$ & $0.2 \%$ & $0.1 \%$ & $0.2 \%$ & $0.1 \%$ & $0.1 \%$ & $0.1 \%$ & & $0.0 \%$ & $0.1 \%$ & \\
\hline 6 to $9 \mathrm{yrs}$ & $0.2 \%$ & $0.1 \%$ & $0.1 \%$ & $0.1 \%$ & $0.3 \%$ & $0.1 \%$ & $0.3 \%$ & $0.1 \%$ & $0.1 \%$ & $0.1 \%$ & $0.1 \%$ & $1.8 \%$ & $0.3 \%$ & \\
\hline 10 yrs or more & $0.2 \%$ & $0.2 \%$ & $0.2 \%$ & $0.1 \%$ & $0.2 \%$ & $0.1 \%$ & $0.2 \%$ & $0.2 \%$ & $0.3 \%$ & $0.2 \%$ & $0.4 \%$ & $0.1 \%$ & $0.8 \%$ & \\
\hline Unreported & $0.1 \%$ & $0.1 \%$ & $0.1 \%$ & $0.1 \%$ & $0.1 \%$ & $0.2 \%$ & $0.1 \%$ & $0.1 \%$ & $0.2 \%$ & $0.0 \%$ & & $0.1 \%$ & & \\
\hline
\end{tabular}


Chapter 4: Table 12

Urban Travel and Population Density

2001 NHTS

STANDARD ERRORS

\begin{tabular}{|c|c|c|c|c|c|c|c|c|c|c|c|c|c|c|}
\hline \multicolumn{15}{|c|}{ Population Density (census tract) } \\
\hline & \multicolumn{2}{|c|}{$<500$} & \multicolumn{2}{|c|}{$500-2,000$} & \multicolumn{2}{|c|}{$2,000-4,000$} & \multicolumn{2}{|c|}{$4,000-10,000$} & \multicolumn{2}{|c|}{$10,000-20,000$} & \multicolumn{2}{|c|}{$20,000-50,000$} & \multicolumn{2}{|c|}{$50,000+$} \\
\hline & NY State & U.S. & NY State & U.S. & NY State & U.S. & NY State & U.S. & NY State & U.S. & NY State & U.S. & NY State & U.S. \\
\hline \multicolumn{15}{|c|}{ Percent Vehicles by Vehicle Type and Age } \\
\hline Auto & $4.3 \%$ & $0.6 \%$ & $2.6 \%$ & $0.5 \%$ & $1.4 \%$ & $0.6 \%$ & $2.6 \%$ & $0.6 \%$ & $3.3 \%$ & $1.2 \%$ & $2.4 \%$ & $2.4 \%$ & $6.4 \%$ & $8.0 \%$ \\
\hline 0 to $2 \mathrm{yrs}$ & $1.0 \%$ & $0.3 \%$ & $0.8 \%$ & $0.3 \%$ & $1.1 \%$ & $0.4 \%$ & $1.0 \%$ & $0.4 \%$ & $1.4 \%$ & $0.7 \%$ & $1.4 \%$ & $1.7 \%$ & $2.0 \%$ & $9.7 \%$ \\
\hline 3 to $5 \mathrm{yrs}$ & $1.1 \%$ & $0.3 \%$ & $0.9 \%$ & $0.5 \%$ & $0.8 \%$ & $0.5 \%$ & $0.9 \%$ & $0.4 \%$ & $1.7 \%$ & $1.0 \%$ & $1.7 \%$ & $1.3 \%$ & $2.0 \%$ & $7.3 \%$ \\
\hline 6 to $9 \mathrm{yrs}$ & $1.3 \%$ & $0.3 \%$ & $1.0 \%$ & $0.4 \%$ & $0.8 \%$ & $0.6 \%$ & $1.2 \%$ & $0.5 \%$ & $1.8 \%$ & $1.0 \%$ & $1.9 \%$ & $2.3 \%$ & $2.1 \%$ & $15.8 \%$ \\
\hline 10 yrs or more & $1.6 \%$ & $0.5 \%$ & $1.1 \%$ & $0.5 \%$ & $1.3 \%$ & $0.6 \%$ & $1.1 \%$ & $0.6 \%$ & $2.1 \%$ & $1.2 \%$ & $2.6 \%$ & $2.3 \%$ & $3.7 \%$ & $12.1 \%$ \\
\hline Unreported & $0.2 \%$ & $0.2 \%$ & $0.3 \%$ & $0.1 \%$ & $0.6 \%$ & $0.1 \%$ & $0.3 \%$ & $0.2 \%$ & $0.7 \%$ & $0.6 \%$ & $1.3 \%$ & $0.9 \%$ & $1.0 \%$ & $0.4 \%$ \\
\hline Van & $0.9 \%$ & $0.4 \%$ & $0.7 \%$ & $0.3 \%$ & $1.0 \%$ & $0.3 \%$ & $0.7 \%$ & $0.3 \%$ & $1.1 \%$ & $0.7 \%$ & $1.5 \%$ & $1.8 \%$ & $1.7 \%$ & $2.4 \%$ \\
\hline 0 to $2 \mathrm{yrs}$ & $0.3 \%$ & $0.1 \%$ & $0.3 \%$ & $0.1 \%$ & $0.6 \%$ & $0.1 \%$ & $0.3 \%$ & $0.1 \%$ & $0.6 \%$ & $0.2 \%$ & $0.5 \%$ & $0.6 \%$ & $0.4 \%$ & $0.3 \%$ \\
\hline 3 to $5 \mathrm{yrs}$ & $0.3 \%$ & $0.2 \%$ & $0.4 \%$ & $0.2 \%$ & $0.7 \%$ & $0.2 \%$ & $0.4 \%$ & $0.2 \%$ & $0.4 \%$ & $0.3 \%$ & $0.3 \%$ & $0.6 \%$ & $1.0 \%$ & $2.3 \%$ \\
\hline 6 to $9 \mathrm{yrs}$ & $0.4 \%$ & $0.2 \%$ & $0.4 \%$ & $0.2 \%$ & $0.4 \%$ & $0.2 \%$ & $0.5 \%$ & $0.2 \%$ & $0.8 \%$ & $0.3 \%$ & $0.6 \%$ & $1.0 \%$ & $0.5 \%$ & $0.1 \%$ \\
\hline 10 yrs or more & $0.5 \%$ & $0.2 \%$ & $0.4 \%$ & $0.2 \%$ & $0.3 \%$ & $0.2 \%$ & $0.4 \%$ & $0.2 \%$ & $0.6 \%$ & $0.5 \%$ & $1.0 \%$ & $1.1 \%$ & $1.1 \%$ & $0.1 \%$ \\
\hline Unreported & $0.1 \%$ & $0.1 \%$ & $0.1 \%$ & $0.1 \%$ & $0.1 \%$ & $0.1 \%$ & $0.1 \%$ & $0.1 \%$ & $0.1 \%$ & $0.3 \%$ & $0.4 \%$ & $0.3 \%$ & $0.5 \%$ & $0.4 \%$ \\
\hline suv & $1.2 \%$ & $0.4 \%$ & $0.7 \%$ & $0.4 \%$ & $1.3 \%$ & $0.4 \%$ & $1.1 \%$ & $0.4 \%$ & $1.3 \%$ & $1.0 \%$ & $1.7 \%$ & $1.7 \%$ & $1.9 \%$ & $4.1 \%$ \\
\hline 0 to $2 \mathrm{yrs}$ & $0.5 \%$ & $0.2 \%$ & $0.4 \%$ & $0.2 \%$ & $0.7 \%$ & $0.2 \%$ & $0.5 \%$ & $0.2 \%$ & $0.8 \%$ & $0.5 \%$ & $1.0 \%$ & $0.7 \%$ & $0.8 \%$ & $0.1 \%$ \\
\hline 3 to $5 \mathrm{yrs}$ & $0.5 \%$ & $0.2 \%$ & $0.4 \%$ & $0.2 \%$ & $0.8 \%$ & $0.3 \%$ & $0.5 \%$ & $0.2 \%$ & $0.7 \%$ & $0.5 \%$ & $0.6 \%$ & $0.9 \%$ & $1.0 \%$ & $4.1 \%$ \\
\hline 6 to $9 \mathrm{yrs}$ & $0.4 \%$ & $0.2 \%$ & $0.3 \%$ & $0.2 \%$ & $0.3 \%$ & $0.2 \%$ & $0.4 \%$ & $0.2 \%$ & $0.7 \%$ & $0.4 \%$ & $1.1 \%$ & $0.6 \%$ & $1.0 \%$ & \\
\hline 10 yrs or more & $0.4 \%$ & $0.2 \%$ & $0.2 \%$ & $0.2 \%$ & $0.3 \%$ & $0.2 \%$ & $0.3 \%$ & $0.2 \%$ & $0.3 \%$ & $0.5 \%$ & $0.9 \%$ & $0.9 \%$ & $0.9 \%$ & \\
\hline Unreported & $0.1 \%$ & $0.1 \%$ & $0.1 \%$ & $0.1 \%$ & $0.4 \%$ & $0.1 \%$ & $0.1 \%$ & $0.1 \%$ & $0.1 \%$ & $0.1 \%$ & $1.0 \%$ & $0.5 \%$ & $0.2 \%$ & \\
\hline Pickup Truck & $1.5 \%$ & $0.4 \%$ & $0.7 \%$ & $0.4 \%$ & $0.8 \%$ & $0.4 \%$ & $0.6 \%$ & $0.4 \%$ & $0.4 \%$ & $0.8 \%$ & $0.5 \%$ & $0.9 \%$ & $0.3 \%$ & $6.8 \%$ \\
\hline 0 to $2 \mathrm{yrs}$ & $0.4 \%$ & $0.2 \%$ & $0.2 \%$ & $0.2 \%$ & $0.2 \%$ & $0.2 \%$ & $0.2 \%$ & $0.2 \%$ & $0.1 \%$ & $0.2 \%$ & $0.2 \%$ & $0.3 \%$ & $0.2 \%$ & $0.2 \%$ \\
\hline 3 to $5 \mathrm{yrs}$ & $0.5 \%$ & $0.2 \%$ & $0.3 \%$ & $0.2 \%$ & $0.4 \%$ & $0.2 \%$ & $0.2 \%$ & $0.2 \%$ & $0.2 \%$ & $0.3 \%$ & & $0.4 \%$ & $0.1 \%$ & $6.8 \%$ \\
\hline 6 to $9 \mathrm{yrs}$ & $0.4 \%$ & $0.3 \%$ & $0.3 \%$ & $0.2 \%$ & $0.5 \%$ & $0.2 \%$ & $0.3 \%$ & $0.2 \%$ & $0.2 \%$ & $0.4 \%$ & $0.1 \%$ & $0.2 \%$ & $0.1 \%$ & $0.1 \%$ \\
\hline 10 yrs or more & $0.7 \%$ & $0.3 \%$ & $0.5 \%$ & $0.3 \%$ & $0.4 \%$ & $0.3 \%$ & $0.4 \%$ & $0.3 \%$ & $0.2 \%$ & $0.6 \%$ & $0.4 \%$ & $0.6 \%$ & $0.1 \%$ & $0.2 \%$ \\
\hline Unreported & $0.2 \%$ & $0.1 \%$ & $0.0 \%$ & $0.1 \%$ & $0.1 \%$ & $0.1 \%$ & $0.1 \%$ & $0.1 \%$ & $0.2 \%$ & $0.1 \%$ & & $0.4 \%$ & & \\
\hline Other POV & $0.5 \%$ & $0.2 \%$ & $0.3 \%$ & $0.2 \%$ & $0.4 \%$ & $0.2 \%$ & $0.4 \%$ & $0.2 \%$ & $0.5 \%$ & $0.4 \%$ & $1.0 \%$ & $0.7 \%$ & $0.7 \%$ & $0.3 \%$ \\
\hline 0 to $2 \mathrm{yrs}$ & $0.1 \%$ & $0.1 \%$ & $0.1 \%$ & $0.1 \%$ & $0.1 \%$ & $0.1 \%$ & $0.1 \%$ & $0.1 \%$ & $0.1 \%$ & $0.2 \%$ & $0.2 \%$ & $0.0 \%$ & $0.1 \%$ & \\
\hline 3 to $5 \mathrm{yrs}$ & $0.1 \%$ & $0.1 \%$ & $0.1 \%$ & $0.1 \%$ & $0.2 \%$ & $0.1 \%$ & $0.1 \%$ & $0.1 \%$ & $0.2 \%$ & $0.1 \%$ & $0.2 \%$ & $0.1 \%$ & & \\
\hline 6 to $9 \mathrm{yrs}$ & $0.1 \%$ & $0.1 \%$ & $0.1 \%$ & $0.1 \%$ & $0.1 \%$ & $0.1 \%$ & $0.2 \%$ & $0.0 \%$ & $0.2 \%$ & $0.1 \%$ & $0.1 \%$ & $0.3 \%$ & & \\
\hline 10 yrs or more & $0.4 \%$ & $0.2 \%$ & $0.2 \%$ & $0.1 \%$ & $0.3 \%$ & $0.1 \%$ & $0.2 \%$ & $0.1 \%$ & $0.2 \%$ & $0.3 \%$ & $0.5 \%$ & $0.7 \%$ & $0.7 \%$ & $0.3 \%$ \\
\hline Unreported & $0.2 \%$ & $0.1 \%$ & $0.1 \%$ & $0.1 \%$ & $0.0 \%$ & $0.1 \%$ & $0.1 \%$ & $0.1 \%$ & $0.1 \%$ & $0.1 \%$ & $0.8 \%$ & $0.0 \%$ & & \\
\hline
\end{tabular}


Chapter 4: Table 13

Urban Travel and Population Density

2009 NHTS

STANDARD ERRORS

\begin{tabular}{|c|c|c|c|c|c|c|c|c|c|c|c|c|c|c|}
\hline \multicolumn{15}{|c|}{ Population Density (census tract) } \\
\hline & \multicolumn{2}{|c|}{$\begin{array}{c}<500 \\
Y\end{array}$} & \multicolumn{2}{|c|}{$500-2,000$} & \multicolumn{2}{|c|}{$2,000-4,000$} & \multicolumn{2}{|c|}{$4,000-10,000$} & \multicolumn{2}{|c|}{$10,000-20,000$} & \multicolumn{2}{|c|}{$20,000-50,000$} & \multicolumn{2}{|c|}{$50,000+$} \\
\hline & NY State & U.S. & NY State & U.S. & NY State & U.S. & NY State & U.S. & NY State & U.S. & NY State & U.S. & NY State & U.S. \\
\hline \multicolumn{15}{|c|}{ VMT/Vehicle by Vehicle Type and Age } \\
\hline ALL VEHICLES & 160 & 157 & 238 & 112 & 233 & 113 & 232 & 151 & 507 & 239 & 538 & 645 & 563 & 1,353 \\
\hline 0 to $2 \mathrm{yrs}$ & 531 & 823 & 473 & 260 & 460 & 447 & 790 & 688 & 1,892 & 628 & 515 & 3,320 & 1,405 & 2,651 \\
\hline 3 to 5 yrs & 247 & 267 & 473 & 189 & 471 & 188 & 365 & 193 & 1,235 & 479 & 950 & 903 & 1,478 & 1,227 \\
\hline 6 to $9 \mathrm{yrs}$ & 316 & 208 & 351 & 192 & 489 & 193 & 384 & 211 & 751 & 510 & 1,241 & 2,065 & 835 & 1,709 \\
\hline $10 \mathrm{yrs}$ or more & 256 & 160 & 319 & 209 & 416 & 227 & 514 & 184 & 707 & 395 & 911 & 580 & 883 & 1,827 \\
\hline Unreported & 708 & 574 & 674 & 1,216 & 961 & 747 & 630 & 648 & 1,691 & 1,475 & 2,998 & 2,082 & 4,199 & \\
\hline Auto & 216 & 156 & 236 & 150 & 251 & 151 & 270 & 187 & 434 & 319 & 687 & 626 & 731 & 1,498 \\
\hline 0 to $2 \mathrm{yrs}$ & 588 & 585 & 760 & 316 & 452 & 501 & 717 & 1,231 & 805 & 781 & 543 & 1,861 & 1,082 & 2,928 \\
\hline 3 to $5 \mathrm{yrs}$ & 389 & 324 & 403 & 272 & 607 & 209 & 462 & 246 & 777 & 726 & 1,374 & 1,274 & 2,015 & 1,227 \\
\hline 6 to $9 \mathrm{yrs}$ & 440 & 277 & 433 & 279 & 427 & 247 & 507 & 219 & 854 & 683 & 1,378 & 1,504 & 1,148 & 328 \\
\hline 10 yrs or more & 393 & 224 & 315 & 262 & 531 & 302 & 646 & 212 & 677 & 572 & 1,180 & 720 & 1,108 & 1,888 \\
\hline Unreported & 905 & 753 & 720 & 2,273 & 2,019 & 1,141 & 821 & 840 & 2,013 & 1,684 & 3,930 & 1,767 & 7,591 & \\
\hline Van & 413 & 330 & 571 & 329 & 757 & 363 & 1,247 & 345 & 1,544 & 883 & 1,243 & 4,183 & 1,007 & 529 \\
\hline 0 to $2 \mathrm{yrs}$ & 2,022 & 1,076 & 1,448 & 933 & 1,366 & 1,197 & 7,553 & 1,190 & 1,936 & 1,726 & 6,217 & 3,651 & 2,004 & 1,911 \\
\hline 3 to $5 \mathrm{yrs}$ & 645 & 768 & 1,049 & 645 & 1,153 & 795 & 1,130 & 1,001 & 2,017 & 1,879 & 1,779 & 840 & 1,787 & 977 \\
\hline 6 to $9 \mathrm{yrs}$ & 588 & 556 & 682 & 468 & 1,415 & 710 & 1,247 & 603 & 1,838 & 2,056 & 1,384 & 17,437 & 2,747 & 715 \\
\hline 10 yrs or more & 711 & 427 & 1,104 & 681 & 1,320 & 495 & 725 & 446 & 1,840 & 774 & 2,895 & 744 & 1,666 & 874 \\
\hline Unreported & 2,080 & 2,331 & 3,454 & 2,353 & 1,461 & 1,397 & 1,225 & 1,295 & 9,625 & 1,357 & 23,714 & 2,341 & 1,074 & 3,387 \\
\hline suv & 340 & 644 & 394 & 205 & 519 & 310 & 439 & 229 & 1,696 & 477 & 863 & 1,804 & 1,135 & 1,604 \\
\hline 0 to $2 \mathrm{yrs}$ & 991 & 2,635 & 707 & 492 & 1,010 & 850 & 1,149 & 944 & 5,819 & 721 & 745 & 7,776 & 3,634 & - \\
\hline 3 to $5 \mathrm{yrs}$ & 505 & 629 & 597 & 289 & 942 & 453 & 565 & 284 & 3,586 & 647 & 1,366 & 2,042 & 1,783 & \\
\hline 6 to $9 \mathrm{yrs}$ & 469 & 612 & 771 & 392 & 1,281 & 505 & 724 & 419 & 1,332 & 623 & 1,880 & 2,037 & 1,668 & 137 \\
\hline 10 yrs or more & 683 & 329 & 1,126 & 523 & 613 & 390 & 1,020 & 386 & 1,455 & 927 & 2,144 & 832 & 1,774 & 1,972 \\
\hline Unreported & 2,695 & 1,077 & 1,529 & 1,217 & 882 & 903 & 1,179 & 1,488 & 4,278 & 3,632 & 4,428 & 8,791 & 420 & \\
\hline Pickup Truck & 383 & 244 & 1,109 & 246 & 608 & 402 & 1,382 & 394 & 1,438 & 537 & 2,132 & 1,827 & 785 & 7,308 \\
\hline 0 to $2 \mathrm{yrs}$ & 1,969 & 995 & 1,072 & 872 & 911 & 1,862 & 6,197 & 1,235 & 2,058 & 1,719 & & 1,989 & & \\
\hline 3 to $5 \mathrm{yrs}$ & 732 & 505 & 2,579 & 505 & 1,163 & 549 & 1,648 & 906 & 4,761 & 1,021 & & 3,762 & - & \\
\hline 6 to $9 \mathrm{yrs}$ & 812 & 454 & 1,133 & 444 & 1,327 & 655 & 1,454 & 596 & 2,625 & 728 & 27,453 & 2,364 & & 7,308 \\
\hline 10 yrs or more & 426 & 313 & 1,403 & 416 & 1,088 & 758 & 1,739 & 648 & 2,339 & 561 & 1,965 & 3,256 & 442 & \\
\hline Unreported & 1,690 & 1,075 & 1,014 & 970 & 4,589 & 2,414 & 2,363 & 626 & 1,964 & 1,967 & & 1,323 & & \\
\hline Other POV & 327 & 436 & 336 & 311 & 827 & 427 & 391 & 179 & 393 & 613 & 930 & 1,473 & 1,159 & - \\
\hline 0 to $2 \mathrm{yrs}$ & 1,180 & 2,151 & 1,316 & 566 & 825 & 708 & 852 & 373 & & 2,489 & 995 & 249 & 1,168 & - \\
\hline 3 to $5 \mathrm{yrs}$ & 794 & 550 & 713 & 625 & 834 & 1,053 & 166 & 279 & 1,018 & 745 & & 6,631 & - & \\
\hline 6 to $9 \mathrm{yrs}$ & 539 & 744 & 716 & 407 & 1,787 & 581 & 395 & 818 & 425 & 549 & - & 612 & 872 & \\
\hline 10 yrs or more & 467 & 341 & 225 & 580 & 1,729 & 854 & 333 & 169 & 103 & 1,111 & 437 & 1,222 & 301 & \\
\hline Unreported & 287 & 823 & 808 & 1,622 & 311 & 264 & 235 & 129 & 3,237 & 1,690 & & 13,879 & & \\
\hline * Numbers reflec & & & & & & & & & & & & & & \\
\hline
\end{tabular}


Chapter 4: Table 13

Urban Travel and Population Density

2001 NHTS

STANDARD ERRORS

\begin{tabular}{|c|c|c|c|c|c|c|c|c|c|c|c|c|c|c|}
\hline \multicolumn{15}{|c|}{ Population Density (census tract) } \\
\hline & \multicolumn{2}{|c|}{$<500$} & \multicolumn{2}{|c|}{$500-2,000$} & \multicolumn{2}{|c|}{$2,000-4,000$} & \multicolumn{2}{|c|}{$4,000-10,000$} & \multicolumn{2}{|c|}{$10,000-20,000$} & \multicolumn{2}{|c|}{$20,000-50,000$} & \multicolumn{2}{|c|}{$50,000+$} \\
\hline & NY State & U.S. & NY State & U.S. & NY State & U.S. & NY State & U.S. & NY State & U.S. & NY State & U.S. & NY State & U.S. \\
\hline \multicolumn{15}{|c|}{ VMT/Vehicle by Vehicle Type and Age } \\
\hline ALL VEHICLES & 246 & 148 & 184 & 179 & 433 & 291 & 266 & 151 & 565 & 1,013 & 855 & 903 & 585 & 3,823 \\
\hline 0 to $2 \mathrm{yrs}$ & 567 & 402 & 344 & 688 & 424 & 542 & 525 & 465 & 1,705 & 602 & 957 & 6,407 & 1,605 & 2,895 \\
\hline 3 to $5 \mathrm{yrs}$ & 455 & 247 & 411 & 279 & 487 & 457 & 451 & 800 & 871 & 2,146 & 3,764 & 1,166 & 1,552 & 3,730 \\
\hline 6 to $9 \mathrm{yrs}$ & 327 & 347 & 407 & 351 & 601 & 409 & 412 & 336 & 1,008 & 4,234 & 1,868 & 3,795 & 1,311 & 8,283 \\
\hline 10 yrs or more & 347 & 281 & 305 & 249 & 1,202 & 714 & 698 & 369 & 642 & 1,526 & 655 & 2,310 & 889 & 11,903 \\
\hline Unreported & 2,598 & 817 & 1,142 & 811 & 982 & 1,103 & 2,603 & 2,178 & 2,179 & 1,625 & 1,884 & 881 & 2,241 & \\
\hline Auto & 356 & 420 & 211 & 206 & 501 & 293 & 343 & 181 & 468 & 1,066 & 963 & 1,210 & 641 & 4,234 \\
\hline 0 to $2 \mathrm{yrs}$ & 898 & 656 & 483 & 456 & 551 & 739 & 633 & 426 & 660 & 623 & 1,194 & 9,085 & 2,187 & 2,895 \\
\hline 3 to $5 \mathrm{yrs}$ & 671 & 748 & 435 & 401 & 622 & 379 & 434 & 462 & 1,157 & 2,561 & 4,430 & 2,636 & 2,109 & 7,595 \\
\hline 6 to $9 \mathrm{yrs}$ & 484 & 1,054 & 468 & 436 & 455 & 476 & 496 & 404 & 694 & 4,041 & 1,766 & 4,690 & 1,606 & 8,283 \\
\hline $10 \mathrm{yrs}$ or more & 479 & 300 & 334 & 376 & 1,581 & 417 & 845 & 247 & 746 & 1,797 & 747 & 2,071 & 813 & 11,903 \\
\hline Unreported & 1,784 & 1,479 & 1,507 & 1,311 & 1,608 & 1,357 & 3,845 & 1,705 & 2,549 & 1,446 & 1,300 & 2,340 & 2,717 & \\
\hline Van & 638 & 662 & 591 & 680 & 505 & 422 & 668 & 728 & 3,383 & 2,497 & 1,327 & 2,447 & 1,864 & 2,523 \\
\hline 0 to $2 \mathrm{yrs}$ & 1,147 & 1,196 & 891 & 1,166 & 733 & 751 & 1,441 & 2,932 & 18,702 & 2,554 & 1,774 & 3,241 & 2,626 & \\
\hline 3 to $5 \mathrm{yrs}$ & 1,227 & 2,090 & 1,957 & 1,059 & 1,106 & 830 & 1,078 & 1,008 & 2,516 & 5,269 & 3,045 & 9,750 & 1,759 & 2,523 \\
\hline 6 to $9 \mathrm{yrs}$ & 1,145 & 927 & 688 & 784 & 1,265 & 1,933 & 1,213 & 1,108 & 3,904 & 12,643 & 1,194 & 1,739 & 1,743 & \\
\hline $10 \mathrm{yrs}$ or more & 1,760 & 674 & 1,196 & 997 & 843 & 1,999 & 1,330 & 1,974 & 2,232 & 1,544 & 2,460 & 7,397 & 3,820 & \\
\hline Unreported & 4,204 & 1,586 & 3,624 & 1,491 & 4,881 & 3,443 & 6,917 & 2,650 & 4,302 & 2,366 & 7,068 & 1,117 & 6,336 & \\
\hline suv & 422 & 625 & 569 & 322 & 663 & 469 & 717 & 446 & 1,400 & 2,568 & 1,573 & 1,362 & 1,179 & 13,775 \\
\hline 0 to $2 \mathrm{yrs}$ & 823 & 781 & 663 & 452 & 1,002 & 563 & 1,164 & 1,679 & 786 & 2,824 & 2,456 & 4,270 & 1,416 & \\
\hline 3 to $5 \mathrm{yrs}$ & 884 & 1,210 & 1,194 & 851 & 993 & 1,574 & 1,527 & 3,657 & 791 & 3,488 & 2,419 & 2,739 & 2,410 & 13,775 \\
\hline 6 to $9 \mathrm{yrs}$ & 850 & 970 & 1,598 & 956 & 2,480 & 1,718 & 1,498 & 1,054 & 5,683 & 2,180 & 4,327 & 3,083 & 1,937 & \\
\hline $10 \mathrm{yrs}$ or more & 839 & 815 & 1,469 & 1,513 & 1,004 & 1,483 & 1,533 & 1,486 & 1,503 & 4,656 & 3,173 & 2,913 & 4,024 & \\
\hline Unreported & 3,966 & 2,912 & 879 & 1,611 & 850 & 2,315 & 3,249 & 4,539 & 8,864 & & 6,940 & 8,826 & 10 & \\
\hline Pickup Truck & 515 & 834 & 600 & 502 & 1,470 & 1,158 & 879 & 367 & 2,765 & 1,782 & 1,166 & 4,842 & 6,653 & 10,964 \\
\hline 0 to $2 \mathrm{yrs}$ & 1,535 & 729 & 930 & 2,403 & 4,544 & 1,170 & 1,433 & 1,277 & 1,373 & 3,032 & 4,838 & 46,396 & 26,887 & \\
\hline 3 to $5 \mathrm{yrs}$ & 634 & 1,469 & 899 & 1,392 & 1,314 & 828 & 1,416 & 2,431 & 2,075 & 2,462 & & 1,004 & 4,995 & 10,964 \\
\hline 6 to $9 \mathrm{yrs}$ & 911 & 1,950 & 1,626 & 1,265 & 3,182 & 1,461 & 2,102 & 927 & 14,654 & 2,581 & 2,934 & 14,012 & 5,644 & \\
\hline $10 \mathrm{yrs}$ or more & 1,140 & 538 & 927 & 424 & 1,211 & 2,037 & 1,586 & 829 & 2,341 & 4,164 & 666 & 5,716 & 18,415 & \\
\hline Unreported & 1,609 & 1,249 & 2,721 & 2,381 & 2,865 & 2,828 & 4,265 & 3,231 & 2,122 & 9,862 & & 15,146 & & \\
\hline Other POV & 1,993 & 812 & 810 & 988 & 1,557 & 790 & 435 & 4,641 & 1,805 & 3,853 & 711 & 4,671 & 3,503 & \\
\hline 0 to $2 \mathrm{yrs}$ & 1,481 & 1,314 & 2,917 & 2,109 & 24,034 & 891 & 2,178 & 28,732 & 1,990 & 29,010 & 365 & & 4,477 & \\
\hline 3 to $5 \mathrm{yrs}$ & 1,317 & 1,644 & 1,805 & 765 & 1,210 & 1,315 & 334 & 5,402 & 2,594 & 1,308 & & & & \\
\hline 6 to $9 \mathrm{yrs}$ & 793 & 2,743 & 3,581 & 2,773 & 4,224 & 7,182 & 606 & 3,913 & 9,949 & 2,060 & 5,970 & & & \\
\hline $10 \mathrm{yrs}$ or more & 401 & 1,162 & 284 & 418 & 1,787 & 263 & 745 & 1,148 & 273 & 5,542 & 949 & 4,671 & 4,121 & \\
\hline Unreported & 20,226 & 745 & 660 & 665 & 1,846 & 4,763 & 903 & 731 & & & 1,917 & & & \\
\hline * Numbers reff & & & & & & & & & & & & & & \\
\hline
\end{tabular}


Chapter 4: Table 14

Urban Travel and Population Density

2009 NHTS

STANDARD ERRORS

\begin{tabular}{|c|c|c|c|c|c|c|c|c|c|c|c|c|c|c|}
\hline \multicolumn{15}{|c|}{ Population Density (census tract) } \\
\hline & \multicolumn{2}{|c|}{$<500$} & \multicolumn{2}{|c|}{$500-2,000$} & \multicolumn{2}{|c|}{$2,000-4,000$} & \multicolumn{2}{|c|}{$4,000-10,000$} & \multicolumn{2}{|c|}{$10,000-20,000$} & \multicolumn{2}{|c|}{$20,000-50,000$} & \multicolumn{2}{|c|}{$50,000+$} \\
\hline & NY State & U.S. & NY State & U.S. & NY State & U.S. & NY State & U.S. & NY State & U.S. & NY State & U.S. & NY State & U.S. \\
\hline \multicolumn{3}{|c|}{ Percent Not Taking Walk Trips in the last week } & & & & & & & & & & & & \\
\hline TOTAL & $1.1 \%$ & $0.7 \%$ & $1.3 \%$ & $0.6 \%$ & $1.6 \%$ & $0.7 \%$ & $1.6 \%$ & $0.6 \%$ & $2.4 \%$ & $1.3 \%$ & $2.0 \%$ & $2.8 \%$ & $1.4 \%$ & $5.3 \%$ \\
\hline 5 to 10 year-olds & $4.9 \%$ & $2.6 \%$ & $4.2 \%$ & $1.9 \%$ & $4.9 \%$ & $2.0 \%$ & $6.3 \%$ & $1.8 \%$ & $4.0 \%$ & $3.4 \%$ & $6.5 \%$ & $4.9 \%$ & $6.9 \%$ & \\
\hline 11 to 15 year-olds & $6.0 \%$ & $1.8 \%$ & $3.7 \%$ & $2.2 \%$ & $4.0 \%$ & $1.9 \%$ & $6.3 \%$ & $2.4 \%$ & $5.9 \%$ & $2.6 \%$ & $4.3 \%$ & $3.7 \%$ & $2.7 \%$ & $28.0 \%$ \\
\hline 16 to 20 year-olds & $3.8 \%$ & $2.7 \%$ & $4.0 \%$ & $2.5 \%$ & $5.4 \%$ & $2.4 \%$ & $5.3 \%$ & $2.2 \%$ & $5.7 \%$ & $4.0 \%$ & $8.2 \%$ & $14.3 \%$ & $4.8 \%$ & $10.1 \%$ \\
\hline 21 to 35 year-olds & $3.2 \%$ & $2.0 \%$ & $2.7 \%$ & $1.5 \%$ & $3.9 \%$ & $2.1 \%$ & $4.3 \%$ & $1.3 \%$ & $4.7 \%$ & $2.3 \%$ & $4.4 \%$ & $6.2 \%$ & $2.2 \%$ & $8.5 \%$ \\
\hline 36 to 64 year-olds & $1.4 \%$ & $1.1 \%$ & $1.4 \%$ & $0.8 \%$ & $1.8 \%$ & $0.8 \%$ & $2.3 \%$ & $0.9 \%$ & $3.2 \%$ & $1.9 \%$ & $3.0 \%$ & $3.3 \%$ & $1.7 \%$ & $5.8 \%$ \\
\hline $65+$ year-olds & $4.7 \%$ & $1.6 \%$ & $2.5 \%$ & $1.4 \%$ & $2.5 \%$ & $1.1 \%$ & $3.7 \%$ & $1.6 \%$ & $4.1 \%$ & $3.5 \%$ & $4.0 \%$ & $6.5 \%$ & $4.4 \%$ & $8.3 \%$ \\
\hline \multicolumn{15}{|c|}{ Avg Minutes Spent Walking per Day } \\
\hline TOTAL & 0.23 & 0.28 & 0.34 & 0.24 & 0.51 & 0.26 & 0.55 & 0.57 & 1.10 & 0.99 & 1.96 & 2.48 & 1.90 & 5.91 \\
\hline 5 to 10 year-olds & 0.48 & 0.36 & 0.61 & 0.26 & 2.32 & 0.53 & 1.86 & 0.81 & 1.99 & 1.80 & 7.27 & 7.16 & 4.30 & 6.34 \\
\hline 11 to 15 year-olds & 1.90 & 0.74 & 1.32 & 0.93 & 0.61 & 1.53 & 1.82 & 3.66 & 2.50 & 1.73 & 2.70 & 6.14 & 3.66 & 14.29 \\
\hline 16 to 20 year-olds & 0.64 & 0.75 & 1.19 & 1.63 & 1.43 & 0.84 & 1.56 & 0.62 & 3.11 & 1.65 & 8.71 & 2.46 & 5.76 & 15.50 \\
\hline 21 to 35 year-olds & 0.63 & 0.40 & 0.95 & 0.43 & 1.14 & 0.54 & 1.05 & 0.60 & 4.08 & 3.11 & 5.33 & 4.76 & 4.43 & 4.78 \\
\hline 36 to 64 year-olds & 0.29 & 0.45 & 0.54 & 0.31 & 0.84 & 0.35 & 1.03 & 0.74 & 0.93 & 1.14 & 2.39 & 2.52 & 2.38 & 13.56 \\
\hline $65+$ year-olds & 0.26 & 0.27 & 0.33 & 0.41 & 0.89 & 0.42 & 0.95 & 0.82 & 3.16 & 1.14 & 3.63 & 2.29 & 2.74 & 9.01 \\
\hline \multicolumn{15}{|c|}{ Percent Not Taking Bike Trips in the last week } \\
\hline TOTAL & $0.8 \%$ & $0.5 \%$ & $1.0 \%$ & $0.5 \%$ & $0.9 \%$ & $0.5 \%$ & $0.9 \%$ & $0.5 \%$ & $1.6 \%$ & $1.0 \%$ & $1.4 \%$ & $1.9 \%$ & $1.1 \%$ & $3.1 \%$ \\
\hline 5 to 10 year-olds & $4.5 \%$ & $2.6 \%$ & $5.6 \%$ & $2.1 \%$ & $7.0 \%$ & $2.1 \%$ & $6.2 \%$ & $2.4 \%$ & $10.2 \%$ & $3.8 \%$ & $5.1 \%$ & $5.6 \%$ & $5.8 \%$ & $20.2 \%$ \\
\hline 11 to 15 year-olds & $5.2 \%$ & $2.1 \%$ & $4.5 \%$ & $2.0 \%$ & $4.8 \%$ & $2.2 \%$ & $4.1 \%$ & $2.3 \%$ & $4.2 \%$ & $3.8 \%$ & $6.9 \%$ & $17.7 \%$ & $2.9 \%$ & $0.0 \%$ \\
\hline 16 to 20 year-olds & $2.2 \%$ & $1.3 \%$ & $3.8 \%$ & $1.4 \%$ & $4.1 \%$ & $1.7 \%$ & $2.8 \%$ & $1.1 \%$ & $4.1 \%$ & $4.1 \%$ & $1.1 \%$ & $4.6 \%$ & $3.5 \%$ & $6.4 \%$ \\
\hline 21 to 35 year-olds & $1.9 \%$ & $1.1 \%$ & $2.1 \%$ & $0.9 \%$ & $1.4 \%$ & $1.1 \%$ & $2.2 \%$ & $0.7 \%$ & $5.5 \%$ & $1.9 \%$ & $6.1 \%$ & $4.9 \%$ & $2.8 \%$ & $3.4 \%$ \\
\hline 36 to 64 year-olds & $1.0 \%$ & $0.6 \%$ & $1.4 \%$ & $0.5 \%$ & $0.9 \%$ & $0.5 \%$ & $1.0 \%$ & $0.5 \%$ & $1.1 \%$ & $0.9 \%$ & $0.8 \%$ & $1.4 \%$ & $1.5 \%$ & $6.8 \%$ \\
\hline $65+$ year-olds & $0.5 \%$ & $0.5 \%$ & $0.6 \%$ & $0.5 \%$ & $0.8 \%$ & $0.5 \%$ & $0.5 \%$ & $0.4 \%$ & $1.1 \%$ & $1.5 \%$ & $1.8 \%$ & $0.3 \%$ & $0.3 \%$ & $0.0 \%$ \\
\hline \multicolumn{15}{|c|}{ Avg Minutes Spent Biking per Day } \\
\hline TOTAL & 0.14 & 0.08 & 0.17 & 0.09 & 0.20 & 0.10 & 0.15 & 0.13 & 0.10 & 0.11 & 0.07 & 0.24 & 0.29 & 0.30 \\
\hline 5 to 10 year-olds & 0.12 & 0.21 & 0.23 & 0.45 & 1.69 & 0.28 & 0.51 & 0.34 & 0.33 & 0.21 & 1.24 & 0.12 & & \\
\hline 11 to 15 year-olds & 0.52 & 0.26 & 0.51 & 0.26 & 0.54 & 0.82 & 0.49 & 0.19 & 0.62 & 0.67 & & 0.16 & & \\
\hline 16 to 20 year-olds & 1.06 & 0.29 & 0.52 & 0.49 & 0.09 & 0.38 & 0.71 & 0.18 & 0.31 & 0.56 & & 0.15 & 0.12 & 1.91 \\
\hline 21 to 35 year-olds & 0.04 & 0.13 & 0.93 & 0.17 & 0.21 & 0.12 & 0.25 & 0.42 & & 0.20 & & 0.75 & 0.71 & \\
\hline 36 to 64 year-olds & 0.14 & 0.10 & 0.09 & 0.12 & 0.23 & 0.12 & 0.26 & 0.24 & 0.13 & 0.17 & 0.09 & 0.34 & 0.64 & \\
\hline $65+$ year-olds & 0.27 & 0.49 & 0.09 & 0.14 & 0.07 & 0.11 & 0.28 & 0.13 & 0.45 & 0.12 & & 0.04 & 0.12 & \\
\hline \multicolumn{15}{|c|}{ Avg Minutes Spent Walking/Biking per Day } \\
\hline TOTAL & 0.31 & 0.29 & 0.41 & 0.28 & 0.56 & 0.27 & 0.61 & 0.59 & 1.10 & 1.00 & 1.96 & 2.58 & 1.95 & 6.04 \\
\hline 5 to 10 year-olds & 0.50 & 0.39 & 0.65 & 0.50 & 3.08 & 0.60 & 1.91 & 0.84 & 2.01 & 1.85 & 6.46 & 7.15 & 4.30 & 6.34 \\
\hline 11 to 15 year-olds & 2.01 & 0.79 & 1.41 & 0.92 & 0.78 & 1.70 & 1.86 & 3.66 & 2.55 & 1.83 & 2.70 & 6.19 & 3.66 & 14.29 \\
\hline 16 to 20 year-olds & 1.23 & 0.81 & 1.25 & 1.70 & 1.43 & 0.86 & 1.70 & 0.66 & 3.15 & 1.63 & 8.71 & 2.49 & 5.74 & 17.41 \\
\hline 21 to 35 year-olds & 0.63 & 0.46 & 1.24 & 0.45 & 1.16 & 0.57 & 1.07 & 0.70 & 4.08 & 3.09 & 5.33 & 5.28 & 4.45 & 4.78 \\
\hline 36 to 64 year-olds & 0.32 & 0.46 & 0.58 & 0.34 & 0.87 & 0.40 & 1.08 & 0.80 & 0.94 & 1.17 & 2.39 & 2.52 & 2.53 & 13.56 \\
\hline $65+$ year-olds & 0.36 & 0.57 & 0.38 & 0.44 & 0.88 & 0.43 & 1.00 & 0.83 & 3.15 & 1.16 & 3.63 & 2.29 & 2.75 & 9.01 \\
\hline
\end{tabular}


Chapter 4: Table 14

Urban Travel and Population Density

2001 NHTS

STANDARD ERRORS

\begin{tabular}{|c|c|c|c|c|c|c|c|c|c|c|c|c|c|c|}
\hline \multicolumn{15}{|c|}{ Population Density (census tract) } \\
\hline & \multicolumn{2}{|c|}{${ }_{\text {NY State }}^{<500}$ U.S. } & \multirow{2}{*}{\multicolumn{2}{|c|}{$500-2,000$}} & \multicolumn{2}{|c|}{$2,000-4,000$} & \multicolumn{2}{|c|}{$4,000-10,000$} & \multicolumn{2}{|c|}{$10,000-20,000$} & \multicolumn{2}{|c|}{$20,000-50,000$} & \multicolumn{2}{|c|}{$50,000+$} \\
\hline & NY State & U.S. & & U.S. & NY State & U.S. & NY State & U.S. & NY State & U.S. & NY State & U.S. & NY State & U.S. \\
\hline \multicolumn{15}{|c|}{ Percent Not Taking Walk Trips in the last week } \\
\hline TOTAL & $1.0 \%$ & $0.8 \%$ & $1.1 \%$ & $0.7 \%$ & $1.5 \%$ & $0.7 \%$ & $1.3 \%$ & $0.5 \%$ & $1.9 \%$ & $1.2 \%$ & $1.4 \%$ & $2.1 \%$ & $1.3 \%$ & $3.9 \%$ \\
\hline 5 to 10 year-olds & * & * & * & & * & & * & * & * & * & * & * & * & \\
\hline 11 to 15 year-olds & * & & * & & * & * & * & * & * & * & * & * & * & \\
\hline 16 to 20 year-olds & $3.4 \%$ & $2.6 \%$ & $4.0 \%$ & $2.5 \%$ & $7.2 \%$ & $2.4 \%$ & $3.8 \%$ & $2.4 \%$ & $5.7 \%$ & $4.6 \%$ & $3.0 \%$ & $7.9 \%$ & $3.9 \%$ & $99.5 \%$ \\
\hline 21 to 35 year-olds & $2.9 \%$ & $1.4 \%$ & $2.7 \%$ & $1.3 \%$ & $3.2 \%$ & $1.5 \%$ & $2.8 \%$ & $1.2 \%$ & $3.4 \%$ & $1.9 \%$ & $3.0 \%$ & $3.5 \%$ & $1.4 \%$ & $1.8 \%$ \\
\hline 36 to 64 year-olds & $1.2 \%$ & $1.0 \%$ & $1.5 \%$ & $0.8 \%$ & $1.7 \%$ & $0.8 \%$ & $1.6 \%$ & $0.8 \%$ & $2.6 \%$ & $1.8 \%$ & $2.6 \%$ & $3.0 \%$ & $1.6 \%$ & $8.3 \%$ \\
\hline $65+$ year-olds & $2.4 \%$ & $1.3 \%$ & $2.8 \%$ & $1.5 \%$ & $3.0 \%$ & $1.6 \%$ & $2.9 \%$ & $1.2 \%$ & $4.9 \%$ & $3.5 \%$ & $4.0 \%$ & $6.0 \%$ & $3.2 \%$ & $58.9 \%$ \\
\hline \multicolumn{15}{|c|}{ Avg Minutes Spent Walking per Day } \\
\hline TOTAL & 0.36 & 0.21 & 0.57 & 0.22 & 0.40 & 0.28 & 1.65 & 0.32 & 1.12 & 0.68 & 1.21 & 0.89 & 0.95 & 4.86 \\
\hline 5 to 10 year-olds & 0.46 & 0.83 & 2.14 & 0.39 & 0.77 & 0.59 & 2.42 & 1.71 & 3.11 & 2.88 & 2.11 & 2.38 & 2.35 & 7.49 \\
\hline 11 to 15 year-olds & 1.03 & 0.41 & 1.76 & 0.67 & 2.43 & 1.10 & 5.91 & 1.46 & 3.87 & 1.55 & 3.53 & 2.96 & 2.51 & 1.11 \\
\hline 16 to 20 year-olds & 0.28 & 0.42 & 1.20 & 0.81 & 2.19 & 1.03 & 3.23 & 1.06 & 4.70 & 1.69 & 3.33 & 2.45 & 2.01 & 48.75 \\
\hline 21 to 35 year-olds & 0.69 & 0.45 & 0.79 & 0.42 & 0.67 & 0.43 & 1.55 & 0.52 & 1.06 & 1.06 & 3.15 & 1.40 & 1.78 & 5.45 \\
\hline 36 to 64 year-olds & 0.72 & 0.25 & 1.09 & 0.34 & 0.57 & 0.26 & 3.72 & 0.30 & 1.19 & 0.94 & 1.56 & 1.17 & 1.22 & 8.55 \\
\hline $65+$ year-olds & 0.49 & 0.49 & 0.71 & 0.54 & 1.30 & 0.51 & 0.85 & 0.50 & 3.30 & 1.11 & 2.49 & 2.18 & 2.38 & 15.60 \\
\hline \multicolumn{15}{|c|}{ Percent Not Taking Bike Trips in the last week } \\
\hline TOTAL & $0.6 \%$ & $0.4 \%$ & $0.9 \%$ & $0.4 \%$ & $1.0 \%$ & $0.4 \%$ & $0.7 \%$ & $0.4 \%$ & $1.0 \%$ & $0.7 \%$ & $1.1 \%$ & $1.4 \%$ & $0.6 \%$ & $4.6 \%$ \\
\hline 5 to 10 year-olds & * & & * & & * & & * & & * & * & * & * & * & \\
\hline 11 to 15 year-olds & * & * & * & * & * & * & * & * & * & * & * & * & * & \\
\hline 16 to 20 year-olds & $3.1 \%$ & $1.4 \%$ & $2.5 \%$ & $1.5 \%$ & $4.1 \%$ & $1.6 \%$ & $5.0 \%$ & $1.5 \%$ & $2.7 \%$ & $2.6 \%$ & $8.4 \%$ & $7.4 \%$ & $2.4 \%$ & $99.5 \%$ \\
\hline 21 to 35 year-olds & $1.3 \%$ & $0.9 \%$ & $1.7 \%$ & $0.9 \%$ & $2.2 \%$ & $0.9 \%$ & $1.5 \%$ & $0.8 \%$ & $2.0 \%$ & $1.3 \%$ & $2.4 \%$ & $2.7 \%$ & $1.4 \%$ & $10.1 \%$ \\
\hline 36 to 64 year-olds & $0.7 \%$ & $0.5 \%$ & $1.2 \%$ & $0.6 \%$ & $1.4 \%$ & $0.5 \%$ & $1.1 \%$ & $0.5 \%$ & $1.7 \%$ & $1.0 \%$ & $0.8 \%$ & $1.1 \%$ & $0.9 \%$ & $0.0 \%$ \\
\hline $65+$ year-olds & $1.5 \%$ & $0.7 \%$ & $1.5 \%$ & $0.6 \%$ & $1.7 \%$ & $0.6 \%$ & $0.7 \%$ & $0.7 \%$ & $0.6 \%$ & $1.1 \%$ & $1.0 \%$ & $1.4 \%$ & $0.6 \%$ & $0.0 \%$ \\
\hline \multicolumn{15}{|c|}{ Avg Minutes Spent Biking per Day } \\
\hline TOTAL & 0.15 & 0.12 & 0.14 & 0.22 & 0.25 & 0.12 & 0.12 & 0.13 & 0.66 & 0.15 & 0.51 & 0.43 & 0.11 & 1.05 \\
\hline 5 to 10 year-olds & 0.79 & 0.81 & 0.64 & 0.96 & 0.59 & 0.52 & 0.40 & 0.60 & 8.72 & 0.81 & 0.45 & 0.04 & 0.22 & \\
\hline 11 to 15 year-olds & 1.51 & 0.51 & 0.73 & 1.04 & 0.67 & 0.69 & 0.82 & 0.44 & 0.27 & 0.47 & 8.15 & 1.01 & 0.75 & \\
\hline 16 to 20 year-olds & 0.09 & 0.15 & 0.10 & 0.52 & 0.15 & 0.20 & 0.10 & 0.41 & 0.24 & 0.11 & 0.02 & 3.02 & 0.09 & \\
\hline 21 to 35 year-olds & 0.16 & 0.06 & 0.02 & 0.31 & 0.27 & 0.08 & 0.11 & 0.21 & 0.27 & 0.16 & 0.75 & 1.04 & 0.22 & 2.74 \\
\hline 36 to 64 year-olds & 0.05 & 0.12 & 0.09 & 0.21 & 0.45 & 0.21 & 0.06 & 0.17 & 0.08 & 0.30 & 0.18 & 0.22 & 0.22 & \\
\hline $65+$ year-olds & 0.11 & 0.05 & 0.58 & 0.19 & 0.46 & 0.09 & 0.67 & 0.06 & & 0.45 & 0.13 & 1.27 & & \\
\hline \multicolumn{15}{|c|}{ Avg Minutes Spent Walking/Biking per Day } \\
\hline TOTAL & 0.40 & 0.23 & 0.59 & 0.32 & 0.48 & 0.33 & 1.65 & 0.35 & 1.35 & 0.71 & 1.29 & 1.04 & 0.97 & 5.11 \\
\hline 5 to 10 year-olds & 0.88 & 1.09 & 2.22 & 1.11 & 1.01 & 0.89 & 2.42 & 1.79 & 10.35 & 2.92 & 2.15 & 2.38 & 2.32 & 7.49 \\
\hline 11 to 15 year-olds & 1.80 & 0.60 & 1.89 & 1.25 & 2.47 & 1.32 & 5.89 & 1.53 & 3.83 & 1.65 & 8.77 & 3.46 & 2.90 & 1.11 \\
\hline 16 to 20 year-olds & 0.29 & 0.45 & 1.20 & 0.94 & 2.17 & 1.05 & 3.23 & 1.12 & 4.70 & 1.68 & 3.33 & 3.51 & 1.99 & 48.75 \\
\hline 21 to 35 year-olds & 0.70 & 0.45 & 0.79 & 0.53 & 0.72 & 0.44 & 1.55 & 0.60 & 1.09 & 1.06 & 3.19 & 1.79 & 1.76 & 7.02 \\
\hline 36 to 64 year-olds & 0.72 & 0.28 & 1.10 & 0.40 & 0.68 & 0.35 & 3.72 & 0.36 & 1.19 & 1.17 & 1.59 & 1.20 & 1.24 & 8.55 \\
\hline $65+$ year-olds & 0.49 & 0.49 & 0.88 & 0.56 & 1.39 & 0.53 & 1.20 & 0.49 & 3.30 & 1.20 & 2.50 & 2.47 & 2.38 & 15.60 \\
\hline
\end{tabular}


APPENDIX C5. SUPPLEMENTAL TABLES FOR CHAPTER 5 


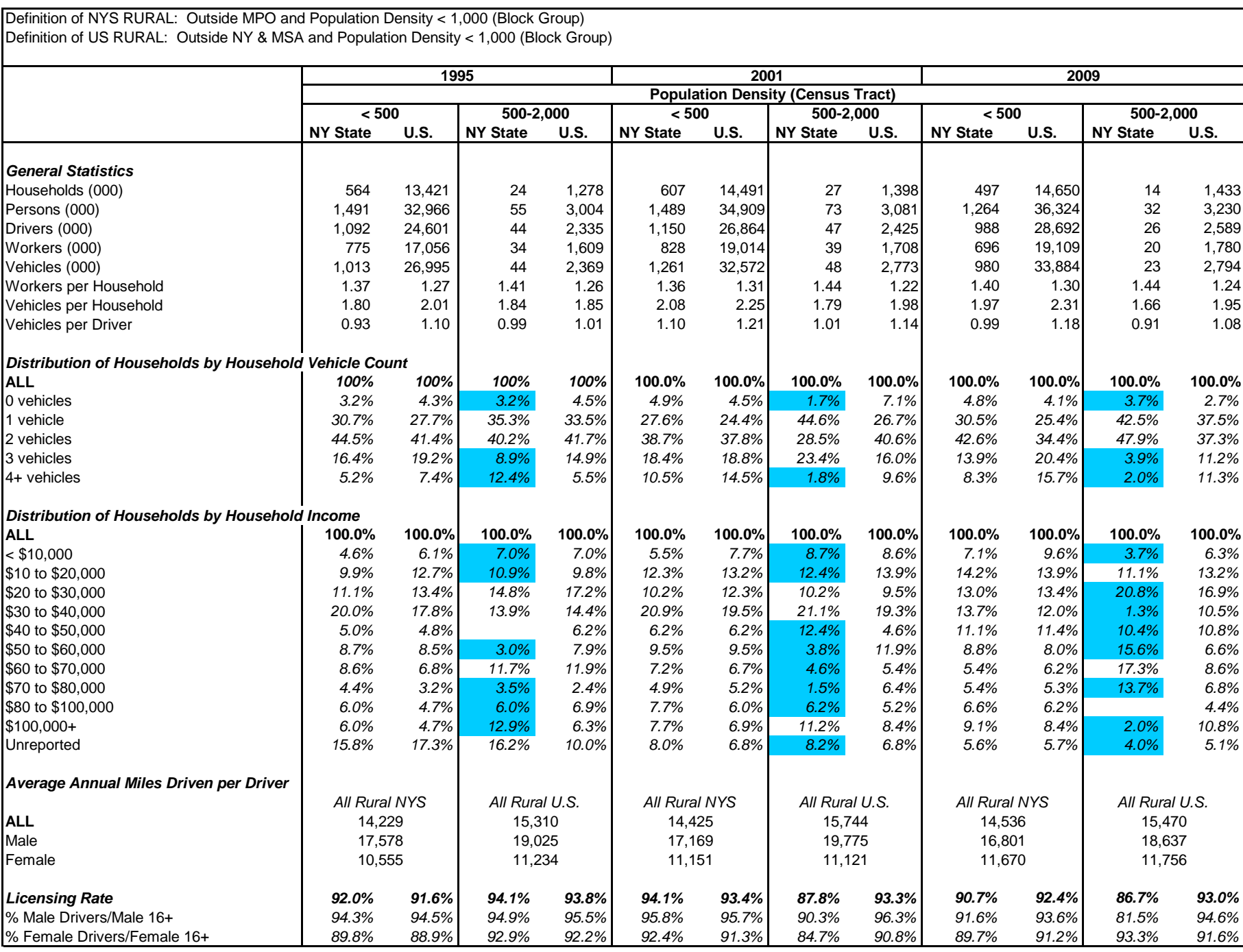




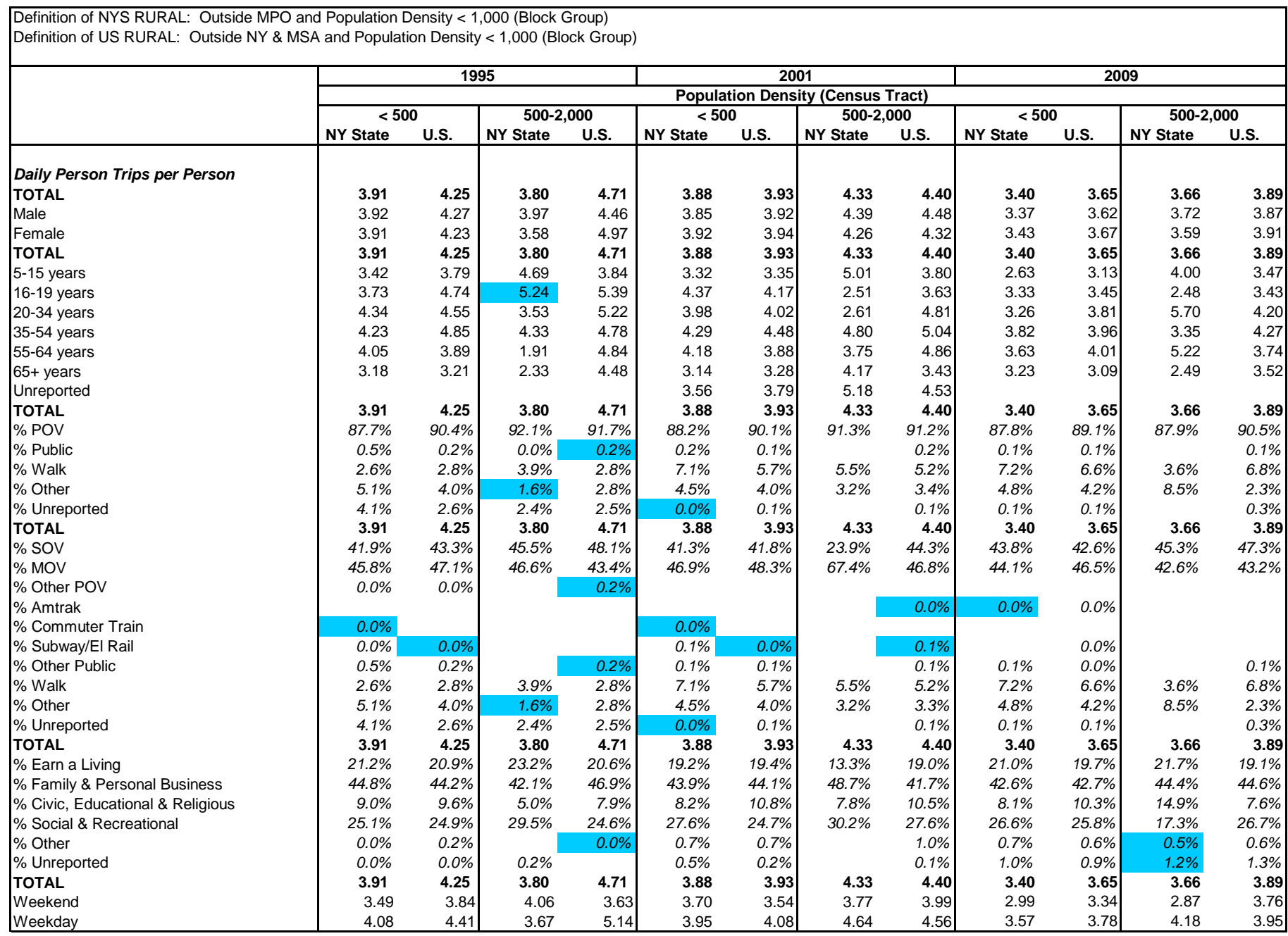




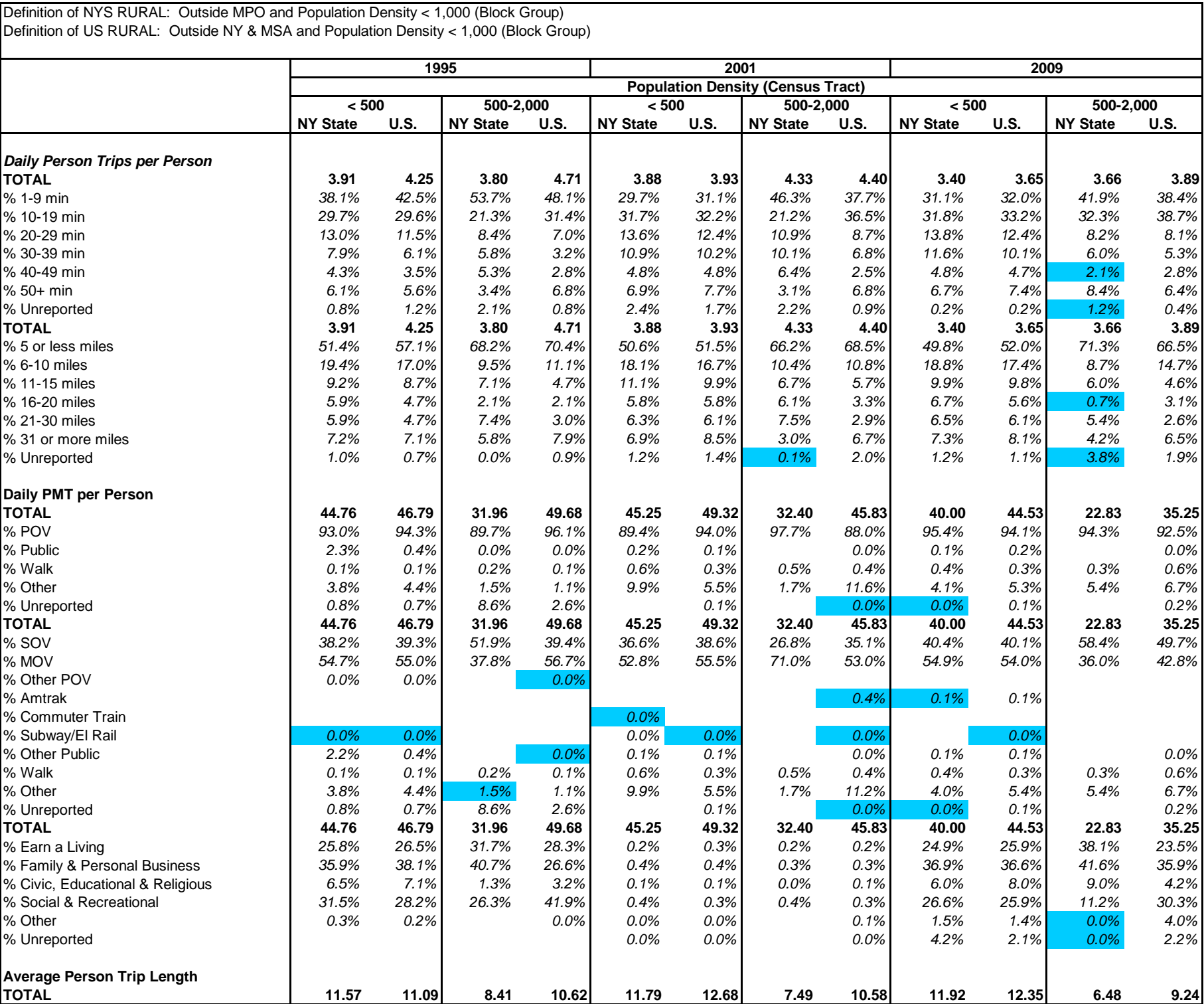




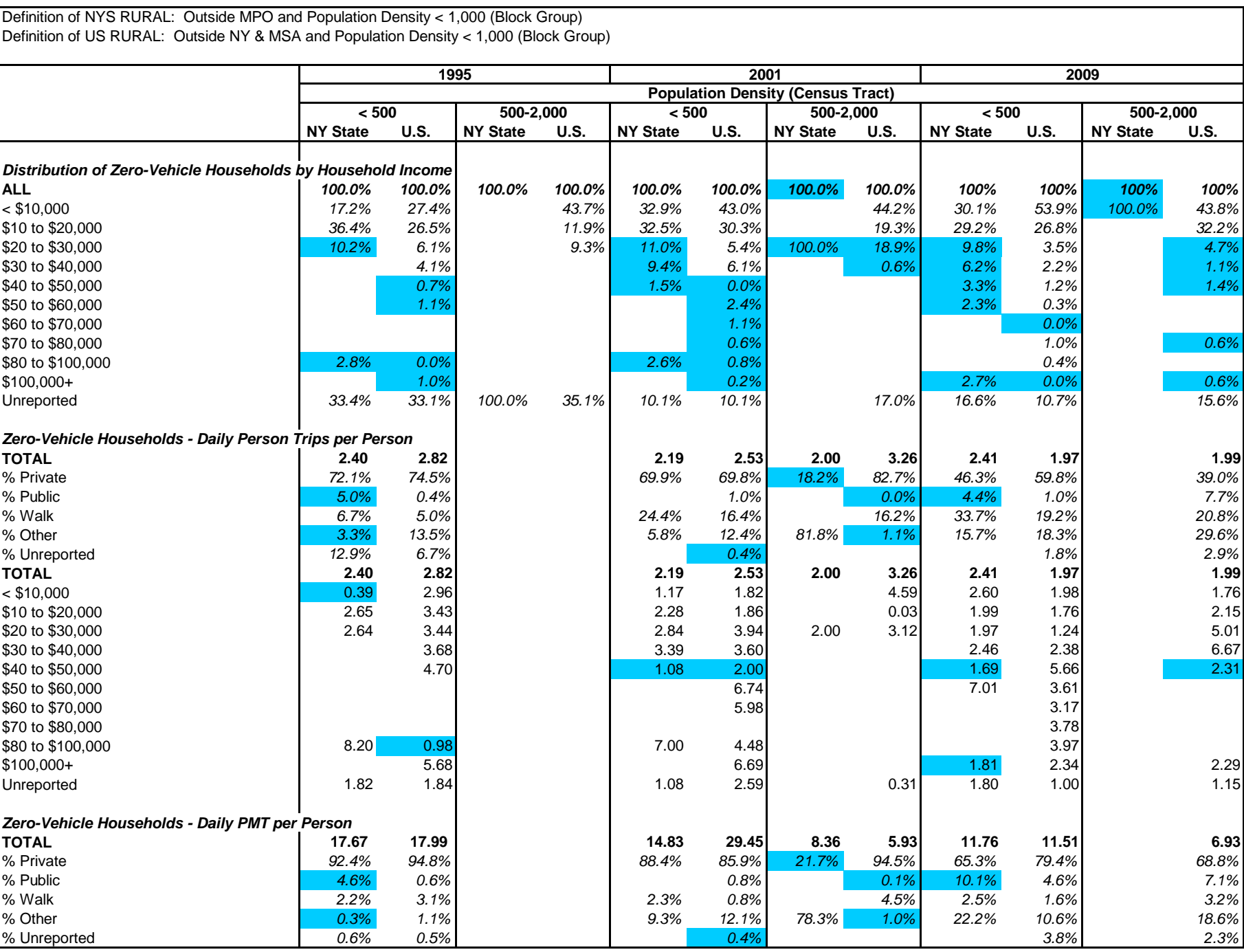




\begin{tabular}{|c|c|c|c|c|c|c|c|c|c|c|c|c|}
\hline & \multicolumn{4}{|c|}{1995} & \multicolumn{4}{|c|}{2001} & \multicolumn{4}{|c|}{2009} \\
\hline & & & & & \multicolumn{4}{|c|}{ Population Density (Census Tract) } & \\
\hline & \multicolumn{2}{|c|}{$<500$} & \multicolumn{2}{|c|}{$500-2,000$} & \multirow{2}{*}{\multicolumn{2}{|c|}{$\begin{array}{l}\text { NY State }^{<500} \text { U.S. } \\
\text { N. }\end{array}$}} & \multicolumn{2}{|c|}{$500-2,000$} & \multicolumn{2}{|c|}{$<500$} & \multicolumn{2}{|c|}{$500-2,000$} \\
\hline & NY State & U.S. & NY State & U.S. & & & NY State & U.S. & NY State & U.S. & NY State & U.S. \\
\hline \multicolumn{13}{|c|}{ Zero-Vehicle Households - Daily PMT per Person } \\
\hline TOTAL & 17.67 & 17.99 & & & 14.83 & 29.45 & 8.36 & 5.93 & 11.76 & 11.51 & & 6.93 \\
\hline$<\$ 10,000$ & 1.25 & 14.64 & & & 8.83 & 8.39 & & 8.97 & 18.54 & 12.17 & & 8.04 \\
\hline$\$ 10$ to $\$ 20,000$ & 16.90 & 18.69 & & & 17.11 & 12.42 & & 0.11 & 14.68 & 10.12 & & 4.69 \\
\hline$\$ 20$ to $\$ 30,000$ & 17.54 & 8.23 & & & 13.71 & 86.53 & 8.36 & 3.27 & 17.66 & 5.33 & & 4.99 \\
\hline$\$ 30$ to $\$ 40,000$ & & 52.52 & & & 22.90 & 44.33 & & & 7.21 & 9.18 & & 28.45 \\
\hline$\$ 40$ to $\$ 50,000$ & & 25.48 & & & 43.08 & 4.00 & & & 4.34 & 23.37 & & 5.19 \\
\hline$\$ 50$ to $\$ 60,000$ & & & & & & 81.66 & & & 14.27 & 57.72 & & \\
\hline$\$ 60$ to $\$ 70,000$ & & & & & & 9.76 & & & & 25.05 & & \\
\hline$\$ 70$ to $\$ 80,000$ & & & & & & & & & & 24.71 & & \\
\hline$\$ 80$ to $\$ 100,000$ & 57.59 & 16.73 & & & 43.64 & 63.67 & & & & 13.24 & & \\
\hline$\$ 100,000+$ & & 44.49 & & & & 423.66 & & & 1.51 & 2.34 & & 9.15 \\
\hline Unreported & 21.05 & 13.98 & & & 0.64 & 13.93 & & 0.31 & 9.31 & 5.21 & & 4.80 \\
\hline \multicolumn{13}{|c|}{ Non-Zero-Vehicle Households - Daily Person Trips per Person } \\
\hline TOTAL & 3.95 & 4.30 & 3.86 & 4.82 & 3.93 & 3.97 & 4.40 & 4.45 & 3.43 & 3.70 & 3.73 & 3.93 \\
\hline$\%$ Private & $88.1 \%$ & $90.8 \%$ & $92.2 \%$ & $92.3 \%$ & $88.5 \%$ & $90.4 \%$ & $92.3 \%$ & $91.5 \%$ & $88.9 \%$ & $89.5 \%$ & $87.9 \%$ & $91.1 \%$ \\
\hline$\%$ Public & $0.5 \%$ & $0.2 \%$ & & $0.1 \%$ & $0.2 \%$ & $0.1 \%$ & & $0.2 \%$ & $0.0 \%$ & $0.1 \%$ & & $0.0 \%$ \\
\hline$\%$ Walk & $2.5 \%$ & $2.5 \%$ & $3.9 \%$ & $2.3 \%$ & $6.9 \%$ & $5.5 \%$ & $5.6 \%$ & $4.9 \%$ & $6.5 \%$ & $6.4 \%$ & $3.6 \%$ & $6.7 \%$ \\
\hline$\%$ Other & $5.2 \%$ & $3.9 \%$ & $1.5 \%$ & $2.9 \%$ & $4.4 \%$ & $3.9 \%$ & $2.2 \%$ & $3.5 \%$ & $4.6 \%$ & $3.9 \%$ & $8.5 \%$ & $2.0 \%$ \\
\hline$\%$ Unreported & $3.7 \%$ & $2.6 \%$ & $2.5 \%$ & $2.5 \%$ & $0.0 \%$ & $0.1 \%$ & & $0.1 \%$ & $0.1 \%$ & $0.1 \%$ & & $0.3 \%$ \\
\hline \multicolumn{13}{|c|}{ Non-Zero-Vehicle Households - Daily PMT per Person } \\
\hline TOTAL & 45.41 & 47.70 & 32.44 & 51.44 & 46.06 & 49.87 & 33.13 & 47.76 & 41.03 & 45.48 & 23.24 & 35.88 \\
\hline$\%$ Private & $93.0 \%$ & $94.3 \%$ & $89.8 \%$ & $96.2 \%$ & $89.4 \%$ & $94.2 \%$ & $98.3 \%$ & $88.0 \%$ & $95.7 \%$ & $94.2 \%$ & $94.3 \%$ & $92.6 \%$ \\
\hline$\%$ Public & $2.2 \%$ & $0.5 \%$ & & $0.0 \%$ & $0.2 \%$ & $0.1 \%$ & & $0.0 \%$ & $0.0 \%$ & $0.2 \%$ & & $0.0 \%$ \\
\hline$\%$ Walk & $3.8 \%$ & $4.5 \%$ & $1.5 \%$ & $1.1 \%$ & $0.5 \%$ & $0.3 \%$ & $0.5 \%$ & $0.4 \%$ & $0.4 \%$ & $0.3 \%$ & $0.3 \%$ & $0.6 \%$ \\
\hline$\%$ Other & $0.1 \%$ & $0.1 \%$ & $0.2 \%$ & $0.1 \%$ & $9.9 \%$ & $5.4 \%$ & $1.2 \%$ & $11.6 \%$ & $3.9 \%$ & $5.3 \%$ & $5.4 \%$ & $6.7 \%$ \\
\hline$\%$ Unreported & $0.9 \%$ & $0.7 \%$ & $8.6 \%$ & $2.6 \%$ & & $0.1 \%$ & & $0.0 \%$ & $0.0 \%$ & $0.0 \%$ & & $0.2 \%$ \\
\hline \multicolumn{13}{|c|}{ Average Person Trip Length } \\
\hline ALL & 11.57 & 11.09 & & & 11.79 & 12.68 & 7.49 & 10.58 & 11.92 & 12.35 & 6.48 & 9.24 \\
\hline Zero Vehicle HHs & 7.35 & 6.51 & & & 6.85 & 12.01 & 4.18 & 1.82 & 5.18 & 6.23 & & 3.63 \\
\hline Non-Zero Vehicle HHs & 11.63 & 11.19 & & & 11.87 & 12.69 & 7.54 & 10.89 & 12.08 & 12.44 & 6.48 & 9.30 \\
\hline
\end{tabular}




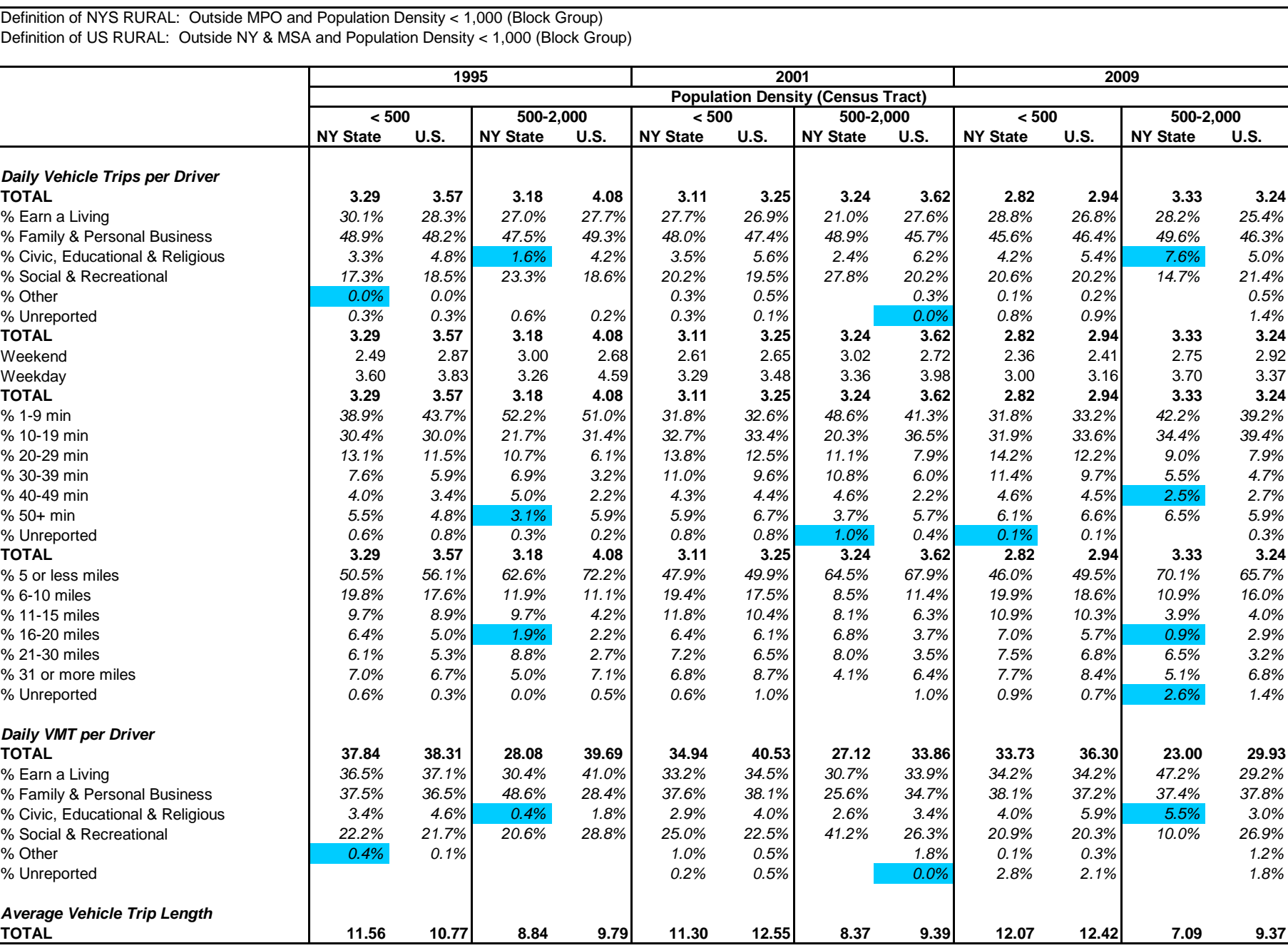




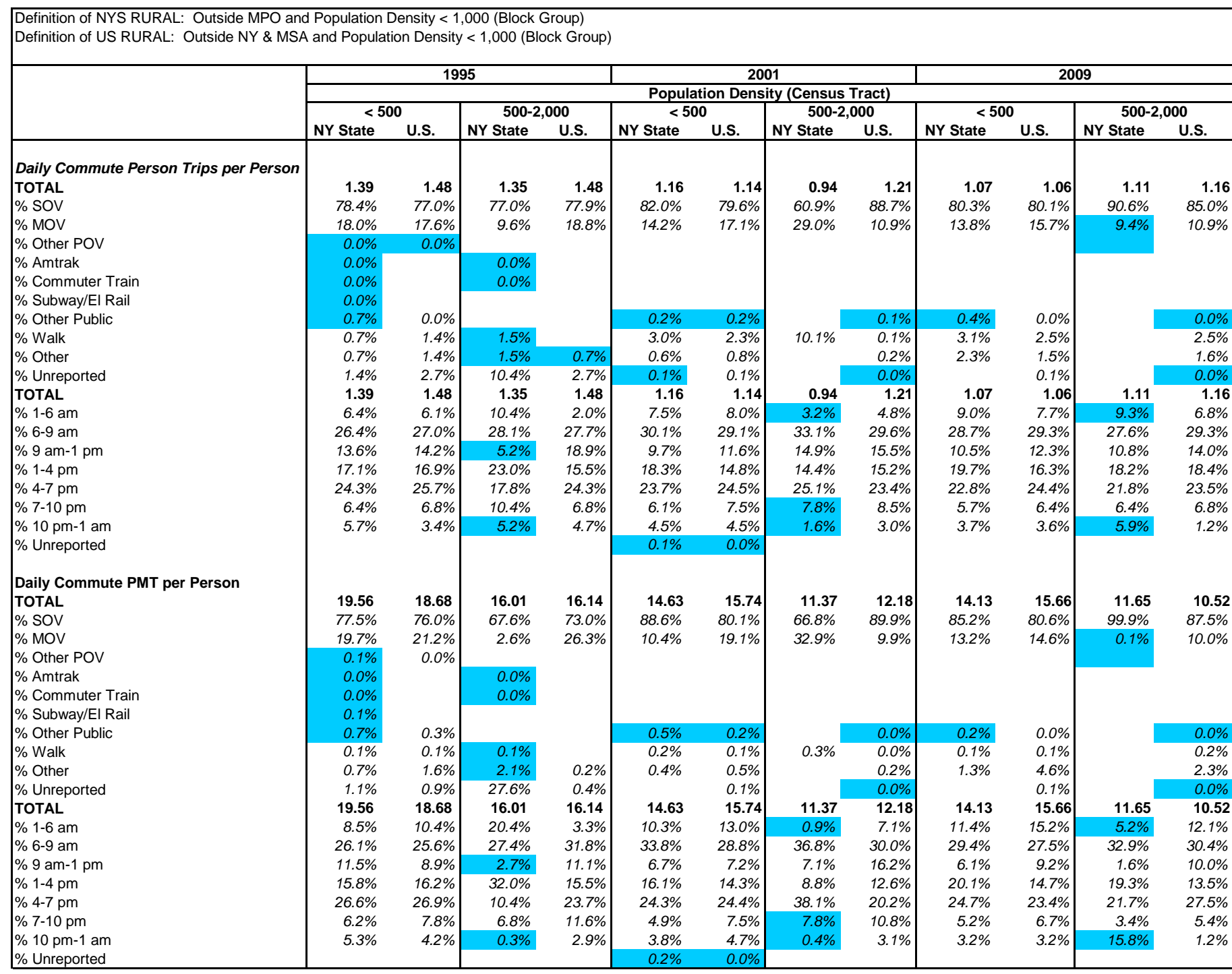




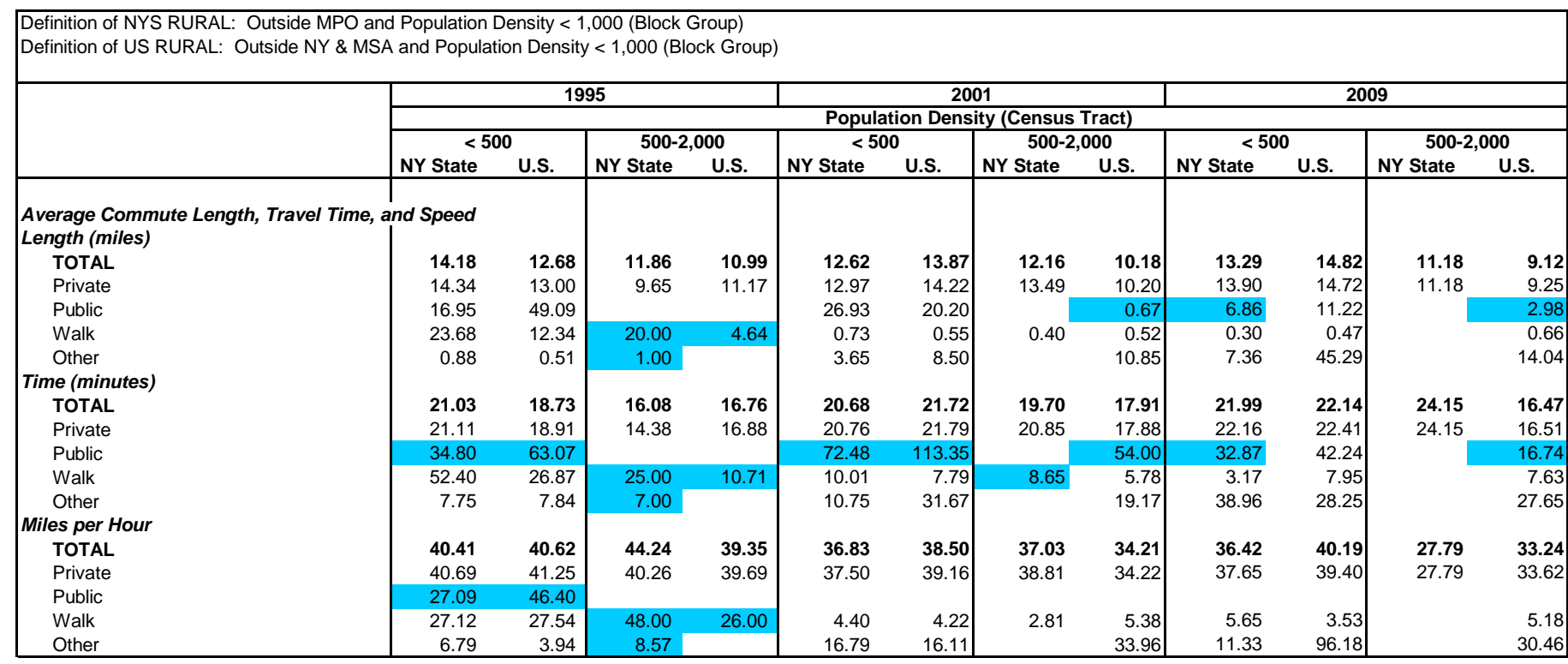




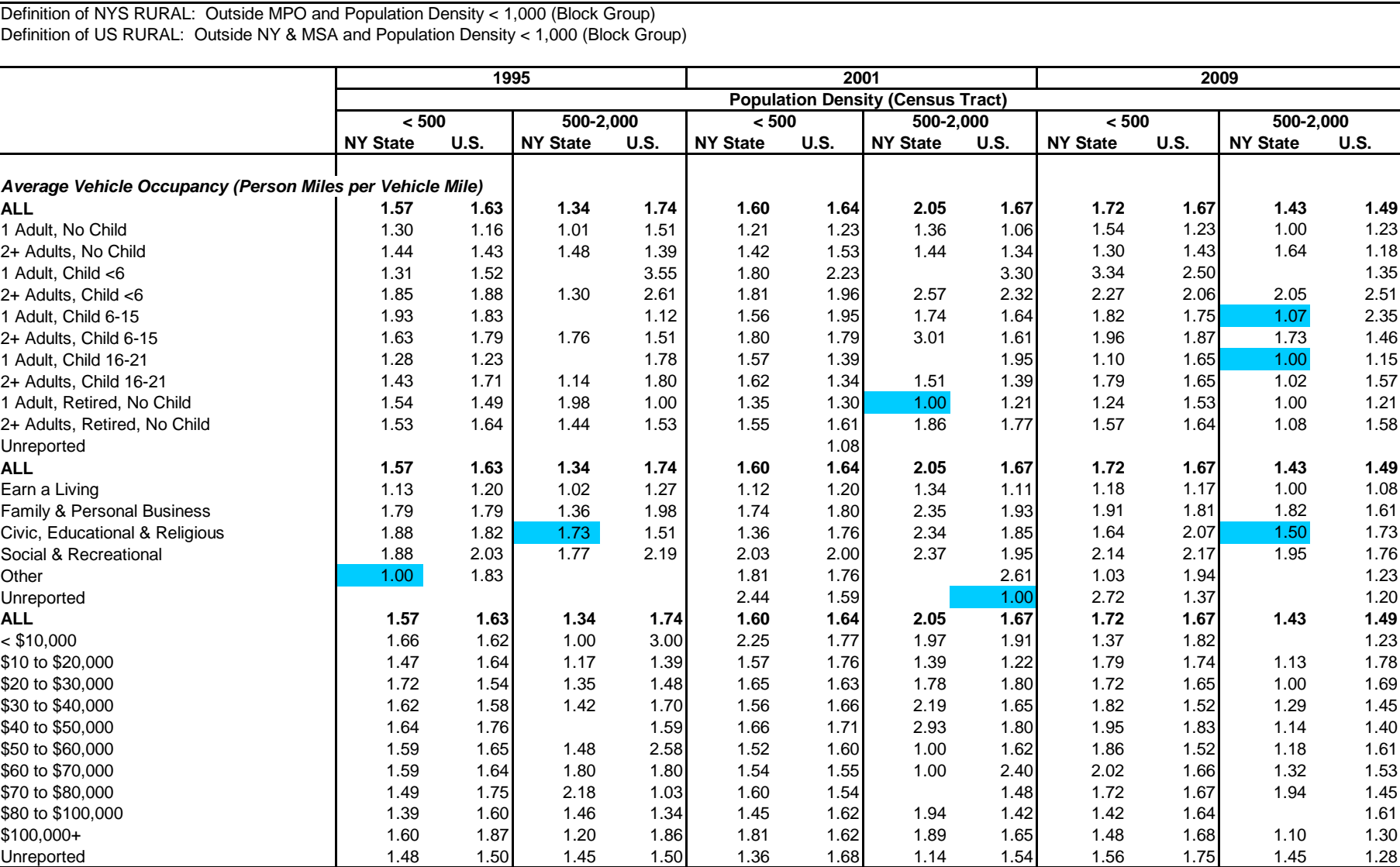




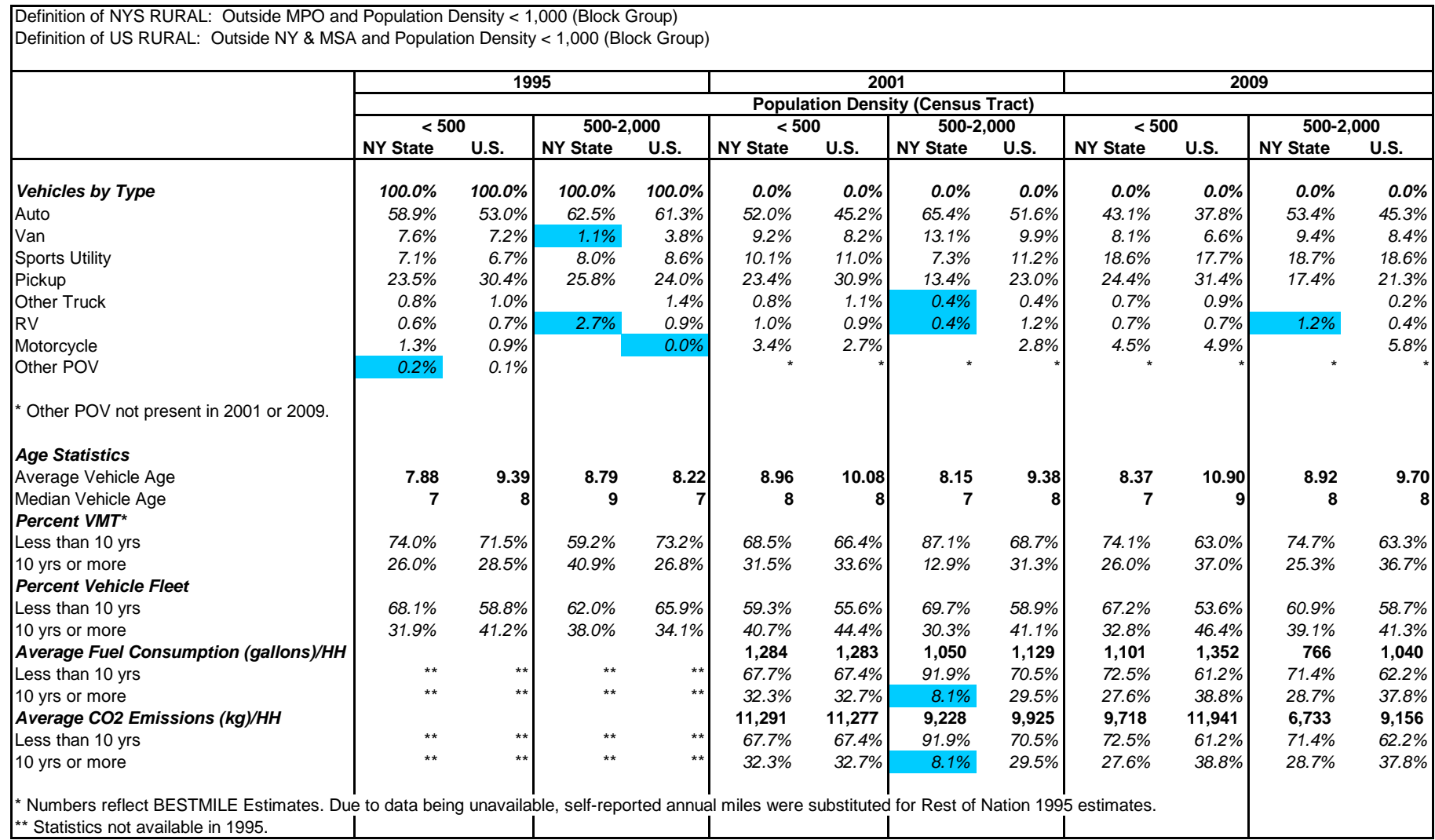




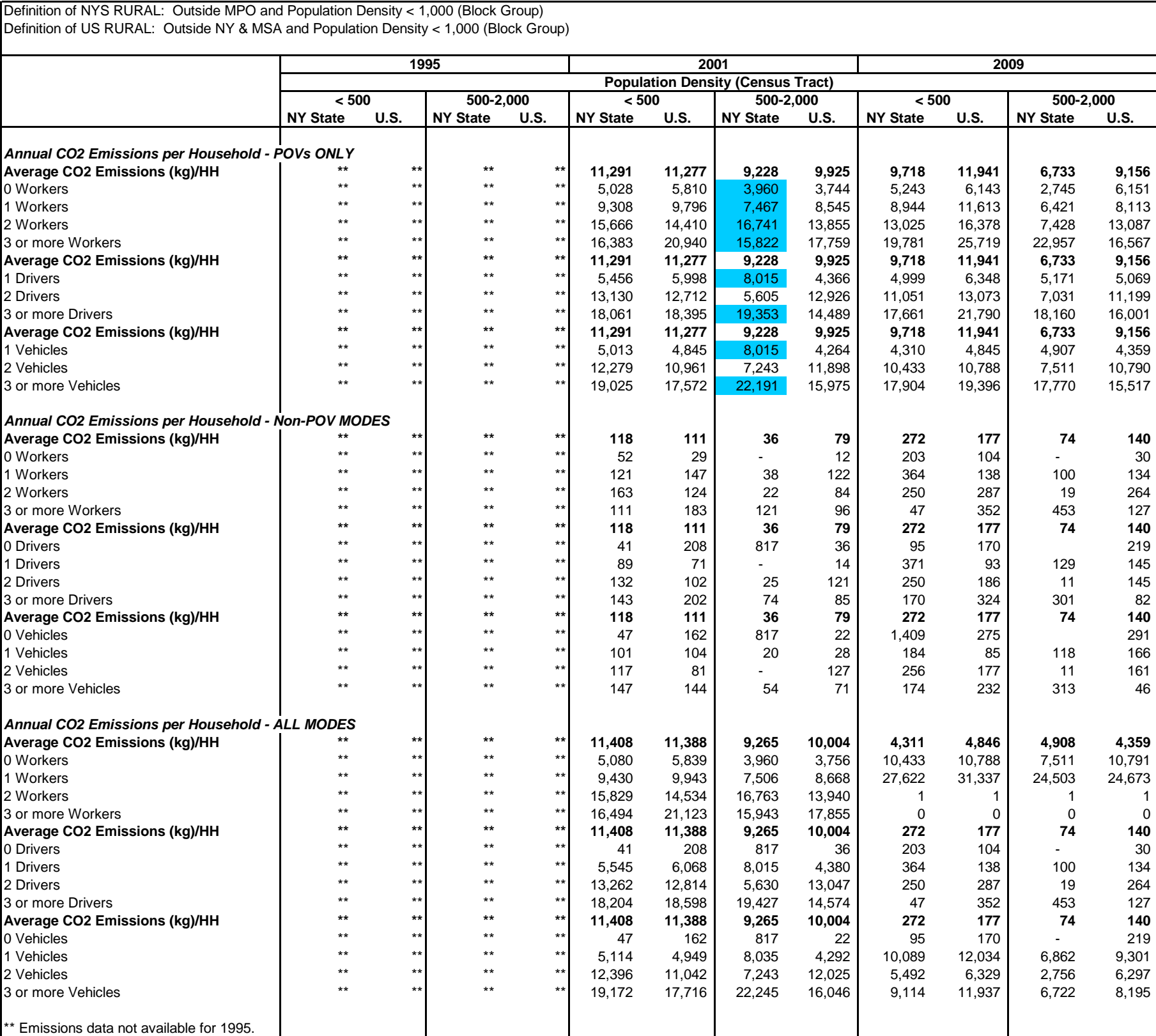




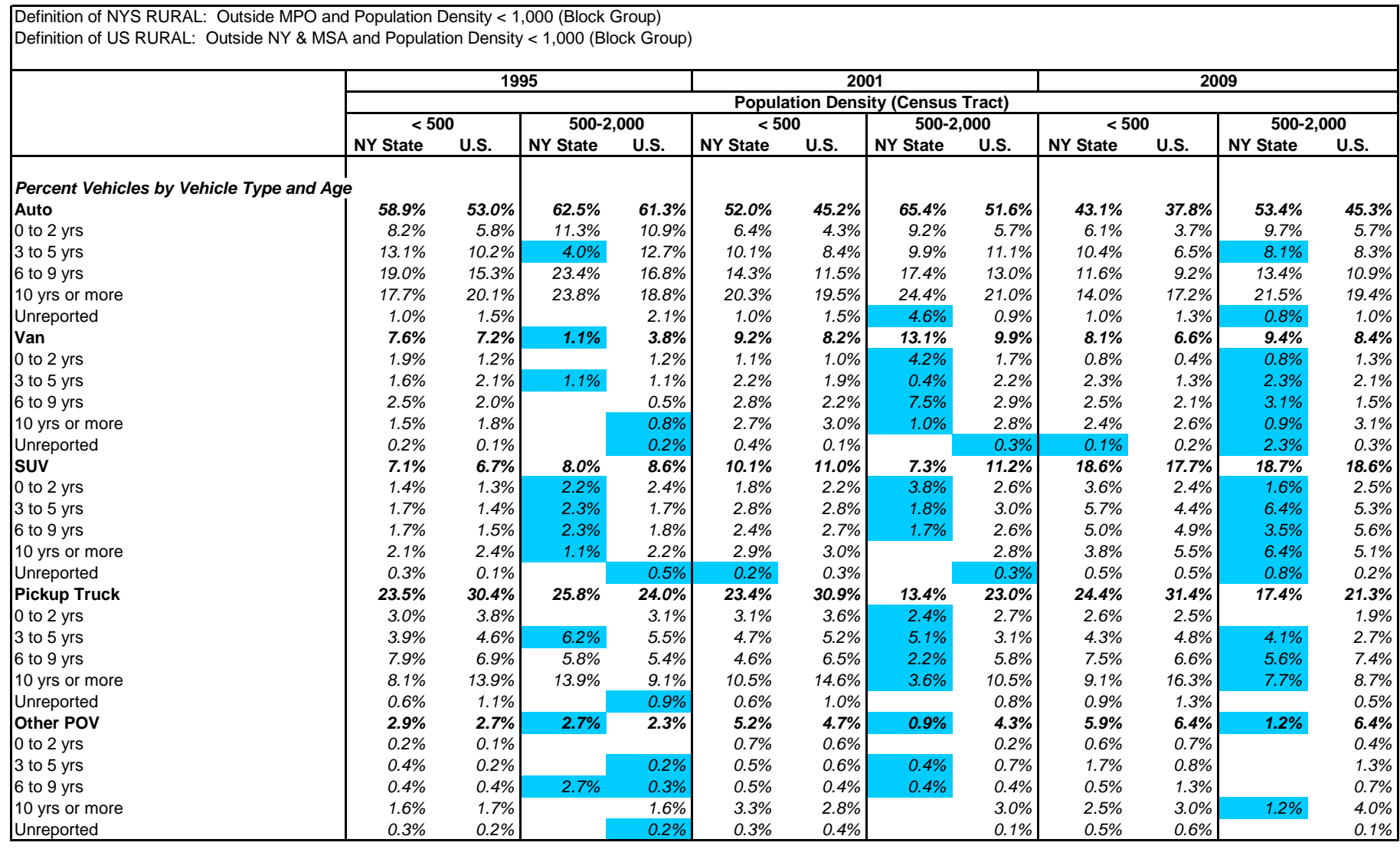




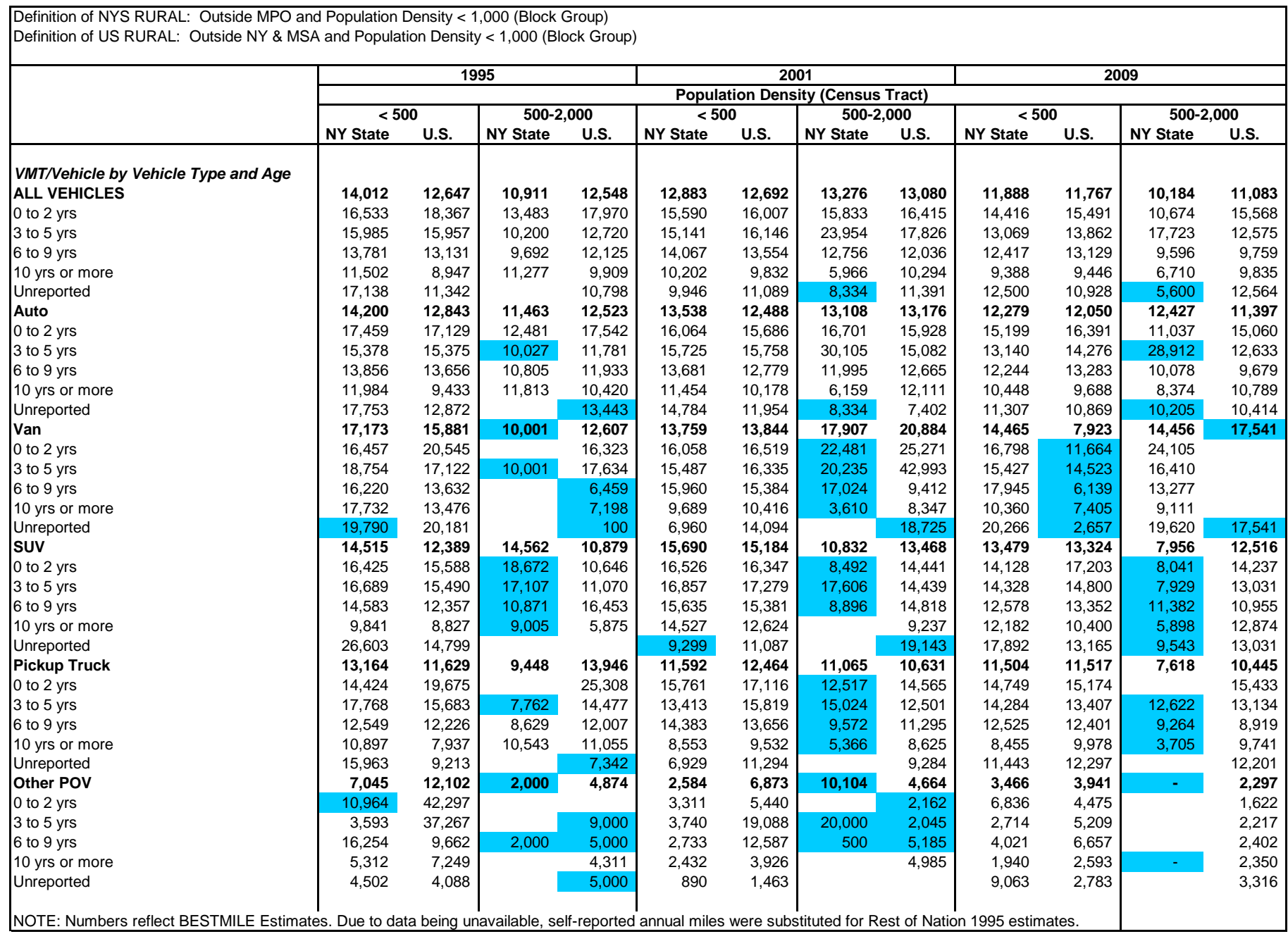




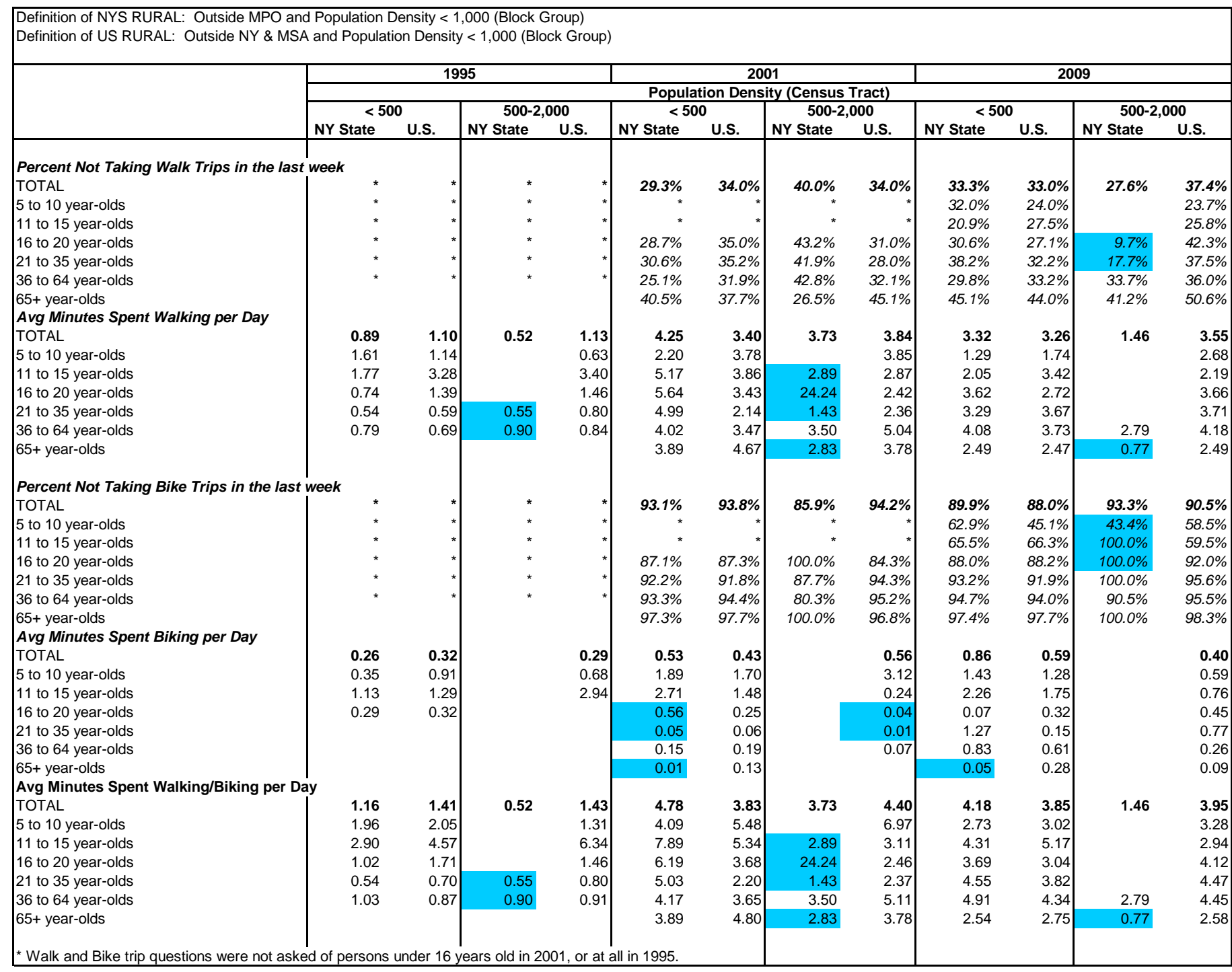


APPENDIX C5A. SUPPLEMENTAL TABLES FOR CHAPTER 5 STANDARD ERRORS 
Definition of NYS RURAL: Outside MPO and Population Density < 1,000 (Block Group) Definition of US RURAL: Outside NY \& MSA and Population Density $<1,000$ (Block Group)

\begin{tabular}{|c|c|c|c|c|c|c|c|c|}
\hline & \multicolumn{4}{|c|}{2001} & \multicolumn{4}{|c|}{2009} \\
\hline & \multicolumn{8}{|c|}{ Population Density (Census Tract) } \\
\hline & \multicolumn{2}{|c|}{$<500$} & \multicolumn{2}{|c|}{$500-2,000$} & \multicolumn{2}{|c|}{$<500$} & \multicolumn{2}{|c|}{$500-2,000$} \\
\hline & NY State & U.S. & NY State & U.S. & NY State & U.S. & NY State & U.S. \\
\hline \multicolumn{9}{|l|}{ General Statistics } \\
\hline Households (000) & 12 & 131 & 4 & 73 & 8 & 174 & 3 & 82 \\
\hline Persons (000) & 30 & 350 & 13 & 176 & 25 & 485 & 8 & 206 \\
\hline Drivers (000) & 29 & 322 & 8 & 145 & 20 & 412 & 6 & 155 \\
\hline Workers (000) & 25 & 286 & 7 & 113 & 19 & 356 & 5 & 137 \\
\hline Vehicles (000) & 31 & 421 & 8 & 146 & 16 & 572 & 5 & 189 \\
\hline Workers per Household & 0.03 & 0.02 & 0.16 & 0.06 & 0.03 & 0.02 & 0.22 & 0.06 \\
\hline Vehicles per Household & 0.04 & 0.02 & 0.14 & 0.06 & 0.02 & 0.03 & 0.18 & 0.06 \\
\hline Vehicles per Driver & 0.02 & 0.02 & 0.07 & 0.04 & 0.02 & 0.02 & 0.11 & 0.05 \\
\hline \multicolumn{9}{|c|}{ Distribution of Households by Household Vehicle Count } \\
\hline ALL & $0.0 \%$ & $0.0 \%$ & $0.0 \%$ & $0.0 \%$ & $0.0 \%$ & $0.0 \%$ & $0.0 \%$ & $0.0 \%$ \\
\hline 0 vehicles & $0.8 \%$ & $0.4 \%$ & $1.7 \%$ & $1.4 \%$ & $0.6 \%$ & $0.4 \%$ & $3.0 \%$ & $0.4 \%$ \\
\hline 1 vehicle & $1.6 \%$ & $0.8 \%$ & $7.8 \%$ & $3.0 \%$ & $1.0 \%$ & $0.8 \%$ & $10.0 \%$ & $3.1 \%$ \\
\hline 2 vehicles & $1.7 \%$ & $0.8 \%$ & $7.4 \%$ & $3.0 \%$ & $0.9 \%$ & $0.8 \%$ & $10.1 \%$ & $2.8 \%$ \\
\hline 3 vehicles & $1.3 \%$ & $0.7 \%$ & $7.5 \%$ & $2.0 \%$ & $0.7 \%$ & $0.7 \%$ & $2.9 \%$ & $1.3 \%$ \\
\hline $4+$ vehicles & $1.0 \%$ & $0.6 \%$ & $1.9 \%$ & $1.6 \%$ & $0.6 \%$ & $0.6 \%$ & $2.1 \%$ & $2.0 \%$ \\
\hline \multicolumn{9}{|c|}{ Distribution of Households by Household Income } \\
\hline ALL & $0.0 \%$ & $0.0 \%$ & $0.0 \%$ & $0.0 \%$ & $0.0 \%$ & $0.0 \%$ & $0.0 \%$ & $0.0 \%$ \\
\hline$<\$ 10,000$ & $0.7 \%$ & $0.5 \%$ & $5.2 \%$ & $1.6 \%$ & $0.9 \%$ & $0.6 \%$ & $3.0 \%$ & $1.1 \%$ \\
\hline$\$ 10$ to $\$ 20,000$ & $1.1 \%$ & $0.6 \%$ & $6.2 \%$ & $2.4 \%$ & $1.1 \%$ & $0.5 \%$ & $5.1 \%$ & $1.9 \%$ \\
\hline$\$ 20$ to $\$ 30,000$ & $1.0 \%$ & $0.6 \%$ & $4.3 \%$ & $1.8 \%$ & $0.9 \%$ & $0.6 \%$ & $9.3 \%$ & $1.8 \%$ \\
\hline$\$ 30$ to $\$ 40,000$ & $1.4 \%$ & $0.7 \%$ & $6.7 \%$ & $2.4 \%$ & $1.1 \%$ & $0.6 \%$ & $1.3 \%$ & $2.3 \%$ \\
\hline$\$ 40$ to $\$ 50,000$ & $0.8 \%$ & $0.5 \%$ & $5.8 \%$ & $1.0 \%$ & $1.1 \%$ & $0.6 \%$ & $6.4 \%$ & $2.1 \%$ \\
\hline$\$ 50$ to $\$ 60,000$ & $0.9 \%$ & $0.5 \%$ & $2.8 \%$ & $2.0 \%$ & $0.7 \%$ & $0.5 \%$ & $9.9 \%$ & $1.0 \%$ \\
\hline$\$ 60$ to $\$ 70,000$ & $0.7 \%$ & $0.4 \%$ & $3.9 \%$ & $1.3 \%$ & $0.6 \%$ & $0.4 \%$ & $7.6 \%$ & $2.0 \%$ \\
\hline$\$ 70$ to $\$ 80,000$ & $0.7 \%$ & $0.3 \%$ & $1.5 \%$ & $1.5 \%$ & $0.5 \%$ & $0.4 \%$ & $6.9 \%$ & $2.0 \%$ \\
\hline$\$ 80$ to $\$ 100,000$ & $0.9 \%$ & $0.3 \%$ & $3.0 \%$ & $1.2 \%$ & $0.7 \%$ & $0.4 \%$ & & $0.7 \%$ \\
\hline$\$ 100,000_{+}$ & $0.8 \%$ & $0.4 \%$ & $4.4 \%$ & $1.2 \%$ & $0.8 \%$ & $0.5 \%$ & $2.1 \%$ & $1.6 \%$ \\
\hline Unreported & $0.9 \%$ & $0.5 \%$ & $3.9 \%$ & $1.2 \%$ & $0.7 \%$ & $0.4 \%$ & $2.8 \%$ & $0.7 \%$ \\
\hline \multicolumn{9}{|c|}{ Average Annual Miles Driven per Driver } \\
\hline & \multicolumn{2}{|c|}{ All Rural NYS } & \multicolumn{2}{|c|}{ All Rural U.S. } & \multicolumn{2}{|c|}{ All Rural NYS } & \multicolumn{2}{|c|}{ All Rural U.S. } \\
\hline ALL & \multirow{2}{*}{\multicolumn{2}{|c|}{398}} & \multirow{2}{*}{\multicolumn{2}{|c|}{298}} & \multirow{2}{*}{\multicolumn{2}{|c|}{456}} & \multirow{2}{*}{\multicolumn{2}{|c|}{367}} \\
\hline Male & & & & & & & & \\
\hline Female & \multicolumn{2}{|c|}{382} & \multicolumn{2}{|c|}{242} & \multicolumn{2}{|c|}{486} & \multicolumn{2}{|c|}{452} \\
\hline Licensing Rate & $0.8 \%$ & $0.4 \%$ & $4.3 \%$ & $1.1 \%$ & $1.1 \%$ & $0.4 \%$ & $5.8 \%$ & $1.0 \%$ \\
\hline$\%$ Male Drivers/Male $16+$ & $0.7 \%$ & $0.4 \%$ & $4.4 \%$ & $1.0 \%$ & $1.7 \%$ & $0.6 \%$ & $10.2 \%$ & $1.3 \%$ \\
\hline$\%$ Female Drivers/Female $16+$ & $1.2 \%$ & $0.5 \%$ & $7.7 \%$ & $1.8 \%$ & $1.0 \%$ & $0.7 \%$ & $7.1 \%$ & $1.5 \%$ \\
\hline
\end{tabular}


Definition of NYS RURAL: Outside MPO and Population Density $<1,000$ (Block Group)

Definition of US RURAL: Outside NY \& MSA and Population Density < 1,000 (Block Group)

\begin{tabular}{|c|c|c|c|c|c|c|c|c|}
\hline & \multicolumn{4}{|c|}{2001} & \multicolumn{4}{|c|}{2009} \\
\hline & \multicolumn{8}{|c|}{ Population Density (Census Tract) } \\
\hline & \multicolumn{2}{|c|}{$<500$} & \multicolumn{2}{|c|}{$500-2,000$} & \multicolumn{2}{|c|}{$<500$} & \multicolumn{2}{|c|}{$500-2,000$} \\
\hline & NY State & U.S. & NY State & U.S. & NY State & U.S. & NY State & U.S. \\
\hline Daily Person Trips per Person & & & & & & & & \\
\hline TOTAL & 0.07 & 0.04 & 0.54 & 0.14 & 0.07 & 0.05 & 0.51 & 0.12 \\
\hline Male & 0.09 & 0.05 & 0.50 & 0.17 & 0.08 & 0.07 & 0.58 & 0.16 \\
\hline Female & 0.10 & 0.05 & 0.67 & 0.18 & 0.09 & 0.07 & 0.65 & 0.14 \\
\hline TOTAL & 0.07 & 0.04 & 0.54 & 0.14 & 0.07 & 0.05 & 0.51 & 0.12 \\
\hline $5-15$ years & 0.16 & 0.09 & 1.33 & 0.28 & 0.17 & 0.09 & 0.29 & 0.27 \\
\hline $16-19$ years & 0.32 & 0.14 & 0.94 & 0.38 & 0.24 & 0.15 & 3.10 & 0.41 \\
\hline $20-34$ years & 0.18 & 0.10 & 1.04 & 0.34 & 0.14 & 0.12 & 0.77 & 0.34 \\
\hline $35-54$ years & 0.13 & 0.07 & 0.71 & 0.26 & 0.11 & 0.09 & 0.73 & 0.23 \\
\hline $55-64$ years & 0.18 & 0.11 & 0.94 & 0.30 & 0.13 & 0.13 & 1.03 & 0.26 \\
\hline $65+$ years & 0.18 & 0.09 & 1.09 & 0.25 & 0.12 & 0.08 & 0.49 & 0.28 \\
\hline Unreported & 0.60 & 0.30 & 2.32 & 1.03 & & & & \\
\hline TOTAL & 0.07 & 0.04 & 0.54 & 0.14 & 0.07 & 0.05 & 0.51 & 0.12 \\
\hline$\%$ POV & $0.7 \%$ & $0.4 \%$ & $2.9 \%$ & $0.9 \%$ & $0.7 \%$ & $0.4 \%$ & $6.3 \%$ & $1.0 \%$ \\
\hline$\%$ Public & $0.1 \%$ & $0.0 \%$ & & $0.1 \%$ & $0.1 \%$ & $0.0 \%$ & & $0.1 \%$ \\
\hline$\%$ Walk & $0.6 \%$ & $0.3 \%$ & $2.1 \%$ & $0.7 \%$ & $0.6 \%$ & $0.3 \%$ & $1.8 \%$ & $0.9 \%$ \\
\hline$\%$ Other & $0.4 \%$ & $0.3 \%$ & $1.8 \%$ & $0.5 \%$ & $0.5 \%$ & $0.3 \%$ & $6.1 \%$ & $0.4 \%$ \\
\hline$\%$ Unreported & $0.0 \%$ & $0.0 \%$ & & $0.0 \%$ & $0.1 \%$ & $0.0 \%$ & & $0.2 \%$ \\
\hline TOTAL & 0.07 & 0.04 & 0.54 & 0.14 & 0.07 & 0.05 & 0.51 & 0.12 \\
\hline$\%$ SOV & $1.3 \%$ & $0.7 \%$ & $7.1 \%$ & $2.2 \%$ & $1.2 \%$ & $0.9 \%$ & $8.5 \%$ & $2.8 \%$ \\
\hline$\%$ MOV & $1.3 \%$ & $0.8 \%$ & $8.9 \%$ & $2.3 \%$ & $1.3 \%$ & $0.9 \%$ & $12.3 \%$ & $2.9 \%$ \\
\hline$\%$ Amtrak & & & & $0.0 \%$ & $0.0 \%$ & $0.0 \%$ & & \\
\hline$\%$ Commuter Train & $0.0 \%$ & & & & & & & \\
\hline$\%$ Subway/EI Rail & $0.0 \%$ & $0.0 \%$ & & $0.1 \%$ & & $0.0 \%$ & & \\
\hline$\%$ Other Public & $0.0 \%$ & $0.0 \%$ & & $0.1 \%$ & $0.1 \%$ & $0.0 \%$ & & $0.0 \%$ \\
\hline$\%$ Walk & $0.6 \%$ & $0.3 \%$ & $2.1 \%$ & $0.7 \%$ & $0.6 \%$ & $0.3 \%$ & $1.8 \%$ & $0.9 \%$ \\
\hline$\%$ Other & $0.4 \%$ & $0.3 \%$ & $1.8 \%$ & $0.5 \%$ & $0.5 \%$ & $0.3 \%$ & $6.1 \%$ & $0.4 \%$ \\
\hline$\%$ Unreported & $0.0 \%$ & $0.0 \%$ & & $0.0 \%$ & $0.1 \%$ & $0.0 \%$ & & $0.2 \%$ \\
\hline TOTAL & 0.07 & 0.04 & 0.54 & 0.14 & 0.07 & 0.05 & 0.51 & 0.12 \\
\hline$\%$ Earn a Living & $0.7 \%$ & $0.5 \%$ & $4.1 \%$ & $1.3 \%$ & $0.9 \%$ & $0.6 \%$ & $4.6 \%$ & $1.4 \%$ \\
\hline$\%$ Family \& Pers & $1.2 \%$ & $0.5 \%$ & $4.8 \%$ & $1.3 \%$ & $1.0 \%$ & $0.7 \%$ & $6.7 \%$ & $2.3 \%$ \\
\hline$\%$ Civic, Educational \& Religious & $0.6 \%$ & $0.4 \%$ & $3.2 \%$ & $1.4 \%$ & $0.6 \%$ & $0.4 \%$ & $6.8 \%$ & $0.8 \%$ \\
\hline$\%$ Social \& Recreational & $1.0 \%$ & $0.5 \%$ & $6.3 \%$ & $1.3 \%$ & $1.1 \%$ & $0.5 \%$ & $7.3 \%$ & $2.8 \%$ \\
\hline$\%$ Other & $0.1 \%$ & $0.1 \%$ & & $0.4 \%$ & $0.1 \%$ & $0.1 \%$ & $0.4 \%$ & $0.2 \%$ \\
\hline$\%$ Unreported & $0.1 \%$ & $0.0 \%$ & & $0.1 \%$ & $0.2 \%$ & $0.1 \%$ & $1.5 \%$ & $0.3 \%$ \\
\hline TOTAL & 0.07 & 0.04 & 0.54 & 0.14 & 0.07 & 0.05 & 0.51 & 0.12 \\
\hline Weekend & 0.14 & 0.09 & 0.35 & 0.25 & 0.13 & 0.08 & 0.91 & 0.29 \\
\hline Weekday & 0.08 & 0.04 & 0.80 & 0.17 & 0.08 & 0.06 & 0.52 & 0.15 \\
\hline
\end{tabular}




\begin{tabular}{|c|c|c|c|c|c|c|c|c|}
\hline & $\begin{array}{l}\text { and } \mathrm{Po} \\
\mathrm{MSA} \text { an }\end{array}$ & ion De & $\begin{array}{l}n s i t y<1, \\
n \text { Density }\end{array}$ & $\begin{array}{l}\text { lock Gro } \\
0 \text { (Block }\end{array}$ & $\begin{array}{l}\text { oup) } \\
\text { (Group) }\end{array}$ & & & \\
\hline & \multicolumn{4}{|c|}{2001} & \multirow{2}{*}{\multicolumn{4}{|c|}{2009}} \\
\hline & \multicolumn{7}{|c|}{ Population Density (Census Tract) } & \\
\hline & \multirow{2}{*}{\multicolumn{2}{|c|}{\begin{tabular}{l}
\multicolumn{2}{c}{$<00$} \\
NY State
\end{tabular}}} & \multicolumn{2}{|c|}{$500-2,000$} & \multicolumn{2}{|c|}{$<500$} & \multicolumn{2}{|c|}{$500-2,000$} \\
\hline & & U.S. & NY State & U.S. & NY State & U.S. & NY State & U.S. \\
\hline \multicolumn{9}{|l|}{ Daily Person Trips per Person } \\
\hline TOTAL & 0.07 & 0.04 & 0.54 & 0.14 & 0.07 & 0.05 & 0.51 & 0.12 \\
\hline$\% 1-9 \min$ & $0.9 \%$ & $0.5 \%$ & $4.4 \%$ & $1.9 \%$ & $1.0 \%$ & $0.7 \%$ & $9.3 \%$ & $2.3 \%$ \\
\hline$\% 10-19 \min$ & $1.0 \%$ & $0.5 \%$ & $3.1 \%$ & $1.8 \%$ & $0.9 \%$ & $0.6 \%$ & $6.9 \%$ & $1.7 \%$ \\
\hline$\% 20-29 \mathrm{~min}$ & $0.6 \%$ & $0.3 \%$ & $1.6 \%$ & $0.8 \%$ & $0.6 \%$ & $0.3 \%$ & $2.9 \%$ & $0.7 \%$ \\
\hline$\%$ 30-39 min & $0.6 \%$ & $0.3 \%$ & $4.0 \%$ & $0.6 \%$ & $0.8 \%$ & $0.3 \%$ & $2.8 \%$ & $0.7 \%$ \\
\hline$\% 40-49 \mathrm{~min}$ & $0.4 \%$ & $0.2 \%$ & $3.4 \%$ & $0.5 \%$ & $0.4 \%$ & $0.2 \%$ & $1.2 \%$ & $0.4 \%$ \\
\hline$\% 50+\min$ & $0.4 \%$ & $0.3 \%$ & $1.4 \%$ & $0.8 \%$ & $0.5 \%$ & $0.3 \%$ & $3.4 \%$ & $0.8 \%$ \\
\hline$\%$ Unreported & $0.4 \%$ & $0.1 \%$ & $1.1 \%$ & $0.3 \%$ & $0.1 \%$ & $0.0 \%$ & $1.5 \%$ & $0.1 \%$ \\
\hline TOTAL & 0.07 & 0.04 & 0.54 & 0.14 & 0.07 & 0.05 & 0.51 & 0.12 \\
\hline$\% 5$ or less miles & $1.1 \%$ & $0.6 \%$ & $5.1 \%$ & $1.8 \%$ & $1.1 \%$ & $0.7 \%$ & $5.7 \%$ & $2.2 \%$ \\
\hline$\% 6-10$ miles & $0.8 \%$ & $0.4 \%$ & $3.9 \%$ & $1.0 \%$ & $0.9 \%$ & $0.5 \%$ & $3.6 \%$ & $1.5 \%$ \\
\hline$\% 11-15$ miles & $0.7 \%$ & $0.3 \%$ & $3.0 \%$ & $0.8 \%$ & $0.6 \%$ & $0.4 \%$ & $3.2 \%$ & $1.4 \%$ \\
\hline$\% 16-20$ miles & $0.4 \%$ & $0.3 \%$ & $1.8 \%$ & $0.6 \%$ & $0.6 \%$ & $0.3 \%$ & $0.6 \%$ & $0.7 \%$ \\
\hline$\% 21-30$ miles & $0.5 \%$ & $0.2 \%$ & $2.7 \%$ & $0.5 \%$ & $0.5 \%$ & $0.3 \%$ & $2.8 \%$ & $0.5 \%$ \\
\hline$\% 31$ or more miles & $0.5 \%$ & $0.3 \%$ & $1.3 \%$ & $0.9 \%$ & $0.6 \%$ & $0.4 \%$ & $2.3 \%$ & $0.8 \%$ \\
\hline$\%$ Unreported & $0.3 \%$ & $0.1 \%$ & $0.1 \%$ & $0.5 \%$ & $0.3 \%$ & $0.1 \%$ & $3.4 \%$ & $0.7 \%$ \\
\hline \multicolumn{9}{|l|}{ Daily PMT per Pers } \\
\hline TOTAL & 2.76 & 1.18 & 5.24 & 6.21 & 1.63 & 1.35 & 4.69 & 2.24 \\
\hline$\% \mathrm{POV}$ & $5.5 \%$ & $1.7 \%$ & $1.2 \%$ & $9.5 \%$ & $1.0 \%$ & $0.8 \%$ & $3.8 \%$ & $2.2 \%$ \\
\hline$\%$ Public & $0.1 \%$ & $0.0 \%$ & & $0.0 \%$ & $0.1 \%$ & $0.1 \%$ & & $0.0 \%$ \\
\hline$\%$ Walk & $0.1 \%$ & $0.0 \%$ & $0.3 \%$ & $0.1 \%$ & $0.0 \%$ & $0.0 \%$ & $0.2 \%$ & $0.1 \%$ \\
\hline$\%$ Other & $5.5 \%$ & $1.7 \%$ & $1.1 \%$ & $9.5 \%$ & $0.9 \%$ & $0.8 \%$ & $3.8 \%$ & $2.2 \%$ \\
\hline$\%$ Unreported & & $0.0 \%$ & & $0.0 \%$ & $0.1 \%$ & $0.0 \%$ & & $0.1 \%$ \\
\hline TOTAL & 2.76 & 1.18 & 5.24 & 6.21 & 1.63 & 1.35 & 4.69 & 2.24 \\
\hline$\%$ sov & $2.7 \%$ & $1.3 \%$ & $8.4 \%$ & $6.0 \%$ & $2.2 \%$ & $1.4 \%$ & $12.3 \%$ & $4.2 \%$ \\
\hline$\%$ MOV & $3.5 \%$ & $1.6 \%$ & $8.9 \%$ & $6.7 \%$ & $2.4 \%$ & $1.5 \%$ & $13.9 \%$ & $4.0 \%$ \\
\hline$\%$ Amtrak & & & & $0.4 \%$ & $0.1 \%$ & $0.0 \%$ & & \\
\hline$\%$ Commuter Train & $0.0 \%$ & & & & & & & \\
\hline$\%$ Subway/El Rail & $0.0 \%$ & $0.0 \%$ & & $0.0 \%$ & & $0.0 \%$ & & \\
\hline$\%$ Other Public & $0.1 \%$ & $0.0 \%$ & & $0.0 \%$ & $0.1 \%$ & $0.1 \%$ & & $0.0 \%$ \\
\hline$\%$ Walk & $0.1 \%$ & $0.0 \%$ & $0.3 \%$ & $0.1 \%$ & $0.0 \%$ & $0.0 \%$ & $0.2 \%$ & $0.1 \%$ \\
\hline$\%$ Other & $5.5 \%$ & $1.7 \%$ & $1.1 \%$ & $9.6 \%$ & $0.9 \%$ & $0.8 \%$ & $3.8 \%$ & $2.2 \%$ \\
\hline$\%$ Unreported & & $0.0 \%$ & & $0.0 \%$ & $0.1 \%$ & $0.0 \%$ & & $0.1 \%$ \\
\hline TOTAL & 2.76 & 1.18 & 5.24 & 6.21 & 1.63 & 1.35 & 4.69 & 2.24 \\
\hline$\%$ Earn a Living & $0.0 \%$ & $0.0 \%$ & $0.1 \%$ & $0.0 \%$ & $1.8 \%$ & $1.4 \%$ & $10.7 \%$ & $2.8 \%$ \\
\hline$\%$ Family \& Personal Business & $0.0 \%$ & $0.0 \%$ & $0.1 \%$ & $0.1 \%$ & $1.9 \%$ & $1.1 \%$ & $7.7 \%$ & $3.5 \%$ \\
\hline$\%$ Civic, Educational \& Religious & $0.0 \%$ & $0.0 \%$ & $0.0 \%$ & $0.0 \%$ & $0.7 \%$ & $0.8 \%$ & $5.2 \%$ & $0.6 \%$ \\
\hline$\%$ Social \& Recreational & $0.0 \%$ & $0.0 \%$ & $0.1 \%$ & $0.1 \%$ & $2.4 \%$ & $1.1 \%$ & $7.2 \%$ & $3.9 \%$ \\
\hline$\%$ Other & $0.0 \%$ & $0.0 \%$ & & $0.1 \%$ & $0.8 \%$ & $0.4 \%$ & $0.0 \%$ & $1.5 \%$ \\
\hline$\%$ Unreported & $0.0 \%$ & $0.0 \%$ & & $0.0 \%$ & $2.1 \%$ & $0.3 \%$ & $0.0 \%$ & $0.6 \%$ \\
\hline rson Trip L & & & & & & & & \\
\hline TOTAL & 0.73 & 0.32 & 0.97 & 1.41 & 0.50 & 0.34 & 0.94 & 0.66 \\
\hline
\end{tabular}


Definition of NYS RURAL: Outside MPO and Population Density $<1,000$ (Block Group) Definition of US RURAL: Outside NY \& MSA and Population Density $<1,000$ (Block Group)

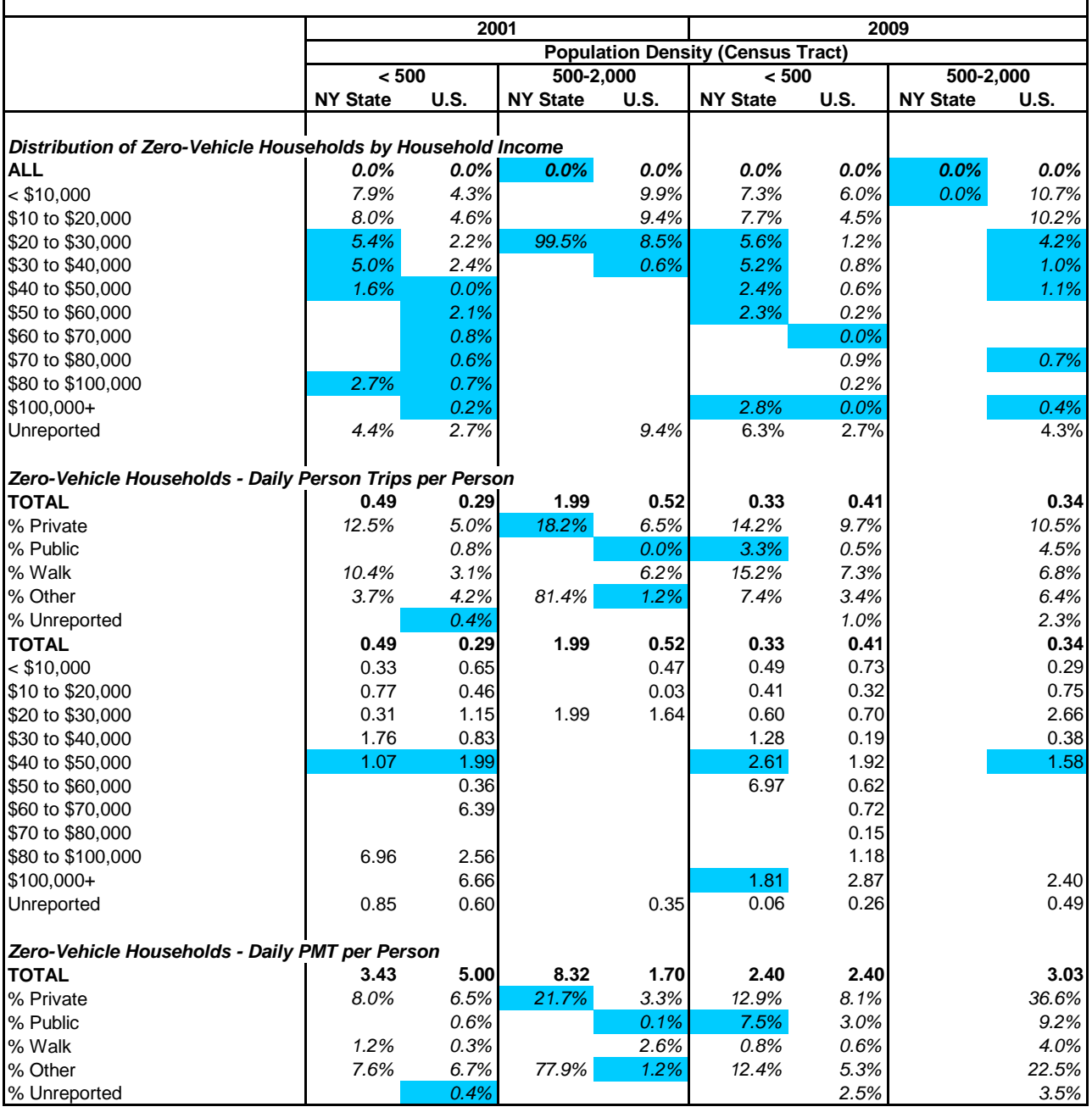


Definition of NYS RURAL: Outside MPO and Population Density < 1,000 (Block Group)

Definition of US RURAL: Outside NY \& MSA and Population Density < 1,000 (Block Group)

\begin{tabular}{|c|c|c|c|c|c|c|c|c|}
\hline & \multicolumn{4}{|c|}{2001} & \multicolumn{4}{|c|}{2009} \\
\hline & \multicolumn{8}{|c|}{ Population Density (Census Tract) } \\
\hline & \multicolumn{2}{|c|}{$\begin{array}{c}<500 \\
Y \text { S }\end{array}$} & \multirow{2}{*}{\multicolumn{2}{|c|}{\begin{tabular}{|c|c|}
\multicolumn{2}{|c}{$500-2,000$} \\
NY State U.S.
\end{tabular}}} & \multicolumn{2}{|c|}{$<500$} & \multicolumn{2}{|c|}{$500-2,000$} \\
\hline & NY State & U.S. & & & NY State & U.S. & NY State & U.S. \\
\hline \multicolumn{9}{|c|}{ Zero-Vehicle Households - Daily PMT per Person } \\
\hline TOTAL & 3.43 & 5.00 & 8.32 & 1.70 & 2.40 & 2.40 & & 3.03 \\
\hline$<\$ 10,000$ & 2.51 & 2.67 & & 2.22 & 9.98 & 3.97 & & 4.95 \\
\hline$\$ 10$ to $\$ 20,000$ & 9.96 & 4.22 & & 0.11 & 6.05 & 2.81 & & 3.28 \\
\hline$\$ 20$ to $\$ 30,000$ & 1.87 & 49.61 & 8.32 & 1.71 & 6.33 & 3.21 & & 0.39 \\
\hline$\$ 30$ to $\$ 40,000$ & 9.03 & 17.35 & & & 5.43 & 11.74 & & 0.64 \\
\hline$\$ 40$ to $\$ 50,000$ & 42.87 & 3.98 & & & 0.40 & 9.30 & & 1.85 \\
\hline$\$ 50$ to $\$ 60,000$ & & 35.18 & & & 14.21 & 48.43 & & \\
\hline$\$ 60$ to $\$ 70,000$ & & 14.96 & & & & 5.66 & & \\
\hline$\$ 70$ to $\$ 80,000$ & & & & & & 1.04 & & \\
\hline$\$ 80$ to $\$ 100,000$ & 43.42 & 2.93 & & & & 3.29 & & \\
\hline$\$ 100,000+$ & & 421.53 & & & 1.5 & 2.9 & & 9.6 \\
\hline Unreported & 0.41 & 9.03 & & 0.35 & 1.19 & 1.81 & & 2.43 \\
\hline \multicolumn{9}{|c|}{ Non-Zero-Vehicle Households - Daily Person Trips per Person } \\
\hline TOTAL & 0.07 & 0.05 & 0.54 & 0.15 & 0.07 & 0.05 & 0.53 & 0.12 \\
\hline$\%$ Private & $0.7 \%$ & $0.4 \%$ & $2.5 \%$ & $0.9 \%$ & $0.7 \%$ & $0.4 \%$ & $6.3 \%$ & $1.0 \%$ \\
\hline$\%$ Public & $0.1 \%$ & $0.0 \%$ & & $0.1 \%$ & $0.0 \%$ & $0.0 \%$ & & $0.0 \%$ \\
\hline$\%$ Walk & $0.6 \%$ & $0.3 \%$ & $2.2 \%$ & $0.7 \%$ & $0.5 \%$ & $0.3 \%$ & $1.8 \%$ & $0.9 \%$ \\
\hline$\%$ Other & $0.4 \%$ & $0.2 \%$ & $1.4 \%$ & $0.5 \%$ & $0.6 \%$ & $0.3 \%$ & $6.1 \%$ & $0.3 \%$ \\
\hline$\%$ Unreported & $0.0 \%$ & $0.0 \%$ & & $0.0 \%$ & $0.1 \%$ & $0.0 \%$ & & $0.2 \%$ \\
\hline \multicolumn{9}{|c|}{ useholds - Daily PMT per Person } \\
\hline TOTAL & 2.83 & 1.21 & 5.30 & 6.51 & 1.63 & 1.38 & 4.79 & 2.28 \\
\hline$\%$ Private & $5.5 \%$ & $1.7 \%$ & $1.0 \%$ & $9.6 \%$ & $1.0 \%$ & $0.8 \%$ & $3.8 \%$ & $2.2 \%$ \\
\hline$\%$ Public & $0.1 \%$ & $0.0 \%$ & & $0.0 \%$ & $0.0 \%$ & $0.1 \%$ & & $0.0 \%$ \\
\hline$\%$ Walk & $0.1 \%$ & $0.0 \%$ & $0.3 \%$ & $0.1 \%$ & $0.0 \%$ & $0.0 \%$ & $0.2 \%$ & $0.1 \%$ \\
\hline$\%$ Other & $5.6 \%$ & $1.7 \%$ & $0.9 \%$ & $9.6 \%$ & $1.0 \%$ & $0.8 \%$ & $3.8 \%$ & $2.2 \%$ \\
\hline$\%$ Unreported & & $0.0 \%$ & & $0.0 \%$ & $0.1 \%$ & $0.0 \%$ & & $0.1 \%$ \\
\hline \multicolumn{9}{|c|}{ Average Person Trip Length } \\
\hline ALL & 0.73 & 0.32 & 0.97 & 1.41 & 0.50 & 0.34 & 0.94 & 0.66 \\
\hline Zero Vehicle HHs & 1.18 & 1.84 & 0.02 & 0.33 & 1.28 & 0.61 & & 1.79 \\
\hline Non-Zero Vehicle HHs & 0.74 & 0.33 & 0.98 & 1.45 & 0.50 & 0.35 & 0.94 & 0.66 \\
\hline
\end{tabular}


Definition of NYS RURAL: Outside MPO and Population Density < 1,000 (Block Group) Definition of US RURAL: Outside NY \& MSA and Population Density < 1,000 (Block Group)

\begin{tabular}{|c|c|c|c|c|c|c|c|c|}
\hline & \multicolumn{4}{|c|}{2001} & \multicolumn{4}{|c|}{2009} \\
\hline & \multicolumn{8}{|c|}{ Population Density (Census Tract) } \\
\hline & \multicolumn{2}{|c|}{$<500$} & \multicolumn{2}{|c|}{$500-2,000$} & \multicolumn{2}{|c|}{$<500$} & \multicolumn{2}{|c|}{$500-2,000$} \\
\hline & NY State & U.S. & NY State & U.S. & NY State & U.S. & NY State & U.S. \\
\hline \multicolumn{9}{|l|}{ Daily Vehicle Trips per Driver } \\
\hline TOTAL & 0.08 & 0.04 & 0.26 & 0.14 & 0.06 & $\begin{array}{r}0.04 \\
0\end{array}$ & $\begin{array}{r}0.42 \\
7\end{array}$ & $\begin{array}{r}0.13 \\
160\end{array}$ \\
\hline$\%$ Earn a Living & $1.0 \%$ & $0.6 \%$ & $4.6 \%$ & $1.6 \%$ & $1.1 \%$ & $0.9 \%$ & $7.1 \%$ & $1.6 \%$ \\
\hline$\%$ Family \& Personal Business & $1.2 \%$ & $0.5 \%$ & $5.3 \%$ & $1.4 \%$ & $1.1 \%$ & $0.7 \%$ & $6.5 \%$ & $2.1 \%$ \\
\hline$\%$ Civic, Educationa & $0.4 \%$ & $0.3 \%$ & $1.1 \%$ & $1.1 \%$ & $0.5 \%$ & $0.3 \%$ & $8.0 \%$ & $0.8 \%$ \\
\hline$\%$ Social \& Recreational & $0.9 \%$ & $0.4 \%$ & $6.0 \%$ & $1.2 \%$ & $1.1 \%$ & $0.6 \%$ & $6.6 \%$ & $2.1 \%$ \\
\hline$\%$ Other & $0.1 \%$ & $0.1 \%$ & & $0.1 \%$ & $0.0 \%$ & $0.1 \%$ & & $0.3 \%$ \\
\hline$\%$ Unreported & $0.1 \%$ & $0.0 \%$ & & $0.0 \%$ & $0.2 \%$ & $0.1 \%$ & & $0.5 \%$ \\
\hline TOTAL & 0.08 & 0.04 & 0.26 & 0.14 & 0.06 & 0.04 & 0.42 & 0.13 \\
\hline Weekend & 0.12 & 0.07 & 0.39 & 0.17 & 0.12 & 0.07 & 0.50 & 0.24 \\
\hline Weekday & 0.08 & 0.04 & 0.39 & 0.15 & 0.07 & 0.05 & 0.57 & 0.15 \\
\hline TOTAL & 0.08 & 0.04 & 0.26 & 0.14 & 0.06 & 0.04 & 0.42 & 0.13 \\
\hline$\% 1-9 \min$ & $1.0 \%$ & $0.5 \%$ & $4.0 \%$ & $2.0 \%$ & $1.1 \%$ & $0.6 \%$ & $9.6 \%$ & $2.8 \%$ \\
\hline$\% 10-19 \mathrm{~min}$ & $1.1 \%$ & $0.6 \%$ & $3.4 \%$ & $1.8 \%$ & $1.0 \%$ & $0.5 \%$ & $9.0 \%$ & $2.2 \%$ \\
\hline$\%$ 20-29 min & $0.6 \%$ & $0.3 \%$ & $1.9 \%$ & $0.7 \%$ & $0.8 \%$ & $0.4 \%$ & $2.6 \%$ & $1.0 \%$ \\
\hline$\% 30-39 \min$ & $0.7 \%$ & $0.3 \%$ & $4.4 \%$ & $0.7 \%$ & $0.8 \%$ & $0.3 \%$ & $3.0 \%$ & $0.8 \%$ \\
\hline$\%$ 40-49 min & $0.4 \%$ & $0.2 \%$ & $2.2 \%$ & $0.5 \%$ & $0.4 \%$ & $0.2 \%$ & $1.6 \%$ & $0.4 \%$ \\
\hline$\% 50+\min$ & $0.4 \%$ & $0.3 \%$ & $1.3 \%$ & $0.6 \%$ & $0.5 \%$ & $0.3 \%$ & $2.7 \%$ & $0.9 \%$ \\
\hline$\%$ Unreported & $0.2 \%$ & $0.1 \%$ & $0.7 \%$ & $0.3 \%$ & $0.0 \%$ & $0.0 \%$ & & $0.1 \%$ \\
\hline TOTAL & 0.08 & 0.04 & 0.26 & 0.14 & 0.06 & 0.04 & 0.42 & 0.13 \\
\hline$\% 5$ or less miles & $1.2 \%$ & $0.6 \%$ & $5.4 \%$ & $1.8 \%$ & $1.2 \%$ & $0.7 \%$ & $6.1 \%$ & $2.5 \%$ \\
\hline$\% 6-10$ & $0.8 \%$ & $0.4 \%$ & $2.4 \%$ & $1.1 \%$ & $0.9 \%$ & $0.5 \%$ & $4.2 \%$ & $1.8 \%$ \\
\hline$\% 11-15$ miles & $0.8 \%$ & $0.3 \%$ & $2.8 \%$ & $0.9 \%$ & $0.8 \%$ & $0.5 \%$ & $2.3 \%$ & $0.9 \%$ \\
\hline$\% 16-20$ miles & $0.5 \%$ & $0.3 \%$ & $2.0 \%$ & $0.6 \%$ & $0.6 \%$ & $0.3 \%$ & $0.8 \%$ & $0.5 \%$ \\
\hline$\% 21-30$ miles & $0.6 \%$ & $0.2 \%$ & $3.1 \%$ & $0.6 \%$ & $0.5 \%$ & $0.3 \%$ & $3.6 \%$ & $0.7 \%$ \\
\hline$\% 31$ or more miles & $0.5 \%$ & $0.3 \%$ & $1.4 \%$ & $0.8 \%$ & $0.6 \%$ & $0.4 \%$ & $3.1 \%$ & $0.9 \%$ \\
\hline$\%$ Unreported & $0.2 \%$ & $0.1 \%$ & & $0.3 \%$ & $0.3 \%$ & $0.1 \%$ & $2.4 \%$ & $0.8 \%$ \\
\hline \multicolumn{9}{|l|}{ Daily VMT per Driver } \\
\hline TOTAL & 1.29 & 0.96 & 3.22 & 2.56 & 1.11 & 0.93 & 4.10 & 2.33 \\
\hline$\%$ Earn a Living & $1.5 \%$ & $1.2 \%$ & $7.2 \%$ & $4.4 \%$ & $1.9 \%$ & $1.5 \%$ & $11.4 \%$ & $3.2 \%$ \\
\hline$\%$ Family \& Pe & $1.6 \%$ & $0.9 \%$ & $6.5 \%$ & $3.3 \%$ & $2.0 \%$ & $1.2 \%$ & $7.3 \%$ & $4.4 \%$ \\
\hline$\%$ Civic, Educational \& Religious & $0.5 \%$ & $0.3 \%$ & $1.8 \%$ & $0.8 \%$ & $0.7 \%$ & $1.0 \%$ & $5.9 \%$ & $0.7 \%$ \\
\hline$\%$ Social \& Recreational & $1.8 \%$ & $1.3 \%$ & $9.5 \%$ & $3.9 \%$ & $1.8 \%$ & $1.1 \%$ & $6.3 \%$ & $4.7 \%$ \\
\hline$\%$ Other & $0.5 \%$ & $0.1 \%$ & & $1.2 \%$ & $0.0 \%$ & $0.1 \%$ & & $0.8 \%$ \\
\hline$\%$ Unreported & $0.1 \%$ & $0.2 \%$ & & $0.0 \%$ & $1.1 \%$ & $0.3 \%$ & & $0.5 \%$ \\
\hline Average & & & & & & & & \\
\hline TOTAL & 0.39 & 0.29 & 1.21 & 0.73 & 0.36 & 0.30 & 1.34 & 0.80 \\
\hline
\end{tabular}


Definition of NYS RURAL: Outside MPO and Population Density < 1,000 (Block Group) Definition of US RURAL: Outside NY \& MSA and Population Density $<1,000$ (Block Group)

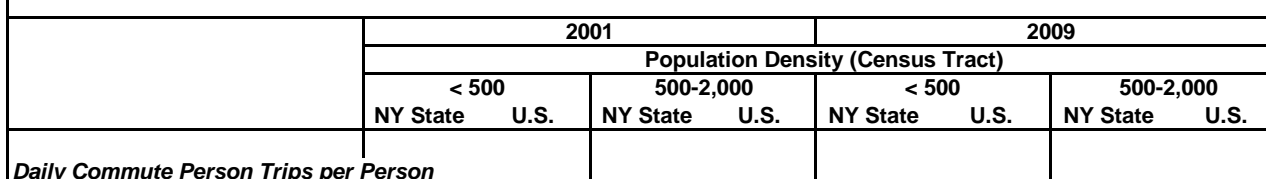

Daily Commute Person Trips per Perso

TOTAL

$\%$ SOV

$\%$ MOV

$\%$ Amtrak

$\%$ Subway/El Rail

$\%$ Other Public

$\%$ Walk

$\%$ Other

TOTAL

$\% 1-6$ am

$\%$ 6-9 am

$\% 9$ am-1 pm

$\%$ 1-4 pm

$\%$ 4-7 pm

$\%$ 7-10 pm

$\%$ Unreported

Daily Commute PMT per Person

TOTAL

$\%$ SOV

$\%$ MOV

$\%$ Amtrak

$\%$ Commuter Train

$\%$ Other Public

$\%$ Walk

$\%$ Other

$\%$ Unreported

TOTAL

$\%$ 1-6 am

$\%$ 6-9 am
$\% 9 \mathrm{am}-1 \mathrm{pm}$
$\%$ 1-4 pm

$\% 1-4 \mathrm{pm}$

$\%$ 4-7 pm

$\% 7-10 \mathrm{pm}$

$\%$ Unreported

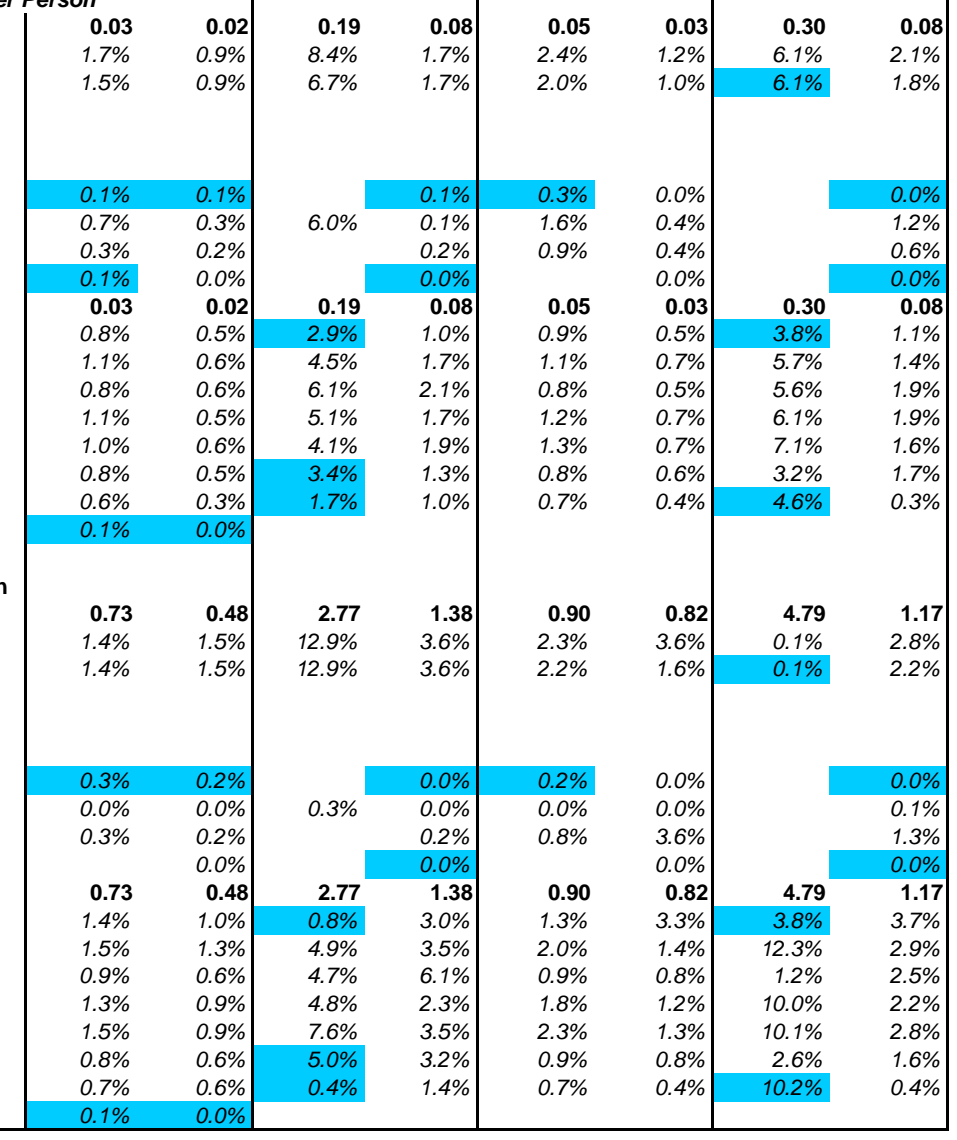




\begin{tabular}{|c|c|c|c|c|c|c|c|c|}
\hline \multicolumn{9}{|c|}{$\begin{array}{l}\text { Definition of NYS RURAL: Outside MPO and Population Density }<1,000 \text { (Block Group) } \\
\text { Definition of US RURAL: Outside NY \& MSA and Population Density }<1,000 \text { (Block Group) }\end{array}$} \\
\hline & \multicolumn{4}{|c|}{2001} & \multicolumn{4}{|c|}{2009} \\
\hline & \multicolumn{8}{|c|}{ Population Density (Census Tract) } \\
\hline & \multirow{2}{*}{\multicolumn{2}{|c|}{$\begin{array}{c}<00 \\
\text { UY State }\end{array}$}} & \multicolumn{2}{|c|}{$500-2,000$} & \multicolumn{2}{|c|}{$<500$} & \multicolumn{2}{|c|}{$500-2,000$} \\
\hline & & & NY State & U.S. & NY State & U.S. & NY State & U.S. \\
\hline \multicolumn{9}{|c|}{\begin{tabular}{|l|} 
Average Commute Length, Travel Time, and Speed \\
Length (miles)
\end{tabular}} \\
\hline TOTAL & 0.51 & 0.39 & 2.18 & 1.07 & 0.72 & 0.68 & 3.55 & 0.98 \\
\hline Private & 0.52 & 0.39 & 2.35 & 1.08 & 0.72 & 0.37 & 3.55 & 1.00 \\
\hline Public & 11.45 & 13.41 & & 0.00 & 6.12 & 4.31 & & 0.98 \\
\hline Walk & 0.10 & 0.09 & 0.31 & 0.24 & 0.18 & 0.05 & & 0.47 \\
\hline Other & 3.04 & 3.16 & & 4.70 & 3.13 & 37.19 & & 5.56 \\
\hline \multicolumn{9}{|c|}{ Time (minutes) } \\
\hline TOTAL & 0.61 & 0.48 & 3.11 & 1.43 & 0.99 & 0.45 & 6.21 & 1.31 \\
\hline Private & 0.62 & 0.49 & 3.41 & 1.44 & 0.88 & 0.46 & 6.21 & 1.34 \\
\hline Public & 26.93 & 6.83 & & 0.00 & 18.67 & 14.78 & & 13.20 \\
\hline Walk & 2.84 & 1.07 & 5.31 & 2.79 & 2.10 & 1.11 & & 1.66 \\
\hline Other & 8.32 & 7.69 & & 13.59 & 13.62 & 6.49 & & 8.62 \\
\hline \multicolumn{9}{|l|}{ Miles per Ho } \\
\hline TOTAL & 0.74 & 0.82 & 2.31 & 1.93 & 1.01 & 1.51 & 7.31 & 1.34 \\
\hline Private & 0.72 & 0.80 & 2.32 & 1.93 & 0.94 & 0.47 & 7.31 & 1.36 \\
\hline \multicolumn{9}{|l|}{ Public } \\
\hline Walk & 0.91 & 0.33 & 0.45 & 1.24 & 0.62 & 0.44 & & 3.05 \\
\hline Other & 13.43 & 5.74 & & 5.65 & 2.96 & 74.82 & & 2.95 \\
\hline
\end{tabular}


Definition of NYS RURAL: Outside MPO and Population Density < 1,000 (Block Group)

Definition of US RURAL: Outside NY \& MSA and Population Density < 1,000 (Block Group)

\begin{tabular}{|c|c|c|c|c|}
\hline & \multicolumn{2}{|c|}{2001} & \multicolumn{2}{|c|}{2009} \\
\hline & \multicolumn{4}{|c|}{$\begin{array}{l}\text { Population Density (Census Tract) } \\
\end{array}$} \\
\hline & $<<500$ & $500-2,000$ & $<500$ & $\begin{array}{r}500-2,000 \\
\end{array}$ \\
\hline & NY State & NY State & NY State & NY State \\
\hline
\end{tabular}

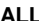

1 Adult, No Child

2+ Adults, No Child

1 Adult, Child $<6$

2+ Adults, Child $<6$

1 Adult, Child 6-15

2+ Adults, Child 6-15

1 Adult, Child 16-21

2+ Adults, Child 16-21

2+ Adults, Retired, No Child

Unreported

Family \& Personal Business

Civic, Educational \& Religious

Social \& Recreational

Other

Unreported

ALL

$<\$ 10,000$

$\$ 10$ to $\$ 20,000$

$\$ 20$ to $\$ 30,000$

$\$ 30$ to $\$ 40,000$

$\$ 40$ to $\$ 50,000$

$\$ 50$ to $\$ 60,000$

$\$ 60$ to $\$ 70,000$

$\$ 70$ to $\$ 80,000$

$\$ 100,000$

es per Vehicle Mi

Unreported

\begin{tabular}{ll|ll|ll|ll}
$\mathbf{0 . 0 4}$ & $\mathbf{0 . 0 2}$ & $\mathbf{0 . 3 3}$ & $\mathbf{0 . 1 2}$ & $\mathbf{0 . 0 7}$ & $\mathbf{0 . 0 3}$ & $\mathbf{0 . 1 6}$ & $\mathbf{0 . 0 7}$ \\
0.06 & 0.06 & 0.32 & 0.04 & 0.14 & 0.04 & 0.00 & 0.11 \\
0.05 & 0.05 & 0.14 & 0.08 & 0.07 & 0.03 & 0.53 & 0.04
\end{tabular}

\begin{tabular}{ll|ll|llll}
0.06 & 0.06 & 0.32 & 0.04 & 0.14 & 0.04 & 0.00 & 0.11 \\
0.05 & 0.05 & 0.14 & 0.08 & 0.04 & 0.04 & 0.53 & 0.04 \\
0.33 & 0.26 & & 2.04 & 1.77 & 0.29 & & 0.07
\end{tabular}

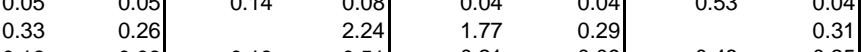

\begin{tabular}{lll|lllllll} 
& 0.12 & 0.18 & 0.20 & 0.35 & 0.12 & 0.15 & 0.01 & 0.08 \\
\hline
\end{tabular}




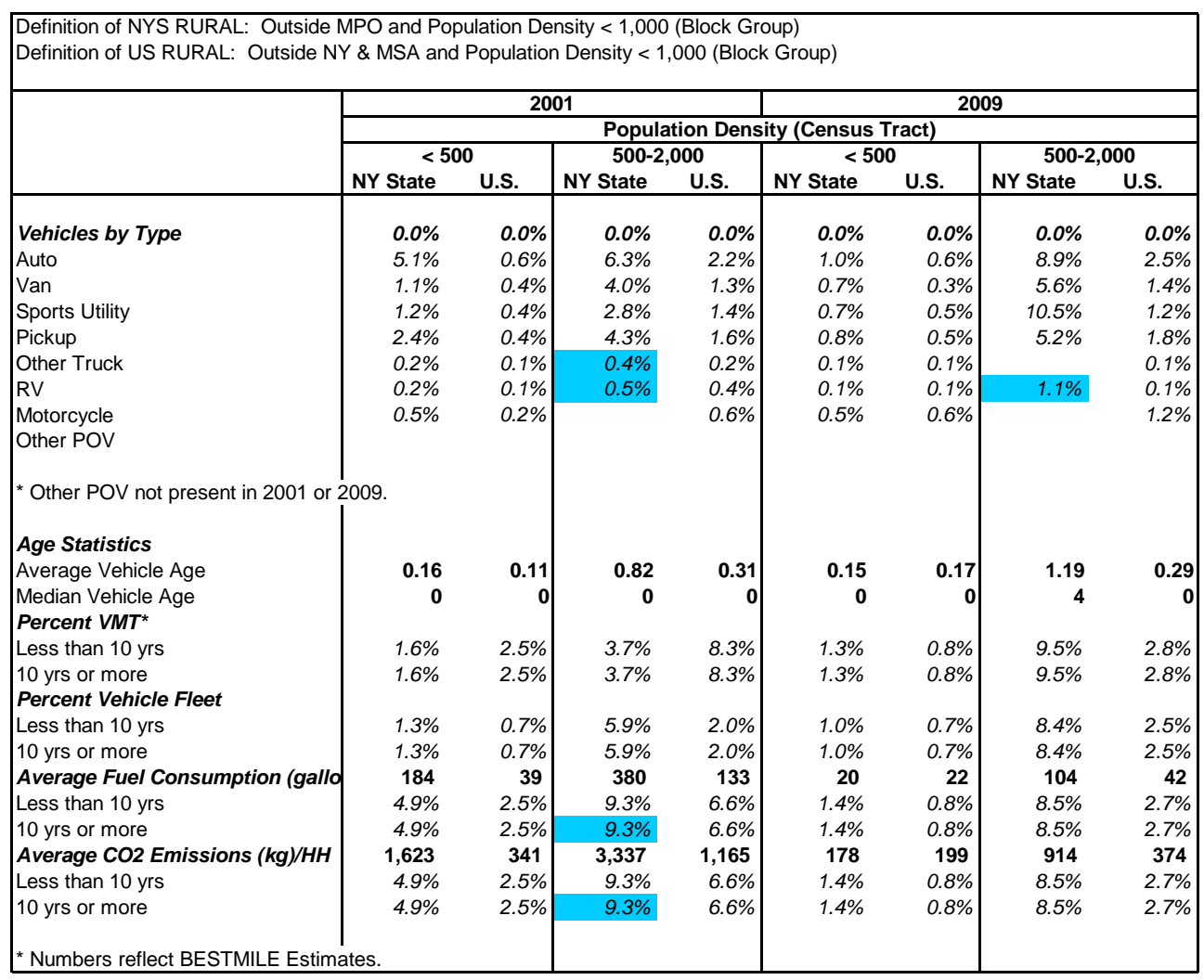


Definition of NYS RURAL: Outside MPO and Population Density < 1,000 (Block Group)

Definition of US RURAL: Outside NY \& MSA and Population Density < 1,000 (Block Group)

\begin{tabular}{|c|c|c|c|c|c|c|c|c|}
\hline & \multicolumn{4}{|c|}{2001} & \multicolumn{4}{|c|}{2009} \\
\hline & \multicolumn{8}{|c|}{ Population Density (Census Tract) } \\
\hline & \multicolumn{2}{|c|}{$<500$} & \multicolumn{2}{|c|}{$500-2,000$} & \multicolumn{2}{|c|}{$<500$} & \multicolumn{2}{|c|}{$500-2,000$} \\
\hline & NY State & U.S. & NY State & U.S. & NY State & U.S. & NY State & U.S. \\
\hline \multicolumn{9}{|c|}{ Annual CO2 Emissions per Household - POVs ONLY } \\
\hline Average $\mathrm{CO} 2$ Emissions $(\mathrm{kg}) / \mathrm{HH}$ & 1,623 & 341 & 3,337 & 1,165 & 178 & 199 & 914 & 374 \\
\hline 0 Workers & 1,139 & 202 & 3,940 & 830 & 276 & 224 & 661 & 462 \\
\hline 1 Workers & 1,852 & 237 & 1,039 & 1,192 & 330 & 282 & 1,121 & 643 \\
\hline 2 Workers & 1,899 & 613 & 12,967 & 2,386 & 426 & 328 & 674 & 649 \\
\hline 3 or more Workers & 3,445 & 1,461 & 15,742 & 9,221 & 1,579 & 1,882 & 8,652 & 987 \\
\hline Average $\mathrm{CO} 2$ Emissions $(\mathrm{kg}) / \mathrm{HH}$ & 1,623 & 341 & 3,337 & 1,165 & 178 & 199 & 914 & 374 \\
\hline 1 Drivers & 1,029 & 200 & 7,974 & 576 & 242 & 262 & 1,468 & 470 \\
\hline 2 Drivers & 1,538 & 589 & 1,528 & 1,999 & 245 & 251 & 685 & 425 \\
\hline 3 or more Drivers & 5,139 & 721 & 4,752 & 2,624 & 850 & 801 & 4,196 & 785 \\
\hline Average CO2 Emissions $(\mathrm{kg}) / \mathrm{HH}$ & 1,623 & 341 & 3,337 & 1,165 & 178 & 199 & 914 & 374 \\
\hline 1 Vehicles & 801 & 196 & 7,974 & 372 & 170 & 230 & 1,377 & 287 \\
\hline 2 Vehicles & 1,416 & 237 & 2,494 & 2,840 & 235 & 222 & 593 & 510 \\
\hline 3 or more Vehicles & 5,333 & 739 & 22,079 & 2,088 & 548 & 383 & 4,847 & 476 \\
\hline \multicolumn{9}{|c|}{ Annual CO2 Emissions per Household - Non-POV MODES } \\
\hline \multirow{2}{*}{\multicolumn{9}{|c|}{$\begin{array}{l}\text { Annual CO2 Emissions per Household - Non-POV MODES } \\
\text { Average CO2 Emissions }(\mathrm{kg}) / \mathrm{HH}\end{array}$}} \\
\hline \multirow{2}{*}{\multicolumn{9}{|c|}{1 Workers }} \\
\hline & & & & & & & & \\
\hline \multicolumn{9}{|l|}{2 Workers } \\
\hline \multicolumn{9}{|l|}{3 or more Workers } \\
\hline \multicolumn{9}{|l|}{ Average $\mathrm{CO} 2$ Emissions $(\mathrm{kg}) / \mathrm{HH}$} \\
\hline \multicolumn{9}{|l|}{0 Drivers } \\
\hline \multicolumn{9}{|l|}{1 Drivers } \\
\hline \multirow{2}{*}{\multicolumn{9}{|c|}{$\begin{array}{l}2 \text { Drivers } \\
3 \text { or more Drivers }\end{array}$}} \\
\hline & & & & & & & & \\
\hline \multicolumn{9}{|l|}{ Average $\mathrm{CO} 2$ Emissions $(\mathrm{kg}) / \mathrm{HH}$} \\
\hline \multirow{2}{*}{\multicolumn{9}{|c|}{$\begin{array}{l}0 \text { Vehicles } \\
1 \text { Vehicles }\end{array}$}} \\
\hline & & & & & & & & \\
\hline 2 Vehicles & & & & & & & & \\
\hline & & & & & & & & \\
\hline Annual CO2 Emissions per Hous & hold - ALL & ODES & & & & & & \\
\hline Average $\mathrm{CO} 2$ Emissions $(\mathrm{kg}) / \mathrm{HH}$ & & & & & & & & \\
\hline 0 Workers & & & & & & & & \\
\hline 1 Workers & & & & & & & & \\
\hline 2 Workers & & & & & & & & \\
\hline 3 or more Workers & & & & & & & & \\
\hline Average $\mathrm{CO} 2$ Emissions $(\mathrm{kg}) / \mathrm{HH}$ & & & & & & & & \\
\hline 0 Drivers & & & & & & & & \\
\hline 1 Drivers & & & & & & & & \\
\hline 2 Drivers & & & & & & & & \\
\hline 3 or more Drivers & & & & & & & & \\
\hline Average $\mathrm{CO} 2$ Emissions $(\mathrm{kg}) / \mathrm{HH}$ & & & & & & & & \\
\hline 0 Vehicles & & & & & & & & \\
\hline 1 Vehicles & & & & & & & & \\
\hline 2 Vehicles & & & & & & & & \\
\hline 3 or more Vehicles & & & & & & & & \\
\hline
\end{tabular}




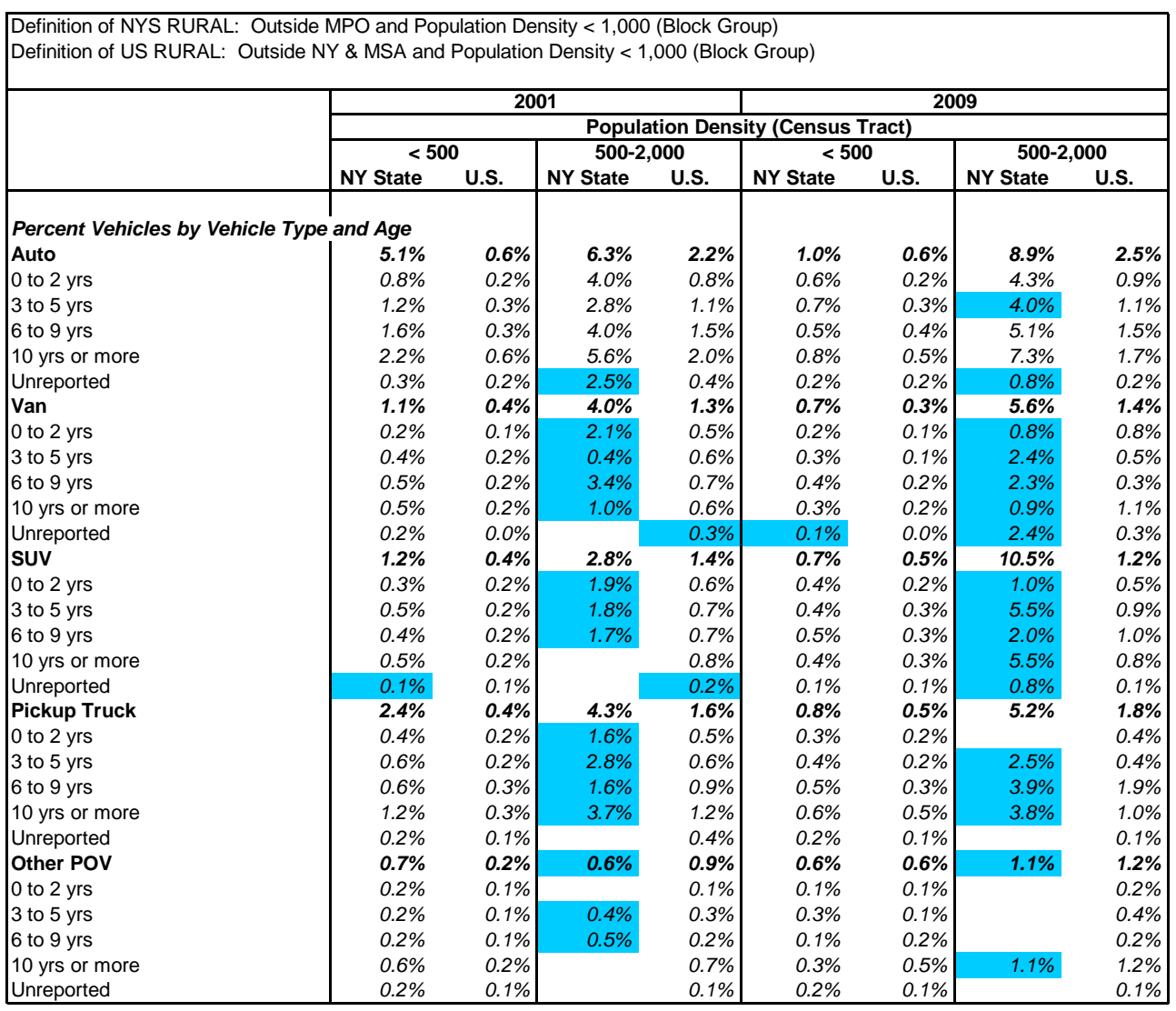


Definition of NYS RURAL: Outside MPO and Population Density < 1,000 (Block Group) Definition of US RURAL: Outside NY \& MSA and Population Density < 1,000 (Block Group)

\begin{tabular}{|c|c|c|c|c|c|c|c|c|}
\hline & \multicolumn{4}{|c|}{2001} & \multicolumn{4}{|c|}{2009} \\
\hline & \multicolumn{8}{|c|}{ Population Density (Census Tract) } \\
\hline & \multicolumn{2}{|c|}{$<500$} & \multicolumn{2}{|c|}{$500-2,000$} & \multicolumn{2}{|c|}{$<500$} & \multicolumn{2}{|c|}{$500-2,000$} \\
\hline & NY State & U.S. & NY State & U.S. & NY State & U.S. & NY State & U.S. \\
\hline \multicolumn{9}{|c|}{ VMT/Vehicle by Vehicle Type and Age } \\
\hline ALL VEHICLES & 256 & 328 & 1,549 & 1,690 & 186 & 164 & 1,594 & 377 \\
\hline 0 to $2 \mathrm{yrs}$ & 595 & 353 & 2,411 & 1,713 & 624 & 414 & 3,756 & 1,509 \\
\hline 3 to $5 \mathrm{yrs}$ & 555 & 1,037 & 6,193 & 11,013 & 363 & 283 & 6,732 & 604 \\
\hline 6 to $9 \mathrm{yrs}$ & 525 & 595 & 2,345 & 1,905 & 293 & 456 & 1,254 & 469 \\
\hline $10 \mathrm{yrs}$ or more & 448 & 301 & 951 & 1,147 & 358 & 181 & 1,896 & 591 \\
\hline Unreported & 1,179 & 793 & 5,982 & 5,991 & 1,553 & 655 & 4,478 & 1,950 \\
\hline Auto & 354 & 309 & 2,016 & 1,025 & 255 & 249 & 2,832 & 478 \\
\hline 0 to 2 yrs & 998 & 606 & 2,545 & 2,539 & 841 & 730 & 4,875 & 1,533 \\
\hline 3 to $5 \mathrm{yrs}$ & 842 & 671 & 8,917 & 1,977 & 491 & 449 & 14,294 & 837 \\
\hline 6 to $9 \mathrm{yrs}$ & 636 & 380 & 3,324 & 2,660 & 471 & 607 & 2,188 & 553 \\
\hline 10 yrs or more & 683 & 399 & 1,141 & 2,079 & 485 & 290 & 3,170 & 938 \\
\hline Unreported & 1,987 & 2,271 & 5,982 & 1,386 & 1,322 & 1,105 & & 1,399 \\
\hline Van & 670 & 480 & 3,517 & 21,047 & 1,534 & 1,034 & 2,353 & 17,453 \\
\hline 0 to $2 \mathrm{yrs}$ & 1,376 & 1,433 & 8,890 & 6,136 & 2,032 & & 13,510 & \\
\hline 3 to $5 \mathrm{yrs}$ & 1,225 & 827 & 20,133 & 80,621 & 1,224 & 14,450 & 1,062 & \\
\hline 6 to $9 \mathrm{yrs}$ & 1,497 & 848 & 5,801 & 1,730 & 4,665 & 5,067 & 1,153 & \\
\hline $10 \mathrm{yrs}$ or more & 1,001 & 1,261 & 3,591 & 2,748 & 438 & 7,368 & 1,543 & \\
\hline Unreported & 3,479 & 2,597 & & 8,442 & 3,327 & 2,643 & 10,223 & 17,453 \\
\hline suv & 893 & 604 & 3,399 & 2,732 & 505 & 265 & 885 & 714 \\
\hline 0 to 2 yrs & 1,305 & 880 & 5,151 & 3,982 & 692 & 865 & 167 & 1,287 \\
\hline 3 to 5 yrs & 1,269 & 1,274 & 17,517 & 871 & 833 & 638 & 5,129 & 758 \\
\hline 6 to $9 \mathrm{yrs}$ & 1,310 & 2,009 & 8,852 & 4,172 & 640 & 476 & 1,951 & 853 \\
\hline \multirow{2}{*}{$\begin{array}{l}10 \text { yrs or more } \\
\text { Unreported }\end{array}$} & 2,740 & 2,518 & & 4,369 & 1,409 & 435 & 1,989 & 1,982 \\
\hline & 2,528 & 1,734 & & 19,046 & 5,356 & 1,813 & & 1,832 \\
\hline Pickup Truck & 483 & 484 & 3,732 & 1,020 & 406 & 223 & 1,468 & 540 \\
\hline 0 to $2 \mathrm{yrs}$ & 1,086 & 580 & 2,918 & 1,589 & 2,525 & 826 & & 1,399 \\
\hline 3 to $5 \mathrm{yrs}$ & 825 & 1,874 & 10,964 & 1,675 & 856 & 445 & 4,002 & 1,022 \\
\hline 6 to $9 \mathrm{yrs}$ & 1,327 & 1,414 & 4,845 & 1,296 & 572 & 419 & 972 & 785 \\
\hline $10 \mathrm{yrs}$ or more & 657 & 419 & 5,341 & 1,802 & 497 & 329 & 559 & 789 \\
\hline Unreported & 1,914 & 1,637 & & 2,837 & 968 & 1,128 & & 1,917 \\
\hline Other POV & 496 & 2,866 & 13,733 & 3,826 & 586 & 478 & - & 780 \\
\hline 0 to $2 \mathrm{yrs}$ & 1,549 & 3,779 & & 1,781 & 2,795 & 785 & & 543 \\
\hline 3 to $5 \mathrm{yrs}$ & 1,941 & 15,937 & 19,899 & 1,037 & 447 & 1,390 & & 551 \\
\hline 6 to $9 \mathrm{yrs}$ & 1,906 & 8,512 & 497 & 2,068 & 736 & 1,311 & & 545 \\
\hline $10 \mathrm{yrs}$ or more & 678 & 1,434 & & 4,867 & 318 & 467 & - & 1,226 \\
\hline Unreported & 613 & 404 & & & 5,409 & 574 & & 1,744 \\
\hline NOTE: Numbers & & & & & & & & \\
\hline
\end{tabular}




\begin{tabular}{|c|c|c|c|c|c|c|c|c|}
\hline \multicolumn{9}{|c|}{$\begin{array}{l}\text { Definition of NYS RURAL: Outside MPO and Population Density }<1,000 \text { (Block Group) } \\
\text { Definition of US RURAL: Outside NY \& MSA and Population Density }<1,000 \text { (Block Group) }\end{array}$} \\
\hline & \multicolumn{4}{|c|}{2001} & \multicolumn{4}{|c|}{2009} \\
\hline & \multicolumn{8}{|c|}{ Population Density (Census Tract) } \\
\hline & \multicolumn{2}{|c|}{$\begin{array}{c}\text { NY State }^{<500} \text { U.S. } \\
\text { N }\end{array}$} & \multicolumn{2}{|c|}{$\begin{array}{c}500-2,000 \\
\text { SY State US }\end{array}$} & \multicolumn{2}{|c|}{$\begin{array}{c}<500 \\
<1<\end{array}$} & \multicolumn{2}{|c|}{$500-2,000$} \\
\hline & NY State & U.S. & NY State & U.S. & NY State & U.S. & NY State & U.S. \\
\hline \multicolumn{9}{|c|}{ Percent Not Taking Walk Trips in the last week } \\
\hline TOTAL & $1.3 \%$ & $0.7 \%$ & $8.6 \%$ & $2.2 \%$ & $1.3 \%$ & $0.7 \%$ & $5.7 \%$ & $2.7 \%$ \\
\hline 5 to 10 year-olds & * & & * & & $4.9 \%$ & $2.4 \%$ & & $7.3 \%$ \\
\hline 11 to 15 year-olds & * & * & * & * & $4.1 \%$ & $2.5 \%$ & & $5.6 \%$ \\
\hline 16 to 20 year-olds & $6.1 \%$ & $2.6 \%$ & $21.6 \%$ & $8.2 \%$ & $4.1 \%$ & $2.6 \%$ & $13.6 \%$ & $6.5 \%$ \\
\hline 21 to 35 year-olds & $3.0 \%$ & $1.2 \%$ & $19.1 \%$ & $4.3 \%$ & $3.4 \%$ & $2.0 \%$ & $20.2 \%$ & $5.0 \%$ \\
\hline 36 to 64 year-olds & $1.4 \%$ & $0.9 \%$ & $9.8 \%$ & $2.7 \%$ & $1.6 \%$ & $1.0 \%$ & $7.5 \%$ & $3.1 \%$ \\
\hline $65+$ year-olds & $2.7 \%$ & $1.4 \%$ & $13.9 \%$ & $5.0 \%$ & $2.2 \%$ & $1.5 \%$ & $21.0 \%$ & $4.5 \%$ \\
\hline \multicolumn{9}{|c|}{ Avg Minutes Spent Walking per Day } \\
\hline TOTAL & 0.52 & 0.22 & 1.74 & 0.63 & 0.32 & 0.18 & 0.81 & 0.50 \\
\hline 5 to 10 year-olds & 0.68 & 0.83 & & 1.53 & 0.52 & 0.32 & & 1.78 \\
\hline 11 to 15 year-olds & 1.43 & 0.61 & 2.72 & 1.78 & 0.81 & 0.53 & & 0.74 \\
\hline 16 to 20 year-olds & 2.72 & 1.00 & 21.14 & 0.46 & 1.78 & 0.62 & & 1.25 \\
\hline 21 to 35 year-olds & 2.21 & 0.30 & 1.54 & 1.04 & 0.85 & 0.62 & & 0.96 \\
\hline 36 to 64 year-olds & 0.48 & 0.31 & 1.83 & 1.51 & 0.42 & 0.24 & 1.73 & 0.88 \\
\hline $65+$ year-olds & 0.73 & 0.63 & 2.98 & 1.27 & 0.50 & 0.25 & 0.97 & 0.72 \\
\hline \multicolumn{9}{|c|}{ Percent Not Taking Bike Trips in the last week } \\
\hline TOTAL & $0.7 \%$ & $0.4 \%$ & $4.4 \%$ & $1.2 \%$ & $0.8 \%$ & $0.7 \%$ & $5.1 \%$ & $1.2 \%$ \\
\hline 5 to 10 year-olds & * & & * & & $4.3 \%$ & $2.3 \%$ & $43.5 \%$ & $10.8 \%$ \\
\hline 11 to 15 year-olds & * & 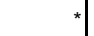 & * & * & $5.1 \%$ & $2.7 \%$ & $0.0 \%$ & $5.5 \%$ \\
\hline 16 to 20 year-olds & $2.7 \%$ & $1.8 \%$ & $0.0 \%$ & $4.9 \%$ & $2.7 \%$ & $2.3 \%$ & $0.0 \%$ & $2.7 \%$ \\
\hline 21 to 35 year-olds & $1.8 \%$ & $0.9 \%$ & $10.4 \%$ & $2.9 \%$ & $2.0 \%$ & $1.3 \%$ & $0.0 \%$ & $1.3 \%$ \\
\hline 36 to 64 year-olds & $0.8 \%$ & $0.4 \%$ & $7.3 \%$ & $1.7 \%$ & $0.8 \%$ & $0.5 \%$ & $8.6 \%$ & $1.2 \%$ \\
\hline $65+$ year-olds & $1.0 \%$ & $0.4 \%$ & $0.0 \%$ & $1.8 \%$ & $0.8 \%$ & $0.3 \%$ & $0.0 \%$ & $0.5 \%$ \\
\hline \multicolumn{9}{|c|}{ Avg Minutes Spent Biking per Day } \\
\hline TOTAL & 0.20 & 0.06 & & 0.30 & 0.29 & 0.09 & & 0.11 \\
\hline 5 to 10 year-olds & 0.92 & 0.43 & & 2.21 & 0.70 & 0.46 & & 0.37 \\
\hline 11 to 15 year-olds & 1.55 & 0.36 & & 0.12 & 1.58 & 0.59 & & 0.53 \\
\hline 16 to 20 & 0.39 & 0.16 & & 0.04 & 0.05 & 0.13 & & 0.40 \\
\hline 21 to 35 year-olds & 0.05 & 0.03 & & 0.01 & 1.12 & 0.05 & & 0.44 \\
\hline 36 to 64 year-olds & 0.08 & 0.06 & & 0.05 & 0.42 & 0.17 & & 0.14 \\
\hline $65+$ year-olds & 0.01 & 0.08 & & & 0.05 & 0.25 & & 0.04 \\
\hline \multicolumn{9}{|c|}{ Avg Minutes Spent Walking/Biking per Day } \\
\hline TOTAL & 0.59 & 0.23 & 1.74 & 0.71 & 0.43 & 0.19 & 0.81 & 0.52 \\
\hline 5 to 10 year-olds & 1.19 & 1.00 & & 2.65 & 0.92 & 0.57 & & 1.81 \\
\hline 11 to 15 year-olds & 2.39 & 0.68 & 2.72 & 1.78 & 1.77 & 0.73 & & 1.04 \\
\hline & 2.71 & 1.02 & 21.14 & 0.46 & 1.78 & 0.63 & & 1.37 \\
\hline 21 to 35 year-olds & 2.22 & 0.31 & 1.54 & 1.04 & 1.37 & 0.62 & & 1.03 \\
\hline 36 to 64 year-olds & 0.48 & 0.31 & 1.83 & 1.50 & 0.57 & 0.29 & 1.73 & 0.89 \\
\hline $65+$ year-olds & 0.73 & 0.63 & 2.98 & 1.27 & 0.48 & 0.28 & 0.97 & 0.73 \\
\hline
\end{tabular}


APPENDIX C6. SUPPLEMENTAL TABLES FOR CHAPTER 6 


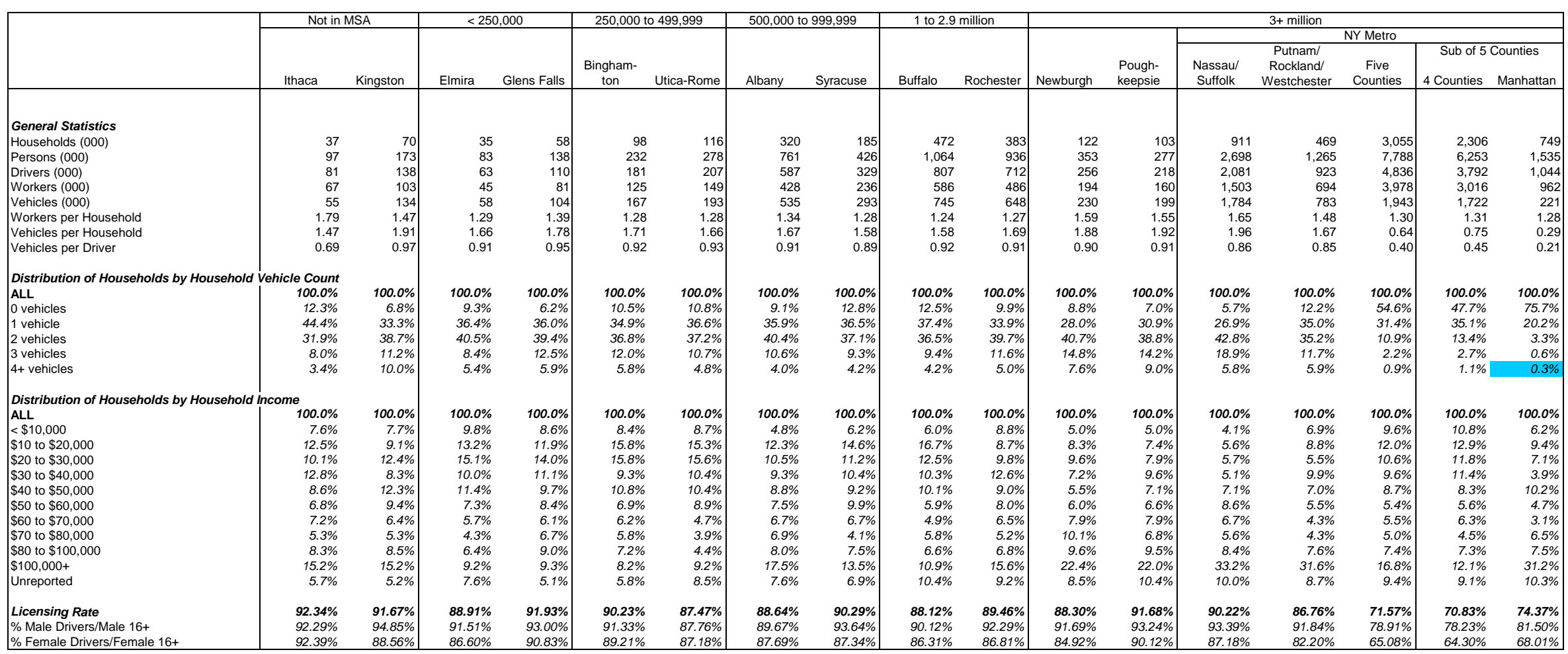




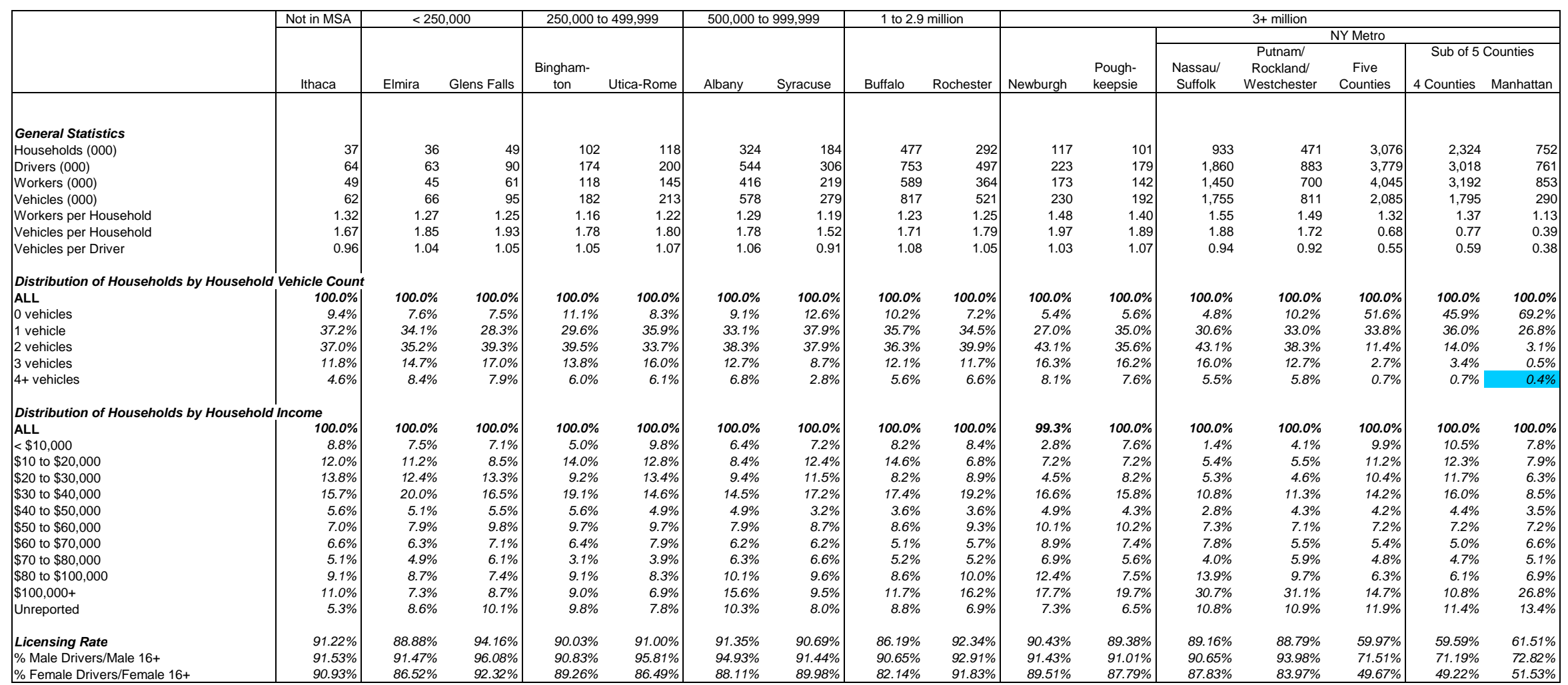




\begin{tabular}{|c|c|c|c|c|c|c|c|c|c|c|c|c|c|c|c|c|}
\hline & \multirow{3}{*}{\begin{tabular}{c|} 
Not in MSA \\
Ithaca \\
\end{tabular}} & \multicolumn{2}{|c|}{$<250,000$} & \multirow{3}{*}{\multicolumn{2}{|c|}{$\begin{array}{l}250,000 \text { to } 499,999 \\
\begin{array}{c}\text { Bingham- } \\
\text { ton }\end{array} \text { Utica-Rome } \\
\end{array}$}} & \multirow{3}{*}{\multicolumn{2}{|c|}{$\begin{array}{l}500,000 \text { to } 999,999 \\
\\
\text { Albany } \quad \text { Syracuse } \\
\end{array}$}} & \multirow{3}{*}{\multicolumn{2}{|c|}{\begin{tabular}{|c|}
1 to 2.9 million \\
Buffalo $\quad$ Rochester \\
\end{tabular}}} & \multirow[b]{3}{*}{ Newburgh } & \multirow[b]{3}{*}{$\begin{array}{l}\text { Pough- } \\
\text { keepsie }\end{array}$} & \multirow{2}{*}{\multicolumn{5}{|c|}{$3+$ million }} \\
\hline & & & & & & & & & & & & & & & & \\
\hline & & Elmira & Glens Falls & & & & & & & & & $\begin{array}{c}\text { Nassau/ } \\
\text { Suffolk }\end{array}$ & $\begin{array}{l}\text { Putnam/ } \\
\text { Rockland/ } \\
\text { Westchester }\end{array}$ & $\begin{array}{c}\text { Five } \\
\text { Counties }\end{array}$ & $\begin{array}{r}\text { Sub of } 5 \\
4 \text { Counties } \\
\end{array}$ & $\begin{array}{l}\text { Counties } \\
\text { Manhattan }\end{array}$ \\
\hline \multicolumn{17}{|l|}{ General Statistics } \\
\hline $\begin{array}{l}\text { Households }(000) \\
\text { Drivers }(000)\end{array}$ & 35 & 35 & 45 & 101 & $\begin{array}{r}117 \\
209\end{array}$ & 326 & 180 & 465 & 279 & 108 & 95 & 886 & 448 & 2,920 & 2,193 & 728 \\
\hline $\begin{array}{l}\text { Divers ( } \\
\text { Workers (000) }\end{array}$ & $\begin{array}{l}70 \\
50\end{array}$ & 41 & $\begin{array}{l}77 \\
59\end{array}$ & $\begin{array}{l}174 \\
115\end{array}$ & $\begin{array}{l}209 \\
151\end{array}$ & $\begin{array}{l}555 \\
410\end{array}$ & $\begin{array}{l}313 \\
244\end{array}$ & $\begin{array}{l}787 \\
562\end{array}$ & $\begin{array}{l}491 \\
366\end{array}$ & $\begin{array}{l}204 \\
158\end{array}$ & $\begin{array}{l}180 \\
136\end{array}$ & $\begin{array}{l}1,783 \\
1374\end{array}$ & 837 & $\begin{array}{l}3,218 \\
3404\end{array}$ & $\begin{array}{l}2,489 \\
2,599\end{array}$ & $\begin{array}{l}730 \\
846\end{array}$ \\
\hline Vehicles (000) & 50 & 55 & 73 & 158 & 189 & 508 & 283 & 667 & 452 & 176 & 161 & 1,464 & 724 & 1,600 & 1,399 & 201 \\
\hline Workers per Household & 1.42 & 1.16 & 1.31 & 1.14 & 1.29 & 1.26 & 1.36 & 1.21 & 1.31 & 1.46 & 1.44 & 1.55 & 1.41 & 1.17 & 1.17 & 1.16 \\
\hline Vehicles per Household & 1.42 & 1.57 & 1.61 & 1.57 & 1.62 & 1.56 & 1.57 & 1.43 & 1.62 & 1.63 & 1.70 & 1.65 & 1.62 & 0.55 & 0.64 & 0.28 \\
\hline Vehicles per Driver & 0.71 & 0.90 & 0.94 & 0.91 & 0.91 & 0.91 & 0.90 & 0.85 & 0.92 & 0.86 & 0.89 & 0.82 & 0.86 & 0.50 & 0.56 & 0.28 \\
\hline \multicolumn{17}{|l|}{ Distribution of Household } \\
\hline ALL & 100.0 & 100.0 & 100.0 & 100.0 & 100.0 & 100.0 & 100.0 & 100.0 & 100.0 & 100.0 & 100.0 & 100.0 & 100.0 & 100.0 & 100.0 & 100.0 \\
\hline 0 vehicles & 9.0 & 8.4 & 6.1 & 6.5 & 6.9 & 8.7 & 8.4 & 11.5 & 7.7 & 5.6 & 7.1 & 5.4 & 9.8 & 52.9 & 46.3 & 72.6 \\
\hline 1 vehi & 42.0 & 37.4 & 29.6 & 36.4 & 34.4 & 32.2 & 33.3 & 37.8 & 31.9 & 31.0 & 26.5 & 29.1 & 30.0 & 33.8 & 36.8 & 24.8 \\
\hline 2 vehicles & 35.0 & 39.6 & 49.6 & 39.8 & 40.3 & 40.2 & 44.3 & 38.1 & 43.7 & 46.0 & 42.6 & 48.1 & 41.2 & 11.2 & 14.2 & 2.4 \\
\hline 3 vehicles & 11.3 & 10.1 & 12.1 & 12.6 & 13.0 & 13.4 & 10.5 & 10.2 & 11.7 & 11.5 & 16.0 & 12.2 & 13.8 & 1.6 & 2.1 & 0.1 \\
\hline $4+$ vehicles & 2.7 & 4.4 & 2.7 & 4.7 & 5.4 & 5.5 & 3.6 & 2.4 & 5.0 & 5.9 & 7.8 & 5.3 & 5.2 & 0.5 & 0.6 & 0.1 \\
\hline \multicolumn{17}{|c|}{ Distribution of Households by Household Income } \\
\hline ALL & $100.0 \%$ & $100.0 \%$ & $100.0 \%$ & $100.0 \%$ & $100.0 \%$ & $100.0 \%$ & $100.0 \%$ & $100.0 \%$ & $100.0 \%$ & $100.0 \%$ & $100.0 \%$ & $100.0 \%$ & $100.0 \%$ & $100.0 \%$ & $100.0 \%$ & $100.0 \%$ \\
\hline$<\$ 10,000$ & $8.9 \%$ & $5.2 \%$ & $4.2 \%$ & $5.2 \%$ & $5.0 \%$ & $4.0 \%$ & $3.6 \%$ & $4.9 \%$ & $2.6 \%$ & $3.0 \%$ & $2.9 \%$ & $1.3 \%$ & $2.9 \%$ & $7.9 \%$ & $8.1 \%$ & $7.3 \%$ \\
\hline$\$ 10$ to $\$$ & $10.8 \%$ & $15.3 \%$ & $16.5 \%$ & $11.0 \%$ & $9.1 \%$ & $7.6 \%$ & $7.2 \%$ & $10.3 \%$ & $6.9 \%$ & $4.6 \%$ & $6.1 \%$ & $4.5 \%$ & $6.3 \%$ & $9.2 \%$ & $9.8 \%$ & $7.6 \%$ \\
\hline$\$ 20$ to & $12.7 \%$ & $11.1 \%$ & $6.5 \%$ & $16.7 \%$ & $12.3 \%$ & $10.5 \%$ & $11.4 \%$ & $13.2 \%$ & $9.4 \%$ & $8.1 \%$ & $5.9 \%$ & $5.9 \%$ & $4.7 \%$ & $11.4 \%$ & $12.5 \%$ & $8.1 \%$ \\
\hline$\$ 30$ to $\$ 40,0$ & $15.7 \%$ & $18.2 \%$ & $14.1 \%$ & $15.2 \%$ & 18.2 & $14.8 \%$ & $10.9 \%$ & $15.6 \%$ & $12.3 \%$ & $14 . C$ & $10.1 \%$ & & $9.1 \%$ & $14.6 \%$ & $15.6 \%$ & $11.9 \%$ \\
\hline$\$ 40$ to $\$ 50,000$ & $4.1 \%$ & $5.9 \%$ & $4.0 \%$ & $3.9 \%$ & $5.3 \%$ & $3.9 \%$ & $4.9 \%$ & $4.8 \%$ & $5.3 \%$ & 4. & 2. & 2.4 & $2.8 \%$ & $3.8 \%$ & $3.8 \%$ & $3.7 \%$ \\
\hline$\$ 50$ to $\$ 60,0$ & & $7.2 \%$ & & $7.6 \%$ & & $8.2 \%$ & $9.5 \%$ & $6.4 \%$ & $9.5 \%$ & $6.8 \%$ & $9.9 \%$ & $6.8 \%$ & $5.6 \%$ & $6.1 \%$ & $6.0 \%$ & $6.5 \%$ \\
\hline$\$ 60$ to $\$ 70,0$ & & $7.4 \%$ & & & & & & $8.4 \%$ & & $9.0 \%$ & & $7.5 \%$ & $6.5 \%$ & $6.3 \%$ & $6.6 \%$ & $5.3 \%$ \\
\hline$\$ 70$ to $\$ 80,000$ & $3.3 \%$ & $5.0 \%$ & $4.9 \%$ & $4.4 \%$ & $4.2 \%$ & $5.4 \%$ & $5.5 \%$ & $4.1 \%$ & $5.8 \%$ & $5.1 \%$ & $6.0 \%$ & $4.7 \%$ & $4.3 \%$ & $3.5 \%$ & $3.3 \%$ & $3.9 \%$ \\
\hline$\$ 80$ to $\$ 100,000$ & $7.1 \%$ & $5.5 \%$ & $5.8 \%$ & $7.2 \%$ & $6.9 \%$ & $9.8 \%$ & $9.0 \%$ & $6.8 \%$ & $8.8 \%$ & $13.4 \%$ & $10.9 \%$ & $13.2 \%$ & $8.7 \%$ & $6.4 \%$ & $6.7 \%$ & $5.3 \%$ \\
\hline$\$ 100,000+$ & $8.2 \%$ & $4.5 \%$ & $5.3 \%$ & $7.5 \%$ & $7.1 \%$ & $8.7 \%$ & $11.7 \%$ & $8.0 \%$ & $13.4 \%$ & $13.2 \%$ & $16.2 \%$ & $22.6 \%$ & $24.4 \%$ & $10.3 \%$ & $7.5 \%$ & $18.8 \%$ \\
\hline Unreported & $14.1 \%$ & $14.7 \%$ & $16.3 \%$ & $14.5 \%$ & $16.5 \%$ & $17.6 \%$ & $16.8 \%$ & $17.3 \%$ & $18.0 \%$ & $18.9 \%$ & $20.6 \%$ & $21.9 \%$ & $24.8 \%$ & $20.5 \%$ & $20.1 \%$ & $21.6 \%$ \\
\hline Licensit & $90.41 \%$ & $86.66 \%$ & $87.99 \%$ & $89.77 \%$ & $89.00 \%$ & $89.93 \%$ & $90.20 \%$ & $86.84 \%$ & $90.98 \%$ & $88.32 \%$ & $89.95 \%$ & $88.22 \%$ & $88.80 \%$ & & & \\
\hline$\%$ Male Drivers/Male 16+ & $93.85 \%$ & $91.25 \%$ & $92.62 \%$ & $91.95 \%$ & $92.33 \%$ & $93.67 \%$ & $93.63 \%$ & $90.81 \%$ & $91.38 \%$ & $93.08 \%$ & $94.58 \%$ & $92.10 \%$ & $92.75 \%$ & $71.44 \%$ & $72.80 \%$ & $66.99 \%$ \\
\hline$\%$ Female Drivers/Female $16+$ & & & $83.59 \%$ & $87.77 \%$ & & $86.69 \%$ & & $83.06 \%$ & & & & & & & $43.53 \%$ & $47.83 \%$ \\
\hline
\end{tabular}




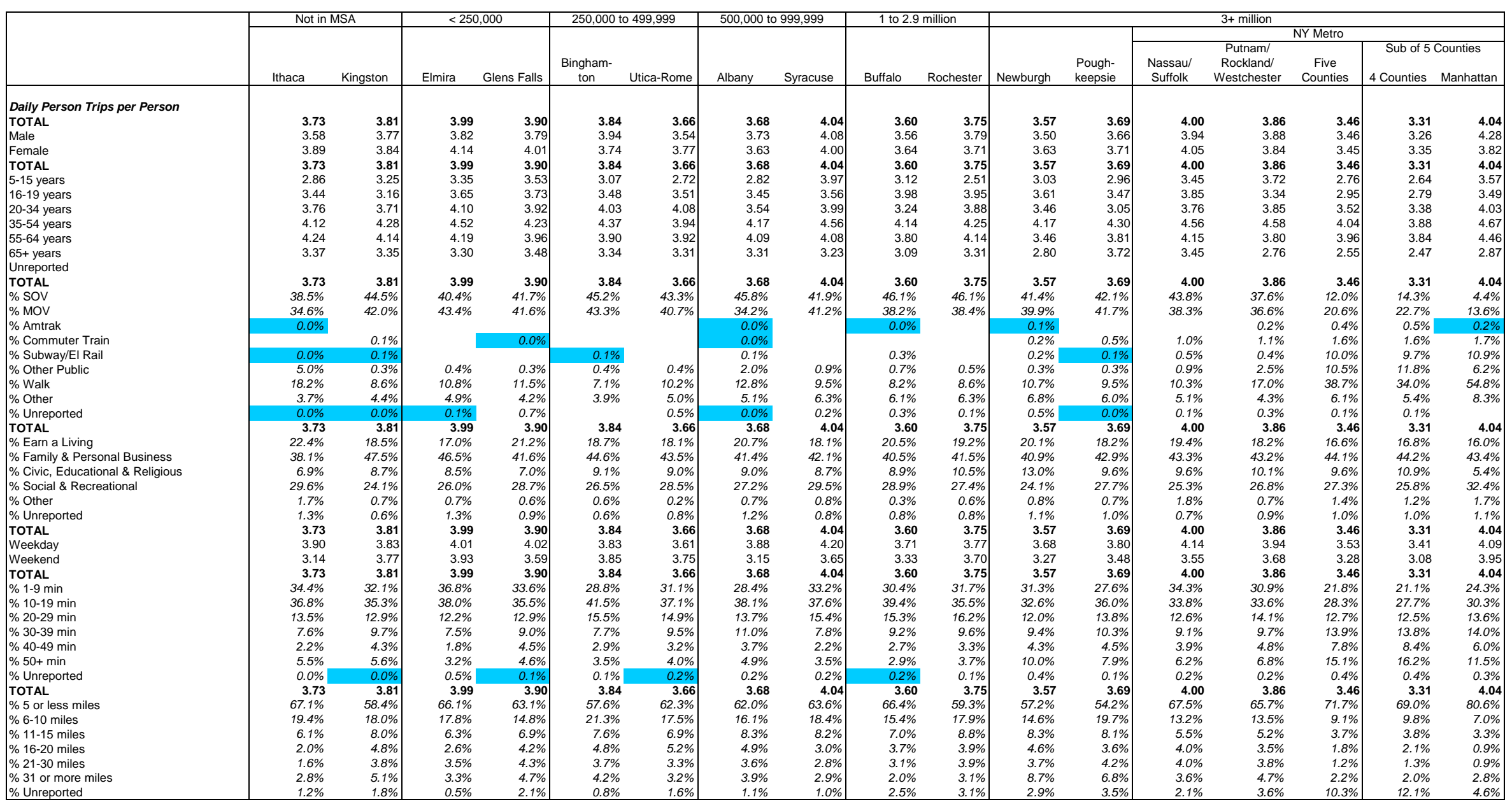




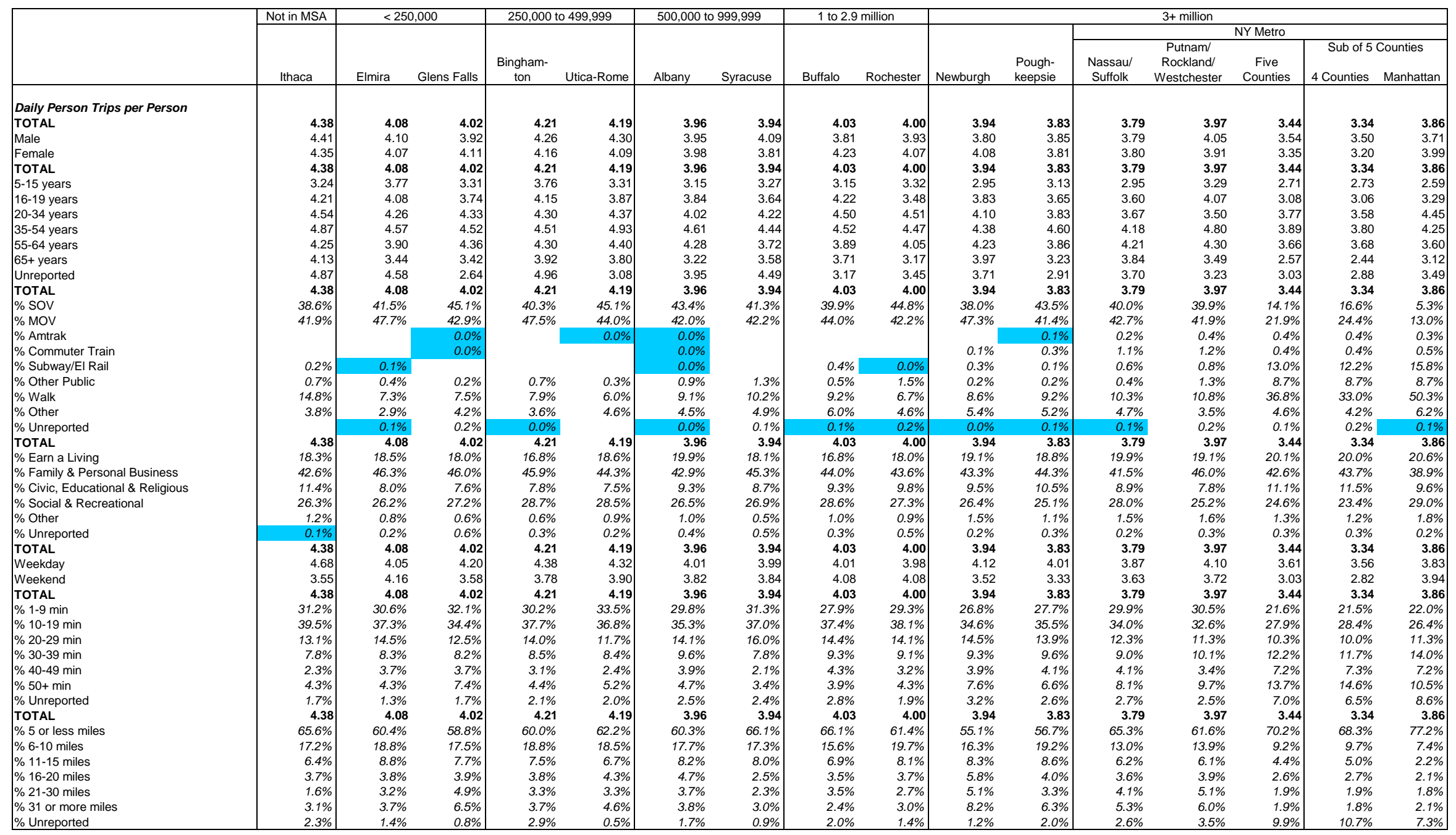




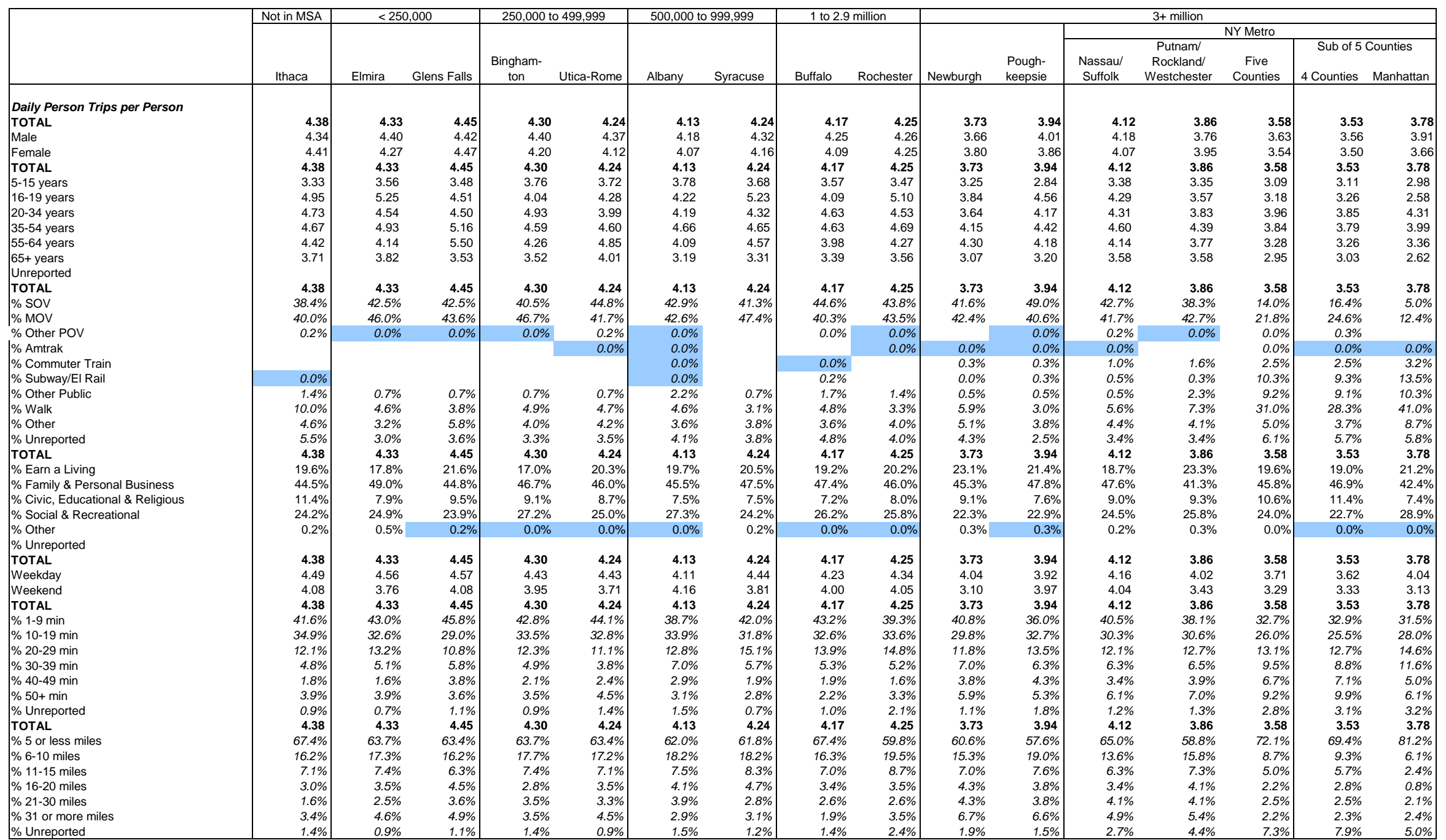




\begin{tabular}{|c|c|c|c|c|c|c|c|c|c|c|c|c|c|c|c|c|c|}
\hline & \multirow{2}{*}{\multicolumn{2}{|c|}{ Not in MSA }} & \multirow{2}{*}{\multicolumn{2}{|c|}{$<250,000$}} & \multicolumn{2}{|c|}{250,000 to 499,999} & \multicolumn{2}{|c|}{500,000 to 999,999} & \multicolumn{2}{|c|}{1 to 2.9 million } & \multicolumn{7}{|c|}{$3+$ million } \\
\hline & & & & \multirow{2}{*}{ Glens Falls } & \multirow[b]{2}{*}{$\begin{array}{l}\text { Bingham- } \\
\text { ton }\end{array}$} & \multirow{2}{*}{ Utica-Rome } & & \multirow{2}{*}{ Syracuse } & & & & & \multirow{2}{*}{\multicolumn{3}{|c|}{ Putnam/ }} & \multirow{2}{*}{\multicolumn{2}{|c|}{ Sub of 5 Counties }} \\
\hline & Ithaca & Kingston & Elmira & & & & Albany & & Buffalo & Rochester & Newburgh & $\begin{array}{l}\text { Pough- } \\
\text { keepsie }\end{array}$ & & & & & \\
\hline Daily P & & 35.80 & 35.46 & 34.74 & 32.71 & & 38.88 & 30.76 & 27.94 & & & & 31.19 & & & 15.44 & \\
\hline$\% \mathrm{SC}-2$ & $36.6 \%$ & $\begin{array}{r}32.9 \% \\
42.9 \%\end{array}$ & $32.0 \%$ & $\begin{array}{r}34.14 \\
43.8 \%\end{array}$ & $43.9 \%$ & $44.9 \%$ & $35.4 \%$ & $44.5 \%$ & $39.4 \%$ & $38.6 \%$ & $49.3 \%$ & $40.8 \%$ & $42.5 \%$ & $41.5 \%$ & $16.5 \%$ & $17.6 \%$ & $\begin{array}{l}18.82 \\
12.7 \%\end{array}$ \\
\hline$\%$ MOV & $54.1 \%$ & $44.3 \%$ & $50.9 \%$ & $41.5 \%$ & $50.5 \%$ & $50.8 \%$ & $44.4 \%$ & $48.5 \%$ & $38.1 \%$ & $46.1 \%$ & $40.7 \%$ & $48.4 \%$ & $39.4 \%$ & $41.6 \%$ & $43.3 \%$ & $41.5 \%$ & $49.2 \%$ \\
\hline $\begin{array}{l}\text { \% Amtrak } \\
\% \text { Commuter Train }\end{array}$ & $0.0 \%$ & $0.9 \%$ & & & & & $0.2 \%$ & & $0.3 \%$ & & $0.5 \%$ & $2.0 \%$ & $3.3 \%$ & $\begin{array}{l}1.5 \% \\
3.5 \%\end{array}$ & $\begin{array}{l}0.1 \% \\
2.4 \%\end{array}$ & $\begin{array}{l}0.2 \% \\
1.4 \%\end{array}$ & $\begin{array}{l}0.0 \% \\
5.5 \%\end{array}$ \\
\hline$\%$ Subway/EI Rail & $0.0 \%$ & $0.0 \%$ & & & $0.7 \%$ & & $0.1 \%$ & & $0.2 \%$ & & $0.6 \%$ & $0.1 \%$ & $0.4 \%$ & $0.7 \%$ & $13.3 \%$ & $13.0 \%$ & $14.2 \%$ \\
\hline$\%$ Other Put & $3.9 \%$ & $0.1 \%$ & $0.1 \%$ & $0.2 \%$ & $0.3 \%$ & $0.3 \%$ & 1. & $0.3 \%$ & $0.5 \%$ & $0.1 \%$ & & & $0.5 \%$ & $1.3 \%$ & $8.4 \%$ & $9.9 \%$ & $3.1 \%$ \\
\hline$\%$ Wa & $1.6 \%$ & $0.7 \%$ & $0.6 \%$ & $1.0 \%$ & $0.5 \%$ & $0.9 \%$ & $0.9 \%$ & $0.7 \%$ & $0.8 \%$ & $0.7 \%$ & $\%$ & $0.6 \%$ & $0.8 \%$ & $1.4 \%$ & $6.5 \%$ & $6.0 \%$ & $8.3 \%$ \\
\hline$\%$ ot -2 & $3.7 \%$ & $11.1 \%$ & $15.9 \%$ & $13.3 \%$ & $4.1 \%$ & $2.8 \%$ & $17.2 \%$ & $5.9 \%$ & $20.7 \%$ & $14.4 \%$ & $6.2 \%$ & $8.1 \%$ & $12.9 \%$ & $7.9 \%$ & $9.6 \%$ & $10.4 \%$ & $7.0 \%$ \\
\hline$\%$ Unreported & $0.0 \%$ & & $0.4 \%$ & & & $0.3 \%$ & $0.0 \%$ & $0.1 \%$ & $0.0 \%$ & $0.1 \%$ & & & $0.2 \%$ & $0.6 \%$ & $0.1 \%$ & $0.1 \%$ & \\
\hline TOT & 26.79 & 35.80 & 35.46 & 34.74 & 32.71 & 26.26 & 38.88 & 30.76 & 27.94 & 34.26 & 37.98 & 39.91 & 31.19 & 30.20 & 16.10 & 15.44 & 18.82 \\
\hline$\%$ Earn a L & $23.2 \%$ & $29.0 \%$ & $16.4 \%$ & $38.0 \%$ & $22.6 \%$ & $23.0 \%$ & $22.1 \%$ & $25.4 \%$ & $27.9 \%$ & $21.0 \%$ & $34.9 \%$ & $26.3 \%$ & $28.4 \%$ & $29.5 \%$ & $29.3 \%$ & $33.1 \%$ & $16.4 \%$ \\
\hline$\%$ Family \& & $30.7 \%$ & $32.6 \%$ & $31.4 \%$ & $28.6 \%$ & $38.2 \%$ & $39.0 \%$ & $23.9 \%$ & $30.5 \%$ & $23.4 \%$ & $28.3 \%$ & $29.0 \%$ & $29.1 \%$ & $27.9 \%$ & $31.1 \%$ & $27.5 \%$ & $28.4 \%$ & $24.7 \%$ \\
\hline cational \& Religious & $6.3 \%$ & $6.6 \%$ & $5.7 \%$ & $4.2 \%$ & $9.7 \%$ & $5.0 \%$ & $4.9 \%$ & $5.5 \%$ & $5.7 \%$ & $6.2 \%$ & 6.5 & $6.5 \%$ & $5.2 \%$ & $5.6 \%$ & $5.5 \%$ & $6.6 \%$ & $1.7 \%$ \\
\hline ecreational & $33.8 \%$ & $25.9 \%$ & $30.1 \%$ & $25.4 \%$ & $26.1 \%$ & $30.3 \%$ & $39.0 \%$ & $35.0 \%$ & $30.2 \%$ & $24.2 \%$ & $25.9 \%$ & $32.6 \%$ & $24.1 \%$ & $29.1 \%$ & $34.2 \%$ & $30.2 \%$ & $47.9 \%$ \\
\hline$\%$ Other & $2.7 \%$ & $1.9 \%$ & $11.9 \%$ & $2.5 \%$ & $1.4 \%$ & $0.1 \%$ & $5.9 \%$ & $2.5 \%$ & $1.0 \%$ & $9.2 \%$ & $1.2 \%$ & $2.1 \%$ & $12.1 \%$ & $2.9 \%$ & $1.3 \%$ & $1.0 \%$ & $2.4 \%$ \\
\hline$\%$ Unreported & $3.3 \%$ & $4.0 \%$ & $4.5 \%$ & $1.4 \%$ & $2.1 \%$ & $2.7 \%$ & $4.2 \%$ & $1.1 \%$ & $11.9 \%$ & $11.1 \%$ & $2.2 \%$ & $3.6 \%$ & $2.3 \%$ & $1.8 \%$ & $2.2 \%$ & $0.7 \%$ & $7.0 \%$ \\
\hline Average & 727 & 9.57 | & 8.93 & أ & 8.60 & 730 & 10.69 & 770 & 796 & 9.43 & 109 & 1121 & 797 & 812 & 530 & 530 & 488 \\
\hline
\end{tabular}




\begin{tabular}{|c|c|c|c|c|c|c|c|c|c|c|c|c|c|c|c|c|}
\hline & \multirow{3}{*}{\begin{tabular}{c|} 
Not in MSA \\
Ithaca \\
\end{tabular}} & \multicolumn{2}{|c|}{$<250,000$} & \multirow{3}{*}{\multicolumn{2}{|c|}{$\begin{array}{l}250,000 \text { to } 499,999 \\
\begin{array}{l}\text { Bingham- } \\
\text { ton }\end{array} \text { Utica-Rome } \\
\end{array}$}} & \multirow{3}{*}{\multicolumn{2}{|c|}{\begin{tabular}{l|}
500,000 to 999,999 \\
\end{tabular}}} & \multirow{3}{*}{\multicolumn{2}{|c|}{$\begin{array}{l}1 \text { to } 2.9 \text { million } \\
\text { Buffalo Rochester } \\
\end{array}$}} & \multirow{2}{*}{\multicolumn{7}{|c|}{$3+$ million }} \\
\hline & & & & & & & & & & & & & & & & \\
\hline & & Elmira & Glens Falls & & & & & & & Newburgh & $\begin{array}{l}\text { Pough- } \\
\text { keepsie }\end{array}$ & $\begin{array}{l}\text { Nassau/ } \\
\text { Suffolk }\end{array}$ & $\begin{array}{c}\text { Putnam/ } \\
\text { Rockland/ } \\
\text { Westchester }\end{array}$ & $\begin{array}{c}\text { Five } \\
\text { Counties }\end{array}$ & $\begin{array}{r}\text { Sub of } 5 \\
4 \text { Counties } \\
\end{array}$ & $\begin{array}{l}\text { Counties } \\
\text { Manhattan }\end{array}$ \\
\hline $\begin{array}{l}\text { Daily PMT per Person } \\
\text { TOTAL }\end{array}$ & & & & & & & & & & & & & & & & \\
\hline $\begin{array}{l}\text { TOTAL } \\
\% \text { SOV }\end{array}$ & $\begin{array}{r}35.19 \\
37.3 \%\end{array}$ & $\begin{array}{r}35.54 \\
38.7 \%\end{array}$ & $\begin{array}{r}39.93 \\
42.0 \%\end{array}$ & $\begin{array}{r}35.95 \\
36.7 \%\end{array}$ & $\begin{array}{r}36.19 \\
43.9 \%\end{array}$ & $\begin{array}{r}34.21 \\
40.7 \%\end{array}$ & $\begin{array}{r}30.45 \\
40.8 \%\end{array}$ & $\begin{array}{r}29.16 \\
41.8 \%\end{array}$ & $\begin{array}{r}33.49 \\
41.5 \%\end{array}$ & $\begin{array}{r}45.54 \\
40.1 \%\end{array}$ & $\begin{array}{r}38.93 \\
40.2 \%\end{array}$ & $\begin{array}{r}31.95 \\
37.5 \%\end{array}$ & $\begin{array}{r}36.50 \\
40.1 \%\end{array}$ & $\begin{array}{r}21.11 \\
16.5 \%\end{array}$ & $\begin{array}{r}18.80 \\
19.9 \%\end{array}$ & $\begin{array}{l}30.84 \\
7.8 \%\end{array}$ \\
\hline$\%$ MOI & $52.0 \%$ & $57.6 \%$ & $50.6 \%$ & $57.3 \%$ & $47.8 \%$ & $48.5 \%$ & $52.1 \%$ & $48.6 \%$ & $47.3 \%$ & $50.7 \%$ & $47.5 \%$ & $47.9 \%$ & $42.5 \%$ & $28.2 \%$ & $30.3 \%$ & $23.1 \%$ \\
\hline$\%$ Amtrak & & & $0.0 \%$ & & $2.1 \%$ & $0.5 \%$ & & & & & $0.7 \%$ & $0.6 \%$ & $1.1 \%$ & $1.0 \%$ & $0.8 \%$ & $1.5 \%$ \\
\hline$\%$ Commuter Train & & & $0.0 \%$ & & & $0.0 \%$ & & & & $0.5 \%$ & $1.8 \%$ & $3.6 \%$ & $3.6 \%$ & $0.6 \%$ & $0.6 \%$ & $0.6 \%$ \\
\hline \% Subway/EI Rail & $0.1 \%$ & $0.8 \%$ & & & & $0.0 \%$ & & $0.3 \%$ & $0.0 \%$ & $1.1 \%$ & $0.1 \%$ & $0.8 \%$ & $1.1 \%$ & $14.2 \%$ & $15.8 \%$ & $10.2 \%$ \\
\hline$\%$ Other Public & $0.5 \%$ & $0.1 \%$ & $0.1 \%$ & $0.8 \%$ & $0.2 \%$ & $0.6 \%$ & $0.8 \%$ & $0.1 \%$ & $1.0 \%$ & $0.4 \%$ & $0.1 \%$ & $0.5 \%$ & $0.7 \%$ & $5.4 \%$ & $6.0 \%$ & $4.0 \%$ \\
\hline$\%$ Walk & $1.4 \%$ & $0.7 \%$ & $0.6 \%$ & $0.9 \%$ & $0.6 \%$ & $0.8 \%$ & $0.8 \%$ & $1.1 \%$ & $0.6 \%$ & $0.5 \%$ & $0.7 \%$ & $1.1 \%$ & $1.0 \%$ & $3.9 \%$ & $3.7 \%$ & $4.4 \%$ \\
\hline$\%$ Oth & $8.6 \%$ & $2.2 \%$ & $6.4 \%$ & $4.3 \%$ & $5.5 \%$ & $8.8 \%$ & $5.4 \%$ & $8.2 \%$ & $9.5 \%$ & $6.7 \%$ & $9.1 \%$ & $7.7 \%$ & $7.2 \%$ & $29.1 \%$ & $22.8 \%$ & $45.4 \%$ \\
\hline$\%$ Unr & & $0.0 \%$ & $0.3 \%$ & & & & & $0.1 \%$ & & & & $0.4 \%$ & $2.8 \%$ & $0.9 \%$ & $0.1 \%$ & $3.1 \%$ \\
\hline TOTAL & 35.19 & 35.54 & 39.93 & 35.95 & 36.19 & 34.21 & 30.45 & 29.16 & 33.49 & 45.54 & 38.93 & 31.95 & 36.50 & 21.11 & 18.80 & 30.84 \\
\hline$\%$ Earn & $23.0 \%$ & $21.3 \%$ & $25.3 \%$ & $19.6 \%$ & $30.8 \%$ & $27.7 \%$ & $25.3 \%$ & $23.5 \%$ & $21.2 \%$ & $29.0 \%$ & $29.9 \%$ & $30.7 \%$ & $30.3 \%$ & $34.1 \%$ & $41.2 \%$ & $16.0 \%$ \\
\hline$\%$ Fam & $39.8 \%$ & $36.6 \%$ & $35.5 \%$ & $47.1 \%$ & $35.8 \%$ & $31.6 \%$ & $30.0 \%$ & $34.9 \%$ & $32.1 \%$ & 30.1 & $29.5 \%$ & 28.1 & $30.2 \%$ & $23.6 \%$ & $27.0 \%$ & $15.0 \%$ \\
\hline$\%$ Civic, Educational \& Religious & $8.0 \%$ & $5.8 \%$ & $5.5 \%$ & $5.6 \%$ & $5.7 \%$ & $5.9 \%$ & $4.9 \%$ & $5.7 \%$ & $8.0 \%$ & $4.8 \%$ & $6.8 \%$ & $3.9 \%$ & $4.4 \%$ & $5.3 \%$ & $6.4 \%$ & $2.4 \%$ \\
\hline \% Social \& Recreational & $25.6 \%$ & $35.4 \%$ & $31.7 \%$ & $27.4 \%$ & $26.7 \%$ & $30.8 \%$ & $39.0 \%$ & $32.3 \%$ & $34.9 \%$ & $30.0 \%$ & $32.8 \%$ & $35.6 \%$ & $30.4 \%$ & $24.3 \%$ & $21.5 \%$ & $31.3 \%$ \\
\hline$\%$ Other & $3.5 \%$ & $0.5 \%$ & $1.2 \%$ & $0.3 \%$ & $0.8 \%$ & $2.2 \%$ & $0.5 \%$ & $3.7 \%$ & $2.8 \%$ & $3.7 \%$ & $1.0 \%$ & $1.6 \%$ & $4.6 \%$ & $9.1 \%$ & $3.7 \%$ & $22.9 \%$ \\
\hline$\%$ Unreported & $0.1 \%$ & $0.3 \%$ & $0.8 \%$ & $0.1 \%$ & $0.3 \%$ & $1.8 \%$ & $0.3 \%$ & $0.1 \%$ & $1.0 \%$ & $2.5 \%$ & $0.1 \%$ & $0.1 \%$ & $0.2 \%$ & $3.7 \%$ & $0.2 \%$ & $12.4 \%$ \\
\hline $\begin{array}{l}\text { Average } P e \\
\text { TOTAL }\end{array}$ & 8.22 & 8.82 & 10.02 & 8.78 & 8.69 & 8.77 & 7.79 & 7.38 & 8.48 & 11.68 & 10.38 & 8.65 & 9.51 & 682 & 6.30 & 8.61 \\
\hline
\end{tabular}




\begin{tabular}{|c|c|c|c|c|c|c|c|c|c|c|c|c|c|c|c|c|}
\hline & \multirow{3}{*}{$\begin{array}{c}\text { Not in MSA } \\
\text { Ithaca }\end{array}$} & \multirow{2}{*}{\multicolumn{2}{|c|}{$<250,000$}} & \multirow{3}{*}{\multicolumn{2}{|c|}{$\begin{array}{l}250,000 \text { to } 499,999 \\
\begin{array}{l}\text { Bingham- } \\
\text { ton }\end{array} \text { Utica-Rome } \\
\end{array}$}} & \multirow{3}{*}{\multicolumn{2}{|c|}{$\begin{array}{l}500,000 \text { to } 999,999 \\
\text { Albany Syracuse }\end{array}$}} & \multirow{3}{*}{\multicolumn{2}{|c|}{$\begin{array}{l}1 \text { to } 2.9 \text { million } \\
\text { Buffalo Rochester }\end{array}$}} & \multirow[b]{3}{*}{ Newburgh } & \multicolumn{6}{|c|}{$3+$ million } \\
\hline & & & & & & & & & & & & & & NY Metro & & \\
\hline & & Elmira & Glens Falls & & & & & & & & $\begin{array}{l}\text { Pough- } \\
\text { keepsie }\end{array}$ & $\begin{array}{l}\text { Nassau/ } \\
\text { Suffolk }\end{array}$ & $\begin{array}{c}\text { Putnam/ } \\
\text { Rockland/ } \\
\text { Westchester }\end{array}$ & $\begin{array}{c}\text { Five } \\
\text { Counties }\end{array}$ & $\begin{array}{r}\text { Sub of } 5 \\
4 \text { Counties }\end{array}$ & $\begin{array}{l}\text { Counties } \\
\text { Manhattan }\end{array}$ \\
\hline \multicolumn{17}{|l|}{ Daily PMT per Person } \\
\hline $\begin{array}{l}\text { TOTAL } \\
\% \text { SOV }\end{array}$ & $\begin{array}{l}31.22 \\
46.5 \%\end{array} \mid$ & $\begin{array}{l}39.67 \\
37.2 \%\end{array}$ & $\begin{array}{r}36.39 \\
38.9 \%\end{array} \mid$ & $\begin{array}{l}34.43 \\
38.5 \%\end{array}$ & $\begin{array}{l}35.27 \\
41.8 \%\end{array}$ & $\begin{array}{l}33.84 \\
41.1 \%\end{array}$ & $\begin{array}{r}36.37 \\
354 \%\end{array}$ & 28.54 & $\begin{array}{l}37.62 \\
34.3 \%\end{array}$ & $\begin{array}{l}34.43 \\
51.1 \%\end{array}$ & $\begin{array}{l}40.35 \\
49.9 \%\end{array}$ & $\begin{array}{r}33.47 \\
392 \%\end{array}$ & $\begin{array}{l}35.82 \\
3660 \%\end{array}$ & $\begin{array}{l}19.08 \\
20.5 \%\end{array}$ & 19.33 & $\begin{array}{l}18.13 \\
15.0 \%\end{array}$ \\
\hline$\%$ MOV & $46.2 \%$ & $58.2 \%$ & $50.9 \%$ & $57.6 \%$ & $54.1 \%$ & $48.3 \%$ & $57.9 \%$ & $50.7 \%$ & $57.0 \%$ & $40.6 \%$ & $42.9 \%$ & $48.6 \%$ & $50.6 \%$ & $38.9 \%$ & $41.2 \%$ & $29.8 \%$ \\
\hline$\%$ Other POV & $0.2 \%$ & $0.0 \%$ & $0.0 \%$ & & $0.1 \%$ & $0.0 \%$ & & $0.1 \%$ & $0.0 \%$ & & $0.0 \%$ & $0.1 \%$ & $0.1 \%$ & $0.3 \%$ & $0.3 \%$ & \\
\hline \% Amtrak & & & & & $0.0 \%$ & & & & & $0.9 \%$ & $0.8 \%$ & $1.2 \%$ & & $0.3 \%$ & $0.2 \%$ & $0.4 \%$ \\
\hline$\%$ Commuter Train & & & & & & & & $0.0 \%$ & & $1.5 \%$ & $1.4 \%$ & $4.4 \%$ & $4.5 \%$ & $5.0 \%$ & $4.4 \%$ & $7.3 \%$ \\
\hline \% Subway/El Rail & $0.0 \%$ & & & & & $0.1 \%$ & & $0.2 \%$ & & $0.1 \%$ & $0.3 \%$ & $0.9 \%$ & $0.4 \%$ & $14.8 \%$ & $15.0 \%$ & $14.2 \%$ \\
\hline$\%$ Other Public & $1.2 \%$ & $2.6 \%$ & $2.8 \%$ & $1.1 \%$ & $0.2 \%$ & $2.7 \%$ & $2.0 \%$ & $1.5 \%$ & $2.4 \%$ & $1.5 \%$ & $0.5 \%$ & $1.9 \%$ & $3.4 \%$ & $9.2 \%$ & $9.5 \%$ & $7.9 \%$ \\
\hline$\%$ Walk & $0.9 \%$ & $0.3 \%$ & $0.3 \%$ & $0.3 \%$ & $0.4 \%$ & $0.3 \%$ & $0.3 \%$ & $0.4 \%$ & $0.3 \%$ & $0.3 \%$ & $0.2 \%$ & $0.3 \%$ & $0.4 \%$ & $3.5 \%$ & $3.0 \%$ & $5.7 \%$ \\
\hline$\%$ Other & $4.0 \%$ & $1.3 \%$ & $6.6 \%$ & $1.9 \%$ & $2.9 \%$ & $5.6 \%$ & $4.0 \%$ & $2.0 \%$ & $4.0 \%$ & $3.4 \%$ & $3.7 \%$ & $2.3 \%$ & $3.2 \%$ & $6.6 \%$ & $3.7 \%$ & $18.4 \%$ \\
\hline$\%$ Unreported & $0.9 \%$ & $0.5 \%$ & $0.5 \%$ & $0.6 \%$ & $0.6 \%$ & $1.9 \%$ & $0.3 \%$ & $0.7 \%$ & $2.1 \%$ & $0.6 \%$ & $0.3 \%$ & $1.1 \%$ & $0.7 \%$ & $0.8 \%$ & $0.8 \%$ & $1.2 \%$ \\
\hline TOTAL & 31.22 & 39.67 & 36.39 & 34.43 & 35.27 & 33.84 & 36.37 & 28.54 & 37.62 & 34.43 & 40.35 & 33.47 & 35.82 & 19.08 & 19.33 & 18.13 \\
\hline$\%$ Earn a Living & $26.9 \%$ & $21.3 \%$ & $29.7 \%$ & $23.3 \%$ & $26.6 \%$ & $28.7 \%$ & $28.5 \%$ & $28.2 \%$ & $20.8 \%$ & $38.0 \%$ & $33.2 \%$ & $30.4 \%$ & $32.6 \%$ & $31.2 \%$ & $31.2 \%$ & $30.9 \%$ \\
\hline$\%$ Family \& Personal Business & $36.8 \%$ & $40.6 \%$ & $34.0 \%$ & $36.1 \%$ & $40.7 \%$ & $34.7 \%$ & $34.7 \%$ & $32.9 \%$ & $41.1 \%$ & $30.4 \%$ & $30.3 \%$ & $33.3 \%$ & $24.9 \%$ & $32.2 \%$ & $31.9 \%$ & $33.3 \%$ \\
\hline$\%$ Civic, Educational \& Religious & $6.5 \%$ & $4.2 \%$ & $8.4 \%$ & $5.2 \%$ & $5.3 \%$ & $4.0 \%$ & $4.9 \%$ & $4.6 \%$ & $4.9 \%$ & $5.3 \%$ & $4.5 \%$ & $5.2 \%$ & $4.4 \%$ & $6.7 \%$ & $7.1 \%$ & $4.9 \%$ \\
\hline$\%$ Social \& Recreational & $29.8 \%$ & $33.0 \%$ & $26.5 \%$ & $35.3 \%$ & $25.4 \%$ & $32.4 \%$ & $31.8 \%$ & $33.9 \%$ & $32.8 \%$ & $26.1 \%$ & $31.9 \%$ & $30.8 \%$ & $38.0 \%$ & $30.0 \%$ & $29.8 \%$ & $30.9 \%$ \\
\hline$\%$ Other & $0.1 \%$ & $0.9 \%$ & $1.4 \%$ & $0.1 \%$ & $2.0 \%$ & $0.1 \%$ & $0.1 \%$ & $0.0 \%$ & $0.4 \%$ & $0.1 \%$ & $0.1 \%$ & $0.4 \%$ & $0.1 \%$ & $0.0 \%$ & $0.0 \%$ & $0.0 \%$ \\
\hline$\%$ Unreported & & & $0.0 \%$ & & & $0.1 \%$ & $0.0 \%$ & $0.3 \%$ & & & & $0.0 \%$ & $0.0 \%$ & $0.0 \%$ & & \\
\hline Average Person $T$ & 724 & 9.23 & 828 & 811 & 8.41 & 830 & 8.6 & 6.94 & 908 & 939 & 10.41 & 833 & 970 & 5.74 & 5.95 & 5.04 \\
\hline
\end{tabular}




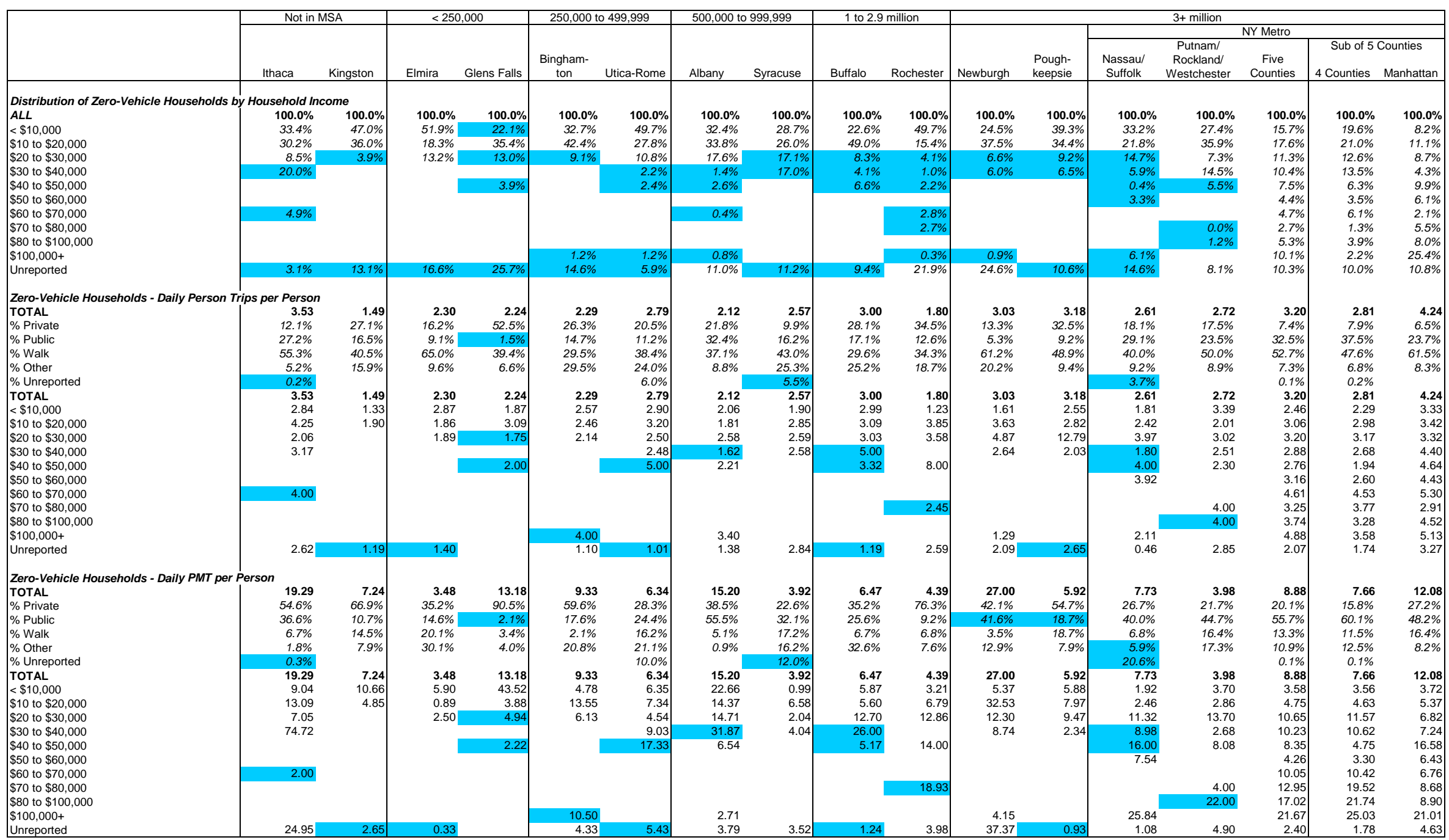




\begin{tabular}{|c|c|c|c|c|c|c|c|c|c|c|c|c|c|c|c|c|}
\hline & \multirow{3}{*}{\begin{tabular}{|c|} 
Not in MSA \\
thaca \\
\end{tabular}} & \multirow{2}{*}{\multicolumn{2}{|c|}{$<250,000$}} & \multirow{3}{*}{\multicolumn{2}{|c|}{$\begin{array}{l}250,000 \text { to } 499,999 \\
\begin{array}{l}\text { Bingham- } \\
\text { ton }\end{array} \text { Utica-Rome } \\
\end{array}$}} & \multirow{3}{*}{\multicolumn{2}{|c|}{$\begin{array}{l}500,000 \text { to } 999,999 \\
\\
\text { Albany } \quad \text { Syracuse }\end{array}$}} & \multirow{3}{*}{\multicolumn{2}{|c|}{$\begin{array}{l}1 \text { to } 2.9 \text { million } \\
\text { Buffalo Rochester }\end{array}$}} & \multirow[b]{3}{*}{ Newburgh } & \multirow{2}{*}{\multicolumn{6}{|c|}{$3+$ million }} \\
\hline & & & & & & & & & & & & & & & & \\
\hline & & Elmira & Glens Falls & & & & & & & & $\begin{array}{l}\text { Pough- } \\
\text { keepsie }\end{array}$ & $\begin{array}{c}\text { Nassau/ } \\
\text { Suffolk }\end{array}$ & $\begin{array}{c}\text { Putnam/ } \\
\text { Rockland/ } \\
\text { Westchester }\end{array}$ & $\begin{array}{c}\text { Five } \\
\text { Counties }\end{array}$ & $\begin{array}{r}\text { Sub of } 5 \\
4 \text { Counties }\end{array}$ & $\begin{array}{l}\text { Counties } \\
\text { Manhattan }\end{array}$ \\
\hline \multicolumn{17}{|c|}{ Distribution of Zero-Vehicle Households by Household Income } \\
\hline & $100.0 \%$ & $100.0 \%$ & $100.0 \%$ & $100.0 \%$ & $100.0 \%$ & $100.0 \%$ & $100.0 \%$ & $100.0 \%$ & $100.0 \%$ & $100.0 \%$ & $100.0 \%$ & $100.0 \%$ & $100.0 \%$ & $100.0 \%$ & $100.0 \%$ & $100.0 \%$ \\
\hline$<\$ 10,000$ & $20.4 \%$ & $41.4 \%$ & $36.3 \%$ & $23.2 \%$ & $28.3 \%$ & $22.4 \%$ & $34.1 \%$ & $32.6 \%$ & $52.6 \%$ & $21.3 \%$ & $30.5 \%$ & $14.3 \%$ & $23.6 \%$ & $16.3 \%$ & $19.1 \%$ & $10.6 \%$ \\
\hline$\$ 10$ to $\$ 20,000$ & $35.3 \%$ & $38.5 \%$ & $18.1 \%$ & $36.6 \%$ & $30.8 \%$ & $20.2 \%$ & $28.8 \%$ & $35.9 \%$ & $22.9 \%$ & $35.8 \%$ & $27.6 \%$ & $29.0 \%$ & $24.7 \%$ & $15.6 \%$ & $18.1 \%$ & $10.6 \%$ \\
\hline$\$ 20$ to $\$ 30,000$ & $15.0 \%$ & $2.2 \%$ & $14.5 \%$ & $11.8 \%$ & $22.4 \%$ & $21.8 \%$ & $19.1 \%$ & $9.2 \%$ & $21.2 \%$ & $14.1 \%$ & $22.4 \%$ & $14.4 \%$ & $4.4 \%$ & $12.0 \%$ & $14.7 \%$ & $6.5 \%$ \\
\hline$\$ 30$ to $\$ 40,000$ & $12.0 \%$ & $2.4 \%$ & $12.8 \%$ & $2.3 \%$ & $0.9 \%$ & $10.1 \%$ & $9.1 \%$ & $7.3 \%$ & $3.4 \%$ & & $12.5 \%$ & $8.6 \%$ & $17.3 \%$ & $12.5 \%$ & $13.8 \%$ & $9.9 \%$ \\
\hline$\$ 40$ to $\$ 50,000$ & & $2.3 \%$ & & & & & & & & & & $2.1 \%$ & $2.5 \%$ & $3.4 \%$ & $3.6 \%$ & $3.0 \%$ \\
\hline$\$ 50$ to $\$ 60,000$ & $3.1 \%$ & $0.7 \%$ & & $1.8 \%$ & & $1.8 \%$ & & & & $4.9 \%$ & & $2.7 \%$ & $1.5 \%$ & $7.6 \%$ & $6.4 \%$ & $9.9 \%$ \\
\hline$\$ 60$ to $\$ 70,000$ & $2.2 \%$ & & & $1.2 \%$ & & & & & & & & $1.2 \%$ & $3.3 \%$ & $3.2 \%$ & $2.3 \%$ & $5.3 \%$ \\
\hline$\$ 70$ to $\$ 80,000$ & $2.0 \%$ & & & & & & & $0.7 \%$ & & & $2.4 \%$ & & $0.7 \%$ & $2.7 \%$ & $2.3 \%$ & $3.5 \%$ \\
\hline$\$ 80$ to $\$ 100,000$ & $3.8 \%$ & & & & & & & $1.0 \%$ & & & & $0.8 \%$ & $0.3 \%$ & $2.8 \%$ & $1.4 \%$ & $5.5 \%$ \\
\hline$\$ 100,000+$ & & & & & & $4.1 \%$ & & & & & & $2.7 \%$ & $2.1 \%$ & $9.5 \%$ & $3.4 \%$ & $21.9 \%$ \\
\hline Unreported & $6.2 \%$ & $12.5 \%$ & $18.3 \%$ & $23.3 \%$ & $17.7 \%$ & $19.6 \%$ & $8.9 \%$ & $13.4 \%$ & & $23.9 \%$ & $4.5 \%$ & $24.3 \%$ & $19.5 \%$ & $14.5 \%$ & $15.1 \%$ & $13.4 \%$ \\
\hline \multicolumn{17}{|c|}{ Zero-Vehicle Households - Daily } \\
\hline TOTAL & 3.12 & 2.60 & 2.14 & 2.36 & 1.99 & 2.48 & 3.10 & 3.07 & 2.45 & 2.68 & 2.63 & 1.96 & 2.71 & 3.30 & 3.04 & 3.99 \\
\hline$\%$ Private & $40.8 \%$ & $46.8 \%$ & $39.3 \%$ & $30.0 \%$ & $48.8 \%$ & $32.6 \%$ & $34.9 \%$ & $28.5 \%$ & $17.3 \%$ & $32.1 \%$ & $49.5 \%$ & $41.9 \%$ & $31.7 \%$ & $13.3 \%$ & $15.0 \%$ & $9.9 \%$ \\
\hline$\%$ Public & $3.9 \%$ & $15.3 \%$ & $14.2 \%$ & $14.8 \%$ & $11.4 \%$ & $17.2 \%$ & $14.4 \%$ & $11.9 \%$ & $38.6 \%$ & $6.5 \%$ & $3.1 \%$ & $1.4 \%$ & $24.0 \%$ & $32.7 \%$ & $35.2 \%$ & $27.5 \%$ \\
\hline$\%$ Walk & $53.6 \%$ & $31.7 \%$ & $43.5 \%$ & $45.1 \%$ & $39.8 \%$ & $42.3 \%$ & $38.3 \%$ & $33.8 \%$ & $40.3 \%$ & $47.0 \%$ & $36.9 \%$ & $37.7 \%$ & $35.4 \%$ & $47.2 \%$ & $43.2 \%$ & $55.4 \%$ \\
\hline$\%$ Other & $1.7 \%$ & $6.2 \%$ & $3.0 \%$ & $10.1 \%$ & & $7.9 \%$ & $12.5 \%$ & $25.8 \%$ & $3.9 \%$ & $14.4 \%$ & $10.5 \%$ & $19.0 \%$ & $8.0 \%$ & $6.6 \%$ & $6.4 \%$ & $7.0 \%$ \\
\hline$\%$ Unreported & & & & & & & & & & & & & $0.9 \%$ & $0.2 \%$ & $0.2 \%$ & $0.2 \%$ \\
\hline TOTAL & 3.12 & 2.60 & 2.14 & 2.36 & 1.99 & 2.48 & 3.10 & 3.07 & 2.45 & 2.68 & 2.63 & 1.96 & 2.71 & 3.30 & 3.04 & 3.99 \\
\hline$<\$ 10$ & 2.56 & 3.59 & 2.41 & 2.57 & 2.75 & 2.56 & 1.51 & 3.90 & 2.77 & 1.63 & 2.10 & 1.72 & 3.16 & 2.83 & 2.67 & 3.43 \\
\hline$\$ 10 \mathrm{t}$ & 1.47 & 2.27 & 2.23 & 3.00 & 2.86 & 2.28 & 3.39 & 3.09 & 1.55 & 5.06 & 3.89 & 2.14 & 2.52 & 3.03 & 2.95 & 3.34 \\
\hline$\$ 20$ to $\$ 30,000$ & 2.08 & 1.57 & 1.71 & 1.80 & 1.24 & 2.62 & $\begin{array}{l}3.97 \\
\end{array}$ & 3.62 & 1.98 & 0.84 & 1.66 & 0.13 & 2.95 & 3.31 & 3.45 & 2.59 \\
\hline$\$ 30$ to $\$ 40,000$ & 7.45 & 5.00 & 2.00 & 2.88 & 2.00 & 2.98 & 3.05 & 1.44 & 3.00 & & 3.99 & 2.80 & 2.87 & 3.16 & 2.87 & 4.32 \\
\hline$\$ 40$ to $\$ 50,000$ & & & & & & & & & & & & 3.00 & 3.75 & 3.93 & 3.77 & 4.21 \\
\hline$\$ 50$ to $\$ 60,000$ & 7.43 & 2.87 & & 3.00 & & 2.08 & & & & 2.00 & & 4.38 & 4.00 & 3.40 & 3.13 & 4.42 \\
\hline$\$ 60$ to $\$ 70,000$ & 2.45 & & & 2.00 & & & & & & & & & 1.29 & 4.42 & 4.93 & 3.68 \\
\hline$\$ 70$ to $\$ 80,000$ & 5.00 & & & & & & & 4.71 & & & 1.95 & & 4.00 & 3.81 & 2.86 & 6.52 \\
\hline$\$ 80$ to $\$ 100,000$ & 3.00 & & & & & & & 4.73 & & & & 5.78 & 1.18 & 4.39 & 4.39 & 4.39 \\
\hline$\$ 100,000+$ & & & & & & 3.23 & & & & & & 7.00 & 3.51 & 4.43 & 3.94 & 4.63 \\
\hline Unreported & 1.20 & 0.33 & 1.91 & 0.84 & 1.93 & 1.91 & 2.68 & 1.86 & & 1.96 & 1.37 & 1.79 & 2.12 & 2.55 & 2.18 & 3.58 \\
\hline \multirow{2}{*}{\multicolumn{17}{|c|}{ Zero-Vehicle $\mathrm{HC}$}} \\
\hline & 7.56 & 4.74 & 12.84 & 7.73 & 8.50 & 8.27 & 9.37 & 6.85 & 6.42 & 16.90 & 30.03 & 4.64 & 7.35 & 17.87 & 17.11 & 19.87 \\
\hline$\%$ Private & $77.6 \%$ & $71.8 \%$ & $88.6 \%$ & $53.8 \%$ & $76.0 \%$ & $63.3 \%$ & $63.5 \%$ & $56.5 \%$ & $21.9 \%$ & $75.4 \%$ & $93.2 \%$ & $56.4 \%$ & $32.1 \%$ & $16.8 \%$ & $13.5 \%$ & $24.5 \%$ \\
\hline$\%$ Public & $11.3 \%$ & $6.3 \%$ & $7.3 \%$ & $22.1 \%$ & $13.2 \%$ & $22.5 \%$ & $17.2 \%$ & $13.4 \%$ & $69.6 \%$ & $7.7 \%$ & $0.1 \%$ & $1.6 \%$ & $55.1 \%$ & $31.5 \%$ & $33.4 \%$ & $27.1 \%$ \\
\hline$\%$ Walk & $9.7 \%$ & $14.8 \%$ & $3.9 \%$ & $13.3 \%$ & $10.8 \%$ & $6.5 \%$ & $6.2 \%$ & $8.2 \%$ & $6.3 \%$ & $4.1 \%$ & $1.7 \%$ & $17.2 \%$ & $8.4 \%$ & $5.7 \%$ & $4.9 \%$ & $7.6 \%$ \\
\hline$\%$ Other & $1.4 \%$ & $7.1 \%$ & $0.3 \%$ & $10.9 \%$ & & $7.7 \%$ & $13.1 \%$ & $21.9 \%$ & $2.2 \%$ & $12.9 \%$ & $5.1 \%$ & $24.8 \%$ & $4.4 \%$ & $45.9 \%$ & $48.1 \%$ & $40.8 \%$ \\
\hline$\%$ Unreported & & & & & & & & & & & & & & $0.1 \%$ & $0.1 \%$ & $0.0 \%$ \\
\hline TOTA & 7.56 & 4.74 & 12.84 & 7.73 & 8.50 & 8.27 & 9.37 & 6.85 & 6.42 & 16.90 & 30.03 & 4.64 & 7.35 & 17.87 & 17.11 & 19.87 \\
\hline & 4.70 & 5.06 & 6.04 & 4.71 & 19.86 & 8.28 & 8.35 & 3.87 & 7.66 & 16.98 & 11.92 & 2.32 & 6.85 & 11.39 & 10.73 & 13.90 \\
\hline$\$ 10$ to $\$ 2$ & 2.88 & 5.16 & 0.70 & 11.19 & & 6.17 & 15.16 & 5.93 & 6.01 & 4.38 & 38.06 & 6.04 & 2.86 & 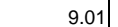 & 7.72 & 14.12 \\
\hline$\$ 20$ to $\$ 30,0$ & 8.40 & 7.61 & 0.85 & 9.91 & 3.36 & 12.19 & 7.00 & 3.33 & 1.26 & 12.61 & 4.34 & 0.80 & 13.75 & & 7.34 & 6.75 \\
\hline$\$ 30$ to $\$ 40,000$ & 4.02 & 3.00 & 72.89 & 1.28 & 10.00 & 10.95 & 8.87 & 37.14 & 12.00 & & 10.09 & 10.99 & 6.12 & 16.12 & 18.15 & 7.86 \\
\hline$\$ 40$ to $\$ 50,0$ & & & & & & & & & & & & 1.00 & 83.57 & 14.07 & 17.03 & 8.99 \\
\hline$\$ 50$ to $\$ 60,000$ & 43.35 & 19.76 & & 7.67 & & 8.73 & & & & 6.00 & & 17.87 & & 13.91 & 13.66 & 14.86 \\
\hline$\$ 60$ to $\$ 70,000$ & 1.61 & & & & & & & & & & & & 1.44 & 17.23 & 20.73 & 12.13 \\
\hline$\$ 70$ to $\$ 80,000$ & 10.00 & & & & & & & 26.12 & & & 107.07 & & 22.02 & 29.83 & 6.26 & 96.93 \\
\hline$\$ 80$ to $\$ 100,000$ & & & & & & & & 6.69 & & & & 12.72 & 23.54 & 16.13 & 14.15 & 17.91 \\
\hline$\$ 100,000$ & & & & & & 16.14 & & & & & & 10.83 & 14.65 & 79.77 & 189.36 & 35.95 \\
\hline Unreported & 0.60 & 0.49 & 5.37 & 5.97 & 6.17 & 1.88 & 4.64 & 4.20 & & 36.44 & 0.50 & 2.30 & 3.28 & 5.65 & 4.16 & 9.83 \\
\hline
\end{tabular}




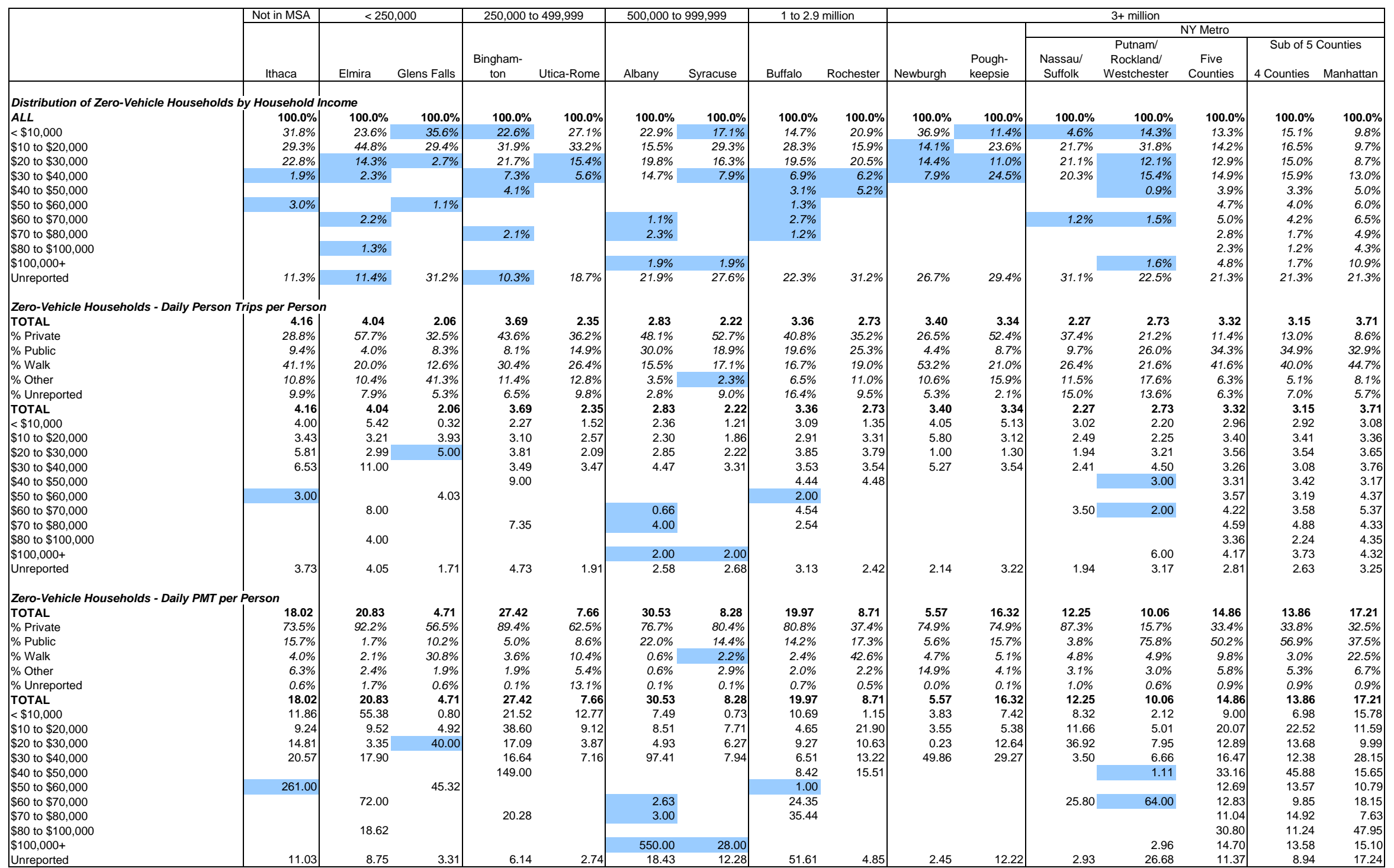




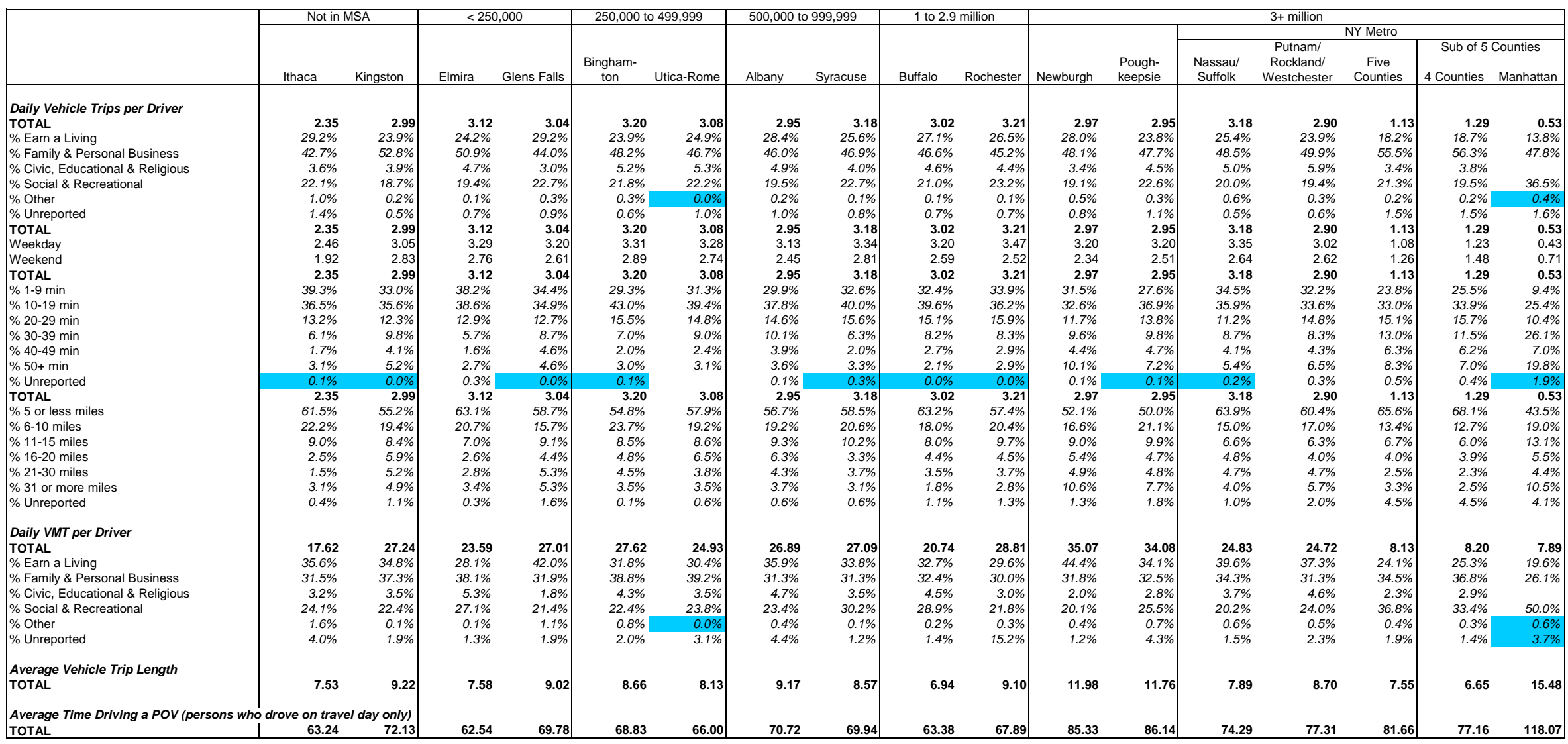




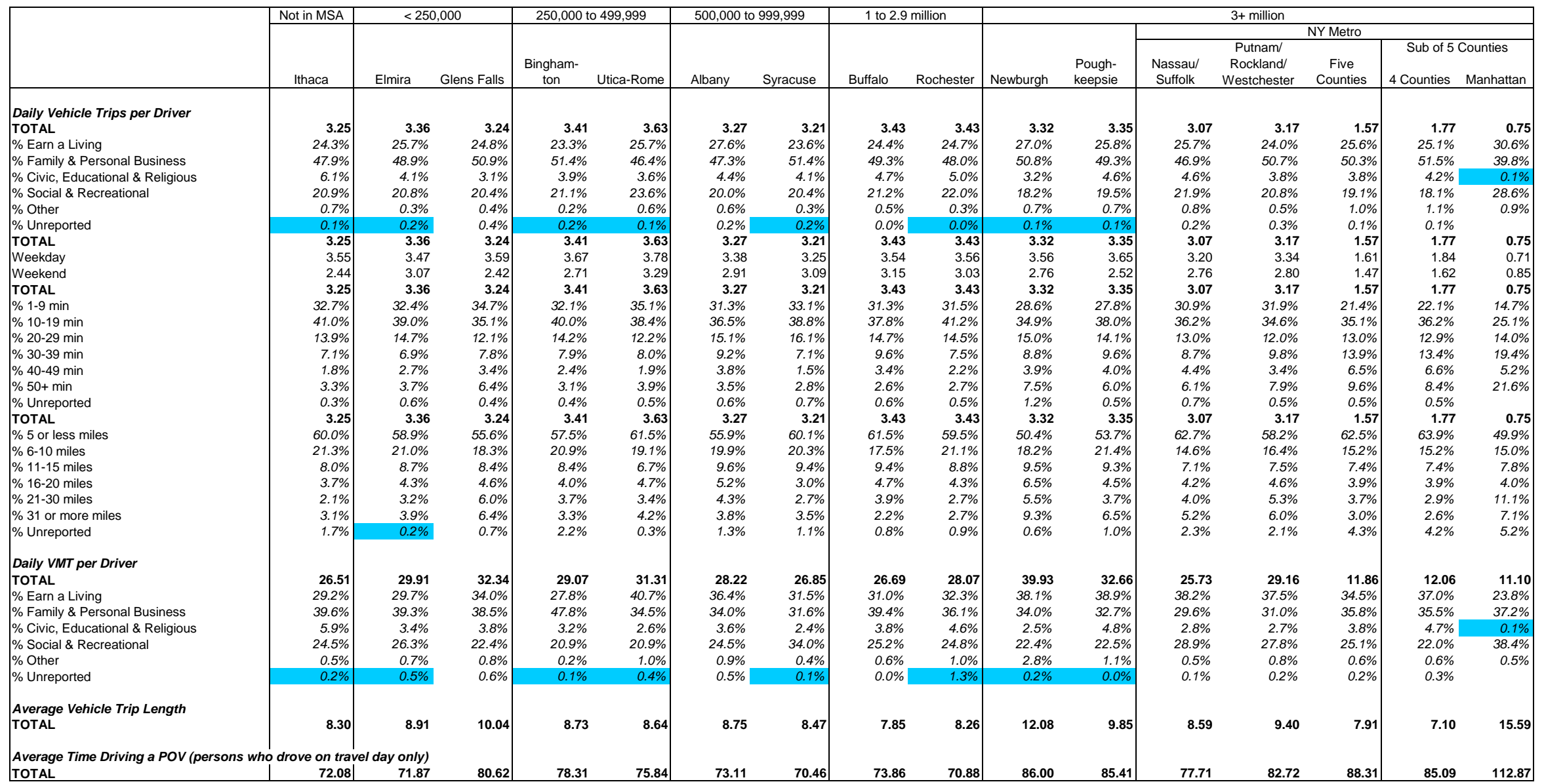




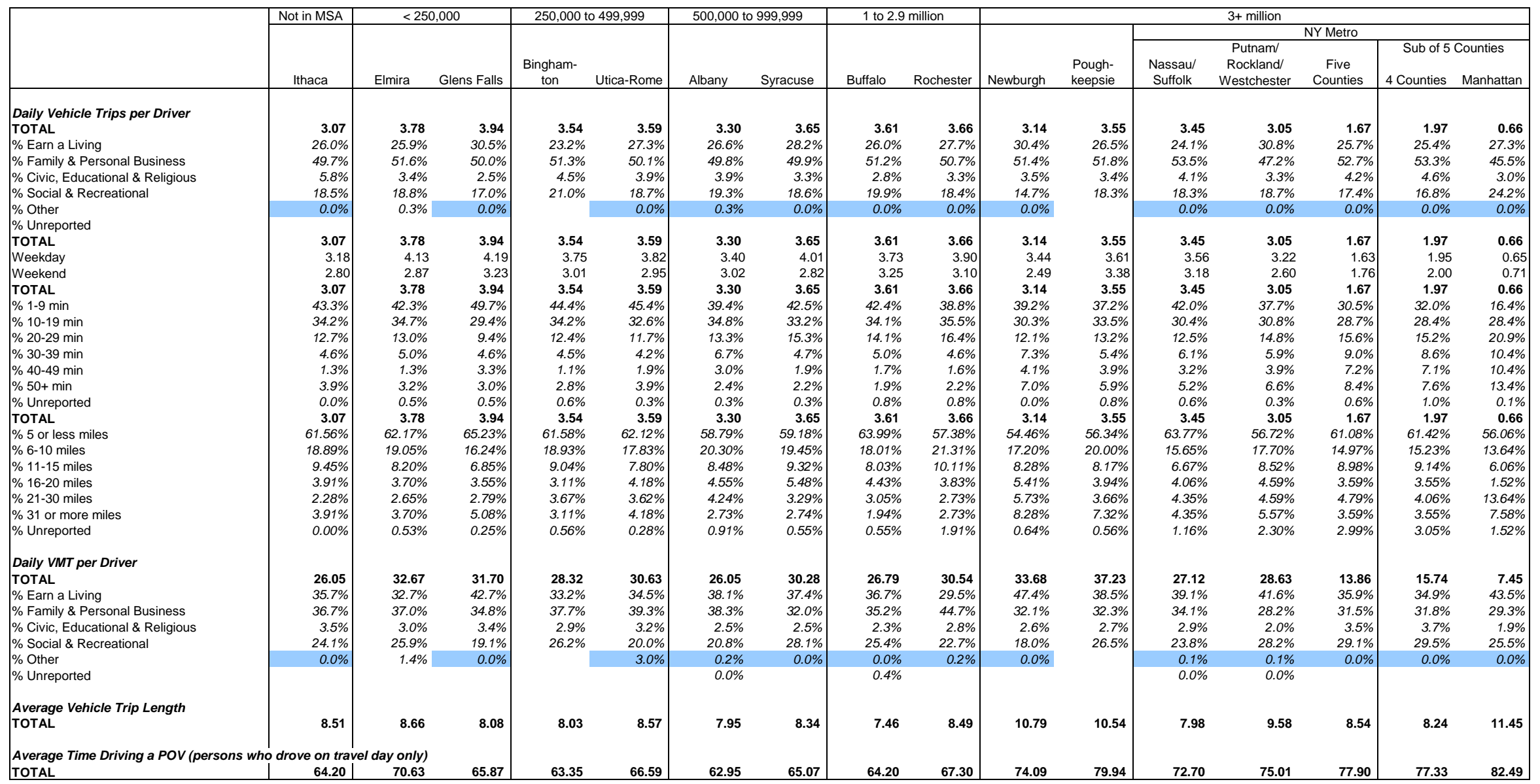




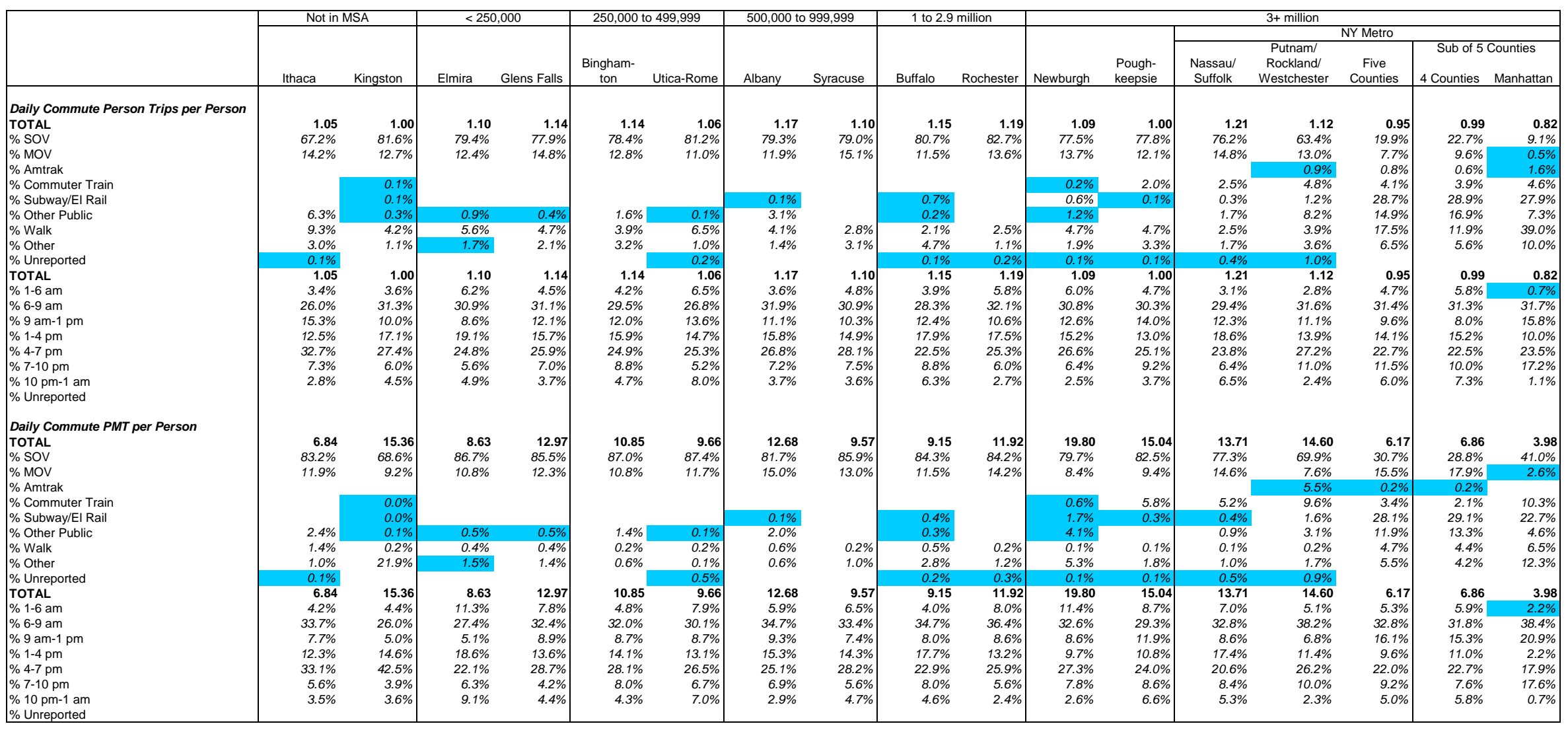




\begin{tabular}{|c|c|c|c|c|c|c|c|c|c|c|c|c|c|c|c|c|}
\hline & \multirow{3}{*}{\begin{tabular}{|c|} 
Not in MSA \\
Ithaca \\
\end{tabular}} & \multicolumn{2}{|c|}{$<250,000$} & \multirow{3}{*}{\multicolumn{2}{|c|}{$\begin{array}{c}250,000 \text { to } 499,999 \\
\begin{array}{c}\text { Bingham- } \\
\text { ton } \quad \text { Utica-Rome }\end{array}\end{array}$}} & \multirow{3}{*}{\multicolumn{2}{|c|}{$\begin{array}{l}500,000 \text { to } 999,999 \\
\text { Albany } \quad \text { Syracuse } \\
\end{array}$}} & \multirow{3}{*}{\multicolumn{2}{|c|}{$\begin{array}{l}1 \text { to } 2.9 \text { million } \\
\text { Buffalo Rochester }\end{array}$}} & \multirow[b]{3}{*}{ Newburgh } & \multirow{2}{*}{\multicolumn{6}{|c|}{$3+$ million }} \\
\hline & & \multirow[b]{2}{*}{ Elmira } & \multirow[b]{2}{*}{ Glens Falls } & & & & & & & & & & & & & \\
\hline & & & & & & & & & & & $\begin{array}{l}\text { Pough- } \\
\text { keepsie }\end{array}$ & $\begin{array}{c}\text { Nassau/ } \\
\text { Suffolk }\end{array}$ & $\begin{array}{c}\text { Putnam/ } \\
\text { Rockland/ } \\
\text { Westchester }\end{array}$ & $\begin{array}{c}\text { Five } \\
\text { Counties }\end{array}$ & $\begin{array}{r}\text { Sub of } 5 \\
4 \text { Counties } \\
\end{array}$ & $\begin{array}{l}\text { Counties } \\
\text { Manhattan }\end{array}$ \\
\hline Daily Commute Pe & & & & & & & & & & & & & & & & \\
\hline TOTAL & 1.09 & 1.16 & 1.12 & 1.15 & 1.20 & 1.15 & 1.20 & 1.09 & 1.17 & 1.12 & 1.07 & 1.14 & 1.11 & 1.08 & 1.09 & 1.06 \\
\hline$\%$ sov & $72.1 \%$ & $81.7 \%$ & $79.6 \%$ & $77.2 \%$ & $79.6 \%$ & $79.5 \%$ & $74.5 \%$ & $81.5 \%$ & $82.6 \%$ & $77.3 \%$ & $80.8 \%$ & $71.2 \%$ & $67.4 \%$ & $25.0 \%$ & $29.4 \%$ & $8.0 \%$ \\
\hline$\% \mathrm{MOV}$ & $16.4 \%$ & $14.3 \%$ & $16.9 \%$ & $16.6 \%$ & $17.6 \%$ & $13.9 \%$ & $14.3 \%$ & $14.0 \%$ & $12.3 \%$ & $15.1 \%$ & $12.2 \%$ & $14.7 \%$ & $14.8 \%$ & $9.7 \%$ & $10.1 \%$ & $7.9 \%$ \\
\hline$\%$ Amtrak & & & $0.0 \%$ & & & $0.1 \%$ & & & & & $0.4 \%$ & $0.9 \%$ & $1.3 \%$ & $1.2 \%$ & $1.5 \%$ & $0.2 \%$ \\
\hline$\%$ Commuter Train & & & $0.0 \%$ & & & & & & & $0.6 \%$ & $1.7 \%$ & $5.1 \%$ & $6.2 \%$ & $1.4 \%$ & $1.5 \%$ & $1.1 \%$ \\
\hline \% Subway/El Rail & & & & & & $0.1 \%$ & & $0.1 \%$ & & $1.0 \%$ & $0.2 \%$ & $1.5 \%$ & $2.1 \%$ & $30.3 \%$ & $28.7 \%$ & $36.4 \%$ \\
\hline$\%$ Other Public & $2.0 \%$ & $0.6 \%$ & $0.7 \%$ & $1.3 \%$ & $0.5 \%$ & $2.4 \%$ & $5.1 \%$ & $0.3 \%$ & $1.8 \%$ & $0.6 \%$ & $0.3 \%$ & $0.2 \%$ & $2.0 \%$ & $12.2 \%$ & $12.3 \%$ & $11.4 \%$ \\
\hline$\%$ Walk & $6.9 \%$ & $1.7 \%$ & $1.8 \%$ & $4.6 \%$ & $2.4 \%$ & $3.3 \%$ & $4.0 \%$ & $3.5 \%$ & $2.5 \%$ & $3.1 \%$ & $2.3 \%$ & $4.6 \%$ & $3.7 \%$ & $16.0 \%$ & $13.1 \%$ & $27.4 \%$ \\
\hline$\%$ Other & $2.6 \%$ & $1.8 \%$ & $0.5 \%$ & $0.4 \%$ & & $0.9 \%$ & $2.1 \%$ & $0.6 \%$ & $0.8 \%$ & $2.4 \%$ & $2.1 \%$ & $1.5 \%$ & $1.8 \%$ & $4.2 \%$ & $3.3 \%$ & $7.6 \%$ \\
\hline$\%$ Unreported & & & $0.6 \%$ & & & & & & & & & $0.2 \%$ & $0.7 \%$ & $0.0 \%$ & $0.1 \%$ & \\
\hline TOTAL & 1.09 & 1.16 & 1.12 & 1.15 & 1.20 & 1.15 & 1.20 & 1.09 & 1.17 & 1.12 & 1.07 & 1.14 & 1.11 & 1.08 & 1.09 & 1.06 \\
\hline$\% 1-6$ an & $2.6 \%$ & $5.1 \%$ & $8.3 \%$ & $4.0 \%$ & $7.2 \%$ & $3.8 \%$ & $6.2 \%$ & $3.7 \%$ & $4.5 \%$ & $6.3 \%$ & $5.9 \%$ & $4.2 \%$ & $3.1 \%$ & $5.0 \%$ & $5.9 \%$ & $1.3 \%$ \\
\hline$\%$ 6-9 & $28.0 \%$ & $27.9 \%$ & $26.7 \%$ & $32.3 \%$ & $27.6 \%$ & $32.8 \%$ & $28.9 \%$ & $30.4 \%$ & $30.2 \%$ & $31.0 \%$ & $27.5 \%$ & $31.1 \%$ & $32.0 \%$ & $31.4 \%$ & $31.0 \%$ & $32.7 \%$ \\
\hline$\% 9$ am-1 pm & $15.3 \%$ & $12.4 \%$ & $11.6 \%$ & $11.0 \%$ & $9.6 \%$ & $11.6 \%$ & $11.8 \%$ & $11.3 \%$ & $13.0 \%$ & $10.0 \%$ & $11.1 \%$ & $11.4 \%$ & $12.3 \%$ & $10.1 \%$ & $10.0 \%$ & $10.5 \%$ \\
\hline$\% 1-4 \mathrm{pm}$ & $14.3 \%$ & $18.3 \%$ & $19.1 \%$ & $16.5 \%$ & $21.4 \%$ & $15.1 \%$ & $17.4 \%$ & $15.4 \%$ & $14.4 \%$ & $15.6 \%$ & $14.3 \%$ & $14.2 \%$ & $14.0 \%$ & $11.0 \%$ & $12.0 \%$ & $7.3 \%$ \\
\hline$\% 4-7 \mathrm{pm}$ & $28.5 \%$ & $22.9 \%$ & $21.2 \%$ & $22.5 \%$ & $23.1 \%$ & $25.8 \%$ & $25.3 \%$ & $25.7 \%$ & $27.3 \%$ & $25.4 \%$ & $23.9 \%$ & $27.6 \%$ & $26.4 \%$ & $26.9 \%$ & $26.2 \%$ & $29.6 \%$ \\
\hline$\% 7-10 \mathrm{pm}$ & $7.5 \%$ & $6.2 \%$ & $7.2 \%$ & $7.8 \%$ & $5.5 \%$ & $6.8 \%$ & $7.0 \%$ & $7.7 \%$ & $6.5 \%$ & $8.1 \%$ & $11.6 \%$ & $7.1 \%$ & $9.4 \%$ & $10.4 \%$ & $9.7 \%$ & $13.0 \%$ \\
\hline$\% 10 \mathrm{pm}-1 \mathrm{am}$ & $3.9 \%$ & $7.3 \%$ & $5.9 \%$ & $5.8 \%$ & $5.4 \%$ & $4.0 \%$ & $3.5 \%$ & $5.8 \%$ & $4.0 \%$ & $3.1 \%$ & $5.7 \%$ & $4.5 \%$ & $2.7 \%$ & $5.1 \%$ & $5.0 \%$ & $5.6 \%$ \\
\hline$\%$ Unreported & & & & $0.1 \%$ & $0.2 \%$ & $0.1 \%$ & & & & $0.5 \%$ & & & $0.2 \%$ & $0.1 \%$ & $0.1 \%$ & \\
\hline Daily Commute P & & & & & & & & & & & & & & & & \\
\hline TOTAL & 8.37 & 10.57 & 14.02 & 10.14 & 11.87 & 11.89 & 9.38 & 10.69 & 10.31 & 20.00 & 16.91 & 14.07 & 15.20 & 7.47 & 7.89 & 5.89 \\
\hline$\%$ sov & $80.6 \%$ & $83.6 \%$ & $79.0 \%$ & $82.5 \%$ & $80.4 \%$ & $83.7 \%$ & $86.3 \%$ & $82.7 \%$ & $88.3 \%$ & $74.2 \%$ & $77.3 \%$ & $68.8 \%$ & $67.4 \%$ & $33.6 \%$ & $37.3 \%$ & $15.0 \%$ \\
\hline$\% \mathrm{MOV}$ & $14.4 \%$ & $14.4 \%$ & $18.3 \%$ & $15.1 \%$ & $18.8 \%$ & $12.9 \%$ & $10.3 \%$ & $16.3 \%$ & $10.8 \%$ & $13.1 \%$ & $10.1 \%$ & $12.7 \%$ & $12.4 \%$ & $13.1 \%$ & $10.7 \%$ & $24.8 \%$ \\
\hline$\%$ Amtrak & & & $0.1 \%$ & & & $1.2 \%$ & & & & & $2.6 \%$ & $1.8 \%$ & $1.7 \%$ & $1.4 \%$ & $1.5 \%$ & $0.6 \%$ \\
\hline$\%$ Commuter Train & & & $0.1 \%$ & & & & & & & $1.8 \%$ & $6.7 \%$ & $11.7 \%$ & $12.4 \%$ & $2.3 \%$ & $2.2 \%$ & $2.8 \%$ \\
\hline \% Subway/El Rail & & & & & & $0.1 \%$ & & $0.1 \%$ & & $3.1 \%$ & $0.0 \%$ & $2.2 \%$ & $1.5 \%$ & $35.0 \%$ & $33.8 \%$ & $40.9 \%$ \\
\hline$\%$ Other Public & $1.9 \%$ & $0.1 \%$ & $0.3 \%$ & $1.4 \%$ & $0.4 \%$ & $1.2 \%$ & $2.3 \%$ & $0.2 \%$ & $0.5 \%$ & $1.0 \%$ & $0.2 \%$ & $0.3 \%$ & $1.0 \%$ & $7.7 \%$ & $8.4 \%$ & $4.3 \%$ \\
\hline$\%$ Walk & $0.7 \%$ & $0.2 \%$ & $0.2 \%$ & $0.5 \%$ & $0.4 \%$ & $0.3 \%$ & $0.2 \%$ & $0.5 \%$ & $0.3 \%$ & $0.1 \%$ & $0.8 \%$ & $0.5 \%$ & $0.4 \%$ & $2.8 \%$ & $2.2 \%$ & $6.2 \%$ \\
\hline$\%$ Other & $2.4 \%$ & $1.7 \%$ & $0.9 \%$ & $0.5 \%$ & & $0.6 \%$ & $0.9 \%$ & $0.3 \%$ & $0.1 \%$ & $6.8 \%$ & $2.3 \%$ & $1.3 \%$ & $2.7 \%$ & $4.1 \%$ & $3.9 \%$ & $5.5 \%$ \\
\hline$\%$ Unreported & & & $1.2 \%$ & & & & & & & & & $0.8 \%$ & $0.5 \%$ & $0.0 \%$ & $0.0 \%$ & \\
\hline TOTAL & 8.37 & 10.57 & 14.02 & 10.14 & 11.87 & 11.89 & 9.38 & 10.69 & 10.31 & 20.00 & 16.91 & 14.07 & 15.20 & 7.47 & 7.89 & 5.89 \\
\hline$\% 1-6$ & $3.8 \%$ & $7.3 \%$ & $11.8 \%$ & $4.8 \%$ & $10.7 \%$ & $5.1 \%$ & $6.3 \%$ & $3.4 \%$ & $7.8 \%$ & $8.7 \%$ & $9.8 \%$ & $9.0 \%$ & $5.5 \%$ & $7.6 \%$ & $8.9 \%$ & $1.1 \%$ \\
\hline$\% 6-9$ & $31.2 \%$ & $26.7 \%$ & $25.2 \%$ & $37.4 \%$ & $29.0 \%$ & $35.6 \%$ & 35.1 & $33.1 \%$ & $31.6 \%$ & $35.2 \%$ & $30.1 \%$ & 31. & $36.5 \%$ & $33.0 \%$ & $31.4 \%$ & $40.9 \%$ \\
\hline$\% 9 \mathrm{am}-1 \mathrm{pm}$ & $14.6 \%$ & $5.8 \%$ & $7.3 \%$ & $9.1 \%$ & $6.9 \%$ & $8.2 \%$ & 5.8 & $15.5 \%$ & $11.1 \%$ & & $7.7 \%$ & 8. & $8.9 \%$ & $7.6 \%$ & 7. & $8.9 \%$ \\
\hline$\% 1-4 p$ & $13.7 \%$ & $22.2 \%$ & $\%$ & $14.6 \%$ & 20. & $\%$ & 17 & 1. & $14.1 \%$ & $12.2 \%$ & $15.0 \%$ & $13.2 \%$ & $12.6 \%$ & $9.6 \%$ & $10.5 \%$ & $4.9 \%$ \\
\hline$\% 4-7 \mathrm{pm}$ & $27.2 \%$ & $23.8 \%$ & $22.0 \%$ & $20.4 \%$ & $23.6 \%$ & $25.9 \%$ & $24.8 \%$ & $24.6 \%$ & $25.7 \%$ & $23.1 \%$ & $23.2 \%$ & $27.2 \%$ & $23.7 \%$ & $27.7 \%$ & $27.1 \%$ & $30.9 \%$ \\
\hline$\% 7-10 \mathrm{pm}$ & $7.0 \%$ & $6.3 \%$ & $7.0 \%$ & $6.9 \%$ & $4.6 \%$ & $6.8 \%$ & $6.2 \%$ & $6.2 \%$ & $5.8 \%$ & $8.1 \%$ & $11.0 \%$ & $6.6 \%$ & $10.1 \%$ & $9.0 \%$ & $9.4 \%$ & $7.3 \%$ \\
\hline$\% 10 \mathrm{pm}-1 \mathrm{am}$ & $2.6 \%$ & $8.0 \%$ & $7.5 \%$ & $6.7 \%$ & $5.1 \%$ & $4.0 \%$ & $4.7 \%$ & $4.2 \%$ & $4.0 \%$ & $4.5 \%$ & $3.3 \%$ & $3.5 \%$ & $2.8 \%$ & $5.5 \%$ & $5.4 \%$ & $6.0 \%$ \\
\hline$\%$ Unreported & & & & $0.1 \%$ & $0.2 \%$ & & & & & $2.8 \%$ & & & $0.0 \%$ & $0.0 \%$ & $0.0 \%$ & \\
\hline
\end{tabular}




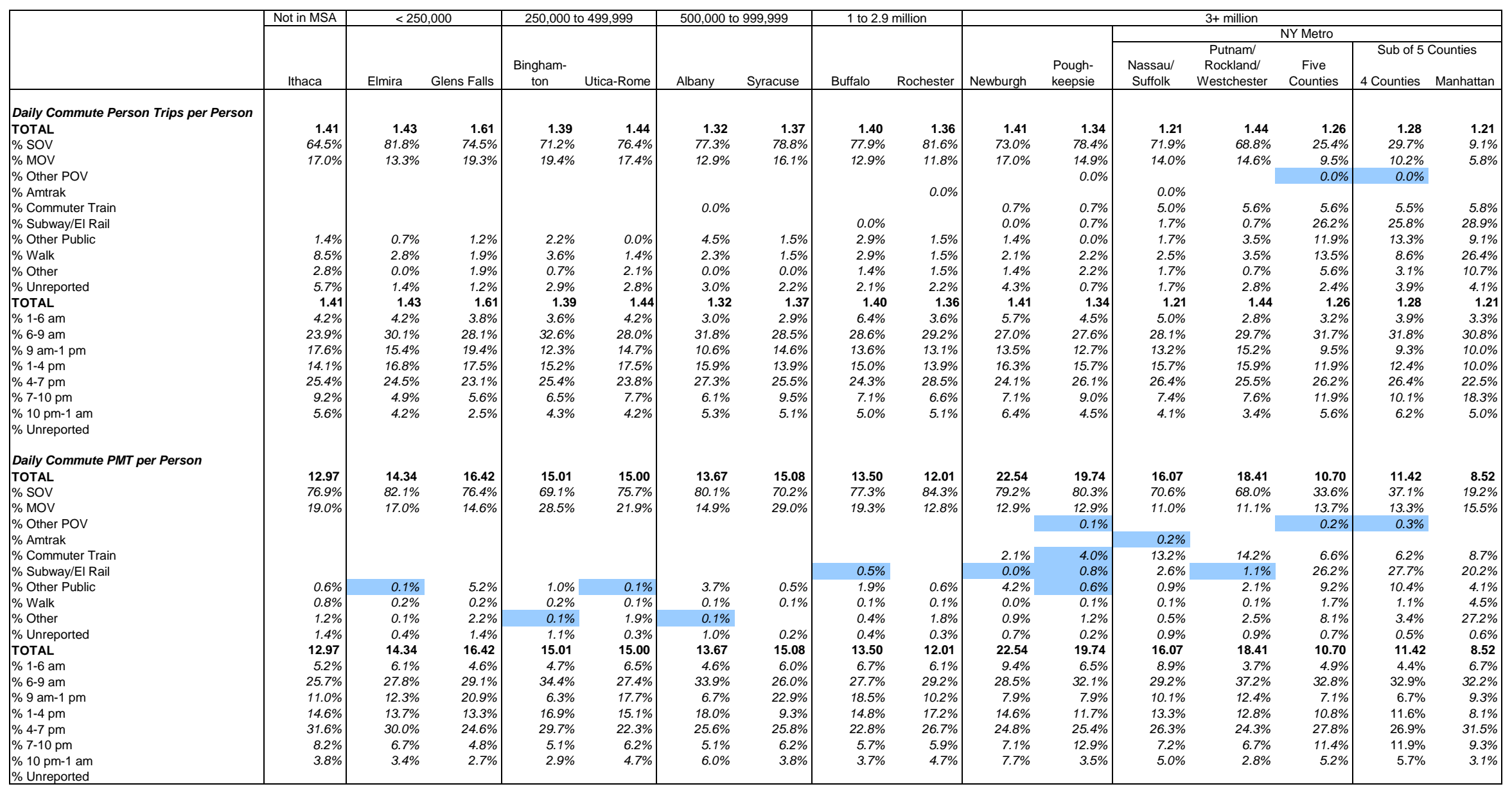




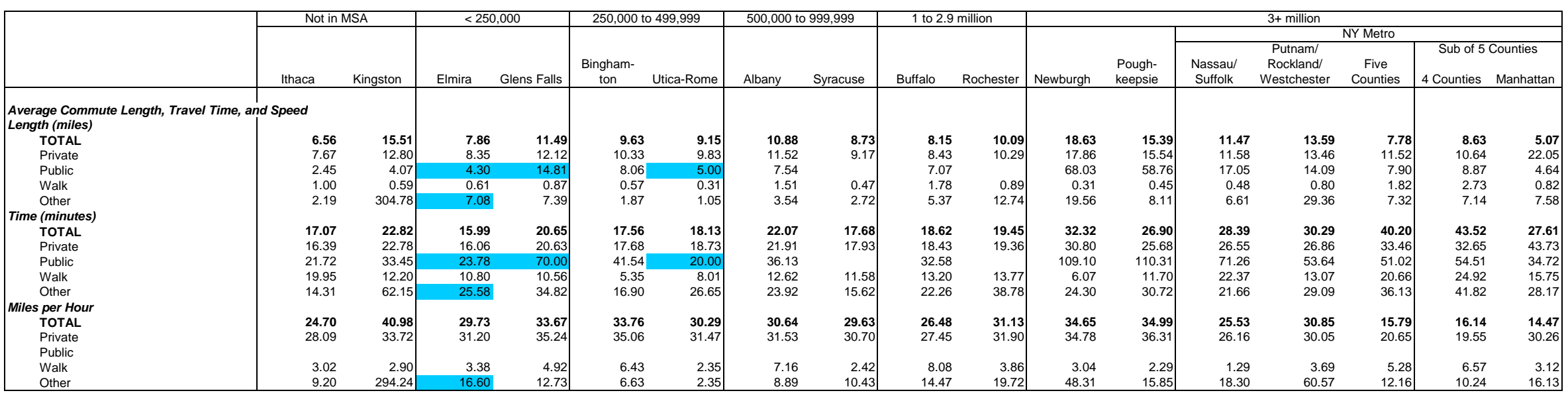




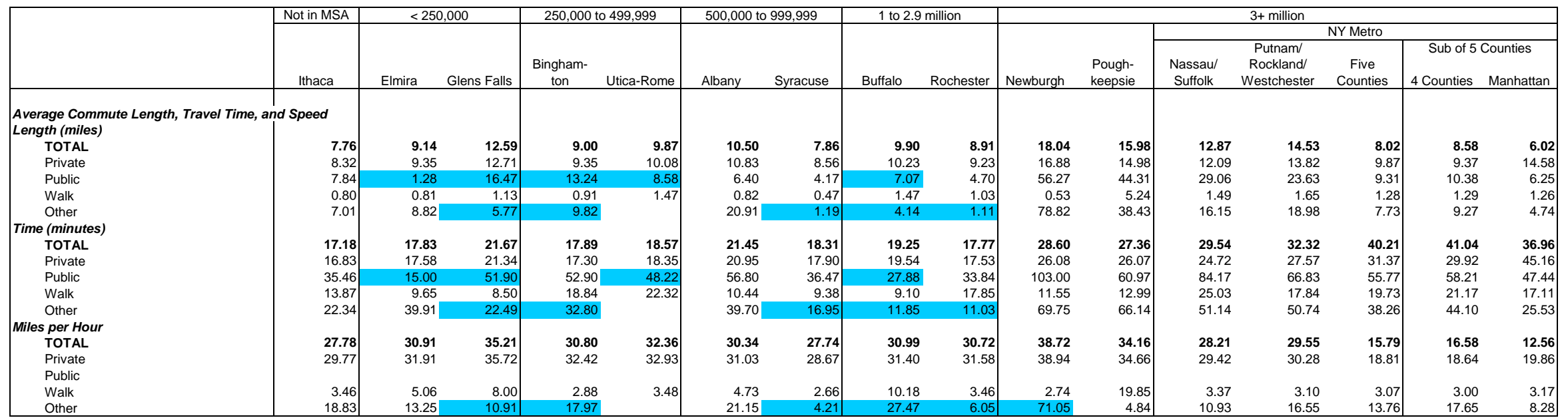




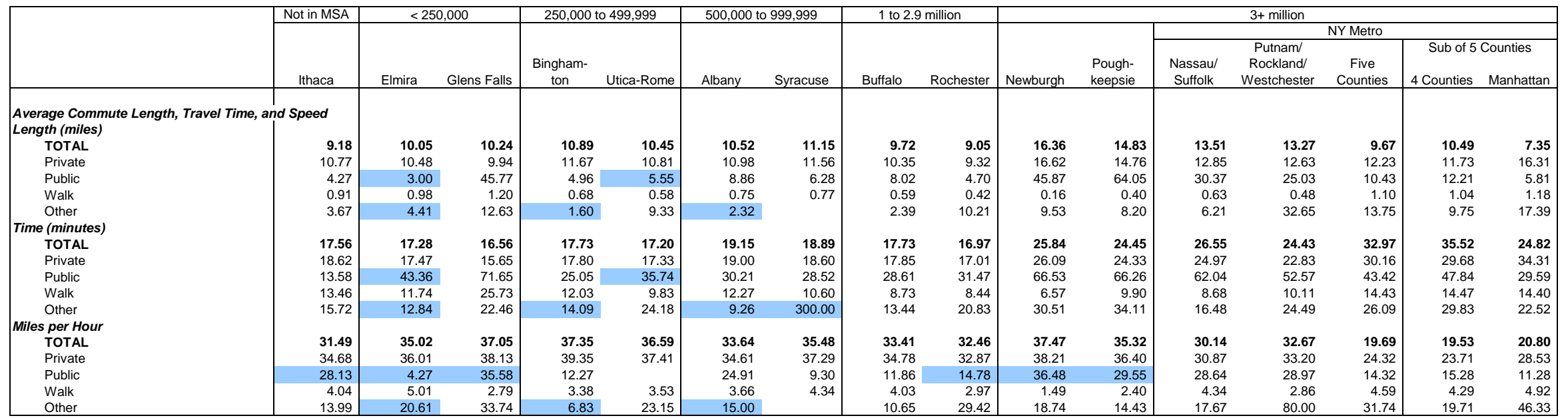




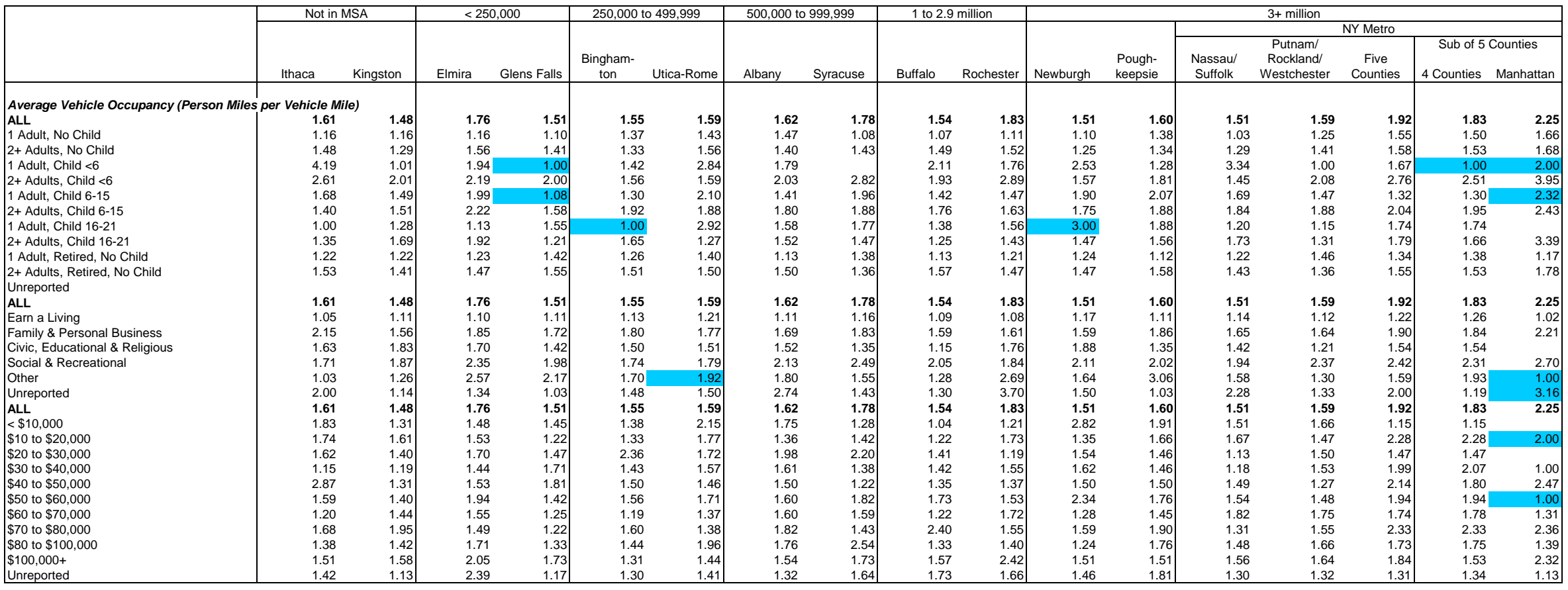




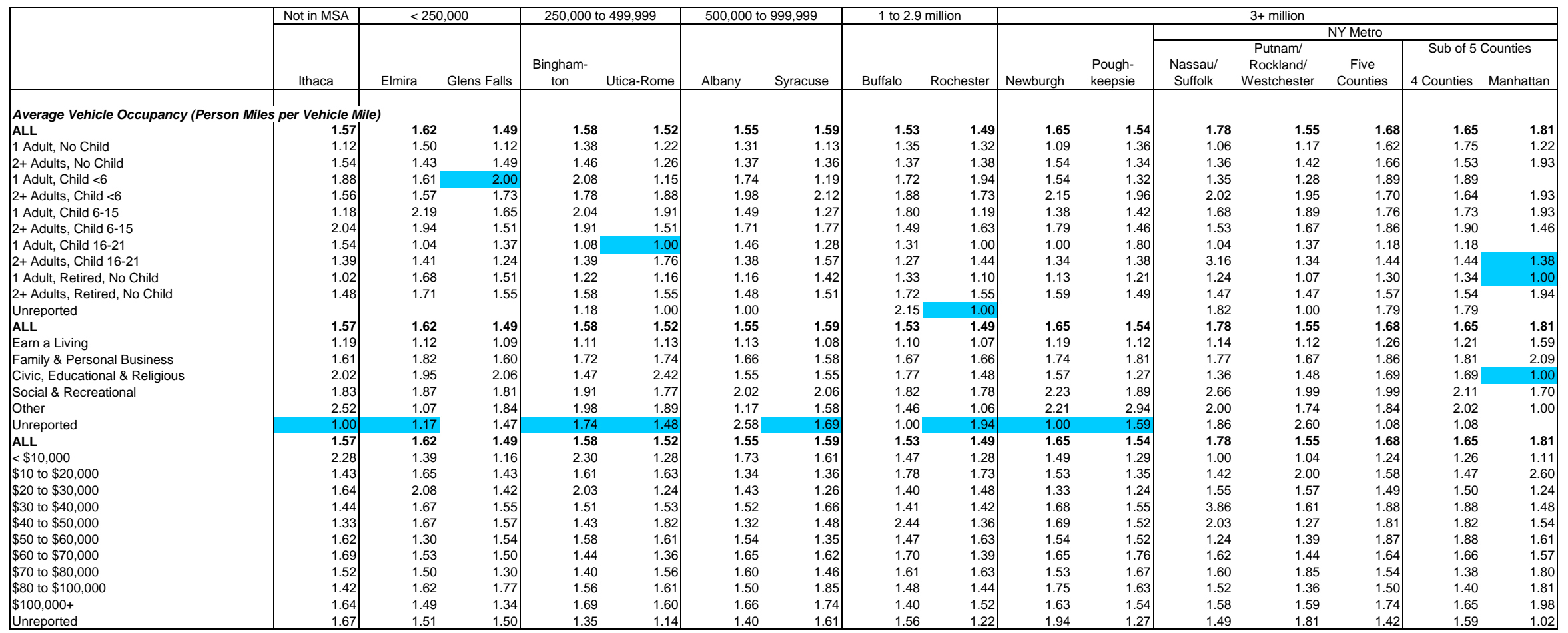




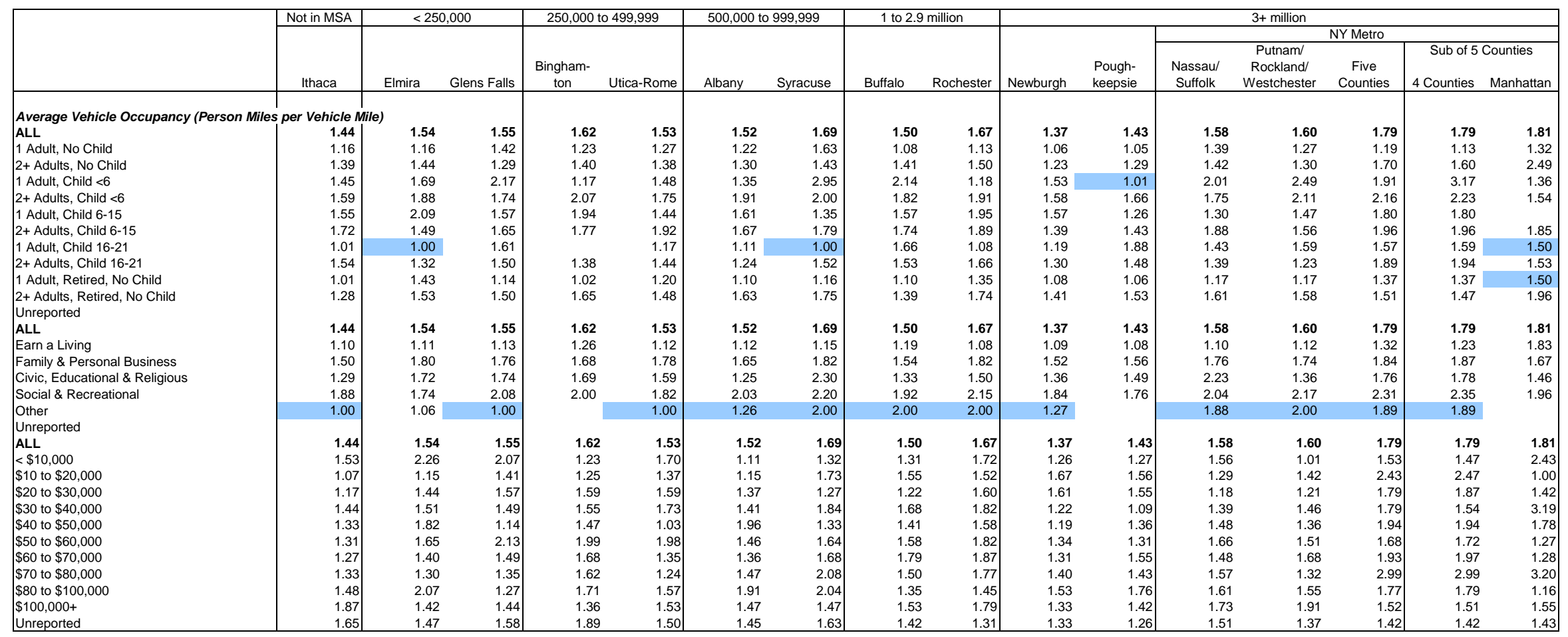




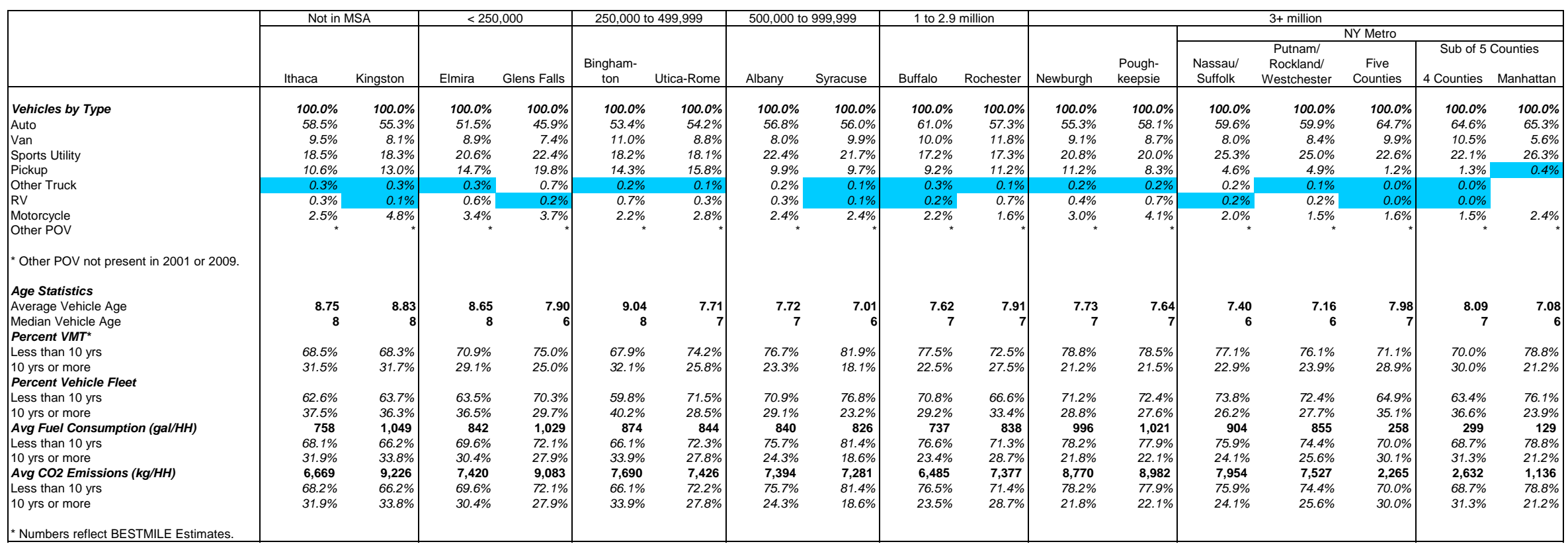




\begin{tabular}{|c|c|c|c|c|c|c|c|c|c|c|c|c|c|c|c|c|}
\hline & \multirow{3}{*}{$\begin{array}{c}\text { Not in MSA } \\
\text { Ithaca } \\
\end{array}$} & \multirow{2}{*}{\multicolumn{2}{|c|}{$<250,000$}} & \multicolumn{2}{|c|}{250,000 to 499,999} & \multicolumn{2}{|c|}{500,000 to 999,999} & \multicolumn{2}{|c|}{1 to 2.9 million } & \multicolumn{7}{|c|}{$3+$ million } \\
\hline & & & & \multirow[b]{2}{*}{$\begin{array}{l}\text { Bingham- } \\
\text { ton }\end{array}$} & \multirow[b]{2}{*}{ Utica-Rome } & \multirow[b]{2}{*}{ Albany } & \multirow[b]{2}{*}{ Syracuse } & \multirow[b]{2}{*}{ Buffalo } & \multirow[b]{2}{*}{ Rochester } & \multirow[b]{2}{*}{ Newburgh } & \multirow[b]{2}{*}{$\begin{array}{l}\text { Pough- } \\
\text { keepsie }\end{array}$} & \multicolumn{5}{|c|}{ NY Metro } \\
\hline & & Elmira & Glens Falls & & & & & & & & & $\begin{array}{c}\text { Nassau/ } \\
\text { Suffolk }\end{array}$ & $\begin{array}{c}\text { Putnam/ } \\
\text { Rockland/ } \\
\text { Westchester }\end{array}$ & $\begin{array}{c}\text { Five } \\
\text { Counties } \\
\end{array}$ & $\begin{array}{r}\text { Sub of } 5 \\
4 \text { Counties } \\
\end{array}$ & $\begin{array}{l}\text { Counties } \\
\text { Manhattan }\end{array}$ \\
\hline Vehicles by Type & $100.0 \%$ & $100.0 \%$ & $100.0 \%$ & $100.0 \%$ & $100.0 \%$ & $100.0 \%$ & $100.0 \%$ & $100.0 \%$ & $100.0 \%$ & $100.0 \%$ & $100.0 \%$ & $100.0 \%$ & $100.0 \%$ & $100.0 \%$ & $100.0 \%$ & $100.0 \%$ \\
\hline Auto & $66.0 \%$ & $58.4 \%$ & $53.1 \%$ & $60.9 \%$ & $58.5 \%$ & $62.4 \%$ & $66.5 \%$ & $64.3 \%$ & $63.3 \%$ & $65.3 \%$ & $64.1 \%$ & $66.8 \%$ & $73.3 \%$ & $75.7 \%$ & $75.3 \%$ & $78.2 \%$ \\
\hline Van & $8.0 \%$ & $10.3 \%$ & $8.5 \%$ & $10.0 \%$ & $9.6 \%$ & $10.1 \%$ & $9.7 \%$ & $10.7 \%$ & $11.3 \%$ & $9.6 \%$ & $8.8 \%$ & $11.2 \%$ & $8.9 \%$ & $9.3 \%$ & $9.7 \%$ & $6.4 \%$ \\
\hline Sports Utility & $9.8 \%$ & $10.4 \%$ & $12.9 \%$ & $10.8 \%$ & $11.8 \%$ & $11.8 \%$ & $11.2 \%$ & $10.1 \%$ & $11.7 \%$ & $11.6 \%$ & $12.7 \%$ & $14.6 \%$ & $13.1 \%$ & $12.4 \%$ & $12.5 \%$ & $11.7 \%$ \\
\hline Pickup & $13.4 \%$ & $16.6 \%$ & $21.0 \%$ & $14.7 \%$ & $14.5 \%$ & $12.2 \%$ & $10.4 \%$ & $11.9 \%$ & $10.7 \%$ & $10.7 \%$ & $9.1 \%$ & $5.6 \%$ & $3.6 \%$ & $1.0 \%$ & $1.0 \%$ & $1.3 \%$ \\
\hline Other Truck & $0.4 \%$ & $0.3 \%$ & $0.8 \%$ & $0.2 \%$ & $0.3 \%$ & $0.4 \%$ & & $0.0 \%$ & $0.3 \%$ & $0.2 \%$ & $0.6 \%$ & $0.0 \%$ & $0.3 \%$ & $0.4 \%$ & $0.5 \%$ & \\
\hline RV & $0.5 \%$ & $1.1 \%$ & $0.5 \%$ & $0.6 \%$ & $0.6 \%$ & $0.7 \%$ & $0.8 \%$ & $0.7 \%$ & $0.6 \%$ & $0.5 \%$ & $0.5 \%$ & $0.1 \%$ & $0.0 \%$ & $0.0 \%$ & $0.0 \%$ & \\
\hline $\begin{array}{l}\text { Motorcycle } \\
\text { Other POV }\end{array}$ & $1.9 \%$ & $2.9 \%$ & $3.3 \%$ & $2.8 \%$ & $4.7 \%$ & $2.5 \%$ & $1.3 \%$ & $2.2 \%$ & $2.0 \%$ & $2.1 \%$ & $4.2 \%$ & $1.7 \%$ & $0.9 \%$ & $1.3 \%$ & $1.1 \%$ & $2.5 \%$ \\
\hline * Other POV not present in 2001 or & & & & & & & & & & & & & & & & \\
\hline Age Statis & & & & & & & & & & & & & & & & \\
\hline Average Vehicle Age & 8.77 & 8.63 & 8.25 & 9.26 & 8.34 & 7.89 & 7.06 & 7.63 & 7.42 & 7.56 & 8.29 & 7.28 & 6.49 & 8.18 & 8.01 & 9.24 \\
\hline $\begin{array}{l}\text { Median Vehicle Age } \\
\text { Percent VMT** }\end{array}$ & & 7 & & 8 & & 7 & & 6 & & 6 & & 6 & 5 & & 7 & \\
\hline Less than $10 \mathrm{yrs}$ & $69.4 \%$ & $70.6 \%$ & $71.2 \%$ & $65.5 \%$ & $72.6 \%$ & $74.8 \%$ & $75.5 \%$ & $75.4 \%$ & $79.7 \%$ & $77.3 \%$ & $74.6 \%$ & $73.0 \%$ & $83.1 \%$ & $69.3 \%$ & $70.6 \%$ & $60.5 \%$ \\
\hline $\begin{array}{l}10 \text { yrs or more } \\
\text { Percent Vehicle Fleet }\end{array}$ & $30.7 \%$ & $29.4 \%$ & $28.9 \%$ & $34.5 \%$ & $27.4 \%$ & $25.3 \%$ & $24.5 \%$ & $24.6 \%$ & $20.3 \%$ & $22.7 \%$ & $25.4 \%$ & $27.0 \%$ & $16.9 \%$ & $30.7 \%$ & $29.4 \%$ & $39.5 \%$ \\
\hline Less than $10 \mathrm{yrs}$ & $58.9 \%$ & $62.4 \%$ & $65.1 \%$ & $57.6 \%$ & $65.1 \%$ & $68.1 \%$ & $73.5 \%$ & $69.7 \%$ & $71.5 \%$ & $69.3 \%$ & $65.9 \%$ & $70.1 \%$ & $75.5 \%$ & $61.3 \%$ & $62.0 \%$ & $57.2 \%$ \\
\hline & $41.1 \%$ & $37.6 \%$ & $34.9 \%$ & $42.4 \%$ & $34.9 \%$ & $31.9 \%$ & $26.5 \%$ & $30.3 \%$ & $28.5 \%$ & 30. & $34.1 \%$ & $29.9 \%$ & $24.5 \%$ & $38.7 \%$ & $38.0 \%$ & $42.8 \%$ \\
\hline otion (gal//HH) & 878 & 1,918 & 1,186 & 941 & 833 & 805 & 706 & 869 & 1,000 & 1,0 & 1,0 & 985 & 80 & 25 & 65 & 211 \\
\hline Less than 10 & $69.3 \%$ & $95.6 \%$ & & $70.3 \%$ & $67.0 \%$ & $73.7 \%$ & $76.0 \%$ & $81.6 \%$ & $79.1 \%$ & & 81. & $76.0 \%$ & $83.4 \%$ & $70.8 \%$ & $72.7 \%$ & $61.2 \%$ \\
\hline $10 \mathrm{yrs}$ or more & $30.7 \%$ & $4.4 \%$ & $\%$ & $29.7 \%$ & $33.0 \%$ & $26.3 \%$ & 24 & $18.5 \%$ & $20.9 \%$ & $19.6 \%$ & $18.9 \%$ & $24.0 \%$ & $16.6 \%$ & $29.2 \%$ & $27.3 \%$ & $38.9 \%$ \\
\hline Avg CO2 Emissions (kg/HH) & 7,718 & 16,859 & 10,421 & 8,266 & 7,317 & 7,076 & 6,20 & 7,633 & 8,790 & 9,496 & 9,255 & 8,660 & 7,036 & 2,866 & 3,215 & 1,858 \\
\hline Less than $10 \mathrm{yrs}$ & $69.3 \%$ & $95.6 \%$ & $86.9 \%$ & $70.3 \%$ & $67.0 \%$ & $73.7 \%$ & $76.0 \%$ & $81.6 \%$ & $79.1 \%$ & $80.4 \%$ & $81.1 \%$ & $76.0 \%$ & $83.4 \%$ & $70.9 \%$ & $72.8 \%$ & $61.2 \%$ \\
\hline 10 yrs or more & $30.7 \%$ & $4.4 \%$ & $13.1 \%$ & $29.7 \%$ & $33.0 \%$ & $26.3 \%$ & $24.0 \%$ & $18.5 \%$ & $20.9 \%$ & $19.6 \%$ & $18.9 \%$ & $24.0 \%$ & $16.6 \%$ & $29.1 \%$ & $27.2 \%$ & $38.9 \%$ \\
\hline${ }^{*}$ Numbers reflect BESTMILE Est & & & & & & & & & & & & & & & & \\
\hline
\end{tabular}




\begin{tabular}{|c|c|c|c|c|c|c|c|c|c|c|c|c|c|c|c|c|}
\hline & \multirow{3}{*}{$\begin{array}{c}\text { Not in MSA } \\
\text { Ithaca } \\
\end{array}$} & \multicolumn{2}{|c|}{$<250,000$} & \multicolumn{2}{|c|}{250,000 to 499,999} & \multicolumn{2}{|c|}{500,000 to 999,999} & \multicolumn{2}{|c|}{1 to 2.9 million } & \multicolumn{7}{|c|}{$3+$ million } \\
\hline & & \multirow[b]{2}{*}{ Elmira } & \multirow[b]{2}{*}{ Glens Falls } & \multirow[b]{2}{*}{$\begin{array}{l}\text { Bingham- } \\
\text { ton }\end{array}$} & \multirow[b]{2}{*}{ Utica-Rome } & \multirow[b]{2}{*}{ Albany } & \multirow[b]{2}{*}{ Syracuse } & \multirow[b]{2}{*}{ Buffalo } & \multirow[b]{2}{*}{ Rochester } & \multirow[b]{2}{*}{ Newburgh } & \multirow[b]{2}{*}{$\begin{array}{l}\text { Pough- } \\
\text { keepsie }\end{array}$} & \multicolumn{5}{|c|}{ NY Metro } \\
\hline & & & & & & & & & & & & $\begin{array}{l}\text { Nassau/ } \\
\text { Suffolk }\end{array}$ & $\begin{array}{c}\text { Putnam/ } \\
\text { Rockland/ } \\
\text { Westchester }\end{array}$ & $\begin{array}{l}\text { Five } \\
\text { Counties }\end{array}$ & $\begin{array}{r}\text { Sub of } 5 \\
4 \text { Counties }\end{array}$ & $\begin{array}{l}\text { Counties } \\
\text { Manhattan }\end{array}$ \\
\hline Vehicles by Type & $100.0 \%$ & $100.0 \%$ & $100.0 \%$ & $100.0 \%$ & $100.0 \%$ & $100.0 \%$ & $100.0 \%$ & $100.0 \%$ & $100.0 \%$ & $100.0 \%$ & $100.0 \%$ & $100.0 \%$ & $100.0 \%$ & $100.0 \%$ & $100.0 \%$ & $100.0 \%$ \\
\hline Auto & $69.7 \%$ & $65.1 \%$ & $64.9 \%$ & $67.8 \%$ & $66.4 \%$ & $72.8 \%$ & $69.7 \%$ & $75.3 \%$ & $76.9 \%$ & $69.6 \%$ & $72.8 \%$ & $78.2 \%$ & $79.7 \%$ & $87.4 \%$ & $87.5 \%$ & $87.0 \%$ \\
\hline Van & $7.9 \%$ & $9.7 \%$ & $7.0 \%$ & $8.8 \%$ & $7.1 \%$ & $6.8 \%$ & $10.9 \%$ & $8.3 \%$ & $8.1 \%$ & $7.2 \%$ & $9.4 \%$ & $8.4 \%$ & $6.5 \%$ & $5.6 \%$ & $6.0 \%$ & $3.3 \%$ \\
\hline Sports Utility & $5.8 \%$ & $6.6 \%$ & $6.0 \%$ & $6.2 \%$ & $7.1 \%$ & $5.9 \%$ & $7.1 \%$ & $5.6 \%$ & $5.4 \%$ & $9.5 \%$ & $7.9 \%$ & $8.5 \%$ & $10.0 \%$ & $5.3 \%$ & $5.0 \%$ & $7.2 \%$ \\
\hline Pickup & $14.4 \%$ & $16.3 \%$ & $20.3 \%$ & $14.6 \%$ & $16.7 \%$ & $11.6 \%$ & $10.8 \%$ & $9.5 \%$ & $8.0 \%$ & $11.3 \%$ & $8.4 \%$ & $4.3 \%$ & $2.7 \%$ & $1.2 \%$ & $1.0 \%$ & $2.4 \%$ \\
\hline Other Truck & $0.3 \%$ & $0.5 \%$ & $0.7 \%$ & $0.3 \%$ & $0.7 \%$ & $0.3 \%$ & $0.4 \%$ & $0.1 \%$ & $0.2 \%$ & $0.7 \%$ & $0.3 \%$ & $0.1 \%$ & $0.2 \%$ & $0.1 \%$ & $0.2 \%$ & \\
\hline RV & $0.7 \%$ & $0.4 \%$ & $0.2 \%$ & $1.2 \%$ & $0.7 \%$ & $0.9 \%$ & $0.5 \%$ & $0.5 \%$ & $0.1 \%$ & $0.3 \%$ & $0.2 \%$ & $0.2 \%$ & $0.3 \%$ & $0.0 \%$ & $0.0 \%$ & \\
\hline Motorcycle & $1.1 \%$ & $1.5 \%$ & $0.9 \%$ & $1.0 \%$ & $1.4 \%$ & $1.5 \%$ & $0.6 \%$ & $0.6 \%$ & $1.3 \%$ & $1.4 \%$ & $1.1 \%$ & $0.2 \%$ & $0.7 \%$ & $0.2 \%$ & $0.2 \%$ & $0.2 \%$ \\
\hline Other POV & $0.1 \%$ & & $0.1 \%$ & $0.1 \%$ & & $0.3 \%$ & & $0.1 \%$ & $0.1 \%$ & $0.1 \%$ & $0.1 \%$ & $0.2 \%$ & $0.0 \%$ & $0.2 \%$ & $0.2 \%$ & \\
\hline * Other POV not present in 2001 o & & & & & & & & & & & & & & & & \\
\hline $\begin{array}{l}\text { Age Statistics } \\
\text { Average Vhicle Age }\end{array}$ & 8.07 & 7.60 & 7.49 & 8.36 & 7.72 & 7.15 & 6.57 & 7.31 & 7.23 & 7.22 & 7.45 & 7.27 & 6.63 & 7.82 & 7.90 & 7.23 \\
\hline $\begin{array}{l}\text { Median Vehicle Age } \\
\text { Percent VMT* }\end{array}$ & & 7 & & 8 & & 7 & & 7 & & 7 & & 7 & 6 & & 8 & \\
\hline Less than $10 \mathrm{yrs}$ & $71.9 \%$ & $75.6 \%$ & $74.9 \%$ & $69.4 \%$ & $77.4 \%$ & $78.6 \%$ & $81.6 \%$ & $74.0 \%$ & $77.7 \%$ & $79.9 \%$ & $74.7 \%$ & $76.9 \%$ & $79.1 \%$ & $70.6 \%$ & $70.1 \%$ & $74.3 \%$ \\
\hline $\begin{array}{l}10 \mathrm{yrs} \text { or more } \\
\text { Percent Vehicle Fleet }\end{array}$ & $28.1 \%$ & $24.4 \%$ & $25.1 \%$ & $30.6 \%$ & $22.6 \%$ & $21.4 \%$ & $18.4 \%$ & $26.0 \%$ & $22.3 \%$ & $20.2 \%$ & $25.3 \%$ & $23.2 \%$ & $20.9 \%$ & $29.4 \%$ & $29.9 \%$ & $25.7 \%$ \\
\hline Less than $10 \mathrm{yrs}$ & $66.5 \%$ & $69.0 \%$ & $71.1 \%$ & $64.4 \%$ & $68.9 \%$ & $73.8 \%$ & $78.6 \%$ & $70.9 \%$ & $73.6 \%$ & $74.4 \%$ & $71.8 \%$ & $72.9 \%$ & $78.7 \%$ & $68.6 \%$ & $68.1 \%$ & $71.9 \%$ \\
\hline $10 \mathrm{yrs}$ or more & $33.5 \%$ & $31.0 \%$ & $28.9 \%$ & $35.6 \%$ & $31.1 \%$ & $26.3 \%$ & $21.4 \%$ & $29.1 \%$ & $26.4 \%$ & $25.6 \%$ & $28.3 \%$ & $27.1 \%$ & $21.3 \%$ & $31.5 \%$ & $31.9 \%$ & $28.1 \%$ \\
\hline Avg Fuel Consumption (gal//HH) & ** & ** & $\star \star$ & $\star \star *$ & $\star *$ & $* *$ & 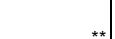 & $\star \star *$ & ** & $\star \star *$ & ** & $\star \star \star$ & ** & $\star * 1$ & ** & $\star \star *$ \\
\hline $\begin{array}{l}\text { Less than } 10 \text { yrs } \\
10 \text { yrs or more }\end{array}$ & ** & ** & ** & ** & $* *$ & ** & $* *$ & ** & ** & ** & ** & ** & ** & $* *$ & ** & ** \\
\hline Avg CO2 Emissions $(\mathrm{kg} / \mathrm{HH})$ & $\star \star \star$ & ** & ** & $\star \star *$ & 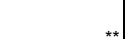 & $\star \star *$ & **] & 太* & ** & & & & & 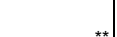 & & $* *$ \\
\hline $\begin{array}{l}\text { Less than } 10 \text { yrs } \\
10 \text { yrs or more }\end{array}$ & ** & ** & ** & ** & $* \star$ & ** & $* \star$ & ** & $* *$ & ** & ** & ** & ** & $* *$ & ** & ** \\
\hline ** Statistics not available in 1995 & & & & & & & & & & & & & & & & \\
\hline
\end{tabular}




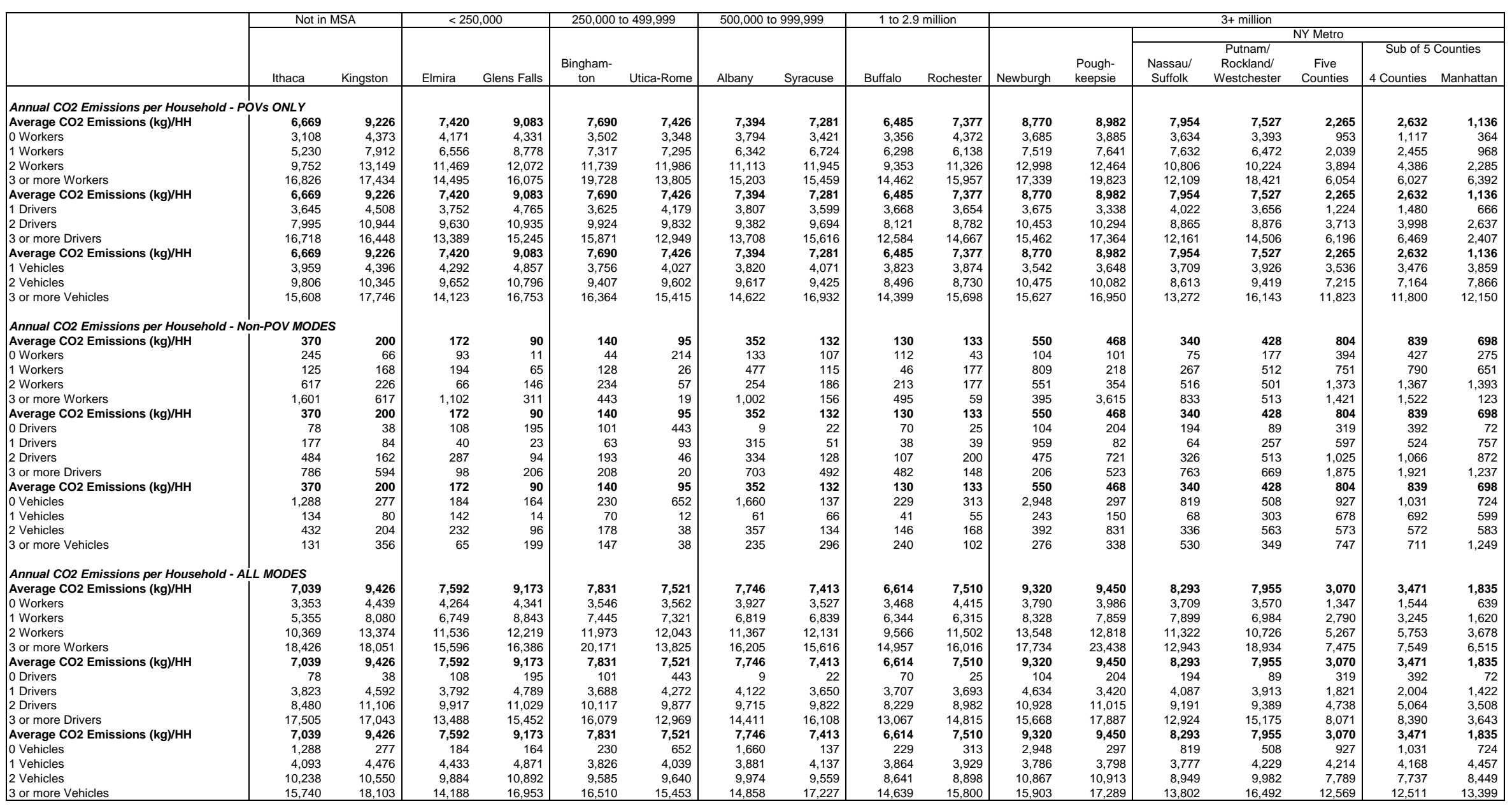




\begin{tabular}{|c|c|c|c|c|c|c|c|c|c|c|c|c|c|c|c|c|}
\hline & \multirow{3}{*}{\begin{tabular}{c|} 
Not in MSA \\
Ithaca \\
\end{tabular}} & \multicolumn{2}{|c|}{$<250,000$} & \multicolumn{2}{|c|}{250,000 to 499,999} & \multicolumn{2}{|c|}{500,000 to 999,999} & \multicolumn{2}{|c|}{1 to 2.9 million } & \multicolumn{7}{|c|}{$3+$ million } \\
\hline & & \multirow[b]{2}{*}{ Elmira } & \multirow[b]{2}{*}{ Glens Falls } & \multirow[b]{2}{*}{$\begin{array}{l}\text { Bingham- } \\
\text { ton }\end{array}$} & \multirow[b]{2}{*}{ Utica-Rome } & \multirow[b]{2}{*}{ Albany } & \multirow[b]{2}{*}{ Syracuse } & \multirow[b]{2}{*}{ Buffalo } & \multirow[b]{2}{*}{ Rochester } & \multirow[b]{2}{*}{ Newburgh } & \multirow[b]{2}{*}{$\begin{array}{l}\text { Pough- } \\
\text { keepsie }\end{array}$} & & & VY Metro & & \\
\hline & & & & & & & & & & & & $\begin{array}{c}\text { Nassau/ } \\
\text { Suffolk }\end{array}$ & $\begin{array}{c}\text { Putnam/ } \\
\text { Rockland/ } \\
\text { Westchester }\end{array}$ & $\begin{array}{c}\text { Five } \\
\text { Counties }\end{array}$ & $\begin{array}{r}\text { Sub of } 5 \\
4 \text { Counties } \\
\end{array}$ & $\begin{array}{l}\text { Counties } \\
\text { Manhattan }\end{array}$ \\
\hline inual CO2 Emissions per House & VS ONLY & & & & & & & & & & & & & & & \\
\hline Average CO2 Emissions $(\mathrm{kg}) / \mathrm{HH}$ & 7,718 & 16,859 & 10,421 & 8,266 & 7,317 & 7,076 & 6,201 & 7,633 & 8,790 & 9,496 & 9,255 & 8,660 & 7,036 & 2,866 & 3,215 & 1,858 \\
\hline 0 Workers & 2,811 & & 9,857 & 3,783 & 3,514 & 1,963 & 3,006 & 3,401 & 3,713 & 5,328 & 3,829 & 3,578 & 2,009 & 1,284 & 1,436 & 804 \\
\hline 1 Workers & 5,041 & 4,586 & 10,007 & 10,103 & 5,070 & 7,162 & 5,642 & 5,422 & 8,178 & 8,117 & 10,421 & 7,167 & 5,070 & 2,193 & 2,634 & 947 \\
\hline 2 Workers & 9,066 & 31,409 & 11,482 & 10,671 & 12,131 & 9,964 & 9,230 & 11,611 & 12,100 & 11,176 & 13,627 & 11,468 & 9,746 & 3,762 & 4,087 & 2,900 \\
\hline 3 or more Workers & 15,831 & & & 24,260 & 15,404 & 8,851 & 5,537 & 13,324 & 27,369 & 20,566 & 16,175 & 14,460 & 13,711 & 7,816 & 8,169 & 6,538 \\
\hline Average CO2 Emissions $(\mathrm{kg}) / \mathrm{HH}$ & 7,718 & 16,859 & 10,421 & 8,266 & 7,317 & 7,076 & 6,201 & 7,633 & 8,790 & 9,496 & 9,255 & 8,660 & 7,036 & 2,866 & 3,215 & 1,858 \\
\hline 1 Drivers & 3,688 & 1,562 & 6,487 & 6,584 & 3,955 & 3,197 & 4,566 & 4,242 & 5,770 & 6,161 & 7,444 & 4,222 & 2,550 & 2,349 & 2,844 & 1,354 \\
\hline 2 Drivers & 8,294 & 20,323 & 10,439 & 9,269 & 10,687 & 10,666 & 6,795 & 9,362 & 10,716 & 10,317 & 11,766 & 10,140 & 9,379 & 4,836 & 4,982 & 4,323 \\
\hline 3 or more Drivers & 15,831 & & 13,332 & 24,260 & 12,454 & 11,179 & 11,835 & 12,229 & 10,817 & 12,775 & 11,643 & 16,116 & 12,348 & 10,140 & 11,415 & 3,601 \\
\hline Average CO2 Emissions $(\mathrm{kg}) / \mathrm{HH}$ & 7,718 & 16,859 & 10,421 & 8,266 & 7,317 & 7,076 & 6,201 & 7,633 & 8,790 & 9,496 & 9,255 & 8,660 & 7,036 & 2,866 & 3,215 & 1,858 \\
\hline 1 Vehicles & 2,635 & 4,586 & 7,704 & 4,497 & 3,283 & 3,820 & 4,468 & 4,657 & 4,877 & 5,879 & 7,111 & 3,515 & 4,080 & 4,288 & 4,049 & 5,059 \\
\hline 2 Vehicles & 10,127 & 31,409 & 11,539 & 10,386 & 7,143 & 10,459 & 9,369 & 8,475 & 9,819 & 10,524 & 11,102 & 10,737 & 9,222 & 7,682 & 7,724 & 6,564 \\
\hline 3 or more Vehicles & 15,161 & & 11,126 & 12,021 & 16,411 & 10,852 & 11,125 & 14,253 & 16,694 & 11,730 & 12,691 & 15,118 & 12,624 & 16,987 & 17,273 & 7,818 \\
\hline Annual CO2 Emissions per House & $n$-POV MODE & & & & & & & & & & & & & & & \\
\hline Average CO2 Emissions $(\mathrm{kg}) / \mathrm{HH}$ & 119 & 68 & 242 & 174 & 230 & 177 & 125 & 128 & 150 & 323 & 274 & 482 & 498 & 737 & 739 & 729 \\
\hline 0 Workers & 4 & 13 & 14 & 65 & 70 & 54 & 74 & 76 & 37 & 106 & 146 & 257 & 62 & 397 & 401 & 381 \\
\hline 1 Workers & 167 & 32 & 621 & 305 & 458 & 126 & 99 & 193 & 228 & 119 & 72 & 285 & 513 & 648 & 706 & 487 \\
\hline & 134 & 98 & 75 & 122 & 184 & 205 & 154 & 128 & 97 & 617 & 291 & 632 & 545 & 892 & 741 & 1,293 \\
\hline 3 or 1 & 91 & 253 & 516 & 238 & 58 & 617 & 301 & 77 & 385 & 394 & 938 & 1,014 & 1,016 & 1,572 & 1,685 & 842 \\
\hline Average CO2 Emissions $(\mathrm{kg}) / \mathrm{HH}$ & 119 & 68 & 242 & 174 & 230 & 177 & 125 & 128 & 150 & 323 & 274 & 482 & 498 & 737 & 739 & 729 \\
\hline 0 Drivers & 21 & 62 & 141 & 357 & 224 & 251 & 171 & 802 & 35 & 399 & & 160 & 518 & 578 & 586 & 555 \\
\hline 1 Drivers & 101 & 17 & 2 & 24 & 423 & 119 & 64 & 66 & 166 & 308 & 226 & 260 & 255 & 700 & 783 & 480 \\
\hline 2 Drivers & 143 & 76 & 331 & 158 & 107 & 102 & 129 & 89 & 87 & 272 & 199 & 511 & 520 & 861 & 727 & 1,280 \\
\hline 3 or more Drivers & 125 & 159 & 420 & 480 & 126 & 610 & 303 & 59 & 384 & 478 & 759 & 894 & 940 & 1,153 & 1,120 & 1,625 \\
\hline Average CO2 Emissions $(\mathrm{kg}) / \mathrm{HH}$ & 119 & 68 & 242 & 174 & 230 & 177 & 125 & 128 & 150 & 323 & 274 & 482 & 498 & 737 & 739 & 729 \\
\hline 0 Vehicles & 103 & 83 & 80 & 308 & 154 & 346 & 345 & 655 & 727 & 271 & 336 & 131 & 450 & 862 & 907 & 772 \\
\hline 1 Vehicles & 155 & 22 & 29 & 13 & 409 & 99 & 73 & 37 & 48 & 295 & 177 & 577 & 402 & 608 & 612 & 592 \\
\hline 2 Vehic & 121 & 78 & 504 & 208 & 170 & 179 & 100 & 99 & 118 & 297 & 260 & 373 & 534 & 553 & 521 & 1,013 \\
\hline 3 or more Vehicles & 43 & 113 & 120 & 270 & 59 & 230 & 141 & 68 & 187 & 412 & 421 & 641 & 624 & 720 & 735 & 526 \\
\hline Annual CC & IODES & & & & & & & & & & & & & & & \\
\hline Average CO2 Emissions $(\mathrm{kg}) / \mathrm{HH}$ & 7,838 & 16,926 & 10,663 & 8,440 & 7,547 & 7,254 & 6,326 & 7,762 & 8,940 & 9,820 & 9,528 & 9,141 & 7,534 & 3,603 & 3,954 & 2,587 \\
\hline 0 Workers & 2,815 & 13 & 9,872 & 3,848 & 3,583 & 2,017 & 3,080 & 3,477 & 3,750 & 5,434 & 3,974 & 3,836 & 2,071 & 1,681 & 1,837 & 1,185 \\
\hline 1 Workers & 5,208 & 4,618 & 10,628 & 10,408 & 5,527 & 7,288 & 5,741 & 5,615 & 8,407 & 8,236 & 10,493 & 7,452 & 5,583 & 2,841 & 3,340 & 1,434 \\
\hline 2 Workers & 9,200 & 31,506 & 11,557 & 10,793 & 12,315 & 10,168 & 9,383 & 11,739 & 12,196 & 11,793 & 13,918 & 12,099 & 10,291 & 4,654 & 4,828 & 4,193 \\
\hline 3 or more Workers & 15,921 & 253 & 516 & 24,498 & 15,462 & 9,468 & 5,838 & 13,400 & 27,754 & 20,959 & 17,113 & 15,474 & 14,727 & 9,388 & 9,854 & 7,381 \\
\hline 22 Emissions (kg)/HH & 7,838 & 16,926 & 10,663 & 8,440 & 7,547 & 7,254 & 6,326 & 7,762 & 8,940 & 9,820 & 9,528 & 9,141 & 7,534 & 3,603 & 3,954 & 2,587 \\
\hline 0 Driv & 21 & 62 & 141 & 357 & 224 & 25 & 171 & 802 & 35 & 39 & & 160 & 518 & 578 & 586 & 555 \\
\hline $1 \mathrm{Dr}$ & 3,788 & 1,579 & 6,488 & 6,608 & 4,378 & 3,316 & 4,630 & 4,308 & 5,936 & 6,4 & 7,670 & 4,482 & 2,805 & 3,049 & 3,627 & 1,834 \\
\hline 2 Drivers & 8,436 & 20,399 & 10 , & 9,427 & 10,794 & 10, & 6,9 & 9,451 & 10,8 & 10 & 11, & 10,651 & 9,899 & 5,697 & 5,709 & 5,603 \\
\hline 3 or more Drivers & 15,956 & 159 & 13,752 & 24,741 & 12,580 & 11,789 & 12,138 & 12,288 & 11,200 & 13,253 & 12,403 & 17,010 & 13,288 & 11,293 & 12,535 & 5,226 \\
\hline Average CO2 Emissions $(\mathrm{kg}) / \mathrm{HH}$ & 7,838 & 16,926 & 10,663 & 8,440 & 7,547 & 7,254 & 6,326 & 7,762 & 8,940 & 9,820 & 9,528 & 9,141 & 7,534 & 3,603 & 3,954 & 2,587 \\
\hline 0 Vehicles & 103 & 83 & 80 & 308 & 154 & 346 & 345 & 655 & 727 & 271 & 336 & 131 & 450 & 862 & 907 & 772 \\
\hline 1 Vehicles & 2,790 & 4,608 & 7,733 & 4,510 & 3,692 & 3,918 & 4,541 & 4,694 & 4,925 & 6,174 & 7,288 & 4,092 & 4,482 & 4,896 & 4,661 & 5,651 \\
\hline 2 Vehicles & 10,249 & 31,487 & 12,043 & 10,594 & 7,313 & 10,638 & 9,469 & 8,574 & 9,937 & 10,821 & 11,362 & 11,110 & 9,756 & 8,235 & 8,245 & 7,577 \\
\hline 3 or more Vehicles & 15,204 & 113 & 11,246 & 12,291 & 16,470 & 11,082 & 11,266 & 14,321 & 16,880 & 12,142 & 13,112 & 15,760 & 13,248 & 17,707 & 18,007 & 8,344 \\
\hline
\end{tabular}




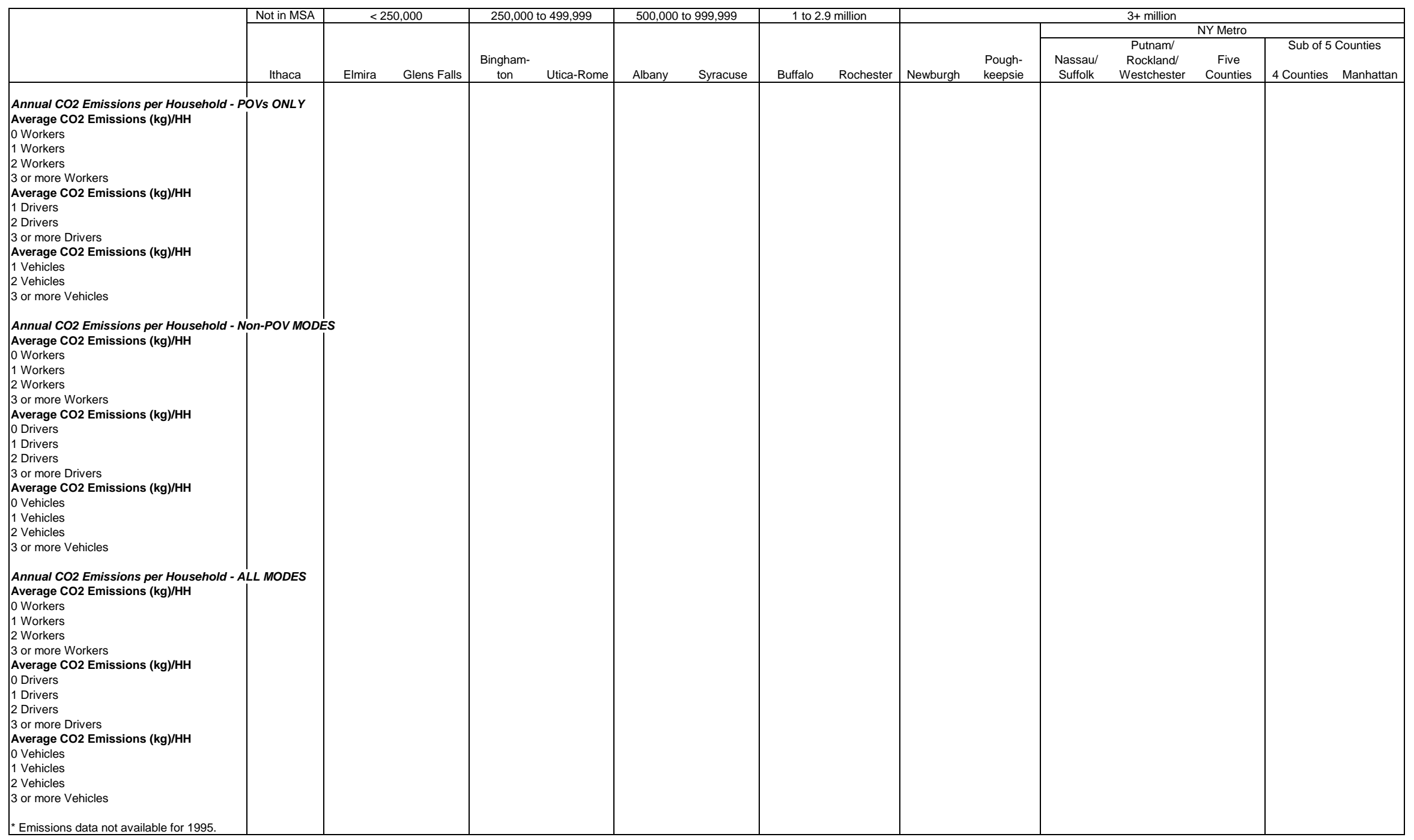




\begin{tabular}{|c|c|c|c|c|c|c|c|c|c|c|c|c|c|c|c|c|c|}
\hline & \multicolumn{2}{|c|}{ Not in MSA } & \multicolumn{2}{|c|}{$<250,000$} & \multicolumn{2}{|c|}{250,000 to 499,999} & \multicolumn{2}{|c|}{500,000 to 999,999} & \multicolumn{2}{|c|}{1 to 2.9 million } & \multicolumn{7}{|c|}{$3+$ million } \\
\hline & Ithaca & Kingston & Elmira & Glens Falls & $\begin{array}{l}\text { Bingham- } \\
\text { ton }\end{array}$ & Utica-Rome & Albany & Syracuse & Buffalo & Rochester & Newburgh & $\begin{array}{l}\text { Pough- } \\
\text { keepsie }\end{array}$ & $\begin{array}{c}\text { Nassau/ } \\
\text { Suffolk }\end{array}$ & $\begin{array}{c}\text { Putnam/ } \\
\text { Rockland/ } \\
\text { Westchester }\end{array}$ & $\begin{array}{c}\text { Five } \\
\text { Counties }\end{array}$ & \multicolumn{2}{|c|}{\begin{tabular}{|c|} 
Sub of 5 Counties \\
4 Counties Manhattan \\
\end{tabular}} \\
\hline Percent Vehicl & & & & & & & & & & & & & & & & & \\
\hline Auto & $58.5 \%$ & $55.3 \%$ & $51.5 \%$ & $45.9 \%$ & $53.4 \%$ & $54.2 \%$ & $56.8 \%$ & $56.0 \%$ & $61.0 \%$ & $57.3 \%$ & $55.3 \%$ & $58.1 \%$ & $59.6 \%$ & $59.9 \%$ & $64.7 \%$ & $64.6 \%$ & \\
\hline 0 to $2 y$ & $4.9 \%$ & $6.1 \%$ & $4.5 \%$ & $7.0 \%$ & $6.6 \%$ & $8.9 \%$ & $8.2 \%$ & $7.9 \%$ & $11.5 \%$ & $8.4 \%$ & $7.5 \%$ & $8.4 \%$ & $9.7 \%$ & $9.4 \%$ & $11.0 \%$ & $10.5 \%$ & $14.8 \%$ \\
\hline 3 to $5 y$ & $11.5 \%$ & $10.9 \%$ & $9.1 \%$ & $11.7 \%$ & $8.5 \%$ & $11.6 \%$ & $11.9 \%$ & $15.7 \%$ & $11.2 \%$ & $12.7 \%$ & $13.6 \%$ & $12.0 \%$ & $12.5 \%$ & $14.8 \%$ & $11.2 \%$ & $11.4 \%$ & $9.9 \%$ \\
\hline 6 to 9 & $15.2 \%$ & $15.9 \%$ & $17.5 \%$ & $13.5 \%$ & $14.6 \%$ & $17.0 \%$ & $17.0 \%$ & $16.5 \%$ & $18.4 \%$ & $15.1 \%$ & $14.2 \%$ & $17.3 \%$ & $17.8 \%$ & $15.9 \%$ & $16.5 \%$ & $16.3 \%$ & $17.8 \%$ \\
\hline $10 \mathrm{yrs}$ & $23.8 \%$ & $20.7 \%$ & $19.7 \%$ & $12.5 \%$ & $22.5 \%$ & $15.2 \%$ & $18.1 \%$ & $14.7 \%$ & $18.3 \%$ & $19.6 \%$ & $18.5 \%$ & $18.2 \%$ & $17.3 \%$ & $17.2 \%$ & $22.6 \%$ & $23.0 \%$ & $19.2 \%$ \\
\hline Unrepo & $3.1 \%$ & $1.8 \%$ & $0.7 \%$ & $1.1 \%$ & $1.3 \%$ & $1.5 \%$ & $1.7 \%$ & $1.3 \%$ & $1.6 \%$ & $1.6 \%$ & $1.4 \%$ & $2.2 \%$ & $2.3 \%$ & $2.5 \%$ & $3.4 \%$ & $3.4 \%$ & $3.6 \%$ \\
\hline Van & $9.5 \%$ & $8.1 \%$ & $8.9 \%$ & $7.4 \%$ & $11.0 \%$ & $8.8 \%$ & $8.0 \%$ & $9.9 \%$ & $10.0 \%$ & $11.8 \%$ & $9.1 \%$ & $8.7 \%$ & $8.0 \%$ & $8.4 \%$ & $9.9 \%$ & $10.5 \%$ & $5.6 \%$ \\
\hline 0 to 2 yrs & $0.5 \%$ & $0.6 \%$ & $1.1 \%$ & $0.8 \%$ & $0.9 \%$ & $0.3 \%$ & $0.9 \%$ & $1.8 \%$ & $1.3 \%$ & $0.7 \%$ & $0.9 \%$ & $0.6 \%$ & $1.1 \%$ & $1.3 \%$ & $1.6 \%$ & $1.5 \%$ & $2.0 \%$ \\
\hline 3 to 5 yrs & $2.5 \%$ & $1.7 \%$ & $2.5 \%$ & $1.8 \%$ & $1.3 \%$ & $3.2 \%$ & $2.1 \%$ & $2.8 \%$ & $1.9 \%$ & $1.9 \%$ & $2.2 \%$ & $2.3 \%$ & $1.9 \%$ & $2.4 \%$ & $1.3 \%$ & $1.4 \%$ & $0.4 \%$ \\
\hline 6 to $9 \mathrm{yrs}$ & $2.9 \%$ & $2.4 \%$ & $1.7 \%$ & $2.1 \%$ & $4.2 \%$ & $2.8 \%$ & $2.9 \%$ & $2.1 \%$ & $3.0 \%$ & $4.8 \%$ & $3.3 \%$ & $3.9 \%$ & $2.5 \%$ & $1.6 \%$ & $1.1 \%$ & $1.1 \%$ & $0.8 \%$ \\
\hline 10 yrs or more & $3.3 \%$ & $3.1 \%$ & $2.6 \%$ & $2.4 \%$ & $4.4 \%$ & $2.2 \%$ & $1.8 \%$ & $2.9 \%$ & $3.5 \%$ & $4.0 \%$ & $1.9 \%$ & $1.5 \%$ & $2.1 \%$ & $3.0 \%$ & $5.1 \%$ & $5.5 \%$ & $2.1 \%$ \\
\hline Unreported & $0.3 \%$ & $0.3 \%$ & $1.0 \%$ & $0.2 \%$ & $0.3 \%$ & $0.4 \%$ & $0.3 \%$ & $0.3 \%$ & $0.3 \%$ & $0.4 \%$ & $0.9 \%$ & $0.4 \%$ & $0.5 \%$ & $0.2 \%$ & $0.9 \%$ & $1.0 \%$ & $0.3 \%$ \\
\hline suv & $18.5 \%$ & $18.3 \%$ & $20.6 \%$ & $22.4 \%$ & $18.2 \%$ & $18.1 \%$ & $22.4 \%$ & $21.7 \%$ & $17.2 \%$ & $17.3 \%$ & $20.8 \%$ & $20.0 \%$ & $25.3 \%$ & $25.0 \%$ & $22.6 \%$ & $22.1 \%$ & $26.3 \%$ \\
\hline 0 to 2 yrs & $2.9 \%$ & $4.0 \%$ & $2.6 \%$ & 4.4\% & $3.5 \%$ & $4.7 \%$ & $6.0 \%$ & $6.5 \%$ & $5.3 \%$ & $3.9 \%$ & $4.5 \%$ & $4.4 \%$ & $7.3 \%$ & $5.7 \%$ & $5.0 \%$ & $4.6 \%$ & $8.2 \%$ \\
\hline 3 to 5 & $5.6 \%$ & $4.5 \%$ & $8.7 \%$ & $7.7 \%$ & $5.2 \%$ & $5.3 \%$ & $6.8 \%$ & $7.8 \%$ & $4.5 \%$ & $4.9 \%$ & $7.7 \%$ & $7.6 \%$ & $7.3 \%$ & $9.0 \%$ & $6.5 \%$ & $6.3 \%$ & $7.7 \%$ \\
\hline 6 to 9 & $5.9 \%$ & $5.2 \%$ & $3.9 \%$ & $4.8 \%$ & $4.5 \%$ & $4.1 \%$ & $5.5 \%$ & $5.0 \%$ & $4.9 \%$ & $4.4 \%$ & $5.2 \%$ & $4.4 \%$ & $6.4 \%$ & $4.9 \%$ & $5.7 \%$ & $5.3 \%$ & $9.2 \%$ \\
\hline 10 yrs 0 & $3.6 \%$ & $4.2 \%$ & $5.1 \%$ & $5.4 \%$ & $4.2 \%$ & $3.5 \%$ & 3. & $1.9 \%$ & $2.0 \%$ & $3.8 \%$ & $3.3 \%$ & & $3.9 \%$ & $4.7 \%$ & $4.2 \%$ & $4.6 \%$ & $1.2 \%$ \\
\hline Unrep & $0.5 \%$ & $0.4 \%$ & $0.4 \%$ & $0.1 \%$ & & 0 & & & $0.5 \%$ & 0 & 6 & & & & $1.1 \%$ & $1.3 \%$ & \\
\hline Pickup Truck & $10.6 \%$ & $13.0 \%$ & $14.7 \%$ & $19.8 \%$ & $14.3 \%$ & $15.8 \%$ & & & & $11.2 \%$ & $11.2 \%$ & & & & $1.2 \%$ & $1.3 \%$ & $0.4 \%$ \\
\hline 0 to 2 & $1.0 \%$ & & & & & & & & & & & & $0.4 \%$ & $1.2 \%$ & & $0.1 \%$ & \\
\hline 3 to 5 & & & & & & & & & & & & & & & $0.2 \%$ & $0.2 \%$ & \\
\hline 6 to $9 y$ & $3.2 \%$ & & $3.2 \%$ & & $3.6 \%$ & & & & $2.1 \%$ & $3.1 \%$ & $3.5 \%$ & $2.6 \%$ & $1.2 \%$ & & $0.4 \%$ & $0.5 \%$ & \\
\hline $10 \mathrm{yrs}$ & $3.8 \%$ & $4.6 \%$ & $6.5 \%$ & $\%$ & $3 \%$ & & 3. & $1 \%$ & $3.4 \%$ & $3.9 \%$ & & $2.1 \%$ & $1.5 \%$ & $1.2 \%$ & $0.5 \%$ & $0.5 \%$ & $0.4 \%$ \\
\hline Unreport & $0.2 \%$ & & & & & & & $0.8 \%$ & $0.1 \%$ & & & & $0.1 \%$ & & & $0.1 \%$ & \\
\hline Other PC & $3.0 \%$ & $5.3 \%$ & $4.3 \%$ & $4.6 \%$ & $3.1 \%$ & & 2. & $2.6 \%$ & $2.7 \%$ & & $3.6 \%$ & $4.9 \%$ & $2.5 \%$ & & $1.7 \%$ & $1.6 \%$ & $2.4 \%$ \\
\hline 0 to 2 yrs & $0.2 \%$ & $0.5 \%$ & $2 \%$ & & $0.3 \%$ & $5 \%$ & $0.3 \%$ & $0.3 \%$ & $0.1 \%$ & $0.3 \%$ & $0.7 \%$ & & $0.2 \%$ & $0.2 \%$ & $0.2 \%$ & $0.1 \%$ & $1.2 \%$ \\
\hline 3 to $5 \mathrm{yr}$ & $0.6 \%$ & $0.8 \%$ & $0.6 \%$ & $1.6 \%$ & $0.1 \%$ & $0.4 \%$ & $0.5 \%$ & $0.3 \%$ & $0.2 \%$ & $0.6 \%$ & $0.1 \%$ & $0.7 \%$ & & & $0.1 \%$ & $0.1 \%$ & $0.4 \%$ \\
\hline 6 to $9 \mathrm{yrs}$ & $0.6 \%$ & $1.4 \%$ & $0.5 \%$ & $1.2 \%$ & $1.0 \%$ & $0.7 \%$ & $0.5 \%$ & $0.9 \%$ & $1.1 \%$ & $0.2 \%$ & $1.3 \%$ & $0.6 \%$ & $0.8 \%$ & $0.4 \%$ & $0.5 \%$ & $0.5 \%$ & $0.7 \%$ \\
\hline 10 yrs or more & $1.2 \%$ & $2.6 \%$ & $1.5 \%$ & $1.0 \%$ & $1.6 \%$ & $1.0 \%$ & $1.4 \%$ & $0.8 \%$ & $1.2 \%$ & $1.1 \%$ & $1.0 \%$ & $1.5 \%$ & $0.5 \%$ & $0.5 \%$ & $0.8 \%$ & $0.9 \%$ & $0.2 \%$ \\
\hline Unreported & $0.4 \%$ & $0.1 \%$ & $0.5 \%$ & $0.4 \%$ & $0.2 \%$ & $0.5 \%$ & $0.1 \%$ & $0.3 \%$ & $0.2 \%$ & $0.2 \%$ & $0.4 \%$ & $1.1 \%$ | & $0.2 \%$ & $0.1 \%$ & $0.0 \%$ & $0.0 \%$ & \\
\hline
\end{tabular}




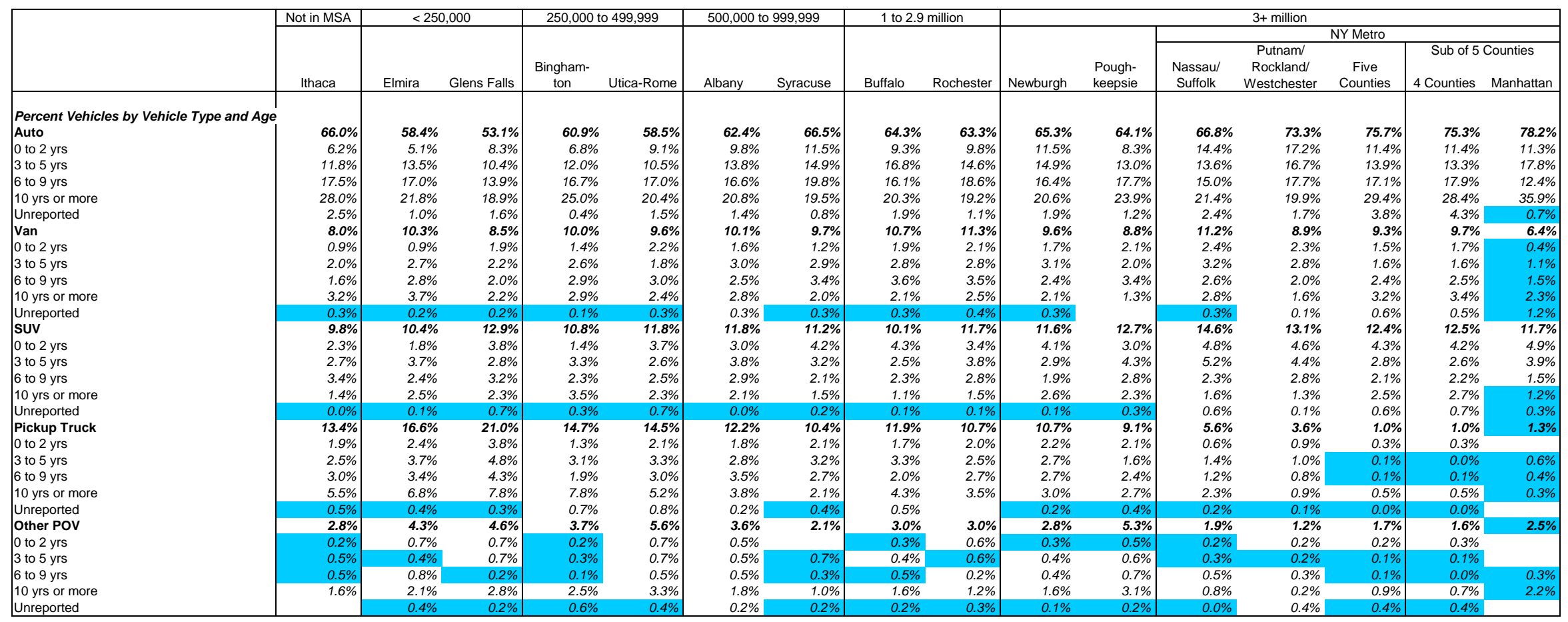




\begin{tabular}{|c|c|c|c|c|c|c|c|c|c|c|c|c|c|c|c|c|}
\hline & \multirow{3}{*}{\begin{tabular}{c|} 
Not in MSA \\
Ithaca \\
\end{tabular}} & \multirow{2}{*}{\multicolumn{2}{|c|}{$<250,000$}} & \multirow{3}{*}{\multicolumn{2}{|c|}{$\begin{array}{l}250,000 \text { to } 499,999 \\
\begin{array}{l}\text { Bingham- } \\
\text { ton }\end{array} \text { Utica-Rome } \\
\end{array}$}} & \multirow{3}{*}{\multicolumn{2}{|c|}{\begin{tabular}{l|}
500,000 to 999,999 \\
\\
Albany Syracuse \\
\end{tabular}}} & \multirow{3}{*}{\multicolumn{2}{|c|}{$\begin{array}{l}1 \text { to } 2.9 \text { million } \\
\text { Buffalo Rochester } \\
\end{array}$}} & \multirow[b]{3}{*}{ Newburgh } & \multirow{2}{*}{\multicolumn{6}{|c|}{$3+$ million }} \\
\hline & & \multirow[b]{2}{*}{ Elmira } & & & & & & & & & & & & & & \\
\hline & & & Glens Falls & & & & & & & & $\begin{array}{l}\text { Pough- } \\
\text { keepsie }\end{array}$ & $\begin{array}{l}\text { Nassau/ } \\
\text { Suffolk }\end{array}$ & $\begin{array}{c}\text { Putnam/ } \\
\text { Rockland// } \\
\text { Westchester }\end{array}$ & $\begin{array}{c}\text { Five } \\
\text { Counties }\end{array}$ & $\begin{array}{r}\text { Sub of } 50 \\
4 \text { Counties }\end{array}$ & $\begin{array}{l}\text { Counties } \\
\text { Manhattan }\end{array}$ \\
\hline \multicolumn{17}{|c|}{ Percent Vehicles by Vehicle $T y P$} \\
\hline $\begin{array}{l}\text { Auto } \\
0 \text { to } 2 \text { yrs }\end{array}$ & $\begin{array}{r}69.7 \% \\
7.0 \%\end{array}$ & $\begin{array}{l}65.1 \% \\
7.0 \%\end{array}$ & $\begin{array}{r}64.9 \% \\
9.2 \%\end{array}$ & $\begin{array}{l}67.8 \% \\
7.5 \%\end{array}$ & $66.4 \%$ & $\begin{array}{l}72.8 \% \\
115 \%\end{array}$ & $69.7 \%$ & $75.3 \%$ & $\begin{array}{l}76.9 \% \\
10.5 \%\end{array}$ & $69.6 \%$ & $\begin{array}{c}72.8 \% \\
11.0 \%\end{array}$ & $78.2 \%$ & 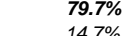 & $\begin{array}{l}87.4 \% \\
10.5 \%\end{array}$ & $87.5 \%$ & $87.0 \%$ \\
\hline 3 to $5 \mathrm{yrs}$ & $12.5 \%$ & $15.1 \%$ & $15.4 \%$ & $13.7 \%$ & $14.1 \%$ & $16.8 \%$ & $17.6 \%$ & $15.5 \%$ & $18.0 \%$ & $19.5 \%$ & $16.0 \%$ & $17.7 \%$ & $17.3 \%$ & $11.8 \%$ & $11.4 \%$ & $14.4 \%$ \\
\hline 6 to $9 \mathrm{yrs}$ & $25.5 \%$ & $19.7 \%$ & $22.2 \%$ & $22.3 \%$ & $22.2 \%$ & $24.8 \%$ & $20.9 \%$ & $22.6 \%$ & $26.2 \%$ & $22.3 \%$ & $22.9 \%$ & $24.5 \%$ & $27.2 \%$ & $33.9 \%$ & $33.7 \%$ & $35.8 \%$ \\
\hline 10 yrs or more & $23.0 \%$ & $20.8 \%$ & $16.7 \%$ & $21.9 \%$ & $19.9 \%$ & $18.2 \%$ & $16.4 \%$ & $21.5 \%$ & $21.1 \%$ & $16.6 \%$ & $21.3 \%$ & $21.7 \%$ & $18.0 \%$ & $27.1 \%$ & $27.6 \%$ & $23.0 \%$ \\
\hline Unreported & $1.7 \%$ & $2.5 \%$ & $1.4 \%$ & $2.4 \%$ & $1.1 \%$ & $1.5 \%$ & $1.8 \%$ & $2.7 \%$ & $1.2 \%$ & $1.6 \%$ & $1.6 \%$ & $2.1 \%$ & $2.5 \%$ & $4.2 \%$ & $4.4 \%$ & $2.5 \%$ \\
\hline Van & $7.9 \%$ & $9.7 \%$ & $7.0 \%$ & $8.8 \%$ & $7.1 \%$ & $6.8 \%$ & $10.9 \%$ & $8.3 \%$ & $8.1 \%$ & $7.2 \%$ & $9.4 \%$ & $8.4 \%$ & $6.5 \%$ & $5.6 \%$ & $6.0 \%$ & $3.3 \%$ \\
\hline 0 to $2 \mathrm{yrs}$ & $1.5 \%$ & $1.8 \%$ & $1.0 \%$ & $1.9 \%$ & $2.3 \%$ & $2.3 \%$ & $3.8 \%$ & $2.6 \%$ & $2.4 \%$ & $2.0 \%$ & $1.9 \%$ & $2.1 \%$ & $2.8 \%$ & $0.9 \%$ & $1.0 \%$ & $0.2 \%$ \\
\hline 3 to $5 \mathrm{yrs}$ & $2.3 \%$ & $1.8 \%$ & $2.5 \%$ & $1.8 \%$ & $1.8 \%$ & $1.6 \%$ & $2.5 \%$ & $2.3 \%$ & $1.8 \%$ & $1.5 \%$ & $2.7 \%$ & $1.5 \%$ & $1.3 \%$ & $1.2 \%$ & $1.0 \%$ & $2.7 \%$ \\
\hline 6 to $9 y$ & $2.1 \%$ & $3.7 \%$ & $1.2 \%$ & $2.6 \%$ & $1.7 \%$ & $1.8 \%$ & $3.3 \%$ & $1.8 \%$ & $2.6 \%$ & $2.2 \%$ & $3.7 \%$ & $2.9 \%$ & $2.0 \%$ & $1.8 \%$ & $2.1 \%$ & \\
\hline \multirow{3}{*}{$\begin{array}{l}10 \text { yrs or more } \\
\text { Unreported } \\
\text { suv }\end{array}$} & $2.0 \%$ & $1.5 \%$ & $1.1 \%$ & $2.5 \%$ & $1.0 \%$ & $1.0 \%$ & $1.0 \%$ & $1.5 \%$ & $1.3 \%$ & $1.4 \%$ & \multirow{2}{*}{$1.1 \%$} & $1.7 \%$ & $0.3 \%$ & $1.3 \%$ & $1.5 \%$ & \\
\hline & $0.1 \%$ & $0.9 \%$ & $1.2 \%$ & $0.1 \%$ & $0.3 \%$ & $0.0 \%$ & $0.3 \%$ & $0.1 \%$ & $0.1 \%$ & $0.1 \%$ & & $0.2 \%$ & $0.1 \%$ & $0.4 \%$ & $0.4 \%$ & $0.4 \%$ \\
\hline & $5.8 \%$ & $6.6 \%$ & $6.0 \%$ & $6.2 \%$ & $7.1 \%$ & $5.9 \%$ & $7.1 \%$ & $5.6 \%$ & $5.4 \%$ & $9.5 \%$ & $7.9 \%$ & $8.5 \%$ & $10.0 \%$ & $5.3 \%$ & $5.0 \%$ & $7.2 \%$ \\
\hline 0 to $2 \mathrm{yrs}$ & $1.0 \%$ & $1.4 \%$ & $1.6 \%$ & $1.6 \%$ & $1.7 \%$ & $1.7 \%$ & $2.1 \%$ & $1.2 \%$ & $1.8 \%$ & $2.6 \%$ & $1.9 \%$ & $2.6 \%$ & $3.6 \%$ & $1.4 \%$ & $1.3 \%$ & $2.4 \%$ \\
\hline 3 to $5 \mathrm{yrs}$ & $1.4 \%$ & $2.7 \%$ & $1.3 \%$ & $0.9 \%$ & $1.2 \%$ & $1.5 \%$ & $1.8 \%$ & $1.9 \%$ & $1.1 \%$ & $2.0 \%$ & $1.8 \%$ & $2.3 \%$ & $1.5 \%$ & $1.4 \%$ & $1.3 \%$ & $2.3 \%$ \\
\hline 6 to $9 \mathrm{yrs}$ & $2.2 \%$ & $1.3 \%$ & $1.6 \%$ & $1.8 \%$ & $2.4 \%$ & $1.1 \%$ & $2.3 \%$ & $1.4 \%$ & $1.5 \%$ & $2.9 \%$ & $2.4 \%$ & $2.1 \%$ & $3.6 \%$ & $1.7 \%$ & $1.9 \%$ & \multirow{3}{*}{$\begin{array}{l}0.5 \% \\
1.9 \%\end{array}$} \\
\hline \multirow{3}{*}{$\begin{array}{l}10 \text { yrs or more } \\
\text { Unreported } \\
\text { Pickup Truck }\end{array}$} & $1.1 \%$ & $1.1 \%$ & \multirow{2}{*}{$1.6 \%$} & \multirow{2}{*}{\multicolumn{2}{|c|}{$\begin{array}{l}1.9 \% \\
0.1 \%\end{array}$}} & $1.7 \%$ & $0.8 \%$ & \multirow{2}{*}{$1.2 \%$} & $0.8 \%$ & $1.7 \%$ & \multirow{2}{*}{$1.8 \%$} & $1.3 \%$ & $1.2 \%$ & \multirow{2}{*}{$0.7 \%$} & \multirow{2}{*}{$0.6 \%$} & \\
\hline & $0.2 \%$ & $0.1 \%$ & & & & $0.1 \%$ & $0.1 \%$ & & $0.2 \%$ & $0.3 \%$ & & $0.2 \%$ & $0.1 \%$ & & & \\
\hline & $14.4 \%$ & $16.3 \%$ & $20.3 \%$ & $14.6 \%$ & $16.7 \%$ & $11.6 \%$ & $10.8 \%$ & $9.5 \%$ & $8.0 \%$ & $11.3 \%$ & $8.4 \%$ & $4.3 \%$ & $2.7 \%$ & $1.2 \%$ & $1.0 \%$ & $2.4 \%$ \\
\hline 0 to $2 \mathrm{yrs}$ & $2.8 \%$ & $3.0 \%$ & $2.4 \%$ & $1.7 \%$ & $2.5 \%$ & $1.6 \%$ & $1.6 \%$ & $1.8 \%$ & $1.0 \%$ & $1.5 \%$ & $1.7 \%$ & & $0.6 \%$ & $0.0 \%$ & $0.0 \%$ & \\
\hline 3 to $5 \mathrm{yr}$ & $1.7 \%$ & $2.0 \%$ & $3.2 \%$ & $2.5 \%$ & $3.5 \%$ & $2.0 \%$ & $2.0 \%$ & $2.2 \%$ & $2.0 \%$ & 2.4 & 1.0 & $0.9 \%$ & $0.4 \%$ & $0.1 \%$ & $0.1 \%$ & \\
\hline 6 to $9 \mathrm{yrs}$ & $4.2 \%$ & $5.7 \%$ & $6.7 \%$ & $3.6 \%$ & $5.2 \%$ & $4.4 \%$ & $4.6 \%$ & $2.7 \%$ & $2.5 \%$ & $3.5 \%$ & $3.0 \%$ & $1.1 \%$ & $1.0 \%$ & $0.4 \%$ & $0.5 \%$ & \\
\hline \multirow{3}{*}{$\begin{array}{l}10 \text { yrs or more } \\
\text { Unreported } \\
\text { Other POV }\end{array}$} & $5.4 \%$ & $5.3 \%$ & $7.6 \%$ & $6.6 \%$ & $5.6 \%$ & $3.5 \%$ & $2.1 \%$ & $2.6 \%$ & $2.0 \%$ & $3.8 \%$ & $2.4 \%$ & $1.5 \%$ & \multirow{2}{*}{$0.7 \%$} & $0.6 \%$ & $0.4 \%$ & $2.2 \%$ \\
\hline & $0.3 \%$ & $0.2 \%$ & $0.4 \%$ & $0.2 \%$ & & $0.1 \%$ & $0.5 \%$ & $0.2 \%$ & $0.5 \%$ & $0.2 \%$ & $0.3 \%$ & $0.3 \%$ & & $0.1 \%$ & $0.1 \%$ & $0.2 \%$ \\
\hline & $2.2 \%$ & $2.4 \%$ & $1.9 \%$ & $2.6 \%$ & $2.7 \%$ & $2.9 \%$ & $1.5 \%$ & $1.3 \%$ & $1.6 \%$ & $2.5 \%$ & $1.5 \%$ & $0.6 \%$ & $1.2 \%$ & $0.5 \%$ & $0.6 \%$ & $0.2 \%$ \\
\hline 0 to $2 \mathrm{yrs}$ & & $0.4 \%$ & $0.1 \%$ & $0.4 \%$ & & $0.2 \%$ & $0.5 \%$ & & $0.4 \%$ & $0.3 \%$ & & $0.0 \%$ & $0.0 \%$ & $0.1 \%$ & $0.1 \%$ & \\
\hline 3 to $5 \mathrm{yrs}$ & $0.4 \%$ & $0.3 \%$ & $0.1 \%$ & & $0.1 \%$ & $0.2 \%$ & $0.2 \%$ & $0.1 \%$ & $0.3 \%$ & $0.1 \%$ & $0.1 \%$ & & $0.4 \%$ & $0.0 \%$ & $0.1 \%$ & \\
\hline 6 to $9 y$ & $0.4 \%$ & $0.7 \%$ & $0.5 \%$ & $0.5 \%$ & $0.4 \%$ & $0.9 \%$ & $0.1 \%$ & $0.1 \%$ & $0.2 \%$ & $0.8 \%$ & $0.2 \%$ & $0.1 \%$ & $0.1 \%$ & $0.1 \%$ & $0.1 \%$ & \\
\hline 10 yrs or more & $1.3 \%$ & $1.1 \%$ & $1.1 \%$ & $1.5 \%$ & $2.2 \%$ & $1.5 \%$ & $0.5 \%$ & $1.1 \%$ & $0.8 \%$ & $1.3 \%$ & $1.1 \%$ & $0.3 \%$ & $0.6 \%$ & $0.1 \%$ & $0.0 \%$ & $0.2 \%$ \\
\hline Unreported & $0.2 \%$ & & $0.1 \%$ & $0.1 \%$ & & $0.1 \%$ & $0.2 \%$ & & & & $0.1 \%$ & $0.2 \%$ & $0.1 \%$ & $0.3 \%$ & $0.3 \%$ & \\
\hline
\end{tabular}




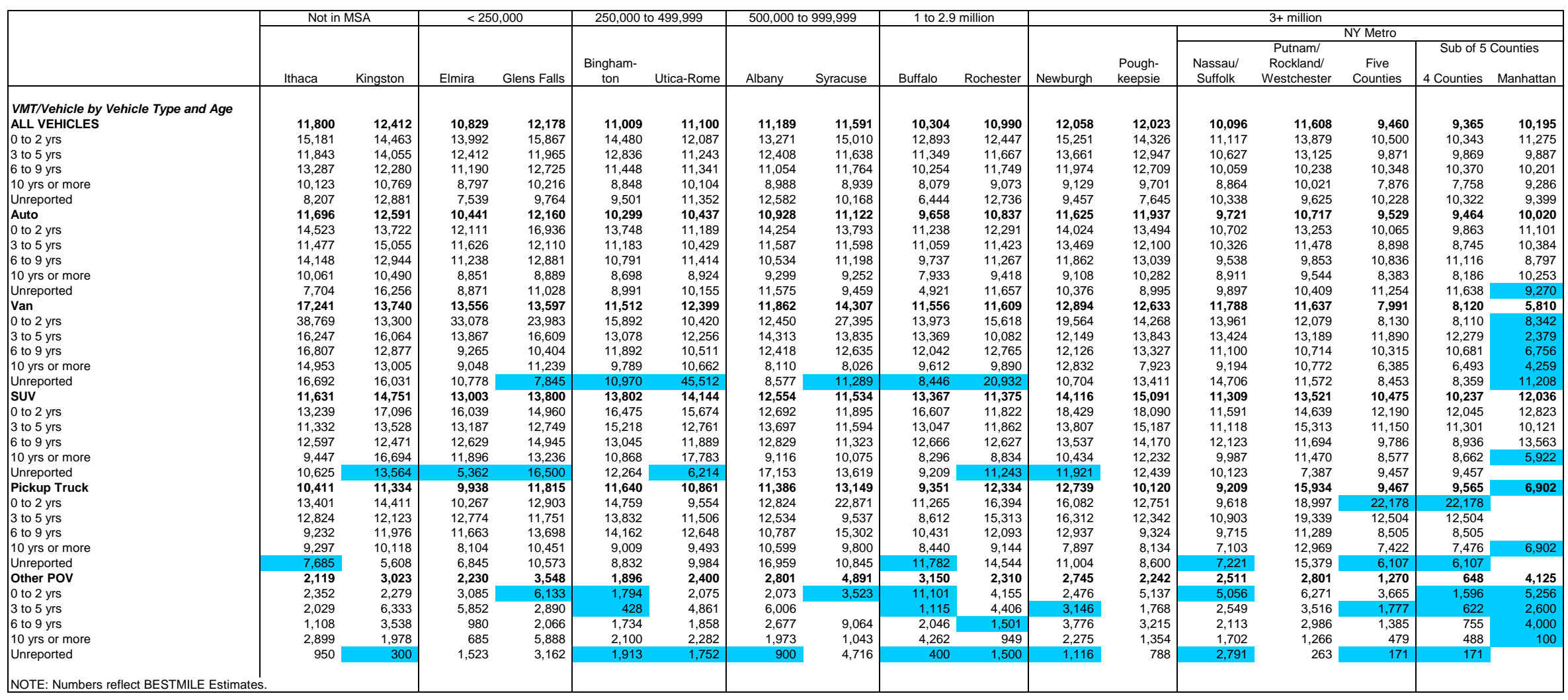




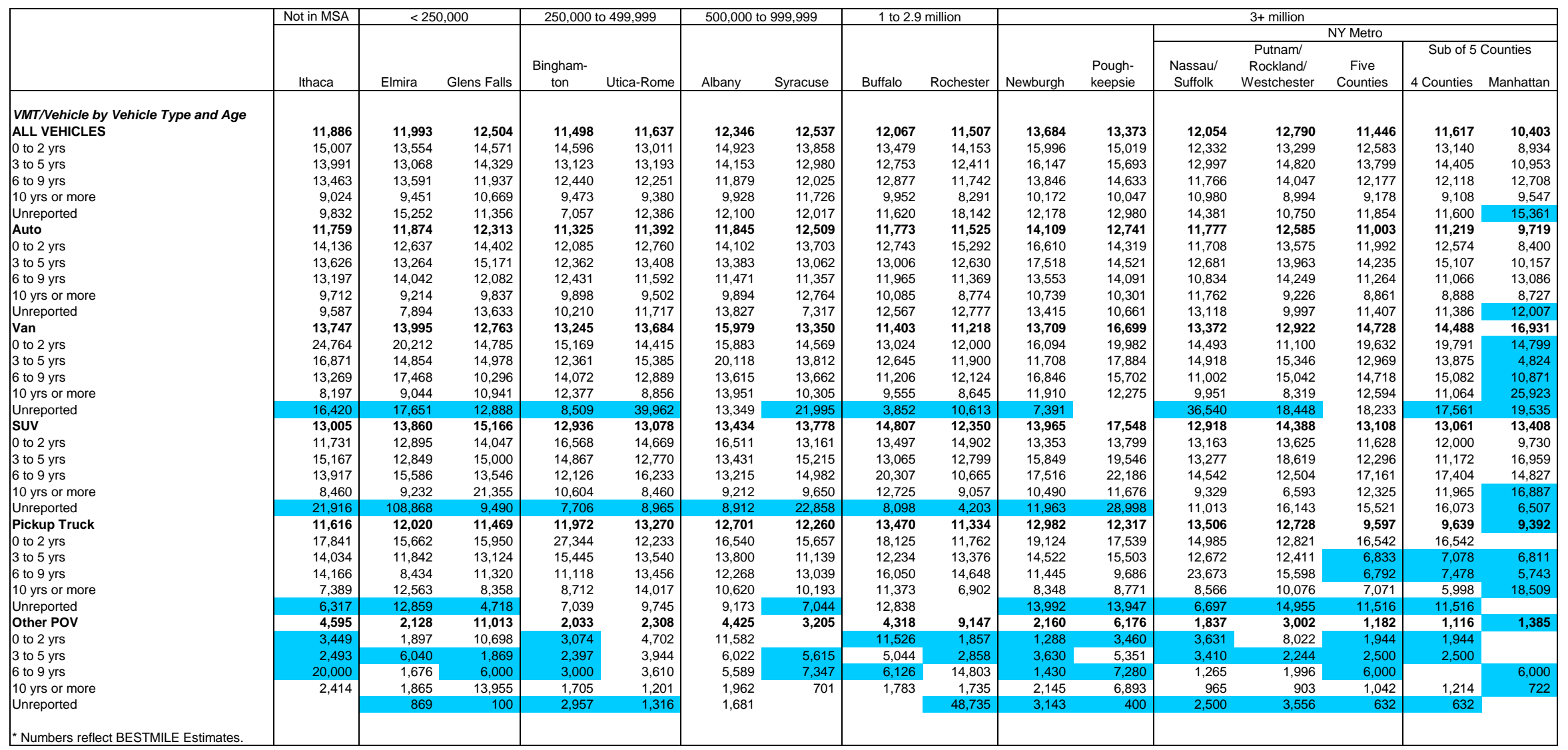




\begin{tabular}{|c|c|c|c|c|c|c|c|c|c|c|c|c|c|c|c|c|}
\hline & \multirow{3}{*}{$\begin{array}{c}\text { Not in MSA } \\
\text { Ithaca } \\
\end{array}$} & \multicolumn{2}{|c|}{$<250,000$} & \multirow{3}{*}{\multicolumn{2}{|c|}{$\begin{array}{l}250,000 \text { to } 499,999 \\
\begin{array}{c}\text { Bingham- } \\
\text { ton }\end{array} \text { Utica-Rome } \\
\end{array}$}} & \multirow{3}{*}{\multicolumn{2}{|c|}{$\begin{array}{l}500,000 \text { to } 999,999 \\
\\
\text { Albany } \quad \text { Syracuse } \\
\end{array}$}} & \multirow{3}{*}{\multicolumn{2}{|c|}{$\begin{array}{c}1 \text { to } 2.9 \text { million } \\
\text { Buffalo Rochester } \\
\end{array}$}} & \multirow[b]{3}{*}{ Newburgh } & \multirow[b]{3}{*}{$\begin{array}{l}\text { Pough- } \\
\text { keepsie }\end{array}$} & \multirow{2}{*}{\multicolumn{5}{|c|}{$3+$ million }} \\
\hline & & \multirow[b]{2}{*}{ Elmira } & \multirow[b]{2}{*}{ Glens Falls } & & & & & & & & & & & & & \\
\hline & & & & & & & & & & & & $\begin{array}{l}\text { Nassau/ } \\
\text { Suffolk }\end{array}$ & $\begin{array}{c}\text { Putnam/ } \\
\text { Rockland/ } \\
\text { Westchester }\end{array}$ & $\begin{array}{c}\text { Five } \\
\text { Counties }\end{array}$ & $\begin{array}{r}\text { Sub of } 5 \\
4 \text { Counties } \\
\end{array}$ & $\begin{array}{l}\text { Counties } \\
\text { Manhattan }\end{array}$ \\
\hline \multicolumn{17}{|l|}{ VMT/Vehicle by Vehicle Type and Age } \\
\hline ALL VEHICLES & 12,596 & 11,244 & 12,815 & 11,871 & 12,864 & 12,210 & 12,614 & 12,138 & 12,073 & 14,725 & 14,252 & 13,215 & 13,299 & 12,281 & 12,577 & 10,271 \\
\hline 0 to 2 yrs & 15,693 & 13,723 & 15,817 & 12,795 & 16,455 & 15,162 & 14,321 & 14,083 & 15,296 & 18,763 & 18,110 & 15,671 & 14,277 & 13,182 & 13,015 & 14,218 \\
\hline 3 to $5 \mathrm{yrs}$ & 13,071 & 12,239 & 13,465 & 13,215 & 13,983 & 12,825 & 12,527 & 12,837 & 12,360 & 16,516 & 14,162 & 12,821 & 13,706 & 11,965 & 12,128 & 11,165 \\
\hline 6 to $9 \mathrm{yrs}$ & 13,034 & 11,327 & 12,548 & 12,569 & 13,493 & 12,090 & 12,515 & 11,162 & 11,385 & 13,568 & 13,460 & 13,646 & 12,755 & 12,014 & 12,443 & 8,873 \\
\hline 10 yrs or more & 10,580 & 8,835 & 11,139 & 10,276 & 9,468 & 9,966 & 10,856 & 11,001 & 10,205 & 11,842 & 12,956 & 11,247 & 12,964 & 11,591 & 11,886 & 9,420 \\
\hline Unreported & 14,276 & 15,175 & 12,128 & 10,502 & 15,232 & 10,648 & 14,585 & 14,638 & 18,231 & 13,518 & 13,530 & 14,558 & 11,764 & 17,519 & 18,201 & 10,252 \\
\hline Auto & 12,479 & 10,919 & 12,450 & 11,555 & 13,182 & 12,043 & 12,705 & 11,579 & 12,124 & 15,087 & 14,203 & 12,806 & 13,274 & 11,851 & 12,204 & 9,442 \\
\hline 0 to $2 \mathrm{yrs}$ & 15,059 & 13,594 & 14,916 & 13,319 & 16,587 & 14,406 & 13,866 & 12,821 & 15,038 & 18,680 & 16,922 & 15,671 & 14,375 & 12,685 & 12,662 & 12,826 \\
\hline 3 to $5 \mathrm{yrs}$ & 13,107 & 11,954 & 12,137 & 12,197 & 14,269 & 12,052 & 12,412 & 11,290 & 12,286 & 17,046 & 14,283 & 12,005 & 13,835 & 11,287 & 11,622 & 9,469 \\
\hline 6 to $9 \mathrm{yrs}$ & 13,250 & 10,462 & 12,559 & 11,433 & 13,698 & 12,164 & 13,126 & 11,586 & 11,407 & 13,708 & 13,544 & 13,124 & 12,677 & 11,809 & 12,269 & 8,774 \\
\hline $10 \mathrm{yrs}$ or more & 10,323 & 9,294 & 11,003 & 10,868 & 10,108 & 10,485 & 10,974 & 10,603 & 10,827 & 12,813 & 13,438 & 11,155 & 12,785 & 11,079 & 11,377 & 8,703 \\
\hline Unreported & 14,692 & 14,688 & 15,350 & 10,055 & 15,704 & 10,817 & 18,194 & 14,947 & 22,739 & 12,527 & 14,020 & 16,050 & 12,944 & 17,117 & 17,793 & 9,905 \\
\hline Van & 14,753 & 12,075 & 14,301 & 14,472 & 17,489 & 16,253 & 13,553 & 16,012 & 12,640 & 16,498 & 14,648 & 16,969 & 11,739 & 13,754 & 13,251 & 20,309 \\
\hline 0 to $2 \mathrm{yrs}$ & 18,024 & 11,065 & 16,731 & 14,665 & 20,328 & 16,975 & 15,847 & 18,304 & 14,604 & 17,179 & 16,201 & 13,994 & 13,746 & 16,147 & 16,308 & 10,419 \\
\hline 3 to $5 \mathrm{yrs}$ & 13,189 & 14,486 & 16,628 & 16,537 & 16,831 & 15,713 & 13,854 & 17,088 & 15,014 & 15,030 & 14,867 & 21,296 & 11,872 & 16,790 & 14,933 & 21,405 \\
\hline 6 to $9 \mathrm{yrs}$ & 15,662 & 12,889 & 12,636 & 14,886 & 15,796 & \multirow{3}{*}{13,322} & 10,789 & 9,580 & 10,922 & 17,431 & 13,704 & 18,706 & 9,674 & 11,453 & 11,453 & \\
\hline \multirow{3}{*}{$\begin{array}{l}10 \text { yrs or more } \\
\text { Unreported }\end{array}$} & 13,205 & 5,912 & 13,790 & 12,551 & 16,353 & & 13,198 & 18,484 & 8,966 & 15,429 & \multirow[t]{2}{*}{14,513} & 14,432 & 9,556 & 13,181 & 13,181 & \\
\hline & 14,923 & 17,599 & 9,536 & 9,106 & 13,578 & & 13,982 & 10,709 & 12,124 & 20,481 & & 16,486 & 3,038 & 10,471 & 9,988 & 15,898 \\
\hline & 12,790 & 12,838 & 15,334 & 14,672 & 13,307 & 11,389 & 13,868 & 13,103 & 11,067 & 15,873 & 16,392 & 14,020 & 15,648 & 14,430 & 14,300 & 15,035 \\
\hline 0 to $2 \mathrm{yrs}$ & 16,191 & 10,906 & 18,008 & 14,536 & 12,503 & 15,527 & 15,519 & 13,736 & 12,964 & 19,192 & 22,395 & 16,733 & 14,800 & 15,654 & 14,034 & 21,171 \\
\hline 3 to $5 \mathrm{yrs}$ & 12,493 & 13,331 & 13,779 & 23,832 & 14,022 & 12,545 & 15,241 & 12,473 & 11,261 & 16,882 & 15,668 & 14,308 & 16,164 & 12,665 & 13,389 & 9,923 \\
\hline 6 to $9 \mathrm{yrs}$ & 15,215 & 13,577 & 13,607 & 14,867 & 16,391 & 9,639 & 13,145 & & 11,219 & 13,449 & 13,479 & 12,934 & 13,956 & 14,108 & 14,050 & \multirow{3}{*}{$\begin{array}{l}15,504 \\
13,493\end{array}$} \\
\hline \multirow{2}{*}{$\begin{array}{l}10 \text { yrs or more } \\
\text { Unreported }\end{array}$} & 5,075 & 12,714 & 15,656 & 10,398 & 9,396 & 7,474 & 8,217 & \multirow{2}{*}{16,842} & 6,355 & 12,838 & \multirow{2}{*}{14,723} & 10,162 & 23,660 & \multirow{2}{*}{$\begin{array}{l}16,341 \\
16,0\end{array}$} & \multirow[t]{2}{*}{17,770} & \\
\hline & 11,999 & 17,698 & & 16,147 & & 3,749 & 16,130 & & 10,729 & 19,664 & & 11,871 & 5,773 & & & \\
\hline Pickup Truck & 12,966 & 11,894 & 13,236 & 11,957 & 11,276 & 13,265 & 11,491 & 13,754 & 11,685 & 12,439 & 13,927 & 13,183 & 13,453 & 23,811 & 27,368 & 13,444 \\
\hline 0 to 2 yrs & 15,886 & 16,885 & 17,094 & 9,461 & 15,205 & 16,924 & 15,365 & 17,271 & 16,385 & 24,283 & 23,203 & 18,609 & 11,362 & 7,307 & 7,307 & \\
\hline 3 to $5 \mathrm{yrs}$ & 13,441 & 12,160 & 17,753 & 12,684 & 11,387 & 17,353 & 10,584 & 19,875 & 11,949 & 12,976 & 7,893 & 13,301 & 11,249 & 32,249 & 32,249 & \\
\hline 6 to $9 \mathrm{yrs}$ & 10,263 & 13,158 & 12,297 & 17,609 & 11,365 & 12,179 & 10,870 & 9,290 & 11,814 & 12,110 & 12,908 & 13,082 & 17,502 & 24,383 & 24,383 & \\
\hline $10 \mathrm{yrs}$ or more & 13,433 & 7,586 & 11,091 & 9,039 & 9,346 & 10,751 & 11,885 & 10,691 & 8,934 & 7,951 & 11,114 & 11,609 & 10,994 & 25,434 & 35,498 & 13,964 \\
\hline Unreported & 12,926 & 11,981 & 10,915 & 19,611 & & 14,102 & 6,658 & 13,146 & 10,683 & 7,857 & 12,467 & 13,088 & & 7,722 & 7,080 & 8,739 \\
\hline Other POV & 4,729 & 7,453 & 7,264 & 3,391 & 2,130 & 4,260 & 3,779 & 3,252 & 12,037 & 4,856 & 4,847 & 2,551 & 2,498 & 19,874 & 20,740 & 2,000 \\
\hline 0 to 2 & & 14,740 & 21,536 & 2,141 & & 19,3 & 5,890 & & 35,106 & 424 & & 857 & 9,600 & 1,714 & 1,714 & \\
\hline 3 to 5 & 11,704 & 3,251 & 3,748 & & 14,000 & 16,949 & 3,3 & 5,000 & 5,013 & 11,341 & 9,000 & & 4,875 & 6,000 & 6,000 & \\
\hline 6 to $9 \mathrm{yrs}$ & 2,307 & 7,656 & 11,868 & 7,210 & 2,614 & 2,032 & 4,000 & 5,000 & 10, & 6,250 & 5,000 & 15,000 & 3,000 & 4,101 & 4,751 & \\
\hline 10 yrs or more & 3,270 & 5,494 & 4,125 & 2,437 & 1,257 & 2,214 & 2,674 & 3,016 & 1,324 & 4,450 & 3,895 & 690 & 1,129 & 3,811 & 4,963 & 2,000 \\
\hline Unreported & & & & 2,000 & & & 1,510 & & & & 10,000 & 3,264 & & 35,246 & 35,246 & \\
\hline NOTE: Numbers reflect BESTMILE & Due to data $b$ & g unavailab & ple, self-report & annual mile & es were subs & or Res & on 199 & & & & & & & & & \\
\hline
\end{tabular}




\begin{tabular}{|c|c|c|c|c|c|c|c|c|c|c|c|c|c|c|c|c|c|}
\hline & \multicolumn{2}{|c|}{ Not in MSA } & \multirow{2}{*}{\multicolumn{2}{|c|}{$<250,000$}} & \multirow{2}{*}{\multicolumn{2}{|c|}{250,000 to 499,999}} & \multirow{2}{*}{\multicolumn{2}{|c|}{500,000 to 999,999}} & \multirow{2}{*}{\multicolumn{2}{|c|}{1 to 2.9 million }} & \multirow{2}{*}{\multicolumn{7}{|c|}{$3+$ million }} \\
\hline & \multirow[b]{2}{*}{ Ithaca } & \multirow[b]{2}{*}{ Kingston } & & \multirow[b]{2}{*}{ Glens Falls } & & & & & & & \multirow[b]{2}{*}{ Newburgh } & & & & & & \\
\hline & & & Elmira & & $\begin{array}{l}\text { Bingham- } \\
\text { ton }\end{array}$ & Utica-Rome & Albany & Syracuse & Buffalo & Rochester & & $\begin{array}{l}\text { Pough- } \\
\text { keepsie }\end{array}$ & $\begin{array}{c}\text { Nassau/ } \\
\text { Suffolk }\end{array}$ & $\begin{array}{c}\text { Putnam/ } \\
\text { Rockland// } \\
\text { Westchester }\end{array}$ & $\begin{array}{c}\text { Five } \\
\text { Counties }\end{array}$ & $\begin{array}{r}\text { Sub of } 5 \mathrm{C} \\
4 \text { Counties }\end{array}$ & $\begin{array}{l}\text { Counties } \\
\text { Manhattan }\end{array}$ \\
\hline Percent Not Taking Walk Trips in the last w & & & & & & & & & & & & & & & & & \\
\hline TOTAL & $26.4 \%$ & $33.5 \%$ & $31.4 \%$ & $30.5 \%$ & $30.8 \%$ & $34.3 \%$ & $29.2 \%$ & $32.5 \%$ & $38.5 \%$ & $36.7 \%$ & $30.9 \%$ & $31.8 \%$ & $35.3 \%$ & $27.7 \%$ & $16.8 \%$ & $18.7 \%$ & $9.5 \%$ \\
\hline 5 to 10 year-olds & $16.6 \%$ & $26.6 \%$ & $17.3 \%$ & $16.1 \%$ & $22.6 \%$ & $15.1 \%$ & $19.7 \%$ & $21.0 \%$ & $42.3 \%$ & $35.4 \%$ & $16.7 \%$ & $31.9 \%$ & $25.2 \%$ & $22.7 \%$ & $18.6 \%$ & $19.8 \%$ & $10.0 \%$ \\
\hline 11 to 15 year-olds & $12.7 \%$ & $36.2 \%$ & $20.0 \%$ & $20.4 \%$ & $24.2 \%$ & $17.2 \%$ & $21.0 \%$ & $33.0 \%$ & $35.1 \%$ & $36.7 \%$ & $23.5 \%$ & $19.7 \%$ & $23.6 \%$ & $16.0 \%$ & $11.5 \%$ & $11.9 \%$ & $9.2 \%$ \\
\hline 16 to 20 year-olds & $43.0 \%$ & $30.0 \%$ & $32.6 \%$ & $33.3 \%$ & $38.0 \%$ & $33.3 \%$ & $22.5 \%$ & $29.6 \%$ & $22.0 \%$ & $31.5 \%$ & $28.3 \%$ & $33.0 \%$ & $25.9 \%$ & $20.1 \%$ & $21.2 \%$ & $22.3 \%$ & $17.1 \%$ \\
\hline 21 to 35 year-olds & $22.5 \%$ & $43.3 \%$ & $24.3 \%$ & $25.4 \%$ & $20.4 \%$ & $39.8 \%$ & $30.4 \%$ & $27.4 \%$ & $49.7 \%$ & $36.8 \%$ & $26.5 \%$ & $26.0 \%$ & $43.0 \%$ & $26.4 \%$ & $12.5 \%$ & $16.3 \%$ & \\
\hline 36 to 64 year-olds & $16.8 \%$ & $29.9 \%$ & $31.0 \%$ & $30.6 \%$ & $29.5 \%$ & $34.0 \%$ & $27.9 \%$ & $31.8 \%$ & $33.7 \%$ & $34.4 \%$ & $32.5 \%$ & $31.9 \%$ & $34.2 \%$ & $25.4 \%$ & $15.9 \%$ & $17.3 \%$ & $10.3 \%$ \\
\hline $\begin{array}{l}\text { 65+ year-olds } \\
\text { Avg Minutes Spent Walking per Day }\end{array}$ & $44.0 \%$ & $37.7 \%$ & $50.5 \%$ & $44.5 \%$ & $43.7 \%$ & $44.9 \%$ & $44.5 \%$ & $46.5 \%$ & $48.5 \%$ & $47.4 \%$ & $51.6 \%$ & $43.5 \%$ & $45.9 \%$ & $49.7 \%$ & $26.2 \%$ & $27.8 \%$ & $19.7 \%$ \\
\hline $\begin{array}{l}\text { Avg } \\
\text { TOTA }\end{array}$ & 9.62 & 4.58 & 4.74 & 6.35 & 3.41 & 5.41 & 6.56 & 4.93 & 4.23 & & 4.83 & 4.87 & 5.65 & 9.32 & 20.35 & 17.27 & \\
\hline & 6.58 & 0.46 & 1.99 & 7.26 & 1.91 & 6.04 & 6.76 & 6.00 & 1.82 & 0.49 & 3.67 & 1.06 & 1.63 & 11.90 & & 14.38 & 15.33 \\
\hline & 9.52 & 1.73 & 5.48 & 7.91 & 1.33 & 7.36 & 7.51 & 3.71 & 4.61 & 2.49 & 3.25 & 1. & 4.82 & 12.91 & & 13.77 & 16.28 \\
\hline & 5.53 & 3.06 & 6.48 & 4.10 & 2.27 & 2.26 & 6.22 & 2.87 & 6.69 & 3.84 & 2.4 & & 4. & 8.38 & & 12.44 & 36.93 \\
\hline & 12.06 & 5.76 & 5.55 & 9.02 & 3.71 & 6.75 & 7.93 & 4.49 & 2.06 & 6.94 & 9.5 & 5. & & 7.69 & & 18.28 & 42.93 \\
\hline 36 te & 11.17 & 5.76 & 4.53 & 6.26 & 3.94 & 5.45 & 6.81 & 6.15 & 5.54 & 5.06 & 4.07 & & 6.8 & 10.55 & 22 & 20.29 & 30.58 \\
\hline $65+$ year-olds & 9.48 & 3.52 & 4.03 & 3.93 & 3.92 & 3.87 & 3.90 & 3.37 & 2.53 & 1.97 & 3.85 & 6.55 & 5.63 & 4.25 & 16.62 & 13.26 & 29.84 \\
\hline $\begin{array}{l}\text { Percent Not Taking Bike Trips in the last we } \\
\text { TOTAL }\end{array}$ & & 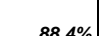 & & & & & & & & & & & & & & & \\
\hline 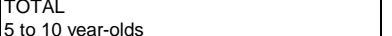 & $\begin{array}{l}84.8 \% \\
67.9 \%\end{array}$ & $88.4 \% \mid>-2>-2$ & $\begin{array}{l}85.7 \% \\
36.2 \%\end{array}$ & $85.2 \%$ & $90.9 \%$ & $88.6 \%$ & $\begin{array}{l}88.8 \% \\
57.4 \%\end{array}$ & $\begin{array}{l}89.5 \% \\
58.8 \%\end{array}$ & $\begin{array}{l}87.1 \% \\
55.0 \%\end{array}$ & $88.0 \%$ & $89.5 \%$ & $88.8 \%$ & $89.8 \%$ & $87.6 \%$ & 93.4\% & $93.4 \%$ & 93.2\% \\
\hline 11 to & $\begin{array}{l}67.9 \% \\
86.8 \%\end{array}$ & $65.9 \%$ & $\begin{array}{l}36.2 \% \\
57.2 \%\end{array}$ & $\begin{array}{l}44.3 \% \\
67.4 \%\end{array}$ & $\begin{array}{l}49.8 \% \\
66.5 \%\end{array}$ & $\begin{array}{l}55.7 \% \\
67.4 \%\end{array}$ & $\begin{array}{l}57.4 \% \\
65.0 \%\end{array}$ & $\begin{array}{l}58.8 \% \\
66.1 \%\end{array}$ & $\begin{array}{l}55.0 \% \\
69.7 \%\end{array}$ & $\begin{array}{l}64 . \% \% \\
68.7 \%\end{array}$ & $\begin{array}{l}55.3 \% \\
78.3 \%\end{array}$ & $\begin{array}{l}51.6 \% \\
64.1 \%\end{array}$ & $\begin{array}{l}62.9 \% \\
74.8 \%\end{array}$ & $\begin{array}{l}53.6 \% \\
65.8 \%\end{array}$ & $\begin{array}{l}79.7 \% \\
92.7 \%\end{array}$ & $\begin{array}{l}80.2 \% \\
93.5 \%\end{array}$ & $\begin{array}{l}76.1 \% \\
87.7 \%\end{array}$ \\
\hline 16 to & $82.0 \%$ & $82.0 \%$ & $81.5 \%$ & $85.6 \%$ & $93.0 \%$ & $95.5 \%$ & $89.0 \%$ & $90.1 \%$ & $79.7 \%$ & $83.6 \%$ & $92.6 \%$ & $91.3 \%$ & $89.1 \%$ & $90.9 \%$ & $95.3 \%$ & $97.8 \%$ & $86.3 \%$ \\
\hline 21 to 3 & $92.1 \%$ & $91.3 \%$ & $88.7 \%$ & $87.7 \%$ & $92.8 \%$ & $95.0 \%$ & $91.6 \%$ & $92.1 \%$ & $87.8 \%$ & $92.3 \%$ & $93.1 \%$ & $91.1 \%$ & $94.6 \%$ & $92.8 \%$ & $89.7 \%$ & $88.1 \%$ & $95.3 \%$ \\
\hline 36 to $64 \mathrm{y}$ & $80.9 \%$ & $94.3 \%$ & $92.4 \%$ & $88.6 \%$ & $96.8 \%$ & $90.4 \%$ & $92.8 \%$ & $93.7 \%$ & $92.3 \%$ & $91.6 \%$ & $95.0 \%$ & $94.2 \%$ & $92.0 \%$ & $91.6 \%$ & $95.5 \%$ & $95.9 \%$ & $94.1 \%$ \\
\hline $65+$ year- & $98.3 \%$ & $97.2 \%$ & $98.3 \%$ & $96.1 \%$ & $99.0 \%$ & $97.8 \%$ & $98.1 \%$ & $98.8 \%$ & $97.4 \%$ & $96.5 \%$ & $97.0 \%$ & $99.5 \%$ & $98.3 \%$ & $98.7 \%$ & $98.2 \%$ & $98.2 \%$ & $98.2 \%$ \\
\hline Spent Biking per Day & 0.49 & 0.47 & 0.62 & 1.0 & 0.28 & 1.00 & 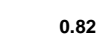 & $1.3 \mathrm{Y}>\mathrm{C}$ & 1.04 & 0.35 & 0.4 & $0.1,0$ & 0.27 & 0.59 & 0.38 & 0.38 & 0.37 \\
\hline year-olds & 0.25 & $\begin{array}{l}0.41 \\
0.82\end{array}$ & 0.38 & 2.23 & & 1.20 & $\begin{array}{l}0.62 \\
1.67\end{array}$ & $\begin{array}{l}1.31 \\
0.72\end{array}$ & 0.6 & $\begin{array}{l}0.35 \\
0.07\end{array}$ & $\begin{array}{l}0.44 \\
0.48\end{array}$ & & $\begin{array}{l}0.27 \\
0.38\end{array}$ & $\begin{array}{l}0.59 \\
2.06\end{array}$ & $\begin{array}{l}0.38 \\
0.19\end{array}$ & 0.22 & \\
\hline & 0.29 & 1.7 & 4.58 & 0.98 & & 5.02 & & 3.32 & & 0. & 0.94 & 0.89 & 0.53 & 0.19 & 0.02 & 0.02 & \\
\hline & 0.03 & & 0.65 & 4.89 & 0.30 & 2. & & 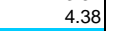 & & & & & 0.44 & & 0.14 & 0.07 & 0.39 \\
\hline & 0.75 & & & & & & & 1.4 & 2.77 & & & & 0. & 0.44 & & 0.55 & \\
\hline 36 to & 0.79 & 0.21 & 0.38 & 0.99 & 0.54 & 0.44 & 0.44 & 0.70 & 0.65 & 0.30 & 0.72 & 0.48 & 0 & 0.75 & 0. & 0.55 & 0.68 \\
\hline $65+y$ & 0.12 & 1.03 & 0.04 & 0.15 & & 0.03 & 0.15 & & 0.15 & 0.53 & & & 0.3 & 0.02 & 0 & 0.10 & 0.37 \\
\hline Spent $V$ & & & & & & & & & & & & & & & & & \\
\hline & $\begin{array}{r}10.11 \\
683\end{array}$ & 1. & $\begin{array}{l}5.36 \\
238\end{array}$ & $9.49 \mid$ & 191 & 724 & & 6.72 & $\begin{array}{l}5.27 \\
2.47\end{array}$ & $\begin{array}{l}4.63 \\
0.56\end{array}$ & 4.15 & $\begin{array}{l}5.49 \\
4.28\end{array}$ & $\begin{array}{l}5.92 \\
2.01\end{array}$ & $\begin{array}{r}9.91 \\
13.95\end{array}$ & $\begin{array}{l}20.73 \\
14.68\end{array}$ & $\begin{array}{l}17.65 \\
14.59\end{array}$ & $\begin{array}{l}33.29 \\
15.33\end{array}$ \\
\hline & $\begin{array}{l}6.83 \\
9.82\end{array}$ & 3. & $\begin{array}{l}2.00 \\
10.06\end{array}$ & $\begin{array}{l}9.49 \\
8.89\end{array}$ & $\begin{array}{l}1.91 \\
1.33\end{array}$ & 12.38 & $\begin{array}{l}8.43 \\
9.32\end{array}$ & $\begin{array}{l}0.12 \\
7.02\end{array}$ & 7.23 & 3.25 & 4.19 & $\begin{array}{l}4.63 \\
2.63\end{array}$ & 5.35 & $\begin{array}{l}13.10 \\
13.10\end{array}$ & $\begin{array}{r}14.00 \\
14.12\end{array}$ & $\begin{array}{l}14.09 \\
13.79\end{array}$ & 16.28 \\
\hline & 5.56 & 3. & 7.12 & & 2.58 & 4.86 & & 7.2 & 7.11 & 4. & 2. & & & & & & 37.32 \\
\hline & 12.81 & 5. & 5.55 & $\begin{array}{l}9.02 \\
9.02\end{array}$ & 3.71 & 7.51 & & 5. & 4.83 & 7.33 & & & & 8.13 & & 18.83 & 42.93 \\
\hline & 11.96 & 5. & 4.91 & 7.2 & 4.48 & 5.89 & 7.25 & 6.8 & 6.2 & 5. & 4. & & & 11.30 & & 20.84 & 31.25 \\
\hline $65+$ year-olds & 9.60 & 4.55 & 4.07 & 4.08 & 3.92 & 3.90 & 4.06 & 3.37 & 2.68 & 2.50 & 3.85 & 6.55 & 5.93 & 4.27 & 16.77 & 13.36 & 30. \\
\hline
\end{tabular}




\begin{tabular}{|c|c|c|c|c|c|c|c|c|c|c|c|c|c|c|c|c|}
\hline & \multirow{3}{*}{$\begin{array}{c}\text { Not in MSA } \\
\text { Ithaca } \\
\end{array}$} & \multicolumn{2}{|c|}{$<250,000$} & \multirow{3}{*}{\multicolumn{2}{|c|}{$\begin{array}{l}250,000 \text { to } 499,999 \\
\begin{array}{l}\text { Bingham- } \\
\text { ton }\end{array} \text { Utica-Rome } \\
\end{array}$}} & \multirow{3}{*}{\multicolumn{2}{|c|}{$\begin{array}{l}500,000 \text { to } 999,999 \\
\text { Albany } \quad \text { Syracuse } \\
\end{array}$}} & \multirow{3}{*}{\multicolumn{2}{|c|}{$\begin{array}{c}1 \text { to } 2.9 \text { million } \\
\text { Buffalo Rochester } \\
\end{array}$}} & \multirow[b]{3}{*}{ Newburgh } & \multirow{2}{*}{\multicolumn{6}{|c|}{$3+$ million }} \\
\hline & & \multirow[b]{2}{*}{ Elmira } & \multirow[b]{2}{*}{ Glens Falls } & & & & & & & & & & & NY Metro & & \\
\hline & & & & & & & & & & & $\begin{array}{l}\text { Pough- } \\
\text { keepsie }\end{array}$ & $\begin{array}{c}\text { Nassau/ } \\
\text { Suffolk }\end{array}$ & $\begin{array}{c}\text { Putnam/ } \\
\text { Rockland/ } \\
\text { Westchester }\end{array}$ & $\begin{array}{c}\text { Five } \\
\text { Counties }\end{array}$ & $\begin{array}{r}\text { Sub of } 5 \\
4 \text { Counties }\end{array}$ & $\begin{array}{l}\text { Counties } \\
\text { Manhattan }\end{array}$ \\
\hline \multicolumn{17}{|l|}{ Percent Not Taking Walk Trips in the last week } \\
\hline $\begin{array}{l}\text { TOTAL } \\
5 \text { to } 10 \text { year-olds }\end{array}$ & $17.2 \%$ & $28.6 \%$ & $25.9 \%$ & $28.0 \%$ & $27.1 \%$ & $26.8 \%$ & $28.6 \%$ & $31.6 \%$ & $31.3 \%$ & $33.2 \%$ & $26.6 \%$ & $31.6 \%$ & $28.7 \%$ & $15.5 \%$ & $17.4 \%$ & $\begin{array}{r}7.9 \% \\
*\end{array}$ \\
\hline 11 to 15 year-olds & & * & & * & & * & & ${ }^{2}$ & & * & & ${ }^{2}$ & * & & & \\
\hline 16 to 20 year-olds & $10.2 \%$ & $42.4 \%$ & $28.2 \%$ & $28.8 \%$ & $20.1 \%$ & $27.4 \%$ & $24.9 \%$ & $29.9 \%$ & $40.7 \%$ & $36.7 \%$ & $21.6 \%$ & $28.9 \%$ & $17.0 \%$ & $13.2 \%$ & $13.4 \%$ & $11.6 \%$ \\
\hline 21 to 35 year-olds & $12.6 \%$ & $22.6 \%$ & $25.1 \%$ & $26.0 \%$ & $19.9 \%$ & $26.7 \%$ & $19.2 \%$ & $29.9 \%$ & $33.3 \%$ & $35.9 \%$ & $28.4 \%$ & $33.0 \%$ & $30.0 \%$ & $11.6 \%$ & $14.0 \%$ & $3.8 \%$ \\
\hline 36 to 64 year-olds & $19.2 \%$ & $25.2 \%$ & $22.7 \%$ & $26.3 \%$ & $25.9 \%$ & $23.6 \%$ & $31.0 \%$ & $29.0 \%$ & $27.3 \%$ & $31.0 \%$ & $27.1 \%$ & $29.7 \%$ & $28.2 \%$ & $16.1 \%$ & $17.5 \%$ & $10.1 \%$ \\
\hline \multicolumn{13}{|l|}{ Avg Minutes Spent Walking per Day } & $33.5 \%$ & & & \\
\hline $\begin{array}{l}\text { TOTAL } \\
\text { TOT STI }\end{array}$ & 9.60 & 4.96 & 5.21 & 5.43 & 3.49 & 5.00 & 5.09 & 5.63 & 6.32 & 4.31 & 3.87 & 6.69 & 6.15 & 16.11 & 14.35 & 23.52 \\
\hline 5 to 10 year-olds & 3.19 & 5.28 & 2.30 & 6.47 & 3.60 & 2.89 & 1.93 & 3.93 & 10.47 & 4.49 & 4.76 & 4.69 & 3.05 & 14.79 & 14.76 & 14.93 \\
\hline 11 to 15 year-olds & $2.47 \mathrm{Y} \quad \mathrm{l}$ & 7.34 & 12.17 & 7.83 & 1.62 & 5.85 & 8.04 & 13.38 & 23.04 & 2.22 & 4.40 & 6.74 & 11.00 & 13.18 & 12.75 & 15.16 \\
\hline 16 to & 11.12 & 6.97 & 2.11 & 6.31 & 1.31 & 3.71 & 9.75 & 4.52 & 4.58 & 2.29 & 1.80 & 8.63 & 5.33 & 14.14 & 13.61 & 18.01 \\
\hline 21 tc & 14.49 & 4.19 & 3.37 & 4.52 & 3.87 & 4.36 & 7.18 & 3.62 & 4.42 & 2.73 & 4.68 & 4.22 & 8.23 & 19.24 & 16.26 & 29.08 \\
\hline 36 to & 8.95 & 5.05 & 5.78 & 4.10 & 3.98 & 5.49 & 3.57 & 6.72 & 4.03 & 5.86 & 3.49 & 8.70 & 5.74 & 15.91 & 14.53 & 21.85 \\
\hline \multirow{2}{*}{\multicolumn{17}{|c|}{ Percent Not Taking Bike Trips in the last week }} \\
\hline & & & & & & & & & & & & & & & & \\
\hline $\begin{array}{l}\text { TOTAL } \\
5 \text { to } 10 \text { year-olds }\end{array}$ & $90.0 \%$ & $\begin{array}{r}93.1 \% \\
*\end{array}$ & $91.5 \%$ & $92.3 \%$ & $91.9 \%$ & $\begin{array}{r}92.3 \% \\
*\end{array}$ & $92.1 \%$ & $91.2 \%$ & $91.0 \%$ & $93.6 \%$ & $90.7 \%$ & $91.9 \%$ & $94.2 \%$ & $94.4 \%$ & $94.8 \%$ & $92.7 \%$ \\
\hline 11 to 15 year-olds & & * & & * & & * & & * & & * & & * & * & & & \\
\hline 16 to 20 year-olds & $91.4 \%$ & $88.4 \%$ & $93.1 \%$ & $88.0 \%$ & $89.4 \%$ & $88.4 \%$ & $76.3 \%$ & $79.8 \%$ & $83.3 \%$ & $89.2 \%$ & $79.9 \%$ & $87.9 \%$ & $76.3 \%$ & $88.5 \%$ & $90.1 \%$ & $77.5 \%$ \\
\hline 21 to & $85.0 \%$ & $93.0 \%$ & $85.4 \%$ & $88.4 \%$ & $84.6 \%$ & $90.7 \%$ & $88.1 \%$ & $94.5 \%$ & $89.7 \%$ & $93.6 \%$ & $90.9 \%$ & $90.8 \%$ & $93.9 \%$ & $92.8 \%$ & $92.9 \%$ & $92.4 \%$ \\
\hline 36 to $64 y$ & $90.5 \%$ & $93.4 \%$ & $92.1 \%$ & $91.5 \%$ & $93.8 \%$ & $91.6 \%$ & $95.5 \%$ & $89.6 \%$ & $90.7 \%$ & $93.6 \%$ & $92.4 \%$ & $91.3 \%$ & $94.5 \%$ & $95.3 \%$ & $95.8 \%$ & $93.0 \%$ \\
\hline $\begin{array}{l}\text { 65+ year-olds } \\
\text { Avg Minutes Spent Biking per Day }\end{array}$ & $98.7 \%$ & $94.2 \%$ & $95.9 \%$ & $99.1 \%$ & $96.3 \%$ & $97.6 \%$ & $95.5 \%$ & $93.2 \%$ & $97.9 \%$ & $96.6 \%$ & $91.2 \%$ & $95.8 \%$ & $99.3 \%$ & $99.1 \%$ & $98.9 \%$ & $99.7 \%$ \\
\hline TOTAL & 0.68 & 1.39 & 0.76 & 0.87 & 0.31 & 1.18 & 0.63 & 0.78 & 0.83 & 0.66 & 0.81 & 0.57 & 0.34 & 0.65 & 0.67 & 0.55 \\
\hline 5 to 10 year-olds & & 3.39 & 1.24 & 5.17 & 1.06 & 1.95 & 0.31 & 2.50 & 3.01 & 1.59 & 3.73 & 0.55 & 0.50 & 2.04 & 2.29 & 0.66 \\
\hline 11 to 15 year-olds & 2.63 & 3.46 & 3.57 & 1.58 & 2.10 & 3.90 & 1.76 & 1.11 & 4.21 & 3.26 & 1.65 & 2.07 & 2.36 & 2.92 & 3.55 & \\
\hline 16 to 20 year-olds & & 0.46 & 0.12 & & & 0.51 & 0.30 & & 0.14 & 0.46 & & 0.20 & 0.07 & 0.08 & 0.09 & \\
\hline 21 to 35 year-olds & 0.68 & 2.82 & 0.63 & & & 1.73 & 1.35 & 0.41 & 0.45 & 0.34 & 0.34 & 0.25 & 0.03 & 0.54 & 0.54 & 0.53 \\
\hline 36 to 64 year-olds & 0.83 & 0.72 & 0.70 & 0.76 & 0.05 & 0.82 & 0.12 & 0.92 & 0.01 & 0.25 & 0.32 & 0.25 & 0.23 & 0.40 & 0.27 & 0.95 \\
\hline $65+$ year-olds & & 0.48 & 0.06 & & & & 0.29 & 0.20 & 0.45 & & 0.57 & 1.48 & 0.27 & 0.05 & 0.06 & \\
\hline \multicolumn{17}{|l|}{ inutes Spent Wa } \\
\hline TOTAL & $\begin{array}{r}10.27 \\
319\end{array}$ & $\begin{array}{l}6.36 \\
867\end{array}$ & $\begin{array}{l}5.96 \\
3.54\end{array}$ & $\begin{array}{r}6.30 \\
1164\end{array}$ & $\begin{array}{l}3.80 \\
466\end{array}$ & $\begin{array}{l}6.19 \\
484\end{array}$ & 5.71 & 6.41 & $\begin{array}{r}7.16 \\
\end{array}$ & 4.97 & $\begin{array}{r}4.68 \\
\end{array}$ & 7.26 & 6.48 & 16.76 & 15.02 & 24.07 \\
\hline 5 to 10 year-olds & 3.19 & $\begin{array}{r}8.67 \\
1079\end{array}$ & $\begin{array}{r}3.54 \\
15.71\end{array}$ & 11.64 & 4.66 & $\begin{array}{l}4.84 \\
975\end{array}$ & 2.24 & 6.43 & 13.47 & 6.08 & 8.4 & 5.24 & $\begin{array}{r}3.55 \\
13.26\end{array}$ & 16.83 & 17.05 & 15.59 \\
\hline 11 th & 5.10 & 10. & 15.74 & 9. & 3.71 & 9.75 & 9 & 14.49 & 27.25 & 5.48 & 6.0 & 8.81 & 13.36 & 16.09 & 16.29 & 15.16 \\
\hline 16 tc & 11.56 & 7.43 & 2.23 & 6.31 & 1.31 & 4.21 & 10. & 4.52 & 4.71 & 2.75 & 1.8 & 8.83 & 5.41 & 14.22 & 13.70 & 18.01 \\
\hline 21 to $35 y$ & 15.18 & 7.01 & 3.99 & 4.52 & 3.87 & 6.08 & 8.53 & 4.04 & 4.87 & 3.07 & 5.02 & 4.47 & 8.26 & 19.78 & 16.80 & 29.61 \\
\hline 36 to 64 year-olds & 9.78 & 5.77 & 6.49 & 4.86 & 4.03 & 6.31 & 3.69 & 7.64 & 4.04 & 6.11 & 3.81 & 8.95 & 5.97 & 16.31 & 14.80 & 22.80 \\
\hline $65+$ year-olds & 7.20 & 3.39 & 6.13 & 7.89 & 3.81 & 4.73 & 4.37 & 3.11 & 3.77 & 4.57 & 4.96 & 7.47 & 4.09 & 14.22 & 12.14 & 23.00 \\
\hline${ }^{*}$ Walk and Bike trip & of persons un & jears o & 01, or & 995. & & & & & & & & & & & & \\
\hline
\end{tabular}




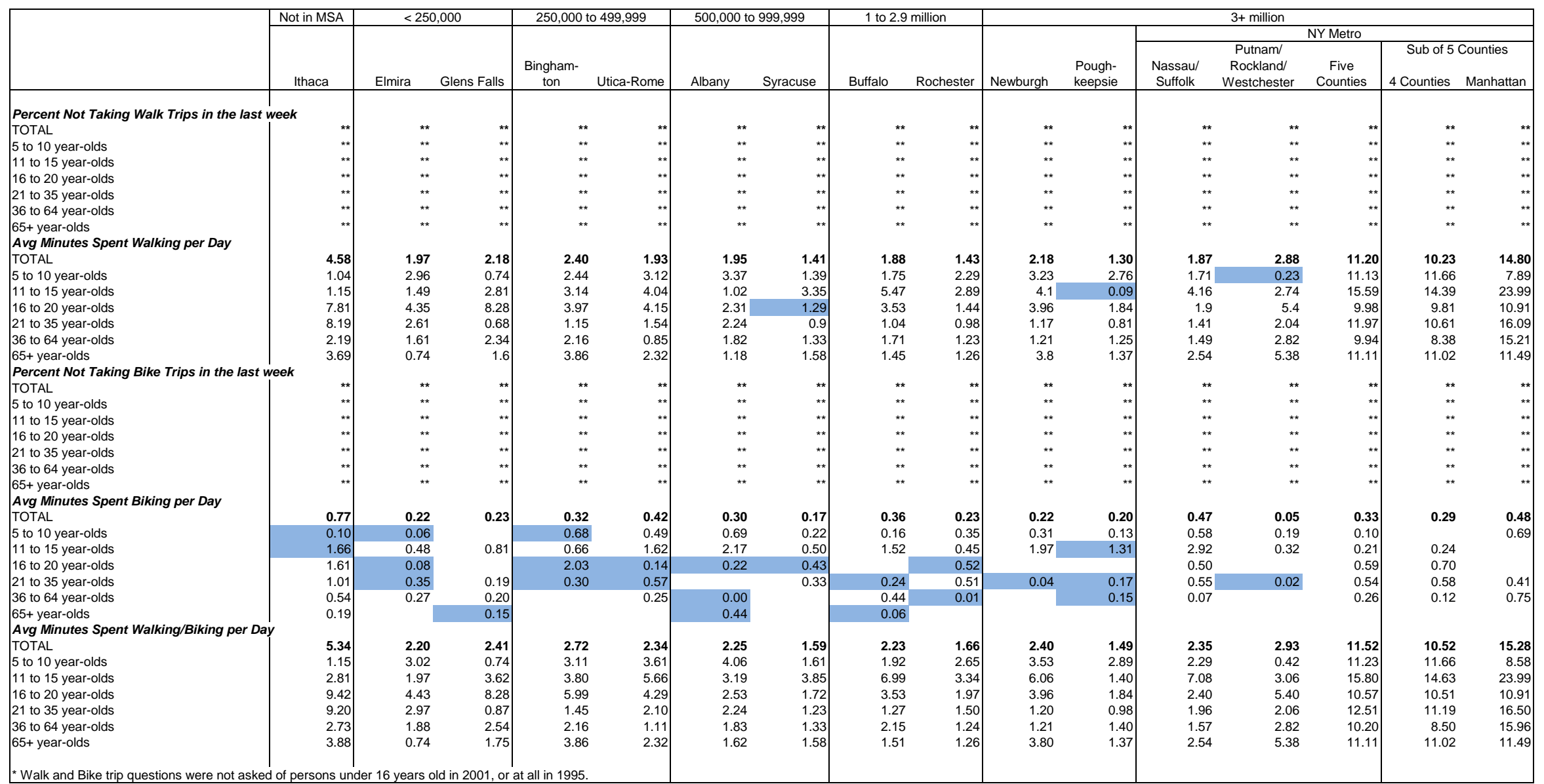


APPENDIX C6A. SUPPLEMENTAL TABLES FOR CHAPTER 6 STANDARD ERRORS 


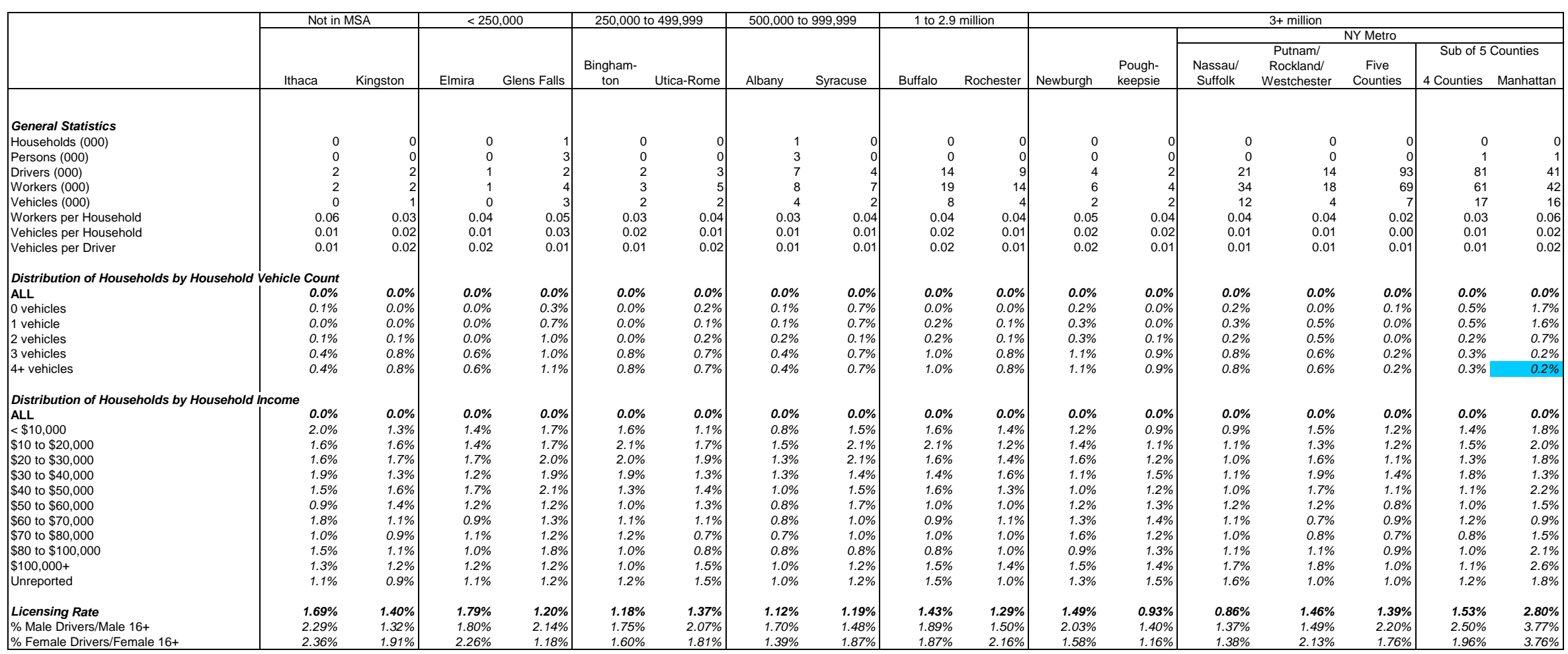




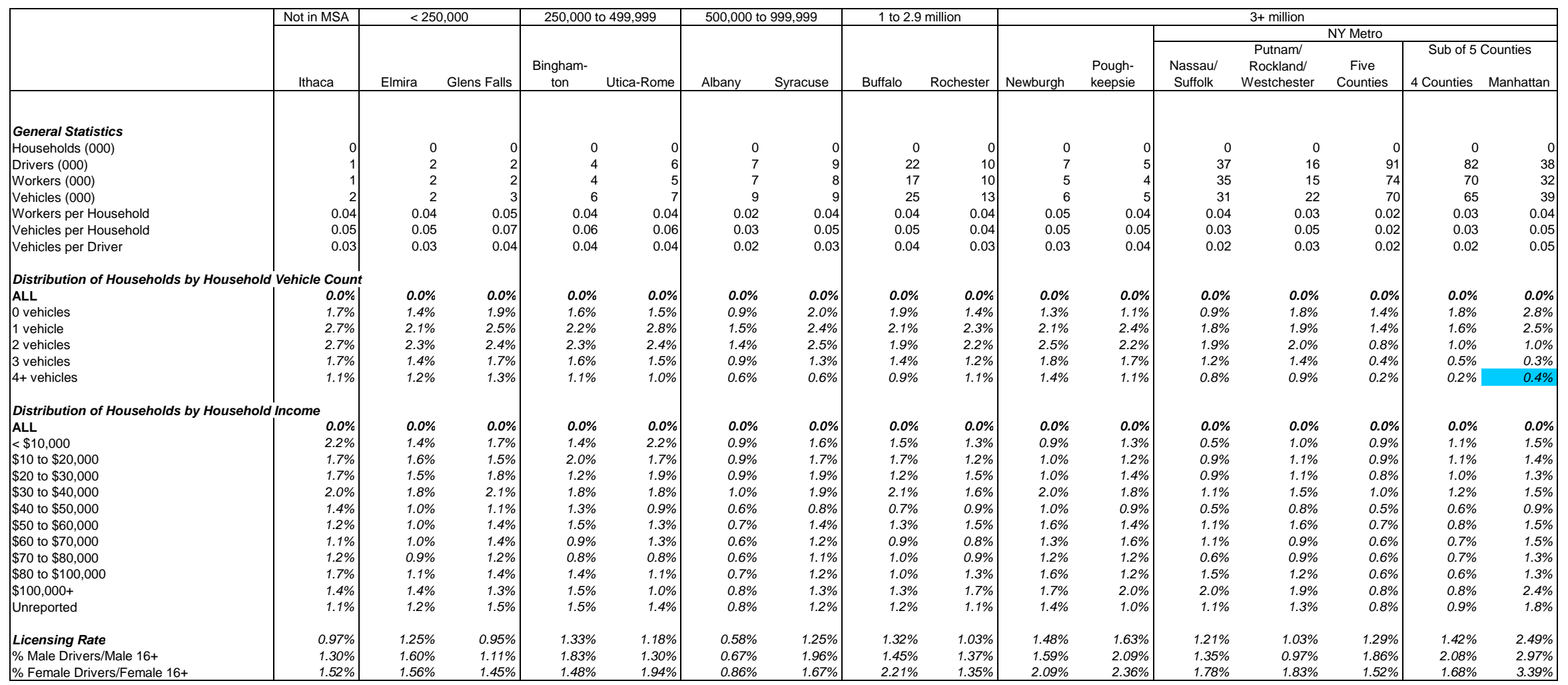




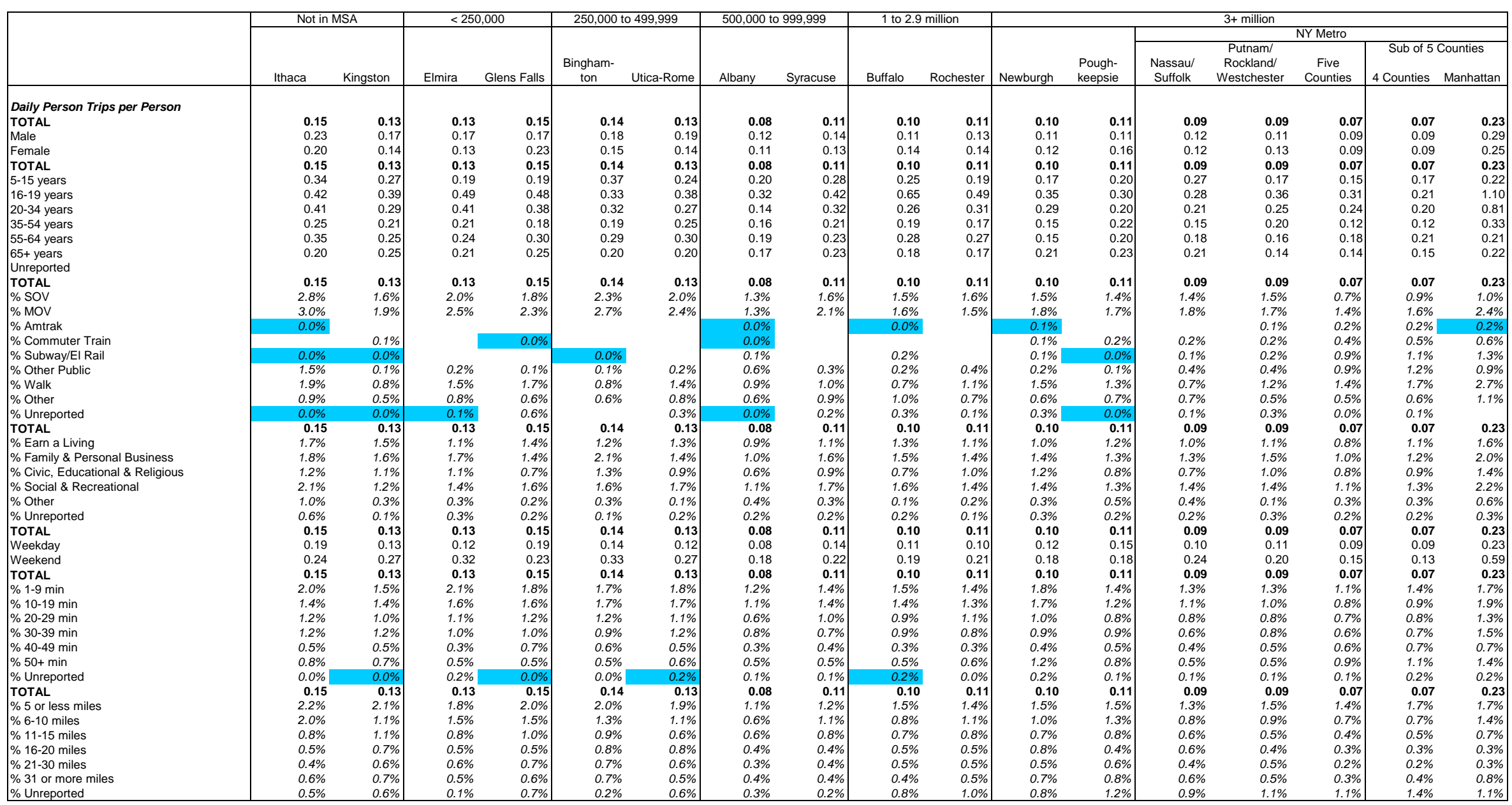


Chapter 6: Table 2

Comparison of Travel Patterns Among NY State MPOs

2001 NHTS
STANDARD ERRORS

\begin{tabular}{|c|c|c|c|c|c|c|c|c|c|c|c|c|c|c|c|c|}
\hline & \multirow{3}{*}{\begin{tabular}{|c|} 
Not in MSA \\
Ithaca \\
\end{tabular}} & \multicolumn{2}{|c|}{$<250,000$} & \multicolumn{2}{|c|}{250,000 to 499,999} & \multicolumn{2}{|c|}{500,000 to 999,999} & \multicolumn{2}{|c|}{1 to 2.9 million } & \multicolumn{7}{|c|}{$3+$ million } \\
\hline & & \multirow[b]{2}{*}{ Elmira } & \multirow[b]{2}{*}{ Glens Falls } & \multirow[b]{2}{*}{$\begin{array}{c}\text { Bingham- } \\
\text { ton }\end{array}$} & \multirow[b]{2}{*}{ Utica-Rome } & \multirow[b]{2}{*}{ Albany } & \multirow[b]{2}{*}{ Syracuse } & \multirow[b]{2}{*}{ Buffalo } & \multirow[b]{2}{*}{ Rochester } & \multirow[b]{2}{*}{ Newburgh } & & & & NY Metro & & \\
\hline & & & & & & & & & & & $\begin{array}{l}\text { Pough- } \\
\text { keepsie }\end{array}$ & $\begin{array}{l}\text { Nassau/ } \\
\text { Suffolk }\end{array}$ & $\begin{array}{c}\text { Putnam/ } \\
\text { Rockland/ } \\
\text { Westchester }\end{array}$ & $\begin{array}{c}\text { Five } \\
\text { Counties }\end{array}$ & $\begin{array}{r}\text { Sub of } 5 \\
4 \text { Counties }\end{array}$ & $\begin{array}{l}\text { Counties } \\
\text { Manhattan }\end{array}$ \\
\hline Daily Person Trips per Person & 0.11 & 0.17 & & 0.13 & 0.14 & 0.07 & 0.12 & 0.11 & 0.10 & 0.11 & 0.12 & 0.08 & 0.09 & 0.06 & 0.07 & 0.12 \\
\hline Male & 0.14 & 0.29 & 0.17 & 0.17 & 0.18 & 0.07 & 0.15 & 0.12 & 0.13 & 0.15 & 0.14 & 0.11 & 0.14 & 0.09 & 0.10 & 0.16 \\
\hline Female & 0.16 & 0.14 & 0.14 & 0.14 & 0.17 & 0.09 & 0.16 & 0.14 & 0.14 & 0.13 & 0.15 & 0.10 & 0.12 & 0.07 & 0.07 & 0.16 \\
\hline TOTAL & 0.11 & 0.17 & 0.12 & 0.13 & 0.14 & 0.07 & 0.12 & 0.11 & 0.10 & 0.11 & 0.12 & 0.08 & 0.09 & 0.06 & 0.07 & 0.12 \\
\hline $5-15$ years & 0.24 & 0.67 & 0.25 & 0.27 & 0.30 & 0.14 & 0.26 & 0.20 & 0.22 & 0.22 & 0.19 & 0.20 & 0.15 & 0.12 & 0.13 & 0.25 \\
\hline $16-19$ years & 0.27 & 0.41 & 0.57 & 0.46 & 0.35 & 0.26 & 0.38 & 0.55 & 0.31 & 0.37 & 0.40 & 0.33 & 0.50 & 0.17 & 0.17 & 0.64 \\
\hline $20-34$ years & 0.22 & 0.26 & 0.26 & 0.29 & 0.24 & 0.13 & 0.28 & 0.20 & 0.30 & 0.27 & 0.21 & 0.17 & 0.19 & 0.13 & 0.14 & 0.22 \\
\hline $35-54$ years & 0.25 & 0.22 & 0.20 & 0.19 & 0.21 & 0.10 & 0.20 & 0.21 & 0.13 & 0.15 & 0.22 & 0.14 & 0.14 & 0.08 & 0.10 & 0.19 \\
\hline 55-64 years & 0.31 & 0.24 & 0.34 & 0.25 & 0.31 & 0.13 & 0.25 & 0.21 & 0.27 & 0.21 & 0.40 & 0.21 & 0.30 & 0.17 & 0.21 & 0.25 \\
\hline $65+$ years & 0.41 & 0.20 & 0.24 & 0.29 & 0.25 & 0.14 & 0.26 & 0.21 & 0.23 & 0.40 & 0.28 & 0.19 & 0.25 & 0.16 & 0.17 & 0.28 \\
\hline Unreported & 1.32 & 0.74 & 0.46 & 1.34 & 0.53 & 0.22 & 0.60 & 0.55 & 0.55 & 0.57 & 0.46 & 0.54 & 0.38 & 0.35 & 0.35 & 0.98 \\
\hline TOTAL & 0.11 & 0.17 & 0.12 & 0.13 & 0.14 & 0.07 & 0.12 & 0.11 & 0.10 & 0.11 & 0.12 & 0.08 & 0.09 & 0.06 & 0.07 & 0.12 \\
\hline$\%$ sov & $2.0 \%$ & $2.5 \%$ & $2.0 \%$ & $1.6 \%$ & $2.1 \%$ & $1.0 \%$ & $2.0 \%$ & $1.9 \%$ & $1.7 \%$ & $1.9 \%$ & $1.7 \%$ & $1.3 \%$ & $1.4 \%$ & $0.8 \%$ & $0.9 \%$ & $1.0 \%$ \\
\hline$\%$ MOV & $2.0 \%$ & $2.9 \%$ & $1.9 \%$ & $1.8 \%$ & $2.1 \%$ & $1.0 \%$ & $2.1 \%$ & $1.9 \%$ & $1.7 \%$ & $2.0 \%$ & $1.9 \%$ & $1.5 \%$ & $1.6 \%$ & $1.1 \%$ & $1.2 \%$ & $1.9 \%$ \\
\hline$\%$ Amtrak & & & $0.0 \%$ & & $0.0 \%$ & $0.0 \%$ & & & & & $0.1 \%$ & $0.1 \%$ & $0.1 \%$ & $0.1 \%$ & $0.1 \%$ & $0.2 \%$ \\
\hline$\%$ Commuter Train & & & $0.0 \%$ & & & $0.0 \%$ & & & & $0.1 \%$ & $0.1 \%$ & $0.2 \%$ & $0.2 \%$ & $0.1 \%$ & $0.1 \%$ & $0.2 \%$ \\
\hline$\%$ Subway/EI Rail & $0.2 \%$ & $0.1 \%$ & .010 & & & $0.0 \%$ & & $0.3 \%$ & $0.0 \%$ & $0.1 \%$ & $0.1 \%$ & $0.1 \%$ & $0.2 \%$ & $0.7 \%$ & $0.8 \%$ & $1.3 \%$ \\
\hline$\%$ Other Public & $0.2 \%$ & $0.2 \%$ & $0.2 \%$ & $0.2 \%$ & $0.1 \%$ & $0.1 \%$ & $0.4 \%$ & $0.2 \%$ & $0.6 \%$ & $0.1 \%$ & $0.1 \%$ & $0.1 \%$ & $0.3 \%$ & $0.5 \%$ & $0.6 \%$ & $0.9 \%$ \\
\hline$\%$ Walk & $1.1 \%$ & $0.8 \%$ & $0.9 \%$ & $0.8 \%$ & $0.8 \%$ & $0.5 \%$ & $1.3 \%$ & $1.2 \%$ & $0.8 \%$ & $1.2 \%$ & $1.2 \%$ & $0.7 \%$ & $0.9 \%$ & $1.1 \%$ & $1.2 \%$ & $1.8 \%$ \\
\hline$\%$ Other & $0.5 \%$ & $0.6 \%$ & $0.6 \%$ & $0.5 \%$ & $0.9 \%$ & $0.4 \%$ & $0.6 \%$ & $1.1 \%$ & $0.5 \%$ & $0.7 \%$ & $0.6 \%$ & $0.5 \%$ & $0.4 \%$ & $0.4 \%$ & $0.4 \%$ & $0.8 \%$ \\
\hline$\%$ Unreported & & $0.1 \%$ & $0.2 \%$ & $0.0 \%$ & & $0.0 \%$ & $0.1 \%$ & $0.1 \%$ & $0.1 \%$ & $0.0 \%$ & $0.0 \%$ & $0.0 \%$ & $0.1 \%$ & $0.1 \%$ & $0.1 \%$ & $0.1 \%$ \\
\hline TOTAL & 0.11 & 0.17 & 0.12 & 0.13 & 0.14 & 0.07 & 0.12 & 0.11 & 0.10 & 0.11 & 0.12 & 0.08 & 0.09 & 0.06 & 0.07 & 0.12 \\
\hline$\%$ Earn a Living & $1.0 \%$ & $1.3 \%$ & $1.2 \%$ & $1.0 \%$ & $1.2 \%$ & $0.6 \%$ & $1.3 \%$ & $1.0 \%$ & $1.1 \%$ & $1.2 \%$ & $1.1 \%$ & $1.0 \%$ & $0.9 \%$ & $0.7 \%$ & $0.8 \%$ & $1.3 \%$ \\
\hline \% Family \& Personal Business & $1.5 \%$ & $1.3 \%$ & $1.7 \%$ & $1.2 \%$ & $1.4 \%$ & $0.8 \%$ & $1.7 \%$ & $1.1 \%$ & $1.5 \%$ & $1.6 \%$ & $1.6 \%$ & $1.1 \%$ & $1.1 \%$ & $0.9 \%$ & $1.0 \%$ & $1.5 \%$ \\
\hline$\%$ Civic, Educational \& Religious & $0.9 \%$ & $1.4 \%$ & $0.8 \%$ & $0.8 \%$ & $0.8 \%$ & $0.6 \%$ & $0.9 \%$ & $0.9 \%$ & $0.9 \%$ & $1.0 \%$ & $1.1 \%$ & $0.7 \%$ & $0.6 \%$ & $0.5 \%$ & $0.6 \%$ & $1.3 \%$ \\
\hline \% Social \& Recreational & $1.3 \%$ & $1.6 \%$ & $1.5 \%$ & $1.4 \%$ & $1.4 \%$ & $0.7 \%$ & $1.3 \%$ & $1.1 \%$ & $1.3 \%$ & $1.6 \%$ & $1.4 \%$ & $1.1 \%$ & $1.1 \%$ & $0.7 \%$ & $0.8 \%$ & $1.7 \%$ \\
\hline$\%$ Other & $0.3 \%$ & $0.3 \%$ & $0.2 \%$ & $0.2 \%$ & $0.4 \%$ & $0.1 \%$ & $0.2 \%$ & $0.3 \%$ & $0.3 \%$ & $0.5 \%$ & $0.2 \%$ & $0.3 \%$ & $0.3 \%$ & $0.2 \%$ & $0.2 \%$ & $0.4 \%$ \\
\hline$\%$ Unreported & $0.1 \%$ & $0.1 \%$ & $0.2 \%$ & $0.1 \%$ & $0.1 \%$ & $0.1 \%$ & $0.2 \%$ & $0.1 \%$ & $0.2 \%$ & $0.1 \%$ & $0.1 \%$ & $0.1 \%$ & $0.1 \%$ & $0.1 \%$ & $0.1 \%$ & $0.1 \%$ \\
\hline TOTAL & 0.11 & 0.17 & 0.12 & 0.13 & 0.14 & 0.07 & 0.12 & 0.11 & 0.10 & 0.11 & 0.12 & 0.08 & 0.09 & 0.06 & 0.07 & 0.12 \\
\hline Weekday & 0.13 & 0.12 & 0.14 & 0.15 & 0.14 & 0.08 & 0.12 & 0.12 & 0.12 & 0.12 & 0.15 & 0.09 & 0.12 & 0.07 & 0.08 & 0.13 \\
\hline Weekend & 0.22 & 0.51 & 0.23 & 0.22 & 0.27 & 0.14 & 0.27 & 0.22 & 0.26 & 0.24 & 0.18 & 0.20 & 0.24 & 0.11 & 0.12 & 0.26 \\
\hline TOTAL & 0.11 & 0.17 & 0.12 & 0.13 & 0.14 & 0.07 & 0.12 & 0.11 & 0.10 & 0.11 & 0.12 & 0.08 & 0.09 & 0.06 & 0.07 & 0.12 \\
\hline$\% 1-9 \mathrm{~min}$ & $1.3 \%$ & $1.6 \%$ & $1.4 \%$ & $1.2 \%$ & $1.7 \%$ & $0.7 \%$ & $1.6 \%$ & $1.1 \%$ & $1.2 \%$ & $1.5 \%$ & $1.8 \%$ & $1.2 \%$ & $1.3 \%$ & $0.8 \%$ & $0.9 \%$ & $1.7 \%$ \\
\hline$\% 10-19 \mathrm{~min}$ & $1.3 \%$ & $1.2 \%$ & $1.6 \%$ & $1.4 \%$ & $1.4 \%$ & $0.6 \%$ & $1.5 \%$ & $1.3 \%$ & $1.1 \%$ & $1.4 \%$ & $1.6 \%$ & $1.0 \%$ & $1.0 \%$ & $0.8 \%$ & $1.0 \%$ & $1.3 \%$ \\
\hline$\%$ 20-29 min & $0.8 \%$ & $0.9 \%$ & $1.3 \%$ & $0.8 \%$ & $0.9 \%$ & $0.6 \%$ & $1.1 \%$ & $0.9 \%$ & $0.6 \%$ & $0.9 \%$ & $0.7 \%$ & $0.7 \%$ & $0.6 \%$ & $0.5 \%$ & $0.5 \%$ & $0.7 \%$ \\
\hline$\%$ 30-39 min & $0.7 \%$ & $0.7 \%$ & $0.7 \%$ & $0.9 \%$ & $0.7 \%$ & $0.4 \%$ & $0.8 \%$ & $0.6 \%$ & $0.8 \%$ & $0.8 \%$ & $0.8 \%$ & $0.6 \%$ & $0.8 \%$ & $0.5 \%$ & $0.5 \%$ & $0.9 \%$ \\
\hline$\% 40-49 \mathrm{~min}$ & $0.4 \%$ & $0.5 \%$ & $0.7 \%$ & $0.4 \%$ & $0.3 \%$ & $0.3 \%$ & $0.4 \%$ & $0.5 \%$ & $0.4 \%$ & $0.6 \%$ & $0.5 \%$ & $0.4 \%$ & $0.3 \%$ & $0.3 \%$ & $0.4 \%$ & $0.6 \%$ \\
\hline$\% 50+\mathrm{mir}$ & $0.5 \%$ & $0.6 \%$ & $0.7 \%$ & $0.6 \%$ & $0.8 \%$ & $0.4 \%$ & $0.5 \%$ & $0.5 \%$ & $0.6 \%$ & $0.8 \%$ & $0.7 \%$ & $0.6 \%$ & $0.8 \%$ & $0.5 \%$ & $0.7 \%$ & $0.8 \%$ \\
\hline$\%$ Unreported & $0.4 \%$ & $0.3 \%$ & $0.3 \%$ & $0.4 \%$ & $0.6 \%$ & $0.3 \%$ & $0.4 \%$ & $0.4 \%$ & $0.3 \%$ & $0.5 \%$ & $0.5 \%$ & $0.3 \%$ & $0.3 \%$ & $0.4 \%$ & $0.4 \%$ & $0.7 \%$ \\
\hline TOTAL & 0.11 & 0.17 & 0.12 & 0.13 & 0.14 & 0.07 & 0.12 & 0.11 & 0.10 & 0.11 & 0.12 & 0.08 & 0.09 & 0.06 & 0.07 & 0.12 \\
\hline$\% 5$ or less miles & $1.9 \%$ & $1.4 \%$ & $1.8 \%$ & $1.7 \%$ & $1.7 \%$ & $0.8 \%$ & $1.9 \%$ & $1.5 \%$ & $1.3 \%$ & $1.8 \%$ & $2.0 \%$ & $1.3 \%$ & $1.2 \%$ & $0.9 \%$ & $1.2 \%$ & $1.6 \%$ \\
\hline$\% 6-10$ miles & $1.1 \%$ & $1.2 \%$ & $1.3 \%$ & $1.1 \%$ & $1.4 \%$ & $0.6 \%$ & $1.5 \%$ & $0.9 \%$ & $0.9 \%$ & $1.2 \%$ & $1.3 \%$ & $0.8 \%$ & $0.7 \%$ & $0.5 \%$ & $0.6 \%$ & $0.8 \%$ \\
\hline$\% 11-15$ miles & $0.8 \%$ & $1.1 \%$ & $1.0 \%$ & $0.7 \%$ & $0.8 \%$ & $0.5 \%$ & $0.8 \%$ & $0.6 \%$ & $0.7 \%$ & $0.9 \%$ & $0.8 \%$ & $0.5 \%$ & $0.5 \%$ & $0.4 \%$ & $0.5 \%$ & $0.5 \%$ \\
\hline$\% 16-20$ miles & $0.6 \%$ & $0.6 \%$ & $0.7 \%$ & $0.5 \%$ & $0.5 \%$ & $0.4 \%$ & $0.4 \%$ & $0.4 \%$ & $0.5 \%$ & $0.7 \%$ & $0.6 \%$ & $0.4 \%$ & $0.5 \%$ & $0.2 \%$ & $0.3 \%$ & $0.4 \%$ \\
\hline$\% 21-30$ miles & $0.3 \%$ & $0.5 \%$ & $0.6 \%$ & $0.5 \%$ & $0.5 \%$ & $0.3 \%$ & $0.4 \%$ & $0.5 \%$ & $0.5 \%$ & $0.6 \%$ & $0.5 \%$ & $0.5 \%$ & $0.6 \%$ & $0.2 \%$ & $0.2 \%$ & $0.3 \%$ \\
\hline$\% 31$ or more miles & $0.4 \%$ & $0.6 \%$ & $0.7 \%$ & $0.6 \%$ & $0.8 \%$ & $0.3 \%$ & $0.4 \%$ & $0.4 \%$ & $0.5 \%$ & $0.7 \%$ & $0.8 \%$ & $0.5 \%$ & $0.5 \%$ & $0.2 \%$ & $0.2 \%$ & $0.4 \%$ \\
\hline$\%$ Unreported & $0.5 \%$ & $0.5 \%$ & $0.2 \%$ & $0.8 \%$ & $0.1 \%$ & $0.2 \%$ & $0.4 \%$ & $0.5 \%$ & $0.3 \%$ & $0.3 \%$ & $0.6 \%$ & $0.4 \%$ & $0.6 \%$ & $0.7 \%$ & $0.9 \%$ & $0.9 \%$ \\
\hline
\end{tabular}




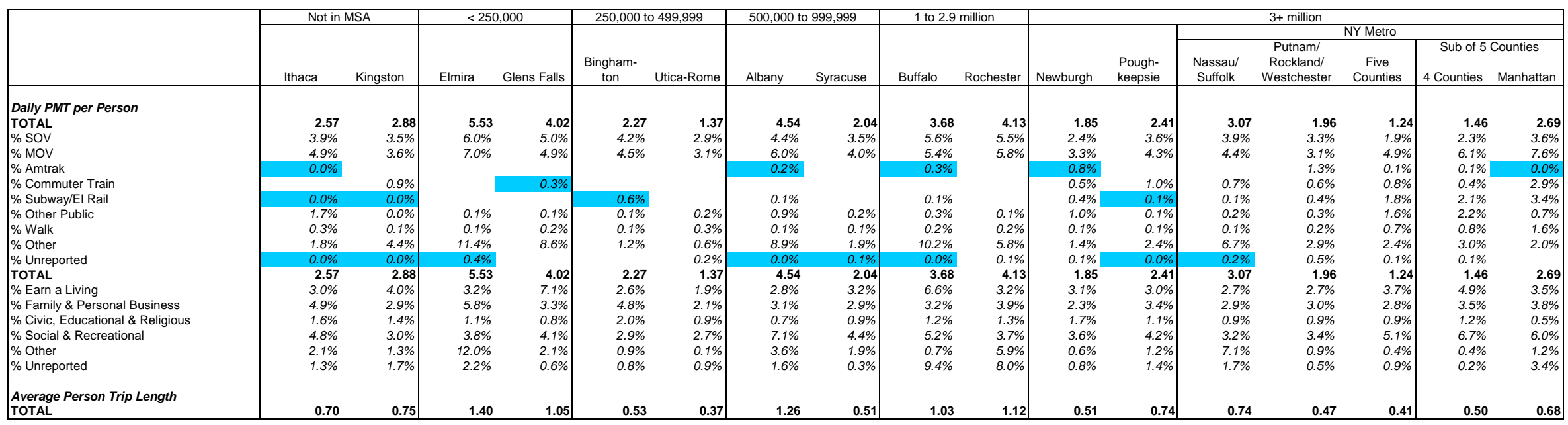




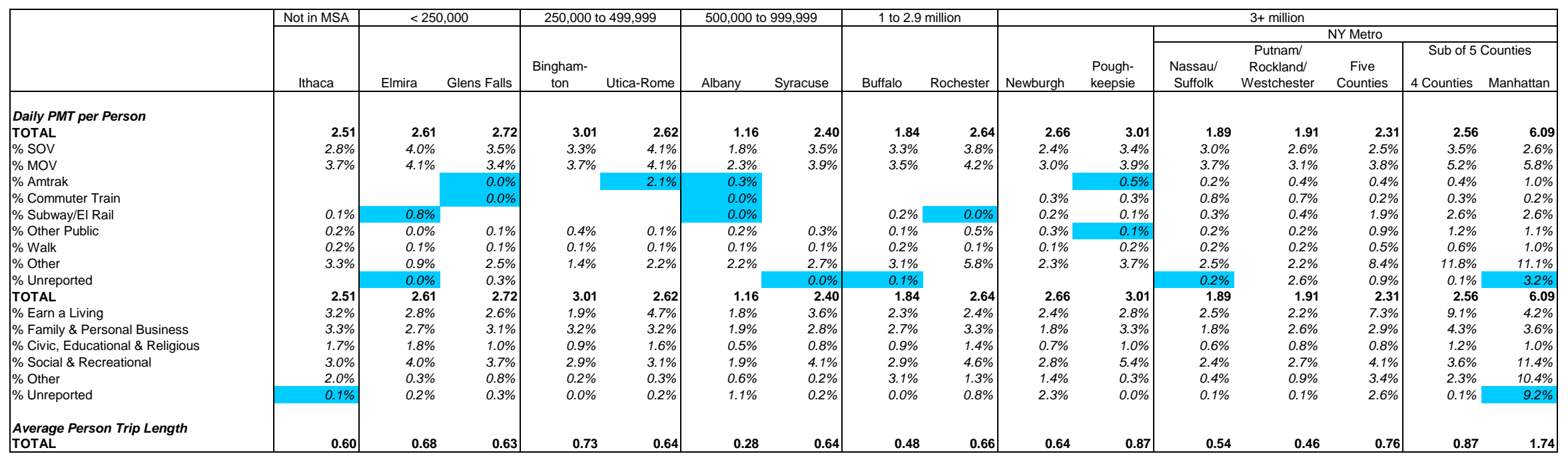




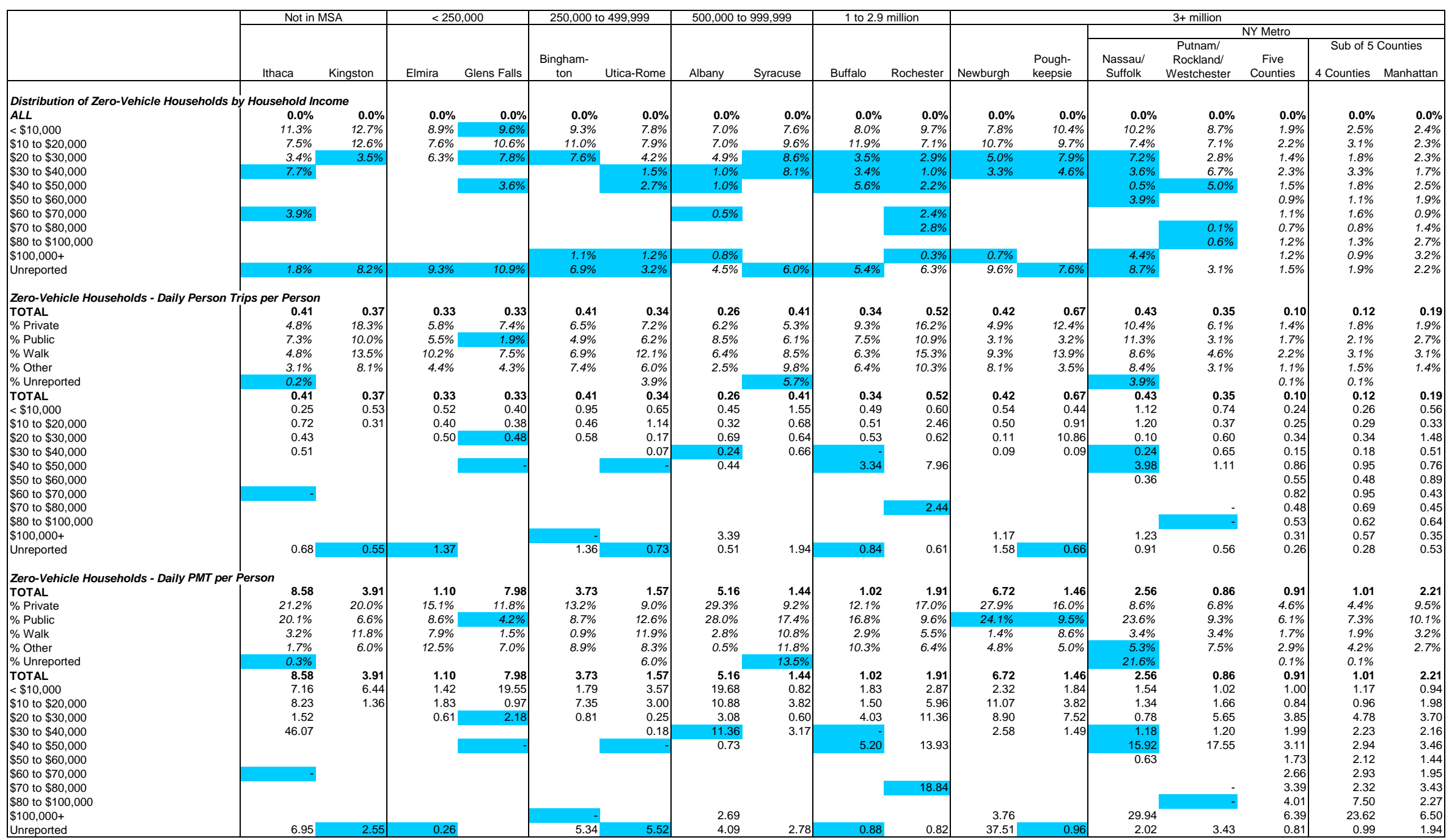


Chapter 6: Table 4

Comparison of Travel Patterns Among NY State MPOs

2001 NHTS
STANDARD ERRORS

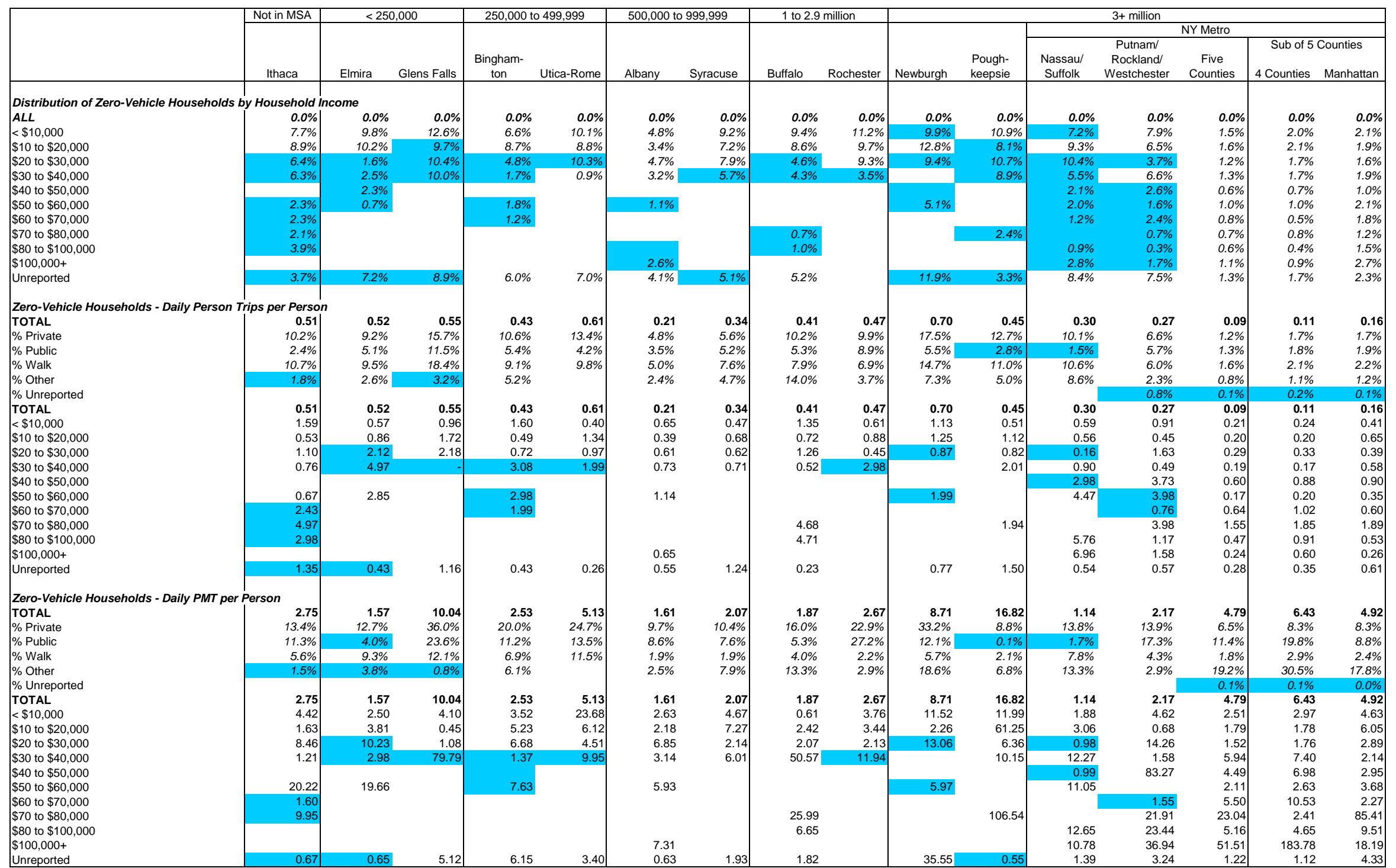




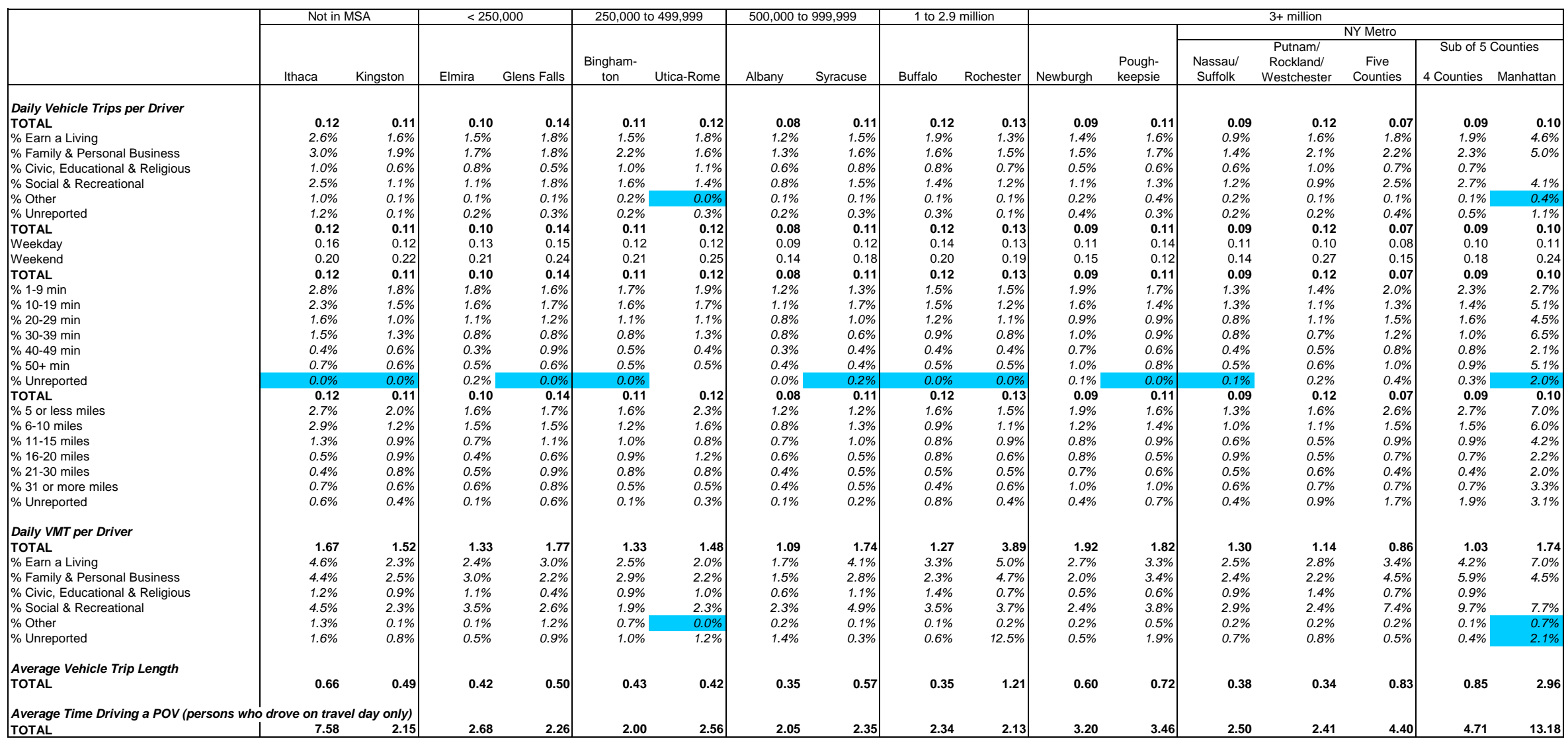




\begin{tabular}{|c|c|c|c|c|c|c|c|c|c|c|c|c|c|c|c|c|}
\hline & \multirow{3}{*}{\begin{tabular}{c|} 
Not in MSA \\
\\
Ithaca \\
\end{tabular}} & \multicolumn{2}{|c|}{$<250,000$} & \multirow{3}{*}{\multicolumn{2}{|c|}{$\begin{array}{l}250,000 \text { to } 499,999 \\
\begin{array}{l}\text { Bingham- } \\
\text { ton }\end{array} \text { Utica-Rome } \\
\end{array}$}} & \multirow{3}{*}{\multicolumn{2}{|c|}{$\begin{array}{l}500,000 \text { to } 999,999 \\
\text { Albany } \quad \text { Syracuse } \\
\end{array}$}} & \multirow{3}{*}{\multicolumn{2}{|c|}{$\begin{array}{l}1 \text { to } 2.9 \text { million } \\
\text { Buffalo Rochester } \\
\end{array}$}} & \multirow[b]{3}{*}{ Newburgh } & \multirow{2}{*}{\multicolumn{6}{|c|}{$3+$ million }} \\
\hline & & \multirow[b]{2}{*}{ Elmira } & \multirow[b]{2}{*}{ Glens Falls } & & & & & & & & \multirow[b]{2}{*}{$\begin{array}{l}\text { Pough- } \\
\text { keepsie }\end{array}$} & \multirow{2}{*}{\multicolumn{2}{|c|}{$\begin{array}{lc} & \\
\text { Nassau/ } & \begin{array}{c}\text { Putnam/ } \\
\text { Rockland/ } \\
\text { Suffolk }\end{array} \\
\text { Westchester }\end{array}$}} & \multicolumn{2}{|l|}{ NY Metro } & \\
\hline & & & & & & & & & & & & & & $\begin{array}{l}\text { Five } \\
\text { Counties }\end{array}$ & $\begin{array}{r}\text { Sub of } 5 \\
4 \text { Counties }\end{array}$ & $\begin{array}{l}\text { Counties } \\
\text { Manhattan }\end{array}$ \\
\hline $\begin{array}{l}\text { Daily Vehicle Trips per Driver } \\
\text { TOTAL }\end{array}$ & 0.11 & 0.11 & 0.10 & 0.12 & 0.13 & 0.05 & 0.12 & 0.12 & 0.10 & 0.10 & 0.14 & 0.08 & 0.10 & 0.06 & 0.07 & 0.13 \\
\hline$\%$ Earn a Living & $1.6 \%$ & $1.4 \%$ & $1.6 \%$ & $1.4 \%$ & $1.6 \%$ & $0.7 \%$ & $1.6 \%$ & $1.5 \%$ & $1.3 \%$ & $1.5 \%$ & $1.6 \%$ & $1.2 \%$ & $1.2 \%$ & $1.3 \%$ & $1.4 \%$ & $4.6 \%$ \\
\hline$\%$ Family \& Perso & $1.9 \%$ & $1.3 \%$ & $1.9 \%$ & $1.4 \%$ & $1.6 \%$ & $0.9 \%$ & $1.7 \%$ & $1.4 \%$ & $1.6 \%$ & $1.5 \%$ & $1.6 \%$ & $1.2 \%$ & $1.4 \%$ & $1.4 \%$ & $1.5 \%$ & $3.3 \%$ \\
\hline$\%$ Civic, Educatior & $1.0 \%$ & $0.6 \%$ & $0.5 \%$ & $0.6 \%$ & $0.5 \%$ & $0.4 \%$ & $0.7 \%$ & $0.7 \%$ & $0.7 \%$ & $0.4 \%$ & $0.6 \%$ & $0.4 \%$ & $0.5 \%$ & $0.6 \%$ & $0.6 \%$ & $0.1 \%$ \\
\hline$\%$ Social \& Recreational & $1.1 \%$ & $1.0 \%$ & $1.4 \%$ & $1.2 \%$ & $1.4 \%$ & $0.6 \%$ & $1.1 \%$ & $0.9 \%$ & $1.1 \%$ & $1.3 \%$ & $1.2 \%$ & $0.9 \%$ & $1.0 \%$ & $1.1 \%$ & $1.1 \%$ & $3.8 \%$ \\
\hline$\%$ Other & $0.2 \%$ & $0.1 \%$ & $0.2 \%$ & $0.1 \%$ & $0.2 \%$ & $0.1 \%$ & $0.1 \%$ & $0.2 \%$ & $0.1 \%$ & $0.2 \%$ & $0.3 \%$ & $0.2 \%$ & $0.1 \%$ & $0.2 \%$ & $0.2 \%$ & $0.5 \%$ \\
\hline$\%$ Unreported & $0.1 \%$ & $0.1 \%$ & $0.2 \%$ & $0.1 \%$ & $0.1 \%$ & $0.1 \%$ & $0.1 \%$ & $0.0 \%$ & $0.0 \%$ & $0.1 \%$ & $0.1 \%$ & $0.1 \%$ & $0.1 \%$ & $0.1 \%$ & $0.1 \%$ & \\
\hline TOTAL & 0.11 & 0.11 & 0.10 & 0.12 & 0.13 & 0.05 & 0.12 & 0.12 & 0.10 & 0.10 & 0.14 & 0.08 & 0.10 & 0.06 & 0.07 & 0.13 \\
\hline Weekday & 0.13 & 0.11 & 0.13 & 0.14 & 0.15 & 0.07 & 0.13 & 0.13 & 0.12 & 0.13 & 0.17 & 0.09 & 0.12 & 0.08 & 0.09 & 0.11 \\
\hline Weekend & 0.20 & 0.26 & 0.17 & 0.21 & 0.23 & 0.12 & 0.24 & 0.26 & 0.21 & 0.17 & 0.21 & 0.14 & 0.19 & 0.11 & 0.12 & 0.24 \\
\hline TOTAL & 0.11 & 0.11 & 0.10 & 0.12 & 0.13 & 0.05 & 0.12 & 0.12 & 0.10 & 0.10 & 0.14 & 0.08 & 0.10 & 0.06 & 0.07 & 0.13 \\
\hline$\% 1-9$ & $1.3 \%$ & $1.5 \%$ & $1.8 \%$ & $1.3 \%$ & $1.5 \%$ & $0.8 \%$ & $1.6 \%$ & $1.2 \%$ & $1.3 \%$ & $1.4 \%$ & $1.7 \%$ & $1.3 \%$ & $1.4 \%$ & $1.3 \%$ & $1.4 \%$ & $3.9 \%$ \\
\hline$\% 10$ & $1.6 \%$ & $1.3 \%$ & $1.7 \%$ & $1.4 \%$ & $1.4 \%$ & $0.7 \%$ & $1.7 \%$ & $1.2 \%$ & $1.0 \%$ & $1.5 \%$ & $1.7 \%$ & $1.2 \%$ & $1.2 \%$ & $1.5 \%$ & $1.6 \%$ & $4.8 \%$ \\
\hline$\%$ 20-29 min & $0.9 \%$ & $0.9 \%$ & $1.2 \%$ & $0.9 \%$ & $0.9 \%$ & $0.6 \%$ & $1.1 \%$ & $0.9 \%$ & $0.6 \%$ & $1.0 \%$ & $0.9 \%$ & $0.7 \%$ & $0.8 \%$ & $0.8 \%$ & $0.8 \%$ & $2.7 \%$ \\
\hline$\%$ 30-39 min & $0.8 \%$ & $0.7 \%$ & $0.7 \%$ & $0.8 \%$ & $0.8 \%$ & $0.4 \%$ & $0.8 \%$ & $0.6 \%$ & $0.7 \%$ & $0.8 \%$ & $0.9 \%$ & $0.6 \%$ & $0.7 \%$ & $0.8 \%$ & $0.9 \%$ & $2.5 \%$ \\
\hline$\% 40-49$ min & $0.3 \%$ & $0.4 \%$ & $0.5 \%$ & $0.4 \%$ & $0.3 \%$ & $0.3 \%$ & $0.4 \%$ & $0.5 \%$ & $0.3 \%$ & $0.5 \%$ & $0.5 \%$ & $0.4 \%$ & $0.4 \%$ & $0.6 \%$ & $0.6 \%$ & $1.5 \%$ \\
\hline$\% 50+\min$ & $0.5 \%$ & $0.6 \%$ & $0.7 \%$ & $0.6 \%$ & $0.7 \%$ & $0.4 \%$ & $0.5 \%$ & $0.4 \%$ & $0.4 \%$ & $0.8 \%$ & $0.7 \%$ & $0.6 \%$ & $0.7 \%$ & $0.7 \%$ & $0.7 \%$ & $3.0 \%$ \\
\hline$\%$ Unreported & $0.1 \%$ & $0.2 \%$ & $0.2 \%$ & $0.2 \%$ & $0.2 \%$ & $0.1 \%$ & $0.2 \%$ & $0.2 \%$ & $0.2 \%$ & $0.3 \%$ & $0.2 \%$ & $0.2 \%$ & $0.2 \%$ & $0.2 \%$ & $0.2 \%$ & \\
\hline TOTAL & 0.11 & 0.11 & 0.10 & 0.12 & 0.13 & 0.05 & 0.12 & 0.12 & 0.10 & 0.10 & 0.14 & 0.08 & 0.10 & 0.06 & 0.07 & 0.13 \\
\hline$\% 5$ or less miles & $2.0 \%$ & $1.6 \%$ & $1.8 \%$ & $1.7 \%$ & $1.5 \%$ & $0.8 \%$ & $1.9 \%$ & $1.2 \%$ & $1.4 \%$ & $1.5 \%$ & $1.9 \%$ & $1.4 \%$ & $1.4 \%$ & $1.7 \%$ & $1.9 \%$ & $3.4 \%$ \\
\hline$\% 6-10$ miles & $1.3 \%$ & $1.2 \%$ & $1.3 \%$ & $1.2 \%$ & $1.2 \%$ & $0.7 \%$ & $1.4 \%$ & $0.9 \%$ & $0.9 \%$ & $1.2 \%$ & $1.2 \%$ & $0.9 \%$ & $1.1 \%$ & $1.1 \%$ & $1.2 \%$ & $3.3 \%$ \\
\hline$\% 11-$ & $0.9 \%$ & $0.9 \%$ & $0.9 \%$ & $0.8 \%$ & $0.7 \%$ & $0.5 \%$ & 0.9 & $0.8 \%$ & $0.8 \%$ & $0.8 \%$ & 0.8 & $0.5 \%$ & $0.7 \%$ & $0.7 \%$ & $0.8 \%$ & $2.3 \%$ \\
\hline$\% 16-$ & $0.6 \%$ & $0.6 \%$ & & $0.5 \%$ & $0.6 \%$ & $0.4 \%$ & 0.5 & $0.5 \%$ & $0.5 \%$ & 0.8 & 0.7 & $0.4 \%$ & $0.6 \%$ & & $0.5 \%$ & $1.5 \%$ \\
\hline$\%$ 21-30 miles & $0.4 \%$ & $0.5 \%$ & $0.7 \%$ & $0.5 \%$ & $0.6 \%$ & $0.4 \%$ & 0.5 & $0.5 \%$ & $0.4 \%$ & $0.6 \%$ & $0.6 \%$ & $0.5 \%$ & $0.5 \%$ & $0.4 \%$ & $0.4 \%$ & $2.8 \%$ \\
\hline$\% 31$ or more miles & $0.5 \%$ & $0.5 \%$ & $0.7 \%$ & $0.6 \%$ & $0.7 \%$ & $0.3 \%$ & $0.6 \%$ & $0.4 \%$ & $0.3 \%$ & $0.9 \%$ & $0.7 \%$ & $0.5 \%$ & $0.5 \%$ & $0.4 \%$ & $0.4 \%$ & $2.3 \%$ \\
\hline$\%$ Unreported & $0.4 \%$ & $0.1 \%$ & $0.3 \%$ & $0.8 \%$ & $0.2 \%$ & $0.3 \%$ & $0.6 \%$ & $0.3 \%$ & $0.3 \%$ & $0.3 \%$ & $0.4 \%$ & $0.5 \%$ & $0.6 \%$ & $0.6 \%$ & $0.6 \%$ & $2.5 \%$ \\
\hline Daily VMT per Driver & & & & & & & & & & & & & & & & \\
\hline TOTAL & 1.46 & 2.26 & 1.87 & 2.22 & 2.74 & 0.68 & 2.05 & 1.59 & 1.60 & 2.22 & 1.89 & 1.43 & 1.28 & 0.88 & 0.89 & 2.17 \\
\hline \% Earn a Living & $2.9 \%$ & $3.5 \%$ & $3.1 \%$ & $2.3 \%$ & $5.2 \%$ & $1.4 \%$ & $3.8 \%$ & $2.5 \%$ & $2.7 \%$ & $2.3 \%$ & $2.7 \%$ & $2.6 \%$ & $2.6 \%$ & $2.6 \%$ & $2.9 \%$ & $6.4 \%$ \\
\hline$\%$ Family & $2.6 \%$ & $2.7 \%$ & $2.7 \%$ & $3.2 \%$ & $3.4 \%$ & $1.4 \%$ & $3.0 \%$ & $3.0 \%$ & $2.7 \%$ & $2.2 \%$ & $2.5 \%$ & $1.7 \%$ & $2.2 \%$ & $2.3 \%$ & $2.0 \%$ & $9.9 \%$ \\
\hline$\% \mathrm{Ci}$ & $2.5 \%$ & $0.7 \%$ & $1.0 \%$ & $0.7 \%$ & $0.7 \%$ & $0.4 \%$ & 0.6 & $0.8 \%$ & 1.0 & 0.6 & 0.9 & $0.5 \%$ & $0.6 \%$ & & $1.6 \%$ & $0.1 \%$ \\
\hline$\%$ Social \& Recreation & $2.7 \%$ & $2.9 \%$ & $2.3 \%$ & $2.5 \%$ & $2.5 \%$ & $1.4 \%$ & 4.1 & $2.4 \%$ & $2.2 \%$ & 2.2 & 3.2 & $2.5 \%$ & $2.6 \%$ & $2.9 \%$ & $2.5 \%$ & $11.6 \%$ \\
\hline$\%$ Other & $0.2 \%$ & $0.5 \%$ & $0.3 \%$ & $0.1 \%$ & $0.4 \%$ & $0.3 \%$ & $0.3 \%$ & $0.2 \%$ & $0.8 \%$ & 1.4 & $0.5 \%$ & $0.2 \%$ & $0.3 \%$ & $0.1 \%$ & $0.1 \%$ & $0.4 \%$ \\
\hline$\%$ Unreported & $0.2 \%$ & $0.3 \%$ & $0.3 \%$ & $0.1 \%$ & $0.3 \%$ & $0.3 \%$ & $0.0 \%$ & $0.0 \%$ & $1.3 \%$ & $0.1 \%$ & $0.0 \%$ & $0.0 \%$ & $0.1 \%$ & $0.2 \%$ & $0.2 \%$ & \\
\hline $\begin{array}{l}\text { Average Vehicle Trip Length } \\
\text { TOTAL }\end{array}$ & 0.47 & 0.67 & 0.54 & 0.66 & 0.69 & 0.19 & 0.66 & 0.43 & 0.45 & 0.61 & 0.57 & 0.47 & 0.39 & 0.51 & 0.48 & 3.13 \\
\hline$e T$ & & & & & & & & & & & & & & & & \\
\hline $\begin{array}{l}\text { AOTAL } \\
\text { TOT }\end{array}$ & $2.57 \mid$ & 3.15 & 3.70 & 4.50 & 4.24 & 1.32 & 3.10 & 2.32 & 2.91 & 2.93 & 3.15 & 2.50 & 2.67 & 2.94 & 2.69 & 12.64 \\
\hline
\end{tabular}




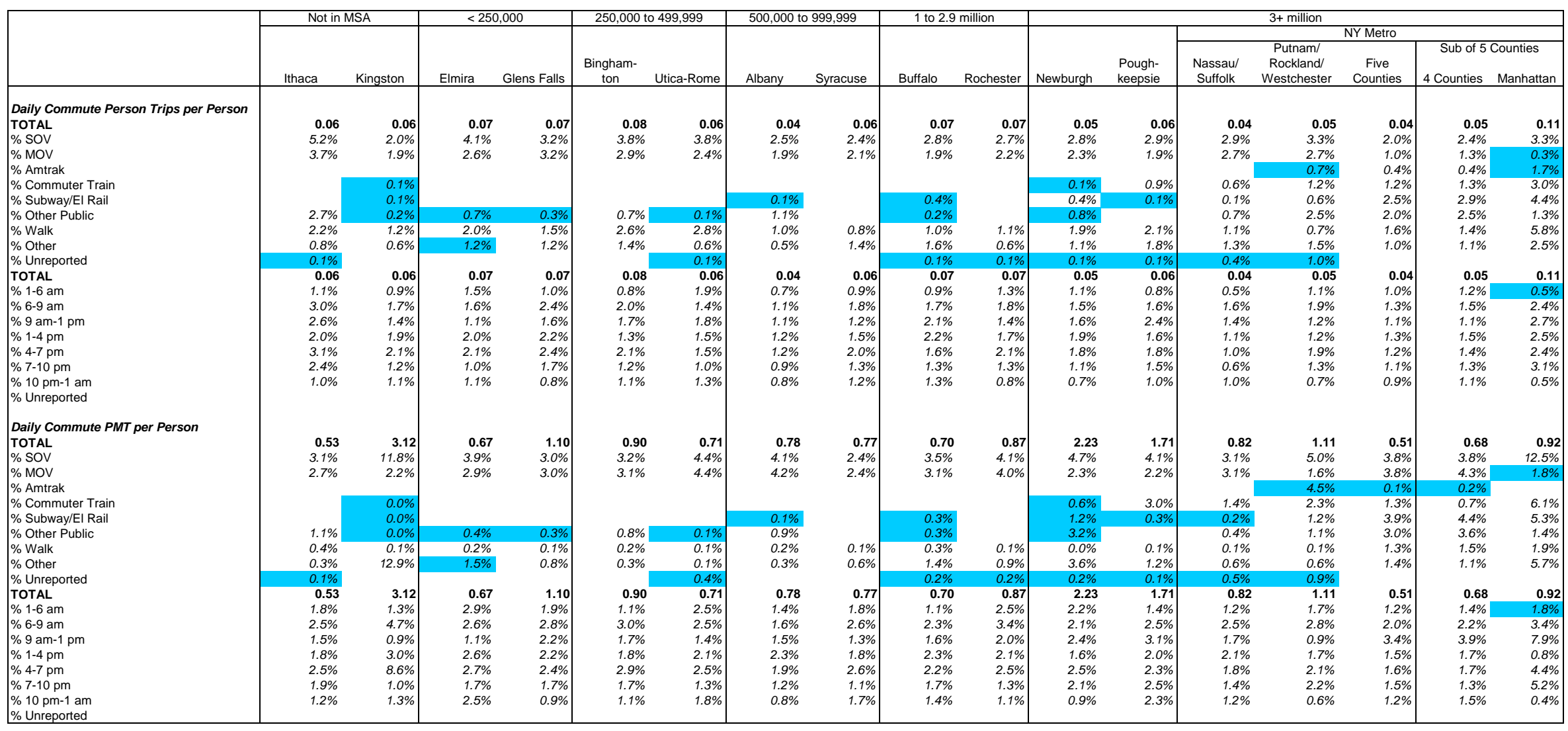




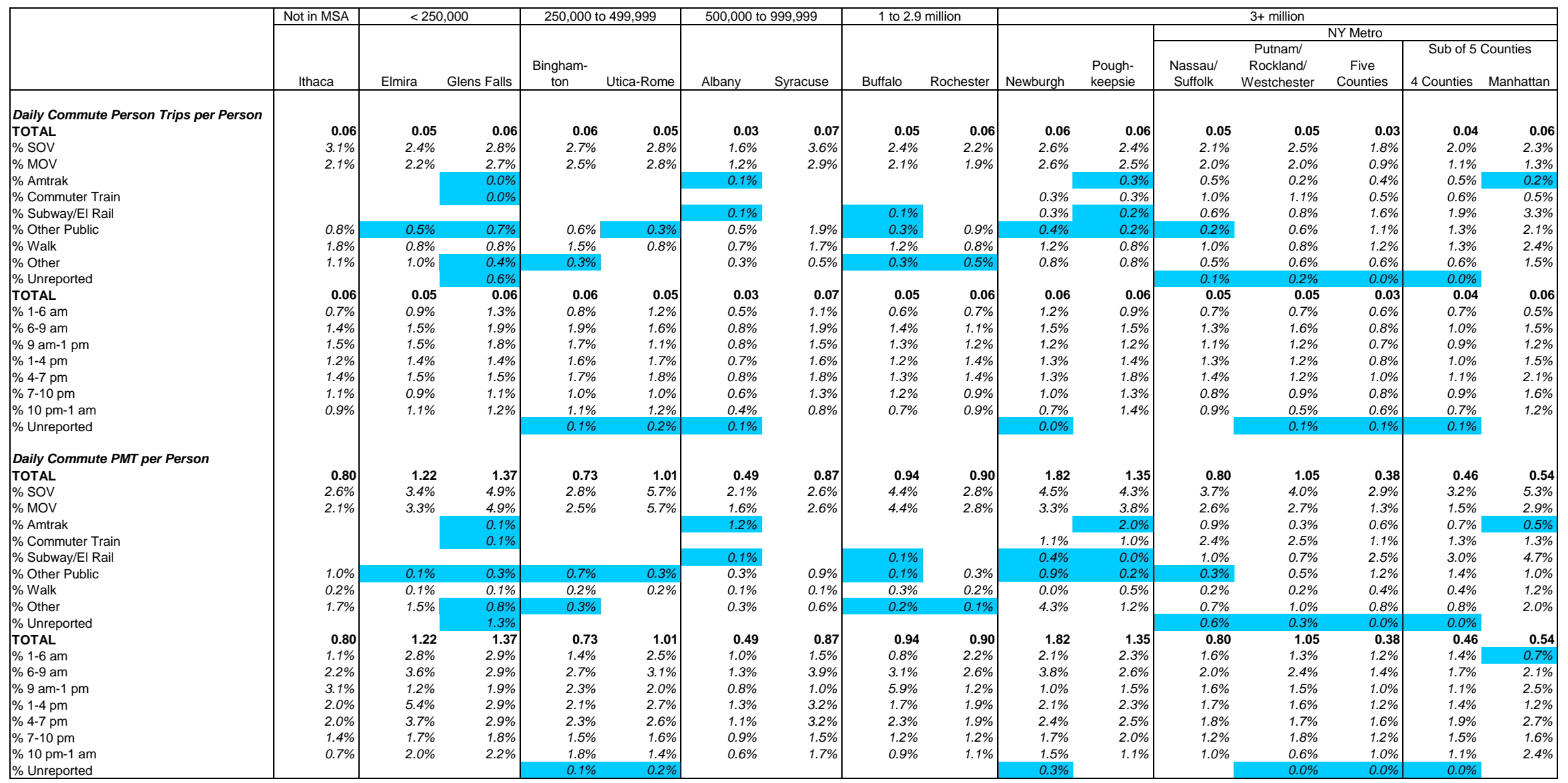




\begin{tabular}{|c|c|c|c|c|c|c|c|c|c|c|c|c|c|c|c|c|c|}
\hline & \multicolumn{2}{|c|}{ Not in MSA } & \multirow{2}{*}{\multicolumn{2}{|c|}{$<250,000$}} & \multicolumn{2}{|c|}{250,000 to 499,999} & \multicolumn{2}{|c|}{500,000 to 999,999} & \multicolumn{2}{|c|}{1 to 2.9 million } & \multicolumn{7}{|c|}{$3+$ million } \\
\hline & \multirow[b]{2}{*}{ Ithaca } & \multirow[b]{2}{*}{ Kingston } & \multirow[b]{2}{*}{ Elmira } & & \multirow[b]{2}{*}{$\begin{array}{l}\text { Bingham- } \\
\text { ton }\end{array}$} & \multirow[b]{2}{*}{ Utica-Rome } & & & & \multirow[b]{2}{*}{ Rochester } & & \multirow[b]{2}{*}{$\begin{array}{l}\text { Pough- } \\
\text { keepsie }\end{array}$} & \multirow{2}{*}{\multicolumn{3}{|c|}{$\begin{array}{c}\text { Putnam/ } \\
\text { Rockland/ } \\
\text { Westchester }\end{array}$}} & & \\
\hline & & & & Glens Falls & & & Albany & Syracuse & Buffalo & & Newburgh & & & & & \multicolumn{2}{|c|}{$\begin{array}{l}\text { Sub of } 5 \text { Counties } \\
4 \text { Counties Manhattan }\end{array}$} \\
\hline \multicolumn{18}{|c|}{$\begin{array}{l}\text { Average Commute Length, Travel Time, and Speed } \\
\text { Length (miles) }\end{array}$} \\
\hline TOTAL & 0.49 & 3.09 & 0.53 & 0.80 & 0.51 & 0.68 & 0.60 & 0.60 & 0.54 & 0.56 & 1.78 & 1.52 & 0.74 & 0.93 & 0.52 & 0.65 & \\
\hline Prive & 0.50 & 0.98 & 0.55 & 0.84 & 0.53 & 0.70 & 0.66 & 0.62 & 0.54 & 0.56 & 1.51 & 1.33 & 0.69 & 1.02 & 1.15 & 1.19 & 6.58 \\
\hline Public & 1.23 & 1.16 & 0.72 & 3.24 & 2.10 & 0.00 & 1.73 & & 3.40 & & 6.22 & 12.37 & 2.20 & 2.34 & 0.65 & 0.76 & 0.57 \\
\hline Walk & 0.13 & 0.12 & 0.16 & 0.18 & 0.08 & 0.04 & 0.44 & 0.07 & 1.40 & 0.19 & 0.10 & 0.07 & 0.07 & 0.33 & 0.45 & 0.86 & 0.09 \\
\hline Other & 0.60 & 272.14 & 5.82 & 2.09 & 0.48 & 0.61 & 1.21 & 1.41 & 1.55 & 5.21 & 15.78 & 2.81 & 7.38 & 16.44 & 2.10 & 1.77 & 4.28 \\
\hline \multicolumn{18}{|l|}{ Time (minutes) } \\
\hline TOTAL & 1.01 & 1.30 & 0.70 & 0.94 & 0.68 & 1.10 & 1.03 & 0.74 & 0.64 & 0.73 & 2.60 & 1.66 & 1.25 & 1.35 & 1.12 & 1.26 & 1.82 \\
\hline Private & 1.05 & 1.26 & 0.74 & 0.95 & 0.58 & 1.14 & 0.92 & 0.79 & 0.62 & 0.72 & 2.42 & 1.35 & 1.33 & 1.39 & 2.02 & 2.15 & 5.05 \\
\hline Public & 3.80 & 3.27 & 8.98 & 1.19 & 3.14 & 0.00 & 8.67 & & 5.35 & & 9.27 & 12.63 & 6.23 & 4.05 & 1.39 & 1.37 & 1.93 \\
\hline Walk & 2.93 & 2.49 & 2.40 & 2.50 & 2.69 & 2.09 & 1.97 & 2.86 & 5.18 & 4.59 & 1.48 & 5.44 & 3.46 & 2.41 & 2.14 & 3.86 & 1.36 \\
\hline Other & 2.39 & 37.71 & 8.95 & 8.97 & 4.42 & 13.22 & 5.09 & 1.97 & 2.07 & 17.37 & 15.32 & 8.33 & 10.84 & 3.24 & 4.43 & 6.29 & 7.34 \\
\hline \multicolumn{18}{|l|}{ Miles per Hour } \\
\hline $\begin{array}{l}\text { Private } \\
\text { Prite }\end{array}$ & 1.21 & $\begin{array}{l}0.25 \\
1.25\end{array}$ & $\begin{array}{l}1.30 \\
1.29\end{array}$ & $\begin{array}{l}1.31 \\
1.19\end{array}$ & $\begin{array}{l}1.24 \\
1.03\end{array}$ & $\begin{array}{l}1.11 \\
1.78\end{array}$ & 0.82 & $\begin{array}{l}1.14 \\
1.05\end{array}$ & 1.14 & $\begin{array}{l}1.04 \\
0.96\end{array}$ & $\begin{array}{l}. .41 \\
1.41\end{array}$ & $\begin{array}{l}1.58 \\
1.48\end{array}$ & 0.97 & $\begin{array}{l}1.15 \\
1.04\end{array}$ & $\begin{array}{l}1.11 \\
1.51\end{array}$ & $\begin{array}{l}1.30 \\
1.61\end{array}$ & $\begin{array}{l}5.40 \\
6.30\end{array}$ \\
\hline & & & & & & & & & & 10 & & & & & & & \\
\hline $\begin{array}{l}\text { Walk } \\
\text { Other }\end{array}$ & $\begin{array}{l}0.32 \\
1.64\end{array}$ & $\begin{array}{r}0.31 \\
73.75\end{array}$ & 0.63 & $\begin{array}{l}0.74 \\
0.89\end{array}$ & $\begin{array}{l}3.73 \\
0.76\end{array}$ & $\begin{array}{l}0.47 \\
4.84\end{array}$ & $\begin{array}{l}1.63 \\
3.03\end{array}$ & $\begin{array}{l}0.36 \\
6.35 \\
0.1\end{array}$ & $\begin{array}{l}2.67 \\
3.17\end{array}$ & $\begin{array}{r}1.04 \\
1.32\end{array}$ & $\begin{array}{l}0.56 \\
8.00\end{array}$ & $\begin{array}{l}0.70 \\
2.40\end{array}$ & $\begin{array}{l}0.21 \\
7.94\end{array}$ & $\begin{array}{r}1.36 \\
28.94\end{array}$ & $\begin{array}{l}0.91 \\
326\end{array}$ & $\begin{array}{l}1.29 \\
278\end{array}$ & $\begin{array}{l}0.34 \\
7.91\end{array}$ \\
\hline
\end{tabular}




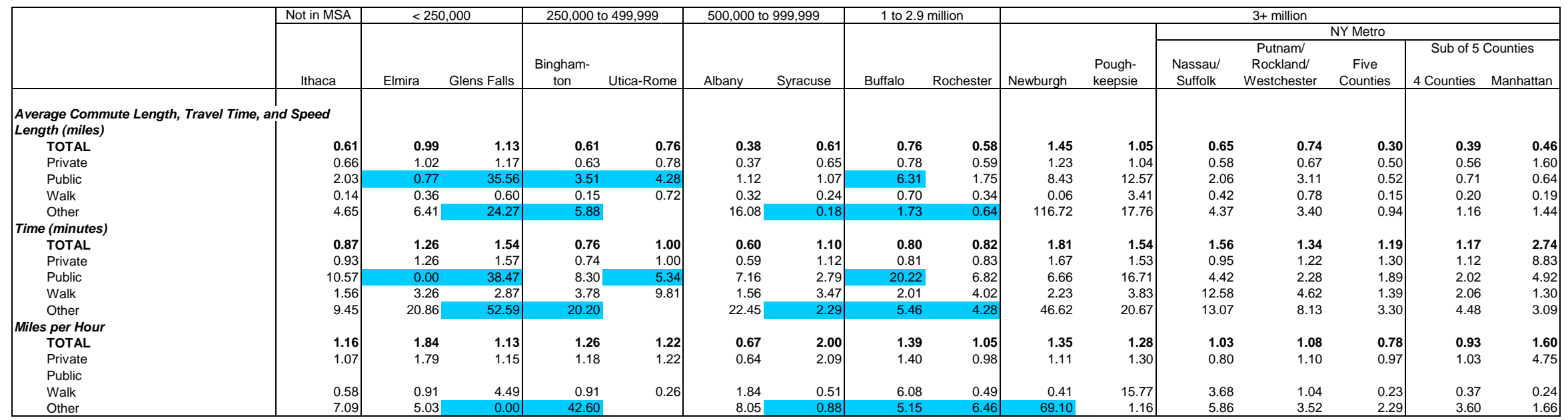




\begin{tabular}{|c|c|c|c|c|c|c|c|c|c|c|c|c|c|c|c|c|c|}
\hline & \multicolumn{2}{|c|}{ Not in MSA } & \multicolumn{2}{|c|}{$<250,000$} & \multicolumn{2}{|c|}{250,000 to 499,999} & \multicolumn{2}{|c|}{500,000 to 999,999} & \multicolumn{2}{|c|}{1 to 2.9 million } & \multirow{2}{*}{\multicolumn{7}{|c|}{$3+$ million }} \\
\hline & \multirow[b]{2}{*}{ Ithaca } & \multirow[b]{2}{*}{ Kingston } & \multirow[b]{2}{*}{ Elmira } & \multirow[b]{2}{*}{ Glens Falls } & \multirow[b]{2}{*}{$\begin{array}{l}\text { Bingham- } \\
\text { ton }\end{array}$} & \multirow[b]{2}{*}{ Utica-Rome } & \multirow[b]{2}{*}{ Albany } & \multirow[b]{2}{*}{ Syracuse } & \multirow[b]{2}{*}{ Buffalo } & \multirow{2}{*}{ Rochester } & \multirow{2}{*}{ Newburgh } & & & \multirow{2}{*}{$\begin{array}{c}\text { Putnam/ } \\
\text { Rockland/ } \\
\text { Westchester }\end{array}$} & NY Metro & & \\
\hline & & & & & & & & & & & & $\begin{array}{l}\text { Pough- } \\
\text { keepsie }\end{array}$ & $\begin{array}{c}\text { Nassau/ } \\
\text { Suffolk }\end{array}$ & & $\begin{array}{c}\text { Five } \\
\text { Counties }\end{array}$ & \multicolumn{2}{|c|}{$\begin{array}{c}\text { Sub of } 5 \text { Counties } \\
4 \text { Counties Manhattan } \\
\end{array}$} \\
\hline Average Vehicle Occupancy & r Vehicle $M$ & & & & & & & & & & & & & & & & \\
\hline ALL & 0.13 & 0.05 & 0.11 & 0.04 & 0.11 & 0.07 & 0.06 & 0.21 & 0.07 & 0.33 & 0.07 & 0.06 & 0.07 & 0.08 & 0.14 & 0.18 & \\
\hline 1 Adult, No Child & 0.07 & 0.07 & 0.07 & 0.04 & 0.11 & 0.25 & 0.35 & 0.04 & 0.03 & 0.05 & 0.06 & 0.13 & 0.01 & 0.12 & 0.23 & 0.34 & 0.14 \\
\hline 2+ Adults, No Child & 0.10 & 0.05 & 0.30 & 0.10 & 0.05 & 0.12 & 0.07 & 0.13 & 0.14 & 0.11 & 0.06 & 0.09 & 0.05 & 0.20 & 0.11 & 0.09 & 0.24 \\
\hline 1 Adult, Child <6 & 2.31 & 0.01 & 0.03 & 0.00 & 0.35 & 0.08 & 0.78 & & 0.00 & 0.22 & 0.14 & 0.03 & 0.00 & 0.00 & 0.32 & 0.00 & 0.00 \\
\hline $2+$ Adults, Child $<6$ & 0.37 & 0.28 & 0.21 & 0.23 & 0.11 & 0.10 & 0.20 & 0.86 & 0.18 & 1.34 & 0.11 & 0.13 & 0.07 & 0.15 & 0.26 & 0.54 & 0.35 \\
\hline 1 Adult, Child 6-15 & 0.08 & 0.25 & 0.15 & 0.00 & 0.25 & 0.51 & 0.19 & 0.38 & 0.09 & 0.25 & 0.55 & 0.08 & 0.41 & 0.41 & 0.15 & 0.15 & 0.00 \\
\hline 2+ Adults, Child 6-15 & 0.09 & 0.08 & 0.29 & 0.08 & 0.42 & 0.30 & 0.15 & 0.27 & 0.18 & 0.15 & 0.22 & 0.15 & 0.22 & 0.21 & 0.14 & 0.13 & 0.54 \\
\hline 1 Adult, Child 16-21 & 0.00 & 0.17 & 0.05 & 0.11 & 0.00 & 0.53 & 0.27 & 0.31 & 0.06 & 0.58 & 0.00 & 0.45 & 0.03 & 0.14 & 0.76 & 0.76 & \\
\hline 2+ Adults, Child 16-21 & 0.16 & 0.13 & 0.38 & 0.07 & 0.19 & 0.08 & 0.15 & 0.12 & 0.11 & 0.09 & 0.22 & 0.23 & 0.11 & 0.08 & 0.27 & 0.29 & 0.37 \\
\hline 1 Adult, Retired, No Child & 0.07 & 0.07 & 0.11 & 0.21 & 0.11 & 0.21 & 0.04 & 0.15 & 0.04 & 0.08 & 0.14 & 0.05 & 0.08 & 0.17 & 0.10 & 0.09 & 0.26 \\
\hline $\begin{array}{l}\text { 2+ Adults, Retired, No Child } \\
\text { Unreported }\end{array}$ & 0.12 & 0.08 & 0.07 & 0.09 & 0.06 & 0.09 & 0.06 & 0.12 & 0.08 & 0.09 & 0.08 & 0.14 & 0.08 & 0.05 & 0.12 & 0.13 & 0.25 \\
\hline ALL & 0.13 & 0.05 & 0.11 & 0.04 & 0.11 & 0.07 & 0.06 & 0.21 & 0.07 & 0.33 & 0.07 & 0.06 & 0.07 & 0.08 & 0.14 & 0.18 & 0.23 \\
\hline Earn a Living & 0.01 & 0.02 & 0.02 & 0.02 & 0.04 & 0.14 & 0.02 & 0.04 & 0.04 & 0.02 & 0.07 & 0.02 & 0.05 & 0.03 & 0.05 & 0.06 & 0.02 \\
\hline Family \& Personal Busines & 0.28 & 0.05 & 0.13 & 0.11 & 0.24 & 0.09 & 0.08 & 0.17 & 0.08 & 0.06 & 0.08 & 0.08 & 0.06 & 0.06 & 0.08 & 0.08 & 0.31 \\
\hline Civic, Educational \& Re & 0.24 & 0.16 & 0.25 & 0.18 & 0.19 & 0.15 & 0.16 & 0.14 & 0.07 & 0.25 & 0.28 & 0.12 & 0.11 & 0.07 & 0.29 & 0.29 & \\
\hline Social \& Recreational & 0.10 & 0.15 & 0.25 & 0.12 & 0.10 & 0.08 & 0.12 & 0.60 & 0.18 & 0.12 & 0.23 & 0.09 & 0.21 & 0.24 & 0.25 & 0.40 & 0.36 \\
\hline & 0.08 & 0.30 & 0.87 & 0.44 & 1.12 & 0.92 & 0.40 & 0.52 & 0.22 & 0.32 & 0.36 & 1.59 & 0.35 & 0.18 & 0.63 & 0.83 & 0.00 \\
\hline Unreported & 0.56 & 0.13 & 0.13 & 0.03 & 0.42 & 0.25 & 0.46 & 0.13 & 0.13 & 1.57 & 0.34 & 0.02 & 0.60 & 0.19 & 0.32 & 0.12 & 0.77 \\
\hline ALL & 0.13 & 0.05 & 0.11 & 0.04 & 0.11 & 0.07 & 0.06 & 0.21 & 0.07 & 0.33 & 0.07 & 0.06 & 0.07 & 0.08 & 0.14 & 0.18 & 0.23 \\
\hline$<\$ 10,000$ & 0.32 & 6 & 0.13 & 0.17 & 0.17 & 0.27 & 0.51 & 0.22 & 0.03 & 0.14 & 1.57 & 0.32 & 0.25 & 0.21 & 0.11 & 0.11 & \\
\hline$\$ 10$ to $\$ 20,000$ & 0.15 & 8 & 0.22 & 0.12 & 8 & 0.21 & 0.10 & 0.13 & 0.10 & 0.46 & 0. & 0.33 & 0.48 & 0.23 & 0.52 & 0.52 & 0.00 \\
\hline$\$ 20$ to & 0.12 & 1 & 0.18 & 0.12 & 2 & 0.18 & & 0.42 & 0.15 & 0.06 & 0.16 & 0.16 & 0.06 & 0.35 & 0.16 & 0.16 & \\
\hline$\$ 30$ to $\$$ & 0.09 & & 0.11 & 0.12 & 0.09 & 0.16 & 0.27 & 0.17 & 0.10 & 0.15 & 0.22 & 0.23 & 0.08 & 0.18 & 0.47 & 0.50 & 0.00 \\
\hline$\$ 40$ to $\$$ & 0.40 & & 0.29 & 0.24 & 0.10 & 0.17 & 0.13 & 0.10 & 0.09 & 0.09 & 0. & 0.24 & 0.25 & 0.10 & 0.18 & 0.24 & 0.23 \\
\hline$\$ 50$ to \$ & 0.09 & & 0.30 & & 0.20 & 0.09 & & 0.31 & 0.24 & 0.18 & 0. & 0.26 & 0.14 & 0.14 & 0.17 & 0.17 & 0.00 \\
\hline$\$ 60$ to $\$$ & 0.10 & & 0.11 & & 0.06 & 0.17 & 0.14 & 0.19 & 0.09 & 0.18 & 0.09 & 0.26 & 0.19 & 0.58 & 0.15 & 0.13 & 0.61 \\
\hline$\$ 70$ to $\$$ & 0.35 & 0.44 & 0.29 & 年 & 0.12 & 0.11 & 0.22 & 7 & 0.27 & 0.15 & 0.29 & 0.24 & 0.06 & 0.13 & 0.83 & 0.97 & 0.56 \\
\hline$\$ 80$ to $\$$ & 0.08 & 0.10 & 0.25 & 10 & 0.09 & 0.54 & 0.19 & 1.13 & 0.11 & 0.07 & 0.07 & 0.08 & 0.09 & 0.17 & 0.17 & 0.18 & 0.25 \\
\hline$\$ 100,000+$ & 0.12 & 0.08 & 0.35 & 0.18 & 0.08 & 0.08 & 0.09 & 0.19 & 0.19 & 0.92 & 0.12 & 0.11 & 0.11 & 0.14 & 0.16 & 0.11 & 0.35 \\
\hline Unreported & 0.11 & 0.07 & 0.63 & 0.08 & 0.18 & 0.10 & 0.08 & 0.27 & 0.37 & 0.23 & 0.19 & 0.27 & 0.09 & 0.16 & 0.08 & 0.08 & 0.15 \\
\hline
\end{tabular}




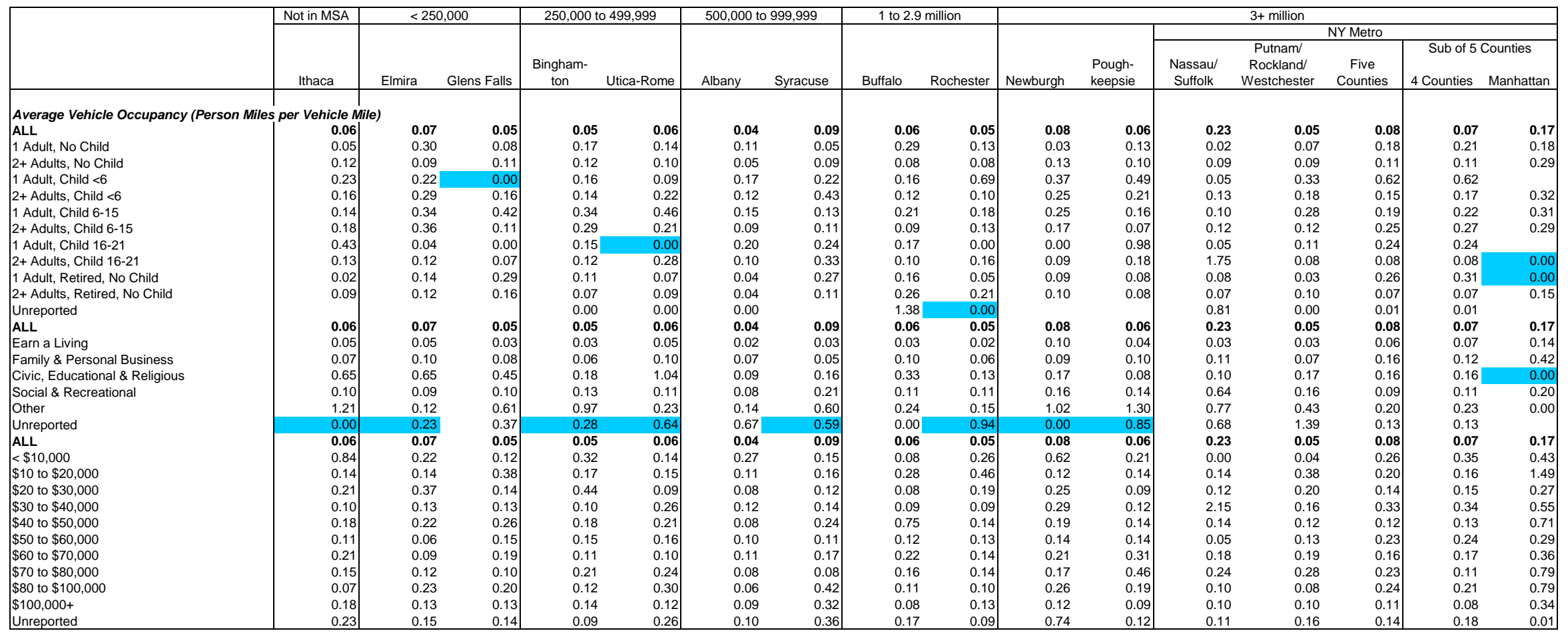




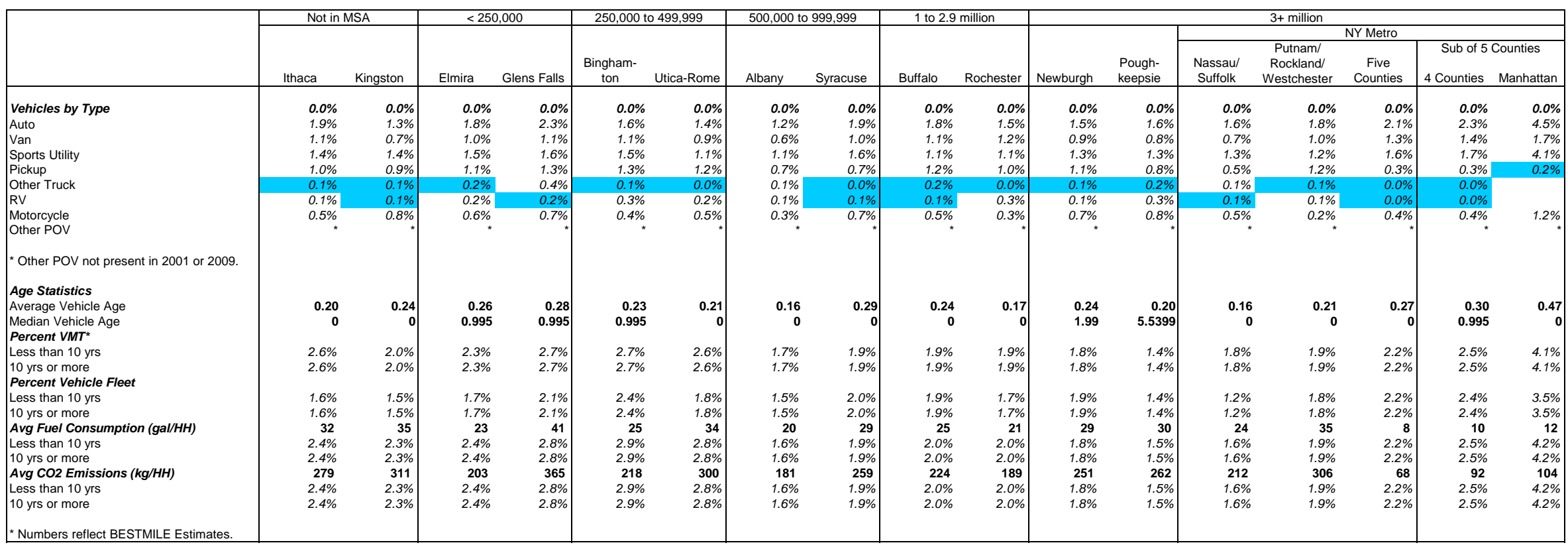




\begin{tabular}{|c|c|c|c|c|c|c|c|c|c|c|c|c|c|c|c|c|}
\hline & \multirow{3}{*}{\begin{tabular}{c|c} 
Not in MSA & \\
Ithaca \\
\end{tabular}} & \multirow{2}{*}{\multicolumn{2}{|c|}{$<250,000$}} & \multicolumn{2}{|c|}{250,000 to 499,999} & \multicolumn{2}{|c|}{500,000 to 999,999} & \multicolumn{2}{|c|}{1 to 2.9 million } & \multirow{2}{*}{\multicolumn{7}{|c|}{ 3+ million }} \\
\hline & & \multirow[b]{2}{*}{ Elmira } & & \multirow[b]{2}{*}{$\begin{array}{l}\text { Bingham- } \\
\text { ton }\end{array}$} & \multirow[b]{2}{*}{ Utica-Rome } & \multirow[b]{2}{*}{ Albany } & \multirow[b]{2}{*}{ Syracuse } & \multirow[b]{2}{*}{ Buffalo } & \multirow[b]{2}{*}{ Rochester } & \multirow[b]{2}{*}{ Newburgh } & \multirow[b]{2}{*}{$\begin{array}{l}\text { Pough- } \\
\text { keepsie }\end{array}$} & & & & & \\
\hline & & & Glens Falls & & & & & & & & & $\begin{array}{c}\text { Nassau/ } \\
\text { Suffolk }\end{array}$ & $\begin{array}{c}\text { Putnam/ } \\
\text { Rockland/ } \\
\text { Westchester }\end{array}$ & $\begin{array}{c}\text { Five } \\
\text { Counties } \\
\end{array}$ & $\begin{array}{r}\text { Sub of } 5 \\
4 \text { Counties } \\
\end{array}$ & $\begin{array}{l}\text { Counties } \\
\text { Manhattan }\end{array}$ \\
\hline Vehicles by Type & $0.0 \%$ & $0.0 \%$ & $0.0 \%$ & $0.0 \%$ & $0.0 \%$ & $0.0 \%$ & $0.0 \%$ & $0.0 \%$ & $0.0 \%$ & $0.0 \%$ & $0.0 \%$ & $0.0 \%$ & $0.0 \%$ & $0.0 \%$ & $0.0 \%$ & $0.0 \%$ \\
\hline Auto & $3.9 \%$ & $2.5 \%$ & $6.6 \%$ & $3.8 \%$ & $6.3 \%$ & $1.7 \%$ & $1.9 \%$ & $4.3 \%$ & $2.9 \%$ & $2.5 \%$ & $4.5 \%$ & $2.5 \%$ & $1.6 \%$ & $3.4 \%$ & $2.4 \%$ & $11.5 \%$ \\
\hline Van & $1.1 \%$ & $1.1 \%$ & $1.4 \%$ & $1.3 \%$ & $1.4 \%$ & $0.6 \%$ & $1.2 \%$ & $1.2 \%$ & $1.1 \%$ & $1.1 \%$ & $1.1 \%$ & $0.9 \%$ & $0.7 \%$ & $1.0 \%$ & $1.0 \%$ & $2.5 \%$ \\
\hline Sports Utility & $1.1 \%$ & $1.1 \%$ & $2.0 \%$ & $1.2 \%$ & $1.6 \%$ & $0.7 \%$ & $1.1 \%$ & $1.3 \%$ & $1.0 \%$ & $1.1 \%$ & $1.4 \%$ & $1.3 \%$ & $1.0 \%$ & $1.1 \%$ & $1.1 \%$ & $3.3 \%$ \\
\hline Pickup & $1.4 \%$ & $1.2 \%$ & $2.8 \%$ & $1.4 \%$ & $1.9 \%$ & $0.7 \%$ & $1.0 \%$ & $1.4 \%$ & $1.2 \%$ & $0.9 \%$ & $1.0 \%$ & $0.7 \%$ & $0.6 \%$ & $0.2 \%$ & $0.3 \%$ & $0.6 \%$ \\
\hline Other Truck & $0.3 \%$ & $0.2 \%$ & $0.4 \%$ & $0.2 \%$ & $0.2 \%$ & $0.1 \%$ & & $0.0 \%$ & $0.2 \%$ & $0.2 \%$ & $0.2 \%$ & $0.0 \%$ & $0.2 \%$ & $0.3 \%$ & $0.4 \%$ & \\
\hline RV & $0.3 \%$ & $0.3 \%$ & $0.2 \%$ & $0.3 \%$ & $0.4 \%$ & $0.2 \%$ & $0.4 \%$ & $0.3 \%$ & $0.2 \%$ & $0.2 \%$ & $0.2 \%$ & $0.1 \%$ & $0.0 \%$ & $0.0 \%$ & $0.0 \%$ & \\
\hline $\begin{array}{l}\text { Motorcycle } \\
\text { Other POV }\end{array}$ & $0.6 \%$ & $0.5 \%$ & $0.8 \%$ & $0.7 \%$ & $1.3 \%$ & $0.3 \%$ & $0.4 \%$ & $0.5 \%$ & $0.4 \%$ & $0.5 \%$ & $0.8 \%$ & $0.4 \%$ & $0.2 \%$ & $0.4 \%$ & $0.3 \%$ & $1.9 \%$ \\
\hline * Other POV not present in 2001 or & & & & & & & & & & & & & & & & \\
\hline Age Stat & & & & & & & & & & & & & & & & \\
\hline Average Vehicle Age & 0.24 & 0.22 & 0.30 & 0.34 & 0.32 & 0.15 & 0.19 & 0.21 & 0.18 & 0.28 & 0.24 & 0.18 & 0.17 & 0.23 & 0.18 & 1.29 \\
\hline $\begin{array}{l}\text { Median Vehicle Age } \\
\text { Percent VMT** }\end{array}$ & & 0 & & 0 & & 0 & & 0 & & 0 & 0 & 0 & 0 & 00 & 0 & 1.4071 \\
\hline Less than $10 \mathrm{yrs}$ & $2.3 \%$ & $2.9 \%$ & $3.0 \%$ & $2.5 \%$ & $2.4 \%$ & $1.3 \%$ & $2.6 \%$ & $2.0 \%$ & $1.7 \%$ & $1.9 \%$ & $1.8 \%$ & $2.4 \%$ & $1.4 \%$ & $2.4 \%$ & $2.6 \%$ & $6.8 \%$ \\
\hline $\begin{array}{l}10 \text { yrs or more } \\
\text { Percent Vehicle Fleet }\end{array}$ & $2.3 \%$ & $2.9 \%$ & $3.0 \%$ & $2.5 \%$ & $2.4 \%$ & $1.3 \%$ & $2.6 \%$ & $2.0 \%$ & $1.7 \%$ & $1.9 \%$ & $1.8 \%$ & $2.4 \%$ & $1.4 \%$ & $2.4 \%$ & $2.6 \%$ & $6.8 \%$ \\
\hline Less than $10 \mathrm{yrs}$ & $2.1 \%$ & $1.9 \%$ & $2.3 \%$ & $2.3 \%$ & $1.9 \%$ & $1.1 \%$ & $1.6 \%$ & $1.6 \%$ & $1.5 \%$ & $1.9 \%$ & $1.5 \%$ & $1.4 \%$ & $1.6 \%$ & $1.6 \%$ & $1.7 \%$ & $5.1 \%$ \\
\hline $10 \mathrm{yr}$ & $2.1 \%$ & $1.9 \%$ & $2.3 \%$ & $2.3 \%$ & $1.9 \%$ & $1.1 \%$ & $1.6 \%$ & $1.6 \%$ & $1.5 \%$ & 1.5 & 1.5 & $1.4 \%$ & $1.6 \%$ & $1.6 \%$ & $1.7 \%$ & $5.1 \%$ \\
\hline Avg Fuel Consumption (gal//HH) & 293 & 1,239 & 123 & 282 & 165 & 89 & 218 & 133 & 19 & 120 & 2 & 186 & 231 & 30 & 39 & 67 \\
\hline Less than 10$\}$ & $28.1 \%$ & $10.5 \%$ & $8.8 \%$ & $11.3 \%$ & $11.8 \%$ & $13.6 \%$ & $20.9 \%$ & $14.3 \%$ & $10.6 \%$ & $12.0 \%$ & $13.4 \%$ & $5.7 \%$ & $4.3 \%$ & $4.5 \%$ & $3.7 \%$ & $21.2 \%$ \\
\hline $10 \mathrm{yrs}$ or more & $28.1 \%$ & $10.5 \%$ & & & $11.8 \%$ & $13.6 \%$ & $20.9 \%$ & $14.3 \%$ & $10.6 \%$ & & $13.4 \%$ & $5.7 \%$ & $4.3 \%$ & $4.5 \%$ & $3.7 \%$ & $21.2 \%$ \\
\hline Avg CO2 Emissions (kg/HH) & 2,578 & 10,887 & 1,083 & 2,480 & 1,453 & 783 & 1,918 & 1,166 & 1,680 & 1,057 & 2,030 & 1,632 & 2,033 & 269 & 346 & 587 \\
\hline Less than $10 \mathrm{yrs}$ & $28.1 \%$ & $10.5 \%$ & $8.8 \%$ & $11.3 \%$ & $11.8 \%$ & $13.6 \%$ & $20.9 \%$ & $14.3 \%$ & $10.6 \%$ & $12.0 \%$ & $13.4 \%$ & $5.7 \%$ & $4.3 \%$ & $4.5 \%$ & $3.7 \%$ & $21.2 \%$ \\
\hline 10 yrs or more & $28.1 \%$ & $10.5 \%$ & $8.8 \%$ & $11.3 \%$ & $11.8 \%$ & $13.6 \%$ & $20.9 \%$ & $14.3 \%$ & $10.6 \%$ & $12.0 \%$ & $13.4 \%$ & $5.7 \%$ & $4.3 \%$ & $4.5 \%$ & $3.7 \%$ & $21.2 \%$ \\
\hline${ }^{*}$ Numbers reflect BESTMILE Esti & & & & & & & & & & & & & & & & \\
\hline
\end{tabular}




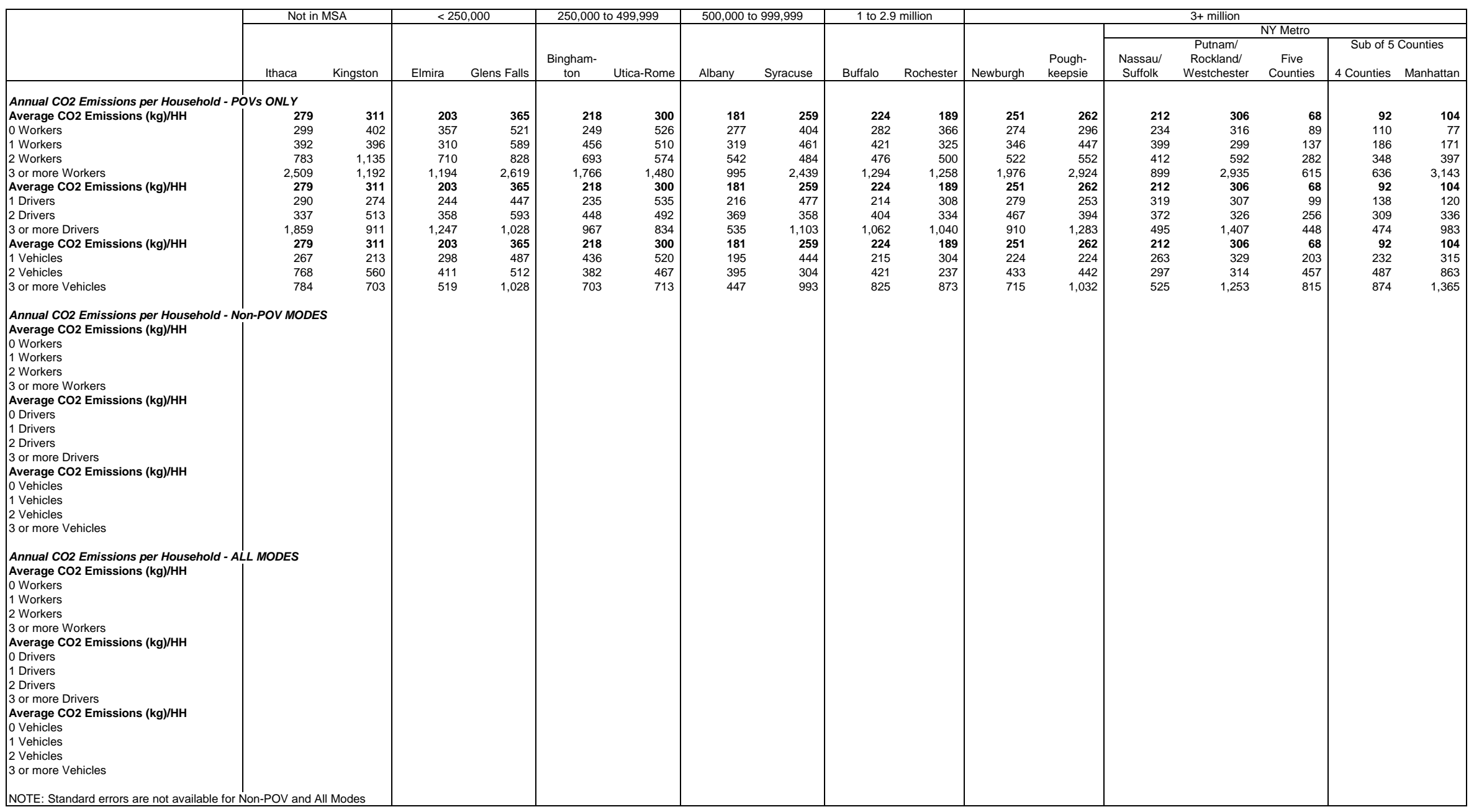


2001 NHTS
STANDARD ERRORS

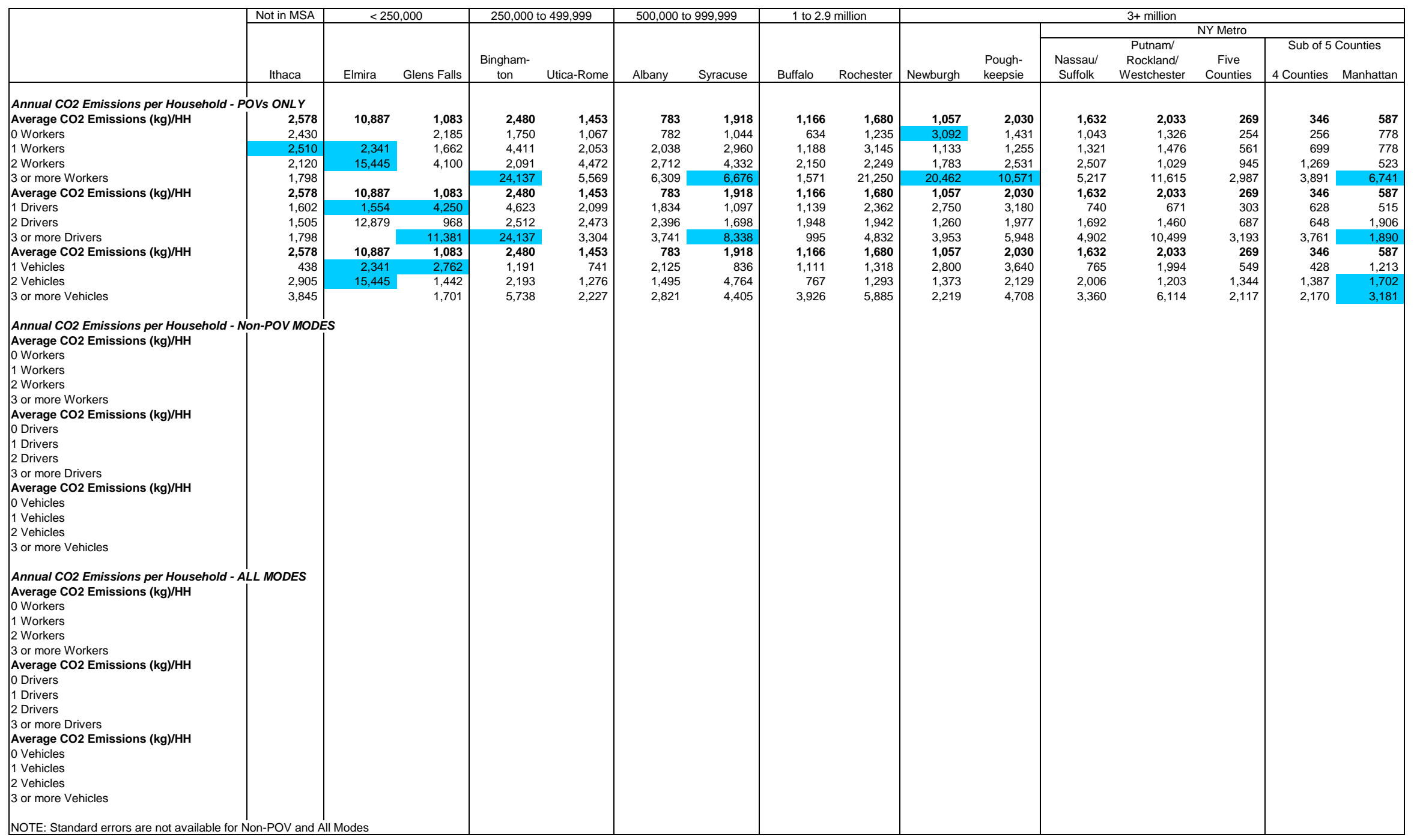




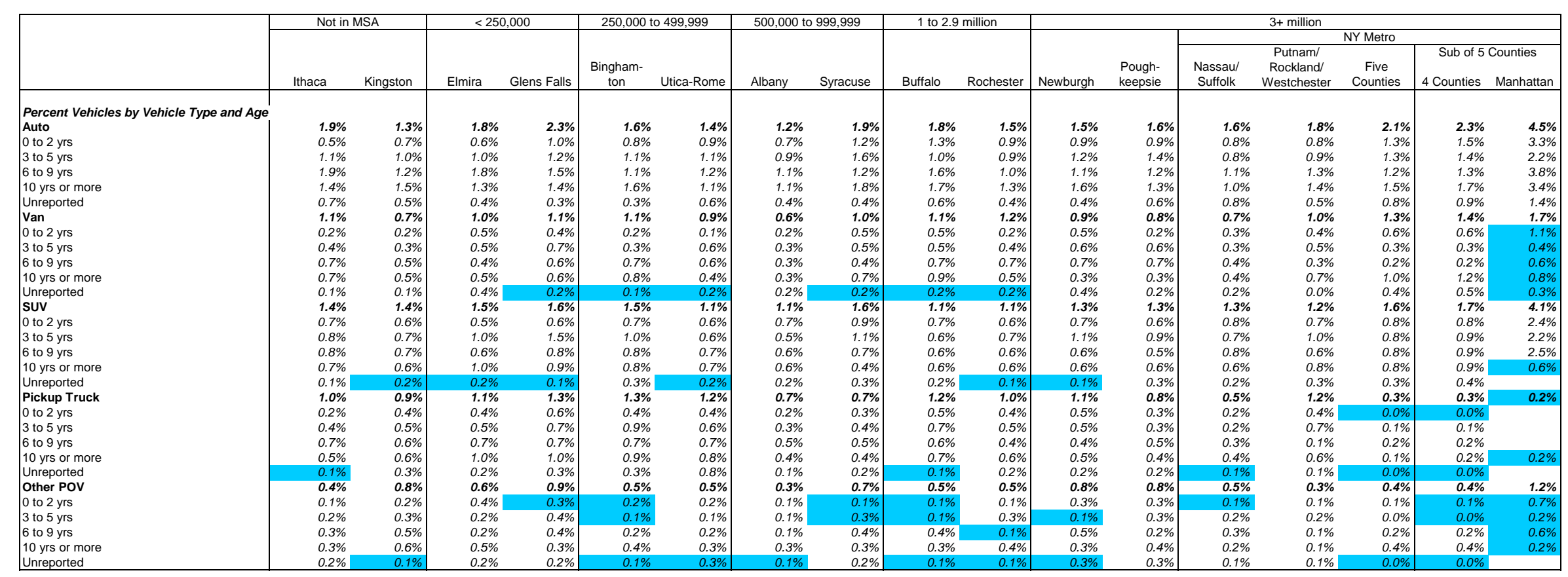




\begin{tabular}{|c|c|c|c|c|c|c|c|c|c|c|c|c|c|c|c|c|}
\hline & \multirow{3}{*}{\begin{tabular}{c|} 
Not in MSA \\
Ithaca \\
\end{tabular}} & \multicolumn{2}{|c|}{$<250,000$} & \multirow{3}{*}{\multicolumn{2}{|c|}{$\begin{array}{l}250,000 \text { to } 499,999 \\
\begin{array}{l}\text { Bingham- } \\
\text { ton }\end{array} \text { Utica-Rome } \\
\end{array}$}} & \multirow{3}{*}{\multicolumn{2}{|c|}{$\begin{array}{l}500,000 \text { to } 999,999 \\
\text { Albany } \quad \text { Syracuse } \\
\end{array}$}} & \multirow{3}{*}{\multicolumn{2}{|c|}{$\begin{array}{l}1 \text { to } 2.9 \text { million } \\
\text { Buffalo Rochester } \\
\end{array}$}} & \multirow[b]{3}{*}{ Newburgh } & \multicolumn{6}{|c|}{$3+$ million } \\
\hline & & \multirow[b]{2}{*}{ Elmira } & \multirow[b]{2}{*}{ Glens Falls } & & & & & & & & & & & NY Metro & & \\
\hline & & & & & & & & & & & $\begin{array}{l}\text { Pough- } \\
\text { keepsie }\end{array}$ & $\begin{array}{l}\text { Nassau/ } \\
\text { Suffolk }\end{array}$ & $\begin{array}{l}\text { Putnam/ } \\
\text { Rockland/ } \\
\text { Westchester }\end{array}$ & $\begin{array}{c}\text { Five } \\
\text { Counties }\end{array}$ & $\begin{array}{r}\text { Sub of } 5 \\
4 \text { Counties }\end{array}$ & $\begin{array}{l}\text { Counties } \\
\text { Manhattan }\end{array}$ \\
\hline \multicolumn{17}{|c|}{ Percent Vehicles by Vehicle Type } \\
\hline $\begin{array}{l}\text { Auto } \\
0 \text { to } 2 \text { yrs }\end{array}$ & $\begin{array}{l}3.9 \% \\
1.0 \%\end{array} \mid$ & $\begin{array}{l}2.5 \% \\
0.7 \%\end{array}$ & $\begin{array}{l}6.6 \% \\
1.4 \%\end{array} \mid$ & $\begin{array}{l}3.8 \% \\
0.9 \%\end{array}$ & $\begin{array}{l}6.3 \% \\
13 \%\end{array}-130$ & $\begin{array}{l}1.7 \% \\
0.6 \%\end{array}$ & $\begin{array}{l}1.9 \% \\
13 \%\end{array}$ & $\begin{array}{l}4.3 \% \\
1.2 \%\end{array}$ & $\begin{array}{l}2.9 \% \\
1.1 \%\end{array}$ & $\begin{array}{l}2.5 \% \\
1.4 \%\end{array}$ & $\begin{array}{l}4.5 \% \\
0.9 \%\end{array}$ & $\begin{array}{l}2.5 \% \\
1.1 \%\end{array}$ & $\begin{array}{l}1.6 \% \\
1.1 \%\end{array}$ & $\begin{array}{l}3.4 \% \\
1.1 \%\end{array}$ & $\begin{array}{l}2.4 \% \\
1.0 \%\end{array}$ & $\begin{array}{r}11.5 \% \\
3.7 \%\end{array}$ \\
\hline 3 to $5 \mathrm{yrs}$ & $1.3 \%$ & $1.2 \%$ & $1.7 \%$ & $1.4 \%$ & $1.6 \%$ & $0.8 \%$ & $1.4 \%$ & $1.5 \%$ & $1.2 \%$ & $1.0 \%$ & $1.4 \%$ & $1.0 \%$ & $1.3 \%$ & $1.3 \%$ & $1.3 \%$ & $3.8 \%$ \\
\hline 6 to $9 \mathrm{yrs}$ & $1.8 \%$ & $1.5 \%$ & $2.1 \%$ & $1.5 \%$ & $2.2 \%$ & $0.9 \%$ & $1.7 \%$ & $1.6 \%$ & $1.4 \%$ & $1.3 \%$ & $1.8 \%$ & $1.1 \%$ & $1.5 \%$ & $1.4 \%$ & $1.4 \%$ & $3.3 \%$ \\
\hline 10 yrs or more & $2.3 \%$ & $1.7 \%$ & $2.8 \%$ & $2.1 \%$ & $2.6 \%$ & $0.9 \%$ & $1.6 \%$ & $1.8 \%$ & $1.5 \%$ & $1.7 \%$ & $2.2 \%$ & $1.4 \%$ & $1.5 \%$ & $2.0 \%$ & $1.9 \%$ & $6.8 \%$ \\
\hline Unreported & $0.8 \%$ & $0.3 \%$ & $0.7 \%$ & $0.2 \%$ & $0.4 \%$ & $0.3 \%$ & $0.4 \%$ & $0.7 \%$ & $0.4 \%$ & $0.5 \%$ & $0.6 \%$ & $0.5 \%$ & $0.4 \%$ & $0.7 \%$ & $0.8 \%$ & $0.6 \%$ \\
\hline Van & $1.1 \%$ & $1.1 \%$ & $1.4 \%$ & $1.3 \%$ & $1.4 \%$ & $0.6 \%$ & $1.2 \%$ & $1.2 \%$ & $1.1 \%$ & $1.1 \%$ & $1.1 \%$ & $0.9 \%$ & $0.7 \%$ & $1.0 \%$ & $1.0 \%$ & $2.5 \%$ \\
\hline 0 to $2 \mathrm{yrs}$ & $0.4 \%$ & $0.3 \%$ & $0.6 \%$ & $0.4 \%$ & $0.5 \%$ & $0.2 \%$ & $0.4 \%$ & $0.4 \%$ & $0.5 \%$ & $0.4 \%$ & $0.5 \%$ & $0.5 \%$ & $0.4 \%$ & $0.4 \%$ & $0.4 \%$ & $0.3 \%$ \\
\hline 3 to $5 \mathrm{yrs}$ & $0.5 \%$ & $0.5 \%$ & $0.6 \%$ & $0.5 \%$ & $0.4 \%$ & $0.3 \%$ & $0.5 \%$ & $0.5 \%$ & $0.5 \%$ & $0.6 \%$ & $0.5 \%$ & $0.5 \%$ & $0.5 \%$ & $0.4 \%$ & $0.4 \%$ & $1.0 \%$ \\
\hline 6 to $9 \mathrm{yrs}$ & $0.5 \%$ & $0.7 \%$ & $0.5 \%$ & $0.6 \%$ & $0.7 \%$ & $0.3 \%$ & $0.7 \%$ & $0.7 \%$ & $0.5 \%$ & $0.5 \%$ & $0.7 \%$ & $0.4 \%$ & $0.4 \%$ & $0.5 \%$ & $0.5 \%$ & $0.8 \%$ \\
\hline \multirow{3}{*}{$\begin{array}{l}10 \text { yrs or more } \\
\text { Unreported } \\
\text { suv }\end{array}$} & $0.7 \%$ & $0.6 \%$ & $0.6 \%$ & $0.7 \%$ & $0.5 \%$ & $0.3 \%$ & $0.6 \%$ & $0.6 \%$ & $0.6 \%$ & $0.6 \%$ & $0.3 \%$ & $0.5 \%$ & $0.3 \%$ & $0.6 \%$ & $0.7 \%$ & $1.2 \%$ \\
\hline & $0.2 \%$ & $0.1 \%$ & $0.1 \%$ & $0.1 \%$ & $0.2 \%$ & $0.1 \%$ & $0.2 \%$ & $0.2 \%$ & $0.2 \%$ & $0.2 \%$ & & $0.1 \%$ & $0.1 \%$ & $0.2 \%$ & $0.2 \%$ & $1.2 \%$ \\
\hline & $1.1 \%$ & $1.1 \%$ & $2.0 \%$ & $1.2 \%$ & $1.6 \%$ & $0.7 \%$ & $1.1 \%$ & $1.3 \%$ & $1.0 \%$ & $1.1 \%$ & $1.4 \%$ & $1.3 \%$ & $1.0 \%$ & $1.1 \%$ & $1.1 \%$ & $3.3 \%$ \\
\hline 0 to $2 \mathrm{yrs}$ & $0.5 \%$ & $0.4 \%$ & $0.9 \%$ & $0.4 \%$ & $0.8 \%$ & $0.3 \%$ & $0.8 \%$ & $0.8 \%$ & $0.5 \%$ & $0.7 \%$ & $0.6 \%$ & $0.6 \%$ & $0.7 \%$ & $0.6 \%$ & $0.6 \%$ & $1.4 \%$ \\
\hline 3 to $5 \mathrm{yrs}$ & $0.5 \%$ & $0.7 \%$ & $0.6 \%$ & $0.6 \%$ & $0.6 \%$ & $0.4 \%$ & $0.5 \%$ & $0.5 \%$ & $0.6 \%$ & $0.6 \%$ & $0.8 \%$ & $0.8 \%$ & $0.6 \%$ & $0.5 \%$ & $0.5 \%$ & $2.4 \%$ \\
\hline 6 to $9 \mathrm{yrs}$ & $0.7 \%$ & $0.5 \%$ & $0.8 \%$ & $0.6 \%$ & $0.7 \%$ & $0.3 \%$ & $0.5 \%$ & $0.6 \%$ & $0.5 \%$ & $0.4 \%$ & $0.7 \%$ & $0.5 \%$ & $0.4 \%$ & $0.6 \%$ & $0.7 \%$ & $0.7 \%$ \\
\hline \multirow{3}{*}{$\begin{array}{l}10 \text { yrs or more } \\
\text { Unreported } \\
\text { Pickup Truck }\end{array}$} & $0.5 \%$ & $0.5 \%$ & $0.6 \%$ & $0.6 \%$ & $0.6 \%$ & $0.3 \%$ & $0.4 \%$ & $0.3 \%$ & $0.4 \%$ & $0.6 \%$ & $0.5 \%$ & $0.3 \%$ & $0.3 \%$ & $0.5 \%$ & $0.5 \%$ & $0.8 \%$ \\
\hline & $0.0 \%$ & $0.1 \%$ & $0.5 \%$ & $0.2 \%$ & $0.2 \%$ & $0.0 \%$ & $0.2 \%$ & $0.1 \%$ & $0.1 \%$ & $0.1 \%$ & $0.2 \%$ & $0.3 \%$ & $0.0 \%$ & $0.4 \%$ & $0.4 \%$ & $0.3 \%$ \\
\hline & $1.4 \%$ & $1.2 \%$ & $2.8 \%$ & $1.4 \%$ & $1.9 \%$ & $0.7 \%$ & $1.0 \%$ & $1.4 \%$ & $1.2 \%$ & $0.9 \%$ & $1.0 \%$ & $0.7 \%$ & $0.6 \%$ & $0.2 \%$ & $0.3 \%$ & $0.6 \%$ \\
\hline 0 to 2 yrs & $0.5 \%$ & $0.5 \%$ & $0.8 \%$ & $0.3 \%$ & $0.5 \%$ & $0.2 \%$ & $0.6 \%$ & $0.4 \%$ & $0.4 \%$ & $0.5 \%$ & $0.5 \%$ & $0.2 \%$ & $0.3 \%$ & $0.1 \%$ & $0.1 \%$ & \\
\hline 3 to $5 y$ & $0.7 \%$ & $0.6 \%$ & $0.9 \%$ & $0.6 \%$ & $0.8 \%$ & $0.3 \%$ & $0.7 \%$ & $0.6 \%$ & $0.5 \%$ & 0.6 & $0.4 \%$ & $0.3 \%$ & $0.2 \%$ & $0.1 \%$ & $0.0 \%$ & $0.4 \%$ \\
\hline 6 to $9 \mathrm{yrs}$ & $0.7 \%$ & $0.6 \%$ & $0.8 \%$ & $0.5 \%$ & $0.7 \%$ & $0.3 \%$ & $0.7 \%$ & $0.5 \%$ & $0.5 \%$ & $0.5 \%$ & $0.6 \%$ & $0.4 \%$ & $0.3 \%$ & $0.1 \%$ & $0.1 \%$ & $0.3 \%$ \\
\hline \multirow{2}{*}{$\begin{array}{l}10 \text { yrs or more } \\
\text { Unreported }\end{array}$} & $0.8 \%$ & $0.9 \%$ & $1.4 \%$ & $1.0 \%$ & $1.0 \%$ & $0.4 \%$ & $0.5 \%$ & $0.8 \%$ & $0.8 \%$ & $0.6 \%$ & $0.6 \%$ & $0.4 \%$ & $0.3 \%$ & $0.2 \%$ & $0.2 \%$ & $0.3 \%$ \\
\hline & $0.3 \%$ & $0.2 \%$ & $0.2 \%$ & $0.3 \%$ & $0.5 \%$ & $0.1 \%$ & $0.2 \%$ & $0.2 \%$ & & $0.1 \%$ & $0.2 \%$ & $0.1 \%$ & $0.1 \%$ & $0.0 \%$ & $0.0 \%$ & \\
\hline Other POV & $0.7 \%$ & $0.6 \%$ & $0.9 \%$ & $0.7 \%$ & $1.4 \%$ & $0.4 \%$ & $0.7 \%$ & $0.6 \%$ & $0.6 \%$ & $0.6 \%$ & $0.8 \%$ & $0.4 \%$ & $0.3 \%$ & $0.5 \%$ & $0.4 \%$ & $1.9 \%$ \\
\hline 0 to $2 \mathrm{yrs}$ & $0.1 \%$ & $0.3 \%$ & $0.3 \%$ & $0.1 \%$ & $0.3 \%$ & $0.1 \%$ & & $0.2 \%$ & $0.3 \%$ & $0.1 \%$ & $0.4 \%$ & $0.1 \%$ & $0.1 \%$ & $0.1 \%$ & $0.1 \%$ & \\
\hline 3 to $5 \mathrm{yrs}$ & $0.2 \%$ & $0.2 \%$ & $0.3 \%$ & $0.2 \%$ & $0.3 \%$ & $0.1 \%$ & $0.3 \%$ & $0.2 \%$ & $0.2 \%$ & $0.2 \%$ & $0.3 \%$ & $0.2 \%$ & $0.1 \%$ & $0.1 \%$ & $0.1 \%$ & \\
\hline 6 to 9 yrs & $0.3 \%$ & $0.2 \%$ & $0.2 \%$ & $0.1 \%$ & $0.3 \%$ & $0.1 \%$ & $0.2 \%$ & $0.2 \%$ & $0.1 \%$ & $0.2 \%$ & $0.3 \%$ & $0.2 \%$ & $0.2 \%$ & $0.1 \%$ & $0.0 \%$ & $0.3 \%$ \\
\hline 10 yrs or more & $0.5 \%$ & $0.5 \%$ & $0.7 \%$ & $0.6 \%$ & $1.3 \%$ & $0.3 \%$ & $0.3 \%$ & $0.4 \%$ & $0.3 \%$ & $0.5 \%$ & $0.6 \%$ & $0.2 \%$ & $0.1 \%$ & $0.3 \%$ & $0.3 \%$ & $1.9 \%$ \\
\hline Unreported & & $0.2 \%$ & $0.2 \%$ & $0.3 \%$ & $0.2 \%$ & $0.1 \%$ & $0.2 \%$ & $0.1 \%$ & $0.2 \%$ & $0.1 \%$ & $0.2 \%$ & $0.0 \%$ & $0.2 \%$ & $0.3 \%$ & $0.4 \%$ & \\
\hline
\end{tabular}




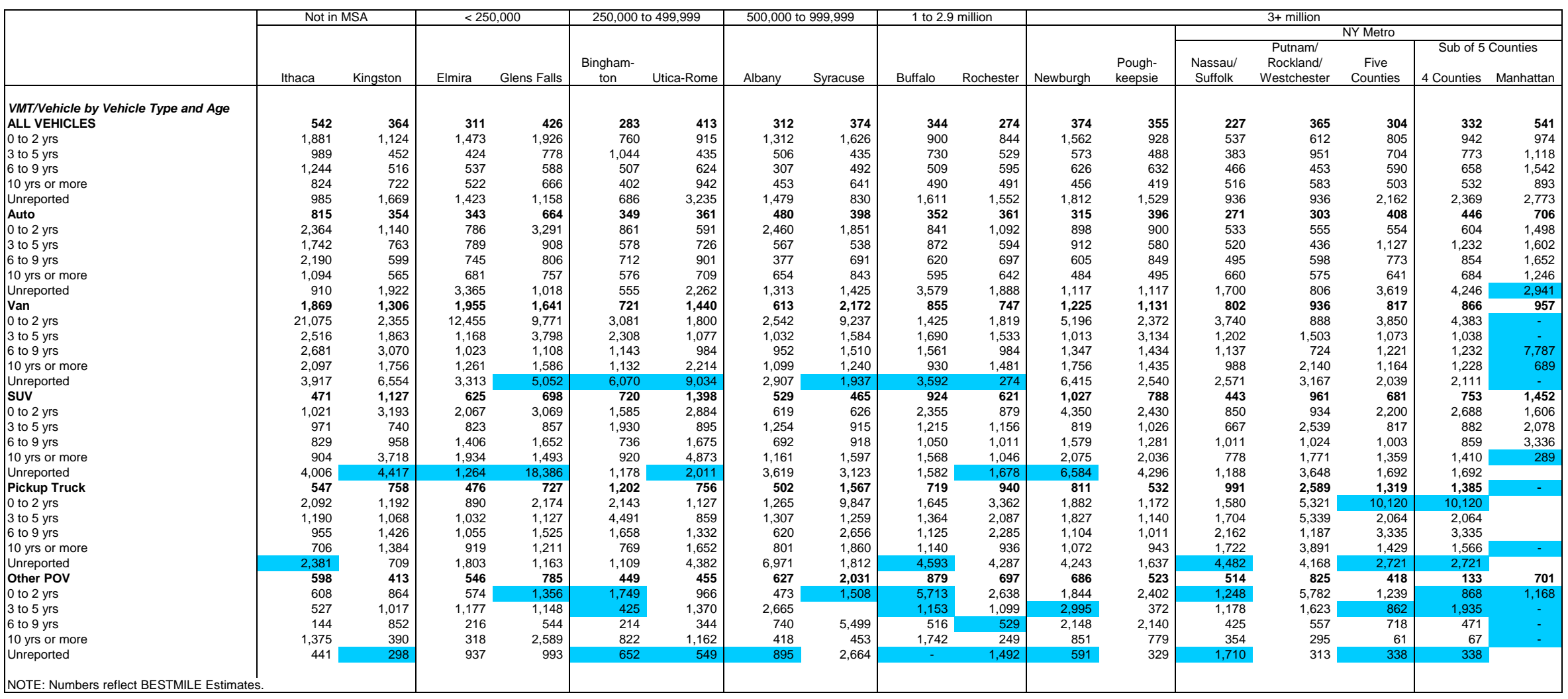




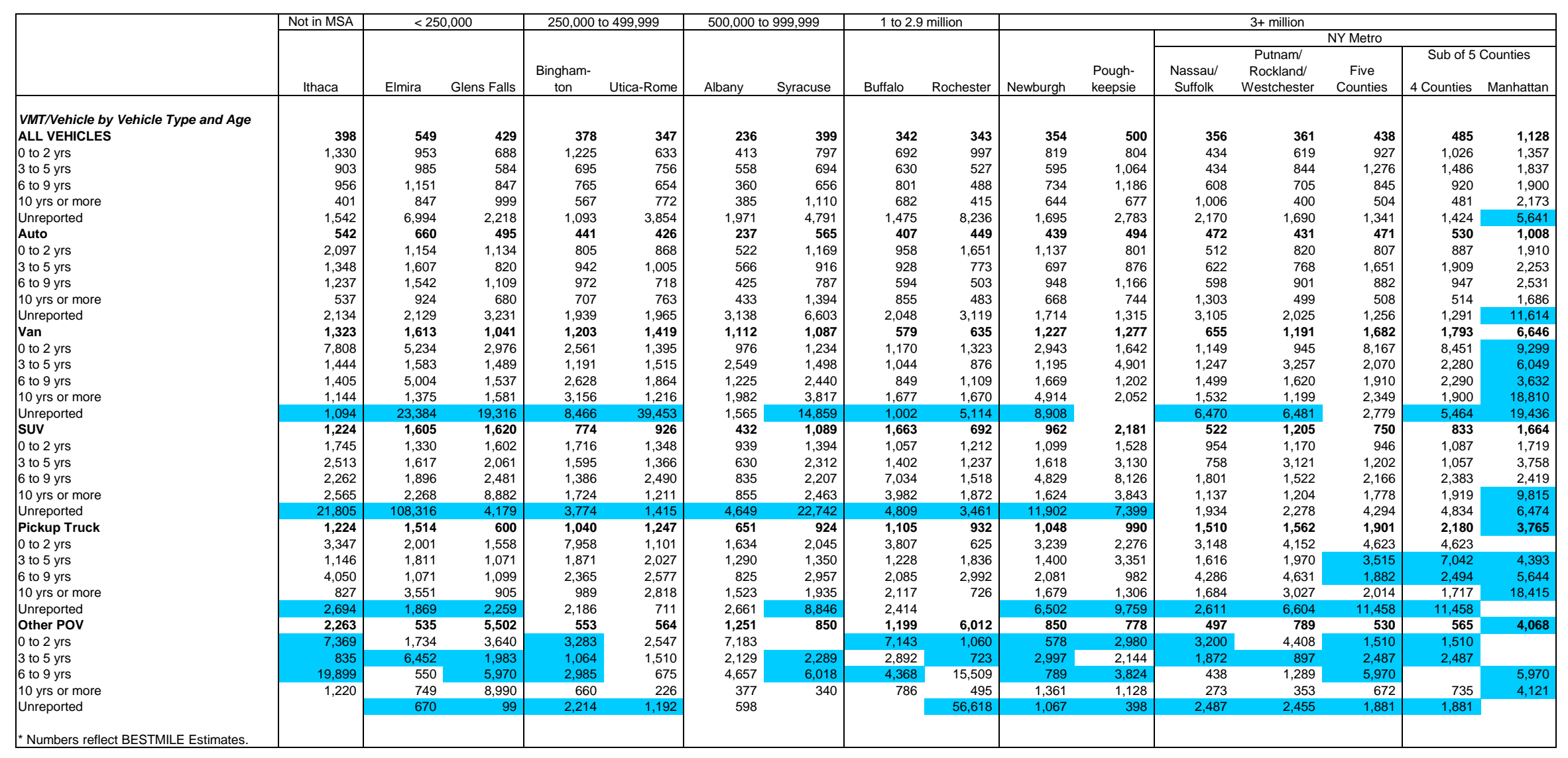


Chapter 6: Table 13

Comparison of Travel Patterns Among NY State MPOs

STANDARD ERRORS

\begin{tabular}{|c|c|c|c|c|c|c|c|c|c|c|c|c|c|c|c|c|c|}
\hline & \multicolumn{2}{|c|}{ Not in MSA } & \multicolumn{2}{|c|}{$<250,000$} & \multirow{2}{*}{\multicolumn{2}{|c|}{$\begin{array}{l}250,000 \text { to } 499,999 \\
\begin{array}{c}\text { Bingham- } \\
\text { ton }\end{array} \text { Utica-Rome } \\
\end{array}$}} & \multirow{2}{*}{\multicolumn{2}{|c|}{\begin{tabular}{l|}
500,000 to 999,999 \\
\\
Albany Syracuse
\end{tabular}}} & \multirow{2}{*}{\multicolumn{2}{|c|}{\begin{tabular}{c|}
1 to 2.9 million \\
Buffalo Rochester \\
\end{tabular}}} & \multirow[b]{2}{*}{ Newburgh } & \multicolumn{6}{|c|}{$3+$ million } \\
\hline & Ithaca & Kingston & Elmira & Glens Falls & & & & & & & & $\begin{array}{l}\text { Pough- } \\
\text { keepsie }\end{array}$ & $\begin{array}{l}\text { Nassau/ } \\
\text { Suffolk }\end{array}$ & $\begin{array}{c}\text { Putnam/ } \\
\text { Rockland// } \\
\text { Westchester }\end{array}$ & $\begin{array}{c}\text { NY Metro } \\
\begin{array}{c}\text { Five } \\
\text { Counties }\end{array} \\
\end{array}$ & $\begin{array}{r}\text { Sub of } 5 \\
4 \text { Counties } \\
\end{array}$ & $\begin{array}{l}\text { Counties } \\
\text { Manhattan } \\
\end{array}$ \\
\hline \multicolumn{18}{|l|}{ Percent Not Taking Walk Trips in the last week } \\
\hline TOTAL & $3.7 \%$ & $1.9 \%$ & $1.9 \%$ & $2.1 \%$ & $2.6 \%$ & $2.0 \%$ & $1.4 \%$ & $1.8 \%$ & $2.4 \%$ & $2.1 \%$ & $2.0 \%$ & $1.5 \%$ & $1.7 \%$ & $1.6 \%$ & $1.1 \%$ & $1.2 \%$ & $2.2 \%$ \\
\hline 5 to 10 year-olds & $5.2 \%$ & $5.4 \%$ & $6.0 \%$ & $5.5 \%$ & $7.3 \%$ & $5.4 \%$ & $4.3 \%$ & $6.2 \%$ & $10.8 \%$ & $13.1 \%$ & $5.1 \%$ & $8.2 \%$ & $5.6 \%$ & $4.4 \%$ & $4.4 \%$ & $5.0 \%$ & $7.2 \%$ \\
\hline & $4.5 \%$ & $6.5 \%$ & $6.7 \%$ & $6.2 \%$ & $7.5 \%$ & $5.0 \%$ & & & $7.0 \%$ & & $6.3 \%$ & $6.6 \%$ & $7.6 \%$ & $3.6 \%$ & & $3.0 \%$ & \\
\hline 16 to 20 year-olds & $11.3 \%$ & $5.1 \%$ & $10.4 \%$ & $9.9 \%$ & $9.0 \%$ & $6.1 \%$ & $4.5 \%$ & $7.5 \%$ & $7.2 \%$ & $7.1 \%$ & $6.6 \%$ & $7.7 \%$ & $6.2 \%$ & $5.3 \%$ & $3.9 \%$ & $4.8 \%$ & $6.6 \%$ \\
\hline 21 to 35 year-olds & $7.2 \%$ & $7.6 \%$ & $4.3 \%$ & $4.8 \%$ & $4.8 \%$ & $5.3 \%$ & $3.9 \%$ & $5.2 \%$ & $6.2 \%$ & $5.3 \%$ & $5.7 \%$ & $4.2 \%$ & $4.4 \%$ & $4.9 \%$ & $2.0 \%$ & $2.5 \%$ & \\
\hline 36 to 64 year-olds & $2.5 \%$ & $2.7 \%$ & $2.4 \%$ & $2.9 \%$ & $3.2 \%$ & $2.7 \%$ & $1.7 \%$ & $2.4 \%$ & $3.0 \%$ & $2.4 \%$ & $2.5 \%$ & $1.8 \%$ & $2.5 \%$ & $2.4 \%$ & $1.5 \%$ & $1.8 \%$ & $2.6 \%$ \\
\hline $\begin{array}{l}65+\text { year-olds } \\
\text { Avg Minutes Spent Walking per Day }\end{array}$ & $7.0 \%$ & $4.4 \%$ & $4.2 \%$ & $4.5 \%$ & $3.4 \%$ & $3.8 \%$ & $3.1 \%$ & $4.0 \%$ & $4.0 \%$ & $3.4 \%$ & $3.1 \%$ & $3.7 \%$ & $4.3 \%$ & $3.4 \%$ & $2.6 \%$ & $3.1 \%$ & $4.1 \%$ \\
\hline $\begin{array}{l}\text { AvT } \\
\text { TOTAL S }\end{array}$ & 1.49 & 0.50 & 0.49 & 0.89 & 0.52 & 1.33 & 0.58 & 0.55 & 0.46 & 0.53 & 0.79 & 0.73 & 0.40 & 0.95 & 1.15 & 1.15 & 3.42 \\
\hline 5 to 10 year-olds & 1.98 & 0.30 & 0.94 & 2.29 & 1.15 & 3.18 & 2.83 & 2.79 & 0.84 & 0.24 & 1.55 & 0.68 & 0.57 & 3.50 & 3.02 & 3.30 & 6.77 \\
\hline 11 to 15 year-olds & 3.99 & 0.73 & 1.91 & 2.76 & 0.66 & 4.36 & 4.57 & 1.03 & 1.18 & 0.77 & 0.81 & 0.53 & 1.98 & 3.05 & 2.23 & 2.55 & 6.40 \\
\hline 16 to 20 year-olds & 4.56 & 1.57 & 2.61 & 3.11 & 2.83 & 0.73 & 1.70 & 0.98 & 3.15 & 2.14 & 1.15 & 1.15 & 1.39 & 2.07 & 3.56 & 3.03 & 10.47 \\
\hline 21 to 35 year-olds & 3.99 & 1.64 & 1.50 & 2.91 & 1.57 & 3.44 & 1.30 & 1.17 & 0.69 & 2.24 & 3.63 & 2.55 & 1.21 & 2.07 & 3.06 & 2.12 & 12.05 \\
\hline 36 to 64 year-olds & 2.36 & 0.90 & 0.66 & 1.12 & 0.69 & 1.56 & 0.69 & 1.09 & 0.86 & 0.57 & 0.54 & 0.93 & 0.58 & 1.57 & 1.39 & 1.65 & 2.62 \\
\hline \multirow{2}{*}{\multicolumn{18}{|c|}{$\begin{array}{l}\text { Dos+yearlors } \\
\text { Percent Taking Bike Trips in the last week }\end{array}$}} \\
\hline $\begin{array}{l}\text { TOTAL NO Taking bike Imps In the last we } \\
\text { TOT }\end{array}$ & & $1.2 \%$ & $1.7 \%$ & $1.4 \%$ & $1.1 \%$ & $1.4 \%$ & $1.1 \%$ & $1.3 \%$ & & & & & & & & & $13 \%$ \\
\hline 5 to $10 y$ & $7.2 \%$ & $6.4 \%$ & $6.9 \%$ & $6.5 \%$ & $7.2 \%$ & $7.5 \%$ & $5.6 \%$ & $6.5 \%$ & $10.9 \%$ & $9.2 \%$ & $6.9 \%$ & $8.1 \%$ & $5.8 \%$ & $7.7 \%$ & $4.1 \%$ & $4.6 \%$ & $9.1 \%$ \\
\hline 11 to & $4.3 \%$ & $5.9 \%$ & $7.1 \%$ & $5.7 \%$ & $8.6 \%$ & $7.3 \%$ & $6.1 \%$ & $5.7 \%$ & $5.9 \%$ & $5.6 \%$ & $4.3 \%$ & $5.9 \%$ & $4.2 \%$ & $6.8 \%$ & & $2.9 \%$ & $4.2 \%$ \\
\hline 16 to & $8.3 \%$ & $4.6 \%$ & $8.5 \%$ & $4.8 \%$ & $2.8 \%$ & $1.7 \%$ & $3.0 \%$ & $4.8 \%$ & $7.2 \%$ & 6.7 & & & $4.1 \%$ & $3.4 \%$ & & $0.9 \%$ & $10.0 \%$ \\
\hline 21 to & $3.1 \%$ & $3.5 \%$ & $3.7 \%$ & $3.4 \%$ & $4.2 \%$ & $2.8 \%$ & $2.1 \%$ & $3.7 \%$ & $4.4 \%$ & 3.0 & $3.9 \%$ & & $1.9 \%$ & & & $2.8 \%$ & $2.3 \%$ \\
\hline 36 to 6 & $6.0 \%$ & $1.2 \%$ & $1.4 \%$ & $2.1 \%$ & $0.9 \%$ & $2.0 \%$ & $1.3 \%$ & $1.2 \%$ & $1.8 \%$ & $1.5 \%$ & $1.2 \%$ & $1.2 \%$ & $1.4 \%$ & $1.7 \%$ & $0.9 \%$ & $1.1 \%$ & $1.2 \%$ \\
\hline 65 - year-olds & $0.5 \%$ & $1.2 \%$ & $0.6 \%$ & $1.7 \%$ & $0.4 \%$ & $0.7 \%$ & $0.7 \%$ & $0.6 \%$ & $1.0 \%$ & $1.3 \%$ & $1.6 \%$ & $0.3 \%$ & $0.5 \%$ & $0.6 \%$ & $0.7 \%$ & $0.9 \%$ & $0.7 \%$ \\
\hline \multicolumn{18}{|l|}{ Avg Minutes Spent Biking } \\
\hline 5 to 10 year-olds & 0.15 & 0.49 & 0.33 & 1.20 & & 0.75 & 0.83 & 0.52 & 0.61 & 0.08 & 0.24 & 3.30 & 0.25 & 2.15 & 0.28 & 0.31 & \\
\hline 11 to 15 year-olds & 0.30 & 1.14 & 2.29 & 0.58 & & 3.78 & 0.93 & 2.24 & 1.22 & 0.43 & 0.48 & 0.94 & 0.32 & 0.08 & 0.01 & 0.02 & \\
\hline 16 to 20 year-olds & 0.03 & 0.3 & 0.54 & 3.83 & 0.19 & 1.59 & 1.79 & 3.53 & 0.36 & 0.18 & & 0.59 & 0.47 & & 0.10 & 0.08 & 0.32 \\
\hline 21 to 35 year-olds & 0.66 & 0.19 & & & & 0.56 & 0.32 & 1.13 & 1.69 & 0.45 & & 0.09 & 0.26 & 0.33 & 0.44 & 0.57 & \\
\hline 36 to 64 year-olds & 0.23 & 0.12 & 0.20 & 0.66 & 0.31 & 0.36 & 0.24 & 0.29 & 0.29 & 0.13 & 0.25 & 0.21 & 0.14 & 0.43 & 0.37 & 0.46 & 0.20 \\
\hline \multirow{2}{*}{\multicolumn{18}{|c|}{$\begin{array}{l}65+\text { year-olds } \\
\text { Avo Minutes Spent Walking/Biking per Dav }\end{array}$}} \\
\hline & & & & & & & & & & & & & & & & & \\
\hline year-olds & $\begin{array}{l}1.53 \\
1.98\end{array}$ & $\begin{array}{l}0.52 \\
0.65\end{array}$ & 0.98 & $\begin{array}{l}1.07 \\
1.81\end{array}$ & $\begin{array}{l}0.56 \\
1.15\end{array}$ & 3. & $\begin{array}{l}0.64 \\
2.82\end{array}$ & $\begin{array}{l}0.76 \\
2.79\end{array}$ & $\begin{array}{l}0.59 \\
1.03\end{array}$ & 0. & $\begin{array}{l}0.8 \\
1.6\end{array}$ & $\begin{array}{l}0.83 \\
3.31\end{array}$ & $\begin{array}{l}0.42 \\
0.64\end{array}$ & $\begin{array}{l}1.09 \\
4.33\end{array}$ & $\begin{array}{l}1.17 \\
2.94\end{array}$ & $\begin{array}{l}1.17 \\
3.21\end{array}$ & $\begin{array}{l}3.45 \\
6.77\end{array}$ \\
\hline 11 & 4. & 1. & 3.28 & 2.86 & 0.66 & 4. & 4.66 & 2.29 & 1.48 & 0 & 1. & 1.08 & 2.00 & 3. & 2.23 & 2.54 & 6.40 \\
\hline 16 & 4. & & 2. & & 2.81 & & & 3.62 & & 2 & 1. & 1. & 1. & 2.07 & 3.55 & 3.04 & 10.42 \\
\hline 21 t & 3. & & 1.50 & & 1.57 & 3. & 1.38 & 1.82 & 1.92 & 2. & & & 1. & 2.12 & 3.08 & 2.13 & 12.05 \\
\hline 36 to 64 year-olds & 2.41 & 0.91 & 0.64 & 1.46 & 0.79 & 1.61 & 0.75 & 1.13 & 0.92 & 0.59 & 0.6 & 0.95 & 0.58 & 1.60 & 1.48 & 1.75 & 2.69 \\
\hline $65+$ year-olds & 1.80 & 1.24[ & 0.94 & $0.81 \mid$ & 0.89 & 0.73 & 0.72 & 1.36| & 0.73 & 0.64 & 0.89 & 2.76 & 1.06 & 0.85 & 2.22 & 2.59 & 2.86 \\
\hline
\end{tabular}




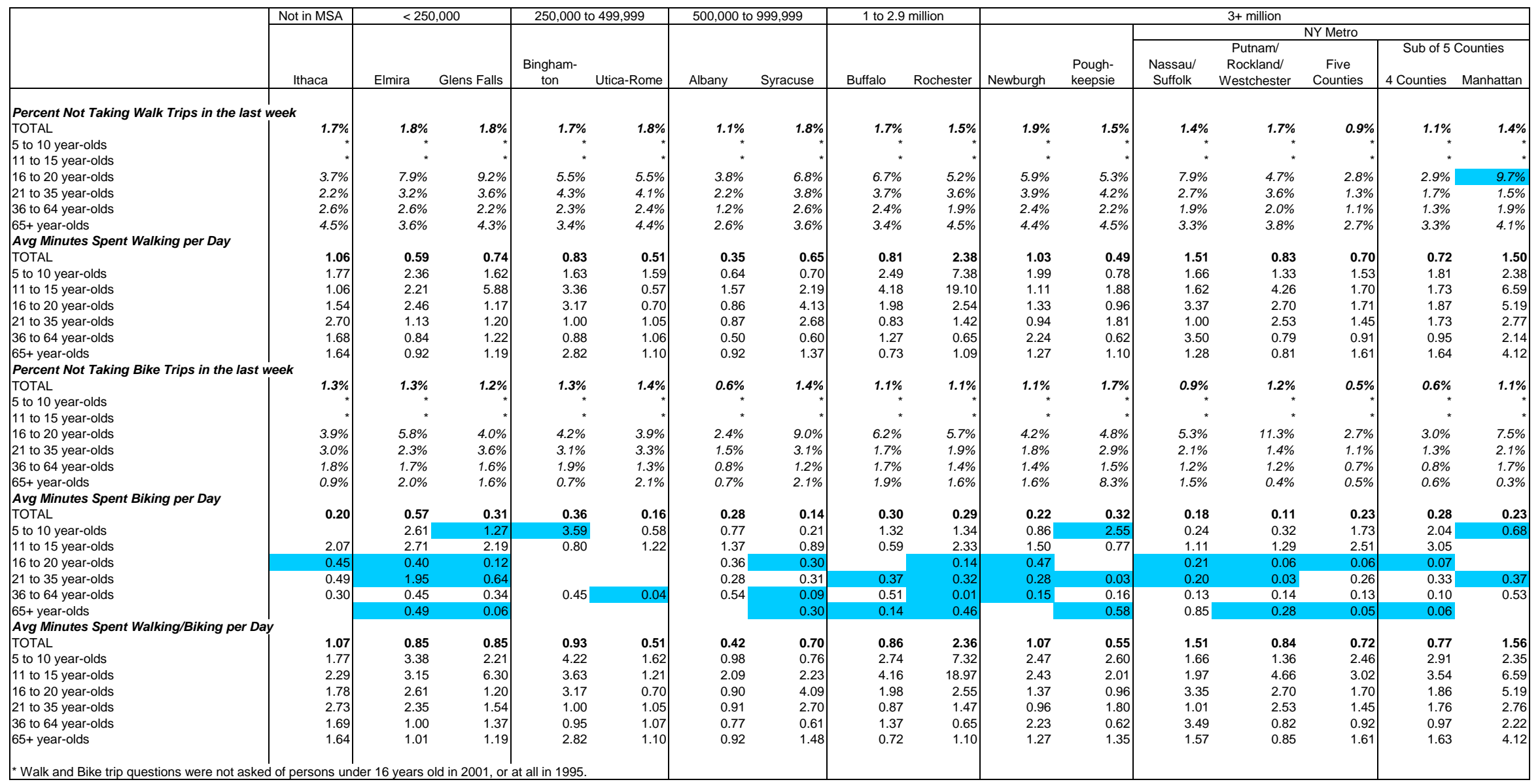



This page intentionally left blank.

D - 2 
Kilograms of CO2 per Passenger Mile by NHTS Mode

\begin{tabular}{|c|c|c|c|c|}
\hline \multirow[b]{2}{*}{ NHTS Modes } & \multicolumn{2}{|c|}{2009} & \multicolumn{2}{|c|}{2001} \\
\hline & $\begin{array}{l}\text { New } \\
\text { York } \\
\text { State }\end{array}$ & $\begin{array}{l}\text { Rest of } \\
\text { U.S. }\end{array}$ & $\begin{array}{l}\text { New } \\
\text { York } \\
\text { State }\end{array}$ & $\begin{array}{l}\text { Rest of } \\
\text { U.S. }\end{array}$ \\
\hline Car & \multicolumn{2}{|c|}{ Record specific } & \multicolumn{2}{|c|}{ Record specific } \\
\hline Van & \multicolumn{2}{|c|}{ Record specific } & \multicolumn{2}{|c|}{ Record specific } \\
\hline SUV & \multicolumn{2}{|c|}{ Record specific } & \multicolumn{2}{|c|}{ Record specific } \\
\hline Pickup truck & \multicolumn{2}{|c|}{ Record specific } & \multicolumn{2}{|c|}{ Record specific } \\
\hline Other truck & \multicolumn{2}{|c|}{ Record specific } & \multicolumn{2}{|c|}{ Record specific } \\
\hline RV & \multirow{2}{*}{\multicolumn{2}{|c|}{$\begin{array}{l}\text { Record specific } \\
\text { Record specific }\end{array}$}} & \multirow{2}{*}{\multicolumn{2}{|c|}{$\begin{array}{l}\text { Record specific } \\
\text { Record specific }\end{array}$}} \\
\hline Motorcycle & & & & \\
\hline Light Elec. vehicle (golf cart) & 0.0000 & 0.0000 & 0.0000 & 0.0000 \\
\hline Local/public bus & 0.2779 & 0.2917 & 0.2736 & 0.2805 \\
\hline Commuter bus & 0.2378 & 0.2428 & 0.2736 & 0.2805 \\
\hline School bus & 0.0725 & 0.0725 & 0.0725 & 0.0725 \\
\hline Charter/tour bus & 0.0500 & 0.0500 & 0.0560 & 0.0560 \\
\hline City to city bus & 0.0500 & 0.0500 & 0.0560 & 0.0560 \\
\hline Shuttle bus & 0.0988 & 0.0988 & 0.1447 & 0.1447 \\
\hline Amtrak/Intercity train & 0.1527 & 0.1527 & 0.2193 & 0.2193 \\
\hline Commuter train & 0.1262 & 0.1494 & 0.1070 & 0.1513 \\
\hline Subway/Elevated Train & 0.0695 & 0.0897 & 0.0839 & 0.1222 \\
\hline Street Car/Trolley & 0.1586 & 0.1586 & 0.2164 & 0.2164 \\
\hline Taxicab & 0.6777 & 0.6777 & 0.6777 & 0.6777 \\
\hline Ferry & 0.5441 & 0.9630 & 0.3592 & 1.3957 \\
\hline Airplane & 0.0000 & 0.0000 & 0.0000 & 0.0000 \\
\hline Bicycle & 0.0000 & 0.0000 & 0.0000 & 0.0000 \\
\hline Walk & 0.0000 & 0.0000 & 0.0000 & 0.0000 \\
\hline $\begin{array}{l}\text { Special transit -people } \\
\text { w/disabilities }\end{array}$ & 1.2872 & 0.9905 & 1.1639 & 0.9522 \\
\hline Other & 0.1205 & 0.1839 & 0.1199 & 0.2362 \\
\hline
\end{tabular}

Source: Derived from US EPA recommended fuel use to $\mathrm{CO} 2$ emissions conversions, and emissions rate estimates derived from the Federal Transit Administration's rail, bus and ferry transit energy consumption database, and average vehicle fuel efficiencies reported by or derived from Federal Highway Administration, American Bus Association, American School Bus Association, and the New York City Taxi and Limousine Commission estimates. 